\title{
Sixteenth Annual Conference on Manual Control
}

May 5-7, 1980

Massachusetts Institute of Technology

Cambridge, Massachusetts

and

Ames Research Center

Moffett Field, California

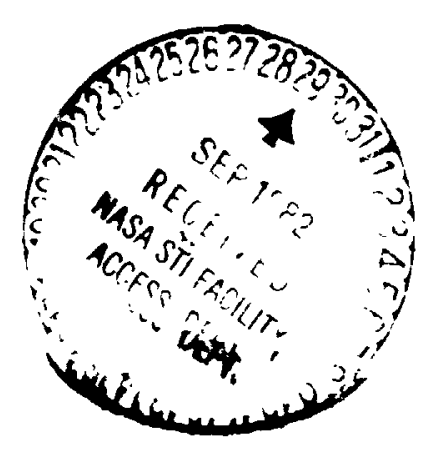


NAASẢ Technical Memorandum 84273

\section{Sixteenth Annual Conference on Manual Control}

May 5-7, 1980

Massachusetts Institute of Technology, Cantridge, Massachusetts Ames Research Center, Moffett Field, Caiifornia

\section{NMSA}

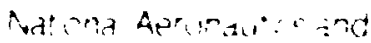

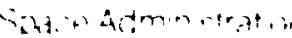




\title{
CONFERENCE CO-CHAIRMEN
}

\author{
Sheidon Baron \\ bult, Beranek and Newman, Inc.
}

Thomas B. Sheridan

Massachusetts Institute of Technology

PUBLICATIONS COMMITEE

Thomas Wempe

NASA-Ames Research Center 
FOREWORD

This volume contains the proceedings of the Sixteenth Annual Conference on Manual Control held at the Massachusetts Institute of Technology at Cambidge. Massachusetts, May 5-7, 1980. It contains complete manuscripts of must of the papers presented at the neeting and abstracts of the others. The papers and abstracts are ordered as presented, with session titles indicated in the table of contents.

This was the sixteenth in a series of conferences dating back to December 1904 . These earlier neetings and their proceedings are listed below:

1. The University of Michlgar. December 1964. (Proceedings not printed.)

2. M.I.T. Februsty 28 to March 2, 1966. NASA Sr-:28.

3. University of Southern California, March 1-3, 1967. NASA SP-144.

4. The Universily of Michlgan, March 21-23, 1968, NASA SP-192.

5. M.I.T. March 27-29, 1969, MASA SP-215.

6. Wright-Pacterson AFB, April 7-9, 1970.

7. liniversity of Southern Calliornia, June 2-4, 1971, MASA SP-281.

8. University of Michigan, Ann Arbor. Michigan, May 17-19, 1972.

9. M.L.T., May 23-25, 1973.

10. Hright-Pattersun AFB, Apri1 9-11, 1974.

11. NASA-Ames Research Center, May 21-23, 1975, NASA TM X-62,464.

12. University of Illinols, May 25-27, 1976, NASA MM X-73,170.

13 M.I.T.. June 15-17, 19?7.

14. University of Southern California, April 25-27, 1978.

15. Wright-Patterson AFB, March 20-22, 1979. 
TABLE OF CONTENTS

Operator Modeling

MODELING OF HUMAN OPERATOR DYMAMTCS IN SIMPLE MANUAL CONTROL UTILIZING TIME SERIES ANALYSIS

Gyan C. Agarwal, Frank Osafo-Charles, Willian D. O'Nefll and

Gerald L. Gottleib

A GUNNER MODEL FOR AN MA TRACKING TASK WITH INTERRUPTED OBSERVATIONS

C. F. Yu, K. C. Wel and M. M. Vikemaniz

SODELING HUMAN TARGET ACQUISITION IN GROUND-TO-AIR WEAPON SYSTEYS

A. V. Phatak, R. L. Mohr, M. Vikmanis and R. C. Wef

THE EFFECT OF VISOAL INFORYATION ON THE MANUAL APPROACH AND LANDING

P. H. Hewerinke

PILOT/VEHICLE MODEL AKALYSIS OF VISUAL AND MOTION CUE REQUTRDEEATS IN FLIGHT SDAULATION

R. Lancraft, G. Zacharias, S. Baron

PURSUIT TRACKING AND GIGHER LEVEIS OF SKILL DEVELOPALANT IN THE GURAN PILOT

Ronald A. Hess

MULTI-AXIS TRACKING VIA AN UPTDMA-CONTROL PILOT MODEI

S. N. Piasad and David K. Schnidt

THE EFFECTS OF MULTIPLICATIVE MOTOR NOISE ON THE OPTIMAL HUMAN" OPERATOR MODE:

Alper :.. Caglayan and Willian H. Levison

MODELLING OF AIRCRAFT IN-TRAIL FOLLONING

Ahwet Buhareli

TRAINING AIRCRAFT DESIGN CONSIDERATIONS BASED ON THE SÜCCESSIVE ORGANIZATTON OF PERCEPTION IN MANOAL CONTROL

Robert $R$. Heffley, Warren $F$. Clement and Samuel J. Craig

Measurement of Human Response

AN EXPERIMENTAL STUDY OF BUMAN PILOT'S SCANNING BEHAVIOR

Kyuichro Wash1zu, Keifl Tanaka and Tatsuo Osawa

INVESTIGATION OF A SUM OF SINUSOIDS REPRESENTATION OF GAUSS-MARROV RANDOM PROCESSES - IMPLICATIONS FOR MANUAL CONTROL, RESEARCH

R. L. Mohr, A. V. Phacak and R. A. Hess

PARAMETRIC IDENTIFICATION OF HUMAN OPERATOR MODELS 
TABLE OF CONTENTS

A COMPUTER SIMULATION APPROACR TO MEASUREMENT OF GUMAN COMTROL STRATEGY

Joanne Green, Esther Lee Davenport, Harold F. Engler, Willian E. Sears

PILOT MDEL HYPOTHESIS TESTING

Juth R. Broussard and Paul W. Berry

Mental Norkload

SUBEECTIVE SCALIMG OF MENTAL WORRLOAD IN A MULTI-TASR ENTIROMEOTT Bahman Daryanian

EFFECT OF COUNTING AND TRACKING ON VERBAL AND PRODUCTION METHODS OF TIME ESTIMATION

Rathleen L. Bird and Sandra Hart

EFFECT OF ESTIMATION TECHNIQUE AND TASK COADITION ON TME ESTIMATION SETHODS

Kathleen L. Bird and Sandra G. Hart

PILOT WORKLOAD IN THE AIR TRANSPORT ENVIRONEEMT: THEORY, MEASURETENT AND THE INFLUENCE OF AIR TRAFFIC CONTROL

Jeff Katz and Robert Simpson

WORKLOAD AND PILOT EYE SCANING BEHAVYOR

J. R. Tole, A. Ephrath, A. T. Stephens and I. R. Young

THE LOCUS OF PROCESSING DEMANDS OF HIGHER-ORDER CONTROL: AN ELECTROPHYSIOLOGICAL APPROACH

Christopher Wickens and RIchard Gill

P1lot/Operator Op 1nion

A MDDEL-BASED TECHNIQUE FOR PREDICTING PILOT OPINION RATINGS FOR LARGE 216 COMERCIAL TRANSPORTS

William H. Levison

AN ARALTTICAL PREDICT:ON OF PILOT RATINGS UTILIZING BOMAN PILOT MODEL. Re1f1 Tanaka and Kyulchiro Washizu

EFFECTS OF HIGHER ORDER CONTROL SYSTEMS ON AIRCRAFT APPROACH AND LANDING 254 LONGITUDINAL BANDLING QUALITIES

Muhalead A. Pasha, John J. D'Azzo and Janes T. S1lverthorn

PILOT OPINIONS OP SAMLING EFTECTS IN LATERAL-DIREC, WML CONTROL

Robert F. Stengel and Geoorge $E$. Miller

A MDDEL OF SUBJECTIVE PROBABILITIES PROM SHALL GROUPS

Willian R. Forrell and Reily Rebm 
TABLE OF CONTENTS

Effects of Motion

VISUAL/MOTION CUE MISMATCH DURING A COORDINATED ROLL MANEUVER

D. K. Shirachi

COMBINED EFFECT OF THE OCULOGYRAL ILLUSION AND OF A FIXED PERIPHERAL, FIELD ON SENSATIONS OF YAW MOTION

J. K. Huang and L. R. Young

A PERFCRMANCE ANALYSIS STUDY OF A COAPLEX G FIELD EXPERTIENT

Daniel $W$. Repperger

A LINEARIZED MODEL FOR VIBRATION EFFECTS ON THE EYE COITROL SYSTEM

Raymond E. Magdaleno and Henry R. Jex

DESCRTPTION/DEYONSTRATION OF "BIODNN-80": A SOFTWARE PACNGE FOR

EVALUATING THE TRANSKISSIBILITY BETWEEN VEHICLE VIBRATION AND WOTIONS

OF HANDS (IN CONTROLS), LIMBS, HEAD AND EYES

Systems Technology, Inc.

MODELING LATERAL ACCELERATION EFFECTS ON PILOT PERFORANCE

Jonathan Korn and David L. Kleinman

A COMPREHENSIVE SYSTEY MODEL FOR YOTION/SPACE SICKNESS - PRELIMINARY RESULTS

Susan A. Riedel

\section{Aircraft Displays}

EVALUATION OF A TKAJECTORY COMMAND CONCEPT FOR MANUAL CONTROL OF

Walter E. McNeill, G. Allen Snith, Jr., Ronald M. Gerdes

WIND SHEAR SIMULATION EXPERIMIENTS

COMBINED USE OF AIRBORNE TRAFFIC SITUATION DISPLAYS

Mark Connelly

APPLICATION OF A PILOT CONTROL STRATEGT IDEATIFICATION TECHNIQUE TO A JOINT FAA/NASA GROUND-BASED SIMULATION OF HEAD-UP DISPLAYS FOR CTOL AIRCRAFT

Wayne F. Jewe 11

PILOT REACTION TO ATTITUDE GYRO FAILURE

Richard L. Newman and David L. Quam

PILOT INDUCED LONG PERIOD OSCILLATIONS CREATED BY CERTAIN DISPIAYS CONFIGURATIONS

James J. Adams

DESIGN, SIMULATION AND EVALUATION OF ADVANCED DISPLAY CONCEPTS FOR THE F-16 CONTROL CONFIGURED VEHICLE

Robert $W$. KleIn and walter M. Hollister

SEPARATION MONITORING WITH FOUR IYPES OF PREDICTORS ON A COCKPIT DISPLAY 439 OF TRAFFIC INFORMATION

Sharon Jago and Everett Palmer 
TABLE OF CONTENTS

Supervisory Concrol

CONBINED DISCRETE NETWORR - CONT UNUOUS CONTROL MDDELING OF OPERATOR BEHAVIOR

R. A. Miller and Deborah J. Selfert

A MODEL. OF HUMAN DECISION MAKING IN GULTIPLE PROCESS MONITORING SITUATIONS

Joel S.Greensteln and WIIIIa B. Rouse

PROCRU: A MODEL FOR AIALYZING FLIGHT CREK PROCEDURES IN APPBOACH TO

LANDING

S. Baron, G. Zacharias, R. Muraldiharan, R. Lancraft

A MODEL FOR REAL-TIME BURAN DECISION-MAKING IN A MULTI-TAST ERTIRONMENT

P. Krishna-Rao, Arye R. Ephrach, David L. Kleinano

APPLICATION OF OPTIMAL CONTROL PRINCIPLES TO DESCRIBE THE SUPERVISORY CONTROL BERAVIOR OF MA CREW MERBERS

Chris Hale and Gecrge J. Valentino

DOES MN ALWAYS ClOSE THE LOOP IN TRYING TO PILOT A LARGE SHIP?

Douglas R. Arnett and T. Govindaraj

SUPERVISION OF DKUAIC SYSTEMS: MONITORING, DECISION-MAKING AND CONTROL

Ted N. White

EFFECT OF INFERENTIAL MONITORING AND VIGILANCE

Janice J. Wrye and Reawlick E. Curry

Automobile Driving

EFFECTS OF MOTIVATION ON CAR-FOLLOWING

Tos Bösser

LEVELS OF STEERING CONTROL: REPROCUCTION OF STEERING-WAEER MOVEMENTS Hans Godthelp

Renoce Manipulation

THE ROLE OF AKTAGWIST rOACTIVATION IN THE CONTROL OF MATURAL MOVEGENT Neville ilogan

A COMPARISON OF CONTROL MODES FOR TIME-LELAYED REMTE MANIPULATTON Gregory P. Starr

EXPERIMENTAL EVALUATION OF THE CONCEPT OF SUPERVISORY MANIPULATION Thurston L. Brooks and Thomas B. Sheridan 
TABLE OF CONTENTS

EVALUATION OF "SMART" SENSOR DISPLAYS FOR MULTIDIMENSIONAL PRECISION CONTROL OF SPACE SHUTTLE REAOTE MANIPULATOR

A. K. Bejczy, K. W. Brown and J. L. Lewis

A NEW FEEDBACK INSTRUMENT FOR ROBOTS AND MANIPLIAATORS, AND ITS USE

IN ROBOT TEACHING, SELF CORRECTION AND LEARNINC:

D. S. Seltzer and D. E. Whitney

THE NOSC/MIT SUBMERSIBLE-MANIPULATOR: AN EXPERIMENT IN REMOTE SUPERVISORY CONTROL OF A MICROPROCESSOR BASED ROBOT

Dana Yoerger and Thomas B. Sheridan

ANALYSIS OF DRIVER PERFORMANCE UNDER REDUCED VISIBILITY

630

Wolf-Dieter Kaeppler 
MODELING OF HUMAN OPERATOR DYNAMICS IN SIMPLE MANUAL CONTROL UTILIZIRG TIE SERIES ANALYSIS

Gyan C. Agarwal, Frank Osafo-Charles, William D. O'Neill, and Gerald L. Gottlieb

College of Engineering, University of Illinois at Chicogo Circle, Chicego, 60680 , and Department of Physiology, Rush-Presbyterian-St. Luke's Medical Center, Chicago, 60612 .

\section{ABSTRACT}

Time series analysis is applied to model human operator dymamics in pursuit and compensetory tracking modes. The normalized residual criterion is used as a one-step analytical tool to encompass the processes of identification, estimatic?, and diagnostic checking. A parameter constraining technique is introduced to develop more reliable models of human operator dynamics. The human operator is adquately modeled by a second order dvnamic system both in pursuit and compensatory tracking modes. In comparing the a. ta sampling rates, 100 msec between samples is adequate and is shown to provide better results than $200 \mathrm{mser}$ sampling. The residual power spectrum and elgenvalue anaiys $1 \mathrm{~s}$ shor that the human operator is not a generator of periodic characteristics.

\section{IMTRODUCTION}

Equipment designers have traditionally called upon man to act as part of control systems. The value of having a human link was recognized long before it became possible to describe systems in mathematical terms. The human operator could be asked to furnish that particular information transduction neered to overcome unexpected environmental situations and compensate for deficiences of the equijment. The advent of costly and increasingly complex equipment has focused attedion upon the need for detailed knowlehge of the human transfer characteristics within its normal operating range. This would reduce the great expense and delay attendant upon modification or redesign of hardware during the development process. The determination of models describing human dynamics in an cperating system is a complex and an important problem.

The human controller has several unique characteristics. H1s input - Output relationships cannot be described as being purely linear, non-1inear, me-variable, random, or discrete. They are complex combinations of all of these characteristics [1]. The problem of identification is further compounded by the fact that the human operator is an adsptive controller who learns from experience.

Presented at the Sixteenth Annual Conference on Manual Control, M.I.T, May, 1980. This work wes supported in part by National Science Founiation Grant ETG-7608754 and grants from the National Institutes of Health NS-00196 and NS-12877. 
Earlier approaches to representing the mathematical characteristics of the human operator using classical control theory (frequency domain analysis, describing functions, and epectral analys28) as well as modern control theory approaches (state variable and optimal estimation - Kalman filtering) have been extensively reviewed in the literature [2]-[12].

For a simple compensatory tracking task with a controlled element of unity gain, Elkind and Forgie [13] obtained the transfer function of the human operator of the form.

$$
G_{H}(s)=\frac{K e^{-\tau s}}{\left(T_{1} s+1\right)\left(T_{N} s+1\right)}
$$

where $K=$ Operator static gain, $T_{1}=$ Lag time constant, $T_{N}=$ Neuromuscular lag time constant, $\tau=$ Effective time ${ }^{l}$ delay.

The parameters were found to be dependent on the frequency characteristic of the input spectrum. In the model development, the net phase lag can be approximated by an effective time delay which is the sum of transport delays and central nervous system latencies, a time varying component of delay and high frequency lead equalization. Thus the effective time delay has a measurable mean value over a particular run, but instantaneous values may vary about this mean [27]. In a study similar to [13], Young, et.8]. [14] obtained the following parameter values for a rectangular input spectrum: $K=40, \tau=0.1 \mathrm{sec}$, $1 / T_{1}=0.3 \mathrm{sec}^{-1}, 1 / \mathrm{m}_{\mathrm{N}}=6.2 \mathrm{sec}^{-1}$.

In a variety of experimental situations and controlled elements, McRuer and his colleagues have snown that the human operator follows a Cross-over model [4] and has a transfer function of the form [12]:

$G_{H}(s)=\frac{K\left(T_{L} s+1\right) e^{-T s}}{\left.\left(T_{1} s+1\right) T_{N} s+1\right)}$

where $T_{L}=$ lead time constant and the other terms are same as in equation ( 1 ).

In recent studies, Shinners [1] and Tanaka, Goto, and Washizu [15] have pioneered the application of stochastic time series analysis in the modeling of human operator dynamics. Shinners basically uses the methods of Box and Jenkins $[16,17]$. In estimating the order and the parameters of an autoregressive/moving average (ARMA) model, a three-stage iterative procedure is used for: a) identification of the order of the model, b) estimation of its parameters, and c) diagnostic checking with the aim of reveaing model inadequacies. In compensators traciking with a controlled element of unity gain, Shinners [1] has obtained the following transfer function for the human operator (his subject $C$ ):

$$
G_{H}(z)=\frac{-0.65\left(1-0.803 z^{-1}\right) z^{-1}}{\left(1-0.386 z^{-1}\right)\left(1-0.97 z^{-1}\right)}
$$

where $z^{-1} x(k)=x(k-1)$ and the data sampling interval was 0.2 seconds.

Tanaka, et.al. [15] have used Akalke's Minimum Final Prediction Error [MFPE] method to obtain the order of the system $[18,29]$. Akalke's information criterion 
(AIC) wich is an alternative method to obtein the order of the syrtem is based on the maxinua likelihood principle.

Recently, Suen and Liu [20] have proposed - Jrmalized Residual Critericis (NRC) which seems to offer several advantages ovt: nther least square tvipe Identification methods. In comparing against Akaike's AIC method, suen s.nd Liu [20] have shown that their method consistently gives as good or better estimates; Akaike's criterion sometimes gires a system order higher by one or two (cf. [28] [29]). O'Neill [21] has successfully applied the IRC method of Suen and Liu to model suspended particulate pollution as an autoragressive process.

Suen and Liu's NRC method has the advantage that it is a one-step analytical tool that encompasses the processes of identification, estimation, and diagmostic checking. Pre-whitening of the input is not necessary (cf. Shinuers' [1]). Also no presimption of stationarity of the data time series is required for effective characterization of the system. A ieview of identification methods is given by Astrom and Eykhort [30]. They also discuss the relative me-its of parametric (such as time series) ?rsius nonparametric (such as impulse response, transfer function) modeling techniques.

The significant difference between this work end previous works, is the intro-uction of a theory which deals with the constraining of the parameters of the estimated time series models. By re-estimating the constrained models, more reliable and significant models for describing human dyamics are obtained. Since Shinners and Tanaka et.al., applied time series analysis to the human subject only in a compensatory tracking mode, this also represents the first time the technique has been extended to invegtigate the human characteristics in both compensatory and pursuit tracking modes.

\section{EXPERIMENTAL JESIGN AND DATA ANALYSIS}

Two subjects we. used for these experiments. They will be referred to as subjests FOC and BXK. Prior to collection of data, both subjests were run through a scaled down set of expe:-1mental practice blocks to allow them to apr.roach asymptotic performance levels.

The experimental set ip is shown schematically in Figure 1. The humai snerator se- before an oscillosco e and fartpulated a one degree of freedom joystick. The jo. ilck moved freely with uo sprine's or dashpots. The plant dynamics consisted of a simple unity gain. Two vertically driven horizontal lines were displayed on the oscilloscope. The first life served as the target in the pursult case and as a zero-error rercrence line is, the compensatory case. The other line disfiayed system output in the pursuit cise and system error in the compensatory case. The lines were adjusted in focus and intensity which made it easy for subjects to discriminate between the two. The sisplay configuration could be changed between pursuit and compensatory by means of a switch. Error was computed oy a simple analog circuit. The entire experiment wis under the control of a regl-time digital computer (General Automation STC-16/65) with $D / A$ and $A / D$ channels. The computer sampied at $20 \mathrm{msec}$ intervals generating the appropriate system 1ujut and recording the system output. The entire observation period of 66.56 secords, 3328 data point arrays both for input and output time series were simultanecusily recorded on magnetic tape. 


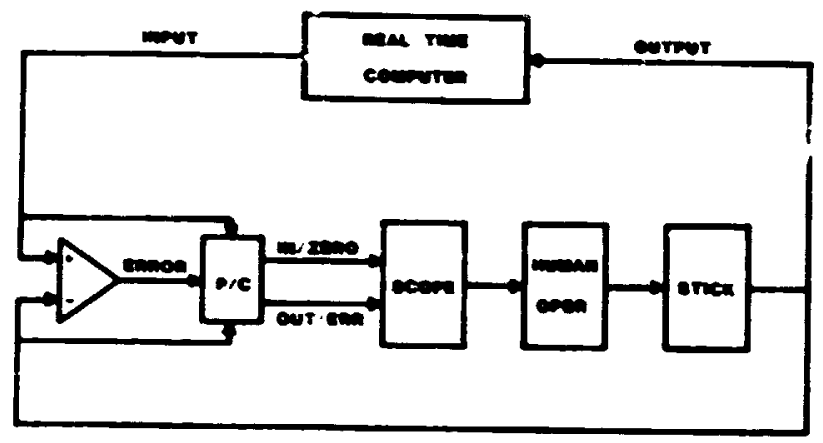

SCMEMATKC OF EXPERumENT

Figure 1: chematic of the experisental set up. The scope is duai beam; one channel is used to display input in pursuit mode and zero reference in compensatory mode; the second channel is used $\mathrm{rai}^{\mathrm{i}}$ output in pursuit and system error in csmpensatory mode. The errof is computed by a simple analog cireuit using an EAI-TR-zO analog compuier. The switch F/ wilowed the display to be changed from pursuit ti compensatory or vice-versa. 
Tro inputs consisting of sumed sinusoids vere used with eech display configuration. The first was a low requency range $(0.0488 ; 0.1465 ; 0.2604 ; 0.4557$; $0.8138 \mathrm{gz}$ ) and the second was a high frequency range $(0.0813 ; 0.1465 ; 0.2604$; 0.4557 ; $1.4811 \mathrm{~Hz}$ ). The sue of anplitudes of indiriduai sinusoids in the imput signsi was always equal to ten and the compreent sinusoids vere equal in axiltude. These sumaed sinusoids benerated a vare form virh vas unpredictable by the subjects. Each operator was tested with four experinenial rariables: pursuit versus compensatory display mode; Ior frequiscy rersus high frequency sumed sine vares.

Host of the statisitical analysis vas done using the Minitab 2 statistical software package on an IBM 370 conputer. Graphics 2 in detailed conutations vere accomplished vith the Speakeasy computer language. Due to size considerstions of Minitab 2 and the ability of the time series technique to use fever semples to model a process that is statiuaary, we could use fever observations than woilj be necessary in Fourier series analysis. Although the experinents vere dane vith 20 ms sapling, the tiwe series analrsis was done first using a sapling inter$\mathrm{ral}$ of $0.2 \mathrm{sec}$. To check the adequacy of the 0.2 sec sapling interval, the frocedure vas repeated using an interval of 0.1 sec. Shinners [1] had ?ound that the faster sapling rate of $0.1 \mathrm{sec}$ did not add an additional wseful informetion to the human transfer runciion podels. This point vill be discussed later $o$. The first 5 seconds of data were discanded in botb cases to exclude the operators start-up transient. Figure 2 shows the last 20 sec of the orifinal data series of the two subjects in compensators and pursuit sracking.

\section{TDE SERIES THDORY}

\section{Transfer Punctions Modeis (TF)}

The tine serieg analysis cas be extended to obtais discrete linear transfer functions of systeas having an input $x(t)$ and cutput $y(t)$. By $x i t)$ and $y(t)$ ve mean pairs of observations that are availabie at equispaced intervals of tive. The behavior of the dynamic systen can be adoquately represented by the present and past responses and the current anc past ijputs of the syster. We denote mis process as TF (r, m) and write its ejuatica as

$$
y(t)=a_{0}+a_{i} y(t-1)+\ldots+a_{n} y(t-z)+\beta_{0} x(t)+\ldots+\beta_{\mathbf{b}} x(t-a)+\gamma(t)
$$

In suation ( 4 ) the parkmeters to be estimated are: $a_{0}, \ldots, a_{n}, B_{0}, \ldots B$, $n$ and $m$ The time series $r(t)$ is a randon term mesuring the differ ${ }^{\prime}$ 'nce between the response $y(t)$ and the variables used to explain the time series data. The parameter a measures the mea: cutput or the response of the process when there are no inpuls, i.e., $y(t)=a_{0}$, for $t \leq 0$.

In precognitive or single sine-vave pursuit tracking mode, the human operator is known to be non-causa. (possesses abllity to anticipate or predict future input [ 3$]$ ). In these experibents, hovever, where mixed sinusoids are used, the human controller behaves as a causal system. Therefore, we can assue $y(t) \equiv 0$ prio- to the applied input. Consequently, the coefficient a can be eliminated fran the wodel to be estimated and equation (4) becomes:

$$
y(t)=\sum_{i=1}^{n} a_{i} y(t-i)+\sum_{j=0}^{m} B_{j} x(t-j)+v(t),(m \leq 0)
$$



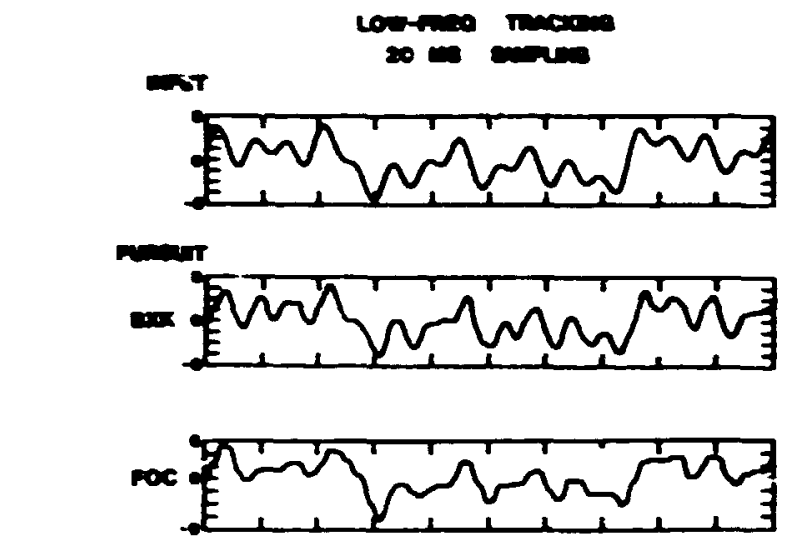

comematour
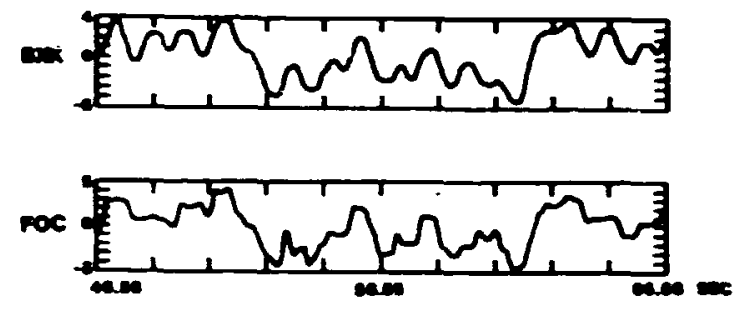

Figure 2: Last 20 seconds of the original data se-

ries at 20 ms sampling vith lor frequency sumed sinerave input. In both pursuit and campensatory, $\mathrm{BXK}$ is slightly better than FOC in their tracking ability. 
ORIGINin: $\therefore \quad$ - is

OF POOR Q.....?

The autocorrelation and the autocovariance Ructions sucsested by Bar and Jenkins [10] as rools for nodel estintion vill not be considered here because these nethods require much trial and error in the estintion procetures. Instead a technique proposed by Suen and Liu [20] and O'Mesil [21] which is simple and very reliable vill be introduced to estinate the desired aodel. This technique wich is a derivation of ordinary least squares regression analy is is called the Ioralized Fesidusl criterion (aRC) and is briefly described below.

\section{Theory of Nonalized Residual Criterion}

Bquation (5) reduces io an autoreoressive nodel $A R(a)$ if $x(t)$ ls onfted fron the nodel, and reduces to a moring average model $M(w)$ if lags of $y$ are ontted. The following assupticns vill be ande concernif $V(t)$ for a giren output time sequence $y(t), t=[0, T]$,

(i) $E[r(t)]=0$

(ii) $E[r(i) r(j)]=\sigma^{2} \delta_{i j}$

where $\delta_{i j}=l_{0}^{2}$ for $i=j$

(iii) T $>\mathbf{n}$.

The last assumption in equation (6) is comonly ade in such analysis [32].

Fran equation (5)

$v(t)=y(t)-\sum_{i=1}^{n} a_{i} y(t-1)-\sum_{j=0}^{m} z, x(t-j), t=1,2, . \quad T-n$

Define

$\sum_{t=1}^{T-n} v^{2}(t)=\|\underline{v}\|^{2}$ and $\sum_{t=1}^{T-n} y^{2}(t)=\|\underline{y}\|^{2}$

Note wat in the discussion below $\underline{V}$ and $\underline{Y}$ are vectars such that

$\underline{V}=\left[\begin{array}{l}r(1) \\ v(2) \\ \vdots \\ v(T-n)\end{array}\right]$ and $\quad \underline{Y}=\left[\begin{array}{c}y(1) \\ y(2) \\ \vdots \\ y(T-n)\end{array}\right]$

Squaring eq (7) and normalizing by the total sum of squares, ve have

$\frac{|| \underline{v} \|^{2}}{\|\underline{y}\|^{2}}=\frac{\left\|y-\Sigma a_{1} y-\Sigma B_{1}, x\right\|^{2}}{\|\underline{y}\|^{2}}=c(n, n, T)$

and therefore

$E\left[\|\underline{v}\|^{2}\right]=E\left[\|\underline{Y}\|^{2} \in(n, D, T)\right]$ 


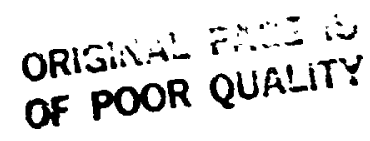

Since $y(t)$, the data series, is deterninistic, eq (U) can be rerritten as:

$E\left[\|\underline{v}\|^{2}\right]=\|\underline{y}\|^{2} E[\varepsilon(n, a, r)]$

Pros eq (g) ve have

$E\left[\|\underline{v}\|^{2}\right]=E\left[v^{2}(1)+v^{2}(2)+\ldots+v^{2}(T-n)\right]$.

which by assuption (ii) in eq (6) reduces to

$E\left[|| \underline{v} \|^{2}\right]=[T-n] \sigma_{r}^{2}$

Substitlting eq (14) in oq (12) we have,

$E[E(n, n, T)]=\frac{(T-n) \sigma_{v}{ }^{2}}{\|Y\|^{2}}$

and by as suption (iii) eq (15) becoues

$E[\cdot(n, m, T)]=\frac{T_{\sigma_{v}}{ }^{2}}{\|\underline{y}\|^{2}}$

The quantity $\in(n, m, T)$ depends on $n, m$, and $T$ and is proportional to the normailized variance of the regression for a giren $n$ and $m$. If this ratio is ninimized orer $n$ and $m$, then the data fit as eeasured by the correlation coefficient $\rho$ vill be maximized.

$\begin{array}{rlrl}\text { Note that } & \rho & =\left[1-\frac{\|\underline{y}\|^{2}}{\|Y\|^{2}}\right]^{\frac{1}{2}} \\ \text { or } & :=[1-\hat{\varepsilon}(n, m)]^{\frac{3}{2}}\end{array}$

were $T$, being a constant for the data, is amitted in the optimization procedure, and $\hat{t} \mathrm{a}, \mathrm{m})$ is the minimu value for $c(\mathrm{n}, \mathrm{m})$. This uptimization technique is the so called Normalized Residual Criterion (KRC).

$V_{a}$ 'jes of $e(n, m)$ vere computed for the various tracking situations and then plotted ilnst different values of $n$ in Figs. 3 and 4 . A typical graph (Fig. $3 A)$, josists of the $A R$ curve $(m=0)$, and a family of TF curres. In Fig. $3 B$ the MA is ve, though a function of $\mathrm{m}$, is superimposed on the $A R$ and $T F$ curves to a ist in comparison among all three models. The ordinate meosures the normailized iesidual, $\varepsilon(a, m)$, and this value is desired to be as small as possible. The analysis of various tracking data showed tiat the MA curve was the worst. The AR curve, though lorer than the MA curve was st1ll much higher than the fantiy of TF curves. Clearly then the $T F$ model is to ise prefered and the question to ask is which $\mathrm{TF}$ model is optimal.

The percentage drop in $\varepsilon(n, m)$ betwo the TF curves is negligible - the excepticn being the graphs for the high-rreq. inpit,. Figure 4, where the drop for $m=0$, is considersole compared to $m=1,2, \ldots, 6$. Thus the selected $T$ model 1.1 have at most $\mathrm{m}=1$ since there is no apparent explanatory difference contributed by $m=2, \ldots, 6$. To add statistical significance to our selection of model order note that the critical test is wether for $a \geq 1$, one can justify going from $n:=1$ to $n_{2}=2$. 

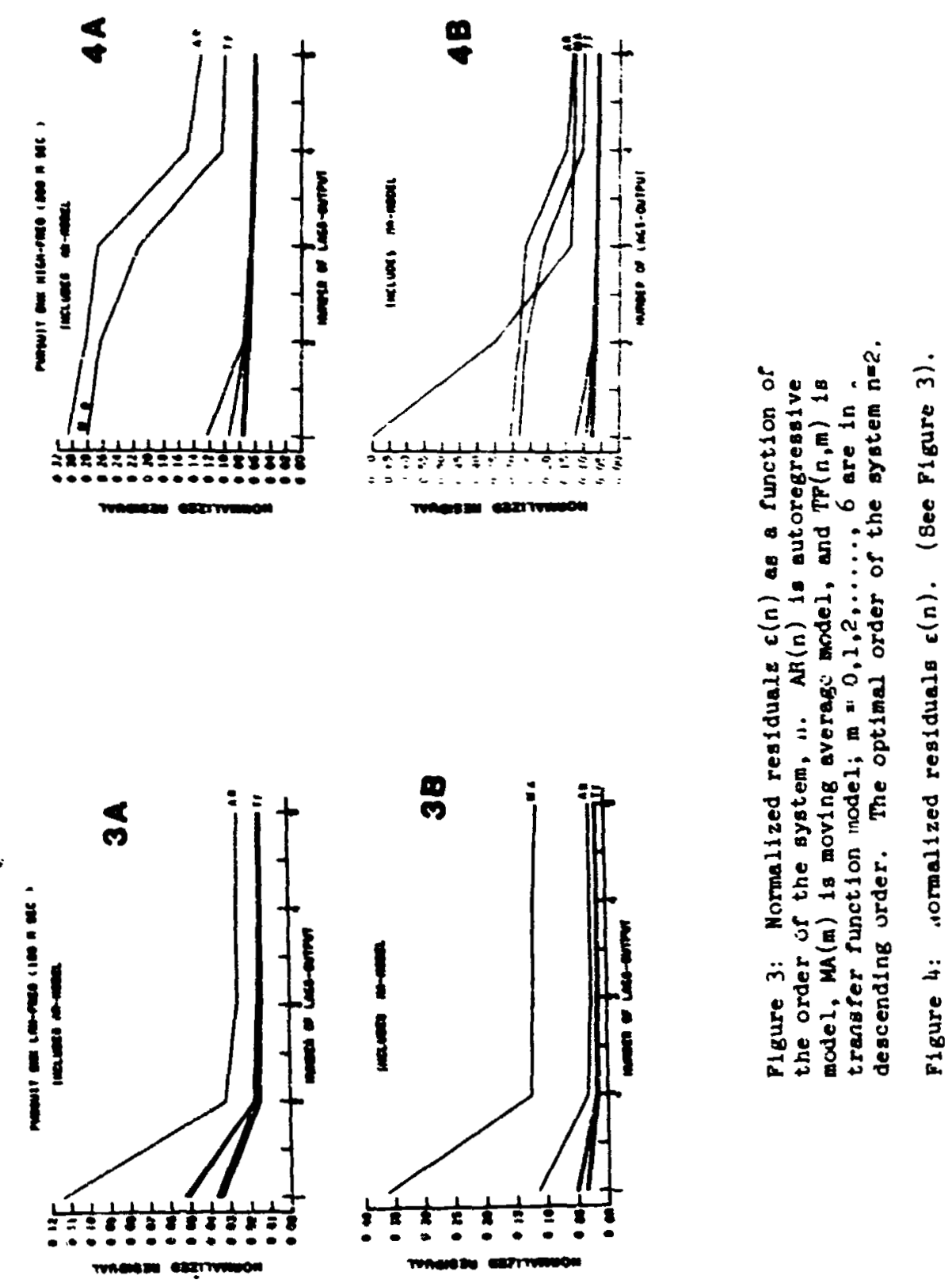


$$
I=\left[\frac{\left\|\left.\underline{v}\right|^{2} n_{2}-\right\| \underline{v} \|^{2} n_{2}}{\|\underline{v}\|^{2} n_{2}}\right]\left[\begin{array}{l}
T-n_{2} \\
n_{2}-n_{1}
\end{array}\right]
$$

is $F\left(n_{2}-a_{1}, T-n_{2}\right)$ distributed for large $T$, we tested this difference in going from $n_{1}=1$ to $n_{2}=2$. For examle in Fig, $4 A$, for $m=1$ in TF model, using $T=$ 3 $30, n_{1}=1$, and $n_{2}=2$, we get $1=297.1$. Since the $F$ - distribution table gives $F_{0.1}(1,120)=0.85$, it is elear that the data decisively rejects the hypothesis of no significant differense in normalized residual for $n=1$ and $n=2$. (cr. istrom and Eykhoff (30)!).

We, therefore, ind that for both input forms, for both sampling intervals, and for both subjects in pursuit as vell as compensatory tracking modes, the optimal laf structure $\dot{n}$ is always equal to 2. Enstrom and Rouse (33) using discriminant analysis noted that considering the tradeoffs between accuracy and feasibility for using a human operator model in real-time applications a second-order model was most appropriate. Beyond $n=2$, the $\varepsilon(n, n)$ curves do not add any explanatory power to the model selested. The resulting estimated models of the operator are of tine form:

$$
y(t)=\dot{x}_{1} y(t-1)+\dot{a}_{2} y(t-2)+\dot{j}_{0} x(t)+\hat{v}(t)
$$

for the low-frequency range, and

$$
y(t)=\dot{a}_{1} y(t-1)+\dot{a}_{z} y(t-2)+\dot{B}_{0} x(t)+\dot{B}_{1} x(t-1)+\hat{v}(t)
$$

for the high-irequency range.

The parameter yolues are $\because s$ ted in Tables 1 and 2 under the column unconstrained sodeis for FCC at $100 \mathrm{~ms}$ samoling and BXK at $200 \mathrm{~ms}$ sampling.

These tables show, as shinrers (1) had observed, that the faster sampling rate of 200 msec did not add any udditional isformation to the human transfer function models. In bcth cases, the model is of second-order. However, the value of the correlation coefficient of regression for pooled data from both subiects (equation 18) are significantly different at the two sampling intervals: $\hat{j}(100 \mathrm{~ms})=0.988$ and $\hat{\rho}(200 \mathrm{~ms})=0.958$. Aithough the $t$-test would show this difference to be significant at $P<0.0005$, the standard $t$-test is not valid for zodels with endogenvis lags [26]. The estimated standard deviation of regression value of the pooled data are also significantly different at 100 and $200 \mathrm{msec}$ samping intervals: $\dot{\sigma}(100 \mathrm{msec})=0.394$ and $\dot{o}(200 \mathrm{msec})=0.751$. Here again, although the $t$-test vould indicate a sienificant difference at $P<0.0005$, it is not $g$ valid test. The mean variance of the residuals $v(t)$ are also significantly different st the two samping intervals: $\sigma_{v}{ }^{2}(100 \mathrm{~ms})=0.495$ and $\sigma_{v}{ }^{2}(200 \mathrm{~ms})=1.988$. Based or. the average values of the correlation coefficients, the estimated stanjard jeviation of regression and the variance of the residuals, the $100 \mathrm{mse}$ samfline is certainly preferable to $200 \mathrm{msec}$ sampling.

\section{ionstrain $A$ Farameter Modeling}

In zenerai. information is transiluced to guide a physical system through a 
ORIGI:As +a:

OF POQ.? GuitutY

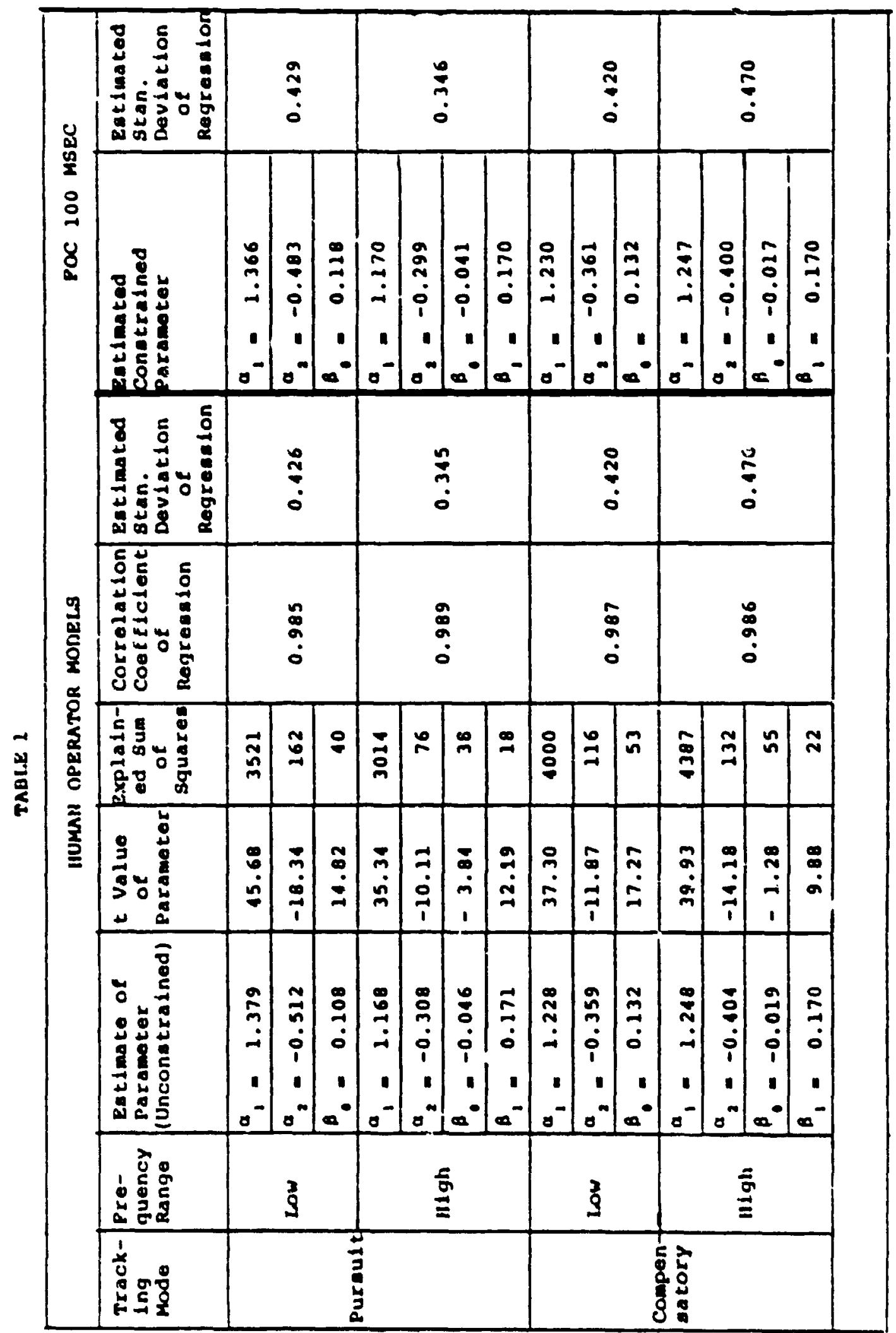




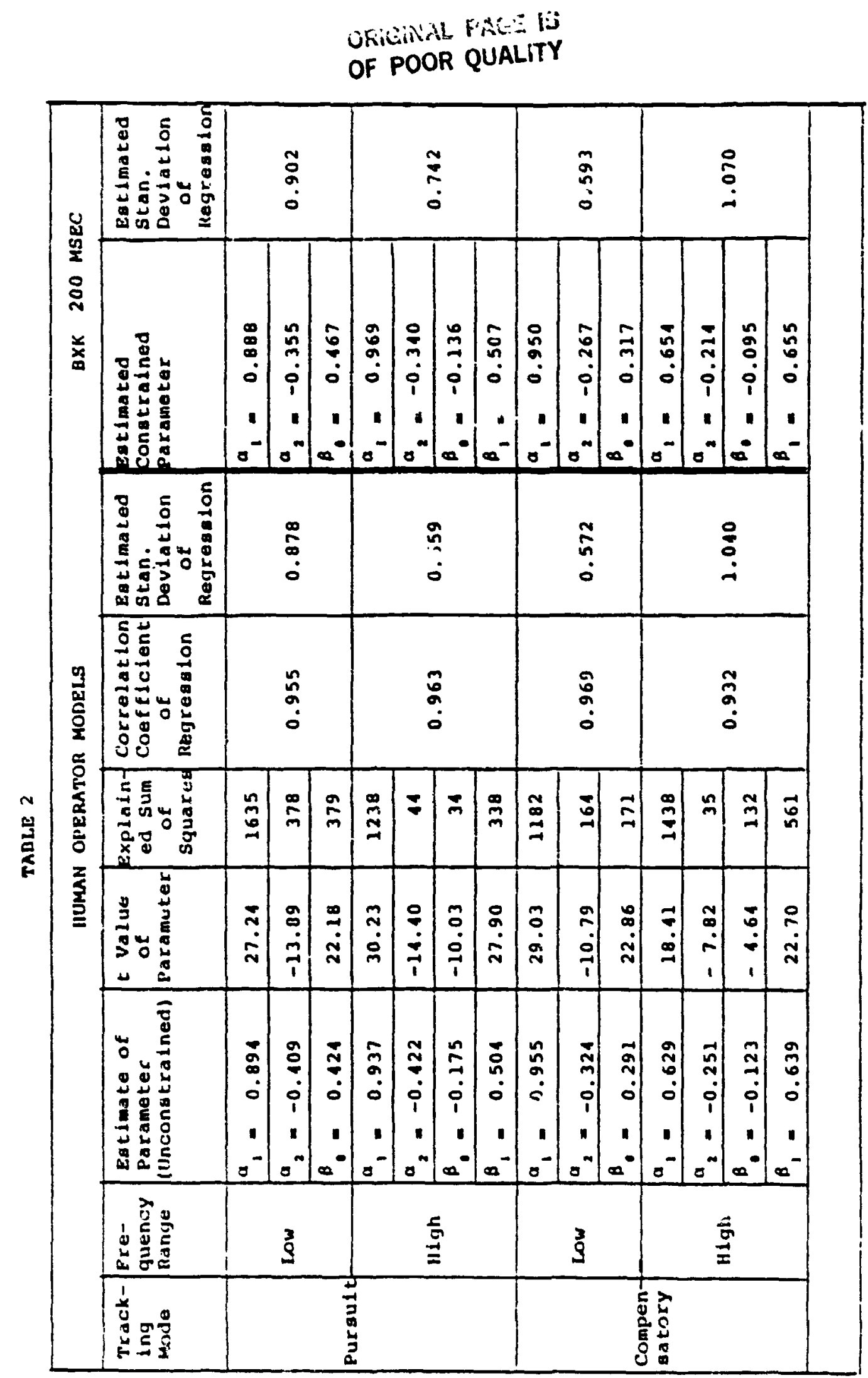


predefined course of action or sequence of states. Th: $s$ is accomplished through a series of decisions, each intended to minimize or otherrise constrain some function of the perceived error [22]. Consequently, a desirable property of any model for the human operator should be the ability, in the steady state, to track constant inputs with zero or negligible error.

Such a model can be obtained from the estimated model under conditions of equilibrium. That is, for sufficiently large $t$

$$
\begin{aligned}
& y(t) \equiv y(t-1) \equiv y(t-2) \equiv y_{e}, \text { and } \\
& x(t) \equiv x(t-1) \equiv x_{e}
\end{aligned}
$$

where $y_{e}$ and $x_{e}$ are the steady state response and input, respectively.

For the estimated models eq. (20) and (21), at physical and statistical equilibrium the hypothesized form of eq (20) with $y(t) \equiv y_{e}, x(t) \equiv x_{e}$ and $E[v(t)] \equiv 0$ become,

$$
y_{e}=a_{1} y_{e}+a_{2} y_{e}+B_{0} x_{e}
$$

and for $y_{e}=x_{e}$ to be true ve must have

$$
B_{0}=1-a_{1}-a_{2}
$$

Substituiting eq (23) in the hypothesized form of eq (20), we get

$$
y(t)-x(t)=\alpha_{1}[y(t-1)-x(t)]+\alpha_{2}[y(t-2)-x(t)]+v(t)
$$

Similarly the hypothesized form of eq (2l) becomes,

$$
y(t)-x(t)=\alpha_{1}[y(t-1)-x(t)]+\alpha_{2}[y(t-2)-x(t)]+B_{1}[x(t-1)-x(t)]+v(t)
$$

using the constraint,

$$
B_{0}=1-a_{1}-a_{2}-\beta_{1}
$$

Again regression analysis is used to estimate the parmeters $a_{3}, a_{2}$ and $B_{1}$. The parameter $B$ is then obtainec from eqs (23) or (26). The resultins parameters are also listed in Tables 1 and 2 under the column constrained models. The differences in the estimated unconstrained and constrained parameters are small as is the change in the estimated standard deviation of regression.

\section{Model Unit Step Response}

To judge the accuracy and performance of the constrained - pasmeter models and the unconstrained - parameter models, they are each tested with a unit step input.

Figures (5) and (6) show the step responses of both the constrained and unconstrained models plotted against time in seconds. The resultant curves are revealing anu the following remarks can be made concerning them: 
ORIGINAL PAEE IS
OF POOR QUALITY.
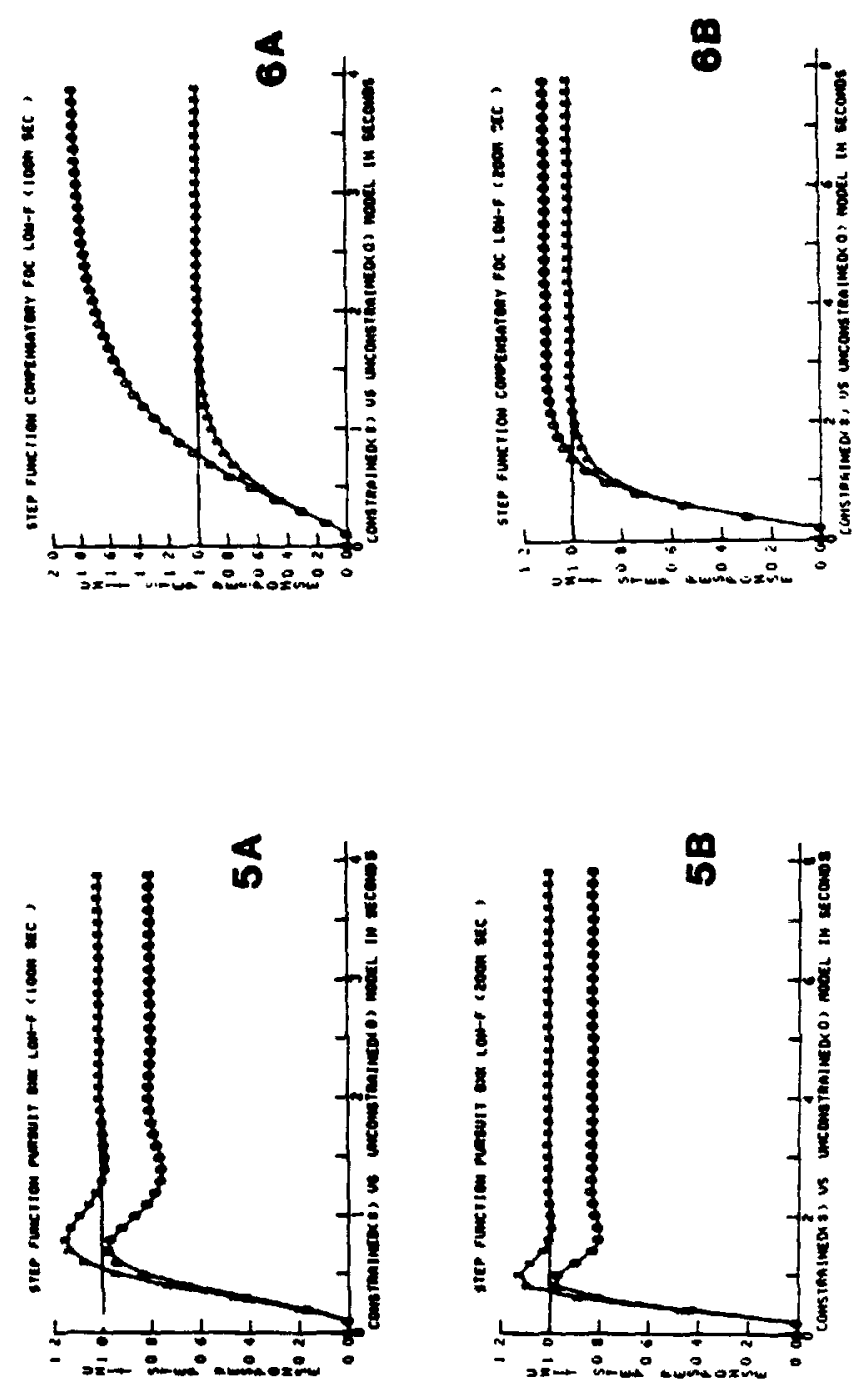

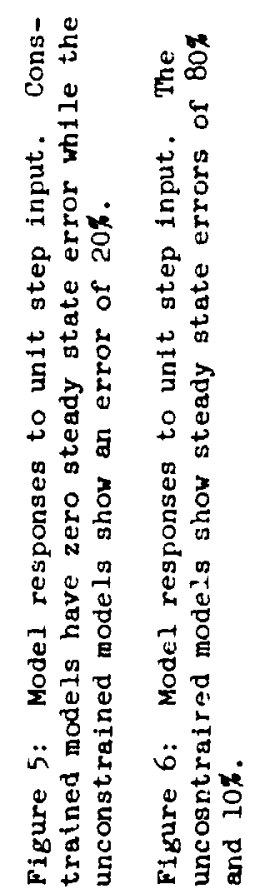


$\because$ Both models have tim aelays of about 0.2 seconds to 0.5 seconds, which is the time required for the response to reach $50 \%$ of the final value of unity.

b) The rise times of the constrained models are shorter than that if the unconstrained models.

c) The constreined models have settling times (the time to reach the 958 of the desired final valve) between 1 and 2 seconds. The uncoristrained models have indeterminate settling times since same never reach within $5 \%$ of the required value of unity due to steady state errors.

d) The uncosntrained models have varying degrees of steady state errors, making them inconsistent in their steady state respanses. For example, the steady state error is about $20 \%$ in both samples of Fig. 5 and about $80 \%$ in the top sample of Fig. 6.

The importance of constraining the operator models is obvious. Since the unconstrained model is inaccurate in transmitting the known response of the unit step signal, it cannot be relied upon to predict the system response to uriknown inputs to which the human may be subjected to in practice. This makes these models undesirable in describing the dynamics of the human controller.

Shinners [1] did not constrain his operator models and his model for operstor $C$ (equrtion $(3)$ ) with unity feedback gives an error of $15.8 \%$ for a step input runction.

In figures (7) and (8), the pursuit and compensatory responses are compered. These graphs also reveal interesting dynamics. For the los-frequency range, the pursult models all have shorter rise time and shorter time delay than the corresponding compensatory models. On the other hand, for the high-frequency range, the situation is reversed, i.e., the rise time and the time delay are shorter for the compensatory models. It is important to observe that the difference between the pursuit and the compensatory tracking modes lies only in the transient atage.

\section{Residial Analysis}

To determine whethe: the probability assumptions of ordinary least squares have been met and also to statistically justiry the selection of $\dot{n}=2$, several statistical tests were performed on the estimated residuals $\hat{\mathbf{v}}(t)$. Basically m require the $\dot{v}(t)$ to have a nornal distribution and to be statistically independent. Since we are estimating a las model, a Durbin-Watson test is inappropriate [21]. While the histograms of residuals appeared to be bell shaped and normal, we need to support this assessment quantitatively. The sampling distribution of this vtatistic is approximately the Chi-square distribution with $K-1$ degrees of freedom, where $K$ is the number of intervals for a given histogram. For example, for the pursuit FOC low-frea at $100 \mathrm{msec}, \mathrm{x}^{2}=0.0503$. Since this is much less than 24.9958 , the value of $x^{2} 0.05$ for $16-1=15$ degrees of freedom, the hipothesis that the residuals come from a normal population cannot be rejected at the 58 level of significance. From this test we conclude that the residuals are almost certainly fram a normal distribution.

Although the $\dot{v}(t)$ values pass the norwality test vell, (our $v^{2}$ tables only go down to significance levels of 0.005 and the measured $x^{2}$ is still orders below that entry), they might be autocorrelated. Such autocorrelation would indicate that more lags should be used in the models of the human operator. In this 


$$
\text { CUD }
$$


sense an autocorrelution test is more important than a normality test. We appplied an autocorrelation test to the residuals. This test was the standard. 'runs' randomness test applied o a sequence [23]. In toj. case, siuce the $v(t)$ have zero mean. If $s_{1}$ is the number $o_{i} t_{1 m e s}$ the $\hat{v}(t)$ are less than 0 anu $s_{2}$ the number of times the $\hat{v}(t)$ are greater than 0 , then the number of runs $q$ of successive $(t)$ signs and $(-)$ signs in the $v(t)$ sequence should be normaliy distrituted wth mean and veriance depending on $s_{1}$ and $s_{2}$. If autocorrelation exists in the $\hat{v}(t)$ then $s_{1}$ and $s_{2}$ wll make $q$ deviate significantly from its expected value. We applied the standardized test statistic.

$$
\bar{q}=\frac{|q-E(q)|}{\sigma_{q}}
$$

$t \quad 311$ of the residuals.

For exampie, for the compensatory BXK high-freq at $300 \mathrm{msec}$, the expected number of runs is $153^{\text {rand }}$ the obs s rved number cf runs is $\mathbf{s}_{3}=141, \mathbf{s}_{2}=165$. This test fos found to be statistically significant at level 0.0000 (rithin the resolution and accuracy limits of Miaitab 2) indicating a measured 100 scofidence that the residuals are certainly uncorrelated. 'Detalls of all of the statistical test appifed in this section can be found in (23]).

\section{SPECTRAL, ARALYSIS}

A stationary stochastic orucess $1 \mathrm{~s} s i \mathrm{~m}_{\mathrm{L}} \mathrm{ly}$ described by its autocovariance function. An equivalent lescription is provided by its pover spectrum, which is the Fourier transform of the autocovariance runction [17].

\section{Residual Spectrs}

In the anlysis of the residuals, Shinners [1] observed that the buman operator is a generator of seasonallty characteristes. He defined seasonality as the periodicity in the ooservations, 1.e., an observation at a particular time is related to observations from previous times in a periodic manner. The seasonality perfods in bis res il acalysis wern calculated to be $0.4,1.6$, and 3.4 sec for a unity feedback system. The origin of this seasonality effect was not clear.

In the residual speptra in Figure 9, for the luwn requency input sigen, the peaks occur at 0 and $0.7 \mathrm{~Hz}$ for both subjects in pursuit and compensatory modes using $100 \mathrm{msec}$ sampling. The necrest inpit frequencies vere 0.4557 and $0.8138 \mathrm{Ez}$. For the high-frequency input, these peaks occur at 0.2 and $1.5 \mathrm{~Hz}$ in three out of four cases and at 0.5 and $1.7 \mathrm{~Hz}$ for BXt in pursuit mode. The . Ighest 1aput rrequeacy vas $1.48 \mathrm{~Hz}$.

The peaks in residual spectra using 200 msec sampling anulysis with low-frequency input occur at $1.25 \mathrm{~Hz}$ in two cases, at $1.35 \mathrm{~Hz}$ and at $2.2 \mathrm{~Hz}$ in one case each. These are outside the input frequency range. With the bigh-srequency loput, the power spectra ihow peaks at 0.7 and $2 \mathrm{~Hz}$ and in scme cases 1 smain high even at the end laterval. Thus the cor spectra for 200 msec sampling sugges's that this rate is not as capable and effective as the 100 msec rate in eproducing the incormation content of the data series.

Shinne:s [i] had used noise generator with a bandridth of $1.5 \mathrm{~Hz}$ (our highest erequency slausoid lnput was at $1.48 \mathrm{~Hz}$ ). His $200 \mathrm{msec}$ agmpling analysis was probably inadequate as ve have observed in our anaiysis. He we fiad that the 
Oplas: :

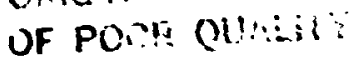

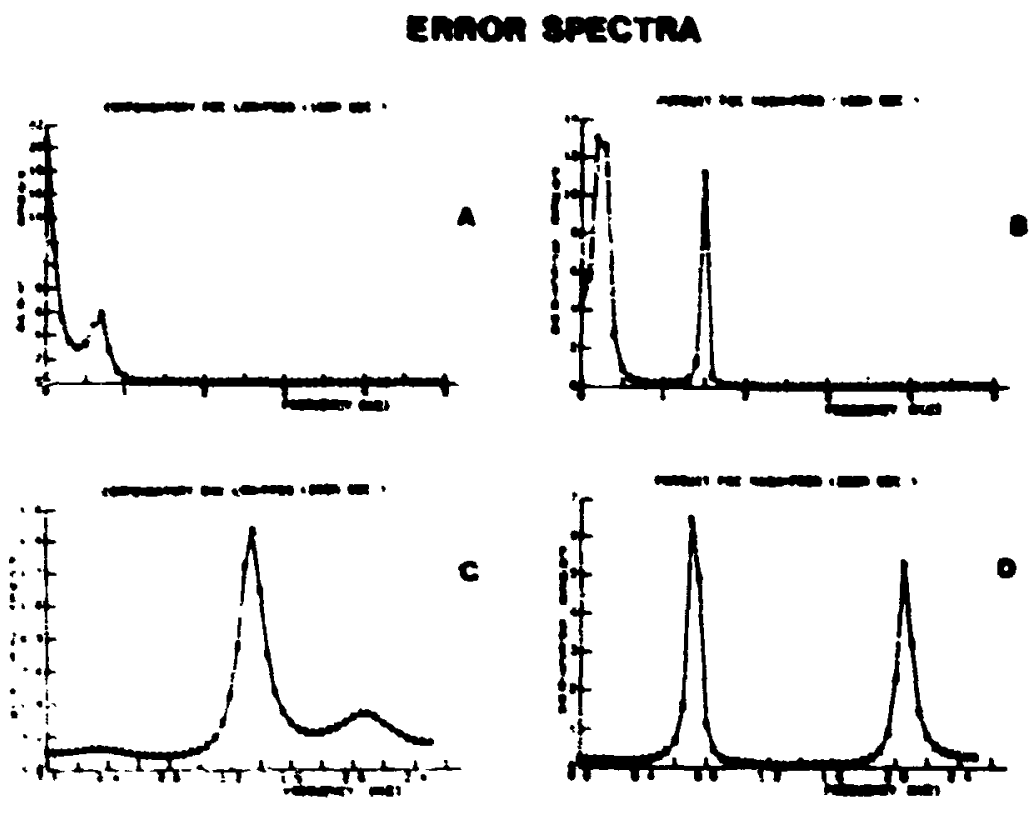

Finure 1) Ever spetta ut the resiluals. 
dominant peak in residuals is at zero frequency for the lov-frequency input and at shout $0.2 \mathrm{hiz}$ for the high-rrequency input. This does not see= to represent operator's generated seasonaiity.

\section{Model Spectra}

In any analysis of a time series model one is temted to retain only the aost significant lags and external variables [21]. Since our primary use of the nodel is for description of the operator dynamics and to sone extent for prediction, ve must aso veigh the su of squares explained by each lag and extermal variable. is indicated in Tables 1 and 2 scoe apparently statistically significant lag coefficients (bigh $t$ ralues), explain little of the total variation in the operator responses. Conversely, sone less signizicant coeficients (low $t$ values) are associated vith lass tal explain a large amount of variation in the data and therefore woult be strong predictors. Rather than arbitrarily elininate lafs from the model, all the lags vere kept regardless of the $t$ values of their coefficients and their expiained su of squares. (The nase "sin of squares" refers to the individuai contribution to the sun of squares of regression). form:

The estimated models (2h) and (25) have deterministic expected value of the

$$
\begin{aligned}
& \bar{y}(t)=\dot{a}_{1} \bar{y}(t-1)+\dot{a}_{2} \bar{y}(t-2)+\dot{\beta}_{0} \bar{x}(t) \\
& \bar{y}(t)=\dot{a}_{1} \bar{y}(t-1)+\dot{a}_{2} \bar{y}(t-2)+\dot{\beta}_{0} \bar{x}(t)+\dot{b}_{1} \bar{x}(t-1)
\end{aligned}
$$

where $\xi(t)=E[Y(t)] ; E[r(t)]=0$ by virtue of the linear regres=ion assumptions and $\hat{a}_{1}, \hat{a}_{2}, \hat{z}_{0}, \hat{B}_{1}$ are the estinated paraneters from Tables $I$ and 2.

Since (23) and (29) are inear, autoncous, difference equations, the stability of their equilibrium deternines thether the predicted operator responses will be bounded in ragnitude as $t$ becones large. The eigenvalues of the nodels, $\lambda$ and $\lambda$, satisfy the charecteristic polyacial:

$$
\lambda^{2}-a_{1} \lambda-a_{2}=0
$$

The equilibrium $F(t) \equiv 0$ is asyeptoticaliy stable if and only if $\left|\lambda_{i}\right|<1,1=$ 1,2. The eigenvalues are listed in $T$ ibies 3 and $h$ for $100 \mathrm{mec}$ sapling models. If $\lambda_{i}$ is complex the ters containing $\lambda_{i}{ }^{t}$ in whe solution $=: \bar{y}(t)$ can be written

$$
\lambda_{i}^{t}=\left|\lambda_{i}\right|^{t}\left[\operatorname{Cos}\left(2 \pi t / T_{i}\right)+\rho \operatorname{Sin}\left(2 \pi t / T_{i}\right)\right]
$$

where $r_{i}$ is the characteristic period associated with $\lambda_{i}$ anc is given by

$$
I_{i}=2 \pi\left[\tan ^{-1} \operatorname{Im}\left(\lambda_{i}\right) / \operatorname{Re}\left(\lambda_{i}\right)\right]^{-1}
$$

where $\operatorname{Im}\left(\lambda_{i}\right)$ and $\operatorname{Re}\left(\lambda_{i}\right)$ are the imagianary and real parts of $\lambda_{i}$, respectively. The $T_{i}$ is the period of oscillation of the components of $\bar{y}(t)^{i}$. The ralues of $T_{i}$ are aiso tabulated in Tables 3 and 4. 


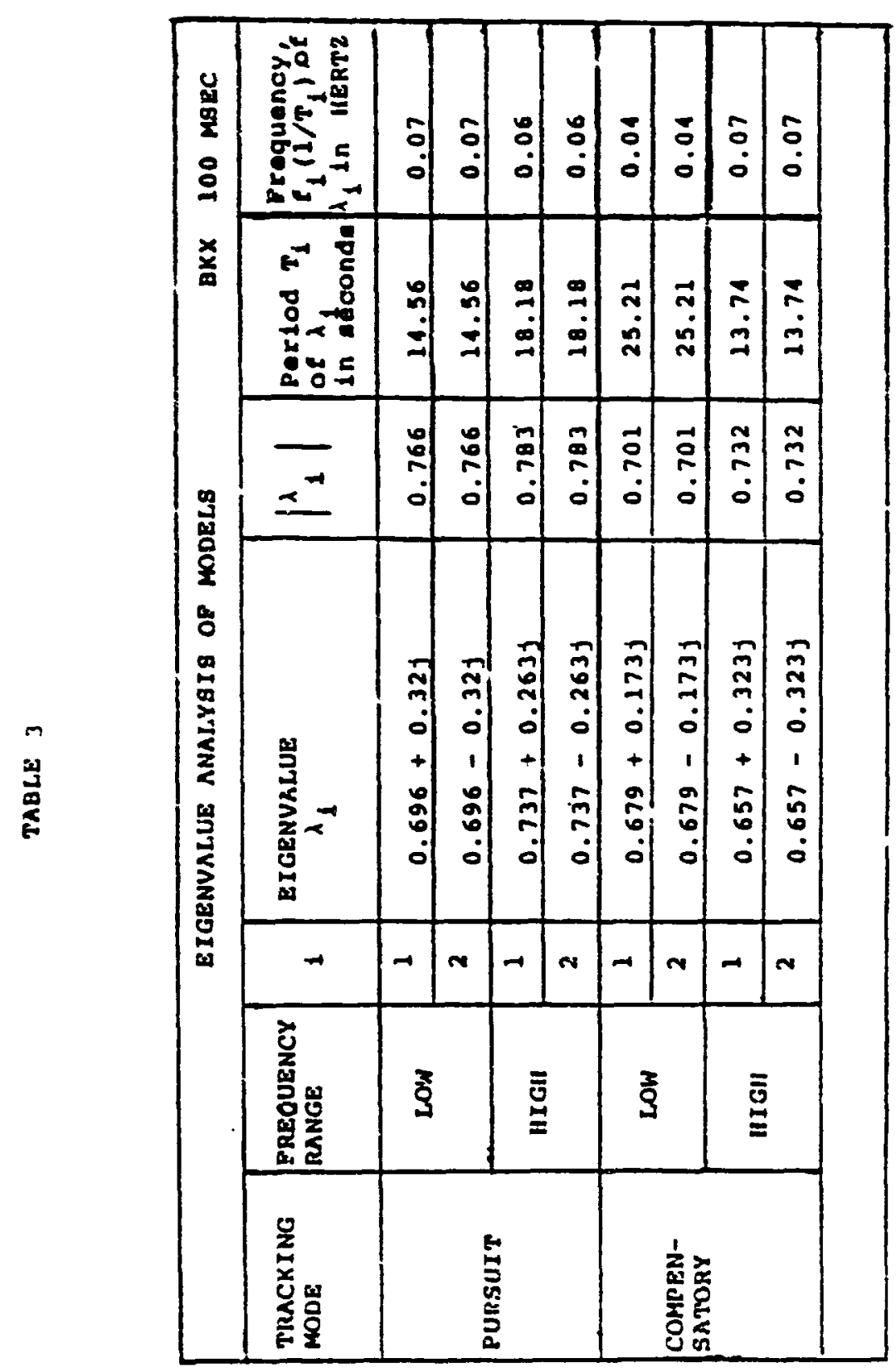


ORIGIBSL T:SE

OF POOR QiAuLi.

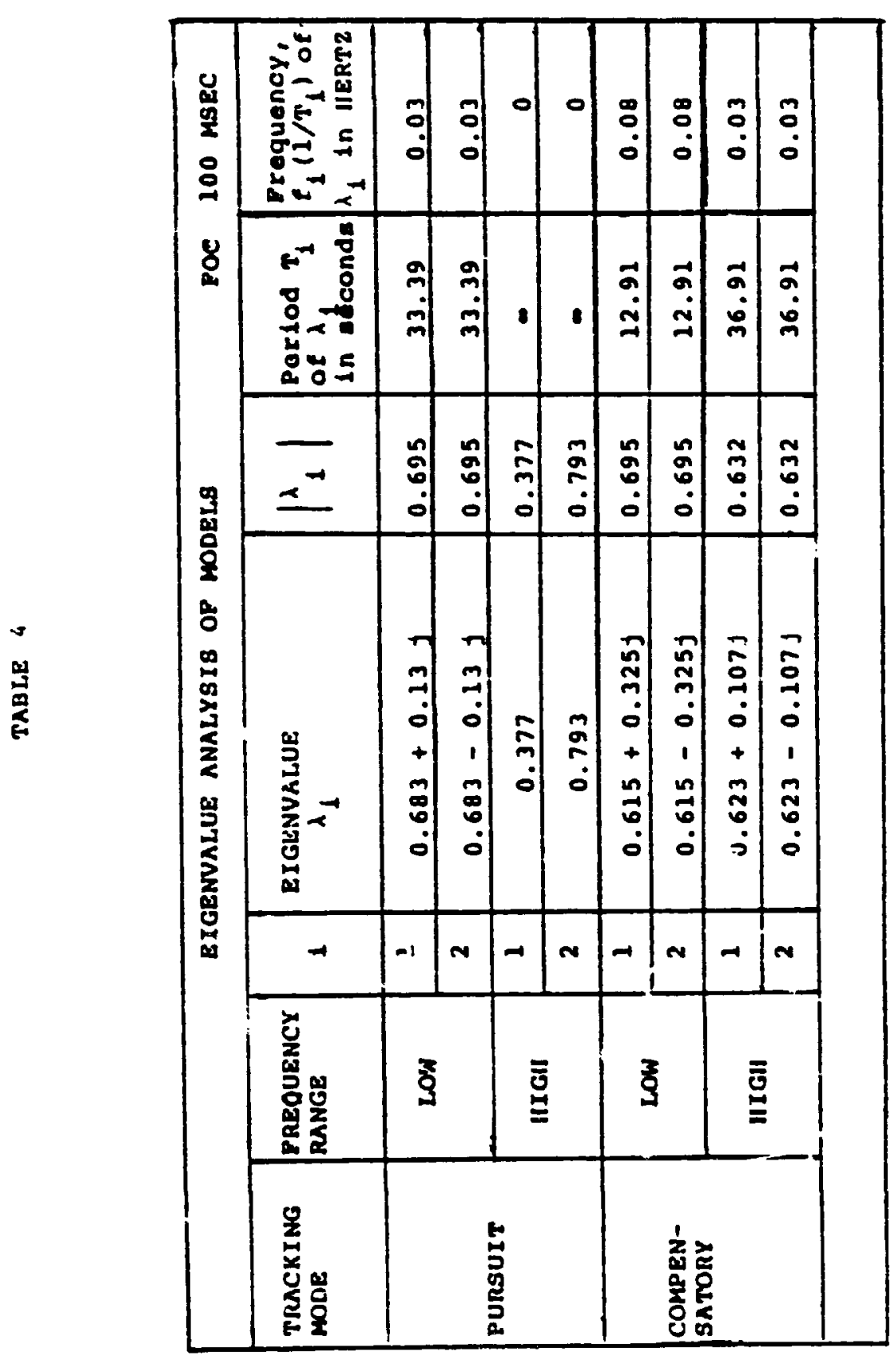


It is inportant to observe that the operator models for the r.ursuit and "arensatory trackin modes in ali catescries produce system ei zanvalues wich have very iarge periods and the system is absolutely stable.

Discrete Time Series models ian be Fourier transtormed into the frequency dusain $1: ?$ ! . hat is,

$$
x: ?)=H(t) x(t)
$$

were

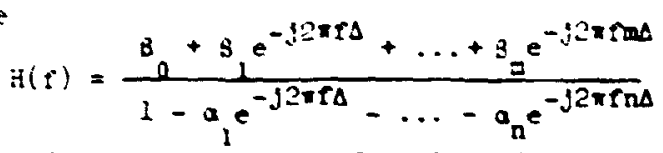

is the erequency response function of the system, $Y(f)$ and $X(:)$ are the Fourier transforms of the response of and input to the system, respectively. The frequency resfonse runction $H(I)$ is of interest becsuse it contains both the anplitude and the phase - shift information. Thus,

$$
H(f)=s(f) e^{j(f)}
$$

where

$$
3(t)=|\mathrm{H}(\mathrm{f})|
$$

ard $\partial(f)=\tan ^{-1}(\operatorname{Im}[\mathrm{H}(f)) \operatorname{Re}(\mathrm{H}(f)])$

The frequency response functions, gain and phase of the closed loop system incorporsting a human operator, are deficued in the Bode plots in Figure 10. The Sode plots reveal interestine and physically flausible dynamics of the human coniroller. The gain and phsse characteristies of both pursuit and compensatory tracking are quite similar. The human operator behaves as a lou-pass rilter. The chase irors ateadily from low to high rrequency. i.e., the outyut lass behind the infut.

\section{HRMAN OPESATOS TRANSFER FUNCTION}

The analysis so far has been concerned with the human operator in the forvard path of a closed-lcop unity feedbock system. Equation (33) defines the slosed-10op transfer function with the parameter values given $i .$. Tables 1 and 2 . Thus, for Foc in the pursuit mode with low frequency input and 100 msec sampling,

$$
H_{1}=\frac{0.138}{1-1.300 z^{-1}+0.483 z^{-2}}=-\frac{G_{H}(z)}{1+G_{H}(z)}
$$

where $J_{i}(2)$ is the human opeza or transier runction (as in equation (3)). Thereicre.

$$
B_{H} z^{\prime}=\frac{0.134}{i_{i-z^{-1}}\left(1-1 \cdot 54 z^{-1}\right.}
$$

The - - transion may be converied into a ianlace transform cunction using the collowne reistion:

$$
\mathcal{L}\left(e^{-n t}\right)=\frac{i}{s+1} \text { and } f_{f}\left[e^{-a k T}\right)=\frac{z}{z-e^{-a T}}
$$




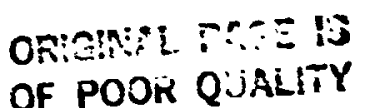
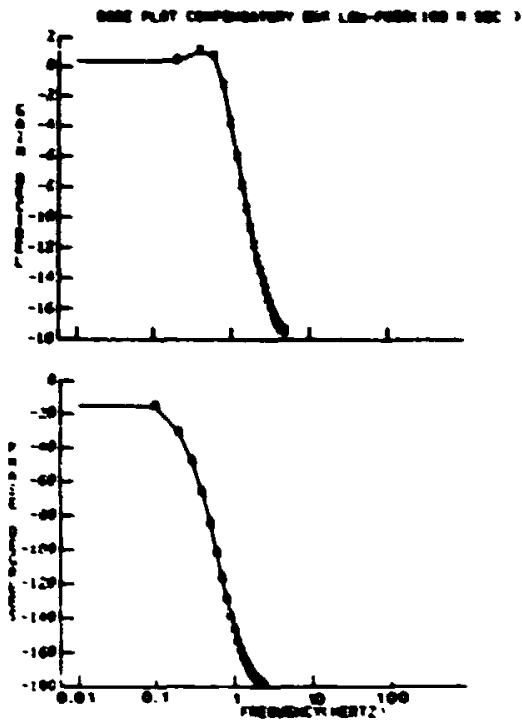

Iigure 10: Frequency response functions of the closed100 p model with unity feedback, subject BXK in compensatory mode. 
where $T$ is the sampling interval.

Fram equations (37) and $(38)(T=0.1 \mathrm{sec})$.

$$
\bar{v}_{H}(s)=\frac{0.134(s+13.3)}{s(s+6.02)}
$$

The human operator transfer functions in $Z$ - transform and Laplace transform equivalents are given in Table 5 for both subjects using $100 \mathrm{msec}$ sampline aralysis. These transfer functions are not in the normal forms given in equation (2) where an effective ime delay is included. The phase lag observed can be accounted for by a second order transfer function and with a zero located in the left half plane for low-frequency inputs and in the right-half plane for high-frequency inputs. The effective time delay is not a measure of the human operator reaction time to unpredictable inputs but a quantity which models the phase lag over the range of experimental input frequencies.

Shinners [1] found the human operator in compensatory tracking to be adequately represented by

$$
G_{H}(z)=\frac{K\left(1-T_{1} z^{-1}\right) z^{-1}}{\left(1-T_{2} z^{-1}\right)} \frac{\left(1+T_{3} z^{-1}\right)}{s e m p l n g}
$$

Fot the sampling interval of $0.2 \mathrm{sec}$, his time constants had the following limits: $O<T_{1}<0.83,0.39<T_{2}<0.99,-0.97<T_{3}<0.54$, and $0.48<K<0.65$.

In our analysis, (Table 5), $T_{2}$ is elways equal to one because the model is constrained to have zero steady state error for a step input. $T_{3}$ ranges between 0.237 and 0.728 rith $100 \mathrm{msec}$ sampling. Our numerator polynomials are different from Shinners and require at most one lag term.

\section{CONCLUSTONS}

Time-series modeling is apcverful and versatile technique in modeling human operator dynamics. Its versatility lies in the fact that it can very effectively model the operator in both the time and the irequency domain. In the former case, wich lies in the realm of paranetrıc modeling, the method is very parsimonious in the use of parameters to represent the model structure.

Fourier series analysis, wich finds its greatest utility in spectral analysis (or frequency domain), does not nutperform the timt-series methods. Tineseries analysis incorporating the stochastic properties of the data is a more useful device for prediction. Time-series analysis does not require any special tyFe of input and can be used in a normal operating environment.

A remarkable feature of the time series technique is its ability to use fewer observations than Fourier anaysis in capturing the necessary dynamies of the syster.

In a recent study, Jaeger, Agarwa, and Gottlieb [24] suggested that the predictor operator performs esseniicily the seme in both pursuit and compensatory tracking modes. Jur findings here are consistent with those results. 


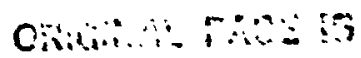

OF POUR QUALITY

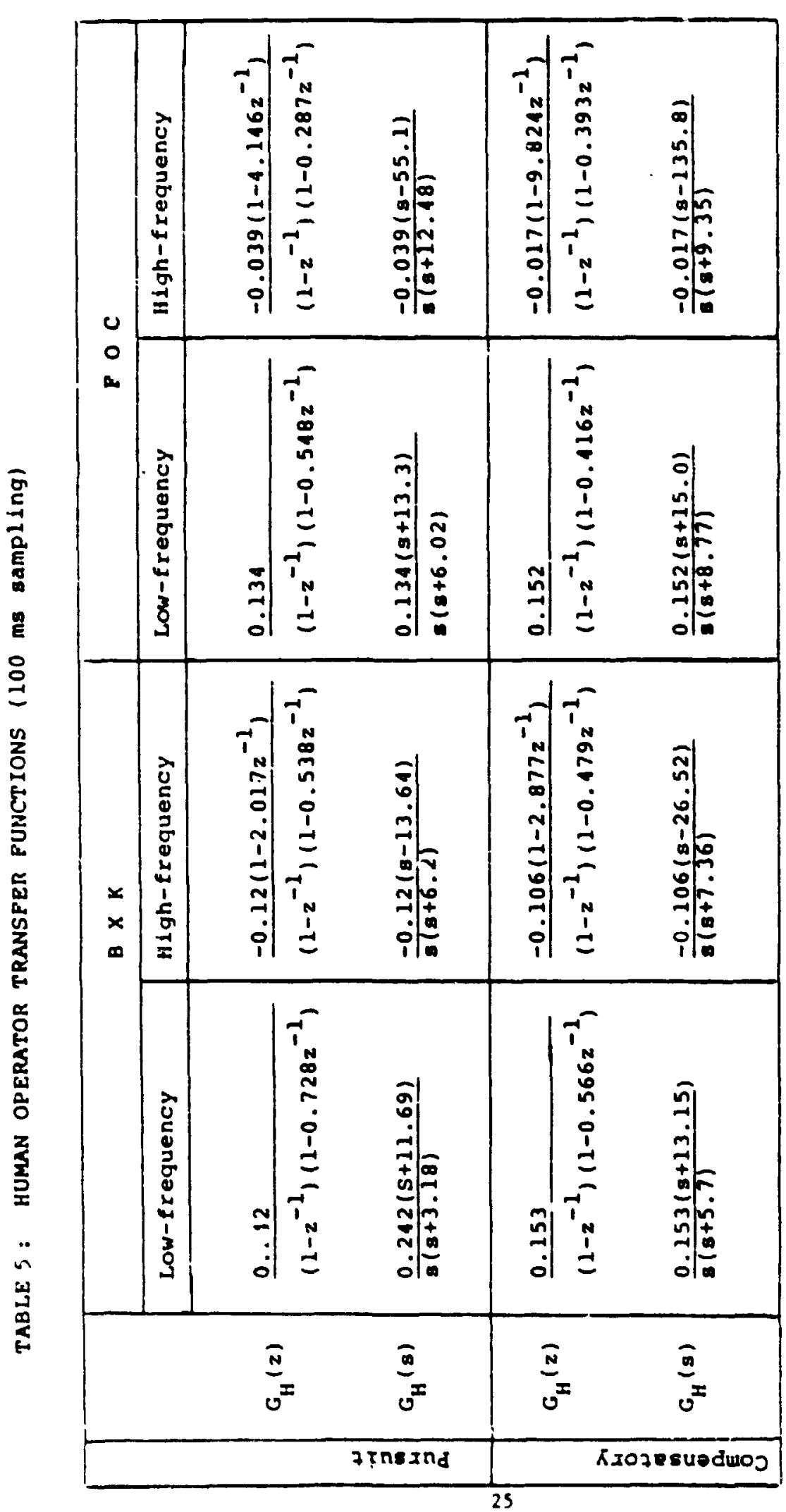


The method of sampling at $100 \mathrm{msec}$ is found to be adequate and effective in eapturing the information from the total observations. The $200 \mathrm{msec}$ interval is less accurate, especially in sampling vith high-frequency inputs, and is not recomended, although the overall dynamics after modeling are similar for the tuo sampline rates.

The Normalized Residual Criterion is a reliable tool for estimation of the model structure; it eliminates the use of the auto-correlation functions (ACF). Autocovariance runstion (ACVF) and the partial corrilation ranction (PCF) [16] and it combines the trial and error procedures of identification, estimation and diagnostic cheking used by Shinners [1] into a one step process.

The importance of constraining the parameters of the estimated time series models are stresged in this study. This is necessary if the models are to be accurate in describing the human dynamics.

The model spectra and the eigenvalue analysis clearly show that the human speratior is not a generator of periodic characteristics. The human controller's respunse eventually reaches a steady state if there is an input or decays asymptotically if the input is removed.

\section{REFERENCES}

1. Shinners, S.M. "Moteling of Human Operator Performance Utilizing Time Series Analysis", IMDE Trensactions on Systems, Man and Cybernetics, Vol. SMC-4, No 5. pp. $446^{\circ}-458$, September, 1974 .

2. SheridaI, T.B., and Ferrell, W.R., Man-Machine Svstems: Information, Control, and Dectsion Mode is of Human Performance, M.I.T. Fress, Cambidge, Mass., 1974.

3. Stark, L., Neurological Control Systems; Studies in Bioengineering, Plenur Press, New York, 1968

4. USuer, D.T., and jex, S.R., "A Revieu of Quasi-Linear Pilot Models", I dxI rans. on Human Facturs in Electronics, Vol. HEE - 8, No. 3, pp. $231-249$, September, 1907 .

5. Stark, L., Iida, M., and Willis, P.A., "Dynamic Characteristics or the Mctor Coordination System in Man". Biophysical iournal, Vol. 1, po. 270 - 300, 1961.

5. Navas, F., and Stark, i., "Sampling or Intermittency in Hand Control System Dynamics", Blophrsical Journal, Vol. 8, pp. 252 - 302, 1968.

T. Taylor, Jr., L.W., "A comparison of Human Response Model in the Time and Frequency Domains". Third Annual MASA - University Conference on Manual Control, NASA SP-133, pp. $137-153,1907$.

5. Shirley, R.S. "A Comparison of Techniqlies for Measuring Human Operator Frequency Response". Elxth Annusl Coafererice on Hanual Control, AFFDL, pp. 803Boo, April, 1070.

J. Kleinman, D.L. Baron, S., anj Levinson, W.H., "An Optimal Control Model or Human Resfonse - I: Thecry and Validation", Automatiea, Vol. 0, pp. $357-370$, 1070 
10. Baron, S., Kleinman, D.L., and Levinson, W.H., "An Optimal Control Nodel of Human "esponse - II: Prediction of Human Perfarmance in a Complex Task", Autcomatica, Vol. 6, pp. $371-384,1970$.

Ul. Young, L.R., "On Adaptive Manual Control", IEgE Transactions on Man-Hachine Systems, Vol. 10, No. 4, pp. 292 - 331, December, 1969.

12. Bekey, G.A., "Description of the Buman Operator in Control Syste" 3", in Modern Control Systems Theory, C.T. Leondes, Bditor, pp. 431 - 462, McGrav and 1111 Book Comp., H.Y., 1965.

13. Elkind, J.I., and Forgie, C.D., "Charecteristic of the Human Operator in Simple Manwal Control Systens", IRT Pransactions on Autcomatic Control. Vol. AC-4, Io. 1, pp. 44 - 55, May, 1959.

14. Voung, L.R., Green, D.M., Wurind, J.I., and Kelly, J.A., "Adaptive Dynamic Response Characteristics of the Human Operator in Simple Manual Cantrol", IMOE Transactions on Juman Factors in Electronirs, Vol. HFE - 5, Pp. 6 - 13, 1964 .

15. Tanaka, K., Goto, K., and Washizu, K., "A comparison of Techniques for Ident1fying Human Operf.tor Dynemics Utilizing Time Series Analysis", Proceedings of the Twelfth Annual Conference on Manual Control, IASA TM X - 73170, pp. 673 $693,1976$.

16. Box, G.E.P., and Jenkins, G.M., Time Serles Analysis: Forecesting and Control, Bclden-Dar Inc., San Francisco, Revised edition, 1976.

17. Jenkins, G.M. and Watts, D.G., Spectral Analysis and Its Applications, HolcenDay, Inc., San Francisco, 1968.

18. Akaike, iH., "Autoregressive Model Fitting for Control", Ann. Inst. Statistics Math., Vol. 23, pp. $163-180,1971$.

19. Akgike, H., "A New Look at the Statistical Mod=l Identificaticn", Imge Transactions on Automatic Control, Vol. AC - 19, No. 6, pp. 716 - 723, December, 1974 .

20. Suen, L.C., and LIu, R., "A Mormalized Residual Criterion for the Determination of Structure of Linear Systems", Pollcy Analysis and Information Systems, Vol. 1, pp. 1 - 22, July, 1977.

21. O'Neill, H.D., "Time Series Modeling of Chicago Particulates", ASCE Journal of Enviromental Englneering, Vol. 105, DE5, pp. 855 - 866, October, 1979.

22. Fogel, J.L. Human Information Processing, Prentice - Hall, Inc., Englevood Cl1f18, N.J., pp. $219-271,1967$.

23. Miller, I. and Freund, J.E., Probsbility and Stet1stics for Fugineerlng, 2nd edition. Prentice-liall, Inc., Englerood CIIffs, R.J., 1977.

24. Janger, R.J., Agarval, G.C., and Gottlieb, G.L., "Predfctor Operator in Pursuit and Compensatory Tracking", Fifteenth Annual Conference on Manual Control, Wright State University., APFDL-TR-T9-3134, pp. 311 - 330, 1979. 


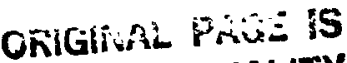 \\ OF POOR QUALITY}

25. McRuer, D.T. and Krendel, Ed. S., "The Kuman Operator as a Servo Syatem

Element" Journel Franklin Inst., Vol. 267, pp. 381 - 403 and pp. 511 - 536, 1959 .

26. Johnston, J., Econcmetrie Methods, and Edition, McGrav-H1ll Co., Nes York, 1972 .

27. Jex, H.R., McDonnell, J.D., and Phatak, A.v., "A Critlcal Tracking Task for Manual Control Research", IEnT Trens. Buman Factors in Electronics, Vol. HFE-7, pp. $138-145,1966$.

28. Maklad, M.S. and Michols, S.T., "A New Approach to Model Structure Discrimination", IFHE Trans. Systems, Man, and Cybernet1cs, SMC-10, pp. $78-84,1980$.

29. Fine, T.L. and Hrang, W.G., "Consistent Estimation of System Order", IEmE Trans. on Autcmatic Control, Vol. AC-24, pp. 387 - 402, 1979.

30. Astran, K.J. and Eykhoff, P., "System Identificstion - A Survey", Autamatica Vo1. 7, pp. 123 - 162, 1971 .

31. Jex, H.R. and Allen, R.H., "Research on a Nev Human Dynamic Response Test Battery", Proceedings of the Sirth Annuel Conference on Manuil Control. AFTDL, WPAPB, pp. 743 - 777, 1970.

32. Mehra, R.K., "On the Identification of Variances and Adaptive KaIman Filtering", IEEE Trans. on Automat1c Control, Vol. AC-15, pp. 175 - 184, 1970.

33. Enstram, K.D. and Rouse, W.B., "Real - Time Determination of How a Human has Allocated his Attention Between Control and Monitoring Tasks", IFES Transactions on Systems, Man, and Cybernetics, Vol. SMC-7, pp. $153-161,1577$. 


\section{$N 8234039 D_{2}$}

A GUNERR MODEL FOR AN AM TRACKING TASR

WITH TNTERRUPTED OBSERVATIONS

C. F. YU

R. C. WEI

Systems Research Laboratories, Inc. Dayton, OH 45440

M. M. VIrakinis

Aeruapace Medical Research Laboratory, Wright-Paiter 300 AFB OB 45433 


\section{ABSTRACT}

This paper deals with the problem of modeling a trained human operators' tracking performance in an ant1-alrcraft sys :em under various display blanking conditions. The input to the gunner is the observable tracking error subjected to repeated interruptions (blanking). A simple and effective gunner model was developed by extending Kou's observer model [1], which dealt with the case of no blanking. Our approach is to model the effect of blanking on the gunner's tracking performance via modeling the observer and contioller gains.

\section{INTRODUCTION}

One of the fundamer.:al goals of the A1r Force in 1te Manned Threat Qualificatlon Program is to evaluate and pr dict the effectiveness of a manned ant1aircraft artille;y system. The main problem associated with it is to deveiop a mathematical model(s) for the gunner so that analysis and computer simulat1ons of the closed loop man-machine system become possible. The fact that a trained human operator performing simple control tasks has consistent response is crucial for the effort of human operatn- modeling.

The mathematical modeling of a human operatcr in a simulated AAA system has been studied by many Investigators during the past twenty years. Basicully, the human operator was treated as feedback controller or compensator in the closed loop system. McRuer [2], us Ing frequency domain analysis, described the human nperator with a linear transfer function and a remant element. Kletnman [3], using an optinal stochastic control formulation, quantified the human operator as an optimsl estimator and controller w.r.t. a lost functiomi and corstraints. Ko: (1), using a reduced order observer, cha racterized the human operator as a 1 inear state feedback controller and Luenberger stat reconstructor, with all system nolses lumped Into one remant. A' $1 t^{\prime}$ ase models were able to explain their laboratory data under certain sfecj ler tracking conditions. For a discussion of model validation and the PID ar sel istaplified optimal control model), see Phatak [4], [5].

This paper develops a blanking model (Interrupted ooservat'ons) for a h.man operator performag a two-axis tracking task in a simulated AAA systam. ho in the previous studies, the human operator percelves his tracking error as a displayed feedback signa?. However, In this case, the display error signal is subjected to repeated triterruptions which occur at pseudo random times. The interruptions are, in the real world, due to electronic/optical councermeasures, or weather condifions like $\mathrm{fcg}$ and visibility, etc. Using the optimal control model, Kleinman [6] has Jonk an Initt,ll st,udy of this conditinn (one second blanking without repetition). In [6], the effects of blanking on tracking performance were modelied via 1ncreasing the observation nolses. We apply the observer formulation, and model the effects of blanking via degrading the observer and controller gains.

\section{THE EXPERIMIENTS AND THE TRACKING DATA}

The general configuration of the manned MA system 1s shown in Figure 1 . For a detalled description of the MA simulator, see Rolek [7]. 


\section{ORIGINAL PAGE IS \\ OF POOR QUALTY}

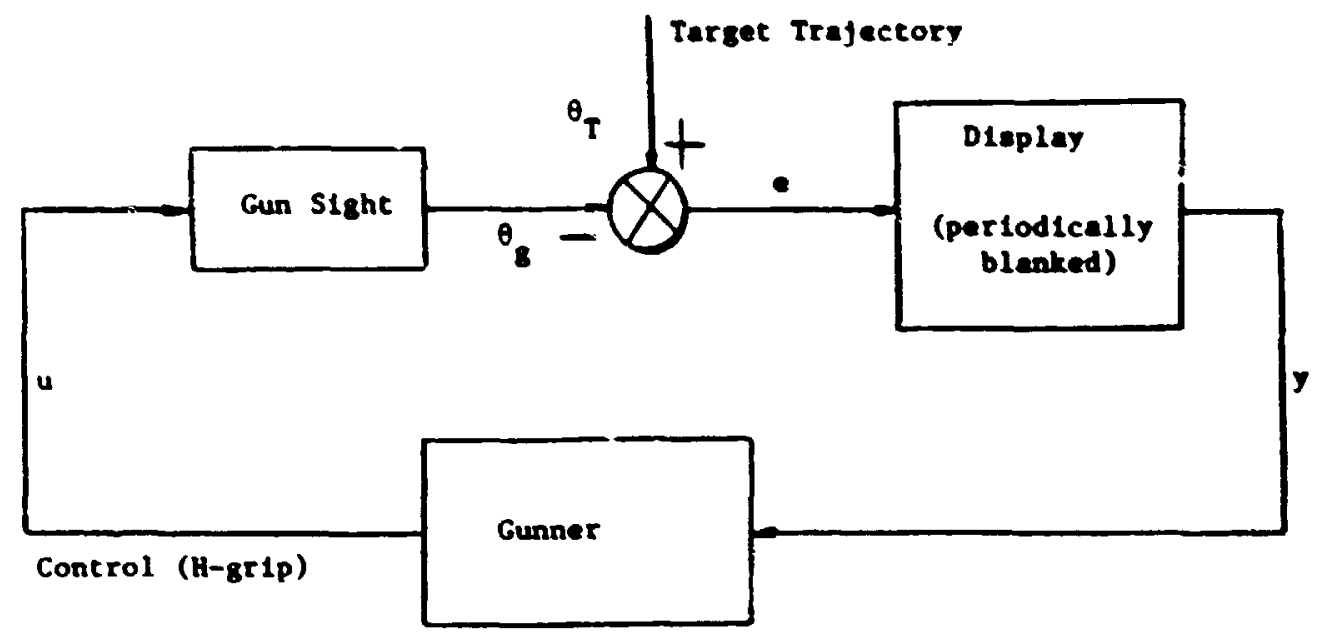

Figure A. General Configuretion of the Blanking Experimenta Conducted at MRL

Three trained subjects wre aked to track a ecying target (almulated alrcraft) on the diadlay screen duriug an ent fre run of epproximately 60 saconds. The subject wed ate centrol to direct the gunelght (pedestal) to follow the target. The ecreen was blenked parlodically eccording to one of the following five bl nking condit lons.

(1) blankiag durat lon 1.5 seconds, percentage of tim blankod 258

(2) blanking duration 3 seconde, percentage of time blanked 253

(3) blanking duration 6 seconds, percentare of time blanked $25 x$

(4) blanking duration 3 seconde, percentage of c1me blanked $25 x$

(5) no blanking during the - Irn run (base line)

There were four pre-programed, deterniniet1c, input terget trajectories, namily, the $2 \times 2$ flyby, the $4 \times 5$ flyby, the recon, and the wapon dellvery. At each run, the subject had no Informetion about (a) which of the four trajectorles was used as the driving input, and (b) which of the five blankins conditions vas being applied. With that experianta! dealfo, the subject wes conaldered as tracking uniknown target mot1un under peoudo-randon interruptions. Esch of the twenty tracking altuations were run 40 time each and the tien hietory of che tracking errors recorded. The seans and standard devlations were then computed from the 40 repllcatione. The wole experiment generated twenty eats of enseabled tracklng data per subject. One subject's trackinr data we selected for the codeline and simulation study.

Soce observation on the tracking data

(1) The thres subjects had reasonabiy coneistent tracking reaponses. The "patterne" of the man tracking errors and the etanderd deviatione were very -1siler. In som slewetione, the eagnitudes of the tracking data differed 


\section{ORIGINAL FRGE IS \\ OF POOR QUALITY}

slighely. The differeaces could be explained as dus to a subject's tracking skill or his individual psychophysical parameters.

(2) The dagration of tracking perfornance due to blanking was very significant. The "induced errors" (relative to ro blanking data) depended on blanking duration, percentage of tine blanked, and local characteristics of target notica. For exaple, if the target acceleration reversed iss direction within a long blanking, the peak tracking errors were significantly auch larger than that of the no blanktng case.

\section{OBSERVER GODEL WITH IDEE VARYIMG GAIS}

A close exmination of the gunner's tracking perforeance Indicates that the gumer can be regarded as a feedback controller. The feedback available to hin consists of the displayed signal (observation) and the non-visuai feedback generated through his control interaction with the dyamics of the systen (perception). With this understanding, we assune that the gunner has an inter.. nal nodei of the closed loop systen driven by his observation and his perception. It is natural to further assune that the gunner's control output is completely based on that incernal model. Also, with the rate control in aind, it is not difficult to realize that the gunner's whole tracking efforts are basically designed to generate a key interaal state variable - the target velocity. The gunner's internal wodel of target velocity was considered as the key variable in his feedback strategy. To quantify the gumner's internal target velocity, we assune that the irternal velocity is actually generated via a luenberger observer or state reconstructor. The assocluted observation or reconstruction gains are, in general, tive varying. The gains depend on tracking conditions (information feedback), rask difficulties (loca: trajectory characteristics), tracking skill, and the gunner's poychophysical paraneters. Finally we assune that the gunner's feedback control lav is linear in his observation and his perception. The closed loop wodel structure is show in Figure . I em (1) to (6) sumarize the odeling assumptions.

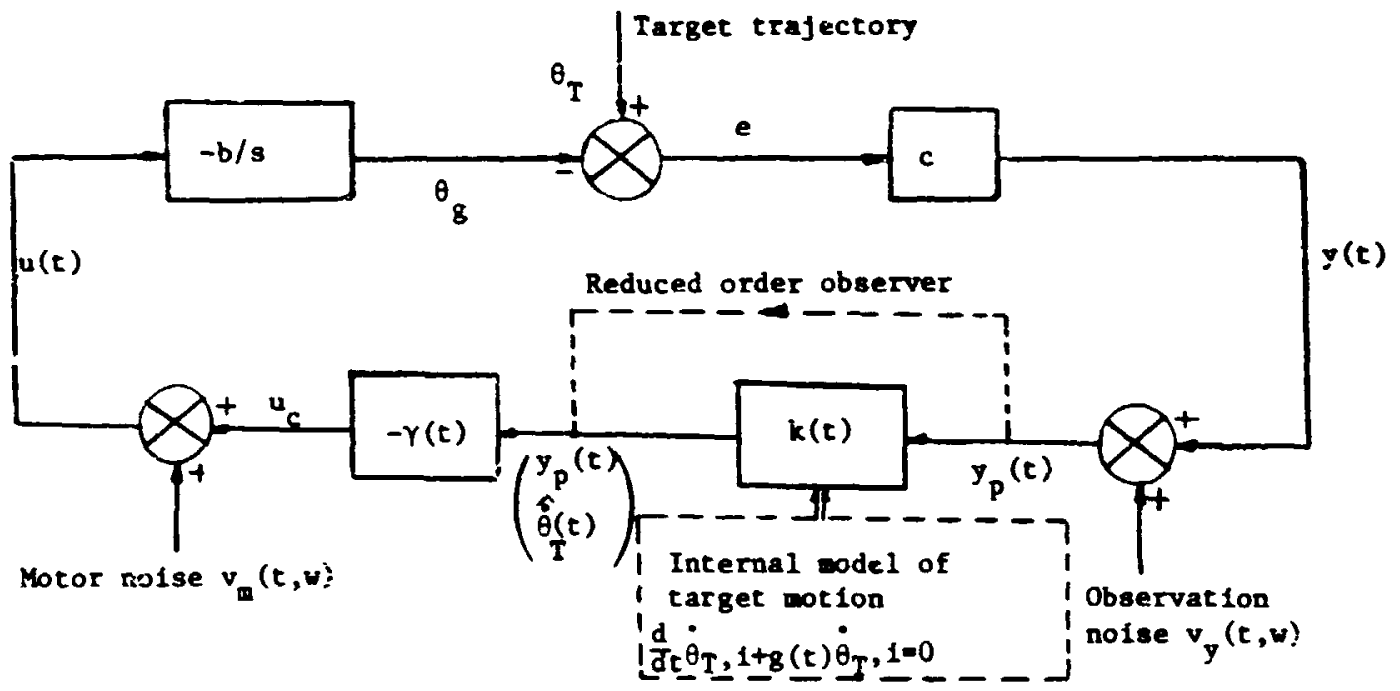

F1gure B. Observer Model with Time-Varying Ga1ns 
The oodeling sesumptions:

(1) Huan operator's internal adel of target wotion (adaptive) $g(t)$

(2) Gun dynanics and visual observation factor (learned by H.0.) -b/e, c

(3) Foedback control law (1lnear)

(4) Eatination error dynanice (reduced-order observer)

(5) Tie delay (naglected)

(6) Notse ecructures (whice, with suztable covariances) $-r(t)$ $k(t)$ 0 $V_{\mathbf{n}}(\mathrm{c}), V_{\mathrm{J}}(t)$

Define the state variables of the closed loop syster a $x(t)=\left(x_{1}(t), x_{2}(t), x_{3}(t)\right)^{T}$. where

$x_{1}(t)-y(t)-c \cdot(t)-c\left(\theta_{T}-\theta_{1}\right)-$ dlaplayed tracking arror

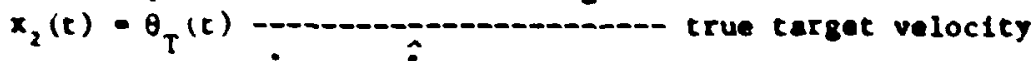

$x_{j}(t)-\dot{j}(t)-\dot{\theta}_{T}(t)-\dot{\vec{\theta}}_{T}(t)-\ldots-\ldots-$ velocity eetination error

In 1 leu of the sasumptions (1) to (6), we have

$$
\begin{aligned}
& \dot{\theta}_{g}(t)--b u(t) \\
& u_{c}(t)--r_{1}(t) y_{p}(t)-r_{2}(t) \dot{\theta}(t) \\
& \dot{B}(t)--\left(k(t)+g(t) B(t)+\ddot{\theta}_{T}(t)+g(t) \dot{\theta}_{T}(t)-k b c z_{m}(t, v)\right. \\
& y_{p}(t)-y(t)+v_{y}(t, w) \\
& u(t)-u_{c}(t)+v_{m}(t, w)
\end{aligned}
$$

The above equations can be uritten in atrix fore we $\dot{X}(t)=\Lambda(t) X(t)+F \ddot{\theta}_{T}(t)+$ noise terms

where

$$
\begin{aligned}
& A(t)=\left[\begin{array}{ccc}
\frac{\dot{c}}{c}-b c \gamma_{1} & c\left(1-b \gamma_{2}\right) & b c \gamma_{2} \\
0 & 0 & 0 \\
0 & s(t) & -(k(t) c+s(t))
\end{array}\right] \quad F=\left[\begin{array}{l}
0 \\
1 \\
1
\end{array}\right] \\
& \text { Noise teras - }\left[\begin{array}{c}
b c v_{w}(t, w)-b c y_{1} v_{y}(t, w) \\
0 \\
-k b c v_{a}(t, w)
\end{array}\right]
\end{aligned}
$$

IV THE DLANKING MODEL NND THE SMMUATION STUDIES

Only the elevetion case to considered here, the axtmith case 1 of ofllar and will be reported elsewhere. Note that $c-1$ and $b-1.34$ for the elevation case. For elmplictiy, we essune that the observation noise can be lupped into the otor nolse (or siply aseune that there 1e no observation no1se). The covarlance of the motor nolse is assumed to be of the fore

$$
E\left[v_{0}(t, w) v_{m}\left(t^{\prime}, w\right)\right]-\left(a_{1}+a_{2}\left[\hat{\theta}_{t}(t)\right]^{2}+a_{1}\left[\ddot{\theta}_{t}(t)\right]^{2}\right) \cdot \delta\left(t-t^{\prime}\right)
$$

The control galns $Y(t)$ and the observation gaine $k(t)$ are codelled as expontent1ally decreasing as che blanking proceeds, and exponentially lncreasing as the 
blanking stops. Both theoretic arguments and actual Identification lead to the relation $b \cdot Y_{2}-$ !, we assume that $Y_{2}(t)$ ls a conatant. Aleo, $g(t)-c$, 1.e., no target acceleraction 1 sercelved by the gunner.

\section{Parameters 1dent 1fied}

(PO) The base line paraweters were identifled fron the $2 \times 2$ flyby - no blanking data:

$k=0.48, Y_{1}=-2.9, Y_{2}=-0.77$

$a_{1}=0.0003, a_{2}=0.009, a_{3}=1.3$

(PB) The time constants we identified froe the $2 \times 2$ flyby - blanking condition 2 data:

$\tau\left(\gamma_{1}\right.$, blanking $)=2.32$ secs $\tau\left(\gamma_{1}\right.$, recovery $)=1.92$ secs

$\tau(k, b l a n k i a g)=13.0$ secs $T(k$, recovery $)=4.0$ secs

The above Identified parameters veru used in the simulation studies. Since the $4 \times 5$ slyby is considered to be sintlar to the $2 \times 2$ flyby, we only 1llustrate sianiation results for the $2 \times 2$ flyby, the recon, and the weapon dellivery. The results under various blanking conditions are shom in Figure 1 through Figure 8. Figure 9 is lacluded for the discussion of an adaptive observer is the next section ( $k=1.2$ Instead of 0.48 ).

\section{v. CONCLUDING REMARKS AND FURTHER RESEARCH}

Modelled as a linear feedback controller and a state recunstructor, the gunner was paraneterlzed by the control geins and the estinatior gains. These if ee varying gains together with the nolse covariances characterized the guriner's tracking performance. The time varying gains directly reflect the gunner's tracking sk111, tracking conditions, and his own paychophysical parameters. thence, the gains were modelled and identifled from the experimental data.

It is worth noting that the tine varying estiation gains in this paper are not completely equivalent to the time-varying gains in kalman filter. (Note that in both cases, the estimators have the sane form of dynamics:

$$
\dot{\hat{\mathbf{X}}}-(\mathbf{A}-\mathbf{R}(t)) \hat{\mathrm{x}}+\text { obs. data). }
$$

The Ricatt 1 equations in the Kalaan filter describe the propegation of error covarlances for given noise statiatics. The time varying nature of the filter gains is due to a finite tine of observation. The noise covariances always affect the filter galas in a fixed anner. If one treats a huan operator as a Kalman filter in his estiantion process, the human operstor's eatiantion gains are optimal w.r.t. mean-square criterion. However, a constrained falan type eatintor can be designed, see Aok1 [8] for an example of limited number of wory elewents. On the other hand. - Luenberger observer can be ex...ded to a stochastic estimator, see Tse [9] for a unifylag approsch. For relevant work on the Impliclt adaptive observer, see Nuyan $[10]$.

The simulation results show very good model vs date matches. However, as indicated frow Figlire (1) to (8), some peak tracking er:ors predirted by the wodel tend to elther overshoot of undershoot. This is due to the non-adaptive internal wodel of target motion in the current simulation $i g(t)-0)$. In the observer formulation, the "local bandwidth" $g(t)$ of the internal velocity directly entera

the observation $g a$ in as $(k(t)+g(t))$. The adgptive nature of the gunner's perception of target wotion can be modelled by cont inuously "updating" the gain. 
In other words, by codeling the galn according to the gunner" perception of targut acceleration, the overahoots can be elininated. Figure 9 show a typlcal aleulation result based on the ldea of an adaptive observer.

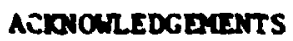

This work was supported by the 6570th Aerospace Madical Rasearch Laboratory, Wr1ght-Patterson NFB, Dayton, Oh10, under Contract F33615-79-C-0500. The authors wish to thank Mr. Halt Sumars. Dr. D. W. Repperger, and Dr. C. M. Day, Capt. A. Dickson for their valuable sugsestion and support. 

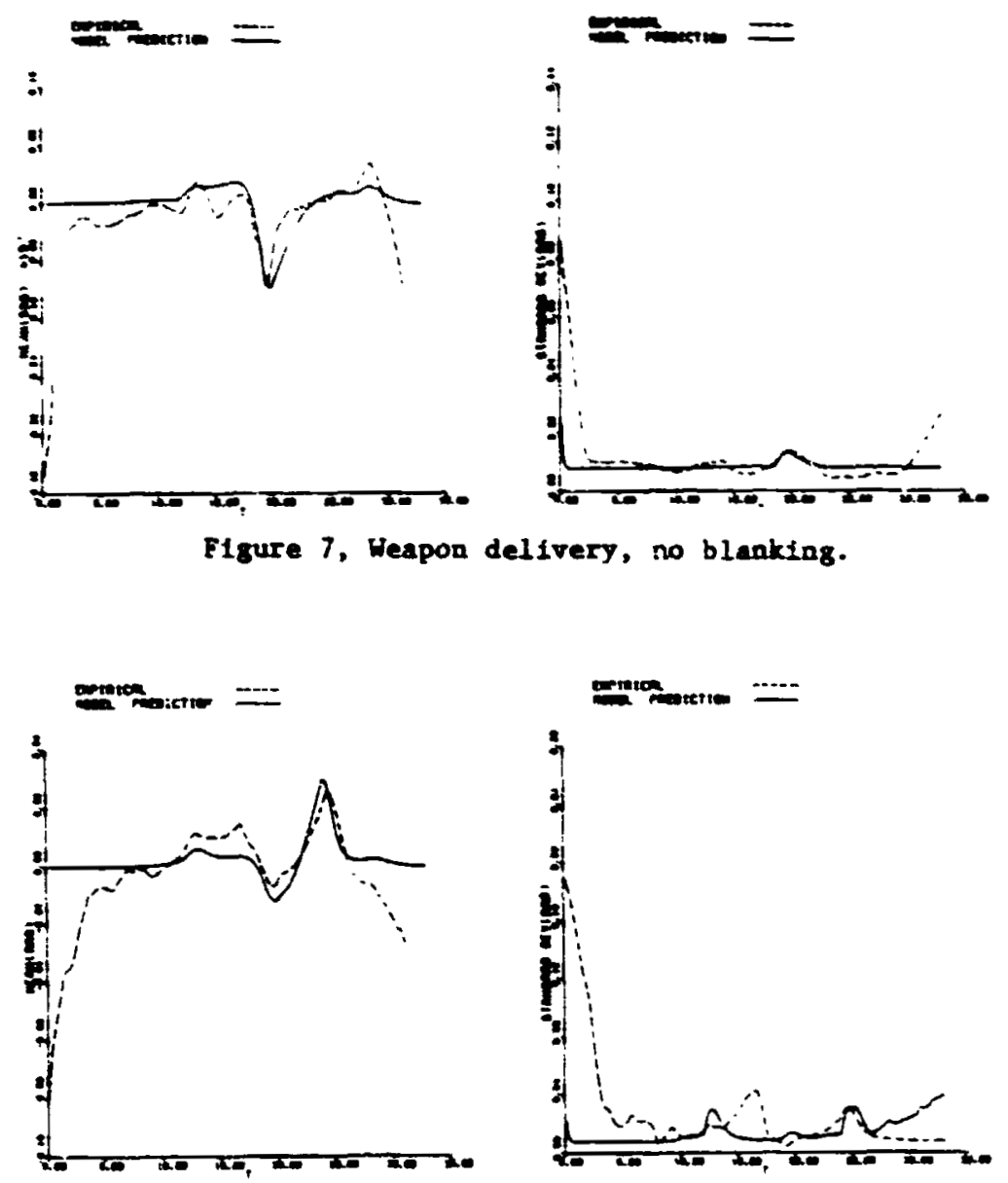

Figure 8, Heapon delivery, blanking duration 3 seconds, 257.
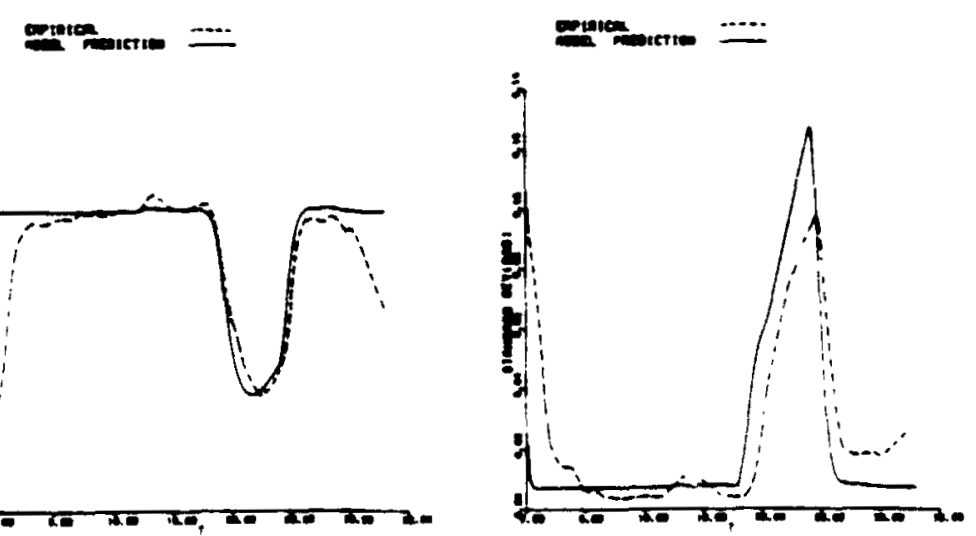

Fig'ire 9, Weapon delivery, blanking duration 6 seconda. 
ORIGITIML PAGE IS

OF POOR QUALITY
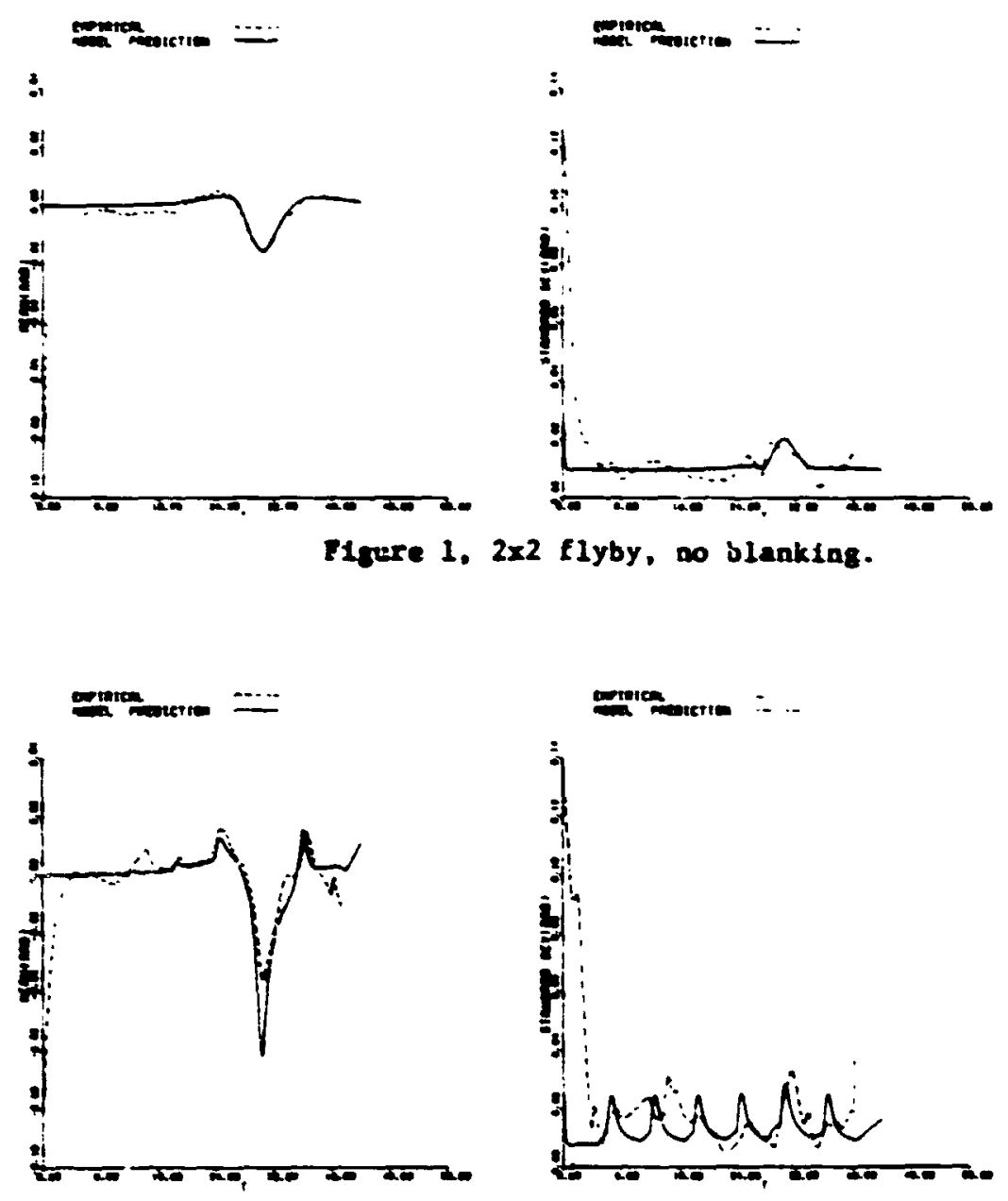

F1gure 2, $2 \times 2$ fljby, bianking duration 1.5 seconds.
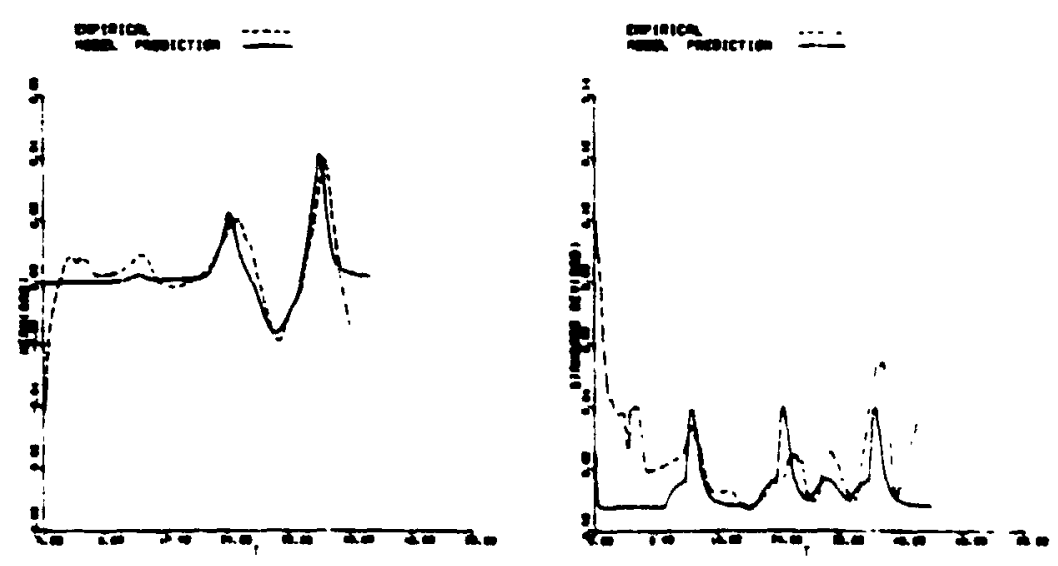

Figure 3, 2x2 flyby, blankling Jur.at tun J scconds, $25 \%$. 
ORIGINAL PAGE IS OF POOR QUALIT:
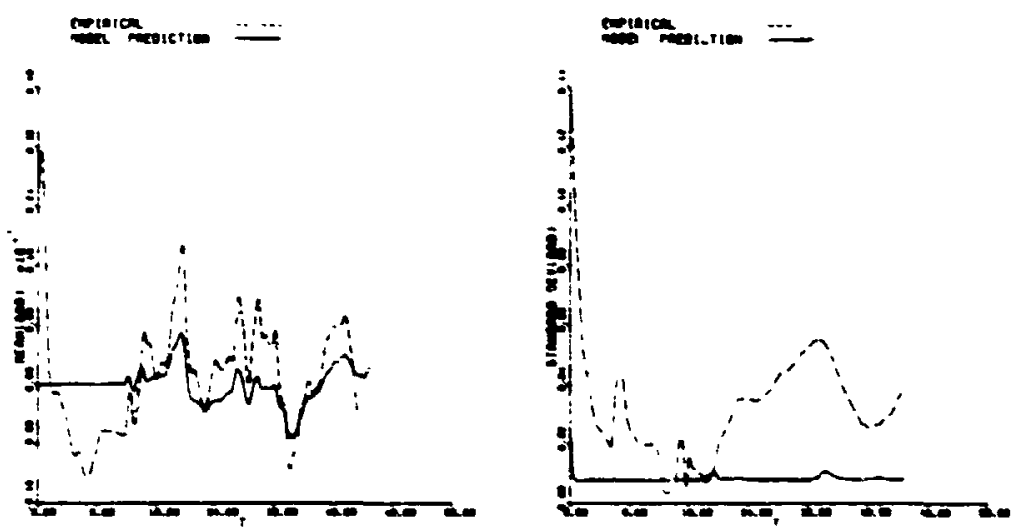

Figure 4, Recon, no braking.
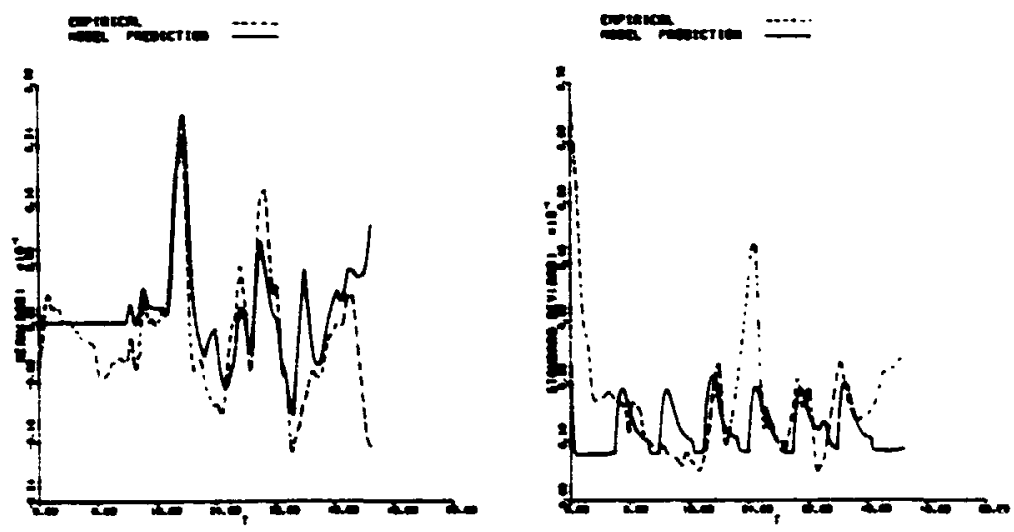

Figure S, Recon, blanking duration 1.5 seconds.
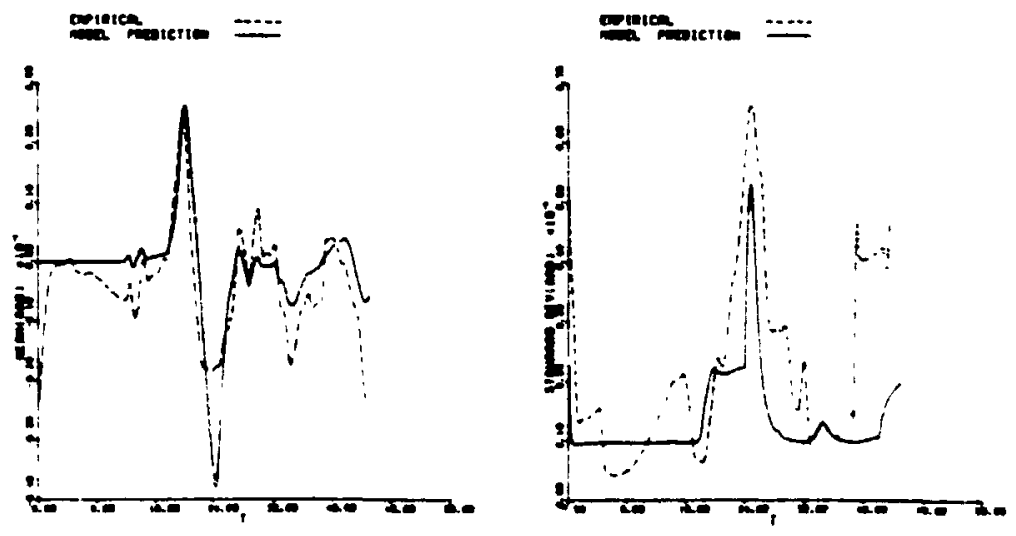

Figure 6, Recon, blanking duration 6 seconds.

39 


\section{REFERANCES}

1. Kou, ? S., B. C. Glass, C. N. Day and M. M. V1koan1s, "Developent of an MA Gunner Model Based on Redused-Order Observer Theory". Proc. 1979 Conference on Decision and Control, San Diego, CA.

2. McRuer, D. T. and E. S. Keendel, Mhthenatical Models or then Pilot Behavior", AGARD-AG-188, 1974

3. KleInana, D. L. aed B. Gless, "Wodeling MA Tracklag Deca Delng the Optinel Control Model", 13th Annual Conference on Manul Control, MI, June 1977.

4. Phecak, A. V., "Inveatigation of Alternate Bunan Oparator Optinal control Hodel Seructures". Proc. of the 15th Annual Conference on Manull Conerol, 1979.

5. Phatak, A. V., "Hodeilng the Huann Gunner in an Ant1-Alrcraft Art1llery (MM) Tracking Tasks" thuan Factora, 1977, 19(5).

6. Klednan, D. L., A. R. Ephrach and P. Krishr. Reo, "A Hodel for the Tarset Tracking Abillty of a Human Operator in an MM Syetem". Techalcal Report EECS IR 79-3, Januery, 1979.

7. Rolek, E. P., "MTQ AZ EI. ArE STUDY", MTQ Experinentation Report No. 5, Systens Research Laboratories, Inc., Deyton, OA, 1977.

8. Tse, E. and M. Athans, "Opt1mal Minimal-Order Observer-Estinators for Discrece Linear Iine Varying Systen", Ined Trans. on Automatic Control. August, 1970.

9. Aoks. M. and J. R. Huddle, "Eatiantion of the State Pector of a Linear Stochastic System with Constrained Estimator". IEEE Trans. on Automatic Control, Auguet, 1967.

10. Nuyar, S. and R. L. Carroll, "Minial Order Arbitrary Fast Adaptive Observers and Idenc1f1ers", IEE Irane. on Automatic Control, Apr1], 1979. 


\title{
$-\overline{8} \dot{2} 34040^{2}$
}

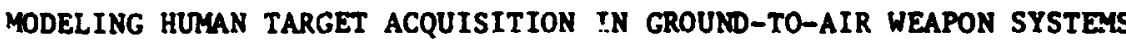

\author{
A.V. Phatak and R.L. Molir \\ - Analytical Mechanics Assoctates \\ Mountain Viex, California \\ H. Vikants \\ AMRL/HEC \\ WPATB, OhIo \\ and \\ R.C. We1 \\ Systems Research Laboratories \\ Dayton, Ohto
}

SUMARY

Several wdels have been developed for describing hum operator Input-output behavior in ground-to-air target tracking tasks. Thase wodels are Intended to be used for predicting humen gunner perfornance and hence anned rapon syotens effectiveness. However, a complete evaluation of a given aysten mast include a quantitative underatanding of huan target acquisition control strategies and resulting perforance.

Th1s paper considers the problems assocleted wth formulating and validating anthentical wodels for describing and predicting humap target acquisition response. In particular, the extenalon of the hum observer nodel to Include the acquistion phase as mell as the tracking segment 1s presented. Relationship of the Observer odel structure to the wore complex Standard Optimal Control odal formulation and to the simpler Transfer Punction/Moise representation is discused. Probles pertinent to etructural identiflability and the form of the parameterization are elucidated. A oyetentic approach towards the 1dent1fication of the observer acquisition model parawters from ensemble tracking error data 1s presented. 


\section{IMTRODUCTION}

The purpose of this paper is to discusa the problems associated with identification of an observer wodel structure for the human gunner in an ant1al rcraft artillery (AM) target-acquisition task. Figure 1 shows the block diagran for he AAA tracking task. The visual display has a $30^{\circ}$ fleld-of-view (FOV) and provides the gunner : $:$ th azimuth (traverse plane) and elevation pointing errors with respect to thr wing target. Experimental data for the acquisltion and tracking of target trafectorles were obtalned at the Aarospace Malical Research Laboratories (AMRL) for a variety of inltial conditions. Ensemble tracking error data for the azf auth and elevation axes were obialned for subsequent use in Identifylng the observer nodel paraneters.

\section{EXPER IMENTAL DATA}

Two trafectorles, a standard $2 \times 2$ flyby and a high-speed flyby called $2 \times 2+$ were simulated. Figure 2 desçribes the two target profiles relative to the gunsight position. The target aircraft begin at che mominal xyz coordinates of $(610,1 \cos 8,610)$ weters and end at $(610,-2743,610)$ weters. At the start of each run, the gunsight display crosa-hair is slewed to the nominal initial target position. This corresponds to the initial condition $(0.0,0.0)$ on the visual display shown in Figure 3. Ten other target trafectorles corresponding to the initial conditions shown in Figure 3 were simulated. The azimuth and elevation angles for the ilyby trajectory any be computed uning

$$
\begin{array}{ll}
\text { Target Asinuth } & \theta_{T}=\tan ^{-1} \frac{y}{x} \\
\text { Target Elevation } \phi_{T}=\tan ^{-1} \frac{z}{\sqrt{x^{2}+y^{2}}}
\end{array}
$$

where: $\quad y=10058-\frac{12801 t}{D}$

$D$ being the duration flight in seconds. Note that $D=70$. for the standerd $2 \times 2$ flyby and 40 - cor the $2 \times 2+4$ flyby trajectory. The different display initial conditions arc sivulated by of faetting the $x_{0}$ and $z_{0}$ coordinates of the target intitial position while keeping $y_{0}$ fixed at $-10058 \mathrm{w}$. Eight rune per inftial condition were obtalned and the Individual tracking errore in the azimuth and elevation axea were proceseed to give encemble error etatistice (man and standard deviation). These data are to be used for 1dentifying the paraseters of the observer codel structure for the target acquisition phase and subsequently for the tracklng segent. The enseble data consista of the following variables:

$$
\begin{aligned}
& t \text { - time } \\
& \bar{e}_{\theta} \text { - wan azimuth error } \\
& \sigma_{\theta} \text { - standard deviation of azimuth error } \\
& \bar{e}_{\phi} \text { - mean elevation error } \\
& \sigma_{\phi}-\text { standard deviation of elevation error }
\end{aligned}
$$




\section{ORIGINAI PAGE IS \\ OF POOR QUALITY}

sampled at intervals of 0.03 seconds. Trafectory data for the 11 targst proftles in the form of

$$
\begin{aligned}
& t: \text { tre } \\
& \theta_{T}, \dot{\theta}_{T}, \ddot{\theta}_{T}: \text { Target aziwuth angle, velocity and acceleration } \\
& \phi_{T}, \dot{\phi}_{T}, \ddot{\phi}_{T}: \text {-arget elevation angle, velocity and acceleration }
\end{aligned}
$$

was also recorded every 0.03 seconds.

Figure 3 also shows the relative apparent initial velocity vector on the display for the 11 trajectories. Targets to the left of the vertical line BB require a counterclockwse slew rate while those to the right denand clockwise sight notion.

\section{OBSERVER MODEL}

Flgure 4 shows a block diagram of the observer theory wodel for the human gunner. The input to the wodel is the displayed error $y$

$$
y=e_{T}=c\left(\theta_{T}-\theta_{8}\right)
$$

where: $\quad c=1$ for the elevation axis

$$
\text { - } \cos \left(\theta_{8}\right)_{\mathrm{El}} \text { for the azimuth axis. }
$$

The observer estimates the target rate $\hat{\theta}_{T}$ according to the equations

$$
\begin{aligned}
& \hat{\dot{\theta}}_{T}=z+k y \\
& \dot{z}=-k c z-(k c+\dot{c} / c) k y-k b c u_{c}
\end{aligned}
$$

where: $\quad u_{c}=-\gamma_{1} y-\gamma_{2} \hat{\dot{\theta}}_{T}$

$\dot{\theta}_{8}=-b u$

$$
\left(\begin{array}{l}
b_{A z}=-1.28 \\
b_{B l}=-1.24
\end{array}\right)
$$

an

$$
u=u_{c}+v
$$

where: $\quad v \Delta N(0, Q)$

$$
Q=\operatorname{cov}(v) \Delta \alpha_{1}+a_{2} \hat{\theta}_{T}^{2}+\hat{\hat{\theta}}_{T}^{2} \text {. }
$$

In this model, $k$ is the observer gain, $Y_{1}$ and $Y_{2}$ are the control law feedback ga'ns, and $\alpha_{1}, \alpha_{2}$ and $\alpha_{3}$ are the ncise model parameters. The resulting quani-stationary (frozen polnt) closed-loop syoten Including the gunsicht and the human gunner is shown in Figure 5 . The equivalent human gunner describing function wodel assuning quast-stationary conditions is given

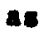




$$
\frac{\mu c}{y}(s)=-\frac{\left(\gamma_{1}+k \gamma_{2}\right) s+k\left(c \gamma_{1}-\frac{\dot{\Xi}}{c} \gamma_{2}\right)}{s+k c\left(1-b \gamma_{2}\right)} .
$$

Note that $Y_{2}=\frac{1}{\mathrm{t}}$ would result in a "type" 1 system guaranteeing zero steadystate track errors for constant tar get angular velor.1ty (1.e., $\dot{i}_{1}$ - constant)
inputs.

The resulting closed-loop systew is described by the equations

$$
\dot{x}=\mathbf{F x}+\boldsymbol{G \theta}_{T}+\Gamma v \text {, }
$$

where: $\quad x=\left(\theta_{8}, z\right)^{T}$

$$
\begin{aligned}
& F_{11}=-b c\left(\gamma_{1}+k \gamma_{2}\right) \\
& F_{1}=b \gamma_{2} \\
& F_{21}=c k\left[\frac{\dot{c}}{c}+c k-b c\left(\gamma_{1}+k \gamma_{2}\right)\right] \\
& F_{22}=c k\left(b \gamma_{2}-1\right) \\
& G=\left(-F_{11}, F_{12}\right)^{T} \\
& \Gamma=(-b, 0)^{T}
\end{aligned}
$$

and $b, c$, and $v$ are described earlier.

Then the enserble statiotics can be computed using

$$
\dot{\bar{x}}=\overline{\mathrm{Fx}}+\mathrm{G} \theta_{m}: \quad \text { Ensemble Mean }
$$

and $\dot{\mathrm{P}}=\mathbf{F P}+\mathbf{P F} \mathrm{F}^{\mathrm{T}}+\mathrm{GQG}^{\mathrm{T}}$ : Enaemble Standard De tation. Then

$$
\begin{aligned}
\bar{y} & =\theta_{T}-\bar{\theta}_{g} \\
& =\theta_{T}-(1,0) \bar{x}
\end{aligned}
$$

gtves the ensemble tracking error, and

$$
\sigma_{y}^{2}=c^{2} P_{11}
$$

provides the ensemble error standard deviation. The observer model paremerers wut te identified so that the model predictions of ensetwile error wan and stardard deviation match experientel data according $t$, surve criterion. 


\section{STRUCTURAL IDETIFIASILIT}

Note that the closed-10op transfer function

$$
\begin{aligned}
\frac{y}{\theta_{T}}(s) & =\frac{a\left(a+c k\left(1-b Y_{2}\right)\right]}{a^{2}+\left(k+b Y_{1}\right) c s+b k\left(c^{2} Y_{1}-\dot{c} Y_{2}\right)} \\
& \equiv \frac{\left.a+B_{3}\right)}{a^{2}+B_{1} v+B_{2}}
\end{aligned}
$$

where: $\quad B_{1}=c\left(k+b Y_{1}\right)$

$$
\begin{aligned}
& B_{2}=b c\left(c^{2} r_{1}-\vdots_{2}\right) \\
& B_{3}=c k\left(1-b r_{2}\right) .
\end{aligned}
$$

For eievation channel, $c=1$ and $i=0$. Thus,

$$
\frac{I}{\theta_{T}}(s)=\frac{s\left[a+k\left(1-b Y_{2}\right)\right]}{s^{2}+\left(k+b \gamma_{1}\right) s+b k \gamma_{1}}
$$

For such a meten, only the sers and two poles of the transfer function can be uniquily identifled from tracking error daca. The two polcs that can be ideat1fied are the roots of the characterlstic equation:

$$
a^{2}+\left(k+' Y_{1}\right)=+b k y_{1}=0
$$

This inpliee two solutions for $k$ and $\gamma_{1}$ given that we have identffied two roots $-a_{1}$ and $-a_{2}$ for the characterietic equation. They are

$$
\left(\begin{array}{r}
k=a_{1} \\
r_{1}-\frac{a_{2}}{b}
\end{array}\right) \text { or }\left(\begin{array}{r}
k=a_{2} \\
r_{1}-\frac{a_{1}}{b}
\end{array}\right)
$$

$Y_{2}$ can be obtained from the alngle zero at $-k\left(1-b Y_{2}\right)$ using $k$ identified in Eq. (27), thus giving rise to $2 w 0$ possible solutions for $Y_{2}$. However, for the Mu rask, it is reasoanble to asaune

$$
Y_{2}=\frac{1}{b}
$$

In crder to ensure "type" 1 ayeten response. 
OFTINL CUITBOL ALTERMTIVE

Finally, the feedback galns $\left(\gamma_{1}, Y_{2}\right)$ need not be free but could be constrained to being optiml with respect to soese standard quadrati = cost functional. Thus, given the gunsight dynarics, the operator's internal wodel for the target ny be assuned to be

$$
\ddot{G}_{\mathrm{T}}=\mathbf{v}
$$

giving a state-space wdel for the suasight/targat srajectory of the for

$$
\begin{aligned}
& \dot{x}_{1}=\dot{\theta}_{T}-\dot{\theta}_{8}=x_{2}+b u \\
& \dot{x}_{2}=\dot{\theta}_{T}=v .
\end{aligned}
$$

The operator ay be assured to be minimizing quad-atic cost

$$
J_{o c}=\int_{0}^{t}\left(c^{2} x_{1}^{2}+g u_{c}^{2}\right) d t
$$

The optinl control $1 \mathrm{~m}^{2}$ ary be obtalned by solving the corresponding Riccatl equation for $t_{f}+\infty$ as

$$
r_{1}=\frac{1}{\sqrt{8}} ; \quad r_{2}=\frac{1}{b}
$$

Thus with $Y_{2}-\frac{1}{b}$ a type 1 systen is guaranteed by the optial reedback controller as would be expected.

\section{PARAMTTER IDENTIFICATIOA APPROACH}

The above discussion elucidates the problem aseociated with odel structure 1dentifiability. The problen Involves the deteralation of the parantera

$$
\text { k - observer galn }
$$$$
Y_{1}, Y_{2}=\text { control gains }
$$$$
\bar{\theta}_{8}(0), \bar{z}(0) \text { - wan state Initial conditions }
$$$$
a_{1}, a_{2}, a_{3}=\text { nolse covariance parameters }
$$$$
P_{11}(0), P_{12}(0), P_{22}(0) \text { - state covarlance initial conditiona. }
$$

These are to be chosen so as to maninlze a cost function 


$$
\begin{aligned}
& \text { CE:min? } F: \because \vdots j \\
& \text { Or PUUN QUALITY } \\
& J=\int_{0}^{t} i(y-\bar{y})^{2}+\lambda\left(\sigma_{y}-\sigma_{y}\right)^{2} j d t \text {. }
\end{aligned}
$$

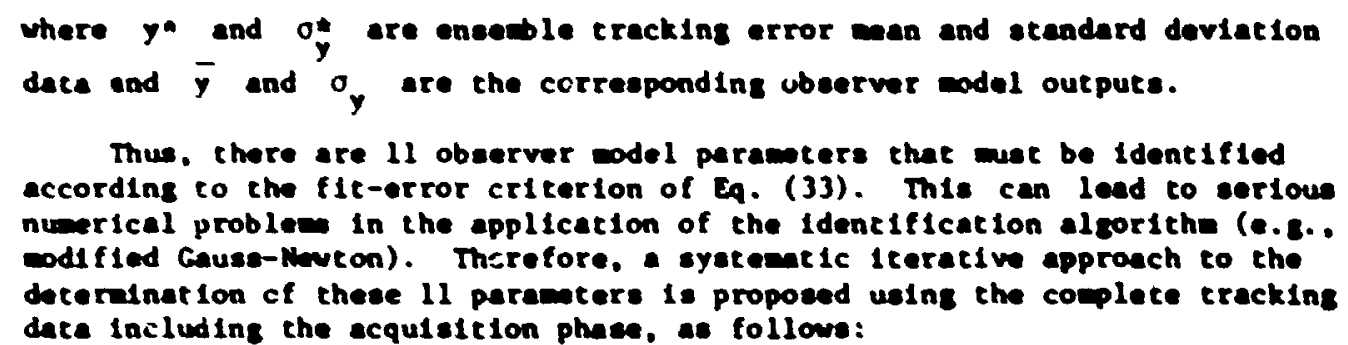

(1) Identify $\left(k, Y_{1}\right)$ uning wan tracklas error daca with $Y_{2}=\frac{1}{b}$.

(2) Identify $\bar{z}(0)$ fron man acquieltion error data uelng $\left(k, Y_{1}, Y_{2}\right)$ iron step 1. and $\bar{\theta}_{8}(0)$ from data.

(3) Identify $\left\{a_{1}, a_{2}, a_{3}\right\}$ froe etendard deviation trackins date uning $\left(k, r_{1}, r_{2}\right)$ from tep 1 .

(4) Identify $\left(P_{12}(0), P_{22}(0)\right)$ fron standard deviacton acquistion data Uolng $P_{11}(0)=\sigma_{\theta}^{2}$ fron date.

(S) Ropact etepe 1-4 for varlous values of $\lambda$ in $J$ of Bq. (33).

(6) Daternine functional codel (1f it exlets) relacins ecquistion odel parantere to crajectory paramete.

\section{Concluding rankes}

The above outline provides framwork for eyetenatic identiflcetion of the observer codel paraestera. It is underetood that the search over $\left(k, \gamma_{1}\right)$ would be reetricted in parameter epace to converge to one of the two posetble solutione given In Eq. (27). Finally, the eseusption of the adequacy of the obearver codel for the ecquieltion phace 1 e implictily seaund in this paper. Thie ay not be fustlfied if the earple t1m hietorles for the gunner input-output varlablee Ind cate nonlinear or wode suteching behavior.

\section{RERLREACES}

1. D.G. Lunberger, "An Introduction to Observers," IEEE Trane. on Auto. Cont.. vo1. AC-16, pp. 396-602, Dec. 1971.

2. A.E. Bryeon, Jr. and Y.C. Ho, Applled Opt1mel Control, Gunn-Bla1edell, 1969. 
$e^{n+\cdots+\cdots+\cdots}+\cdots$

of foun verat

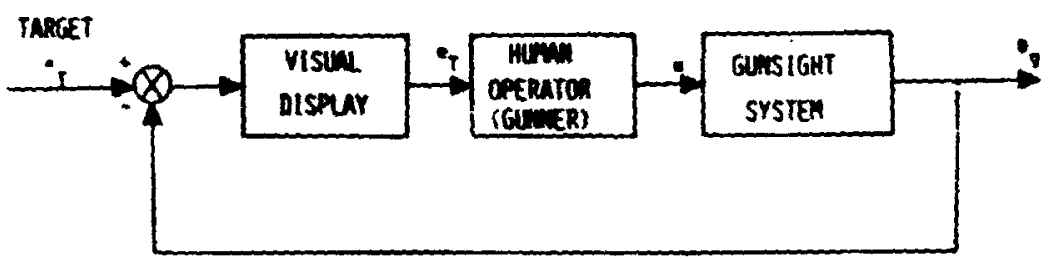

Figure 1. Block Diagran of an MA tracking System
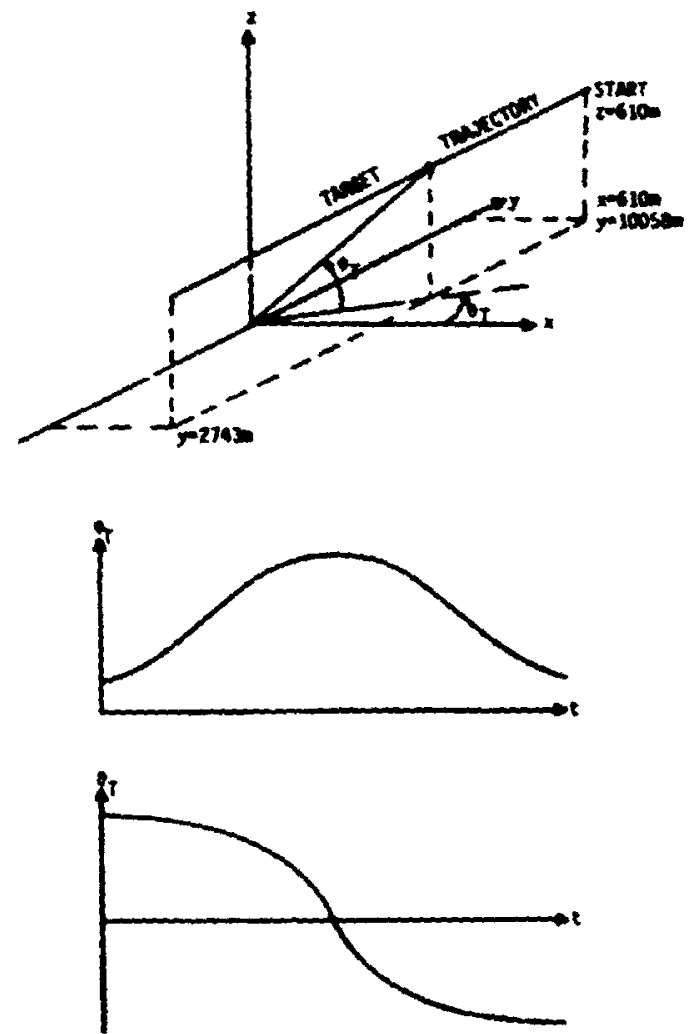

Figure 2. Fiyby Trajectory 


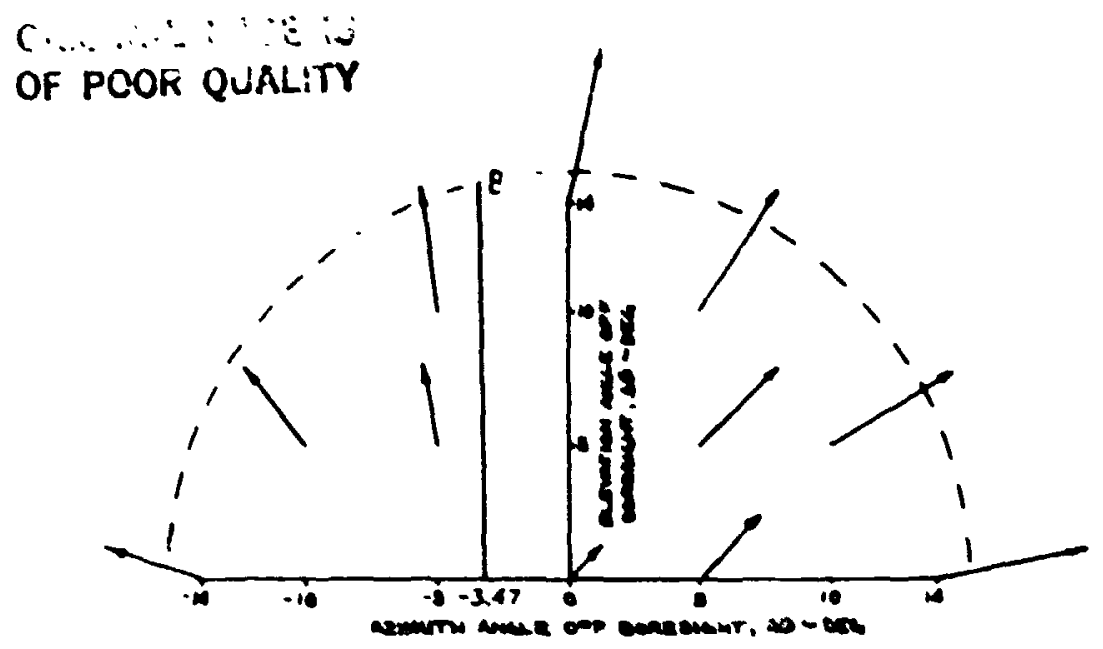

Figur. 3. Cunsight Display

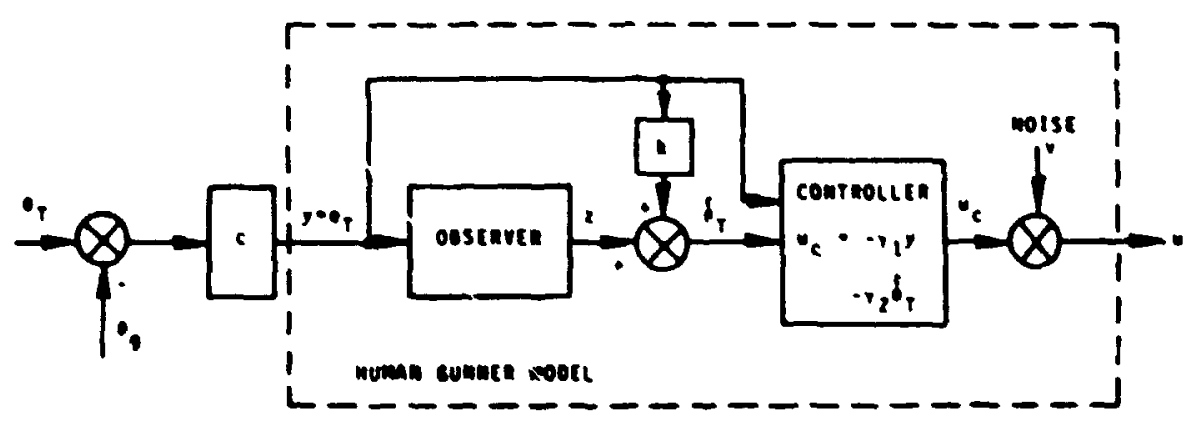

Figure 4. Obeerver ibdel Structure

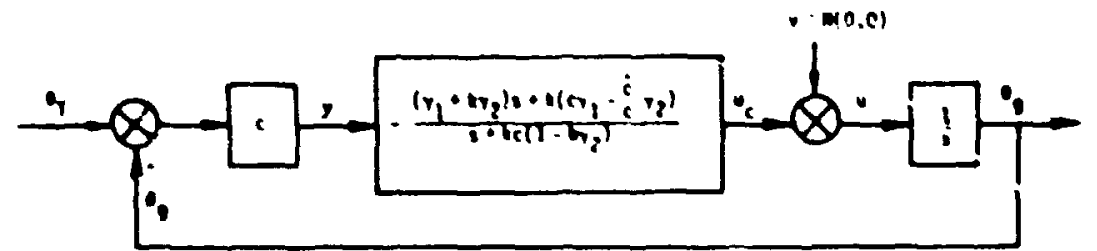

Figure 5. Equivalent Queet-statlonery dideram of the MA Closed-Loop Syatee 
THE EFFECT OF VISURi IMFORMATIOA OI THE

MANUAL APPROACH ARD LARIDIMG

by P.H. Weverinke

National Aerospace Iaboratory NLR

The Netherlands

ABSTRACT

The visual scene is an important source of information for the manual approach and landing task. This paper deals with the effect of this information in combination with besic display information on the approach performance. In this context, a pre-experimental model analysis has been performed in terms of the optimal control wodel.

The resulting aircraft approach performance predictions vere compared with the results of a moving base simulator program.

The results illustrate that the model provides a meaningrul description of the visual (scene) perception process involved in the conplex (multivariable, time varying) manual approach task with a useful predictive capability. The theoretical framework has been shown to allow a straightforward investigation of the complex interaction of a variety of task variables.

\section{INTTRODUCTI.}

The manual approach and landing is a complex manual control task. The process is time (range) varying and involves multivariable task objectives, visual scene and display information and a complex pilot's control strateg. Although many studies have dealt with variety of aspects of this approsech and landing task, accident statistics indicate that there are still important unanswered questions.

This poper sumarizes the results of a theoretical and experimental program addressing the effect of visual information on the manual approach and landing. Specificaliy, this conceraed visual scene information which vas the subject of a previous study (Refs. 1 and 2) and basic (aead-up) display information. From that study it could be concluded that the visual scene perception process can be modelled (described) on the basis of linear perspective gecmetry and relative motion cues.

In the present study the effect of visual scene information was investigated by considering three (good, poor and aight) visibiiity conditions. These three conditions were combined with three basic head-up 


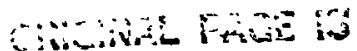 OF POOR QUALIT:}

display (HUD) configurations representing a variety of visual cues. This is discussed in the following.

A pre-experimental model analysis has been performed resulting in a varlecy of aircraft approach performance predictions. These predictions will be comparel with the results of an experimental program on a moving base simulator in order to investigate the predictive capability of the model.

VISUAL IMPORMATION IN THE MANUAL APPROACH

Visius approach scene

The visual scene provides a variety of perspective gecmetrical and relative motion cues. A previous study (Rer. 2) has demontrated that these characteristics can be considered as separate cues anong which the human operator must divide his attention. A schematic version of the visual approach scene is shown in figure 1. The cues which are assumed to be derived from this scene are indicated.

The most important cue for lateral guidance is derived from the inclination of the runvay sides and or the runway centerline. The lateral Ceviation is zero if the inclination of both runway sides is the same $\left(\omega_{Y}=\omega_{f}\right)$ and the inclination of the centerline is zero $\left(\omega_{c}=0\right)$.

vertical guidance must be based on the (averagel inclination of the runway sides when no runway end and no horizon is visible. In that case, the observer must know the nominal inclination (which is range varying). However, a better indication of the rertical position can be obtained when the depression of the runway tr eshold with resfect to the horizon is risible. Also in that case, the utserver must know the nominal depression angle, which is, however, constant during a standard approach (i.e. 3 degl. The final approsch and landing requires also the estimation of the distance is touchdown. This can be based on the apparent size of ground objects, the most important one probably being the rumray vidth.

Aircraft attitude providing "inner loop" information for aircraft control can be derived from the relative position and inclination of (e.g.) the horizon and any aircraft reference. In the figure the three attitude angles are indicatsd.

In this paper the effect of two visual scene conditions is considered: a good visibility condition (GVL implying that tine complete visual scene including the horizon is visible and a poor visibility condition (PV $j$ such that no munray end and no horizon can be discerned. These visual scene conditions vere combined vith three display configurations resulting in six task configurations considered in the following theoretical and experimental analysis. 


\section{CR:GWNAL FAEE IS \\ OF POOR QUALITY \\ Display information}

In a visual approech the pilot is provided vith not only the visual scene but also display information. Typical aircraft variables of interest are the rate of descent, airspeed, or groundspeed, aircrart position, etc.. In the study described in this paper three display consigurations vere involved so as to investigate the effect of various aircrast variables on the manual approach performance and theis interaction vith the visual scene information.

Figure 2 contains the visuai information invoived in the three head-up display (KUD) configurations. The "no KUD" configuration (MI) involves only an aircraft refereace lloving a rough estimation of the airerart attitude. The "simple tUD" configuration (SH) is included to investigate the effect of accurate, aircraft attitude information. This configuration involves a fixed reference line which nominally coincides with the touchdown line. This reference provides primarily accurate aircraft attitude information and, to some extent, approach position information. The "advanced HUD" configuration (AH) conteins, in addition, the aircrart velocity vector (earth-related), the runway contor rs including the centerline and touchdown line and the horizon line. This configuration was intended to investigate the effect of precise movement informntion and synthetic perspective ruavay information which was hypotbesized to become userul in reduced visibility sitivations.

The six task configurations are summarized in table 1.

MODEL ANALYSIS

Once the visual scene characteristics are linearly related to the aircraft variables of interest (system states) the visual cues of both the visual scene and the EIVD can be described in terms of the perception and information processing model (Rers. I and 2) which is part of the optimal control model (Rer. 3 ).

The approach task considered consisted of the control of a medium veight tvin engine jet in the presence of moderate turbulence (details are given in reference 4). A steady-state model anclysis ves performed assuming that the aircrart vas "frosen" at a fixed point of the approsch on:h corresponding with a nominal atitude of $200 \mathrm{ft}$ for a 3 approach. -rs addition, a time rarying nodel analysis was performed accounting for the tsxi varying turbulence characteristics during a descent and the time saryin; (renge varying) visual cues.

Model parameters

Model parameters can be divided in parameters which are constant for all configurations and parameters which vere considered as the remaining model variables. 
It was assumed that the pilot adopts a control strated that minimizes a performance index consisting of a veighted sum of mean-squared path, attitude and control variables. The veightings were selected by first determining maximum allovable values ("limits") of each variable and then setting the weighting equal to the square of the reciprocal of the corresponding limit. For details the reader is refered to reference 4.

The selection of the visual perception parameters is based on the results of previous studies (Ref. 2). The key model puraneters are the perceptual thresholds summarized in table 2 . Herein, $\varepsilon$ is the approach angle (deviation), $f$ is the relocity rector deviation from the touchdorn point; the subscript 0 means: with respect to touchdown and the subscripts $g$ and $l$ refer to the rertical (glideslope) and lateral (localizer) direction, respectively. Only those rariables are given among wich the pilot divides his attention (optimally, i.e. minimzing the afore-mentioned performance index). An equal attention was assumed between the vertical and lateral task.

Typical values vere used for the remaining model parameters which have been found to be relatively constant or insensitive (task independent): a perceptual time delay of $0.2 \mathrm{~s}$, an overall level of attention of $-18 \mathrm{~dB}$ and a motor noise ratio of $-25 \mathrm{~dB}$.

\section{Steady-state model analysis}

Based on the model assumptions and parameter values discu'ssed before model predictions could be made for the six task configurations of table 1. The results consist of standard deviations of system variarles (path errors $d$ and $y$, forward velocity $u$, aircrart attitude angles $\theta$, bind and control deflections $\delta$ and $\delta$, and pilot workload. The latter can be predicted using the workload model discussed in reference 5 .

System performance is summarized in table 3 for tasks $\mathrm{Cl}$ to $\mathrm{Cl}$. The model predicts that approach performance is clearly improved when the simple HUD is provided. A substantial improvement is obtained for the advanced HUD. This demonstrates clearly the favourable effect of EUD information on the manual approach performance, both vertically and laterally, especially in terms of path deviations.

The effect of visibility can be appreciated by comparing configuration Cl with $\mathrm{Cl}$. The mode! predicts that reduced visibility results in a minor performance deterioration laterally. The vertical perfnrmance remains the same. This somewhat surprisingly result is explained by the predicted pilot's shift in attention allocation among the visual cues (Ref. 4). For the simple and advanced KUD configurations the effect of visibility is negligible. Because of the favourable HUD information almost (in case of simple HUD) all (in case of the adranced HUD) attention is devoted to the HUD cues. Consequently, a reduction in visibility has no effect as long as the touchdown point is visible (or indicated).

Pilot workload predictions (Wl. are also given in table 3 containing also the overall performance index $J$. Workload is relatively constant for 
the four vertical control configuraticns. Significantly more effect is predicted for the lateral tasks. The vorkload results for the combined tasks indicate that pilot's workload is the same for the good and poor vasibility condition. Furthermore, the effect of the simple HUD is farourable with respect to not only the approach performance but also the corresponding workload. The model predicts that the superior performance of the advanced IUD corresponds to a somewhat higher level of pilot workload than corresponding to the simple HUD configuration.

Time varying analysis

A time varying analysis vas performed to account for possibly range dependent effects of the approach task involved in the simulation program. Apart from the height dependent turbulence (only a varying turbulence bandwidth was considered) the range varying vieving characteristics vere included in the analysis. The latter implied range varying visual cues and pilot's control strategy. For further details the reader is referred to reference 4 .

It was assumed that the pilot's allocation of attention among the visual cues was constant during the approach. This "average" allocation or attention was identical to the optimal allocation of attention (yielding the best approach performance) computed in the steady-state model analysis. Also the same (equal) division of attention betreen the rertical and lateral task was assumed.

The experimental approach task which will be discussed in the next chapter began at a range of $5813 \mathrm{~m}$ from the touchdown point (corresponding with a nominal altitude of $1000 \mathrm{ft} L$ vith zero intial deviations. The same initial condition was adopted in the following model analysis.

The model results of configuration $C 1$ are given in terms of the standard deviation of the path errors (in figure $3 \mathrm{a}$ ) and of the aircraft attitude angles and control deflections (in figure $3 b$ ) as function of the range. It will be clear from the figure that (linear) patb deviations ( $d$ and y) are strongly range dependent.

Pitch attitude and elevator activity increase during the approach. This result orginates partly from the model assumption that the pilot's control strategy is determined by the angular glidepath deviation. This implies that during the approach relatively more weight is placed upon (linear) glidepath error than upon pitch attitude and elevator deflection.

The roll angle and aileron activity increase sonewhat during the approach. Heading is slightly decreasing. Analogous to the vertical task this results from the range varying control strategy.

It is interesting to compare the results of the time varying analysis with the steady-state results. Therefore, steady-state results are indicated in figure 3 corresponding vith a nominar altitude of 200 st and a nominal 
altitude of $600 \mathrm{st}$. Both the path errors and the attitude and control acores closely agree for the steedy-state andysis and the time varying analysis (with the exception of the low range height error and pitch attitude angle). Thus, range varying effects can be investigated by a steady-state model analysis at different approach positions. Tedious time varying analysis is necessary, hovever, when dealing vith deterministic processes such as windshears (Rer. 6 ).

\section{EXPERIMERTAAS, PROGRAM}

Th sbjective of the experimental program was to test the foregoing model results. In addition, the experimental results might allow model refinements thereby extending the predintive capability of the pilotaircrart model.

\section{Description of the experiment}

The experiment vas conducted on the NLA moving base simulator. Details about the apparatus, experimental and data anelysis procedures are given in reference 4. The flight simulator was configured to represent the linear squations of motion of a medium veight twin engine jet transport having a weight of $29,000 \mathrm{~kg}$.

The task was to track a $3^{\circ}$ slight path to touchdown under VFR conditions beginning at a range of 5813 in from the touchdown point. Each mun lasted approximately $90 \mathrm{~s}$. The subjects were instructed to conceive the task as a realistic approach task (given the simplified circumatances) using exclusively the outside world information. Apart from the aforementioned good and poor visibilit, conditions also a night condition was included. These visual scene conditions were combined with the aforementioned three HUD configurations yielding $\rightarrow$ experimental conditions.

Three experienced pilots participated in the experiment. In each session the 9 configurations vere presented to the pilots in a random order. On the first two days and at the beginning of the third day each pilot wes trained such that a relatively stable performance level was reached for each condition. All together, 225 trairing trials vere performed. On the third and fourth day the subjects "flev" 6 formal sessions containing the 9 configurations in a random order for data collection. Thus, 6 replications per experimental condition per pilot vere obteined. No performance was fod back during the formal seasions. Data vere collected in terms of ariety of system variables and subjective ratings concerning pilot vorkload and visual informational aspects. 
For an extensive presentation of all experimental results the reader is referred to reference 4 . In this paper, only the principal experimental results of the same configurations as involved in the model analysis will be considered.

The model performance predictions reflect the stochestic nature of the approach task. The statistical measures are given in terms of standard deviations of path errors and aircraft attitude and control angles. These random deviations result from the system disturbances (turbulencel and pilot's randomess in perceiving and processing information and executing control deflections. The corresponding experimental measures for the vertical approach task are the standard deviations of the ensemble (six replications times three subjects). The ensemble means of some configurationa clearly reflect specific control strategy. This is discussed in reference 4. For the lateral approach task no systematic ensemble mean bas been found. So for this task the best orerall experimental messure of random pilot control vehavior is the root-mean-squared value (RMS).

The resulting approach performance of configuration ) ( good visibility, no HUD) is shown in figure 4 as a function of the ranis: The afreement between the model predictions and experimental beight errors is excellent. The lateral deviations do not match as vell. The model predicts somewhat larger errors than the experimental scores. A close match, however, can easily be obtai $\$$ when assuming that somewhat more attention is devoted to the lateral task (corresponding with a reduced obs. rvation noise rativ of $2 \mathrm{~dB}$ ). This is indicated in the figure by the dashed line.

The aircraft attizude and control scores are sumbrized in tabje 4 as averages over four range intervals. The agreement for the pitch attitude and elevator deflection is quite good. The model predicts an increase in pitch angle with decreasing range. This effect is only partly reflected by the experimental pitch angles for this configuration 1. However, the experimental pitch attitude results of almost all other configurations did confirm this model prediction (Rer. 5).

The roll angle scores agree closely. Both the model and experimental results exhibit an increase in roll angle with decrensing range. The model predicts a heading angle and aileron activity which are clearly larger than the corresponding experimental scores. This could be the result of a somewhat different pilot's control strategy.

The effect of visual scene information can be appreciated by comparing configuration 1 and 4 . The model predicts that reduced visibility does not result in a deterioration of the vertical approach performanze. This is confirmed by the experimental results showing no significant difference between both configurations. Laterally, hovever, the model predicts that reduced visibility results in (15\%) larger laterai deviation. This trend is in accordance with the experimental results: the lateral deviation of configuration 4 is, on the average $(30 \%)$ larger than the one of configuretion 1 . 
As predicted by the model no significant effect of visual scene information was found experimentally for tte simple and arvanced HUD configurations.

The effect of HWD information is illustrated in firure 5 fur the zood visibility condition. The model predicts that the simple uld yields an improvement in vertical appros $\mathrm{ch}$ jerformance. The experimental results show the same (statistically signijicant) trend although the effect is larger than predicted. The model predicts a substantial iuprovement in vertical performance when the advanced HUD is provided. This corresponds rather well with the experimental results showing approximately the same fractional (statistically significant) improvement.

Laterally, the model predicts that the simple EUD, providing the pilot with more accurate attitude information, results in reduced lat ral deviations. This result is not nbtained experimentally. Figure 5 shows thet the simple HUD results in subs nntial larger lateral deviativas.

One explanation might be that tt- pilot spent, during the first part of the approsch, less attention to the lateral task than assumed in the model analysis. This is illustreted in figure 6 shoving the lateral model results of the simple EUD configuration for both the orginally assumed level of attention and for half of this level. During the first part of the approach the data elosely match the model results assuming half of the original level of attention. In the course of the approach (below a range of $3 \mathrm{~km}$ ) the levsl of attention is increased resulting in lateral approach performance as approximately predicied by the model.

Pilot workload results in terms of nomelized subjective ratings and the model predictions (larger values signify higher pilot workload) are summarized in table 5. The experimental differenses are not statisticaily significant (at the 0.05 level) parly tauase of the subject variability. Nevertheless, the model prediction that the simple HLD (C2) corresponds with a lower workioad level than the no HUD configuration ( $C_{i}$ ) seems to be apported ixperimentally. Furthermore, the model prediction that the advanced display (C3) corresfonds to a lower workload level than the no IUD configuration is not supported experimentally. The model predicts that visibility has hardly any effect on pilot workload (c.f. Cl and C4). On the sverage. this seems to be supported by the subjective ratings.

\section{CONCLUDING ROMARKS}

A detailed comparison of model predictio, and axperimental results of the "Bood visibility, no EUD" condition has demonstrated that the predictive capability of the pilot-aircraft model describing the complex, time-varying approach task is substantial. 
The model predicts that reduced visibility has no effect on the vertical approach performance and some segative effect on the lateral approach performance. This is supported by the experimental results. Furthermore, as predicted by the model, no significant effect of visual scene information was round experimentally for the simple and advanced IUN configuration.

Th model predicts that the simple ild yields an improveneat in verical approsch performance. The experimental results show tine same trend al though the effect is larger than predicted. The model predicts a substantial improvement in vertical ferformance when the advanced HUD is providea. This agrees vell vith the experimenisl results. Laterelly, the model predicts that the simple HUD results in a better approsch performance. The experimental results, however, show iarger lateral deviations. This can be closaly matched by the model when assuming that for this configuration less attention is aecicated to the lateral task during the first part of the approach. The same applies to the advanzed HUD.

\section{REFEREJCES}

1. Wewerinke, P.H.: A theoretical and experimental analysis of the outside world perception process. Paper presented at the 14 th Annual Conference on Manual Control, Los Angeles, Afril 1978 (Also NLR MP $78020 \mathrm{U})$.

2. Wererinke, P.H.: Visual scene perception process involved in the manual approech. NLR TR $78130 \mathrm{U}$, October 1978.

3. Baror, and Levison, W.H.: Display anelysis with the optima? control model of the human operator. Human Factors, 1977, 19(5).

4. Weverinike, P.H.: The effect of visual information on the manual spproach and landing. ILR TR 80 U (forthcomingl.

5. Wewerinke, P.H.: Performance and workload analysis of in-flight helicopcer missions. NLR MP 77013 U, June 1977.

6. Levison, H.H.: Analysis and in-simulator evaluation of display and control concepts fc: a terminal configured vehicle in final approach in a windshear environment. NASA CR 3034 , 4ugust 1978 . 
OFiGing: PSIE 'S

OF POOR QUALITY

\begin{tabular}{|l|l|l|}
\hline CONF. & DISPLAY & VISIBILITY \\
\hline 11 & NO HUD & \\
\hline C 2 & SIMPLE HUD & COOD \\
\hline C 3 & ADVANCED HUD & \\
\hline$\approx 4$ & NO HUD & \\
\hline C 5 & SIMPLE HUD & POOR \\
\hline C 6 & ADVANCED HUD & \\
\hline
\end{tabular}

Table 1 Task configurations

\begin{tabular}{|l|c|c|c|}
\hline \multirow{2}{*}{ PARALETER } & \multicolumn{3}{|c|}{ DISPLAY } \\
\cline { 2 - 4 } & KH & SH & AH \\
\hline$\dot{\theta}_{0}$ & 1 & 0.1 & 0.1 \\
$\dot{\theta}_{0}$ & $i$ & 0.2 & 0.2 \\
$v_{0}$ & $1(2)$ & 0.2 & 0.2 \\
$\varepsilon_{B}$ & $1(2)$ & - & - \\
$\omega_{C}$ & 1 & 0.1 & 0.1 \\
$\delta_{B}$ & $0.5(2)$ & $0.5(2)$ & $0.2(2)$ \\
$\delta_{l}$ & 2 & 2 & 2 \\
\hline
\end{tabular}

$(\cdot)$ : poor visibility condition; all variables in units of degrees visual are

Table 2 Visual thresholds used for the model analysis 


\section{CF POOR QUALITY}

\begin{tabular}{|c|c|c|c|c|c|}
\hline \multirow{2}{*}{ TASX } & \multirow{2}{*}{ PAYNATSER } & \multicolumn{3}{|c|}{ COMTIGURATION } & \multirow[b]{2}{*}{$\mathrm{CH}^{2}$} \\
\hline & & Cl & $c 2$ & C3 & \\
\hline $\begin{array}{l}\text { V } \\
\text { E } \\
R \\
T \\
1 \\
C \\
\text { A } \\
\text { L }\end{array}$ & $\begin{array}{l}o_{d}(m) \\
o_{\theta}(d e g) \\
o_{u}(a / s) \\
o_{g}(d e g) \\
j e^{\prime}(-) \\
w(d B)\end{array}$ & $\begin{array}{l}7.1 \\
1.5 \\
1.4 \\
1.1 \\
0.14 \\
10.1\end{array}$ & $\begin{array}{l}5.8 \\
1.3 \\
1.2 \\
1.0 \\
0.09 \\
9.7\end{array}$ & $\begin{array}{l}4.1 \\
1.1 \\
1.3 \\
1.1 \\
0.06 \\
10.4\end{array}$ & $\begin{array}{l}7.2 \\
1.5 \\
1.3 \\
1.1 \\
0.14 \\
9.0\end{array}$ \\
\hline $\begin{array}{l}L \\
A \\
T \\
E \\
R \\
A \\
L\end{array}$ & 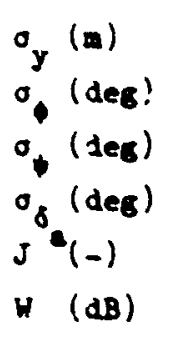 & $\begin{array}{c}9.4 \\
3.6 \\
3.5 \\
2.6 \\
0.48 \\
14.0\end{array}$ & $\begin{array}{l}7.1 \\
=0 \\
3.4 \\
2.4 \\
0.35 \\
13.0\end{array}$ & $\begin{array}{l}6.0 \\
3.1 \\
3.4 \\
2.7 \\
0.35 \\
13.4\end{array}$ & $\begin{array}{l}10.6 \\
4.1 \\
3.6 \\
2.8 \\
0.54 \\
13.8\end{array}$ \\
\hline total & $\begin{array}{l}J_{t}(-) \\
W_{t}(d B)\end{array}$ & $\begin{array}{l}0.62 \\
10.4\end{array}$ & $\begin{array}{l}0.64 \\
15.5\end{array}$ & $\begin{array}{l}0.41 \\
15.8\end{array}$ & $\begin{array}{c}0.69 \\
10.2\end{array}$ \\
\hline
\end{tabular}

Table 3 System performance and workload predictions 
ORIGINAL FEEE is

OF POOR QUA:TTY

\begin{tabular}{|c|l|l|l|l|l|}
\hline PAR. & $\begin{array}{l}\text { RANGE } \\
\text { IMTERVAL }\end{array}$ & $R 1$ & $R 2$ & $R 3$ & $R 4$ \\
\hline \multirow{3}{*}{$\delta$} & measured & 1.1 & 1.1 & 1.5 & 1.2 \\
\cline { 2 - 6 } e & model & 0.9 & 1.0 & 1.4 & 2.0 \\
\cline { 2 - 7 } & measured & 0.52 & 0.72 & 0.77 & 1.1 \\
\hline \multirow{3}{*}{$*$} & model & 0.43 & 0.51 & 0.74 & 1.2 \\
\cline { 2 - 7 } & model & $j .1$ & 3.4 & 3.5 & 3.8 \\
\hline \multirow{3}{*}{$\delta$} & measured & 2.1 & 2.3 & 2.1 & 2.3 \\
\cline { 2 - 7 } & model & 3.8 & 3.9 & 3.8 & 3.6 \\
\cline { 2 - 7 } & measured & 1.6 & 1.5 & 2.3 & 1.7 \\
\hline
\end{tabular}

Table i A comparison of model acd experimenta: sttitude and cortrol scores - Configuration?

\begin{tabular}{|l|l|l|l|l|}
\hline \multirow{2}{*}{$\begin{array}{l}\text { Horkluad } \\
\text { measure }\end{array}$} & C1 & Ca & C3 & C4 \\
\cline { 2 - 5 } $\begin{array}{l}\text { model } \\
\text { prediction } \\
\text { demand } \\
\text { rating } \\
\text { effort } \\
\text { rating }\end{array}$ & 16.4 & 15.5 & 15.8 & 16.2 \\
\hline
\end{tabular}

rable 5 "zdel and experimental rorkload measures 


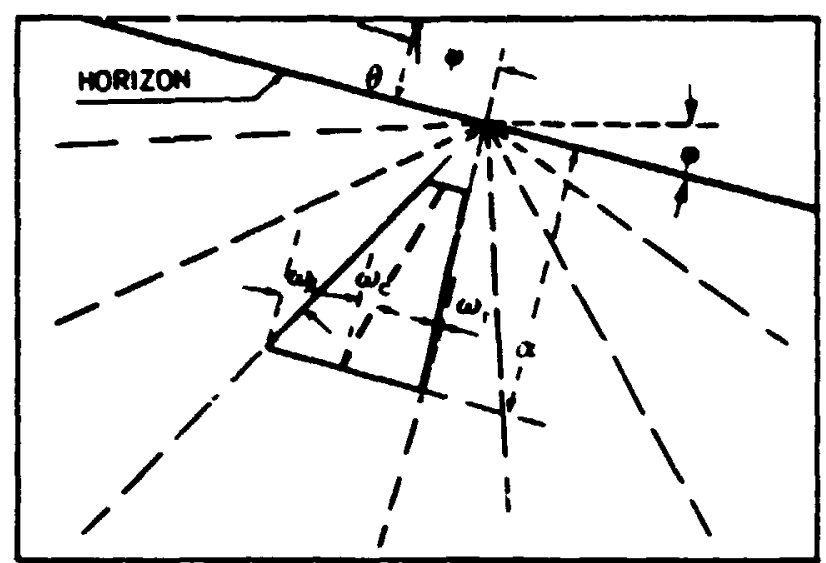

Fig. 1 Cues derived from the visual approach scene

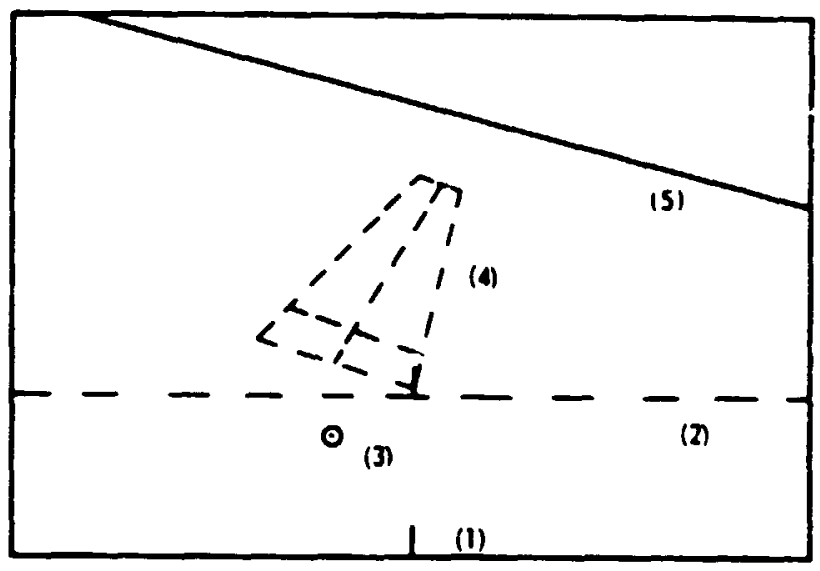

\begin{tabular}{|c|c|}
\hline CONF. & CUES \\
\hline$N_{\text {NO HUD. }}$ & $(1)$ \\
\hline $\begin{array}{l}\text { SIMPLE } \\
H_{,}, S H\end{array}$ & $(2)$ \\
\hline $\begin{array}{l}\text { ADVANCEO } \\
H_{\text {, AH }} \text { AH }\end{array}$ & $(2,13,(4),(5)$ \\
\hline
\end{tabular}

(1) AIRCRAFT REFERENCE

(2) REFERENCE TO TOUCHDOWN POINT

(3) VELOCITY VECTOR

(a) RUMWAY CONTOURS

(I) ARTIFICIAL HORIZON

Fig. 2 Hend-up display information 


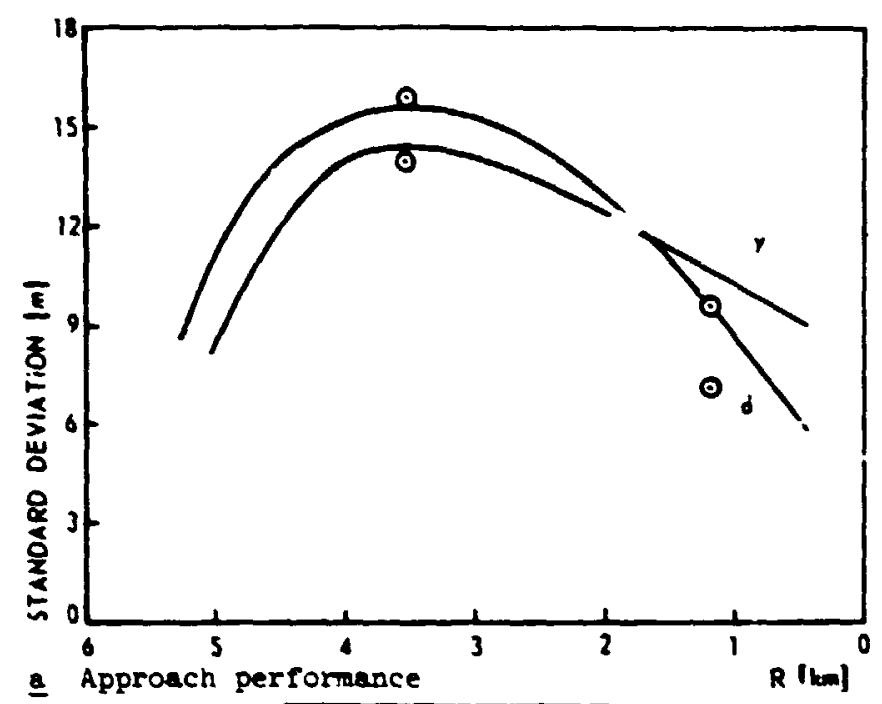

a Approach performance

$$
\begin{aligned}
& \hline \text { : TIME VARYIMG } \\
& \text { : STEADY STATE }
\end{aligned}
$$

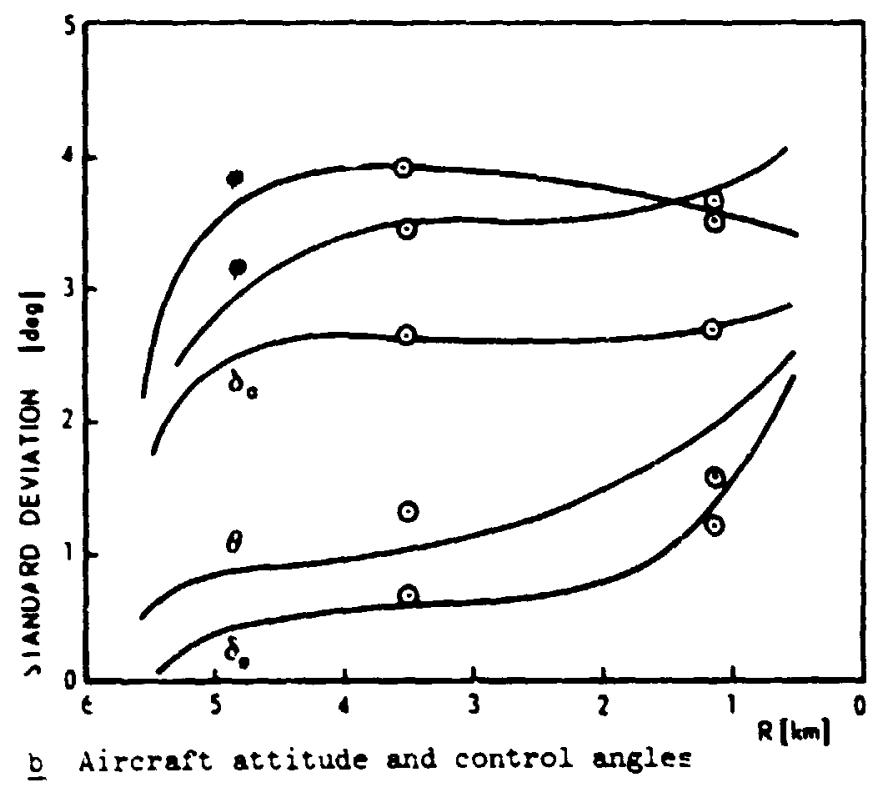

Fig. 3 Approach performance predictions as a rinction of range - Configuration $\mathrm{Cl}$ 
OF PUC:R Qunitity

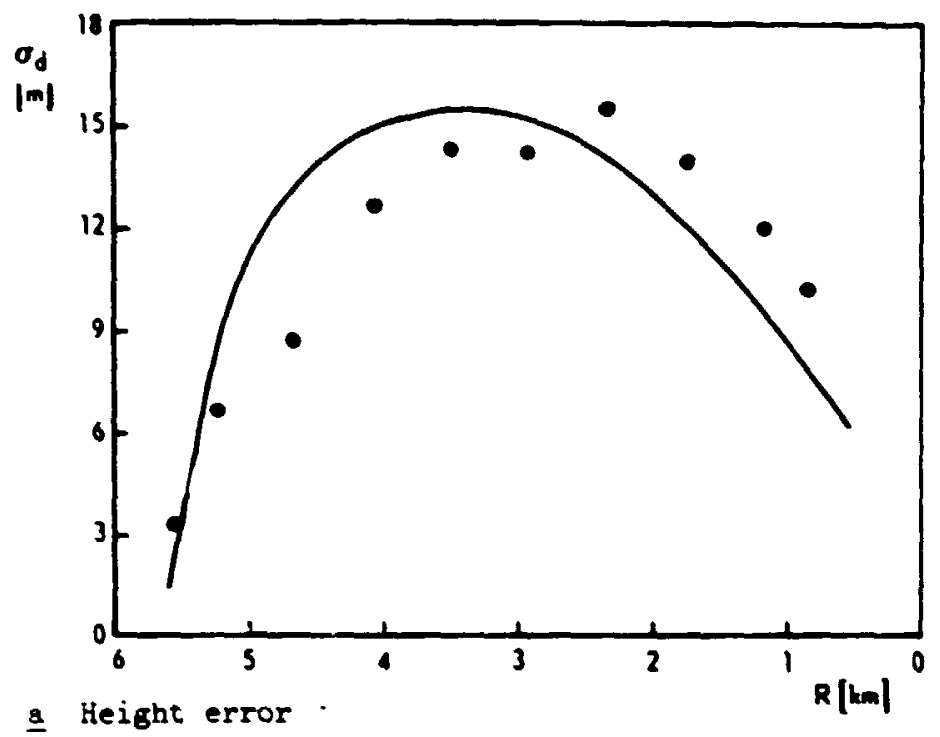

- MEOESLRED

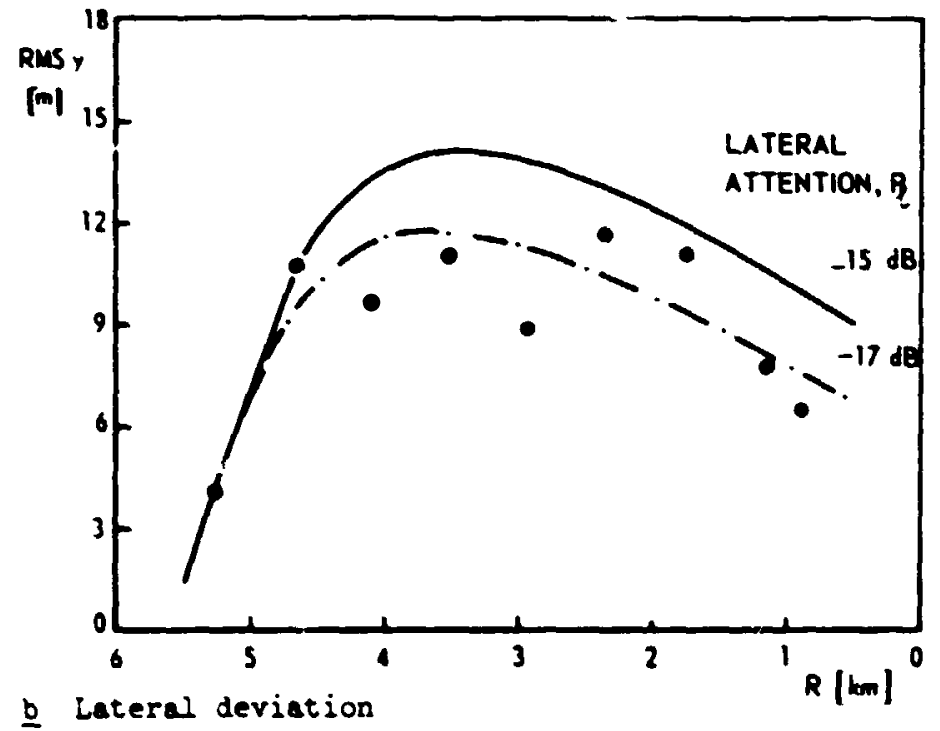

Fig. 4 Comparison of model and experimental approach performance - Configuravion $\mathrm{Cl}$ 
C:
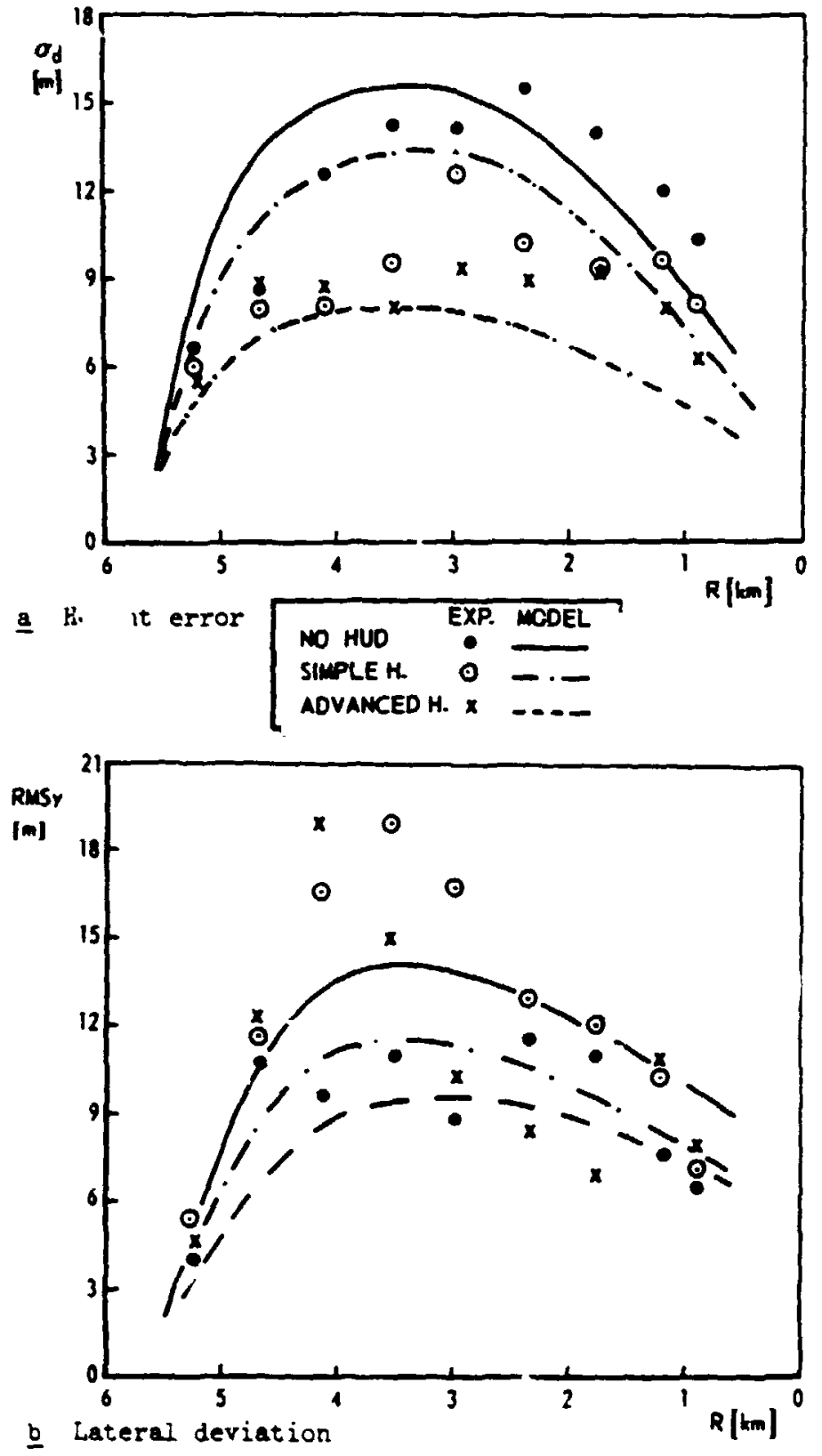

Fig. 5 Comparison of model and experimental approach performance-The effect of HUD information for the good visibility condition 
Grianis TaEs is

OF POÜR QUALITY

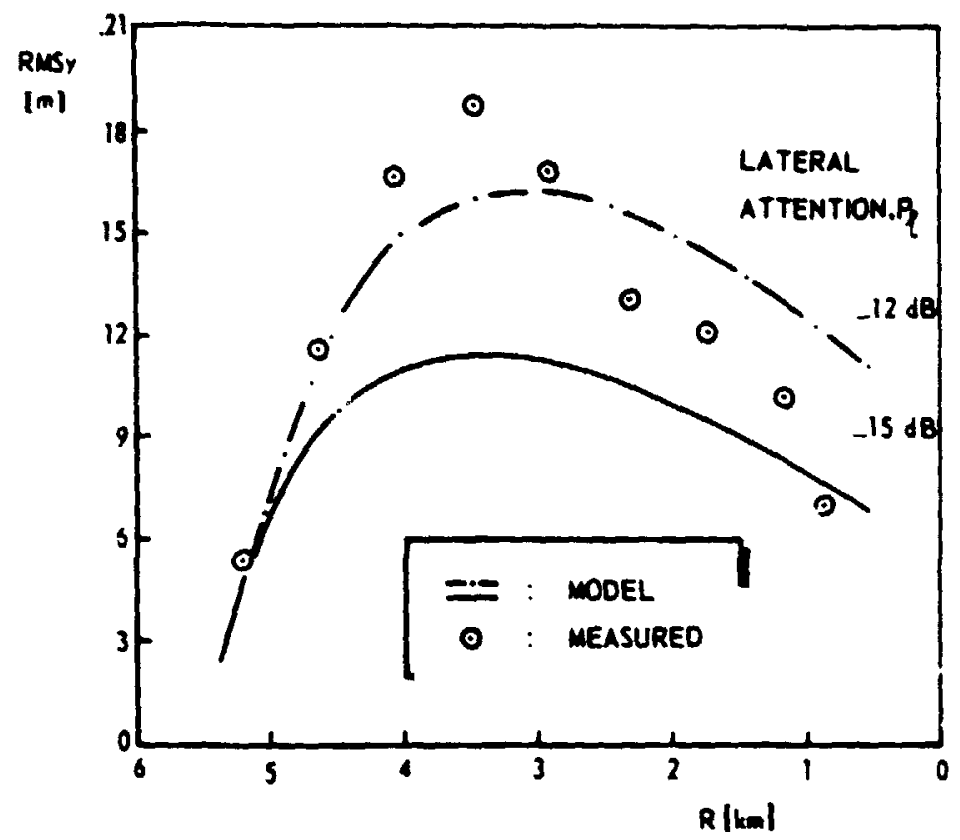

Fig. 6 Comparison of aodel and experimental laterai approach performance - Configuration $\mathrm{C2}$ 


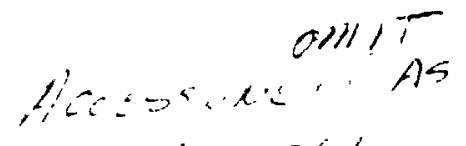

$$
\begin{aligned}
& \text { g1+13656! }
\end{aligned}
$$

Pllot/Vehicle Model Analysis of Visual and Motion Cue Requirements in Flight Simulation

R. Lancraft, G. Zacharias, S. Baron

\section{ACKNOWLEDGEMENT}

The work reported here was performed under NASA Ames Research Center Contract Number NAS2-10145. The authors wish to thank Mr. Frank Crane, technical monitor for MASA, for his assistance throdghout the course of the prograw.

\section{ABSTRACT}

The optimal control model for pilot/vehicle analysis is used to explore the effects of a CGI visual system and motion system dynamics on helicopter hover simulation fidelity. This is accomplished by expanding the perceptual aspects of the model to include motion sensing and by relating CGI parameters to information processing parameters of the model. Simulator fidelity is examined by comparing predicted performance and rurkload for flight with that predicted for various simulator configuration.

The results of the analysis suggest that simulator deficlencies or a reasonable nature (by current standards) can result in substantial performance and/or workload infidelity. Both CGI and motin system effects are signiflcant for this task. There is also a distinct interaction between the two sources of pilot cues. In particular, the presence of motion reduces the sensitivity to CGI limitations.

With respect to the CGI system, the most important parameter in terms of its effect on performance was display delay. This was followed in order of importance by display resolution and field-of-view. The main effect associated with motion system bandwidth was introduced by going to a fixed-base only configuration.

\section{INTRODUCTION}

As flight control and management tasks become more complex so, too, do the simulators used to investigate these tasks. The designers of simulations are confronted with difficult choices between requirements for slmulation fidelity and the needs for cost-effective methods of simulation. The latter demands have resulted in a trend toward the use of digital equipment in simulation ooth in modeling the vehicle and in generating visual 
cues (CGI systems) for the pllot of the simulator. These digital simulations can have characteristics that are significantly different from those desired. In particular, unwanted delays frequently result in such a simulation. Wher motion cues are also needed, the problems can be aggravated further both by delays in generating motion cues (even with analog hardware) and by the potential lack of correlation between visual and motion cues. The significance of these problems has been amply demonstrated in recent studies (Gum and Albery (1977), Queijo and Riley (1975)).

In this paper, the optimal control model for pilot/vehicle analysis is used to investigate the closed-loop consequences of the performance limitations associated with a computer generated inage (CGI) visual system and a six degree-of-freedom motion simulator (VMS) in a helicopter hover task. The specific problem addressed in this study was to determine the potential effects of CGI and VMS system characteristics on closed-loop hover performance and pilot workload, and to evaluate these effects in lignt of performance/workload levels we might expect to see in the actual flight situation. To accomplish this, the basic OCM is elaborated to include sensory perception of both CGI-generated visual cues and VMS-generated motion cues.

\section{MODEL IMPLEMENTATION}

Our objective in this section is to describe how this task is modelled in the context of the Optimal Contrul Model (OCM) of the p1lot. Inasinuch as the model has been documented extensively, the discussion dill be brief, with emphasis on those aspects of the model that are of special relevance to this study.

Figure 1 presents in block diagramatical form the structure of the OCM as envisioned for this study. Notice that the basic OCM is Immediately distinguished as the lower portion of the dashed block labelled pilot model. The upper portion of the pilot model displays the form of the expanded perceptual model. Observe that output signals from the simulator pass through dynamical blocks representing the $v i s u a l$ and vestibular sensory systems of the human (such as inner ear dynamics) is corm two display vectors, one from each modality. The displayed signals are then combined via a monitor. The monitor allocates attention tc the individual elements, to form the usual display vector. The other blocks in Figure 1 represent the simulator hardware in a straightforward and conventional fashion. The main frame digital computer is assumed to generate the vehicle dynamics and its characteristics are a part of that block. Likewise tile display computer characteristlcs are included in the simulator drive logic block. In our study, stick 
dynanics and stick transducer dynamics (such as computer generated force loading) were not considered. Also, flight instruments were not displayed to the pllot and can be ignored.

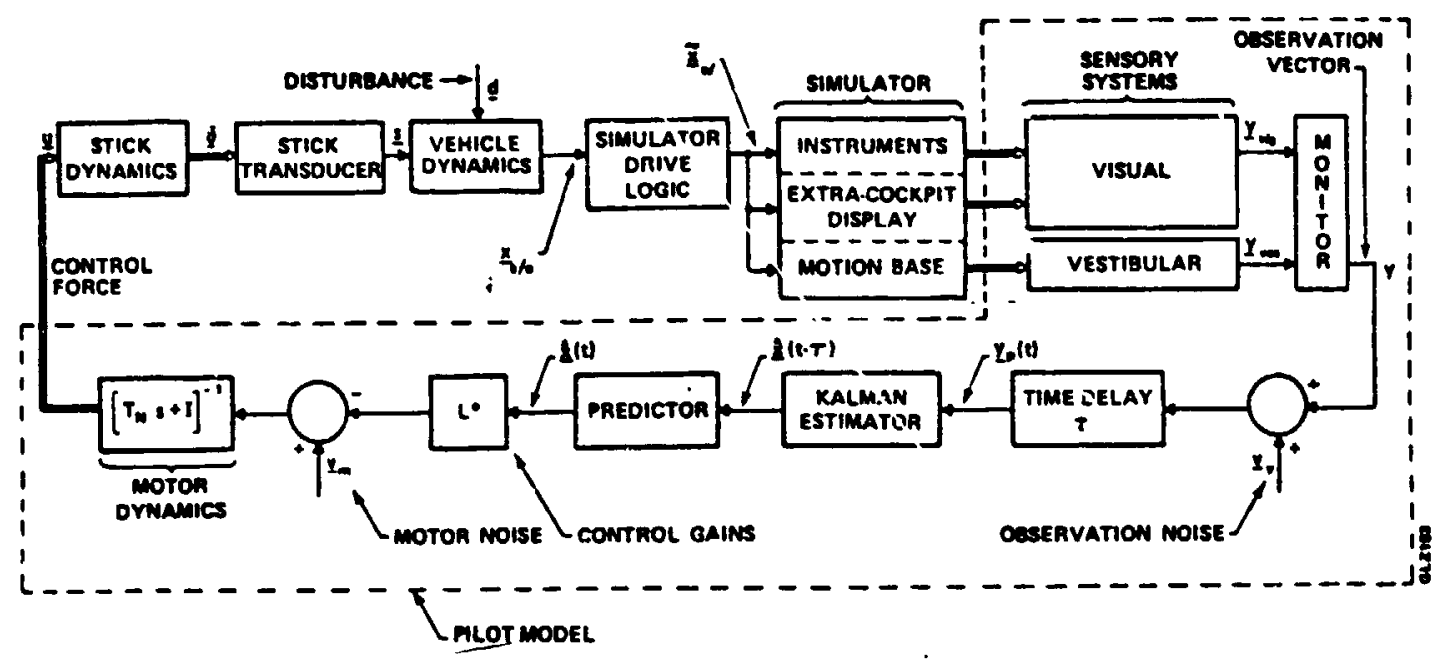

Figure 1: Overall pilot/vehicle system

Our basic modelling approach will be to define simulator liardware and human sensor dynamics, where appropriate, and to form a mapping between simulator and hO perceptual limitaitors and established OCM parameters. To this end, we will begin with a brlef description of the task/vehicle, followed by a statement of the basic simulator (main frame computer, VMS, and CGI; characteristics and how they were modelled. A simple model for the perception of the visual scene will then be discussed along with the vestibular models. Finally, a summary of model parameters and assumptions will be presented.

\section{Task/Vehicle Description}

The pilot's tas is to hover over a fixed point at a fixed altitude, in the presence of disturbances generated by air turbulence. Control is to be maintained by relying on extra-cockpit visual cues obtained from an out-the-window view and by motion cues associated with helicopter rotation and translation. Where visual cueing is provided by a computer generated image (CGI) system, and motion cueing is provided by a vertical motion simulator (VMS).

In spite of Its name, the VMS is not restricted to vertical motion cues; it is a six degree-of-freedom cueing system. 
he specific helicopter chosen for this study was the $\mathrm{CH}-47$ tandem rotor transport helicopter. The linearized and decoupled equations of motion for the helicopter, as well as the Drygen gust models for the air turbulence, were obtained from hot fman et al (1976). The reader is referred to this report for specific detalls concerning the basic airframe equations.

The hovering task is modelled as a disturbance regulation task. As is standard procedure for application of the OCM, it is assumed that the objective of the task may be characterized as minimization of the following cost functional (see kleinaan $(1976))$ :

$$
J=E\left[\left(y_{i} / y_{i_{\text {max }}}\right)^{2}+r_{j u_{j}}\right]
$$

where $y_{i_{\text {max }}}$ is a performance tolerance on the corresponding varlable. The values for $y_{1_{\max }}$ were chosen to be $5 \mathrm{ft}$ and $1 \mathrm{ft} / \mathrm{sec}$

for position $(x, y, z)$ and velocity $(\dot{x}, \dot{y}, \dot{z})$ variables and 1 dez and $.05 \mathrm{deg} / \mathrm{sec}$ for attitude $(\psi, \theta, \phi)$ and attitude rate $(\psi, \theta, \phi)$ variables; these values were taken from Hoffman et al (1976). The weightings on control rate activity, $r j$, were chosen by means of an error-control tradeoff analysis. This resulted in a value os approximately 1 for the diagonal elements of the $T_{N}$ matrix.

It should be noted that hover control of the unaugmented $\mathrm{CH}-47$ is not an easy task. The results of the reference cited above suggest that the task cannot be performed to within acceptable tolerances under IFR conditions.

Main-Frame Computer

The vehicle equations of motion were implemented on a digital computer, operating at a nominal update rate of $30 \mathrm{~Hz}$. Based on results from the analytic study by Baron et al (1978). we assumed for simplicity that the integration routine introduced no "distortion" in the continuous vehicle dynam." cs being modelled, and that the only effect of digitization was the introduction of a sample and hold delay associated with the base cycle time of the main-frame computer.

\section{CGI Characteristics}

Table 1 summarizes the characteristics used to define the nominal CGI conflguration. The nominal field-of-view specification is 11 listrated in figure 2 as screen configuration $B$. Notice from the table that no dynamics were associated with the CGI system. 

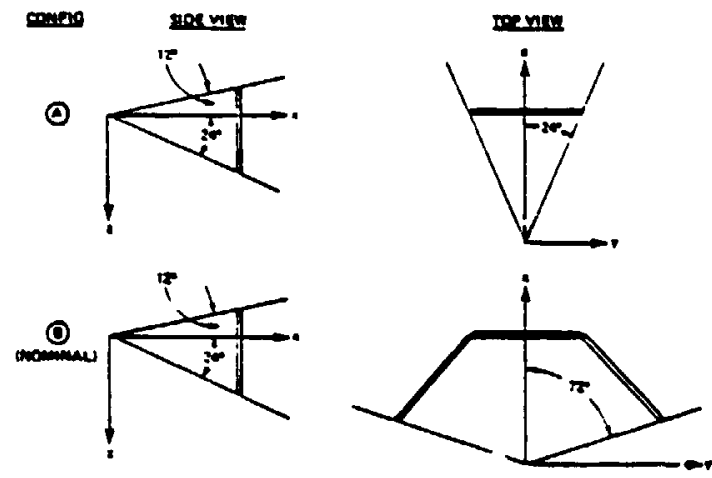

()

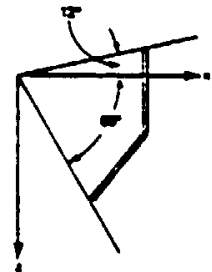

Figure 2: CGI Screen Configuration
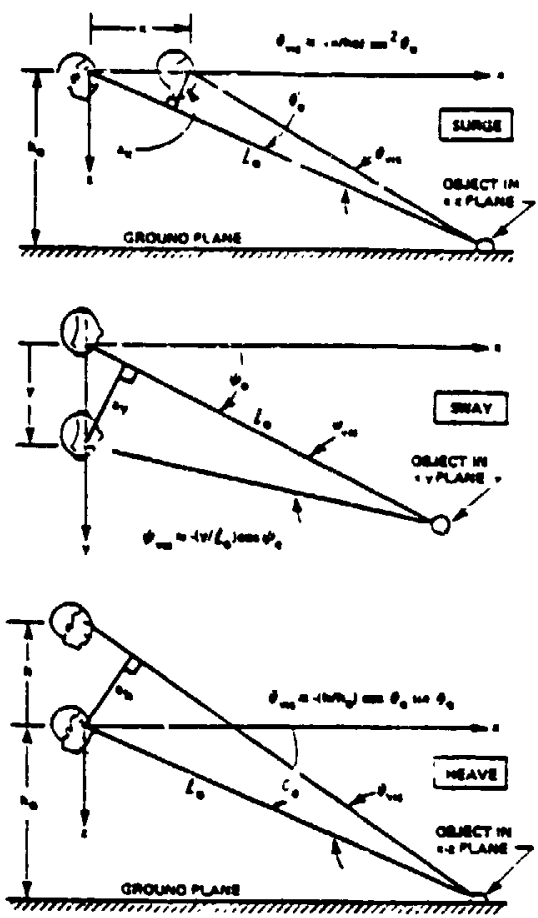

F1gure 3: LoS Changes Due to Translation

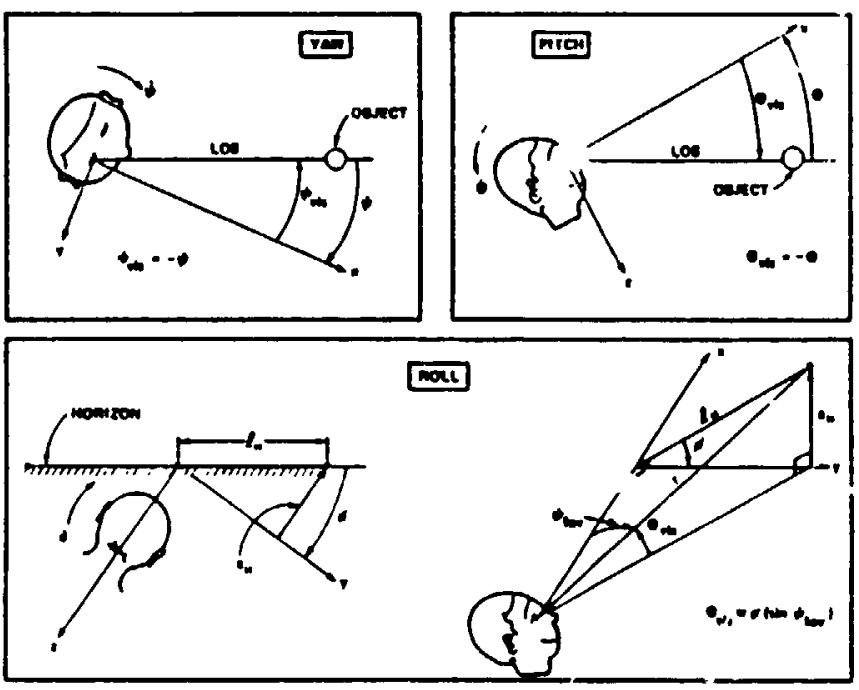

Figure 4: LOS Changes Due to Rotation 
Table 1: Nomiral CGI characteristics

$\begin{array}{lc}\text { Picture Refresh Rate } & 30 \mathrm{frames} / \mathrm{s} \\ \text { Display Compute Time } & 66 \mathrm{msec} \\ \text { Bffe: iye Sampie Rate/Delay } & 15 \mathrm{~Hz} / 99 \mathrm{msec} \\ \text { Scen? Content } & 6000 \mathrm{edges} / \mathrm{frame} \\ \text { Pield-of-View } & 3 \text { screens across (1440 horiz, 360 grt) } \\ \text { Display Resolution } & 1024 \text { lines/frame } \times 1024 \text { pixe+s/line }\end{array}$

The graphics computer was nodelled in the same fash: in as the main frame computer; 's . sample and hold delay based based on the refresh rate and a reap':te delay. Because the display computer is in seri ss with the vrame computer the total visual delay must include the main $f$. lay. The effective sample rate is simply the slowest cumpun...... chis path (i.e.., the fastest rate at which infornation can change: . This determines the affective visual hold time for information so that the total visual de: yy can simply be written as:

$$
T_{v i s}=T_{c}+T_{d}+1 /\left(2 f_{e f f}\right)
$$

where $f_{c}$ is the reciprocal of the base cycle time of the main $f r a m e$ cumputer, $T_{3}$ is the displisy compute time, and $f_{e f f}$ is tie effective sample rate. $T_{v i s}-3 T_{c} / 2$ seconds of the total delay was modelled is a pade delay in the visual path, while the rest of the delay was lumped into the human's time delay. (Since the main frame delay is common to both the vis and the CGI)

jcene content was not modelled except insofar as it was needed in the assumptions foi our visual perception model. Field of view serves to limit the vilitity of the displayed information and its afiect will be seen when we discuss the pilot's perception of the isual scent. Screen resulution limits the ineness of lecail the (.SI systrr. is able to present. Therefore, we have modelled it as a threshcld equal in value to the average vertical and horizontal angular resolution level. This threshold is, o course, in addition to any H.O. imposed threshold, and will be described shortly. 


\section{CTGin $i 1$ PAGE IS \\ OF PUOR QUALIYY}

VMS Characteristics

The nominal VMS was modelled in all axes as a second-order dynamic model witn approprizte position/rate/acceleration servo imits. Table 2 defines the nominal parameter values associated with each motion axis. The nominal motion system did not include washout filters as all predicted motions except the surge $(x)$ motio. were well sithin their respective simulator limits. In addition to dynamical models for the Vis servo systex, there is an effective motion system delay due to the main frame computer.

Table 2: vuS Model Paramecers

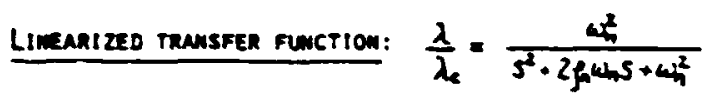

Panurctens:

\begin{tabular}{|c|c|c|c|c|c|c|c|}
\hline & Axis & $\omega_{n}^{\prime \prime}$ & $f_{n}$ & $\bar{\lambda}^{-\infty}$ & $\bar{\lambda}^{\infty}$ & $\pi$ & $x$ \\
\hline $\begin{array}{l}\text { nou } \\
\text { Pitor } \\
\text { van }\end{array}$ & $\begin{array}{l}(\phi) \\
(\theta) \\
(n)\end{array}$ & $\begin{array}{l}9.4 \\
9.4 \\
9.4\end{array}$ & $\begin{array}{l}0.7 \\
0.7 \\
0.7\end{array}$ & $\begin{array}{l}50 \% s^{2} \\
50 \% s^{2} \\
50 \% s^{2}\end{array}$ & $\begin{array}{l}15 \% / s \\
15 \% / 5 \\
15 \% / s\end{array}$ & $\begin{array}{l}-22^{\circ} \\
-24^{\circ} \\
-29^{\circ}\end{array}$ & $\begin{array}{l}22^{\circ} \\
26^{\circ} \\
29^{\circ}\end{array}$ \\
\hline $\begin{array}{l}\text { slanef } \\
\text { smar } \\
\text { reave }\end{array}$ & $\begin{array}{l}(x) \\
(y) \\
(y)\end{array}$ & $\begin{array}{r}9.4 \\
18.8 \\
18.8\end{array}$ & $\begin{array}{l}0.7 \\
0.7 \\
0.7\end{array}$ & $\begin{array}{l}36 \mathrm{rT} / \mathrm{s}^{2} \\
24 \mathrm{~s} / \mathrm{s}^{2} \\
32 \mathrm{rT} / \mathrm{s}^{2}\end{array}$ & $\begin{array}{c}2 \mathrm{FT} / \mathrm{s} \\
10 \mathrm{FT} / \mathrm{s} \\
2 \mathrm{neT} / \mathrm{s}\end{array}$ & $\begin{array}{l}-2.5 \mathrm{FT} \\
-20 \mathrm{FT} \\
-30 \mathrm{FT}\end{array}$ & $\begin{array}{l}2.5 F T \\
20 \mathrm{FT} \\
30 \mathrm{FT}\end{array}$ \\
\hline
\end{tabular}

Visual Perception Model

In contrast to the relatively well-defined set of visual cues provided by within-cockpit instrumentation, the extra-coc pit visual scene can provide the pilot with an exceptionally rish stimulus ervironment, even for a relatively simple display. At tempting to describe and quantify this stimulus environment has been the ubject of many studies and is well beyond the suope of this paper. The reader is refered to Brown (1973), Staples (1970), and Gibson (1950).

Our Initial approach to modeling the visual scene was to follow the perspective geometric arguments of Wewerinke (1978). 
Consequently, eacr object of importance wouid be modeled as a series of line regments, and incorporated into the display matrix c. As a resu", each object can yield many cues. In his study of the spproach and landing of a conventional aircraft there were a limited number of well-defined line elements comprising the visual scene, and thu the construction of the display matrix $C$ was a relatively straightforward exercise. However beczuse of the nature of the hover task, no single object is important. Instead, a pilot can use various portions of his visual field, and any number of objects or parts of objects to raintain hover position and attitude. Furthermore, in our study ro specific scene was available. As a consequence, we have assumed that a relatively "realistic" visual scene is made availalle to the pilot. Since such a scene is typically comprised of thousards (or perhaps tens of thousands) of discriminable line elements (and hence cues), the display analysis used by Wewerinke was not emf'eyed.

Our approach, instead, was to take a much simpilfied view of visual cue processing, based on the following notion. Information from cues involve changes in the location, and/or orientaion of the various line elements comprising the visual scene. These changes, in turn, can be expressed in terms of changes to the angular coordinates associated with the line element, two coordinates per foint for our siuvy, we have taken these two coordinates io be the azimuth and elevation angles assoclated with the line-of-sight (LOS) to a particular line element endpoint. This is illustrated in figures 3 and 4 , which show how specific vehicie rotatiors and translations result in changes in the azimuth and elevation angles associared with the line-of-sight to specific points in the visual scene.

Changes in the LOS angles are due to changes in vehicle state (position and attitute). Assuming small changes, we in use linearized relations, so that

$$
\begin{aligned}
& \psi_{v i s}=c_{\psi}^{\prime} x \\
& \theta_{\text {vis }}=c_{\theta}^{\prime} x
\end{aligned}
$$

where vis and ${ }^{\theta}$ is are the azsmuth ...d elevation LOS angles, $c$ and $c_{3}$ are tne display "gains", and it is understood that the abova relation holds (with different gains) for each specific point in the visual scene. We then assumed, for each vehicle state the pilot was trying to estimate, that he would chose one particular point in the visual scene to provide the most appropriate visual cue, and then share his attention among these now competing cues. Thus, if the vericle state is comprised of three rotational coordinates and three translational coordinates, then, in general, 


\section{CRBGHAL FNCE is
OF POOR QUALITY}

there would be six specific points in the visual scene the pilot would use for inferring shanges in vehicie states. Notice there is a many on one mapping between the vehicle state and each point in the scene, however, rather than postulating a cue decoupling model it was assumed the pilot was able to perform the inverse transformation needeo to infer correct vehicle motion (via many observations).

It is now appropriate to consider the fact that tne piist: il I be limited in his ability to detect changes in the Los angle cues available to him. This limitation will be due ejther to his own inherent sensory/perseptual limitations, or, in the siarlator situation, possibly due to CGI-imposed resolution liaits. The effective visual cue threshold will be the greater of the two thresholds associated with the pilot and the display hardware, and will ultimately limit the pilot's ability to inser vehicular state changes from charges in the visual scere. Naturally, if isisplay hardware is not involved (as in the actual helicopter envirornent), then the effective threshold will be determined soisly by the pilot's visua: limitations.

Turning first to the pilot's visual ligitatinns, we rake a distinction between angular resolution threshold $\left(a_{p}\right)$ and angular discrimination inreshold $\left(a_{D}\right)$. The former refer 3 to his visual acuity, and his abili y to resolve small angular differences in the LOS angle, when given a visual reference which, in angular distance, is very close to the object being sighted. The latter refers to the pilot's ability to discriminate between two large visual angles, and thus his ability to identify a small angular difference in the LOS angle, when given a visual riference which, in angular distance, is relatively far from the abject heing sighted.

The angular resolution threshold $(\alpha R)$ might be chosen on the basis of measured human visual acuity, which appears to be on the

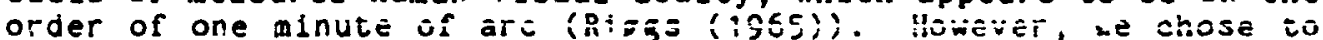
set it at a slightly higher level, based on an earlier analysis of the data obtained from dynamic tracking experiments (Levison (1971)):

$$
a_{R}=0.05 \mathrm{deg}
$$

The angular discrimination threshold $\left(a_{n}\right)$ was chosen in accordance with the Weber-Flechner law (Luce and Galanter (1963)), and set at a fixed fraction of the total angle heing viewed: 


$$
a_{D}=a_{0} / 3 c
$$

where $\alpha_{0}$ is the total angle being viewed.

We now define the pilot-associated visual threshold as the maximum of the resolution and discrimination thresholds:

$$
a=\operatorname{MAX}\left(a_{R}, a_{D}\right)
$$

The overall pilot/sigulator visual threshold will be given by

$$
Y=\max (\alpha, \beta)
$$

where $\alpha$ is the effective pilot threshold obtained previously, and the overall simulator threshold is:

$$
\begin{aligned}
& B=\left(B_{H}+B_{v}\right) / 2 \\
& B_{H}=\text { horizontal CGI resolution threshold } \\
& B_{V}=\text { vertizal CGI resolution threshold. }
\end{aligned}
$$

The discussion to this point has concentrated on static "positiun:" thresholds. To determine dyramic "velocit;" threshoids associated with visual cueing, one might attempt to assign a value on the basis of past psychophysical motion tetection/d+scrimination experiments. However, a review of the subject by Graham (1965) shows that a wide rarge of values can be assigned, deperding on the particular experimental situation and expirical me=sures used. We again chose to assign a value on the basis of . Lier Jynamic tracking experiments.

In a study of tracking, with a quantized visual display (Levisur: et al (1972)), a good OCM model match was obtained by setting $\dot{y}_{T H}$ equal to the display quantization ievel, and adjusting $Y_{\text {IH }}$ to provide the best fit to the data. This resulted in

$$
\begin{aligned}
& Y_{\text {TH }}=0.25 \text { deg } \\
& \dot{\gamma}_{\text {TH }}=1.1 \mathrm{deg} / \mathrm{sec}
\end{aligned}
$$

yielding a $\dot{\gamma}_{\mathrm{TH}} /{ }^{\gamma} \mathrm{TH}$ ratio of approxlately 4.4 . Cther studies have shown simllar ratios between velocity and position thresholds, and thus we chose for this study to specify the visual velocity threshold according to:

$$
\dot{\gamma}=4 \gamma
$$


where, if $Y$ is given in degrees, $\dot{y}$ is given in d Hence, we tie the rate threshold to tre position thresh in turr, depends on the pilot-associated and display. resoiution limitations. These ideas are summarized bel

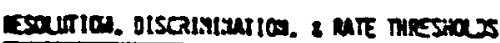

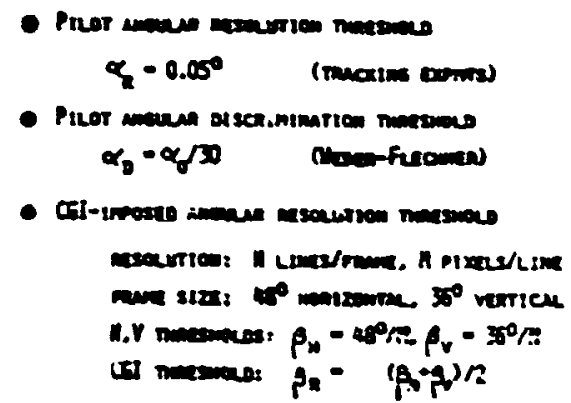

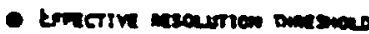

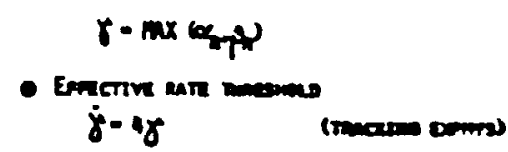

We are now in a position to define the effective "informational" thresholds, associated with the visual cues avallable to the pllot. As we noted earlier, we assume the pilot can "invertn the appropriate display equations to obtain an estimate of the vehicular attitude/position change from the visual cues available to $h i m$. If we assume that the effective visual threshold applies equally to the azimuth ( $\psi_{\text {vis) }}$ and elevation $(\theta$ yis) LOS changes, we can use figures 3 and 4 to generate informational threshold functions as shown in table 3 .

This table relates visual scene thresholds to (displayed) vehicle state thresholds. To determine the specific values for these informational thresholds, first assume a nominal hover alt 1 tude $\left(h_{0}\right)$ of $10 \mathrm{ft}$, and a nearest eye level visual target at a distance $\left(1_{0}\right)$ of $50 \mathrm{ft}$. Note that the maximum lateral field of view ( $\psi_{\text {FOV }}$ ) and LOS depression angle $\left(\theta_{0}\right)$ are both set by the screen configuration. Then, minimizing the threahold functions of Table 3 and solving for $\theta$ and $\psi$, for each screen configuration and display resolution considered, determines the "best" viewing locations along with the values for the irformational thresholds. The resulting thresholds are sumarized in Table 4. 
Table 3: Visual Scene Inforastional Function

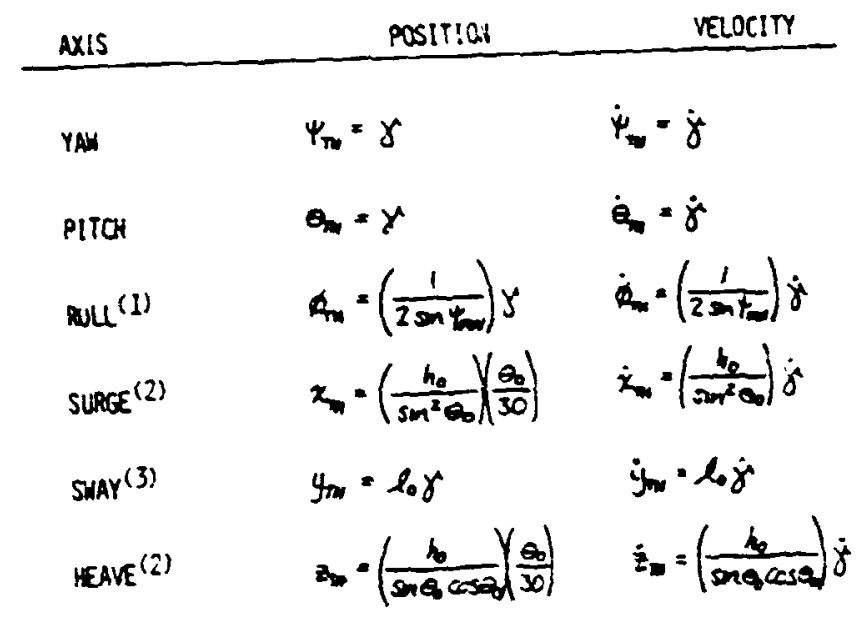
T ble 4: Visual Scene Informa- tonal Threnhold Values

\begin{tabular}{|c|c|c|c|c|c|c|c|}
\hline \multirow{2}{*}{$\operatorname{nos}$} & \multirow{2}{*}{ Amonom } & \multicolumn{3}{|c|}{ 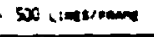 } & \multicolumn{3}{|c|}{ 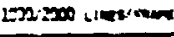 } \\
\hline & & $\therefore$ & 3 & 5 & 2 & $\xi^{*}$ & $i$ \\
\hline Mataita & & & & & & & \\
\hline & & . & 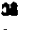 & a & .5 & $\mathbf{3}$ & 5 \\
\hline & & . & yn & - & 20 & 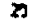 & $m$ \\
\hline & & : & $\mathbf{m}$ & * & $\dddot{x}$ & .65 & 5 \\
\hline & & 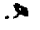 & 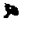 & $\mathbf{x}$ & 20 & $\pi$ & ב. \\
\hline & & . & 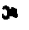 & $\because 2$ & $\boldsymbol{\alpha}$ & $\boldsymbol{z}$ & $x$ \\
\hline & & .2 & i6 & $\therefore$ & z & 3 & 3 \\
\hline imention & & & & & & & \\
\hline & & $\therefore$ & m & $\because$ & 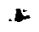 & w & 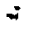 \\
\hline & & .5 & $\mathbf{x}$ & 3 & $\because$ & 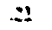 & y \\
\hline & & 5 & $\Sigma$ & 5 & I. & .5 & .57 \\
\hline & & $\cdot i^{*}$ & تن & $\therefore$ & פי & .80 & it \\
\hline 78 & & :נ. & 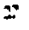 & $\because$ & .3 & $\infty$ & $\therefore$ \\
\hline & & . & $\mathbf{3 0}$ &. & تن & $\ddot{z}$ & z. \\
\hline
\end{tabular}

1) FACTOR OF 2 aCECUNTS FOR TWO END-POINT HORIZON

(2) POSITION THRESHOL is oIsCRIMIMATION LIMITED

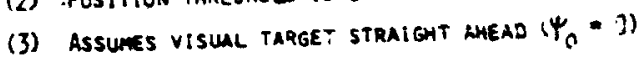

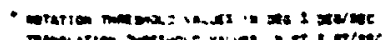

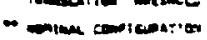

In summary, since the perceptual dynamics of the human visual system are relatively wide-band with respect to the system dynamics we are nodelifing, we chose not to include any dynamic visual effects. This allowed us to implement our visual percepcion model by simply thresholding the appropriate syst n state variables: the inear/angular positions and velocities of the (simulated) vehicle.

Vestibul ir Perception Model

Models of vestibular motion perception have been the subject of study for a number of years, and we will not attempt to summarize this work. Instead, we refer the reader to a relatively recent review of notion cue models by Zacharlas (1978), in which a number of these models are described and critically reviewed.

Figure 5 st. ws the vestibular model in block diagram form. The upper portion models the seml-circular canals as transducers of angular velocity, while the lower portion nodels the otoliths as transducers of specific force. Tabla 5 sumarlzes the parameter values used in each of the vestibuiar models. 


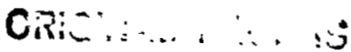

OF POOñ gunitity

Flgure S: Vestlbular Model

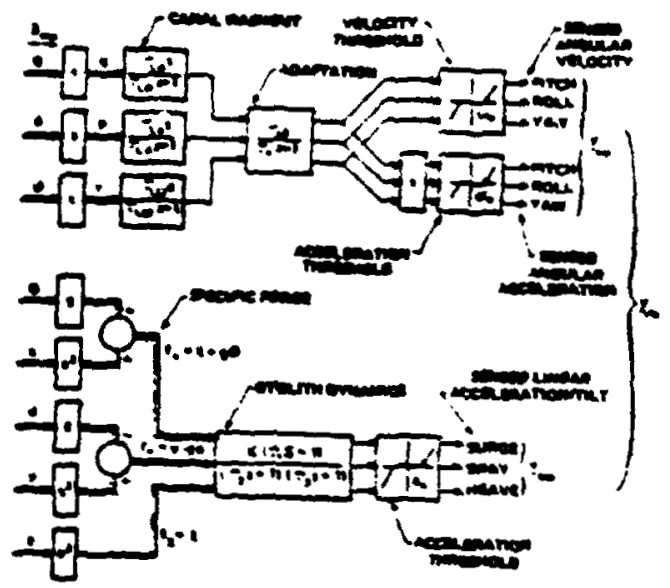

Comel Prensetess

\begin{tabular}{|c|c|c|c|}
\hline$a \times 1 s$ & $\tau_{L}(a, d / s)$ & $\omega_{0}(x \in E / s)$ & $\alpha_{0}\left(x \in G / s^{2}\right)$ \\
\hline PIta (e) & 5.3 & 3.6 & 0.67 \\
\hline noed $\infty$ & 6.1 & 2.5 & 0.41 \\
\hline$m$ & 10.2 & 4.2 & 0.41 \\
\hline
\end{tabular}

Orocits Pakumetexs

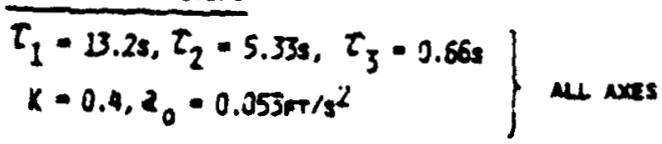

Toble 3: Paraeter Values for Veatlbular Model

To reduce cimputational requirements imposed by the vestibular model, we performed an analysis of the power spectrum of the vestibular signals. By comparing the power spectra of incoming vestibular signals to that of their filtered outputs, pass-bands were ldentifled which accounted for the wajorlty of the correlated power. Utilizing this information allowed the elidination of any lead or lag el. "s having break frequencles not in the pass-bands. Tabl u outlines the resulting simplifications. Although any of the vestibular dynamies were simplified or eliminated, the vestibular thresholds given in table 5 were still implemented. 


\section{ORiúi:-AL FALE IS \\ OF POOR QUALITY}

Table 6: Simplifications to the Vestibular Model

Axis

Simplification

Pitch $(\theta)$

Roll (\$)

Yaw $(\psi)$

Surge $\left(f_{X}\right)$

Heave $\left(f_{z}\right)$

Sway $\left(f_{z}\right)$

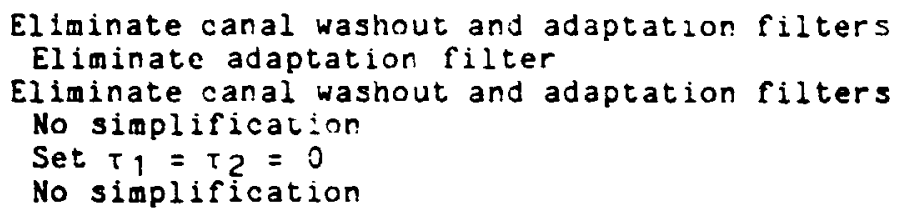

Attention-Sharing Model

The general features and method of implementation of the attention-sharing nodel are well known (see, for example, kleinman (1976)). Here, we wish to describe features of the nojel which are specific to the particular helicopter hover task under consideration.

In our modelling of the hover task, we assumed that "full attentzon" corresponds to an overall noise/siznal ratio of $-20 \mathrm{~dB}$, a level which is consistent with the finding of many earlier manual control studies (see, Kleinman et al (1971)). Further there rasld be an optimum allocation of attention axong the displayed variables subject to several constraints. These constraints are slinmarized in Table 7 .

Table 7: Monitor Constraints change.

1. $f_{\text {LAT }}=f_{\text {LONG }}=.5$

2. $f_{s}=f_{3}$; ie equal attention to a signal and its rate of

3. $f_{\text {ves }}=f_{v i s}=$ total axis attention

4. T TOT $_{\text {TO }}=1.0$

Notice, although the lateral axis control task is more demanding than the longitudinal axis (see Hoffman (1976)), for the purpose of this study we assumed an equal split of attention between the two axis. In addition no interference is allowed between modalities (1e. visual and vestibular signals are processed in parrallel). This requires that within an axis the total visual attention equal the total vestibular attention. This last assumption will clearly favor the use of motion cues, provided they are useful for control, since the pilots total attention to the task is effectively doubled. 


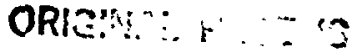

OF POOR QuALitr

Sumary of Model Implimentation Characteristics

- raxicarctive

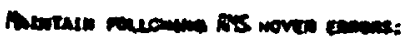

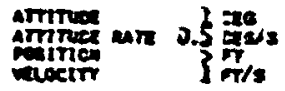

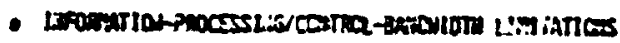

octenmerion molss/s:ame eurto

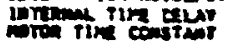

8.

- vasor rangostios ress

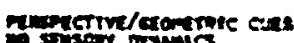

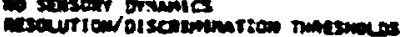

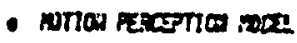

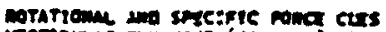

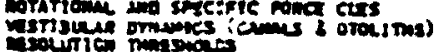

- anemor-suriso maca

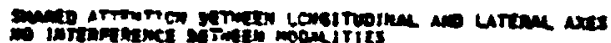

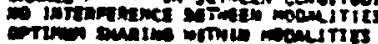

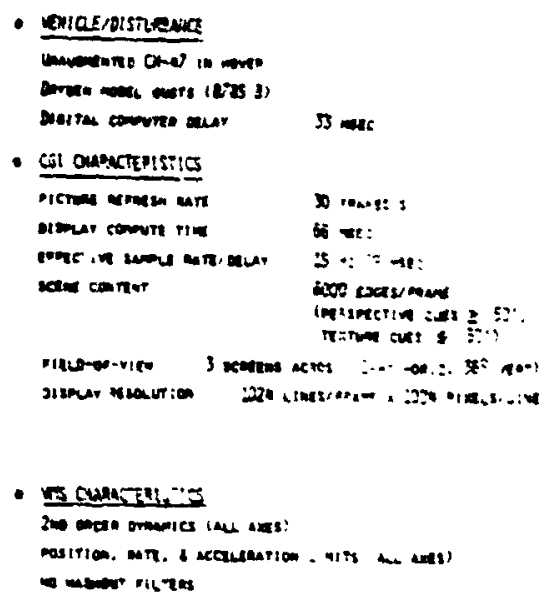

\section{CLOSED-LOOP ANALYSIS OF CGI AND VMS EFFECTS}

In this section, the optimal control model with the expanaed perceptual model is used to analyze the effects of CGI and VMS limitations on closed-loop hover performance. The goal of this analysis is to determine the effects of CGI and VMS characteristics on simulator fidelity (more precisely, performance and workload). To this and, a "perfect" or ideal simulator is defined in which there are no simulation tiae delays, no motion system dynanics, and an infinite resolution imagery system. This simulator configuration corresponds essentially to flight and provides a berchmark against which to measure simulator deficiencies. In addition to the nominal and perfect wotion conditions, results were also obtained for a no-motion" or fixed-base simulator configuration.

Through an oversight, the assumptions for the perfect configuration included a field-of-view constraint relevant to the nominal CGI corfiguration. Inis degraded performance only slightly from what would have been obtalned without the constraini. 


\section{ORIGINAL PAEE: IS \\ OF POOR QUALITY}

Thus, there were six basic simulator configurations to be analyzed so as to evaluate the effects of the visual and motion systems, separately and together. These configurations are listed in Table 8 .

Table 8: Simulator Configurations

\begin{tabular}{|c|c|}
\hline casfigurAtias & DESCRIPTION \\
\hline Perfect (Flight) & $\begin{array}{l}\text { No simulator delays, nominal field of view. } \\
\text { huren operator threshol ts, no vis dynamics }\end{array}$ \\
\hline $\begin{array}{l}\text { Perfect CCI- } \\
\text { Realiste vMS }\end{array}$ & $\begin{array}{l}\text { Includes min srame computer delays and } \\
\text { vis platform dynamics }\end{array}$ \\
\hline $\begin{array}{l}\text { Real } 2 \text { st is CGI- } \\
\text { Perfect Vis }\end{array}$ & $\begin{array}{l}\text { Includes masn frame and disolay computer } \\
\text { delove, cel imposed visual thresholds, no } \\
\text { platfirm dynames }\end{array}$ \\
\hline $\begin{array}{l}\text { Real } 28 t 10 \text { CGI- } \\
\text { Realistic VMS }\end{array}$ & $\begin{array}{l}\text { Includes all smulator nominal } \\
\text { character } 2 \text { stcs (see Table } 5.1 \text { ) }\end{array}$ \\
\hline $\begin{array}{l}\text { Perfect CGI- } \\
\text { Fixed Base }\end{array}$ & $\begin{array}{l}\text { Includes main fiame =omplter delays in } \\
\text { visial cues, no motion cties }\end{array}$ \\
\hline $\begin{array}{l}\text { Raalistic C(iI- } \\
\text { Fixed Base }\end{array}$ & Includes CGI limitations, no mot:0.2 cues \\
\hline
\end{tabular}

Results and Discussion

The effects $O_{i}$ CGI and motion system characteristics will be examined largely in terms of relative performance in the hovering task. For each axis, relative performance is defined as

$$
\text { Performance }(\text { in } s)=100 \times\left(J-J_{F L T}\right) / J_{F L T}
$$

where $J$ is the vaiue of the cost functional of Eq. 1 and JFLT corresponds to the value of $J$ obtained for flighi or the "perfecti simulator. Thus, relative performance is a normalized metric of performance that leasures the percent deviation from "flight" performance introduced by the simulator characteristics. In this sense, relative performance is a measure of simulator fidelity.

The results will be presented in terms of $J$ (rather than individial error and control scores) because this quantity is a scalar met $c$ of overall performance and, therefore, provides a concise desaription of the simulator effects. In addition, Hess (1977) has shown that the value of $J$ may be correlated with vehicle flying qualities, so increases in $\mathrm{J}$ owing to simulator deflciencies may be related to degraded fiying qualities for the simulator. Nonetheless, Individual error and control scores may also be of interest ar these are presented later in table 9 for the six simulator confligurations. 


\section{ORIGINAL PACE IS \\ OF POGR QUALITY}

Table 10 summarizes the optimal attention split found for the nominal fixed and moving base simulator configurations. As discussed in Kleinman (1976), the attention paid to a variable indicates its relative importance to the task. Table 10 shows that pitch and pitch rate information is the single most important visuaily obtained variable for the longitudinal axis, while roll and roll rate are most useful for lateral control. of the vestibular cues, pitch, pitch rate, and z-axis specific force are all important for longitudinal control, while y-axis specific force is the most useful cue for lateral control.

\begin{tabular}{|c|c|c|c|c|c|c|c|c|c|c|}
\hline \multirow[b]{3}{*}{ varieble } & \multirow[b]{3}{*}{ Unit: } & \multicolumn{6}{|c|}{ Desupaneed $\mathrm{CW}-11$ ormenics } & \multicolumn{3}{|c|}{ Aunowted $\mathrm{CH}-17$} \\
\hline & & \multirow[b]{2}{*}{ Psin } & \multirow[b]{2}{*}{$5 \mathrm{cct}$} & \multirow[b]{2}{*}{$\begin{array}{l}\min _{0} \\
\mathrm{ccrit}\end{array}$} & \multicolumn{3}{|c|}{ Jinviator Configwratlm } & \multirow[b]{2}{*}{$\because 510$} & \multirow[b]{2}{*}{$\begin{array}{l}\text { R vis } \\
\text { n cril } \\
\end{array}$} & \multirow[b]{2}{*}{$\begin{array}{ll}\text { C } \\
n \text { cat }\end{array}$} \\
\hline & & & & & 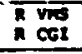 & $8 \mathrm{cot}$ & crot & & & \\
\hline & & C.0s & 3.14 & 3.72 & 3.03 & 3.49 & 6.07 & 2.16 & 3.05 & J. 32 \\
\hline & eteree & 0.92 & $0 . \infty$ & 1.09 & 1.13 & 1.4 & 1.30 & t.35 & 0.10 & 0.63 \\
\hline & & 1.71 & 1.21 & 2.06 & 2.11 & 2.11 & 2.4 & 4.98 & 1.12 & 1. J1 \\
\hline & fe/oee & 0.60 & 0.60 & 0.67 & 0.10 & 0.90 & 0.07 & 0. 39 & 0.12 & 0.36 \\
\hline 1 & & $0.02^{\circ}$ & 0.97 & 9.96 & 1.00 & 0.92 & $1.1 \mathrm{~J}$ & 0.5 & 0.31 & 0.56 \\
\hline 0 & no/sece & $\bullet .85$ & $\bullet .12$ & $\bullet .99$ & 2.03 & 0.97 & 1.17 & 0.13 & 0.16 & 0.13 \\
\hline & & 6.30 & 6.98 & 9.46 & 7.52 & 1.37 & 9.72 & 4.31 & 4.36 & 3.63 \\
\hline & $8 t /$ aec & 1.21 & 1.35 & 1.04 & 3.46 & 1.65 & 1.91 & 0.00 & 0.92 & 1.15 \\
\hline$\bullet$ & $\infty$ & 1.12 & 1.76 & 1.11 & 1.12 & 1.90 & 2.06 & 1.33 & 1.54 & 1.62 \\
\hline$\%$ & $\operatorname{dos} /$ ace & 1.03 & 1.1 & 1.10 & 1.20 & 1.27 & 1.46 & 0.63 & 0.67 & n.ग \\
\hline$\bullet$ & $d n$ & 0.42 & 0.14 & 0.37 & 0.47 & 0.19 & 0.62 & 0.06 & 0.06 & 0.07 \\
\hline & m/loet & 0.15 & 0.16 & 0.15 & 0.11 & 0.20 & $\bullet .24$ & 6.04 & 6.05 & 0.09 \\
\hline & Inctien & 0.21 & 0.23 & 0.23 & 0.24 & 0.23 & $\bullet .24$ & 0.24 & 0.24 & 1.24 \\
\hline & Inctive: & 0.14 & $0.1:$ & 0.15 & 0.15 & 0.13 & 0.16 & 0.12 & 0.12 & 0.13 \\
\hline & Inethes & 0.16 & 0.16 & 0.17 & $0.17^{\circ}$ & 0.11 & 0.14 & 0.27 & 0.27 & 0.20 \\
\hline 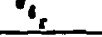 & lacher & 0.03 & 0.03 & 0.03 & 0.03 & 103 & 0.04 & 0.04 & 0.04 & 0.04 \\
\hline \multicolumn{11}{|c|}{ 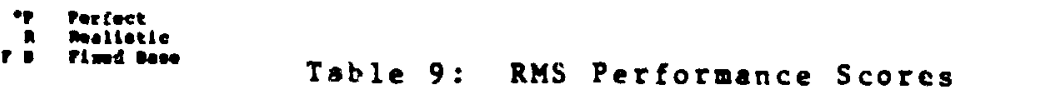 } \\
\hline
\end{tabular}

Table 10: Attention Allocation Nominal Configurations

\begin{tabular}{|c|c|c|c|}
\hline & Sald & rove & $\lim _{4 x}$ \\
\hline & $\mathbf{x , i}$ & 0.00 & 0.005 \\
\hline & $2 . j$ & 9.00 & נ35 פ נ \\
\hline & 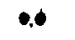 & 2.8x & 0.422 \\
\hline & & 3.50 & $20 m$ \\
\hline & " & 2.01 & \\
\hline & $r=$ & ע. & \\
\hline & $\bullet \bullet$ & 0.281 & \\
\hline & & 0.155 & o $\mathrm{cm}$ \\
\hline & $\because$ & 0.2 & 0.86 \\
\hline & $9 . i$ & 0.00 & 3.2x \\
\hline 3 & & $\overline{0.500}$ & $\overline{: 5 x}$ \\
\hline & $n$ & 0.23 & \\
\hline & 0 & 9.201 & \\
\hline & $\varphi, \ddot{\varphi}$ & סח. & \\
\hline & & $\overline{0.500}$ & \\
\hline
\end{tabular}

82 


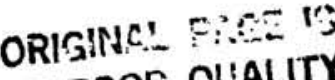 \\ OF POOR QUALITY}
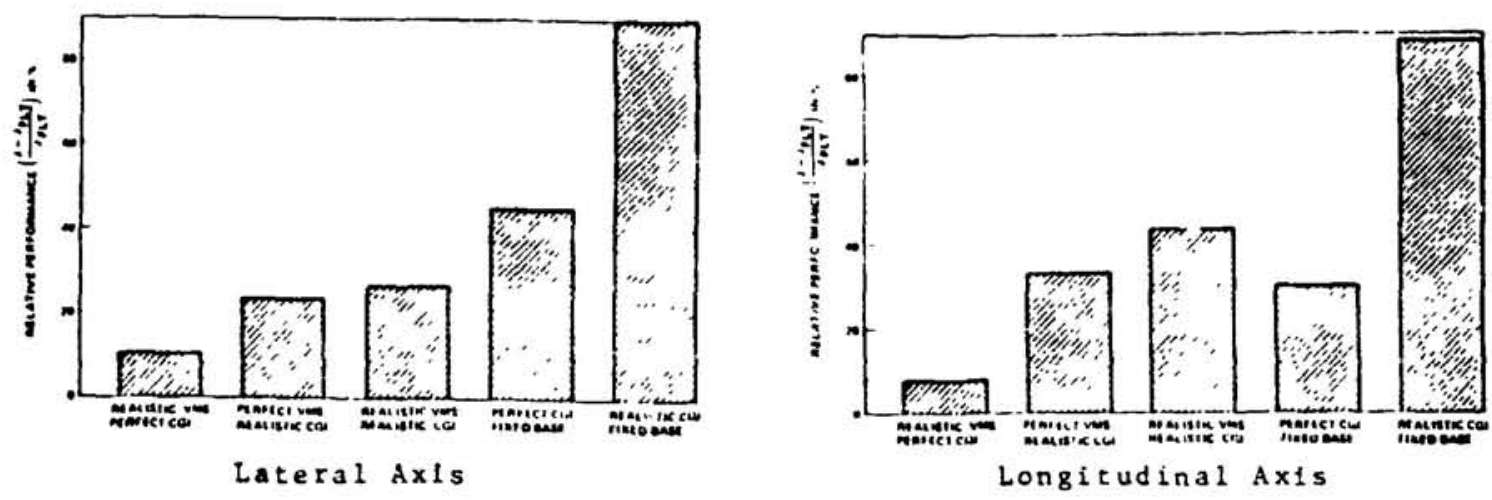

F1gure 6: Relative Performance vs. Simulator Configurations
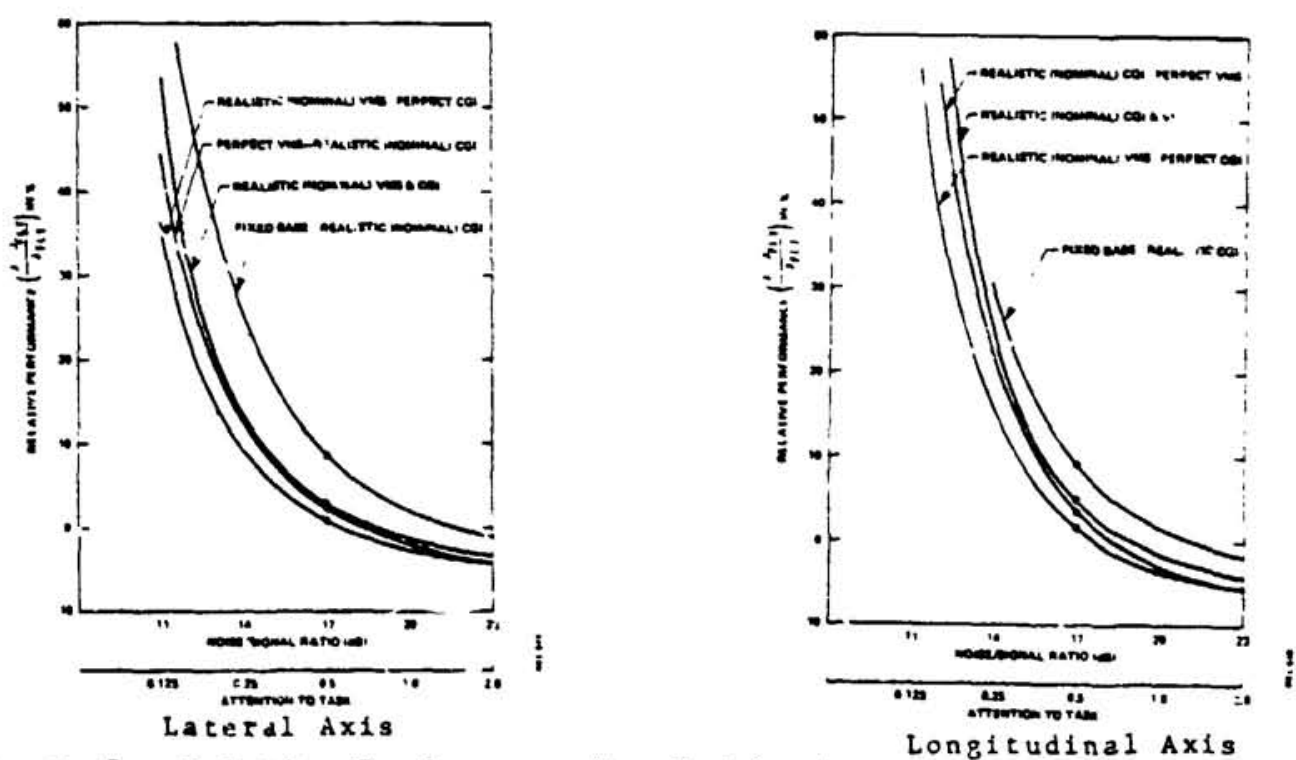

Figurc 7: Relative Performance Vs. Worblogd

Overall CGI and Motion System Eifects

Figur $6 \mathrm{pr}$ ssents the model perforuance predictions for the five simulator configurations, relative to that expected from the "perfect" simulator (which, by definition, has a relative performance of zero). With respect to longitudinal performarse, it can be seen that the efiect of the CGI is nuch more significant (35\%) than that of the motion system $(10 \%)$. Indeed, performance is better with a perfect CGI and no motion than with perfect motion and a realistic CGI. However, motion is -till important particularly if the realistic CGI deficlencies ure accounted for. Th1: is shown by the prediction of approximately twice the relat ve pertormance for the realistic CGI-fixed base configitration as for the realistic CGI-realistic VMS configuration. 
The results for the lateral control task are similar to those for the longitudinal task, but motion is even more important. In this case, having a perfect CGI doe: not compensate for lack of motion, since the fixed base configurations are worse than any other motion configuration. Compared to ' z longituainal task, going from perfect to realistic motion introduces less performance degradatio: Also, notion ameitorates the consequences of any visual deficiencies.

For either longitudinal or lateral control, the performance change $(10-15 \%)$ due to introducing the realistic motion system alone is probably within the inter - and intra-pilot vari.ions that: might be expected However, once realistic CGI jets are considered, or notion is re loved entirely, this is no longer likely to be true for skilled pilots inasmuch as the ceviations predic ad can be substantially greater unan $20 \%$.

Table 9 gives the effects of simulator configurations on indivijual rms error scores. These scores generaliy tend tc parallel the effects shown for relative performance, as wsuld be expect.d. However, it is interesting to note that predicted control scores are less affected by simulator changes than are output variables. Indeed, the control scores remain firly constant over the variuus conditione.

The above model predicticns are based on the assumption that the pllot will maintain a flxed level of atiention for the longitudinal and lateral cortrol tasks regardless of simulator configuration. However, in actuaitiy, the pilot may choose to devote more (or less) attention to the cuntrol tasks, hased on simulator configuration. To explore the effects of such a change ir strategy, model predictions were obtained for various attention levels. The results are presented in figurs 7 . Note that the soild dots on the curves indicate the nominal levi? of attention for that simuidtor configuration. It can be seen that the reiative ordering of simulator configurations is mai.utained at all levels of attention. At high levels of at intion, the performance with the realistic CGI-perfect VMS configuration approaches that for the realistic VMS-perfect CGI configuration. Apparently, if the noise/signal ratio is lowered sufficientily on the motion cues, it can offset some of the visual ceficiencies associated with the nominal CGI.

As a result, inner loop variables ( $\theta$ ard $\phi)$ are somewhat less affected than outer loop ciantities $(x, y, z a$ a $\psi)$. 
If it is assured that the pilot adapts his behaidior and increases attentior ievels to achieve performance equivalent to that in -ight, then the incremental attention required may be conside: : 3 workioad penaicy associated with the simulator. The curves ca figure 7 can be used to determine this workload penalty or maintaining flight :evel performance in the simuldtor; one simply deterdines che incersection of the particular sensitivity curve with the line of zero relative performance. The computed attention or workloat penalties for the various configurations analyzed in figure ? are given in table 11 . For the nozinal CGI and motion system, the pilot would have to increase attenticn by 508 over that needed in Ilight in order it achieve the sane performance, whereds almost three times as much attenticr is required for a fixed base simuiation.

\section{Effects of CGI Parameters}

The resilts of the previous section suggest that the visuai processing ligitations introduced by a nominal CGI configuration could result in significant deteriorations of closed-loos nover performance. Here, we examine the effects of variatiuns in indivitual, Jesign-related CGI parameters. In these inalyses, a single paraweter is varied while all other CGI paramecers are keft at their luminal or realisill values. Results wili be presented for both realistic =ution base and fixed base corigurations.

Figures 8 and 9 show the effect of increxertal deiays on relative performarice for notion-base and fixed-base simulators, respectively. Resul:s are presented as a function of CGI display computer delay, for three values of main-frame computer delas $\left(T_{c}\right)$. Recall, the nominal display delay is $99 \mathrm{msec}$. For the range af delays considered. relative performance appears to degrade linearly as a function of either display delay or zain-frane delay, when motion is present. Compariscn of figures 8 and 9 (note the difference in scale) reveals that the absence of zotion cues will accentuate the deterioration of perfornarce for a given delay. Moreover, for a fixed base configuration, performance tegrades wore rapidly than iinearly. it san also be seen from these figures that the longitudinal control task is more sensitive to increases in delay tinar is the lateral task, particularly to insreases in display delays.

In geverai, the agnitude of the effects of display delay are quite sigrificant. Increasirg dispiay delay from zero to the nominal, but reasonably conservative, value of 99 nsec, causes ar increase in relative perforxance of approximately 20-302 for the motion-base simulation and about 40-50\% for the fixed-base case. 


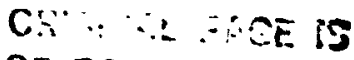

OF POUIR QUALITY
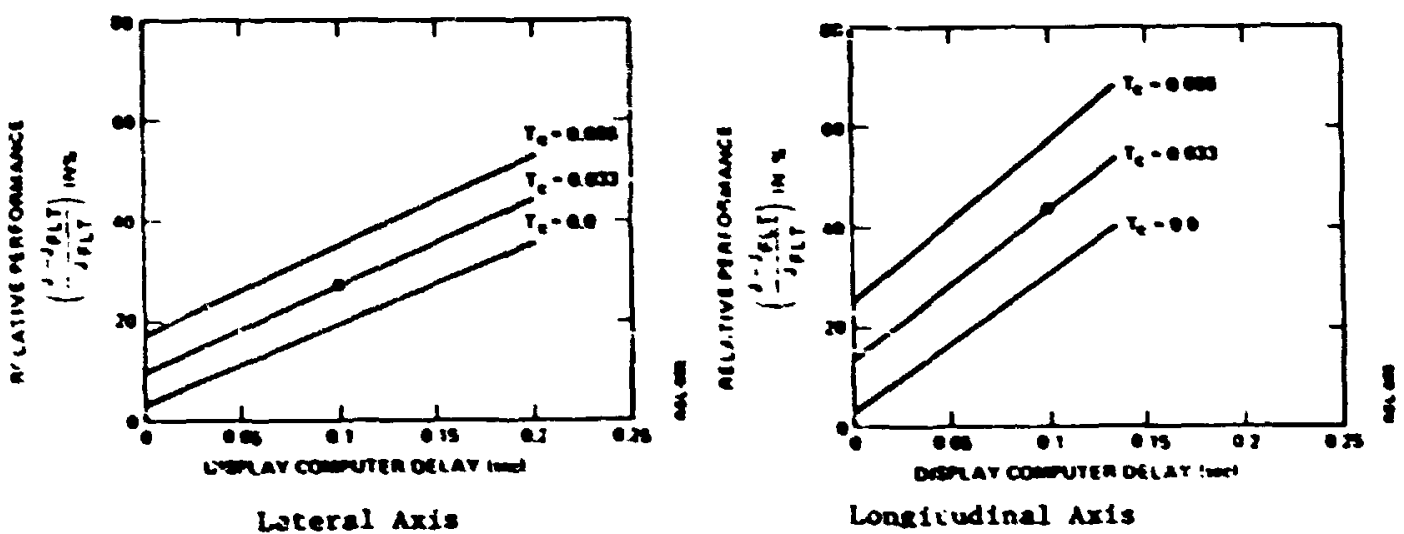

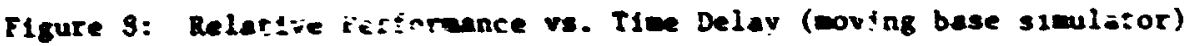

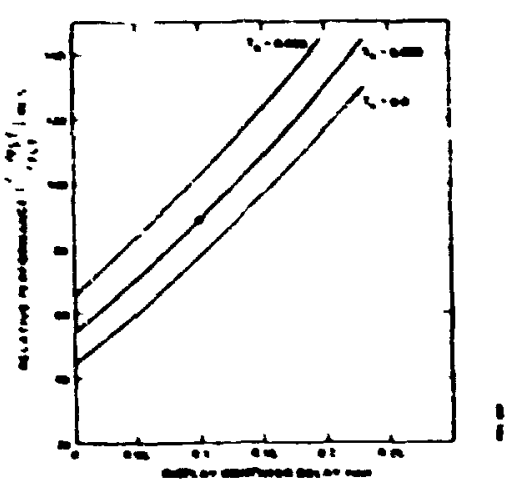

Lateral Axis

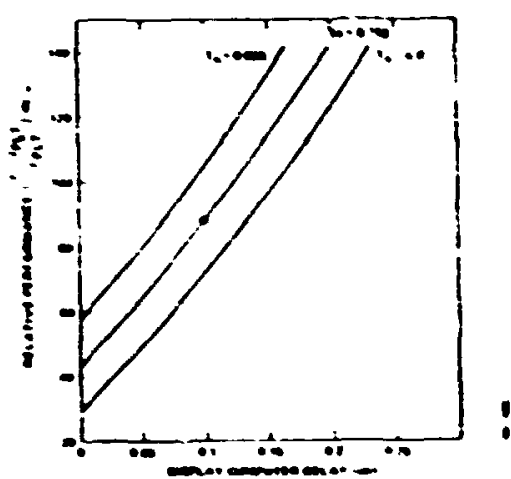

Longltudinal Axis

Figute 9: Relative Performanc.s re. Time Delay (fixed base simulator)
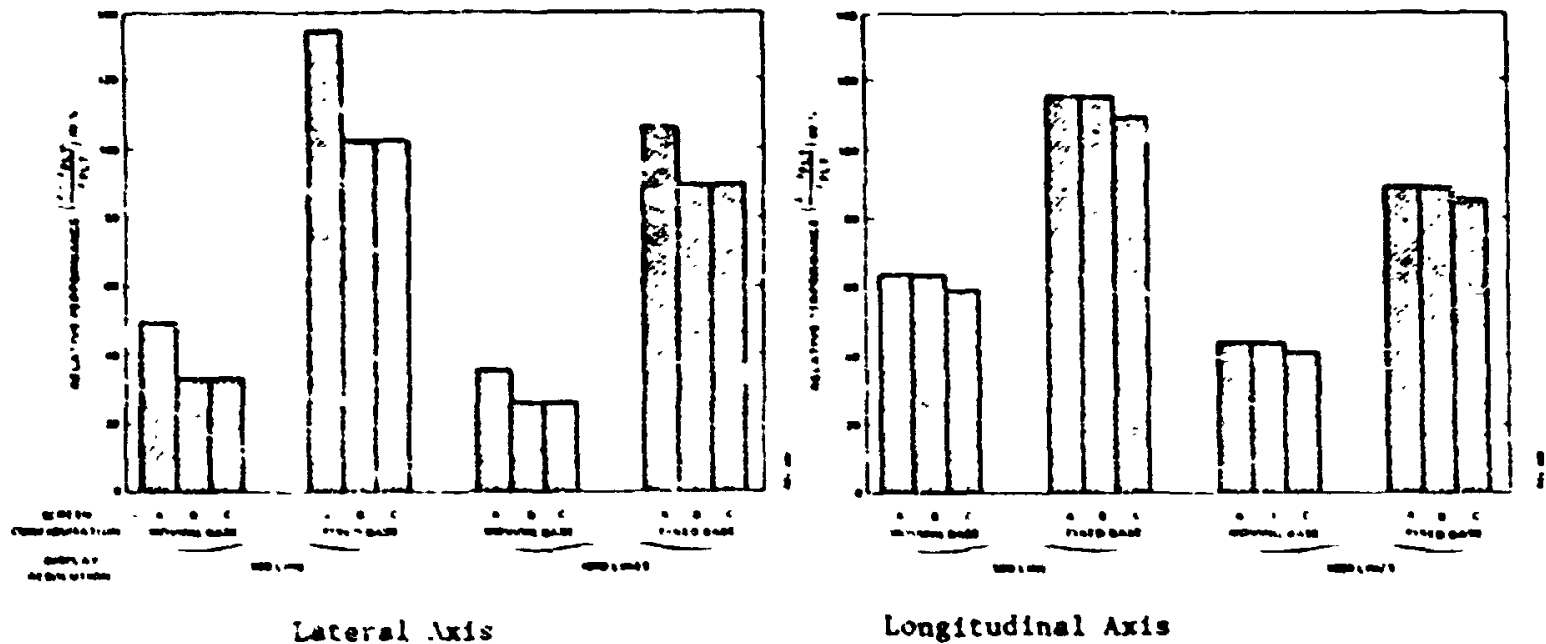

Longitudinal Axis

Figure li: Relative Petforance rs. Flels of View and Displav Resolution 
An examination of the relative performance values for zero display and computer delay shows that the effects of other CGi or sotior systea limitations are auch less significant (at nominal values) than are the efrects sue to delays.

The effects of fleld-of-view and display resolution are presented in figure 10. Recall that screen configuration $B$ is the noainal configuration corresponding to $144^{\circ}$ horizontal. $36^{\circ}$ vertical field of view. Configurations $A$ and $C$ provide $48^{\circ}$ by $36^{\circ}$ and $147^{\circ}$ by $72^{\circ}$ flelds of view, respectively. the noainal display resolution is 1024 lines. Both rield of view and display resolution are assumed to affect observational thresholds as discussed previously.

It can be seen froa figure 10 that decreasing the horizontal fleld of view (conflguration $A$ ) does not affect longitudinal performance and increasing the vertical fielt-of-view has no effect on lateral performarce. This is expected because of the assuaed decoupling between longltudinal and lateral control tasks. Figure 10 also suggests that increasing vertical field-oi-view has very little performance payoff and probably would rot be justified on the basis of these results. On the other hand, the improvenent in performance with increased lateral field-of-view appears to be significart, especially if the cue aresentation is degraded in other ways, such as poorer resolution or no aotion. For the 500 line display, fixed base conflguration, reduction of the horlzontal rleld-oi-view from $144^{\circ}$ to $48^{\circ}$ degrades relative performance by more than 308 .

The effects of display resolution are somewhat different than ror fleld-of-view in that sreater effect is observed for the longitujina! task than the lateral task. Witn aotion, longitudinal perforance 13 boout 208 poorer for the 500 line display as compared to about a 58 degradation in the lateral case; for the flxed-base conflgurations, these effects are increased to about 25-308 and 108. respectively.

Before leaving this discussion of the effects of individual CGI parameters. It should be noted, is a caution. that the assunptior of a sne-to-one correspondence with model paraaeters is aude for siaplicity. In reality, design charges can alter several ractors relited to inforation processing and tradectes are often

The posslbie etrects of Ircreased rield of view provising usetul perlpheral inforaction on vehicle rates have not been examined here. 
ORIGINA: PAEF :3

OF POUR QUALITY

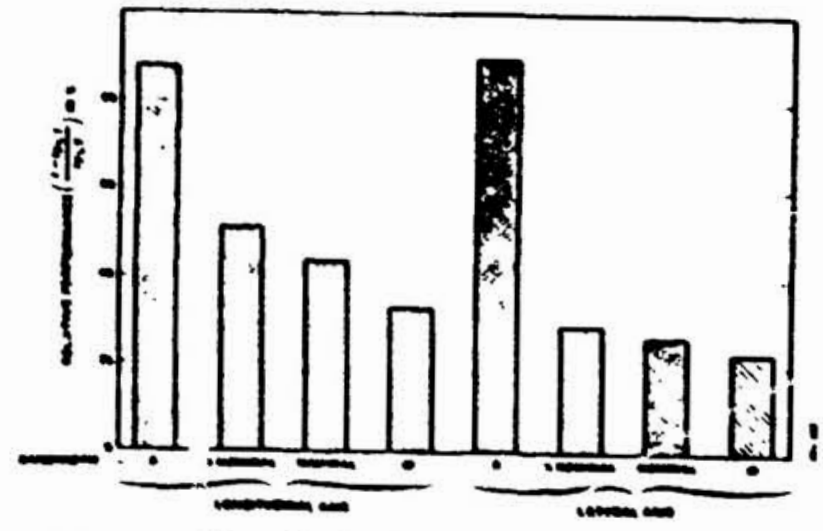

Fisure: 1: Relacive "erforeance va. VMS Platerer Bandwidzh

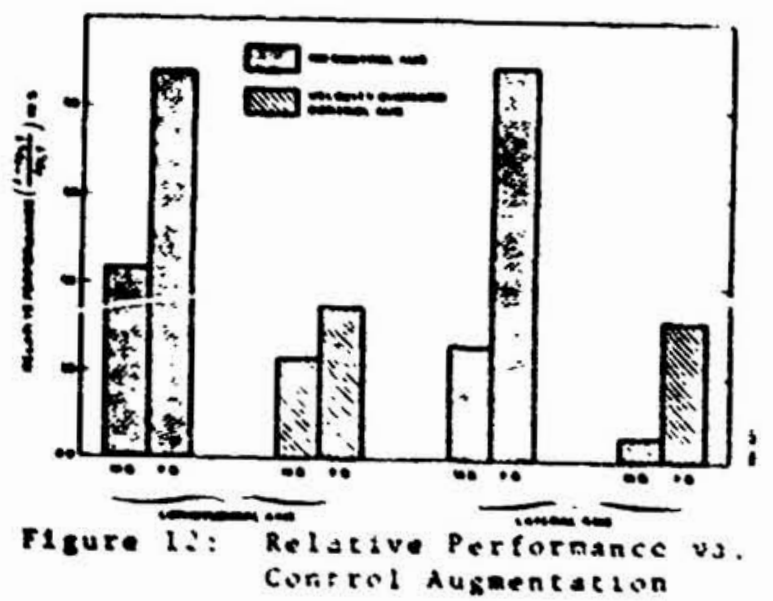

Table 11: Simulacor Workload Penalties

\begin{tabular}{|c|c|c|c|}
\hline Compirion & \multicolumn{3}{|c|}{ - Arrenirion - } \\
\hline & . & .5 & \\
\hline R. Wis. P. C6I & .55 & .50 & 1.0 \\
\hline P. Wo. R. Col & .86 & .69 & 1.55 \\
\hline R. Wr. R. Cit &.$\pi$ &.$\pi$ & 1.58 \\
\hline R. CऽI - F. 8. & 1.25 & 1.5 & 2.25 \\
\hline
\end{tabular}

the result. For example, laproved scene content aay lower nolse/signal ratios but asy require sore computation and, nence, Increase delay.

\section{Efrects of VMS Paraneters}

Relative performance is plotted as a function of platform bandwideh and control task in figure 11. A barjwidth of zero corresponds to a 1 ixed base configuration and an infinite bandwidth corresponds to llight moticn. It can be seen that changing the bandwisth does not have an appreclable effect on relative perforance, so long as a reasonable degree of aotion fidelity is malnealnect. The affects of bandwitth are somewhat pore pronounced for the longltudinal control task than for the lateral. 


\section{Errects of Vehicle Dynarics}

The effects of siaulator parameters will depend on the specifics of the task, including the vehicle dynantes. This has already been lliustrated in differences between predicted longitudiral and lateral perforance. To explore further the effects of vehicle dynaics, results were obtained for the $\mathrm{CH}-4 \mathrm{~T}$ with velocity comand control augaentation systen, as specified in Hoffaan et al (1976) as systen $F$. The augaented vehicle presents a significantly less difficult control task. Figure 12 ives relative perforaance as a function of control augaentation for the noainal siaulator configuration (and for the nominal fixer-base configuration). The effect of sieulator characteristics is 3 bstartielly less for the augaented vehicle. However, the effect is still significant for longitudinal control and for fixed-base simulation of lateral (augaented) control.

\section{SUMMARY AND CONCLUSIONS}

The optimal control aodel for pllot/vehlcle analysis has been used to explore the effects of a CGI visual systea and aotion system Jyramics on nelicopter nover siaulation fidelity. Inis was accosplished by expanding the perceptual aspects of the nodel to include aotion sensing and by releting EGI parameters to inforation processirg paraneters of the aodel. Siaulator fidelity was exaulred by compa-ing predicted performance and workioad for flight with that predicted for various siaulator conflgurations.

The results of the andysis suggest that simulator deflciencies of a reasonable nature (by current standarts) can result in substantial perforance and/or workload infidelity. Both CGI and gotion systea effects are significant for this task. Thers is an inceraction between the two sources of pllot cues. In partisular, the presence of motion reduces the sensitivity to CGI ilaltailons.

With respect to the CGI systea, the nost iaportant paraneter in teras of lis effect on perforaance was display delay. This was followed in order of iaportance by displey resolution and rield-or -vien.

The main effect associated with notion system bandwidth was introduced by going to a fixed-base configuration. Halving the Viss platform bandwiden or going to full filght motion aase only arginal change in the perforance predicted for the nominal vis bandwidens. 
The trends of the results are falrly conslstent although there were some differences between lateral and longitudinal control tasks. The magnitude of the efiects and relative importance of various parameters are clearly dependent on the task as exemplifies here oy longitudinal vs. lateral ans unaugaerted vs. ungnerted vehicle dyranis. It is, of course, for this reaser that nodels of the pllot vehicle system are needed to evaluate the iaportance of sioulator parameters for a given situation.

\section{REFERENCES}

1. Baron. S. and Levison, W. M.., "A Manual Control Theory Analysis of Vertical Situation Displays for STOL Aireraft." NASA CR-114020, April 1973.

2. Baron. S., Muralitharar R. and Klelnman, D. L., "Closed Loop Models for Analyzirg the Effects of Slaulator Characteristics". AIAA Flight Simulatior Jech. Eorf.. Arlirgton, IX, September 1975 .

3. Brown. J. L.. "ilisual Elements in Flaght Simulation", Unitersity of Rochester. TR-73-2, December 1973.

4. Gibson, J. J., The Perceotion of the Visual dorls. hiverside Press, Cambrijoe, Mass.. Ty5u.

5. Grahan, C. H. "Ferception of Movement", r. Vislor and Visual Perception, C. H. Graham (editor), John iiley anj Sons. M.Y., T905.

6. Gum, D. R, and Albery, W. B., "Time Delay Problems Encount :ea in Integrating the Advanced Simulator for Undergraduate 1 - lot rraining". J. of Aircraft. 4. 1977.

7. Hess, R., -prediction of rilot Opinion katings Using an Optimal Pilot iodel", Human Factors. 19. 1977.

8. Hoffman, W. C., Kleinman, D., and Young, L., "Display/Control Reguirements for Automated VTOr Aircraft", ASI-TR-76-39, October 1976 .

9. Kleinman, C. L.. "Solving the Optimal attention Allocation. Probler in Manual Control", IEEE $\dot{T}$ rans. On Automatic Control, AC-21, 1976 .

10. Rleinman, D. L., Baron, S. and Levison, W. H.. "A Control Theoretic Approach to Manned-Vehicle Systems Analysis". IEEE Trans. on Auto. Control, AC-16, 1971 .

11. Levison, W. H.. The Effects of Display Gain and signal Bandwidth on Ruman Controller Remnant", AMRL-TR-70-93, Wright-Patterson Air Force Base, Ohio, March 1971. 
12. Levison, W. B., Elkind, J. I., and Mard, J. I., "studies of Wultivariable Manual Control Systems: $A$ model tor Task Interference", NASA-Ames Research Center, NASA CR-1746, May 1971.

13. Quiejo, M. J. and Riley, D. R., Fixed-Base Simulator study of the effect of Time Delays in visual Cues on Pilot Tracking Performance", NASA TN D-8001, October 1975.

14. Riggs, L. A.. "Visual Aruity" in Vision and visual Perception, C. B. Grana (editor), John Wiley and Sons, NY. 1965.

15. Staples, K. J., Motion, Visual, and Aural cues in piloted Flight Simulation". AGRRD Conference proceedings No. 79 on Simulaticn, AGARD CP-79-70, March 1970.

16. Newerinke, P. B., "A Theoretical and Experimental Analysis of the Ourside Worid Parception Process". Proceedings of the Fourteenth Annual Conference on Manual Control. NASA cont. Pub. 2060. Noverber I\$78.

17. Zacharias, G. L., Motion Cue Models for Pilot-Vehicle Analysis". AMRL-TR-78-2, Wright-Patterson A1r Force Base. Ohio. May 1978 . 


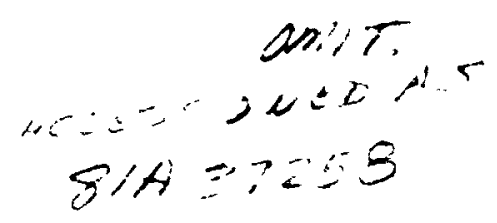

PURSUIT TRACKIMG AND HICHER LEVEIS OF SKILL DEVELOPAENT

IN THE BUUAN PILOT

Bonnld A. Hess

MASA Anes Research Center, Hoffett Fieli, CA 94035

\section{ABSTRACT}

This papex serves a a eyoptic of the research reported in Ref. 1. In Ref. 1, adel of the huan p1lot is offered for pursuit tracking tasks; the odel encompasses an existing wodel for compensatory tracking. The central hypothesis in the developeant of this model states that these prinary structural elesents in the compensatory nodel responsible for the pllot's equalization capabilities reain intact in the pursult wodel. In this latter case, effective low-frequency inversion of the controlled-elenent dyanics occurs by feediagforward derived input-rate through the equalliztion dranics, with low-f requency phase "droop" alninized. The sharp reduction in lor-frequency phase lag beyond that assoclated wth the disappearance of phase droop is seen to accompany relatively loargain feedback of vehicle output. The results of sone recent notion cue resentch are discussed and interpreted in terns of the compensatorypursult display dichotony. Tracking with laput preview 18 discussed in a qualltively way. In terns of the oodel, preview is shown to demand no fundenental changes in atructure or equalisation, and to allow the pllot to elininate the effective tine delay that accrue in the inversion of the controlled-element dyantes. Precognitive behnolor is discussed and a model that encomparses all the levels of skill developant outlined in the succe' sive organizations of perception (SOP) theory is finally proposed.

\section{IMTRODOCTION}

Nearly all the anual control displays used in continuous tracking tasks can be classifled as elther "compensatory" or "pursult" in nature, depending upon the anount of informetion presented to the operator. Consider the functional block dlagrase of $\mathrm{Fig}$. 1, which represent a patr of slagle-axis tracking tasks (scalar syate Input and output). In F18. 1a, the operator 1s presented vith a display of ayste error alone. This display, shown $1 \mathrm{~F} 1_{8}$. 2a, is referred to as coupensatory. The visuslly displajed effects of the operator's responses are not distlagulshable from the ayste input. In $\mathbf{7 8}$. 1b, the operator is presented with both syste Input and output. The corresponding display, shown 1a $\mathbf{~} 1 \mathrm{~g}$. 2b, 1s referred to as pursuit. Here the cperator's corrective responses can be distingulshed from his laput. Note that ayaten error can be easily Inferred frow the spatial separation of the "target" and "follower" dyabols.

It Is the purpose of the research described in Ref. 1 to provide a structural model tor pursult tracking that is sillar to the compensatory nodel Introduced in Ref. 2 and refined in Ref. 3. As in Ref. 3, it is hoped that such a model can provide 1) a theoretical franework within which a varlety of empirical pilot-vehicle reaponse phenomens can be interpreted, and 2) some insight into the mechanises of skill developenent. 
Fig. 3 is a block diagras of a gructural wodel of the human pilot for cospensatory behavior. The model vas discussed in detall in Ref. 3 and shown capable of antching humen pllot-descrihing functions and reminant for a sde vartety of controlled-eleaent dynamics. The central hypothesis in the development of a pursuit oodel of the human pilot is that the pribary struitural elements in the compensatory behavior model also serve as the prinary structural elements of the pursult sodel. Fig. 4 shows the proposed pilot model for pursult behavior. The prianty difference between Figs. 3 and 4 lies in the physical definition of the variable $u_{s}$. In the compensatory aodel, $u_{\text {, }}$ is proportional to error (suitch pasition 0 ) or to error-rate (position 1). "In the pursuit model. u 1s postulated to be proportional to a weighted difference of error and output (position 0), to error-rate lone (position 1), or to input-rate alone (position 2). As was the case in the compensatory aodel, Input-rate is assumed to be a derived quantity with a time delay $t$ asaoclaced with the rate calculation. In the nodel of Fig. 4, the operation of the switch will be paraneterised by $P_{1}$ and $P_{3}$, the respective probabilities of the switch belag in position 1 or 2 at añy Inetant. The probability of lts belng in position 01 , , of course, siaply $1-P_{1}-P_{2}$. Note that by allowing $Y_{d}$ $Y_{d}-P_{2}-0$, the pursult model is identical ${ }^{2}$ to the compensatory aodel.

It is show in Ref. 1, that the feed-forward of input-race through the dranalcs $u_{j}(j \omega) / u_{,}(j w)$ can effectively invert the controlled-elewent dynantes at low frequencles.

Fig. 5 shows a comparison of the comenastory and purauit display describing functions froe Ref. W with the describing functions obtained froe the compensatory and pursult acolels of Figs. 3 and 6 using the parameter values shown in Table 1 . The oodel describing functions vere obtalned by ualng an approximation procedure discussed in some detall in Ref. 3. Note the model's abllity to capture the large low-frequency phase differences.

\section{SORE RESULTS FROM MOTION-CUE RESEARCB}

Reference S sumarlses some recent rasearch Involving a single-axis plloted tracking task that was perfemed on aotion simulator constrained to rotate sbout the longitudinal or roll axis. In an alr-to-air tracking scenario, the cesk consisced of following the target's roll angle whlle suppressing guet disturbaices. F1ga. 6a and 6b show, reapectivley, block diagra of the trackIng taek and the pllot'a compensatory visual displav. The experisenta mere perforwed vith (1) no wetion. (2) vith full wotion and the roll axis horizontal (p1lot noulnally erect). (3) with full wotion and the roll axis vertical (pllot nominally supine), (4) with washed-out wotion, and (5) with attenuated woticn. the lacter two conditions vere atudied wth the roll-axis horizontal. The first and third of the these experinents, and to some extant, the fourth, vere deaigned to suppress the oo-called "t1lt cue" which the pilot recelves when traik"ng with fuil wotion and the roll-axis horizontal.

Figure? sumarises the describling functions for experinents (1-3) fust descrtbed. Wo distinct deacribing functione were measured for each of the

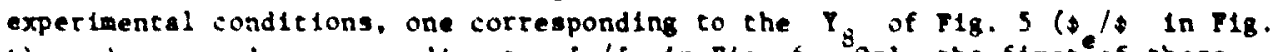
$0)$, and a second corresponding to $3 / 5$ In Fig. 6 . Only the firgt of these will be discussed here since these the in with the measurements of Ref. 4 . 
If we extend our concept of "display" to inciude vestibular cues, the experimental condition of Ref. S are quite sinflar to the compensatory and pursult tracking displays discussed prevlously. In the static case (ST), of course, the only display is visual and compensatory in nature: that is, - alone is displayed. In the full-wotion-erect case (FO), the vestibular "Eiit cue" is avallabe as an additional display elewent, effectively giving the pilot information about the controllad-element output in addition to the displayed error $\$$, thus yielding a pursult display. In addition, the Fo case nay allow higher derivatives of to be sensed, but the effect of this feedbeck will be beyond the frequency range of interest here $(\omega<4 \mathrm{rad} / \mathrm{sec})^{5}$. When the cab is rotated $90^{\circ}$ (F90), the tilt cue is no longer avallable to the pilot, leading to a compensatory display.

Fig. 8 illustrates the nodel-generated describing functions corresponding to the controlled-element dynamics of Ref. 5 and the models of Figs. 3 and 4. The corresponding model paranters are liated in the last two rows of rable I. Model parameters vere selected using the technique diecussed in Ref. 3. Strictly specking, only the static case (ST of Fig. 7) should be subject to conparison because the wodels of Figs. 3 and 4 are not specifically formulated for motion cues involving higher derlvatives of the vehicle output. If ve restrict out attention to the lower frequenc ies ( $\omega<4 \mathrm{rad} / \mathrm{sec}$ ), howerer, a qualitative, if not quantitative, coaparison of modeling results with the experimental motion daca is reasonable. As $\mathrm{Hig}_{\mathrm{g}}$. 8 indicates, the model can capture the sallent differences in the experimatal data in terms of the compensacory-pursult dichotony just suggested.

Th1s liaited discussion of sotion-cue research has emphasized the concept that in tracking taske the human pilot can be viewed as a data-organiring device. This organiration tends to be independent of the physical nature of the display and proceeds along linee suggested by the model of Fig. 4. That 1s. sensory stimull cend to be utilized in a maner that allows the pilot ot progress froe compensatory to pursult behaptor.

\section{TRACXING WITH PREVIEN AND PRECOGNITIVE BEHAVIOR}

Reference 1 suggests that, In terms of the nodel that has beon discussed hare (Fig. 4), tracking with preview would resi $t$ in isproved perforance. prianilly by allowing reduction of the "open-loop" time delay $\tau_{1}+T$. which occurs in feeding-forward Input-rate. Theoretically, this delay can be reduced or coepletely elininated throuch preview by allowing the subfect to estinate $\dot{c}(t)$ at $t-t+T_{1}+T$. If one gereralizes the concept of a preview display to include an Input wave fom or atimulus inceralle generaced by the p1lot In the higher levels of the central nervous syeten, then the structure of Fig. 9 can serve as a paredion for anual control behavior not considered as tracking activity per se; that is, the "pr.cognitive" mode viewed by Krendel and MeRuer as the higheat for of skill tevelopent. Fig. 9, a slight modification of $\mathrm{FIg}$. 4, now Includes the possibility of the pllot internally generating a $c\left(t+T+t_{f}\right)$ sigaal. Wote that Fig. 9 encoupasses all the nodels that describe lover levels of kill developent or display ut1lization.

\section{CONCLUDINT RETURKS}

A model of the human pilot has been offered for pursult tracking tasks; the nodel encompassas the nodel for compensatory tasks introduced in Ref. 2 
and refined in Ref. 3. The central hypothesis in the development of this model is that the structural elements in the compensatory model that are responglble for the pllot's equalization capabilities remain intact in the pursutt model. The ut111ty of the model propsed in Ref, 1 and described briefly here does not lie in 1ts "predlctlve"capability in the onee of generating performance estimates, nor in its ability to offer a structure involving the minimum number of parameters necessary to simulate neasured pilot frequency doan in characterlstics in a partcular task. Rather, its value lies in its ability to serve as tosl for unifying the entire base of single-axis tracking data and to provide a stuctura for underatanding aspects of wotor skill development.

\section{RETERFNCES}

1 Hess, R. A.. "Pursult Tracking and Higher Levels of Sk111 Developaent In the Hutan PIlot," submitced to IEEF. Trereections on Systens, Men, and Cybernetice.

Hess, R. A. "A Dual-Loop Model of the Hunn Controller," Journal of Guljance and Control, Vol. I, No. 4, Pp. 254-260, July-Aug. 1978.

3

Hess, R. A., "' Structural thodel c the Adaptive Human P1lot," to appear in Journal of Guidance and Contzol, Sept.-Oct. 1980.

jas1cko, R. J., McRuer, D. T., ano Magdaleno, R. E., "Human Pllot Dynanic Response In Single-Loop Systens ist:h Coapensatory and Pursult Displays," Air Force Flight Dynmice Laboratory. AFTLL-TR-66-137, 1966.

SJex, H. R., Magdaleno, R. E., and Junkar, A. M. "Roll Tracking Effects of G-Vector T1le and Vartous Types of Motion Wastout:" Proceedings of the 14th Annual Confierence on Manual Control. Apr11, 1978, pp. 463-502.

6rande1, E. S., and McRuer, D. T., "A Servomechan1ams Appronch to Sk111 Developant," Journel of the Franklin Inut1tute, Vol. 269, No. 1, Pp. 24-42 Jan. 1960. 


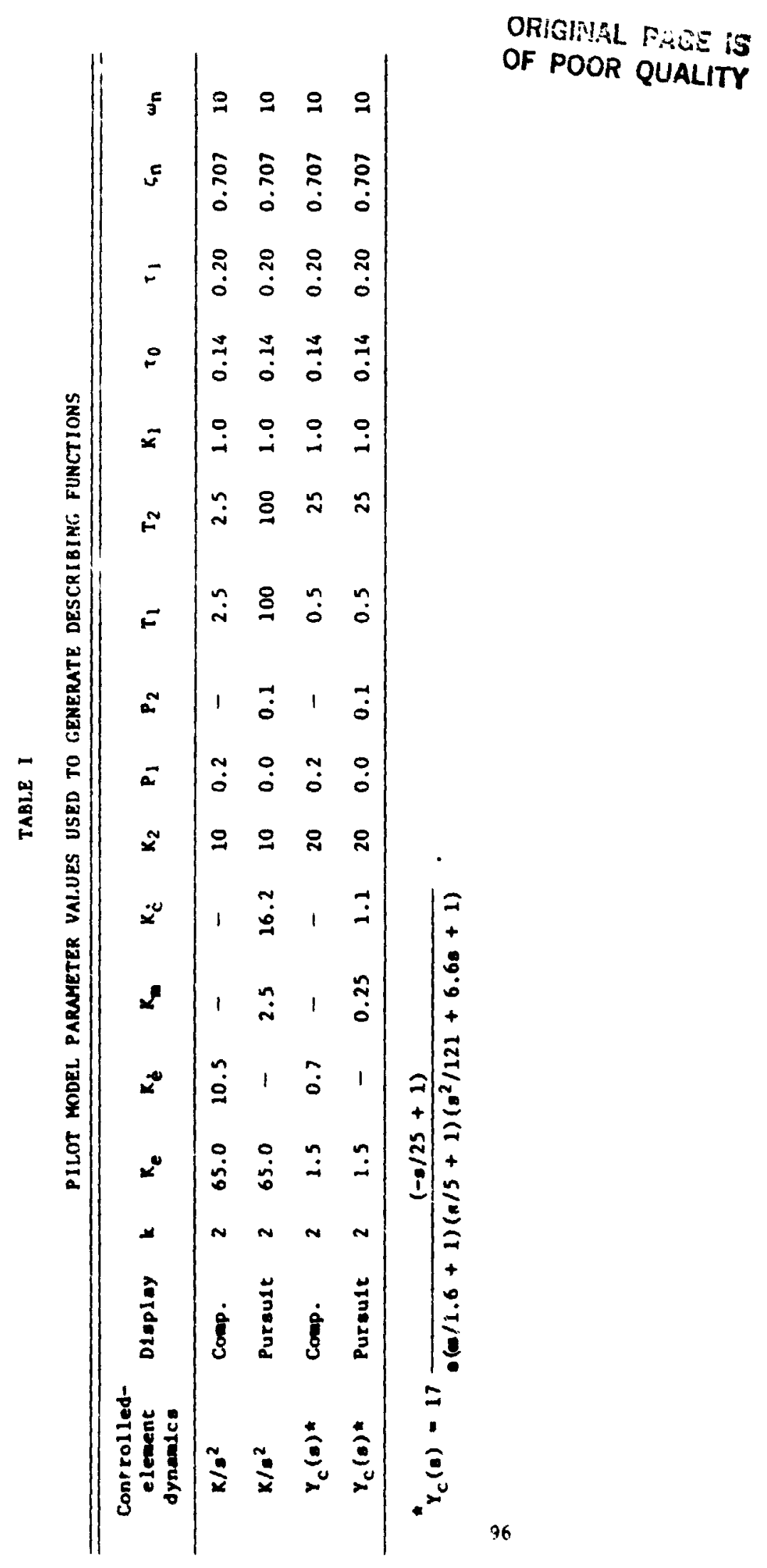


ORIGINAL PUISË IS'
OF POOR QUALITY

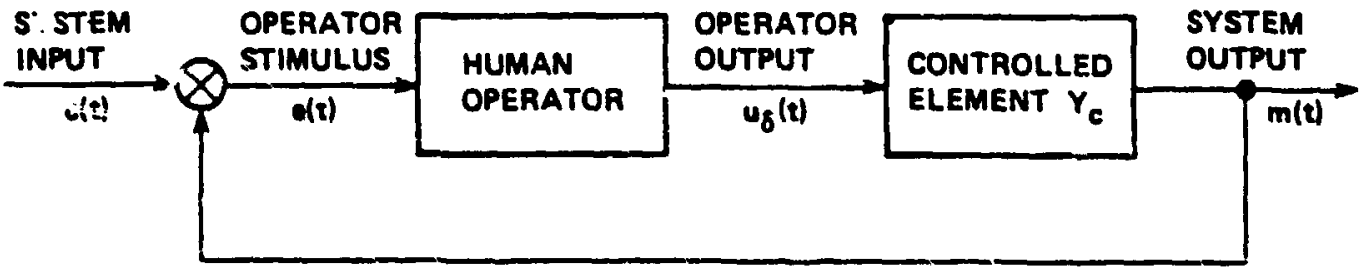

(a) SOMPENSATORY BEHAVIOR

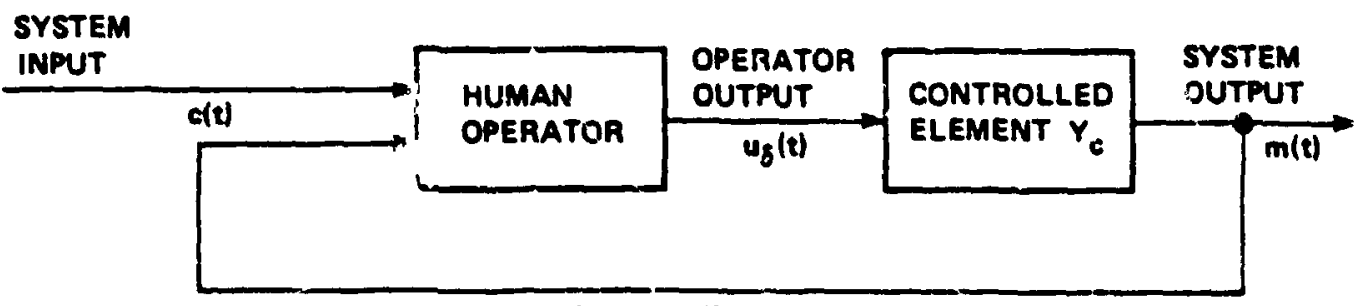

(b) PURSUIT BEHAVIOR

F1gure 1. Compensatory and Pursuit Manuui Control Systens. 
ORIGI:AI FIGE IS
OF POOR QUALIT
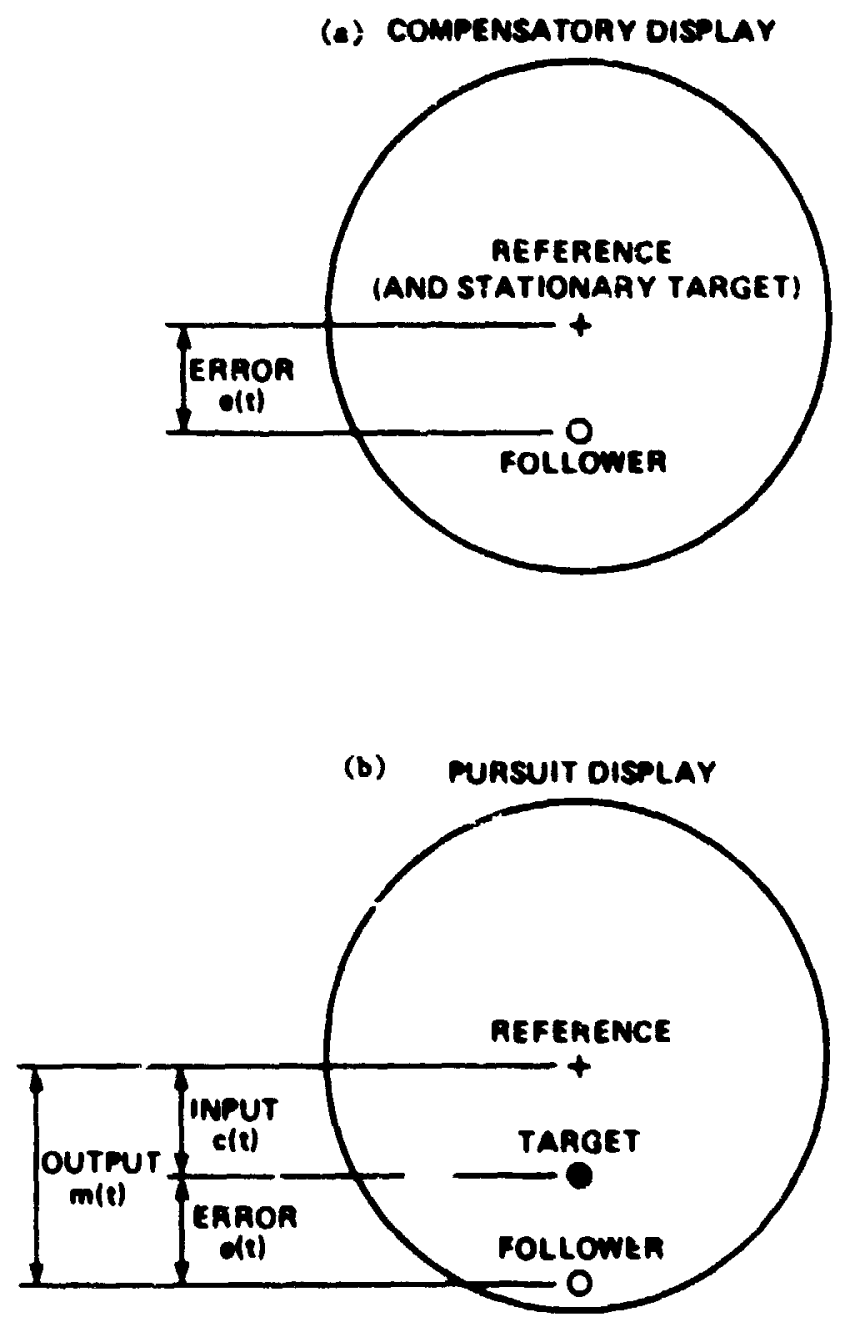

Figure 2. Componatory and Puraute Dlapiaye. 
URGINAL F.MLE IS

OF POOR QUATiIY

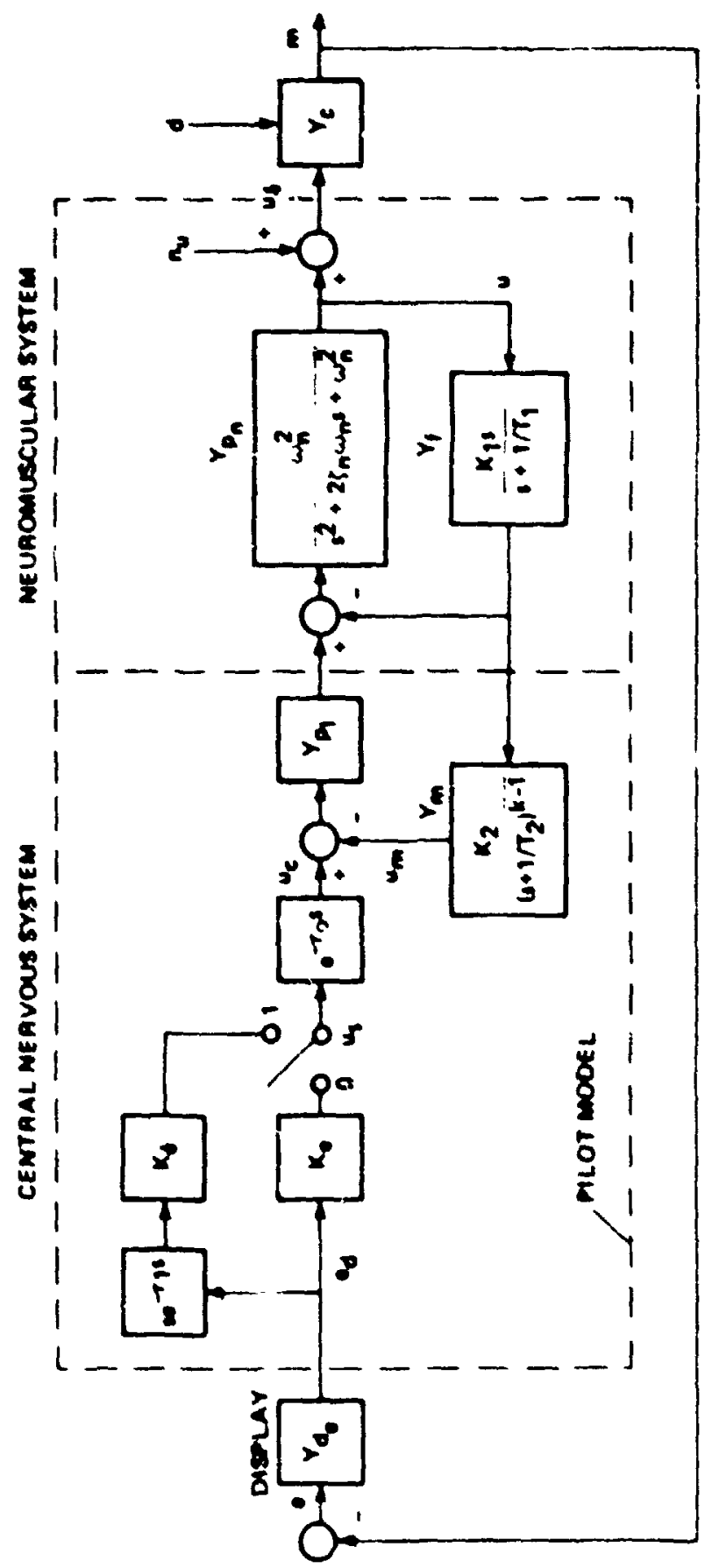

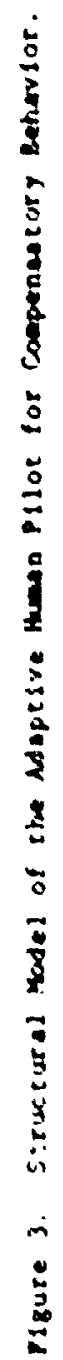




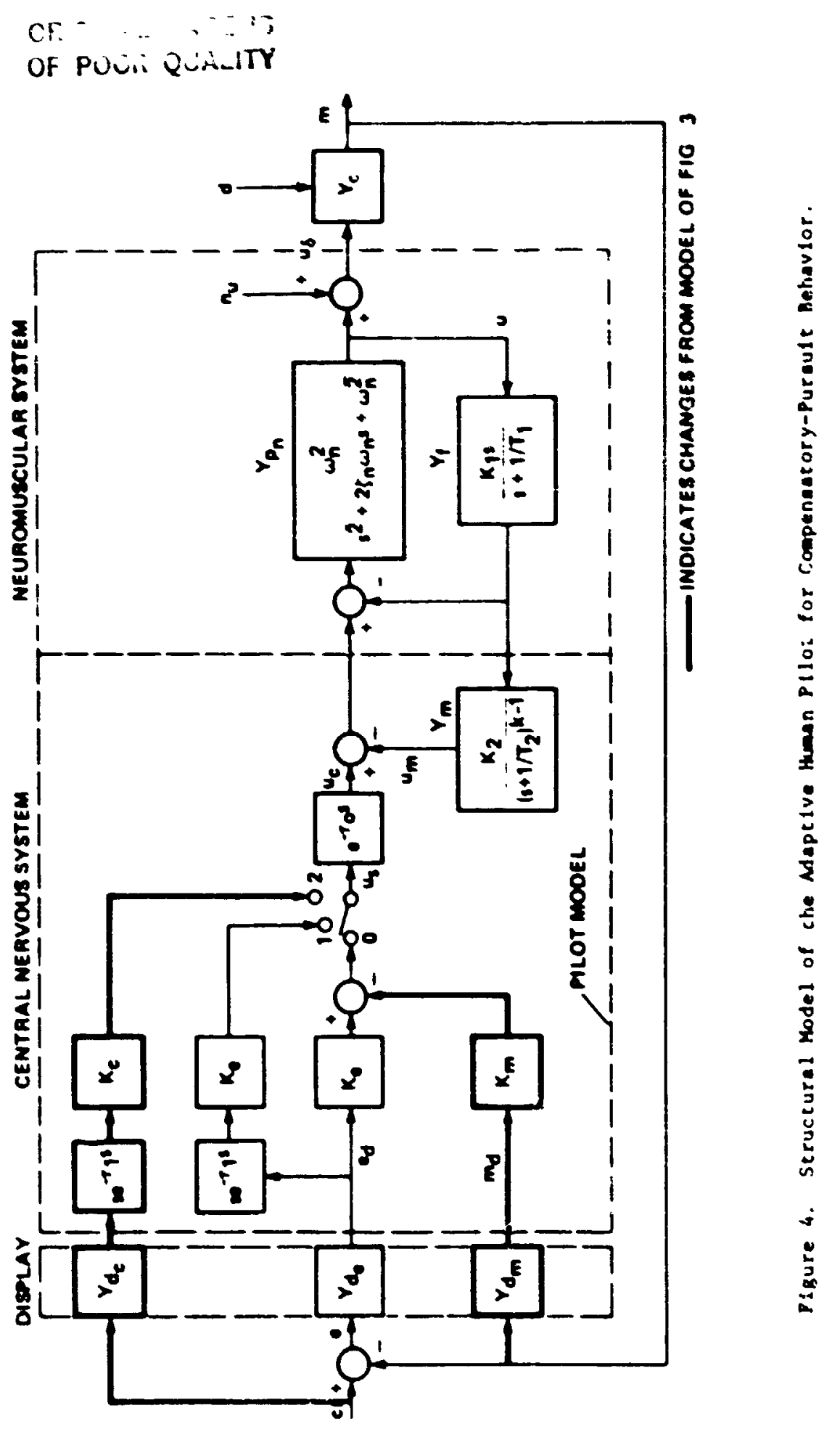


ORIGINAL FACE IS

CF POOR QUALITY
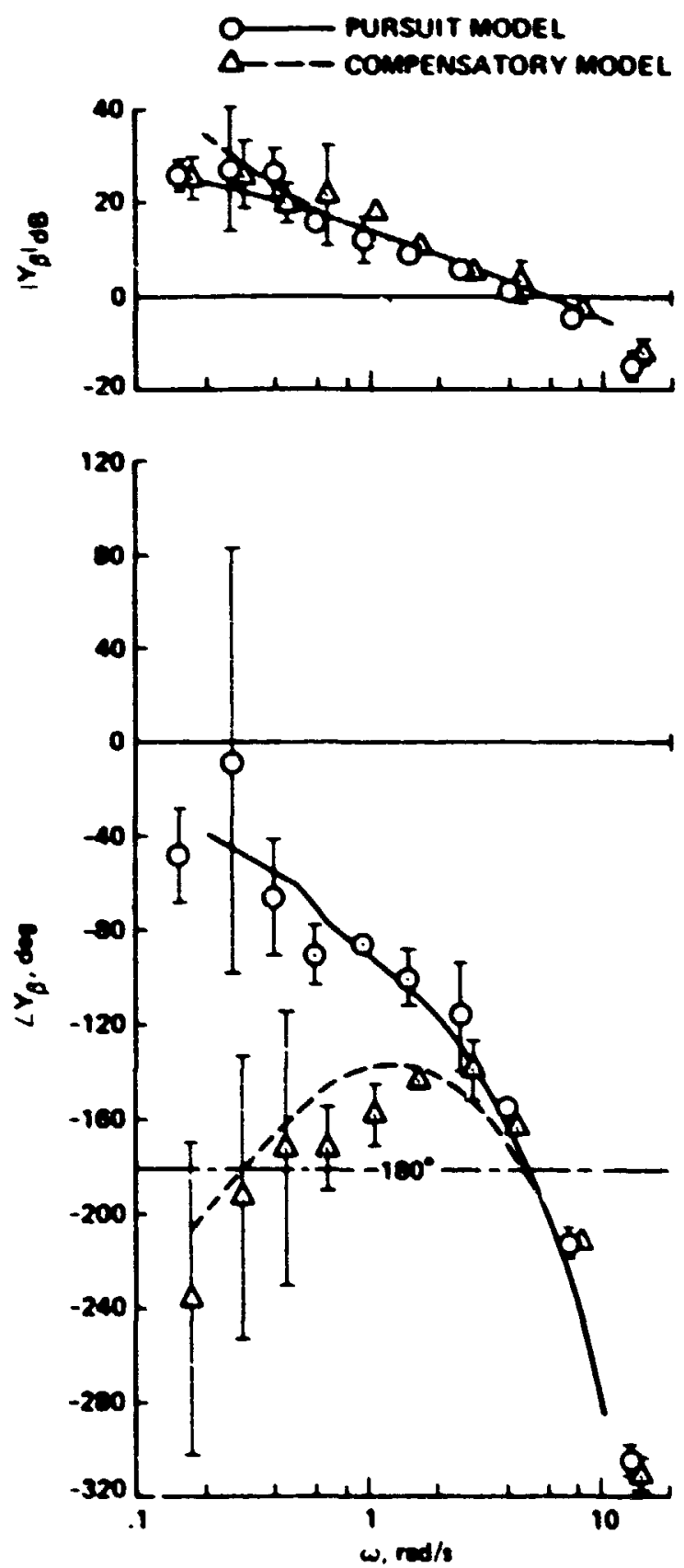

Figure 5. Coparioun of Puravit and Comeneatorv niaplav Deacribing Functions irce Ref. \& with Hodel Describing Runctione. 


$$
\text { of int. }
$$

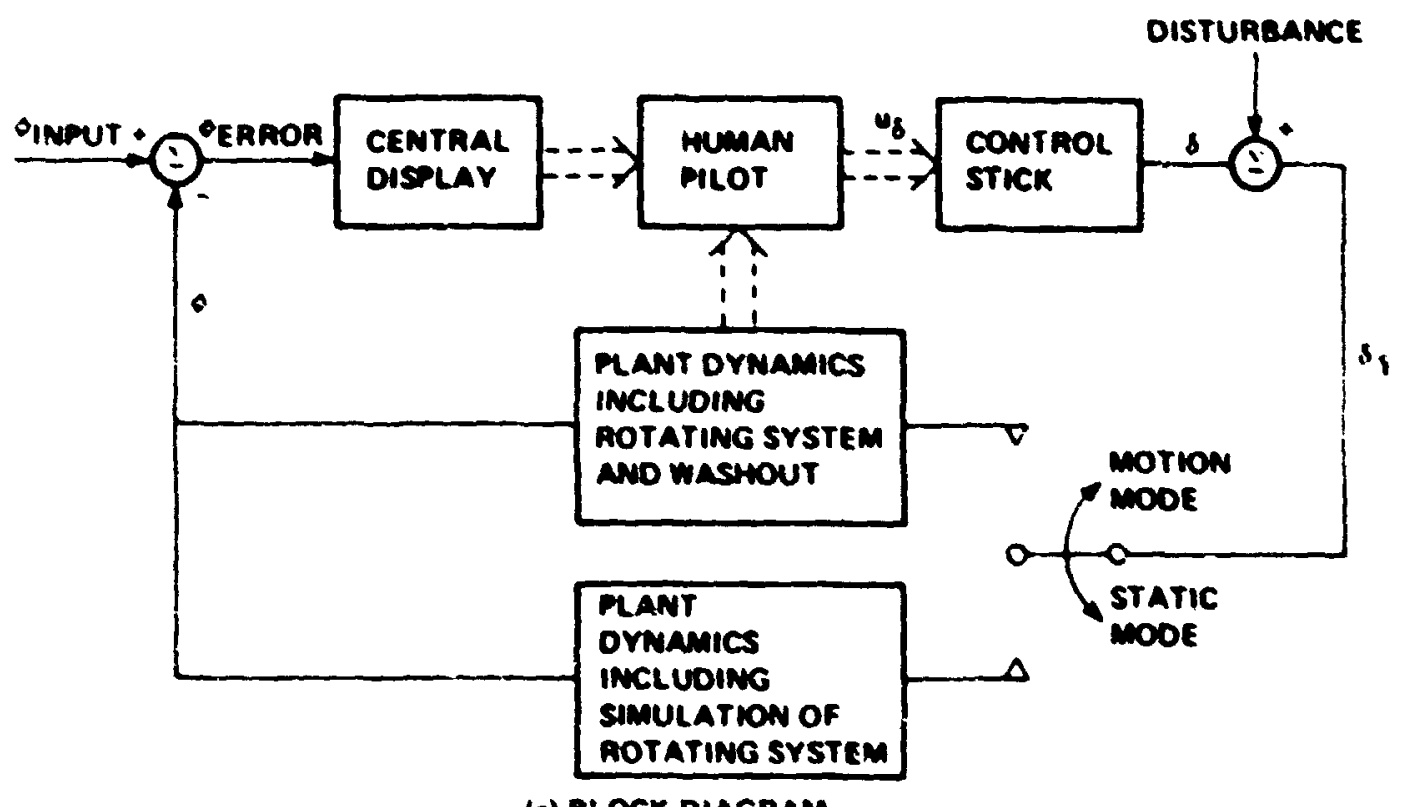

(a) BLOCK DIAGRAM

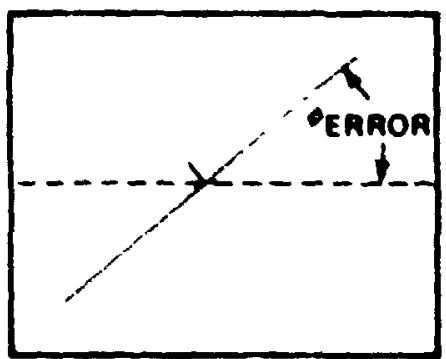

(b) Display

Figure o. Expertaencal Tracklng Eask of kof. S. 
OR:Gi: :

Of POUn
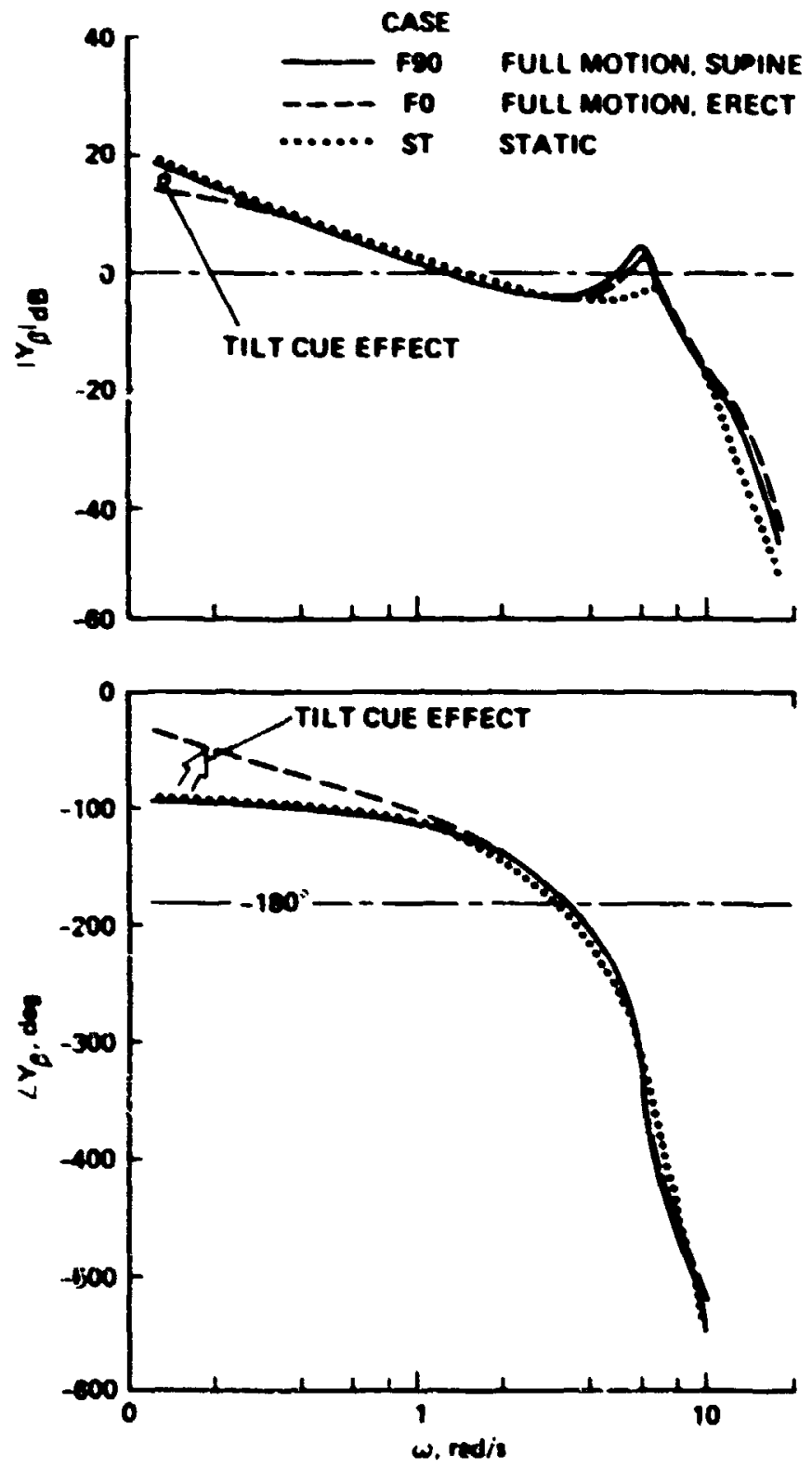

Figure 7. Comparien of Exporimental Deacribing Tunctions from Ref. S. 
of fivin
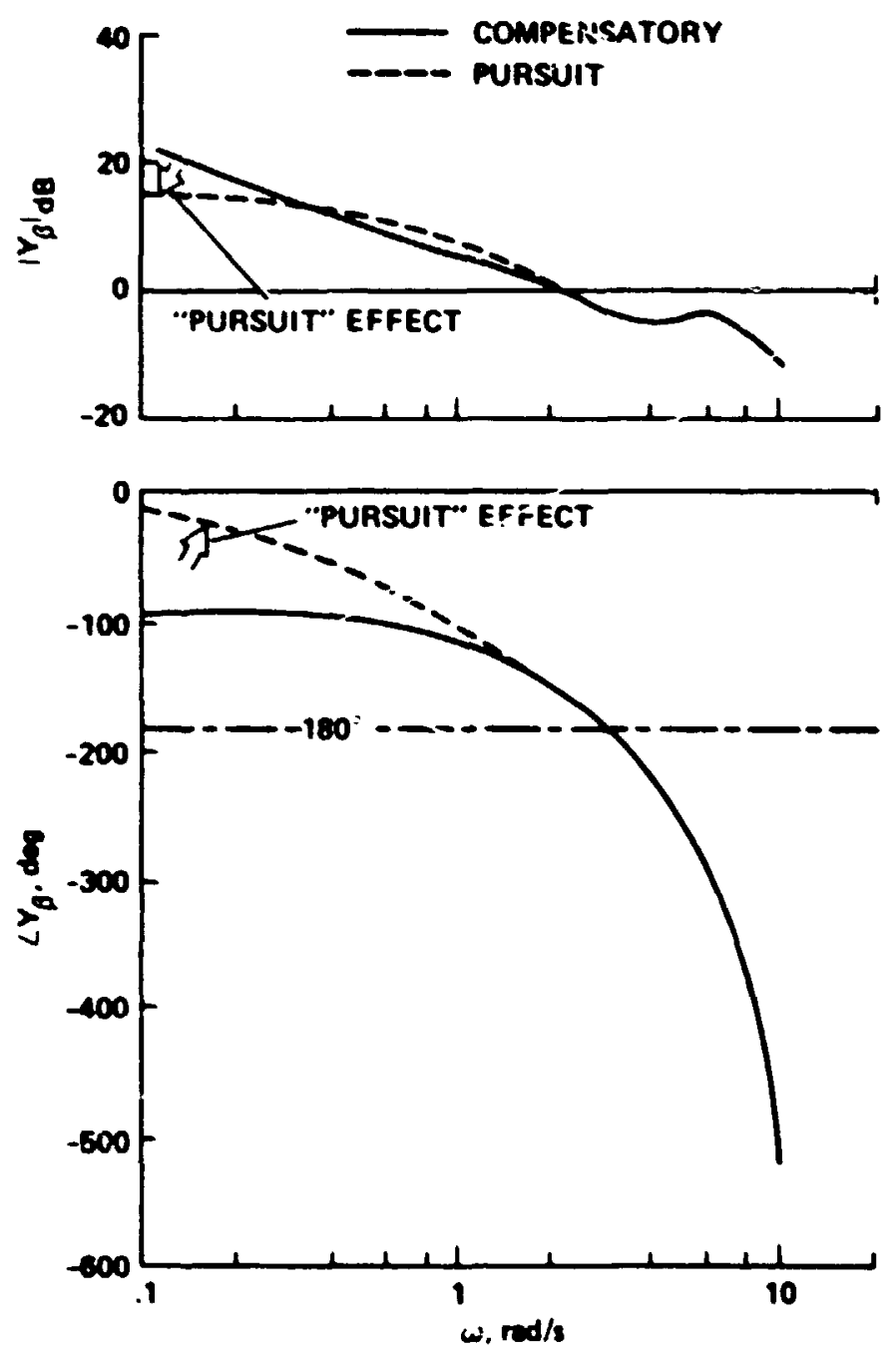

Figure 8. Comperison of Pursuit and Compensatory Model Deecribing Functions. 


\section{Of POOR GuAiniry}

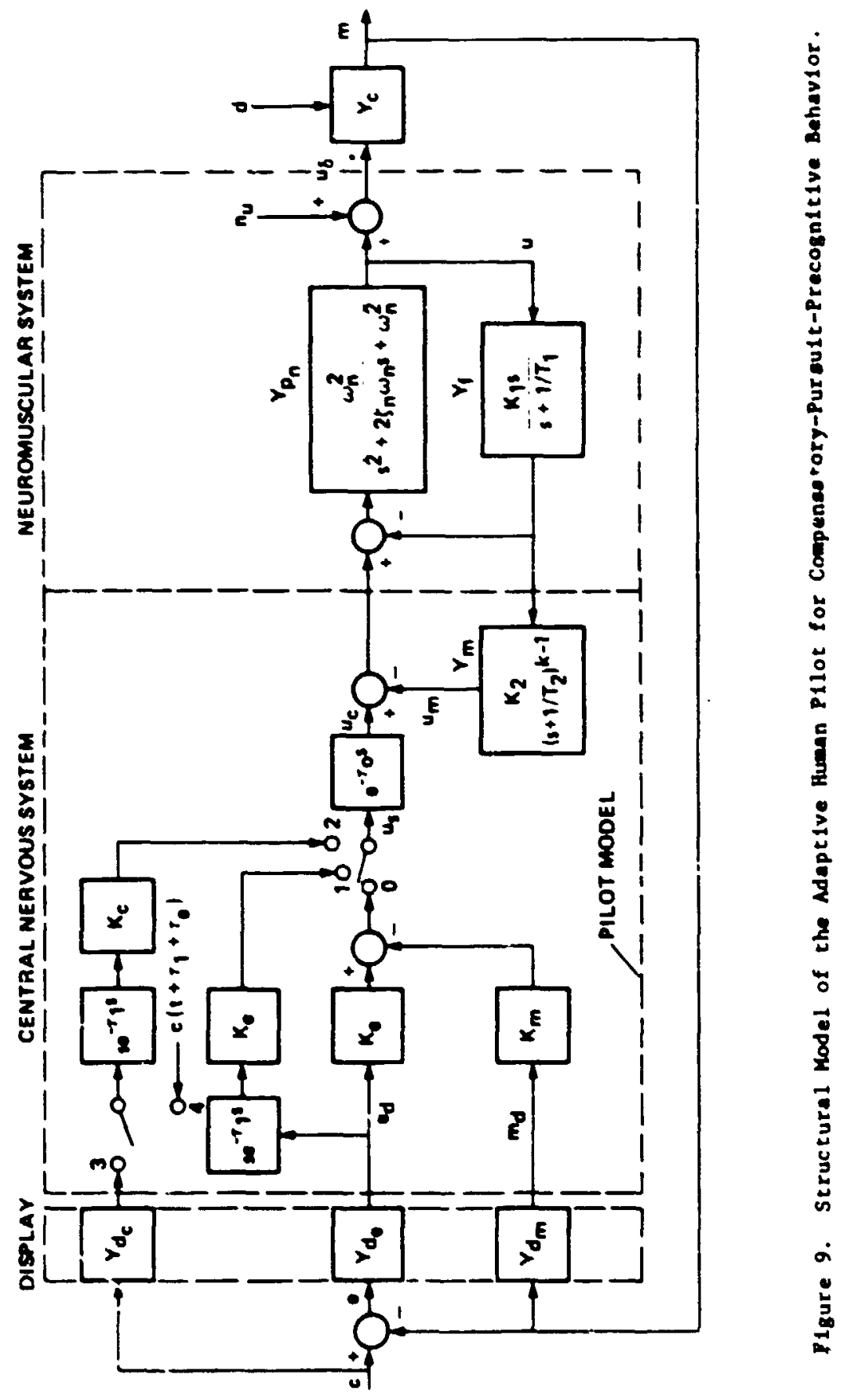




\section{N82. $34042^{1 / 5}$}

\section{MULTI-AXIS TRACKIMG VIA}

\section{AN OPTIMAL-CONTROL PILOT MODEL}

by

S.N. Prasad and David K. Schmidt

School of Aeronautics and Astronautics

Purdue University

Hest Lafayette, IN 47907

The well known optimal control model (OCM) of the human operator has been applied numerous times to the piloting task, with air-to-air tracking or landing approach tasks comprising typical operational situations. However, almost all investigations consider essentially singleaxis tasks, the longitudinal and lateral-directional axes evaluated independently. This approach is preferred to lintt the order of the dymamic model, and in wings-level flight, the equations of motion yield uncoupled vehicle dynamics.

In contrast to this situation, the problem addressed here is the application of an optimal control model (OCM) to Investigate tracking in a highly banked turning flight condition. The analytical (model) results are compared to experinental data obtained in the large amplitude motion simulator (LAMARS) at the Air Force Flight Dynamics Laboratory, Wright-Patterson AFB.

It will be shown that significantly increased observation noise resulting from reduced available attention and possibly threshold effects, as well as high motor noise are required to match the experimental results. 
Bolt Ber anek and Newman Inc.

THE EFFECTS OF MULTIPLICATIVE MOTOR NOISE ON THE OPTIMAL HUMAN OPERATOR MODEL

by

Alper $\mathrm{x}$. Caglayan and W11liam $\mathrm{B}$. Levison Bolt Beranek and Newman Inc.

50 Moulton street

Canbilge, MA

\section{ABSTRACT}

The effects of a multiplicative motor noise model on the optimal-control human operator model have been analyzed. A study of the Interaction between multiplicative motor noise variance. plant dynamics, and predicted operator response behavior shows that, in general, an increase in motor noise variance produces a decrease in operator gain and a decrease in high-frequency reanant. An increase in multiplicative notor nolse varisnce is also reflected by an increase in the effective motor time constanti in the absence of a cost penalty on commanded control, the motor time constant equals the motor nolse variance.

\section{INTRODOCTION}

A substantial body of manual control data, obtained in a variety of laboratory tracking tasks, has been analyzed with the "optimal-control" pilot/vehicle model. For many of these studies, pilot response bshavior has been reflected in terms of a relatively invarlant set of values for pllot.related paranetersi apecifically, a "motor time constant" of between 0.08 and 0.1 seconds, a "tIme delay" of between 0.15 and 0.2 geconds, and an "observation nolse/slgnal rat $10^{\circ}$ of about $-20 \mathrm{~dB} 1-3$. These tasks have largely involved wide-band dynames with minimal delays.

Consistent deviations from these "nominal" values have been noted for certain kinds of tasks. Of partirular interest here are the larger values for motor time constant (implying reduced operator bandwidth) that have been found for tasks involving control of slowly-responding systems $4-6$.

The predictive capability of the optimal-control model will be enhanced if we can find either an alternate set of pilot-related parameters that are more nearly invariant, or a consistent rule for adjusting the current parameter set according to the characteristics of the task. The apparently consistent trend of the motor time constant with respect to the resoonse characteristics of the controlled element sugaests that this qoa* is achievable. 
Bolt Beranek and Newman Inc.

In this paper we explcre the posslbility that changes in motor time cu.stant reflect, in part, a multiplicative motor noise process underlying human controller responee behavior. The notion of a multiplicative nolse process is consistent with the empirical finding that, in idealized control situations, both motor nol se and observation noise appear to scale with the variances of corresponding control and display varlables. In previous studies, these processes have been considered to affect only the estimator (Kalman filter) portion of the pilot model, in this paper, however, we consider the multiplicative motor noise process to influence the control gains.

OPTIMAL GUMAN OPERATOR MOCEL MITE MULTIPLICATIVE MOTOR NOISE

The following linearized description of the vehicle dynamics will be assumed:

$$
\dot{x}(t)=A x(t)+B u_{p}(t)+B w_{g}(t)
$$

where $x$ is the $n$-dimensional state vector Including the variables corresponding to the gust states, up is the r-dimensional oparator input, and Wg is the white Gaussian process noise with covariance $W_{g} \delta(t-s)$. We will assume the following multiplicative motor noise model for the human operator's input dynamics:

$$
\dot{u}_{p_{1}}(t)=u_{c_{1}}(t)+u_{c_{1}}(t) w_{m_{1}}(t)
$$

where $\mathrm{u}_{\mathrm{C}}$ is the $1^{\circ}$ th component of the commanded control rate in the absence of motor nolse and wis the $1^{\text {t }}$ th component of the r-dimensional motor nolse which is a witte Gaussian process with covariance $w_{m} \delta(t-s)$. The effective additive noise, $u_{c}, w_{m i}$, in equation 2.2 will have the following groperties for the stationary case:

$$
\begin{gathered}
E u_{c_{1}} w_{w_{1}}=0 \\
B\left[u_{c_{i}}(t) w_{m_{1}}(t)\right]\left[u_{c_{i}}(s) w_{m_{1}}(s)\right]=\left(B u_{c_{i}}\right) w_{m_{1}} s(t-s)
\end{gathered}
$$

Comparison of the covariance of the effective additive nolse with that of the emplrical relationship in 1 reveals that the variance of the multiplicative notor nolse in the model above cor responds to the motor nolse ratio in 1 with a scale factor of $\pi$. The multiplicative motor noise model specifled by equation 2.2 would also allow corzelation between the nolse components $w_{1}$ for the multi-input case through the off-diagonal elements in the wotor noise covariance $w_{m}$. The task requirements for the human operator will be expressed by the standaid quadratic cost functional: 
Bolt Beranek and Newman Inc.

$$
J=\frac{1}{2} E \int_{0}^{\infty}\left(x_{0}(t) Q x_{0}(t)+u_{C}(t) G u_{C}(t) d t\right.
$$

where $x_{0}$ is the state vector augmented with the operator input $u_{p}$.

It can be shown 8-10 that under suitable regularity conditions the optimal human operator control in the space of liriear controls with full state feedback will be given by:

$$
u_{c} *(t)=-F x_{0}(t)
$$

where the feedback gain $\mathbf{F}$ is defined by

$$
F=(G+P(K))-1_{B} R
$$

with the positive-semidefinite matrix $P(K)$ defined by

$$
P(x)_{i f}=x_{n+1, n+j H_{m j}} 1, j=1,2, \ldots, r
$$

where $R$ is the positive definite solution of the algebraic Riccati equation

$$
K A_{0}+A_{0}^{\prime} K+Q-K B_{0}(G+P(K))-1_{B_{0}^{\prime}}^{\prime} K=0
$$

with the augmented system matrices $A_{0}$ and $B_{0}$ (of dimension $n+r \times n+r$ and $n+r \times r$, respectively) given by

$$
A_{0}=\left[\begin{array}{ll}
A & B \\
D & 0
\end{array}\right] \quad B_{0}=\left[\begin{array}{l}
0 \\
I
\end{array}\right]
$$

The comparison of the Riccati equation above with that given in reference 1 shows that the control dependent noise effectively increases the control weighting $G$ further by the term $P(X)$ relative to the case with additive motor nolse. For a fixed set of control we ghtings $Q$ and $G$, the effect of the muitiplicative motor noise is to reduce the control gaine of the human operator from their values corresponding to the additive motor noise case. This effect of the multipilcative motor noise model is expected since the control effort has some destabilizing effect on the system through the control dependent nolse. This relationship between the motor noise and the control gains should be useful in modelling the learning behavior of inexperfenced human operators 11 .

The term $G+P(K)$ in the Riccatl equation 2.9 can be considered as an effective control welghting matrix. If the nultiplicative motor nolse covariance $w_{m}$ ir chosen to be positive definite, then $P(X)$ will be positive definite even when the commarced control is not penalized in the human operator's cost function (1.e. G=0). This result is intuitively pleasing in that the nultiplicative motor nolse models the human operator's inherent constinined 
Bolt Bor anek anà Newman Inc.

control capability. That is, even if no explicit or subjective penalty is associated with control activity, the predicted control gains will remain finite.

While it is possible to find an equivalent commanded control rate welghting, $G_{e}$, for any solution of the Riccati equation (2.9) corresponding to a certain $Q, G$ combination $\left(G_{e}=G+P(R)\right)$, the multiplicative motor nolse model brings new interpretations to the motor time constart and control gairs and provides a link between the human operator's control gains and the motor noise ratio. These issues wili be discussed in the later sections. In the multi-input case, the equivalent control rate weighting $G_{e}$ would have of $x$-diagenal terms when the control dependent noise components a correlated. Therefore, trial and error search for an equivalent control rate weighting $G_{\text {e }}$ would be more complicated for the multi-input case.

The effect of the multiplicative motor nolse on the human operator model characteristics has been studied using several plant dynamics. A lower order Riccati equation (2.9) excludir.z the gus state variables is first solved using an algorithm similar to that in 10 and then the the gains on gust variables are obtained by solving a linear algebraic equation similar to the deterministic case. For these studies, the filtering part of the human operator mode $i$ has been taken from the pseudo motor noise model in 4 . In order to differentiate betwee.. the different motor noise ratios, we will call the one used for the control computations as the control motor noise ratio, the one used for the estimator computations as the filter motor noise ratio (called pseudo motor noise ratio in $4)$, and the real driving motor noise as the actual motor noise ratio. In the sequel, "motor nolse ratio" without an explicit reference will imply control motor noise ratio.

\section{POECTS ON THE MOTOR TIME CONSTANT}

In the single input case, with $G$ and $W_{m}$ scalars in (2.8) and (2.9), (G $=g, W_{m}=v$ i, the motor time constant, $T_{N}$, defined as the inverse of the gain on pilot Input up, will be given by

$$
T_{N}=g+v
$$

where $P$ is the lower right element $r_{n+1} n+1$ of the solution of the Riccati equation (2.9). As can be seen from equation (3.1), the motor time consant is cumposed of two terms: The first one, $g / p$, is directly proportional to the control rate weighting in the human operator's objective function. The second term, $v$, is equal the variance of the multipli it ive motor noise and colresponds to the motor noise ratio defineu in 4 , scaled by a factor of $\pi$. 
The effects of multiplicative motor noise on the optimal human operator model has been etudied using the following set of vehicle dynanics:

\section{Rate Dynamics:}

$$
\begin{aligned}
& \dot{x}=\left[\begin{array}{rr}
-2 . & 0 \\
1 . & 0 .
\end{array}\right] x+\left[\begin{array}{l}
0 . \\
1 .
\end{array}\right] u+\left[\begin{array}{l}
1 . \\
0
\end{array}\right] w \\
& y=\left[\begin{array}{ll}
0 . & 1.1 \\
1 . & 0.1
\end{array} x+\left[\begin{array}{l}
0.1 \\
L .1
\end{array}\right] u\right.
\end{aligned}
$$$$
3.2
$$

\section{Yaw Dynamics:}

$\dot{x}=\left[\begin{array}{rrrrr}-1 . & 0 . & 0 . & 0 . & 0 . . \\ 533 . & 0 . & 0 . & 0 . & 0 . \\ -16 . & 1 . & -33.3 & 0 . & 0.0 \\ 0 . & 0 . & 19 . & -19 . & 0 . \\ 0 . & 0 . & 0 . & 1 . & 0 .\end{array}\right] x+\left[\begin{array}{r}0 . \\ 533 . \\ -16 . \\ 0 . \\ 0 .\end{array}\right] u+\left[\begin{array}{l}1.41 \\ 0 . \\ 0 . \\ 0 . \\ 0 .\end{array}\right] w$

$y=\left[\begin{array}{rrrrr}0 . & 0 . & 0 . & 0 . & 1 . \\ 0 . & 0 . & 0 . & 1 . & 0 . \\ 0 . & 0 . & 0 . & 1 . & 0 . \\ 0 . & 0 . & 19 . & -19 . & 0 .\end{array}\right] \times$ 


$$
\text { of Fovin } 4 \text { inom }
$$

Dolt Beranek and Meman Inc.

Filtered Rate Dynamics:

$$
\begin{aligned}
& x=\left[\begin{array}{rrrr}
-2 . & 0 . & 0 . & 0 . \\
0 . & 0 . & 1 . & 0 . \\
0 . & -1 . & -1.414 & 1 .
\end{array}\right] \times\left[\begin{array}{l}
0 . \\
0 . \\
0 .
\end{array}\right] u+\left[\begin{array}{l}
1 . \\
0 . \\
0 .
\end{array}\right] w \quad 3.6 \\
& y=\left[\begin{array}{llll}
0 . & 1 . & 0 . & 0 . \\
0 . & 0 . & 1 . & 0 .
\end{array}\right] \times
\end{aligned}
$$

In eact case, $t-.2$ eec. for the human operator tine deley. -90 dB for the actual notor nolse ratio, -10 dB for the eliter wotor nolee ratlo, -20 ab for the observation nolse ratio were used for the wodel paraneter values. The plant with the rate dynaice represent alocity control task under a velocity disturbance created by a flrat nrder nolee epectru with break frequency 2 $\mathrm{rad} / \mathrm{sec}$. The flitered rate dymenice le the ene plant as the rate dynamics with a two-pole Butterworth filter of cutofe frequency 1 radisec. Yas dynamice represent $k / a^{2}$ dymanics with approxinatuly 60 asec. the delay.

The effects of different anltipl fcetive motor nolse levela on the notor tim constant have been analyzed uning the dymancs above. The control rate welghting. g. wes chosen to obtain a nowinal value of .1 ete. For $T_{N}$ at the -40 dB notor nolse level. In general, an Increase in the notor nolse level produced a higher motor time constant $T_{Y}$. The reaults are cabulated in Table $I$. Bringing up the notor nolee ratto to the -20 dB level resulted in - 108 Increase in the notor time constant $T_{n}$ compared to the negligible motor nolse case $(-10 \mathrm{~dB})$ In all of the three dynanics tested.

As predicted by equation (3.1), the motor nolse ratio starts -ffecting the motor time conatant $T_{N}$ when ite value 18 araund -20 dB. This level corresponds to ator nolee ratio of ve.0314. 
Since the term $p$ in $(3.1)$ is a function of both $g$ and $v$ and since incressing $v$ results in a higher $p$, the term $g / p$ decreases as the motor noise ratlo is increased to -20 da level. However, In all of the three cases tested, the decrease due to the g/p term was nore than compensated by the increase in the motor nolse ratio $v$.

When the comanded contrcl is not weighted (1.e. ga), a notor ..: ae ratio of $-15 \mathrm{~dB}$, as predicted by equation 3.1 . resulted in a motur time constant $T_{N=.1}$ sec for all the dynamics tested. In this case with no penalty on comended control rate, the wotor tiae constant in is equal to the variance of the multiplicative motor :uise ( $($. I). That ij. the notor nolse ratio value completely specifies $\mathrm{T}$ ifisependent of the plant dynanics. In this cese, the ?.jman onerator $z$ cost function $(2.5)$ would only consiat of mean-squared error which 1 s the real objective in a romensatory tracking task.

\section{BEFTCTS ON TITE HUNAN OPERATOR TEANSFER FUNCTION}

The effects or varying the multiplicative motor nolse varlance on the huran operator 's eg:ivalent kescribing function have been analyzed by using the plant dynanics in the previous section. Figure I shows the results for the filtered rate dynanics.

in yenezal, for lricreasing notor nolse ratlo, the human operatur"s equivalent describing function galn decreases as expected with greatest varlation occurring for frequencles -1 $\mathrm{rad} / \mathrm{sec}$ andw>8 rad/sec. Motor nolse ratio variation has a san - fect on the phase of human operator" transfer function. The greatest change is around the 8-10 rad/sec range since lncreasing the notor nolse ratio to -17 dB fron the -40 dB level results in the shift of pole due to the motor $t$ ine constant from $10 \mathrm{rad} / \mathrm{sec}$ to $8.5 \mathrm{rad} / \mathrm{sec}$. "Remnant" (control activity not correlated with the tracking input 7 ) decreases at $h / g h$ frequencies ( $\omega>8 \mathrm{rad} / \mathrm{sec})$ as the motor nolse. atlo is increased to -17 dB level. This result is to be expected since the bandwidth of the controller ls decreased due to the Increase in the control dependent nolee. These reaults indlcate the coneervative nature of the feedbeck controller based on a multiplicative moters nolse model. In sumary. an Increase in the ruttplicative notor nolse varlance causes a decrease in the gain and. at high frequencles, acrease in the remint fr: che human operator"s equivalent describing function.

\section{VARIATION IN TN WITH BANDWIL H}

In this sect. 21 , we will discuss how the multipl lcative motor noiso model can be used in explaining the inverse varistion of the motor time constant $T_{N}$ with glant bardwidth. For this analysis, the following set of dyinamics are used: 
KSG Dinamics

$$
\begin{aligned}
& \dot{x}=\left[\begin{array}{cc}
-2 . & 0 . \\
15 . & 0 .
\end{array}\right] x+\left[\begin{array}{c}
0 \\
20 .
\end{array}\right] u_{p}+\left[\begin{array}{l}
2 . \\
0
\end{array}\right] w \\
& y=\left[\begin{array}{cc}
0 . & 1 \\
1.5 & 0 .
\end{array}\right] x+\left[\begin{array}{l}
0 . \\
2
\end{array}\right] u_{p}
\end{aligned}
$$

BW Dynamics

$$
\begin{aligned}
& \dot{x}=\left[\begin{array}{cccc}
-2 . & 0 . & 0 . & 0 . \\
10 . & 0 . & 0 . & 0 . \\
0 . & 1.0 & -1.411 & -1 . . \\
0 . & 0 . & 1 . & 0 . .
\end{array}\right] x+\left[\begin{array}{r}
0 . \\
20 . \\
0 . \\
0 .
\end{array}\right] u_{p}+\left[\begin{array}{l}
2 . \\
0 . \\
0 . \\
0 .
\end{array}\right] w \\
& y=\left[\begin{array}{cccc}
0 . & 0 . & 0 . & .02 \\
0 . & 0 . & .02 & 0.02 \\
0 . & .02 & -.028 & -.02
\end{array}\right] x
\end{aligned}
$$

\section{Bii2 Dunsmics}

$$
\begin{aligned}
\dot{x} & =\left[\begin{array}{cccc}
-2 . & 0 . & 0 . & 0 . \\
10 . & 0 . & 0 . & 0 . \\
0 . & 1 . & -2.82 & -4 . \\
0 . & 0 . & 1 . & 0 .
\end{array}\right] x+\left[\begin{array}{c}
0 . \\
20 . \\
0 . \\
0 .
\end{array}\right] u_{p}+\left[\begin{array}{l}
2 . \\
0 . \\
0 . \\
0 .
\end{array}\right] \times \\
y & =\left[\begin{array}{cccc}
0 . & 0 . & 0 . & .02 \\
0 . & 0 . & 0.02 & 0.08 \\
0 . & .08-0.056 & -.08
\end{array}\right] x
\end{aligned}
$$


Bolt Beranek and Newran Inc.

These dynamics correspond to three laboratory tracking experiments. The plant with the KSG dynamics represents velocity control task under disturbance. BNI and Bw2 dynamics represent the same plant with a two-pole Butterworth filter of cut -ff frequency 1 and $2 \mathrm{rad} / \mathrm{sec}$, izspoctiveiy. Model atching analyals of the actual data has shc::n that an increasn in the value of $T N$ from. 06 sec to .15 sec : 3 needed as the bandwidtn -8 decroased (change fram trse to BWi d) namics). With the standard human operator model, these fifferent values of $T_{N}$ are obtalned by selscting a different corterol rate weighting, 9, value for each case. An mitle I shows, with the multiplicative motor noise based model, it is posalble to watch the variation in $T_{N}$ wth only one value for the control rate welghting $g$ and the antor nolse ratio $v$.

\section{CONCLUSIONS}

The effects of a multiplicative motor noise model on the optimal-control human operator model have been analyzed. A etudy of the interaction between multiplicative motor noise varlance. plant dynamics, and predicted operator response behavior shows that, In general, an increase in motor noise variance produces a decrease in operator gain and a decrease in high-frequency rennant. An increase in multiplicative motor nolse variance is also reflected by an increase in the effectlve motor tiwe constants in the absence of a cost penalty on comanded control, the wotor time constant equals the motor nolse varlince.

For the cases explored in this analysis, variations in the motor time constant mere accounted for by fixed values assigned to motor nolse ratio and cost of control. Thus, ever though a new parameter was added to the optimal control model, the number of degrees of freedom required to account for variations in controlled-element dynamics was actually reducedl further work is required to determine the extent to which a fixed set of cost and noise parameters can explain human operator behavlor across a varlety of task conditlons, including the tifferences observed between inexperienced and trained human operators 11 .

\section{REFERENCES}

1. Kleliman, D. L.. S. Baron and H. H. Levison, "An Optlmal Control Model of Buman Response, Part I: Theory and Validation", Automatica, Vol. 6, pp. 357-369, 1970.

2. Kleinman, D. L., S. Baron and $W$. H. Levison, "A Control Theoretic Approach to Manned-Vehicle systems Analysis". IEBs Trans. on Auto. Control, Vol. AC-16, No.6, vecember 1971. 
Bolt Beranek and Newman Inc.

3. Levison, W. H. J. I. Elkind and J. L. Ward, -studies of Multivariable Manual Control Systems: A Model for Task Interference" NASA CR-1746, May 1971.

4. Levison, N. B., S. Baron and A. M. Junker, "Modeling the Effects of Environental FActors on Human Control and Inforaation Fiocessing". Nright-patterson Air Force Base, Oh10, NMRL-TR-76-74, August 1976.

5. Levison, W. H. "A Model for the Pilot's Use of Roll-Axis Motion Cues in steady-state Tracking Tasks", Report No. 3808 . Bolt Beranek and Newman Inc.. Cambridge, MA, May 1978.

6. Levison, W. H. The EFfects of Display Gain and signal Bandwidth on Bunan Controller Remant", MMR-TR-70-93. Wright-Patterson Air Force Base, Ohlo, March 1971.

7. Levison, W. B., S. Baron and D. L. Kleinman, "A model for Eunan Controller Reanant". IBEs Trans. On Man-Machine Syst.. Vol. MS-10, Ni. 4. Dec. 1969.

B. Mclane, P. J., Optimal stochastic Control of Linear Systems with State and Control Dependent Disturbances". IBss Trans. on Auto. Contr.., Vol. AC-16, No. 6, Pp. 793-798, Dec. 1971.

9. Nonhan, W. M.. "Random Differential Equations in Control Theory". Probabiliztic Methods in App. Math., $A$. T. Bharucha-Reid, Bd., New York, Acadenic Press, 1970.

10. Rleinman, D. L., "Optimal stationary Control of Iinear Systema with Control Deperdent Nolse", IEEs Trans. on Auto. Contr.. vol. AC-14, Pp. 673-677, Dec. 1969.

11. Levison, W. B., R. B. Lancraft and A, M. Junker, "Bffects of Simulator Delays on Performance and Learning in a Roll-nxis Tracking Task. Proc. of the Fifteanth Annual Conf. on Manual Control, Deyton, Oh1o, Mareh 1979. 


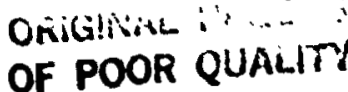

Bolt Beranek and Newman Inc.

\begin{tabular}{|c|c|c|c|}
\hline Dynamics & $\begin{array}{c}\text { Hotor Noise Ratio } \\
\mathrm{dB}\end{array}$ & $\mathbf{g}$ & $\mathbf{T}_{\mathbf{N}}$ \\
\hline $\begin{array}{l}\text { rate } \\
\text { rate } \\
\text { rate }\end{array}$ & $\begin{array}{l}-40 \\
-30 \\
-20\end{array}$ & $\begin{array}{l}4 \times 10^{-4} \\
1 \times 10^{-4} \\
1 \times 10^{-4}\end{array}$ & $\begin{array}{l}0.100 \\
0.101 \\
0.110\end{array}$ \\
\hline $\begin{array}{l}\text { yaw } \\
\text { yaw }\end{array}$ & $\begin{array}{l}-40 \\
-20\end{array}$ & $\begin{array}{l}1.58 \times 10^{-2} \\
1.58 \times 10^{-2}\end{array}$ & $\begin{array}{l}0.100 \\
0.106\end{array}$ \\
\hline $\begin{array}{l}\text { filtered rate } \\
\text { filtered rate } \\
\text { filtered rate }\end{array}$ & $\begin{array}{l}-40 \\
-20 \\
-17\end{array}$ & $\begin{array}{l}8 \times 10^{-6} \\
8 \times 10^{-6} \\
8 \times 10^{-6}\end{array}$ & $\begin{array}{l}0.100 \\
0.107 \\
0.113\end{array}$ \\
\hline
\end{tabular}

TABLF I. Variation of $T_{N}$ with Respect to Notor Noise Ratio

\begin{tabular}{|c|c|c|c|}
\hline Dynamics & Motor Noise Ratio, aB & $g$ & $T_{N}$ \\
\hline KSG & $-1 i$ & $8 \times 10^{-6}$ & .0645 \\
BW2 & -17 & $8 \times 10^{-6}$ & .114 \\
BW1 & -17 & $8 \times 10^{-6}$ & .143 \\
\hline
\end{tabular}

TABLE II. Variation of $T_{N}$ with Bandwidth Using Multiplicative Motor Noise Model 
OF PUUti unhitil

Bolt Beranek and Newman Inc.

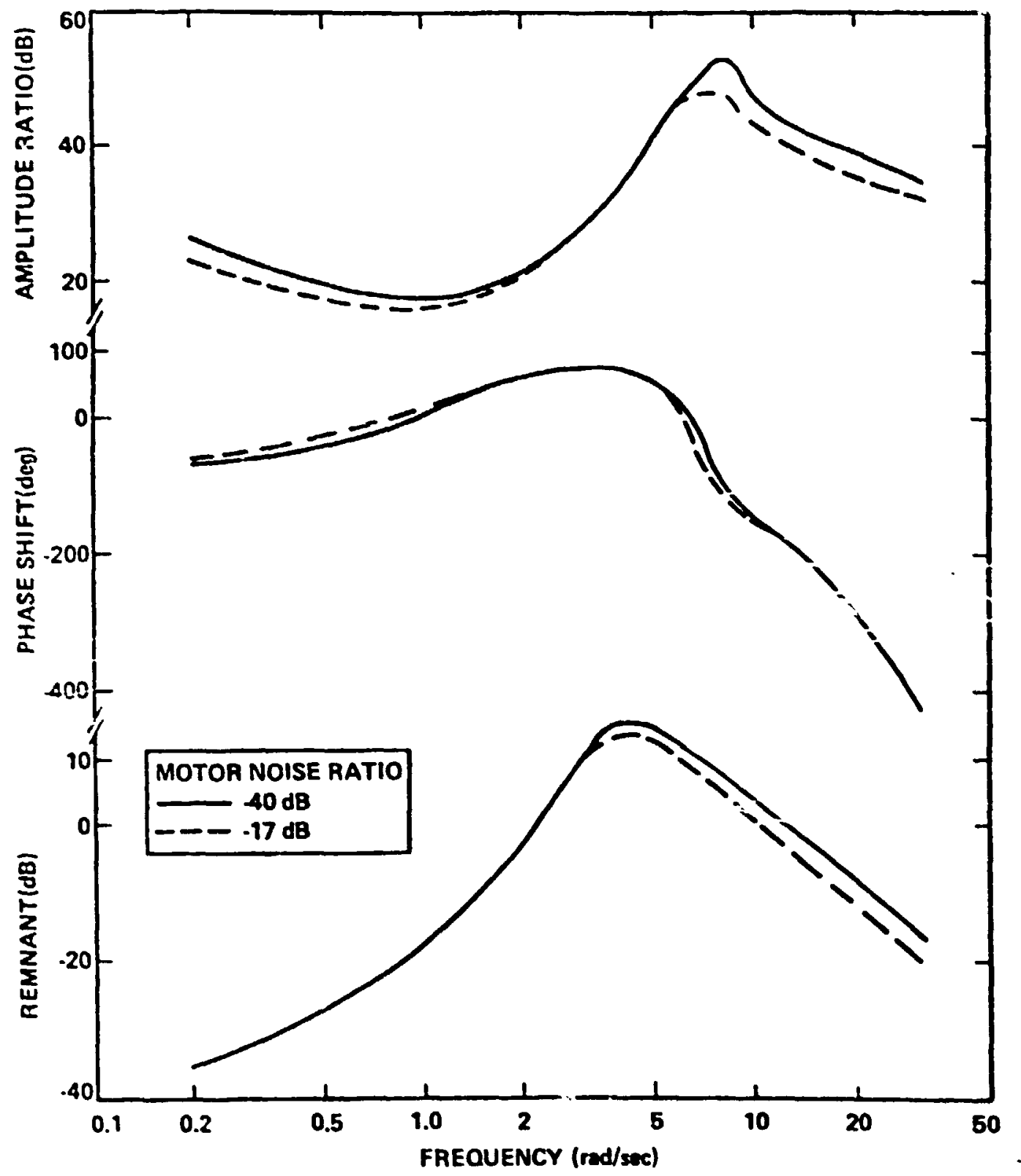

Figure 1. Human Operator Transfer Functions Variations Due to Motor Noise Ratio (filtered rate dynamics) 
Ahet Buharal1, Man-Mach1ne Systems Laboratory, M.I.T., Cabridge, M

This profect is aninly concerned with the Investigation of airplanes following each other in string as often occurs during the landing procese, where the string has an average velocity, which any be constant, plecewiseconstant or continuously decreasing.

The basic differential equations for the etring are derived and codera control theory ts used to describe the cheracteristics of the feedback control by the pilots. Two different kinds of performance lndices are ueed and a compartion between them to inde.

To obtaln the lewents of the cost metrices and because such data was not evallable, soes data analyses wre derived using a bastc nodel for one alrcraft. This was then applied to the complete sering of alrplanes by weans of some simulatlon to adjust the confictente unt1l aone reasonable crajectories were obtalned.

The pilot's goal was to eliminate collision with the leading alrplane and to avold excessive acieleration. It was assured that the following pilot could not see wore than two leading alrplanes. The ala velghtion on the feedback was based on velocity and distance error.

Some other factors and use of som former researchers concerning carfollowing wols are discussed. These suggeat lese error senstivity when the spacing is Incrensing and wore error senstivity with decreasing epacing. Varlable feedbeck coefficlents which are inversely proportional to buth velocity and spacing error are also taken into consideration. Even though the afor portion of the work consists of simulation done with consent everage velocity, sove oodels dealing with continuously decreasing average velocity are also studied.

The effect of ace thresholds and different sampling intervals are also dis iussed.

All these different factors were aupported with simulations which showed the response of the syate to varlous kinds of dieturbances by seans of sose nuberical and graphlic 1 l output. 


\title{
ORIGINAL FFiE I3 OF POOR QUALITY
}

TRAININC AIRCMAFT DESIGR: CORSIUERATIOA:S BASF. ON TIF.

SUCCESSIVT. ORGANITATIO!I OF PFRCF.PTION II: IIANUAL CO:ITROL

\author{
Roiert K. leffley and !'arre: F. Clement \\ Systems iechnolopy. Inc. \\ llountain View, California 94043 \\ and \\ Samuel J. Crain \\ Voughe Corporation \\ Hawthorne, Callfornia 9n25n
}

\begin{abstract}
The thesis of this work is that pllot skill dovelopnent in the lavy approach and landing task is very stron:ly tled to the ifrcraft closure rate and, therefore, that pllot tralning for this task should be based on an appropriate progression closure rate. This, In turn, lears to a rational and explictt determination of design point approach speeds as well as other important aerodynamic features for training alccraft. One key is to recugnize the significance of transitiontiag fron a purely compensatory control loop technique to one involving a pursult crossfeed between thro:tle and pitch attitude. Such transitionin? requires significant skill development, yet reduces pilot workload while enhancing flight path and alrspeed performance. The second key is to address the terminal flight path adjustiont in terms of ranpe-to-go. This establishes a bridşe between the visual field and the comination of manual control technique and vehicle flight dynarics. A desig: sumory plot is thus created in termo of: 1) perfurmance ( $f 1 i$, the path handwidth), 2) critical range-to-go (for terminal path correction), and 3) closure rate. This performance-range-closure rate space serves to map the trainino, pronression in light of the vartous critical alrcraft and control technique constraints. A speciflc advanced trainer design polnt can thus be established for any comblnation of primary tralier and operational fleet alrcraft.
\end{abstract}

\section{NUCRVIFY}

Command of an afrcraft consists of two types of tasks:

1) Psychomotor tasks requiring the pllot to be active in close: - loop regulation of the alrcraft $f$ ighi nath; control cormends are inposed and effects of eisturbances a re suppressed.

2) Discrete, normally open-loop, tasks wherein the pllot comminicates, navigntes, operates systems, etc.; these rasks usually are not required to be performed at an exact time but durin? a spectfic time perior. 


\section{ORIGINAL FAGE IS
OF POOR QUALITY}

Muring a maneuver, the portion of avallable time required for performin: the psvchoivutor flying tasks is called "attentional workload" in the literature (c.9., Refs. 1 and 2 ).

The nethodology and rationale for psychowotor skill development npplied here follows the Successive Organiration of Perception (SOP) theory of manual control terived fron Krendel and ikRuer (Ref. 3). This hypothes is of paychomotor skill developnent is based on the concept that a supervisory control systen of the human dominates the learning process. It is the limitation of the supervisory system that sets the pllot workload margin; as akill is developed in a given sensory motor task, supervisory involvement and, hence, perceptual-motor loating. (1.e., workload) becone less. Furtherwore, it is theorized that skill development involves a propression from an instant-byinstant conscious perceptual-motor action to execution of propranned responses. The three stages of developrsent are described by this theory of manual control skill develupnent to be:

- Compensatory; the pllots acts mainly in response to an error sigrai (he is "behind the alrcraft").

- Eursult; most of sile pilot's actlons are latrned responses to discrete perr-ptual cues or sets of perceptual cues.

- Precognitive: most of the pilot' actions are executions of learned control routines and strategles.

These chree stages of skill development represent levels of the pllot's workload capacity.

In sctual filght situations, the pilot attempte to cope with each contrci cask by use of strategles which reduce hls workloed and Improve his performance. Pllots reach their maximum performance capacity when they gain the abllity to primarily use precognitive skills for alrcraft control.

IEETHODOLOGY AID APPROACH

The thesis of this specific application is that the pllot's skill development tr the liav approach and landing task is very strongly tied to the alrcraft closure rate snd, therefore, that pllot training for this task should be based on an oppropriate progzession in closure race. This, in turn, leads to a rationdl determination of design approach speeds as well as other key aerosynamlc features for training alrcraft.

The following sumarizes the analysis approach for choosing, In particular, the deslg,n point for au advanced jet tralner in the context of the night carrier approach task. Thls context includes a variety of important factors, 1.e.,

- Prescribed longltudinal plloting technique:

- Overall nultiaxis control task. 
- Desiret manual control performance, t.e., minimum path errots and system stablilty.

- Alrcraft flisht dynamics (flight path, speed or AON).

- Mutsite visual perception.

- lieed for excess tine to communicate (with I.SC, instruc. tor nilot (IP), etc.l.

lost inportant, we are able to view these factors in terms of the prozression of trati Ing from introduction to the prtmary trainer, through an advanced trainer, to the fleec aircraft.

The analysis approach that covers the ahove is lllustrated in Fio. 1. It begins with statement of the task and a prospectus of the control loop structure needed to accomplish that task. A control loop analysis is then performen to Identify the important features of the vehicle, of the displays (outside visual and cockpit instruments), and of the plloting technique.

Following that, we estimate the pilot's Alscrete task duty cycle and compare that to h1s multiloop excess control canacity in order to assess his partition of worklisad between continuous and discrete tasks. Pllot/vehicle performince

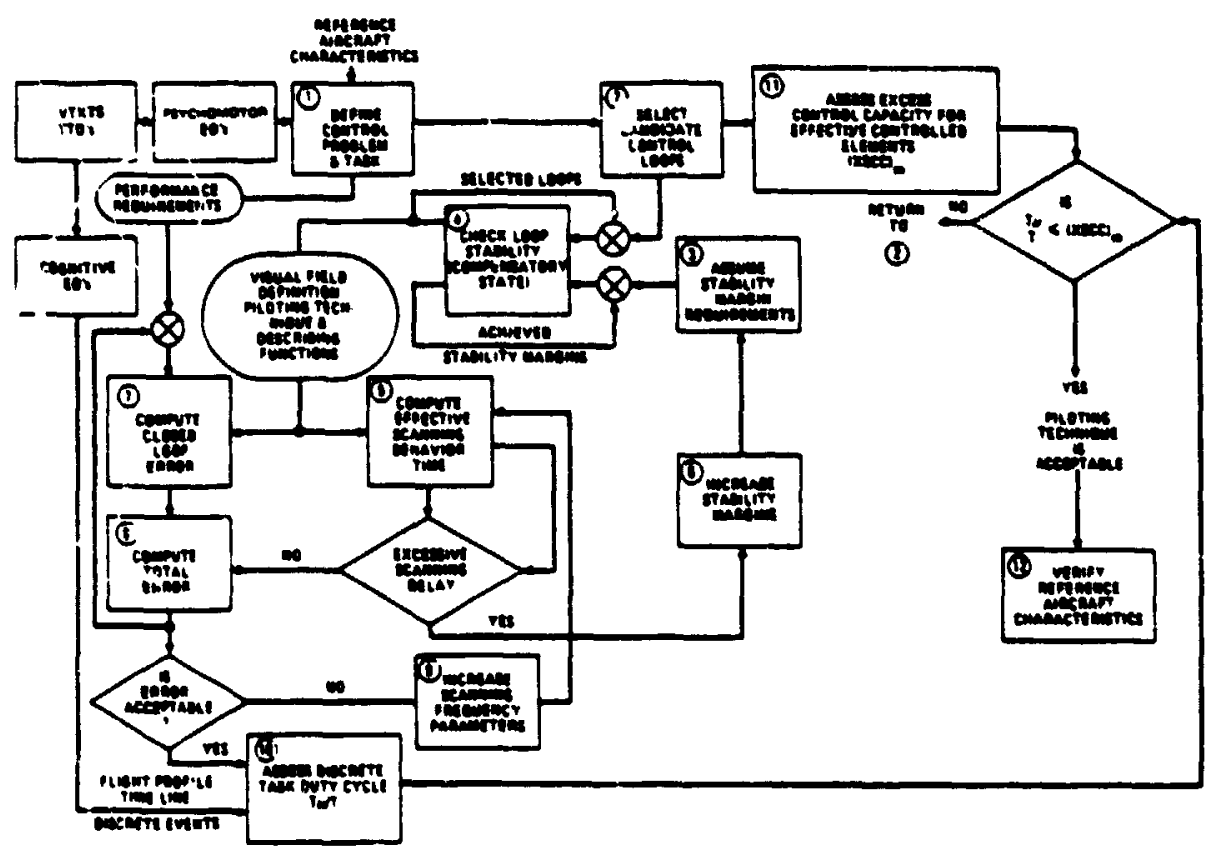

Flaure 1. Flow diagran of process for selection of flipht medla requirements based on imposed workload 


\section{TIGINAL FRER IS \\ OF POOR QUALIT'}

is broupht into the analysis along with visual motion effects, and this finallv nermits us to formulate a manareable quantification of all factors in connon terms. The resulting, orerall systen parameters consist of alrcraft snced (airsneed and clositre rate), aerodvamic flight path senstivity

$\left(n_{z_{0}}\right)$, rance-to-ro, and pllotin"; technique (regarting, fliogt path and speed). i hrifice common to each of these parameters is the hel ght repulatinn handwitth (expr issed as crossover freauency, $\left(\omega_{c_{h}}\right)$.

The problem, hrtefly stated, is to accomplish a manual soproach and landing, in the flect nlght $C V$ environrent and to constder the training, nroaression required to bulld up to this. The Navy's pregeribed pllotiny technique spectfically calls for heloght corrections with throttle and speed (or ADA) corrections with itch attitude. Taken literally, this correaponds to our concept of a narallel compensato y loop structure (with an inner series loor, of pltch att _ude controlled by elevator).

A key point of the analysis is that a nurely compensatory structure will not permit satisfactory execution of the approach and landin? task, especlally In adverse conditions. Rather, the nllot must ultimntely develop a pursult crossfeed of throt:le-to-uitirude in order to enable full reallantion of the alrcraft's fllght path regulation potential (sce Fig. 2). This pursust crosefeed satisfles the prescribed lavy tcchnlque, but $1:$ brings about a quantum decrease in pilot zorkload (Increase in excess control cadacity) with a compensurate inprover:ant in flight nath performance. We see, in $f$ act, that the crossfeed hecomes essentisl to success in the CV environment as apprnach speed increases to that trpically encountered in fleet altcraft (1.e., flighter) attack).

Two key parnmeters descrlbe the relevant alrplane dynamics, 1.e., total airspeed, $v$, and normal acceleration sensitivity, $n_{z_{a}}\left(-C_{L_{g}} / C_{L}\right.$ or $\left.\rightarrow r_{r}^{\prime} g\right)$. These parameters, for example, provide accurate estimates of att 1 :ud constralned speed and heave nodes, $1 / T_{\theta_{1}}$ and $1 / T_{\theta_{2}}$, respectively, $1, \mathrm{r}_{2}$ :

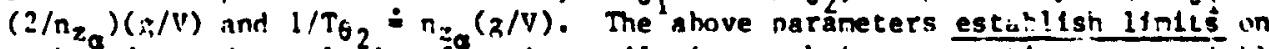
path and speed rezulation för niven plloting technique varations, especially compensatory versue pursult crossfeeds.

- Comfortable compensatory bandwidth $=1 / \tau_{\theta_{1}}\left[:\left(2 / n_{z_{a}}\right)(s / v)\right]$.

- I.1nit compensatory bandwidth $(=\sqrt{2}(g / v)$.

- Limit pursult crossfeed hindwitth $\left(: 1 / T_{\theta_{2}}\left[\dot{n_{3 a}}(s / V)\right)\right.$.

The above constraints are marped in the nerformance-ranne-closure rate space in F18. 3. The piloting technique and alrcraft-dependent deterined limits are show as normalized performance measures, and are characterized hy the nornalized fllght path bandwidth and range-to-go. The normalization of the scales relates the differences in approach speed between the advancer tralner and flect alrcraft to the sk111 level iat the student acquires at the end of its primary training. Unity, on the range-to-ro scale, at end of orimary tralnin:; is 200 feet distance and the correspondinr flishe nath perforsance is a bandwidth frequency of 0.5 radlans per second. Banre-to-ro :s defined as the pllot's final path correction distance. These nornalized netrics provide standards relative to student sk1ll. The 1llusiration in 

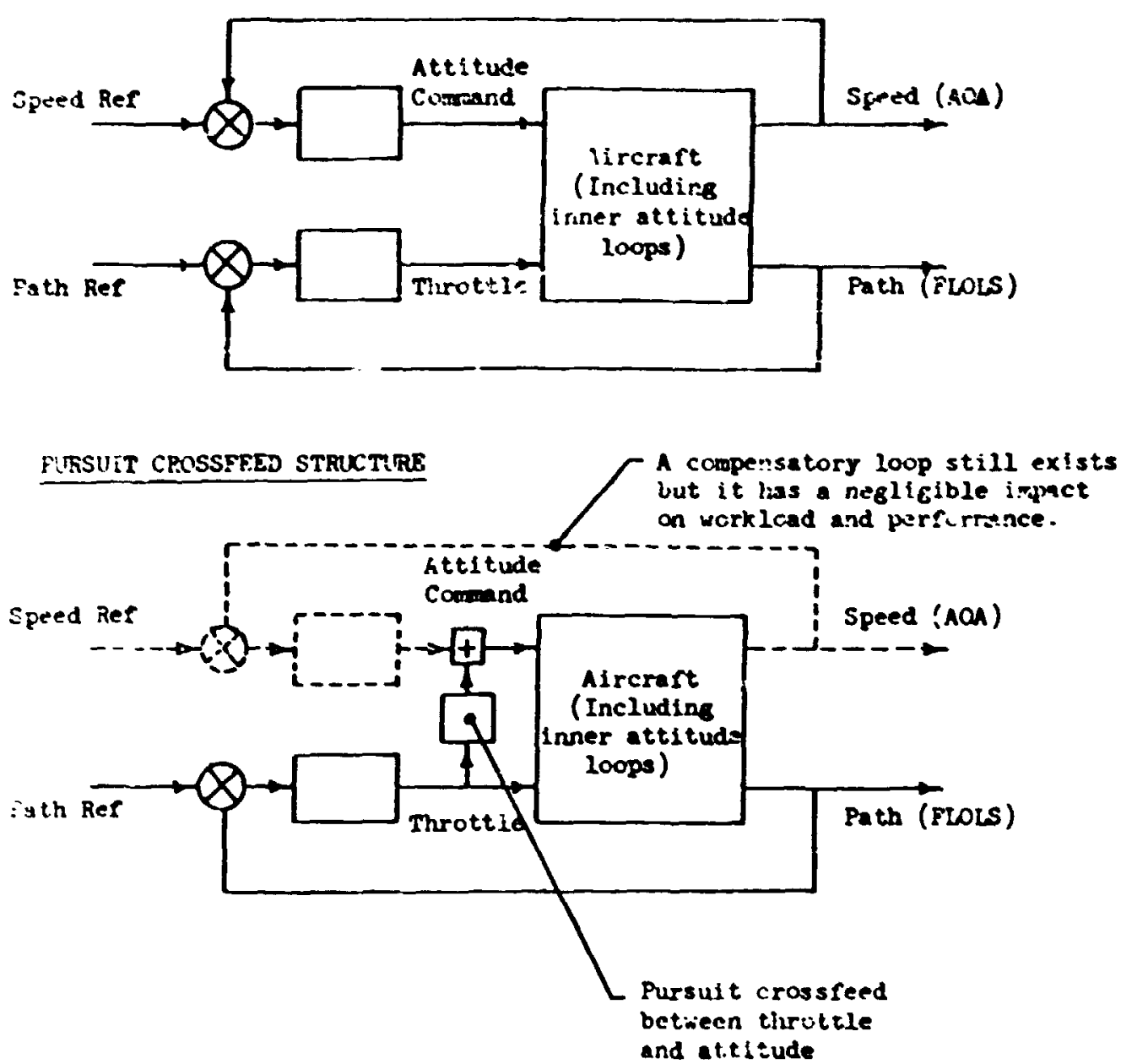

Figure 2. Comperien of p1lot loop etructure fores (In teras of Succeselve Ortenisation of Percer $t 10 n)$ 


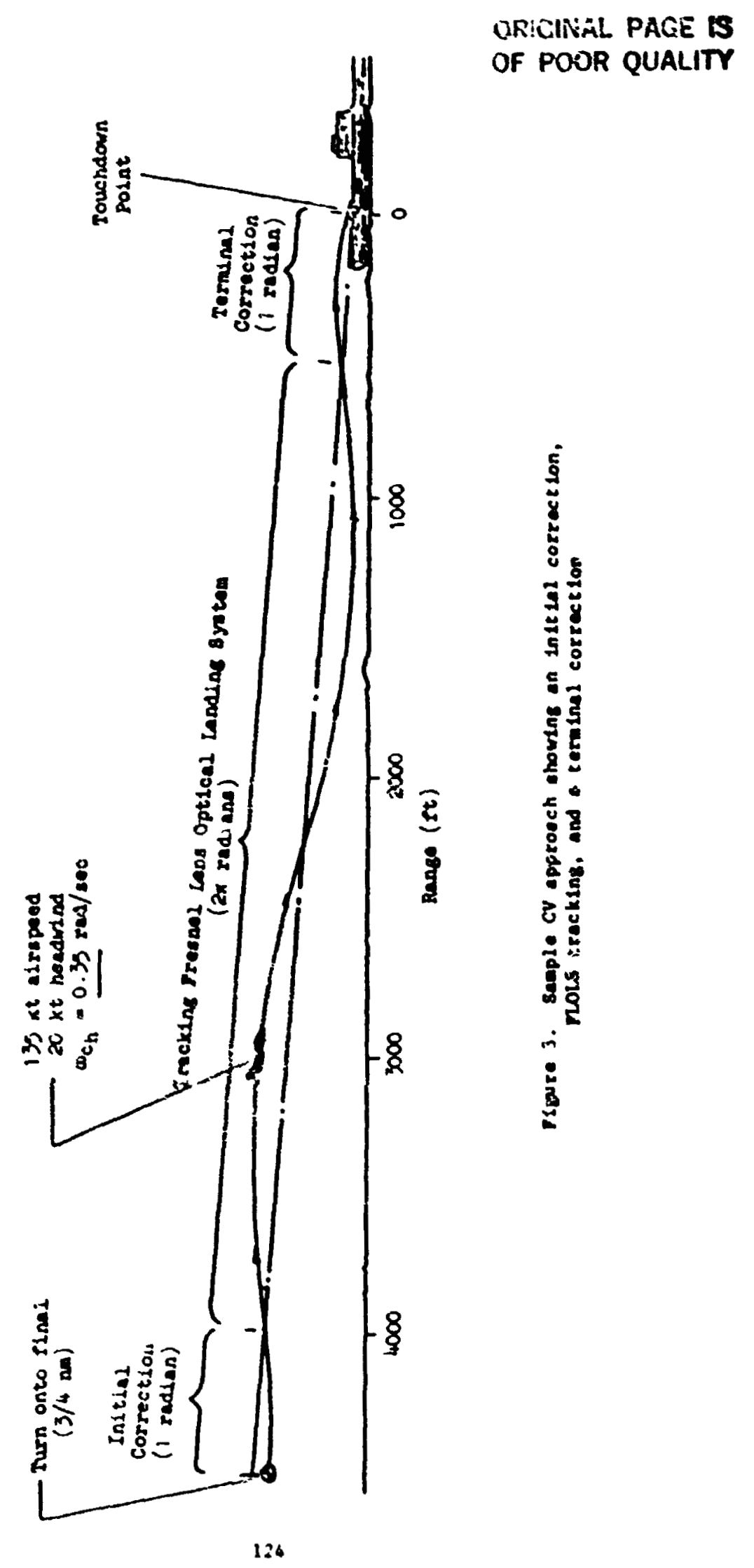




\section{OFi: VALL FAGE IS \\ OF POCR QUALTY}

He. I Indicates chat for a night carrle: sppranch, the design point is Ins knots alrsped for a 20 kwat headulnd with path reaponae ( $n_{z,}$ ) approymately equal ti. 3.0 Thls level oi n., is establiahed by the need to insure that the stindent reaches his response linlt for the pursult control terhnlque. iy aibicring this ic:-i of skill he will be rapable of operatinf to the iffrale-dependent linte for the flect altcraft. The covern-

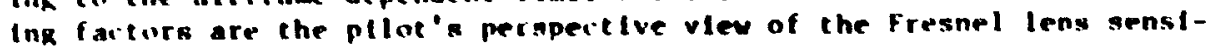
itier and landing area.

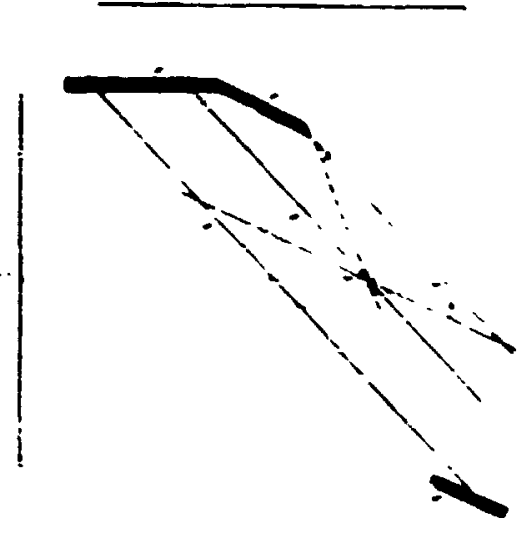

Figure 4. Appruach periormance design constralnts of arcraft for nighe qualification

\section{TRAINING IAPLICATIONS}

A training scenarlo can be derived from the analysis. As shown in Fig. S. the student's skill development begins with the primary cralner at Point $A$. For clarity, the anall arrows are used to trace tie student's sklll develooment wile the "bolder" arrows Indicate points for advancecent In craining. In his "nafve" state, the student applies the presertbed Wavy flight path control technique in the compensatory manner. At this level of profirtency. the governing alrcraft paraneter is the

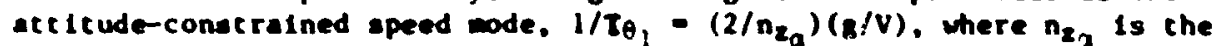
normal load factor sensitivity to change in angle of attack. V is true alrapeed, and 8 is the gravicational constant.

As his proflciency increases fron the compensatory level, his performance loproves unt 11 he reaches an intermediste perforance constraint (1.e.. Point B) laposed by the alrcraft phugold response characteristics ( $-;)$ in radians per second. 


\section{oucunt pues in \\ cr podin cinin}

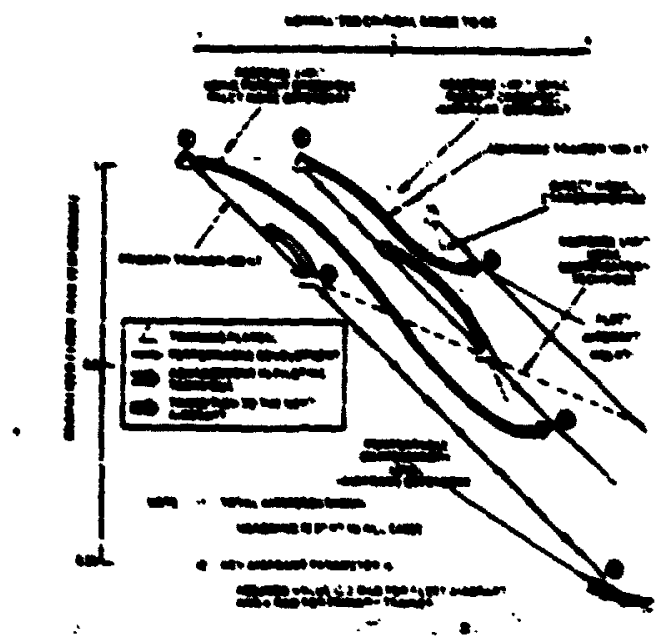

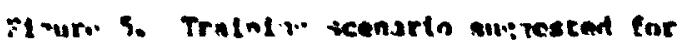
nit the nuiltiftention

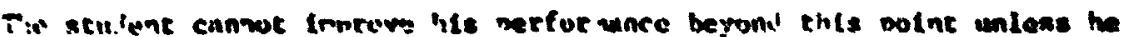
le.urns a nore effleleut control strateng. Fils vecurs throush the Th prome-

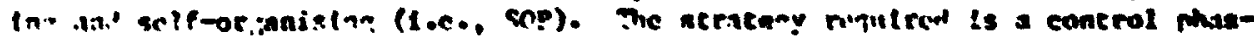

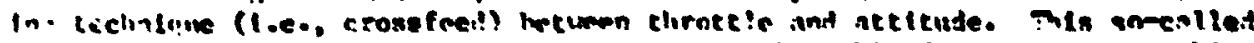

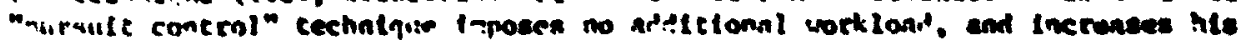

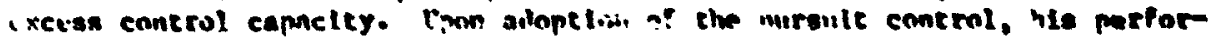

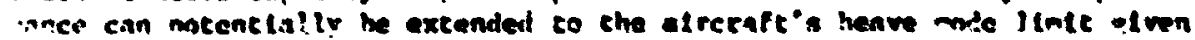

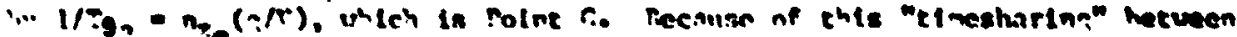

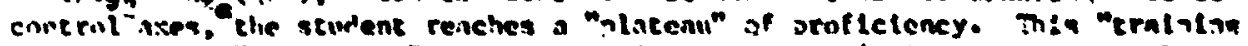

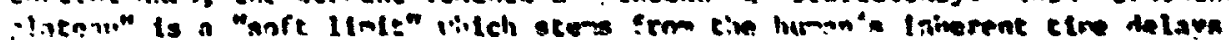

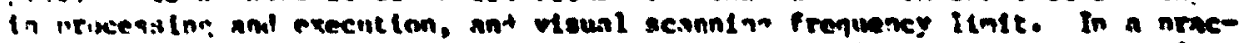

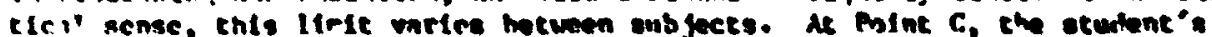

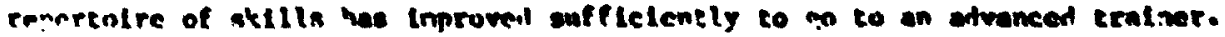

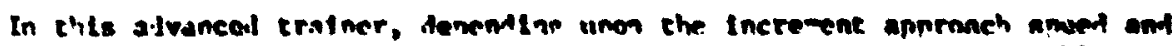

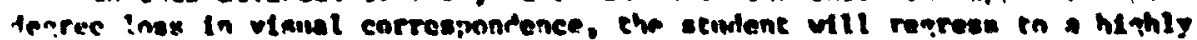

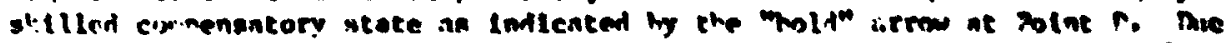

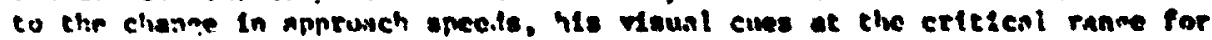
fectstons of the arvanced tratner do not corresmont to thoas learnet in the

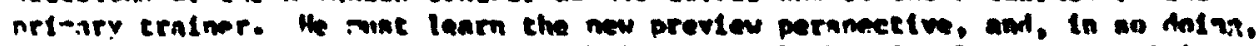
he re-resses tn the compenatory techniques until the visuml nuen nom timino strite :y necessary for advancinn to the mirsult techninue have been re-

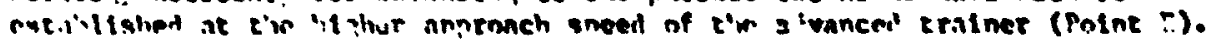

The flnal nroureaston in the learnl an crels la the eranaltion to the

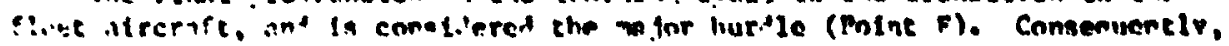




\section{ORIGWAL PAGE W \\ OF POOR QUALTY}

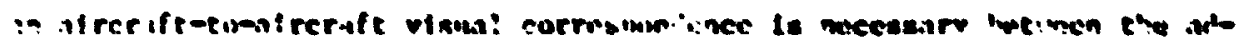

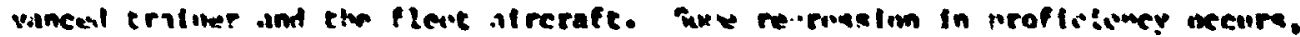

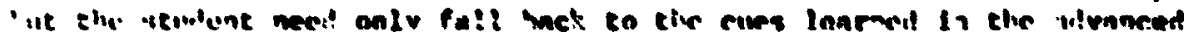

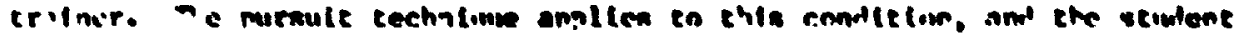
Is filly c.lminle of arnoransin" in blill to the li-tes of the flect alrerifte

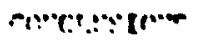

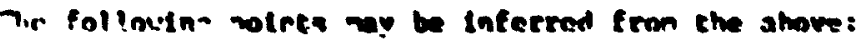

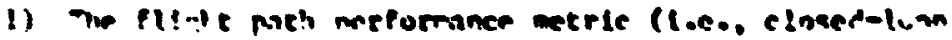

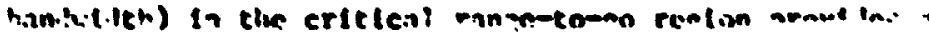

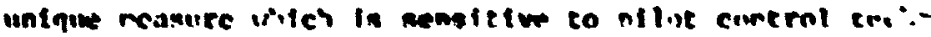
nime and nilot proftelency lewl. Tia netric coul."

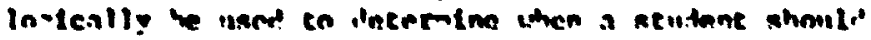
s.vancer in cralntyo.

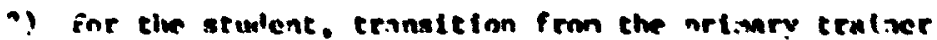

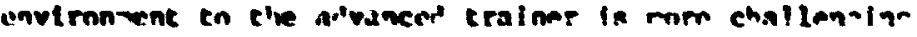

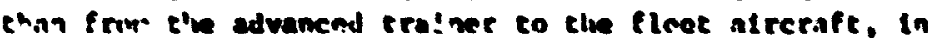

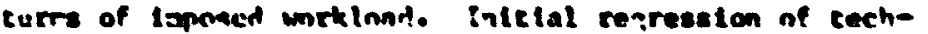

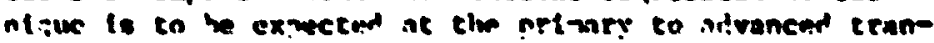
stclon, hut verv litele reviension in profletoncy Is morlsulhin in emastioni 7:: to the flect alrerift. mierefore, waul cotreepondence hetwern these itreraft 18 matacal 14 .

3) Increneed trating time ing be requitro." if a hth

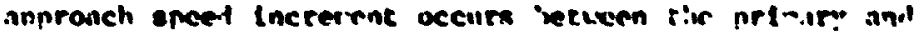
li!uneril cralner.

1) Aircrift charactertatica mich enhance tralith: nromreesion aro exnlictely teterainm!.

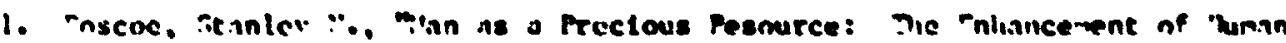
iffectiveness in Fitst merations." Ald Pamer 76-13ng, presentel it II.W

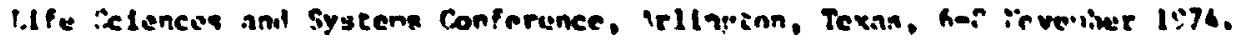

-. Jer, Tenry "., and iurren F. Clerent, "refininm and :eawiring Percentual-

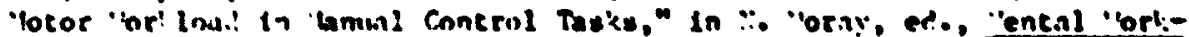
lon!. :ew York, Pler.ur Prese, 1n7!.

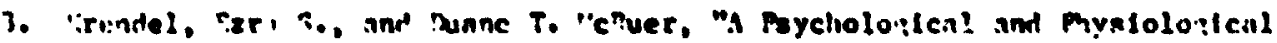

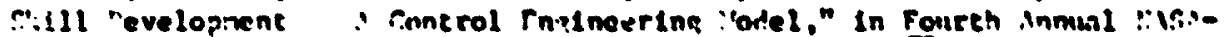

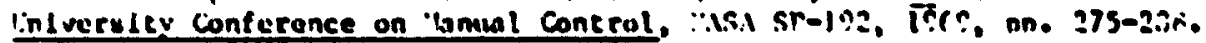


AN EXPERTMETIAL STUDY OF HUAN PILOT'S SCAMIING BEHAVIOR

by

Kruichiro Washizu*, KeiJi Tanaka** and Tatsuo Osava*

- Debartment of Aeronautics, University of Tokyo, Tokyo, * Instrumentation and Control Division, Mational Aerospace Laboratory, Tokyo

\section{INTRODUTTION}

In order to disclose the characteristics of the human pilot who controls the multi-variable systen, ve have to investigate both the control behavior and the scanning behavior. Researches on pilot's scanning beharior dur'ng the actual operation of airplanes have been conducted previously, tron which the data concerning the scanning properties amons various instruments have been already obtained I. Furthermore, various models of pilot's draanifs based upon multi-variable manual control experinents have been constructed ${ }^{2-4}$. There are, hovever, very few wich sumarize these scanning properties taking account of the various control situations where the pilot is actunliy placed.

The aim of this paper is to larestigate the scanning behavior and the control behavior of the pilot who manually controls the two-variable system, wich is the most basic one of multi-variable systeas. In our experiment, ve set up two control tasks, which simulate the actual aimplane attitude and airspeed $r$ ntrol. In order to simulate the change of the situation were the pilot is placed, such as changes of Right phase, mission and others, the subject was requested to vary the veightings, as his control strategy, upon each task. Changes of human control dynanics and his scanning properties caused by the modification of the situation have been investigated.

By making use of the experimental results, the optinal oodel of the control behavior and the scanning behavior of the pilot in the two-rariable systen is proposed from the standpoint of making the perfursance index aininal. This model enables us to predict both the optinal huan control drnamics and the optimal scanning properties. The nodel ralidation is done by compartan the model predictions with the experimental results.

\section{EXPERTIBTT}

The previous works have already pointed out that the pilot's scanning behavior varies according to the Instruments he attends to; namely, the drell time on the nlight director is relatively long and spreads wdely, whereas, the dwell time on cther instruments, such as the airspeed indicator, is short and reasins almost constant ${ }^{2}$. Referring to this fach, the subject is assigned to two tasks, the main task and the side task, each javing different characteristics in this experiment. As show in Fig.l, each error between the forcingfunction and the oltput of the controlled elesent is displayed on each CRT. The subject actuates the respective controller by making use of the displayed 
information. Thus, each control loop forms a compensatory tracking task. As we postulate the situntions similar to the actual operation, we shose as the main task the stable controlled element to whlch the randos-appearing forcingrunction is added, and as the side task the unstable first-order controlied element to which no forcing function is added. The following three inds of controllad elenents are employed for the anin task:

$$
\begin{aligned}
& G_{\mathrm{col}}(s)=5 /\left(s^{2}+F_{s}+5\right) . \\
& G_{\mathrm{cm} 2}(s)=1 / s, \\
& G_{\mathrm{cm} 3}(s)=1 ;
\end{aligned}
$$

while the controlled element for the side task has a rirst-order divergent dynamics:

$$
G_{c s}(s)=0.3 /(s-0.3) \text {. }
$$

On the other hand, in order to evaiuate the total control performace, the performances of both the matin tast and the side task aust be considered. In this paper.

$$
J=x_{s} \overline{e_{s}(t)^{2}}+x_{s} \overline{e_{s}(t)^{2}}\left(K_{m}+K_{s}=1\right)
$$

was postulated as the total performance index, where $\overline{c_{m}(t)^{2}}$ and $\overline{e_{s}(t)^{2}}$ are the mean-squared error of the main task and the side task respectirely. $K_{m}$ and $K_{s}$ are velghting coefficleats, and these are considered to be rariable according to the change of situation, such as night phase or r:1ssion, in case of the actual operation. Referring to $\mathrm{Eq}$. (5), ve change the experimental mode by ilrecting the velightings rerbelly. The experimental mode are as follows: mode $w$ : put wore woighting on the min task $\left(K_{m}, K_{0}\right)$ mode WE ; almost equalize the weightings $\left(K_{m}=K_{s}\right)$ mode WS, put more weighting to the side takk $\left(K_{m}<K_{g}\right)$

The results of the experiment are summarized as follows. 1) As seen in the time history indicated in Fig.2, the control of the in task is done almost continuously, whereas, the control of the side task bas the tendency to be interrupted during the period between I1xations.

2) The dvell time on the mats-task display is relatively long and spreads videly, wereas, the dvell time on the side-task display is short and anost constant.

3) The control perforance of each task varies according to the weightings. 4) As lndicated in Fig.3, the drell time on the display of each task varies according to the veightings. This change is observed mainly in the dvell tine on the main-task display. The dwell tife on the side-task display remains almost constant.

The mean value of the sum of the both drell times 1 s defined as a scanning period. The scanning perlod varles according to the dvell tine on the anintask display, since the drell time on the side-task display 18 alnost constant. ,Flgs. 5 and $T$ indicate that, when the scanning perlod $T$ increases, the maintask control performance becomes better, whlle the side-task control performance becomes worse.

As the main-task control can be considered to be continuous, we can apply the time serles analysis using Multiple Fiaal Prediction Error method to the data of the main task'. 
6) Using the results of the tine series anclysis, the describing runctions of the pilot are obtained. These show the tendency for the gein to deteriorate as the scanning period becoses shorter.

On the other hand, the control of the side task, vtich seens to be interrupted between fixations, Indicate that the pilot perceives both the error and its rete of change during a short drell tine.

7) As shown in F16.6, there is a proportional relatinaship between the magnitude of error and the pilot's control, when pilot's eres are fixed on the sidetask display. The pilot's gain for the side task bas a tendency to decrease when the scanaling perlod becomes loager.

\section{NODEIIN}

We propose here a nodel of the scanning behavior based upon the results of the experiment. This wodel consists of the optimal contral nodels far both tasks and the optinal scannins aodel.

Since the contral of the min tank appears to be continuous, the pilot's optimal transfer function, which aninir ss the performance index,

$$
J_{n}=\overline{e^{-(t)^{2}}}+\overline{t^{2} c a(t)^{2}} \text {. }
$$

is derived from Wiener's optimn filtering theory. Here, on and $c_{n}$ denote the error and the control of the anin teak respectively. The effects of the scanalns are dealt by adding the relevant observation notse to the systee. In Rer.2, there 1s an exanple of assuming the power spectrum density of the observation noise orv by:

$$
\text { iv }=T_{s} \overline{e^{2}} / w
$$

where $T_{s}$ is the sampling period of the display and $\overline{\overline{2}^{2}}$ is the wean squared error. Referring to $\mathrm{Eq} .(7)$, we assume that the ratlo of the emplitudes of the observation noise up to $\mathrm{I}(\mathrm{red} / \mathrm{sec}]$ and of the error corresponds to the square of the ratio of the dvell time on the side-task display $T_{d s}$ and the scanning period $T$, nanely the pover spectrum jensity of the relevant observation niose orr is assumed to be obtalned by the rollowing equation:

$$
\text { orr }=\left(T_{d s} / T\right)^{2} \overline{\theta_{d}(t)^{2}} \text {. }
$$

The drell time on the side-tnsk dsplay $T_{d s}$ resains alnost constant in all the cases. For the nodel, we flxed as:

$$
\text { Tds }=0.4 \text { [sec]. }
$$

Thus, the pilot's optimal tranafer nunction and the min-task performace can be obtalned as the function of T. F16.4 showe a compariean of the frequency response of the optinal nodel obtalned above and the pllot's describins rinction obtalned tro the experinent. Fig.5 sbow the experinentel results of the control performance and the prediction by the optinal nodel. It seens possible for the model to predict the average of the experinentel values if $T$ is given. The modeling of the control of the lde task is based upon the descretetime optimal regulator. Here, we replaced the sapling period with the scanning period, assuming that one plece of information is percelved at one fix- 
ation and that the pliot controls in such a way that he interrupts his control during the period betveen fixations. When the controlled elenent of the side task is the first-order unstable system as Eq. (4). the pilot's optinal control model has proportional characteristics; the gain of the model changes according to the scanning period $T$. As shom in $51 \mathrm{g.6}$, there is a proportional reletionship between the error (1.e. pllot's input) and the pilot's citput, and it Indicates a good accord with the gain of the optimal control nodel. Horeover, as seen in Fig.7, the control performace of the side task for each I can be predicted by using this model.

As stated above, the control performance of each task is predicted by eaploying the optinal models for botb tasks as the runction of the scanning period T. According co Eq. (5), the total task performance is also obtained as the function of $T$. The optinal scanning period $T$ satisfies the equation:

$$
\mathrm{dW} / \mathrm{dT}=0
$$

Comparisons betreen the model prediction and the experinental ralues of the drell time on the main-tasix display are shown in Fig.8, under assuptions that the drell time on the side-task display is held constant and that the folloring veightings can be applied to the experiment: $K_{0}=0.6-0.8$ vith wode th, $K_{m}=0.4-0.6$ with mode $W E, K_{m}=0.2-0.4$ with mode WS. Fote that in Fig.8, the average of the display dwell time is expressed. These results indicate that ve can predict the scanning behavior by using the proposed model.

\section{CONCLUSION}

By setting up an experisental con'ition similar to the actual operation of airplanes, t'ic data of two-vartable manual control system were sucress rully obtained. It was confina in that the pilot's control dymamics and his scanning properties change $\because, n$ the weightings put on the tro assigned task. The proposed pilot model in the two-variable manual control system can predict both the pilot's dynamics and the arerage tendencies of the scanning properties.

\section{RETERETCES}

1. Spady,A.A.Jr.: Airline Pliot Scan Patterns During Simulated ILS Approsches, MASA TP-1250, 1978.

2. Allen,R.W.; Clement,W.F.; and Jex,B.R.: Research on Display Scanning, Sampling, and Reconstruction Using Separate Main and Secondary Tracking Tasks, MASA CA-1569, 1970.

3. Levison,W.H.; Elrind,J.I.; and Ward,L.L.: Studies of Multivariable Manual Control Systems: A Model for Task Interference, RASA CR-1746, 1971.

4. Kefoman,D.L.; ad Baron,S.: Manned Vehicle Systema Nalysis by Means of Modern Control Theory, MaSA CR-1753, 1971.

5. Tanaka,K.; Goto,N.; and Wash1zu,K.: A Comparison of Techniques for Ident1fying Human Operator Dynamics Utillzing Time Series Anolysis, Proc. of 12 th Annual Conf. on Manual Control, USA M X-73,170, 1976, pp.673-693. 
ORIGINAL PAGE IS
OF POOR QUALITY
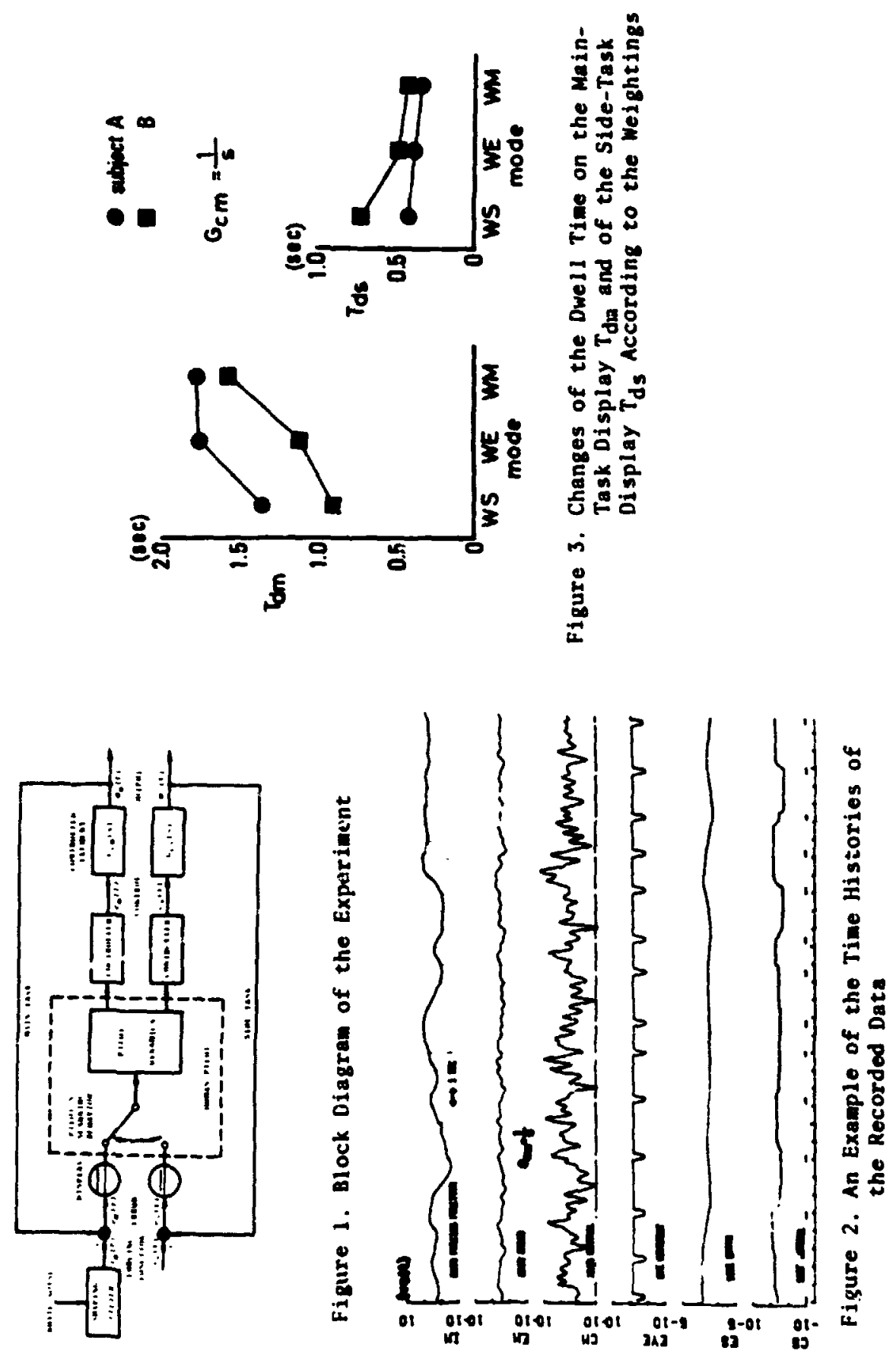
ORIGINAL PAGE IS

OF POOR QUALITY.
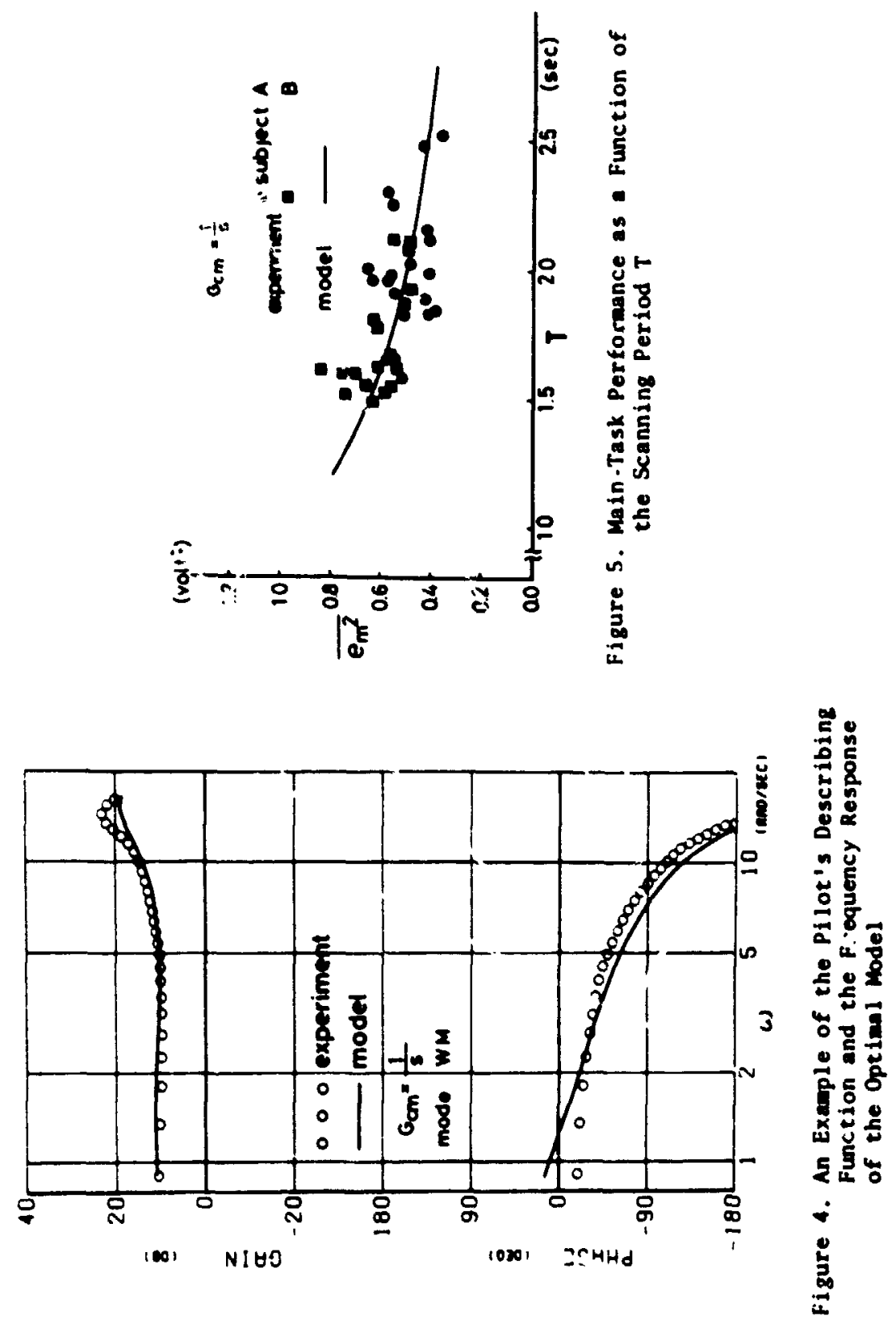
ORIGINIAL PAGE IS

OF POOR QUALITY
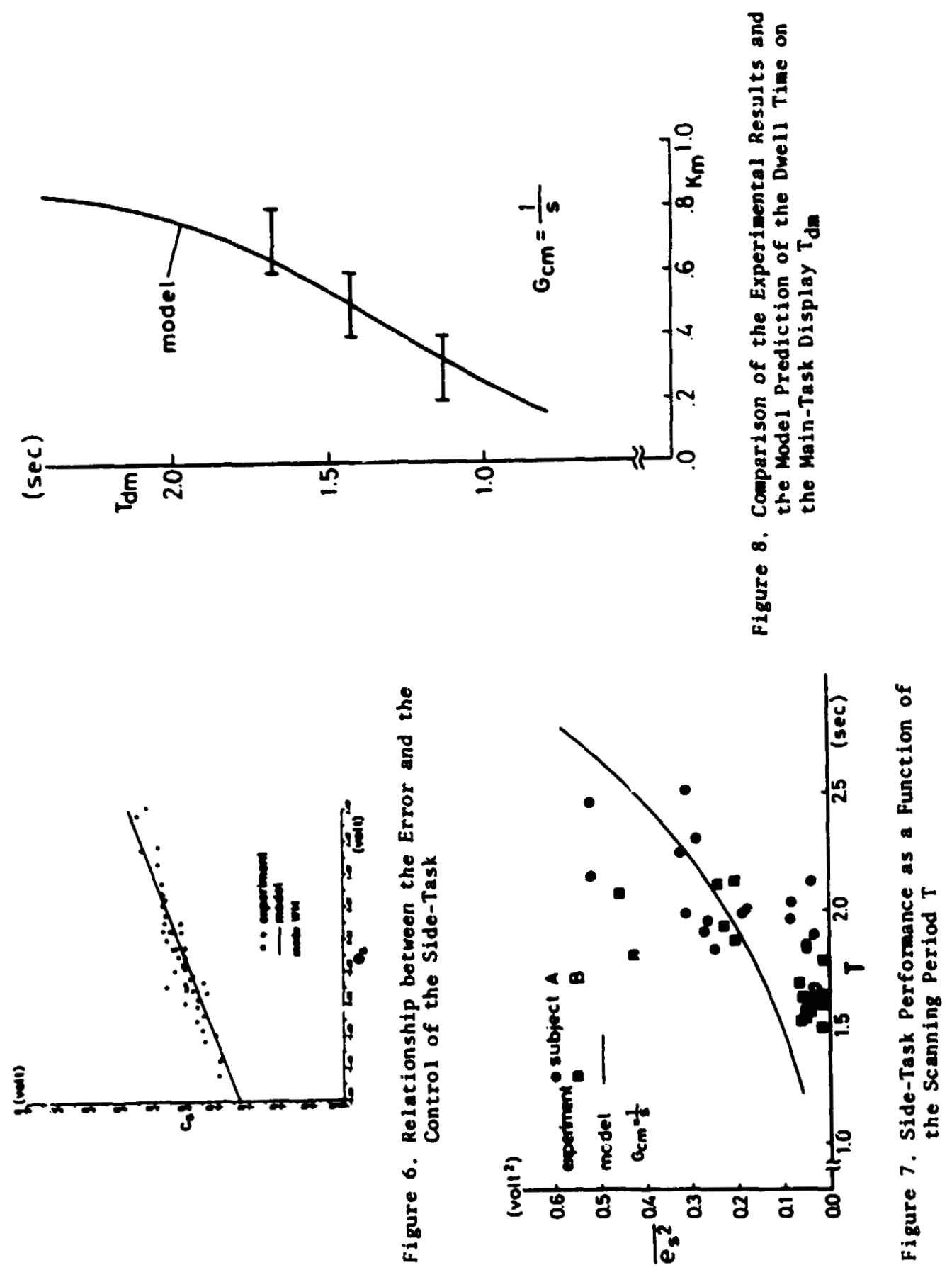
INVESTIGATION OF A SUM OF SINUSOIOS

REPRESEMTATION OF GAUSS-MARKOV RANJOM PROCESSES

- IMPLICATIONS for maNLAL Cü.itrol RESEARCH

\section{R.L. Mohr and A.V. Phatak}

Analytical Mechanics Associates, Inc.

Mountair. View, CA

\section{R.A. Hess}

NASA/Ames Research Center Moffett Field, CA

\section{Abstract}

An important problem in the design of piloted simulation experiments is the selection of appropriate mathematical models for the external wind gust disturbance inputs. Wind gust turbulence spectra are typically represented as gauss-markov random processes, such as the "Dryden" or "Preyss-Meadows" modeis. Assuning that turbulence spectra are rationa:, these models provide an efficient and adequate approach towerds simulating the effects of external gust disturbances. However, such gauss-markov gust models are not necessarily the best represeniation to use if the objectives of the manned simulation experiments are not merely $a$. rical experimental analysis but include the identification of a dynamic inputoutput pilot model. The drawbecks of using gauss-markov disturbance models relate to the statistical properties of the pflot model parameter and spectral estfation procedures when fint te data segwents are used for identification. These problens do not arise if a sum of sinusoids is used to modei the gust turbulence spectra. At present, the numuer, relative amplitudes, frequencies and phase angles of the sinusoids are selected to match the characteristics of the desired spactrum according to some qualitative or quantitative criterion. Furtiermore, these representations are used interchangeably in the formulaticn of optimal control theoretic adel: for the huan operator, which require the assumption of state-space "internal mocels" for the plant/sisturbance dunanics. 
Recent work has shown the iapact of varying internal models for the random disturbances on the optimal control model describing function and remant outputs. Therefore, a better understinding of the relationehip cetweer idom signals and sun of sinusoids representation shou:d provide valuable insight into plausible internal models for the plant/disturbance dymanics adopted by the trained hum operator.

This paper presents results of a preliainary investigation into the mathenatical relationsto.p between a state-space nodel for external disturzances to a pilot-vehicle system and an "equivalent" deterministic sum of sinusoids representation of that disturbance. Systematic model structure determination and maxima likelihood parameter identific ion are applied to su of sinusoids data and variables (as in standard $k$, $k / s$ and $k / s^{2}$ laboratory tracking tasks) excited by sum of sinusoids data . The purpose ws to study the effects of various paraneters. such as run length. sapling rate. and su of sinusoids variables (muber. relative aplitudes. frequencles and phase angles) on the identified state space model structure and parameter estimates.

The results are compared to state-space models assuned by previous investigators, and the implications to man-whicle stwulation and man operator modeling are discussed. 


\title{
$-\pi 8234045 D_{B}$
}

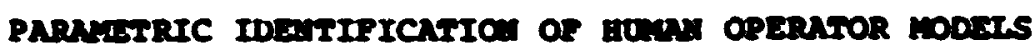

\author{
Torbere R. Hinz \\ Departinat of Buan Factors Engineering \\ and simulation
}

Vil-Company Breman

Federal Republic of Germay

\begin{abstract}
surenger
The accurate and efficient identification of the huan oparntor is still a need in huan factors engineering especially concerning mitivariable control. Control theoratic identificatica wehods need to be tested with huan operator nodels under realistic boundary conditions. The requirements and criterla for the use of parameric nethods, selected nodels as wil as the Maxtin Iikellhood rethod and the Bxtended ralman Filter are displayed. The experiments and results are comarativly discussed from the point of practical engineering.

\section{nirtoodcrios}

The multivariable control of man-naschlne-systems by the hunn operator vill remin even in highly copplex systens like present and future alrcraft generations. For exaple, questions concerning crewconcepts nut also be answered. In the fleld of continuous manual control not only in categories of decision theory. In the optinization of manual controlled systeis the identification of thie human operator is a supposition to solve this task on analytical wethods. For this purpose som models for the manual control of single and multivariable control have been developed an tested $/ 1,2,3 /$. The use of even efficient models as a tool for design engineers is nomally restricted by the capacity of identification methods and generates the need for powerful identification approaches.

In the past non-parantric methods were preferred which produced an operator description in graphical form like the Bode-plot. This curve had to be approxinated by those of a model to achieve an analytical form. Generally the wighting function or transferfunction via correlation wethods were co puted. The expense in computing time and effort were high and normaliy only capable in
\end{abstract}


research expertmente and in single variable control tasks. The identification of model-paramers and information about the huan operator remant were not avallable in the san identiflcation run.

In the last ycars in ldoptification, paranexic nothods based on eatimation theory becan available and were tested on technical systems $/ 4 /$. These results cannot be transferred on an-anchinesystens without further investigations for the boundary conditions are not comparable. In the huan factors field paranetric whods were often used with restrictions in the operator nodel (no remnant) or in special control situations were parts of the model wre neglectable (two delay) or unusual forma appared (all icments of the vtate vector masurable).

The als of this work is to test paranetic methods without speciflc restrictive assunptions to gain experience on their versatlilty as an engineering tool for a broader scope of control tasks.

Starting with requirements for modeliling questions of the ldent1flability of the guast-linear rodel and the optinnl Control hodel have to be answered and also attention has tc be payed on the convergence criteris of the identification wehods under test. These are the Mexinu Likelihood kethod and the Extended Ralnan Filter. Both were used in ldentifying the computer-sinulated manmachine-systens lncluding the huma operator. Also exparinents with manual control tasks performed by testpersons wro achieved. The accuracy and convergence in regard to the software, hardware and computing time expense will be valuated.

\section{REOUIPEMIETS ND CRITERIA FOR THE USE OF PARANTTRIC METEODS}

Identifleation methods are characterised by their convergence. This includes that they evaluate the true parameters with a minimum of masured data and aninum error. A very desirable quality is an asymptotic unblased estinate with ainimin variance. The achlevability of this performance depends on the 1dentification wehod ltself and on the structure of the man-machinesyot m-model.

The Maximum-L1kelihood method provides thls guality if a canonical form of the man-machine-system-model 1 sound and som sther conditions concerming the deta acquisitions are fulfliled $/ 6 /$.

The Extended Kalman Filter w11l only reach suboptinal estinates In the described sense for the inearisation of the systen-model and the variances 1111 alwaya be greater than that of a minimuvariance-estimator $/ 5 /$. Nevertheless the use of canonical forms supports convergence.

For eingle-variable control canonical forme have unlque solution: wich is not true for multivariable control models and in addition the effort to achieve a canonical form ts extrealy higher $18 /$.

Normally the human operator models do not have a canonical form in their orgin so that the model parameters and the "canonical" parameters are not Identical. The Identiflcation wothod will 
estinte the "canontcal" paraneters wheh have to be transfornd back into nodel paranters to rork wth. Thls requires the deterinistic 1dentiglability of the nodal prameere out of the canonleal for $/ 7 /$. These agulremate do not only concern that a huin operator indel can we enployed for ldentifying parantere from real date and to not only able to describe huma behaviour. Besides the performance in convergence the usefulnese of an ldenetfication mthod as an englneering tool in humn fectors has also be taken Into account by the on/off-11ne capabil1ty. needed computer-size and computing tim.

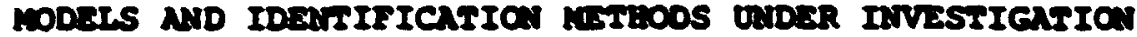

For the testing of paranter estination nethods under hunn factors condition validated hume operator nodels wre used. The discussion of the nodels in a general cense wa not the subject of the recenreh. To reduce the effort in conputer and progran handling a ingle controlled variable taak we choeen with a firet order whicle dyanic (F1g. 1). Ihis does not restrict the validity of the reaulte in reppet to multivariable control for the structure of the nn-anchine-system-nodels and the 1dentif1cation nethods cower both caes.

Som versions of the Qund-11near model and the optinal Control rodel wre checked if the man-machlno-groten-model Including the could fulfil the requirements for a structure wich can provide ninturin-variance estinates.

The system with the Quas-innear-yodel is lconl Identifyable

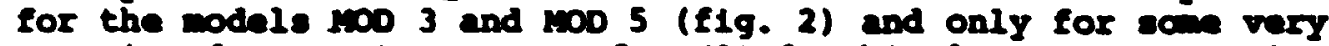
restricted paranter spaces for mo0 6 . This last atatenent is als valld for the version of the optimal control hodel proposed co ldentifyable in /2/. M1 nodel veralons are designed for singlo-veriable control that a canonical or atnianl form can be found with a unique solution. The presentation of the an-michlooaystem-nodel is witten in the state-opace description

$$
\left[\begin{array}{c}
\dot{x}_{1} \\
\vdots \\
\vdots \\
x_{n}
\end{array}\right]\left[\begin{array}{ccccc}
0 & 0 & \ldots & 0 & 1 \\
-b_{0} & 0 & \ldots & 0 & -a_{0} \\
-b_{1} & 1 & \ldots & 0 & -a_{1} \\
-b_{n} & 0 & \ldots & 1 & -a_{n}
\end{array}\right] \cdot\left[\begin{array}{c}
x_{1} \\
\vdots \\
\vdots \\
x_{n}
\end{array}\right]+\left[\begin{array}{l}
1 \\
0
\end{array}\right] v\left[\begin{array}{l}
1 \\
0 \\
0
\end{array}\right] x
$$

It is an extended equation of a standard canonical form of the operator model and contalns one additional non-zero elcaent for the vehicle dynanic. With the aseuption that this dymanic is known this element is no paraneter to be estimated so that this minimal form fulfils the criterla for convergence of the ldentiElcation wethods in use. 
The ald problen ariese when the orlgta pareneters have to be conputed from the elemats of the estimated parmeter vector in Ioturn. In the cases of moD 6 and mob $\mathrm{B}$ this leads to extensive andyt1ca: expresstons with higher order term dopandlog on the selected pad-approxtmation of the tin delay. In the fram of testing ldont1fication methods the effort to obtain a colution was not benrable for the optenal control model and all expert-

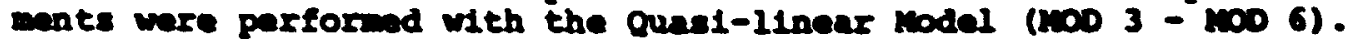

The Maximu-Likel thood Identification as an acknowledged and powerful wethod in control englueering wes choeen and the Bxtended Ralma Filter for 1ts principal on-11ne capability. With the Inplematatica of the Mathu-Iikelibood Mathod on the nnanchine-gyste under investgation arices the problen. that the covarlance-natrix of the aseurenent nolse is ingular. for the valcle output contains no nolse with the asouption that under laboratory conditions masureint nolse cnn be neglected. The remant on the other hand wat be interpreted as manuronent no1se. The singularity of the covarlancenatrix prevente a steady-state solution of the Riccati-equation in the Illkelihoodcouputer. The following alrection have been tried to by-pene thls afficulty:

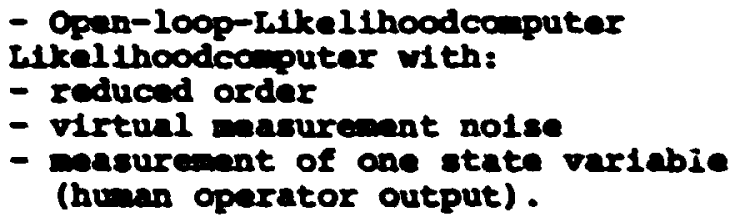
corralation-analya1s on the same data. Th1 acknculedged method in human factors was performed via FET and a Direct search to obtain an analytical expression out of the Bode-plot. 


\section{EXPERIRINTSS AND RESULTS}

Al mentioned Ident1fication wehods wre tested on acquisitio: ed data from a mn-machine-systen computersinulation and on data measured with tespersons. In the computersimulation the humn operator wodel was implemented with an exact tiwe delay. The remnant and the disturbance were introduced as filtered white noise inta the conicrol loop. During the Identification with the simulation derived data the identification nethod used the sam model as the sinulation except the pad-approximation of the tim-delay. All model versions wre trled out on the testpersons data.

The results are sumarized in fig. 3 and 5 . The label of the ldentification program is referred to the model's label of $\mathrm{fig}$. 2 . All tires in the table are based on the described computer type and on 2043 data sets wich were wasured with 20 cps.

Beginning with the Maximum-Likelihood rethod, a asymptotical convergence is achlevable with all versions of the used operator model if the starting values are selected properly. The number of values leading to convergence reduces with the model's order. Increasing nolse-to-signal ratio of tise remant gains the estmation error and the number of lterations necessary to reach the maximum of the likelihoodfunction. Increasing the number of data increases the accuracy but levels out at 1500 data sets. The accuracy is witinin good acceptance for all model versions and also for rednat levels wall above that of typical human operators. The Identification of the testpersons data gives results which could be expected for a flrst order dynanic of the controlled lemant. The Maximum-Iikellhood mathod could be validated also for these real world data for the - zrametersets of all models applied, generate an equivalent tranal $r$ function.

The Extended Kalman Filter requires more comutation time per cycle than avaliable on a 20 cps data acquisition basis. So an on-line use 13 not possible. This time cannot be reduced significantly due to the chosen continuous filter and the RuageRutta-algorithm.

The fliter is very sensitive to the selection of starting valies which Influences the speed and the accuracy of convergence ccnsiderably. Another disadvantage 1s that the covariance-matr1x 1:2cluding the remnant must be known a priorl. The estimation of the remant covariance influences also the convergence of the filter. For there is no possibility except a faster computer to accelerate the filter algorithm into a region where on-iine conputation can be performed. The filter was not used with higher order models which would increase computation time again.

Comparing the parametric identification whods the superiority of the Maximum-Likelihood Method 18 ghown (f1g. 3). If the crosscorrelation analysis in the here implemented sophisticated form is taken into account this is not that clear for it takes a 
12-fold computation time. The cross-correlation analyals can be applied very easily on a spectrum of models. The prograndng of the Maximum-Likelihood Method 1 s always special for each of the model version and needs more algebratc effort. Nevertheless for hlgher order models the Maximum-Ilkelihood Mothod is the wost accurate (E1g. 4).

\section{CONCLUSIONS}

The Extended Ralman Filter could not fulf1l an-1ine requiremante. In comparison with the Filter and a sophisticated crose-correlation analysis the Maximuin-Likelihood Mthod proved to be the nost accurate, but the analyeis with FIT and Direct Scarch is faster and needs not to be programed for every model veraica. Ident1f1cation of real human operators and the simulation showed that the Maximum-Likelihood Hethod and still the cross-correlation analye1s are powerful inatruments for englneering in huin factors even without restrictive nodels or conditions. Hore attention should be payed to ldentifyable multivariable models for the huna controller.

\section{REFERENCES}

1. Baron, S., Elkind, J. I., Levison, M. B.: "Application of Optimal Control Theory to the Prediction of Buman Performance In a Complex Task", Bolt, Beranek and Mewman Inc. MrDLI-IR-81 1970

2. K1rchhoff, U.: "Beitrag 2 ur Ident1fizierbarke1t des BBa-yodils und die Bedeutung des Hodelis als Beschrelbungsform der Arbeltawe ise des wenschen in teilautomatischen Flugfohrungssystemen" Dissertation, Technische Oniveretitat Berlin 1978

3. McRuer, D., Jex, H. R.: "A Review of Quas1-Linear P1lot nodel" IEEE Transaction onf Buman Factors in Electrontes vol He-8 No. 3,1967

4. Isermann, R.: "Prozesaldent1eikation", Springer-Varlag Berlin, Beldelbarg; New York 1974

5. Schrick, R. W.: "Anwendung der Ralman-F1lter-Technik" Oldenburg Verlag 1977

6. Stepner, D. E., Mehra, R.: "Maximum-Llkelihood Ident1fication and Optimal Input Deaign for Identifying Mircraft Stability and Control Derivatives", System Control Inc. UASA CR 2200 1973

7. Glover, R., W1llems, J. C.: "Parametrizatlons of Ilnear Dynamical systems" Canonical Forms and Identifyability" IEEE Transactions on Autsmat1c Control Vol. AC-19, No. 6,1974

8. Denham, M. J.: "Canon1cal Form for the Identification of Multivariable Linear Systems", IEDE Transactions on Automatic Control Vo. AC-19, No. 6, 1974

9. N1nz, N. R.: "Vergleichende Untersuchung von Ident1fikationsverfahren fur Regler-Mansch-Modelle". Inet1tut fur Llit- und Raumfahrt, Technische Universitgt Beriln, ILR-Bericht Nr. 48, 1980 


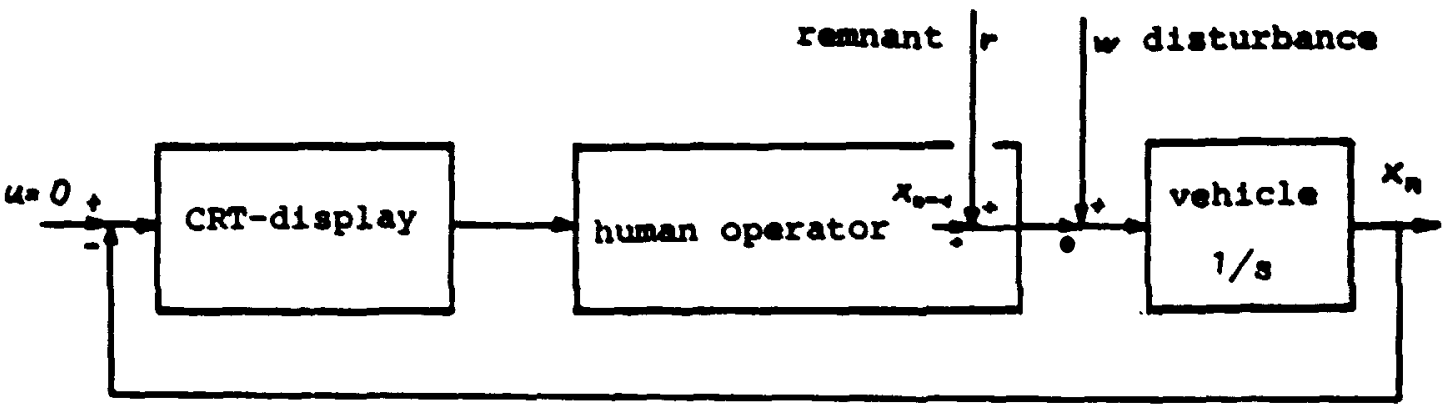

Figure 1: S1mulated man-machine-system

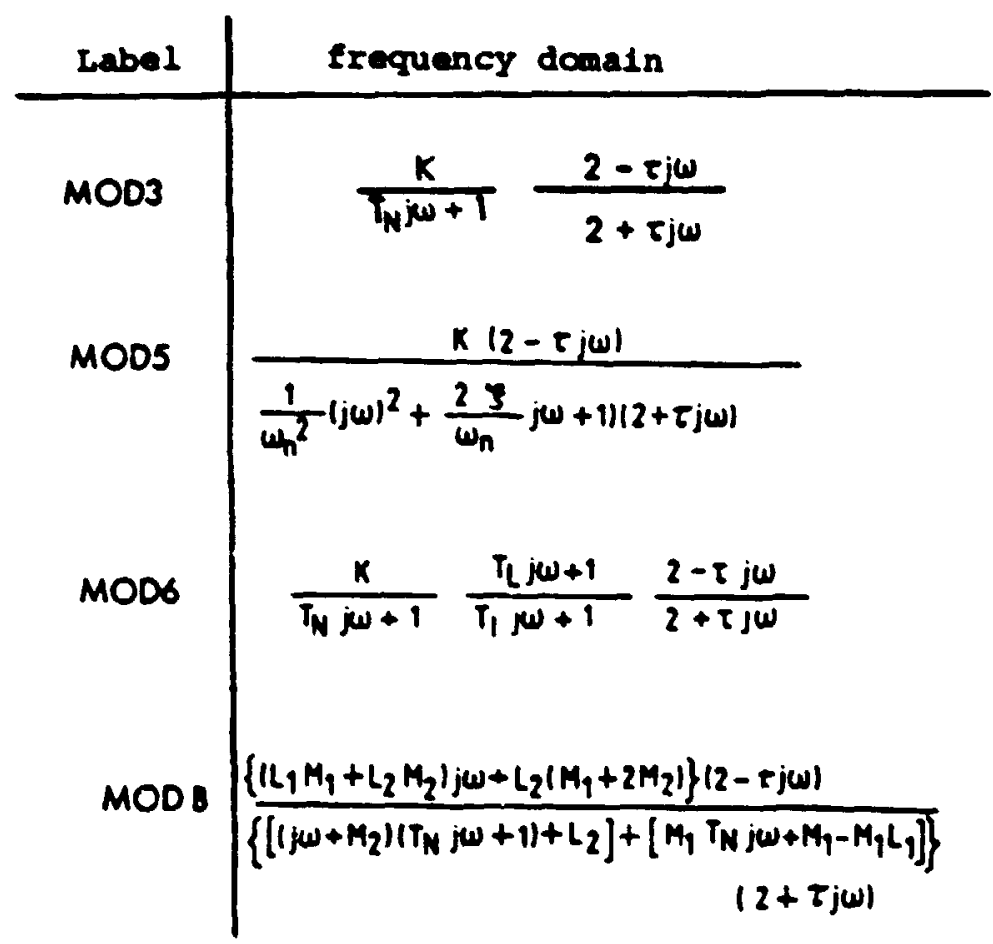

F1g. 2: Examinated versions of human operator models 


\section{ORIGINAL PAGE IS \\ OF POOR QUALITY}

\begin{tabular}{|c|c|c|c|}
\hline & & EKF3 & $\operatorname{MN} \times 3$ \\
\hline \multirow[t]{5}{*}{ Mean estimation error } & $\lambda_{r}=0 \%$ & $7,5 \%$ & 4,6 \\
\hline & $\lambda_{r}=5 \%$ & $24 \%$ & - \\
\hline & $\lambda_{r}=10 \%$ & $21 \%$ & - \\
\hline & $\lambda_{r}=20 \%$ & $29 \%$ & 3,7 \\
\hline & $\lambda_{r}=47 \%$ & - & 5,1 \\
\hline Computing time on CD 6600 & & Th 20 min & $\begin{array}{l}x w \text { sec for } \\
10 \text { Iteration }\end{array}$ \\
\hline core-requirements (k-words) & & 12 & 16 \\
\hline parameter for remant & & no & covartance \\
\hline required Starting valuas & & 9 & 4 \\
\hline
\end{tabular}

Fig. 3 = Comparison of the Extended Xalman Filter with Maximum-I1kel Ihood-Method

$\lambda_{r}=$ Nolse-to-signal ratio of remnant to controlled var1able 
ORIGIin? FrEE is

OF POOR QUALITY

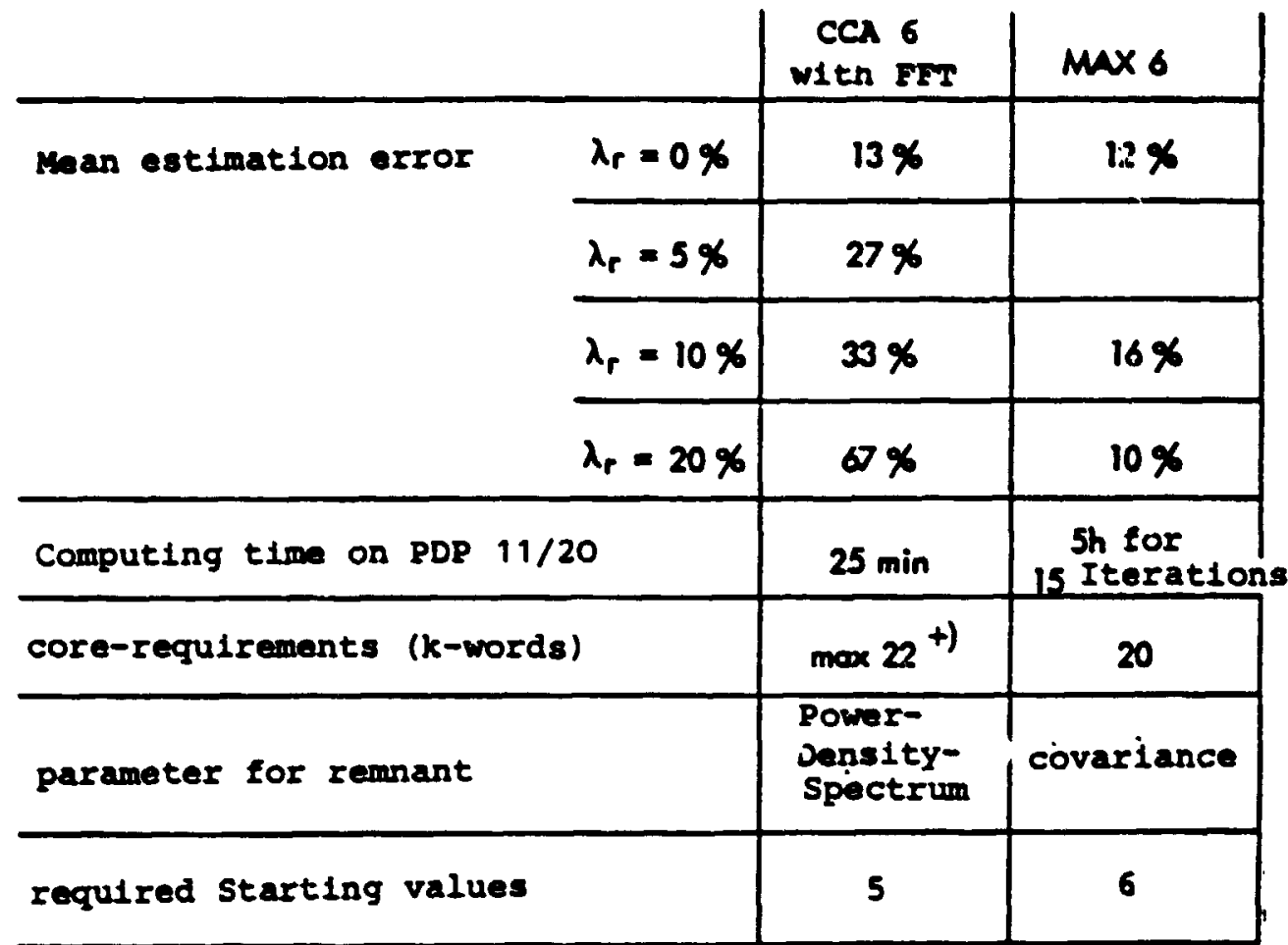

Fig. 4: Comparison of cross-correlation analysis via FFT and Direct Search approximation with Maximum Likelihood-method

*) Several programs are inttialized in sequence

\begin{tabular}{|c|c|c|c|c|c|c|c|}
\hline Program & $\hat{K}$ & $\hat{T}_{N}$ & $\hat{\tau}_{I}$ & $\hat{i}_{L}$ & $\hat{\xi}$ & $\hat{u}_{W}$ & $\hat{\tau}$ \\
\hline $\operatorname{Max3}$ & 2,4 & 0,23 & & & & & 0,11 \\
\hline $\operatorname{Max5}$ & 2,5 & & & & 1. & 16,6 & 0,18 \\
\hline $\operatorname{Max6}$ & 2,5 & 0,23 & 0,21 & 0,19 & & & 0,1 \\
\hline
\end{tabular}

51g. 5: Results of the identification runs on human operator data with Maxtmum-Likelihood-method 


\section{N82 34046 Iq}

A COAPUTER SImULATION APPROACh TO MEASUREgENT

OF HURAN CONTROL STRATEGY

Joenne Green, Esther Lee Davenport,

Harold F. Engler, Willian Z. Sears, III

Syatem Engineering La'oratory

Ingineering Experinent Ptition

Georgia Institute of Technology

This research hat involved the developent and testing of a paychologically-based computer simulation designed for mesurement of strategy changes during the learning of continuous control behavior. Strategy in task pertormance is believef py many to be an important determinant of the quality of performace. $, 2,3$ What comprises an individual's control etrategy? First, a defined in this research, it incl :des criteria for behaviorial output in various appects of the task. These criteria include subjective performance standards and criteria associated with the style of wotor sovements. Second, an individual's control strategr' guides criteris for perceptual input. This includes selective attention to certain enviromental cues. Finally, control stetegy dictates how attention is allocated to catal processes. This includes a sequence for those antel processes which wake high demands in mental resources, ald hence canuot be performed in parallel. In sumary, control strategy has been defined for this research as the set of paraweters deternining the functirning of wentel processes important in manual control.

It has been suggested that variation in control strategy is the means by wich the individual tailors hio behavior to the deand of a secific task. Thus, mesurement of control strategy could perwit identification of important individual differences ang trainees. Control strategy is sensitive to the nature of envirormental cues, and its measurement will allow better identification of the effects of these cues. This is especially important for the design of training simlator were the inclusion of a mininal set of critical cues can greatly increse cost-effectiveness.

The ain of the research is to weasure human control atrategy through use of a paychologically-based computer simulation wich reflec. broader theory of control behavior. The simlation is called the hunan operator perforance culator, or BOPE. HOPE was designed to enulate control learning in a une-dimensional preview tracking task and to meanure control strategy in that setting. When given a nunericel representation of a track and inforation about current position in relation to that trask, BOPE generates positions for atick controlling the cursor to be woved along the track. In other words, HOPE generstes control stick behavior corresponding to that which wight be used by a person learning preview tracking.

The basic organisation of BOPE is depicted in Figure 1. HOPE wa: designed to be consistent with the paychologicel litereture on wental processee in continuous control. Tor exemple, in BOPE there is distinction ande between ental processes wich dewand considerable wental rewources, wuch as perforence conitoring and evaluation, and thos's pro- 
CRIGLIVAL BES IS

OF POOR QUALITY

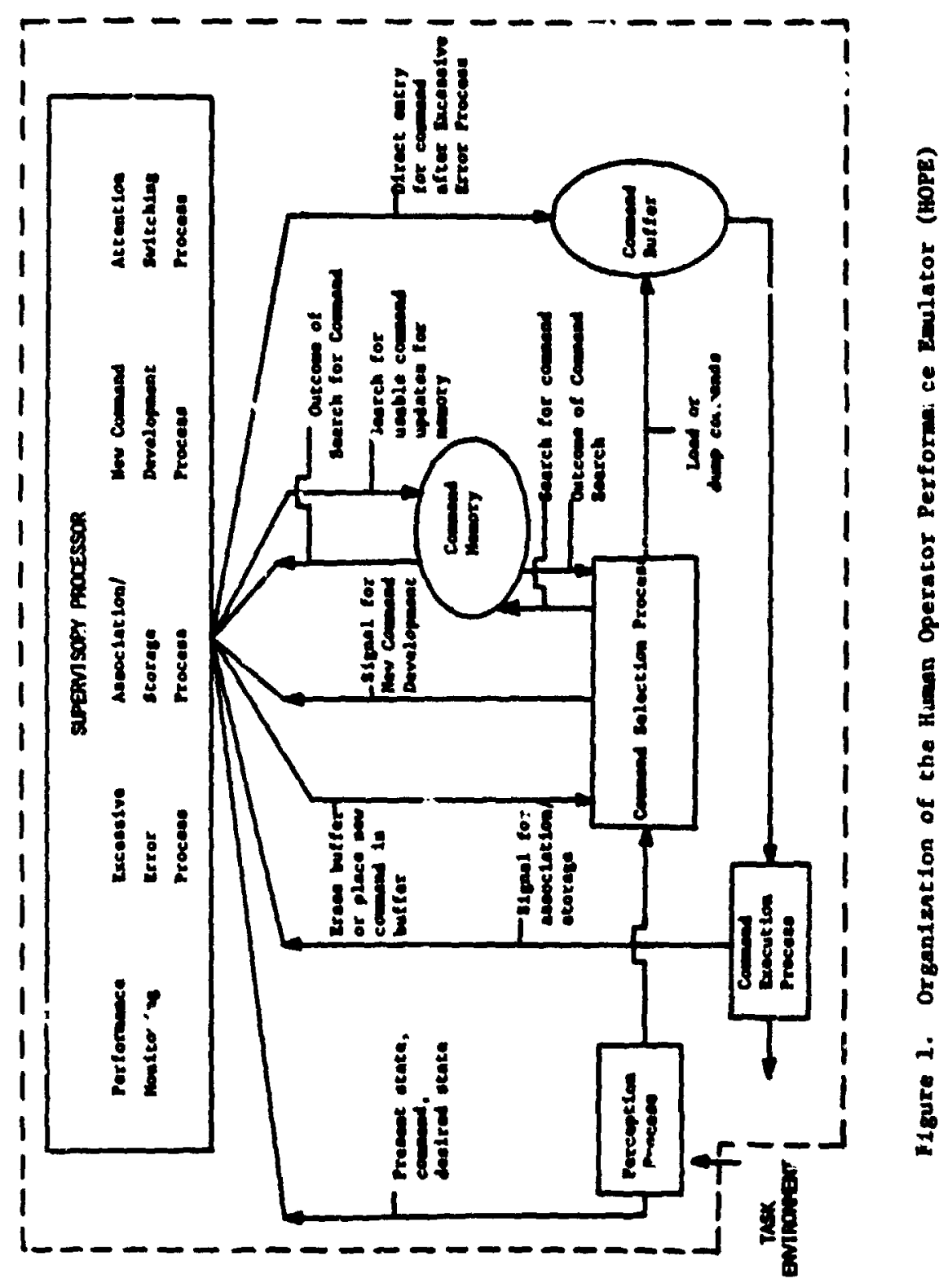


cesses which demand ninjal resources, such as executior of an already selected notor comand. In HOPE, processes believed to be mentally dewanding are perforwed by the Supervisory Processor in a serial fashion. Less deanding processes, such as comand execution or comand selection, the accessing of a stored wotor comand, are done in a core parallel fashion. HOPE improves its performance by building a Comand Menory descri. 'ng control stick positions apprupriate for soving between specific pai:s of cursor positions. This feature allows BOPE to model learning and to model control of bcth linear and non-linear control dynamics.

Control strategy is represented in BOPE's operation by control otrategy paraneters wich dictate how certain processes function. The current ROPE includes three sontrol strategy parameters: Comand Operative Tine, ERRLIH, and ADJUST. Colmand Operative Time, or COT, is an upper linis on the frequency with which ncs control stick positions are elected, and affects, for example, Comand Execution. It is rensitive to cues such so rrack frequency. Shocter Comand Operative Times are more appropriate for more quickly varying tracks, where position wust be changed aore frequent1y. ERRLIM, a subiective pariornance standard, dictates the mount of cursor position error allowed before drastic action is taken to reduce ponition error. ERRLIM's value, either large or amall, dictates whether the perforance monitor in HOPE judges perforance as acceptable. As ERRLIM grow larger, a larger posicion error is tolerated before ajor corrective action is taken. ADJUST, the third control strategy paraneter, helps ietecmine the agnitude of the corrective adjustaent caken in response to excessive error. A large ADJUST represents mre sggressive cosrective action.

These control atrategy parameters, Comand Operative Tine, ERLIh, and ADJST, represent aspects of huan contrcl atrategy in the learaing of ane-dimen inal preview tracking task. How is HOPE used to measure huan conirol stra. gy? Subjects are asked to perfore ane-dimenaional previev tracking task. Subjects ere asked to use a control stick to keep arsor on the center line of an apparently randomly curving track, scrolling down from the top of a screen. The cursor can be controlled only in the horizontal dimension, coving left and right. The plant dynamics are nonlinear, and allow first order, position control of the cursor. As the subject perfnras this task, his control stick position is recorded every 40 asec.

ROPE Operates on a numericel representation of the ane track as that followed by the subjects HOPE is run multiple tives, each tive using different set of coctrol strategy parameter values and generating a different pattern of control stick positions. Each run generates a HOPE model of human behavior and learning guidel by a particular control etrategy. Current testing isvolves generation of 100 -rodels of behavior using all of the possible combinations of five values of COT, five values of ERRLIM and four values of ADJUST (see Figure 2 ). 


\section{(.5 F. . R Qlintir}

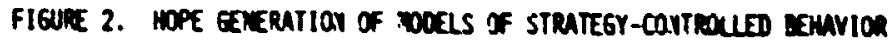

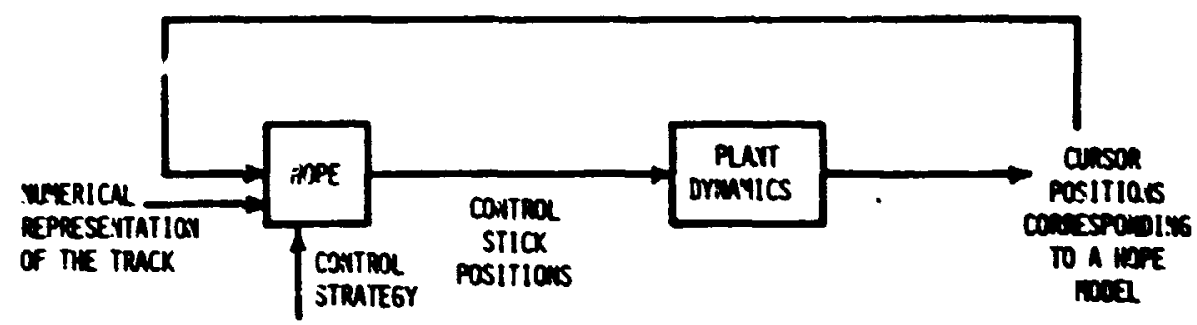

का (30, 120, 160, 200, on 240 nseC)

ERrein $(1.5,3.0,4.5,6.0$, on 7.5 (n)

ADUST $(1.2,2.4,3.6$, on $4.8 \mathrm{cs})$

Qumen control stick positions in a given time interral are watched against each nOPS sodel's control otick positions for that sam interval. The root eaen equare difference score is used to pick the BOPE codel which beat eatches huen behevior during that tim interval. The values of the coatrol etrat-gy paraneters codulating the KOPE nodel thet beet antches huan behavior are identified as the huan cootrol atrategy for that interval.

This approsch to mesuresent using BOPE has received some validacion teating, the res.lts of wich are quite encouraging. BOPE nodele are able to watch human control otick behavior renarkably wll. In preliaiaary and ongoing validation teats, BOPE nodels have succeeded in watching over 902 of the subject control stick behavior senerated within $10 \%$ of the control s:ick's range of motion. Figure 3 illuetrates the sinilerity of huen end MOPE control behaviors, as well as the ieprovement in eatching, when the control etrategy in BOPE is pernitted to vary. In addition to BOPE'. ability to watch huan behevior, the human control otrategies identified by BOPE have intuitive eppeal in view of treckins requiremente. For exsople, Figure 4 depicts the averages of the Comand Operative Tibes weesured for four subjects. These oubjects had five, three-ainute trials cracking a rando track with a he cut-off frequancy. Then they tracked five trials of a randon 4 se cut-off frequency track, followed by five trials on the wase Hz treck as they experienced earlier. Their masured Comand Operative Times are longer on trials with the Br track and shorter on trials with the $4 \mathrm{~Hz}$ track. These changes anke semse in viow of the aore apidly varying nature of the $\mathrm{Hz}$ track. 
Figure 3. Sample of control selck postelone ueed by a subject during tea tim blas of eracklas and those uned by (a) the BOPt codel which bestatches humen behavior durins each 2 sec clae bla, (b) those senerated by a single HOPE codel for he twe irawe tracked by the subject. The subject had experienced about 9.2 alnutes of tracking

a $1 / 4$ Hz cut-off frequeniy track when this sample was taken.
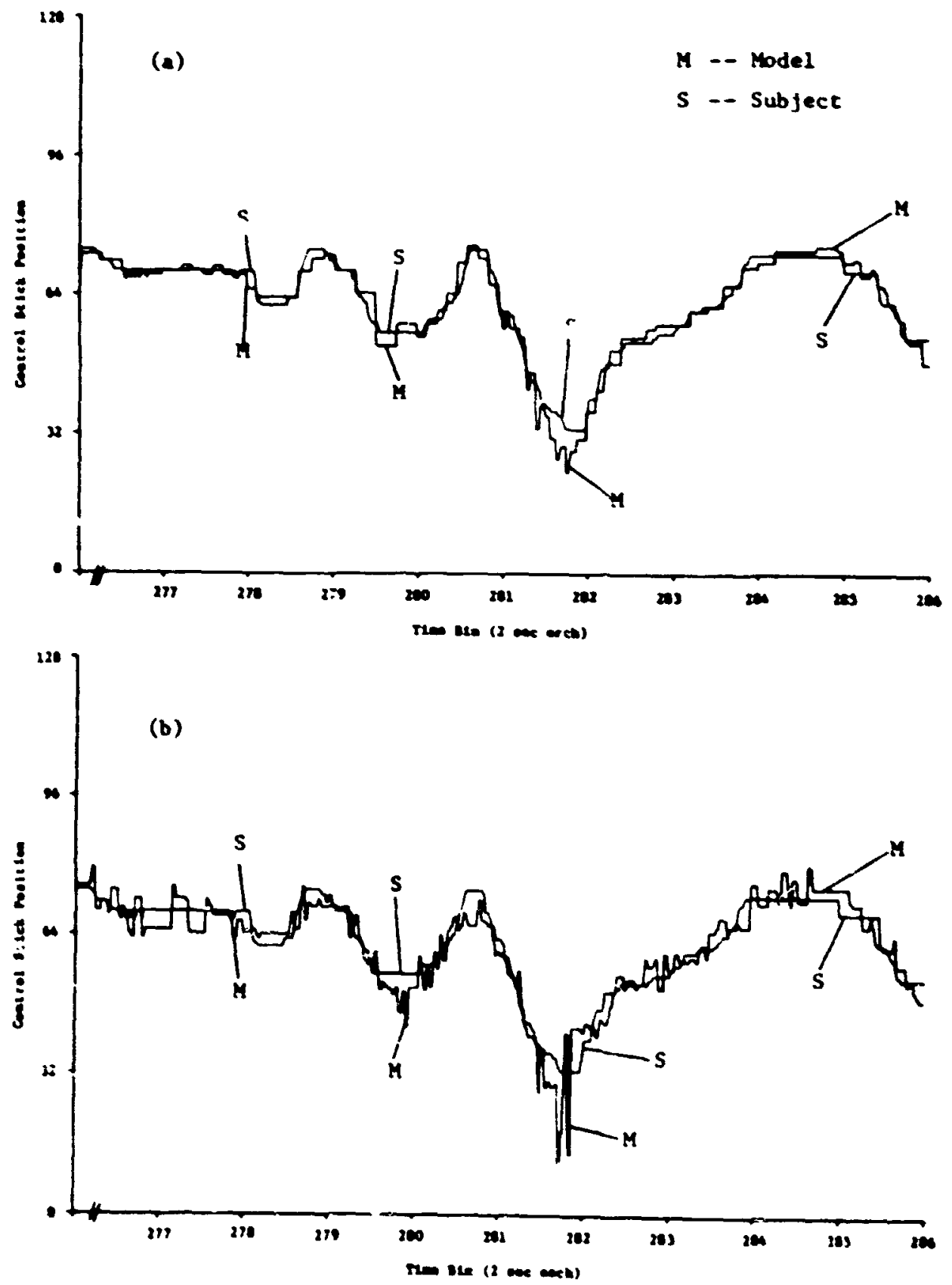


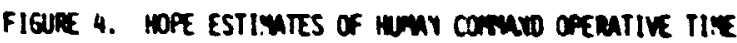

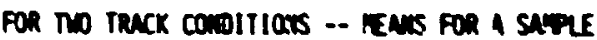

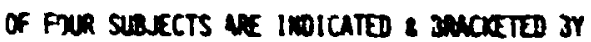

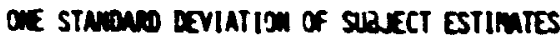
Amoun The rear.

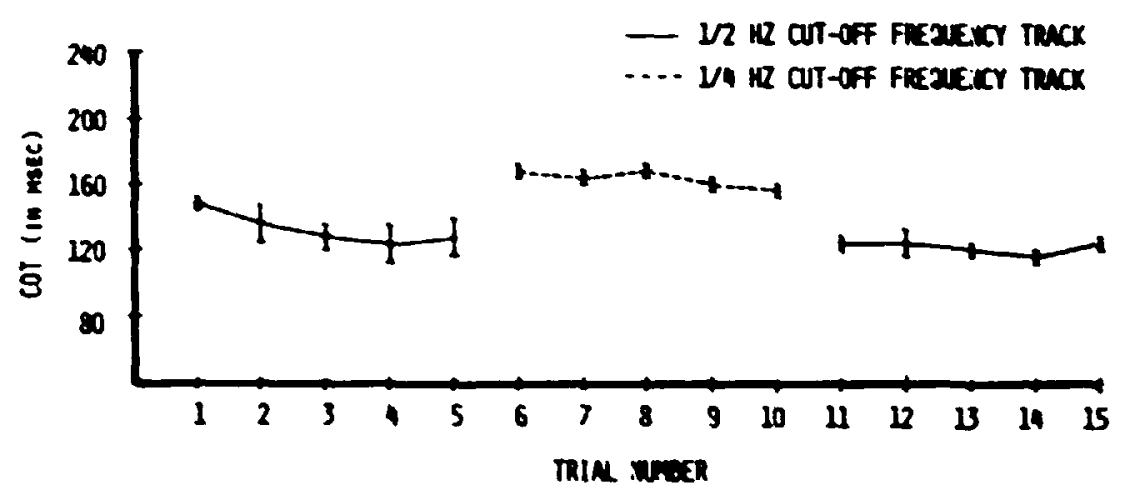

These results are encouraging and ungseat that BOPE can provide a useful supplesent to current eeseures of anuel control behavior. BOrE bas particular potential because it can masurs behavior in a variety of conditions for which curreat models vere not originally designed. In aew tracking environment, hopt begine vitb no data on the form of plant dyanics or on the external forcing function, but builds up a representecion of this knowledge from experience in the task iv way that is repreaentative of huan learning. Siace BOPt adels the leerning of control dyneacs, it can be used to masure the control otrategy of both trained and untrsi=s! operators. HOPE nodels previev tracking behavior, en important inatance of control behavior largely uneddreased by other current modele. Finslly, and nost important 1y, BOPE can model and wasure e rich, paychologically meaningful representation of human control etrategy. Meav"reant of control strategy through use of hOPE has great potentiel for trovias our understalding of the changes in behavior that occur durin, ning, for ll lowing us to describe individual differences in behevior, : aidias the design of effective training of control behavior, and for providing insight into how unobeervable mental procesese and etructures are operatiag.

\section{References}

1. Welierd, A. T. Fundamentals of Skill. London: Methuen c Company, Led., 1968.

2. Muray, $N$. The etrategic control of inforeation processing. In G. Underwood (Ed.), Straterien of Information Proceesing. Mew York: Acedenic Press, 1978.

3. Poulton, E. C. Tracking Skill and Menual Control. Mew York: Acedenic Press, 1974.

4. Rert, B. Troceseine deande during mentel oparations. Meory and Coraition, 1973, 1, 401-412. 


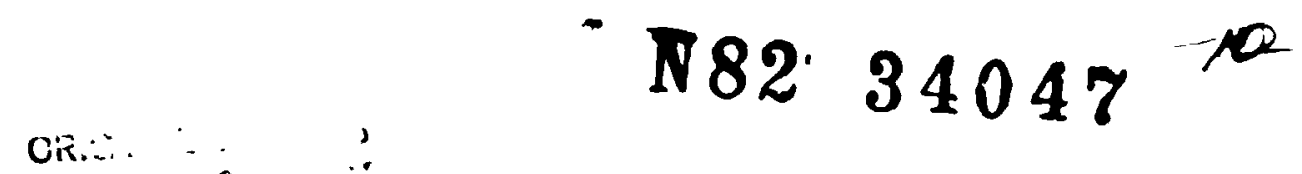

PILOT MODEL HYPOTHESIS TESTING

Joing R. Broussard

Information \& Control Systens: Inc.

28 Research Drive

Hapton, Virginia 23666
Paul W. Berry

The Analytic Sciences Corporation

Six Jacob Way

Reading, Massachusetts 01867

\section{ABSTRACT}

The optinal control codel of a huma pilot has been used in previous studies in an atterpt to sodel and understand a pilot's discretionary behavior in departure-prone maneuvering tasks for a fighter aircraft. When the pilot codel's internal model of the aircraft's dynanic response is different from the actual aircraft dynanics, pilot-aircraft instabilities can be pedicted that are very sinilar to observed piloting difficulties. This paper attenpts to verify the predictions and conclusions of the previous studies by rigorous analysis of the aircraft control tine history predi-ted by the optianl control pilot adel and actual pilot tracking date obtained from MASA Langley's Differential Haneuvering Simulator (Das). The analysis is perforned using a bypothesis testing schene nodified to allow for changes in the true bypothesis. A finite nuber of pilot models, each with different hypothesized internal wodel representations of the aircraft dyanics, are constructed. The bypothesis testing schene deternines the relative probability thot each pilot nodel best atches the Dus data. By observing the changes in probabilities, it is possible to jeternine when the pilot changes control strategy and wich bypothesized pilot wodel best represent's the pilot's control behevior.

\section{IPTRODUCTION}

When a pilot controls and monitors an aircraft, it is recognized ([1], [2]) that the pilot uses an internal nodel of the systen to deternine a control strategy. The assumpion of a perfect internal oodel appears to be satisfactory in any instances where the pilot has astered the skills necessary to execute maneuvers with precision. There are situations, however, in which the pilot's internal model can differ significantly fron the aircraft's dynamics. Examples of these situations include rapid maneuvering, which causes significant changes in the aircraft's angle of attack, and conponent fallures.

The optimal control pilot oodel is a comlex optial control systee which has beed shown to capture fundanental aspects of human operator control behavior ([3], [4]) and is constructed using a perfect anteral ondel of the system belag conirolled. Previous studies ([5], [6]) have investigated 
the use of the optial control pilot codal to investigate the effects of an interasl nodel arsatch by the pilot in an effort to predict pilotins difficulty. In [5] and [6], the effect of internal sodel variation vas studied along vind-up turn menver. The angle of atinci of the piloted aircraft lacreases significanty along the wind-up turn maeuver. Six resulte about pilot-alrcraft stability were obtained in the study: (1) The pilot nodel casily stabllized the aircraft througbout the abeuver using perfect internal sodel of the aircraft dynanics; (2) If the pilot coocl is contiolling the bare frane ${ }^{*}$ using only lateral and longitudinal stick, the pilotarcraft systea has a divergence instability (unstable sprial code) if the pilot wodel keeps a low $\alpha_{0}$ (below 12 des $x_{0}$ ) flight condition internal codel of the arcraft while the aircraft's actusl flight coadition exceeds 16 des $a_{0}$; (3) The pllot wodel can compensate for control difficulties beyond 16 deg $\alpha_{0}$ witbout changing the low $\alpha_{j}$ internal nodel by using lateral stick and pedals; (4) Difficulties can still occur beyond 25 des $a_{0}$ usine stick and pedals if the pilot codel keepa a low $a_{0}$ control stratesy; (5) If ooly pedals are used, no difficulties are encountered up to $30 \mathrm{des} \alpha_{0}$ when the pilot wodel keeps a luw $a_{0}$ interanal codel of the aircraft; (6) If a particular aileron-rudder interconnect systea is activated, the pilot-aircraft divergence instability is elininated, but the Dutch roll node can becone unstable. These results tend to agree with observed behavior of a huan pilot flying the aircraft with the SAS off.

The research reported in this paper atteapts to validate the approach used to investigate the above problew. Additionally, the use of the optinal control pilot codel to deternine wen changes in the internal nodel of the pilot occur is investigated. The wethod used to perfor the anolysis is a hypothesis testing scbere developed in [7] and [8] and outlined in the paper. For a finite number of pilot nodels, each with a different bypothesized internal sodel of the aircraft, the bypothesis testing schene deternines the relative probability that each pilot nodel best anches recorded pilot data. The changes in probability give an indication of the pilot's actual adaptive control procedure.

The pilot data used in the bypothesis testing schene is obtained from one MASA Langley pursuit-tracking simulation using their Differential Maneuvering Simulator (DHS). The Dis consists of an enclosed hemispberical screen within which a pilot sits in a cockpit mock-up. The pilot views computer-controlled display of a tracking situntion on the screen. The pilot generates control comands which drive the nonlinear computer nodel of the arcraft. The compter portrays the resulting aircraft cotions on the screen as rewed by the pilot.

The pilot nodel bypatbesis testing schene discussed in the paper is very general art is not restracted to investigating situations where the pilot model s internal wodel varies. Any situation in which there is wore than one chorce for pilot adel paraneter can be tested to determine which

\footnotetext{
FThe stability augentation systea (SAS) is off and an aileron-rudder interconnect systee (ARI) 23 not operating.
} 
pilot model best antches ae data. This capability is also demonstrated in chis paper using differer. chorces for tie optimal control pilot nodel's cost function quadratic weights.

\section{OPTIMAL CONTROL PILOT MODEL}

This section briefly reviews the elenents of the optinal control pilot model to be used in hypothesis testing. The optimal control pilot wodel for which detailed athentical development can :e found in [5] is based on the preaise that a notivated, well-trained human controls a systea optially. To construct the pilot oodel, the assumptions needed to specify an optinal controller are formulated, then nodified to reflect basic huma characteristics and linitations. The hypothesis testing scheme requires an analytic pilot model, hence, the pure time delay in the optial contrcl nodel representing the huan's lumed time delay is replaced by its Pade approximition. The straightforward solution for the optial control pilot nodel with the Padé approxiation is given in [9]. A block diagran is shown in Fig. 1. The antheatical representation is

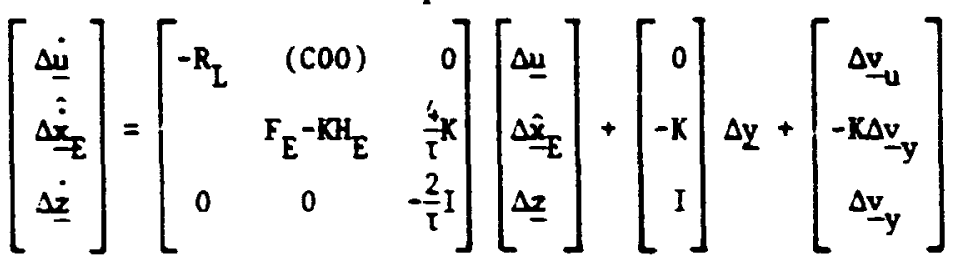

The n-vector, $\Delta x(t)$ in Fig. 1, represents the perturbation aircraft dynanics, arcraft sas states, tracking error states, and target states for which a more detailed discussion is given later. The aircraft's stick inputs are represelued by the a-vector $\Delta u(t)$; $w(t$; represents white Gaussian noise disturbances affecting the aircraft oodel dyanaics as perceived by the pilot. The pilot's observations, $\Delta y(t)$, are degraded by zero aean white Gaussian nolse, $\Delta v_{y}(t)$, then processed by a lead-lag network which is a Pade approximation to the pilot tine delay. The resulting signal is tie measurement vector for the pilot adel's Kalman filter which generates a best estiate $\left(\Delta \hat{x}_{-} 10(1)\right)$ of the states controls, and lagged observation states. The state estimate component of $\Delta_{\bar{F}_{E}}$ is aultiplied by the pilot model's state

feedback atrix, $C$, to form the pilot model's interaal control comand, Au $(t)$. A special quadratic cost functional is used to find the linear-optial regulator gan C. The comand is corrupted with additive, zero-mean white, Gaussian nolse, $\Delta v_{y}(t)$ which together for the input to the neuronuscular dynanics model which represents the huan's neuromotor bandwidth linitation. The output is the pilot model's aircraft control, $\Delta u(t)$ which drives the alreraft model's control actuators. The matrix, $K$ in $(1)$, is the pilot model's Kalman filter gain. The filter gain, $K$, depends upon input $s i g$ al levels, neuronotor nosse levels, and observation nosse levels; the latter are related to the former by constant noise-to-signal ratios. The atrices $K$ and $C$ are fetermined by solving Riccati equations which depend on the pilot's internal description of the aircraft. The pilot model is unadapted when the internal aodel description of the arrcraft used to determine the piln: model is not the sane as the matheantical model of the arcraft at the flight condition under iavestigation. 


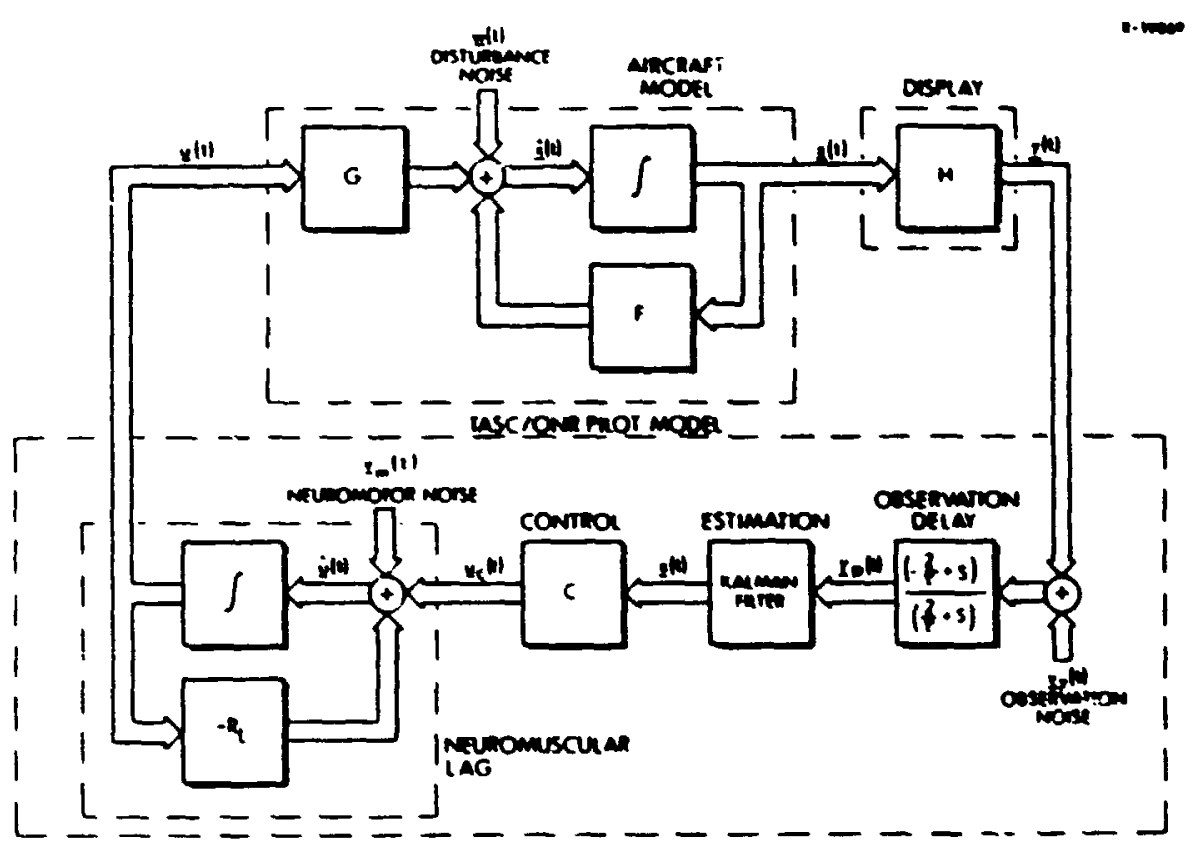

Figure 1 Block Diagran of the Pilot Hodel Containing the Padé Approximation to Pure Tive Delay

In order to use (1) in hypothesis testing, discrete tine representation is required. Assuniag that a sapling intervel, $\Delta t$, is chosen small enougb so that $\Delta y$ is essentially constant over the interval, the discrete representation of the pilot sodel is

$$
\Delta \underline{x}_{k+1}=\phi_{P M} \underline{x}_{k}+r_{P M} \Delta \underline{y}_{k}+\Delta \underline{w}_{k}
$$

where

$$
\begin{aligned}
& \Phi_{P M}=e^{F_{P H} \Delta t} ; r_{P M}=\int_{0}^{\Delta t} e^{F_{P H} t} d t K_{P H} \\
& \underline{\Delta x}^{T}=\left[\underline{\Delta u}^{T}, \underline{\Delta \underline{x}^{I}}, \underline{\Delta z}^{\mathrm{T}}\right] \quad ; \quad \mathbf{R}_{\mathrm{PH}}^{\mathrm{T}}=\left[\begin{array}{lll}
0 & -\mathrm{K}^{\mathrm{T}} & \text { I }
\end{array}\right]
\end{aligned}
$$

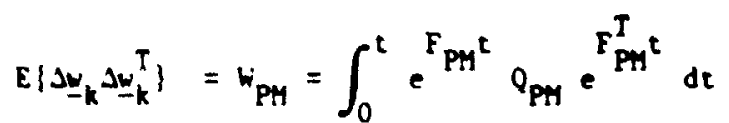


ORIC:a- - : : : :

OF POCii i c.... $\because:$

The matrix $F_{P H}$ is the systed astrix in (1) while $Q_{P H}$ is the covariance of the nolse vector driving the dynanics in (1).

\section{HYPOTHESIS TESTING}

The hypothesis testing philosophy for investigating pilot control adaptation in flight is to construct auber of pilot adels, each using different internal models, and then determine which pilot model best represents the actual pilot control behavior. The hypothesis testing procedure, illustrated in Fig. 2, is based on adel structure identification algorith (see [i] and [8]) modified to allow for changes in the true hypothesis.

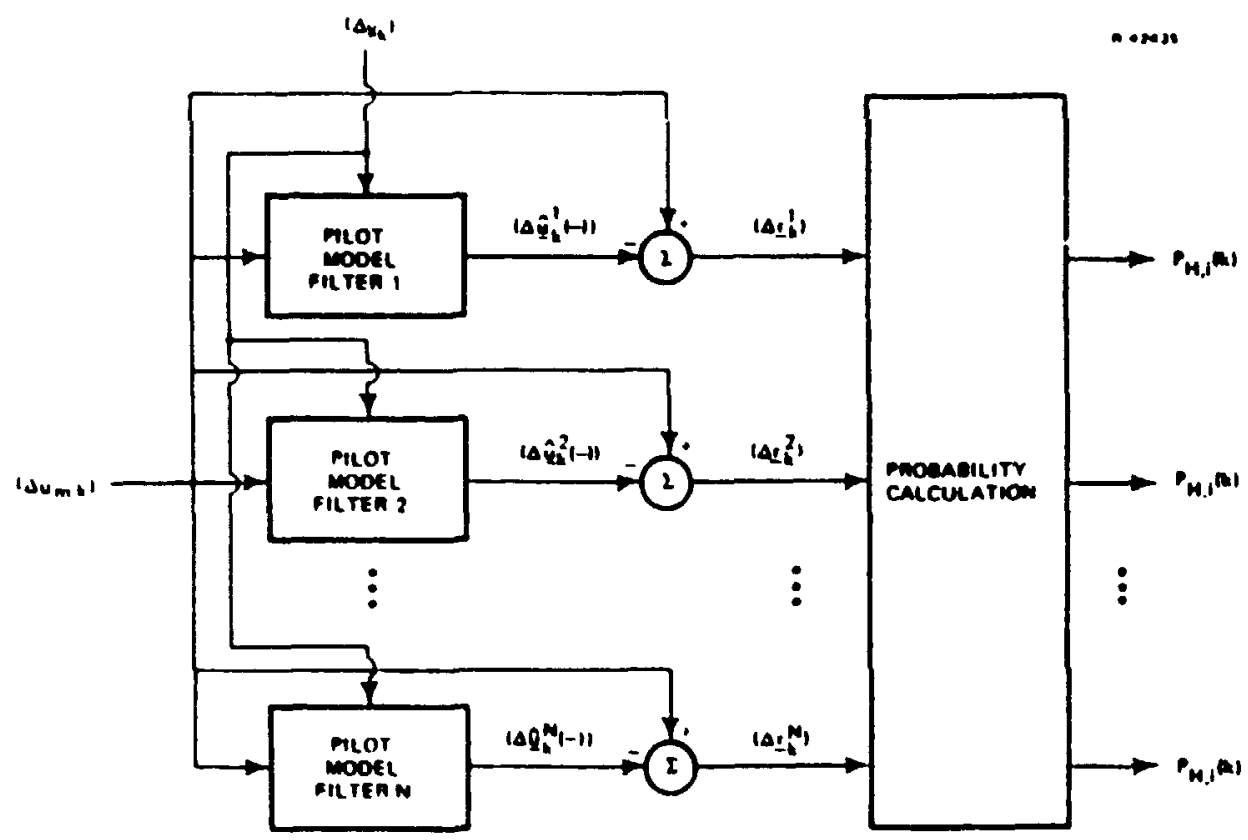

Figure 2 Kalman Filter Approach to Pilot

Control Strategy Hypothesis Testing

The notation used in the figure is as follows:

Du,k: aesured value of pilot perturbation control it $t_{k}$

$\Delta y_{k}$ : measured values of perturbation states assumed observed by the pilot 


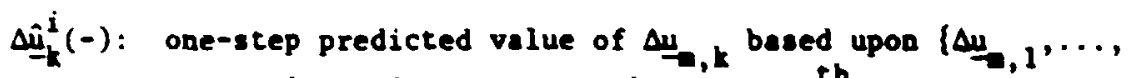
$\Delta u, k-1\}$ and $\left\{\Delta y_{1}, \ldots, \Delta y_{k-1}\right\}$ for the $i^{\text {th }}$ pilot wodel ralma fijter

$\Delta \underline{r}_{k}^{i}$ : one-step predicted residual at the $k^{\text {th }}$ step for the $i^{\text {th }}$ pilot model Kalman filter

$P_{H, i}(k)$ : probability that the $i^{\text {th }}$ pilot sodel is best, based upoo knowledge of $\left\{\Delta_{-}, 1, \ldots, \Delta u, k-1\right\}$ and $\left\{\Delta \underline{y}_{1}, \ldots, \Delta \underline{y}_{k-1}\right\}$

Mathenatically, the bypothesis testing schene is inplemented by viewing each pilot odel represented in (2) a a dyanic syste whose input is the pilot observation vector, $\Delta y_{k}$, with process noise, $\Delta y$, , and whose measurement output vector is the actinl measured pilot control (a) vector,

$$
\Delta_{\mathbf{u}, k}=\left[\begin{array}{lll}
1 & 0 & 0
\end{array}\right] \quad \Delta \underline{x}_{k}+\underline{v}_{k}
$$

$\underline{v}_{k}$ is a zero-mean gaussian eeasurement noise with covariance $v$. The $i^{\text {th }}$ pilot model Kalma filter shown in Fig. 2 using the $i^{\text {th }}$ pilot wodel as the plant and the control measurements as the observation vector is constructed

$\mathbf{a s}$

$$
\begin{aligned}
& \Delta \underline{\hat{x}}_{-k}^{i}(+)=\Delta \hat{\underline{x}}_{-k}^{i}(-)+k_{u}^{i}\left[\Delta_{-k}-\Delta \hat{\underline{u}}_{-k}^{i}(-)\right] \\
& \Delta_{\hat{x}_{k+1}}^{i}(-)=\phi_{P H}^{i} \Delta_{-k}^{i}+\Gamma_{P H}^{l} \Delta y_{k} \\
& K_{H}^{i}=P^{i}(-)\left[\begin{array}{l}
I \\
0 \\
0
\end{array}\right]\left\{\left[\begin{array}{lll}
I & 0 & 0
\end{array}\right] P(-)\left[\begin{array}{l}
I \\
0 \\
0
\end{array}\right]+V\right\}^{-1} \\
& P^{1}(-)=\phi_{P M}^{i} P^{i}(+) \phi_{P M}^{i T}+w_{P M}^{i} \\
& P^{1}(+)=\left[\begin{array}{lll}
I & -x_{H}^{i}
\end{array}\left[\begin{array}{lll}
I & 0 & 0
\end{array}\right]\right] P^{i}(-)
\end{aligned}
$$

In this application, the above Kalman filter is assumed to be in steady state. If the $1^{\text {th }}$ pilot model is correct, the filter residuals

$$
\Delta \underline{r}_{k}^{i}=\Delta \underline{u}, k-\Delta \underline{u}_{k}^{2}(-)
$$

are a zero-mean white gaussian nolse sequence with covariance 


$$
E\left\{\underline{\underline{r}}_{k}^{2} \underline{\underline{r}}_{k}{ }^{I T}\right\}=\left[\begin{array}{lll}
I & 0 & 0
\end{array}\right] \quad \mathrm{P}^{i}(-)\left[\begin{array}{l}
I \\
0 \\
0
\end{array}\right]+V=s^{i}
$$

If the pilot model is not correct, then $\Delta \mathbf{r}_{x}^{2}$ any not be a white gaussian norse sequence and does not satisfy (13). The pilot aodel Kalman filter just described is not to be confused with the lncernal Kalman filter in the pulor wodel.

For notational purposes, let

$$
U_{k}=\left\{\Delta u_{-1}, \ldots, \Delta_{t}, k\right\}
$$

Applyag Bayes' rule, it is shown $1 \mathrm{n}$ [8] and [9] that one can write:

$$
P_{H, i}(k)=\frac{P\left(\Delta \Delta_{-2, k} \mid H, i, U_{k-i}\right) P_{H, i}(k-1)}{\sum_{i=1}^{N} P\left(\Delta_{-a, k} \mid H, i, u_{k-1}\right) P_{H, i}(k-1)}
$$

Using the fact that $\Delta_{-k}$ is assuned to be a zero-mean gaussian sequence, along with the assuption that the Kalan filter state vector $\left[\underline{\Delta u}^{T}(-), \Delta \hat{x}_{E}^{\Lambda}(-)\right.$, $\left.\Delta x^{T}(-)\right]^{T}$ is also gaussian, it follows that

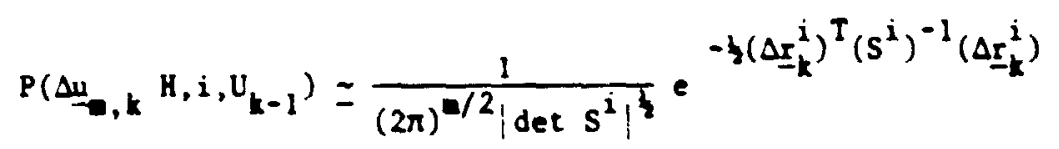

At each tiae interval, the measured pilot control is used to compte the residual in (12). The residual and (13) are used to compute tbe probability in 116). The probability is used in (15) to recursively update the probabilaty that pilut model 2 best matches the data. The residual and measured values of states assuned observed by the pilot are used to update the kalman filter in (7) and (8) and the process is repeated with the next control mesurement.

The solution to the probled of computing the $\mathrm{P}_{\mathrm{H}, 1}(\mathrm{k})$ when the true hypothesis changes with ine is given in $|10|$. Under certalo siaplifying assumptions at can be shown that the solution requires $\mathrm{N}^{2}$ parallel filters to discriniale between the $N$ possible hypothesis at ang given time. Since this may impose an excessive computational burden, on efficient suboptimal approach to ihe problea is developed in [8]. The suboptiand approach is nearly optial in situations where the probability of switching hypotheses at any given tiae is low. The suboptieal approach is derived by noting that 


\section{ORIGINAL PAGE IS \\ OF POOR QUALITY}

if the $i^{\text {th }}$ pilot model is true then the recursive salculation in (15) causes $\mathrm{F}_{\mathrm{H}, \mathrm{i}}$ to approach 1 . If $\mathrm{P}_{\mathrm{H}, \mathrm{i}}$ should equal one, it will remain "trapped" at one regardless of changes in the pilot's control strategy. To prevent this, each probability is checked at each time instant to determine if it has fallen below some minimum value $\varepsilon$. If any probabilities are saller than $\varepsilon$, they are reset to $\varepsilon$ and the other probabilities are suitably wodified so that they all sun to one. This procedure can be inglenented with only Narallel filters. Results presented later in this paper, usirz $\varepsilon=0.05$, indicate that this suboptimal procedure is effective in detecting changes in the true hypothesis.

\section{FLIGHT TEST SELECTION}

The simulated flight test selected for study in a wind-up turn tracking task implemented on the NASA-Iangley Differential Maneuvering Simulator (DMS). The pilot is instructed to track a target aircraft which is displayed on a large hemi-spherical screen, within which the cockpit is nounted. A sky-eartb representation is also displayed. The target aircraft's trajectory is prestored. There are no intentional disturbances affecting either the target aircraft or the piloted aircraft, although the prestored target trajectory exhibits rapid and continuous aneuvering. The pilot is flying a complete nonlinear computer nodnl of a high performance fighter.

The pilot is instructed not to use rudder pedals. Lateral-directional control by the pilot is accomplished using only lateral stick. The simulation is perforwed with the pitch and yaw SAS ope:ational, although the roll Comand Augmentation System (CAS) is off. The yas SAS improves the lateral-directional stability of the aircraft at high angles of atteck. This means that the stability boundaries of the bare-aircraft deternined in [5] and [6] cannot be used directly to evaluate pilot perforance and the performance of the bypothesis testing scheme. The SAS states also have to be included in the aircraft model increasing the dimension of the problea.

The view through the cockpit which is useful in constructing the tracking error equations $1: 3$ shown in Fig. 3. The vertical and lateral conponents of tracking error are $\varepsilon$ and $\varepsilon$, respectively, which the pilot can directly perceive. The difference betheen the pilot's fixed pipper and the aircraft's velocity vector are the angle of attack, $a$, and sidesip angle, $\beta$, which the pilot cannot directly perceive. The difference between the arcraft's stability-axis roll angle, , and the stability-axis roll angle of the target, ${ }^{\prime}$, is $\delta \phi_{y}$ and is directiy perceived by the pilot. The pilot does not have any motion cues. Any computational time delay in the DiS between the pilot's stick movement and changes on the screen is assuned to be small and is not modeled in the analysis. A complete record of the aircraft state and control histories is recorded at 32 saples per cecond. Additiona: $1 y$, the tracking angles and range to the target are recorded, and carg-c motion is inferred from these measurenents. The aircraft measuremen:s are computer generated and togather with the pilot's control movenents have virtually no measureme.t noise. This implies that $V$ in $(6)$ is zero and the process noise in (1) contains no contributicn from possible measurenent noise errors in $\Delta y$.

The wind-up tum tracking task lasted $30 \mathrm{sec}$. At $50 \mathrm{sec}$ into the run, the pilot is forced to saturate lateral stick almost continuously in order to contiaue tracking. Because of this, only the first $40 \mathrm{sec}$ of the 

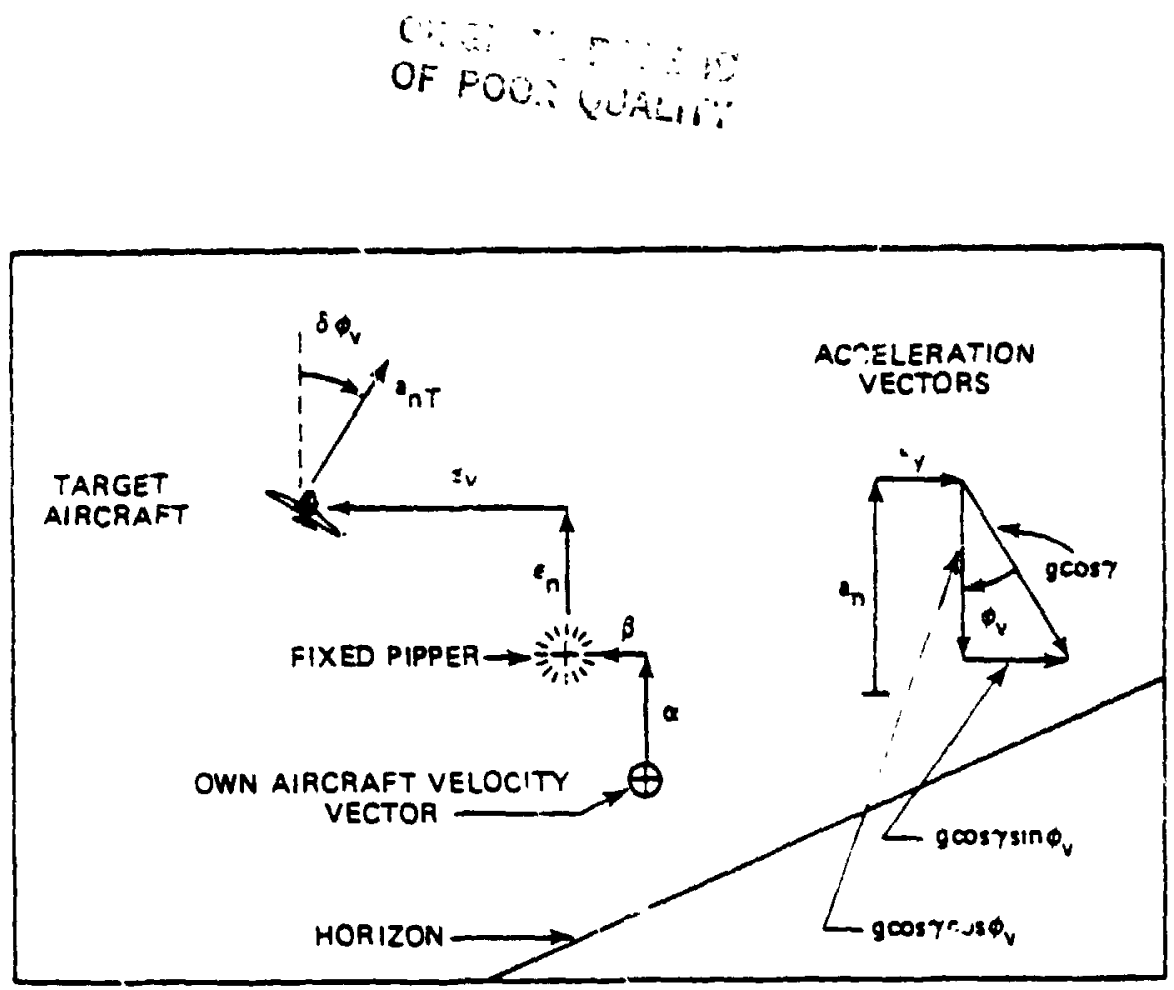

Figure 3 Pursuit-Tracking Task View Through the Cockpit

run are analyzed. Only the lateral-directional jynanics are investigated with the pilot aodel.

Variations of angle of attack are shown in Fig. 4 for the 40 . . interval. The aircraft remins at a low angle of attack flight condi-1on for the first 10 seconds. then the aircraft angle of attack increases to a caximun of 21 deg as t.ne aircraft enters the wind-up turn. Using the aircraft time histories ;hown in Fig. 4. the pilot nodel hypothesis test can be well posed: when the angle of attack of the aircraft increases beyond 5 deg, significantly changing the aircraft's dpaam:-s, does the pilot's control behavior reasin fixed to a 5 deg $\alpha_{2}$ strategy or does the pilo change his strategy to match the aircraft's filanging dynamics? To begin answering this question, the modei of the aircraft-target dynamics and the pilot model paran." eters are presented in the next two sections, respectively.

\section{TRACKING TASK MODEL}

The tracking task aocel is composed of four components at the aduptation point; the linearized dynanics of the subject aircraft, the SAS dynanics, the linearized tracking error dyanics, and the linearized target nodel. A derivation of the nodels is presunted in [9]. A sumarv of all the linearized models is given in Table 1.

The tracking task model is typical of air-to-air comat models 125 cussed in [11] ano [12]. In both referen' is the aircraft models ale ... ap... fled linear tine-invariant longitudinal dynanics impiemented or simuis" $\because$. Simple target dynames art used both in the simulation an: ae model. ir. 

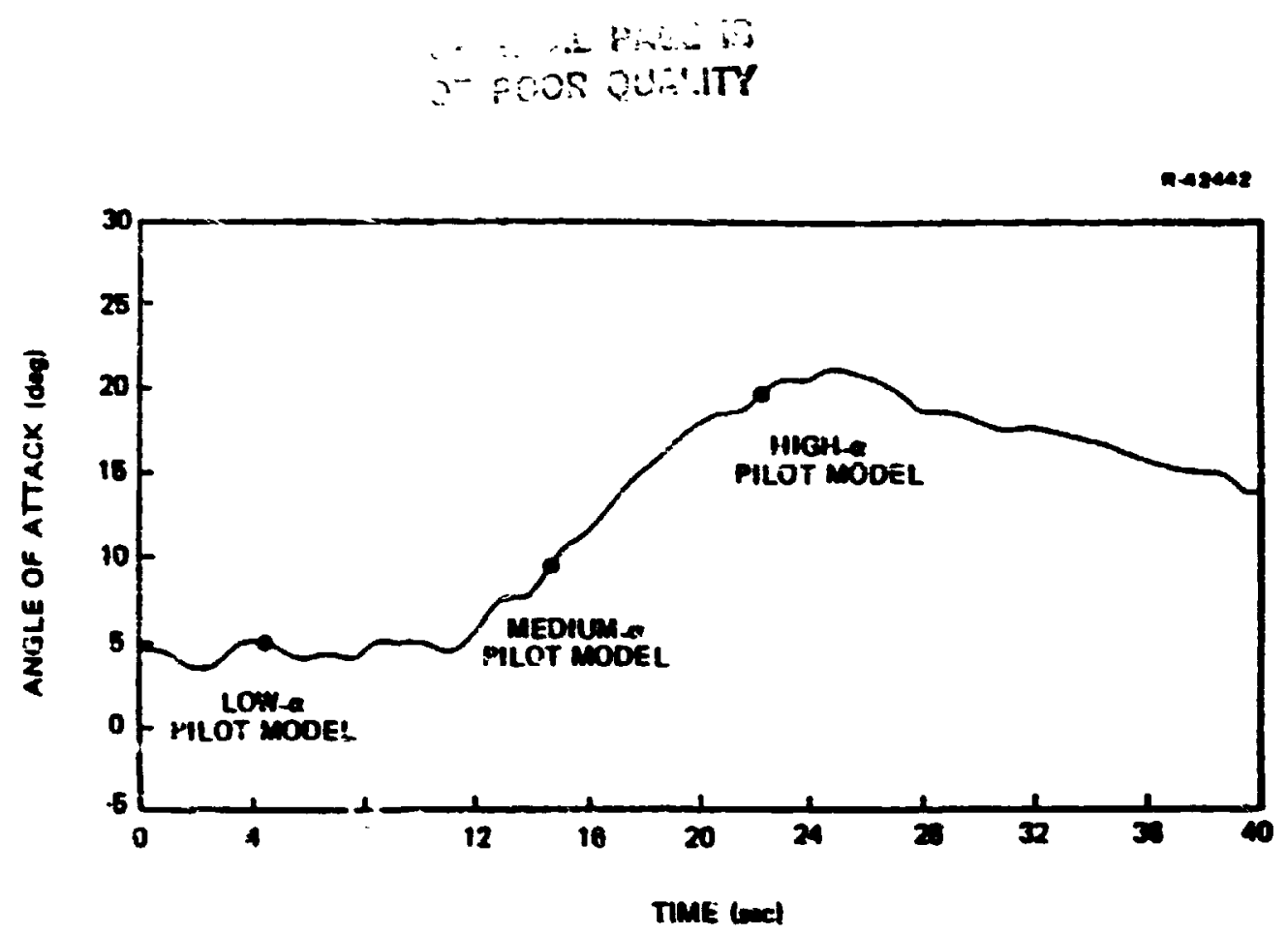

Figure 4 Angle of Attack Tine Histo.y

this case, the $\cdot$ of the complete target aircraft nodel (another fighter aircraft) in the tracking task nodel is infeasible. An approximation wheraby oriy the target aircraft states $\Delta p_{\text {. }}$ and $\Delta$ are nodeled in the tracking tusk model is ande. Unaodeled target tyanits are lunped into a zero mean geufsian ncise ter $\Delta$, wich drives Ap, as shown a 4, Table 1 . The inplication is that the bunan bas no explicit information about the dyaancs driving $\Delta p_{w T}$ and 2 lso regards the effect os white noise. The paraneters in the sipp-

lified target nodel in Table 1 are deternined by identification based on measured values of $\mathrm{vT}$ as discussed in [9]. The values used are $a_{1}=-4.4$, $a_{2}=1.6$ and $E\left\{w_{T}^{2}\right\}=4.0\left(\operatorname{deg}^{2} / \sec ^{2}\right)$.

\section{PURSUIT TUACKING PILOT MDDEL PARAMETERS}

The paraneters yer to be spacified at this point are the pilot observations, the flight conditions, a choice of tie pilot model's quadratic state weighting atrix and the standard paraceters of the pilot model. The flight conditions are priori specifications of eircraft-target dynanics along the aneuver under investigation at which the pilot ay fortulate a control strategy.

From Fis. 3, the pilo: observations are the lateral error, $\Delta$, , and

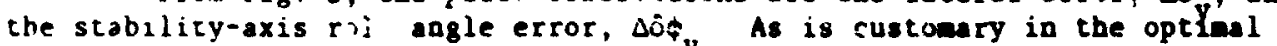
contro! wodel, the rates of these states ar" also assueed observed. Fron 


\section{L. . . i}

TABLE 1

LIMEARITTD TRACKING WODEL DYNAMICS

\begin{tabular}{|c|c|}
\hline 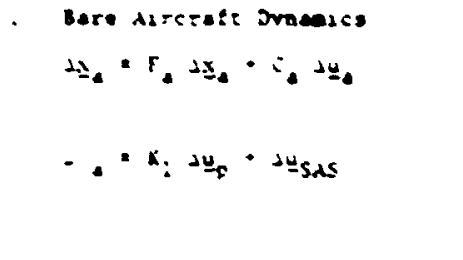 & 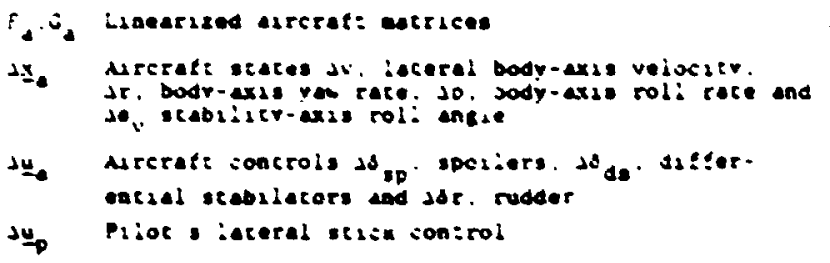 \\
\hline 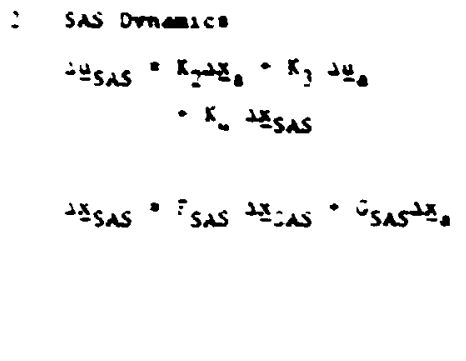 & 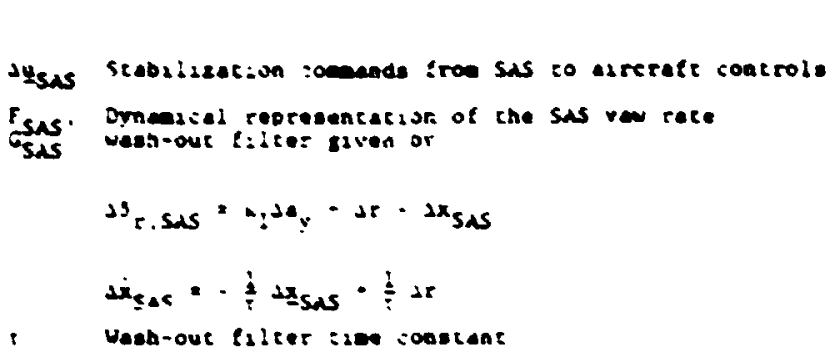 \\
\hline 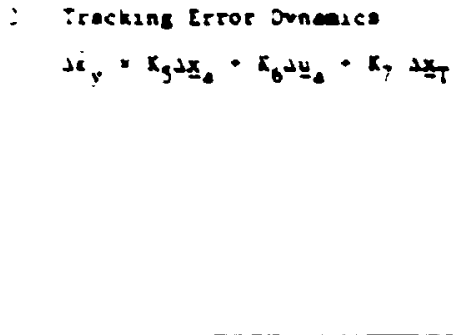 & 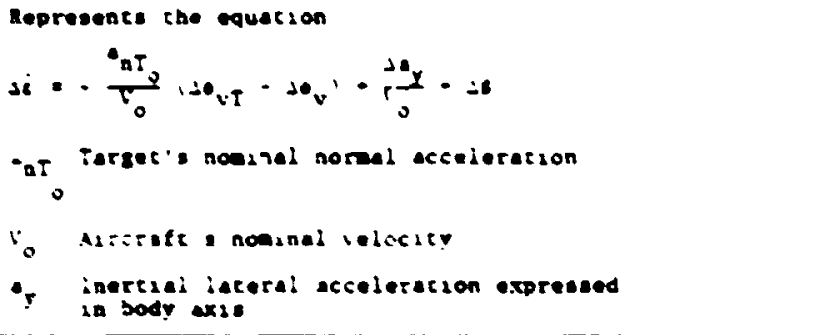 \\
\hline 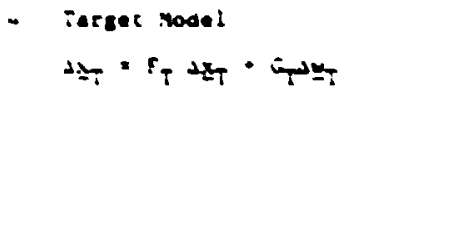 & 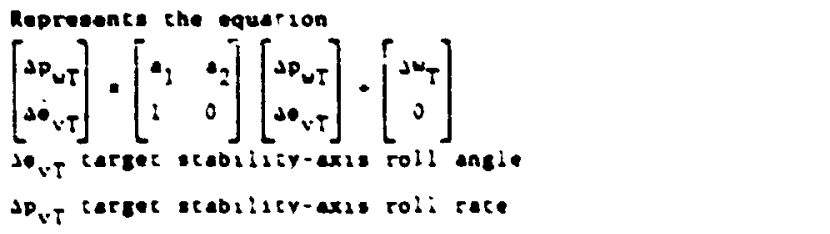 \\
\hline
\end{tabular}

Fig. 4, three :light conditions which primarily differ in angle of attack are chusen to form the p.lot's internal model: low ( $\sigma_{0}=5.2$ des), nediun, $\left(a_{0}=9.3\right.$ deg $)$ and high $\left(a_{0}=19.2\right.$ des $)$.

The quadratic cost function weights used to construct the pilot model quantify the pilot's tradeoff of tracking error and control effort. High weights imply that the pilot expends significant control effort in order t)iniaize tracking error. He can be ias to be "bigh-gain" or "tight" pilot. On the other hand, low quadratic weights typify "low-gan" or "lonse" piloting cechnique. The specitac values for the state quadritic weights used 10 . Te cests reported here are given in Table 2 . The tracking error rate weight in the plot nodel's cost function 1 s chosen to be oneiourth of the iracking error weight, as suggested in Ref 11 . Based on plots 
of these states during the anouver, laterai velocity is wighted and

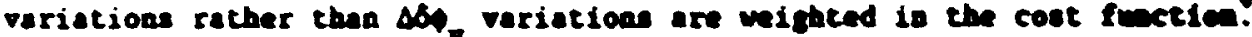
At the low $a_{0}$ and eediu $a_{0}$ flight cooditions io Table 2 , a bigh wight.

cost function (2), and a Low wight, cost function (1), are spacified. Ine rest of the pilot codel paranters are standard (huna percepiul tiv daley of 0.2 sec, nem romenculer tin constant of 0.1 sec, obeervation soles to sigan ratir if $-20 \mathrm{db}$ and a surcotor noise to sigal ratio of $-30 \mathrm{~b}$ ).

TANT 2

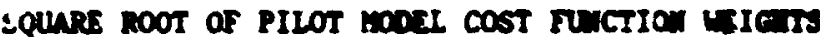

\begin{tabular}{|c|c|c|c|c|c|}
\hline $\begin{array}{l}\text { AIRCRATT } \\
\text { AHEE OF } \\
\text { ATTACT }\end{array}$ & $\begin{array}{c}\text { cost } \\
\text { runciran }\end{array}$ & $\begin{array}{l}\text { LATXNL } \\
\text { VulocIT }\end{array}$ & $\begin{array}{l}\text { DOLI } \\
\text { NHELS }\end{array}$ & $\begin{array}{l}\text { sucting } \\
\text { Benos }\end{array}$ & 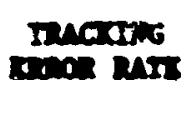 \\
\hline 3.2 & 1 & 0.25 & 0.50 & 5.0 & 1.25 \\
\hline 5.2 & 2 & 0.50 & 1.00 & 10.0 & 2.5 \\
\hline 9.3 & 1 & 0.25 & 0.25 & 5.0 & 1.25 \\
\hline 9.3 & 2 & 0.25 & 0.25 & 10.0 & 2.5 \\
\hline 19.5 & 1 & 0.25 & 0.25 & 5.0 & 1.25 \\
\hline
\end{tabular}

The reavi: Los pilot wodel feedbect gais elonente are chom in Table 3. The gaiss exhibit iftele choge when the cost function changes between 1

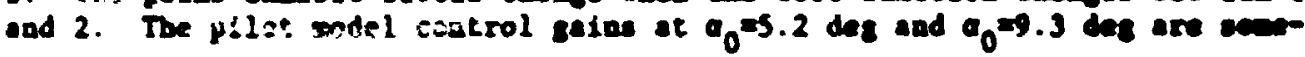

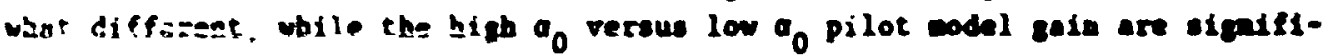
cantly different. These differences indicate the hypotbens to -ing sctran sbould be able to wake a clear decision between the high and low $a_{0}$ etratenies.

\section{MPOTHESIS TESTIMG RESULTS}

This section presents the resules froe the bypotbests cestian ectum in two fornets. In tin first fornet, the one-step predicted pilot odel control tine history is overlatd on the accul pilot's leteral atsu control tiwe history. The closer enese two trajestories watch, che better che indcetion is that the aseund piln: a wiel is correct. The second fornet 18 caposed of plots of ite probebilities that each pilot sodel is the best of those tented. The first forme gives an absolute isdicate of pilot codel perforwace wile the second forwat sives a relative indication of parformace between the pilot wodel.

irpobesis testing procedure and the accomparing walne filter

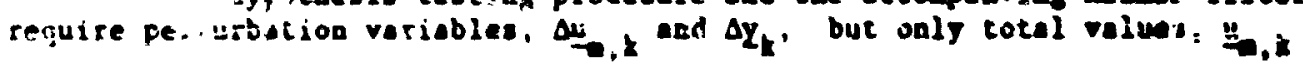




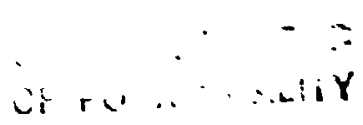

TABLE 3

PILOT MODEL LATERAL STICX GAINS

\begin{tabular}{|c|c|c|c|c|c|c|c|c|c|}
\hline $\begin{array}{l}\text { MIRIRAFT } \\
\text { IMc:LF of } \\
\text { ITTAIX }\end{array}$ & $\begin{array}{c}\text { rest } \\
\text { rinnction }\end{array}$ & $\operatorname{sim}_{x \rightarrow y}$ & 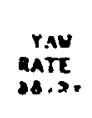 & $\begin{array}{l}\text { ROLL } \\
\text { RATE } \\
\text { OA }>0\end{array}$ & $\begin{array}{l}\text { FOLL } \\
\text { AMCLE } \\
\text { AA . }\end{array}$ & 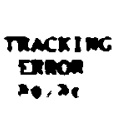 & 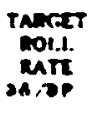 & 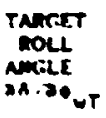 & $20,0 v_{3,1}$ \\
\hline ' : & I & -169 & -51 & $2 \infty$ & $-9 A$ & $\$ 10$ & -122 & -900 & in in \\
\hline c : & $:$ & -119 & $-0 \Leftrightarrow$ & $:-i$ & i 05 & 320 & -1.26 & .570 & , 53 \\
\hline 3 & 1 & -145 & $-10: 3$ & 130 & P os & $66:$ & -0.787 & $-4.6 \theta$ & .123 \\
\hline 1 & $:$ & -18 & -10 ホ5 & $1 \cdots$ & 418 & $B \times$ & $-n$ sal & -401 & -396 \\
\hline$\checkmark$ : & ! & 140 & -72 & 516 & -302 & $-\infty 3=$ & 610 & !9 & $-9 A \wedge$ \\
\hline
\end{tabular}

and. $I_{k}$, are avallable froe the flight tests. A bigh-pass filter (wasb-out filterf was initially tested with the procedire. It was determaed that the pllot manges to keep $c_{y}$, $\delta v$, and $\delta$, near the zero axis and the bigh pass tilter proved to be unnecessary. A bigh-pass filter would be necessary for investigating the lon? tudial axis with the bypotbesis testiag procedure.

Initial trisls of the bypothesis testing calculation procedure with the piloted data ladicited a severe misatch occurs between the Kalman filter's estinate of lis output error covariance, S in (13), and the actual output error covariance. Whicb is calculated as

$$
S_{k}=\frac{1}{k} \sum_{i=1}^{k}\left(u_{n, 1}-\underline{u}_{-1}(-)\right)\left(u_{-, 1}-\underline{\underline{u}}_{1}(-)\right)^{T}
$$

Fyr a large number of data polats (k 25 large in (17i), the antrax sh shoula approach S fur a Inear. time-invariant system. Tue misat:: ocqurs because the plot's iaternal model of the carget osiving covariance. $E\left\{\delta_{T}^{2}\right\}$, appears to differ continuously frma the aciual constalit value discussed previously. The ersatch also arises due to the existence oi unwodeled dynaniss, nonlinearities, and due to the tiee-varyiag uature of the actual piloted simulation.

To resolve thas ansatch. - Cmile approach 13 lised whereby an estamate of S, based on ( $1 i)$, is used in the hypothesis testing schere. The usefuiness of chis oodification is cunfined by the agseenent observed in the next paragraphs between the hypothesis tesing results and the pilot control trajectory comparsons

Comparisons of the actual glict control tume bistory to the pilot

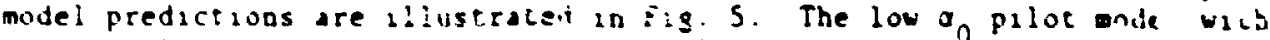
normal doluting technique shown in Fis Sa atches the Pctual pllot's 
responses quite well, except perbaps in the regions circled. The low a pl lot model with especially "tight" piloting technique (Fig. Sb) exhrbils no discernable difference from the low a nomal pilot oodel. The aediu a $\alpha_{0}$ pllot model $\left(F_{18}\right.$. 5c) does not atch bie pilot control inputs as well as lhe low $a_{0}$ plot wodel except perhaps vithin the circled regions. The high $a_{0}$ pl lot model does a poor job of predicting pilot behavior even in tagh a fl 1 ght. Thas pilot does not significantly adapt his control stratery tf atch the changes in aircraft dyanics. Note that ao conlusion regardiag quadratic weight ("thet" or "nornal" control effort-tracking error tradeoff) can be ende based on visual inspection of these figures. The reasonable atch in Fig. Sa tends to justify the nodeliug simplifications used in the analysis and the attempt to capture huan control behovior usang tbe optinal coatrol model. The fact that different assusptions in the construction of the model produce a poor match as shown in Fig. Sd adds further credence to these conclusions.

The hypothesis testing pilot model probabilities are show 10 Fis. 0 . Recall that the results take the for of a probability for each of the hypothesized pilot models: the sun of the probabilities of all bypocheses in a given test is equal to one. The hypothesis testing aigorith is allowed to choose between the low $\alpha_{0}$. nedium $\alpha_{0}$ and high $a_{0}$ pllot wodels with naninal quadratic weight. The low $\&_{0}$ model best autches the pilot's responses except in the circled regions. The mediu a pilct model best atches the pilot's response in the circled regions. At ho tive does she high a wodel predict the actual pilot's iebavior, even when the arcraft reaily if in a high $a_{0}$ flight condition. The hypothesis testing result confins the qualitative analysis of the control time histories.

Chosce of pilot tracking error control effort trade-off (quadratic we: ght ievel) could not be mide from a visual exanunation of the control responses, but the bypothesis testag aigorith clearl odicates in Fig. 7 chat the "normal" weights give a much better fit to the data than the "bigh" weights. This indicates that tre "hi h-gain" or "taghe" pilot codel is not as good a representation of what the pilot actually jid in this test as is the normal or "low-gain" pilot model values.

\section{SURRARY}

This paper presents a method for comparing actual pilot control $a=: 20 n s$ in the time doman with pilot nodel predictions. A modified hypothesis testing schene coabined with the linear optial control pilot codel is developed that can be lised to analyze nonlinear piloted aircraft jata. Actual data fron the NASA Differential Maneuvering Siaulator of pilot in pursu:t-tracking of an arcroft target is analyzed with the bypothesis testing scheme The primary result is that for the lateral directional coutrol channel, the pilot, throughout most of the sieulation, did not change his internal codel of the alrcraft's dynanics from a low angle of attack flight condition to another model better repre entative of the alrcraft dynar'cs. This observation valianies the approach used in $(5)$ and 16 ; where a priori predictions of pilot-aircraft instabilities are mde using a nadapting pilot model It is suggested that the reason the pilot ay not choose to continually adipt is as ween in $|0|$ : the aninue control effort strategy. To adapt to h. h $a_{0}$. the pllot would have to incresse has control effort by 

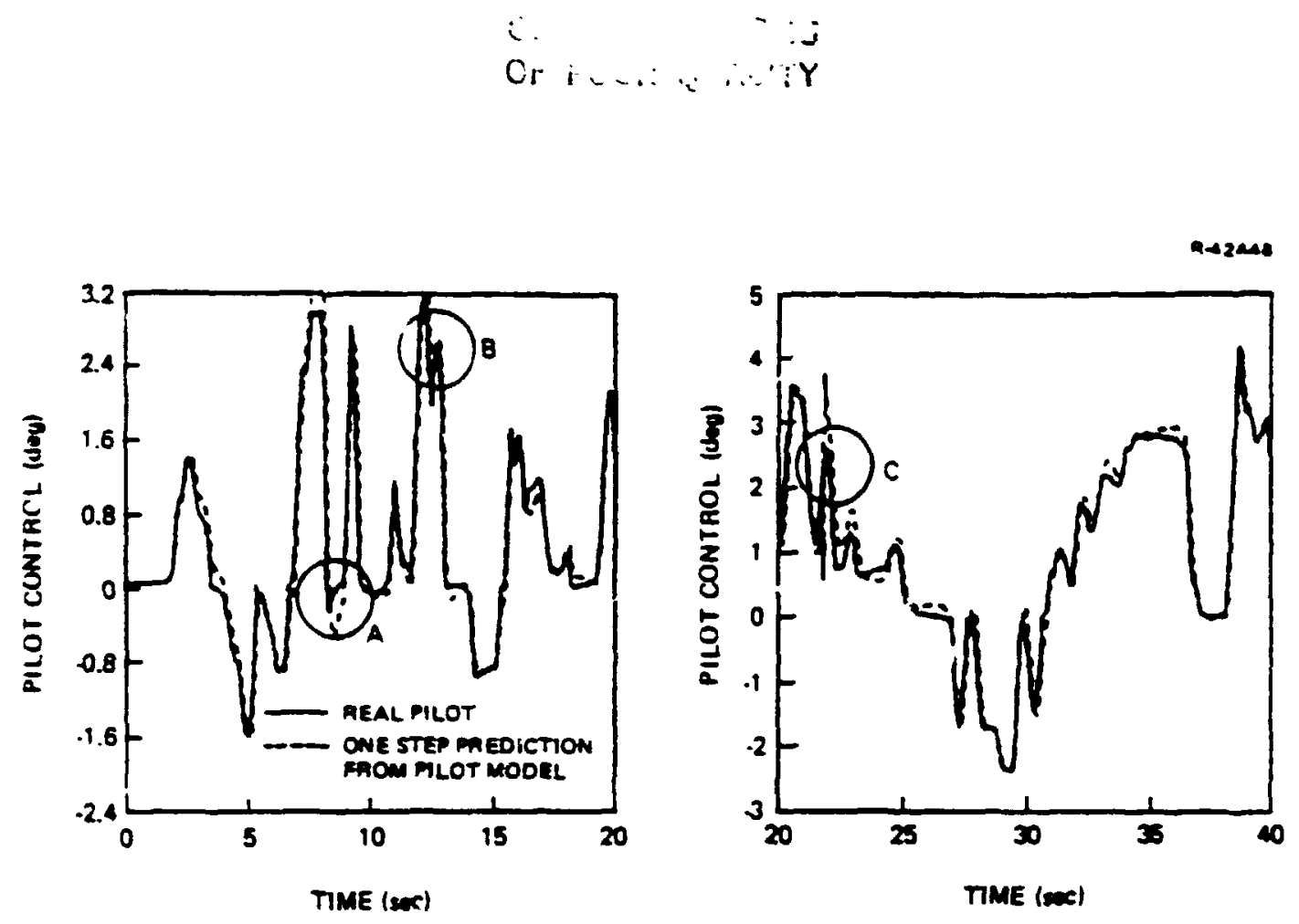

a) Low $\alpha_{0}$ Pilot Model With Noninal Quadratic Cost Weights
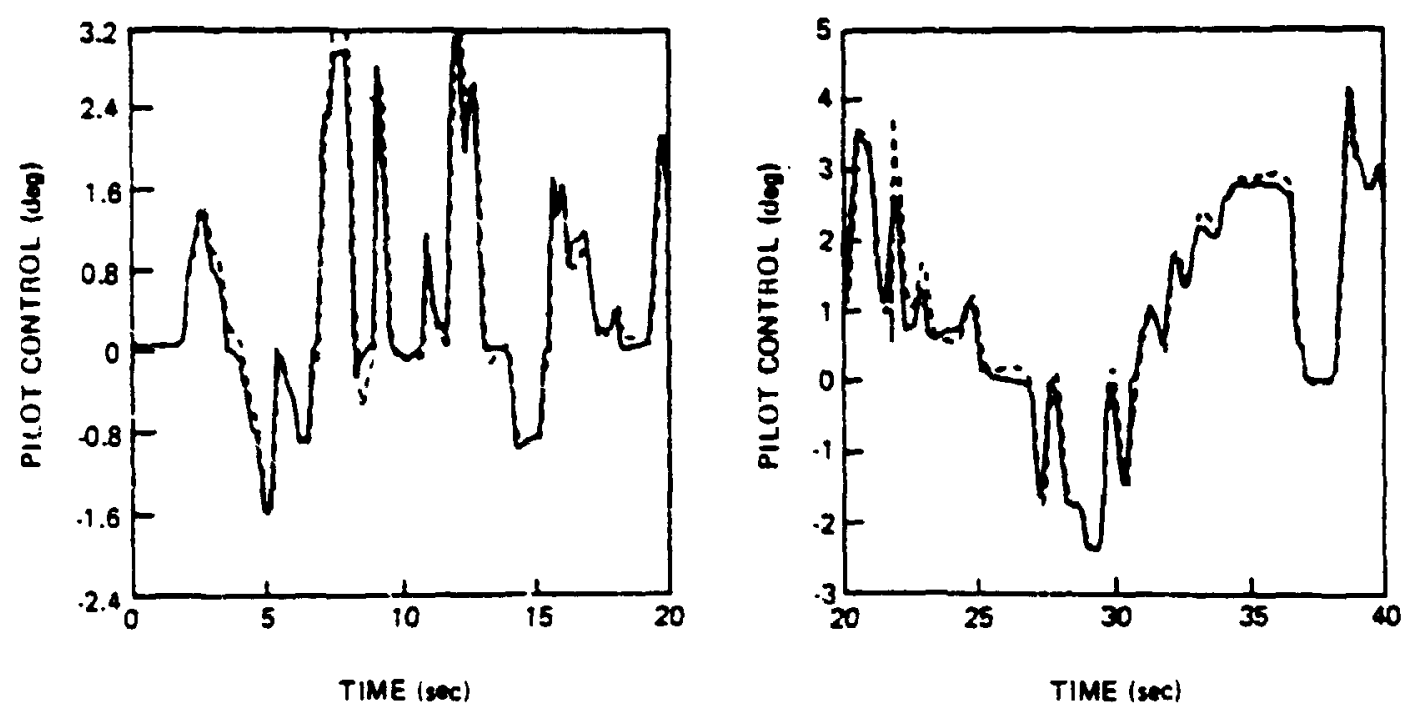

b) Low $a_{0}$ Pilot Mode! With High Quadratic Cost Weights

Figure 5 Comparison of Actual and Predicted

Prlot Controls 

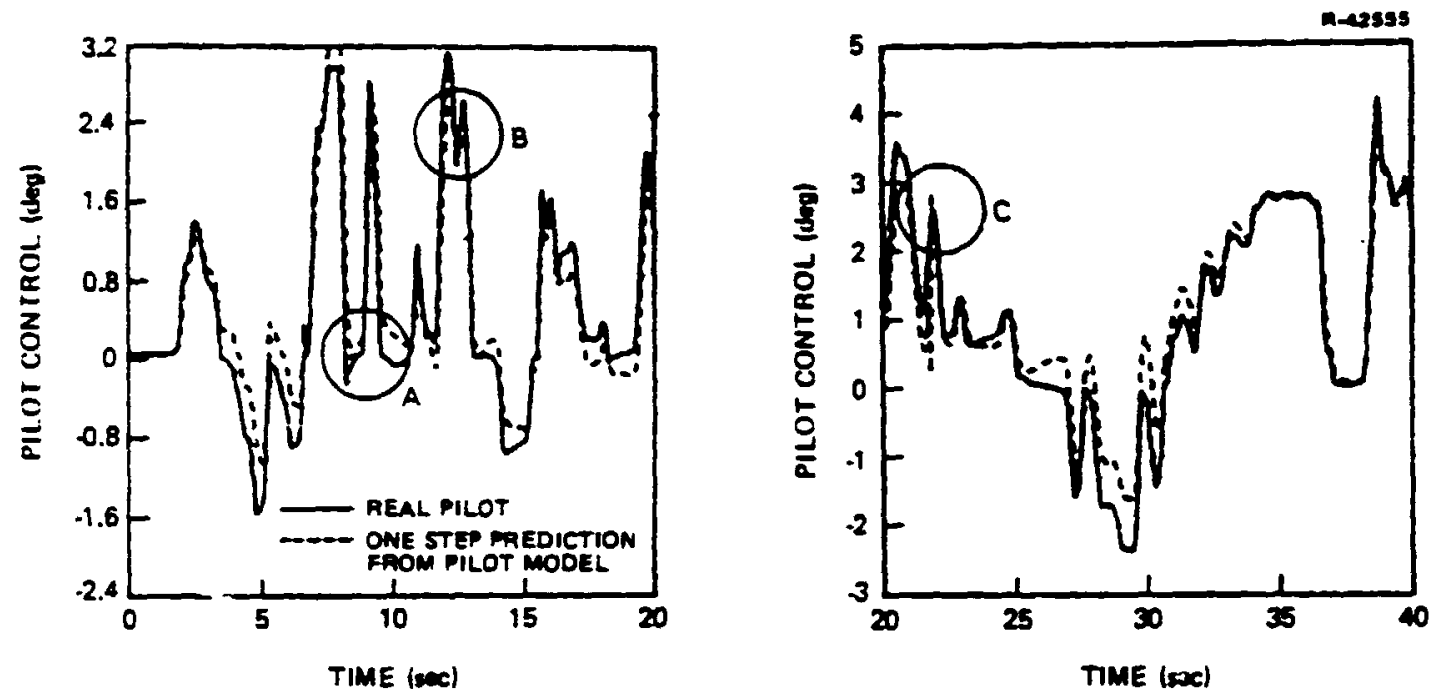

c) Mediu $\alpha_{0}$ Pilot Model With Nominal Quadratic Weights
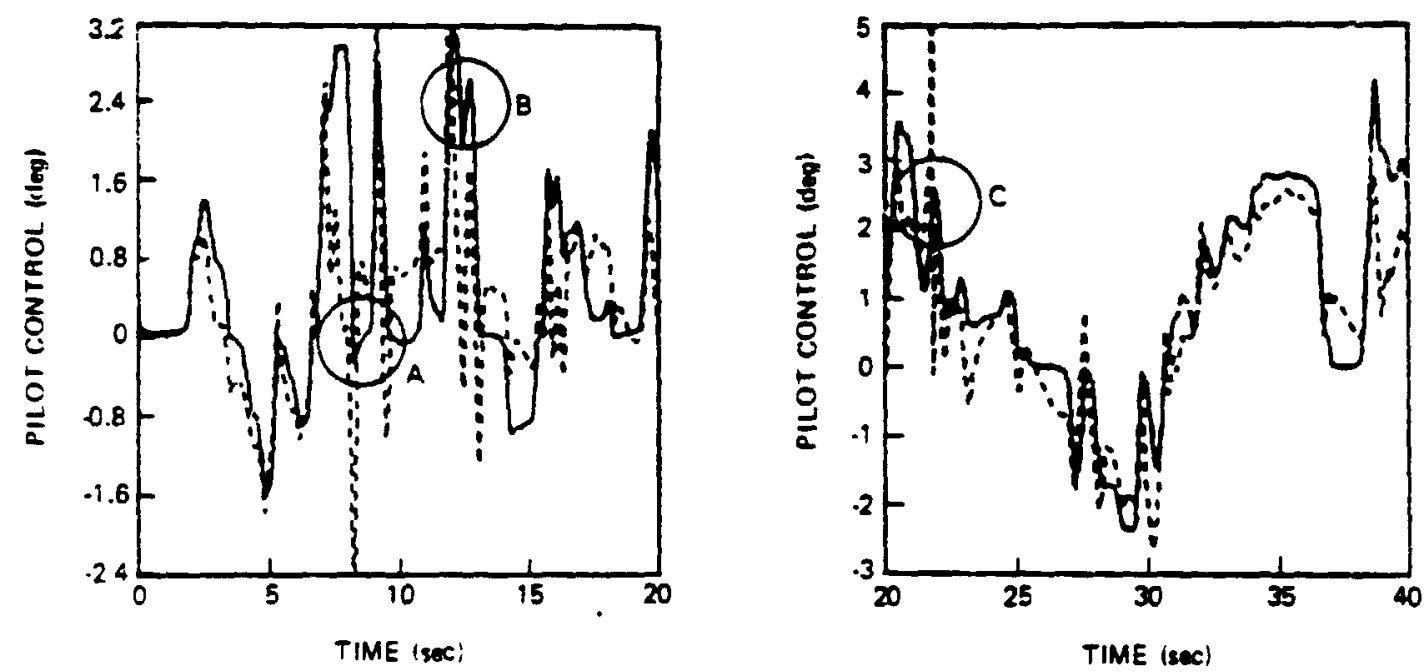

d) High $\alpha_{0}$ Pilot Model

Figure 5 Comparison of Actual and Predicted Pilot Controls (Continued) 


\section{ormgining fage is \\ OF POUR QuALITY}

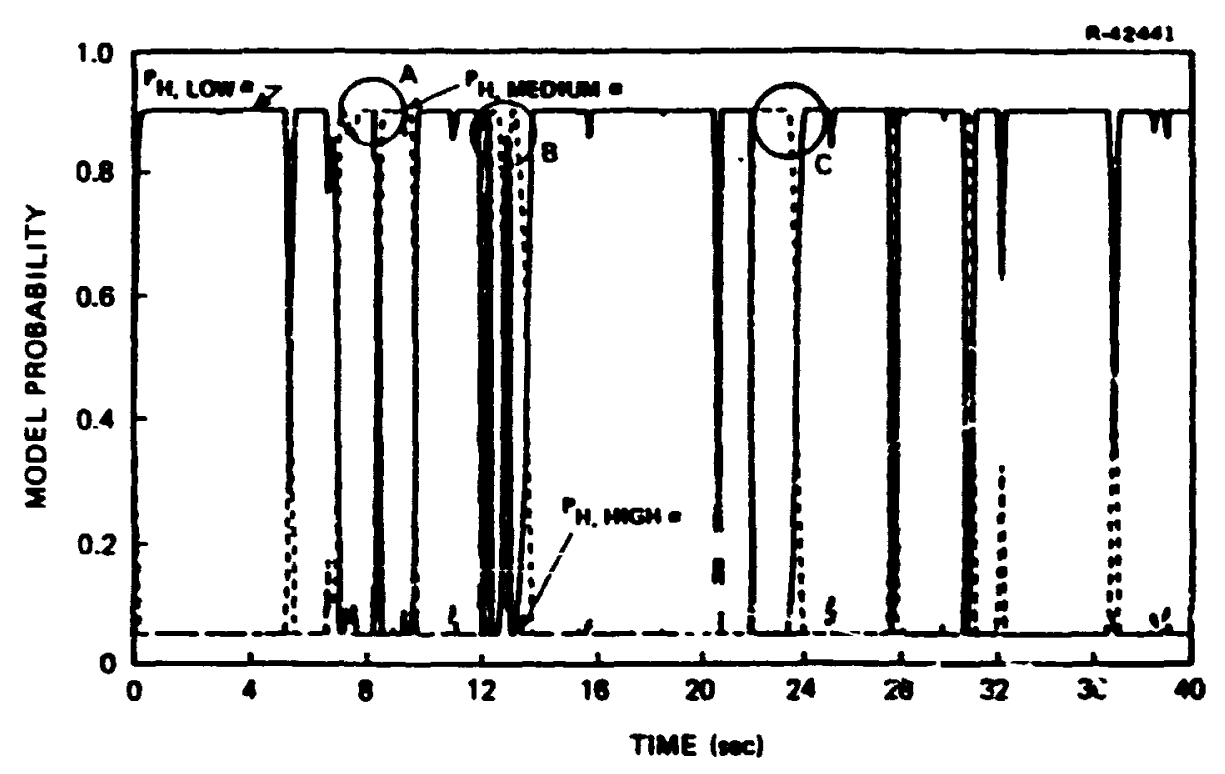

Figure 6 Pilot Hodel Probabilities

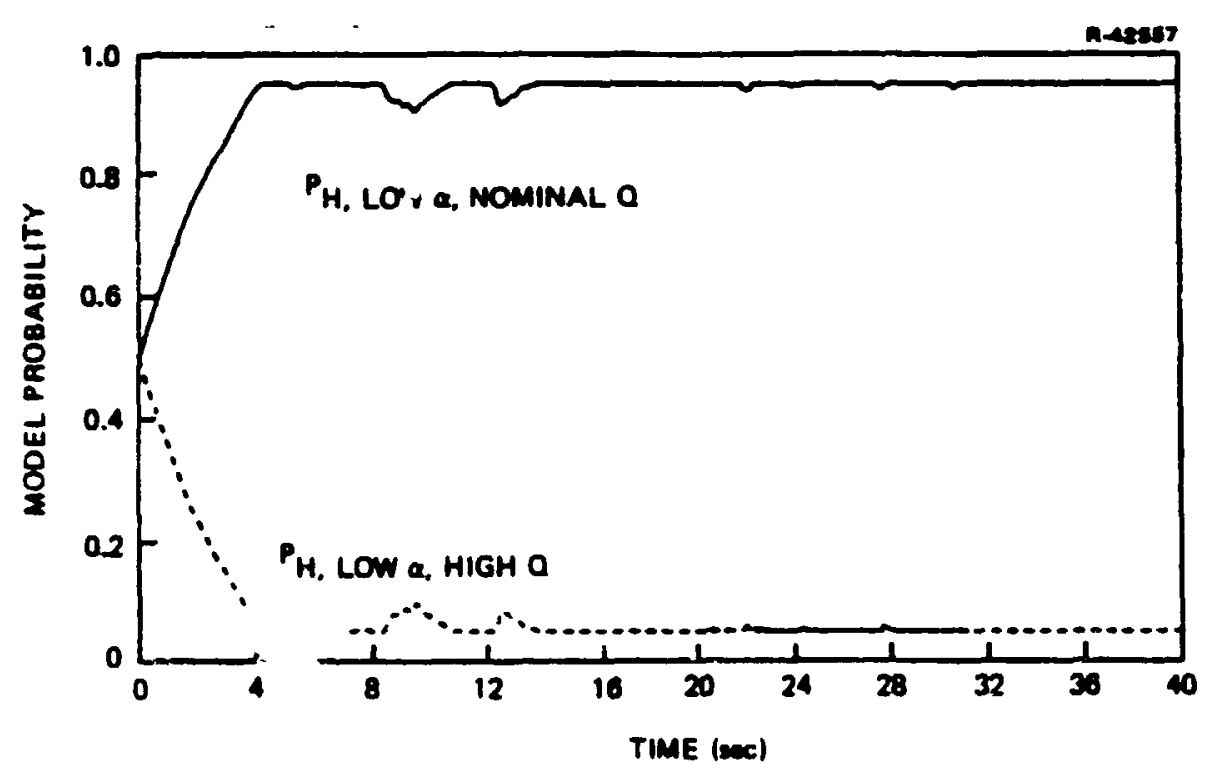

Figure 7 Pilot a iel Probabilities for Two Pilot Models at $\alpha_{0}=5$ des with Different Quedratic Weights 
subjectively incressing his feedbeck gain as shown in Table 3. Even when the internal aircraft oodel in the pilot nodel reains the one preferred by the pilc:, the hypothesi. testing schene shows in Fig. 7 that the pilo* does not. at any time, adestly increase his feedoack gain for the flight condstion to wich be is sdapted.

These results dencnstrate the feasibility and usefulness of the bypothesis testing approach using one piloted trajectory. It is apparent that analysis of may trajectories, with an improved target dyanics nodeling effort, as in [13], is necessary before are general conclusions can be ande.

\section{ACOOHOWEDGEMENT}

The authors wish to thank Prof. R.F. Stengel, now at Princeton University, for suggesting the hypothesis testing approach to the problem. The autbors are grateful to L.T. Nguyen for providing the NASA Dus data. This work was perforned at The Aaslytic Sciences Corposation and sponsored by the Office of Naval Research under Contract No. No0014-75-C-0432.

\section{REFERENCES}

1. Baron, S., and Berliner, J., "The Effects of Eeviate Inffrnal Representations In the Optial Model of The Hunan Operstor," 15 IEIS Confereace on Decision and Control, Clearwater, Florida, Decenber 1976.

2. Jagacinsk1, R.J., and Miller, R.A., "Describing the Huan Operator's Interaal Model of a Dyanere Systen," Hunan Factors, Vol. 20 No. 4, 1978.

3. Kleinan, i.L. and Baron, S., "Manned Vebrcle Systens Analysis by Means of Modern Control Theory," Bolt Beranek and Newan, Inc., Canbridge Mass., BBH Rep. 1967, June 1970.

4. Kleinana, D.L., Baron, S., and Levison, W.H., "A Control Theoretic Approacb to Manned-Vehicle Systeas Aalysis," IEEE Trans. On Autoestic Control. Vol. AC-16, No. 6, Decenber 1971.

5. Stengel, R.F., Broussard, J.R., Berry, P.H., and Taylor, J.H., "Modern Methools of Aircrft Stability and Control Analysis," ONR-CR215-237-2, May 1977. Pilot model results reported in "Prediction of Pilot-Airraft Stability Boundaries and Performance Contours." IEEE Trans. on Syateas, Man, and Cybernetacs, Vol. SMC-B, No. 5, May 1978.

b. Stengel, R.F., Taylor, J.H., Broussard, J.R., snd Berry, P.W., "High Angle of Attack Stability and Control," ONR-CR215-237-1. April 1976. $P_{1}$ lot oode! results reported in "Stainilty of the Pilot-Aircraft Systen in Maneuvering Flight," J. of Aircraft, Vol. 14, No. 10, pp. 950.y65, October 1977 . 
7. Fiske, P.H., and Price, C.F., "A New Approach to Hodel Structure Ideatification," AIM Atwospheric Flight Mechanics Conference, Paper No. 77-1171, Hollywood, Florida, Auguet 1977.

8. Fiske, P.H., "Advanced Estination and Control Concepts for Air-to-Air Missile Guidance," The Analytic Scieaces Corporation, Report No. TR-1353-1, February 1979.

9. Berry, P.W., Broussard, J.R., and Gully, S.W., "Validizion of ligh Angle of Attack Methods." OUR-CR215-237-3, Septenber 1979.

10. Chans, C.B., and Athans, M., "State Estimation for Discrete Syatens with Switching Parameters," IEEE Trensactions on Aerospace and Electronic Systens, Vol. AES-14, No. j, May 1978.

11 Harvey, T.R. and Dillow, J.D., "Tly and Fisht: Predicting Piloted Performance in Air-Lo-Air Conbst," Proceetings of the loth Annual Confersace on Manual Control, Wright-Patterson AFB, April 9-11, 1974.

12. Korn, J., Boal, H.S., and Vibmanis, H., "Modeling Buma Trackins Performace in a High g-Stress Environent," 17th IEEE Conference on Decision and Control, San Diego, California, Janury 1979.

13. Rao, P.R., Kleiman, D.L., and Ephrath, A.R., "Adaptive Estiation Schemes for Mininizing Uncertainty in Manual Control Tasks," 17th IEEE Conference on Decision and Control, San Diego, California, Jenuary 1979. 


\section{N82 34048}

SUBJECTI YE SCAIT NG OF MENTAI WORKIOAD

IN A MULTI-TASK ENVIRONIENT

Bahman Daryanian

M.I.T.

\section{NTRODUCTION}

This paper reports and examines the results of a mental workload (MWL) experiment which was carried out in a simulated multi-task environment. The objective of tine experiment was to develope and examine a method that would qualitatively and quantitatively identify those factors in a multi-task environment that contribute to the operators" "sense" of mental work'oad. In the experiment. the subjective judgment as conscious experience of mental effort was decided to be the appropriate method of measurement.

Thurstone's law of comparative judgment was enployed in order to construct interval scales of subjective menial workload from paired compariscns data.

An experimental paradigm (Simulated Multi-Task Decision.Making Environment) developed by Tulga (1), was employed in this work to represent the ideal experimercilly cratrolied environment in which subjects (human operator's) wers asked to "attend" to different cases of Tulga's decision-malcing tasks.

Through various statistical analyses it was found that, in general, a lower number of tesks-to-be-processed per unit time (a condition associated with lorger interarrival times), results in a lower mental workload, a higher consistency of judgments within a subject, a higher degree of agreement among the subjects, and larger distances between the cases on the Thurstone scale of subjzctive mental workload.

The overall method employed in this experiment brings into notice the effects of various control var ables and their interactions, and the different characteristics of the subiects on the variation of subjective mental workload.

\section{THE EXPERI MENT}

A multi-task cecision-making sitiation in Tulga's experimental paradigm is characterized by a number of blocks (tasks) of differing dimensions simultaneously displaved on the CRT (Figure 1), randomly appearing and moving to the right 
ORIGIIUAL P:AE IS

OF POOR QUALITY
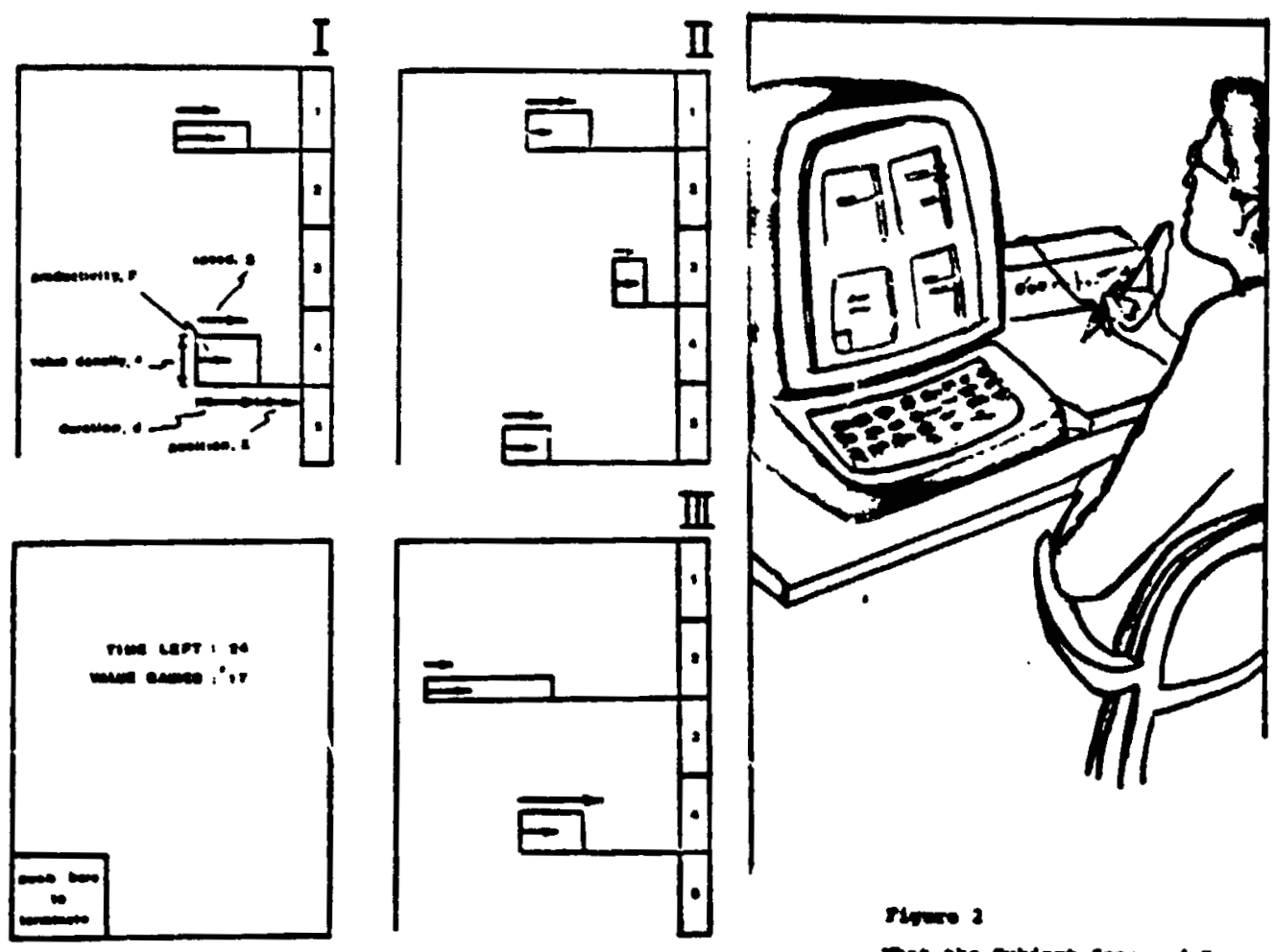

Plpues 1.1 Paredign of

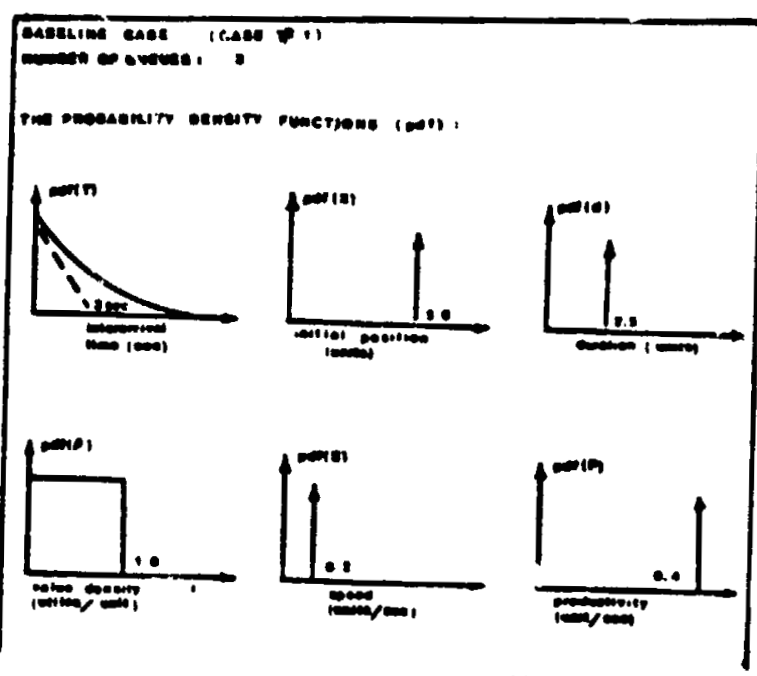

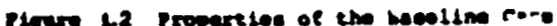

bnt the sebject saen and oove.

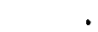


towards a deadine, efter which they disappear. Each block is characterized by its "importance" (indicated by the height of each block), and the operator's "productivity" (the rate at which the width of a block is decreased through the action of the operator).

The subject "attends" to these tasks $c$ : at a time by holding the cursor of a data-tablet to the right of the block (Figure 2), when thus attended the width if a block decreases at a constant rate. The subject is asknd to maximize ris/her total value gained, which is the sum of the raductirn in areas of all blocks attended to by him/her, i.e. the t.:tal area diminished.

Blocks appear randomly with Poisson arrival and $\cdots$ at differing speeds towards the deadine. Height or "impus ance" of a olock can be thought of as the "value density" of the tas 2 : wnich indicates the benefit accrued per unit time the operator acts on it. Value can then be earned as the time integras of value densitzes of tasks acted upon. The value density for each case has a rectangular probability density distribution of 1.0 unit/time.

Thu explicit parameters that differ for each case (trial) are speed "S", productivity "p", and interarrival time "Tr" of the blocks (tasks). For three levels of each. a factorial experiment requires 27 cases where,

Task Speeds

$$
s_{1}=0.2, s_{2}=0.4, s_{3}=0 \text { units/sec }
$$

Operator Productivities, $P_{1}=0.4, P_{2}=0.8, P_{3}=1.6$ units $/ \mathrm{sec}$

Interarrival times

$$
T_{1}=3.0, T_{2}=6.0, T_{3}=12 \text { seconds. }
$$

In short, the operator monitors the arrival of different tasks, evaluates the tasks, chooses one, and acts in it before it hits the deadine.

One female subject (operator 1), and two male subjects (operators 2 and 3 ), were invited to participate in the experiment. After initial stages of training each subject was asked to "attend" to multi-task decisior-making cases for 100 seconds each; and then compare the cases on a pair-wise basis in order to give a subjective assessment of the relative mental workload induced by the pair.

Cases were presented in a ranjom fashion. Care was taker: to avoid any noticable order in the presentation of the cases. Most of the pairs were presented more this orce. For eash subject the experiment was carried out ir. a period of swo to three weeks for a total of 35-45 hours.

The paired comparisons judgmerits cf a subject resulted in one of the threc categories of respons:s,

A- $m r^{-}$it $j z: t$ was ceriain that the mental woirload iriv. in by ore of the casers was greater tran the other. 
B- The subject thought that probably the mental workload induced by ne of the cases was greater than the other.

C- The subject was unable to make a relative judgment between the cases.

THE SCALI ME METHOD

The "Ifw of comparative judgment", which is based on 1hurstone:- judgment scaling model, provides the necessary $\delta$ nplifyia, asumptions and the set of equations that transform the paired comparison data into the scale values of mental wri iload (rem's 2,3,4).

Thurstone's model assumes that the psychological distance between t.u stimuli is proportional to the normal deviate transform of the proportion uf times a difference between the stimuli is noticed. The distance between a pair of stimuli is highest if one is always judged to be greater than the other, and zero if they are judged to be equal. Therefore, the subjective scale of Thurstone is based upon the degree of confusion of the subject in the judgment of relative intensity of the psychological attribute in a pair of stimuli.

\section{Thurs tone's Judgment Scaling Nodel}

Thurstone postulated that for any given attribute (e.g., mental wurkload) of a series of stimuli (e.g., decision tasks) there exist a "psychological continuum" associated with that attribute. A subject presented with a series of stimuli mould react "discriminally" with respect to the given attribute (e.g., the subject would discriminate between the different levels of mental workload associated with a series of decision tasks). The process by which the subject identifies the attribute and reacts discriminally to it is called a "uiscriminal process"; and each of the "discriminal responses" associated with a discriminal process has a value on the psychological continuum associated with that attribute. It is assumed that due to the stochastic nature (noise generation, momentary :luctuation) of the 0.4gans of the human mind (sensation and cognition), i.e. of the discriminal processes, the discriminal response associated with a given attribute of a stimulus could be thought of as having a frequency distribution on the psychological continuum. Furthermore, it is postulat sd that the frequencies with which the discriminal responses are associated have the form of a normal distribution.

In a normal frequency distribution the modal, mean, and the mode coincide. A possible choice for the "scale value" of the attribute on psychological continuum is the "modal discriminal response ".

Figure 3 provides examples of discriminal responses on a psychological continuum for four stimuli. Note that the modal 
C:
O: $\therefore$ is $\quad$ is

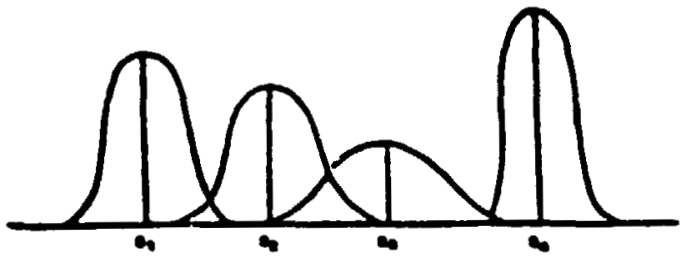

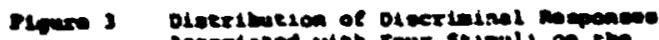

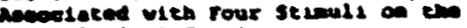
in

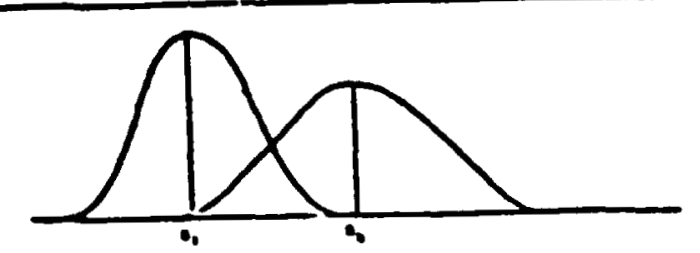

Tlpure 4 Distritution of Oleczininal mepoonece

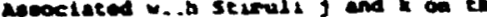
prebsolepsen, conesmut.

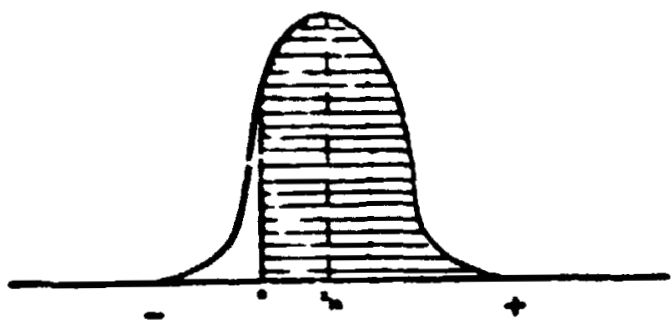

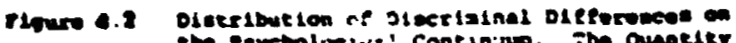
H. to the difgermee in seile values

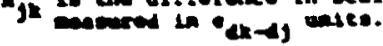


discriminal responses $s_{1}, s_{2}, s_{3}$, and $s_{4}$ and the respective discriminal dispertions vary for each stimulus.

It is assumed that the subject can not directly report the modal values of the discriminal responses or their dispersions on the psychological continuum. However, presumably he can judge and report relations among stimuli (e.g., judgment of relative orders).

The Law of Comparative Judgment

The law of comparative judgment is a set of equations relating the scale values and discriminal dispersions of a set of stimuli on the psychological continuum to the proportion of times any stimulus is judged greater than the others for a given attribute.

When a pair of stimuli is presented to a subject the difference between two discriminal responses (discriminal differences, $d_{j}-d_{k}$ ). should also form a normal distribution. The mean of this distribution is equal to the difference in scale values of the two stimuli. The standard deviation of differences is computed from

$$
\sigma_{d_{j}-d_{k}}=\left(\sigma_{j}^{2}+\sigma_{k}^{2}-2 r_{j k} \sigma_{j} \sigma_{k}\right)^{1 / 2} \text {. }
$$

where $r$ is the correlation between momentary values of discriminal responses associated with stimuli $j$ and $k$.

As a result of Thurstone's judgment model the following rolation holds for the difference in scale values of the two Btimuli.

$$
s_{k}-s_{j}=x_{j k} \sigma_{d_{j}-d_{k}}
$$

where $\bar{X}_{j k}$ (see Pigure 4 ), is evaluated from the table of areas under the unit normal curve, and it is in units of the standard deviation of discriminal differences.

Combining Equations 1 and 2. the fundamental equation of the law of comparative judgment resuits

$$
s_{k}-s_{j}=x_{j k}\left(\sigma_{j}^{2}+\sigma_{k}^{2}-2 r_{j k} \sigma_{j} \sigma_{k}\right)^{1 / 2} \text {. (Eq-3) }
$$

In general, for $n$ stimuli, there are $n$ scale values, $n$ discriminal dispersions, and $n(n-1) / 2$ independent correlations which are unknown. Against these, there are only $n(n-1) / 2$ observable equations corresponding to the independently observable proportions. In order to decrease the number of unknowns some simplifying assumptions are necessary. It should be noted that $X_{j k}$ is related to the proportion of the times stimulus $j$ is judged greater than stimulus $k$.

\section{A Jorkable Set of Equations}

Assuming that the standard deviation of discriminal differences is constant and the same for all pairs of stimuli, a "least squpre" solution results in the following equation for detemining the estimated scale values of stimuli, 


$$
s_{k}=\frac{1}{n} \sum_{j=1}^{n} x_{j k}
$$

$(n=1,2, \ldots \ldots n)$

(2q.4)

In derivation of this equation it was assumed that the orifin of the scale is set at the mean of the estimated scale values.

\section{REDUCTI ON OF THE DATA}

A. mentioned before, the subjects judged the relative greatness of mental workload for a pur of multi-task decisionaraling cases, and the verbal responses resulted in one of the three categories of A, B, or C.

By accumulation of these paired comparisions date verbal -esponse matrices "R". were constructed whose elements were one of the five posaibilities (certainly greater, probably greater. *qual, probably less, certainly less) for "relative" mental workload induced by each pair of cases. Due to replication, as shown in the example of Figure 5, some elements contained more than one response. The diagonal matrices were left blank. assuming that the resocnse of any subject when a case is compaired to itself would be " $\mathrm{C}$ ". In addition, in order to indicate wether a case represented by a row induced more mental workload or the one represented by the column, the verbal responses were added $a$ "t or -- prefix. Hence. the response matrix of the Figure 5 is skew symmetric matrix. These verbal responses were transformed into the frequency response form by the criteria show below:

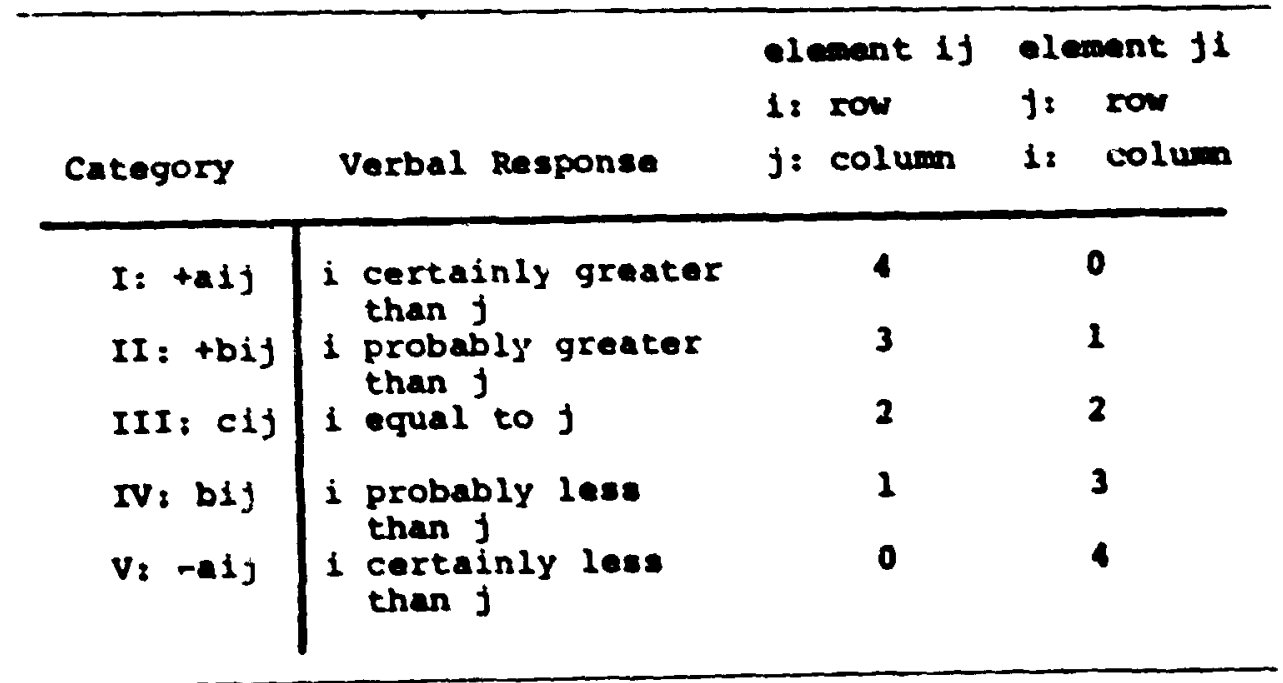

Verbal to Frequency

rransformation Criteria 


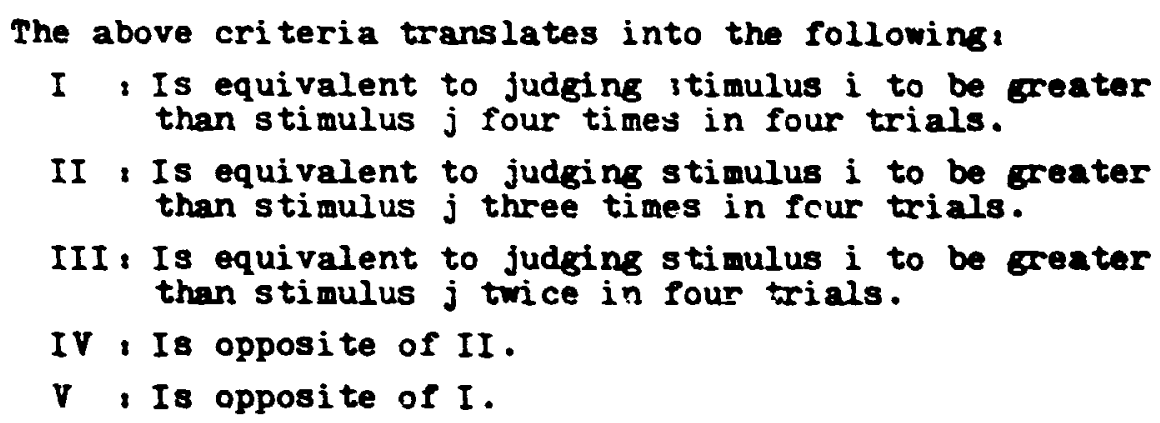

According to this criteria the verbal response marix of Figure $S$ is transformed into the requency response atrix " $P$ " of Figure 6. In turn, matrix $" F^{*}$ is transformed into the proportjon matrix " $P$ " of Figure? by deviding each element of $f_{j k}$ by $\tau_{\text {ire sum of }} f_{j k}+f_{k j}$. From matrix "P*, matrix " $x^{\infty}$ of FI gure 8 is constructed those elements are equal to the unit normal deviate corresponding to the elewent pir. Finally, by substituting the values of $x_{j k}$ in Equation 4 the scale of Pigure 9 is constructed.

Pigure 10 presents the resulting Thurstonian scales of subjective mental workload for each of the subjects.

ANALYSIS OP DATA, RESULTS, AND CONCIUSTONS

For the purpose of the study of the experimental data three independent techniques of analysis were employed,

i) Analysis of variance, which tests the significance of the effects of different variables of decision-task environment ( $I_{i}$ interarrival time, $S_{i}$ task speeds? $P_{i}$ productivityi $O_{\text {s }}$ operators) on the variation of subjective mental workload.

ii ) Analysis of agreement among the subjects, which tests how well subjects agree among themselves in their judgments.

iii) Analysis of transitivity, which provides a basis upon which the consistencies of the judgments of subjects are compared.

It was found that the interrarival time "T" of the tasks has the most significant effect (among all the control variables) on the variation of mental workload (see Table 1). As could be seen in Figure 10, the 27 cases are clustered into 3 seperate groufs corresponding to 3 levels of interarrival time "Tw. Based on this finding, analyses of variance was performed for each level of "T". Results are shown in Tables 2 to 4.

Analysis of agreement is based on computing the Spearman's Rank Correlation Coefficients for paire of subjects and testing their significance for the final rank ordered results. Also included in the analysis was the computation and testing of the 
ORIGINAL PAGE IS

OF POOR QUALITY

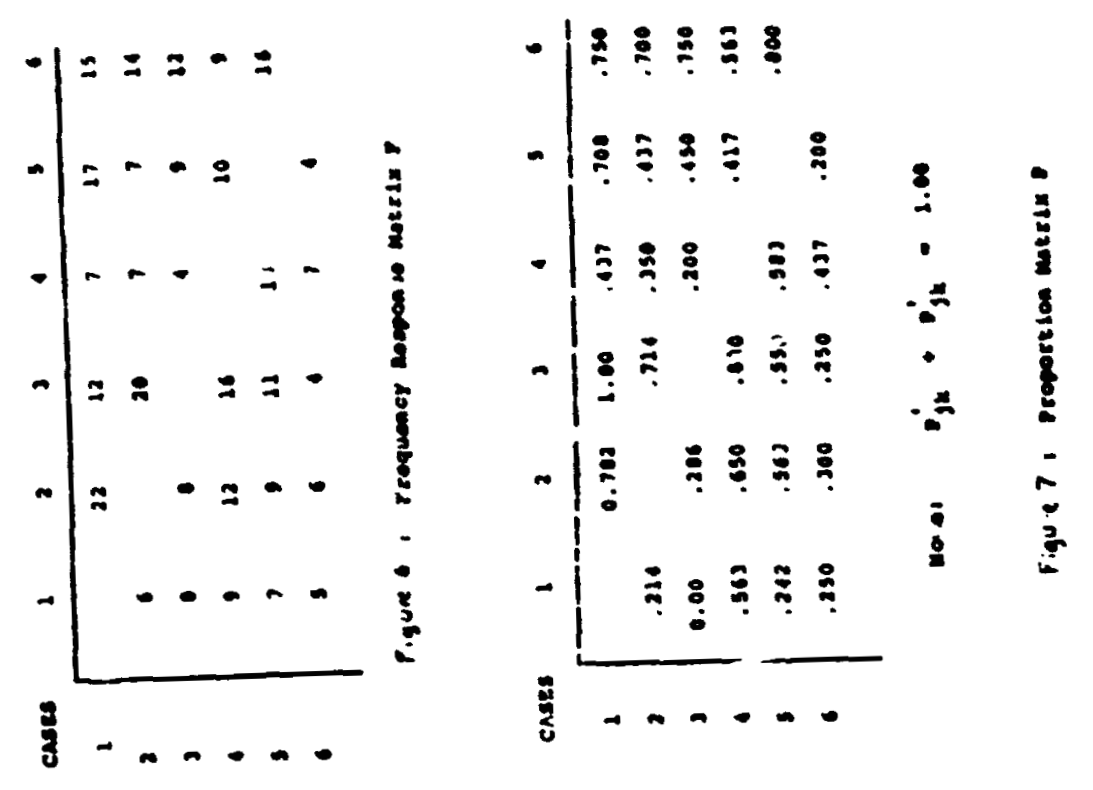

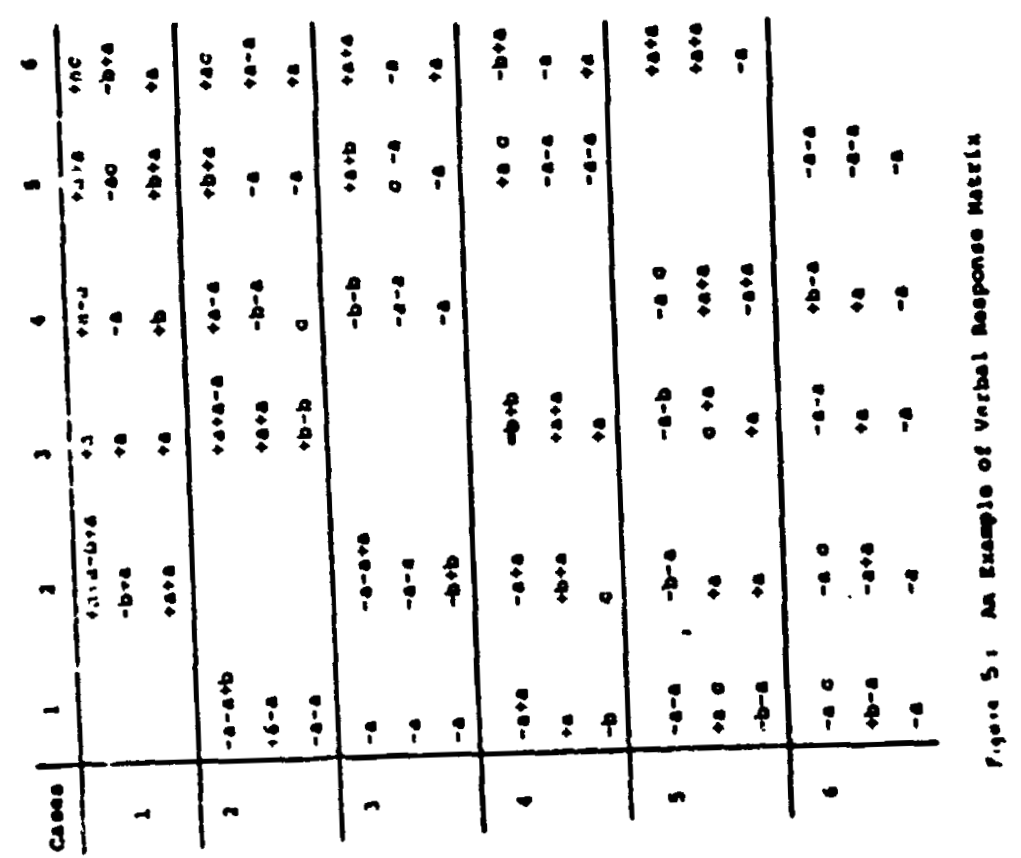




$$
\begin{aligned}
& \text { ORIGIIIL FALE IS } \\
& \text { OF POOR QUALITY }
\end{aligned}
$$
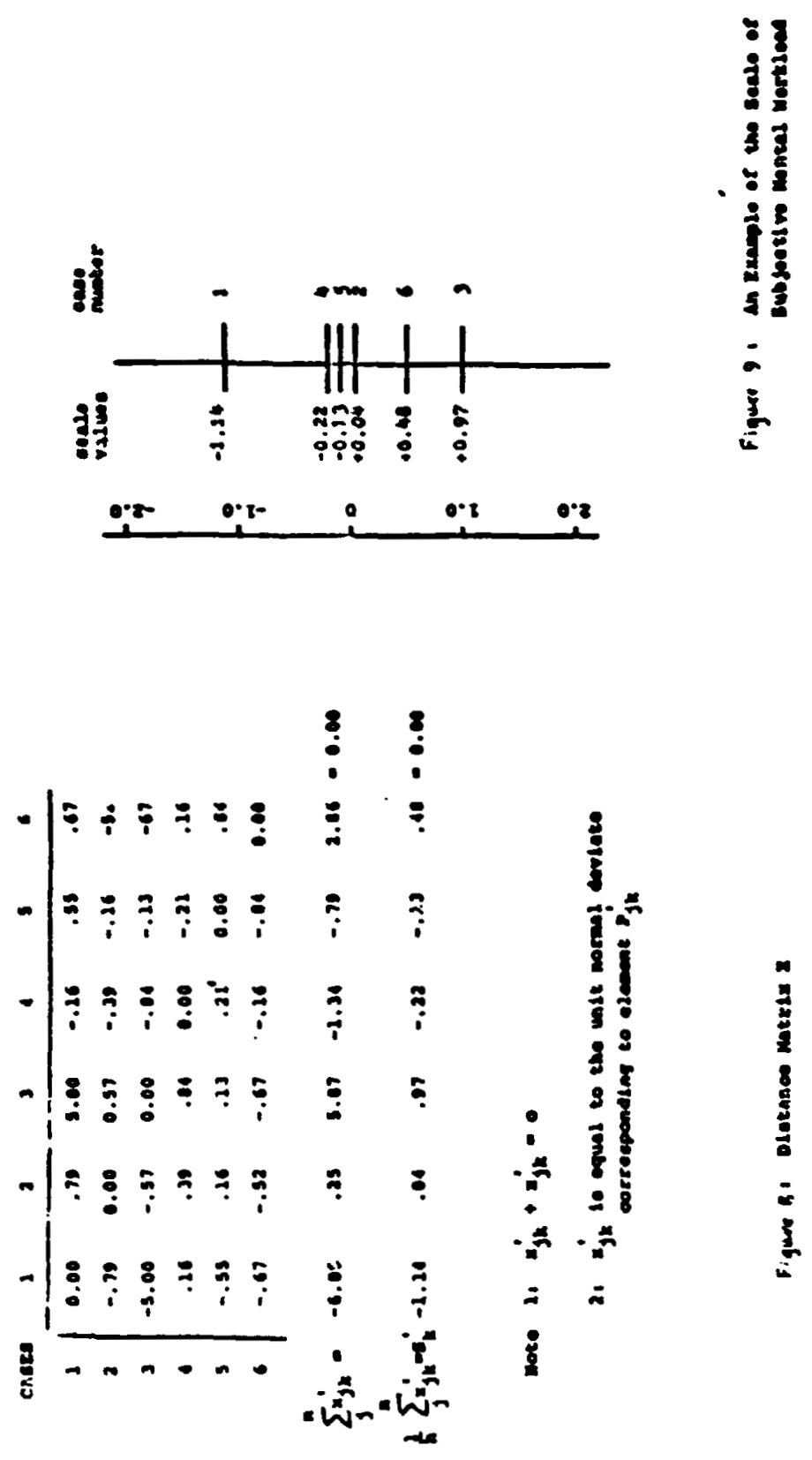


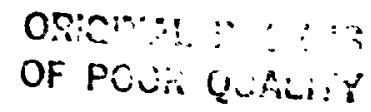

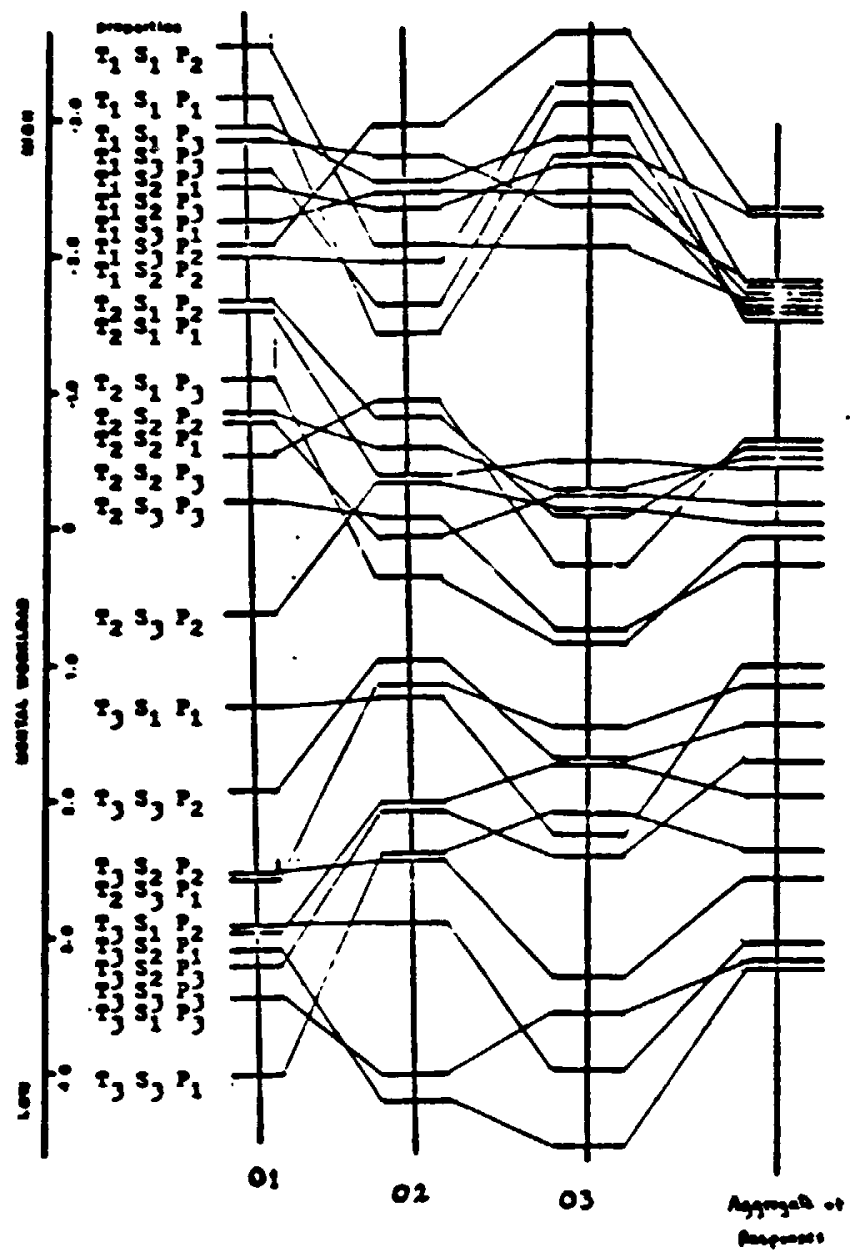

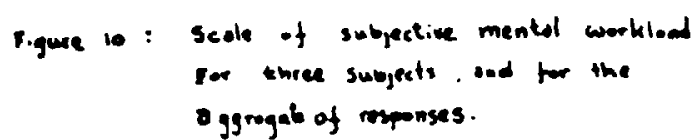


Coefficient of Concordance. Results are shown in Table 5 .

Analysis of transitivity is based on the computation of the number of the inconsistent triads for the subjects' responses. The diagram below illustrates the meaning of the transitivity (consistency of responses). Results are shown in Table 6 .
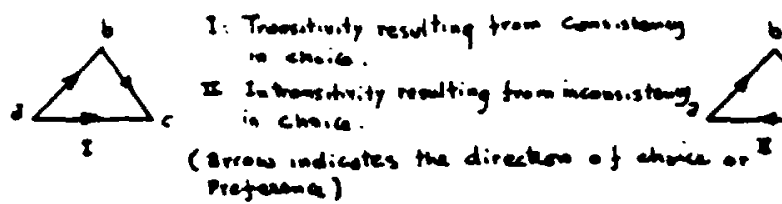

The following is an overview of the results of the analyses. For a more detailed exposition of the results the reader should refer to Ref. 6.

The experimental environment and the results of the subjective judgments provide support for a conceptual model of subjective mental workload wi th the following general properties,

- Subjective mental workload is stochastic in nature.

- Subjective mental workload is a property of the environment-operator interface, and it depends on both environment and operator characteristics.

- Subjective mental workload can be quantified on a unidimensional scale, as demonstrated by this work.

- There exists a substantial degree of agreement among subjects in their judgments of mental workload.

The following more specific conclusions can be dram from the study:

1- Among the experimentally controlled variables the interarrival time between tasks "T", has the most significance effect on the variation of subjective mental workload. A longer interarrival time, which is associated with a lower number of tasksto-be-processed per unit of time, results in a lower subjective mental workload.

2-In general, a lower number of tasks-to-be-processed per unit time (a condition associated wi th longer interarrival times) is associated with the following:

- lower subjective mental workload.

- higher degree of consistency (more transitive responses) wi thin subje: ts.

- better agreement among subjects on rank ordering of cases with respect to their associated mental workicads.

- laree intervals between ad jacent cases on the aggregate scale of subjective mental workload (see figure 10).

3- Analysis of consistency indicates a high degree of transitivity of responses for the aggregate data except for short 
Table 1

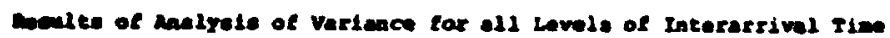

\begin{tabular}{|c|c|c|c|c|c|}
\hline vature of efenet & soures & $\begin{array}{l}\text { Sunt of } \\
\text { equares }\end{array}$ & d. 2 . & $\begin{array}{l}\text { Veriance } \\
\text { Esciante }\end{array}$ & $\begin{array}{l}\text { SLghiflenece } \\
\text { Lovi }\end{array}$ \\
\hline Mactor: & $\begin{array}{l}5 \\
5 \\
0\end{array}$ & $\begin{array}{c}4301.19 \\
9.15 \\
32.67\end{array}$ & $\begin{array}{l}2 \\
2 \\
2 \\
2\end{array}$ & $\begin{array}{r}2252.60 \\
4.93 \\
16.34 \\
0.00\end{array}$ & $\begin{array}{l}1 \\
15\end{array}$ \\
\hline $\begin{array}{l}\text { Iaceraet } \\
\text { batwon } \\
\text { pelix of } \\
\text { lactors }\end{array}$ & $\begin{array}{l}\pi \\
\pi 0 \\
50 \\
50 \\
0\end{array}$ & $\begin{array}{r}94.74 \\
35.92 \\
1.03 \\
93.25 \\
93.72 \\
24.44\end{array}$ & $\begin{array}{l}4 \\
4 \\
4\end{array}$ & $\begin{array}{r}21.19 \\
13.99 \\
0.26 \\
23.32 \\
23.43 \\
6.11\end{array}$ & $\begin{array}{l}1 \\
5 \\
5 \\
1 \\
1 \\
=\end{array}$ \\
\hline $\begin{array}{l}\text { Interaction } \\
\text { between } \\
\text { riplos of factors }\end{array}$ & $\begin{array}{l}\text { spo } \\
\text { rmo } \\
\text { rso } \\
\text { Tst }\end{array}$ & $\begin{array}{l}36.07 \\
31.09 \\
32.31 \\
31.04\end{array}$ & 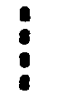 & $\begin{array}{l}1.31 \\
4.75 \\
6.20 \\
6.30\end{array}$ & $=$ \\
\hline $\begin{array}{l}\text { Interactien of } \\
\text { all tectors }\end{array}$ & $\begin{array}{c}\text { Tseo } \\
\text { meldual }\end{array}$ & $\begin{array}{c}57.29 \\
0\end{array}$ & $\begin{array}{l}16 \\
0\end{array}$ & $\begin{array}{l}3.57 \\
0\end{array}$ & \\
\hline
\end{tabular}

i slquilicant arfecte

it computed by ilecter interpolation

Table 2

Donite of Analyais of varience at mort Inter-

arxival The (T - 3 seconde)

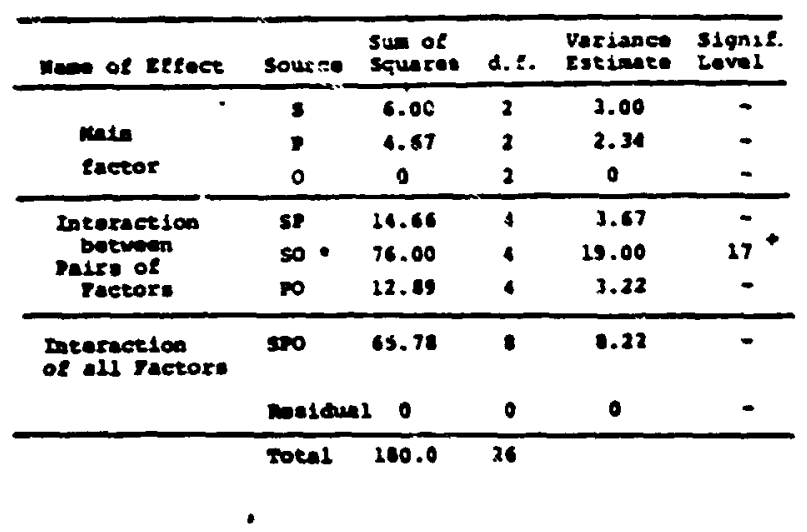

- elgaleleant elfecto

- or linaar incerpolatios 
ORIGIVAL PAOE IS
OF POOR QUALITY

Table 3

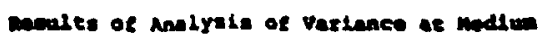

Iaterarzival Tt=s $(5 \cdot 6.0$ socosde)

\begin{tabular}{|c|c|c|c|c|c|}
\hline ter of sefect & souree & $\begin{array}{l}\text { sin of } \\
\text { Square }\end{array}$ & d. $\varepsilon$. & $\begin{array}{l}\text { Yariance } \\
\text { Sucingee }\end{array}$ & $\begin{array}{l}\text { signte. } \\
\text { tovel }\end{array}$ \\
\hline $\begin{array}{l}\text { male } \\
\text { receer }\end{array}$ & $\begin{array}{l}5: \\
0 \\
0\end{array}$ & $\begin{array}{c}60.67 \\
17.36 \\
0 \\
\end{array}$ & $\begin{array}{l}3 \\
2 \\
2\end{array}$ & $\begin{array}{c}30.30 \\
8.70 \\
0 \\
\end{array}$ & 24 \\
\hline 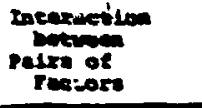 & $\begin{array}{l}\infty \\
\infty \\
\infty\end{array}$ & $\begin{array}{l}32.44 \\
18.44 \\
21.33\end{array}$ & 4 & $\begin{array}{l}8.11 \\
4.62 \\
5.33\end{array}$ & $\begin{array}{l}10^{\circ} \\
- \\
=\end{array}$ \\
\hline \multirow[t]{2}{*}{ 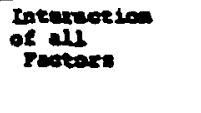 } & $\infty$ & 28.36 & $\bullet$ & 3.70 & - \\
\hline & Bostoned & - & - & - & - \\
\hline
\end{tabular}

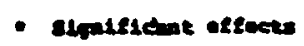

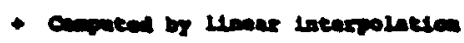

Toble 4

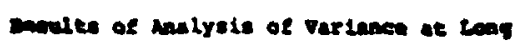

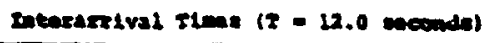

\begin{tabular}{|c|c|c|c|c|c|}
\hline now of serect & tontes & $\begin{array}{l}\text { seo of } \\
\text { equere }\end{array}$ & a.k. & $\begin{array}{l}\text { Vorianes } \\
\text { rovines }\end{array}$ & slgnile. \\
\hline neserex & 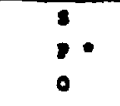 & $\begin{array}{c}0.22 \\
3.20\end{array}$ & $\begin{array}{l}2 \\
2 \\
2\end{array}$ & $\begin{array}{c}4.11 \\
27.49 \\
0\end{array}$ & $\begin{array}{l}- \\
5 \\
-\end{array}$ \\
\hline 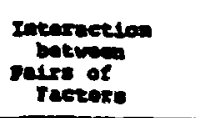 & $\begin{array}{l}10 \\
\infty\end{array}$ & $\begin{array}{l}4.63 \\
21.71 \\
13.78\end{array}$ & $\begin{array}{r}.4 \\
4 \\
.4\end{array}$ & $\begin{array}{r}27.41 \\
3.48 \\
3.45\end{array}$ & $\frac{1}{16}$ \\
\hline $\begin{array}{l}\text { Intermetson } \\
\text { of all } \\
\text { rectere }\end{array}$ & masemes & $\begin{array}{c}11.69 \\
0\end{array}$ & a & $\begin{array}{l}1.46 \\
0\end{array}$ & - \\
\hline & soend & 160.0 & 26 & & \\
\hline
\end{tabular}




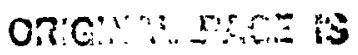

OF POOR QJALITY

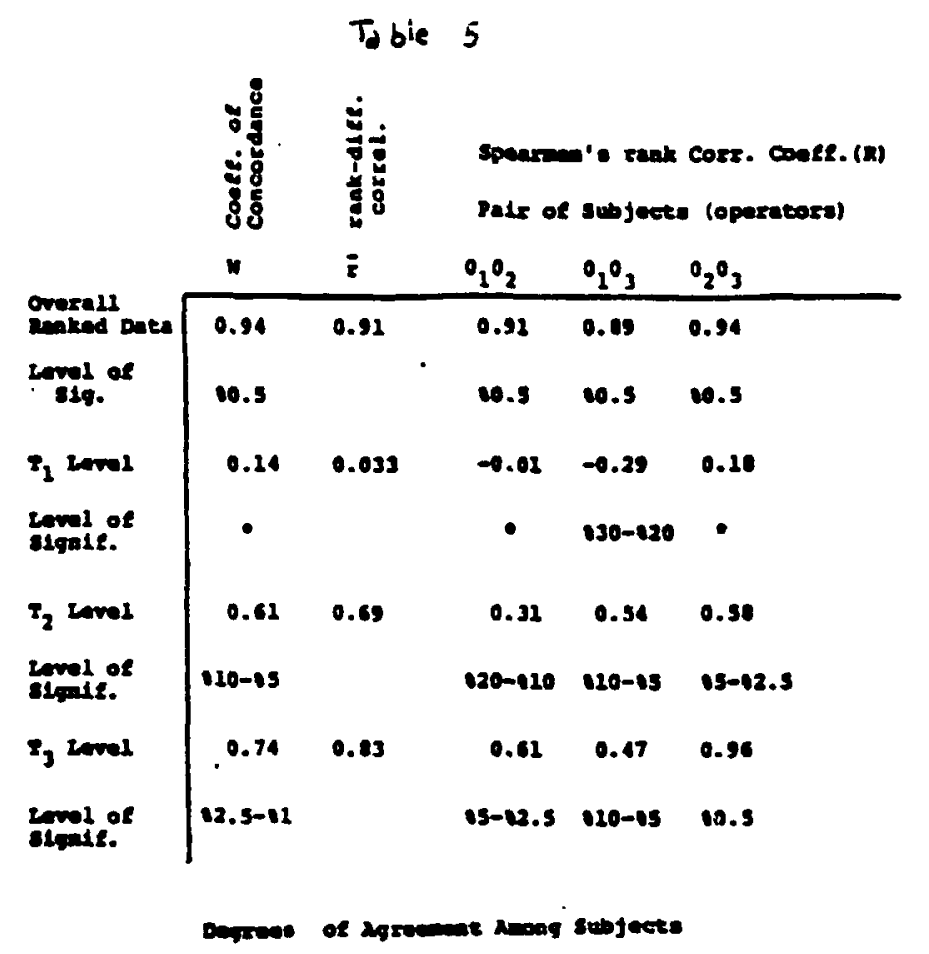

\begin{tabular}{|c|c|c|c|c|}
\hline & ${ }_{20}^{27} 211$ & $\begin{array}{l}\text { more intex- } \\
\text { arrivel ei= } \\
\sum_{1}\end{array}$ & $\begin{array}{c}\text { Madiug loter } \\
\text { arrivel } \\
T_{2}\end{array}$ & $\begin{array}{l}\text { Lang incer- } \\
\text { axrival eim } \\
T_{2}\end{array}$ \\
\hline & 100 & 25.5 & s & 22.4 \\
\hline & .8 & .48 & .83 & .38 \\
\hline \multirow{2}{*}{ है: } & 33.7 & 22.0 & 14.8 & , \\
\hline & .01 & .25 & .5 & .70 \\
\hline \multirow{2}{*}{8} & 136.2 & 19.2 & 29.1 & 12.2 \\
\hline & .83 & .35 & . 36 & .39. \\
\hline \multirow{2}{*}{$\begin{array}{l}38 \\
8 \\
8 \\
8\end{array}$} & 44 & 26.2 & 7.5 & 3.25 \\
\hline & .94 & .11 & .79 & .22 \\
\hline
\end{tabular}

4. nuber of lwoonslstant eriede

x. conftefient of conesotency

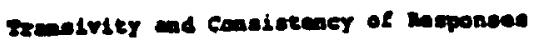

- Table 6 
interarrival times of tasks, which supports the hyrothesis of the existence of a undimensional psychological continuum associated with the attribute of subjectiv ental workload for medium and low levels of mental workload.

4- Absence of agreement among the subjects with rer nent to the ordering of the experimental cases according to their mental workload, and a very low degree of consistency (low transitivity of responses) at the shortest interarrival time indicate that either,

i) mental workload is a multidimer. cnal psychological attribute at high levels of mental workload; or,

ii) the difference between scale values of mental workload for cases become less noticeable (i.e., differentiable) at higher levels of mental workload, thus indicating the approach of an upper threshold of mental workload. The author accepts the second interpretation.

5- Analysis of consistency resulted in is higher depree of transitivity of responses for the agsregate data than that of each indivitual subjects' data exsept for the short interarrival time, thus indicating that the aggregate scale of subjective mental workload is a more reliable scale than the individual scales of the subjects.

6- Short and medium interarrival times are associated with cases which demand some degree of monitoring and decision making. whereas the long interarrival time is associated with cases that require little monitoring and decision making and may even provide fine times between the appearances of tasks. Therefore, the nature if the decision-making environment is fundamentally different for diffe-ent levels of interarrival times. At different levels of interarrival timeg experimentally controlled task variables and their interactions have different effects on the variation of subjectivi. mental workload, as discussed in detail in reference 5 .

7- The study supr l..ts the notion that slibjects form inter.mal models of environment bas:d on their own abilities, dispositions, and te. encies which resuit in their dissimilar perceptions of mental workload. In the analysis, the underlying characteristics of the subjects was inferred from their judgment patterns. The differences of opinion cmong subjects with respect to mental worliload occures when the subjects' personal characteristics result in adaptation of different strategies of action. It is postulated shat for environments, where inly one optimal strategy of action exists, trained subjects would be in better agreement. 
REFERENCES

1. Tulga, M.K., "Dynamic Decision Making in Multi-Task Supervisory Control: Comparison of an Oprimal Algorithm

2. Thurndike, E.L. " "Handwriting", Teach, Coil. Rec., 11. no. 2, 1910.

3. Thurstone, I.I., "A Law of Comparative Judgment", Pgychol. Rev. 1927, 24, 273-286.

4. Torgerson, W.S., "Theory and Methods of Scaling", John Wiley and Sons, Inc., 1958.

5. Daryanian, B. Subjective Scaling of Mental Workload in a Multi-Task Environment", M.S. Thesis, MT, February 1980. 


\author{
EFFECT OF COJYIING AXD TRACKING OX VERBAL AXD \\ PRODUCTIOX METHOSS OF TIME ESTIMATION \\ Kathleea L. Bird \\ san Jose state universicy \\ Sandra Aart** \\ Tufes Universicy
}

\begin{abstract}
This stuiy investigaced the effects of tine esiacion cechnique and task condicion on the production and verbal estiation of clae incervals ranging froe 5 co lisec. Sixteen alie college studencs yere ranjoaly assigaed co two groups, each of uhich utilized a Iifferent escinacion aethod: (a) production; or (b) verbal escleacion. The subjects tere lascrucced elcher co produce or co give a verbal estiace of che juration of chese cine lacervals during each task conditioa: (a) pretracking, (b) cracklag isubject perforaed a one-axis tracking task). and (c) postracking. Each subject uaed each of the cwo estinacton cechniques: (a) rocal countiaz and (b) no counting. The racto of the subjects tiae estiate to actual interval leagth uas coaputed for each cril.

Productions were cyplcally loager than rerbal estiates of the same duracion and produced duracions iere typlcally coo loag uhereas rerbal eaclaces vere coo shorc relactue to the correct duraclon. These effects were evident in boch the counting and aocountiaz condicions, with and wichout a concurtent tracklng tak.

A significant inceraction was found between counting techalque and tracking condition for both estiation eethods. Hhen subjects were inscructed to count cut loud they dere able to perfora an addicloas crackiag task while alataining consistentand accurate performance on the tine estiantion cask. In conctast, uhen subjects yere Instructed not to sount out loud, chelr abllity cokeep track of tine while perforelng a tracking task was reduced.

A sigiflcant effect could be ateributed to the addition of a cracking task: produced duracions lncreased lo length. whereas verbal estiates decreased la length. The juracions produced without counting rere olgnificantig lea accurace and consiatent itch the addition of a tracking task. Verbal estinaclon mean accuracy. but not consistency, was adversely affected by the addition of a tracking cask when the subjects vere instructed not co count.
\end{abstract}

- This research was conducted at NASA-Ames Research Center and was sponsored by NaSA grant MCC-2-34 to San Jose State University.

- This research was conducted at MASA-Ames Research Center and was sponsored by wSA grant NSG-2156 to Tuft ; University. 


\begin{abstract}
Perforaance on a secondary task is ofter used as an ladex of priasry cask worklosi. Many secondary tasks are designed to increase the overall worklosd in order co weasure residual capacity for work sti:l avallabl Jurlag perforeance on the alin cask. The assumption is that processing resources are linited and that perforance dill decerlorate when several activities coapece for the same resourcas (Noraans Bobrow. 1975). A secondary cask ay incerfere $u$ ith perforance on the ala task if it eaplus the sane sensory-motor pathways or incerferes functionally with ic (Michon. 1956). A secondary task eay employ the same sensory-aocor pachuay if for instance. an operator uatches a complicated display and calls out the inforation obtalned. While ac the aare tiae perforaing s secondary task that conslsts of calling out randoe wequences of letters presented visually. Less obvlous, hovever, is the possibility chat a secondary task ay incerfere functionally uith che ain cask whout akkigg use of the saee peripheral pathyays. For instance. If one of the tasks used to investigate workload was the selectlon of a changlng number in serles of elghe digle numbera and the ealn task consisced of deciphering nuaerical codes. che perforance of one rask vould interfere functionally w: h perforance on the other task even if one task was presented audicorially and the other visually because they require che saee processing resources.
\end{abstract}

An alternative type of secondary task is one which does aot incerfere utch che ezin task but joes requite sone atcent sa. Ag dicention required by the priary cask lacreases. second. task perforance decerioraces, chus providing an indirect eesure of priasty task deands.

Tiae estiaction tasks which aesure the infividual's abliliy to futge the passage of tiae under differeit circunstances have been used ss secondary aeasures of priwary task workload (Loldstona. Boardaan. S Lhawon, 1959; Hare. icPherson, Looals, 1978). is primary cask deands increase and atcention lo drawn away from clae esclasion, est laaces typtcally become less accurate anj oore variable. reflecting the level of concurrent priancy task deanda. However. this occurs without degrading perforance on the priariy task.

There are three experiaencal dechods coanonly used to obcasn clme estinstes: (a) verbal estlation. In uhich subjects vertally report fuigeents of elapsed tiae between presentaclon of atiall. (b) profletion, In which subjects physlcally generate a clae incerval spectiled by the experlaenter. anj (c) reproduction. In which sublects physically generate a tiae incerval praviously deaonsicraced by che experinenter.

It has been suggested that Individuals use two baslc aodes of estimation: actlue. (prospective) and retrospective. Active astination involves a conscious attempt to keep track of time continuously luring the designated intervai. Various timekeeping techniques an be tried such as counting, mentally 
replayinz zuslesl passaze of zppropriate turation, and countiaz heart beats or breaths. In retrospective astiation subjects a annot or to not atend to the passize of tina luetaz an tncerval. tnsteal. thay ay racall evants that occurrej luring tha interval, compare thaz teaporally dth axparlences of known juration. 301 arrive it an estiate of the laount of thae that elapsed furinz the intervil at lis conclusion.

Yliks, ylller, and cinsbournz (1976) have suzzesced that che apparent incoasistencles found smonj fifferent tiae estieation sculias ay ba ateributed to 3 fallure to Ilstinguish between ases (active and recrospective) eaployet. Blndra ant isksberg (1955) further suzzest these inconsistenciea lay be explainel ta teras of the expariaental athot (e.s.. production, verbal estinatioa, reprojuction) eaployej. For exalple, a comoon findinz is that the lenzths of proiusej ant verbally estiasted furaclons are Inversely ralated. Jleh the projuction asthol, subjests are required co perfora a task, e.3.. lepress key for a spacifled parlot of tae. If they atteapt to eaploy an uctlve ade of estintion sush is counting "one thousand one, one thousand two." and ara tistracted luring tha interval, they dill generilly resuae countinz where ihey lefe off. Thelr performance will, therefore, consiee vore tiae than they estinate, resulting in underestiation of elapsed tine and produced furation that is too long. If tistractel froa active tlaekeapinz Jurinz the presentation of an laterval uhose lenzth wust be verbally estinated, subjects will agala unjerestiate the alapset tae slace they tend to prerlook the perlod of tistraction la resurinz chelr countinz, and the verbal estinate d.iration. : l be too short. Thus the lengths of actively ale verb.l est.ates ant projuztlons, unter slalarly distracting condicions, will be inversely related lithough boch occur as a consequenze of unjerestiation of elapsed tiae.

Technlques such as counting or tapplaz that fosus the

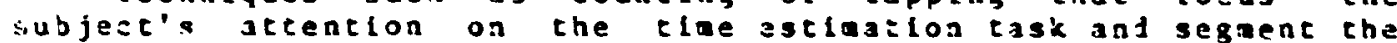
interval lnto concreze, stantarjized lates, result in protused $\therefore$ '.ations that are less varlable and less subject to the distractIng effects of suncurtent activity (Hact, MaPherson, S Loods, 1)79). $L \cdot 3$ concrete protuction techniques. sush as rentally replayirzas experlence of known duracion, resule in produztions that aore varlable and nore subject co jistraction froa concurre tasks. The accuracy ant zonststenty of active' naje verbal estinates should also be affected by the estlation technique enploye1. Techalques such as counting and tapplnz that fosus artention on the pass3ge of the should result in verbal estiates chat are less subject to the jistrating effects of concurrent activities. The interactive affects of estintelon technique and consurrent ac:-ovity on verbally estinated ant prodused turations has not be-l stulled in such a manci as to allod lirect conparlson between ire results obtalnad wlth the two rethods. 


\begin{abstract}
: ie proposed stuly exazlnad the effects of a consurrent asual control task on tine astimates ade by the verbal estlation ant production aethols. Spzcifically. It atceapted to ansier these questlons: (a) joes the presence of a concurrent task result in verbally estiated furations that are inversely related to profucloas obcalnzl under sidillar clecunstances? (b) Joes s vosalcountinz techaiqua resule ln core stable verbal estiastes than a no-countlnz teshalque wlth no sonsurent activlty? (c) lec verbal tha estlastes that use cojtinuous rocal counting affected by the introduction of a concurzent task? (d) lre verbal tiae estinates based on no systenatic estination teehnique affected by the latroJuction of a concurrent cask?
\end{abstract}

YETHOD

Subjzets

SIxteen ale colleze stujents ranzing in aze frox 19 to 35 servej 13 pald volunteers. They dere ilternately assignet by order of appearance to the verbal estiaclon nethod group or projuction sechod 3roup. None of the subjects hal particlpated la previous tine estiacton rasearch.

\title{
Appacates
}

This stuly was conducted in a sall, enclosed experifental chabar. The subjects were seated lone in coafortable chalr la front of a cathole-ray tube (CRT). A control stick ulth s response bucton was located flectly in front of the subject's shalr. The respoase butcon, uset to inlelace and teralnace productions and co bezin the verbal estiastion trials hat an audible click upon boch depressioa ind relezse. An tatercod transateter/recelver was locaced on the 3 lit naxt to the subject to slloy the subject and experianter to conaulcate verbally.

Visual display. The experteental tracklng task was ilsplayed on 39 c $x$ cr CRI whlch was located approximacely ac che subjeat: seye l-vel. The subject yas able to aljust the jistance fron the chile to the cit between tha range of 43.90 and 57.15 ca co llow for intividual differenzes in visual aculey.

Experlaencer's sracton. Data requlstilon and presentation of experizental conjlitions vare controllet by a Digltal Equlprent Corporation oj?-12 conputer. The experimenter was seatej outside of the experinenta chanber neat the POP-12 conputer. A secont Intercoa transiteter and recelver was located next to the axperinenter.

\section{Prosedure}

Subja:ts ware faniliarized with the experiaencal chander ant askej to put thelt watches (if any) in thelr pockets. Instrustons 3pproprtat for each expertaental condition dere read sloud and subjests dere glven three practlee trlals to faniliarize thex dith the procejure. Each subject was requited to use each of the twis 
time-ceapinz tachaiquas (vosal countinz ani no-countinz) anj one of tdo astiation athots (protustion or verbal estination). The subjects astiated or projused time intervals with and without a concurrent task. tll subjects recelved the follodinz sequeaca nf conlitioas for countinz and no-countinz: (a) no trackinz, (b) erackinz, ant (c) no trackinz. The order of preseatatlon of the experimental contitions was the saye for both the profuction ant verbal estination tethojs hodevar, half of the subjects reselved the nocounting trials first ant half cecalved the counting trials first. Thus, ejsh subject experiencad a total of six condtions ( $T a b l e l$ ). Ien duratlons, eash presented twlce, were presented in 3 Jifferent raniom orter for tha six conditions experienced by eash subject. The IJ Intervals ranged in length froa 5 to lit sec in l-sec steps.

Verbal Estinatioa. The lnterval to be verbally estinatel was demonstrated by fifferent messazes on the CRT. The assiges gestn INIERVAL and "END OF INTERVIL" proviled the interval bounjarles. The assage "INTERVAL" was displayed continususly furing the incerval. Subjects were requlred to lcknowledge that they had notlead the bezinnting and end of the interval presentation by pressinz the response butcon. After each interval a ressage "Est IMATE appearej on the screen indicatiag that the subjects should verbally report thele juigaent of the Juration of the interval (to the nearest secont) ovar the intercon systed. The experinenter then recorded each estinate. The leagth of the interval between presentation of erials was 5 sec.

Production. The messaze "BEGIN PROD.[N SECl- was displayad on the CRT (uhere N equals the number of seconds). The subject depressed the response buiton to latciate che profuston. The nessage on the screen changed to "PROD. [Y SECl" to reatint subjects of the cask called for. The subject depressed the response button azala when he felt that the spectelej anount of tiae had elapses. and the assaze, "ENo OF PROD." appeared on the screen. The subject produced the 10 different tine intervals twlce. The intercrial interval length was 5 sec.

Countiaz/no counting. In the no-countinz condltion, subjects were asked not to count (vocally or subvocally) or perfornany rhythal: activities while profucting an interval or during presentation of the Interval whose duration was to be verbally estimatej. They we instructed that if they should find theaselvas counting or tappinz, to try to think of sonething else anj report te to the exparlaenter. For the counting sonjtition, subjects wera asked to count iouj using the aethol "thousand one, thousand two, ete."

Irackinz task. The trackinz task conststed of a CRT display upon which wis lisplayed a moving $5.56 \mathrm{~cm}$ vertical line (the cursor). The subjects were Instructed to keep this curgor cencerej between two stationary 2.11 ca vertical lines by aneuverlnz the control stlik tight and left. Maxamum displacement of the cursor 
das 12.J7 ca subcenting a visual angle of .32 rats ( 16 teg of arc). yaxinum rate of cravel was 53.50 calsec.

The movement of the surgor was generated by the flltered output of randoa number generator. The rantoa zusber generator provided a rectanzular distribution of frequencles wich a baniwidth of 5) rat/ses. These values were passed through flrst order filter with a natural frequeacy of 1 rat/sec. The stantard jevlation of the forcing function was $1.18 \mathrm{ca}$ (ses Fizure l).

\section{RESULTS}

Effezt due to langth of interval

I $\mathrm{ch}$ subject gave two verbal estiaces or ade two productons for eash of tha 10 different interval lengths under each of $t$ : : six axperiaental coajiclons he experienced. The nean duration or the iwo estiates was ootalned and a ratio was formet with the leagch of the interval to be judged. Values greacer than 1.0 signifled verbal estinates or productions that were too long and values less than 1.0 signifled verbal estiastes or profuctions that ware too short. These ratios were conpared dithin each tiae estlation condition using twelve osz-way anslyses of variance for repeaced veasures to deteratne whether the length of the lnterval estiated resulced in relative Jifferences in subjective judgeencs of duration. Only one of these f values exceedes the critlcal value of 1.74 for 9 and 33 dezrees of freedon (DLxoas Yassey, 1957). Usinz the 10: s'sulficance level, it is expected that i in 10 f tests ull be falsely significant thus, the appearance of one sigatelcant $E$ value $(\underline{F}(9,63)=1.75, p(.1 J)$ ls aot unreasonable. Since no signiflcant differences were found for verbal esclares or productions attributable to the length of the tine lnterval judged, the acan ratios were conblnet for subsequent analyses.

Coupartson of pretracklnz and postracklng (averaze turation) 42 Tcountinz-no count $\frac{\operatorname{lng} \text { ) } x-2}{2}$ (pre-vs. posteracklnz) analysis of varlance with repeaced zeasures on both factors was compited injivilually on verbal estimates and profuctions. These analyses were performed to leterulne the relationshtp between estimates obtalned prlor to anj following the tracking task. Fith the protuction rethod, no slgntelcant effect atcributable to

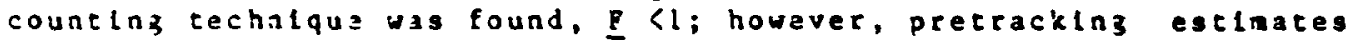
were signtfleantly shorter than posteracking estiates, $(1,7)=$ 7.85. $p<.05$. Tnere was no slgnifleant inceraction between countlng te=hnique ani pre- anj postracking estimaces, $F(i, 7)=4.11$, p >.05.

Nith the verbal estimation method there was no signtficant erfect atcributable to courting cechnique alone. F < i: however, pretracktng estloates were slgnlficantly longer than postcrackinz estimates, $\underline{F}(1,7)-5.29$, $P<.05$. No significant interaction between counting technique and pre- and postcracking estinates was 
Gani: $\because \cdots \cdot-?$

OF Fous G-RLiti

Eoun1, E $(1.7)=3.14$. p >.05 (s3as siguee 2).

Hthouzh pretrackinz produztlons were slzntfleantly shorter thin posteracking, thatr iveraze langth as still shorter ( 1.14 ) chan tha main of the zacking profustlons (1.32), as would ba expectej. Dretrazking verbal astlates dara lonzer than posterackinz estinates, however thelr averaze leagth (.91) was still longer thin lil tricking estinates (. 35$)$. In effect, the subjacts undarestinated =lapset time are at the ent of the expertaent than the bezinning for both the production ant verbal estimation aathods. Is prejleted, the lenzth of verbally estinated and produzad lurations were inversely related.

Compicison of pratcackinz and postcrackinz (variabilicy)

12 (countinz technlque) $x$ ? (pre-vs. posteracklnz contition) inalysis of varlance with repeated measures on both factors was perforaed on the within-subjacts stanjard laviations for the verbal estialion int projuction methoss individually to compare estinatas obtalinej before and aftel, protalng the tracking task. For the production acthod, there was no sign lcant difference between pre- and posttrackinz estimates, $f(1.7)=1.38, p) .05$. nor was there any signiflcant interaction batween sounting technique anj cracking conjlelon, $F(1,7)=4.55$, p >.05. Estimaces made without counting were signiflcantly more variable than those adse with countinz for both pre- and postcrackinz conjitions, E $(1.7)-19.25, p<.01$.

For the verbal estiation vethod there was no sizntflcant difference between pretracklnz and posteracklnz, F $(1,7)=4,12$, p $>.05$, nor was ihere a signifleane lnteraction between sounting techniqua and the pretrackinz and postcracklng conditions, $F(1,7)$ - 3.06. P >.05. There was s lgniflcant effect due to the counting techntque. F $(1,7)=18.10$, p <.01 (see Elgute 3 ).

Effect of counclnz techalque and tracklng conjltion on projustion nethoj (average duration)

The effact of countinz technique (counting ant no-countinz) and tracking conticlon (pretracklaz and irasking) on production gethof was evalusted using a 2 (countinz technlque) $x$ ? (trackinz conjieton) analysis of variance with repeatej geasures on both factors. There was as slgnificant differenze attributable to countinz techatqua alone. $F(1,7)=1.34, p>05$. There dis 3 slgnifliant difference attributable to tracking contition, F (1,7). 17.68. $P<.01$, ant a sgniflcast lnteraction batween countelnz ceshnlque anjeracklnz conjtition, $E(1.7)=12.19$, P<.05. Durtnz the pretracking condleton, productions obtalned with and without tha countinz techalque were not signiflcantly jifferent (Table 2 ). Howaver, whan subjests were requlred to perfora a concurtent trackinz task, productions ade without counting lncreased in length by nearly 50 : (fros 1.03 co 1.51 ) whereas the productions vide aleh counting lncreased only slighely (from 1.04 to 1.12 ). See Flgure t. 


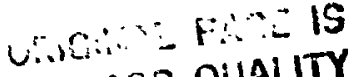 \\ OF PROR QUALITY}

Effect of cougting techntgue and tracking condition on production methol (varisbility)

12 (countinz technlque) $\times 2$ (pretracklng vs. tracklng condition) snslysis of varlance with repested neasures on both tactors was perforaed on the vithin-subjects staniard leviations of the ratios of protused Juration to the speclfied futation. Durations produced with no counting were signiflcantly noce variable chan those ade wlth countinz, F $(1,7)-18.87, \mathrm{p}<.01$. Although there was no signtfleant oversil difference in production variability ateributable to the tracklng conjition, $(1.7) \cdot 4.77$, $P$ ).05, there was a sigriflcant interaction between counting technique and cracking confleton, $p(1.7)=12.16, p<.05$. The aean scandard leviations canged frod .04 to.37 with no sounting and from .01 to .17 wich counting. With sounting, mesn standart deviations were . OS both with and without tracking. Hhen subjects were not 3 llowet to count, however, mean standard deviations increased to . Il with no concurrent tracking task and to. 22 for the trackinz conticlon isee sigure 5 ).

Effect of councinz technique and tracking condiclon on verbal estlastion method (average duration)

The effect of counting techolque and tracklng (pretracklaz vs traiklng) condition on verbal estiates was evaluated la. (counting technlque) $x$ ? (tracking condition) anelyets of variance with repeated measures on both factors. There das no signtflesit difference sttrlbutable to counting technique slone, $F$ <l ans no signifleant interaction between counting techolque and trackirg contition. $F(1,7)=5.33, p>05$. Pretracklng estiates were algnlficantly longer, $F(1,7)=15.62$, $<$ <.01, than estlates obtalned Juring tricking ( $.9 \overline{5}$ versus .79) althouzh both were shorter than the stanjard. Although there was no slgalfleant interaction between counting technique and tracking contition, the lifference between the aean ratios of the no counting condteion for pretracklaz and trackinz contletons was. 23 , whlle the difference was only .04 in the counting conjition (see Flgure 5 ).

Effect of counting ceshnigus and trasking condition on verbal estimation (variability)

12 (counting technlqus) $x$ ? (pretracklng vs. cracklng) analygis of varlance with repeaced sasures on both factors was perfortef on the within-subject standird deviations of the ratlos of verbally astiated to standird duraclons. Estinates ade dehout countinz dere signlfieantly are varlable, $F(1,7)=12.47$ $p<.01$. than those ade with countinz. but no alin effect due to cracking contltion was found. F $(1,7)-2.85$, p >.05. The interaction betwaen countinz technique ant tracking condtelon was slgnlfleant, $F(1,7)-7.10$, p<.05. Pretracklnz estiastes jere sore variable (.17) than estlustes obtalned in the trackinz condition (..11) for the no counclng technlque, a lecrease rather than the expeztes lnerease. With counting, sandarj deviations of verbil estinates were nearly ldentical with ant wlthout tracking (.0s 
Inl. .05, respeetLely). Sae Flgure 7 .

Comparison of the verbal estlagtion and production mechods (averaze Iusation)

The effect of estimation uethod yas exarined la 2 (estimation nethod) $\times 2$ (countinz technique) $\times 2$ (pretrasklnz vs. trasking

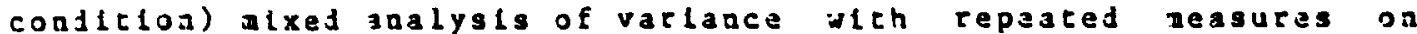
counting technique and tracking contlion. There das 318 sifi-

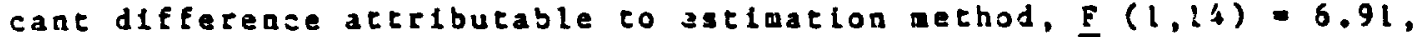
p <.05. Producel turatlons were typlcally lonzar than the stantart Whereas verbal estlates of duration dere typically shorter. There was no significant difference due to sountinz technlque alone, F $(1,14)=1.83, p$, $>05$, or trackinz conjltion alone (pretrasklns and trasking), F(t, $\left.f_{4}\right)=1.65, p>.05$. A signifleant lnteraction was found bacwee $\bar{n}$ estimaclon aechot and trackinz condition, $F(1,14)$ $32.36, p<.001$ anoag escleaclon method, counting tech̆nique, and tracking $=0$ atitioa, $\underline{F}(1,14)=17.30, p<.001$.

The length of the subject's productions lncreased at th the cracking task (with and without counting) hosever, chere ias less Increase when subjects were pernitced co count. The length of the subjects' verbal estlates lecressed Jurlaz the tracklaz task conditlon, wh ant without countiaz. Agatn, tha agaltule of the change was less when the subjects were parmitced to count. Durlng pretrackinz, mean produced durations were virtually the sane ileh and without counting ( 1.03 and 1.04$)$, hovever the verbal estiates wade with countinz (.97) were signtflcantly shorcer than those rade without $(1.05)$.

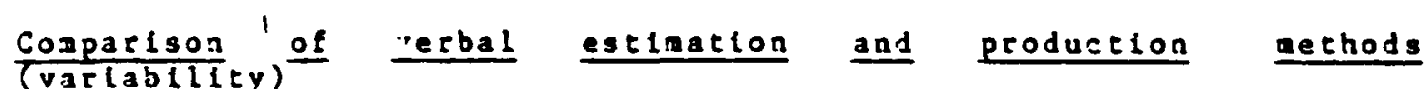
A 2 (estimatlon method) $x 2$ (counting technique) $x 2$ (pretracklng va. tracklaz contlelon) alxed anklysis of varlance wlth rapeated messures on tha counting techntque and trackinz condition was performed on the scaodard devlations of the ratios. No sizalficant differeaces actribucable to varlabllity were found for estlaation wethol, $E$ (l, or tracklng condition (pretracklnz vs. trask(nz), $F(1,14) \div 1 . i 7, p$ p. 05 . Varlabllity was stgatelcanely greate $\bar{r}, \underline{E}(1,14)=31 . \frac{1}{2} 9, p<.001$, for the no counting technique (ranze .04 50.37 ) than the countinz technlque (ranze.01 to.17). There was a significant interaction between astimation weshod and tracklng conticlon, $\frac{f}{(1,14)}=7.46$, $p$ <.05 and ancag estingtion zethod, countinz téchnique, and tracklnz coalition, $F(1,14)$. $18.89, p<.001$. Nith the counting cecholque, there was a slight incresse in aean varlability of verbal estinates with the ajdition of tha tracking task (frod.05 to .06); however, there was as change for the production method (.050 versus .050). Wlehout countinz, however, verbal esciuation varlabllity decreased between the pretrackins (.17) and tracklas (.11) condttions. Inerewas 


\section{ONIGIPIAL PARE !G \\ OF POOR QUALITY}

substantial tnarease in aean vartablitty between the pretrackinz (.11) and tracking (.22) conditions for the production method. The decrease in varlabltity for the no-counting verbal estiations nay have oceurret if the subjects becasa very distracted by the trackinz task ant responted by repeatedly teporting the saae astiate, therefore decreasinz tha variabllity anong estinates for the track$\ln 3$ conjlition.

\section{DISCUSSION}

Each subjact conslstently overestimated or underesinated the ilfferent lncervals by a relatlvely conststent percentage lndepenjent of the interval length. For this reason tha raclos of estluated to actual durations within each experimental condition wers pooled for subsequent analyses.

A conslstent differsace was found between the lengths of proJucet and verbally estlated Jurations: produstloas were conslstently longe: than verbal estinates of the sane tntervals (flgure 2). In addition, profucet durations ware typlcally too 1008 whereas verbal estimates were coo short relative to the correct duration. These effects were evident in both the counting and nocountlus contitions, wleh and without a concurrent tracklnz task.

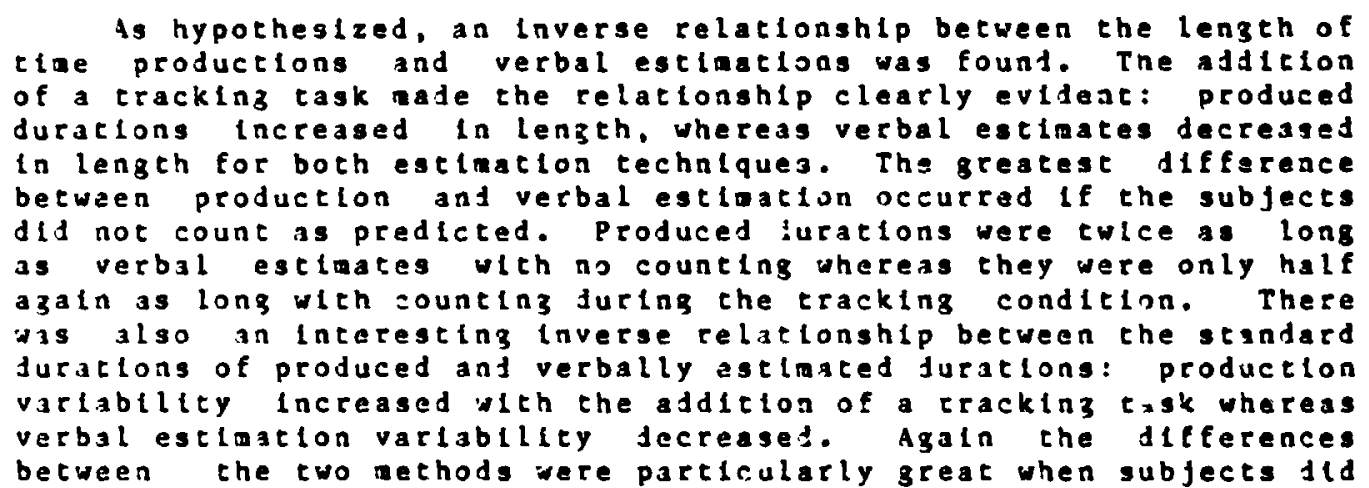
not count.

Although there das no stgntfleant difterence in productions or verbul egtiates due to counting technique alone, a sinfleant interaction was founj between councing cechnique and tracking conditi, n for both estiation nethods. When subjects were permited to use an overt form of thekeeping, they were able to perforn an adflttonsl tracklng task whlle malntatnlng consiscent and accurate perfornance on a production or verbsl estination task. There was only a slight decrease in the length of verbal estimations ind sight lnerease in the length of productions when the subjects performet a tracking task while vocaliy countinz. 
In concrast, when the subjects ware instructed not to count out loud, that abllity to kaep trick of tin? while perforning a trackinz task was reduced. The lurations produced without countinz were signiflcasty less accurate ant consigtent with tha judtion of a trasing task. Verbal estimation azcuracy, but not consistency, was adversely affected by the ad:ltion of a tracklnz task if tha subjacts ware instructed not to count.

Bacause performace on the tracking task was the same h both profuction and varbal estimation techniques, 1 appears the subjact's shift of tetention away frox time estimation with tha no countinz technique was not because subjects couls perform both tasks but metely that thay did not. When atect. u. as forused on tha tine estimation task by che countinz technique, production anj verbal estimation accuracy das not dezraded anj there was no concomitant dezrajation of tracklnz task performance.

These results support the finfings of Hart (1975) who asked subjects to estiate and profuce 10-, 20-, and 30-sec lntervals while performing six different comensatory tracklnz tasks. Production lengths anj arlabllity increased and verbal estimate lengths decreased as concurrent task difflculty increased.

The overall difference between the counting and no-countin?, techntque on the ratio of estinated to required time was greatcr for tha production pethif ( 1.25 vs. 1.13) than for the verbal estimation rethot $(.88$ vg. .85$)$ as was the difference ln average withln-subject stantard devlation (.16 vs. .05 for productions ant .13 vs. .05 for verbal estimates). In adjition, the magnitude of the tnteraction between counclnz technique and presence or absence of consurrent actlvity was greater for productions than verbal estidates. Whather or not the subject was perittef to vocally count did not seem to have as large an effect on the length of the subjects verbal estimates as it did on his proiuced lurations.

These experinental results support the findings of Hart, YcPherson and Loomis (1979) who report that techniques such as counting or tapping that focus the subject's attertion on the time estimation task sezment the Interval Into concrete, stanjardized unlts, resulting in produced durations that are less variable and less subjact to tha Jistracting effects of concurtent activity. Presumably, courting should have slalliar effect on the verbal estimation method and result in estlmates that are less subject the distracting effects of concurrent activitles, when in fact the subjects' estinates of the juration of the lincervals were quite slalliar for both the countinz and the no-counting contltions when the subjects performed the tracktng task.

The nature of the two estimation methods are somewhat fifferent. The production aethol is an actic process in that the subject plays a role ln actually produclng the time Interval. The 
verbal estimation method is a noce passtue proceps in that the subjact aust verbally estimat the Juration of the laierval but rlays no role in delimiting the actuli interval length. Bacause of che passive nature of the verbal estination method the posstblltey exists that the subjacts juiged tha interval duration relative so the precedinz lnterval or used some form of categortzation to jucige which incerval had wan presented rather that viowing the tine Intervils as a whole serles of indepanjent estinates. It is difficule co jeteralne if, $l_{u}$ fact, these aethodological differences contributed to the different experinental cesults, however the possibllity wust be considered.

4 stgniftcant difference was found between the pretracking and pos :rackinz baseline conditlons for the production and verbal estimation methods. The length of the productions lacreased froy pretracking to postcrackinz for both counting and no countinz =echniques, although the lacrease was greater without counting thar sith counting. Conversely, verbal estinates decreased in length for both the counting and the no-counting conditlong, and agaln the difference was greater with the no-counting technique than ior the countinz technique. Tnese results are slalltar to those reported by Carlson and Felnberg (1970) who fount that counting rate decreased from the beglaning to the end of each session for the production mathod. With a decreased counting rate, the length of the projuctions would be expected to lncrease. They turther reported an insrease in counting rate whth the verbal estiation nethod which would results in a decrease la the length of verbal estruatlong over trlals.

No slgrificant lnceraction was found between counting rechnique anf pre- anf posttracklng condlelong for elther estimation method desplte the fact that the no-counting and counting conditiong were affected somewhat differently by the trasking condition (pre or post tracklng). These contrajletory results nay have oscurred tue to th arge withia-subject varlabllity encountered in the no-countinz constition.

These cesulis would seez to suppoit llogan's ( 1978 ) prealse cnat borlnz tiae lintervals are experlenced as longer than nouborinz intervals. When subjects perforned a tracklnz task while verbaliy estlating the lengths of time lntervals, the estinstes decreasid in leagth. When they perforned a tracking task while producing tiae intervals, che productions increased in length. It is coaceivable that the subjects percelved the cracklnz task intervals as ore stimulating or lnteresting chan the non-tracklnz tntarvals, thus shorter. When the tracklng tast was rearod and the tine intervals ware less stimulating or Interasting for the subjects, verbal estinate lenzths Increased and prodiction leneths decreased, Infleatinz that ne subjects nay have experienced boredom. 


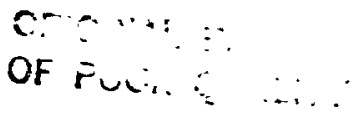

The lenzths of the postragklaz profuctions int verbal estlaicions ay hive 3 lso been Influencel by a fatique factor. The subjeses dere cequited to ljjust to the posctrackinj coniltion ifter they hid experlencet the rore stlauliclng tracklaz task conlition. The deczeisa in the sogntefveluocor stinulation ay have rasulted in less vialiant tetention to the rine esriagtion eask.

These cxportesial results fenonstrite: (a) The relative

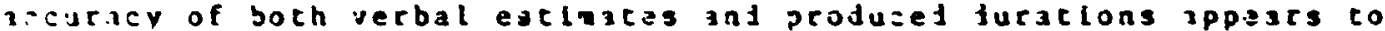
he rouzhly quivalent for scintard intervals canglaf fros 5 to 14 s:c, Intic tinz sons sonststency in Intivitust esclaction abllicy or strle. (b) is the difflculty of concuerent activity is increased. th. leazth of tiae protustons incrased ant the length of verbil estlations tecreasal. (c) If subjects count while producinz or verbilly estiesting the length of sa lnterval. tha resultinz estinates will be aore conststenl. (d) countinz technlquas (vocal countinz vs. no counting) differentially affect the lengths of tive projuctions int wibal estigations both in the presenze or absence of addlelonal tasks. (e) The lenzth of proluctions lacreased and the lenzth of verbal estinations decreased froe before trackins to tfer traskias. ( $f$ ) The affect of concurrent $l=t l v i c y$ on the sitiations was less pronouncel dhen subjects were pergitted to use the vocal councinz techatque anj ( $B$ ) Verbal estlast-s jbtalnel ileh both =ounting techniques were less affected by a consurrent task than were productions.

\section{REFEREVCES}

3inj:a, D.. S daksberg. H. Yethols anj Lerninolozy la scudies of tiae estiation. Psyshologleal Bulletin, 1955, 53 (2), 155-159.

Carlson, V.R. S Felnberg, I. Time judgient as a function of methi: practice, and sex. Journal of Experinental Psycholozy, $1970,35(2), 171-180$.

Dixon. W.J., Yussey, F.J. Introluseton to stattstical anslysty. Ned York: $\quad y=3 r a w-H I 11,1957$.

Hart, S.G. Ilae estiastion as a seconiary task to measure worklojt. (Prrecedings of the lith annusl Conference on ianus control. N.IS I T:1 Y-62, 45*). Hashlagton, D.C.: U.S. Coverament Priniliz Jiflce, 1975 .

Hart, S. G.. YePherson. D.. S Leomls. L. L. Paper presented at the i $9 \mathrm{ch}$ Innul Meeting of the Aerospaze Medical issoctation, Los inzeles. Californta, 1978 .

Goldstons. S., zoardasn. W. K., S Lhaman. W. T. Klnesthetlc cuas it tha levelopaent of tine concepts. Journal of ganetic Psysholezy, 1955, 93, 195-19, 


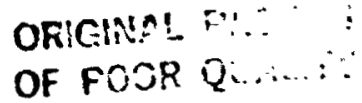

Htaks, R. E., Ylllier, S. A., S Klnsbourna, Y. Prospectlve and

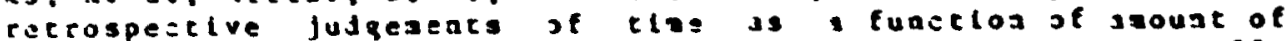
inforastion processed. Haertcan Journil of Piychoiogl. 89. $719-733$.

Hozin. 4.ג. I theoretisel reconcillation of coapeclas viess of ile perception. Alerfcan Jourall of Psysholozy. 1973. 91 (3). $417-\$ 23$.

ilchon. J. A. Ispplng rezulatity as leasure of percepsual nocor losj. Ergonoelcs. 1965,9 (5), 40!-\$12.

raran, D.1.. S Bobrow, D.S. On daca-lielted int rasource-lielted processes. Cogntelve Psychology. 1975. 


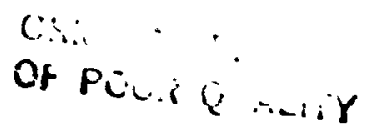

Table 1

Diagrjomatis Representaricn of

Experiaental Desizn.
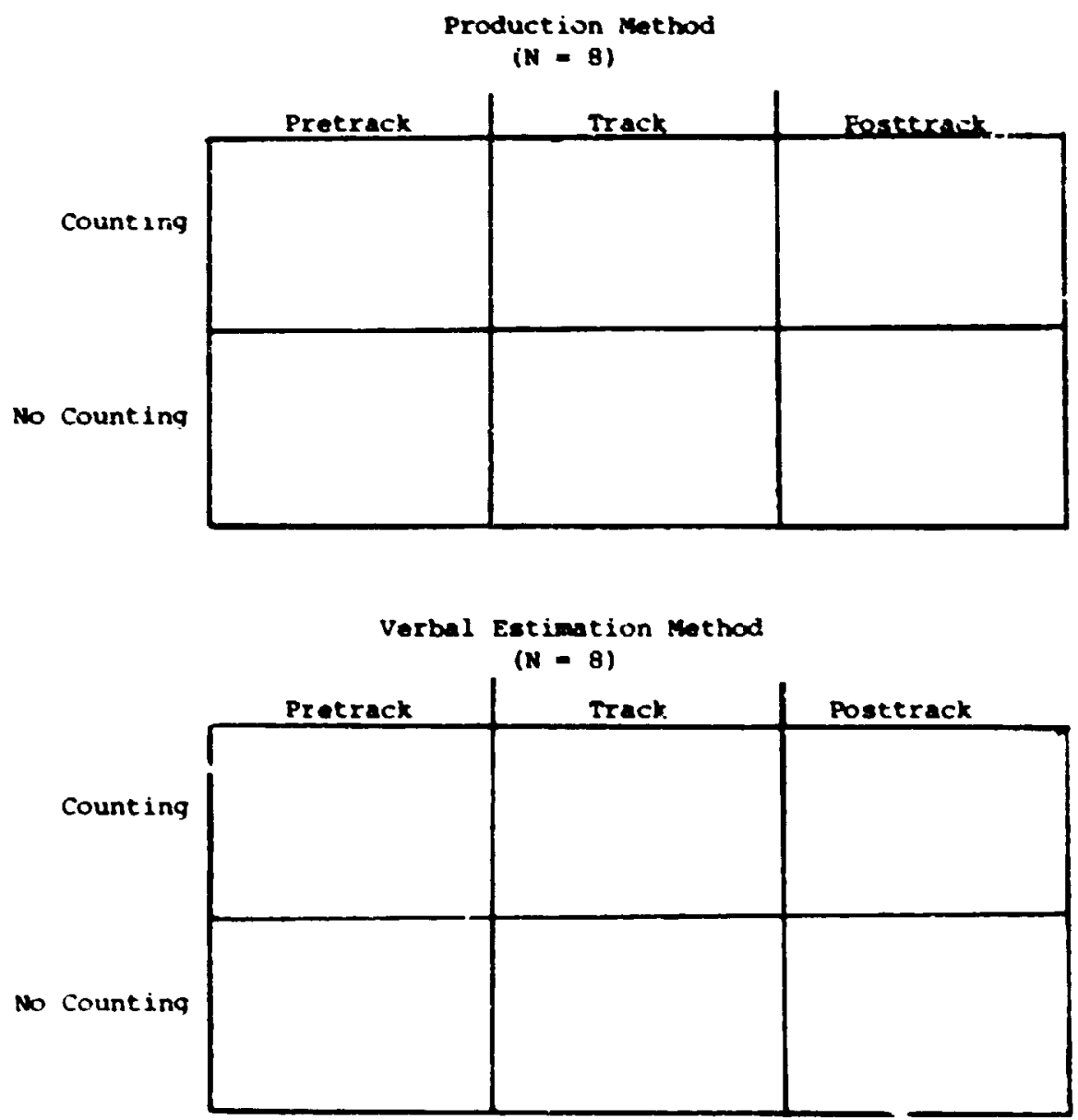
ORICINin F:EE IS

of POON OU.ALITY

rable 2

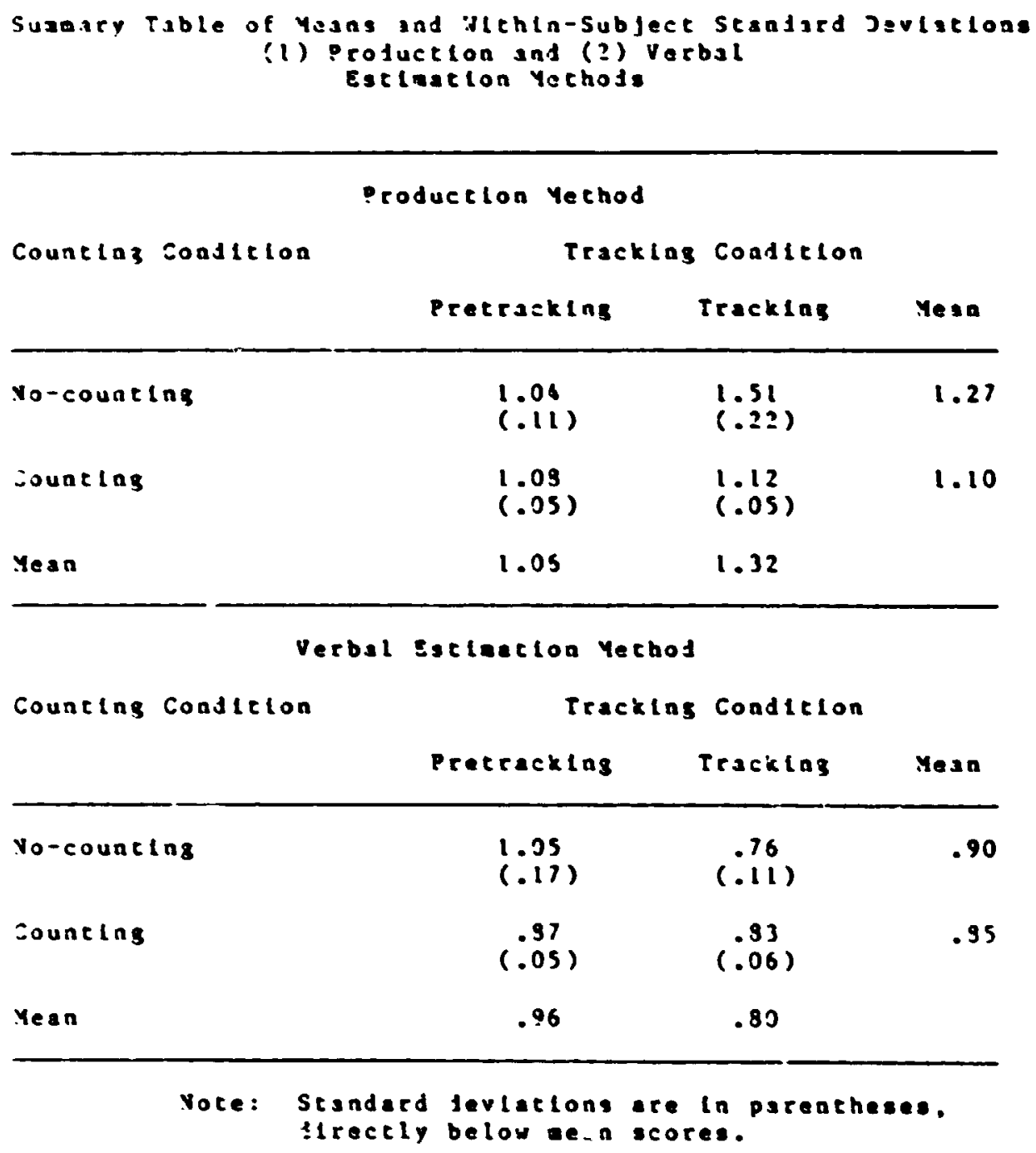

204 


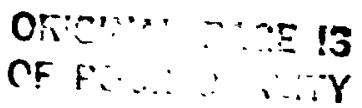

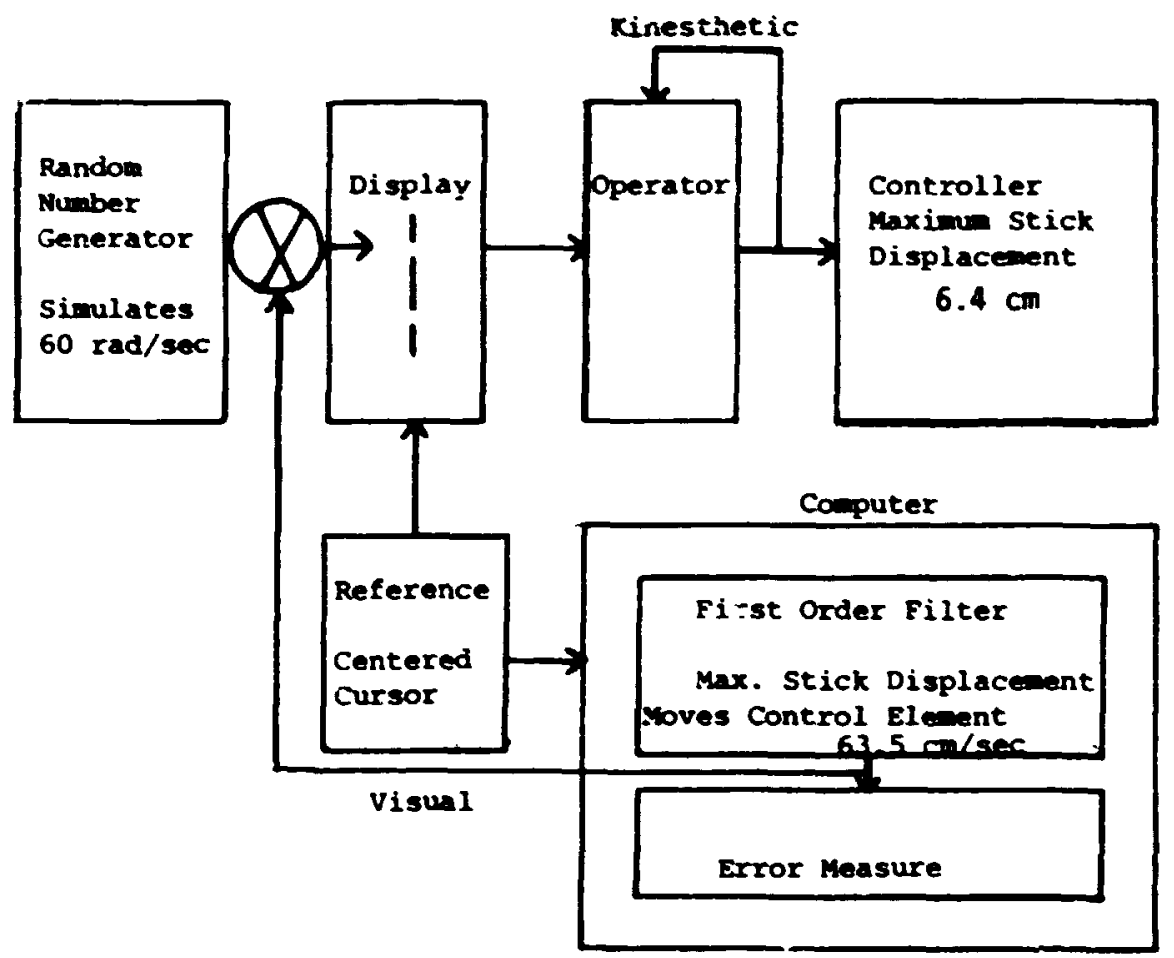

Figure 1. Diagramatic Representacion of Tracking Task 
ofic...:.

OF POOR Gutici?.

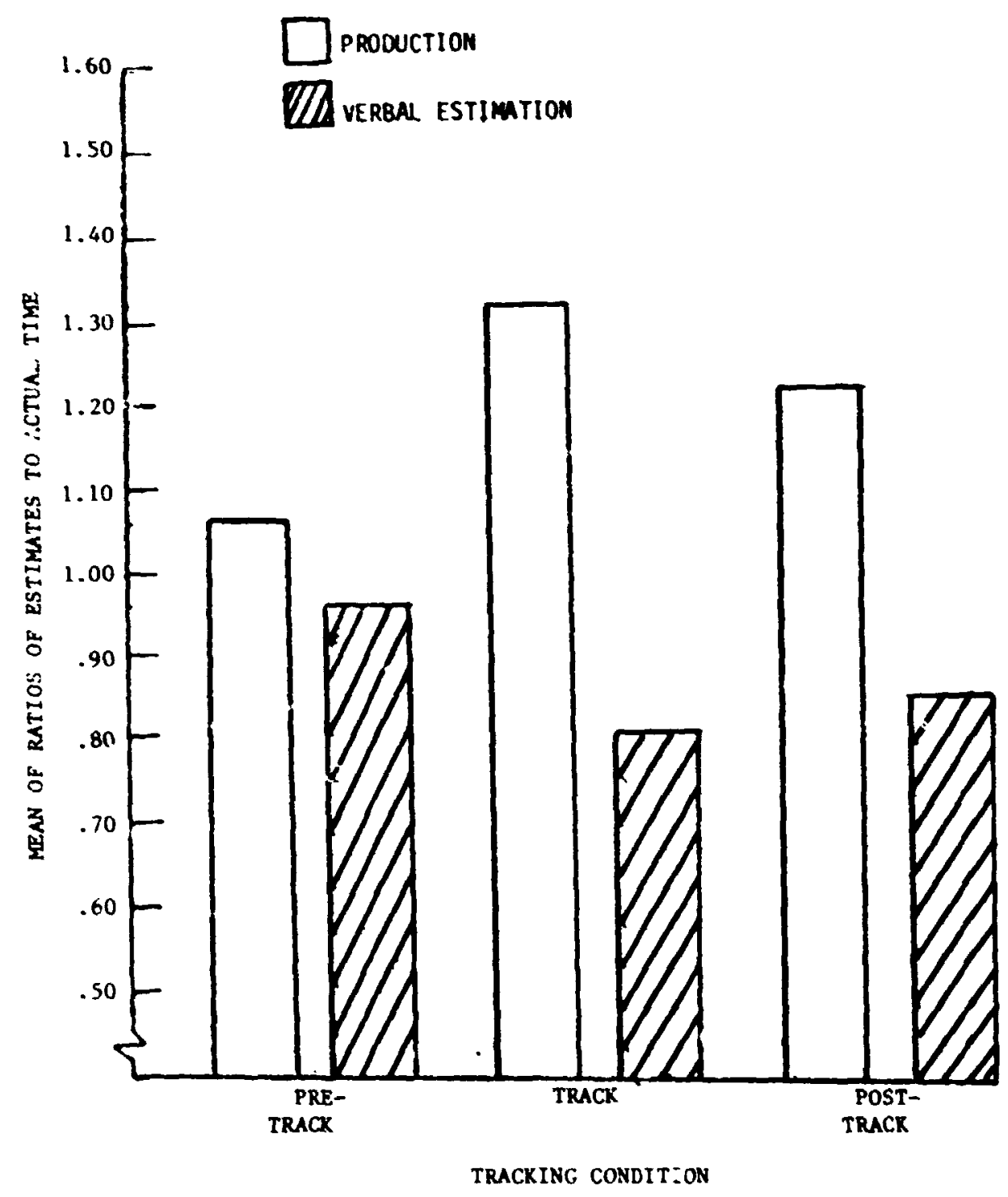

Figure 2. Man of Ratios of Estimates to Actuai Time for Production and Verbal Estimation Methods (N - B) 
OF POL.Y Q

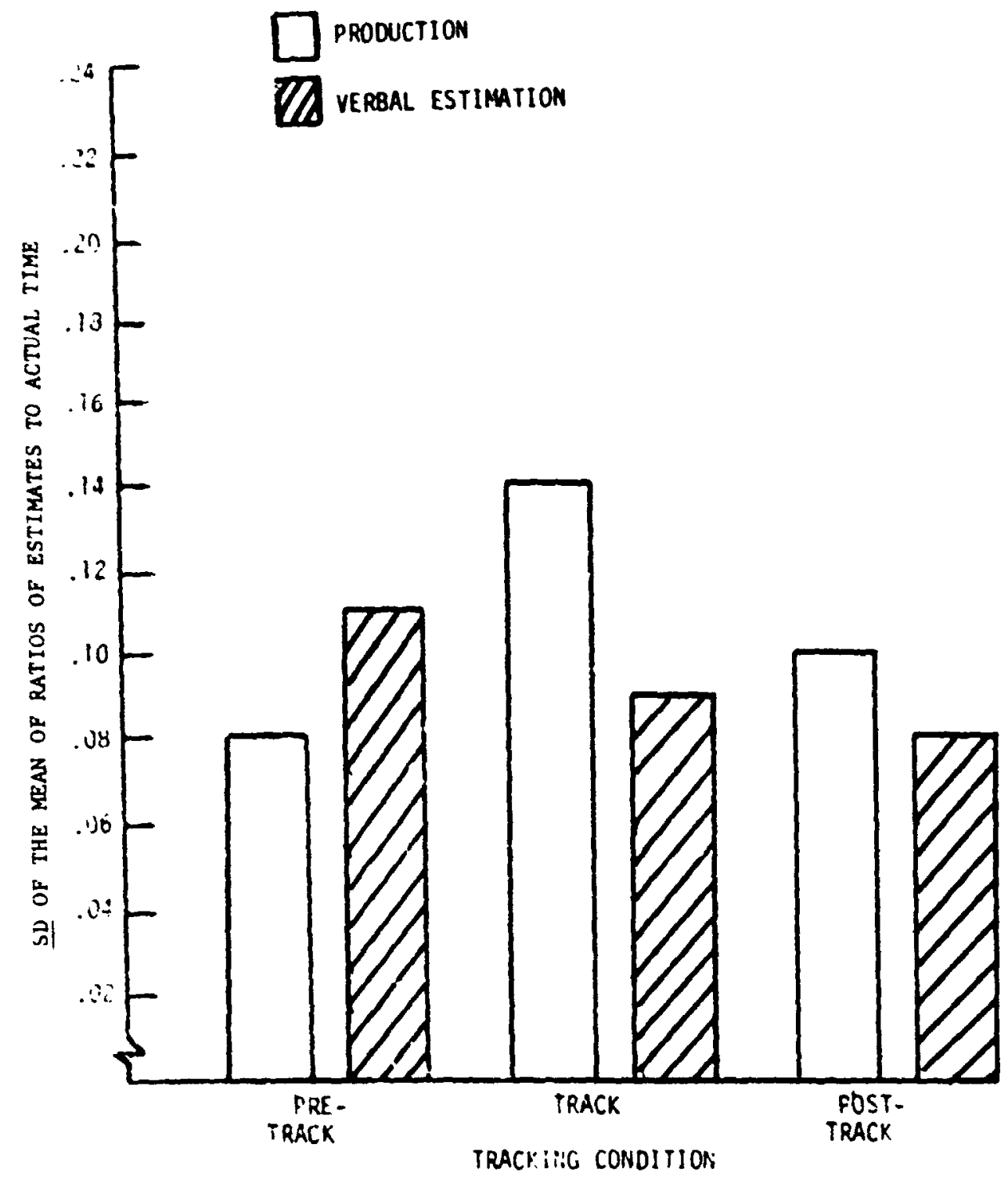

Figure 3. Standard Deviation of the Mean of Ratios of Estimates to Actual Time for Production and Verbal Estimation Methods $(N=16)$ 


\section{Oriti::}

OF POC.

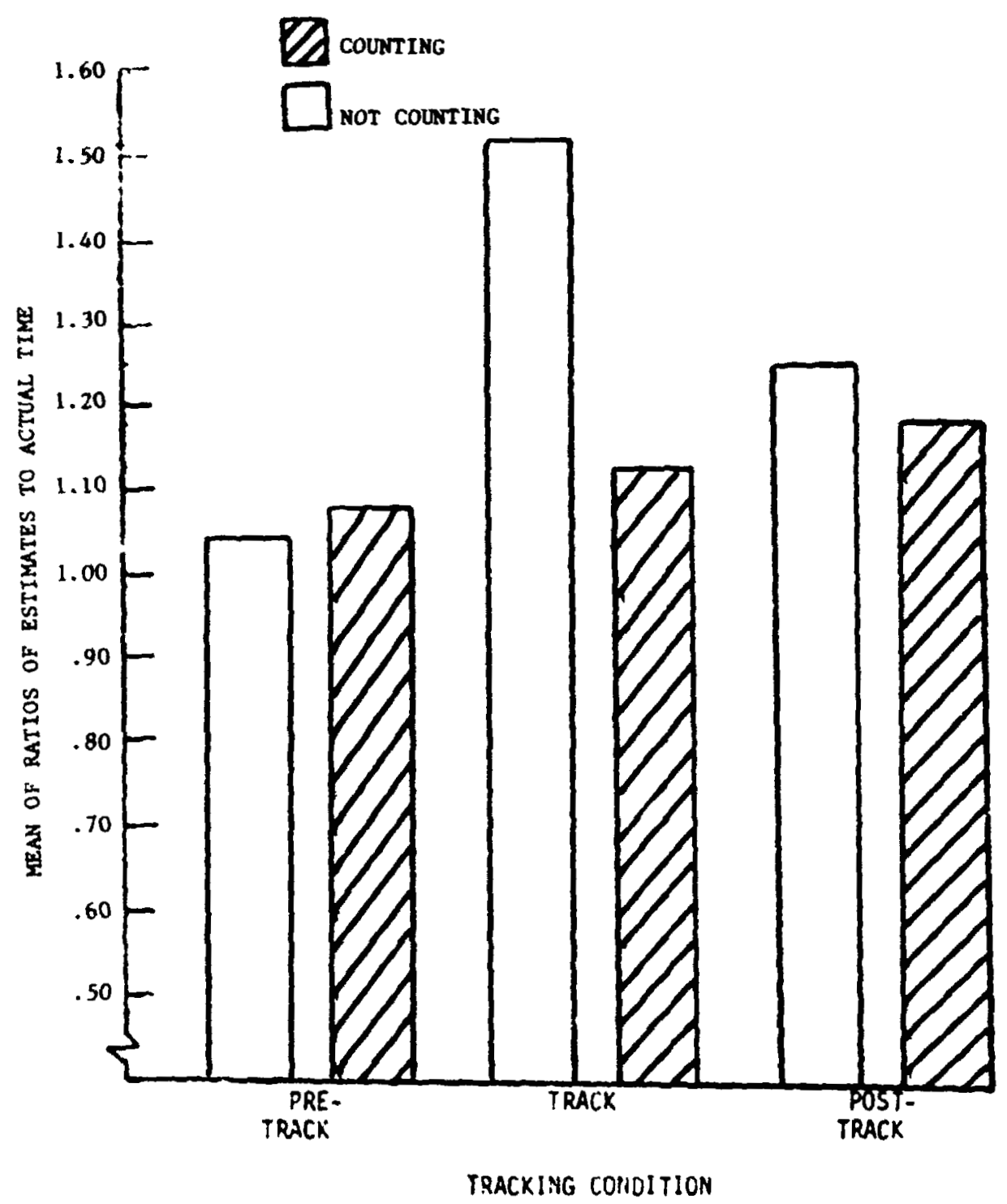

Figure 4. Mean of Ratios of Estimates to Actual Time (No Counting - Counting) for Production Method $(N \cdot 8)$ 

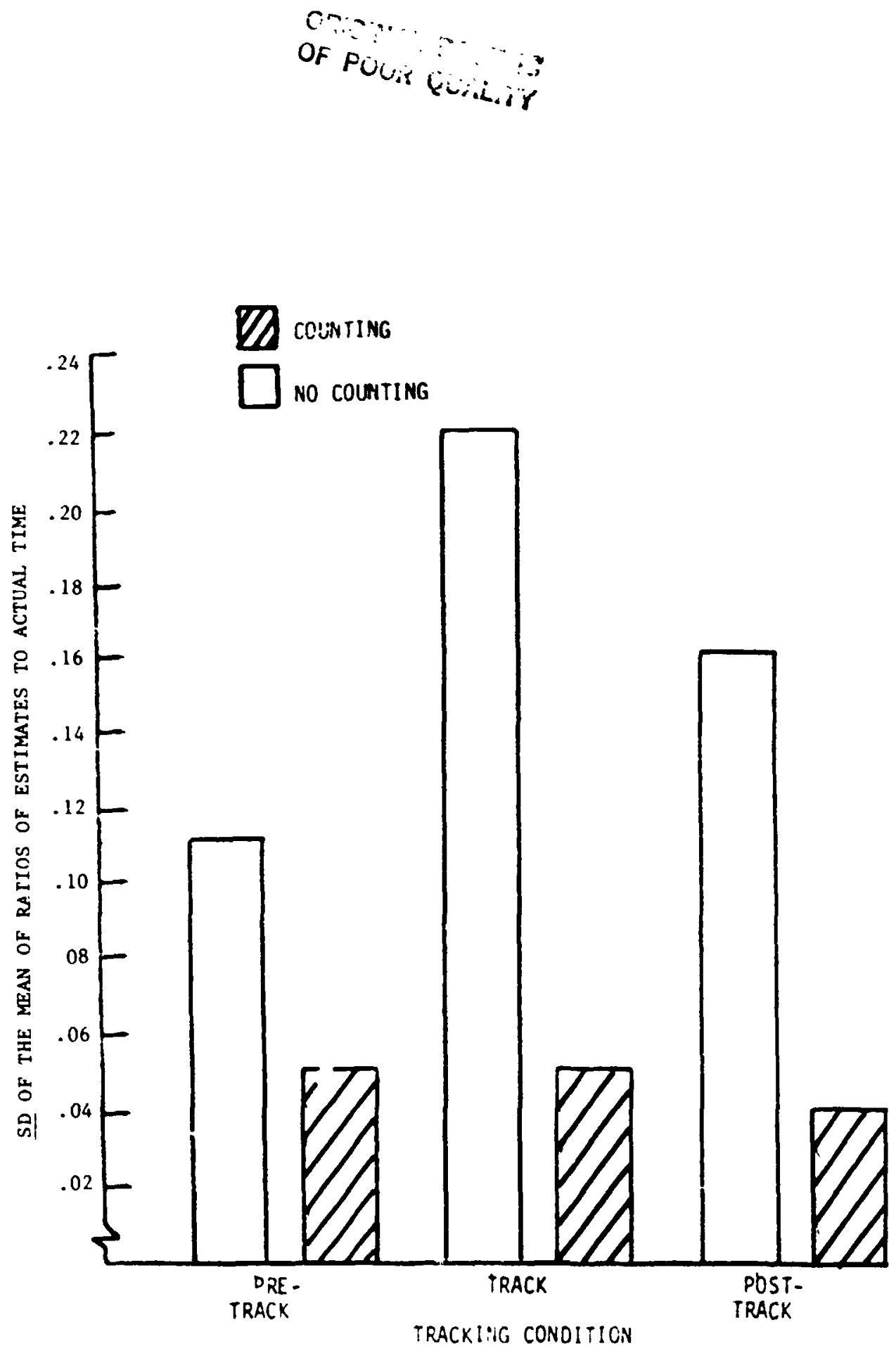

Figure 5. Standard Deviation of the Mean of Ratios of Estimates to / tual Time (No Counting - Counting) for Production Method $(N=8)$ 


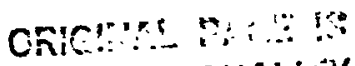

OF POOR QUALIIY

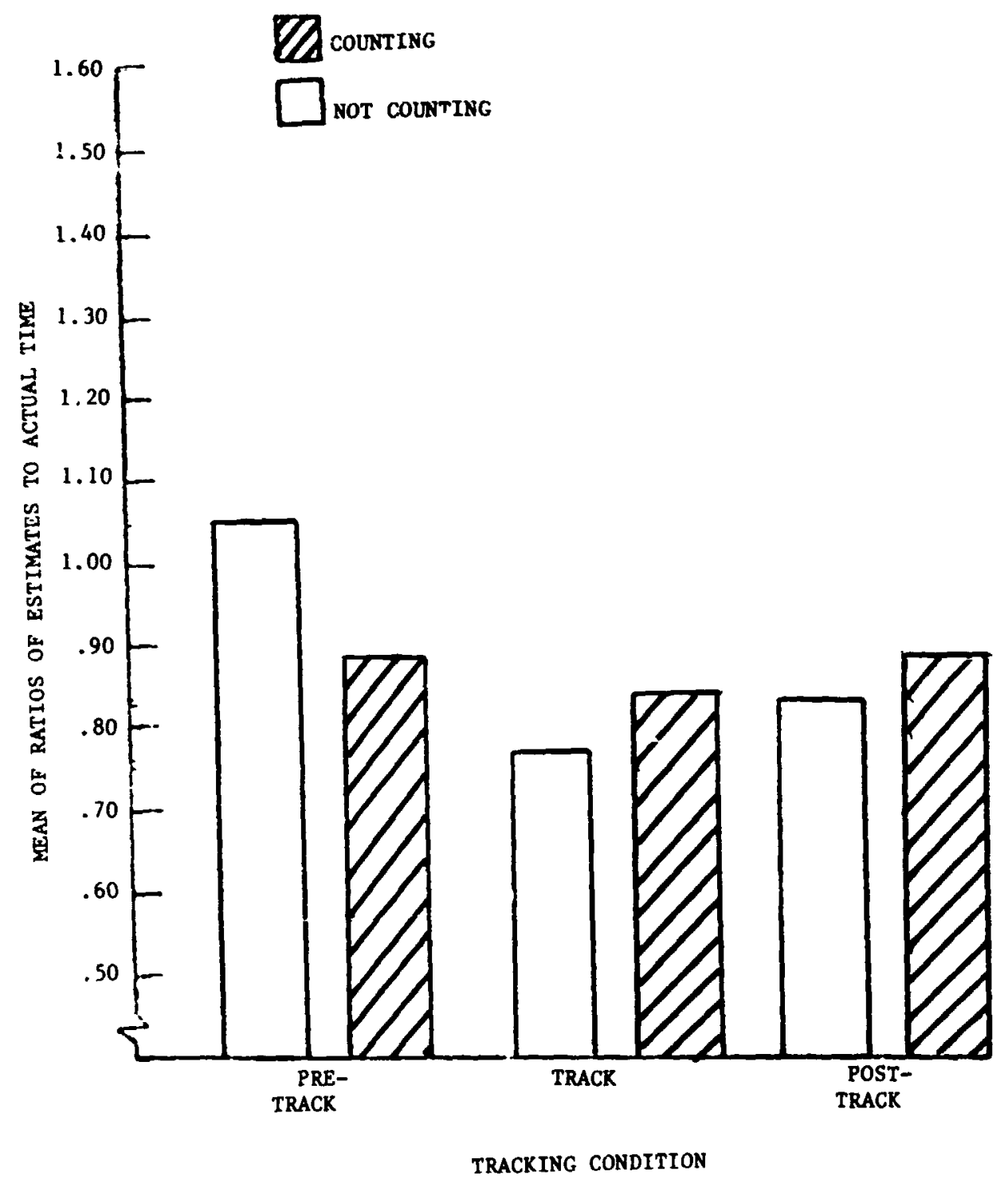

Figure 6. Kean of Ratios of Estimates to Actual Time

(No Counting - Counting) for Verbal Estimation Method $(N=8$ ) 

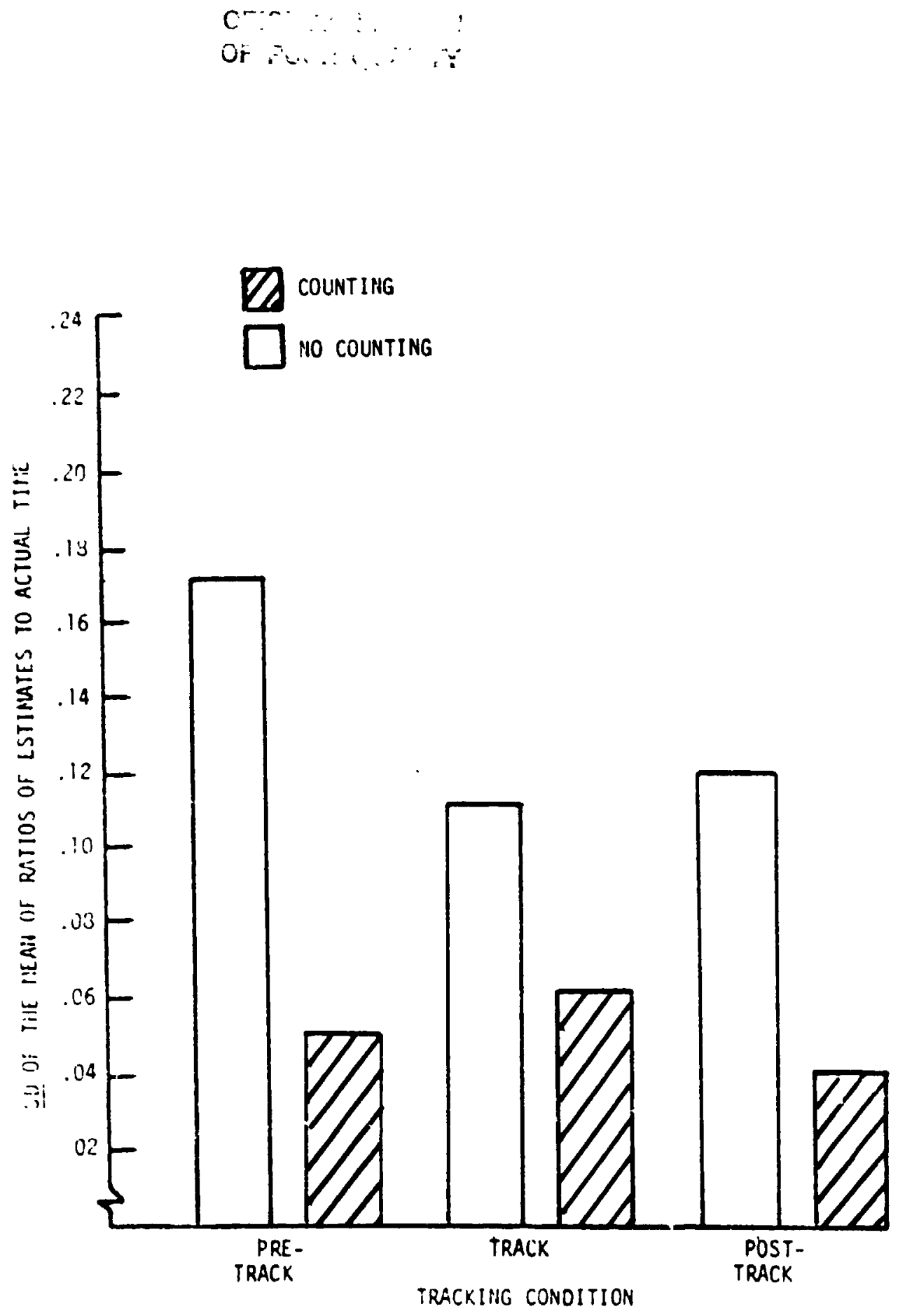

Figure 7. Standard Deviation of the Mean of Ratios of Estimates to Actual Time (No Counting - Counting) for Verbal Estimation Method $(N=8)$ 


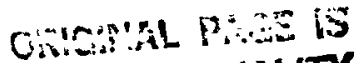 OF POOR QLIALITY.}

EFFECT OF ESTMMATION TECHNIqUE AND TAST CONDITION ON TIME ESTIMATION METHODS

Rathleen L. Bird, San Jose State Unfv, and Sandra G. Bart, Tufts Univ.

This siudy investizatad tia affacts of tine estination iacinizue and tusk sondition an the production and verbai estimation of tije intervals

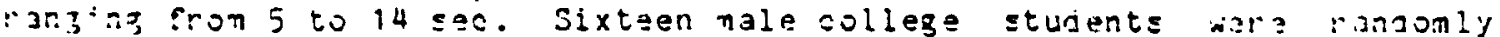

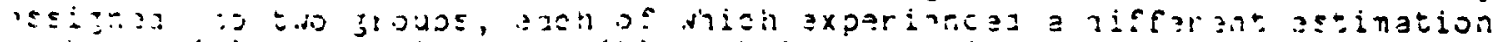
7otios: (a) provdetion; or (b) verbal estination. Tha subjects wera instruetza bo either produe or give a verbal estinate of the furation of inase ina intervals jurinz each task conaition: (a) baseline 1 (preFrackinj baseline); (b) trazkinz (subject perfornea a ona-axis tracklnz tusc); ans (c) baseline 2 (posttrackinz daseline). All subjects perfornea the tine astingtion task with each sondition using both estination teshniques: (a) vocal countinz ano (b) no counting. The ratio of subjects tine estinate to actual interval lenzth was computej for each trial.

A sonsiston: difference was foung between the lenjths of proauced zn: verbaliy estinated Jurations of tha 10 tine intervals. Tha subjects prosuctions were typically longer than the verbal estinates of iho sane juratian. Progucea aurations were typisally too lons and verbal estinates Nar a too short relative to the actual interval auration. These effects were eviaent in both the sounting and ro-counting conjitions, with 3 as without a concuryent trackinz task.

Estination technique alone jij not produce a siznificant effect for either tine estimation nethoo possibly aue to the larze within-subject variability for the no-countinj conuition. A significant interaction was foung betisen estimation technique anj task conaition for both estination methojs. Vhen subjects were instructej to count out louc they were able to jarform an adaitional tiackinz task shile maintaining consistent anj acsurate performance on the time estination task. In contrast, when subjects were instructed not to count out loud, their ability ta keep track of ilne while performing a trackins task was rejuces.

A siznificant effect could be attributed to the aojition of a tracki.:3 task: proouced jurations increased in length, whareas verbal esti7ates jecreasez in length with and without counting. The durations proaiced without countinz were signifiadntly less accurate and consistent vita the adation ot a tracking task. Verbal estination acouracy, but i.2t sonsistancy, was ajversely affected by the addition of a tracking task, if tha subjects were insiructed not to count.

These findings injleate that there is an inverse relationship betwes tha lenzth of subject's productions anj the lenzth of ve:bal estinztes. Nhen tije subject is instructso to vocally colint, tha withinsubject varizbility jecrezses and the subject's ability to estimate time interval Jurations is less affectej by performance of a concurrent trackinj tas'x. In contrast, when the subjest's were instructes not to count, the acsuracy of tina projuctions 3 an verbal estinates was hingerea by ihe azaizion of a concurrent traekinz task.

Parfornance on a secondary task, a.3., estinating tine intarvals, is ofien used as an injex of primary iask wiorkloas, in this a ase, $a$ conpensatory sracking task. The assunption is that processinz resources are ifitej anj tinat perfoinance will jeteriorate when several activitias ionpete for the sane resources. The results injicats that both tims setilation nethode were similiarly affectes by the adaition of a trackinj isc. The inoreas.3 in productio. lengths and secrease in verbal estinate linjihs bath resulted fron unjerastimation of eljpsod tine. ilia. subjects ware instrustaj to count, ans were jistractea by a task, the.' jener $311 y$ resunes sountioz where they left off. The interval, therefore, :onsum? gore ing than the subject estingtes lesultinz in proauses jurations that ware too lonz and verbal estimates that wore too short. 


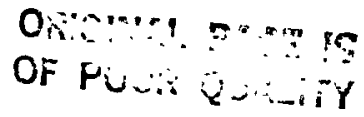

Jeff Ratz and Robert Simpaon

Flight Transportaion Laboratory, Dept. of Aeronautics and Astronautics, M.I.T., Cambridge, MA

Title: Pilot Workload in the Aip Transport Envi ronment: Theory, masurement, and the influence of Air Traffic Control

\section{ABSTRACT}

The operating envi ronment of an air tri isport crew is characterized by multiple inteirupting tasks, these tasks being composed of a mixture of purely physical control and purely mental planning processes. Measurement of crew werkload is thus a difficult undertaking due to the necessity to resolve workload contributions imposed by several sources. These sources include physical efforts, mantal efforts, random task Interruptions, and emotianal disturbances.

A subjective opinion rating scale is presented for use as an effective workload measure for this air transport cockpit environment. Flight simulator experiments will be run to evaluate the degree of pilot acceptance and the consistency and sensitivity of the rating scale. During these experiments other candidate workload measures (sinus arrythmia, task performance, flight control activity) will be recorded for comparison with the ratings from the subjective scale.

Finally, an analysis is presented which indicates that a major component of workload is induced by the federal air traffic control system. Machanizalions of this loading include speed and altitude restrictions imposed by regulation, confinement and restraint imposed by the structure of the National Airspace System, and loads induced by a stochastic interruption process associated with volce communications. Flight simulator experiments will be run that attempt to measure loading effects due to the presence of air traffic control volce communications during the approach phase of a flight mission. 
Workload and Pllot Eyw Scanning Behavlor

Tole.* J.R.. Ephroth. A.. Stophens. K.T., and Young, L.R,

Blamalcal Englneering Center for $C_{1} \ln (c a l$ Instrumantatian and Deportmont of Aeronoutles and Astronautles. M. I.T.

A number of schemes have been advanced over the years to measure the pllot"s mental worklood. These schemes include side task.. phisiolojical masures, and subjective questionalres. Lille these mothods work reasnnably wall in the laboratory and in ground based slimulators. geriurally they are not woll sulted to tho production of continuous. roal ime quantitativ data in flight. In an effort to deviop a technique sulteble for implementation in the fleld. we have investlgoted the plsot"a instrumert scanning behovior under varlous lewels of mantal loading.

In the current work. exporiments were conducted in the Torminal Conflgured Vekifel. (TCV) ground bossd flight simulator at MASA Langley Research Center. Three NASA test pllots wore presented with a plloting tosk. an arlthmetic task designed to vary mental la-tina, and a side task for cal tbration of the mental looding task. The pllot lookpoint was obtalited using a highly modifled Honoywel: oculometer system. Pilot oye scan of instruments was recorded in all cases, as discussed belaw. The piloting task inwolwed flying a curved Mlerowow Landing System (MS) opproach from a specif lod wapoint to touchdown. To alr in date andysis the approoch was divided into six sogments: downwind. turn to base. base. turn to approoch. opprooch. and fiare. Tho pillats were alded by a now generotion oi fl lght iristruments based on CRT displays which wore instolled in the simuletor

The mental laoding task was chosen so as not to interfere with the visual scanning of the pllot while providing constant looding during the oppr ach. A serles of ouenly spaced threo-number sequences which wore present a piually. The pllots were asked to werbolly lndicate the relotive ordering ct o sier!es. he wos instructed to give inese responses a priority equal to trie priminy plioting task. The difficulty of the task was centrollect by varying the interval betwen numbe sequences.

The workload mosuring slde task emplayed two 1 lghts, ane mounted sivove the other placed just outside the pllot"s peripheral view just abow the inst-ument panel. This wos done only when the pljot had tim left from performing the primory task of flying the airplane. Thus the number of correct responses on the lights gave a mecsure of the residual capacity of the pllot from which worklced can be colculated.

Tr.s conditions wre the presence or cbsence of traftic cother alrplanes In the sam approach pottern) on the pllot's CRT display. presence or absence of the side tosk 1 lggits. and montal loading lask (no numbers. three-number sequences at 28 sec and 16 soc intervals). Two rapl lcollons wore obtolnod for coch pilot.

$V i s u a l$ inspoction of $X-Y$ plots of pllot scan own each approoch segmont show iarge qualitative differences betweon ifferent lewis of loacing. First-order. discrete-state, discrete-transition Markou models ore used as $c$ Pirst step in the data analysis. It is assumad that workload is constant along each of the six approoch segments since the worklood and plloting tasky are essentlally constant over exch segment. This allow comporison of the instrument tronsllion motrlcles for occh segment with those obtailiod under different looding conditlons. The relatlonship betwen visual sconning and workload is given by the enange in the elemonts of these matrices as looding vorlos.

This work was stiported by MPSA cooperot iw agreoment ANCCI-23

maddress: Dr. J.R. Tole. 26A-113. MIT. Cambrlatie. Mass. 


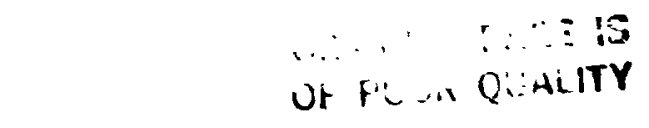

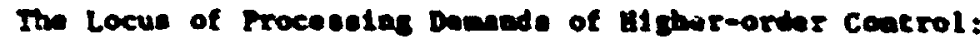

An Electrophysologleal Approach

Chrletopher D. Hickens and eleherd 6111

tairereity of Illinota

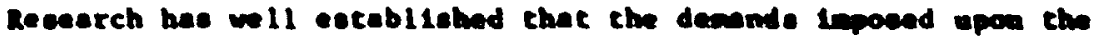

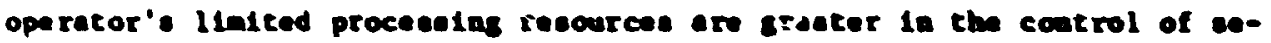

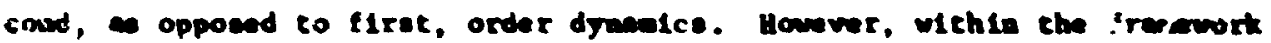

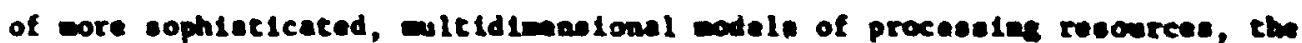
locue of such decande is not wil ecteblibhed, Second order coetrol ay

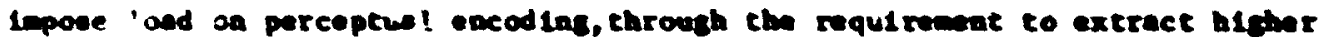

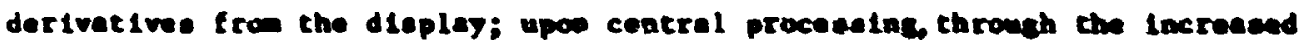

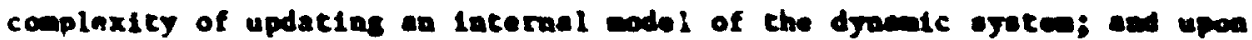
responee procesees, through the requiremat to gearrete alterantive "boasboag" respoese progrem.

In the data reported, the evohed corticel potentivi is aploged to pro-

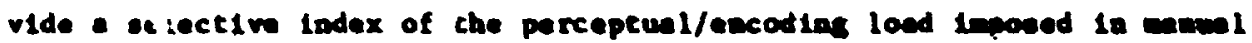

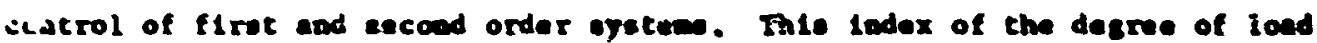
turthermore to correleced on e triel by crial beste with vartatione in pares

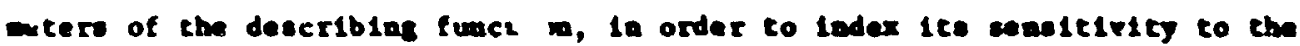
extent of loed generatlon end perceptual or notor nolee.
\end{abstract}




\title{
: N8234050
}

A Hodel-Based Technique for Predicting Pilot Opinion

Ratings for Large comercial Transports

Willian R. Levison

Bolt Beranek and Newman Inc.

50 Moulton street

Cambr idge, un

\begin{abstract}
A model-based technique for predicting pilot opinion ratings is described. Peatures of this procedure, which is based on the optimal-control model for pilot/vehicle systens, include (1) capability to treat "unconventional" aircraft dynamics, (2) a relatively free-form pilot nodel, (3) a simple scalar netric for attentional workload, and (4) a straightforward manner of proceeding from descriptions of the flight task environment and requirewents to a prediction of pilot opinion rating. The ethod was able to provide a good match to a set of pilot opinion ratings obtained in a manned simulation study of large comercial aircraft in landing approach.
\end{abstract}

\section{INTRODUCTION}

Manufacturers of commercial aircraft require nore general and nore reliable nethods of predicting aircraft handling qualities trian currently exist. Existing criteria have been developed primarily for military aircraft ard have been validated largely for high-performance alrcraft such as fighters. At present, reliable techniques for extending existing criteria to large comercial transports are not available.

This paper sumarizes the results of a study performed by Bolt Beranek and Newman Inc. (BBN), with the aid of Douglas Aircraft Company (Douglas), to develop and test a model-based technique for predicting the influence of aircraft response parameters and other relevant factors on pilot opinion ratings. While the procedure is intended to have reneral application, the focus in this paper is on large transports. Frequent reference is made to a manned simulation study performed by Douglas in 1975.** To facilitate

\footnotetext{
The research described in this paper was supported by NASA Langley Research Center under Contract No. NAcl-15529.

* This efiozt included a subcontract to Douglas Company to provide a data hase extractcd from the 1975 Douglas simulation study and to provide other consulting services. Mr. William W. Rickard was project engineer for the Douglas effort.
} 
discussion, the analytic study that is the subject of this paper will be referred to as the "BBN study", whereas the preceding sinulation progran will be referred to as the "Douglas study". Further documentation of the BBN study is provided in reference 1.

\section{Vehicle-Centered Bandling Qualities Criteria}

Bandling qualities specifications are based aloost exclusively on open-loop vehicle response characteristics ${ }^{2}$. Criteria are specified for botid transient response and frequency response characteristics. Requirements of this sort allow the aircraft manufacturer to evaluate aircraft performance through a serles of relatively straightforward in-flight tests.

Despite the relative convenience with regard to conpllance testing, application of vehicle-centered handing qualities specifications to large comercial transports is ilnited in a number of ways. For exanple (1) existing hancling quallties criteria have been developed prinarily for high-performance military aircraft; (2) nost existing criterla are based on siople models of aircraft dyneics in which phugoid and short-period response characteristics can be distinguished -- a condition not necessarily net by aircraft having relaxed static stability and substantial control augientation; (3) turbulence sffects are largely ignored; (4) effects of displays (ouch as flight directors). which may influence overall mission sultability, are not considered; and (5) present nethods do not consider effects of dynanic aeroelasticity.

\section{Model-Based Schemes for Predicting Bandling Qualities}

Pilot/vehicle analysis can allow considerably greater insight into the handing qualities of an alrcraft control systen than can be obtained by analysis of open-loop response, and the deands made on the pllot can be explored. The effects of external disturbances and control/display parameters, as well as inherent pllot linitations, can be consldered. Furtherwore, predictive schenes based on pilot/hehicle analysis are not constrained to deal with - conventional- dynaics and are thus potentlally more general than techniques based solely on open-loop vehicle characteristics.

Unt1l recently, application of pllot/vehicle analysis to studies of vehicle handilng quallties has been based primarily on servo or "classical" control techniques. Perhaps the most 
comprehensive effort of this type has been conducted by $R$. 0 . Anderson and his associates in the development of the "paper pilot" analysis scheme ${ }^{3}$. This scheme relates pilot rating to metrics of both closed-100p system performance and pilot workload, and it introduces the concept that the pilot operates so as to minimize his rating score.

Pilot rating is assumed to be an explicit function of system performance and pilot lead requirements (lead compensation being the index of pilot workload in this scheme). A frequency response pilot nodel is used in this scheme, and pilot parameters are adjusted to minimize pilot yating. Good matches to experimental data have been obtained for a variety of control tasks through appropriate formulation of the rating expression and adjustrent of the relative weighting coefficients associated with performance and workload (i.e.. pilot lead; $3-6$

While the "paper pilot: scheme realizes many of the advantages of a model-based approsch, Its applicability is limited by lack of gereral rules for choosing the form of the rating expression and for quantifying the various weighting coefficients. Other factors limiting the generality of this and other procedures based on servo-theory models include: (a) use of a relatively constrained fixed-form pilot model; (b) the need to assume specific loop closures prior to analysis; (c) a cumbersome treatent of pllot workload, especially when multiple loops are closed; and (d) the inability to account directly for factors related to the perceptual environment (e.g.) perceptual resolution linitations, whole-body motion cues).

More recently, Hess ${ }^{7}$ has described a scheme for predicting pilot ratings based on optimal (or "modern") control theory. Be suggests an index of performance that consists of a weighted sum of integral- (or mean-) squared error and control terms. "Error" is a vectur quantity that consists of the system variables that the pilot wishes to maintain within acceptable limits. The pliot is assumed to adopt control and estimation strategles that minimize this performance index.

Hess tested his scheme against 19 different configurations covering a range of pilot ratings. "Cost" coefficients of the quadratic performance index were chosen to match experimental scores, and pilot-related model parameters were chosen partly on the basis of previous results and partly to match observed performance. Pilot ratings could be matched to within \pm 1 rating unit by a linear relationship between pilot rating and the logarithm of tl.e performance index. More recently, schmidt has used this prediction scheme as the basis for a model-based control design procedure ${ }^{8}$. 
Although not validated as a reliable predictive tool, Eess" procedure lays the foundation for a schere that seens, overcowe some of the Iimitations inherent in techniques based on classical servo analysis. The basic forn of the perfornance index 18 consistent across tasks, the forn of the pllot model and nature of loop closures are deternined by the optinal pilot nodel and need not be specified by the user, a scalar metric of workload is provided, and factors rulated to perceptual enviroment are considered.

Perhaps the most severe ilnitation of the optinal-model-based approach, as developed so far, is the requirement to specify numerous task- and pilot-related nodel paraneters. To some extent, the "artistry" in specifying pilot model forns and loop closures for servo-theory nodels is replaced by the artistry in apecifying paraneters (especially weighting matrices) of the optinal-control model.

Another linitation, in the opinion of this author, 18 the lack of a suitable netric for information-processing workload. The netric proposed by Bess (the number of aysten variables to be regulated) does not appear to add to the rating scheme beyond what is encompassed by the performance index. That is, if workload is to be realted to controlled variables that are of concern to the pilot, then only those variables contributing significantly to the performance index will increase pilot workload. Such effect: are accounted for by the numeric value of the index itself.

The methodology described in this paper builds upon the work of Hess and encompasses a pllot rating prediction scheme based on the optinal-control model for pilot/vehicle performance. Bophasis is placed on the predictive aspects of the procedure, and a rationale is offered for selecting model parameters on the basis of an adequate description of the task and in the absence of experimental data. In addition, a vell-deflned model paraseter is suggested as a potential scalar workload wetric for the purposes of predicting pilot opinion ratings.

Because pilot opinion is assumed to reflect both pllot workload requirements as well as aystea performance capabilities, methods for predicting pilot ratings ahould include consiatent and straightforward treatients of workload.

The term "workload" is intended to refer to information-processing - rather than physical -- activity of the pilot. Speciflcaily, workload 1s considered synonymous with "attention" in the remainder of this paper. Although attention 18 not defined here in a way that lends itself :o direct physical 
measurement, the pilot model used in the rating prediction scheme does include. a parameter that can be related tc attention on both theoretical and empirical grounds. Thus, for the purposes of obtaining rating predictions, attention (workload) is an unambiguous and workable concept.

\section{METHODOLOGY}

\section{Basic Approach}

The prediction scheme described in this report is based on the following assumptions: (a) pilot rating is a function of the flight task; (B) for a given flight task there exist one or more critical subtasks which serve as the primary determinants of pilot rating; (c) performance requirements are well defined for each critical subtask; (d) pilot opinion is based partly on the degree to which desired performance is achieved and partly on the information-processing workload associated with the task; and (e) a reliable model exists for predicting performance/workload tradeoffs for relevant flight tasks.

These assumptions lead to the procedure diagramed in Figure 1. The following steps are required for predicting an average pilot rating for a specific situation.

1. Task Definition. Pilot opinion ratings are task dependent. For example, the rating associated with a specific vehicle, relative to other vehicles or other configurations of the same basic aicframe, may not be the same in final approach as, say, in high-altitude cruise. Therefore, separate assessments must be made for each flight task of interest.

2. Subtask Definition. Use of the methodology requires a quantitative description of the specific task or subtask for which predictions are to be obtained. For example, if ratings are desired for landing approach, a critical aspect of that task (say. ILS tracking) must be quantified. Task specification requires a linearized description of vehicle dynamics plus a quantitative description of the external environment le.g., spectral characteristics of the wind gusts if the subtask is path regulation in the presence of zero-mean random turbulence).

3. Define Performance Criteria. Performance criteria must be defined in precise quantitative terms. In order to obtain performance/workload predictions with the pilot/vehicle model used in this procedure, a quadratic performance index containing errorand control-related terms must be specified. The user must specify both the terms to be included in the performance index as well as 


\section{ORIGINAL PAGE IS OF POOR QUALITY}

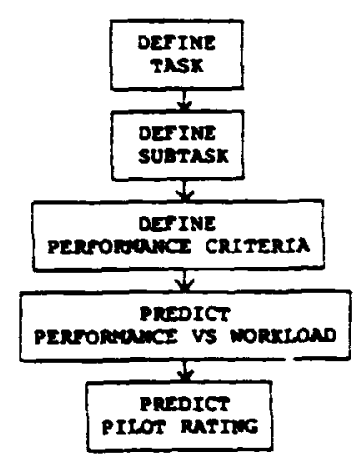

Figure 2. Procedure tor Predicting pilot Rating

values for the cost weighting coefficients. Cost weighting coefficients based on assuned maximu allowable values are suggested. As lllustrated below, these coefflcients are deternined partly from the physical constraints of the flight control systen, partly frow objective performance requirements of the closed-loop systen, and partly from pllot preference. The performance criterion used in the rating expression should be a monotonic function of this quadratic performance index.

4. Predlct Performance Norkload Tradeoff. The "optimal-control" pilot/vehicle nodel is used to predlct perfornance as a function of information-processing workload. "Workload"--considered synonyous with "attention" in the context of the mudel--is defined in terms of a model parameter relating to signal/noise characteristics of the human operator.

5. Predict pilot Rating. The results of the preceding step are used in a rating expression to predict the pllot rating. If 
experimental data are available for the flight task/subtask of interest, a regression analysis is performed to "calibrate" the independent parameters of the rating expression; in this case, absolute rating predictions are obtained. In the absence of such calibration data, rating parameters are adjusted on the basis of previous results, and rating predictions are interpreted on a relative basis with regard to predictions obtained for other vehicle configurations.

\section{Pilot/Vehicle Model}

The prediction technique described in this paper is built around the so-called "optimal-control" model for pilot/vehicle systems. The theoretical foundation for this nodel has been described in the literature, and the model has been validated for both simple laboratory tracking tasks as well as for more complex control situations. As discussed above, this model has also been shown to yield good handling qualities predictions?.

Only key features of the model are summarized here. Readers unfamiliar with the optimal-control model are directed to the references cited in Reference 1.

The human operator is assumed to adopt strategies of state estimation and control that minimize a scalar quadratic performance index. For airplane piloting tasks, this performance index consists of "error" terms relating to path, attitude, speed, and control variables. Pilot-related limitations reflected in the model inclucie information-processing delay, response bandwidth limitations, and limitations associated with attention-sharing and perceptual resolution.

Attentional and perceptual limitations are accounted for by a set of "observation noise" parameters. Each perceptual variable utilized by the pilot is assumed to be perturbed by a Gaussian white noise process linear.ly injependent of other such noises and of exteinal inputs to the syscem. In the case of an idealized single-variable tracking tast., the variance of each observation appears to scale with tha variance of the associated perceptual variable. In this case, response randomess is accounted for by a noise/signal ratis. A more complex definition of the observation noise variance has been derived for situations in which perceptual resolution limitations ire important?.

The model is able to reproduce pilot r'sponse behavior in a number of simple laboratory tracking tasks with a nearly constant value of noise/sigrial ratio of about 0.01 (i.e., -20 iB). The consistency of this farameter across tasks and across subject 
populations suggests that it reflects a basic central-processing (rather than perceptual or motor) limitation, and. these results have led to the following model for central attention sharing:

$$
P_{1}=\frac{P_{0}}{E_{i}} \cdot \frac{1}{E_{t}}
$$

where $f_{t}$ is the fxartion of attention devoted to the tracking task as a whole, $f_{i}$ is the subfraction of such attention devoted to display variable $Y_{1}$, and $P_{0}$ is the baseline nolse/sjgnal ratio associated with a high-workload single-variable tracking task (typically, $-20 \mathrm{~dB}$ ).

The attention-sharing model of $\mathrm{Eq}$. (1) has a theoretical base 10 and has been validated in a study of nulti-axis tracking by Levison, Elkind, and wardll, who found that this model yielded accurate predictions of mult1-axis system perfornance. Wewerinkel2 has also obtained generally good agreement between subjective workload assessments and "workload Index" based partly on this model.

The model parameter, $f_{t}$, representing attention to the control task as a whole, serves as the metrle for workload in the proposed handing qualities prediction scheme. Because it is a scalar quantity, it wiy be used in atralghtforward manner to fzecict handling qualities for mult-variable, multi-axis flight control tasks. Unlike miktoad metrics used in alternative model-based prediction schemes, the attention parameter defined here has a theoretical as well as empirical basis.

Because the predicted "cost" for a glven task increases monotonically with increasing noise/signal ratio, and because noise/signal ratio is related inversely to the attention paraneter $f_{t}$, cost is a monotonically decreasing function of "workload" as we have defined it here. Thus, if other independent model parameters are kept fixed, tradeoff curves of performance versus workload can be predicted for configurations of interest. As described below, these curves can be further processed to yield predictions of pilot rating.

\section{Prediction of pilot Rating}

In keeping with Anderson's philosophy ${ }^{3}$, pilot rating is predicted by means of a mathematical expression that includes both performance and workload effects. In general, "performance" is defined in terms of a scalar function of the signal deviations predicted by model analysis. As described above, "workload" is 
synonymous with the total attention to the task, $E_{t}$, which affects performance through the noise/signal ratio.

Best results in this study were obtained through use of a performance metric defined as the joint probability of one or more system variables being outside their respective "limits" (i.e.. maximum desirable values). The following alternative philosophies were tested and found to yield good replications of experimentally obtained pilot ratings: (1) pilot rating is determined by the performance achievable at some particular level of workload; (2) pilot rating is determined by the workload required to achieve some criterion level of performance; and (3) pilot rating is a continuous function of both performance and workload, and the pilot operates at a workload so as to minimize the numeric value of his rating (i.e., achieve the best ratina).

These philosophies were implemented, respectively, by the following rating expressions:

$$
\begin{aligned}
& R= 1+9 \frac{S}{S+S_{0}} \mid A=A_{0} \\
& R=1+9 \frac{A}{A+A_{0}} \mid S=S_{0} \\
& R=10\left[\frac{S}{S+S_{O}}+\frac{A}{A+A_{0}}\right] \\
& 1 \leq R \leq 10
\end{aligned}
$$

where $R$ is the predicted pilot rating on the Cooper-Harper Scalel3, $S$ is predicted performance in terms of a probability as defined above, $A$ is the attention model parameter (equivalent to $f_{T}$ of Eq. (1)), and $S_{O}$ and $A_{0}$ are constants of the rating expressions.* For convenience, we shall refer to these rating expressions as the "performance model", the "attention model", and the "minimum-rating model".

The first two expressions are intended as predictors of rating only, not as predictors of the specific point on the perfccmance-workload tradeoff curve at which the pilot will operate. The minimum-rating expression of Eq. (4), on the other hand, embodies the notion expressed by Anderson that the pilot trades between performance and workload in such a way as to minimize the rating score. In principle, use of the minimum-rating expression should allow one to predict pilot workload nd overall system performance as well as the pilot rating.

* Numer lcal values for $A_{0}$ and $s_{0}$ may vary from one expression to the next. 


\section{DATA BASE}

The data base used for developing and testing the handing qualities prediction scheme was obtained from two sources: (1) an experimental study performed by Douglas Aircraft Company in 197514, and (2) the results of a questionnalre, submitted during the course of this study, to the test pilots who participated in the Douglas study.

\section{Description of Experiments}

A manned simulation study was conducted by Douglas to explore the applicability of various handing qualities criteria to longitudinal flying qualities of large tre sport alrcraft in the landing approach. Criteria that were evaluated included several vehicle-centered criteria from MIL-F-8785B 1 , vehicle-centered criteria from other sourcesi4, and a pitch tracking criterion involving a closed-loop pilot model 2 . This gtudy is described in detail by Rickardi4; a summary of the experiments is given below.

The Douglas study explored a total of 42 vehicle configurations. The first group of 26 configurations were obtained by selecting stability derivatives typical of wide-body aircraft and either varying the simulated $\mathrm{cg}$ location from far forward to far aft of the neutral point, or by varying a single stability derivative. Configurations of the second group were obtained by specifying vehicle frequency-response characteristics and then solving for the stability derivatives. All handing-qualities variations were confined to the longitudinal control axis; lateral-directional a -igraft parameters were kept fixed throughout the experiment to pr ide response characteristics typical of a wide body transport.

Five Douglas test pilots performed evaluations of these configurations on a $3 i x$-degree-of-freedom moving-base simulator. Each evaluation typically consisted of two ILS approaches: the first performed in the absence of simulated atmospheric disturbances, the second in the presence of simulated zero-mean turbulence. Approach was initlated at a range of $7.4 \mathrm{n}$. mi. from $r$ unway threshold at an altitude of 1500 feet on the extended $r$ unway center line. The 3-degree gllde slope was intercepted at a range of about $4.7 \mathrm{n}$. ml.', the pilot flew down the glide slope relying on ILS instrumentation for path information to an altitude of about 700 feet, at which point the pilot transitioned to a visual display for flare and touchdown.

The test pilots were encouraged, in general, to perform maneuvers that would ald in thelr evaluations (e.g., intentionally 
impose and then eliminate a path or attitude error), but no specific set of maneuvers was required. A single Cooper-Harper rating was given by each pilot for the pair of stili-air and turbulent-air approaches for each configuration. Some configurations were evaluated more than once by some of the test pilots. Evaluations were performed on the basis of approach performance only; flare and touchdown characteristics were not considered.

\section{Configurations Explored in the BBN study}

The rating expression described in Eg. (2) - (4) were tested against eight configurations selected from the first group used in the Douglas study. Three configurations were chosen to span a $r$ ange of pilot ratings as well as a range of handling qualities problems. Modal characteristics for the configurations explo-ed in the $B B N$ study are given in Table 1.

The test pilots were assumed to utilize the ILs instrument, attitude indicator, and airspeed indicator as their primary displays during the instrument-flight portion of the simulated approach.

Zero-inean turbulence was simulated in the three linear and three rotational degrees of freedor in the Douglas study. Turbulence models (based on models suggested in the flying qualities specificationsl) were used to provide disturtances to longitudinal-axis variables. Rus $u-$ and $w-$ gust levels were $f$ ixed at $7.8 \mathrm{ft} / \mathrm{sec}$ and $6.5 \mathrm{ft} / \mathrm{sec}$, respectively. Further detalls on these gust models are given in reference 1 .

\section{Performance Requirements}

Application of the prediction scheme described above requires that one or more specific subtasks be selected for analysis and that performance requirements be specified for each subtask. To obtain this information, a questionnaire was prepared by $B B N$ and administered by Douglas personnel to 4 of the 5 test pilots that had participated in the 1975 manned simulation study. Through this questionnaire the pilots were requested to (1) state whether or not pilot ratings were determined primarily by longitudinal handing characteristics; (2) specify whether ratings were based mainly on the instrument-flight portions of the approach; (3) specify in order of priority, the subtasks that were important determinants of pilot rating; and (4) specify in as quantitative manner as possible the "desired" and "acceptable" levels of performance for each subtask. A sample of the questionnalre is provided in reference 1. 


\section{DIGINAS PAGE IS OF POOR QUALITY}

TABLE 1

Configuration characteristics

$\checkmark-140 \mathrm{kes} Y=-3^{\circ}$ we $=390,000 \mathrm{Lbs}$

\begin{tabular}{|c|c|c|c|c|c|c|c|c|}
\hline $\begin{array}{l}\text { Conf1s." } \\
\text { Number }\end{array}$ & $\omega$ & $\overline{s p}$ & $\omega_{\mathrm{ph}}$ & $\xi_{p h}$ & $a / a$ & $d Y / d V$ & $\begin{array}{c}W / T_{01} \\
\text { or } \\
\text { fw }\end{array}$ & $\begin{array}{c}1 / T_{02} \\
o f \\
\text { (E) }\end{array}$ \\
\hline 1 & 0.346 & 0.628 & 0.286 & 0.072 & 3.80 & $-0.0 \times 3$ & -0.186 & $=\frac{1}{-0.506}$ \\
\hline 3 & $(-0.633)$ & $(-0.307)$ & 0.086 & 0.318 & 4.16 & -0.069 & -0.082 & -0.356 \\
\hline 4 & $(-0.821)$ & $(+0.090)$ & 0.200 & 0.363 & 4.20 & -0.091 & -0.082 & -0.366 \\
\hline 5 & $(-0.909)$ & $(+0.158)$ & 0.184 & 0.210 & 4.24 & -0.053 & -0.082 & -0.560 \\
\hline s & 0.811 & 0.662 & 0.196 & 0.041 & 3.80 & -0.364 & +0.041 & -0.631 \\
\hline 13 & $(-0.991)$ & $(+0.225)$ & 0.211 & 0.388 & 6.29 & -0.055 & -0.082 & -0575 \\
\hline 16 & $(-1.06)$ & $(+3.291)$ & 0.210 & 0.331 & 4.35 & -0.097 & -0.082 & -0.583 \\
\hline 21 & 0.641 & 0.665 & 0.170 & $0.08:$ & 1.09 & -0.285 & {$[0.149]$} & {$[0.678]$} \\
\hline
\end{tabular}

$\nu_{\text {sp }}$ - shortapersod natural erequency, rad/zec

Fr - short-poriod dnping retio

$w_{p h}=$ sisugold setural Exequeacy, zad/sec

iph - phugoid damping tatio

$n / 2$ - normal accelozation pet unit angle of attack.

dr/dV - paith angle change per speed ehange, deg/ke

$I_{y}=$ numerator time sonstant, sec

1 signifies Elrat-ordir Eactor

- Consiguraeion number of :he Doirg is study $[25]$

All four pilots agreed that lateral-directional handling qualities were quite satisfactory and that pilot ratings were influenced primarily by longitudinal handling characteristics. They all stated that the instrument-flight phase was more important in determining ratings.

All subjects indicated at least three subtasks as important determinants of plizt rating. Relative imporcanre of these 


\section{ORIGINAL PAGE IS
UF POOR QUALITY}

subtasks fo the subject population as a whole war deternined from "priority . to*, computed by assigning 5 "points" to ar. Iten receiving highest priority, \& points to the next priority, and so on to 1 point for tasks ranked fifth or more in the list. Priority scores for each task are shown in rable 2, along with the total score obtained by summing across pilots.

\section{Table ?}

Priority Scores for Important subtales

\begin{tabular}{|c|c|c|c|c|c|}
\hline Subcask & $\mathbf{L B}$ & $\begin{array}{l}\mathrm{Pri}^{1} \\
\mathrm{BM}\end{array}$ & $\begin{array}{l}1<y \\
\mathrm{JM}\end{array}$ & $\begin{array}{l}5 c o r \\
\text { AT }\end{array}$ & Total \\
\hline 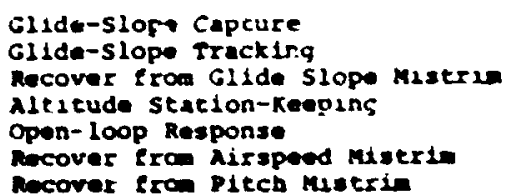 & $\begin{array}{l}5 \\
4 \\
3 \\
- \\
-\end{array}$ & $\begin{array}{l}5 \\
- \\
3 \\
4 \\
2 \\
-\end{array}$ & $\begin{array}{l}4 \\
2 \\
1 \\
5 \\
3 \\
1 \\
1\end{array}$ & $\begin{array}{l}4 \\
5 \\
1 \\
- \\
- \\
-\end{array}$ & $\begin{array}{r}18 \\
11 \\
11 \\
3 \\
8 \\
3 \\
1\end{array}$ \\
\hline
\end{tabular}

Table 2 shows that 1 atings were largely deteinined by the ability of the pilot to regulate path error. Highest priority was given to tasks involving transient maneuvering (glide-slope capture, correcting self-induced height arror). Next in importance were zasks requiring continuous regulation of helght error (al-itude station-keeping prior to glide slope acquisition, post-acquisition glide-slope tracking). Open loop response and correction of pitch and airspeed mistrin were of substantially less importance overall in terms of influencing pilot opinton.

Obtaining quantitative comments related to performance requirements was considerably more difficult than anticipated. Only two of the four pilots provided quantitative responses, and only one of these (Subject JM) difierentlated between "desired" and "acceptable" performance. " Performance requirements indicated by these two subjects for tagks requiring continuous regulatinn a-e given in Table 3 .

To ald the pilot In making this distinction, adequate
performance was defined in the qurstionnaire as corresponding to
the boundary between a rating of 6 and 7 , whereas "desired"
performance was to be associated with a cating of 1 .




\section{ORIGINAL PAGE IS \\ OF POOR QUALTY}

Table 3

subjective Peifocmace Dequiremes

\begin{tabular}{|c|c|c|c|c|c|}
\hline \multirow[b]{3}{*}{ Wigat Error } & \multicolumn{4}{|c|}{$\mathbf{m}$} & \multirow{2}{*}{$\frac{\infty}{\text { es }}$} \\
\hline & $\begin{array}{c}\text { Alt. } \\
\text { osidiced } \\
\end{array}$ & $\begin{array}{l}\text { gulatios } \\
\text { accectenble }\end{array}$ & onstred & $\begin{array}{l}\text { recleing } \\
\text { necopteble }\end{array}$ & \\
\hline & $\pm 30 \mathrm{et}$. & $\pm 100 \mathrm{Et}$. & $\pm 1 / 4$ dot & $\begin{array}{l}+1 / 400 \% \\
\text { et } 200 \% \\
\text { te } 1100 .\end{array}$ & $\pm 1 / a$ dot \\
\hline $\begin{array}{l}\text { Sintrate Exror } \\
(f(t) / \text { ext }\end{array}$ & $\div 200$ & \pm 300 & $\pm 2 e$ & \pm 500 & - \\
\hline $\begin{array}{l}\text { Airapoed Erxor } \\
\text { (keooss) }\end{array}$ & \pm 5 & \pm 19 & \pm 2 & \pm 5 & $-5 .+10$ \\
\hline
\end{tabular}

\section{Pilot Ratings}

Mean and standard deviations of the pilot ratings obtained in the Douglas study are given in rable 4, along with handling qualities levels as detrinined from two of the vehlele-centered criteria considered by Rickard. Rating statistics were derived by first averaging nuItiple ratings (where such existed) for each pilot fo: each configuration, and then using these averages to compute a mean and standard deviation across subjects for each configuration. Table shows both a wide spread of average pilot ratings across the configurations explored in the BEn study as weil as a variety 0 : handling qualities problens. The ohort-perlod response criterion predicts adverse handling qualities for five of the configurations - four of which exhibit static iristability. Two of the renaining configurations, on the other hand, exhibit adverse flight path stability (dY/dv).

\section{TEST OP MTTEODOLOGY}

The prediction schene described above and diagraned in Flgure 1 was applied to the data base obtained in the 2975 Douglas study. In order to apply this schese, twenty independent wodel parameters had to be specifled. As the following discussion demonstrates, eighteer. of these paraneters were defined largely on the basis of task analysis, tempered by some er.gineering judgement. Once selected, three paraneter values were held flxed throughout the analysis; only the two parameters of the rating expression were adjusted to match experimental data.

Ratings shown for Eonfloueations 4 and 5 differ sighty from those presented by Rickard, who computed the mean of ail ratings pertaining to a glven configuration regardless of the number of evaluations per pilot. 


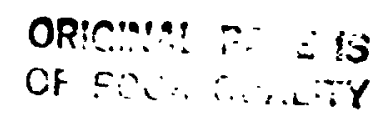

$\operatorname{Table} 4$

plor opinion ketings

\begin{tabular}{|c|c|c|c|c|c|}
\hline $\cos 2 \times \theta$ & $\begin{array}{l}\text { P1lot } \\
\text { manan }\end{array}$ & $\begin{array}{l}\text { Rating } \\
\text { I so }\end{array}$ & $\begin{array}{l}\text { ldridy } \\
\text { Lenel }\end{array}$ & $\begin{array}{l}\text { so re. n/a } \\
\text { corel }\end{array}$ & $\begin{array}{c}\text { seacic } \\
\text { stability }\end{array}$ \\
\hline $\begin{array}{c}1 \\
3 \\
5 \\
15 \\
15 \\
21\end{array}$ & $\begin{array}{l}2.3 \\
4.3 \\
1.2 \\
5.3 \\
6.3 \\
6.7 \\
7.7 \\
6.2\end{array}$ & $\left\{\begin{array}{l}1.5 \\
2.3 \\
2.1 \\
1.6 \\
2.1 \\
1.5 \\
2.5 \\
3.5\end{array}\right.$ & $\begin{array}{l}1 \\
1 \\
1 \\
1 \\
1 \\
1 \\
1 \\
1\end{array}$ & $\begin{array}{l}1 \\
1 \\
4 \\
1 \\
4 \\
1 \\
2\end{array}$ & $\begin{array}{l}Y \in= \\
Y \in= \\
100 \\
10 \\
Y \in 0 \\
10 \\
10 \\
Y \in=\end{array}$ \\
\hline
\end{tabular}

man rating tor 5 pilots, configurations 1.2 .4 .3

wan rating for 1 plocs, conelqurations 3.15 .16 .21

\section{Problea Definition}

The wethodology described in this paper was applied to the general flight task of final approach, exclusive of landing. On the basis of the questionnaire subitted to the Douglas test pilots, two specific subtasks were initially selected for atudy: continuous glide-slope tracking in turbulence, and recovery from intentional glide-slope offset. Prelininary exploration of the latter (transient) task was performed, but resources permitted a complete analysis of only the continuous tracking task. Therefore, discussion is confined to tests based on the contiruous tracking task.

Although continuous in nature, glide-slope tracking following capture is not, strictly speaking, a steady-state task because of time variations in various task paraneters. For exanple (a) turbulence bandwidth changes with altitudes (b) path control becomes more important as the touchdown point is approached; and (c) since the ILS instrument displays path error in terms of angular deviation, the effective display gain (inches of indicator deflection per foot of helght error) also varles with range. Nevertheless, Decause these tiwe variations are slow compared to the time constants of important systea variables, plecewise-steady-state analysis can yield meaningful predictions of pilot/vehicle performance at varlous points along the glide path.

A "frozen-point" analysis was performed at a simulated altitude of 1000 feet. Parameters of the turbulence model appropriate to this altitude (see reference 1) were chosen for this analysis.

Weighting coefficients for the quadratic performance index given in Eq. (1) were selected as the reciprocals of the maximum 
allowable deviations (or "limits") on important systen variables -a procedure that has been followed with apparent success in previous applications of the optimal-control pilot model.9.15 Linits of $117 \mathrm{ft}$. height error (corresponding to 1 dot glide-slope deviation at an altitude of $1000 \mathrm{ft.}$ ) and $10 \mathrm{kts}(16.9 \mathrm{ft} / \mathrm{sec})$ airspeed error were chosen on the basis of pilot comentary sumarized in Table 3. Iimits of 40 pounds stick force (10 degrees elevator deflection), 60 pounds/sec force rate, and 21,500 pounds thrust were chosen, in part, on the basis of physical constraints of the control systen. A limit of 10,750 pounds/sec rate of change of thrust was chosen to induce a control-related lag tiwe constant of about 2 sec; this selection was based on the assumption that the pilot would not make continuous wide-band throttle movements during approach.

No linits (i.e.. no terms in the quadratlc performance index) were associated with either sinkrate error or attitude variables. Penalties on attitude variables were onitted because no linitations on such variables were opecified by the test pilot, sinkrate error was onitted fron the performance index to prevent overemphasis on height-related variables. Despite the lack of explicit performance penalties on attitude variables, the penalties on control-related variables constrained the nodel to predict a reasonable "inlx" of height, attitude, and control deviations.

The gilots were assursad to make longitudinal-axis flight-control inputs primarily on the basis of perceptual information obtained from the ILS, attitude, and airspeed instruments. Rate information was also assumed to be obtained from the ILS and attitude indicators. Thus, the "display vector" assuned for nodel analysis consisted of helght, sinkrate, pitch, pitch rate, and airspeed errors.

Attention was assused to be divided equally between the ILS, attitude, and airspeed instruments; no attention-sharing penalties were considered between displacement and rate information from the same physical display. On the basis of anglysis performed in a previous analytic study of landing approach, 14 of the pilot a attention was assuned to be "lost" because of large eye novements required to scan the flight-control instrunents. Thus, fractional attentions of 0.22 were associated with the ILS, attltude, and airspeed displays.

Bffective perceptual thresholds were computed fron the display gains (1.e.. Inches of display deflection per unit change in problem variable), the eye-to-display distance, and assumed values of perceptual resolution Iinitations pased on previous laboratory experiments as described by Levison. $A$ residual nolse was also 
CRIGINAL FAR:

OF PCSR Quititir

associated with perception of pitch attitude change. Display and performance-related model parameters are given in Table 5 .

Table 5

Olaplay- and periormance-kelated iociel paraneters

\begin{tabular}{|c|c|c|c|c|c|}
\hline var: bie & $\operatorname{tin} 25$ & $\begin{array}{c}\text { Cost } \\
\text { Coefticient }\end{array}$ & maresholt & $\begin{array}{c}\text { Res : dusel } \\
\text { yo: } 50\end{array}$ & $\begin{array}{l}\text { Reletive } \\
\text { Aetention }\end{array}$ \\
\hline $\mathbf{2}$ & 212 & $-.31 E-05$ & 9.3 & J & .22 \\
\hline i & - & - & 32. & o & .22 \\
\hline$\neq$ & - & - & .43 & 0.5 & .22 \\
\hline 9 & - & - & 1.72 & a & .22 \\
\hline$u_{1}$ & 16.9 & $3.5 E-03$ & 2.9 & 0 & .22 \\
\hline 6 & 40 & $6.25 \equiv-04$ & - & - & - \\
\hline$\dot{\delta}$ & 60 & $2.78 \leq-04$ & - & - & - \\
\hline${ }^{6} t$ & 21,500 & $2.16 \varepsilon-09$ & - & - & - \\
\hline${ }^{s} e$ & 10.750 & $8.65 \equiv-09$ & - & - & - \\
\hline
\end{tabular}

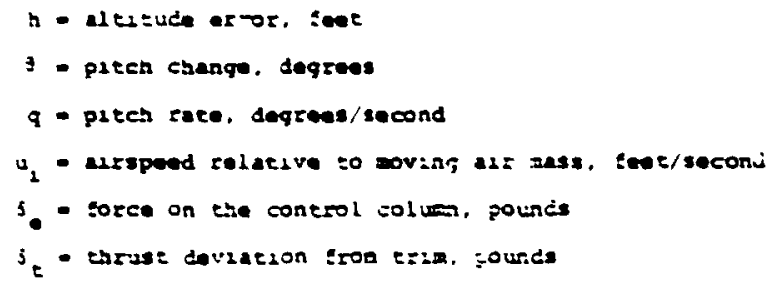

Additional pilot-related model parameters -- not shown in the table -- were (a) an observation noise/signal ratio of -20 dB associated with a relative attention of unity, (b) a motor noise; signal ratio of $-60 \mathrm{~dB}$, and (c) a time delay of 0.2 seconds. 


\section{Prediction of Performance/Workload Tradeoffs}

Performance/workload tradeoffs were predicted for each of the eight configurations defined in Table 1. For purposes of predicting handling qualities, "performance" was defined as the probability of one or more systen variables exceeding naximum allowable values. To obtain an approxination to this foint probability, systea variables were treated as independent Gausian var iables.

where $P r_{i}$ is the probability that the ith variables of interest will 1 ie outside its prescribed boundary, and $P r$ is the probability that it least one such variable is out of bounds. The probability Pri was readily computed from the predicted varlance of the 1 th system varlable. (5!nce we considered steady-state conditions, all variables were assumed to be rero-mean Gaussian processes.) "Workload" was represented in the analysis by the attentional variable $f_{t}$; the $f_{1}$ were adjusted to reflect attention-sharing as shown in Table 5. A nolse/signal ratlo $p=0.01$ was associated with a relative attention of unity. Thus, varlations in attentional workload were reflected by changed in the nolse/signal ratios according to Bq. (1).

Predictions of performance versus attentlonal workload are shown in Figure 2 for the elght configurations explored in the BBN study. Values of attention shown on the abscissa are relative to that inferred from data obtained in a standardized laboratory tracking task. That is, unity attention is intended as a benchark level of workload and does not necessar $11 \mathrm{y}$ relate to naxinum effort of capability. Thus, for configurations in which predicted performance is especially sensitive to attention, predictions are shown for relative attentions greater than unity.

The trends show: in Figure 2 are consistent with the pllot ratings given in Table 4 . Bxcept for conflguration 8 , the ordering of the performancr/workload curves 18 consistent with the ordering of the pllot ratings. For attentions of 0.5 and greater, predicted performance for the renaining seven configurations follcws the trend of the ratings. Operation on these results to yield predicted pilot ratings is discussed below. 


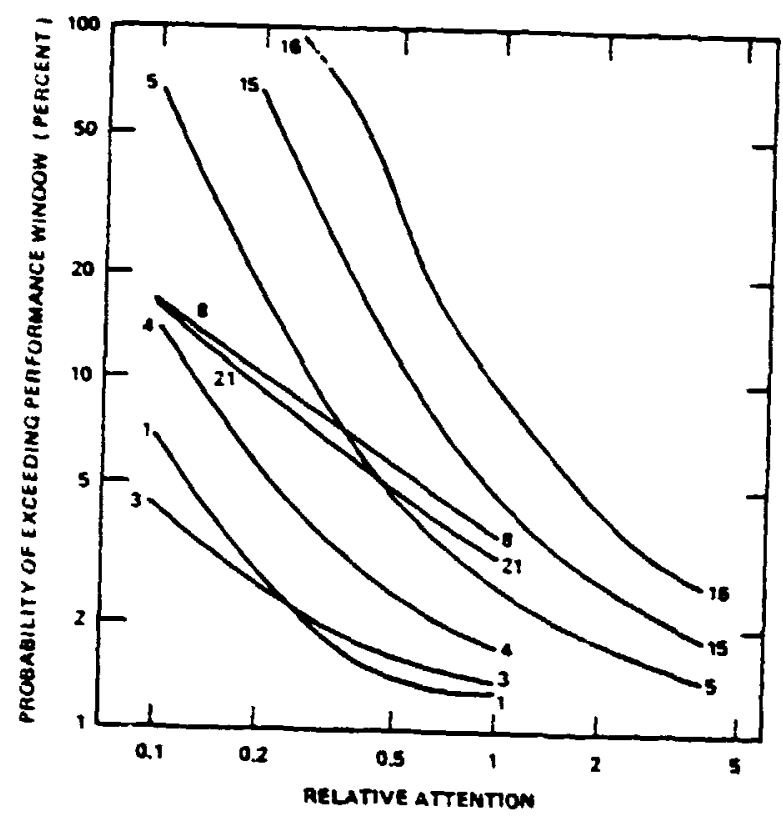

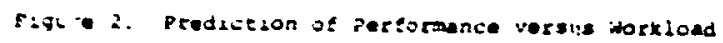

\section{Predicted Ratings}

The three rating expressions presented in Bqns. (2-4) were applied to the performance/workload tradeoff curves to provide a test of the proposed wethodology. Values were assigned to the independent parameters of each expression as shown beluw in Table 6.

The value of $\lambda_{0}$ of the performance model was chosen to represent a moderate-to-high workload level, and the corresponding value for $S_{0}$ was found through a regression procedure that minimized the mean-squared difference between predicted and experimental pilot ratings, normalized with respect to the variance of each experimental rating. The value for so of the attention model was selected to represent a moderate-to-stringent performance requirement, and the value for ho was found through a similar regression analysis. 


\begin{tabular}{l|r|l}
\multicolumn{1}{c|}{ Expressior } & $\sigma_{0}$ & $A$ \\
\hline Performance Model & 5.38 & 0.50 \\
Attention Model & 5.08 & 0.47 \\
Minimum-rating Model & 10.08 & 2.0
\end{tabular}

Because of the lack of a tractable analytic expression relating performance to workload, the parameters $s_{0}$ and $\lambda_{0}$ of the minimum-rating model were not found through a computerized regression analysis. Rather, pairs of integers were explored on a trial-and-error basis to provide a good match to experinental pilot ratirgs. The predicted (minimum) rating for a given configuration was obtained by superimposing the predicted performance/workload tradeoff curve (Figure 2) on the curves of constant rating, shown in Flgure 3 .

Because of the difficulty in matching the predicted pllot ratings of Configuration 8 , ratings for this configuration were onitted from all three regression analyses.

Pigure 4 provides a graphica comparison of predicted versus experimental pilot ratings for the three rating expressions. Dashed lines indicate boundaries of 1 rating unit. The three $r$ ating schemes performed abcut equally well on the average and were - Jle to match 6 of the 8 experimental ratings to within one rating unit. The configuration matched least well was Configuration 8 , which was omitted from the regression analysis.

prediction errors may be compared against the variability of the experimental data in Figure 5. Experimental ratings are indicated by filled circles, with brackets to indicate 1 standard deviation; open symols indicate predictions obtained with the three rating expressions.

Except for Configuration 8, predicted ratings are within one standard deviation of the experimental mean. Even for the worst case, the prediction error is well within two standard deviations of the mean. Thus, the rellabllity of the predlcted ratings is commensurate with the reliability f the experimental data. 
ORIGINAL PAGE IS
OF POOR QUALITY

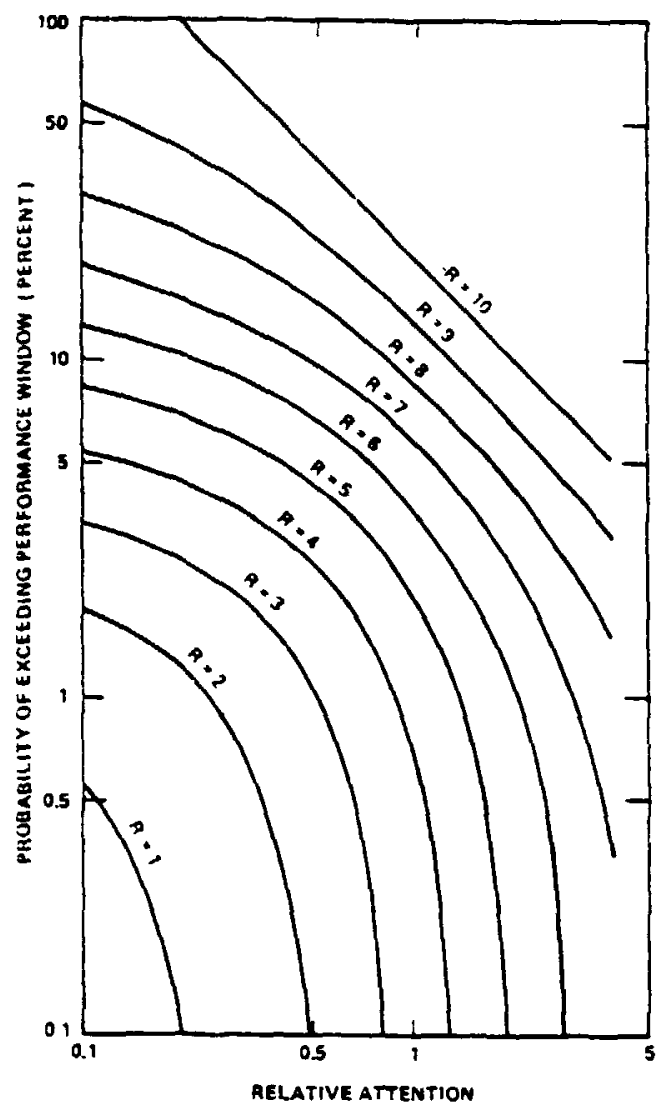

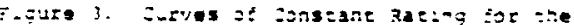

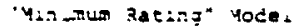

$i^{2}=-2 \pi \quad x^{2}=$ :

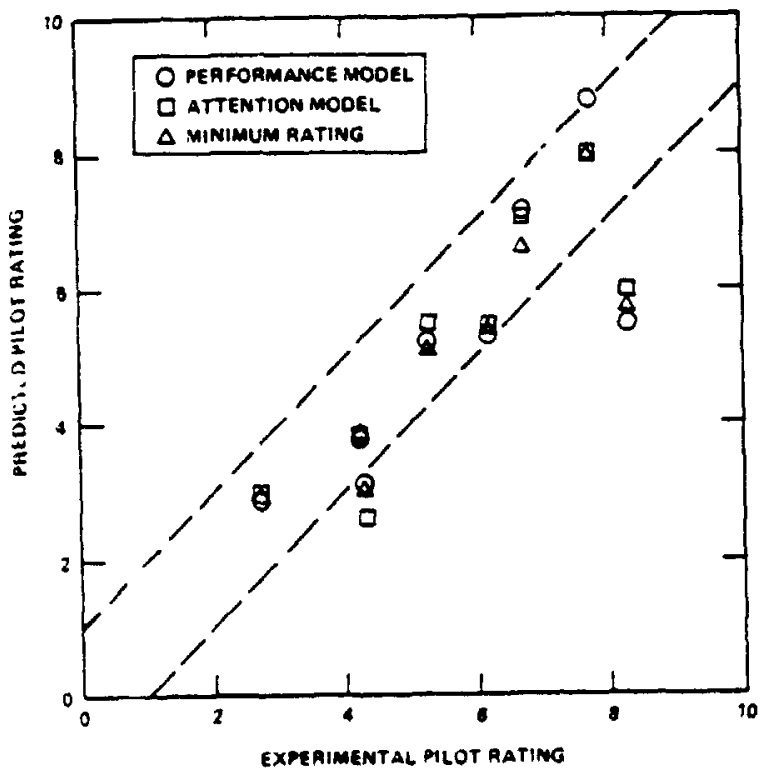

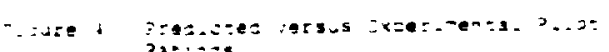
23:: : $: 3$ 
Or:Gi:n:

of poon on:

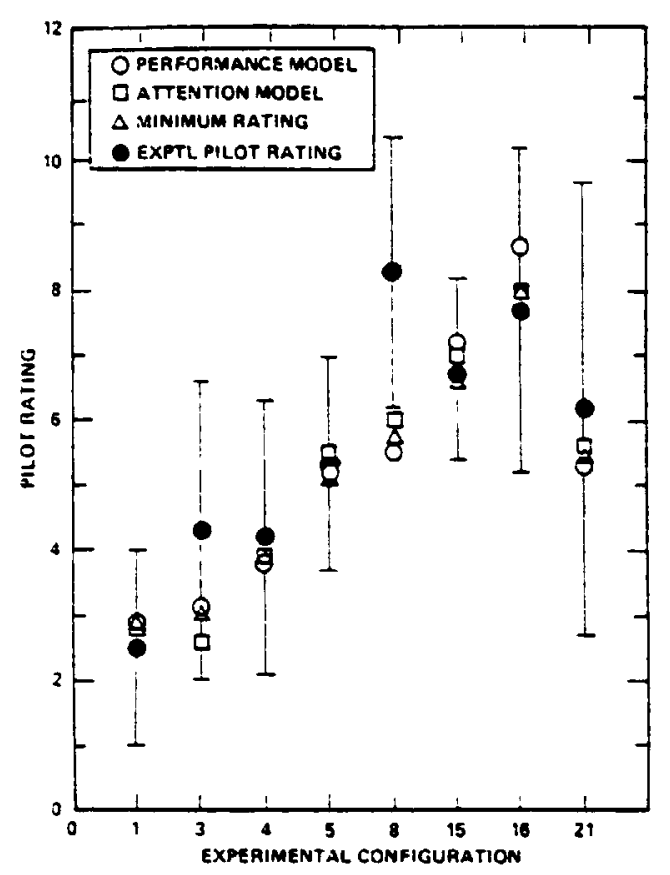

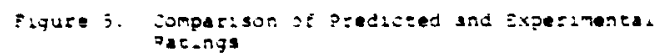




\section{Discussion of Results}

The generally good match between "predicted" and experimental pilot opinion ratings demonstrates the validity of the model-based approach described in this paper. The technique is shown to replicate experimental results reasonably well across a set of conditions that spans a range of handling qualities levels and problems. Because the procedure is based on a pilot/vehicle model of considerable generality and demonstrated validity. this schene ought to be valid for uther aircraft configurations and, with appropriate definitions of performance requirements, ocher flight tasks as well. Further study is required to compare the BBN techniques against other model-based procedures and to further compare the usefulness of the three rating expressions tested in this study.

Resources did not permit a detailed study of the inability to obtain a good match to the experimental rating for Configuration 8. The differences between the average ratings for configurations 8 and 21 (which our prediction scheme predicts to be negligible) were apparently not due to training effects; these two configurations were presented to the test pilots in a balanced order.

It should be noted that all tests of the proposed methodology have been based on steady-state analysis appropriate to conditions at a single altitude. Although steady-state-like tasks were important determinants of pilot opinion, transient-response behavior was also important. There may have been some aspects of glide-slope capture and other transient maneuvers that were es-iecially adverse for Configuration 8. Additionally, it is possible that a different choice of steady-state parameters (e.g.. turbulence appropriate to a lower altitude, different "limits" on throttle response) may have differentiated between Configuration 8 and 21 .

Data from the Douglas experiments were used in the BBN study because of their applicability to large transports. Because the experimental study was performed well before the BBN analytical study, the Douglas effort was not designed to allow a thorough test of the model-based prediction to scheme. Bindsight reveals the following methodological deficiencies:

1. Sparclty of Performance Measurements. pilot opinion $r$ atings were the only data pubished relating to closed-loop pllot/vehicle performance. Objective performance measures such as rms errors, pllot describing functions, spectra, or time historles are not avallable. Thus, we cannot determine the pllot's "operating point" in terms pilot-related model parameters, and we cannot verify the ability of the model to predict objective performance measures. 
2. Large Rating Variability. Standard deviations for pilot ratings, as determined across subjects, were relatively large, reaching a maximum of 3.5 . Clearly, large variability in the data hinders a rigorous test of the prediction scheme. To some extent, the large standard deviations resulted from a small subject population (only 3 subjects provided ratings for 4 of the configurations explored in the BBN study). As described below, a more significant factor may have been an insufficiently specific evaluation procedure.

3. Insuffictently specteic Evaluation procedure. Typically, each pilot was allowed two Fllghts per configuration: an initial flight without turbulence, and a follow-up flight with moderate turbulence. The pilots were encouraged to perform maneuvers that would aid in developing their rating, and they vere asked for a single overall rating of the configuration of the end of the two slights. While all subjects appeared to consióer the same basic maneuvers and subtasks (glide-slope capture, glide-slope tracking, recover from mistrim, open-loop vehtcle response), we do not know the extent to which each pilot welghted the varlous response categories. Different weightings might have led to different ratings for the same configuration -- a possible explanation for the large pllot-to-pilot variability observed in this study. Differences in the pilot's expectations of system performance are another potential source of rating variability.

Consideration of these methodological shortcomings suggests alternative approaches in future studies, as outlined below.

\section{CONCLUSTONS AND RECOMMENDATIONS}

A technique based on the optimal-control model for pilot/vehicle systems has been developed for predicting pilot opinion ratings. Three varlations of this technique provide a good match to opinion ratings obtained in a manned simulation study of large commercial transports in landing approach.

The model-based technique developed in this study has a number of features which should enhance its applicability to other aircraft conflgurations and other flight tasks and should allow wider application than alternative handing qualities prediction scheme 8:

1. One is able to proceed in a stralghtforward manner from a description of the task environment and of task requirements to a prediction of pliot oplnion ratings. The general form of the 
rating expression and of the underlying pilot model is invariant across applications.

2. No constraints are placed on the nature of he vehicle response and the pilot model is relatively free form. Thus, "unconventional" aircraft dynamics may be considered.

3. A scalar metric for attentional workload is expressed in terms of a model parameter related to the signal/noise properties of the pilot's rasponse. Thus, the treatment of workload is independent of the details of the flight task.

4. The effects of display parameters, turbulence, and other environmental factors on pilot opinion rating are readily considered.

Encouraging results obtained with the model-based technique tested in this study warrant further research to provide a more rigorous test of the procedure and to determine its range of validity. Such a study should be subjected to the following quidelines:

1. Flight Test Standardization. The flight tests performed for the purpose of obtaining plot opinion ratings should be standardized so that all pilots perform the same maneuvars on the aircraft. Either separate ratings should be obtalned for individual maneuvers, or $\mathrm{ca}_{1}$, should be taken to assure that all pilots weight the various maneuvers in the same manner when assigning an overall rating to the aircraft.

2. Define Performance Criteria. Through a carefully prepared and administered questionnaire, subjective performance criteria should be determined for th varlous test maneuvers. If practical, test pilots should be encouraged to adopt a common set of criteria to minimize rating variability.

3. Performance Measurement. Objective measures of system performance and plot response behavior should be obtained, in adaition to pilot opinion ratings, to provide a more rigorous test of the method.

\section{REFERENCES}

1. Levison, W. H., "A Model-Based Technique for Predicting Pilot Opinion Ratings for Large commercial Transports", NASA Contractor Report No. 3257, April 1980. 
2. "Flying Qualities of Piloted Airplanes", Military Specification, MIL-F-8785B (ASG), 1969.

3. Anderson, R. O.. "A New Approach to the Specification and Evaluation of Flying Qualities". Wright-Pattersen Air Force Base, AFFDL-TR-69-120, 1970.

4. Arnold, J. D., R. B. Johnson, and J. D. Dillow, "Pitch Paper Pilot Revisited". Proceeóings of the Ninth Annual Conference on Manual Control. Massachusetts institute of Technology, Cambridge, Massachusetts, 1973.

5. Naylor, F. R., J. D. Dillow, and R. A. Hannen, "Roll raper Pilot", Proceedings of the : inth Annual Conference on Manual Control, Massachusetts Institute of Technology, Car.jridge, Massachusetts, 1973.

6. Stone, J. R.. "paper Pilot Ponders Supersonic Transports", Proceedings of the Ninth Annual Conference on Manual Control, Massachusetts Institute of Technology, Cambridge, Massachusetts, 1973.

7. Eess, R. A., "Prediction of Pilot Opinion Ratings Using an Optimal Pilot Model", HUMAN FACTORS, 1977, 19(5), 459-475.

8. Schmidt, D. K., "Optimal Flight Control synthesis via Pilot Modeling", Journal of Guidance and Control, Vol. 2, No. 4, Jul. -Aug. 1979 .

9. Baron, S. and W. B. Levison. "Display Analysis with the Optimal Control Model of the Human Operator", BUMAN PACTORs, :977, $19(5)$ 437-457.

10. Levison, W. H., "A Model for Mental Workload in Tasks Requiring Continuous Information Processing", Mental Morkload Its Theory ard Measirement, Plenum Press, New York and London, 1979.

11. Levison, W. H., J. I. Elkind and J. I. Ward, "studies of Multi-Variable Manual Control systems: A Model for Task Interforence", NASA CR-1746, May 1971.

12. Wewerinke, P. B., "Biman Operator Workload for Various control Situations", Tenth Annual Conference on Manual Control, Wr Ight-patter son AIr Force Base, bhio, 1974.

13. Cooper, G. E., The Use of P1lot Rating in the Evaluation of Aircraft Handing Qualities", NASA TW D-5153, Apr 11 1969. 
14. Rickart. W. W., "Longitudinal Flying Qualities in the Landing Approa-h". Proceedings from the melfth Annual Conference on Manual Control, NASA TMX-73,170, MaY 1976.

15. Levison, W. B.. Analysis and In-Simulator Evaluation of Display and Control Concepts for a Terminal Configured Vehicle in Final Approach in a Windshear Environment", NASA Contractor Report 3034. August 1978. 
AN ANALYTICAL PREDICTION OF PILOT RATINGS

UTILIZING HUAN PILOT MODEL

by

\author{
Keiji Tanaka* and Kyuichiro Washizu** \\ -Instrumentation and Control Division, National Aerospace \\ Laboratory, Tokyo, "Department of Aeronautics, University \\ of Tokyo, Tokyo
}

\begin{abstract}
In orfer to analytically predict pilot ratings an evaluation method of a manual control systea which consists of an aircraft and a human pilot, is proposed and examined. The nethod is constructed upon the assuptions that the control mission determines the critical frequency the pilot should bring to his focus, and that the degree of closed-loop stability and the hunan compensation necessary to attain the stability detersine the huan subjective evaluation of the systen. As a result, a simple evaluation chart is introduced. The chart enables us to predict the subjective evaluation, if the controlled element aynamics and the mission are given. The chart is in good acccrd with almost all of the existing results of pilot ratings. This nethod has the following four advantages: (i) Simplicity, in a sense that the method needs to evaluate only two typical controlled element paraneters, nanely, the gain slope and the phase at the critical control trequency; (ii) Applicability to unstable controlled elements; (iii) Predictability of controllability limits of manual centrol; (iv) Possibility of estimating human compensatory dynamics.
\end{abstract}

\title{
INTRODUCTION
}

In recent years, handling quality criteric of aircraft have been influenced by rapid development of the automatic flight control system. Newly developed flight control syste enables aircraft to be desigmed with any handling sharacteristics. Sircraft with those flight control systens are sometimes called higher order system (HOS), the response of which doesn't indicate significant short period mode any wore. Urged by thus obtained increase of degrees of freedoa in designing aircraft handling characteristics, revisions to the handling quality criteria have been proposed $l-3$.

These re ions, however, have the following common problems: (1) There is no direct resationship between the criteria and the human pilot models; (2) To measure gain or phase characteristics, careful attention is needed. If 
measured frequencies differ, the result becowes guite different.

The objective of this paper is to propose and examine an improved method to perdict pilot ratings, which fully utiiizes human pilot models and their limitations, and which aims at overconing the above probleas. In this paper, we treat a typical single-loop manual control system keeping in aind the applic: :ion of this method to deternining the short-period pitch aneuver response requirements for aircraft design.

\section{FORULLATION OF AN IMPROVED METHOD}

\section{Evaluation Process of Manual Conerol Systen by Huan Pilot}

In this paper, we treat a tyoical single-loop manual control system shown in Fig.1. Evaluation by a huan pilot is considered as follows: when he is assigned a control aission, his evaluation is due to the amount of his workload and the extent of fulfilment of the nission. To aake the above notion clear, let's define the following terms:

(1) Control mission This is the objective of anual control set up by external factors of the huan pilot. To be concrete, the external factors are the features of the forcing-function and the controlled element, etc.. We assune that the aission is represented by the gain-crossover frequency wc, which we hereafter treat as the critical control frequency. If the aission is a severe one, the systee should be tightly closed; then the larger wc becones appropriate.

(2) Pilot Workload This ay be divided broadly into mental workload and physical workload. The ental workload corresponds to the human compensatory characteristics, which means the pilot's self-adjustment of his control dynanics according to the controlled element dynanics in order to accomplish the control mission. The nental workload imposed by pilot compensation can be neasured by using an identification rechnique of human describing functions. On the other hand, the physical workload corresponds to the amount of physical work done by the pilot. Measures of the physical workload can be the magnitude of control colum deflection $c$, or physiological responses. As modern aircraft are equipped with power-boosted control, it is possible to adjust the control colurn gain at the designer's option. Under this trend, we had better distinguish the problen of designing the control $C \mathrm{n}$ gain from man-machine closed-loop aralysis. Hence, we hereafter cha :e mental workload, or in another word, pilot compensation, as the index or in pilot workload.

(3) Control Performance This is expressed by the variance of the error. In general, manual control systens sometimes have insufficient stability anong various representative closed-loop characteristics. For such cases control performance : mainly deternined by the closed-loop resonance.

(4) Pilot Rating This is a rated mark put to a given systen by the hunan pilot. He subjectively evaluates the system putting his workloed and the control performance together.

(5) Pilot Compensation This is the most influential factor upon the mental worklcad and the control performance. The human pilot compensates the controlled eiement so that the total closed-loop response shows satisfactory 


\section{ORicinil pare is
OF POOR QUALIT}

characteristics.

\section{Analysis of Manual Control System}

In order to obtain the closed-loop characteristics, it is convenient to employ the amplitude-phase plots of the open-loop transfer function $Y_{p} Y_{c}(s)$ in Fig.1. As typical examples of $Y_{p} Y_{c}$ plots, Fig. 2 is quoted from Ref.1; in the figure we arranged the plots so that the preselected bandwidth (BW) becones $w_{c}$. It can be seen that in most cases the plots are approxinated by an essentially straight lines near $\omega_{c}$ in anplitude-phase plane, and the slopes of the plots are relatively shallow so that the closed-loop resonance is directly estimated by the gain margin (M, rather than the phase margin $1 M$. For such a case, $Q M$ can be approximated by using the slope of the plots and $m$ as:

$$
Q \mathbf{Q}=\left\{\mathrm{d}\left|\mathrm{Y}_{\mathrm{p}} \mathrm{Y}_{\mathrm{c}}\right| / \mathrm{d}_{2} \mathrm{Y}_{\mathrm{p}} \mathrm{Y}_{\mathrm{c}}\right\}_{\omega=\omega \mathrm{c}} \cdot A M \quad[\mathrm{~dB}] \text {. }
$$

where $P M$ is defined as follows:

$$
M=i Y_{c}\left(j \omega_{c}\right)+\left\langle Y_{p}\left(j \omega_{c}\right)+\pi[\mathrm{rad}] .\right.
$$

It is worth noting here that the above $G M$ and $M$ can be defined even though the controlled element has one or two unstable poles. When the controlled element has unstable poles, there exists a permitted range of gain variability which can make the system stable. In those cases, there are two phase-crossover frequencies. If we choose the larger frequency, the plots similar to Fig. 2 are obtained.

Consider the human compensation which is necessary for closed-10op stability. We rewrite Eq.(1) by using Eq. (2) as:

$$
\left\{d\left|Y_{c}\right| / d(\log \omega)\right\}_{\omega=\omega_{c}}=\frac{G\left\{\left(d Y_{p} Y_{c} / d(\log \omega)\right\}_{\omega=\omega_{c}}\right.}{\left\langle Y_{c}\left(j \omega_{c}\right)+{ }_{\alpha} Y_{p}\left(j \omega_{c}\right)+\pi\right.}-\left\{d\left|Y_{p}\right| / d(\log \omega)\right\}_{(j)=\omega_{c}}
$$

In Eq. (3), pilot dynamics is expressed by; $\left\langle Y_{p}\left(j \omega_{c}\right),\left\{d\left|Y_{p}\right| / d\left(\left\lfloor\circ \omega_{w}\right)\right\}\right.\right.$ and $\left\{d, Y_{p} Y_{c} / d(\log w)\right\}$. Awong these, the first and the second have difiexf relationship with hifiman compensation. On the other hand, it is difficult to find a simple relationship between $\left\{d \angle Y_{p} Y_{c} / d\left(\log _{w}\right)\right\}$ and huan compensation, for human pilot dynamics contains the reaction "Wfe delay which appears only in phase characteristics. For simplicity of the analysis, $\left\{d Y_{p} Y_{c} / d(\log \omega)\right\}$ is tentatively held constant. Referring to Eq. (3), the

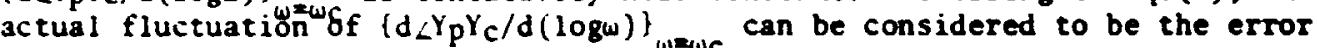
of the assumed $G M$.

Now, we estimate the degree of compensation which the filot can produce by employing human pilot models as follows 4,5 :

and

$$
\begin{aligned}
& Y_{p}(s)=k_{p} e^{-\tau s}\left(1+T_{L} s\right), \\
& Y_{p}(s)=K_{p} e^{-\tau s}\left(1+T_{L} s+T_{L} s^{2}\right), \\
& Y_{p}(s)=K_{F} e^{-\tau s} \frac{1}{1+T_{I} s},
\end{aligned}
$$




\section{SriviliriL PAGE is \\ OF POOR QUALITY}

where s denotes the Laplace variable, and the huan reaction tine delay, denoted by $\tau$, contains the neuro-muscular lag time constant and is fixed here as:

$$
\tau=0.3[\mathrm{sec}]
$$

Then, the relations between $\left\{d\left|Y_{p}\right| / d(\log w)\right\}_{w=w c}$ and $\angle Y_{p}\left(j w_{c}\right)$ are obtained as follows: for Eq. (4),

$$
\left\{d\left|Y_{p}\right| / d(\log \omega)\right\}_{\omega=\omega_{c}}=10(1-\cos 2 *)[d B / \text { decade }] ;
$$

for Eq. (5).

$$
\begin{gathered}
\left\{d\left|Y_{p}\right| / d(\log \omega)\right\}_{\omega=\omega_{c}}=20+10 \sqrt{1+\operatorname{tatan}^{2} \phi}(1+\cos 2 \phi),(9) \\
{[d B / \text { decade] }}
\end{gathered}
$$

where $a=T_{L}{ }^{1} / T_{L}{ }^{2}$; and for Eq. (6),

$$
\left\{\mathrm{d}\left|Y_{\mathrm{p}}\right| / d(\log \omega)\right\}_{\omega=\omega_{c}}=-10(1-\cos 2 \varphi)[\mathrm{dB} / \mathrm{dec} a d e] \text {. }
$$

In the above equations, denotes the anount of masn phase compensation at $\omega=\omega c$ as:

$$
-\angle Y_{p}\left(j \omega_{c}\right)+\tau \omega_{c} .
$$

There are sufficient amount of huan describing functions for confirming the human compensatory dynamics, which have been obtained through various experinents so far. We can sample the hum compensatory dymanics in the for of $\left\{d\left|Y_{p}\right| / d(\log w)\right\}$ and $\left\langle Y_{p}\left(j \omega_{c}\right)\right.$. Comparison of these data with Eqs. (8), (9) and (10) are shown in Figs. 3 and 4 , which indicate distinct features of human compensatory dynanics and their linitations. It should be noted that for simplicity, we employ an approxination: $\omega_{c}=\sqrt{2} \omega_{n}$ for the cases of secondorder controlied element; that is due to the fact that the nost effective factor in deternining the crossover frequency for those cases seens to be the natural frequency of the controlled element. In sumary, for cases where huar: phase lead is negative, we can approximate $Y_{p}$ with Eq. (6); for cases where is positive and within $\pi / 2$ [rad], we can use Eq. (4); for the cases where is greater than $\pi / 2$ [rad] and within $\pi[\mathrm{rad}]$, we can use Eq. (5). Using these huan pilot wodels and their limitations, we now introduce an analytical wethod for estimating pilot ratings.

\section{Derivation of Evaluation Chart}

Let's make an -valuation chart which shows the distinct relationship between the controlled element characteristics at wc and the closed-loop performance determined by human compensation.

firstly, we derive conditions of the controlled element in which closed- 
loop stability holds for a given human pilot model.

(i) stability conditions of the closed-loop system without any pilot compensation

The closed-loop system is stable when

and

$$
Q M>0 \quad[d B]
$$

$$
S M>0 \quad[\mathrm{rad}] \text {. }
$$

Substrtuting the above conditions into Eqs. (1) and (2), we obtain:

and

$$
\left\{\frac{d Y_{p} Y_{c}}{d(\log \omega)}: \frac{d I_{p} Y_{c}}{d(\log \omega)}\right\}_{\omega=\omega c}^{>} 0[\mathrm{~dB} / \mathrm{rad}]
$$

$$
Y_{c}\left(j \omega_{c}\right)-\tau_{c}>-\pi-\phi \quad[\mathrm{rad}] .
$$

In general,

$$
\left\{d<Y_{p} Y_{c} / d(\log \omega)\right\}_{\omega=\omega_{c}}<0 \quad[\mathrm{rad} / \text { decade }] .
$$

thus, from Eq. (14):

$$
\left\{d\left|Y_{c}\right| / d(\log \omega)\right\}_{\omega=\omega c}<-\left\{d\left|Y_{p}\right| / d(\log \omega)\right\}_{\omega=\omega c}[d B / \text { decade }] .
$$

As the pilot eaploys no compensation:

and

$$
\begin{aligned}
\left\{d\left|Y_{p}\right| / d(\log \omega)\right\}_{\omega=\omega_{c}} & \bullet 0 \quad[\mathrm{~dB} / \text { decade }] \\
& =0 \quad[\mathrm{rad}] .
\end{aligned}
$$

Substituting the above equations into Eqs. (15) and (17), we finally obtain the following stability conditions:

and

$$
\left\{d\left|Y_{C}\right| / d(\log \omega)\right\}_{\omega=\omega_{C}}<0 \quad[d B / \text { decade }]
$$

$$
Y_{c}\left(j \omega_{c}\right)-\tau \omega_{c}>-\pi \quad[\mathrm{rad}] \text {. }
$$

The human pilot can stabilize the controlled elements in the region satisfying Eqs. (20) and (21) without any compensation: the region is shown in the chart of Fig.5, where the abscissa is $-Y_{c}\left(j \omega_{c}\right)-\tau \omega_{c}$, and the ordinate is $\left\{d\left|Y_{c}\right| / d(\log \omega)\right\}$. Hereafier, we explain the following regions by using the same cr.rt. $\omega=\omega_{C}$

(ii) stability conditions with first-order pilot lead Stability conditions are the same as Eqs.(15) and (17). Employing Eq. (8), we can rearrange Eq. (17) a :

$$
\text { (d) Yclid }(\log \omega)\}_{\omega=\omega c}<-10(1-\cos 2 \phi)
$$

The human filot can stabllize the controlled elements in the region satisfying the above conditions with first-order lead. Noting that Eq. (8) holds when 
$0 \leq \phi \leq \pi / 2[\mathrm{rad}]$, the region in -ne chart is obtained by moving the region satisfying conditions (i) in parallel along:

$$
\left\{d\left|Y_{c}\right| / d(\log \omega)\right\}_{\omega=\omega c}=-10(1-\cos 2 \downarrow)(0 \leq \downarrow \leq \pi / 2[\mathrm{rad}]) .
$$

(iii) stability conditions with second-order pilot lead

Substituting Eq.( 9 ) into Eq.(17), we obtain the conditions:

$$
\left\{d\left|Y_{c}\right| / d(\log \omega)\right\}_{\omega=\omega_{c}}<-20-10 \sqrt{1+4 \tan ^{2} \phi}(1+\cos 2 \phi)
$$

and Eq. (15). The widest region is obtained when $\alpha=0$ in Eq. (24) as:

$$
\left\{d\left|Y_{c}\right| / d(\log \omega)\right\}_{\omega=\omega c}<-10(3+\cos 2 \phi) .
$$

Noting that Eq. ( 9 ) holds when $\pi / 2<\phi \leq x[\mathrm{rad}]$, the region in the chart is obtained by moving the region satisfying conditions (i) in parallel along:

$$
\left\{d\left|Y_{C}\right| / d(\log \omega)\right\}_{\omega=\omega c}=-10(3+\cos 2 \phi)(\pi / 2<\phi \leq \pi[\mathrm{rad}]) \cdot(26)
$$

(iv) stability conditions with first-ordar pilot lag

Sinilarly, the region in the chart is obtained by woving the region satisfying conditions (i) :- narallel along:

$$
\left\{d\left|Y_{c}\right| / d(\log \omega)\right\}_{\omega \text { awc }}=10(1-\cos 2 \phi)(-\pi / 2 \leq \phi<0[\mathrm{radj}) .(27)
$$

(v) stability conditions with first-order pilot lead and lag

This region is obtained by moving the region satisfying conditions (ii) in parallel along Eq. (27), just as the region satisfying conoitions (iv) is obtained from the region satisfying condiitons (i).

Secondly, we derive conditions of the controlled elenent in which $G M$ is kept greacer than a certain value. As an example, the following condition is examined:

$$
\mathrm{Q}>1.5 \text { [dB]. }
$$

It seems proper as condition of the phase slope to choose:

$$
\left\{\mathrm{d} \angle \mathrm{Y}_{\mathrm{P}} \mathrm{Y}_{\mathrm{c}} / \mathrm{d}(\log \omega)\right\}_{\omega=\omega_{\mathrm{c}}}=-4 \quad[\mathrm{rad} / \text { decade }] .
$$

Using Eqs. (28) and (29), the conditions are:

$$
\left\{d\left|Y_{c}\right| / d(\log \omega)\right\}_{\omega=\omega_{c}}<\frac{-6}{\left\langle Y_{c}\left(j \omega_{c}\right)-T \omega_{c}+\phi+\pi\right.}-\left\{d\left|Y_{p}\right| / d(\log \omega)\right\}_{\omega-\omega c}
$$

and Eq. (15).

(vi) $G M>1.5$ (dB) without any pilot compensation

The conditions are directly obtained from Eqs.(30) and (15) as:

and

$$
\left\{d\left|Y_{c}\right| / d(\log \omega)\right\}_{\omega=\omega c}<\frac{-6}{Y_{c}(j \omega c)-T \omega c+\pi}
$$




$$
\angle Y_{c}\left(j \omega_{c}\right)-T \omega_{c}>-\pi
$$

In the same way, the following conditions are obtained:

(vii) $G M>1.5[d B]$ with first-order pilot lead

(viii) $G M>1.5(d B)$ with first-order pilot lag

(ix) $G M>1.5(d B)$ with first-order pilot lead and lag

COMPARISON OF THE EVALUATION METHOD WITH PREVIOUS DATA

The $\operatorname{data}\left\{d\left|Y_{c}\right| / d(\log \omega)\right\}, \angle Y_{c}\left(j \omega_{c}\right)$ and corresponding pilot rating are obtained from previous experrfments. Firstly, comparison with the data from Ref. 1 is shown in Fig.6, where we tentatively set $\omega_{c}$ as equal to $B W$. Fig. 6 indicates: (1) If the human pilot can keep $Q M>1.5$ [dB] without any compensation, pilot rating is acquired as $P R \leq 3.5$; (2) If the human pilot can keep QPB].5[dB] with first-order compensation, pilot rating is acquired as 3.5<PR: 6.5 ; (3) Otherwise, $6.5<P R$.

Now, we examine the method in the extreme cases near human contrgllability limits. The controllability limits are reported in various papers $9-12$. $\alpha_{c}\left(j \omega_{c}\right)$ and $\left\{d\left|Y_{c}\right| / d(\log \omega)\right\}$ of the second-order controlled elements in the region of human controllabilffy limits are shown in Fig.7, where we set wc as equal to $\sqrt{2} w_{n}$. Note that for these cases the human reaction time delay is modified as $\tau=0.2[\mathrm{sec}]$. It can be seen from Fig.7 that near the controllability limits the human pilot employs second-order lead. Finally, it is noted that the controllability limits of the first-order divergent elements are also explained by this chart. It should be added here that experimental results of these cases are somewhat greater than the analytical results; this implies that controllability limits are not determined by $G=0$ but that $G M$ should be greater than a some positive value.

\section{DISCUSSION ON ADVANTAGES AND DISADVANTAGES OF THE EVALUATION METHOD}

The precedent comparisons indicate that the proposed evaluation method can generally predict the ratiags by human pilots. Advantages of this evaluation method compared with existing ones are as follows: (1) Easiness of evaluation; (2) Applicability to any controlled element irrespective of its stability; (3) Predictability of contro:lability limits of manual control; (4) Possibility of estimating human pilot dynamics simultaneously with control difficulty or pilot control efforts.

Items to be discussed concerning this evaluation method are as follows: (1) The method gives no definite $\omega_{c}$. In general, $\omega_{c}$ depends on the control mission. It seems proper that $\omega_{c}$ should be classified according to the flight phases just as Ref.2. Nevertheless, the proposed method has another advantage: the results of the method is insensitive to the change of $\omega_{c}$. Referring to Bode's theorem, $\angle Y_{c}\left(j \omega_{c}\right)$ has cortelation with $\left\{d\left|Y_{c}\right| / d(\log \omega)\right\}$ when the controlled element is of minimum phase system; thus the results wove almost in parallel along to the borders and then slightly laterally due to the difference of $\omega_{c} ;$ (2) In the cases to which the assumptions of this method 
cannot be applied, the results may have large error. Possible origins of such error may be: assumptions that closed-loop stability is most effective in the determination of pilot ratings, that $\tau$ and $\left\{d_{L} Y_{p} Y_{c} / d\left(\log _{\omega}\right)\right\}_{\omega \omega_{c}}$ are set to be constants.

\author{
CONCWSION
}

By fully making use of human pilot models and their linitations, an analytical evaluation method of predicting pilot ratings is proposed and examined. The evaluation chart can generally explain the pilot ratings and human controllability limits. The method can be widely applied to problens of single-loop manual control.

REFERENCES

1. Neal,T.P.; and Smith,R,E.: An In-Flight Investigation to Develop Control System Design Criteria fnr Fighter Airplanes, AFFDL-TR-70-74, 1970.

2. Chalk,C.R.; Difranco,D.A.; Lebacqz,J.V.; and Neal,T.P.: Revisions to MILF-8785B(ASG) Proposed by Cornell Aeronautical Laboratory, AFFDL-TR-72-41, 1972.

3. Ashkenas, I.L.; Hoh,R.H.; and Craig,S.J.: Recomended Revisions to Selected Portions of MIL-F-8785B(ASG) and Background Date, AFFDL-TR-73-76, 1973.

4. Tanaka,K.; Goto,N.; and Washizu,K.: A Comarison of Techniques for Identifying theman Operator Dynamics Ltilizing Time Series Annlysis, Proc. of 12 th Annual Conf. on Manual Control, NASA TM X-73,170, 1976, pp.673-693.

5. McRuer,D.T.; Graham,D.; Krendel,E.S.; and Reisner,W.Jr.: Huan Pilot Dynamics in Compensatory Systems, AFFDL-TR-65-15, 1966.

6. Tanaka,K.: Morihisa,H.; and Noguchi,K.: On the Relationship between Pilot Rating and Pilot Dynamics, Part I. An Experimental Approach, Trans. of the Japan Society for Aeronautical and Space Sciences, Vol.21, No.53, 1978 , pp.128-138.

7. Goto, N.: - Part II. An Analytical Approsch, - pp.139-152.

8. Washizu,K.; Tanaka,K.; and Osawa,T.: A Study of the Effect of Forcing Function Characteristics on thean Operator Dynanics in Manual Control, Proc. of 14th Annual Conf. on Manual Control, NASA CP-2060, 1978, pp.19-32.

9. Washizu, K.; Tanaka, K.; Endo,S.; and Itoko,T.: Motion Cue Effects on Huan Pilot Dynamics in Mamual Control, Proc. of 13th Annual Conf. on Manual Control, 1977, pp.403-413.

10. Jex,H.R.; Cormwel1,C.H.; and Siskind,R.K.: Correlation of Experimental and Theoretical Limits for Pilot Control of Unstable Second Order Systems, WADD TM-56, 1960.

11. Washizu,K.; and Miyajima,K.: Controllability Linits of a Human Filot, AIAA J., Vol.3, No.5, 1965, Pp.941-947.

12. Smith,R.H.: On the Limite of Manual Control, IEEE Trans., Vol.HFE-4, 1963, pp. 56-59. 


\section{ORIGINAL PACE IS \\ OF POOR QUALITY.}

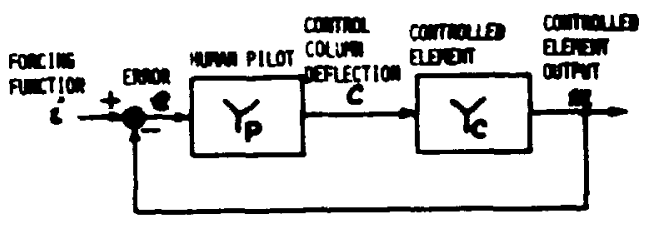

Figure 1. Single-Loop Manual Control System

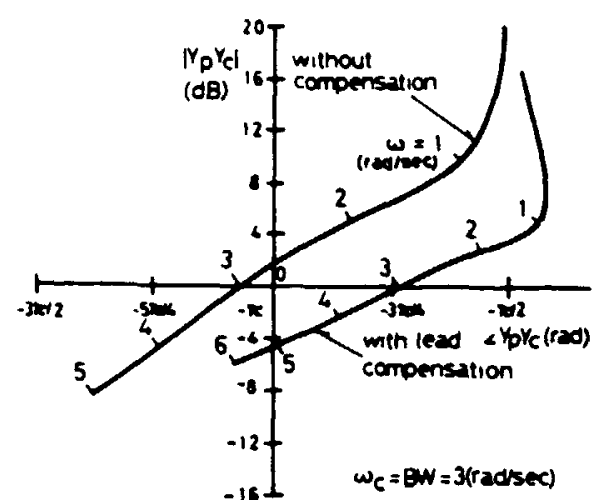

Figure 2. Example of Amplitude-Phase Plots from Ref.1

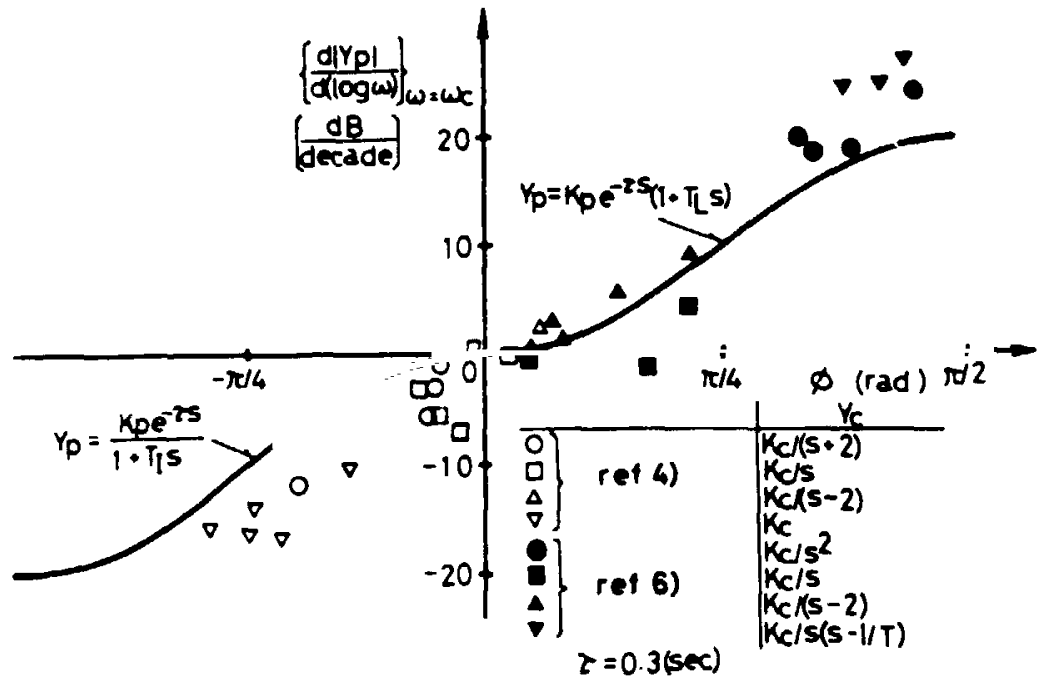

Figure 3. Comparison between Human Pilot Models and Experimental Results 


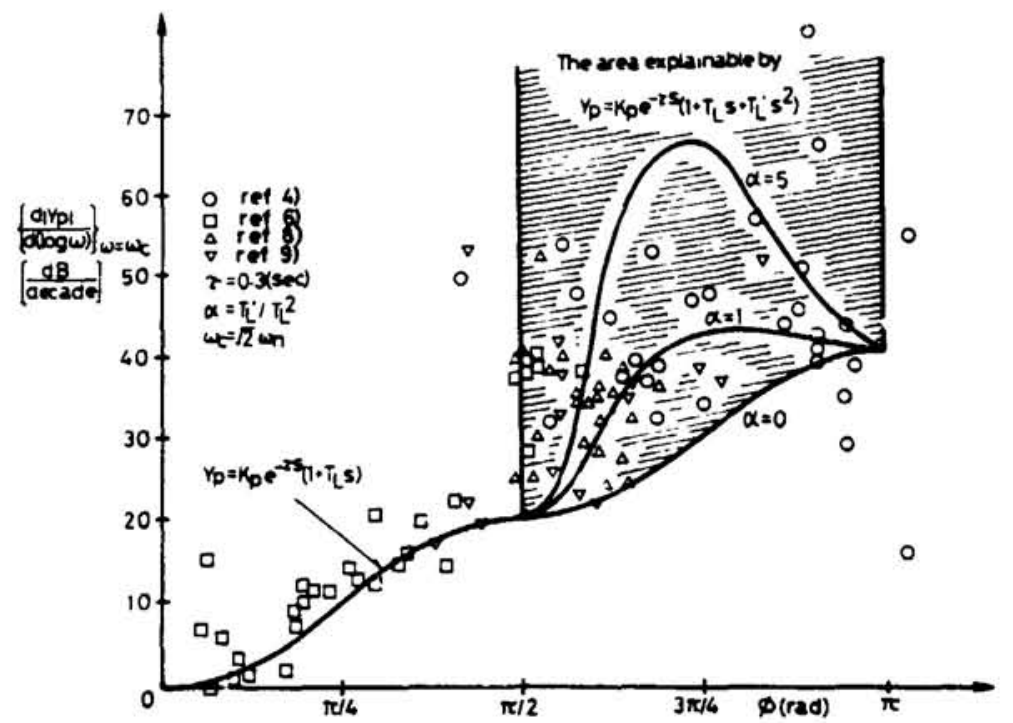

Figure 4. Comparison between Human Pilot Models and Experimen:al Results when $Y_{c}=\omega_{n}^{2} /\left(s^{2}+2 \zeta \omega_{n} s+\omega_{n}^{2}\right)$

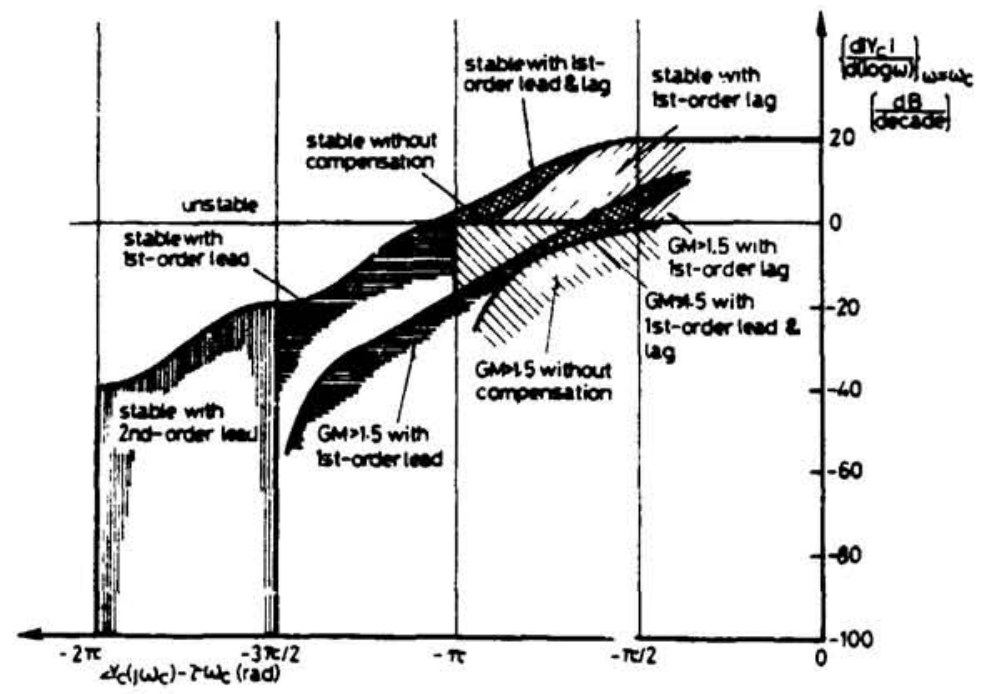

Figure 5. Chart for Evaluating Manual Control System 


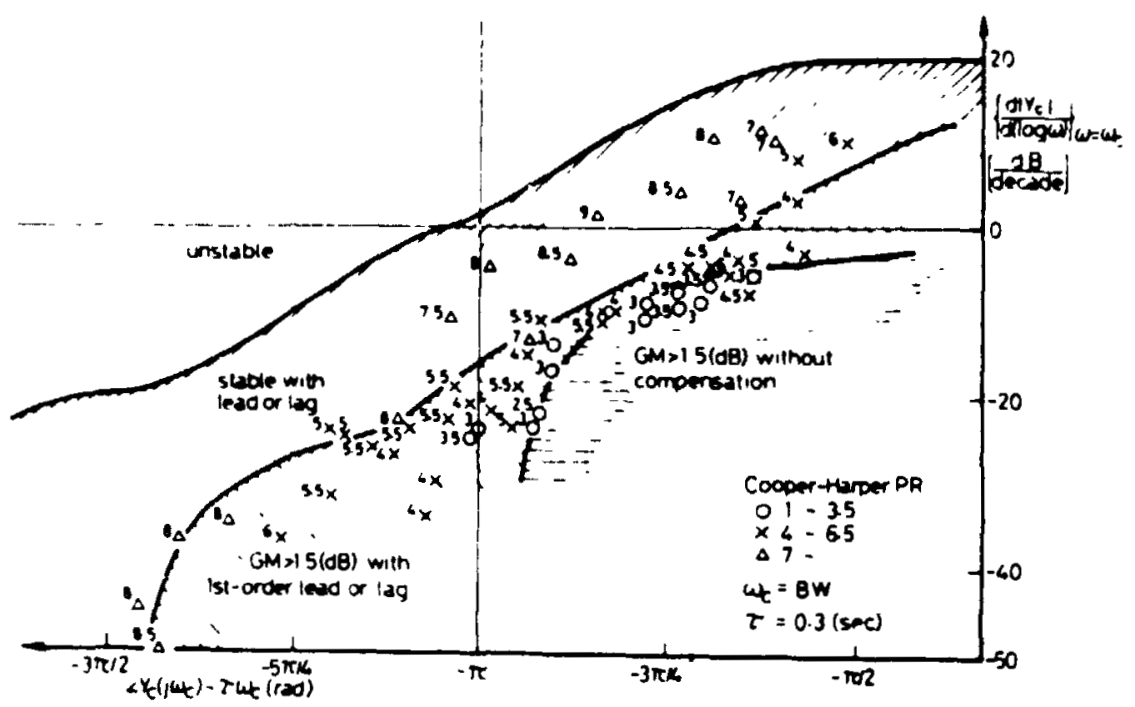

Figure 6. Proposed Evaluation Method Plotted Against Experimental Results from Ref. 1

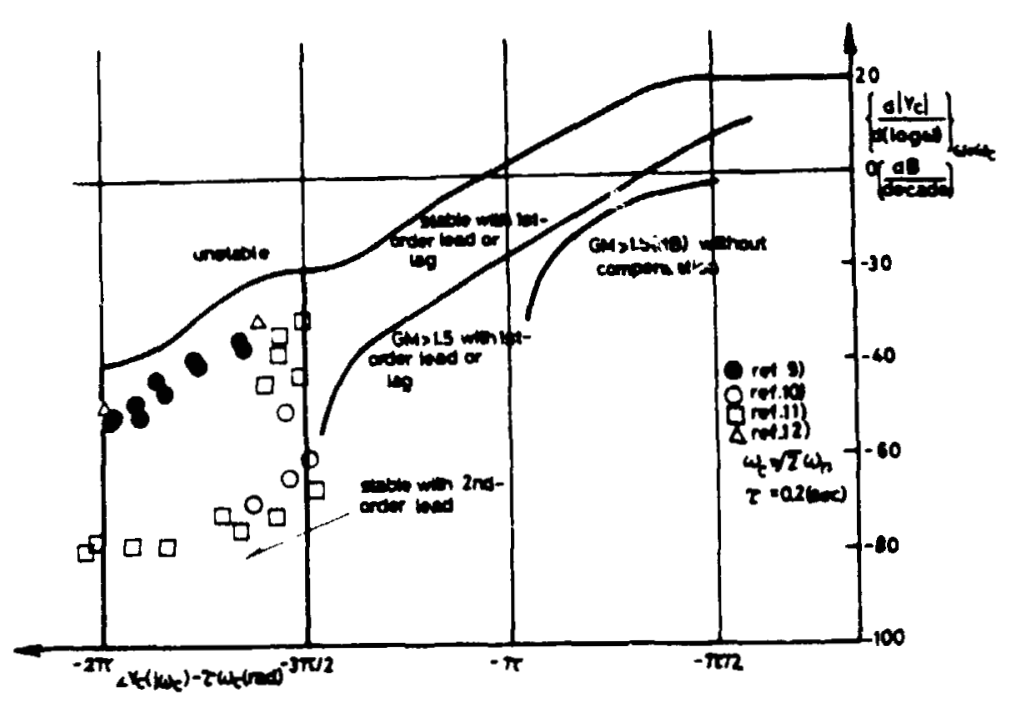

Figure 7. Proposed Evaluation Method Plotred Against Expezimental Controllability Limits when $\gamma_{c}=\omega_{n}^{2} /\left(s^{2}+25 \omega_{n}^{2} s+\omega_{n}^{2}\right)$ 


\section{$\therefore 8234052^{-5}$}

EFFECTS OF HIJHER ORDER CONTPJL SYSTEAS ON AIRCRAFT

APPROACH AND LANDINE LONGITUDIMAL HANDLING QUALITIES

Sqd. Ldr. Muhamad A Pasha

Pakisti. Afr Force

DR. JOHN J. D'AZZO

Professor of Electrical Engineering

Air Force Institute of Technoiogy
CAPT JAMES T. SILVERTHOnN

Assistant Professor

of Aeronautical Engineering

Air Force Institute of Technology

\section{ABSTRACT}

This report presents a study of approach and landing longitudinal fiving qualities, based on data generated by Calspan using a variable stability NT-33 aircraft combined with significant control system dyramics. An optinum pilot lead time for pitch tracking, "light $\rightarrow$ th angle tracking, and combined pitch and flight path angle tracking tasks is determined from a clused-10op simulation using integral squared error (IIS) is a performarice measure. Pilot gain and lead time werc varied in thr a-loop simulation of the pilot and aircraft to obtain the best er: . . ce fai different control systen configuraticns. The results lead to the selection of an optimin lead time using ISE as a performance criterion. Using this value of opt inum lead time, a correlation is then found between : ilot rating and per formance with chanoes in the control system and ir. the aircraft dynamics. It is also shown that pilot ratir. is closely related to pilot workload which, in turn, is related to the mount of lead which the pilot must generate to obtain satisfactory response. The results also indicate that the pilat may use pitch angle tracking for the approach task and then adds flight pati angle tracking far the flare and touchdown. 


\section{INTROOUCTION}

Aircraft handling qualities and pllot behavior during the glide slope, flare, and landing phases of the fight realne are considered in this paper. The results are extracted from the study performed by Pasha. and complete details may be obtained from that report. This study is based on data generated by Calspan ${ }^{2}$ wich investigated the effects of control system dynanics on approach and landing longitudinal flying qualities by using an XT-33A variable stability aircraft. A large number of aircraft/control systea configurations were flown by Caispan and pilot coments and ratings are contained i: "ef. 2. Anderson has postulated that pllot rating is closely related to p.lot workload and that this is determined by the anount of lead wnich the pilot must generate to maintain reasonable response. Using these postulates, the direction of this study was to investigate: (1) the relationship between pilot workload and airc. aft control systen dymanics, (2) the output variables of primary interest to the pilot. This was accomplished by simulating the combined pilot model, aireraft dymaics, and control system as a closed-loop fitch angle and fifght path angle tracking task with the objective of finding a correlation between the closed-loop performance and the pilot ratings. The closed-loop pitch response to a step pitch command was studied. Pllot yain and pl ot generated lead were varied in order to obtain the "best" performance for different control system configurations. This was repeated for closed-loop flight path angle response (both with and without pitch feedback). The closed-loop fitch and flight path angle responses were studied for different air..aft dymantcs. Again the pilot gain and pilot generated lead were varied to obtain the best response. The integrai of error squared (ISE) was used throughont as a measure of perfomanc:.

\section{Aircraft Equations}

The linearized longitudinal aircraft $e$ juations are well known 4,6 and are not repeated here. The coefficients used in these equations for the different aircraft dynanics are included in the original reports 1,2 . The dircraft forward speed was constdered constant. The phugold wode is easily controlied by the pllot and, since the time frane in which the landing task is completed is relatively smali, only the short period alrcraft annantcs nere used in this study.

\section{The canding Task As Seen By A Pllot}

Ouring the approach-to-landing phase of flight the alrcraft is inftially on the glide slope and the pllot must decide on the inimum helght to plare. At this time the pltch attitude $\theta$ and the flight path angle $\gamma$ appear to ve of considerable importance to the pilot. The minimu hetght to plare is an imagina. 'window on the glicie slope wich the pllot selects relative to the runway L., eshold or touchdown point. The selection of the tmaginary window in space depends on the aircraft forward speed, alrcraft dynamic characteristics, and the experience of the pllot in handing the alrcraft. During the flare maneuver the sink rate $h$ (verifcal velocfty) and the slant ringe rate $k$ (the rate at which the runway threshold or touchdown point appears to be approaching) art visual motion cues for the pllot. The pllot pitches uf an." estabiishes a desired $h$ and/or until touch down, where $h, h$ and $R$ go to zero. All three output variables, $h, h$, and $R$, are mathematically related to the flight fath angle $\gamma$ as shown below. 
For small angles the flight path angle $Y$ is given by 4

$$
Y=\theta-\alpha
$$

The sink rate $\dot{h}$ is given by:

$$
\dot{h}=\operatorname{sim}=U_{0} Y
$$

The slant range rate $\dot{R}$ is the $v$ :tor sua of $U_{0}$ and $\dot{h}$. Since $U_{0}$ is assuned constant, $\dot{R}$ is directly proportional to $\dot{h}$ or $Y$. Therefore, all the aotion cues are direct functions of flight pat'l angle $\gamma$. Hence the dynatic behavior of $\theta$ and $y$ for elevator comands $\left(\delta_{e} j\right.$ is representative of the overall landing task.

Pilot Describing Function

The basic McRuer pilot mode ${ }^{5}$ used in this study is represented by

$$
Y_{p}(s)=K_{p} e^{-r s}\left(T_{L} s+1\right)
$$

By adjusting $K_{p}, T_{i}$, and $\tau$ the pilot achieves the level of closed-loop systea performance which he considers desirable or necessary. This is accomplished at the experse of pilot activity and workload. One way to optinize performance is to adjust the model parameters to minimize the integral of squared error (ISE). The "lead on ly" form of piligt model was used because pilot lag may be neglected when higher-order control syrtem lags are present. A value of $\tau=0.3$ was used.

\section{Pilot Rating Concepts}

Pilot Ratings are based on numerical rating scales, such as the CooperHarper scale, which represent an attempt to relate pilot coments about the ease of difficulty with which airplanes can be controlled in certain fight situations. The ratings are ordinal scales subjectively applied and hence are difficult to ouantify. Predictions of pilot ratings require wathenatical relacions between the numerical rating scale and "hm hard a pilot must work" to achieve "desired closed-loop performance". Developing mathematical relation appears to be extremeiy complex, though certain trends have been identiffed. for example a pilot objects if he has to generate "leads" $\left(T_{L}\right)$ of more than

0.5 to 1.0 seconds [6]. The factors which may be taken into account by a skilled test pilot in providing an opinion or rating are 5 : Measure of task performance, Pilot workload, and System sensitivity. These factors are obviously affected by the particular aircraft dynamics, including any additional control systems. As a mathematical function, pilot ratings (PR) can be expressed as:

$$
P R=f(\text { Performance, workload, sensitivity,...) }
$$

Pilot Horkload

The pilot workload can be divided into pilot activity and pllot equalization. Pllot activity is dependent on the pliot gain $K_{p}$ and is an important component of Pilot Rat: Pilot gain is also dete

the presence of gust disturbances and remnant. led by the mechanical arrangement of the controls 
OF Fris:

olaced between the pilot and the elevator. The data generated by Calspan, allowed the pilot to select the gearing ratio for each flight evaluation 2 . The pilot equalization can be represented" by the pilot's "lead" time constant and is used in this study to represent workload.

\section{Analog Computer Simulation}

An analog computer simulation was used to find an optimu pilot lead time which yields the best system performance for the aircraft-control system. The objective was two fold: (1) To see if a correlation exists between performance and Pilot Rating. (2) To see if the pilot could improve the system performance by choosing different forms of pitch angle and flight Dath angle feedback. The pilot gain $K_{p}$ and lead, $T_{L}$ were adjusted to minimize ISE (the perfomance criterion) when the pilot performed a tracking task for a step comand. The effects of adding control systens on the performance were first studied for an aircraft characterized by a short period natural frequency and damping ratio of $1.02 \mathrm{rad} / \mathrm{sec}$ and 0.74 respectively, here after referred to as $A / C 1$. See Raf 2 for the stability and control derivatives of this aircraft. The tracking task was analyzed in three phases: 1) Inner-loop pitch attitude $(\theta)$ tracking for a step pitch comand; 2) outer-loop flight path angle $(\gamma)$ tracking for a step $\gamma$-comand; and 3) combined pitch and flight path angle tracking (inner and outer loop) to minimize the error in the flight path angle for a step $\gamma$-command. These three phases were repeated for four additional aircraft using the baseline control system (control system = 1) to observe the performance variations between the five aircraft configurations. The objective of the analog simulation study was to find optimu pilot parameters $K_{p}$ and $T_{L}$ wich would minimize the ISE for a particular tracking task.

\section{Pitch Attitude Tracking Task}

The block diagram used for the sisillation is shown in Fig. 1. The aircraft with no control system dynamics was an?lyzed first. The control systems which were flown ${ }^{2}$ with this aircraft were the.1 =imulated.

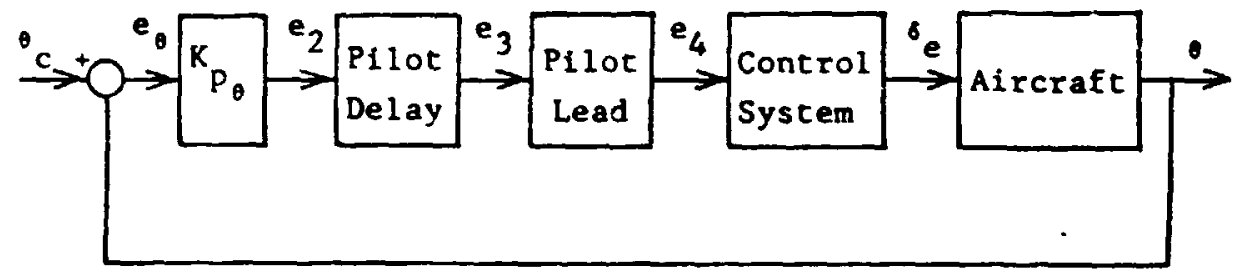

Figure 1. Block Diagram of Pitch Tracking Task

The pilot lead time $T_{1}$ was varied from $C$ to $1.25 \mathrm{sec}$ in steps of $0.25 \mathrm{sec}$. For each va?ue of $T_{L}$, the pllot gain $K_{p}$ was varied and the value of ISE was recorded for a step pitch command $\left(\theta_{c}\right)$. Represc... ative grapts showing the data thus generated are shown in Figs 2 thru 5 . While pilot lead times greater t'an 0.5 or $0.75 \mathrm{sec}$ produce a slight improvement in the system 


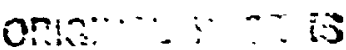

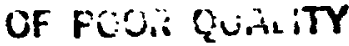

performance, they do so at the expense of greater pilot workload. Also, the curves for 1.0 and $1.25 \mathrm{sec}$. lead time show much larger variations in the valise of ISE about the minimum, thus indicating higher system sensitivity to pilot gain variations. Therefore, a value of 0.5 or $0.75 \mathrm{sec}$. pilot lead seems to be the optimum choice. Fig. 4 shows the performance curve with control system dynamics $? /(s+2)$. Since this control system introduces a significant amount of lag near the short period natural frequency of the aircraft (i radisec), the aircraft dynamics response is very sensitive to gain change. In other words. for good performance the pilot must hold the gain very steady to maintain geod performance. This amounts to an additional worklcad in terms of pilot concentration and hence a degraded pilot opinion of the task. The value of minimum ISE and the corresponding pilot ratings are plotted in Figs. 6 and 7 for a 0.5 and $0.75 \mathrm{sec}$. pilot lead, respectively. The plots show an increase in pilot rating as the perfomance degrades for control systems which introduce lag. The reverse trend for control systems which introduce lead is a puzzle which could not re explained.

\section{Flight Path Angle Tracking Task}

During the flare maneuver, the sink rate information is one of the visual cues the pilot uses in performing the landing task. Since flight path angle $\checkmark$ is directly related to the sink rate, it is logical to anaiyze the pilot in the $y-100 p$. This was done by first assuming no pitch angle feedback. The block diagram used for this simulation is shown in Fig. 8.

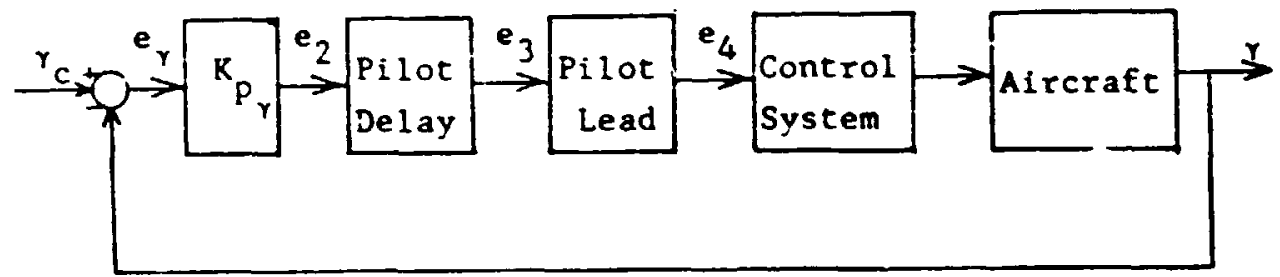

Figure 8. Block Diagram of Y Tracking Task

The ISE $\left(\epsilon_{i}^{2}\right)$ was measured for a step $\gamma$-command. The pilot parameters $K_{p_{\gamma}}$ and $T_{L}$ were varied and the procedure used for the analysis of oitch ioop was repeated, vis-a-vis, measuring the value of ISE until a minimum is reached, as $K_{P_{Y}}$ and $T_{L}$ were varied. Similar performance was obtained as for the pitch angle control and the results are contained in Ref. 1. The optimum pilot lead was 0.75 . However, the minimum values of ISE achieved were much greater than for pitch angle tracking. Therefore it wrs concluded that the pilot is more inclined to use pitch angle tracking while on the glide slope. 
Combined Pitch and Flight Path Angle Tracking

The next step was to study the effect of feeding both pitch and fight path angle as a multi-output system for a single input stap $\gamma$-comand. Figure 9 shows a block diagran of the system used for simulation.

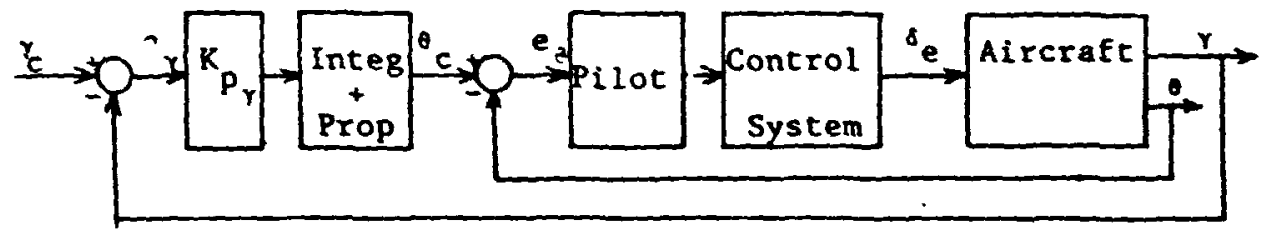

Figure ${ }^{\circ}$. Both $j$ and $y$ Tracking Task For A Step $Y$-Comand

The analysis was restricted to aircraft $I$ and the lag controi systeas flown with aricraft 1 . The 'lead only' form of pilot dynamics was used for the pilot in the pitch loop. Two values of $T_{L}, 0.5$ and 0.75 seconds, ware used, and the corresponding gains $\mathrm{K}_{\mathrm{p}_{\theta}}$ whict minimized the :SE in the pitch tracking task were obtained. Since the closed-loop pitch transfer function rorms a type zero system, using only pilot gain $k_{p_{\gamma}}$ in the outer loop would result in a steady-state error $e_{\gamma}$ for a step $\gamma$-command input ${ }^{7}$. Therefore an, integral plus proportional contro? system was used, as shown in Figure 9, to represent the pilot in the outer loop. Pilot reaction time del ay was not included in the outer loop. The transfer function used for integral and proportional control has the form;

$$
G(s)=1+\frac{a}{s}
$$

Determining the appropriate value of ' $a$ ' to be used for the task was the next step. Therefore, $k_{P_{\gamma}}$ was varied and the ISE $\int e_{\gamma}^{2}$ was masured for a step $i$-command, while the value of "a" was varied from 0.1 to 0.4 in steps of 0.05 . This priceedure was used with both a $T_{L}$ of 0.5 and 0.75 seconds for pilot

lead in the pitch loop. The data thus generated showed that a value a $=0.2^{-}$ minimized the ISE, and this value was used for subsequent analysis.

The lag control systems flown with aircraft 1 were simulated to study the effect of performance degrajation on pilot rating. The outer loop pilut gain $K_{P_{\gamma}}$ was varied and the ISE $\int e_{\gamma}^{2}$ was recorded for a step $\gamma$-command. 
Figure 10 shows a olot of ISE $\int e_{Y}^{2}$ versus the $K_{p_{Y}}$ for various lag control systems. The pilot rating (PR) is also shown. The effect of perforwance degradation on pilot rating can be clearly seen from these plots. Figure 11 shows the plot of minimum ISE $\int e_{y}^{2}$ veisus the PR for afreraft 1 without the control system and with the lag control systems. These figures indicate a direct relationship between $P R$ and performance for a fixed pilut workload.

In this control system an outer loop gain and integral plus preportional control is required from the pilot. The task of integrating an error essentially means remembering the past errors and thus represents an increase in the pilot workload. Whether the pilot likes this kind of additional w- $k-$ load or if the additional workload is worth the improvement in the performance needs to be determined. Also, for a multi-output tracking task, how the pilot would time share iis control of the two outputs $\theta$ and $\gamma$ needs to be investigated. It may be possible that during the glide slope the pllot is flying the aireraft by tracking orily the pitch angle $\theta$ up to a certain altitude where the sink rate $h$ becomes important. This altitude may be about 100 feet, where the pilot may begin tracking both pitch angle and fight path angle until the flare maneuver. During flare, especially the last 50 feet, the pilot may switch over to tracking only the altitude, assuming that he has done his best to stabilize the $\theta-100 p$. A plot of ISE versus $K_{p}$ is show in Figure 12 $f$ a pitch loop $T_{L}$ of 0.5 and 0.75 seconds for the three tracking tasks 4 ing aircraft 1 without the control systems.

The above hypothesis, i.e., during approach the pilot is essentially tracking the pitch attitude and during flare and landiny phase the pilot $i j$ tracking the flight path angle while holding a fixed optima pitch loop erformance may be verified by the following proceedure. In a large umber of flight conflgurations flown, the pilot evaluated the approach task and the overall landing task separately and provided two different ratings. An optimum pilot workload and performance evaluation can be performed on an analog computer. The proceedure described in this paper and those flight configurations for which both ratings were provided may be used; first as a pitch tracking task, and then as $r$-loop tracking isk with the pitch loop optimized as per the first analysis. Tne results thus obtained can be correlated with the corresponding approach and overall pilot ratings to validate the rupotheses. This analysis was not carried out due to lack of time. The data generated in this study indicates a possible correlation with pilot ratings but is insuffictent to draw positive conclusions about inis hypothesis.

Pitch Attitude Tracking for Different Aircraft

The previous analysis was extended to other aircraft. Sinilar results were obtained for all aircraft as shown in Fig. 13.

Summary of Resuits of Closed-Loop Analog Simulation

The following are the results of the study:

1) A lead time of 0.5 to 0.75 seconds seems to be the optimum pilot lead for most of the aircraft-cortrol system combinations.

2) Control systems generating significant lag at the short pertod natural frequency tend to make the system very sensitive to gain changes. 
3) Performance, measured in terms of ISE, has a direct correlation with PR for aircraft with control systems which introduce lag.

4) Closing both the pitch and flight path angle loops for a $\gamma$-comand. improves the performance but at the cost of increased pilot compensation.

\section{BIBLIOGRAPHY}

1. Pasha, M.A.: Analysis of the Effects of Higher Order Control Systens on Aircraft Approach and Landing Longitudinal Handling Qualities, M.S. Thesis, Air Force Institute of Technology, AFIT/GE/EE/79-27, 1979. ODC No. ADA-08C519.

2. Smith, R. E. Effects of Control System Dynamics On Fighter Approach and Landing Longitudinal Flying Qualities, Vol I. AFFDL-TR-T?-122. WPAFB, Ohio: Air Eorce Flight Dynamics Laboratory, March 1978.

3. Anderson, R. O., A. J. Conners, and J. D. Dillow. Paper Pilot Ponders Pitch. AFFDL/FGC-TM-70-1. HPAFB, Ohio: Flight Control Division, ATr Force Flight Dynamics laboratory, November 1970 (Revised January 1971)

4. Blakelock, John H. Automatic Control of Aircraft and Missiles. New York: John Wiley and Sons, Inc., 1965.

5. McRuer, D. T. and E. S. Krendel. Mathematical Models of Human Pilot Behavior. AGARD-AG-188: North At lantic Treaty Organtzation, January 1976.

6. Roskam, Jan. Flight Dynamics of Rigid and Elastic Airplanes. Lawrence, Kansas: Roskam Aviation and Engineering Corporation, 1972 .

7. D'Azzo, John J. and Constr.ıtine H. Houpis. Linear Control System Analysis and Design: Conventional and Modern. New York: McGraw-HilT Book Company, 1975. 

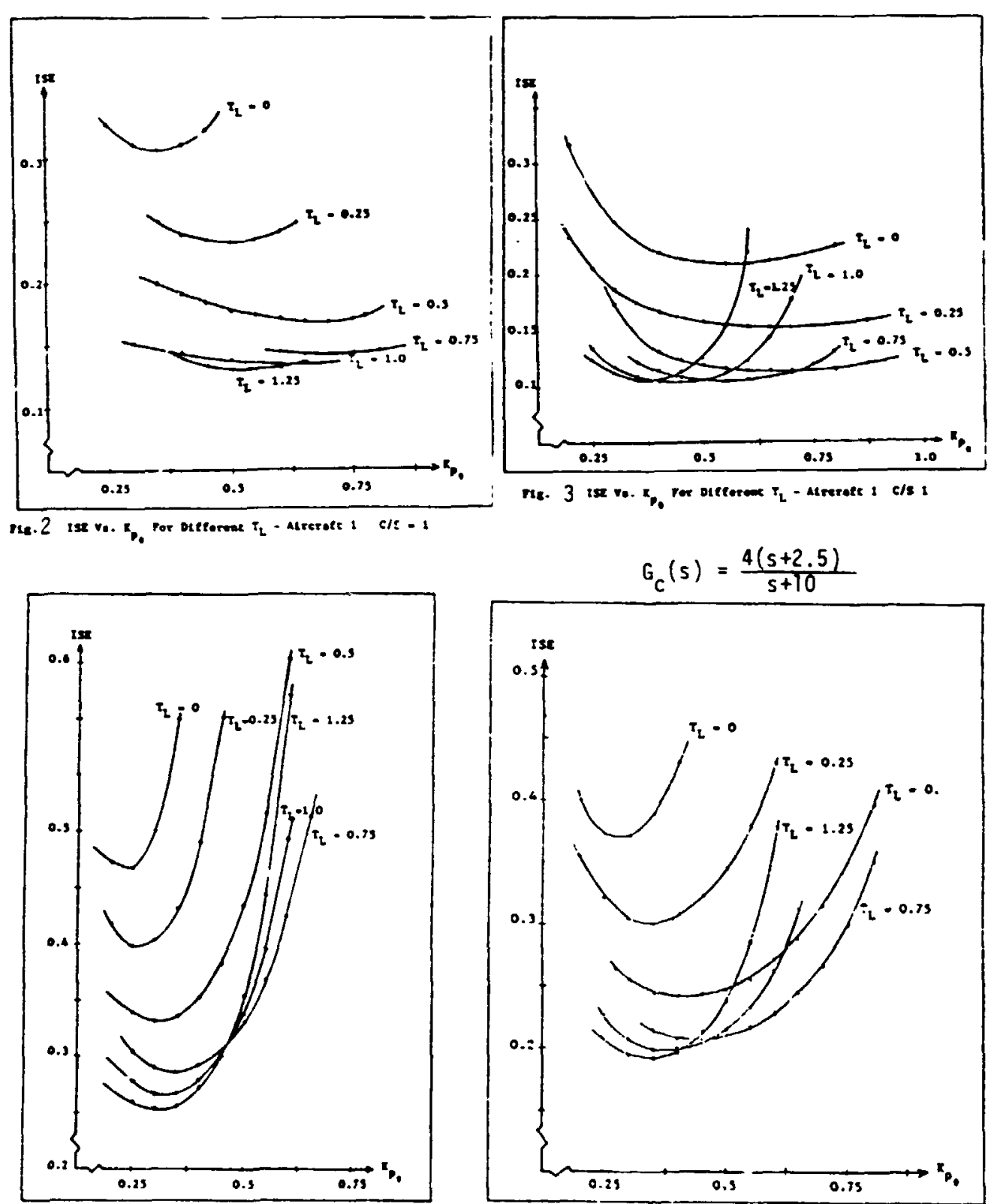

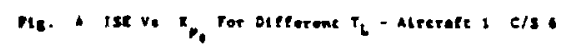

$$
G_{C}(s)=\frac{2}{s+2}
$$

$G_{C}(s)=\frac{4(s+2.5)}{s+10}$

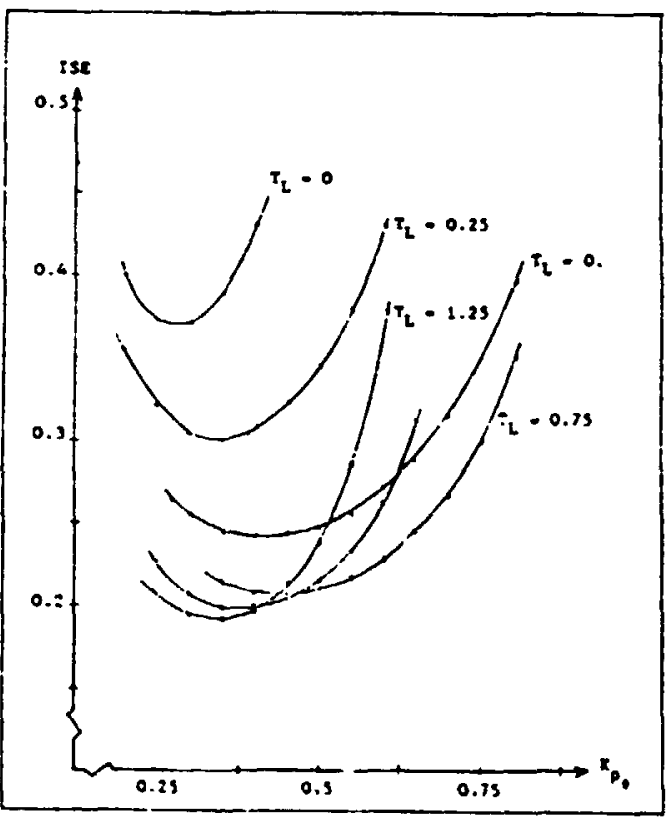

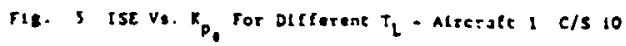

$$
G_{C}(s)=\frac{81}{s^{2}+12.6 s+81}
$$



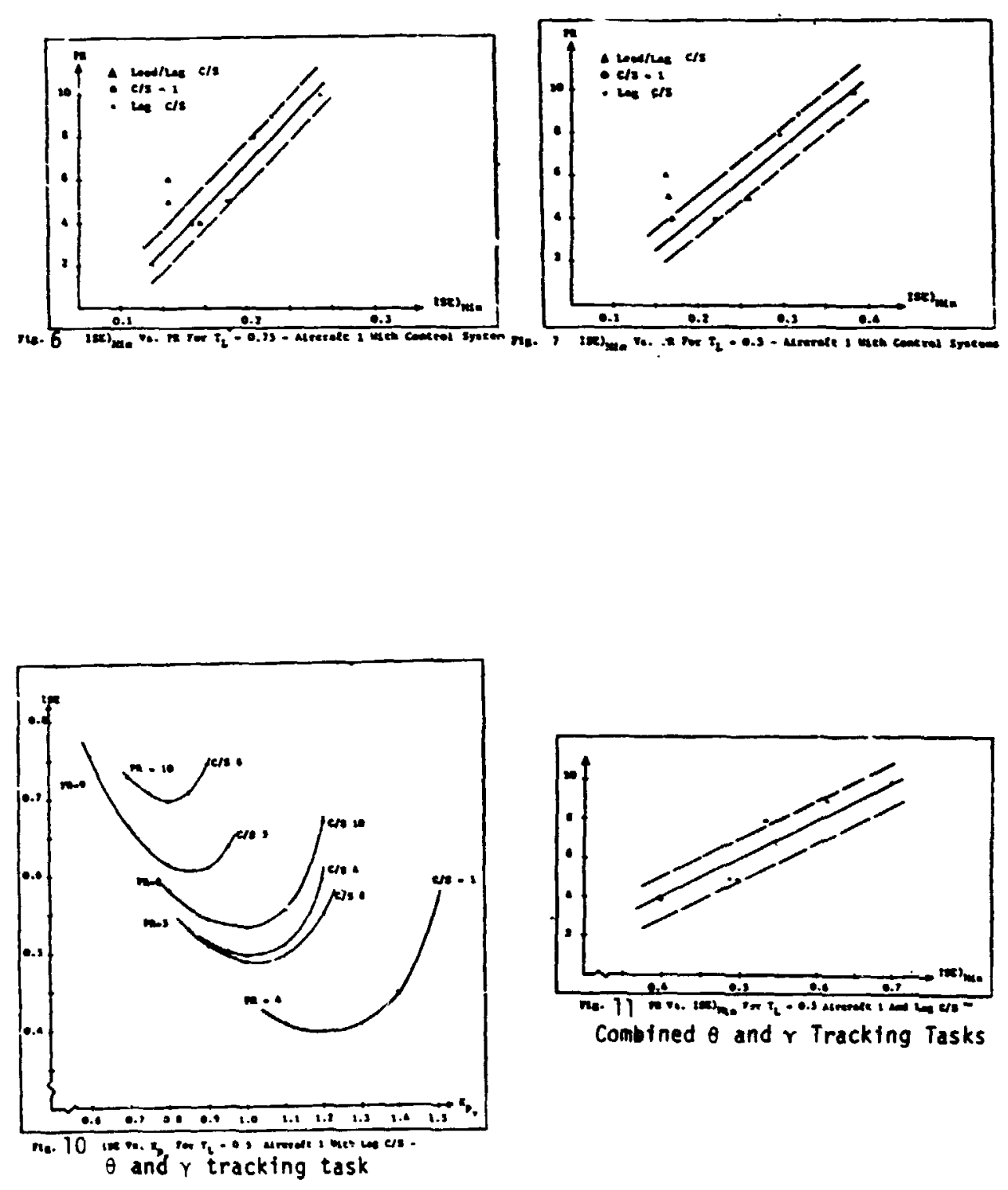


\section{OF FOOA Gislity}
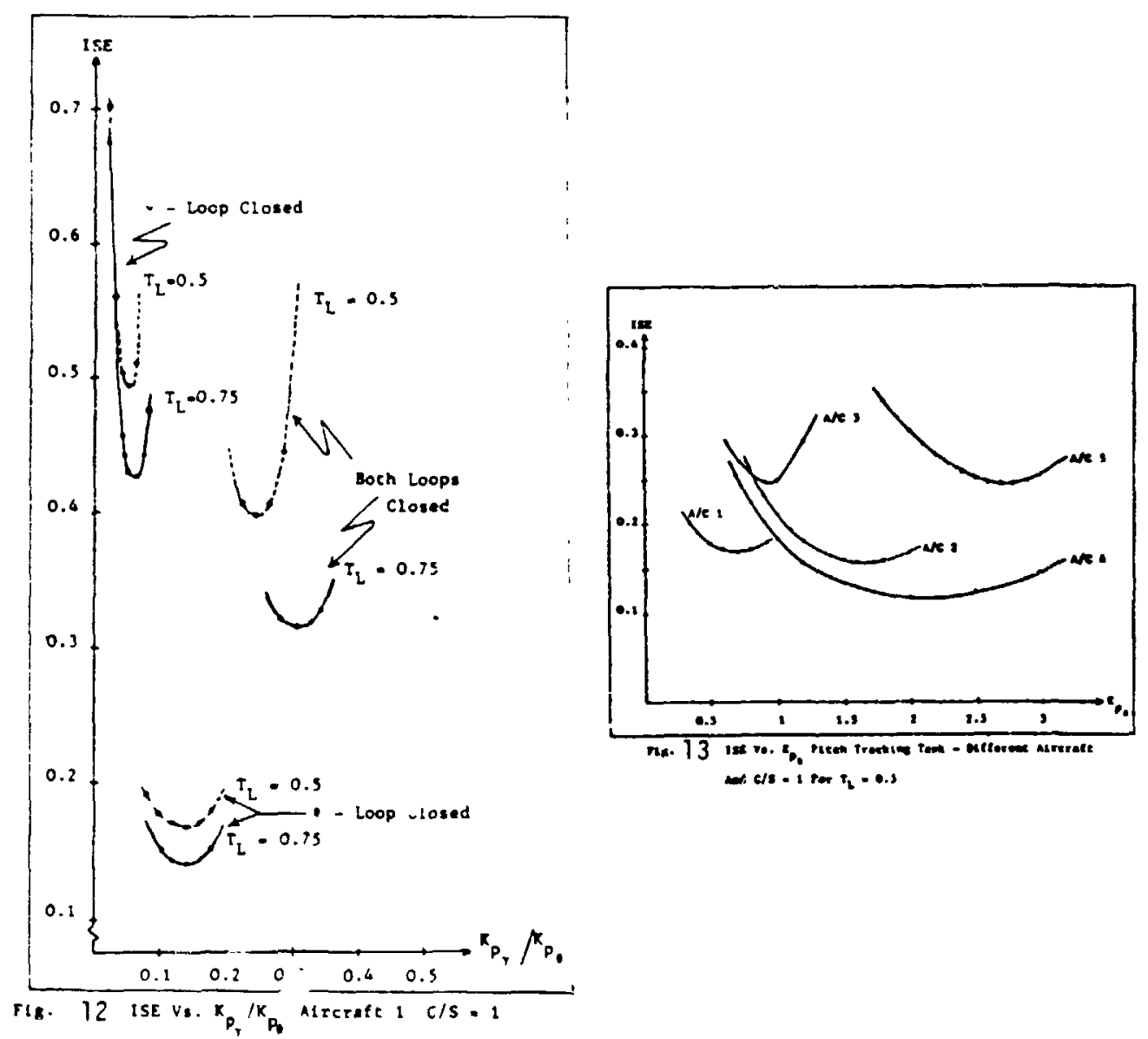


\title{
N82 34053
}

\author{
PILOT OPINIONS OF SAMPLING EFFECTS \\ IN LATERAL-DIRECTIONAL CONTROL \\ Robert F. Stengel* and George E. Milier* \\ Fliglt Research Laboratory \\ Princeton University \\ princeton, N. J. 03544
}

Flight experiments with $a$ microprocessor control

system have been conducted to determine the effects of variations in sampling parameters on several pilots' opinions of lateral-directional flying qualities, - Princston's VariableResponse Research Aircraft (VRA), which is equipped with a microprocessor-based ligital flight control system (Micro-DFCS), was the test vehicle. Two U.S. Navy pilots evaluated the effects of sampling ra:e, quantization, and pure time delay during tracking, approzch, and landing. Aircraft carrier approach tasks were conducted using a Navy approach mirror. Afquisition and tracking of fixed objects on the ground provided additional information related to the Navy mission.

This research is an extension of the longitudinal investigation reported in Ref. 1 . In the present case, the longitudinal controls were implemented with analog electronics, while the lateral-cirectional pi'ot inputs (stick and rudder) were fed to the Micro-DFCS, which commandnd the ailerons and rudder. Full details of the systems and experimental procedures can be found in Refs. 1 to 3. Figure 1 illustrates the conceptual relationship betweer the evaluation pilot's lateraldirectional inputs, the flight computer, and the aircraft.

\footnotetext{
- Associate Professor of Mechanical and Aerospace Engineerinc.

* Member of the Technical Staff.

+ This work was conducted under Contract No. N00014-78-C-v?57 for the office of Naval Research.

Presented at the 16 th Annual Conference o: Manual Tontrol. Cambridge, Mass., May, 1980.
} 
The flight test results are summarized in Figs. 2

to 4. For simulated carrier landing approaches. he two naval aviators founc sampling rates of 10 per sec or higher acceptable, with computational time delay fixen as $10 \mathrm{msec}$, as indicated by pilot opinion ratings 4 of 3.5 or less (Fig. 2). Holding sampling rate at 20 per sec, equivalent time delays if about $100 \mathrm{msec}$ or less were acceptable, and the degradation $x$ pilot sating was found to be $d$ inear in the delay. (The equivalent delay is defined to be the computational delay plus half the sampling interval). With sampling rate $>$ id pure delay fixed at 20 per sec and $10 \mathrm{msec}$, respectively, control word lengths of 10 bits were found to be acceptable, while the allowable value dropped to 8 bits for tracking at altitude (Fig. 3), Figure 4 illustrates that somewhat lower values of sampling rate were found asceptable when tracking at altitude, but the tolerance to equivalent time delays was greatly reauced.

The present results are applicable to the VRA with unaugmented dynamics; the effects of dynamic variations, which can be provided by the VRA's variable-stability system, remain to be defined.

\section{REFERINCES}

1. Stengel, R。 F, and Miller, G. E., "Flight Tests of a Microprocessor Control System", AIAA Yaper No. 79-1962 Los Angeles, Oct 1979 (to appear in tise AIAA Journal of Guidance and Control; .

2. Seat, J. C., Miller, G. E., and stengel, R. F., "A Microprocessor System for Flight Con. rol Research", Proceedings of the 1979 National Aerospace i Electronics Conference, Dayton: $M=j$ i979, pp. 319-326.

3. Stengel: R. F., "Digital Flight Control Pesearch Using Microprocessor Technology", IEE: Transaction. in Aercspace and Electron $\vdots$ C Systems, Vol. AES-15, No.3, May 1979,pp.397-404.

4. Couper, G. E., and Harper, R. P., Jr., "The Use of Pilot Racing in the Evaluation of Aircraft iandling qualities", NASA TN D- 53, April 1969. 


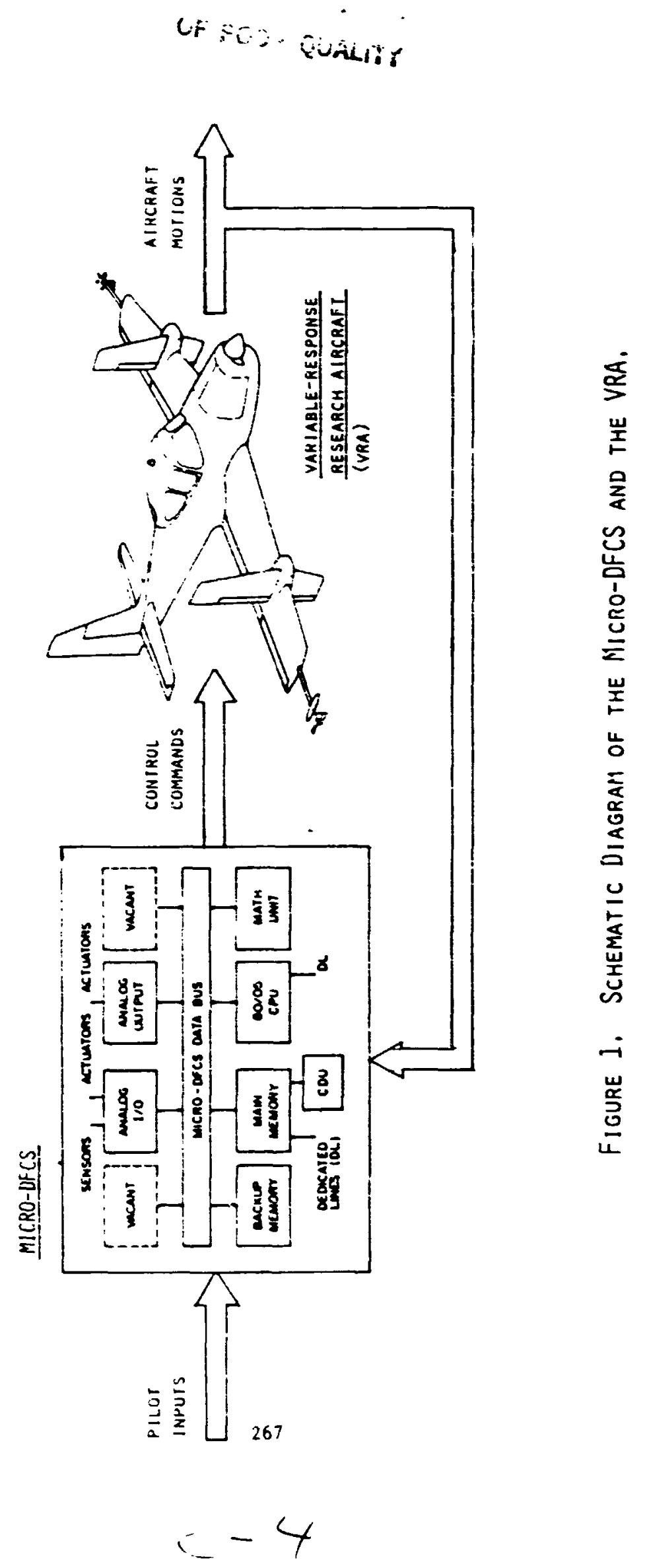



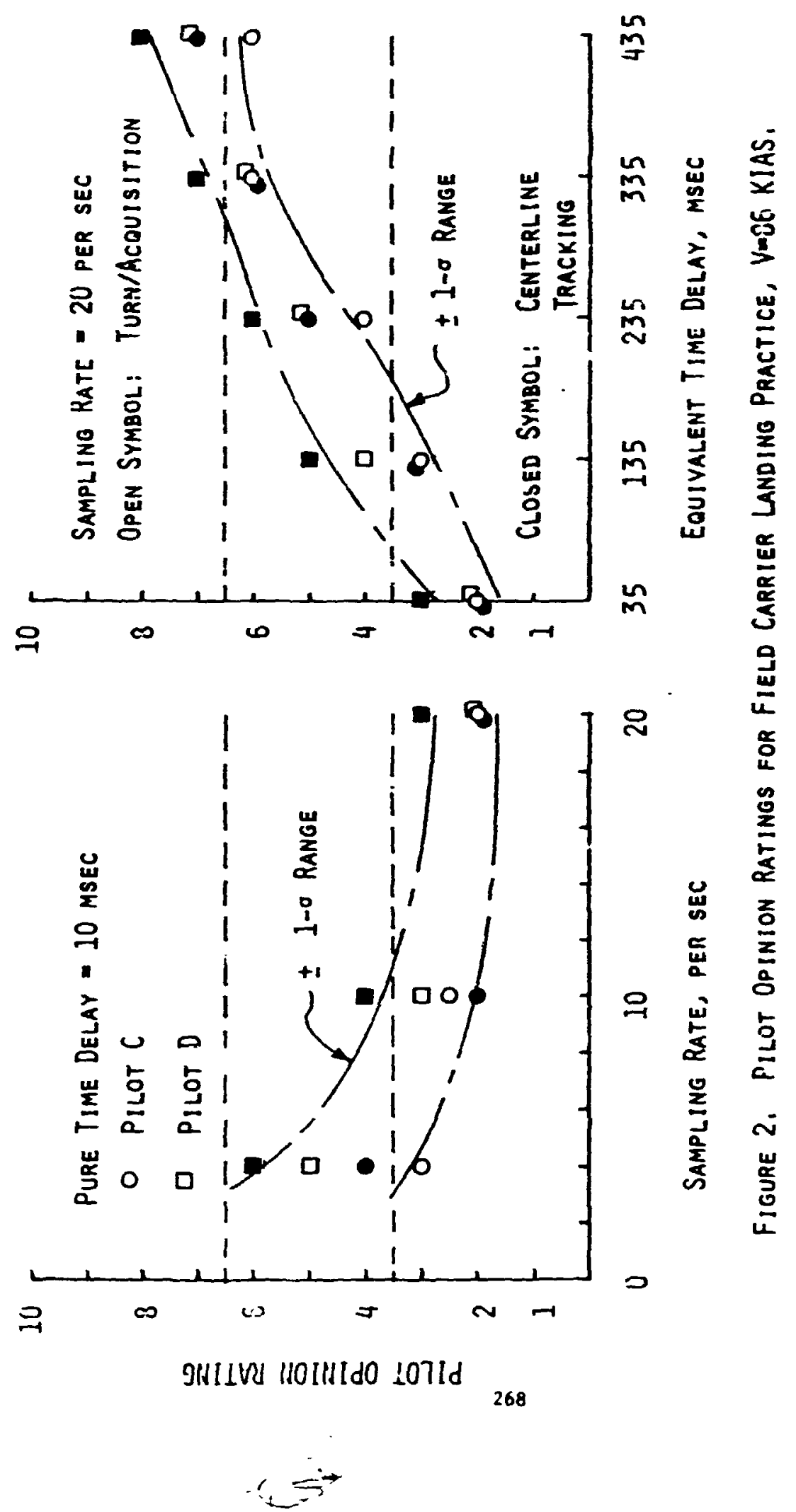
CRICHAL PS: Is

OF POOR Qjaliti

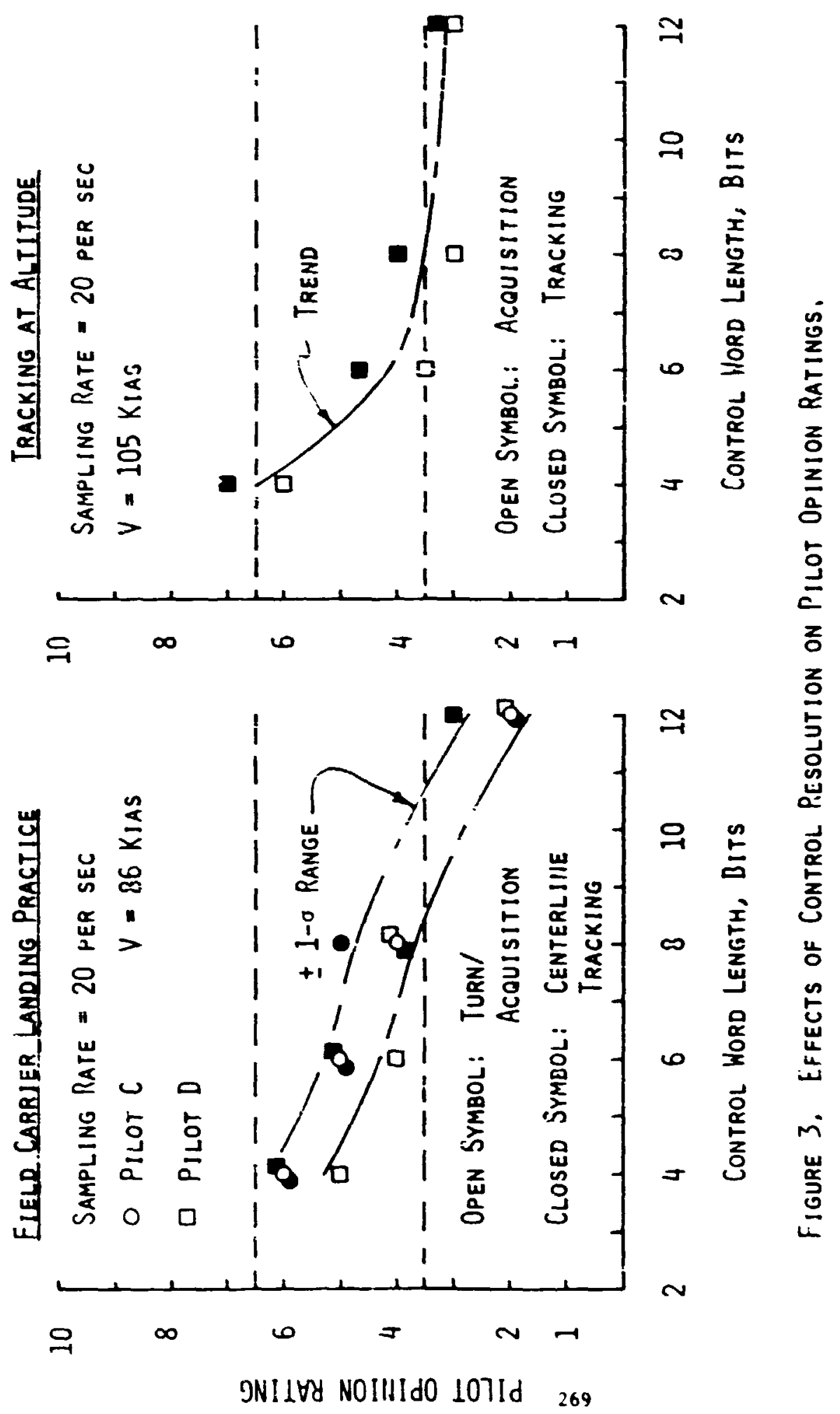




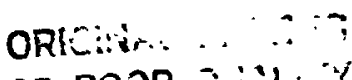

OF POOR EjiL: "Y
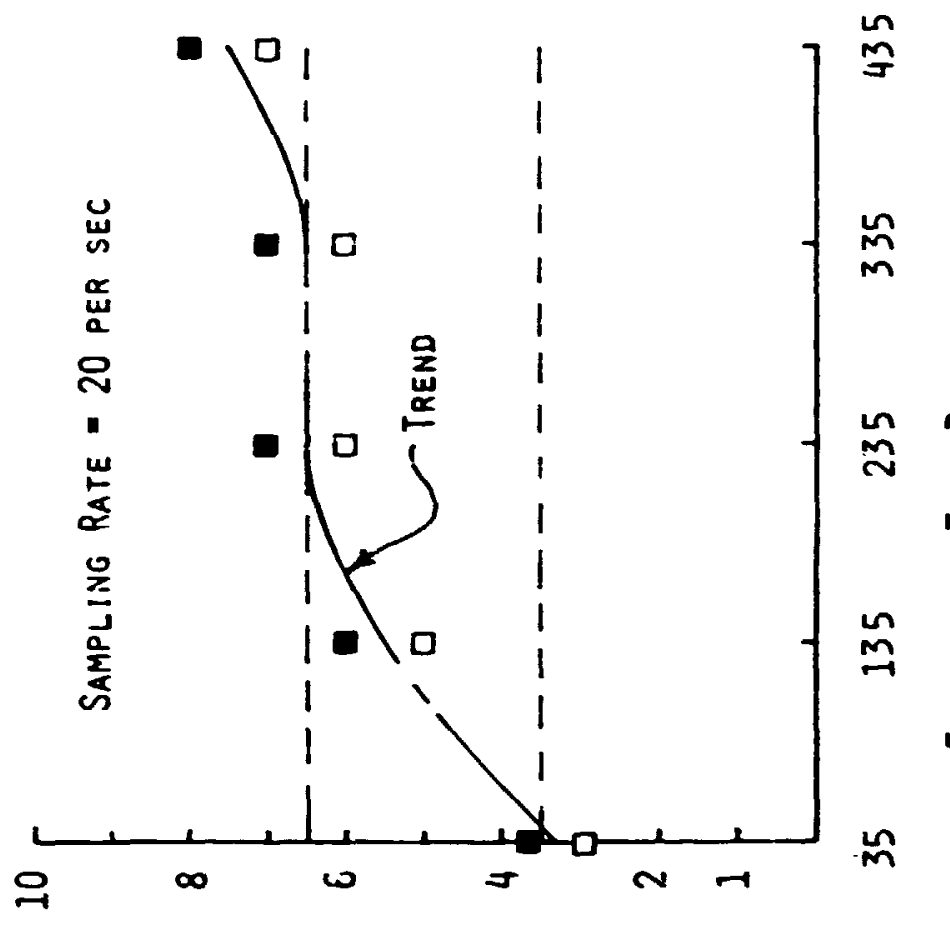

崫

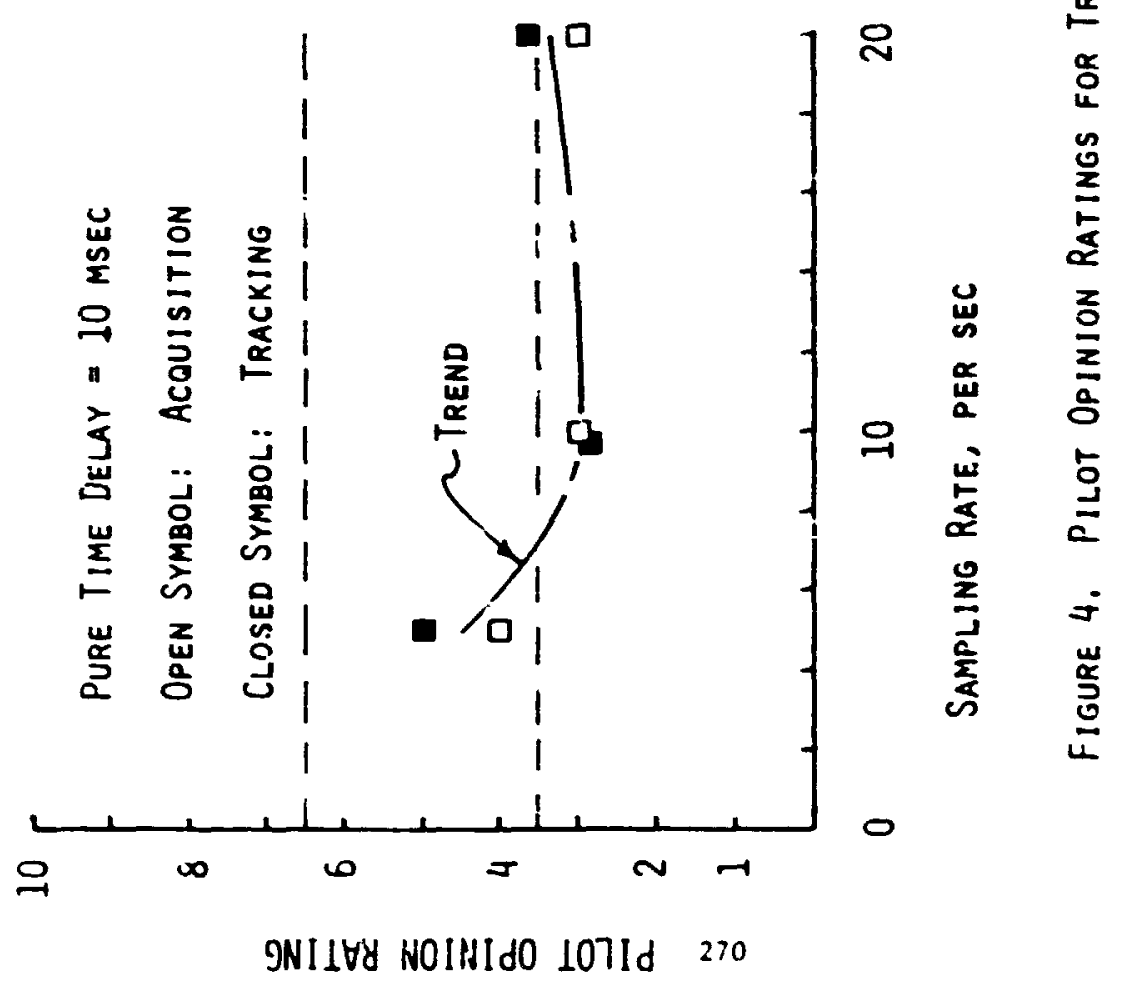




\section{N82 $3405 \underline{-7}$}

A MOOEL OF SUBJECTIVE PROBABILITIES

FROM SMALL GROUPS*

William R. Ferrell

and

Kelly Rehn

Huan Factors/Man-Mach ine Systems Laboratory

Departiment of Systews and Industrial Engineering

The University of Arizona

Tucson, Arizona 8572 ?

\section{INTRODUCTION}

There is good evidence that the quality of probabilistic forecasts, and meteorological forecasts in particular, is isproved by aggregating the opinions of individual forecasters. $8,9,10,: 2$ The question of how best to do the aggregation has raised a numer of important issues. How large should the group be? Should it be a nominal group or one in wich members interact, and if the latter, what sort of interaction? By what mathematical rule should individual judgments be combined to form the group judgment, or, alternatively, should the group produce a consensus forecast? How should individual judgments be weighted mathematically?

A major step toward an experimental answer to these questions, excepting that of group size, has been made by Seaverb, 7 in his study of probability judgments by grmups of 4 people. The research reported here used the decision variable partition model of subjective probability and a simple model of the effects of interaction on judgments to simulate the group judgment of discrete probabilities investigated by Seaver. The initial results of the simulation are very promising in that (1) they show the principal effects Seaver ob ved and (2) these effects can, for the most part, be traced to specific character. istics of the models. This work may this provide a tasis for further investigation of how best to aggregate individual forecasts.

\section{SEAYER'S EXPERIKENT}

Seaver 7 investigated the performance of groups of 4 people, acquainted with each other, at making probability judgments about discrete events and about continuous randon variables. Only discrete events will be considered here, since the decision variable partition model used in the simulation does not, in its present form, acconnodate continuous distributions. Seaver posed general knowledge questions of the sort: "Absinthe is: a) a liqueur or (b) a precious stone." Group members individually chose an answer and recorded a subjective probability $r$, on the half-range .5 to 1.0 , of being correct. They then interacted accorsing to a prescribed method and then again chose an answer and recorded probability judgments. In addition, they rated themselves and the other group members on expertise. Finally, group judgments were created by different mathematical methods of weiahting and combining the individu:l judgments.

This work was supported by the National Science Foundation, Division of Engineering under Grant ENG-7809365, "Bayesian Methodology for Rainflood Forecasting and Reservoir Control." 
The exferimental conditions for wich Seaver obtained results, from eleven groups with 20 questions per group, are set out in Table 1 . The consitions simulated by the model are also indicated. The differences anong the types of interaction are given in Table 2. Since Seaver found no reliable differences ameng the interaction methods, all of which allowed individuals to consider the judgments of others. the methods were lumped together as interaction for modeling purposes.

The aggregation methods produce a group probability PG for the correct hypothes is from individual probabilities $p_{i}, i=1,2,3,4$. The value of $p_{i}$ is the individual's half-range response $r_{i}$ if he chose correctly and $\left(1-r_{i}\right)$ if he did not. Similarly, the group response $r_{G}$ is $P_{G}>.5$ and $\left(1-p_{i j}\right)$ if $P_{G}<.5$. The equations for $\Gamma_{G}$ under the different aggregation methods are set out below, where $w_{i}$ is the weight assigned to the $i$ th individual's judgment, and the weights sum to one over the group.

1) Linear combination

$$
P_{G}=\sum_{i=1}^{4} W_{i} P_{j}
$$

2) Heigited geometric mean

$$
p_{G}=\frac{\prod_{i=1}^{4} p_{i} w_{i}}{\prod_{i=1}^{4} p_{i} w_{i}+\prod_{i=1}^{4}\left(1-p_{i}\right)^{w_{i}}}
$$

3) Likei inood ratios

$$
\frac{P_{G}}{\left(1-P_{G}\right)}=\prod_{i=1}^{4} \frac{p_{i}}{n-p_{j}}
$$

The latter relation (3) reduces to (2) when all $w_{i}$ are equal to one.

Seaver used three weighting thods: equal, normblized self ratings, and DeGroot weights wich are determined for an individual from others' ratings of his expertise. Since there is no model to predict the assignment of weights, only the equal weight case could be simulated, i.e. $w_{i}=1 / 4$.

\section{SEAVER'S RESULTS}

Seaver summarized his results in terms of 1) a quadratic scoring rule score, 2) the average probability assigned to the cornct answer, and 3) calioration curves, the plot of the proportion correct $p(C \mid r)$ is a function of response $r$. The actual proportions of correct response were not reported. Al though interaction on the whole had a significant effect, the several methods of interaction could not be shown to differ significantly. In addition, the differences among the weighting methods were slight, in keeping with the rasults of previous research. Pf But it seems likely that differential weighting would be advantageous if certain questions were to require different specialized knowledge and the groups were composed of people with diverse expertise.

Figure $I$ shows the observed effects of aggregation and interaction on calibration. The frequent finding of over-confidence for individuals is evident. 4 


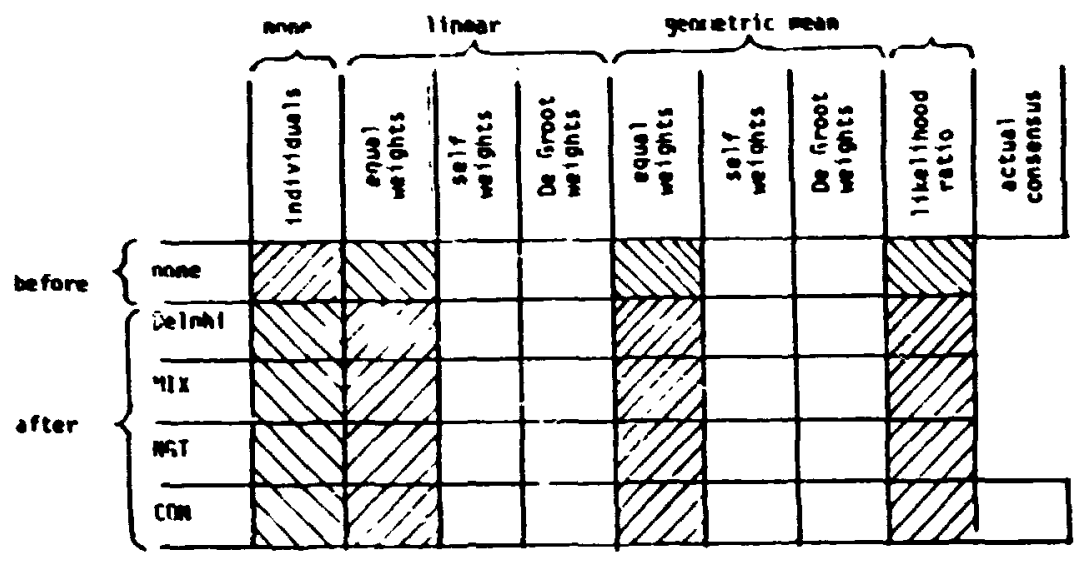

Tole 1. The conditions for Seaver's exoerfients. Each cell represents - condition for mich jubents were obtained. Each shaded reaton Indicates a separate condition represented by the mad ind for wich sfulation results are cotained. In the odel no distinction is ade anong interaction types.

\begin{tabular}{|c|c|c|c|c|c|}
\hline $\begin{array}{c}\text { Type of } \\
\text { InEernevion }\end{array}$ & $\begin{array}{l}\text { Meconalider vith } \\
\text { Information about } \\
\text { oether Judements } \\
\end{array}$ & $\begin{array}{c}\text { Xnowlodes of } \\
\text { Judpinent } \\
\text { souree }\end{array}$ & $\begin{array}{c}\text { Verbul } \\
\text { Information } \\
\text { Exchange }\end{array}$ & $\begin{array}{c}\text { uncontrolied } \\
\text { O2seusesion }\end{array}$ & $\begin{array}{l}\text { Conseneve } \\
\text { meceneary }\end{array}$ \\
\hline $\begin{array}{l}\text { Nome } \\
\text { Selphi } \\
\text { MIX } \\
\times 6 T \\
C 0 \pi\end{array}$ & $\begin{array}{l}\text { Yee } \\
\text { Yed } \\
\text { Yoe } \\
\text { Yes }\end{array}$ & $\begin{array}{l}\text { Yes } \\
\text { Yes } \\
\text { Yes }\end{array}$ & $\begin{array}{l}\text { Yes } \\
\text { Yee } \\
\text { Yes }\end{array}$ & $\begin{array}{l}\text { Yes } \\
\text { Yea }\end{array}$ & Yes: \\
\hline
\end{tabular}

Tabis 2. Differences anong the severel tyoes of

interaction e ifned by Seaver. These differences did

not orousce s: iffcant differences in performance. 
ORIGINAL PAGE IS

OF POOR QUALITY
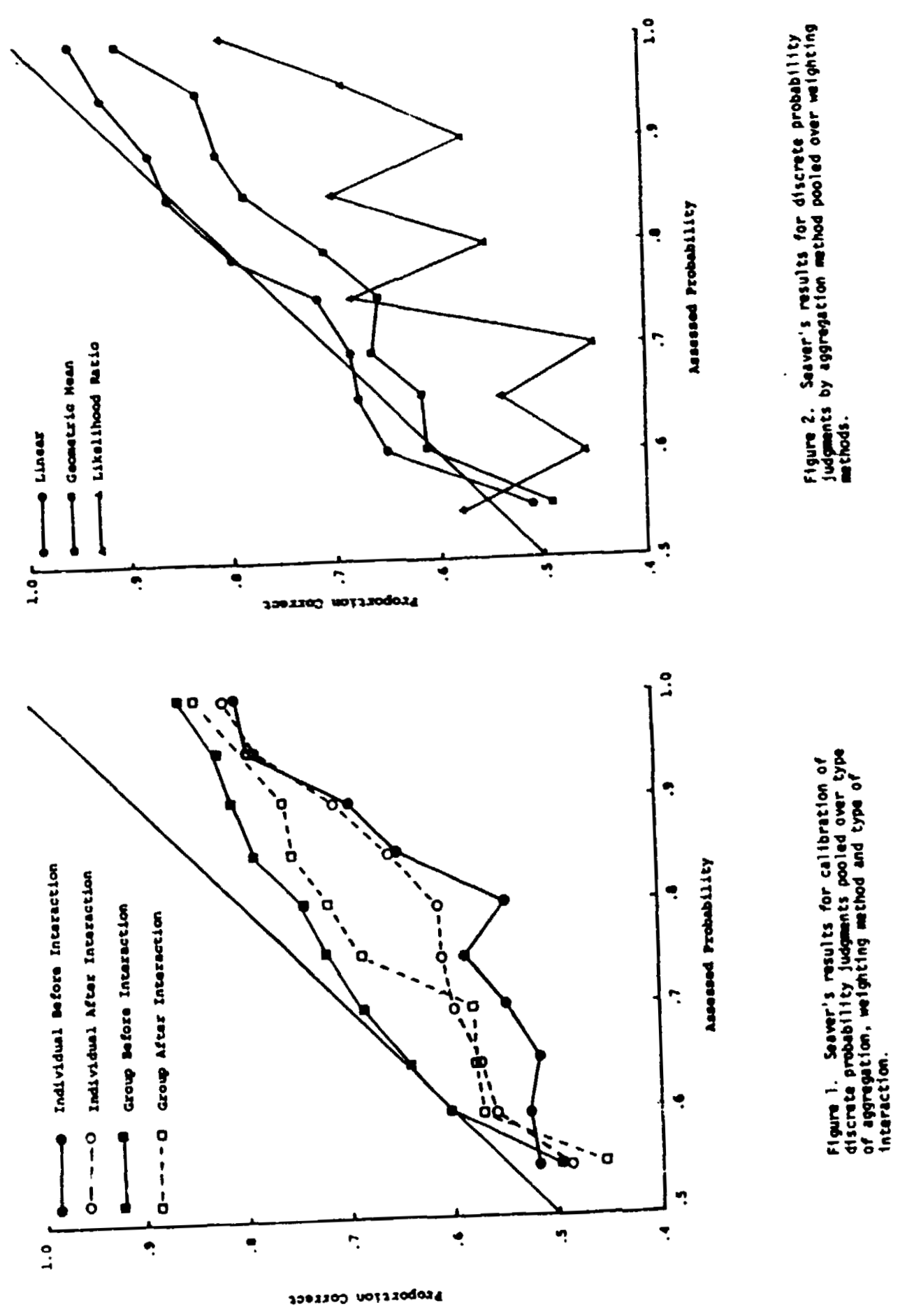
The results are pooled over interaction methods and aggregation methods. It appears, and Seaver concluded, that over-confidence is reduced by aggregation, and that interaction increases over-confidence for groups but decreases it for individuals. Figure 2 shows the differential effects of aggregation method, pooled over weighting methods. Linear combination gives the least and likelihood ratios the most over-confidence. For each aggregation method interaction produced greater overconfidence.

\section{THE MODEL FOR GROUP JUDGMENTS}

\section{Structure of the Model}

The model of subjective probability judgments by groups assumes that individuals initially make judgments in a manner described by the decision variable partition model of Ferrell and McGoey? However, it is assumed that individual judgments $p_{i}$ are then aggregated according to the appropriate mathematical scheme. When there is interaction, a deterministic model of the effects of the group on individual opinion is applied to modify the $p_{i}$ values before aggregating them into a group opinion. The model of interaction attempts to take account of two phenomena frequently observed in small groups, conformity ${ }^{3}$ and polarization. 5

\section{The Decision Variable Partition Model}

The decision variable partition model of calibration 2 , applied to two alternative forced choice questions of the sort used in Seaver's study, assumes that consideration of each answer by each individual generates a scalar random variable $Y$ which is differently distributed for correct answers $C$ than for incorrect ones $C$. For simplicity, nonmal distributions are assumed:

$f(y \mid c)=\phi\left(y-d^{\prime} / 2\right)$ and $f(y \mid c)=\phi\left(y+d^{\prime} / 2\right)$, where $\phi$ is the probability density function of the standard normal and $d^{\prime}$ is a parameter of the model. The individua! chooses as correct the answer that gives the larger value of $Y, y(1)$, and jases his judgment of confiaence on the difference between the values of the two variables $y(1)-y(2)$. Let $X=Y(1)-Y(2), X>0$. The individual partitions the range of $X$ into $m$ intervals by the set of cutoff values $\left\{x^{i}\right\}$, associating with each interval a member of the allowed set of $m$ probability responses $\left\{r_{j}\right\}$. The partition is selected, within the 1 imits of the individual's knowledge, to achieve good calibration, The expected values of the resulting calibration can be determined from $\left\{x^{i}\right\}$ and the distributions of $x$ conditional on correct and incorrect choice.

When the $Y$ distributions are assumed normal, as above, the distributions of $x$ are readily found to be: $f(x \mid c)=\$\left(\frac{x-d}{\sqrt{2}}\right)$ truncated below at $x=0$, and $f(x \mid \bar{c})=\phi\left(\frac{x+d}{\sqrt{2}}\right)$ al $\leqslant 0$ truncated below at $x=0$. The expected values of the calibration proportions, $p\left(C \mid r_{j}\right)$ aro found in general by

$p\left(C / r_{i}\right)=\frac{p(C)\left[F\left(x^{i} \mid C\right)-F\left(x^{i-1} \mid C\right)\right]}{p(C)\left[F\left(x^{i} \mid C\right)-F\left(x^{i-j} \mid C\right)\right]+[1-p(C)]\left[F\left(x^{i} \mid C\right)-F\left(x^{i-1} \mid C\right)\right]}$

where $p(C)$ is the proportion of correct choices and $F$ is the cumulative distribution function. For the present case, the values of $p(C)$ and $[1-p(C)]$ that weight the truncated normals cancel with those in (4) to give 


\section{UREDiviL HFiE IS \\ OF POOR QUALITY}

$p\left(C \mid r_{i}\right)=\frac{\Phi\left[\frac{x^{i}-d^{d}}{\sqrt{2}}\right]-\Phi\left[\frac{\left.x^{i-1}-d^{\prime}\right]}{\sqrt{2}}\right]}{\Phi\left[\frac{x^{i}-d^{\prime}}{\sqrt{2}}\right]-\Phi\left[\frac{x^{i-1}-d^{\prime}}{\sqrt{2}}\right]+\Phi\left[\frac{x^{i}+d^{\prime}}{\sqrt{2}}\right]-\Phi\left[\frac{x^{i-1}+d^{\prime}}{\sqrt{2}}\right]}$

where $i$ is the cumulative distribution function of the standard nonmal. The parameter $d^{\prime}$ is related to the proportion of correct choices by

$$
p(c)=\Phi\left(d^{\prime} / \sqrt{2}\right) \text {. }
$$

Figure 3 shows a partition that gives approximately perfect calibration for $d^{\prime}=1(p(C)=.76)$. Perfect calibration is not always possible. Figure 4 shows the calibration curves that result from holding a partition constant and varying $p(C)$.

It was concluded by Ferrell and McGoey ${ }^{2}$ that people tend, unless given feedback about calibration, to use a partition 5 uited to a value of $p(C)$ around .75 regardless of tne difficulty of the questicns. An example of the model, with constant $\left\{x^{j}\right\}$, fittea :0 calibration results from Lichtenstein and Fischhoff 4 is shown in Figure 5 . The effect of $P(C)$ is clearly evident.

\section{The Interaction Model}

Knowledge of other group members' views is assumed to affect each member's confidence which is represented in the model by the decision variable $x$. For computational convenience, the range of the decision variable $X$ is taken to be the entire real line, with negative values indicating choice of the incorrect alternative and positive ones choice of the correct one. The partition $\left\{x^{i}\right\}$ is symmetric about $x=0$, with intervals on the negative range producing the same subjective probability responses $r$ as those in the corresponding interval on the positive range, but being associated with the incorrect answer.

Interaction, in the model, operates thusly: an individual's initial value of $x$ is influenced by the average $\bar{x}_{3}$ of the $x$ values of the other three members to give a new individual value $x^{\prime}$ according to

$$
\begin{array}{ll}
x^{\prime}=x+k_{1}\left(\bar{x}_{3}-x\right)+k_{2} \bar{x}_{3}, & 0<k_{1}<1, \\
& 0<k_{2}<1 .
\end{array}
$$

The first term mimics conformity in that the value of $x$ (confidence in : it right answer) moves toward the mean of the other members' confidence. The second term mimics extremity shift in that the value of $x$ moves in the positi.a or negative direction depending on whether the mean of the other members' feelings is positive or negative. The individual member's new confidence $x^{\prime}$ is transformed into a response $r$ in the same way as the original value. And, in all cases, aggregation to give a group judgment is performed only upon the responses (or one minus them if the individual chose wrongly) not upon the $x$ values, which are assumed not to be explicitly avallable in numerical form.

\section{The Simulation}

The simulation program (available from the authors) computes four pseudo random numbers $x_{i}$, with intercorrelation $\rho$, distributed normally with mean 

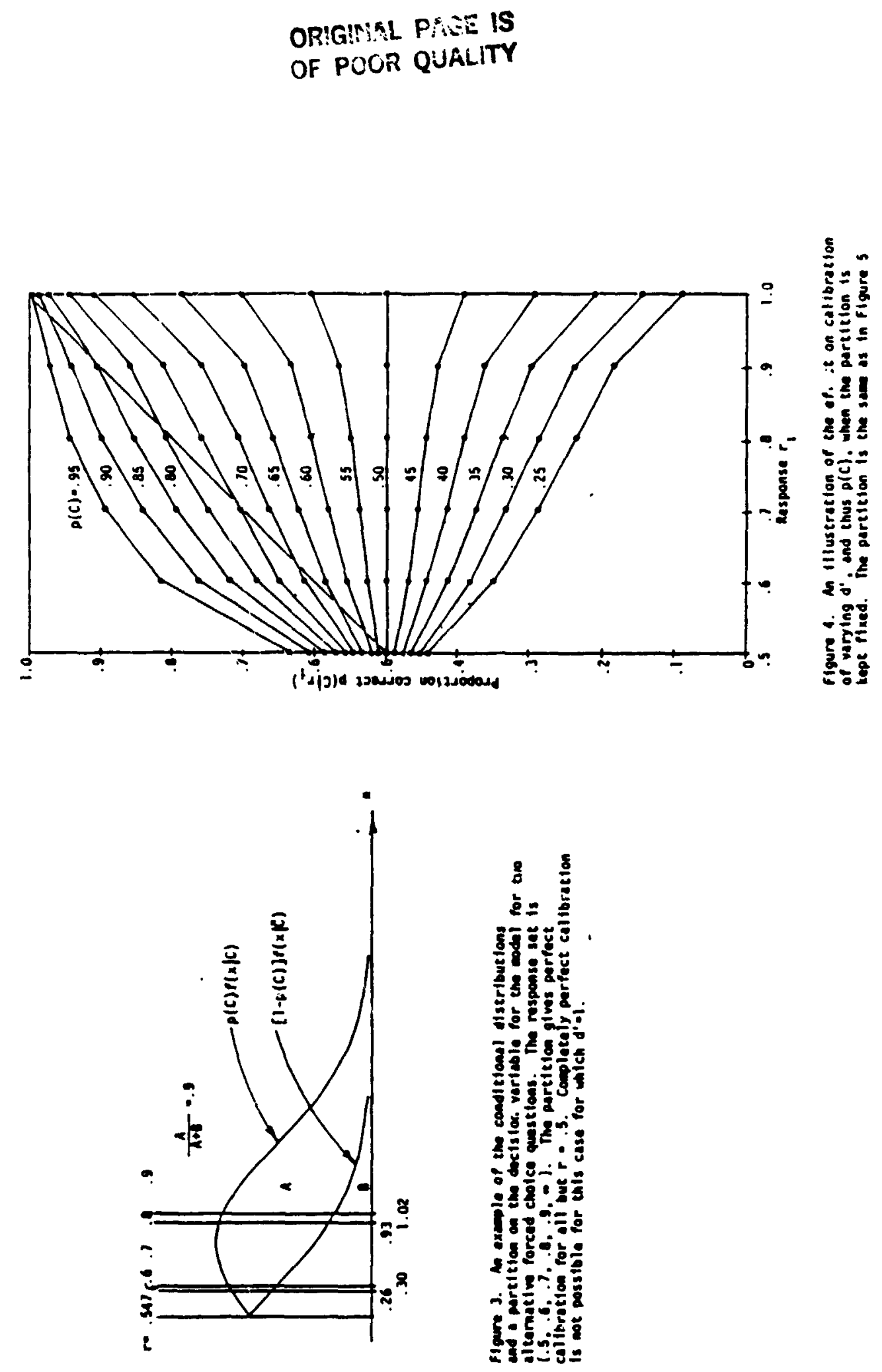
ORIGIBSL PUE IS
OF POOR QUALTY

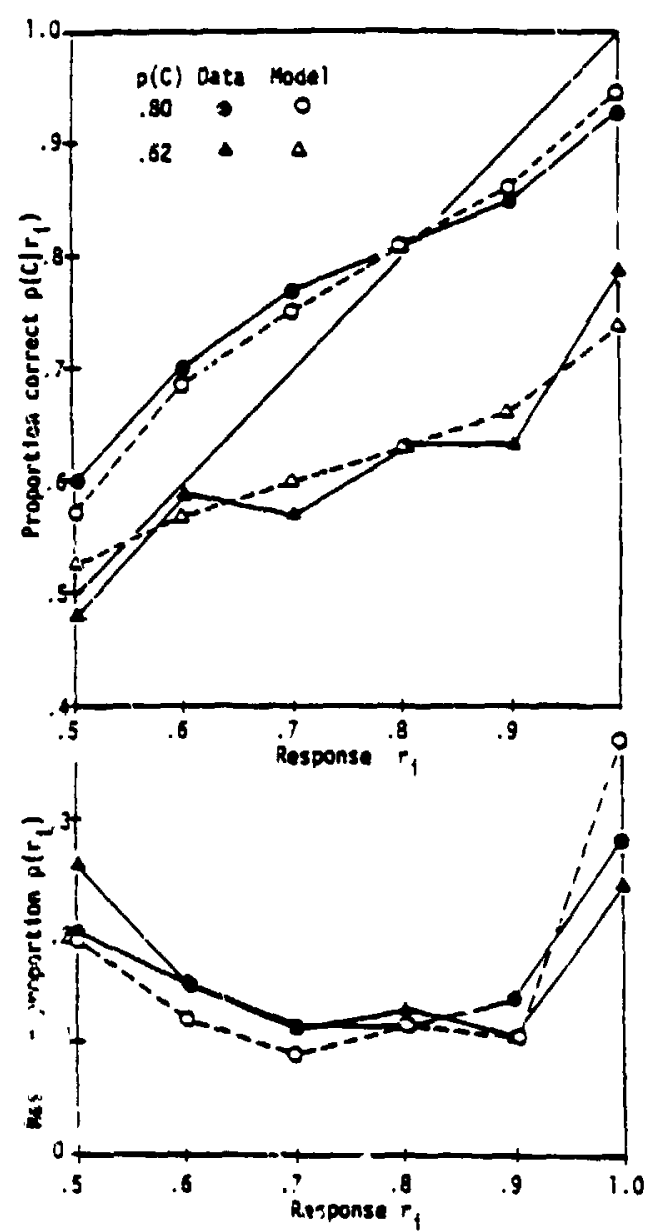

Figure 3. Hodel and dots from !tentenstein and fisennoff's experiment 5. $\left(x^{\prime}\right)=\{0, .347, .5 \% 0, .744, .902,1,219,-\}$. Response proportions for $p(C)=.62$ witted exactly. 
$d^{\prime} / \sqrt{2}$ and variance $i .0$. These are the group menbers isicial confidence estimates. Negative values indicate preference for ine incorrect altemative. All individuals are assumed exactly alike in their proportion of correct responses (see equation 6 ) and in their partitions $\left(x^{i}\right)$. These are only approximations, and would still be so even if the model of individual behavior were exact. The intercorrelation reflects the commonality of shared information. Edch group member dces not have entirely independent information atout se correct answer.

The initial values of $x$ for the group members are traisformed into response vives $r$ by the partition and the results contribute to the simulation of individuals before interaction. The response values are then aggregated according tc equations $(1),(2)$ and (3) to contribute to calibration proportion; for groups before interaction. The $x$ values are then transformed by equation ( 7 ) and responses $r_{j}$ calculated according to the partition and these contribute to calibration statistics for individuals and groups after interaction. Simulation of $25,00 \mathrm{C}$ groups $(100,000$ individuals) gives stable calibration prope-tions.

\section{SIMURATION RESULTS}

\section{Mode : Parameters}

The decision variable partition nodel was fitted to the experimental calibration curve for individuals before interaction shown in Figure 1 . The degree of cver-confidence suggested a proportion correct $p(c)=.65$ and thus a yalue of $:^{\circ}=545$. With an interactive computer program an approximate fit to the datı was obtained with

$$
\left\{x^{i}\right\}=\{0, .2, .36, .53,1.045, \infty\} .
$$

The othe: parameters were chosen unsystematically, but with a view toward producing culibration curves that resembled those obtained by Seaver. If his data were availabie, it might be possible to estimate the parameters from it. However, ob:aining suitable values was not difficult, i.e., the effects are not dependen: on criticai parameter values, and the values chosen also seem plausible a priori. Parameters used were: $\rho=.4$, the member's intercorrelation; $k_{1}=.1$ the confismity parameter; and $k_{2}=.2$ the polarization parameter.

\section{Model Re;ults}

Figure 6 shows calibration curves from Seaver ${ }^{7}$ wich allow comparisen between individuals and the equally weighted iinear conbination (i.e., the averdie) lof grrip mentei"s' judgments. Figure 7 shows the results of the model for trie same conditions. The effects found by Seaver are clearly evident in the midel's output. Over-confidence is markedly reduced by taking the group average, and interaction has the upposite effect on groups that it has on individuals. With individual judgments, the conformity effect makes them slightly resemble group judgments, and thus less over-confident, and the polarization eftect makes them somewhat larger, triss more over-confident. The net result is slightly less over-confident after intr-raction for individual judgments. With groups, on the other hand, the conformity effeci is already at a maximum, because of the explicit averaging, sofnlarization due to interaction makes the judgments more extreme and increases over-confidence. Note that, in the model, the fact that crou judgments are better calibrated than the individuai judgments is simply a insequence of the fact that the individuals are over-confident to begin with. liveraging their responses improves the proportion correct $p(C)$ (from .64 to .71 $n$ this casu) and with fixed partition $\left\{x^{i}\right\}$ this causes a reduction in overi:onfidence. Had the individual group members been well calibrated, the groups rould have proved to be under-confident, and interaction would reduce the 

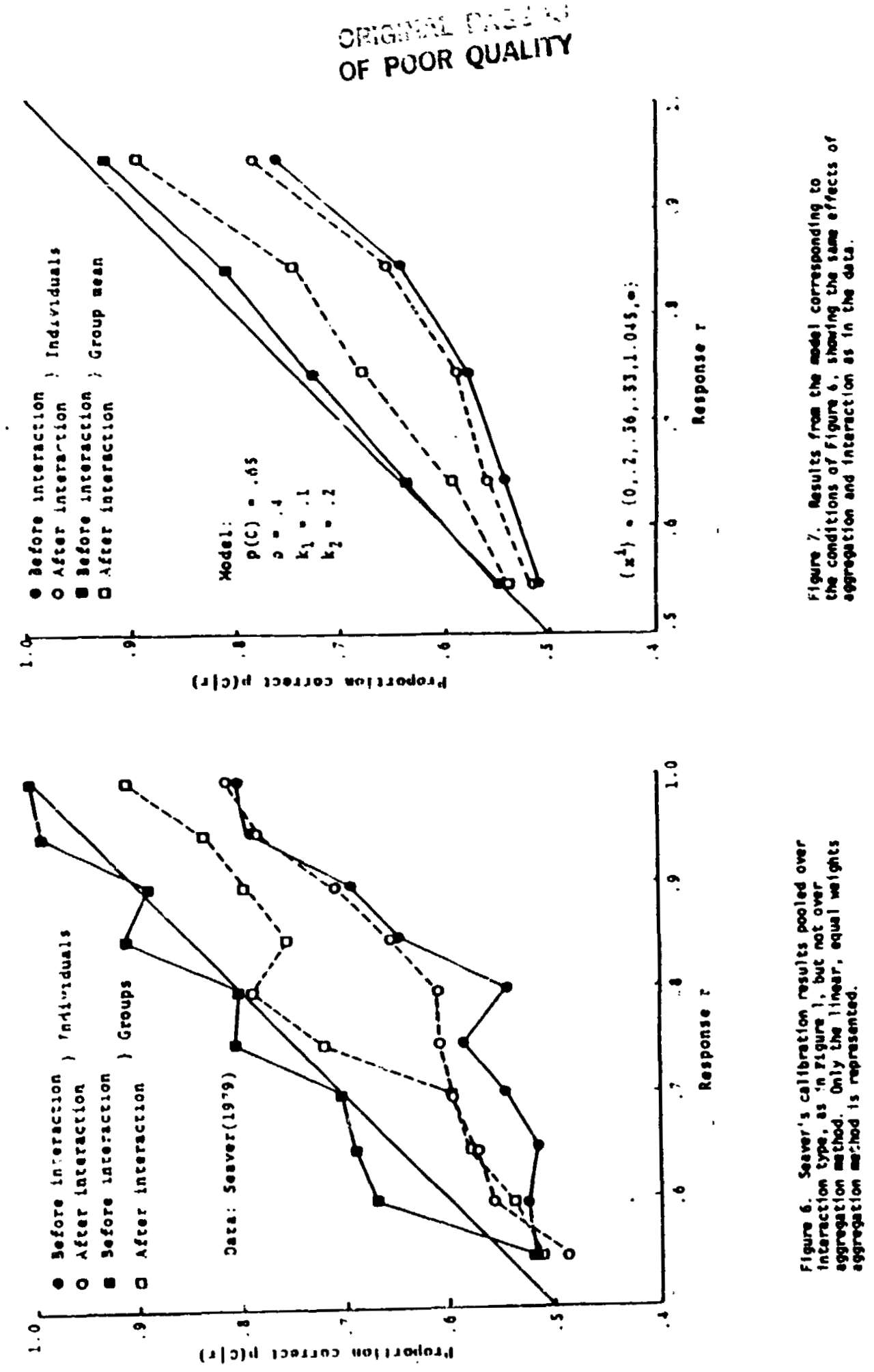
under-confidence for sroups ard increase it for individuals. This predicted effect is shown in Figure 8 , in which the group calibration is the worst. but still least over-confident. It would be interesting to test this prediction empirically.

The effects of the different aggregation methods (equations 1,2,3) as found by Seaver are shown in figure 9 . to be compared with output from the model in Figure 10. Agsin the model reflects Seaver's findings in that the geometric mean and the likelihood ratio methods of aggregation compensate less well for the over-confidence of individual members. Each of these methods gives more extreme values (and thus more over-confidence) than the simple average. at least when the component values tend to agree, the likelihood ratio giving much more extreme values. The model does no: give results for the likelihood ratio method as close to Sedver's as it does for the other methods, and this may be due to its extremeness interacting with the rather coarse partition ( $m$ - 5 response categories).

The model results in terms of quadratic scure and average response probability for each condition have been computed. The model scores are much highe: than those Seaver found and this may be due to the assumed proporticn of correct response being too high. The average response probabilities from the model are somewhat too high but they follow the same pattern over conditions as Seaver reports. Since the model was not fitted in any precise way and has been used only to demonstrate that it reproduces the structure of the experimental results, the numerical values are not included here. If model parameters could be estimated from data, however, it would be important to lnok for consistency at such a level. But the data is not yet available.

\section{CONCLUSIONS}

Seaver's basic findings about calibration of group and individual aiscrete probability judgments can be accounted for in a consistent and intuitively satisfying way by the decision variable partition model of individual subjective probabllity judgment coupled with a simple linear model of the effects of group interaction on individual certainty. The effects Seaver reworts are then due to two competing influences. The first is grouping, whereby combining judgments leads to a greater proportion of correct responses and thereby to reduced over-confidence or even under-confidence. The effect is the same as that of an increase in $p(C)$ on individual calibration. The second influence is extremeness whereby the judgmenis are made larger and thereby incredse over-confidence.

Aggregation methods all manifest grouping to some extent. Dut of those considered only linear averaging avoids introducing extremeness effects which tend to counteract the effect of grouping on reduction of overconfidence. Intercorrelation of individual judgments also counters the effects of grnuring. Group interaction also =ombines groupina. as a manifestation of conformity, and extremeness as a manifestation of polarization. These psvchological characteristics of interartion are widely observed and reported.

The practical implications of these findings for aggregating group judgments are substantial.

1. The guality of calibration of aggregated judgmints depends. in a complex rut predictable way. on the qualtiy of individual calibration. If individuals are quite over-confident groups will be less so, but if Individuals are well calibrated, groups will be under-confident. Inis result has not been reported blit is predicted. 


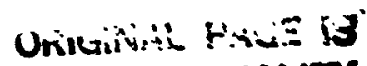

OF POOR QUALITY

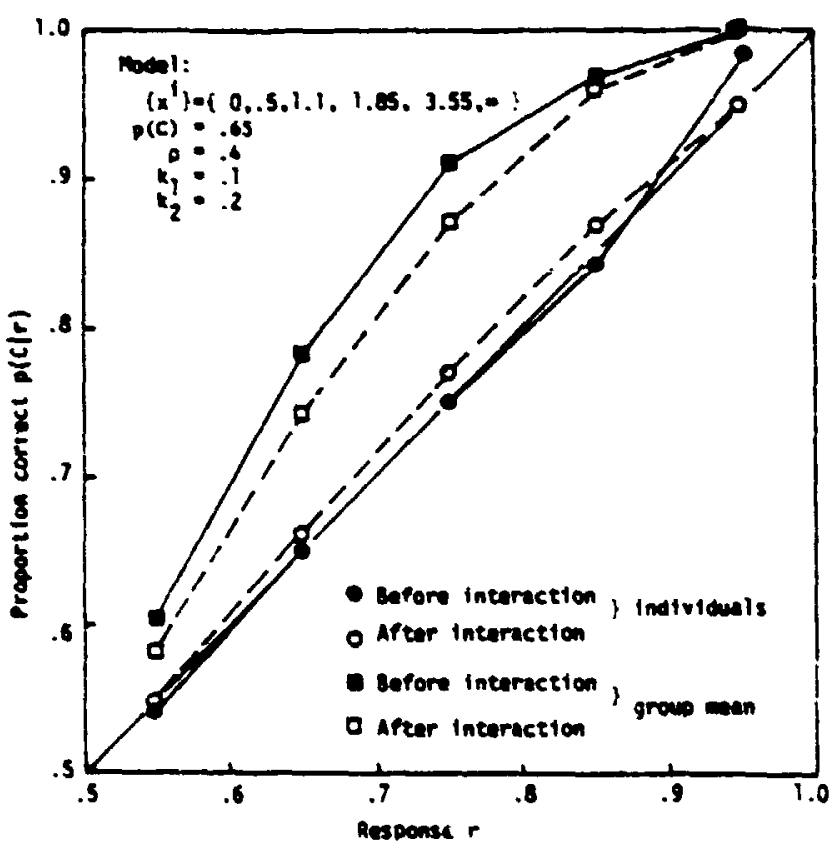

Figure 8. The epfect on growp ealibration

prodicted by the mesel hen Individuis is ar

- Il callbrated; groups an then unem conflant. 

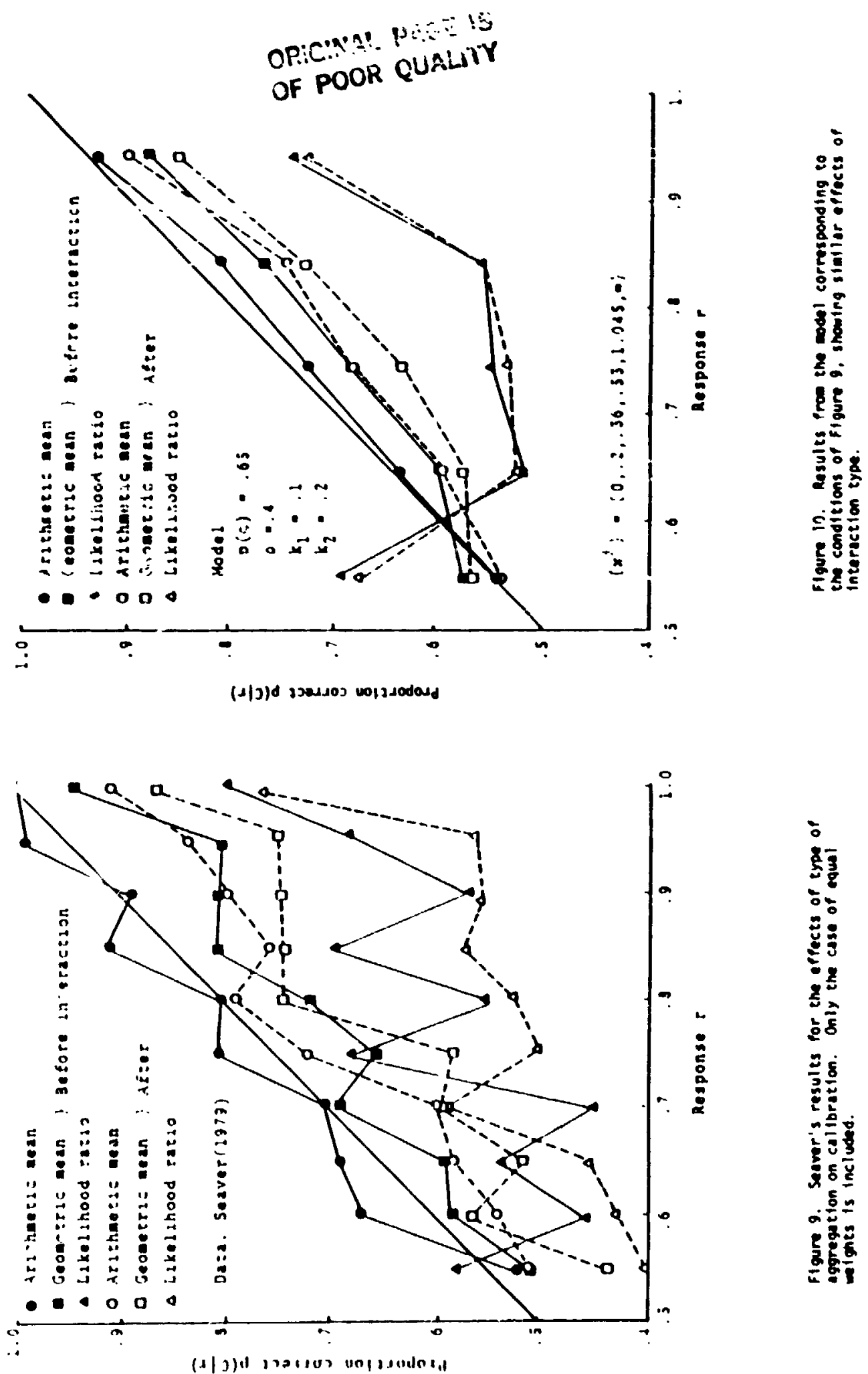
2. Aggregation methods can be tested beforehand for their influences on calibration.

3. Interaction, for questions of the sort studied by Seaver, is of no practical value since $i$ ts beneficial effects of grouping can be obtained by averaging.

4. If individual calibrations were known, the effects of aggregation could be predicted and the aggregation method adjusted to give perfectly calibrated group judganents.

\section{REFERENCES}

1. DeGroot, M., Reaching a Consensus, Journal of the Anerican Statistical Association, 69, 118-121, 1974.

2. Ferrell, M.R. and McGoev, P.J., A Model of Calibration for Subjective Probarilities, Organizational Behavior and Human Performance, 1980 (in press).

3. Kiesler, C.A. and Kiesler, S.B., Conformity, Reading, MA: Addison-Wesley, 1969.

4. Lichtenstein, S. and Fischhoff, B., Do Those who Know More Know More About How Much They Know? Organizational Behavior and Human Performance, $20,159-183,1977$.

5. Myers, D.G. and Larm, H., The Polarizing Effect of Group Discussion, American Scientist, 63, 297-304, 1975.

6. Seaver, D.A. How groups can assess uncertainty; Human interaction vs. mathematical models, Proceedir.gs: International Conference on Cybernetics and Society, 185-189, 1977.

7. Seaver, D.A. Assessing Probability with Multiple Individuals: Group Interaction versus Mathematical Aggregation. Unpublished doctoral dissertation, University of Michigan, 1979.

8. Sanders, F., On Subjective Probability Forecasting, Journal of Applied Meteorology, 2, 191-201, 1963.

9. Stael von Holstein, C.A., An Experiment in Probabilistic Weather Forecasting, Journal of Applied Meteorology, 10, 635-1971.

10. Winkls r, R.L., The Consensus of Subjective Probability Distributions, Management Science. 15, 61-75, 1968.

11. Winkler, R.L. Probabilistic prediction: Some experimental results, Journai of the American Statistical Association, 66, 675-685, 1971.

12. Winkler, R.L., Murphy, A.H. and Katz, R.W., The Consensus of Subjective Probability Forecasts: Are Two, Three... Heads Better than One? Fifth Conference on Probability and Statistics in Atmospheric Sciences. Boston, MA: imerican Meteorological Society, 1977. 


\title{
- N82 $34055^{-18}$
}

VISUAL/MOTION CUE MISMATCH DURING A COORDINATED ROLL MANEUVER

\author{
D. K. Shirachi
}

Computer Sciences Corporation

Mountain view, California

\section{ABSTRACT}

Two major factors involved in creating realistic simulations are the visual and motion systems which provide important cues of vehicular attitude. velocities and accelerations to the pilot for purposes of stable coricrol and simulation realism. However, it is difficult to match the dynamic response characteristics of these two display systems to each other because of the inherently nigher inertia, limited available power and constrained positioning for the motion system. Furthermore, as a means of dynamically compensating for simulator dimensional constraints, washout filters are used which in turn modify the frequency characteristics of the motion simulator.

The purposes of this experiment were to detemine the following:

(1) the effect of a performance mismatch between the simulator visual and motion display systems on pilot performance while engaged in a compensatory tracking task, and

(2) the effect of a reduction in simulator motion scaling, maintaining constant visual scaling, on pilot performance for this same task.

A jet transport aircraft with motion in the roll and lateral simulator axes was used as a test vehicle for this computer simulation investigation. The aircraft was disturbed by moderate levels of turbulence which resulted in flight path deviations in the roll and lateral axes. The pilot's task was to maintain flight formation behind the aircraft in front of him as displayed by a video monitor located in the simulator cockpit.

Experimental data consisting of pilot describing functions and pilot performance scores are presented and discussed as they relate to previously published experimental evidence. 
COMBINED EFFECT OF THE OCULOGYRAL ILLUSION AND OF A FIXED PERIPHERAL FIELD ON SENSATIONS OF YAW MOTION

J.K. HUANG AND L.R. YOUNG

man Vehicle Laboratory. M. I.T.

\section{INTRODUCTION}

It is well known that visual and vestibular information interact in perception of spatial orientation and in pilot control tasks. The perception of selfrotation while viewing an isolated visual target rotating with the subject is several times more sensitive than without the target. 4 This is the oculogyral illusion 6 (OGI) and thresholds for OGI are significantly lower than thresholds in the dark. In contrast, measurements of vestibular nucleus unit activity in rotating alert monkeys show that the firing rate with a conflicting visual field is significantly lower than the firing rate in the dark, 15 indicating that the threshold for perception of self-rotation could be lower in the latter case. The purpose of this work was to study the combined effect of the oculogyral illusion and of a fixed peripheral visual field on sensations of rotation about a vertical axis.

METHODS

Subjects were seated in a rotatable .. ainer with four possible visual fields: DK (dark); OM (a dim peripheral field fixed with respec io the subject- $60 \mathrm{fc}$ illumination near the bulb); LT (the same as OM, but witn $80 \mathrm{fc}$ ); and $0 G 1$ (only a fixed spot can be seen). For OK, OM and LT, the subjocts particpated in three sub-experiments: Threshold measurement, closed-loop velocity nulling, and openloop magnitude estimation. A total of 13 male subjects participated, aged 22 to 29, in norma! health.

A modified Link GAT-I trajner, driven as a velocity dependent servo, rotates about the vertical axis. 16 During $L T$ and $O H$, a projector presents a vertical stripe pattern to the subject via two translucent side windows. A l" diameter white spot is fixed 30" in front of the subject. For OK, the subject is blindfoled with eyes open. For the closed-lonp velocity nulling method, a featureless control wheel in the horizontal plane in front of the subject is used to null the trainer velocity. For the open loop magnitude estimation method, a pen was affixed at the edge of the wheel and the subject asked to use it as a pointer to a laboratory fixed location.

Threshold measurement: Six subjects were instructed to use the wheel to indicate the direction of rotation as soon as possible. All had six randomized sessions. In each, six accelerations were used with periods of 15 s and with $30 \mathrm{~s}$ between stimuli. Closed-loop veloclty nulling method: The trainer was driven by a disturbance signal d which is a pseudo-random, zero-mean, velocity command signal with a period of $409.6 \mathrm{~s}$, consisting of a sum of 12 sinusoids spanning the range from 0.007 to $0.715 \mathrm{~Hz}$. Four subjects were instructed to use the wheel to keep the trainer as motionless as possible by concentrating on their sensed angular velocity. The wheel deflection was added to the disturbance to drive the trainer with a net velocity $w$. The subject was trained to null the velocity as best he could and was given the same six sessions as before with four minute intervals between runs. A sepurate experiment compared conditions in $O K$ and $O G I$ with four runs for each subject (two each for OK and OG1). Open loop magnitude estimation method: The subject was required to estimate his rotational displacement relative to a fixed laboratory frame for two types of stimuli - triangular (TRI) and trapezoidal (TRZ) woveforms. TRI weveforms were selected as they approximate stimuli experienced in natural motion 


\section{ORIGINAL FEFEE IS \\ OF POCR GJALITY}

and avoid difficulties with unnatural stimulation. ${ }^{8}$ six subjects were instri-:ted to move the pointer in a compensatory direction so that it maintained a fixed (compass) heading as the trainer was rotated. After practice, the same six sessions were given. In each, seven TRI stimulations with four types of acceleration were used with $30 \mathrm{~s}$ between stimuli. To investigate open loop magnitude estimates during sudden decelerations, two stimuli were constructed as follows: $5 \% / \mathrm{s}^{2}$ acceleration to a constant velocity of $30 \% / \mathrm{s}$ for 20 to $26 \mathrm{~s}$, followed by a deceleration of $15^{\circ} / \mathrm{s}^{2}$ or $20 \% / \mathrm{s}^{2}$ to zero. Because of the long and different durations of constant peak velocity, the subject senses both himself and the trainer in a stationary state until the onset of the upredictable deceleration causes an after-rotation effect in the opposite direction. The subject was asked to ignore the first acceleration, but to perform the same pointing task as before to show the after-rotation effect. There were again six sessions, each using two types of deceleration, with one minute between each. Subjects were instructed to look at the white spot during LT and DM.

RESULTS

Threshold measurement: The latency time $f$ - perception of angular rotation was measured. All the data were averaged and are plotted in Fig. 1, along with other results 2,11 corresponding to OK stimuli. The 'Mulder Product', at (acceleration $x$ latency) $=K$, is plotted to fit the data for each visual presentation. A t-test shows no significant difference between the DM and

LT. However, the threshold for the $D M$ and $L T$ stimuli is significantly lower than the threshold in the DK.

Closed-loop velocity nulling method: Using the same analysis techniques established by Zacharias 6 the describing function can be evaluated after Fast Fourier Transformation of the wheel input and trainer output signals in the frequency domain. The amplitude ratio data were obtained by pooling the subject data across the test population. The parameter values of a lag lead transfer function were obtained from

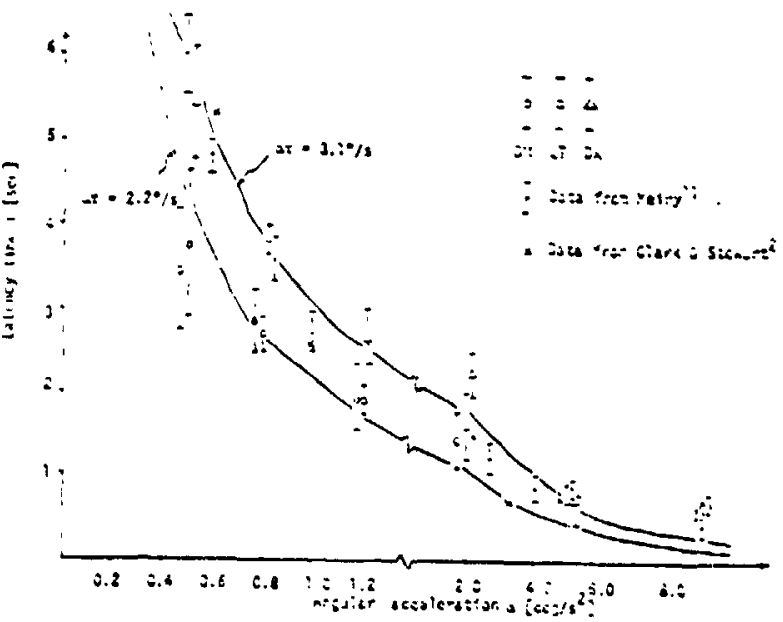
1T. and ax visut inast

a nonlinear regression program providing a least-squares parameter fit to the data.5 A dead time is added to the phase data tn obtain a better fit. The AR asymptotes and the values of all parameters are shown in Fig. 2.

The gains for the LT (or DM) and OK, at the low frequency, are significantly different, as is $\tau_{2}$. The changes in $\tau_{1}$ and $\tau_{d}$ are not significantly different. Although the gain for the $L T$ is slightly higher than that for OM, the difference is not significant nor is that in $\tau_{2}$ for the LT and OM. Furthermore, the highest gain was in $O G I$ and all subjects stated that there was a clear oculogyral illusion which they could use to detect the direction of self-rotation or to estimate the magnitude of velocity. This was especially true at low frequency and acceleration. 


\section{OFGGINAL PESTE IS OF POOR QUALITY}

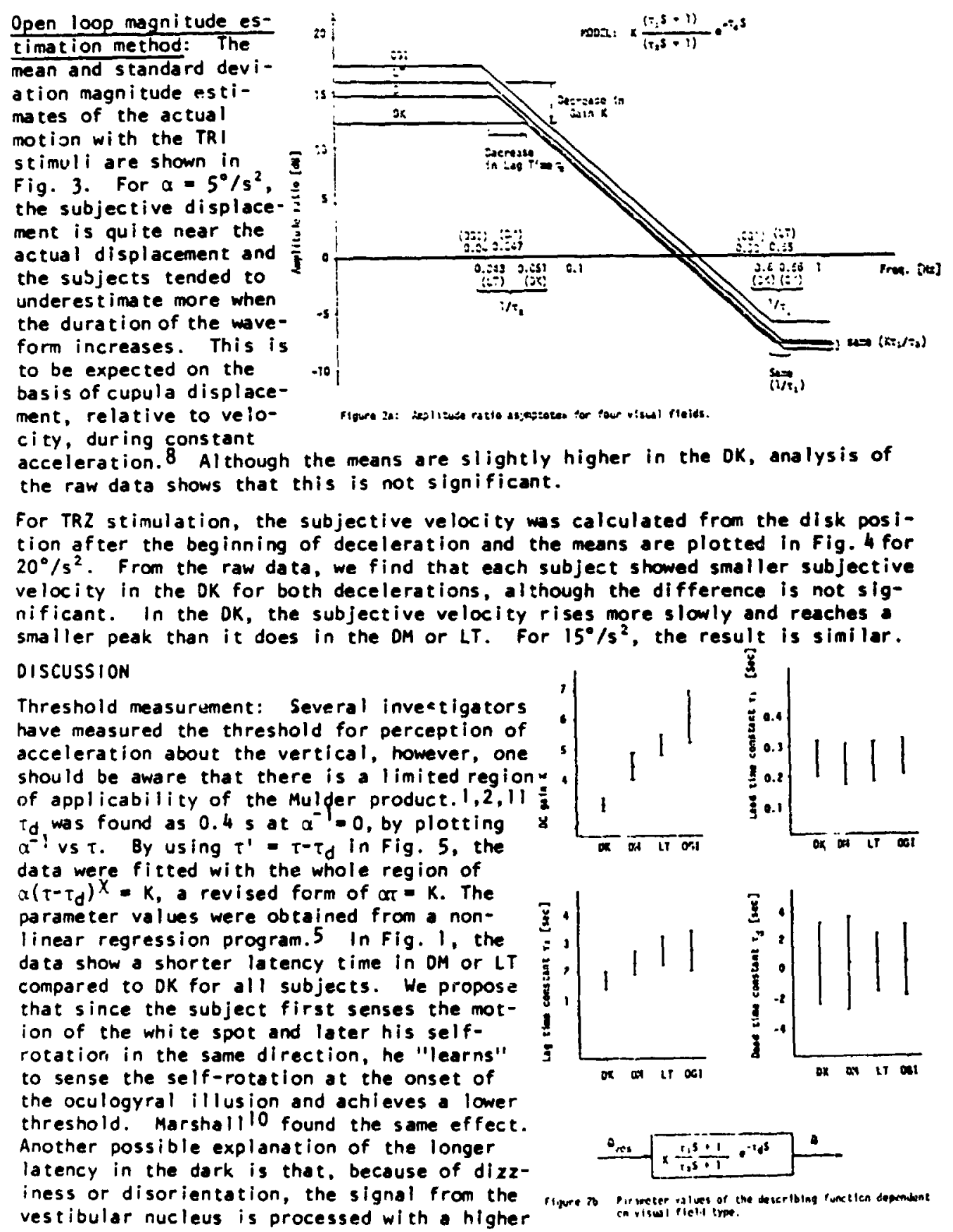




\section{ORIGINAL FARE IS}

OF POOR QUALITY
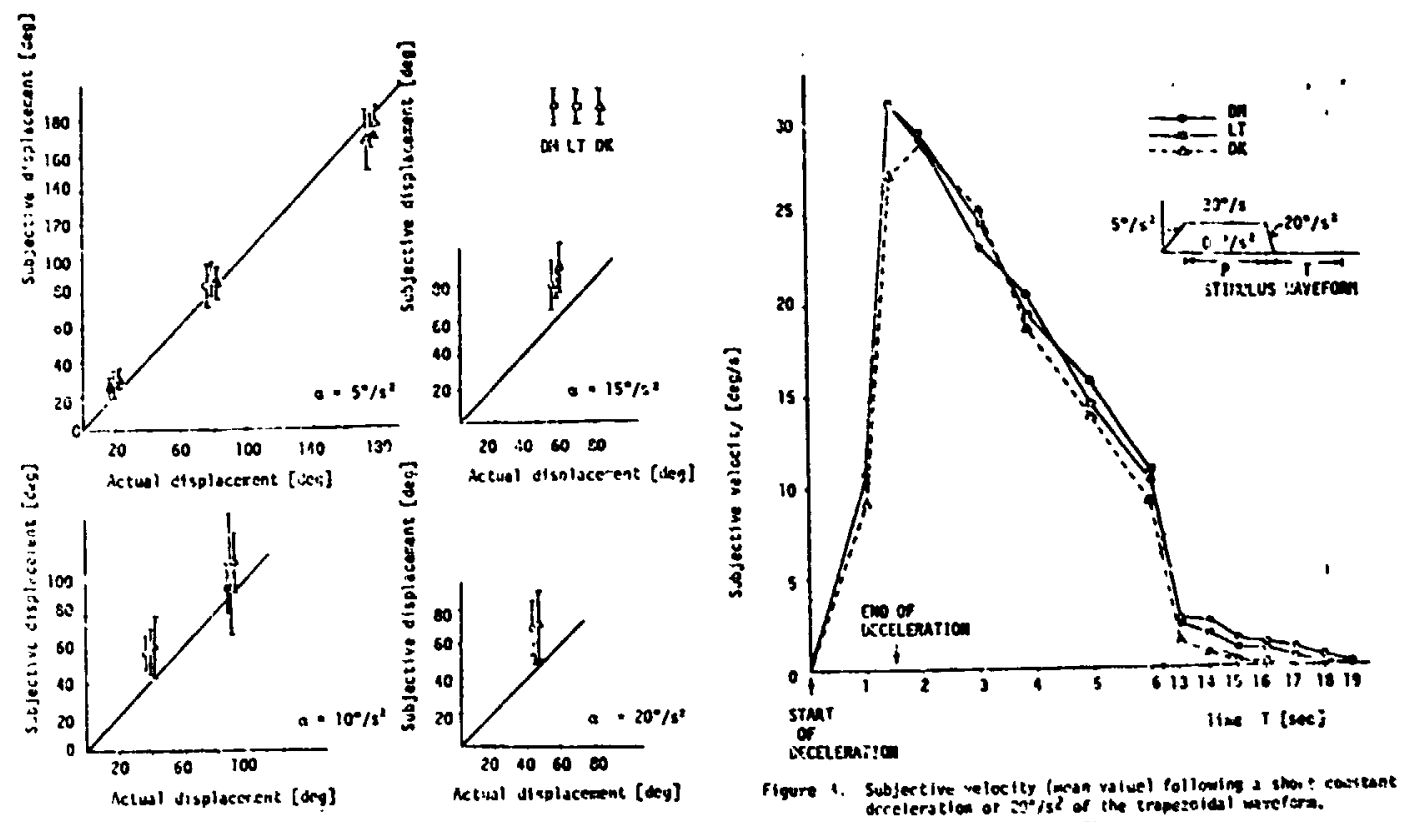

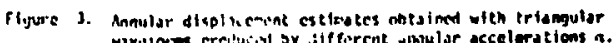

threshold and has longer latency. The alertness of the subject in the DM and LT fields may also be a reason for the low threshold with the $061,3,7$ Henn et a 19 showed that alertness changes, evident in eye movements, did not affect the vestibular nucleus units' response to angular acceleration. Fron fig. 1, it can be seen that there is no significant difference between the OM and LT. For $0.5^{\circ} / \mathrm{s}^{2}$ acceleration, it is interesting that every subject showed 2 shorter latency time in DM. Higher illumination will increase the non-uniformity of the background and increase the sensation of stationarity of the stripes.6 This may explain the higher threshold in LT and DM and also the higher ihresholds in light found by Waespe et al. 14

Closed-loop velocity nulling method: The gain in LT (or DM) is higher than in DK (Fig. 2a). The difference appears at frequencies below $0.06 \mathrm{~Hz}$. Here, $\alpha$ is below $2.41 \% / \mathrm{s}^{2}$ (from disturbance frequency spectrum), and the threshold is significantly lower in the DK with smaller a (Fig. 1). The oculogyral illusion presumably produces the lower threshold and results in greater sensitivity and a higher gain for nulling rotation in LT (Or DM).

Open loop magnitude astimation method: With TRI stimulation, the magnitude estimates of the actual motion showed no significant difference between DK, DM and LT. Because of the strong stimulation and short duration, such a stimulus can be regarded as similar to a mid or high frequency sinusoidal stimulus. The vestibular system can sense the motion quickly ard the jidgment presumably does not reiy upon the effect of visual input. These results are confirmed by those of the first experiment. For the TRZ stimulation, we found a quicker rising speed, iarger subjective velocity, and longer duration of the after-intation effect in the illuminated presentation than in the $O R$. Jnd we can expest to find greater differences with lower intensity stimulation. 13 


\section{CONCLUSIONS}

All of the current results concerning detection and reaction to angular acceleration in the dark and with a fixed visual field show that, for low accelerations, tive visual input enhances the sensitivity to self-motion since the visual surround is fixed with respect to the subject, and might imply a "no motion" or null signal if interpreted as a clrcularvection input, it conflicts with the true rotation sensed by the semicircular canals and might be expected to inhibit the motion sensation. Furthermore, vestlbular nucleus unit activity was shown is to be inhibited by a fixed visual surround in similes circumstanse: and compensatory eye movements are suppressed by visual fixatinn. We n'ributa the enhancement at low acceleration to the sensitive motion detectic ociated with the oculogyral illusion of relative motion of a fixed sput dur i ject rotation.

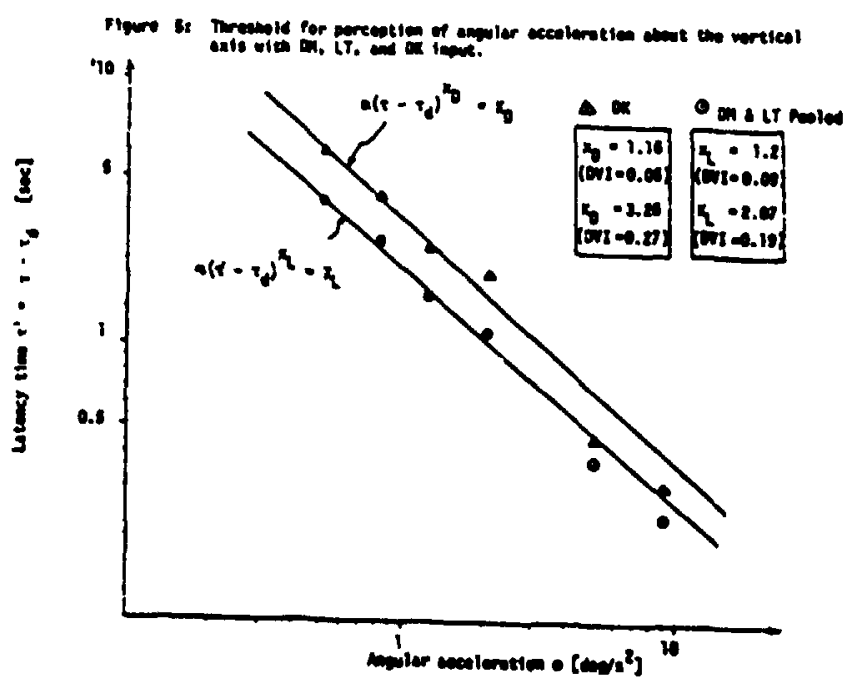

\section{REFERENCES}

Clark. B., Aerospace Med 38:443-450, 1967.

Clark, B., Stewart, J.D., Aerospace Med 33:1426-1432, 1962.

Clark. B., Stewart, J.D., Perception and Psychophys ics 3:253-265, 1968.

Clark, B., Stewart, J.D., Aerospace Med 43:8-12, 1972

5 Dixon. W.T., BMD-Blomedical Computer Programs, University of California Press, 1973.

6 Graybiel, A., Hupp, D.1., J Aviat Med 17:3-27, 1946.

7 Guedry, F.E., In: Vestibular System Part 11: Psychophysics, Applied Aspects and General Interpretation, H.H. Kornhuber (ed), 1974.

8 Guedry, F.E., Stockwell, C.W., Norman, J.W., Owens, G.G., Acta 0tol 71: 439-448, 1971 .

9 Henn, V.S., Young, L.R., Finley, C., Brain Res 71:144-149, 1974.

10 Marshall, J.E., Visual-Vestibular Interaction and Threshold for Angular Acceleration. USAMRL, Fort Knox, RY, T967.

II Meiry. J.L.. The Vestibular System and Dynamic Space Orientation, Sc.0j Thas is, MIT, Cambridge, MA, 1965. 
12 Melvill Jones, G., Young, L.R., Acta Otolar 85:45-53, 1978.

13 Parsons, R.D., J Exp Psychol 84:230-238, 1970.

14 Waespe, W., Waespe, B., Hen, V., Pflug. Arch ges Phy: ol 373 S:sppl. R87, 1978.

15 Waespe, W.. Henn; V.. Exp Brain Res 33:203-211, 1978.

16 Zacharias, G.L., Motion Sensarion Dependence on Visual and Vestibular Cues Ph.D. Thesis, MIT, Cambridge, MA, 1977. 


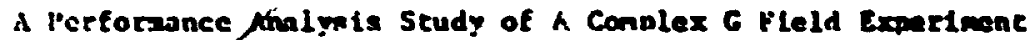 \\ D. L. Keprerger \\ AFaitrl. Wright Patcerson Alr Force Bace, Ohio 45433
}

Iatroluction:

When a iuman is subjected to a G fietd scress enviromant, the effect of this stress variable on tracking perfornance can be studled several wys. This pafs: will conduce a perforance analysis on data fron an experiment destgned at the Mir Force derospace iledical leseareh Laboratory by an effort ta cooperation with the lat versity of Coanecticut. The detalls of chis expertent have been vell focumented and chis study hes provided an intereselos data base which Illustruces the degradation of tracking perfornance as the bean is subjected to the environancal stressor $(1-6)$. The prtanty soal of ehis emertenet was to obtala data for developias odela utillsiag the opeinel coatrol rodel. Sines this study has provided a daca base which show performace changes under the stress condition. the wosk conducted here is coscerwad with defining wre exlicicly the perfornance changes and exalaiog scatistical properties of baran tracking with and without the stress effects.

The extant Heerature on the seudy of the effect on buan of acceleration stress is extensive. Ode masure of the mount of literature avallable can be seen in the classic work of Fraser (5) utich lists 199 raferences in the area at chat polnt in tim. The paper by Broere (6) Lats 100 refereaces and quite

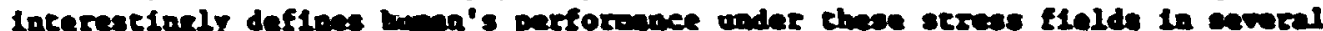

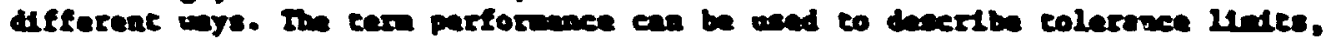
changes in reaction tin, propriocepelve changes, flsual perception loes, degredation in scores obcalond fro differeac wetor related encter, and a

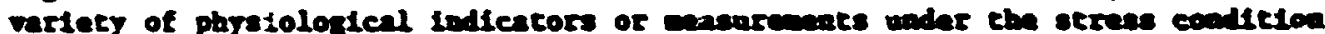
ca bunens.

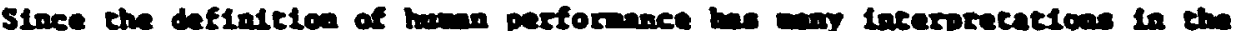
acceleration stress ares, it we dectded in this paper to lock ac

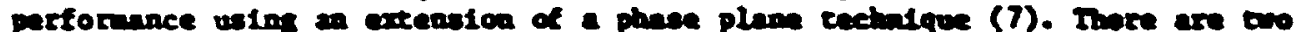

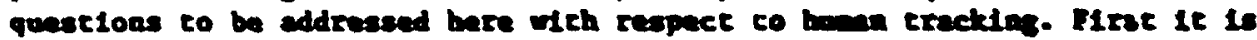

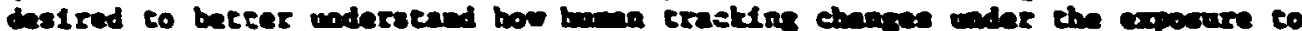

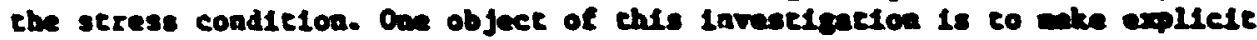

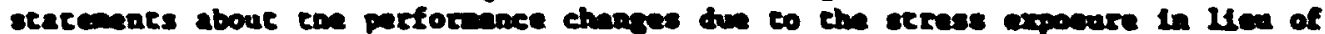

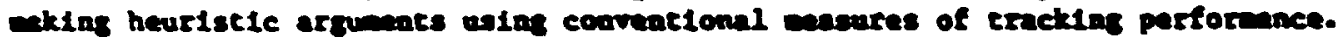

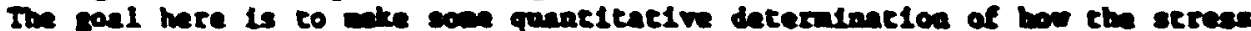
effects the performace charactertactes of binan's tracking in the 100p. The quancleative dece:alnation of strese effects on performace oill be defiecd

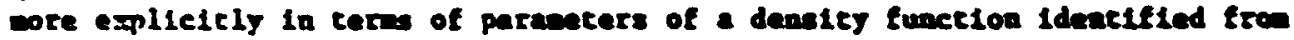
the eaptrical data.

A secood objective of this study is to decarnion exacely whe the discribution functions are.thich characeerize tracklns in a phece plane representation of the closed loop ertor algall. The aseuncioa in (7) whe that the distrabutions of che error signal and les dertivetve in the phase plawe were nornal. The credibility of that assuaption will be ceated in this paper for a differene cracking cask and across a maber of subjects. The daca base $(1-4)$ vill be used to exinine the disertbations of the exror atganl and the flrse derivative of the ertor signal. This eapirleal data Fill be studied usins - test for armality $(8,9,10,11)$. The Idenctfled medians becen the boudarles of the phise pline on their respective axes; the ideacified variances iadicate the confidence in this eatinate of the nedian value.

A z-sististic is used to desamine if the oodians and variances of the

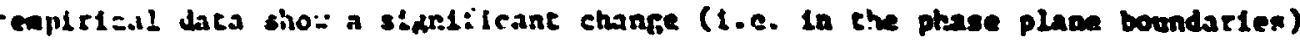

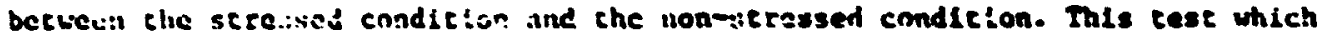
has the penperty of bi!nk "dlscribution free", provfiles the fraesvort to eate a

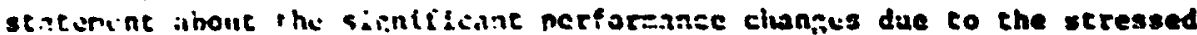

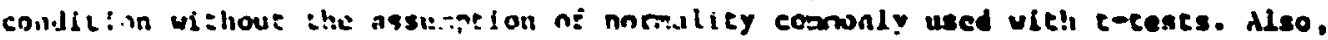

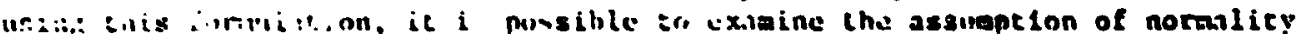

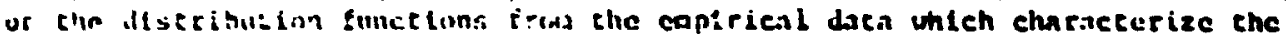




\section{ORIGINAL PAGE IS \\ OF POOR QUALITY}

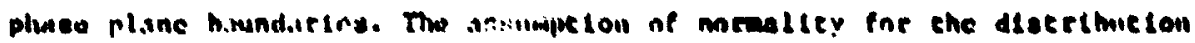

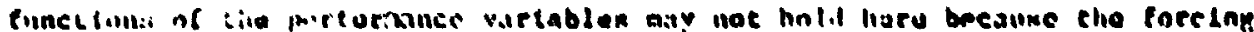

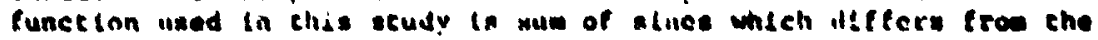
deturminisele cracking caak cousiderod in (7).

The C slluag firlal timeriment:

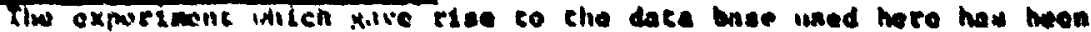
extonsivaly documented in $(1-\phi)$. In chis mper clio dach used in this coulyets

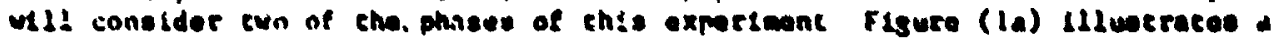
block diserat of I human involved in thle mun-anchlne inceraction. To deecrite

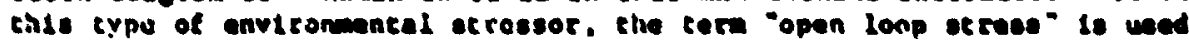

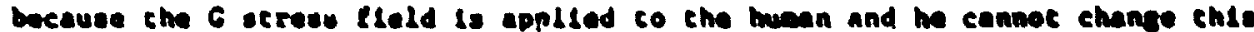
et roes tield clurough his atfek cumande. Figure (Ib) Illwetrates phase II of chle experteone which lo tarwed, "cloeed loop otrees". Ia this cese the munn's

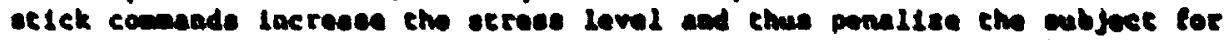

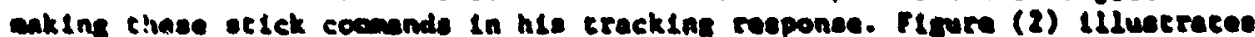

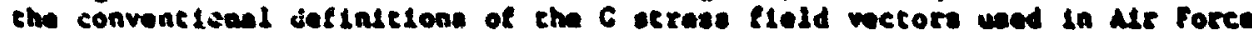
relaced eppilcestons. Uolas the rector dafielclona in elgure (2). the open and cloeed loop portione of this exporimat cen bo defined en tollow: mase I:

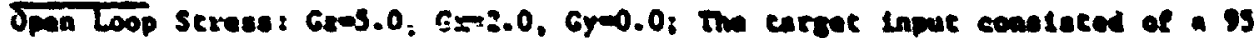

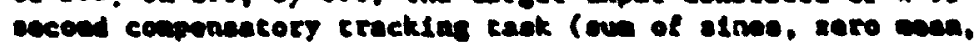
conocent weriance).

Prace 1I:

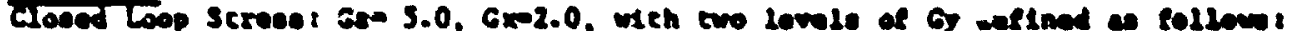

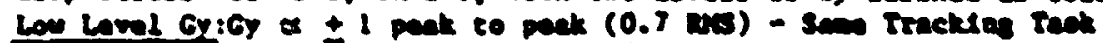

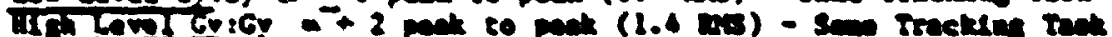

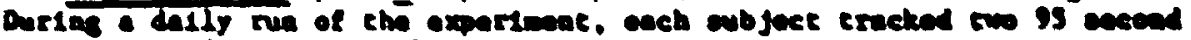

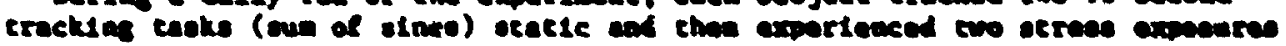

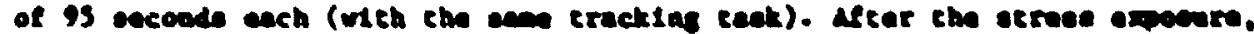

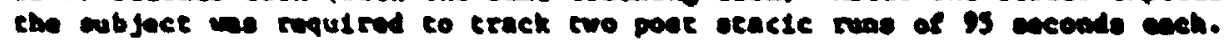

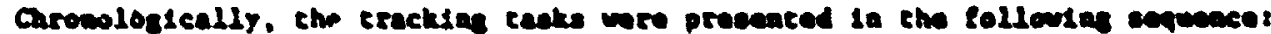

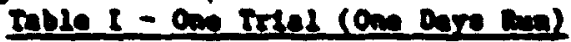

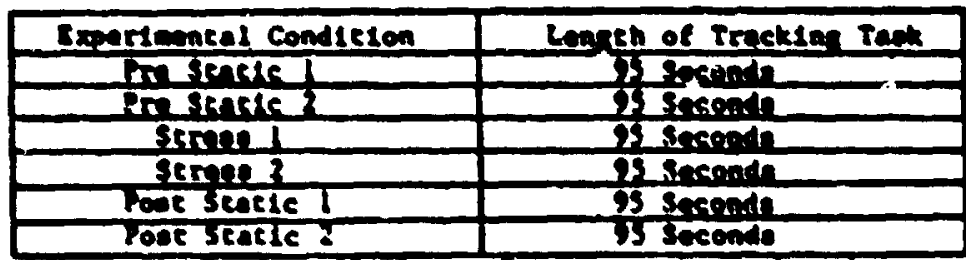

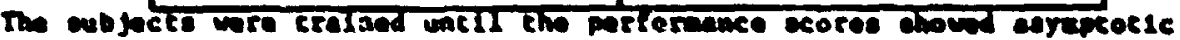

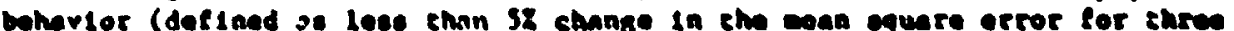
conecutive repllentlone) and too cech subject mintalmed edequate tolorance to the etrees level. The colerance we detereland through the sub ject's and

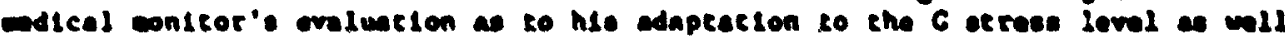

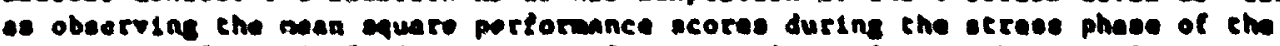
experleant. In table I. during phase I. etreses 1 and 2 were the open loop type etrese described previously. In phase It the ectese 1 and 2 wre.

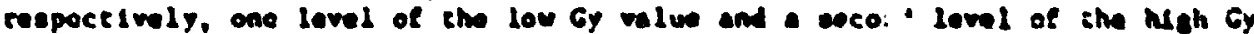
value. The orders of presentaction of the hy levels were altermated from ersal

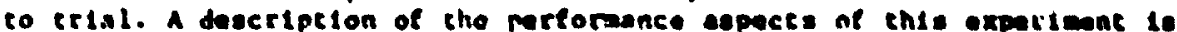
presented mext. Portarmine Analrats of the Dites:

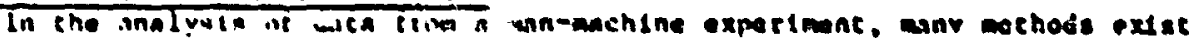

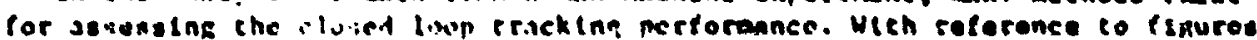

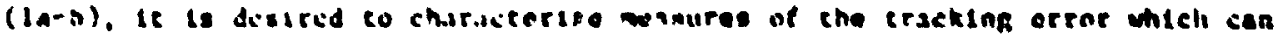

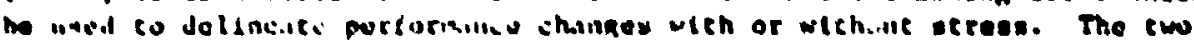

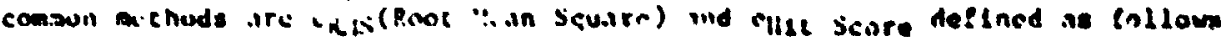
(i): 


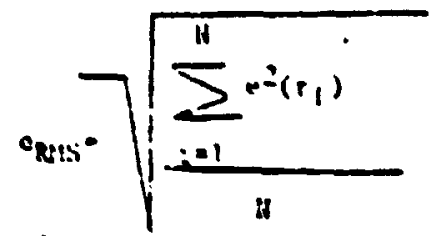

where $\$$ is the nusher of s.inplis at tine twatants $t_{i}$. ehit scorg or tine an carget c.in be sefined in cerns ot whon the crror signil is similer than a windor of a spectified size. Ev diefinteion:

Hic score The tumber of Samples when $\left|e\left(t_{1}\right)\right| \leq R_{1}$

where $K_{1}$ is the ulndow $s i=0$. The clase on target is dafined by:

Tlue on Target - Cylt Score Sapling rate (enconda)

The use of hit score enalysis is veluable coul to assess perforance changes; however, It is scmetime difflcult to apply chis performance aetric to scudy large blocks of deca over various window slzes and to dray comperlsons between the different experimental conditions. An easier wr co secudy the window probleas (and to relate the ensulng phese plane analys ts co the window study) is chrough the use of a Cusulative Distribution Function (COF). Figires $(3 a-3 b)$ 1lluscrate the density funcelon (asound to be norml in the diagran) and its correspondint Cumilative Distribution Function (the firse iacegral of the Jenstey function, defined as follows:

$$
\begin{aligned}
& \text { Deneicy function - } f(x)-1 / \sqrt{2}-0-(x-n)^{2} / 2 x^{2}
\end{aligned}
$$

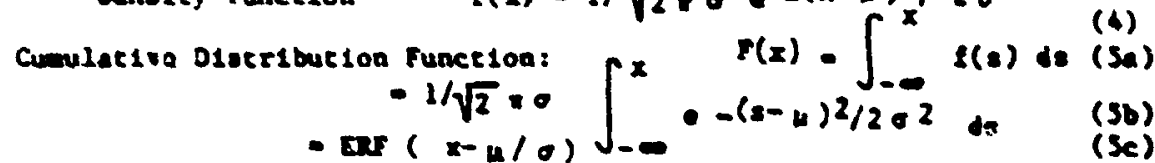

Whare the dafinition of Exf in equetion (Se) le represented by cquation (Sb). For a randon variable $x_{\text {, the }} \operatorname{cor}$ has the proparty that:

$$
F\left(x_{0}\right)=P\left\{x \leqslant x_{0}\right\}
$$

Thet 1s, the probebility that the error signal is senller then a rindow of s1se $h_{0}$ is equal to the velue of the CDF function for chat velue of $x_{0}$. To lisusi iate the sopllesbilley of this approach for developlus a beter

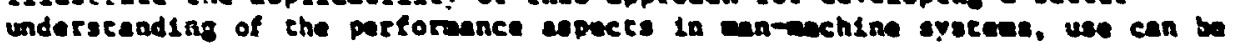
ade of the CDF to compare two trackers and two differont control oystems (figures ta-tb).

In ligure ín). It to noted that the COF $(12,13)$ for a sood eracker (one (rial) is to the lefe of a poor eracker. This lo true because the good cracker keeps all values of che error slgnal wiehin a window of size $K_{1}$ while the poor cracker must have . uindow of stse $R_{2}$ to concaln all the saef les of the error sigmal. To interpret vindow analyats from fleure (4a), this lo seleplefled by using the hortzontal IInts st e Eraction of the COF value. For example, for CDF-.5, it is noted that the good stecker keeps $50 z$ of the error vithin a window of $1:=e K_{3}$; howerer, the poor cracker keeps $9 ; 7$ of the error within a vindow of size $K_{\text {. }}$. A masure of cxaparison between the crackers is ehu distance $K_{i}-K_{j}$ whlch indicates how auch of a window differance extses between these srackers sot of tho tise. Th! smalvels is then repested for COF -0.8 and from the COF plocs, che window of slie $K_{6}-R_{5}$ llluarraces the vindow difference for soz of the exror in the experiment.

Tho COF is a valuable cool to assese alrcraft performance as cen be seen In ligure (4b). In chita diagrian the shaded region A Indicates the range of valucs elist: coutioi ivstes nay have an influence on the clinsed loop

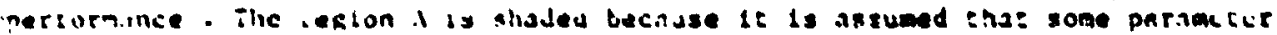
of clic cuntrol sys-ew is raried over a ranse of values co chanpe the cloved

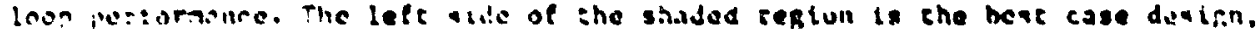

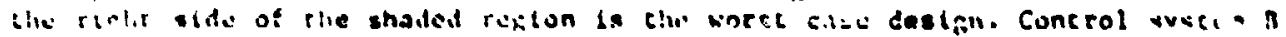

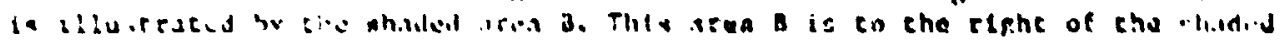

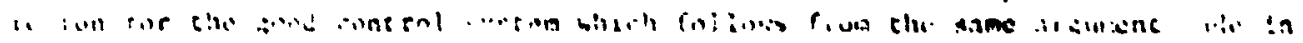

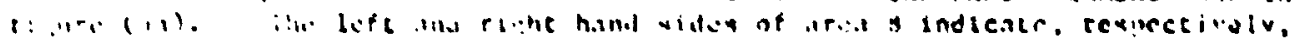

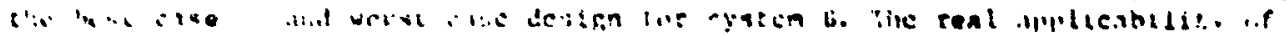




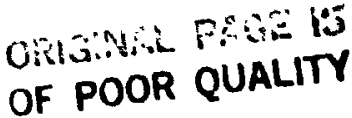

fipule ( $(5)$ ) is in the compirisolly betwren oystems by projectinn llnes it

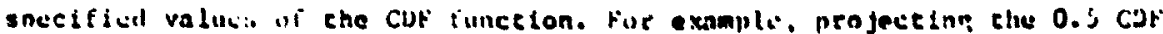
hoilizuncal line acrose thu dipran, one can decermine the range of uiadnw values where ench system is effected. From figure ( $4 b)$, it is seen that conerol syster $A$ will iave 50\% error varlations with window ranges $K_{1}$ en $K_{2}$. Control

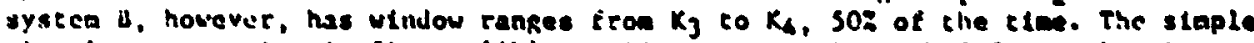
visulal presentution in figure (Ab) provides a valuble wethod for evaluating systea performance when non-iinearities are present in systeiss and enaparisona era desirad butwrer the rite dumala response chnraclerisitlcs of thuse syycens.

Fifure (j) Idlistrates how to 1.til', the powefful techniques of the CDF to

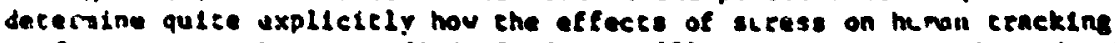

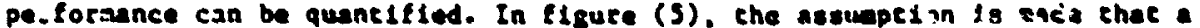

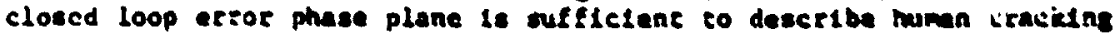

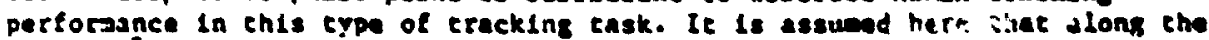
$e(1)$ or $:(t)$ axds, thit chere extses unknown densicy funct tona to describe the boundaries along the two axis. The aedien value of the denstey function to the unknotr boundary polnt and this parameter as wll as the verlance of this density fuaction, will be deternalned frow the eapirical data. Froe figh (s) It is seen that 4 uaknoun paraneters axdac wich cherecterize the densiteles in the following manaer:

$$
f_{1}(x)-1 / \sqrt{2}=\sigma_{i}-\left(x-n_{i}\right)^{2} / 2 \sigma_{i}^{2}
$$

where for no etress $(1-2,6)$ and the tour unknowns $H, O$ a te to be

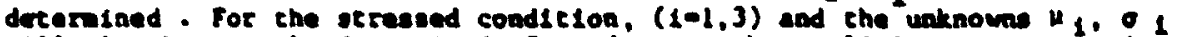
vill also have to be deternined. In order to anke explicit stecements aboute perforance changes, It vill be ancessary to flrst deternige the paraneters,

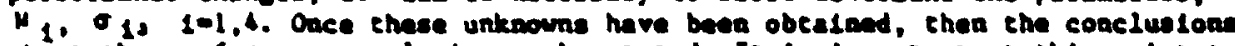
aboue the perfornance enalyese can be exaced. It is inportane at chie polat to

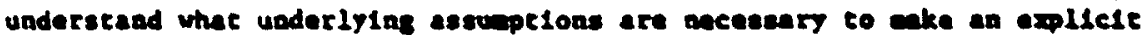
stackeane about perfornance changes.

One could, concelvaly, ralse the question conceralns the assumpelon that the denstcles $f_{f}(x)$ are aormal. If thay are not normel, the cor table teats can

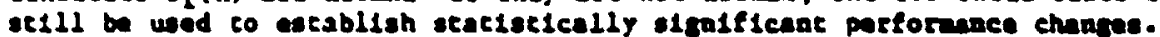
However, thare st11l would exdat the uncertalney as to bow the bounderles ta flsure (s) ere charecterised. The purpose of this papar 1o two fold. Firet it 1 deslred to study the sesunpelon of noralisy from the caplricel data for enis coeplex $G$ fleld experiente. Socondly, te is deelred to eake explicte statenenta un the effect of the 6 strese on producing a degradetion in trackine parforanence. In order to achseve the second soul, ona ause be careful to exanise the underlyine deasieles. The aechod considered here involves the

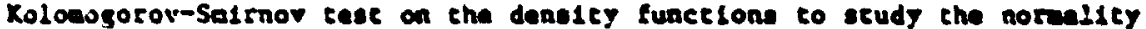
quassion.

The Koloosoror-Sml rnov Tese To Studr the Densileles:

The kulaogoroy-sinirnov Test is dlscussed hare In an affore co anke som stacenenta sbout the underlyng densities chat characterise the phase plane boindartes in figure ( 3 ). The cast can be deflned as followe: Definielon-iive $\mathrm{N}-\mathrm{S}$ Isac:

Given if saeples of dats from $\hat{F}_{n}(x)$ a Cusulative Distribution function of the

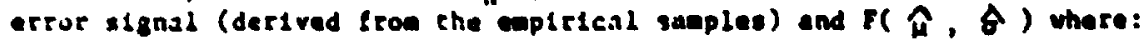

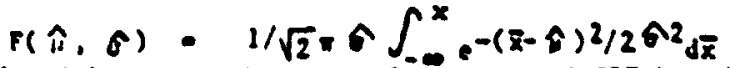

Fron equsetun (s), $F(\hat{v}, \hat{A}$ ) is the chenretical or assued c.DF besed on the

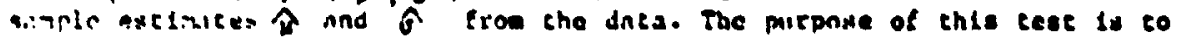
Eonsidur two lappothesty:

$$
\begin{aligned}
& \text { III: } \quad f(x) \text { is nomnal } \\
& \text { III: } \quad f(x) \text { is noc notmn I }
\end{aligned}
$$

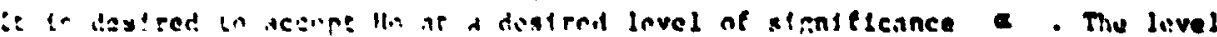

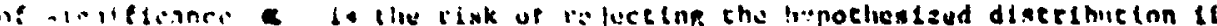

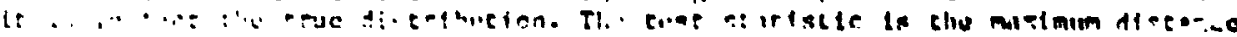

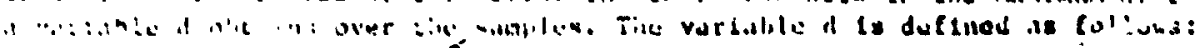




\section{ORIGINAL PAGE IS OF PCOR QUALITY}

$d=\operatorname{man} \quad x_{1}\left|\hat{k}_{n}\left(x_{1}\right)-r(\hat{u}, \delta)\right|$

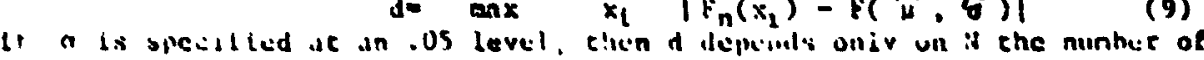

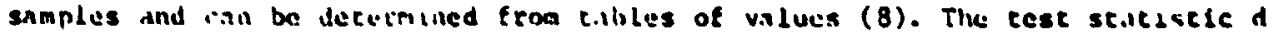
is - randow viriable which sacisfles:

$0 \stackrel{0}{=} k_{l}$

where $k_{1}$ is from the cable of valius $(8)$. If equielan (10) is not suclistied for a spectelied $\&$ level, then $\mathrm{H}_{0}$ is rejected. If $(10)$ is true, then the hypothesized distribution cannot be rejected and it can be vald cluat it is reasonable to assube that the hypochesized distribucton is clie true distzibution.

To apply tliss text to the phase plane axalysis, It is necessary to assume that the distribution of the buundary of the $Q(t)$ axis is identical for the posicive axis as well as for the nagat ive axis. This symectry esoueption secess reasonable in light of the fact that the tracking task is syamerical taeto mean, Constant vartance, sum of sincs) and also the stick has symecrical response charscteriselcs. Therefore we assume tigures in the fure of $(6 a-b)$ in which the density of $e(t)$ is normal. This sawe argument holds for the $C(t)$ axis.

Results Fron the Data:

As - prelininary invescigation on chis analyels, consider first the cese for 1 subjact, 1 ertal, and 2 experimencal condielons. Figures $(7 a-1,7 a-2)$ illuscrace the suple tensity function $f o r e(t)$ and $(t)$, reapectively, (related to the corresponding $F\left(x_{i}\right)$ ) frov the data sapples for one trial in the prestatic condition. Flgures $(7 b-1,7 b-2)$ is the stress councerpart of figures $(7 a-1,7 a-2)$ and shows the density obcalned under the extass condition. It should be enphasized that flgures $(7 a-b, l-2)$ all wee the absulute valuas of the variables $e(t)$ or $:(t)$ which link the hit viadou concept with the phase plane diagras and the CDF appraech used here.

Figure (3) displays the rasuleing CDF's obtainad from the sapples of $(E)$ data in figures ( $7 a-b$ ). One cotices the degradacion of performance level entfests Itself by shifes co the righe. Eron observacion of figurea (7e-b) and (8), one can now see how the two objectives of chis paper relace to the capirical daca base considered here. First it is desired to say whether figure (7a-b, $1-2)$ can be approxdaced by normal deasteles. Secondly, from g1gure (8) it 18 desired to say someching about how wuch perforannce change is introduced by the scress effect. Obvioualy with one trial, conclusions cannot be drava. It is necessary to epeat this procedure across repllcations and ecross subjects. Flfure (9) 1s drawn to lllustrace the and product of this effort. The boundary points on the $e(t) a x 1,: 50$ butat aned by the median polats of f18ures $(7 \mathrm{a}-\mathrm{h}$ ) (the 0.5 pinte of the $\mathrm{rng}$,. Likewise the sam procedure is repested fo: iic). This yillt: she bounderles of figure (9) and the polats ablasned are 11luer=:-oed in Table II:

Table 11 - Nedians Obealned Fron 1 Trlo.1 of Fach Condition

\begin{tabular}{|c|c|c|}
\hline $\begin{array}{l}\text { Experimencal } \\
\text { Condl=10n }\end{array}$ & $\begin{array}{c}\text { Variable } \\
\text { (c) }\end{array}$ & $\begin{array}{c}\text { Variable } \\
\text { i(t) }\end{array}$ \\
\hline Prescatic I & .060 & 0.25 \\
\hline $\begin{array}{l}\text { Stress T } \\
\text { (Phice II -lligh } \\
\text { fiv (inndiction) }\end{array}$ & .11 & 0.33 \\
\hline
\end{tabular}

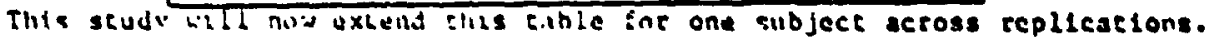
Uaing che ssine sungect as displued in Table II, the analyals procedure is now

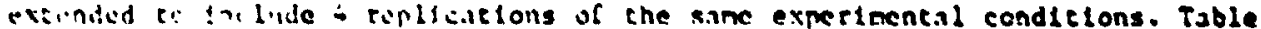
III is now sonst:ucted fros shese fuur replicilitons of the plinse II dasa. The

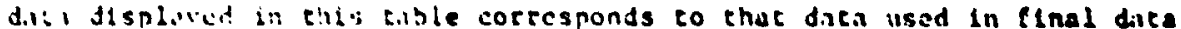
d..... ivis :a $(1,25,15)$ : 


\section{ORIG̈INAL PAGE IS OF POOR QUALIT}

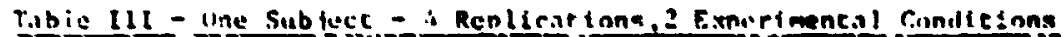

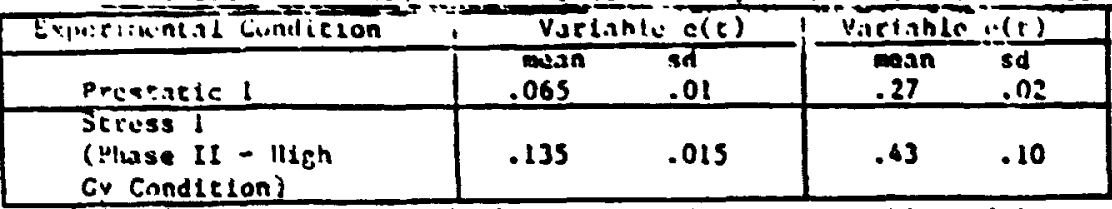

Figure $\left(1 \mathrm{U}_{2-h}-h\right)$ Hllustrates the CDF's obeained for the varlables of $(t)$ and $i(t)$. To deceraine the nhsice plane boundaries, the 0.5 line is projected horizoncally on Eigure $(10 a-b)$ and chen projected dounuard on the window exds zo deteraine the median points. Also troe this projection, the variablilty in this estiante aboule the mean ls obcesned by plocting the one scandard deviacion envelope of

this curve. Figure (11) cen now be drawn. This represente the true screse regions and non-strase reglons with the appropriate boundarles. The variability In the phase plane boundaries can be observed in figure (11) wit they caa also be cested using t-cests on the CDF's displayed in tigures (10n-b). The maxt section will discuse the tests used.

Statstical Tests on the Endrical Duta sase:

The first goel of this paper is to study the oornallty properties of em density functions obtalned fron the eptrical data ueins the Kolonogoror seirnor cest. This allowe a beter laterpretacion of the phese plane bousdartes

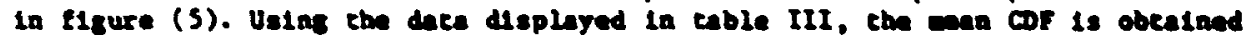
for the streseed coodition and the noastresend condicioa for one subject and 4 replleations. To beter wederstand the X-S teat, it to formulated hare in a eteristical fraconort.

Probles Sormulation (Testing Densleles For Horzelltr):

Consider the tollowing scacisticsl problea with two alcernative typocheals:
Ho: $f(x)$ is omen $M(\hat{A} \hat{A})$
HI : $f(x)$ is oot aomal n(j,O)
(11)
(12)

where $\hat{H}$. $\hat{\partial}$ are che sapple wean and standerd devtation, respectively. mare are 4 elements of any staciselcal cest for hypotbests testiag. The two hypothesis llsted above are the t1rat two elements. The thisd elenent is the cest statistic; the fourth element is the rejection or extefeal reglon. The

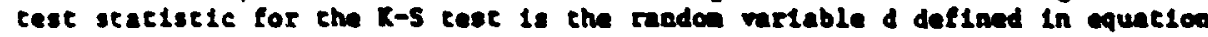

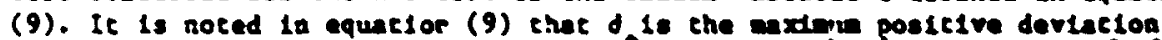
becueen the suo disctibuesion functions $\hat{F}\left(x_{1}\right)$ and $F(\hat{A}, \partial)$. The CDF $F(\hat{\mu}, \hat{\sigma})$ is the theorectical function given in equacion (Sb) with the sample date esciantes $\hat{\mu} \hat{\partial}$ replacing $u$ and $\sigma$. The CDF $f\left(x_{1}\right)$ is the eanple CDf obtalaed fron the eccuinulacion of error esores over a varfery of differont window sises.

The fourth eleane of this tese is the deternimation of the rajection or criticsl reglon. Fo: any hypothesis cest, there exters two typas of error. A type I extor is the rejectior of Ho when tho 18 true: Let a denote the probahility of a erpe I error. A type II error is the scceptance of Ho when $\mathrm{HI}$ is erue. Let denote the probubillty of a type II error. Deaoting Da wa ta $(14,17)$ critical value of d such that:

$$
\text { P Id Dn ? 1- a }
$$

The exprasston given in equiation (13) defines the rejection or critical region ond this provides the fourth element of the $k-S$ test. It is noted chat on is found in castes which only depend on $X$ and $a$ and not on the underlying . coniznunus $(A)$. hilte che $k-j$ test is only perforaed on the diacribucions if $\hat{n}, \hat{\sigma}$ : and $P\left(r_{2}\right)$.

The minner in whlish she k-S tese lo applted hare with respect to table tII

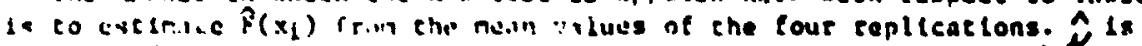

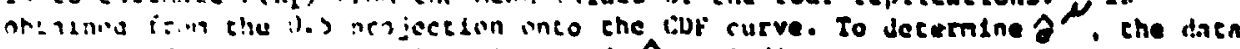

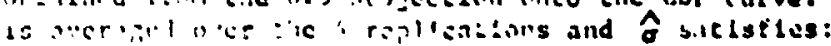

$$
\hat{v}:=1 !(\because-1) \quad \sum_{i=1}^{N}\left(a_{1}-\hat{v}\right)^{2}
$$




\section{ORIGINAL FMË IS \\ OF POOR QUALITY}

fiur ench riplicicion, tho cwo CDF's ire nomalized de follows:

Thin:

$$
\text { Let } \quad y=\left(x_{l}-\hat{u}\right) / \hat{v}
$$

$$
F(\hat{u} \cdot \hat{v})=1 / \sqrt{2} s \int_{-\infty}^{y} e^{-x^{2} / 2} d x
$$

Where $y_{1}-\left(x_{1}-\hat{11}\right)^{\prime} \hat{v}$ for $x_{1} \leq x_{0}$ (16c)

The resules of the test for Table III can be lllustraced as follows:

\begin{tabular}{|c|c|c|c|c|}
\hline Experiaental Condition & $\begin{array}{c}d \max \\
\text { theoretical }\end{array}$ & $\begin{array}{c}d \max \\
\text { theoretical }\end{array}$ & $\begin{array}{c}\text { d ax } \\
\text { cheorec lcal }\end{array}$ & $\begin{array}{c}\text { deax } \\
\text { enplitical }\end{array}$ \\
\hline Prescactc e(c) & .264 & .296 & .356 & .617 \\
\hline Seress I e (E) & .264 & .294 & .356 & .462 \\
\hline Prestacic e $(c)$ & .266 & .296 & .356 & .478 \\
\hline Scress I (c) & .264 & .294 & .356 & .632 \\
\hline
\end{tabular}

Table IV - Resules of The K-S Teat $(X-20)$

In this cable che discance variable d :efers to the definition given in equation (9). From the results of these tests for one subject, and 4 replications, we reject Ho and cherefure conclude that we cannot accept the hypothesis that the densitles are normal. It is noted fron table $V$ that the sample CDF obtained is ourside the band which describes 992 of all sanple CDF's from normal densities. This is a positive ladication for this cype of trackins task trat another cype of density is required.

Using this CDE repre. entation, however, allows the deceraination of $e$ cescs for significance of perforance changes. In eddifion, it will be of Interest to scudy the ainimue window sizes where strese effects appear to be signifleant. As a flrst uess on the perforwance changes between scruss and non-seress, an analysis will be conducted on the dace displayed in f1gures (10a-b). In both of these tigures, horlzontal lines are drawn at conseane values of CDFofl and projected down on the window values for all points on the 1 o earelope of the curves. The results of this projection are lllustrated in table $v$ :

Table $V$ - Resules of The Horlsoncal CDF Profections

\begin{tabular}{|c|c|c|c|c|c|c|c|c|}
\hline \multirow{2}{*}{$\begin{array}{l}\text { Experiantal } \\
\text { Varlable }\end{array}$} & \multicolumn{2}{|c|}{$C D F=0.2$} & \multicolumn{2}{|c|}{ CDF -0.6} & \multicolumn{2}{|c|}{ COF- 0.6} & \multicolumn{2}{|c|}{$C D F=0.8$} \\
\hline & rean & s.d. & acan & s.d. & mean & s.d. & mean & s.d. \\
\hline $\begin{array}{r}\text { Slatic } \\
\text { e(e) } \\
\end{array}$ & .025 & .004 & 1.0563 & .005 & .0812 & .006 & .125 & .007 \\
\hline $\begin{array}{r}\text { Sc.leic } \\
\dot{e(t)}\end{array}$ & .103 & .010 & .206 & .012 & 0.30 & .0125 & .622 & .018 \\
\hline $\begin{array}{l}\text { Seress } \\
e(t)\end{array}$ & .05 & .012 & .11 & .018 & 0.16 & .04 & .27 & .05 \\
\hline $\begin{array}{c}\text { Stress } \\
i(t)\end{array}$ & .159 & .028 & .318 & .056 & .306 & .0844 & .72 & .103 \\
\hline
\end{tabular}
(One subject - 4 Raplications)

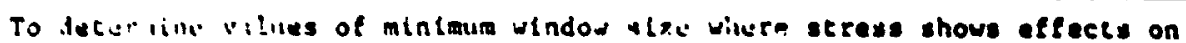
perfurmance, the $c$ staclstc tests are compuced as follow:

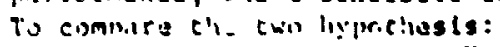

$$
\begin{aligned}
\text { Ho : } & \mu x-\mu y \\
H 1: & \mu x>\mu y
\end{aligned}
$$

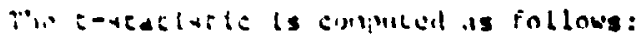

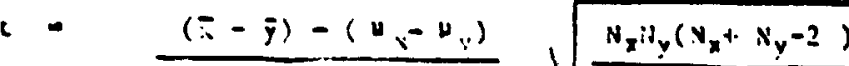

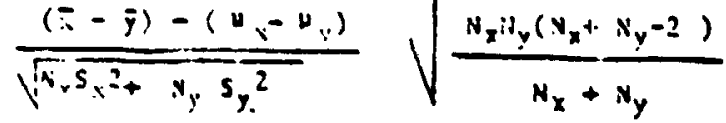

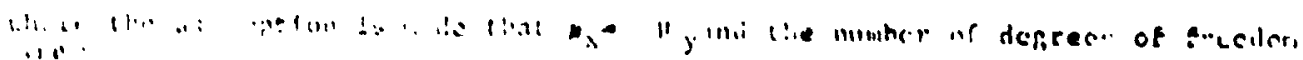


The cesules of the cests are displayed in Table VI:

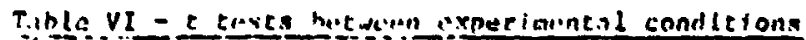

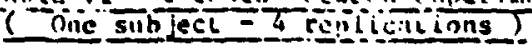

\begin{tabular}{|c|c|c|c|c|}
\hline 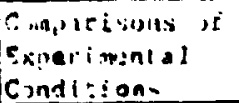 & CIIf $=1) .=$ & CUE $=0.4$ & $C D F=0.6$ & CUr $=0.8$ \\
\hline 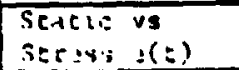 & $\begin{array}{r}\text { A level } \$ .01 \\
t=3.524\end{array}$ & $\begin{array}{c}\text { devel }=005 \\
t-4.979\end{array}$ & $\begin{array}{c}\text { a leve } 1 \leq \mathrm{En} 1 \\
t=1.613\end{array}$ & $\begin{array}{c}\alpha 1.001 \leq .119 \\
{[=2.47]}\end{array}$ \\
\hline $\begin{array}{l}\text { St.li. ic vs } \\
\text { Stross } \&(t)\end{array}$ & $\begin{array}{c}\text { तlevel } 2.1123 \\
t=3.263\end{array}$ & $\begin{array}{c}\text { d tevel }=-1) t \\
t-3.388\end{array}$ & $\begin{array}{c}\text { Level }=1415 \\
t=4.143\end{array}$ & $\begin{array}{c}- \text { level } \\
\text { t }-4.981\end{array}$ \\
\hline
\end{tabular}

One can see frima Table VII that the ffucts of seress on perfornunce are quite pronounced for one subject and 4 replicatione. Surnary and Conclustons:

A porforantics tcudy ius ixsan conducted on humen cracklng under a complex $C$ field. This paper 1 llustrates three leportant polncs. First it shows the connection between the phrse plene bondary polnts and uindow asasures through the use ot a CDF function on the data. Secondly, the effects of seress on cracking performance antests lesulf via che $t$ ceses ecross CDF's under two experimentel conditions. It is shown tor one subject and b replleacluns that there exist. asignifteant miffocmance degrudation due to seress.

A chled polnt ade by chis peper is that a $\mathrm{K}-\mathrm{S}$ cest on the discributions of the phase plane crajectortes indicate the non-normallty of the captrical density tunctions. This stackent can be ande utch greater chan 998 confidence. It is interestins in this case to have such a result hold for a cracksns tack which is sum of sines and to contrast this resule to the decerminists ceete constured in $(7)$.

\section{References}

(1) Korn, J., A. R. Fphrach, and D.L. Kletman, "Humn Oparator Modellns For ierial Trackins", IR-79-16, The Universiky of Connectleuk, Novenber, 1979.

(2) Korn, J. and D. L. KleImen, Moduling Lateral Acceleracton Effects on Pllot Performance in a Vector Force Flghter", The 1980 Anmul Conference on Manuai Conerol, May, 1980.

(3) Korn, J. and D.L. KleInen, "Mdvances In Modeling P1loc Trackins Performance in the Presence of Sustained Lineer Acceleration" Proceedings of th: 15 th. Annual Conference on Manuel Conerol, 1979.

(6; Korn, J., Kleinion, D.L., and Repperger D.W. "Frequency Domala Measuras of Human Parformance Under r-Setess". Proceedings of The I8th Conference on Dectstou and Control, Decerier, 1979.

(5) Friser, T.il. "Human Responae To Sistalned Acceleration" Yasnd sp-lo3, 196.i.

(6) Brown J.L., - tcceleracton and lhuxu Portomance - In H.W. Stettio (Ed),

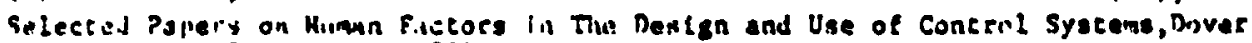
Dublteiclons, Inc., N.Y., 1961.

(7) O.H. R.nperjer, S.L. Ward, E.J. Hartecll, B.C. G1.199, and W. C.. Summers, "An

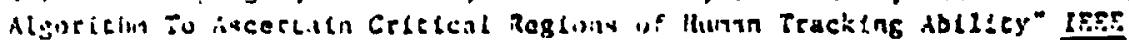

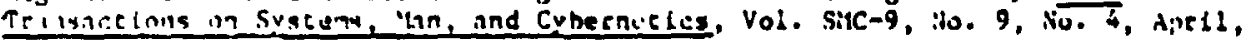
[119, Pl) 153-19\%.

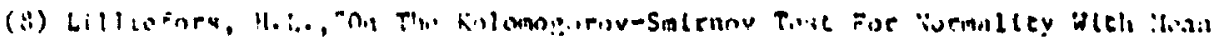

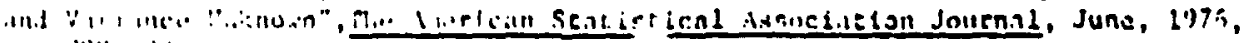

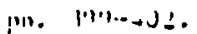




\section{CRISMNI PAGE IS \\ OF POOR QUALITY}

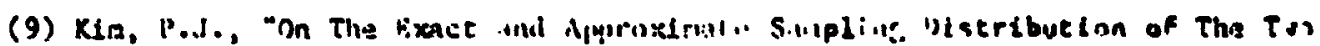

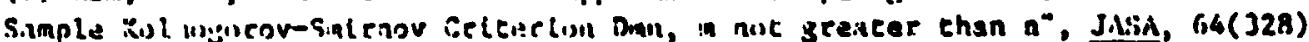
$1963,1625-(i) 17$.

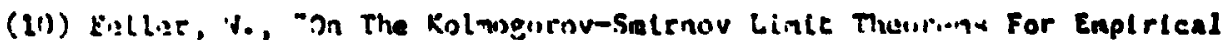

Distelbot lons", Annals of Machematlcal Seactset.:4, 19, i?7-i99.

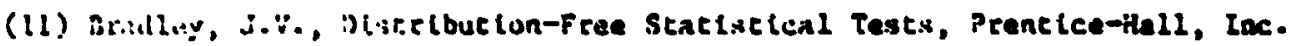
Nev Jersey, 1968, 367-369.

(12) R. Hood, M. Garland, and E. Meschko, "YF-16 Control Conffgured Vehicle (CCV) Operacioinal Pocential, Flying Qualieles, and Perforance Evaluation", AFFTC-TR-77-23, January, 1978.

(13) General Dyanics Corporation, Fighcer CCV Phase IV Report Volum IIFlight Test Daca Evaluat1on", AFFDL-TR-78-9, Volum II, Fobruary, 1978.

(14) H. M. Halker, J. Lev, "Seatistical Inference", Benry Holt and Conpany, 1953.

(15) J. Frazier, D.H. Repperger, V. Skowronsk1, and D. Toth, "Humen Iracktas Performance Changes During Combined tGz and tCy Strese". Preprints of the 1980

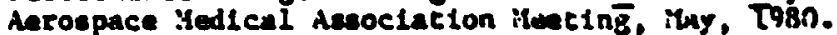

(16) D. Toch, D.W. Repperger, J. Frazler, "The Effeces of Test and Training

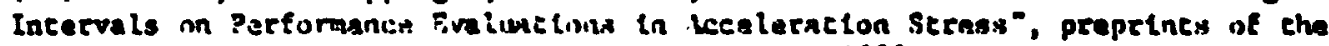

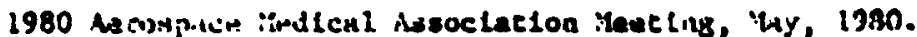

(17) P. G. Hoel, "Introducetion To Watheratical Scaclactes", John ditley f.Sons, Ine., 1962. 
ORIGINAL PAGE IS

OF POOR QUALTTY

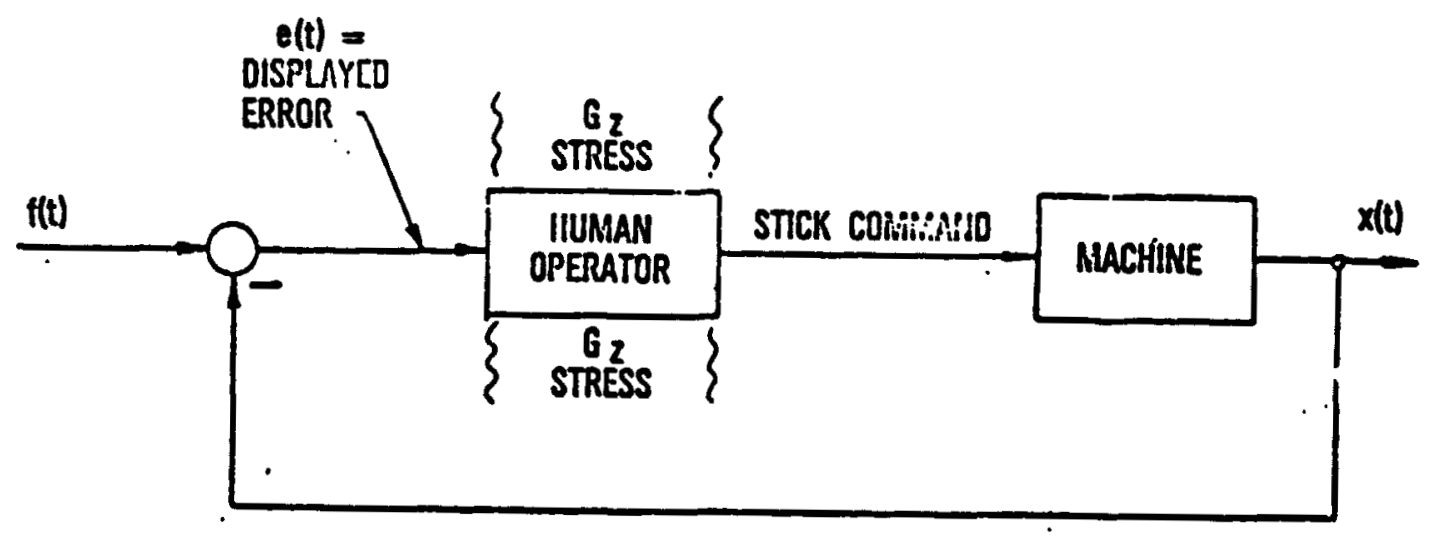

FGURE (1a) - OPEA LOOP STRESS

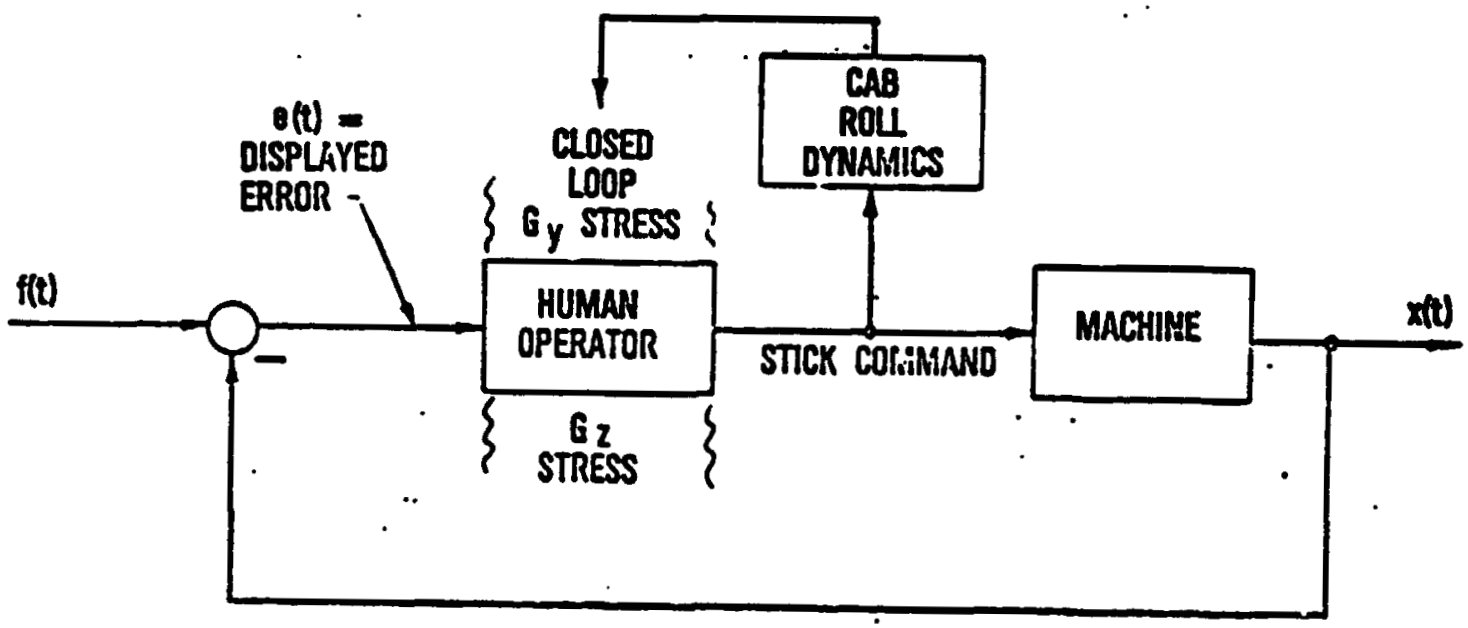

FIGURE (1b) - CLOSED LOOP STRESS 

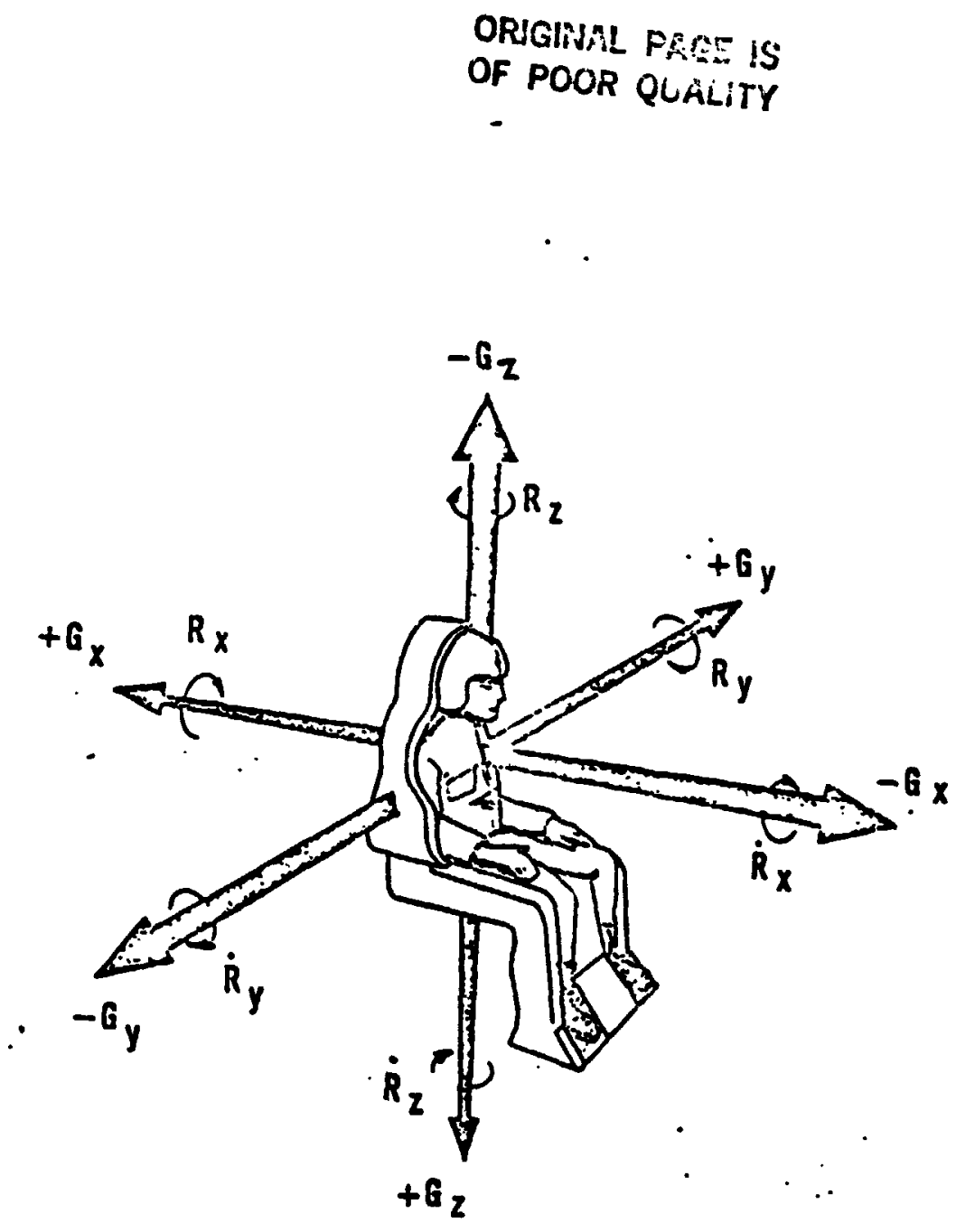

FIEURE (2) - THE G STRESS FIELD VECTOR 
FGURE (3a) - THE DERSITY FURCTION

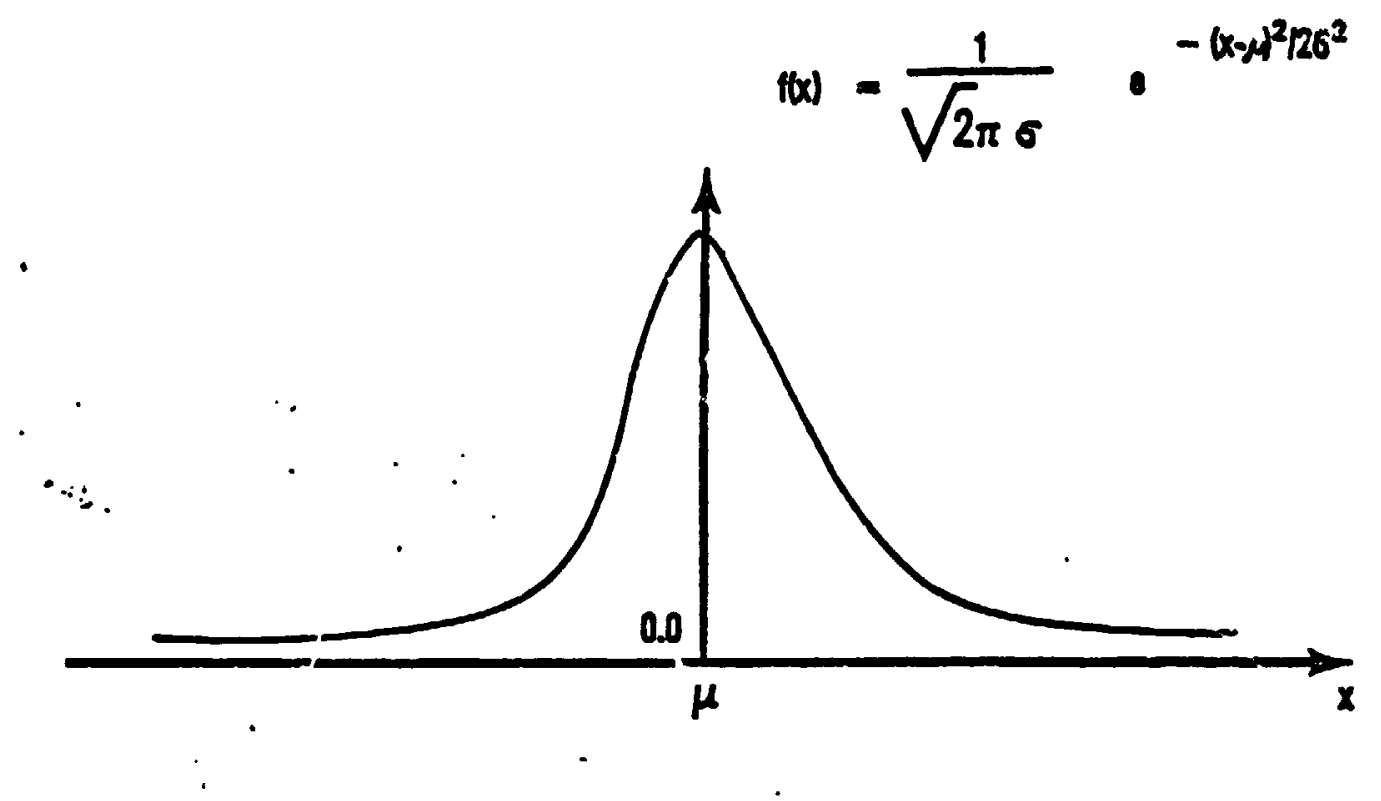

FIGURE (36) - THE CUMULATIVE DISTRIBUTION FUNCTION

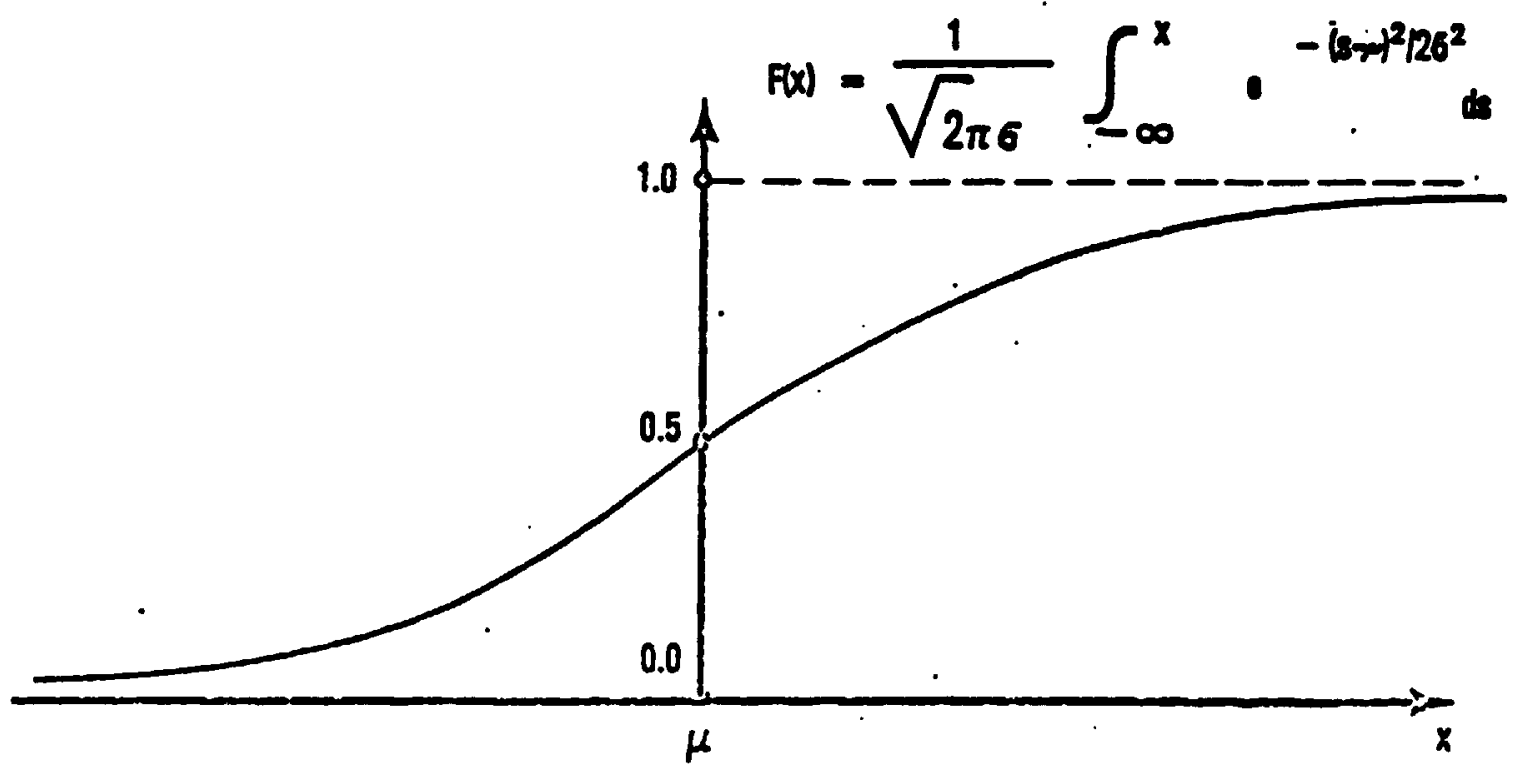




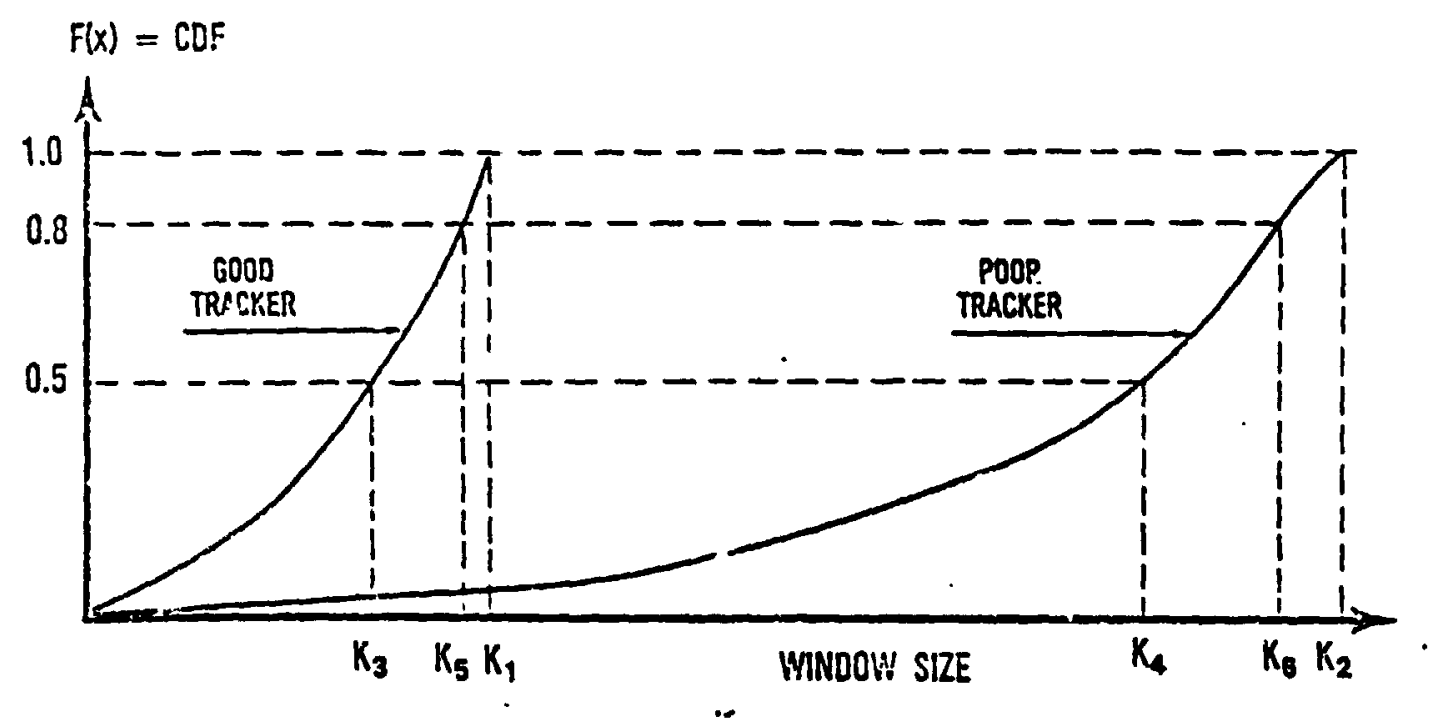

FIGURE (MA) - COASPARISON OF TWO TRACIERS USNG COF'S

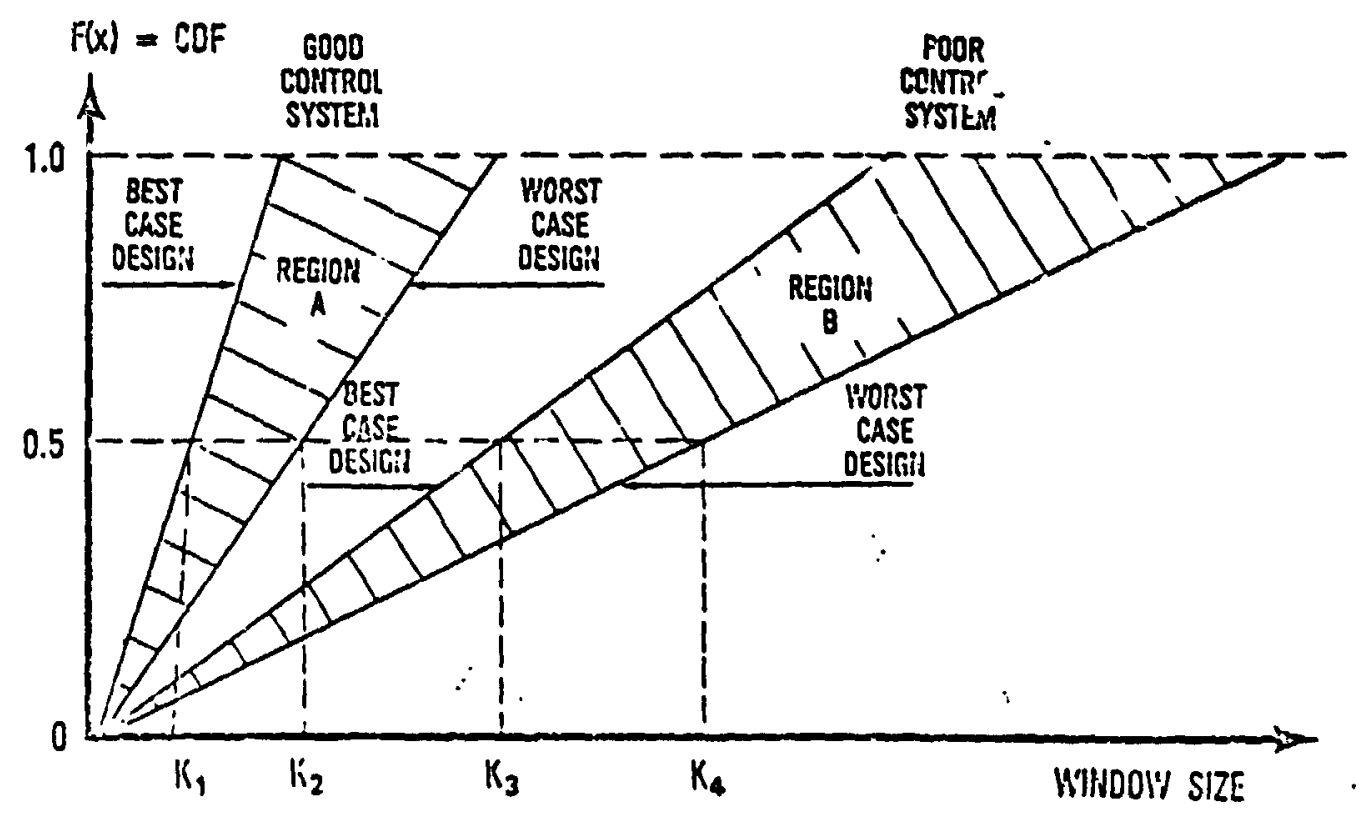

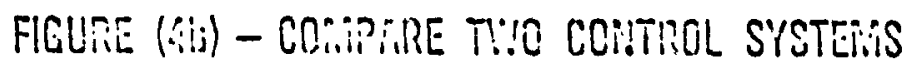




\section{CR!GINAL PAGE IS}

\section{OF POOR QuALTY}

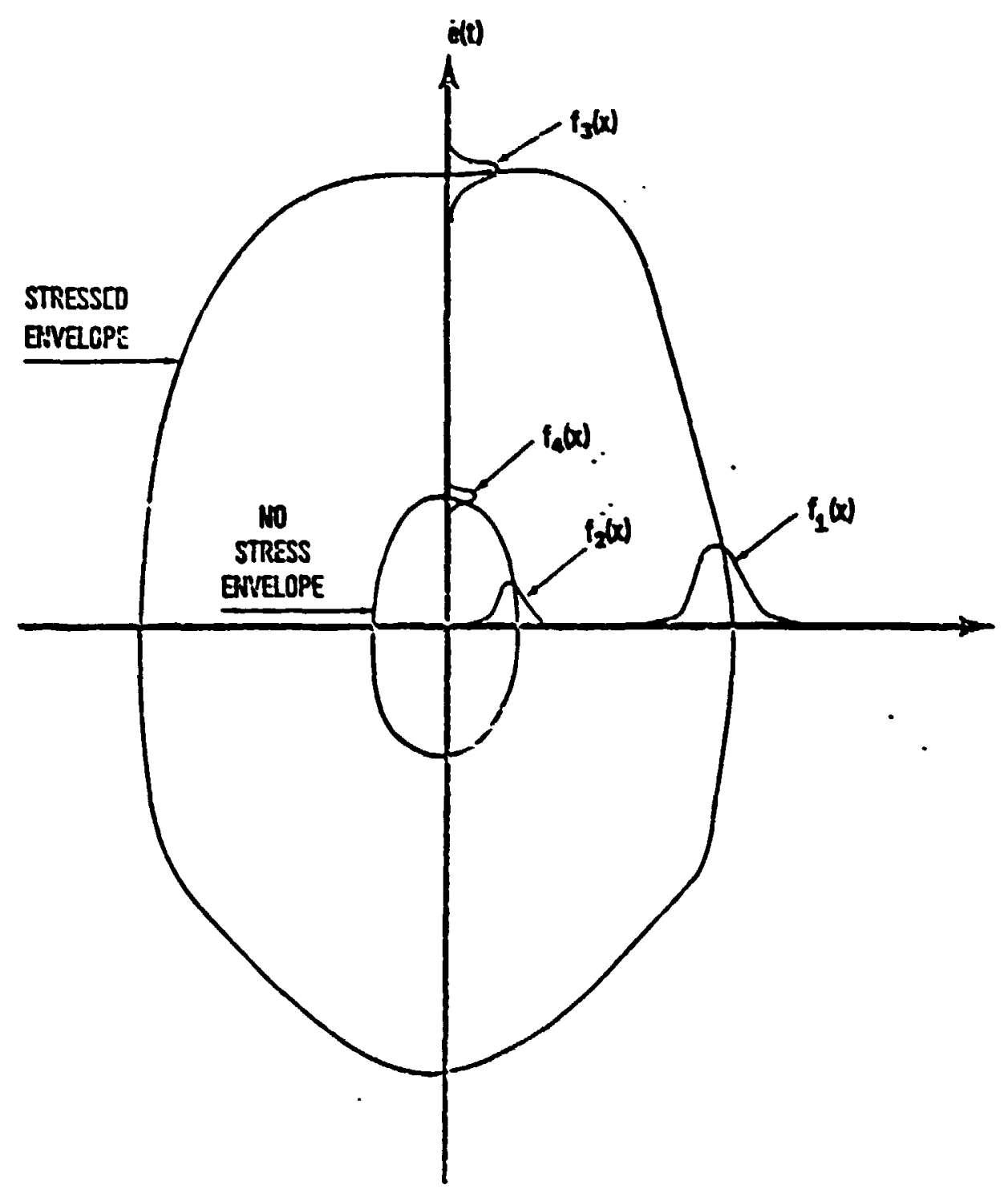

FICL:IE (S) - THE PHASE PLANE REPRESENTATION WITH ANO WITHOUT STRESS 


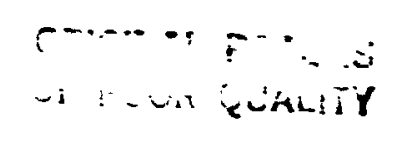

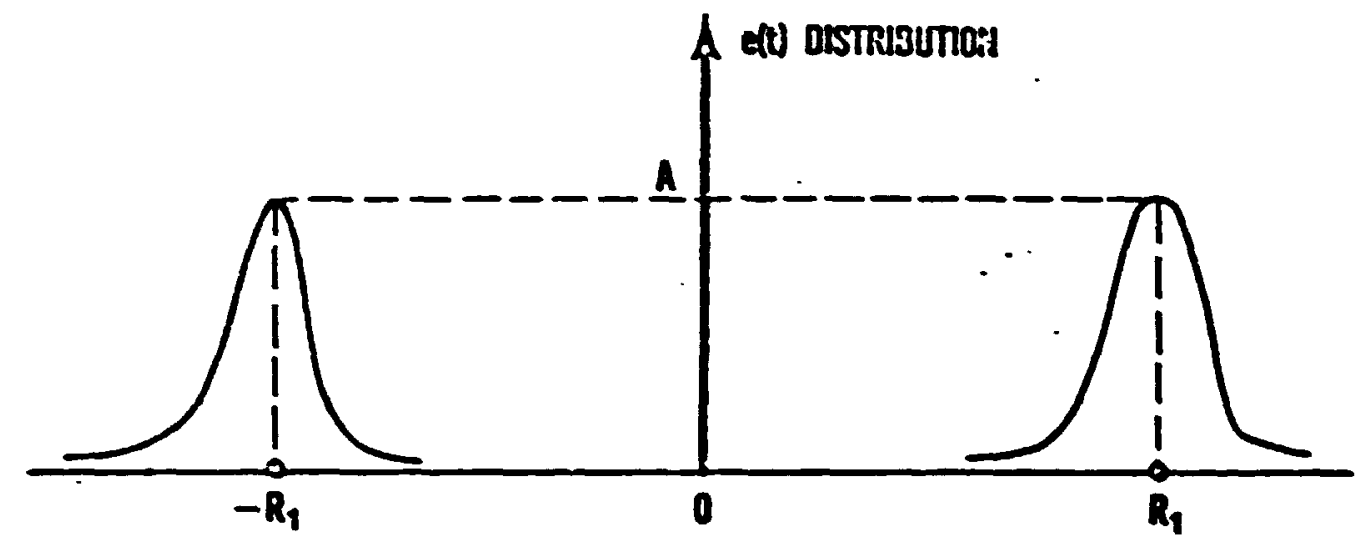

FGLRE (Sa) - SIDE VIEN DISTRIBUTION OF THE PHASE PLARE

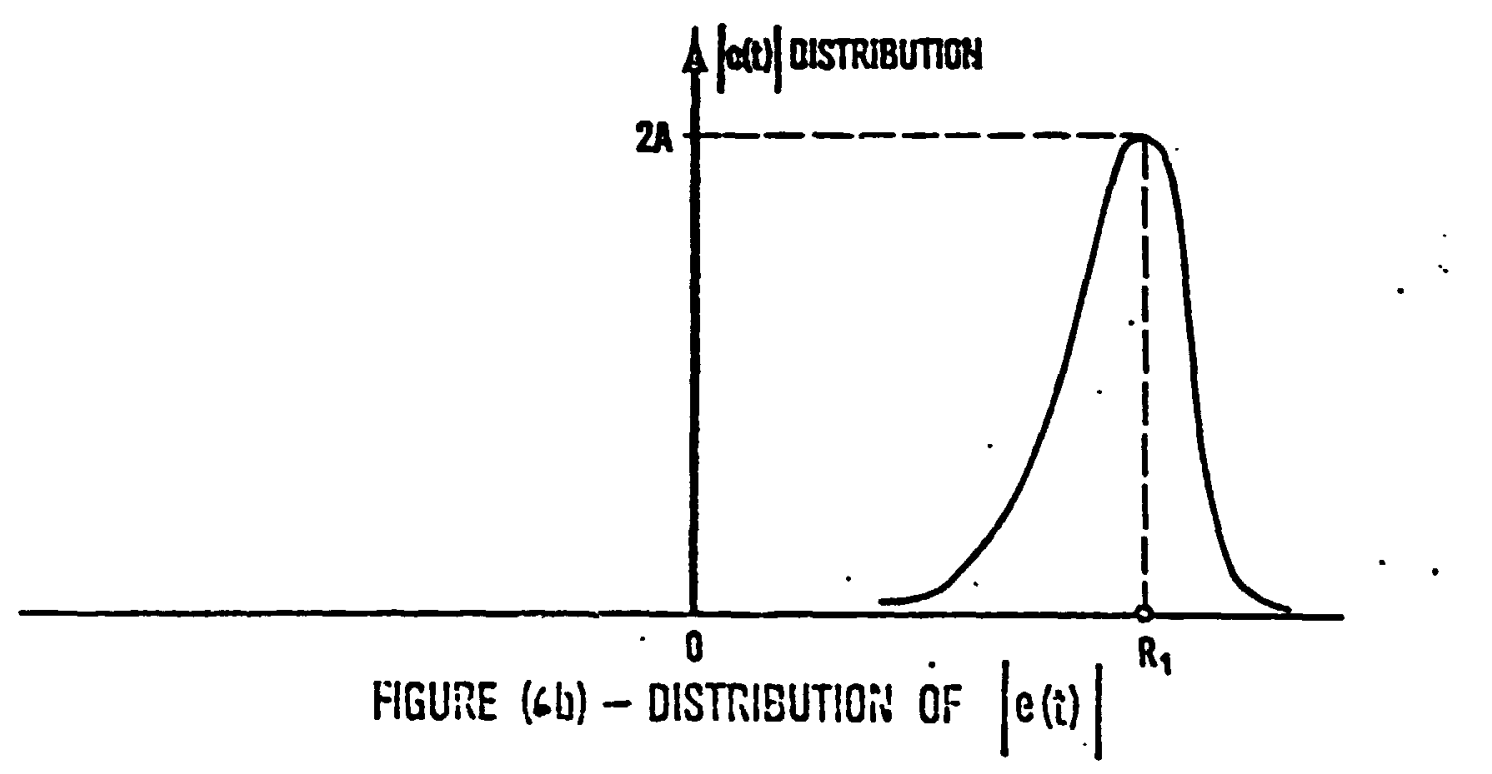




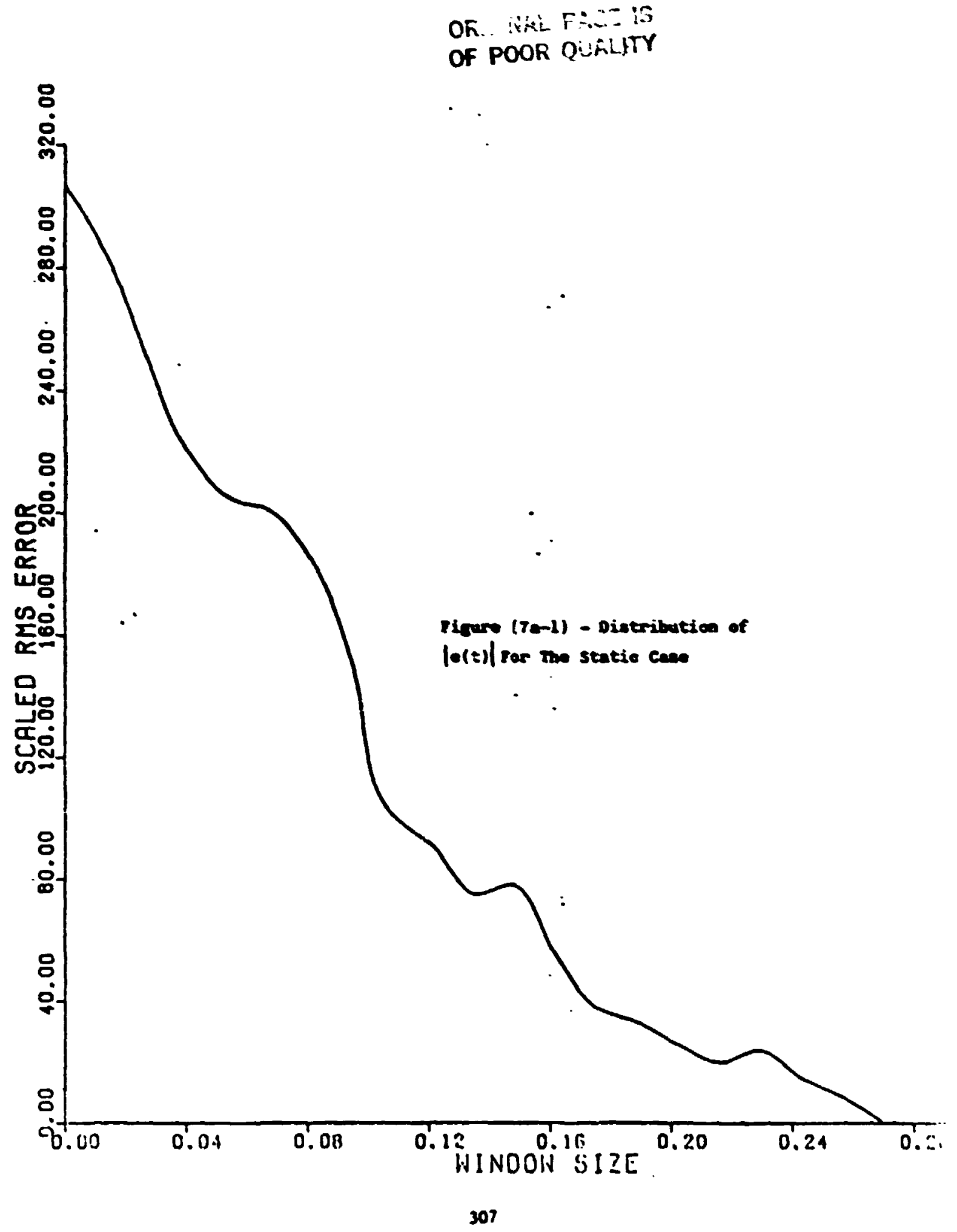


OR!C:PAL P:SE IS

OF POOR QUALITY

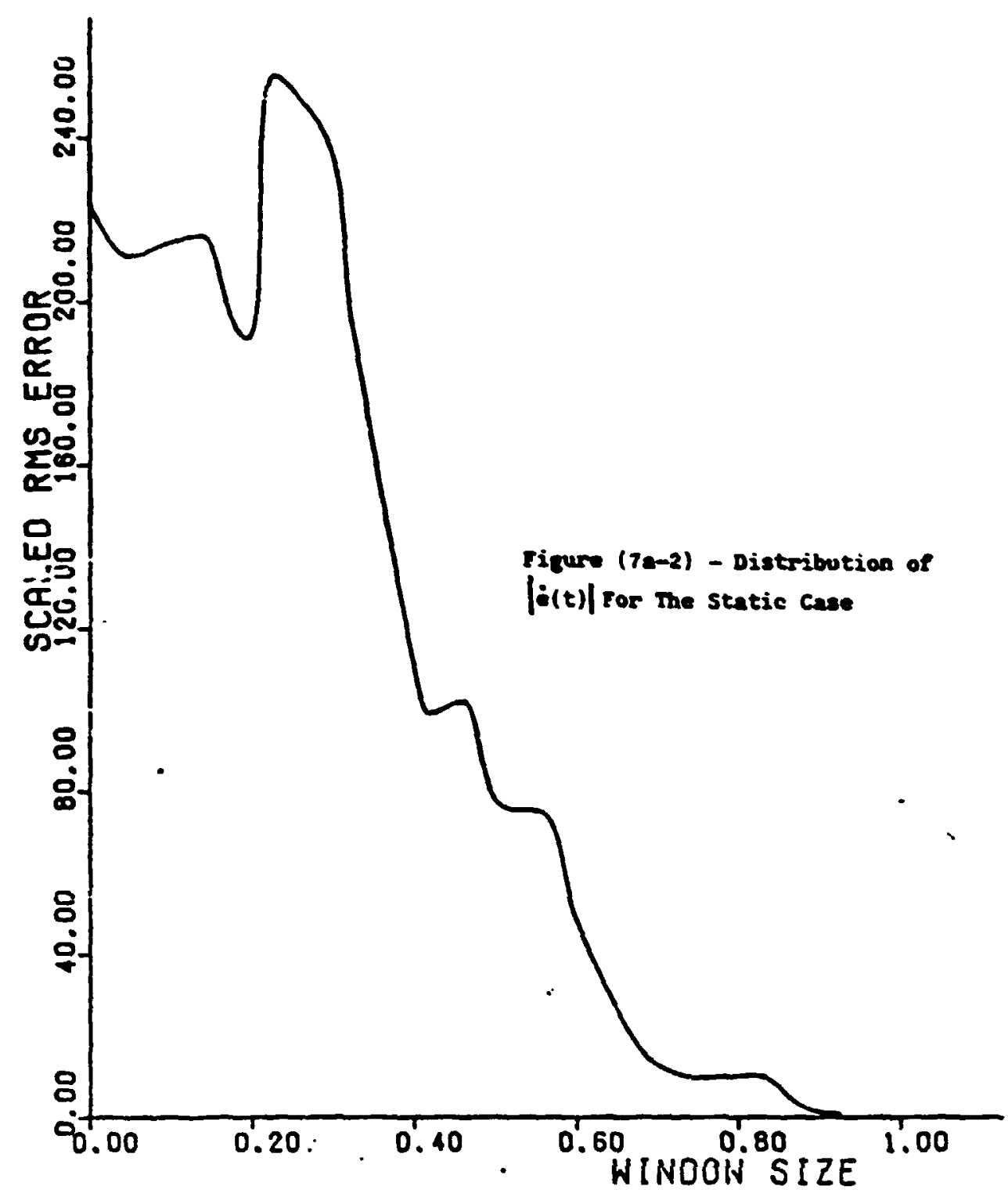


ORIGISR F- F. IS
OF POOK GUALIY

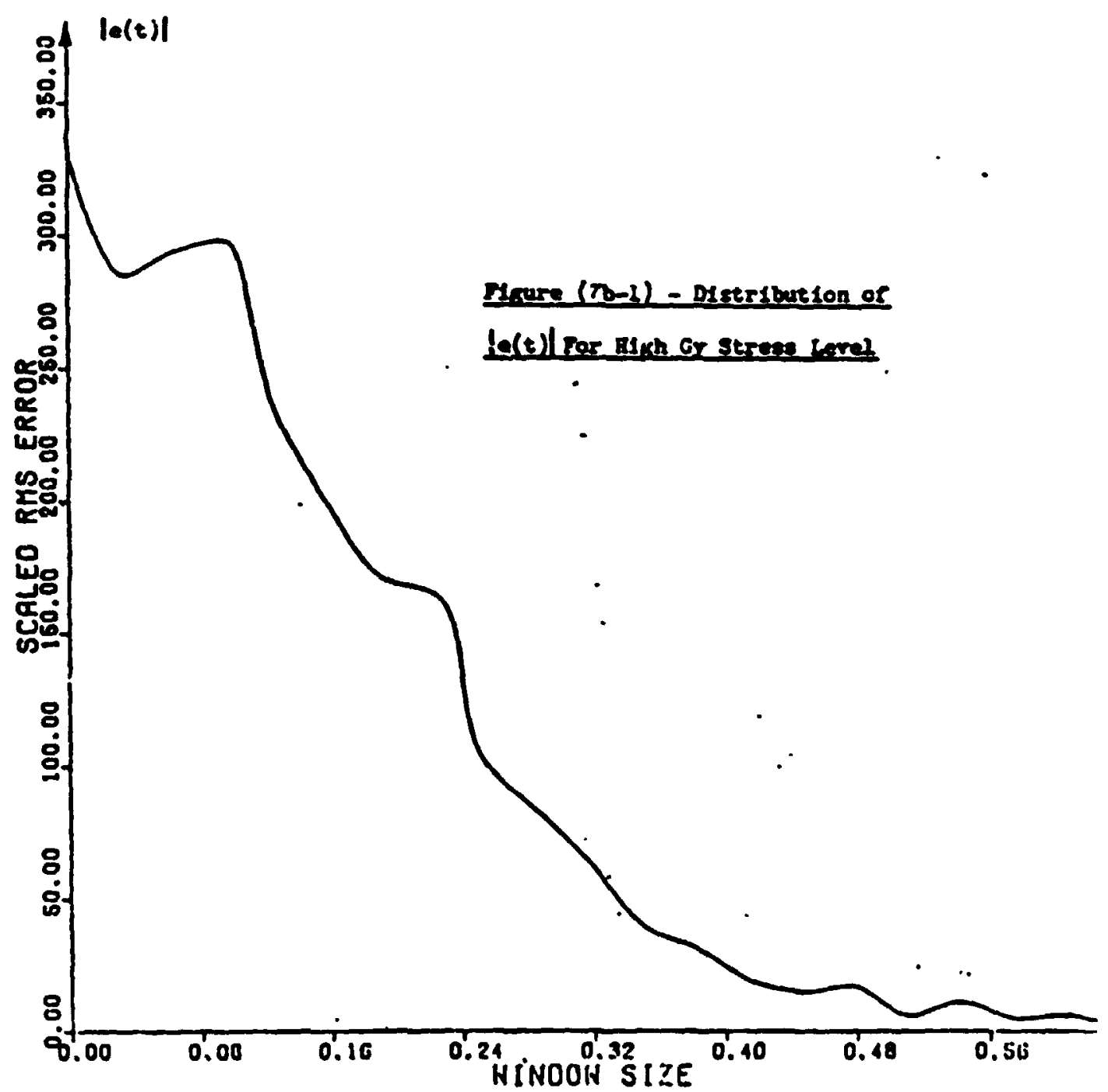


CE:?ㄱ:? PEGS :3

OF POUIS GuALITY.

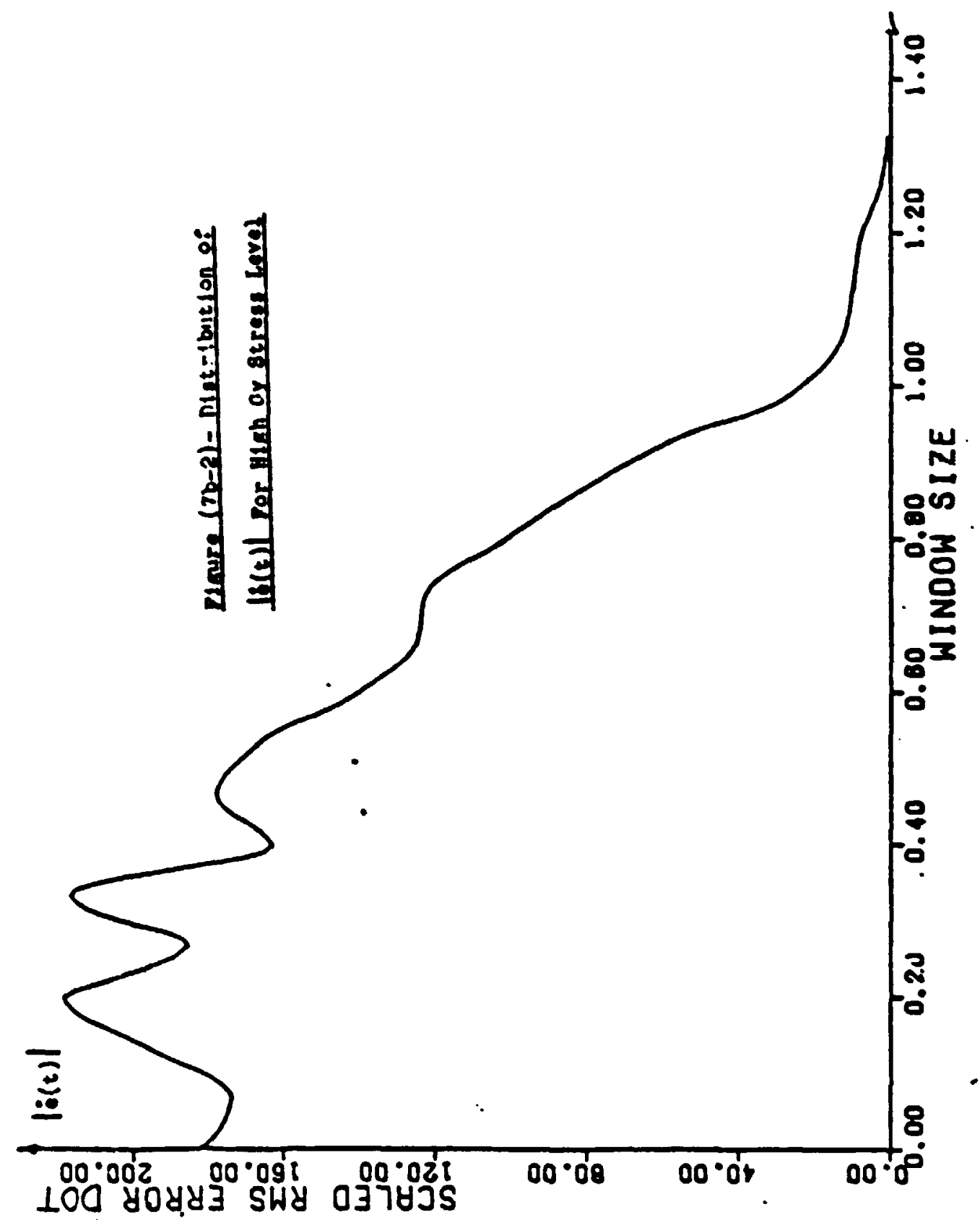




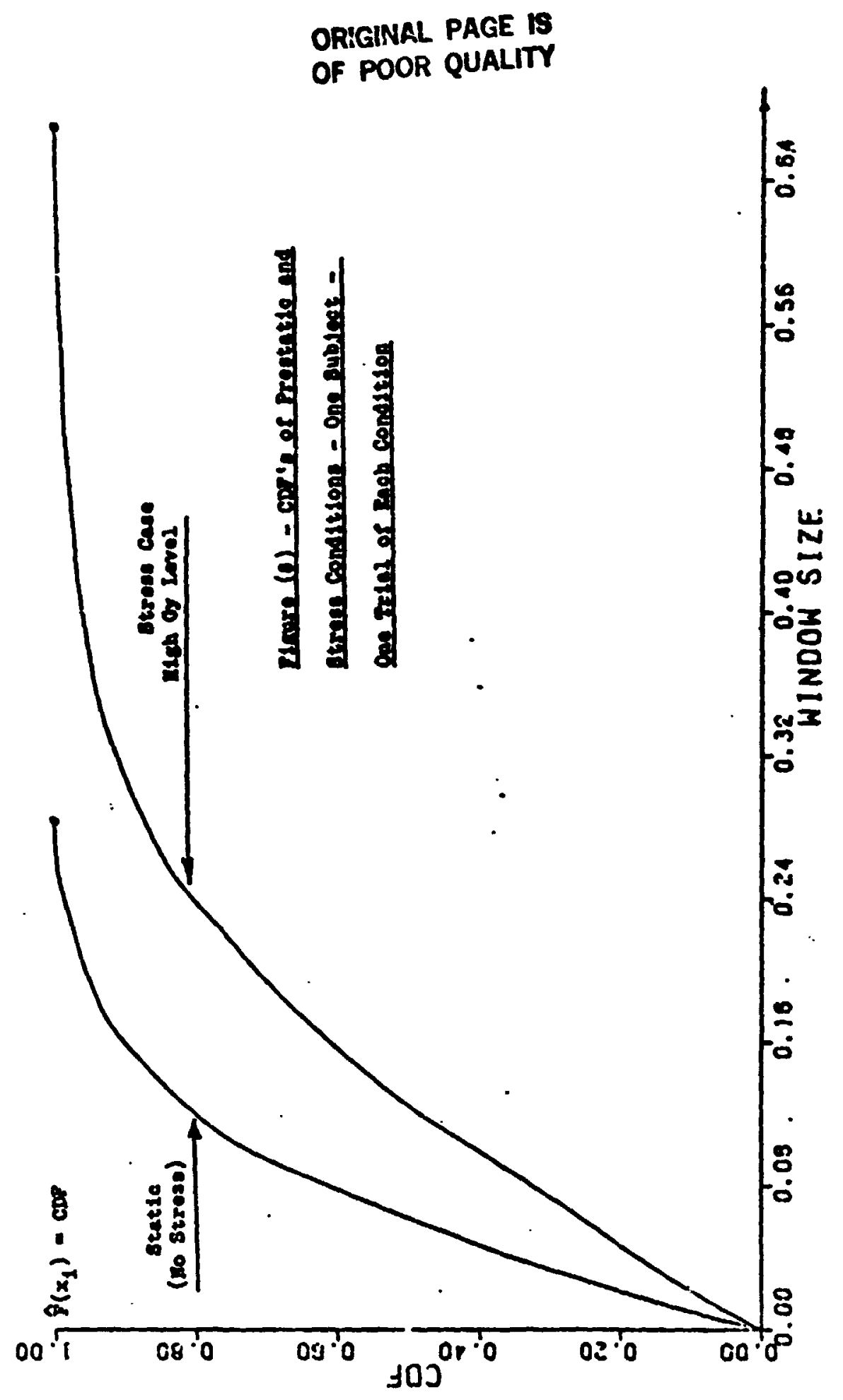



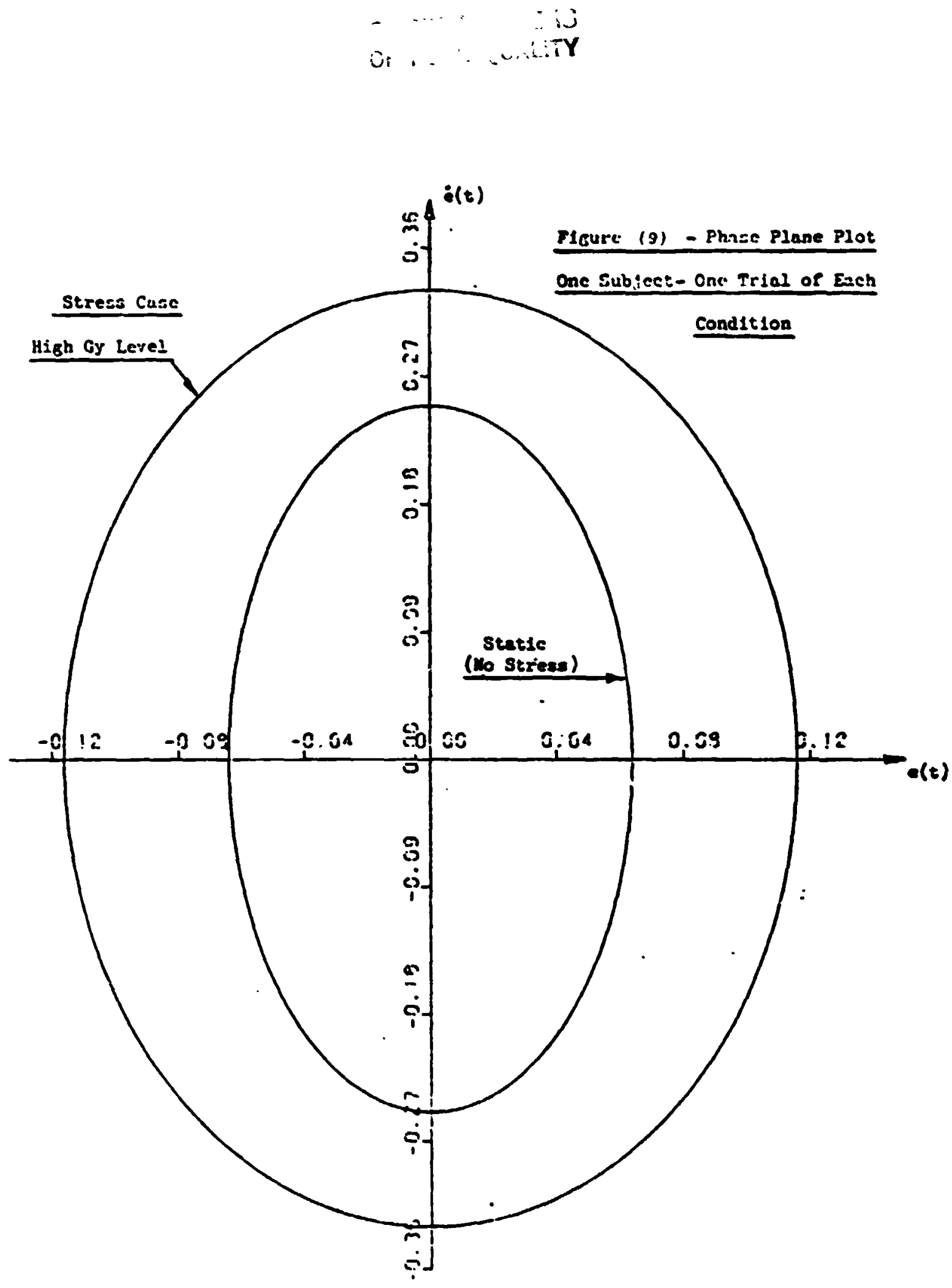


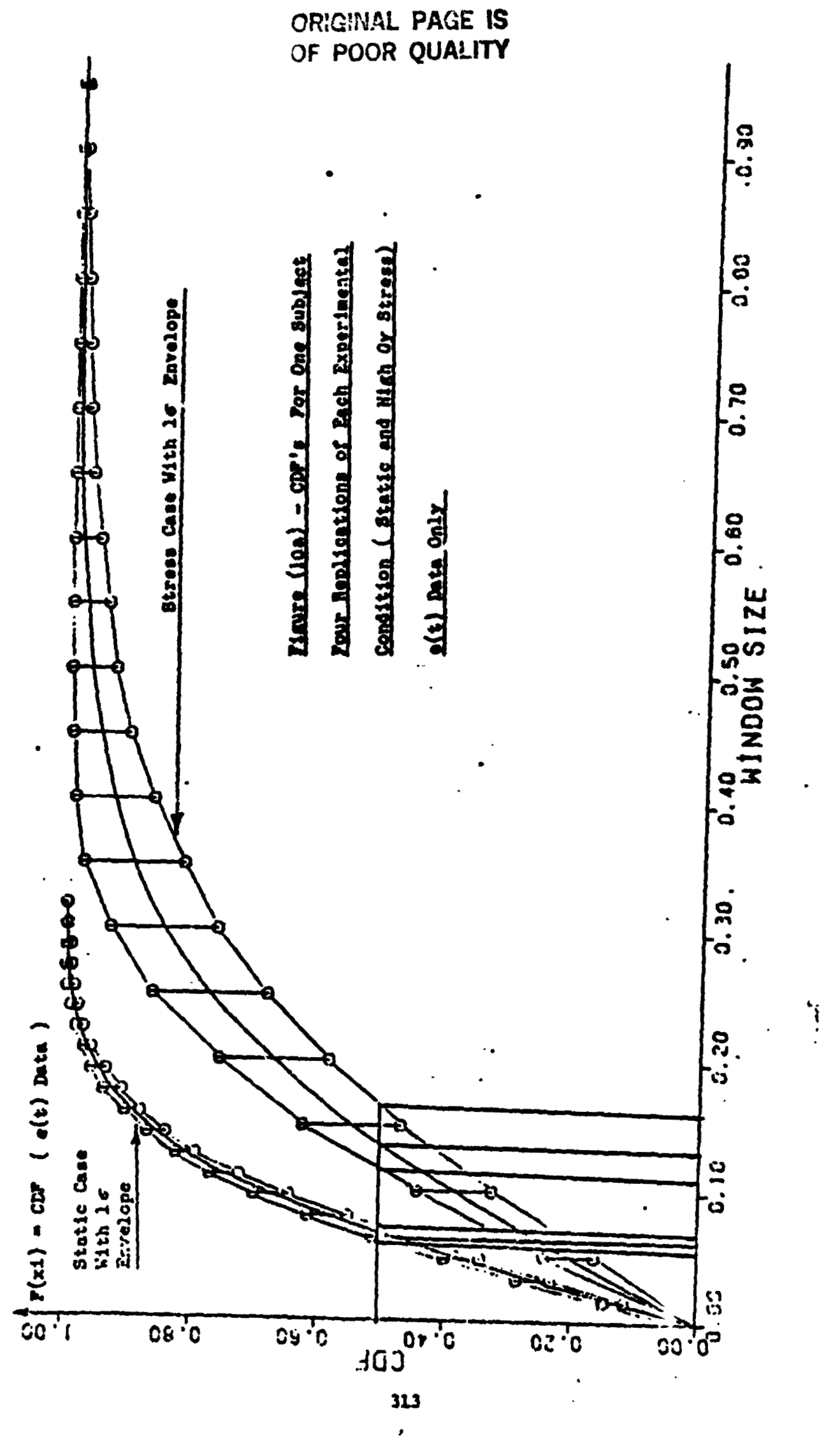




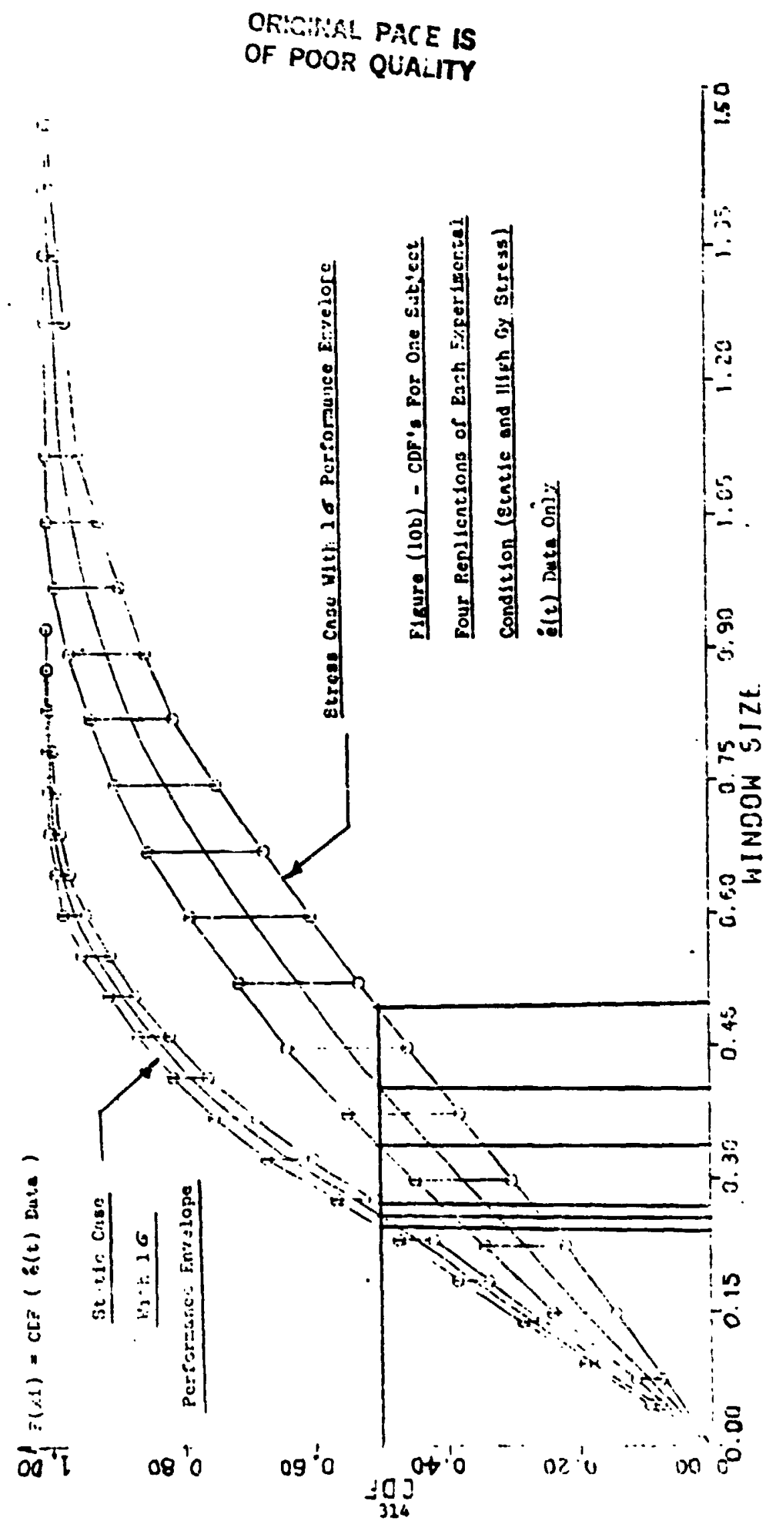


ONGGINAL. PAGE IS

OF POOR QUALITY

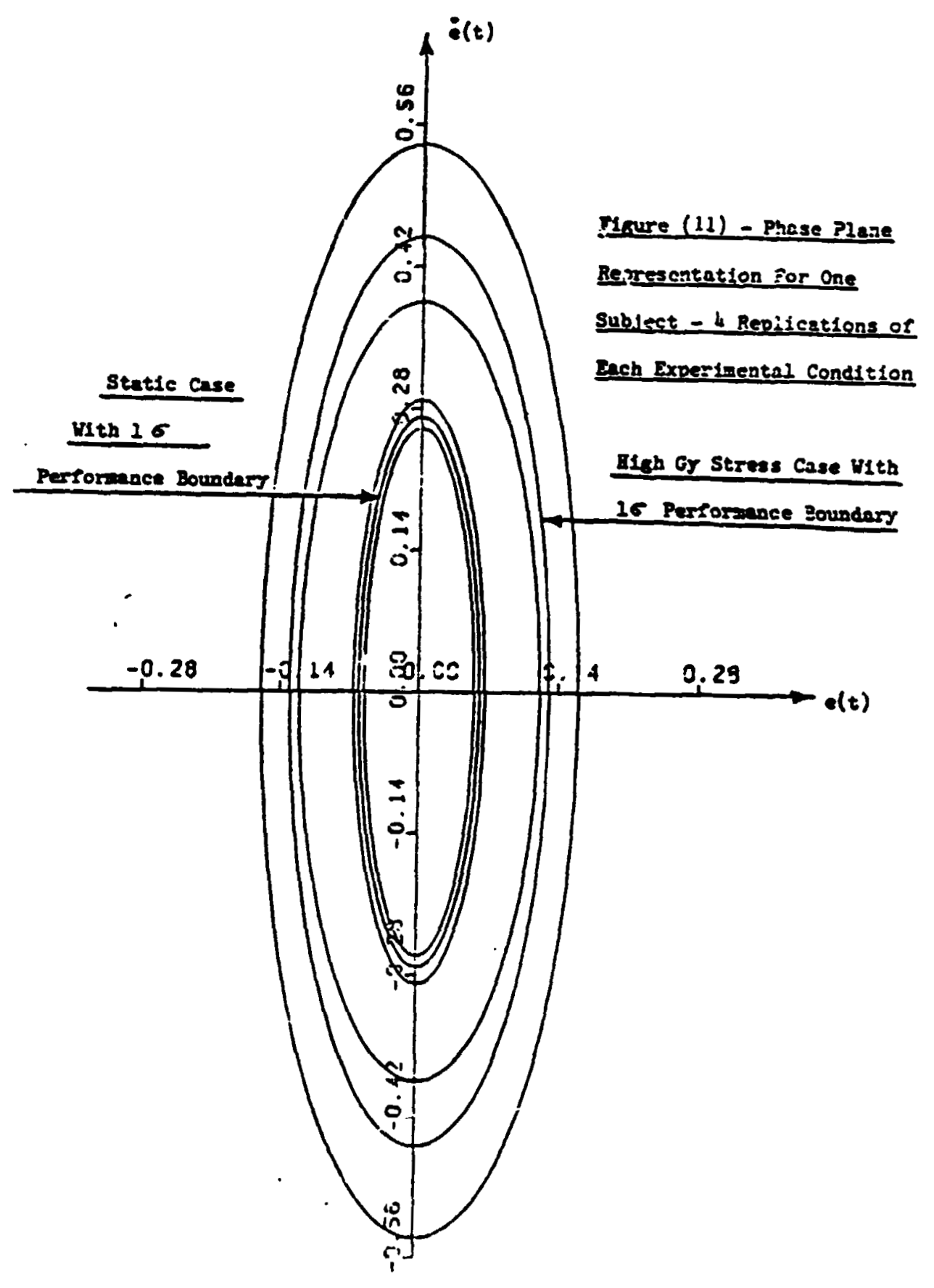




\title{
A LTIEARIZED NODEL FOR VIBRATION EFTECTS
} ON THE EYE CONTHOL SYSIHYY

Raymond E. Bagdaleno

Henry R. Jex

Systems TechnoLogy, Inc.

13766 South Hawthorne Boulevard

Hawthorne, Callfornia 90250

\begin{abstract}
In a recent report* the euthors presented a model "BIODYN-78", for the biomechanical effects of vertical vibration "feedthrough" to a pilot's control actions and head bobbing motions. The effects of the absolute and relative motions of the head and display on the eye's (image) motion were outlined there in block diagram form, but the element dyamics were not complete. In this paper we rlesh out the block diagrams, based on a review of the data and models in the literature, and exercise the resulting model tc 1llustrate some of the basic phenomenn. Although the model presented here is for vertical (heave and pitch) ribration, its form is equally suitable for transverse (sway and yaw and roll) and fore-aft (surge and pitch) vibrations. In fact, mach of the data on eye response to head motions comes from yaulng experiments. The basic assumption is that the vibratory motions produce small perturbations around a "trimed operator posture, so that the equations of sensorimotor control can be linearized about each operating condition.
\end{abstract}

The model formulation for vertical eye movements has been guided by work of Benson and Barnes (1977), Dallas and Jones (1963), and our interpretation of eye muscie dynamtes from Robinson (1971). Dallas and Jones presented some frec. cy resporse data for eye response to both sine wave and random forcing functions. The low variability of the latter set fustified using a proprietary model fitting procedure (MPP) to investigate model element forms involved in the fixation reflex.

The model is exercised to reveal qualitatively wat Lappens in a number of special cases of rrequent interest, such as: moving target with head IIxed; moving head with target fixed, and both head and target woving (e.8., head mounted displays). The risual performance implications of the model's image motions are consistent with the related experimental data of Benson and Barnes (1978), on letter reading performance.

\footnotetext{
* Jex. Henry R., and Raymond E. Mgrdaleno, "Biomechanical Models for Vibi stion Feedthrough to Hands and Head for a Sintsupine P1lot," Aviation, Space and Envirommental kediclne, Volume 49, No. 1, Section II, Juruary $197^{8}$
} 


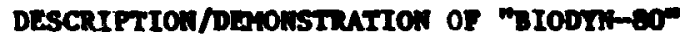

A Sof tware Package for Evaluating the Tranamiasibllity Between Vehicle Vibration and Motions of Handa (In wntrols),

\author{
Limbs, He: $t$ and Eyes
Susan A. RIetel, Henry R. Jex, and Raymond E. Magdaleno \\ Systems Technology, Inc. \\ Hawthorne, Callfornia 90250
}

\section{ABSTRACT}

A user-orlented program for exercising the 1980 version of the STI blodynartic model "BIODYN-80" has been completed under the sponsorship of the US.AF/ ARL, B10Dynamic Branch. The user 1r.puts (modiftes) some 80-!00 variables describing the assumed posture, Interface charecteristice ie.8., stick "feel" properties), and vestibular characteristics. ine computer calculetes the transfer functions between vibration input and varioun selected outputs of interest to the user. Another opt_on 1s to output the operator' torso-11mbneuromuscu'ar loop transmiselbilitis as seen at the stek, as required for the NIRL/BBN "PIVIB" corputer progran for computing tracking performance effects of vibrution. Applications to some current problem will be demonstrated.

\section{Drmoovertom}

BIODYN-80 is a computerized tool used to compute transinisibilities (transfer functions) between vertical and/or fors- 't vibration inputs and varlous blodynamic outputs, such as notlons of the torso, head, eyes, artws or hands. The sttuation covers a seated pilnt gripping an arbitrary angle stc': and viewing a display, possibly engaged in tracking task. The physical model uses an isoworphic, "lumped parameter," approach to rapresent the doulnant whole-body joints and resulting nodes of motion. he sof tware model includes a chain of interacting parallel and serial second-order elements, with complex neuromuscular and force feedbacks at the arm ard head. The resulting equations are in "second-order element" matrix form and are fairly general. A separate Input f1le, which describes the particul..: set of parameters to be used, is created by the user (usually by nodifying one of a cataloged set). This file 1s Incotporated in the antrix to produce the linearized coefficlents for perturbations about the selected equilibriun postur

"Th1s research is sponsored by the Alr Forie Neromedical Research Laboratory, Wright-Patterson AFB, unider Cont-act F33615-79-C-0519; the technical montior is Charles Harmon. 
Cramer's nule is used to evaluate the desired transmissibility trsnsier funcclons, and these are uritten to flle in forats sultable for plotting or use in other proxrams. Typeuriter-drawn frequency response plots (Bode format) are avallable to screen interestiag results.

BInOY:- : gne result of a several year tevelopnent effort, reported in

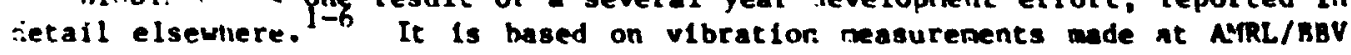
and elseuhere. Most of the torso, $11 \mathrm{mb}$ and stick model elenents haye been validated by independent vibration measurements (e.g.. Jex and Allen'), and the neck, head and eye effects show proalsing currelations with the fer avallable measurenents on Image mition effects. "However, many aspects remain to be explored, valldated or "graded as more experiments are cun and 1aterpreted via BIODYI-BO.

The possible applications of this interactive tool are many. It should be helpful in the early stages of experinental design for determining the optinal locations for vibration mensurenents and/or selection of frequencies. It can be used by developient engineers for solving practical pllot-vehic' incerface design probiess such as pllot-induced oscillations and for choosi. the best anong design alternatives such as seating location, ortentation and suspension parabeters. Flight control systen dealgners can make use of BlODN output in optimizing vehicle/aircrew ride qualities and visual perforance effects, posatbly incorporating anci-vibration devices to inprove the destgn. These are but a few of the uide range of potential applications for this couputerized, Interactive model.

One further application of BIODN-80 deserves special aention. Its vibratlon-input ti blodynamic paraneter-output transfer functions are ideally sulted as Input to PIVIB, another software package wich relates pllot trackIng peiformance to th vibration environment. Inputs to PIVIB require blomechanical cransfer functions which are output by BIODN-80. The detgils of the "IODYN-80/PIVIB Interface are found in the BIODM-80 user's manual."

Figure 1 providea functional block llagran deacription of the elements in sIonn ain lis incerface with PIVIh. The realinder of this report detalls the nee of BIODYN-80, Including the molel used, the creation of the requited input flies, an exanple problem from stait to finish, and a suggested interpretation of results.

\section{ovrenith}

The BIODYN-80 package is comprisad of three prograns. The first, called CREATE, interactively assembles the two input files used by BIODry. The second, called BIODY, is the actual "number cruncher," which sets up ami solves the slomecharical equations and corputes the desirad tre-sfer functions. The third, called PLOT, reads the file of sIODN transfer functions, prints selected ones in a form readily comprehended by the user, and prepares "quick plot" Bode plots on the line printer, to facllitace a visual interpretation of the transfer function Information. Both BIODYN and PLOT are deslgned as batih program while, as stated sove, CREATE is user-interactive.

A subequent link in this series of program is PIVIB. It is a large batch program with three udules. The first, BDiOD, conputes the reaponse 
ORIGINAL PAGE IS

OF PCOR QUALITY

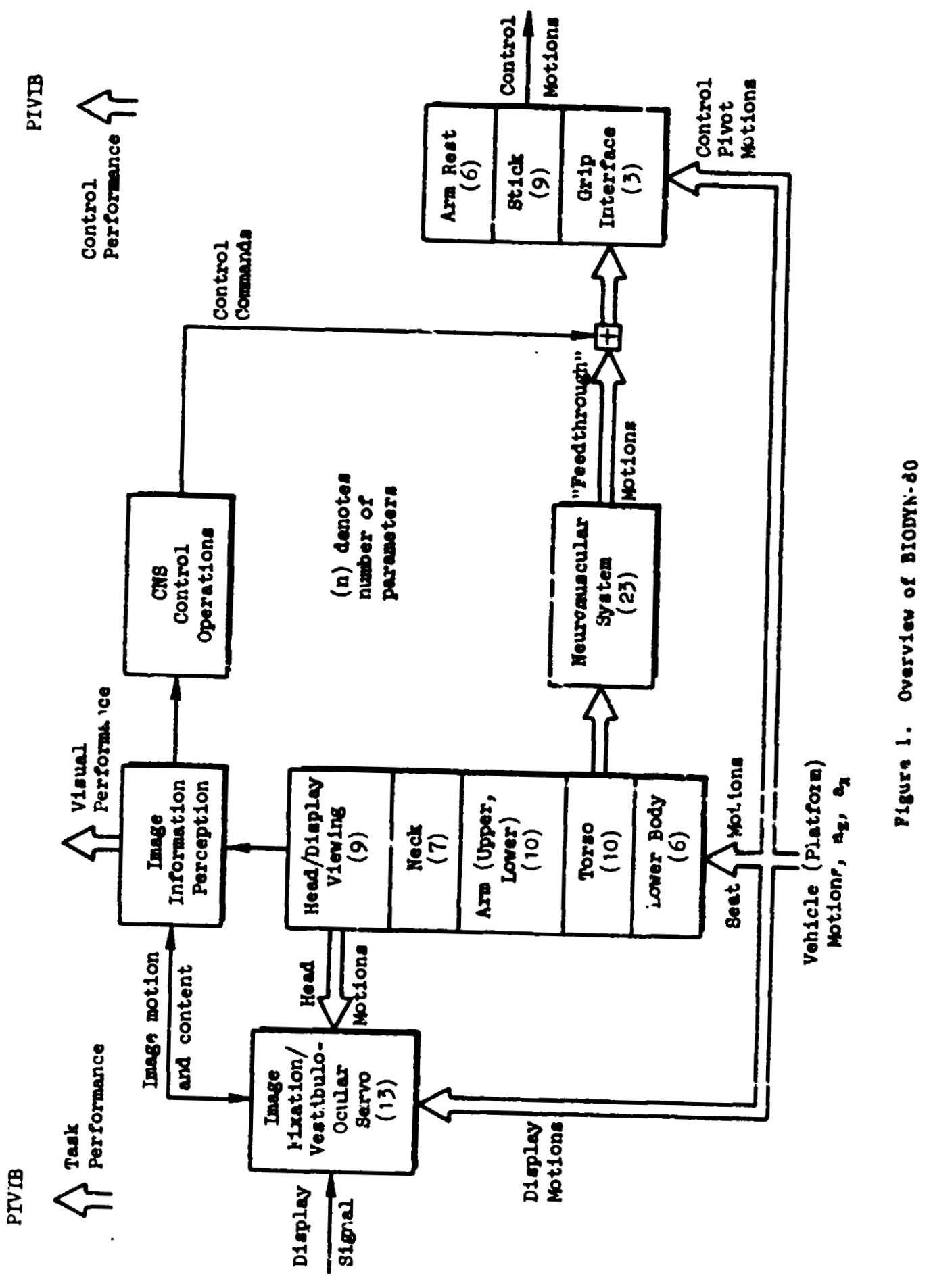


behavior of the various blonechenical subsystens. The second, PViod, uses the results of BDiton and the BBN optimal control nodel to estimte pilot tracking performance within the vibracion envitonment. The final nodule, VExec, provides the top level communication Interface between BDiOD and PVIOD, and performs no actual conputation. It 18 in the Boind module where biodynanic transfer functions must be specifled, and this is the location of BIgDYi-PIVIB interface. Further detalls may be found in the PIVIB naer's anual."

BIODYi-80 uses three separate files in the process of performing its computations. The PARAIETER file contains the set of 96 paraceters used to define the specific ptlot-posture-vibration-display configuration. CRFATE Is used to assemble this file and can modify an existing file or produce an entirely new flle. The cholCES file contalns the list of destred transfer functions to be conputed and output by BIODYN, se well as directives for producing the line printer Bode plots. Again, this CHOICES file is asseabled by CREATF. Finally, the tF flle is used to store the resulting transfer functions output by BIODYN, and is read by the PLOT routine for generating the Bode plots.

PIVIB eaploys single large file to direct lts flow of execution. ithis file defines the vibration environaent, blomechanical transfer functions, tracking dynarics, tracking perforance requitements, and pllot lialtations (bandwidths, time delays, etc.). Currentlv, this file is assembled in the editor, using output fron BIODYN-80 if desired.

BIODYA-80 and each of lts predecessors were developed on the Trmohare, Inc., PDP-10 computers. BIODYN-80 has been adapted to the COC 6600 conputer at WPAFB in order to Increase its avallabllity to AIr Force users, and to interact with PIVIB, also resident on the WPAFB CDC computer. The detall. presented here will address its use on the CDC machine.

Figure 2 presents flow chart lllustrating the use of BIODTw and PIVIB in a given session. Note that the flow of execution can be used to solve single problew, by submitcing a single batch requeat, or to iterate on a design by submitcing a number of batch requests using the same choices file and slightly altered PARAIETER files.

\section{HODEL Descriftion}

Three distinct subsystem models are included in BIOOYN-80. They are described individually below.

\section{Blonechanical Model}

Figure, (updated fron Fig. 2 of Ref. 3) presents the blomechanlcal model and def Ines many of the necessary parameters that describe the nominal (or trin) sltuation. It utilizes an "isonorphic," or llfe-like representation, of the mafor body segments in thelr orlentations, slmplifled to a rinimum number of lumped parameter equivalents. The blomechanical features include: 


\section{ORIGINAL PAGE IS \\ OF POOR QUALITY}

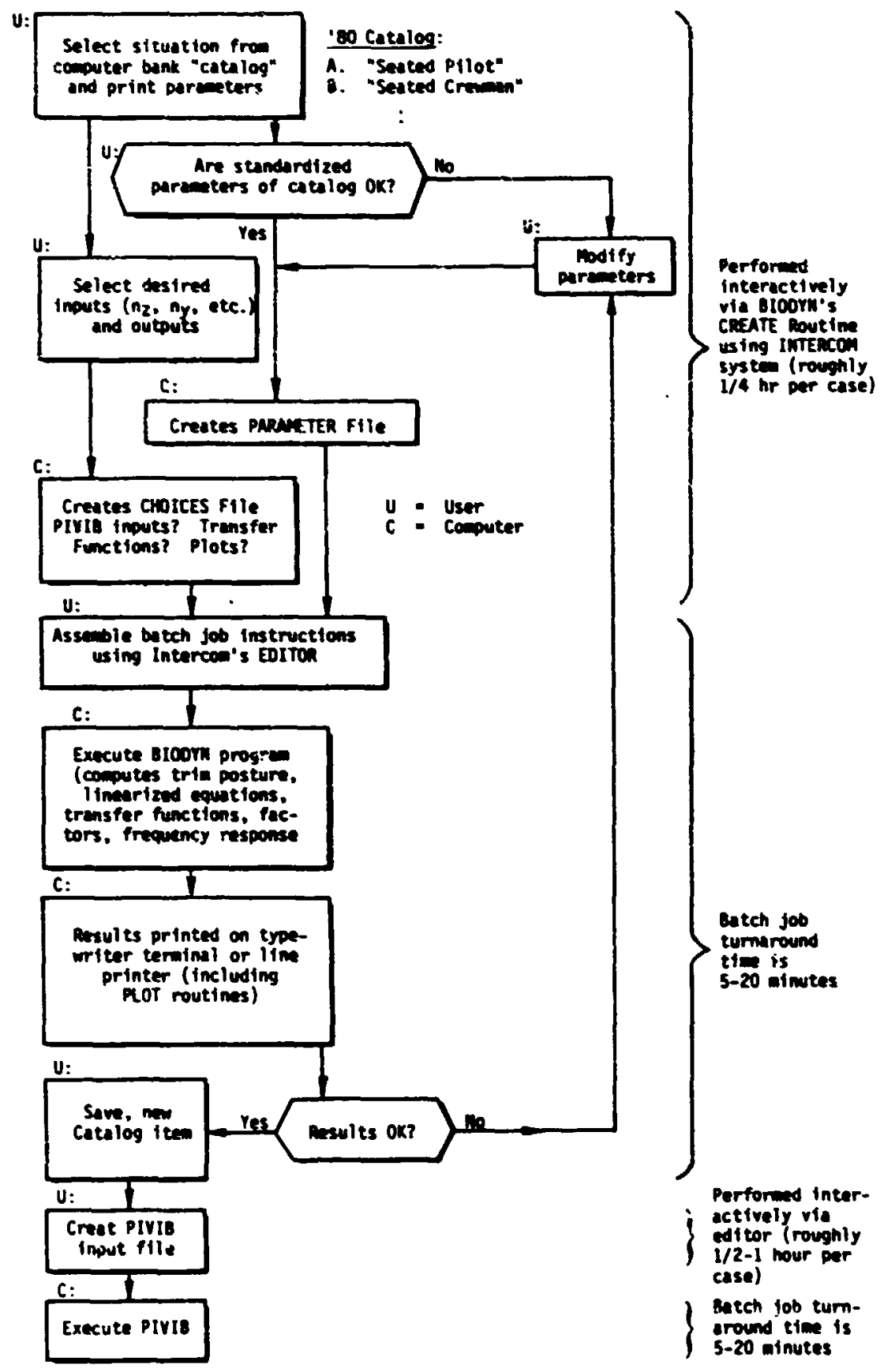

Figure 1. BIODNi-80 Flow Chart 


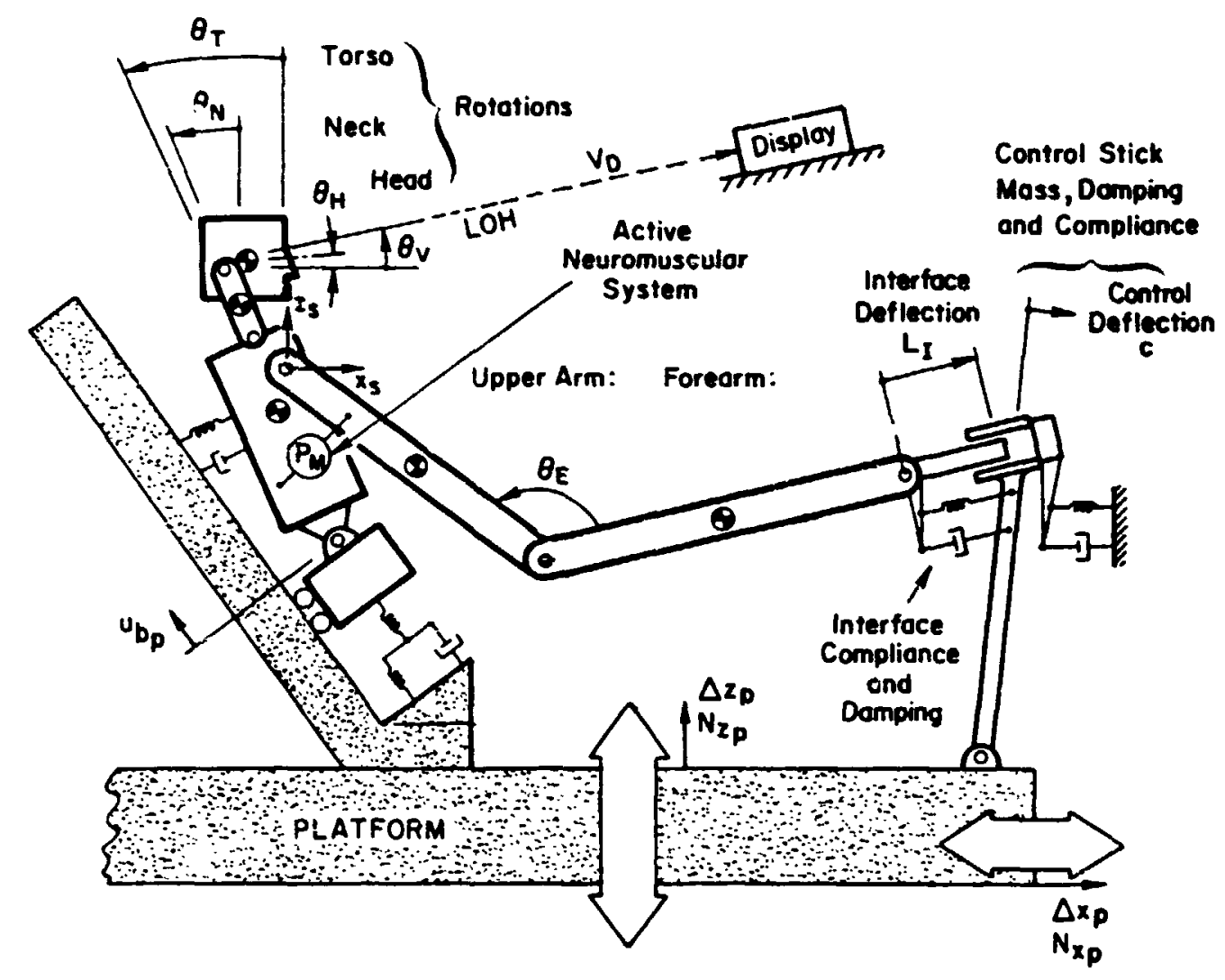

F1gure 3. Major Bionechanical Elenente (Sc:Response Varlables Are Identified) 


\section{GitivivaL PAGE IS \\ OF POGR QUALITY.}

- Senisuplne torso; sliding hip plus rocking chest supported on a compllant buttocks/seat.

- Head bobbing on an articulated neck with pasalve compllance, or active neuromscular system.

- Upper ara and forearm links plus grip-interface corr pliance, driven by an active neuromucular system.

- Arm-rest restraints (optional).

- Stick "feel systea" dynanics from zero to infinite stiffness, and any angle of stick or grip.

The siaplified torso nodel was derived to describe the dominant motions of the head and arm elewents; the "pin jolnt" node between upper and lover torso segments is not meant to represent any physical feature. In practice, the masses and Inertias are obtained from tabulated blowechanicyl and anthropowetric data for the approprlate aled person (e.s., Magdaleno'), the postural angles are based on the actual stcuation (preferably via a side-view phota), and the spring forçep and damping coefficlente are ficted to data or taken from other wotions. 3,10

\section{Limb Neuromuscular Model}

The active neuromuscular system noted on Fig. 3 is a shanatic representation of the net effect of coaplex agonistiontagonist mucle pairs controlling

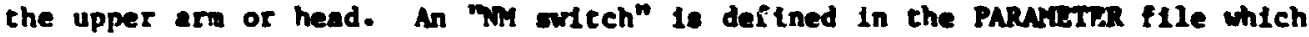
causes this neuromuscular model to control the :1mb (MA - O) or the hend (NM 1). A linearized representation of the limb neuromiscular nodel is show in F13. 4, while the head neuromacular bodel 1s depicted in Fig. 5. This nodel relates the ection of the uscle palrs to the effective (opindle) sensors of wuscle length and force as well as proprioceptive senses from the stick-grip Interface (In the case of the limb neuromuscular model) or the head-neck interface (1a the case of the head neurocuscular node1), to coaplete the loop through central nervous system processing.

Unless the neuromuscular properties are bying investigated, it is recommended that the given values of the parameters be used. They are representative of a normal person's arm-hand or head-neck syatem, and generally yfelt reasgnably damped neuromuscular cervo properties. The neuronuacular paran:ters ${ }^{8}$ are characteriscle of the largest muscles in the body ( $. .9 .$, the legs) but experience has show that the dynamic properties (torque/inertia ratios. damping ratios, natural frequencles, etc.) are about the same for all postural muscle pairs. Here, an empirical ecale factor $S(>1.0)$ is used to scale the norwalized wacle to particular configuration, whough the musle acied normal to the upper arm fi $^{8}$. More detalled description of the neuromuscular 
CRier:- PAEE IS

OF Fo TH QUNLITY

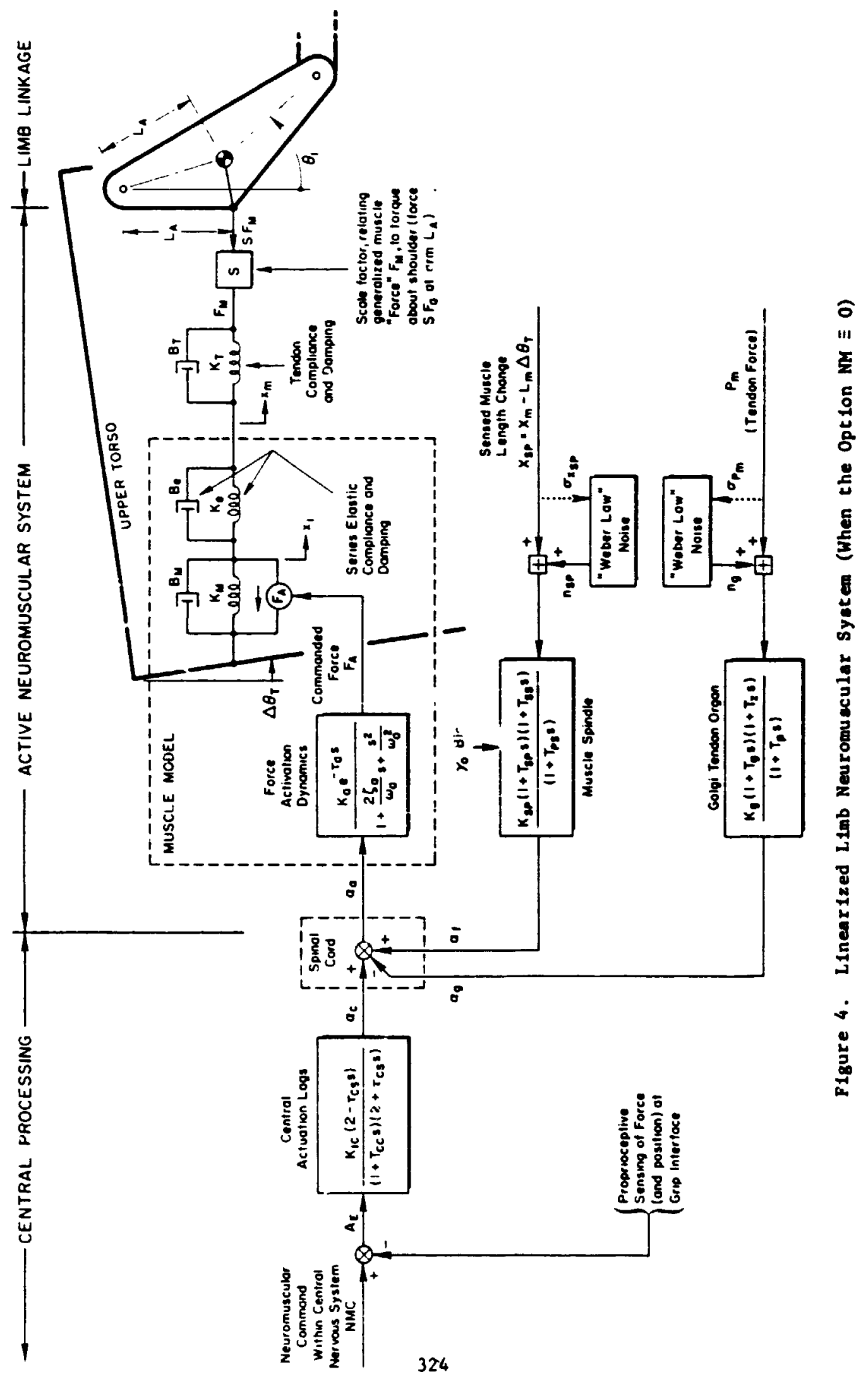


OniGritat. PACE IS

OF POCR QUALITY

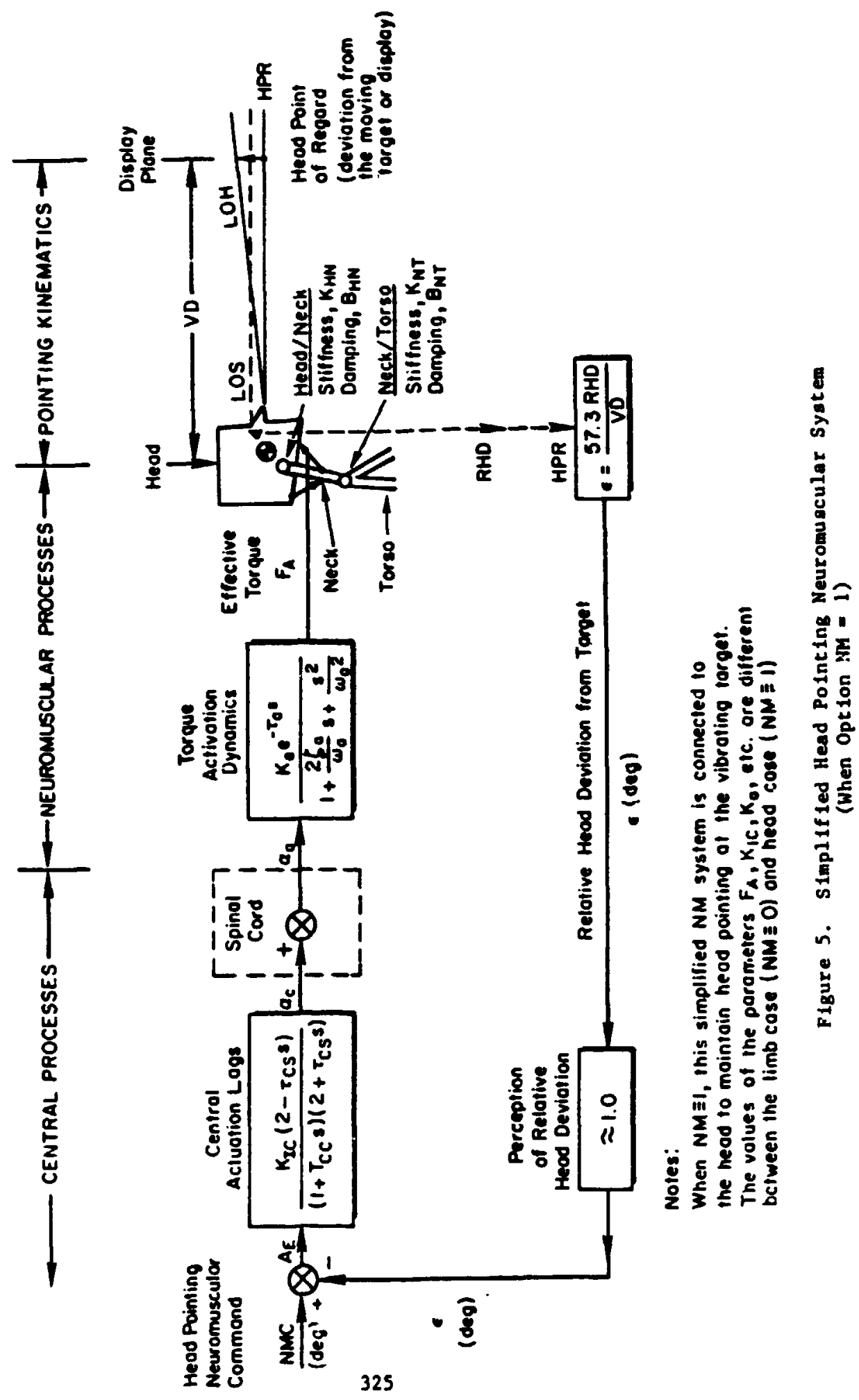


Neck/Head/Eye Model

Figure 6 illustrates the basic elements involved in the neck/head/eye nodel. Detalls involving validation and exanple use of this subsysten model are found In Ref. 6. The task is to keep the eye flxated on the target, 1.e., null the relative eye (point of regard) deviation (RED) at the display. The moving base can produce image error disturbances, both from Induced head rotation and translation as well as target motlons. The "vestibulo-ocular reflex" $\left(C_{v} G_{y}\right)$ is a "crossfeed" (or "feedforward") that rotates the eye oppositely to the head to compensate for head rotation, l.e., to maintain approximate inerthal eye fixation.

The "Flxation Reflex" or feedback tracking loop $\left(G_{E} G_{Y}\right)$ involves the subject's efforts to null the image error $\theta_{I}$ by conpensatory eye novenents. The "Target Pursult" path $\left(G_{p} G_{p}\right)$ models the subject"s "feedforward" operations on the perceived absolute target motions in inertial space (as distinct from the image error motions). For highly predictable a.d percelvable target notions the Target Pursuit path is capable of greatly reducing the Image errors.

The linearized model formulation assunes that the target remains within the foveal area ( $3-4$ deg fleld), and that angular velocitles are sall (1.e., less than $20 \mathrm{deg} / \mathrm{sec}$ ) such that saccades are rate and can be 1 gnored for most purposes. Additionally, the vibration-induced motions will always be small enough to peralt linearization of all angular functions and allow quasilinear representation of the dynamlc elements about each "operating point" (posture, view georetry, frequency).

The three subsystem models described above contain parameters which mast be assigned values via the PARNIETER file, in order to describe the desired problen to BIODYN. These parameters are defined elsewhere.

\section{Al EXMLE RROBLA}

This section presents a typical terminal session in the Intercom 4.7 operating system, accessing the CSA mainframe at Wright-Patterson AFB's ASD Conputer center. The dialcg is annotated so that a beginning user can follow the entire job from start to finlsh. All user responses are underlined.

This particular session on the computer was an Investigation of the differer.cas in the DTH/DXP and RHD/DXP transfer functions between a pllot in an ere:: orlentation and a pllot in a senisupine orientation. Only two parame2.r3 are changed: in the erect posture, the angle between the torso-c.8.-tohips pivot and vertical is $10 \mathrm{deg}$, while in the senisupine posture the angle 18. 65 deg; and in the erect posture, the angle between the head c.g. and head/neck pivot is $70 \mathrm{deg}$, while in the semisupine posture the angle 18110 der.

The steps followed in the investigation are listed below:

1) Los in to Intercom.

2) Attach the PARAMETER file to be modified and name it TAPE20. 


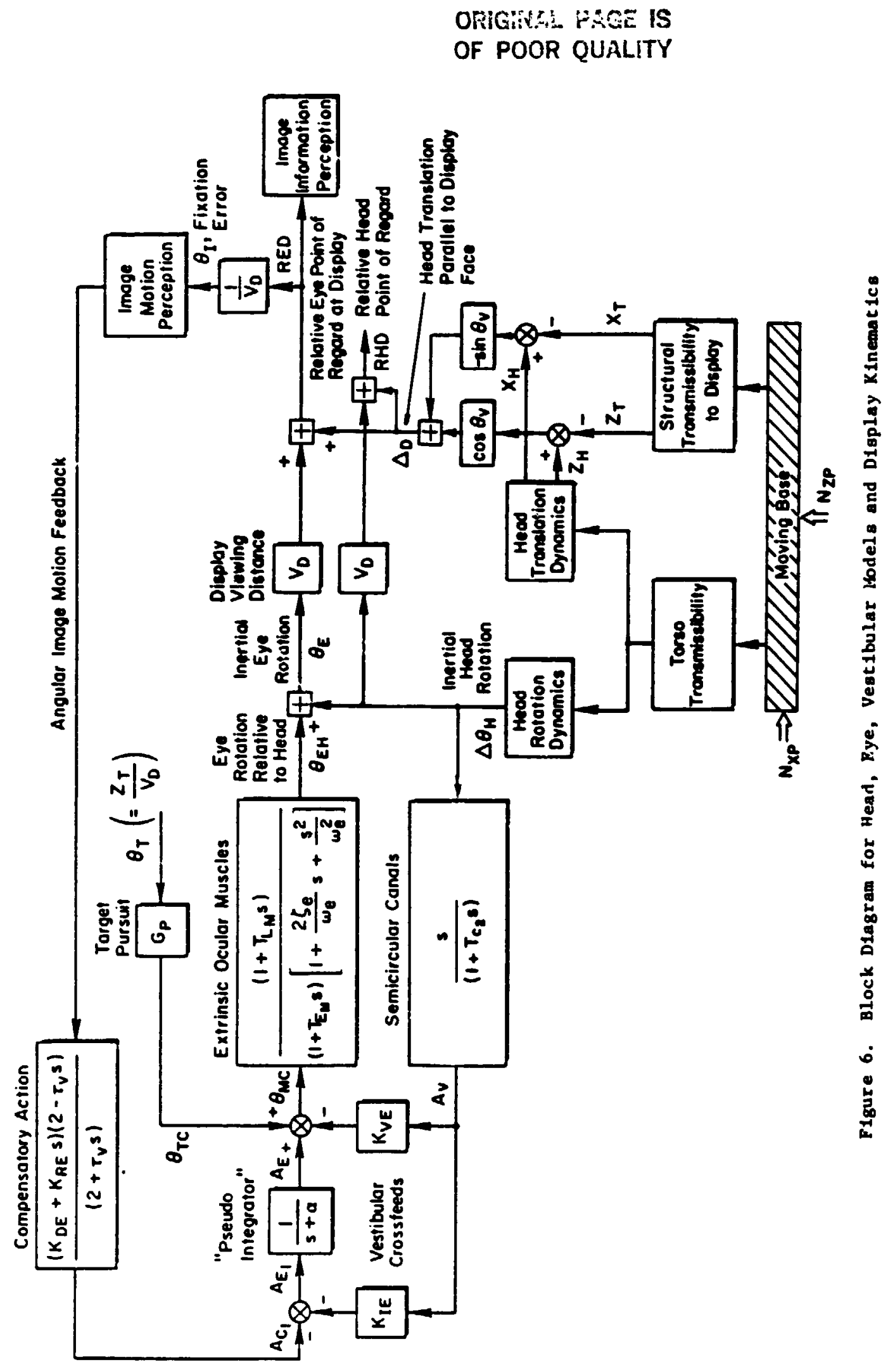


3) Attach the CRFATF program, called F.XECRT.

4) Run EXECRT, make changes to existing file, assemble new CHOICES file.

5) Assemble batch job to run BIODYN and PLOT, using the two PARAMETER files (old and modifled) and the new CHOICES file.

6) Subrit batch job to input queue.

7) When job completed, 11st the output file.

\section{ADDITIONS TO BIODTH-80}

Three areas of interest w11l be investigated to improve and update the sof tware package described herein. These include:

- Validation of the head/eye/display model. BIDDYN-80 will be exercised to verify that it correctly predicts past and current experimental data; In add1tion, new experiments will be suggested and performed for any renaining validation areas.

- Extension of nodel. The roll-sway modes of vibration will be incorporated in the BIODYN-80 model, so as to be responsive to experimental interest in lateral-directional vibration. Keen interest in helmet-mounted displays and helmet-nounted sights dictates that this capability also be incorporated into the model.

- Improved graphics outputs. Additional work in this area centers around constructing stick figure graphles on a CRT to display node shapes in a visually compeliling manner. 
ORIGINAL P:ET:-;

OF FOOR QUIALIYY

\section{Typical InTERcom Torminal Sesaton}

\section{LOGIN}

ENTER FROBLEM MUMBER-LBO0015

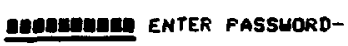

ENTER 3-DIGIT TERMINAL ID-000
1. Log in.

2. Attach files.

3. Attach EXECRT to run CREATE.

4. Run EXECRT.

Get a liating of file to be modified. If response is not recognized, query repeats.

Session continues 


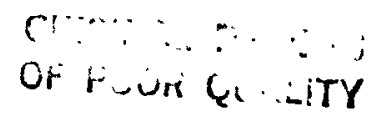

Continuing

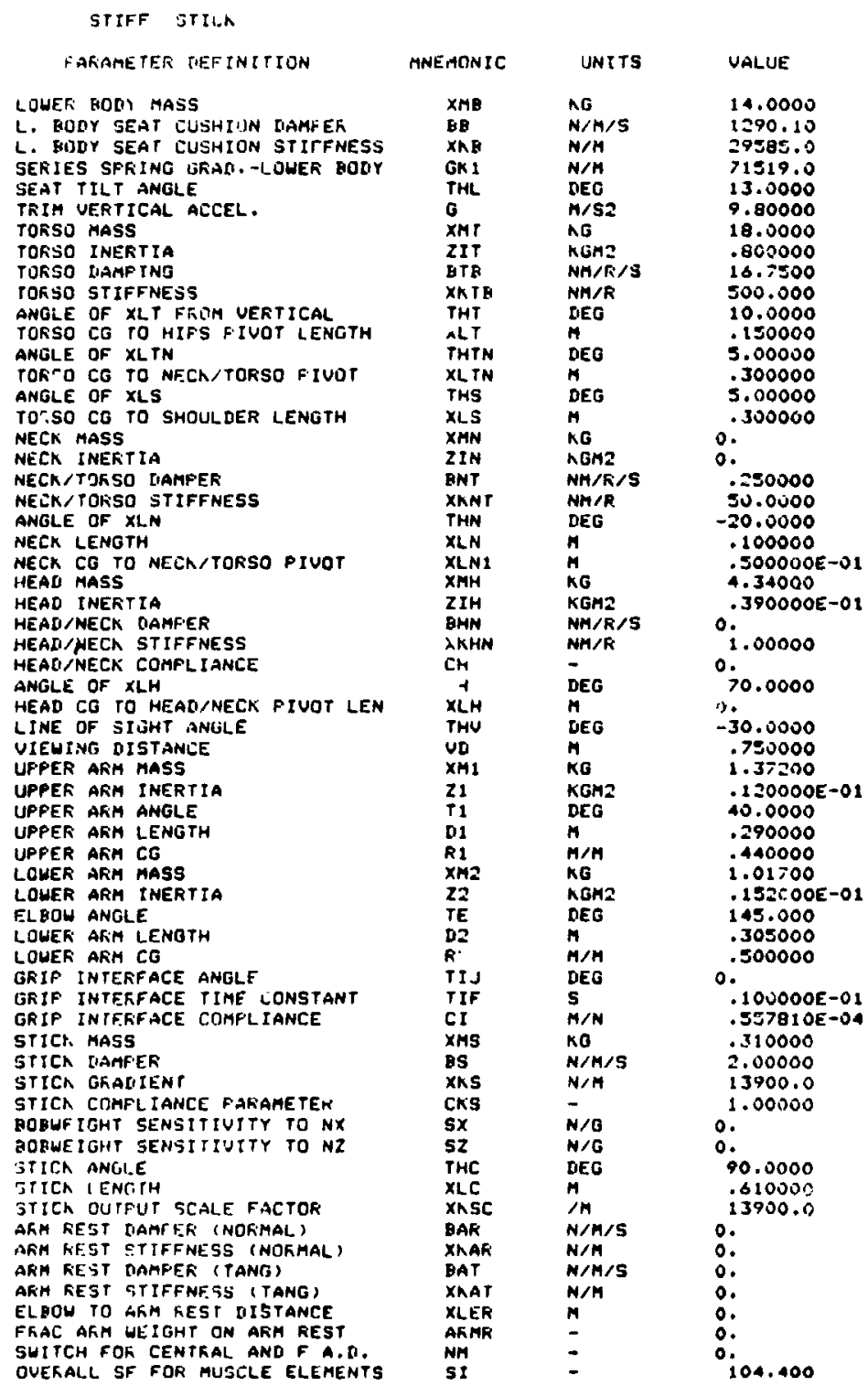

Session continjes 
ORlamerit.

OF PCOP

\section{Continuting}

N/M ACTUATION GAIN

N/M ACTUATION GAIN

N/H ACTUATION TIME TELLAY

GAIN OF F.A.D.

DAMFING IN F.A.D.

IN $F$. A. D

TIME DELAY IN F.A.D.

HTLLS LAL DAMFER

SPRING IN N/A SYSTEM

SERTES ELASTIC ELEMENT GRAD

TENTION DAMPER

SPINDLE MODEL GAIN

SPINDLE LEAD TIME CONSTANT

SPINDLE LAO TIHE CONSTANT

SPINDLE HI FREO LEAD T.C.

GOLBI MODEL GAIM

GoloI LEAD TIME CONSTANT

GOLOI HI FREO LEAD TIME CONST

GOLOI LAO TIME CONSTIN

FIXATION ERROR GAIN

FIXATION RATE OAIN

PSEUDO INTEORa TOR DREAK LOOP

PESDO INTEGR TOR BRE

TARGET PURSUIT OAIM

SENS

PESTIMUA OAIN

EOM LAG TIME CONSTANT

SU LEA TIME COMSTA

SWITCH FOR EOH FAST

EOM DAMPING RATIO

NATURAL FREQUENCY TO EXIT, TYPE XXX.

DHT THS.

HWEMONIC WER MOT PERMISSTBLE. PLEASE REIMPIJT. TH .1100 .

WARNINB - RECOMMENDED RANGE FOR THIS PARAMETER IS DO YOU UANT TO CHAMGE THE UALUE?

re.

PLEASE RETMFUT

IH $\quad 110$.

TITLE IS STIFF STICK

Y.

NEU TITLE

SEMI-SUF INE

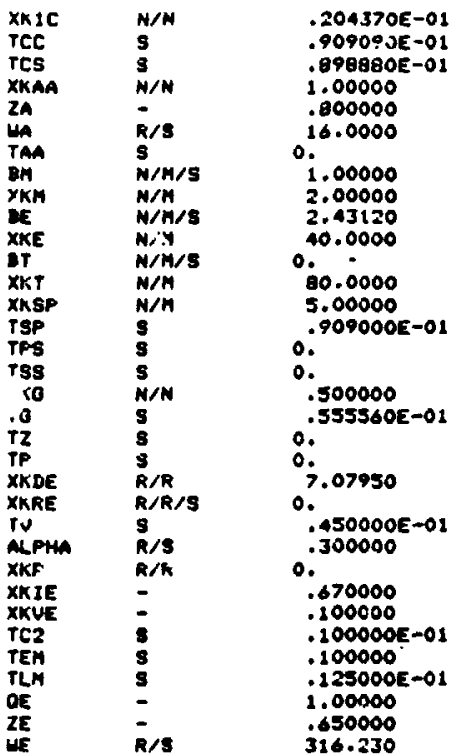

Hodify file

Error aesage if nemonic not recognized.

Aarning if value

Tit1 $\bmod 1 f 1 e d$

Seseion cortinu-a 


\section{Opiginal pace is OF POOR QUAUTY}

\section{Contimins}

IE

ILUNe on ISHIOAT LISITHO

sis

PARAME TERS FOK:

SEnt-sur Ime
Lieting of nodificd fule

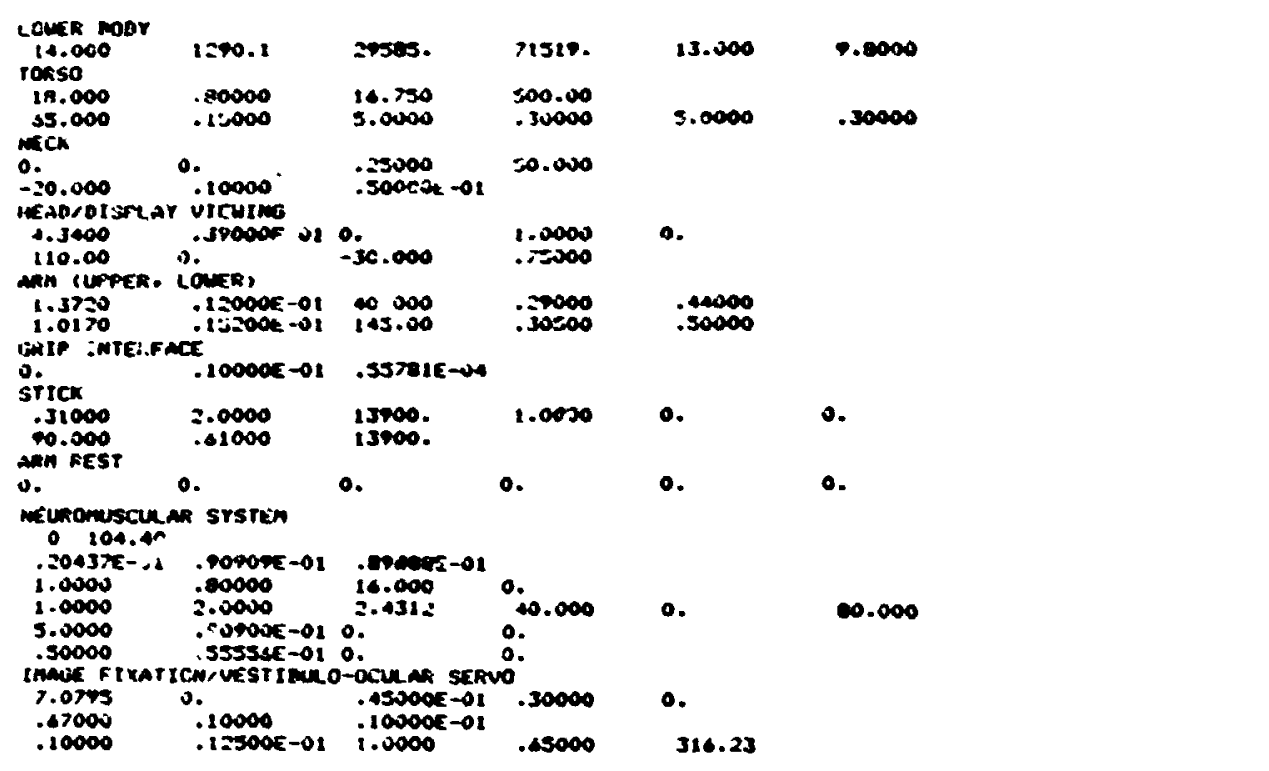




\section{ORIGINAL PAGE LS \\ of POOR QuAmT}

\section{Contsiming}

re

wow antats rthe .

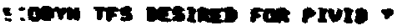

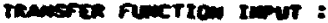

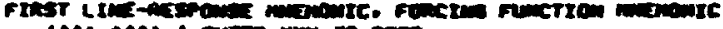

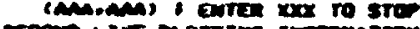

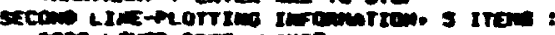

wace conar rave. Cinrt

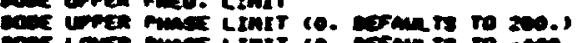

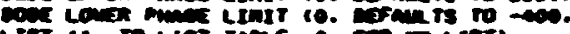

if ist it. To LIST rack.

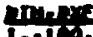

Inetrintenten

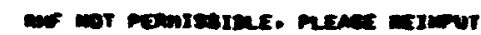

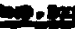

-1.20.0.0.0...1.

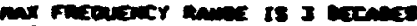

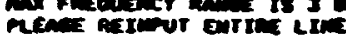

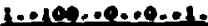

sto.

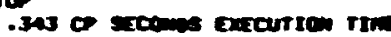

anenil corces etue.

Inocmetens for Inme.

\section{Trror sacenge if}

memente not fown.

Exror navenge if

freprency range > 3 decendes

mere mies. 


\section{ORIGI:IRL FAGE IS \\ OF POOR QUALT}

coatining

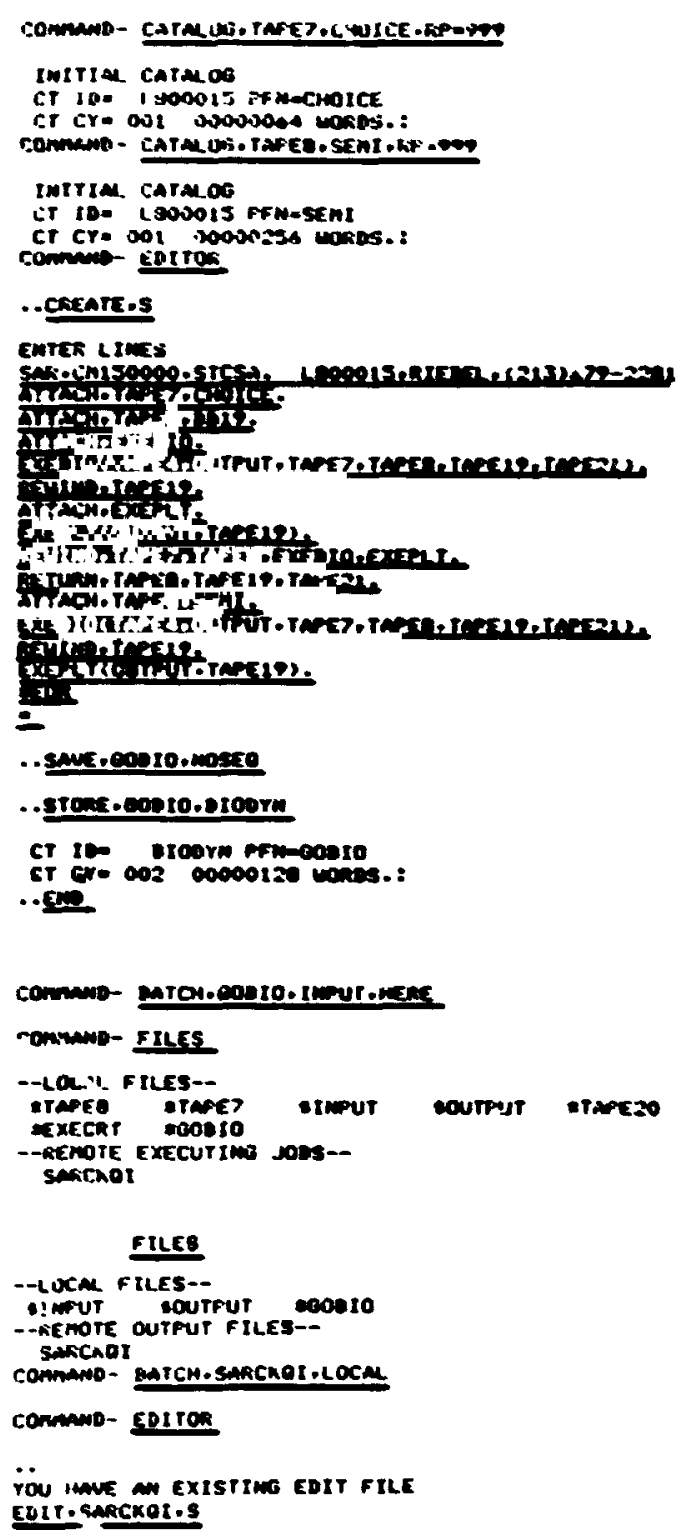

Cacalor Ravirin and Caroras files.

5. Vee Eorton to anemble bech job for ruabing Brojel (wedero) and pwor (D.t.tT).

Dote that BIOUn requites Cans0000.

6. Sublt becb job.

\author{
Iecover outpat flle.
}

Seseion continuea 


\section{ORIGINAL FAGE IS}

OF POOR QUALTY

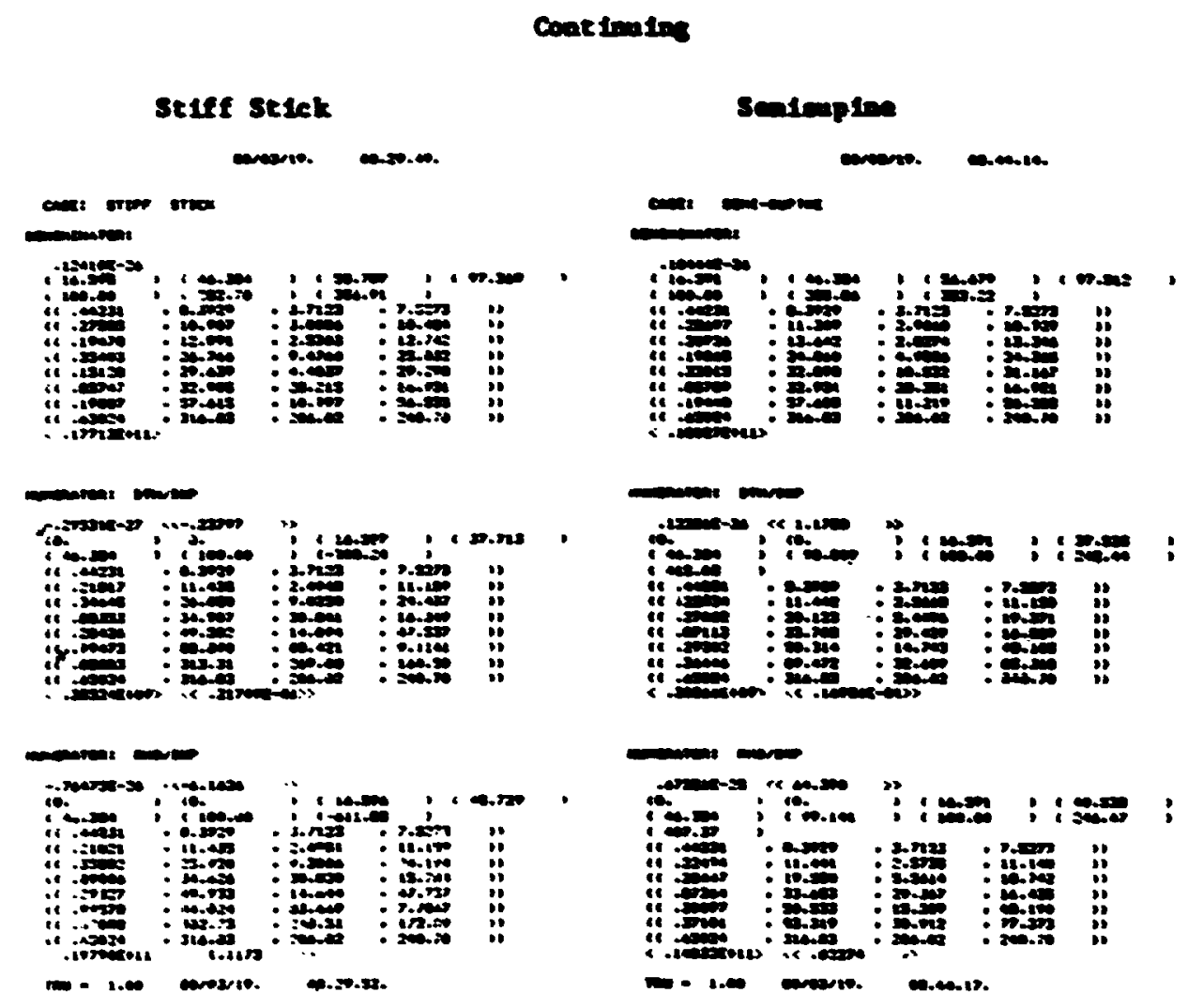

Secolon continen 


\section{ORICNAL PAGE IS \\ OF POCR QUALTT}

\section{Coatining}

Stiff Stich

Senteptos

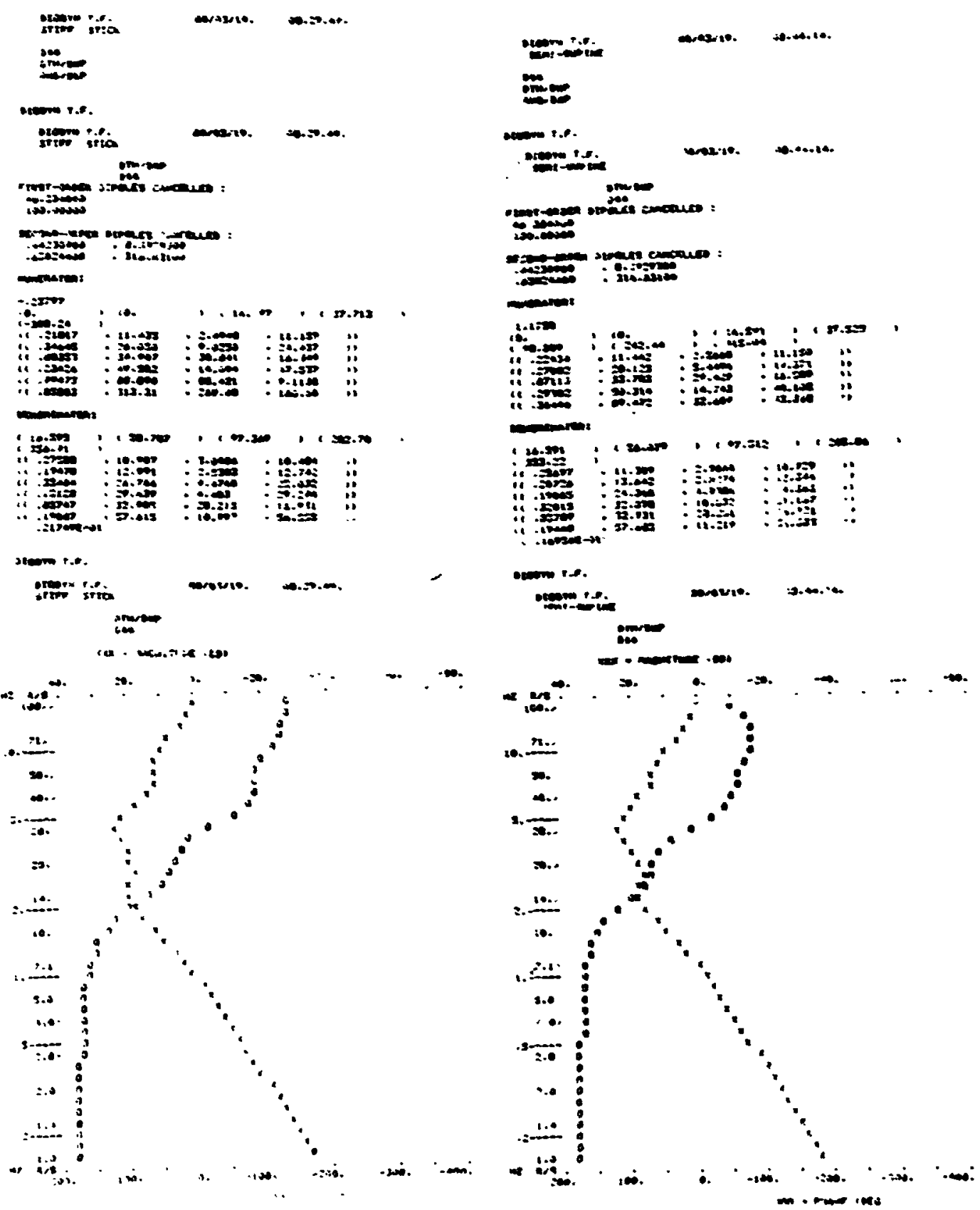

session continues 
ORIGINAL PAGE IS

OF POOR QUALTYY

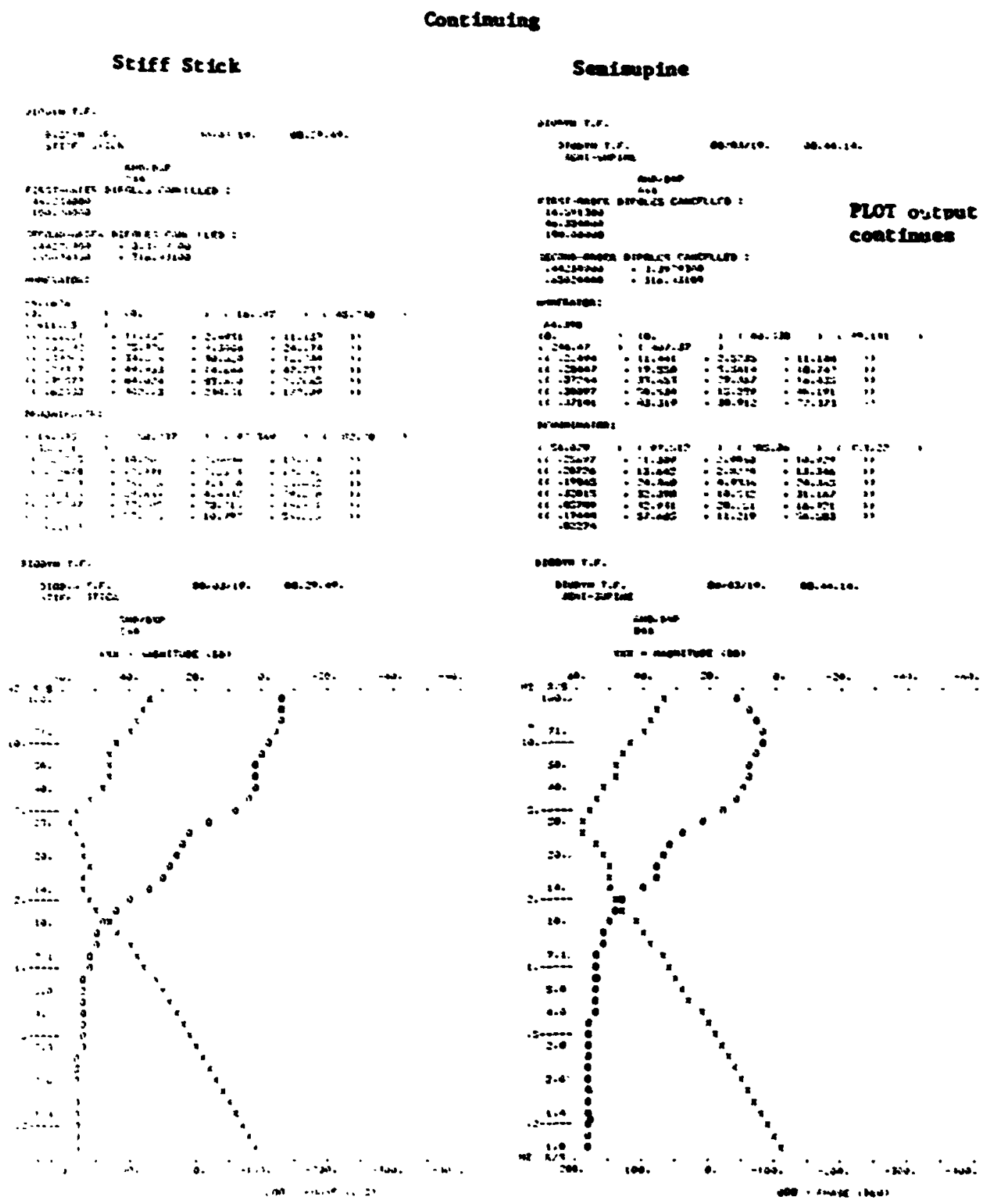

Session continues

337 


\section{CWENH PRGE IS \\ OF POOR QUALITY}

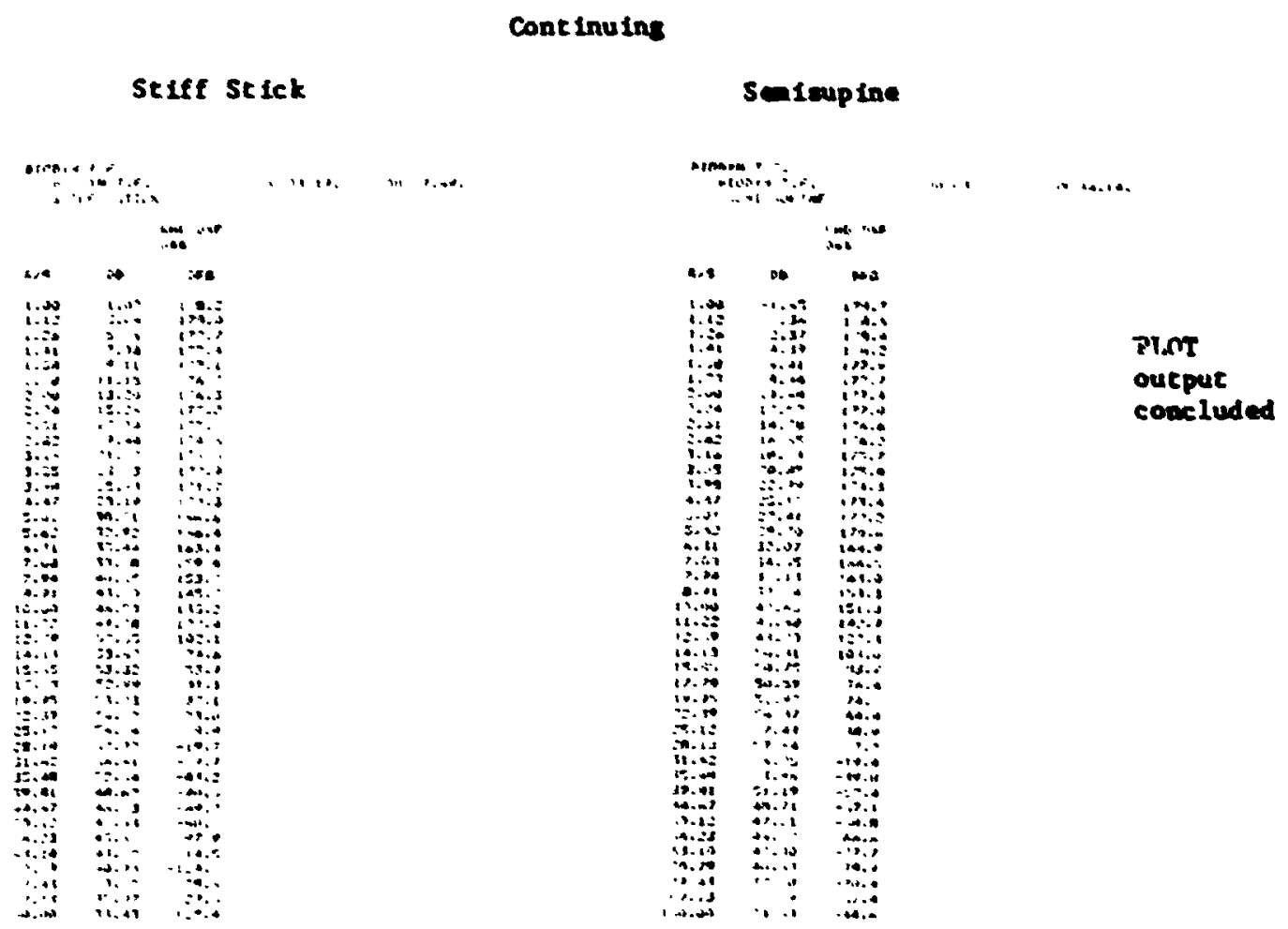

Seseton concluded 


\section{ORIGINAL PFEET IS \\ OF POOR QUALITY}

\section{Rronenos}

l.lex, H. R., and R. F., Yaqdaleno, iodeling Miodvnanic Fiffects of vibration, Fifth Year: Final Setentiflc Report, Systers Technology, Inc., Ska037-1, Aug. 1979.

2Jex, 4. R., and R. F. Ingdaleno, Progress In iknsuiring and Modeling the E.ffects of Low Frequency Vibration on Perforance," ibotele and Analopues Eor the Rvaluation of thinan Blodvmanic Response, Performance and Protection. AGAKD CP-253, June 1979, Pp. A29-1 throush A29-11.

Jex, I. R., and R. E. ingdaleno, Minnechanical Models for Vibracion Feerthrough to lands and llead for a Sentoupline Pilot," Avtacion, Space and Environmental Med., Vol. 49. Vo. 1, Jan. 1978, pp. 304-316.

4:lagtaleno, R. E., and H. Z. Jex, User's Gulde to Bronmi-78, in Interactive Computer Progran for 'todeling Mlodwnamic Peedthrough to a Plot's Pands and lead, Systeme Technoloay, Inc., TK-1037-2, July 1979.

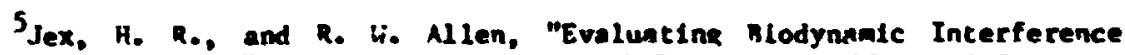
with Operactional Crews," Vibration and Conbl ned Stresses in Advanced Sysecema. ACAKD CP-1. ilar. 1975, pn. .26-1 throngh p24-1k.

6Jex, $\%$. R., and R. E. ilagdaleno, Ibodeling Blodynantc rffects of Vibration; Fourth Year Interin Scientiftc Report, Syntens Technolosv, Inc., Ist:-1037-4, Sept. 1978.

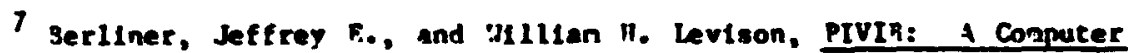
Prouras Eor Analysis of P1lot Btodynanle and Tracking Responee to Vibration, holt, heranek and Hewan, Pept. 3457 , Dec. 1976.

SRiedel, S. A., R. F. Iagdaleno, and M. R. Jex, Ueer's Culde to IIODYi-Rn; An Interact Ive Sof tware Package for Hodelling slodynamic Feedthrough to a Pllot's tands, liagd and Fyes, System Technology, Inc., Tr-1146-1, 21 :Lar. 1580.

${ }^{9}$ Braune, H., 0. Ftscher, J. Anar, and U. T. Denpster, thuman techanLcs; Four ilonokraphs Abridked, Aithl-TOR-63-123, Dec. 1963.

10"syaposiun on Mlodynamic "lodels ant Thelr applications," Mayton, Ohio, 15-17 Feh. 1!17, moblishet in Av., Snuce and Environ. lied., Vol. 49, ito. 1. Jan. 1978 .

Il. lagdaleno, R. F., D. T. 'keRuer, and G. P. ibore, Snall Pertiviontion Dvnanics of the :ieuromuscular Svated in Tracking Tasks, MASA CP-1212, nec. 126R. 


\title{
N8̄ं 34058
}

ORIGI:AL FHGE IS

OF PC:R QIALITY

MODRIING LATERAL ACCRLERATION ETtECTS ON PILOT PERFONMNCE

\author{
Jonathan Korn and David L. Kleinan \\ Depattwent of Electrical Engineering and Computer Science \\ Universicy of Connecticut \\ storrs, Connecticut 06268
}

Chis Attendant to the direct side force (m) aneuver of a ectored Porce Fighter (wim is the transverse acceleration imposed on the pilot. Inis lataral acceleracton $\left(G_{Y}\right)$, when combined wth a postive $G_{\text {stress, }}$ is a potential source of pilot tracking performace impalrwent. T research effort to investigate these performance decrements includes experimental as well as analytical

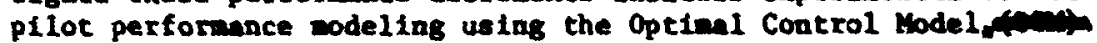

\section{ensa Autmir}

\section{Introduction}

The Vectored Force Fighter (VTF) is characterised by several new and unconventional features, specifically its capability to use direct side force (DSE) to Institute apid transverse (lateral) aneuver independent of aircraft attitude. This menveriag capability is potentially desirable in an air-toair combat encounter, as it greatly increases the alrcraft's moblitty. On the one hand, the evading VFr provides peculiar visual cues that can not be readily interpreted by the attacker. Aiternatively, the atcacking VFT can significantly enhance the pilot's lateral tracking perforenace by virtually ellalnating the time required to enter into a conventional curn.

Along with the desirable properties of the DSF aneuver, increased levels of lateral acceleration $(G y)$ are imposed on the pilot. This unfaniliar stress environment, which may be superinposed on the usual noranl $\left(+G_{2}\right)$ comonent, is an unavoldalbe result of the vectored force anaeuvering. An andyel of the impact (on pllot concrol performance) of such uncomon acceleration is the aubject of this paper.

Empirical research into the effects of of -normal acceleration stress on lateral tracking task performance was conducted by Loosc, et al [1]. They found that it was "harder" to perform the task when under Gy etress, and sighted a $20 x$ increase, fron the fixed base condteton, In the Bus tracking 
error values. These results have wolvated further quantification of p1lot performance under vartous levels of $G$ strase, using cracking scores and ocher performance entrics. In addition, a norentive pilot nodel, capable of predicting perfornance changes as a function of $G y$ levels has becom a developental goal. Consequently, a jolnt experimental/enalytical progrem has been undertaken by the Aerospace Medical Reecerch Laboratory (ARL), MPAB, and the Untversity of Connecticut.

The experiental phace included compensacory cracking taske in the lateral plane, and was coaducted on the Dyoandc Enviroanent Simulator (Das) centrifuge. of the various wodes aployed in the experiment, three are considered in this study: (1) static - fined base (ST); (2) Dyanic - woderate Gy strese (DI); and (3) Dyantc - strong G, strese (D2). The exper1mental dealgn and the subsequent data saniyais are discuseed in detail in Sections II and III.

The ensulang codeling phase resultad in a predictive perfornance aodel besed upon the Optimal control Hodel (OCMI). The codel has been codified to Include the effects of a closed-loop elde force conbined with a constant $G_{z}$ stress. The $\mathrm{OCM}$ parmeters that are censitive to $G$ and/or $G_{z}$ are identifled and related quantitatively to the various accelerations. It is shom that

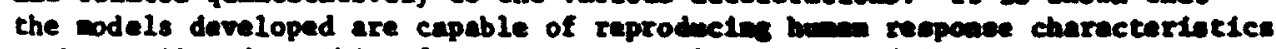

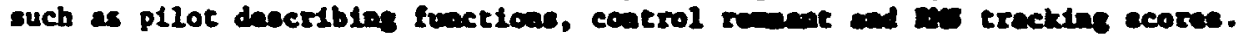
Section IV detalls the modelint apronch and reculten.

II Exertenter Datall

The cotion-rigual loop weed in the NRL experimats is given in Figure 1.

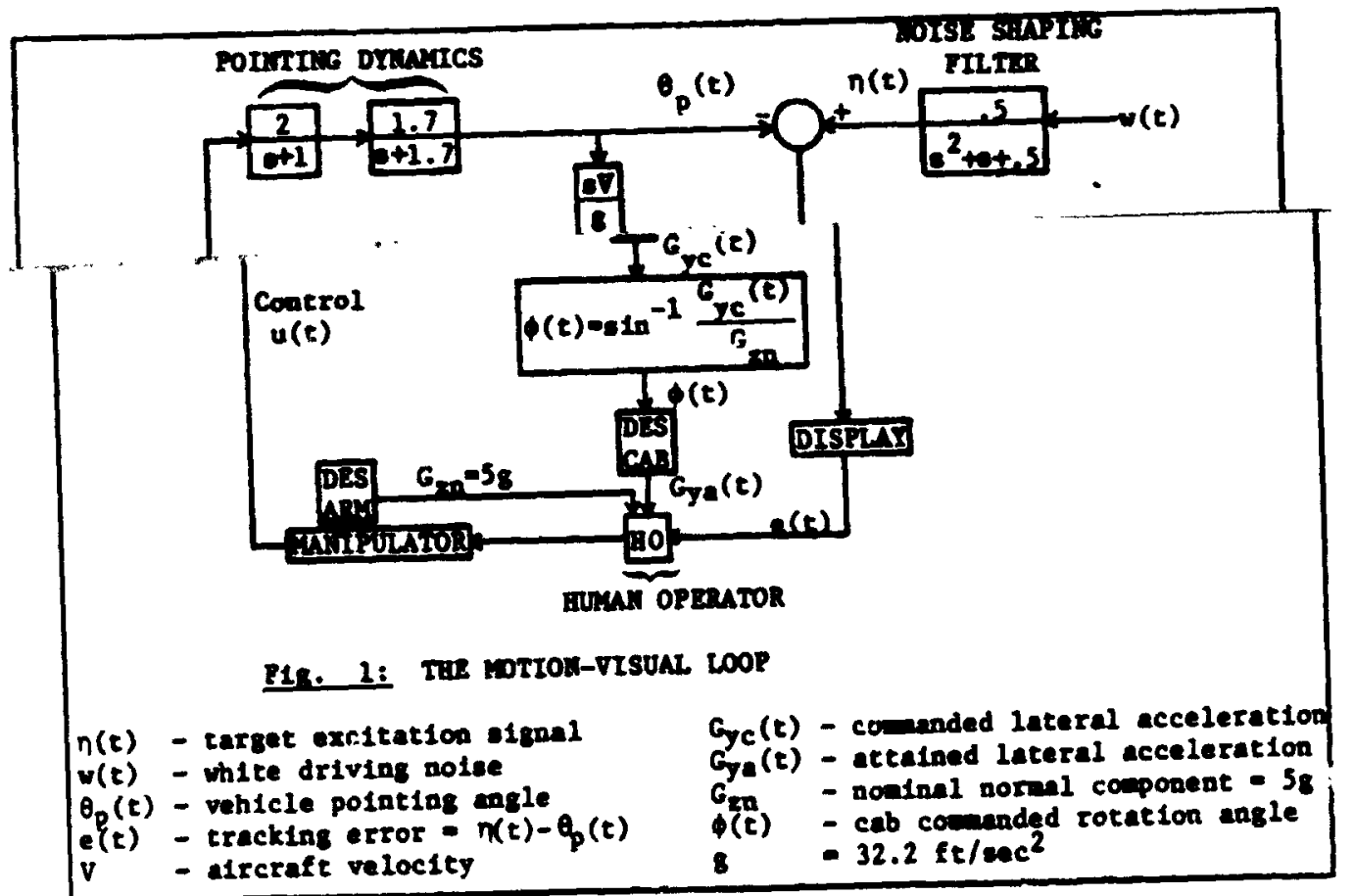


Specifics concerning the lateral axis compensatory tracking takk way be found in [2]. The anjor addition in the present experipent is the provision for the closed-10op DSF-induced motion. In order to simulate the lateral acceleration, it was necessary to centrifugate the subjects to a noninal vereical acceleration plateau $\left(G_{z n}=58\right)$, and to rotate the DES cab to produce an off-noral $G$ cowponent. The roil comand input to the $c a b, \phi(t)$, generated in conjunction with the pilot control signals, is directly related to the pointing angle rate, viz.,

$$
\sin \phi(t)=\frac{G_{y c}(t)}{G}, G_{y c}(t)=\frac{v}{g} \dot{\theta}_{p}(t)
$$

The driving signal and the plant dyanatcs were designed to be in harmoay with the DES capabilitiea.

Three experinental conditions were studied:

(1) ST mode - The control condition (static), no $G_{\varepsilon} / G$ acceleration present.

(2) D1 mode - Moderate $G$ level. In this condition $v-1500 \mathrm{ft} / \mathrm{sec}$. And $G_{z}=G_{z n}=58$. The resulting ensemble wean RMS level of $G_{y a}$ was $.49 \pm .138$ (see Section III).

(3) D2 node - strong $G_{y}$ level: $V=3000 \mathrm{ft} / \mathrm{sec}, G_{z}-G_{2 n}-5 g$. The resulting $G_{y a}$ RMS level was .76士.118.

Each session included two static runs followed by a D1 run and by a D2 run. The order of eaploying the D1/D2 wodes was alternated from one session to another in order to eliminate any possible interaction effects. Five subjects participated in a total of 20 sessions. With the removal of the outliers, ensemibles of 37 static, $19 \mathrm{D} 1$, and $19 \mathrm{D} 2$ runs resulted.

\section{Data Anaiysis}

of the numerous time-historles that were recorded those that are pertinent to this study are the tracking error, $e(t)$, the pilnt control laput, $u(t)$, and the attained level of $G_{y}, G_{y}(t)$. The data vere cranisarmand to ahtsis frequency domain measures which were then (across-subject) ensemble-averaged at the input frequencies. Th1s procedure yielded the first- and second-order gtatistics of :

a. Pilot describing furetion, $H(j \omega)$ (asgattude and phase).

b. Pilot remant, R(w).

c. RMS scores of eit), $u(t)$ and $G_{y e}(t): s_{e}, s_{u}$ and $G_{y}$, ras respectivelyt It is possible now to relate modes $D 1$ and D2 to the respective attained $G$ levels. From the FFT analysis we obtain (1) D1: $G_{y}, r w=.49 t .138$, and (2) D2: $G_{\text {. }}$ rws $=.76_{-}^{+} .118$.

Figure 2 illustrates the differecces in (average) pilot gain, phase, and remant for the three exper'mental conditions. Table I lists the pirs scores ( $t$ one tandard deviation). Multiple comperison type of MiOVA tests that have been performed on the reduced data reject a hypothesis of perfornance Invar-lance among the three experimental conditions. Significant differences ( $P<.05$ ) exist awong the pllot gains, remunte and tracking erzor scores. These tifferences rccur throughout virtually the entire frequency range. The phase exhlbit:

$F$ The absolute values of $s_{e}$ and $u$ are determined, of course, by the driving noise $(w(t))$ covariance, $W$. In this study We.36. For detalls see [2]. 
aignificant differences only at the higher frequencies and no trands are evident in the control scores. Several obeervations are pertinent:

(1) Figure 2a clearly Indicates that Increased levels of lateral acceleration effect reduced pilot gains and lover control banduldthe. The gain decreases by an wach as 3-4 dB between ST and DI modes, and then further decreases an additional $2-4$ dB in the D2 sode. This trend 1s ilkely a consequence of the closed-loop acceleration stress, as the subjects tend to decrease their control activity for which they are penalized by lateral jolting.

(2) An indication of a narrover control bandwidth is also anifested in Figure $2 b$, where increased $1 a 8$ at the higher frequencies with increased $G_{y}$ stress, is evident. At the highest frequency $(15.57 \mathrm{rad} / \mathrm{sec})$, for example, the phise las difference betwen the static and the D1 condition is as much as $26^{\circ}$, and up to $44^{\circ}$ between the static and the D2 condition. In the modeling section (IV), we attribute th1s laselng tendency not only to a narrow control bandwidth, but also to an Increased human reaction tim delay.

It is our belief that the gradual pllot galn decrease and banduldth narrowness is ascribed to $G$ strese only, and that the normal ecceleration component has no effect on this mode of hinen perforance. This has been ascertained in a parallel research profect reported in [3]; the control task was sinflar, but only $G_{2}$ stress was enployed-1.e. no of $f$-noranl accelerations were present. The resulting pilot tranafer function (both gain and phase) remained unchanged in both control- and $G_{z}$ stress conditiont.

(3) Increased randomess in pilot control is another facet of the acceleration stress. Figure $2 C$ indicates that with increasing $G$ levels the pilut control remant increases. The snount of increase is very aignificant: fion the atatic condition to the DI node the increase $183.9 \mathrm{~dB}$ on the average, and from D1 to D2--an additional $2.6 \mathrm{~dB}$. This remant increase is attributed to $G_{y}$, as well as to $G_{z}$ stress. Based upon the results of $[2,3]$, the coderate $G_{y}$ level (DI) does not affect the remant level, a In both DI and the constant $G_{z}$ strese condition $[2,3]$ the rement levals are precisely the save. Only the higher level of $G y$ strese (D2) further ralees the rewant.

(4) Very significant ( $P<.01)$ Increases in the Dis tracking error values in $D 1$ and D2 are Indicated in Table $I$, and dopicted In F1gure 6 . The increace frow the ST to the DI condition is by 278 and from DI to D2-by $18 x$. As in (3), these increases are partly attributed to the sustalned $G_{2}$ stress: a 137 Increase in tracking scores was noted in the constant $G_{2}$ condition in $[2,3]$.

\section{Nodeling Results}

The analytic sodel used in this effort 1o the OCM [4]; the nodeling detalls are einflar to those of $[2,3]$. The parenters in the OCA that ere descriptive of

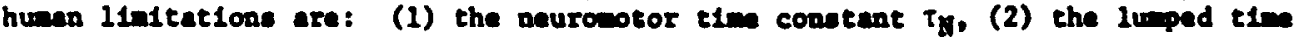
delay $\tau_{D}$. (3) the wotor poise ratio $p_{u}$, and (4) the error and error-rate observation noise ratios $D$ and $0:$. The presence of the subject-comanded $G$ ecceleret100, wich correlates with the siganl $\theta_{p}$ in the viaual loop, requires an add1tional paranter. (5) the error Indifference threshold is. The loclusion of this paranter 1s based upon the assumpton that a closed-10op etrees Increases the iuna's error Indifference threchold. In enother words, the hune's consideration

F Reference [3] 1e an updated varalon of [2]. It has been sugeseted in [2] that sone minor differences existed between the pilot galns in the static and the $G_{z}$ otrees cond1itions, but a eubsequent statisticel test did not oustain chis sasertion. The data base used in [3] is much broader than in [2], and these anor diesinilarities totelly dininish. 
ORIGINAL PAGE IS

OF POCR QUALITY

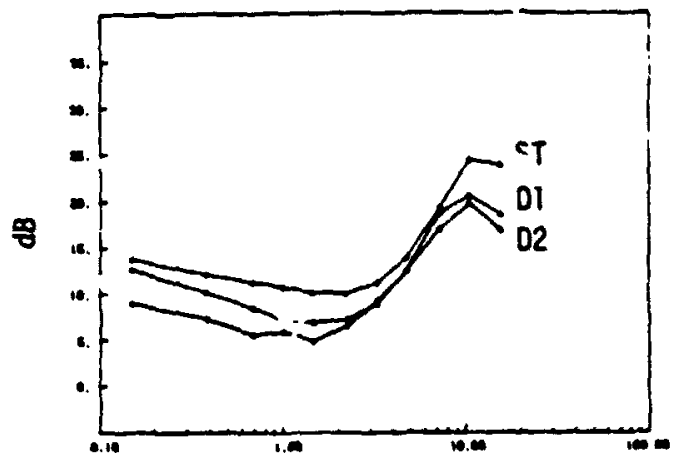

a. GAIN

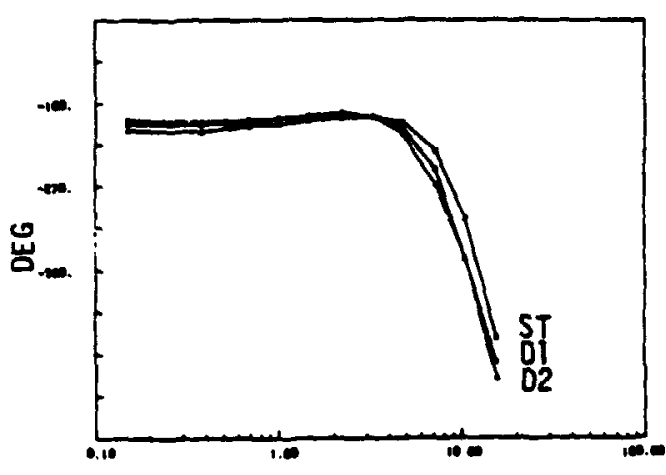

b. PHASE

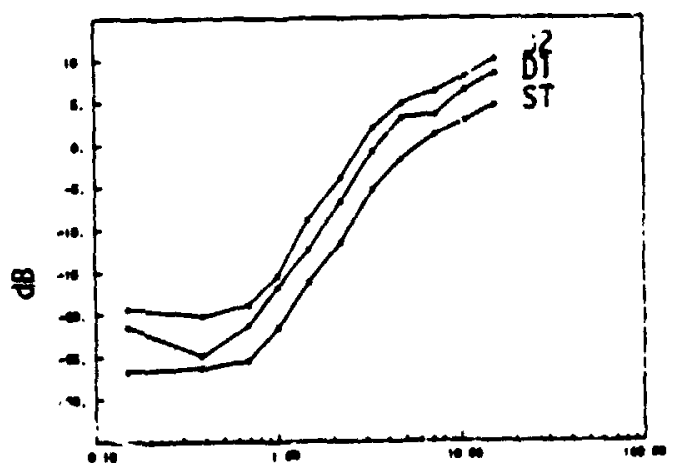

c. REMNANT

FIG. ?. COMPARL IN OF MODES ST, 01,02

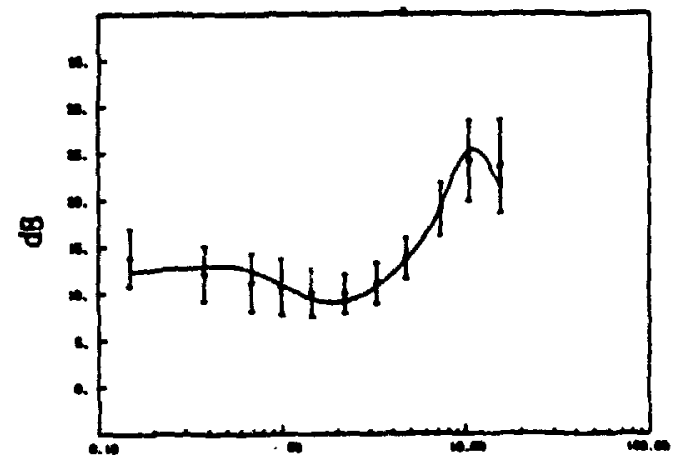

a. GAIN

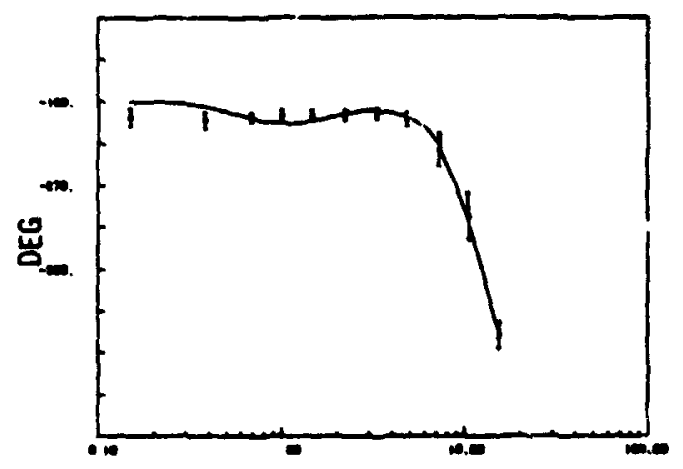

b. PHASE

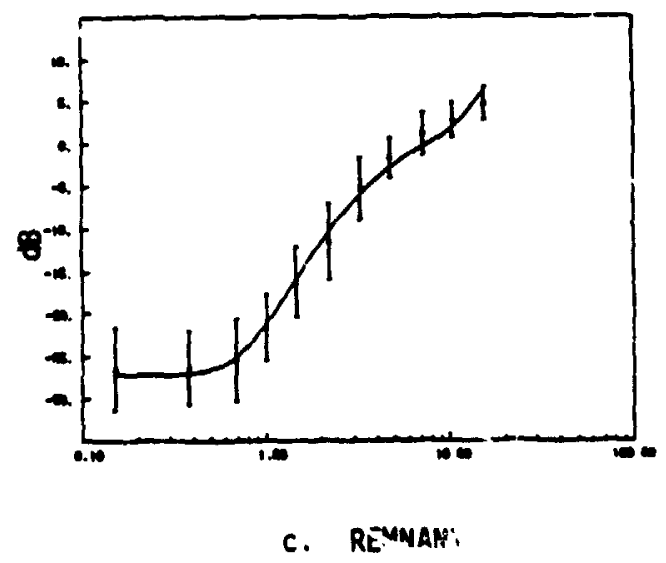

FIG. 3. HAEL-DATA COR AR:SOM ST MODE. 


\section{GRIGINRE PAGE IS
OF POOR QUALIT}

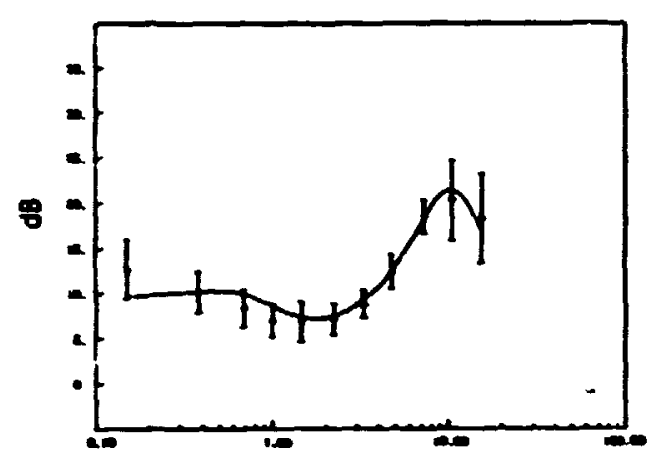

a. GAIn

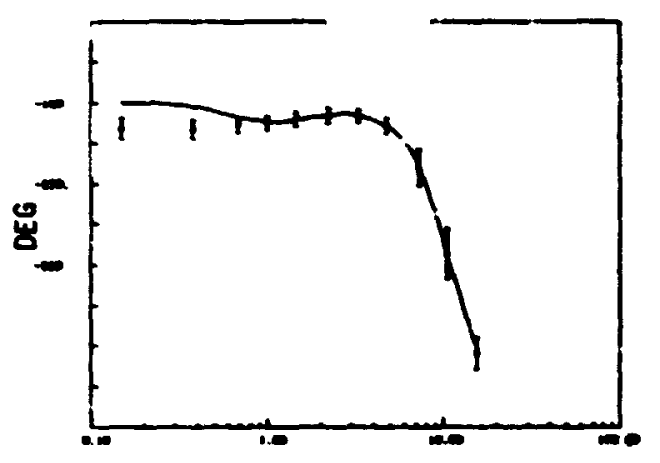

b. PHASE

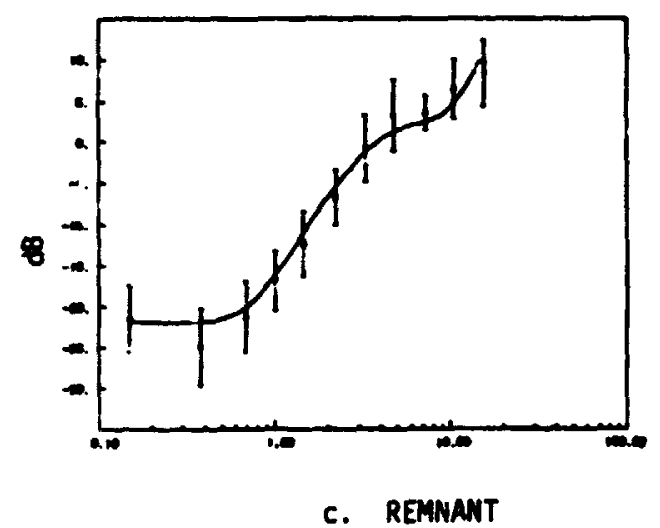

FIG. 4: MI ITA COAPARISON

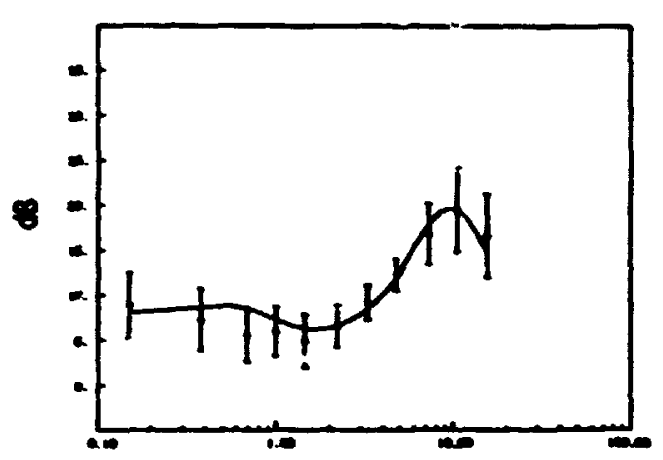

a. GAIn

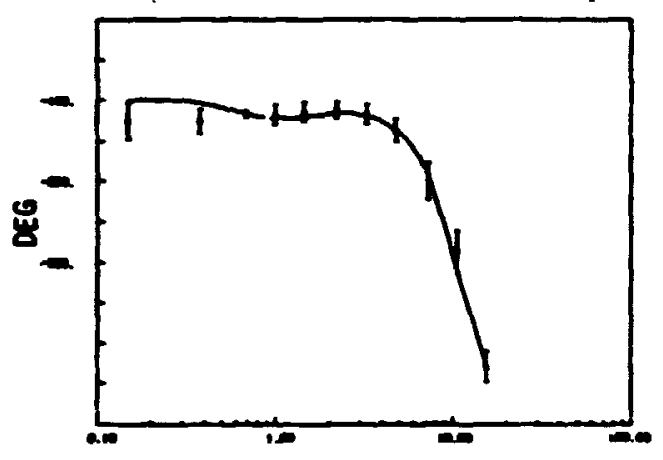

b. PHISE

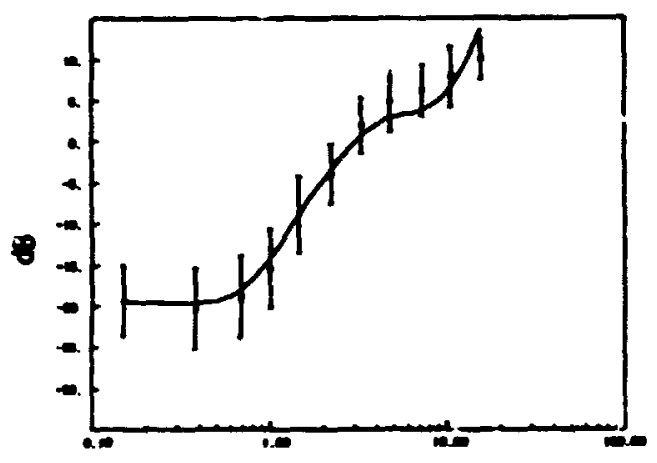

c. REMANר

FIu. 5: MODEL-DATA COMPARISUN O2 MODE 


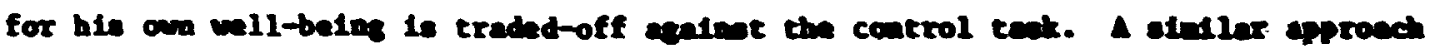

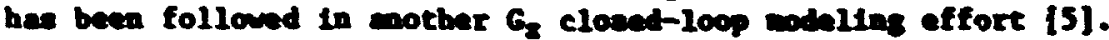

In practice, the Indifference threehold permoter in reprosented in the col b) Its equitralent Rendon Input Describtes Fucted [6],

$$
n\left(a_{e} / \sigma_{e}\right)-\sqrt{\frac{2}{\pi}} \int_{-\infty}^{-a^{e} / \sigma_{e}} e^{-\frac{x^{2}}{2}} d x \leq 1
$$

there of is the predicted wis tracting error. This fonction nodifies the nodel In 200 inge $[3,6,6]$ :

(1) Obearvation boles: We replace the unal equetion for copputing the error obeervation voles $\nabla_{e}$ with

$$
v_{e}=\frac{\pi \rho_{e} \sigma_{e}^{2}}{n^{2}\left(a_{e} / \sigma_{e}\right)}=\pi \rho_{e}^{*} \sigma_{e}^{2} ; \rho_{e} \Delta \frac{\rho_{e}}{r^{2}\left(a_{e} / \sigma_{e}\right)}
$$

Botice that the effective oolse rat10. $p_{e}^{*}$, to the caly identifiable paremen in. Bq. (3).

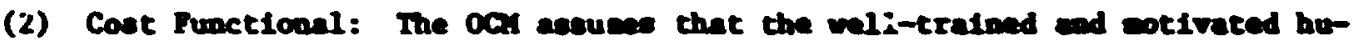
en operator adopts on optinal covirol strategy, subject to his inberent pojebophyelological iffication. The eathenatical interpretatica of this statenat is that the pilot, in the case at had, will antedse the coet functional.

$$
J(u)=E\left\{\lim _{T \rightarrow \infty} \frac{1}{T} \int_{0}^{T}\left[q_{e} e^{2}(t)+q_{t} i^{2}(t)\right] d t\right\} \text {, }
$$

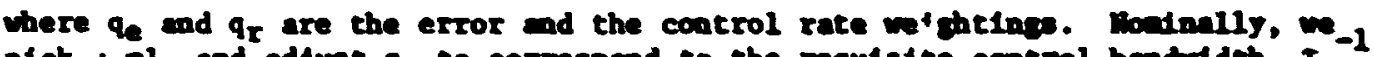
pick $t_{e}^{-1}$, and adjust $q_{r}$ to correspond to the requileite control bendudth, $T_{y}{ }^{-1}$. Equation (4) is applicable in the abeence at ay threshold effects. When the error indifference threshold is no longer negligible, one should replace the displared error in (4) wth the perceived one. This gield a revised cont functional

$$
\left.J(u)=\varepsilon \int_{T \rightarrow \infty} \frac{1}{T} \int_{0}^{T}\left[q_{e} u^{2}\left(a_{e} / \sigma_{e}\right) e^{2}(t)+q_{x} u^{2}(t)\right] d t\right\} .
$$

It is evident now that Increased a effects lower $w$. itheing on the error, as should be expected. This in turn results in hicher relative wighting of the control rate, and consequently an increase in the neuromener tar conatant $\tau_{\mathbf{H}}$.

Figures 3,4,5 and $6 f$ present the 1dentified codel ve. deta comperisons for the ST (control), D1, and D2 conditions. Chow are the p1lot deacribins tunction angoftudes and pheses, remante, an I bis tracklos errore (scores). The eppirical trackias control ecores $\left(s_{e}, s_{u}\right)$ are also comared with their nodeled counterparts $\left(J_{e}, \sigma_{u}\right)$ in Table I. 


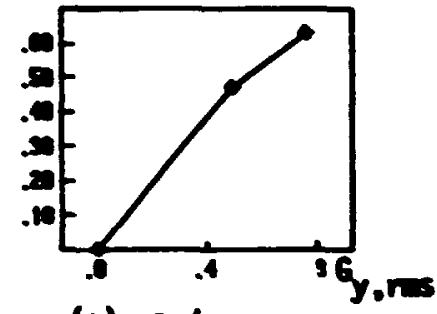

(a) $/ \sigma_{e}$

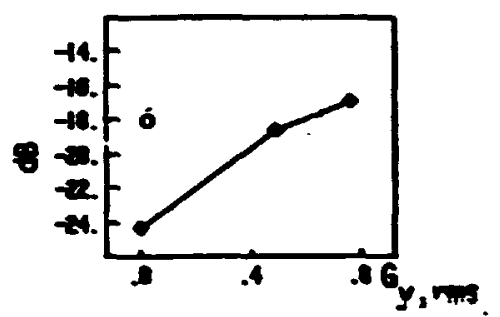

(d: $P_{\mathbf{u}}$

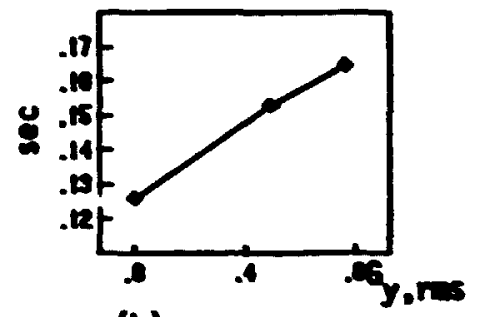

(b) $\tau_{n}$

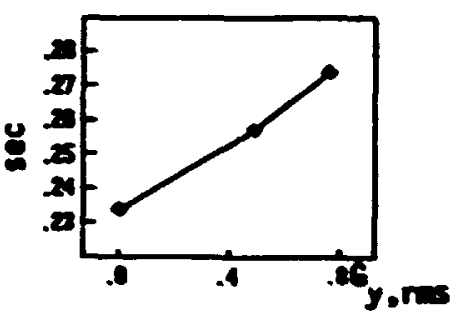

(e) $\tau_{0}$

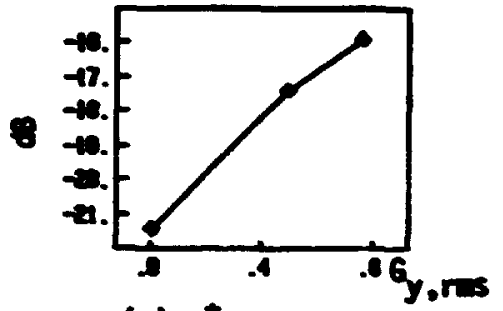

(c) $P^{*}$

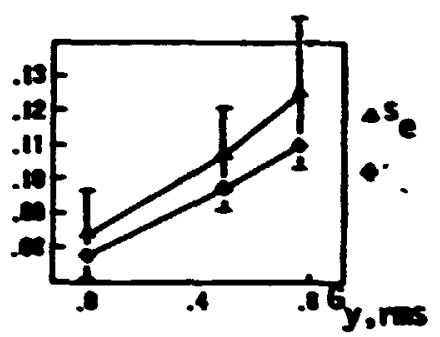

(f) scoues

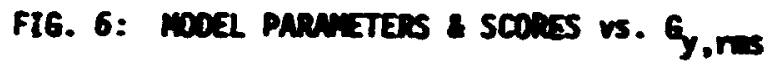

(o ImDICATES OPEW lOOP $G_{2}$ onr

\begin{tabular}{|c|c|c|c|c|}
\hline & . & $\sigma_{e}$ & a & $\sigma_{\mathbf{n}}$ \\
\hline $\mathbf{S T}$ & $.083 \pm .012$ & .078 & $.3 \times 1.10$ & .33 \\
\hline D1 & $.106 \pm .015$ & .098 & $.35 t .0 s$ & \\
\hline D2 & $.125 \pm .022$ & .110 & $.34 t .11$ & .32 \\
\hline
\end{tabular}

TARE I Ris scoies

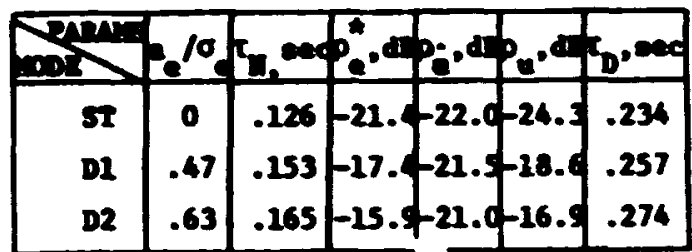

THBLE II MOEL PAMHETESS

Ine codel parmentere are Lleted in ISble II, ad plotted 0 a function of

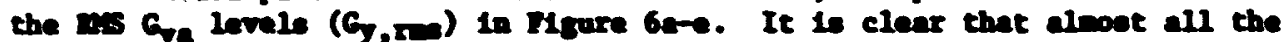

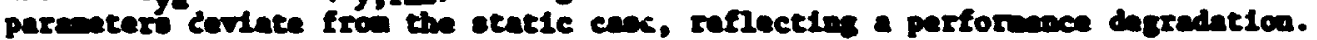
These Increasen, homenr, con not be attributed to the $G$ streas alons: the

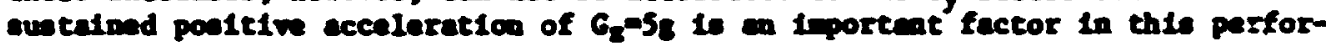
ance inpalront. The following is our proposed theory of how the variow acceleration compocante affect the ocil paremeters.

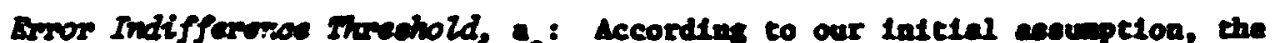
threshold parmeter is affected caly by the closed-100p G streas. IIfure 6a

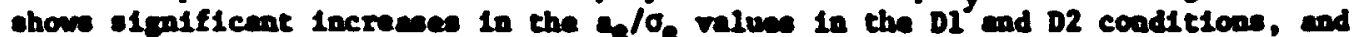
1t 10 clear that the subjecto $110 \mathrm{w}$ for larger tracking errors in order to atainse thetr joletint.

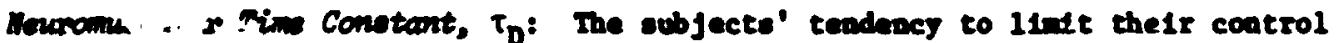
benduldth, under closed-100p lateral acceleretioa, io clearly enenfested by the 


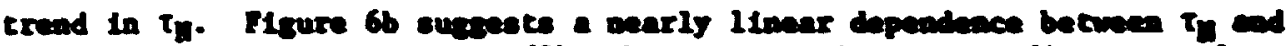

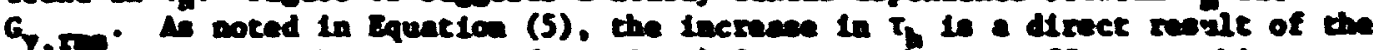

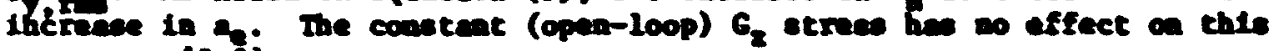
paraneter $[2,3]$.

Obecrustion boice Betio, $D_{e}$ : Ireditionally, postelve ecceleration otreas $\left(G_{2}\right)$

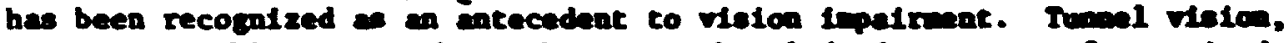

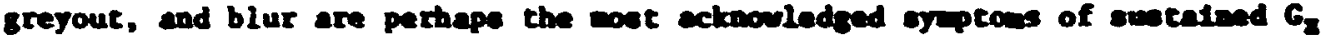

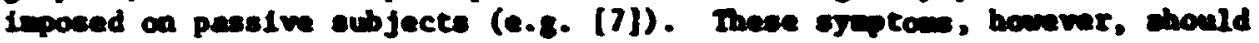

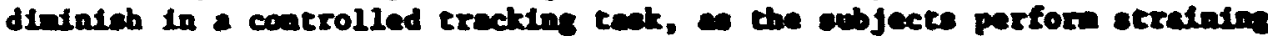

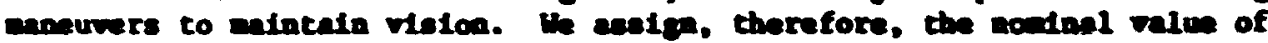

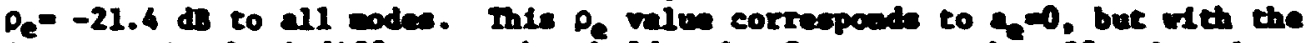

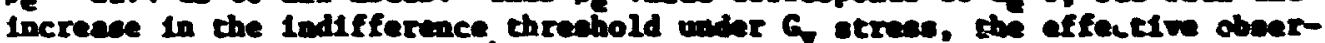

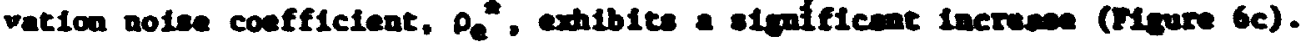

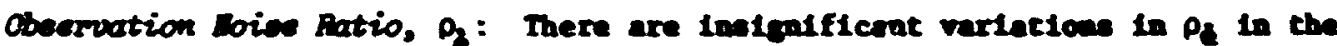

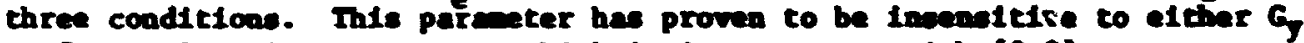
or $G_{2}$ acceleration component, wich is in agrecued with $[2,3]$.

Motor Doise Cosfficient, $p_{n}$ : Mis parmeter minly affects the pilot control remant. As stated In Section III, secribe the remate Increase in the DI

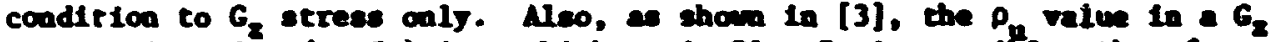
strese situation (w G.) is a hIth a in DI. It is poseible, therrefore, to conjecture that 100 to moderate levels of $G$ hwe no subetantial effect on the buan's wtor notse. Only increased levels of lateral acceleration $(>, 58,5)$ effect hicher $P_{u}$. Bipher rement/ $\rho_{u}$ under $G_{z}$ or $G_{z} / G$ streas is a clear indication of decrenente in otior performace. It he been widely reported that the operator paycho-gotor performece is inpalred undar $G_{8}$ otreas (e.8. [8]), but no reference to $G$ effects has ever been ande.

Tive Delog, $T_{D}$ : The reasons for the increased time-deloy under $G$ strese are Dot well understood. The lacreasing phase lage with lncreasing $G, \pi$, as exhibited by the epirical date in Figure 2, clenrly thow the Increasing response 1as. Bowever, there in no apriort resen to expect to to dapand on $G$. What one alght be seeing is an increase in the effective dely as position Information (e) is degraded relative to rate (8) infornation. A sintlar phenonenon of increasing $T_{D}$ occurs wen a tracking displey is soved into the peripheral field.

\section{Conclusions}

An investigation of the effects of a direct side force (DSF) mancuver on p1lot tracking perfornance has been undertaken. The resuarch Includes $G_{7} / G_{8}$ slress tracking experiments, and pllot performace wodeling wins the OCh.

It is suggested that the huan operator adaits Larger tracking errors, under sloeed-10op G strese, by tncreasing his error indifference threahold. Consequent1y, in an atteapt to anllorate his leteral acceleration, the subject adopts a control strates that lowers his gein and constrains his bendwdeth. In addition, an increased phase las in the pilot tranfer function is obsarved, when under $G$ stress. The pertinent $O C A$ parasters: the indifference threshold, the neuronotor time-constant, and the operator time-delay all increase, causing substantial perfornace degradation. We attribute these parancer deviations to $G$ stress alooe, as past research has shown that open-loop (and constant) $G_{2}$ stress had no effect on these modes of huan perfornace. 


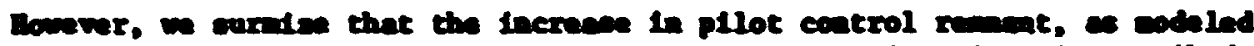

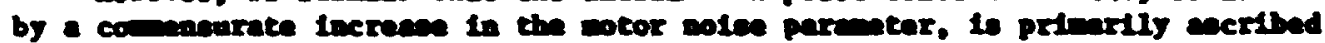
to $G_{z}$ etreses. Inoed upon past resenreh, w postulate that ouls the otronpr

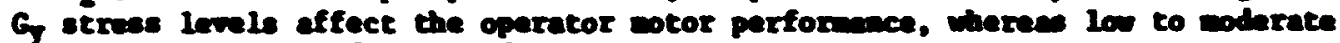
levelo have no efontficat effect.

\section{Defereaces}

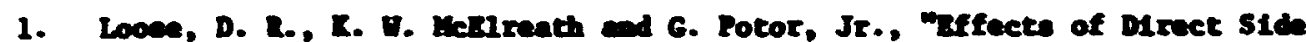

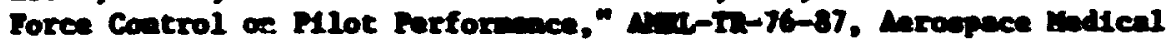
Desearch Leborator, WND, Chio.

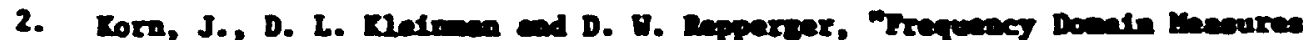
of than Performen vader C-streas," Frocendins of the 18th IAx Contereace an Decteloa Concrol, Decenber, 1979.

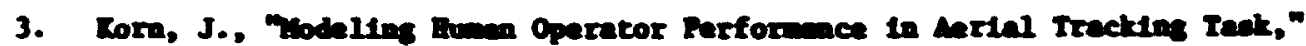
wort in progrees.

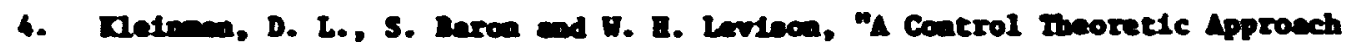

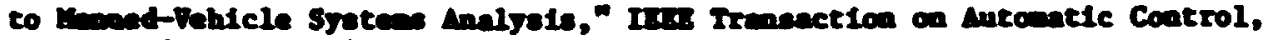
Dol. $\triangle C-16$, to. 6, 1971.

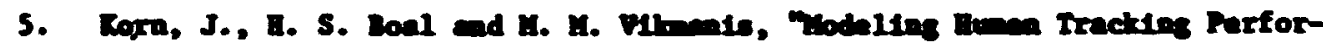
nence in a Biph C-etreas Eviroment," Frocending of the 1978 Conference on Dectaton an Control, Jemary 1979.

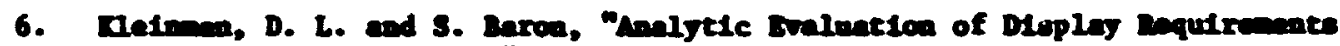

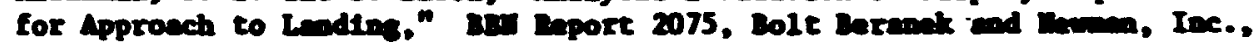
Combidee, Maes. Narch, 1971.

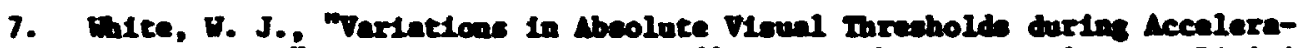
tion Streas," wnd Tectmical Eport 60-34, Brifht AIr Developenent Divielon, IRAS, Ohlo.

8. Browa, J. L. ad H. Lecheer, "Acceleration and Bung Performance," Aviation Fedicine, Februng 1956. 


\title{
CF:GRAL PR:AE IS OF POOR QUALITY
}

\section{N82 34059}

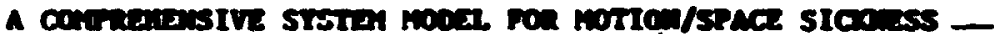

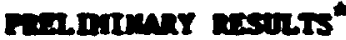 \\ Susan A. Riedel \\ Syaten Technolony, Inc. \\ Hauthorme, Callfornis
}

Mstinct

Recent wotion sickness research literature puts forth several pronising conceptual theortes wich attempt to "nodel" vartous portions of the mution/ space sickness syndrone. Perhaps the nost inviting of these is the "sensory conflict" theory, advanced by Reason and others, which susgeets that the barrape of sensory oriencation cues fron the eyes, vestibular syoten, proprioceptors, etc., are Interpreted and even nodified by a central "cooparator" in the brain, with respect to a "neural store" of expected correlations in normal experience. This theory qualitatively explains nam of the observed notion/ space slckness phenosena; yet, no comprehensive quantitative syaten nodel exists for researchers to exercise. Such a syaten nodel of notion/apace sickness 1s needed to: categorize and order the oiverved facts into atonal semeture; effictently encode the neasured data and dynanic processes; and reveal key expertments needed to predict and/or prevent ation alckness on earth and in space.

Th1s paper reports a preliminary attempt to satisfy the tirst of these goals. It presents an "array of key facts" as assembled fron the recent literature, consiscing of a collection of mocion/space sickness observetions which should be accounted for in the comprehersive model. A nodel structure which is responstve to the "array of key facts," as well as to the other requirements of working research cool (wodularity, ease of use, conciseness. etc.) is also suggested.

\section{Inmodoction}

The seening cooplexity of motion sickness in all of its eanifestations has kept untold numbers of reseerchers busy for at least the past 40 years. An overutielining amount of data has been collected, observations made, prelininary conclusions draun. Reseerch worldulde has covered a large range of incerest, ising human subje zs and anianal subjects, measuring physical, pejcholosical, behavioral, and sutononic variables, with the sosl of flscovering causes and cures of this debllitating affliction. Even its nost fundanental effect,

"This research 1s sponsored by the tiational Meronautics and Space Administration under Contract NAS2-1043n; the technical ponttor is Yelvin Sadoff. 
nausea, is puzzling; as Treisenn' points out, motion sickness syptomatology has no logleal survival benefit in an evolutionary sense.

Pecently, a theory has been advanced by Reason ${ }^{2}$, Benson ${ }^{3}$, and others which appears to tie weh of the eotion sicknase research results togethar. This so-called "sensory confllct" theory states that wricus phyelological sensors combine with a set of pejehological expectations, someines reaulting in a sensory conflict: motion/space elckness. Qualitatively. this theory explains eny of the obeerved phenomene sesoclated with wotion/space stckness. But the need selll extete for a comprehenot ve, dynante (time doesta) codel which predicts the tise course of sotion stckneas a function of the environimental Inputs and andlating or allorative setions. Such a codel should:

1) Quantitatively eccount for the key facts of the ootion slcknees sondrone which have ben identified by research to date.

2) Catsloz these effects in an orderly and afficleut wy.

3) Identify tey experinente destgned to vilidate and teet the model in vartous wyse.

4) Provide wore prectes wasures and mehode for predictIng Individual rusceptibllity.

5) Sugsest treatmente searsd to prevent eotica/space stcknese.

These are the objective of the wodeling effort deacribed here.

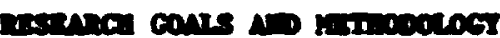

In order to sccomplish these goals, a throe-gear, three-phase research effort has begun at System Techoolog, Inc. The ultinate hope is to better understand, logically organize, and render predlctive the large amount of data which has arteen out of the wotion/apece slekneas resentch to date. To this end, the curreat research plan to structured a follow.

Phace I: Surver and Tentative Model Developente

Thres separate Itew comprise this phase. The flrst is a search of the avallable literature on option/opace steknese, concentrating on two anjor areas: key faces which describe ootion slekneas in a dynanic, quantifled way; and all types of ik .1 : developed in the jast relating to wotion stcknese and 1te partpheral af .. .. Visits to several key research facllitles are planned so that ongolng W..K ar be Incorporeted In the odel as mil. These viste are aleo a flrst step In establishing open cotsunication lines with the wotion sicknese reseatch comunity so that the model wil become en interactive basts for the exchange of ldeas in this fleld. 


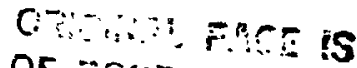 \\ OF PEUR QUALITY}

The second work Item will assemble the results of the literature search into an "array of key racts" which relate to notion sickness and must be accounted for and predicted by the comprehensive model. In constructing this fact array the following criterla will be used:

- Degree of concordance among linvestigators.

- Degree of ublquitnusness anong various forms of notion sickness.

- Avallability of appropriate quantitative input/output information.

- Existance of a model which accounts for this effect.

- Interrelation with other elements in the fact array.

- Priority of the effect within the array.

The final step in this first phase is to suggest a tentative model struccure which accounts for the array of key facts and the interactions among the array elements. An eclectic policy will be adopted, such that the best and most appropriate type of wodel will be Incorporated in each subsyaten. Since many models already exist for various portions of the comprehensive nodel, the majority of effort in this task will be establishing the interconnections among these several parts.

\section{Phase II: Validation, Refinement and Conputerization}

Validating the model developed in Phase I consists of obtaining the predicted set of outputs to a given set of Inputs, such that the key facts assembled in Phase I are all taken into account. Valldating the model is also tled in with bodel refinement as a three-step process: 1) exercise the nodel to match exist: ug data or predict new results; 2) perform expertments to verify predicted results or obtain new results; and 3 ) update the norlel accordir-1y. Cumputerization of the comprehensive model satisfies the need for a usa:orlented tool which is readily avallable to the entire research community. T. this end, an interactive FORTRAN software package is envisioned such that the tool will be readily usable by a wide range of practitloners, who need not be familiar with the detalled mechanization. The Phase II goals can be realized only if flextble, modular structure serves as the foundation for the conprehens I ve model.

Phase III: Applicatlons, Space Experiments, and User's Gulde

This phase covers the maturing stages of the model development as the tool is made available to researchers in the form of User's Guide to the software. It is anticlpated that once the model is used in a variety of applicatlons, and from a weslth of different viewpolnts, the maturing process will be hastened by new experiments and a constantly enlarging data base. Particular- 
ly Interesting are potential applications of the model in 0 g environinents (e.g., the Space Shuttle), since concerns centering around preventing sjace sickness anong Space Shuttle crews originally motivated this search for a corr prehensive motion/space sickness nodel.

The remainder of this paper presents work coopleted and ongoing in Phase I. Areas addressed are nodeling principles, the array of key facts, and a preliminary model which incorporates some of the key facts. It 18 clear that this nodel-bullding effort would be enorwous were it not for the solld groundwork provided by past researcher's. Perhaps the ignificance of this past work w11 become wore apparent when seen in the context of an overall dynamic process. The ultimate goal in constricting such a wodel is to provide an arena where the Interrelationships can be observed and evaluated as a routine element in motion sickness research.

\section{constomations in modednug}

Before the array of facts is assembled fron the modeling viewpoint it is important to Identify the for considerations in modeling. There are two iaportant concerns wich must be addressed: the types of nodels which wil form subsections of the comprehensive model; and the characterlstics essential to the proposed nodel. These concerns will be discussed next.

In defining the types of models to Incorporate in the overall wodel the present polnt of view is that of a system engineer describing the inputs and outputs of a complex dynanic process - the human subsyatem involved in motion sickness. Thus, it 1s laportant to allow leeway in assenbling the wodel, such that the best types of models are used where they are nost appropryste. The model types include:

- Conceptuaj wodels. These are the nost Important starting points as they are a culuination of insight, wechanisas, and qualitative assessants of interacting elements. Since such models are not quantitative, hovever, they are of limited predictive value for specific problens.

- Input/output models. The logical extension of a conceptual Eodel is a numerically exerclsable "math" model which encodes known data in a veridical and efficlent way. So-called "Input/output" systea models requite knowledge of the functional relationships (statiatical or ignal correlations) of the aystem under study, lithough the detalled Internal mechanisns need not be specifled. Dynanic systen wodels are appropriate for several motion sickne subsystems, and an existing arsenal of mathematical tools and system 1dentifiention techniques can be broupht to bear on the problem. Previous succeageg using this approach are evident in the 1iterature. $4-8$ 
- Physical models. Whenever the fundamental physical processes of a given subsystem are well understood, a detalled physical math nodel can be constructed. For sone of the human subsystems involved in motion ickness such models do indeed exist (e.g., semicircular canals and otoliths, ${ }^{-12}$ ). Yet, for several reasons, ocher physical models which are desirable for the conprehensive model may be a long way off: mechanisms are poorly understood and not readily quantifled; the process is partly poychologlcal; the complexity necessary to capture essential details makes a complete physical nodel inpractical.

- Living models. In motion sickness research, much use is made of animal models and himan models in Investgating environmental, psychological, and drug effects as manifes-ed in motion sickness. When such godels are feasible, they lend much insight into the motion sickness syndrome as a whole. Th1s permits an important slimpse at the overall picture, but often inposes a problem when trying to sort out specific aspects, symptons, causes, and effects. In addition, the use of animal codels Imposes the problems of scaling the effects between animal and human and of experimental protocol constraints.

The second consideration in modeling defines the characteristics desirable for the proposed comprehensive model. The key requirements are enumerated as follows:

- Modular. It 1s Important to maintain a subsysten approach to facilitate updates, revisions, and corrections and also to ald in computerization.

- Dynanic. The tine course of symptoms, adaptation, and habituation should be represented.

- Interactive. The modular interconnections are 1aportant here in understanding the overall motion sickness plcture. And, In the other sense of "Interactive," the conputerlied morlel will be user-oriented and userinteractive, both fundamental ingredients for a useful cool.

- Nonlinear. Many Important aspects of motion slckness are best represented by nonlinear elements such as thresholds, saturations, and allocation algorithms.

- Wuantitative. Validation of the morlel demands that ke: experimental reaults be predicted in q quantitative sense by exercising the notel. 


\section{Orising PACE 15 \\ OF POOR QUIM!_ITY}

- Functionally Isomorphic. Architecturally, the subelements of the model will have a functional structure which is an isomeph with its human counterpart. This allows modules to be 1dentifled with distinct human elements (Labyrinth, eyes, neck proprloceptors, etc.) even if a detalled physical nofel is not avallable for the particular element.

- Computationally Efficlent. A cuisprehensive model which is difficult, ilme consuning, or expenstue to exercise will find few users in the research laboratories, no matter how accurate it 1s. Care must be taken in constructing the software package and in preparing the user's guide so as to assure lts effictency for a wide range of users.

- Validated. The refinement and vaiidation of the model is an ongolng process as new data are forthconing, new experiments are suggested, and increased understanding of Interconnections is gained. The nodel structure wust be such as to readily acoonodate validation and subsequent refinement.

- Predictive. It is essential that the motion sickness nodel be predictive, so that its continued validation, refinement, and use be extended to new situations. Then $1 t$ can serve as an integral part of motion sickness technology and not merely as a computerized "11brary" of experimental results.

- Insightful. The ublquitousness of the motion sickness syndrome implies that some very basic cause-effect relationships are involved. It is hopcd that the construction of this comprehunsive model will llluminate these basic "motion sickness principles," which have heretofore been unclear.

The types of models which may potentially comprise the comprehensive nodel, and the fundarental characteristics to which the nodel must adhere, have been discussed. The final section suggests a start at encoring some key facts in motion sickness within the prescribed structural boundarles.

\section{MODELING THE ARAT OF RE FACTS}

As an example of the priscedures involved in structuring $t$.omprehensive model, some of the key facts pleaned from a survey of motion a ckness literature have been used to construct soundation for the model. An attenpt is made to begin at the most fundanentsl levels, defined by those elements of tha fact array wilch are mast universally reported and agreed upon. Bullding fron this baseline, enbelilshments and refinements are made which account fo: more elenents in the array. When care is taken in nodular construction, the formulation of this architectural hierarchy should progress snoothly. 


\section{$C: \because \cdots: \therefore: \therefore: 13$ \\ DF FOC:T QUALITY}

The first four elements culled from the fact array serve as the baseline for the model:

1) Labyrifing defective subjects are immune to notion sickness.

2) ilotiog sfickness symptons can be induced by pure visual stimi-

3) Motigg-3ickness symptons can be Induced by pure motion stimulus. 20-21

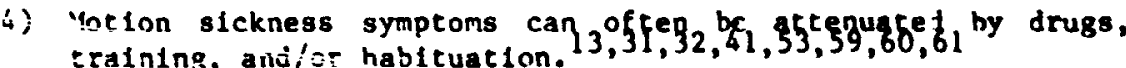

Together, these widely-agreed-upon and well-vaifated facts specify sone of the key components in the nodel. In order to accomnodate each of the facts, the notel mat include the vestibular sysien, the visual systen, a neuro-chemical system whereon drugs may act, a "learning center" (presumably In the central nervous systen) to inclurie tiatning and habltuation effects and a nauseogenic systen which scrually produces the notion sickness symptom. The sensory confitct theory discussed briefly in the Introductiun appears to be an appropriate conceptual model which structures the elements and their interconnections In a global model, such as shown In Fig. 1.

In order to beg!n validating the nodel suggested by the F1g. 1 structure, the various elenent blocks must be replaced by wethenatlcal mortels which can generate quantitative data for a given visual/mction environment. This necessitates a return to the fact array.

5) The vestibular system is composed of the semicircular canals, whic! : respond to head angular acceleration and Indicate head arigular velocity, and the ocoliths, which sense gravity a id linear acceleration and 1 igdigate $3^{\text {atatic }}$ head orlentaiton with respect to vertical. $2,10,22-23$

6) The visual systen senses IInear and angular velocity. 19,24 7) The semictrculag canals may he nodeled as a damped torsion
pendulun. $10,23,25-26$

8) The otoliths may be modeler as linear aç̧eleroneters with threshold and neurological adaptation.9,25-26

These facts suggest replacement of the "vestlbular systen" and "visual system" blocks of F1g. I with the I1nearized approximate mathematical models shown in F1g. 2. As suggested in the discussion on nodeling, the gi ial model is separated Into a set of nodules, anc Fig. 2 esents only the radules for the visual and vestibular systems. Note that the particular ratheritical representation of the physical systems shown in the figure are only one exam ple of the possible models which could be used. Also, important detalls suct, 
ORIGINAL PAGE IS

OF POOR QUALIT:

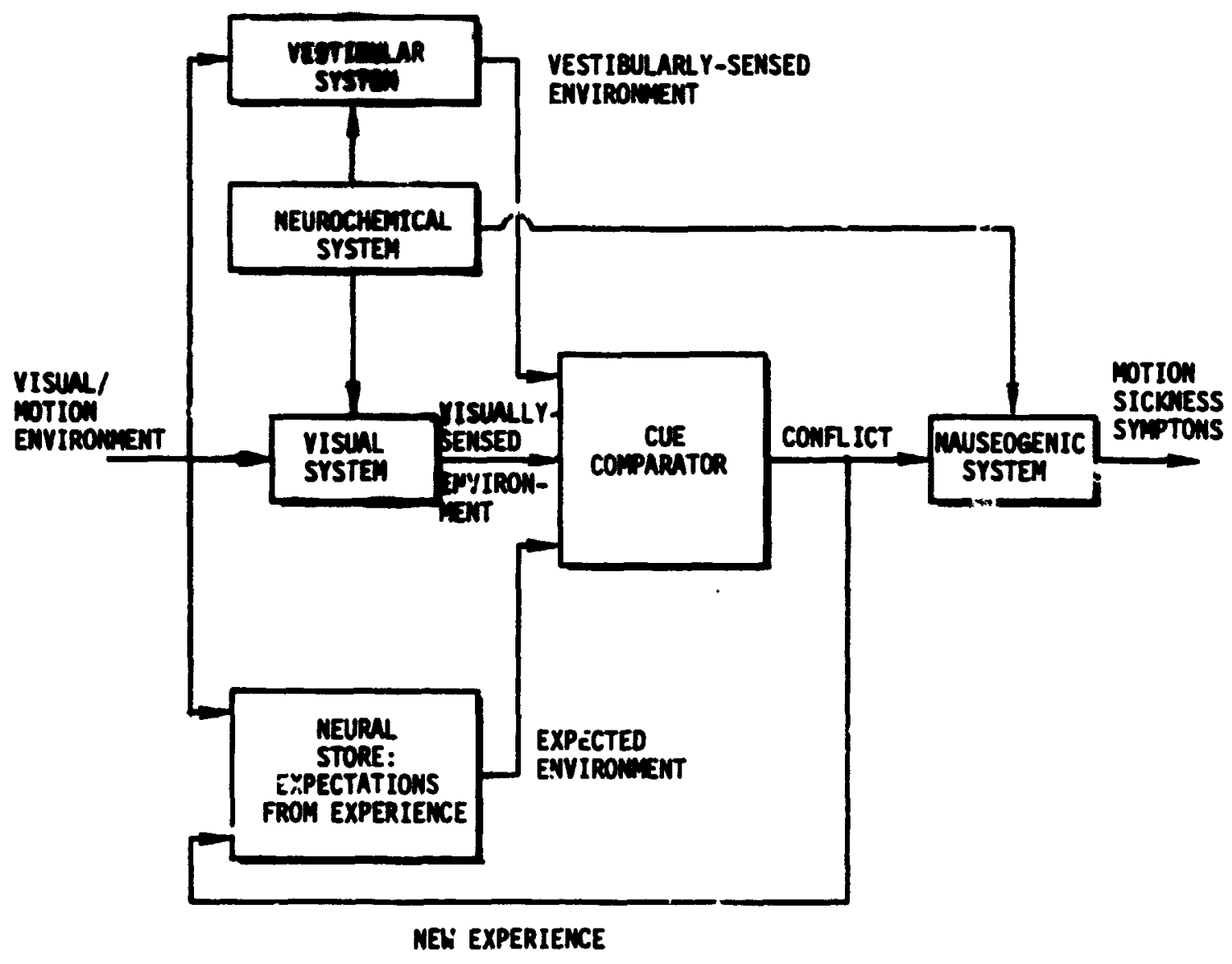

Figure 1. Comprehensive odel: Globel structure saed on Cosceptual "Cur Conflet" vodel 
ORIGINAL PAGE IS

OF POCR QLALITY

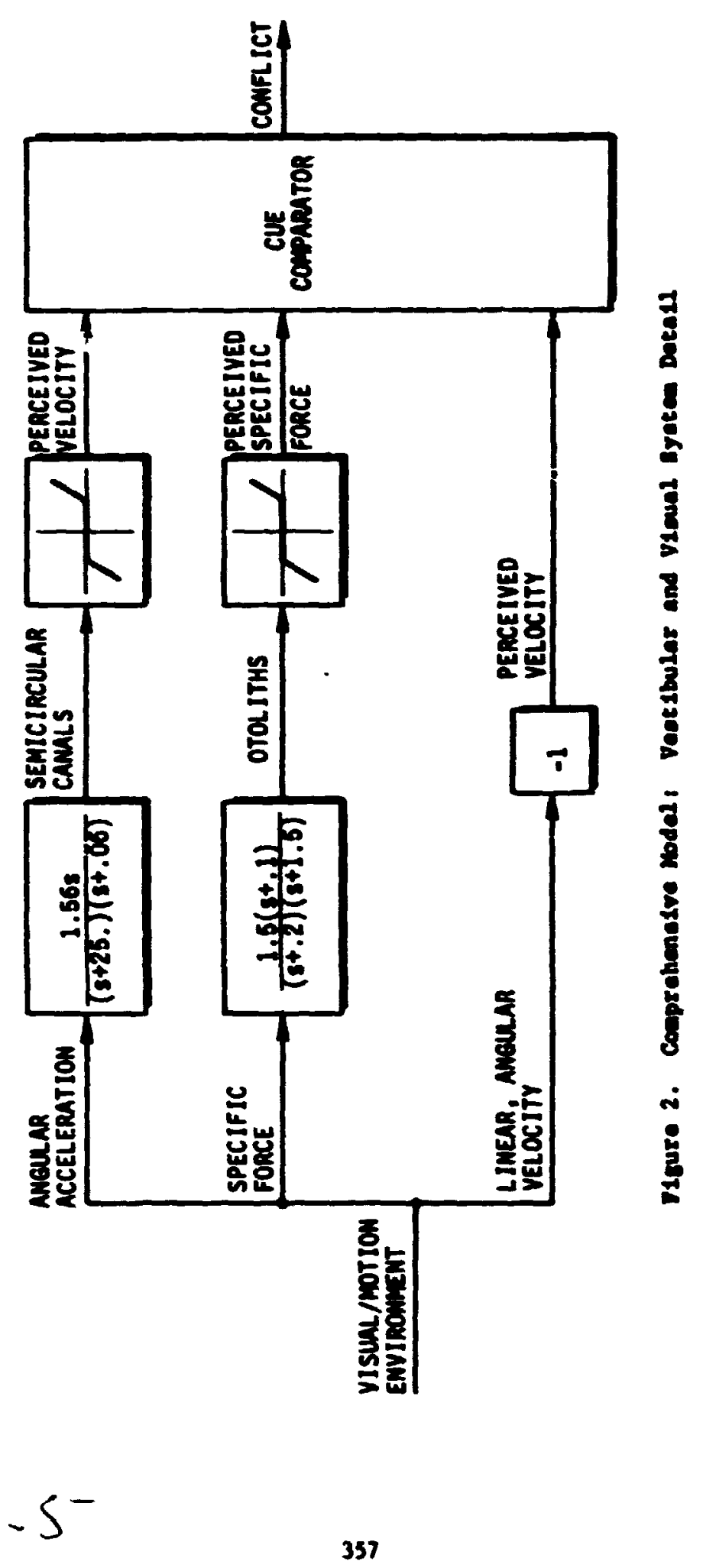




\section{ORIGINAL PAGE IS \\ OF POOR QUALTY}

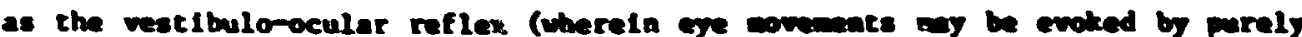

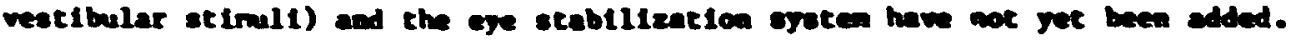

A in example of en ewa finer level of lecell, further hey fecte wheh ore carefulty explore the cue comarator etructure ate cunded next.

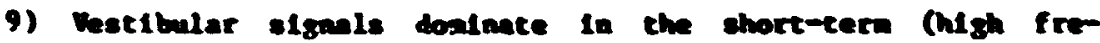

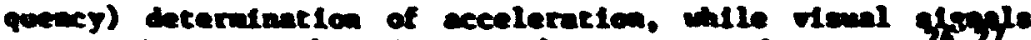

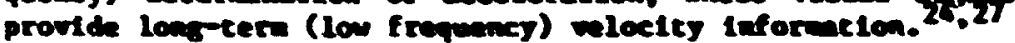

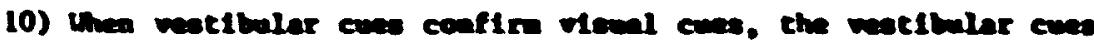

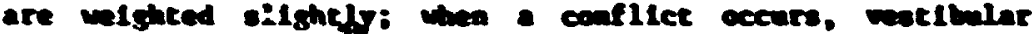
semactow doderes.

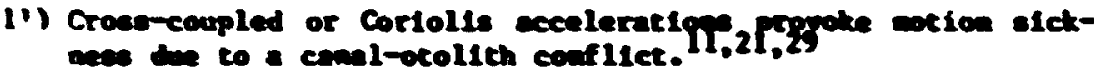

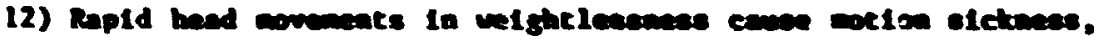

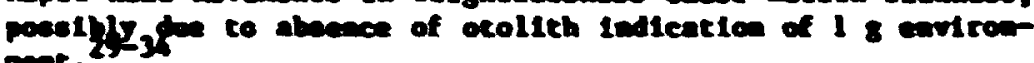

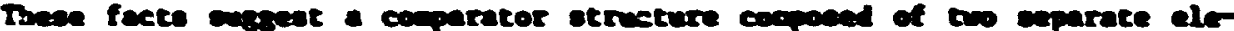

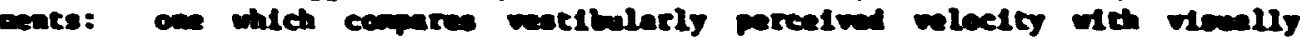

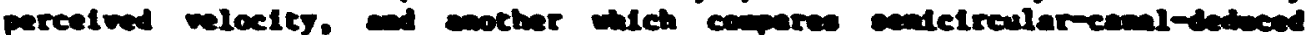

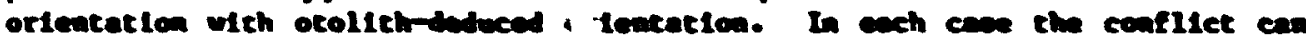

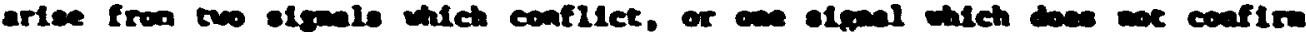

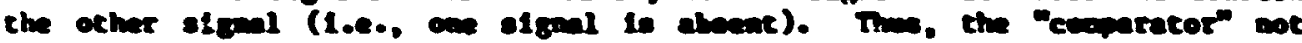

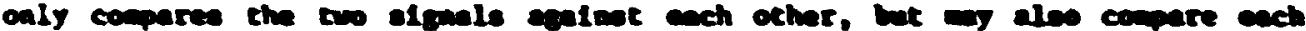

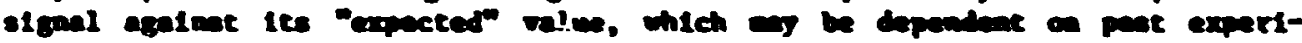
ence, untal set, tratuins. ete.

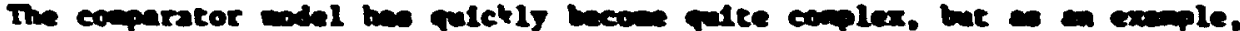

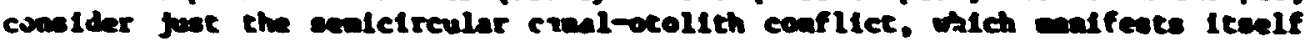

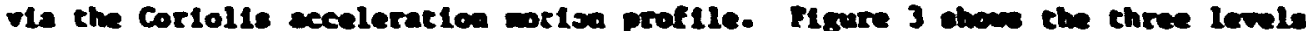

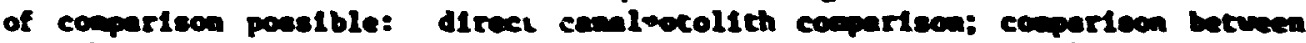

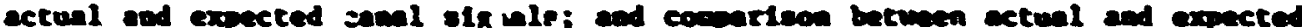

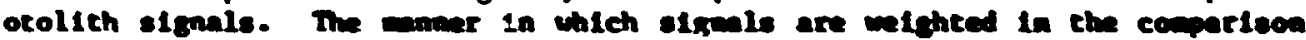

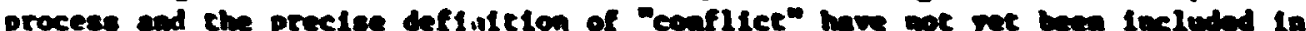

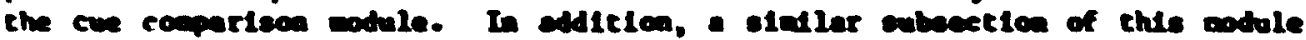

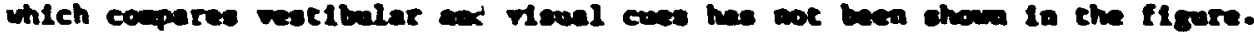

\section{in:}

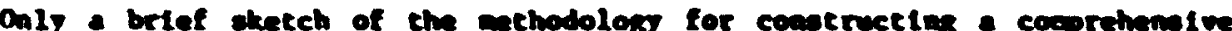

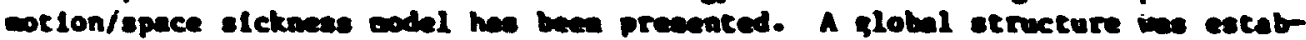

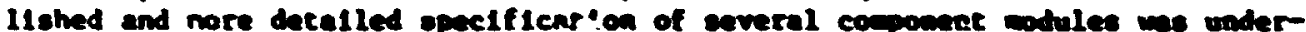

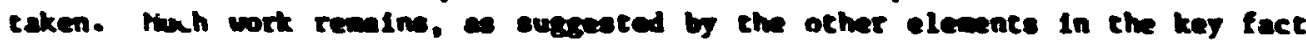

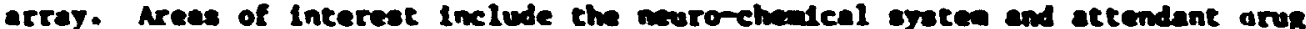

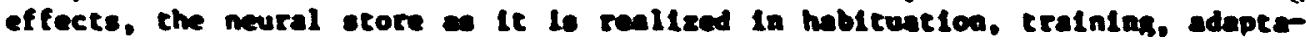

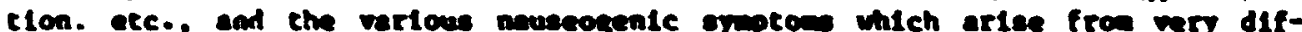
ferent vieul and opton emotronments. The appendiz contale the full erray 
original page Is

OF POOR QUALTY

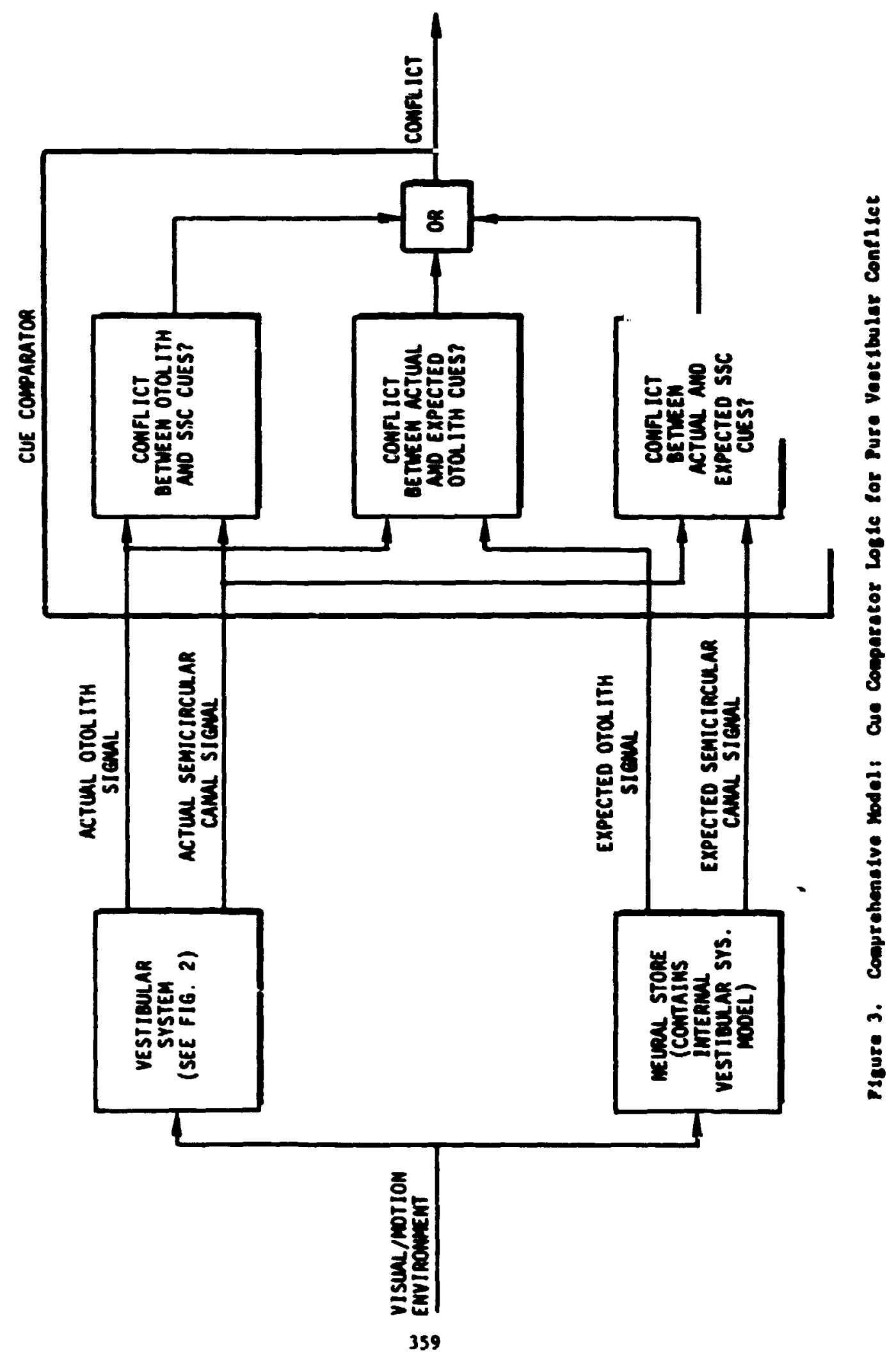




\section{ORIGINAL PAGE IS \\ OF POOR QUALITY}

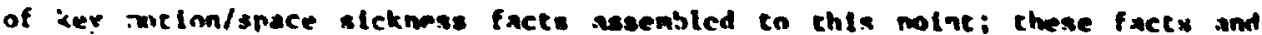
others iron ungoulne reseacch vill be enployed in the contimution of tils model-millatins affort.

Arming

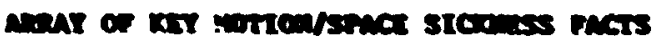

\section{Role of the Veatibular syaten}

Labyrinthine defectives (LD) do not get cotim stek. 15,16

La never experience the inversion IIIusion. 14

1.Me exhibte erenter levels of A and F-phenomens Mias thang nomals, and the patterns of appatent tilt wa. nctual cllt are ilfferent. Is

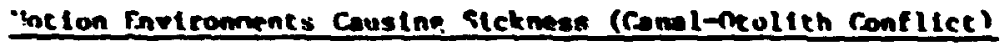

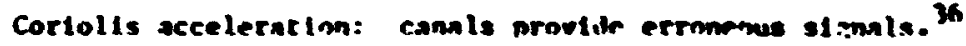

Airect correlation exlats petumen atressor Inhiced by head novernent and chatr rotat loas veloctey.

Hecessury merameters in predicting the manticurle of the crous-counled anesilar acceleration disturhance are boch the momitude of the Individyal

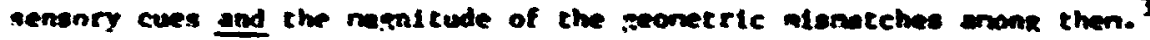

Vertical oscillation: nost nuweengente frequency is sround $n .2$ lis. Slckneas Atnintshes ahove that and is nonexistent above 0.0 He.

The probuhllistic assunption that ench conponene in a sintof-simasids

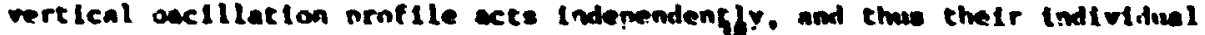
nausemsentc effects add, does mot mold truse.

tubert and theller effects (E- and A-nhenomena): lateral tlle with no visual reference induces an overconmenentino hise in subjective estimtion of cllt anvile at 15-20 dea (5-phenomina) and an un-tercompenaatine bias at larger ansles ( $A$-phenomena). 39

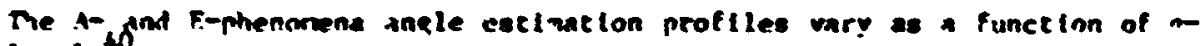
level.

Wel tht leseness/ggrom motion slekness nay be Inluced nerely by mowinn the heat in zero p.

Increaxed freetion of woveivent in "ayel sht less environment cairses Increased

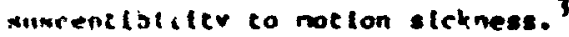

llead mvetvents are essent lal to produce notion sickmess in zero $9.41,62$ 


\section{ORIGINAL PAGE IS \\ OF POOR QUALT}

Syaptow of extion and spece elcknese are Drtually Identical. 43

Crose-coupled anfular acealeration potion are particularly affective in

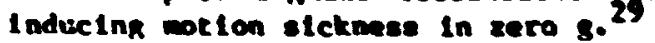

Recurn to mormokravic environment from sero 8 is accoepanted by feelings of Inetabllity and postural disturbance, rather than nowees and romitins. 21,62

In roller conster flight (parabollc manuvers) it is found that ouscoptibility to x-axis acceleration chanpes in pigher than to z-axte acceleration ehanges In eliciting wotion sickoses.

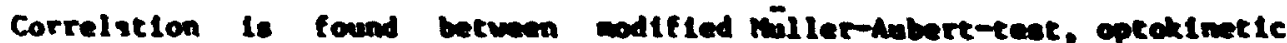

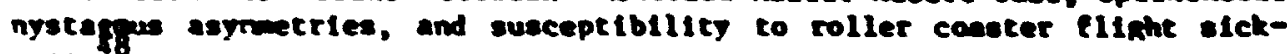
ness.

\section{Visual Invironsents Causing Stckoess (Visual-Vestibular Conflicte)}

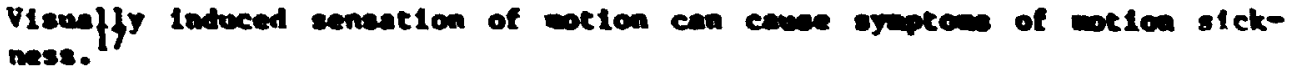

Peripherel field ant be eximalated in order to induce self motion. 4

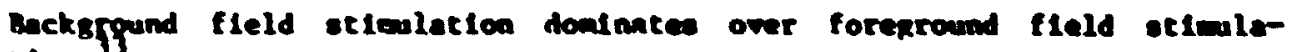
rion. 33

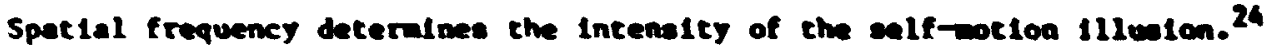

Pitch and roll visually Induced self wotion is stromisly dopendent on head

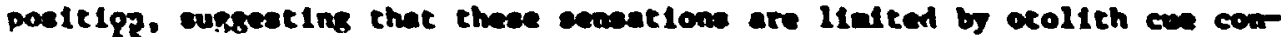
flict.

Subjets experience stronger seneations of pltchios dow than pitching up. $\$$

Pltch asyanetry is fixed with reapect to the had, rather than to the subjective Iopressigg of "down," Indlcating that Ite origin is visual rather than vetibuler.

Visua:ly Induced tile presents a puredoxical lllueton of contimous body and target novenent combined with liatted sensed displacement of both; this constrains the apparent Induced onife. 46

Circularwection: angular acceleration detection threaholds are increased when acceleration opposes circularvection difpction, Ioplying that the vestibular threshold to not purely mehanical. 20

Unearvection: detection threshoida for beckwarde tV are sonsistently amaller chan for formerde LV. 
Delay in LV onset ts attributed to short tern (hish frequency) veatibular dominance (LV Is nost coapelling, then acceleration co constant veloctty is belou the vestibular threshold). 19

Breakdown of the pursult reflex and suppression of the vestibulo-ocular reflex occyy over the sane frequency region, inplying a sintlarity of aechanises.

Vestibular Cortolis effects and optokinetcafly induced peeudo-cortolis effects cannot be distiaguished qualitatively.

Optokinetic motion sickness syptoos are very different fron those elfetted ra restibular atimulation. Also, execution of hesd novenents

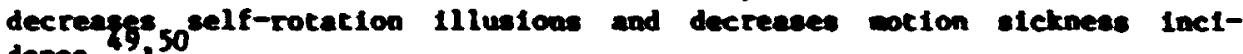
dence. 9,50

\section{Coabined Visual/Motion Eavirounents Causins Sickneas}

Vesclbular sigmals doalate in the short term deteraination of acgeleracton, while vieunl ignals provde longetern velocity informetion. 27

When restbulat cues confire visual cues, the restibular cues are weighted slightly; when a conflict occure, the vestibular seasectom doninate. 2

Vestibular etimalation can wdify the dsuel evalueton of inge motion. 51

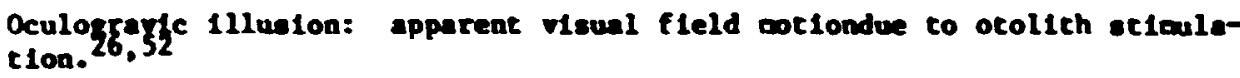

In wightlessness, objects Hewed againat a dark background apper dis-

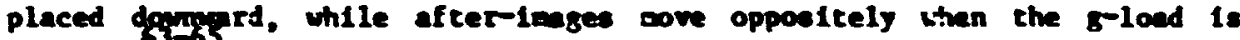
reesoed. Ocuiogral 1llusigf:, apparent visual field motion due to semicircular
camal seimulation.

\section{Drus Effects}

Optokinetic and vetibular motion sickness are siallarly sffected by antinotion-sickness druge, Implying a comon pathway for both. 3

Drug comblnations which act synergistically to geduce notion sickness Include an ant1-cholenergic and esmathentertic. 13

Anc1-motion-sickness drug effects: Increase subjective acceleration thresholis; dininish post-rotational 5 jsetagmus; wet probable site of action is restibular mucletc symapses. 53

Drugs successful in treating wotion jickness also seem to retard symptoms of dysaetric dyelexia and dyspraxie. sh 


\section{Psychological Factors}

Field-independent subjects make a priori assurntions about a given notion environment based on past experience and, when confronted with a new situation, preduce motor responses which may be inappropriate for the environment. Field-dependent subjects produce notor responses directly in response to the current environment. Field-inģipendents are more susceptible than field-dependents to notion sickness. 35

Field-independent $\$ 6,59$ nore likely to experience simulator sickness than
field-dependents. Vestibular thresholds increase if workload increases. 58 Yestibulag thresholds decrease if subject has pricr knowiedge of notion
profile.

\section{Adaptation, Habituation, Training}

Active head 3 body wovenents are superior to passive in developing adaptaLeast disturbing/wost effic: int means to Coriolls acceleration adaptation is without visual reference. 21

Adaptetion to zero 8 occurs within 3-6 days and syptons never recur. 32

Corlolis accelerations are very provocative on the ground and in transient weightlessness, but after adaptation to zero $g$ they are ineffective in producing ootion sickness. 30,31

Mdaptation to zero 8 does not transfer to seasickness. ?l

Motion sickness susceptibility to Coriolis stinulus does not accurately predict susceptiblitty to space sickness. 36

Autogenlc feedback training is a compelling and sugcessful technique for adaptation to notion-sickness-causing environments.

\section{Miscellaneous Facts}

Visual cyess dominate proprioceptive cues in determining limb and body position. 62 
Lhanduces

Treisman, M., "Mtotion Sickness: An Evolutionary Rypothesis," Sc'ence, Vol 197, 1977. pp. 493-495.

2Reason, J. T., mblotlo. Stckness: Sone theoretical and Practical Considerations," Applied Frgononics, Vol. " No. 3, 1978, pp. 163-167.

Benson, A. J., Posstbie Mechanisas of Hotion and Space Sickness, RAF Inst. of Av. Med., 197 ?.

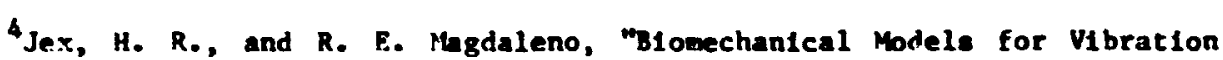
Fseathrough to hands and Head for a Sealsupine P1lot," Av., Space, and Environ. :ted.. Vol. 49, No. 1, Jan. 1978, pp. 304-316.

FicRuer, D. T., and E. S. Krendel, Blathematical Models of Human P1lot Behavior, AGARD-AG-198, Jan. 1974.

GMcRuer, D. T., and H. R. Jex, "A Review of Quasi-Linear Pllot Models," IEEE Trans., Vol. HFE-8, Ho. 3, Sept. 1967, pp. 231-249.

7HeRuer, D., Munan Dynanics in Man-Hachine Systems," presented at 7th Triennial IFAC World Congress, Helsink1, June 1978.

Brleinaan, D. L., S. Baron, and W. H. Levison, "An Optimal Control Model of Puman Response, Parts 1 and 2," Automatica, Vol. 6, 1970.

${ }^{9}$ Young, L. R., and J. L. Melry, A Revised Dyanalc Otollth Model, MRL-TR$66-209,1968$.

100rasby, C. C., Model of Bumen Dynamic Orientation, MASA CR-132537, Jan. 1974 (also MIT, Ph.D. Thesis).

1'Young, L. R., "A Control Model of the Vestibular Syster," presented at IFAC Symposiun of Technical and Blological Problem in Cybernetics, Yerivan, Armenia, Sept. 1968.

${ }^{12}$ Van Egmond, A. A. J., J. J. Groen, and L. B. H. Jonkees, "The Mechanics of the Seniclrcular Canal," J. Physlology, Vul. 110, 1949, pp. 1-17. 1-3.5.

13 Money, K. E., "Motion-S1ckness," Physiol. Rev., Vol. 50, Jan. 1970, Pp.

${ }^{14}$ Grayblel, A., and R. S. Rellog8, "The Inversion Illusion In Parabolic Fligit: Its Probable Dependence on Orolith Punction," Aerosp. Med., Vol. 38, 1967, pp. 1099-1103.

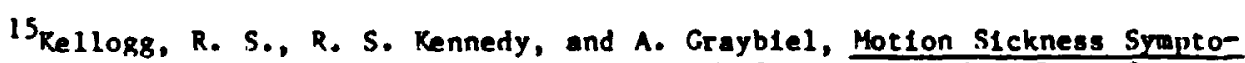
matology of Labyrinchine Defective and Normal Subfects During Zero Gravity Maneuvers, AMRL, June 


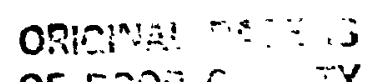

OF FOOR

16 Kennedy, R. S., A. Fraybiel, R. C. IkDonough, and F. D. Bockwith, Symptomatology Under Storm Condttlons in the Horth Atlantic in Control Subjects and in Persons with Rilateral Labyrinthine Defects, Nav. Sch. of Av. iled., ISA:1-928, iay 1965.

17.liller, J. W., and J. F. roodson, Motion Sickness in a Hellcopter Simulation," Aerosn. Med., Vol. 31, 1960, pr. 204-212.

18 pichgans, J., and Th. Brandt, "Optokinetic Motion Sickness and PseudoCorlolis Effects Induced by Hoving Visual Stimuli," Acta Otolaryng., Vo?. 16, 1973, pp. 339-348.

19Berthoz, A., B. Pavard, and L. R. Young, "Perception of Linear Horizontal Self-totion Induced by Peripheral Vision (Linearvection): Basic Characteristics and Visual-Vestibular Interactions," Exp. Brain Res., Vol. 23, 1975, pp. $471-489$.

20 Barnes, G. R., Vestibulo-Ocular Responses to Head Turning Movements and Their Functional Signiftcance During Visual Target Acquisition, Univ. of Surrey, England, Ph.0. Thes1s, 1976.

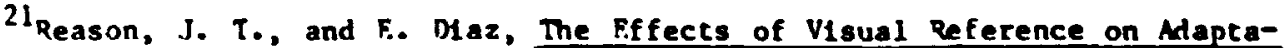
tlon to Corlolls Accelerations, Flying Personnel Res. Conm., London, Rept. FPRC-1303, :lay 1970.

${ }^{22}$ Young, L. R., C. Y. Dran, R. E. Curry, and J. M. DHchgans, "A Descriptive ilodel of lulti-Sensor Human Spatial Orfentation with Appllcations to Visually Induced Sensations of Yocion," AIM Paper 73-915, 1973.

${ }^{23}$ Young, L. R., "The Role of the Vestibular System In Posture and Ilovenent," in V. R. Mountcastle, ed., Medical Physiology, St. Louts, C. V. Mosby Co., 1974.

24 Young, L. R., "Visually Induced Motion in Flight S1mulation," presented at FiP Specialists Meeting on Plloted Alrcraft Environment Simulation Techniques, Brussels, 24-27 Apt. 1978.

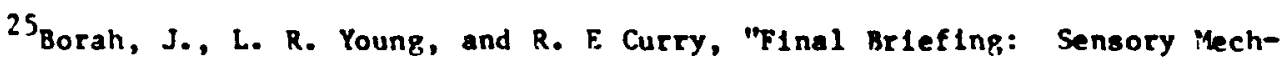
anisn Vodeling Study," AFHRL, WPAFB, Contract F33615-76-6-0039, 1977.

${ }^{26}$ Peters, R. A., Dynanics of the Vestibular System and Their Relation to Motion Perception, Spatial Orientation and Illuslons, NASA CR-1309, 1969.

27Young, L. R., "On Visual Vestibular Interactions," Fifth NaSA Symposium on the Role of the Vestibular Organs in Space Pxplorat: 13n, MASA SP-314, 1970.

28 Yuung, L. R., J. Dichgans, R. Plurphy, anc Th. Brandt, "Interaction of Optokinetic and Vestibular Stimuli in Iotion Perception," Acta Otolaryng., Vol. 76, 1973, DP. 24-31.

29yller. E. F. II, and A. Grayblel, Motion S1ckness Produced by Head licvenent as a runction of Rotational Velocity," Aerosp. :led., Vol, 41, 1970, pp. $1180-1184$. 
${ }^{3 n}$ Graybiel, h., R. S. Kennedy, and R. S. Kellogi, Moriu--Sickness Prectn1tated in the Weightless Phase of Parabolle Fllght by Coriolis Accelerations, Nav. Aerosp. led. Inst., NAMI-ID61, 1969.

${ }^{31}$ Graybiel, A., F. F. M1ller, and J. L. Honick, "Experiment i-131. Hunan Vestibular Function. 1: Susceptibility to ilotion-sickness," Proc. Skylab Life Sclences Symposiun, IASA TY X-58154, Vol. 1, 1974, pp. 169-198.

32 Berry, C. A., "Findings on Anerican Astronauts Rearing on the Issue of Artificlal Gravity for Future ilanned Space Vehicles," Fifth Symposium on the Role of the Vestibular Organs in Space Exploration, NASA SP-314, 1973, PP. 1522 .

${ }^{33}$ Berry, C. A., and J. L. Honick, "Findings on American Astronauts Bearing on the Issue of Artificial Gravity for Future itanned Space Vehicles," Aerosp. iled., Vol. 44, 1973, pp. 163-168.

34Miller, E. F. II, and A. Graybiel, Motion Sickness Susceptibility Under Uefghtless and Hypergravity Conditions Generated by Parabollc Flight," Aerosp. Med., Vol. 40, 1969, pp. 862-868.

35illler, E. F. II, A. R. Fregley, and A. Grayblel, Conparison of Visual Horizontal Jisdgments by Subjects with Known Defects and Hormal Persons Tilted U1th Respect to Gravlty, Nav. Aerosp. Med. Inst., NAMI-989, 1966.

${ }^{36}$ Graybiel, A., E. F. Miller, and J. L. Houlck, "Individual Differences in Susceptibility to Motion-Sickness Among Six Skylab Astronauts," Acta. Astronautica, Vol. 2, 155-174.

${ }^{37}$ Cuedry, F. E., Jr., and A. J. Benson, "Corlolls Cross-Coupling Effects: nisorienting and Nauseogenic or Not?" Av., Space and Environ. Med., Vol. 49, No. 1, 1978, Dp. 29-35.

${ }^{38}$ Gulgnazd, J. E., and M. E. McCauley, Mlotion S1ckness Incidence Induced by Complex Perlodic Waveforms," Proc. 1977 Annual Meeting of the Human Factors Soc1ety, 1977.

39itller, E. F. II, A. R. Fregley, G. Van den Brink, and A. Graybiel, Visual Localization of the Horlzontal as a Function of Body Tilt Up to $\pm 90^{6}$ from Gravitatlonal Vertical, Nav. Sch. of Av. Med.. NSAM-942, 1965.

Gilller, E. F. II, and A. Grayblel, Magnitude of Gravito-inertial Force, an Independent Variable in Egocentric Visual Localization of the Horizontal," J. Exp. Psychol., Vol. 71, 1966, pp. 452-460.

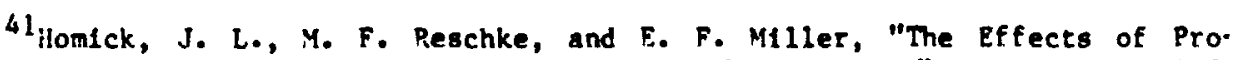
longed Exposure to Helghtlessness on Postural Equilibrium," Proc. Skylab Life Sclences Syaposium, NASA TM X-58154, Vol. 1, 1974, pp. 221-238.

42 felvill Jones, G., "Adaptive Neurobiology in Space Flight," Proc. Skylab Life Sclences Symposium, NASA Iil X-38154, Vol. 2, 1974, pp. 847-R59. 


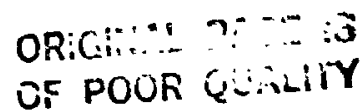

${ }^{43}$ Graybtel, A., "Structural Elements in the Concept of Yotion-Sickness," lerosp. iled., Vol. 40, pp. 351-367.

${ }^{44}$ Held, R., J. M. Dichgans, and J. Bauer, "Characteristics of Moring $V$ 'sual Scenes Influencing Spatial Orientation," Vision Res., Vol. 14, 1974, pp. 1-9.

${ }^{45}$ Young, L. R., C. \%. Onan, and J. Y. Dichgans, "Influence of Head Orlentation on Visually Induced Pitch and Roll Sensation," Av., Space and Environ. lled., Va1. 46, 1975, pp. 264-268.

${ }^{46}$ Dichgans, J., R. Held, L. R. Young, and Th. Brandt, mloving Visual Scenes Also Influence the Apparent Direction of Gravity," Sclence, Vol. 178, 1972, pp. 1217-1219.

47 Barnes, C. R., A. J. Benson, and A. R. J. Prion, "Visual-Vestibular Interaction in the Control of Eye ilovements," Av., Space and Environ. iled., Vc?. 49, No. 4, 1978, pp. 557-564.

48 von Baungarten, $R$. J., B. P IAright, H. Vogel, and R. Theumber, "Physiological Responses to Hyper- and Hypogravity During Rollercoaster Flight," Av., Space and Environ. Med., Vol. 51, No. 2, 1980, pp. 145-154.

${ }^{49}$ Lackner, J. R., and R. A. Telxelra, "Optokinetic Motion Sickness: Continuous Head Movenents Attenuate the Visual Induction of Apparent SelfRotation and Symptoms of Motion Sickness," Av., Space and Environ. Med., Vol. 48, No. 3, 1977, pp. 248-253.

${ }^{50}$ Guedry, F. E., Jr., "Visual Counteraction of Nauseogentc and Disorienting Effects of Some Wide-Body ilot Lons: A Proposed Mechanism," Av., Enace and Environ. Med., Vol. 49, No. 1, 1978, pp. 36-41.

51 Pavard, B., and A. Berthoz, "Linear Arceleration Modifles the Perceived Velocity of a lloving Visual Scene," Perception, Vol. 6, 1977, pp. 529-540.

52Grayblel, A., "The Oculogravic Ill'sion," Arch. Ophthal., Vol. 48, 1952, pp. 605-615.

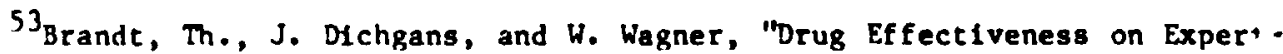
mental Optokfnetic and Vestibular Motion Sickness," Aerosn. Med. Vol. 65, No. 11, 1974, pp. 1291-1297.

54 Frank, J., and H. N. Levinson, "Seasickness Mechanisms and iledications in Dysnetric Dyslexia and Dyspraxia," Academic Therapy, Vol. 12, No. 2, 1977, pp. 133-153.

5SAle: inder, R. A., and G. V. Barrett, "Relationship Retween Perceptual Style and Responses to Visual Motici Under Active and Passive Vlewing Cond1tlons," J. App. Psychol., Vo1. 60, No. 4, 1975, pp. 507-512. 
S6rarret, G. V., and C. L. Thornton, "Relationehtp Between Percedtual Style and Simulator Sickness," J. Appl. Psychol., Vol. 52, 1968, Pp. 304-30\%.

${ }^{57}$ Testa, C. J., The Prediction and Evaluation of Simulator Illness Symptomatology, UCLA, Unpublished doctoral diseertacton, 1969.

58 Hosman, P. J. A. W., and J. C. van der Vaart, Vest Sbular Models and Thresholds of "lotion Perception; Results of Teste in a Fight Simulator, Delft Univ. of Tech., Rept. T.R-265, 1978.

59likaelian, H., and R. Held, "Two Types of Adeptation to an OptianllyRotated Visual Field," Am. J. Paychol., Vol. 77, 1964, pp. 257-263.

60 Reason, J. T., and A. J. Benson, "Voluntary Movenent Control and Mdaptation to Cross-Coupled Stimilation," Av., Space and Environ. Med., Vol. 49, No. 11. 1978, pp. 1275-1280.

${ }^{61}$ Cowings, P. S., "Autogenic Feedback Tralning for Controlling Vestibular Synptomatology," Proc. of a Space Mot lon SLckness Sytaposium, NASA/JSC, 1978.

62 Lackner, J. R., and A. Grayblel, "Somatosensory Motion After-Effect Following Earth-Horizontal Rotation About the Z-Axis: A New Illusion," Av., Space and Environ. Med., Vol. 48, Ne. 6, 1977, Pp. 501-502.

${ }^{63}$ Gerathewohl, S. J., and H. D. Stallyngs, "Experiments Di:cing Welghtlessness: A Study of the Oculo-agravic Illusion," J. Aviat. Mzd., Vol. 29, 1958, pp. $504-516$.

64 Roman, J. A., B. H. War-en, J. I, Niven, and A. Brahblel, "Some Observations on the Behavior of a Visual Target and Visual After-Image During Parabolic Flight Maneuvers," Aerospace Med., Vol. 34, 1963, pp. 841-846.

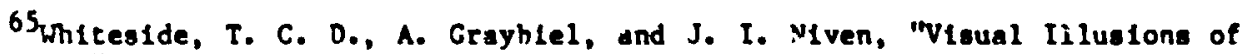
Movenent," Brala, Vol. 88, 1965, pr. 193-210.

6hGraybte1, A., and D. I. Hupr, "The Oculo-Gyral Illuston, a form of Apparent Motion Which May Be Obaervid Following Stimulation of the Sentelrcular Canals," J. Aviat. Med., Vol. 17, 1946, Pp. 3-27. 


\title{
EVAWATTON OF A TRAJECTORY COMYAND CONCEPT FOR MANAAi CONTROL OF CARRIER APPBOACHES AND LANDDNGS
}

\author{
Walter E. Mcleill, Aerospace Engineer \\ G. Allan Smith, Jr., Aerospace Ingineer \\ Rorald M. Gerdes, Aerospace Engineer and Pilot \\ National Aeronautics and Space Adninistratican \\ Ames Research: Center \\ Moffett Field, CA 94035
}

\section{SURARY}

A novel trajectory control system cancept has been implemented to provide manual control of a conventional jet aircraft. This concept, called Total Aircraft Flight Controi System (TAFCOS), Utilizes an inverse model of the aerodynamic and propuision characteristics and employs feedfarwand control to provide the required acceleration command. The concept requires an-boand digital computations which can easily be handled by a modern airbarne computer.

The system was studied in a piloted simulation of the carrier approach and landing task with primarily visual flight and guidance cues. The principal modes of vertical flight-path control investigated were vertical velocity command and vertical acceleration command. The study included manial carrier approaches with and withour moderate ship motion and associated air disturbances, and tests of the effects of discrete gusts.

Manual control of flight path through this rew concept was shown to be feasible as an addition to an autamatic control systen ind to have potential as an improved mode of control over conventional control for the carrier approach task. The concept also offers several advantages, among which are design flexibility, automatic compensation for external disturtances, and prevention of abusive pilot control.

\section{INTRODUCTION}

Manual control of Navy shipboand aircraft during carrier approach ss and landings is a demanding task which becomes increasingly difficult as external disturbances grow mrse severe. Tha probiem of vertical flight-path, or "meathall", zontrol is the one that presents the greatest difficulty, particularly near' touchdown, where the ship's air wake and deck motion require close coondination of pitch attitude ard engine thrust.

..is paper reports the results of a piloted simalation study of an application of a novel feedfonwand trajectory - command flight control system to the maxial rarrier approach and landing task. On the basis of previous flight and unramed simulation struties of such svstems applied tc aurtomatic control, it appeared that improvements in manui carrier approaches could be achieved in terms of better flight-path control, reduced touchdown scatter, and reduced pilot woriload. 
This system, alled Total Aireraft Fight Contral Syste (TNFCos) has been in developent at $A=3$ Resemch Center for the past five yeurs $1,2,3$ and has been tested successfully both in ground-based simlators and in flight with STOL aircraft. Adaptation to manul contral is streightforind and provides an atrective and logical adjunct to an automic control systen, as IAFUi :as originally conceived. The advent $i$. recent yours of the airbarne digital cunpurer enables the basic systen stucture and the recuired additions to be prograned readily and inepensively.

In the present study, samal control through IAroos was applied to the Navy A-TE attack aircruft perforing straight-in visual curvier epprouches and lantings, to assess the feasibility of the sconcept for the task and to copare i provenents in flight-path contral and ianting perfasunce using different vertical oc and wodes.

\section{STixols}

A rough $\infty$ anded attitude direction cosine antrix

As swoth conanded attitude direction cosine atrix

$\hat{A} \quad$ neasured attitude direction cosine matrix

$\mathrm{C}_{\mathrm{D}}$ comanded drag coefficient

c.

conanded lift coefficient

$\mathrm{C}_{\mathbf{c}}$

conded rolling-anent coefficient

$\mathrm{C}_{\mathrm{m}}$

ounded pitching-want coefficient

c

comanded yauing-mont coefficient

$\mathrm{C}_{\mathrm{T}}$

comandsd thrust coefficient

acoeleration due to gravity

R

rough camanded position vector

$R_{\mathbf{S}}$

snooth comanded pesition vectar

$\hat{\mathbf{R}}$

measured position vector

$\mathbf{V}_{\mathbf{r}}$

rough comanded velocity vector

S

surooth cominded velocity vector

$\hat{v} \quad$ measured velocity vectar

$\dot{v}_{v}$ rough comanded acceleration vectar

$\dot{v}_{s} \quad$ smooth commanded acceleretion vector 


\section{Cri: $: \cdots \cdot$ : \\ OF PUOFi Quititi?}

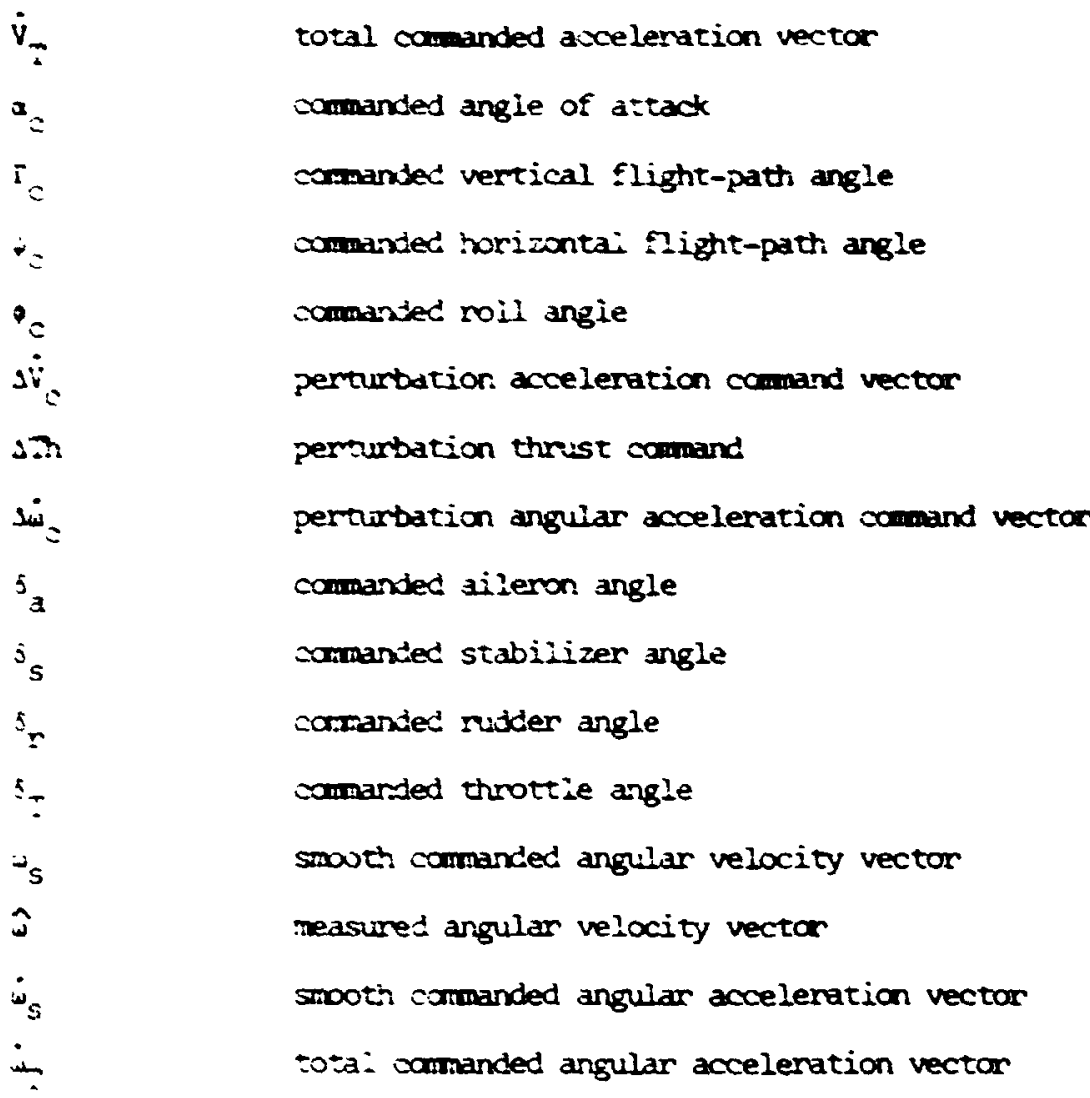

DONTROL SYSTEY DESCRTPTION

System features. - TAFCOS uses a balance of open-loop feedforwand controi and closed-loop feedback control. The presence of detailed models of the aircraf: Esrce, mument and thrust characteristics in the feedforwand path enabie it to provije most of the control. Feedback is needed only to compensate for external disturbances and for differences between the models and the actual aincraft. The basic arnangement of these control loops is shown in sigure 1.

In TAFCOS: pilot input commands of aircraft velocity, airspeed or accejanation are conbined, smovthed, and linited to provide a smooth executable ranslational acceleration command vector in inertial axes. Then the system forces the aircraft to follow closely this acceleration command and the corresponding velocity and position trajectory.

Figure I shows that the feedforward path (solid lines) includes a trim nap which is an inversion of the aircraft model. This trim map in series with the actial airrraft provides an approximate identity (i.e., output neariy equals input). The tashed lines indicate tow ile feedback is compared 


\section{OF PCOR TH:}

with the comand to form an error signal which is then used to close the feedback loop. It should be noted that the feedback loop is closed ahead of the trim mad so that it includes the identity; thus the feedoack $100 \mathrm{p}$ is linear and conventional linear techniques can be used in the design of the regulator.

Representation of variables by three-conponent vectors and angles by their three-by-three direction cosine matrices permits easy transfaration of quantities between different coandinate systems. Pilot comands are in relative velocicy axes and $x$ ent calculations are performed in body aces.

System structure.- Since the IAFCos concept is different from comentional designs, a beief explanation of its structure will be helpful in understanding its operation. For the present application a manually-piloted stabilit; augmentation system and trajectory comind system has been sreated by additions to a completely artomatic control systen. This procedure is in contrast to the usual simplification of an autcomatic systen to provide mamual control. The increase in complexity is considered justified bv potential performance advantages and by design flexibility. Advances in airbocre digital romputers have made these capabilities possible and relatively inexpensive.

Figure 2 is a signai flas diagrem of IAFCOS. Again to enphazise the open-loop characterisitces, the feedfarwand paths are shom by solid lines while the corrective feedbacks are shown by dashed lines. Most of the variables are three-component vectors; $e_{. g}, v_{k}$ is the rough comanded relucity vector in inertial aces and is smoth comanded angular-aceler ation in body aces. The three pilot isputs are: (1) farwand anl aft movements of the control stick to command either vertical velocity ar vertical acceleration in inertial axes; (2) left and right displacement of the stick to command rate of change of lateral acceleration in velocity axes; and (3) throttle lever position to comnand airspeed. All rough command signals are directly propartional to the magnitide of the control wotir. For exalf le, the first velocity axis is directed along the aircraft veioc. vectar with the second axis in the horizontal plane so that a cansiant lateral stick deflection comands a constant build-up of centripetal acceleration. When the stick is returned to neutral, a corstant centripetal acceleration in the horizontal plane and perpendicular to the instantaneous velocity vector is commanded. The result is a circillar flight path with a constar.t bank angle.

The tajectory time sequencer combines the various pilot signals and calculates a total rough commanded acceleration vector in three-dimensional inertia: space. It also salculates corresponding inertial velocity and position vectors. These vector comands are rough in the sense that they may have excessive and abrupt rates of change and call for maneuvers trat may not be executable by the aircraft within the desired stall margin, comfartable angular acceleration or attitude limits, $\alpha$ engine response and control surface limits.

The trajectory command generetor smooths, linits, and rotates the rough commands to provide an executable comanded-acceleration vector $\dot{v}_{s}$ and corresponding velocity and position vectors $v_{s}$ and $R_{s}$ in velocity axes. Each channel of the trajectory command generator includes four integrators and 


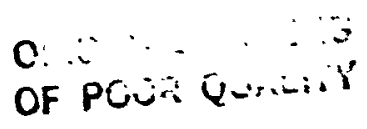

appropriate internal feedback loops so that a specific dyn-mic response om be provided by poie placenent $a$ other linear techniques. The cosponts of the smooth commanded velocity resolved back into inertial aces give the commanded horizontal and vertical flight-path angles $t_{c}$ and $r_{c}$.

The force trim map accepts the counanded specific force vector and combines it with comanded dynamic pressure and wing area. It then calculates commanded total $\mathrm{lift}$ and trag coefficients which include the effects of engire thrust. An inverse interpolation of the aircraft ift and dreg characteristics stored as tabular data then yields the angle of attack and thrust coefficient required to follow the trajectory. Figure 3 is a representation of the force trin map data. It is seen to be a family of lift-drag polars for several values of twust coefficient $C_{T_{C}}$. An exauple is shom by the small circle. If a lift coefficient of 1.2 and a drag coefficient of zero are commanded, then an angle of attack of 12 degrees and a trurst coefficient of 0.2 would be the outputs. At this point the comanded irpurt lift and crag coefficients are limited to the perineter of the trim map $\sigma r$ to a subperimeter to provide suitable safety margins.

The horizontal and vertical flight-path angles $\|_{c}$ and $r_{c}$, the roll angle $c$, and the angle of attack $\alpha_{c}$ are combined in figure 2 to give the commandcd direction cosine matrix from inertial to body aces $A_{2}$. This commanded aircreft attitude is the input to the attitude comand generator.

The attitude command generator has a similar function to the trajectocy command generator. It has two integretars and appropriate internal feedback loops. The output is a smooth, executable comanded angular acceleration vector $\dot{\omega}_{s}$, the corresponding consistent angular velocity vector $\omega_{s}$, and the attitude matrix $A_{S}$.

in thrust coefficient from the farce trim map $C_{T_{c}}$ is processed by a power cumand generator and engine trim map to calculate the required throttle angle $\delta_{T}$. The power command generator and engine trim map perform the same type of function as the trajectory command generator and force trim map. They provide a smoot. command with suitable dynamics. The engine trim map imvolves inverse interpolation of a table of engine charecteristics.

The moment trim map is the last element in the feedforward path. Its input is the sommanded angular acceleration which is first multiplied by the aimpact iliertia matrix to give the moment vector. It is then converted to mare.' coefficients by carioination with dynamic pressume, wing area, chard and ipan. The moment trim map involves a calculation of the moment already rmo xded by angle of attack, engine thrust, and body rates to determine 1. . much more moment must be supplied by the aerodynamic control surfaces. An inverse interpolation of the aircraft moment data yields the required control surface deflections.

This open-loop control system is then supplemented by feedback loops shown by the dashed elements in figure 2. The smooth translational position and velori-y commands $R_{S}$ ard $V_{S}$ are compared with the measured response $\hat{R}$ and $\checkmark$ anc combined with suitable gains an! limits in the trajectory regulator to \&uve a closed-10op perturbation translational acceieration vector $\Delta V_{C}$. $i$.s vector is added to the open-100p signal $\dot{V}_{S}$ to give the total signal $\dot{V}_{T}$ as inpu:t to the force trin map. The gains in the regulator are chosen by $a$ 


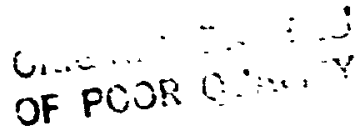

linear pole-placement technique to give a satisfactary dynamic respanse. The vector $\Delta V_{C}$ is genervally a small frection of $\vec{v}_{s}$ and the feedback loop is essentially linear. Similar techniques are used to determine the gains in the ittitude regulatar.

\section{APPLICATION TO CARRIER APEROACH}

Carrier approach task.- Figume 4 shows the normal mamual carrier approach scenario. A level leg is esiablished first, where visual line-up is achieved priar to tip-over. When the pilot receives the proper indication from the Fresnel Lens Optical Landing System (FIOLS) or from the SFN-41 shipboand tracking radar cross-pointers in the coclpit he begins a constantrate descent which, for the present simulation conditions of airspeed 66.4 meters/second ( $129 \mathrm{knots)}$, glide path $3.5^{\circ}$ with respect to the ship, and wind over the deck of 15.4 meters/secand ( 30 knots), was just over 3 meters/second (600 feet per minute). Drring the final descent, guidance is entirely visual with vertical fight path cues provided by the FLOLS.

For the present study, the FLOLS display infocmation was calculated so that an on-glide-path approach resulted in the tail hook touching down midway between the second and thind arresting wires, of which there were four, spaced 12.2 meters ( 40 feet) apant. The FLOLS was assumed to be line stabilized; i.e., glide path stabilized against ship pitching motion but not against heave.

Command modes studied.- The vertical velocity command (VWC) mode and the veritical accleration comand (VAC) mode were selected for study. In making this selection, one line of thought was that a given magnitude of stick inpur should command a given FLOLS "meatball" rete at a particular range. This reasoning led to WC as the prime candidate for the carrierapproach control mode. In crder to de-sensitize meatball response to vertical flight path changes rear the ship, provision was made for decreasing command gain with decreasing range. Both this variable gain and a constant gain were investigated.

The terms VVC and VAC apply only to the rough commanded quantities proportional to stick displacement. Smooth commanded accelerations and velocities are always generated and used within TAFCOS.

Test facilities.- The study was conducted using a fixed-base simulator with a full complement of flight instoments and a set of hytraulicallyloaded fighter/attack aircraft cockpit controls. A closed-cincuit television landing display was used, complete with a scale modei aircraft carrier with heave motion and a servo-driven mechanical representation of the FLOLS to display glide-path error. All simulation calculations were performed by a Signa 9 general purpose digital armputer.

\section{RESULTS AND DISCUSSION}

In the discussion which follows, time histories of control system and airplane behavion are presented for typical simulated straight-in carrier approaches. These approaches include one using vertical velocity cummand with ship motion and air disturbances, followed by a series of trree which show comparisons between vertical velocity command and vertical acceleration 


$$
\text { O: }
$$

comnand, then one that sinows responses to discrete gust disturbances. Pilot comments are also presented, followed by discussions of numerical pilot ratings and touchdown performince data.

\section{Aircraft Response during Carrier Approaches}

Vertica' velocity oumand with ship motion.- Figure 5 shows a time history of a manual carrier approach and landing with TAFCos vertical velozity cammand mode selected. Ship motion consisted of +0.9 meter $(+3$ feet) of heave with a standard set of ship air wake (burble) distunbances. For this approach, tip-over was initiated at abourt 10 seconds after the start of the run. In arder that the pilot would not have to hold his stick input to command a steady rate of descent following tip-over, a vertical veiocity trim function was provided using the pilot's trim button. Thus, the total rough commanded vertical velocity was the sum of the trim input (third trace, fig. $5(a)$ ) and a signal proportional to the stick input (second trace). The fifth trace shows the resulting vertical velocity, which closely followed the smooth cammand. The bottom trace shows that the aircraft height followed the commanded height (integrated vertical velocity) well within 0.3 meter (one foot) error, except during the last few seconds before touchdown. Additional details of the approach are shown in figure $5(\mathrm{~b})$. The aerodymawic flight path angle (measured with respect to the air mass) is shown to change to about -30 , the angle that would be expected for 15.4 meters/second ( 30 knots) of wind over the deck. Pitch attitude changes generated by TAFCOS, though probably greater than a pilot would call for if he were controlling attitude directly, did not appear to be excessive.

Comparisons between command modes.- Figure 6 shows comparisons between vertical velocity command and vertical acceleretion command as they influence the nature of the pilot imputs and the resulting airplane vertical response. For VVC with ship motion (fig. 6(a)) the stick deflection was characterized by more or less contimuous activity as vertical velocity corrections were required following initial triming at tip-over. As he approached the ship, the pilot's glide-path error information from the FLOLS improved and the need to tighten his control loop (especially in the presence of deck motion) became apparent. The increased frequency and magnitude of his inputs, beginning at about 37 seconds, are obvious. The complete stick deflection tine history (in addition to the trim input) is reflected in the rough conmarked vertical velocity. (Because the VVC mode was in use, rough cammanded vertical acceleration was zero.)

Figure 6(b) shows the results using VAC, with the same time history of ship motion and air disturbances that was used for VVC. In this case, the stick inputs were applied more in the manner of pulses, with more time spent at zero deflection. The rough commanded vertical velocity took on more the appearance of a succession of ramps as the rough acceleration pulses were integrated. igain, the effects of following the deck motion are seen in the latter half of the rough commanded and actual vertical velocities.

Without ship motion (fig. 6(c)), the VAC inputs, again in the nature of individual pulses, were more infrequent than with ship motion. In this case, since there were no other disturbances, the pilot at any given time had only to apply small corrections to the aircraft motion resulting fram his ow previous infuts. 


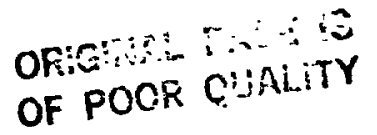

Response to gusts.- Figure 7 shows a time histacy of the airplane response to discrete 3 meter-per-second (10 foot-per-6ecand) vertical gusts introduced chring a manual approach with WC selected and no ship motion or other disturbances. These gusts were more severe than any nomally encountered in practice but they show how TAFCOS was able to respond and control flight path.

Vertical acceleration perturbations of 1.8 meters per second squared ( 6 feet per second squared or $0.2 \mathrm{~g}$ ) and angle of attack perturbations of 2.6 degrees whe to the gusts are noted in figure $7(a)$. The resulting vertical relucity and the error between instantaneous and smooth commanded height (bottan trace) showed pertumbations of only 0.76 meter per second (2.5 feet per second) and about 2 meters ( 6 feet), respectively. Some pilot stick response to the first (down) gust is noted; hovever, essentially no respanse was made to the onset of the second gust, while TAFCSS is seen to have corrected the height error in well under 10 seconds.

Figure $7(b)$ shows that pitch attitude underwent fairly large excursions ( 12.40 maximum to $6.5^{\circ}$ minimm) in combined response to the gusts and the stabilizer deflections applied by TAFCOS. The power lever angle and thrust transients that were required to hold cammanded airspeed were signficant in magnitude; however, recovery to a reasonably normal thrust level was made about five seconds prior to toundom.

\section{Pilot Comments}

General comments.- Pilot comments indicated that general acceptability of manual trajectory control through TAFCOS was good. Lateral-directional maneuvering was natural, with no umusual ar adverse characteristics. In roll entries and reversals, behavior was essentially that of a roll-rate command system. Lateral maneuvers to correct line-up were easy to make, with no lateral PIO tendencies noted.

Vertical flight-path control was good, with smooth response to commands. Scmewhat exaggereted pitch attitude changes were noted as TAFCOS responded to the trajectory commands. These excursions seemed somewhat unnatural and amoying at first to the pilots (who are accustamed to having direct control of pitch attitude). It was found that pilots soon adapted to this response and it is believed that with practice carrier pilots would not find this characteristic objectionable. Speed control was considered excellent; response to speed change commands was praut and precise.

Effect of ship motion and air disturbances.- Ship motion and air disturbances had a large effect on height control close to the ship, as reflected in the ability to keep the meatball centered. This difficulty in turn had a degrading effect on both touchdown precision and pilot rating (discussed later).

Effect of command mode.- With or without ship motion and air distumbances there did not appear to be any large differences in results using vertical velocity command or vertical acceleration command. With ship motion, VAC scmetimes required excessive maneuvering during the final stages of the approach to keep the meatball centered, probably dis to the pilot's not having a preset camanded vertical velocity to retum to on relaxation of his control 


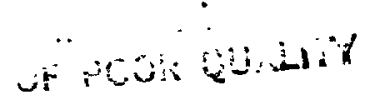

input, or his tendency to use a "pulse-and-wait" technique with VAC. The pilot also reported a need to mentally integrate his acceleration comand inputs in an attempt to predict changes in vertical velocity. This effort was not a totally fruitful one since the smooth commands, not the rough conmands, are the ones integrated within IAFCOS.

Although the VVC trim control provided a "standard". commanded rate of descent about which stick-commanded pertumbations could be made, it constituted an additional (retrimming) step in the control procedure which was not required with VAC.

Effect of variable gain.- De-sensitizing the vertical velocity response by decreasing pillot input control gain with decreasing range did make it easier to effect small flight-path corrections near touchdown, but there were cases when lange corrections were called for and full stick inputs were applied without obtaining sufficient corrective response from the airplane. Constant gain was prefereable to this situation.

\section{Pilot Rating Data}

Figure 8 shows pilot ratings obtained during the study using the cooperHarper scale. ${ }^{4}$ The rating data, grouped according to absence or presence of ship motion and air disturbancec. were based on 10-run samples. (For those cases with ship motion, the ship drive signal was 'itiated so that the vertical deck position at touchdown was not repeated Irom run to run.)

Effect of ship motion and air disturbances.- Figure 8 reflects to a langer degree the pilot corment made earlier reganding effect of ship motion by showing that the langest single factor affecting pilot rating was the absence or presence of ship motion and air disturbances. Although +0.9 meter $(+3$ feet) of vertical deck travel would be considered moderate, it did (in combination with the standard air wake) add considerably to the pilot's task. If one considers the most favomably-rated case in each main group (i.e., TAF $O S$ with VVC, constant gain), a degradation of at least from 2 to 6 is noted. The reasons given by the pilot for this degradation were increased difficulty in keeping the meatball centered prior to touchdown and deterionation of touchdown point accuracy.

Effect of cormand mode.- Although the evaluation pilot did not report any large differences between command modes, the ratings in figure 8 with or without ship motion do show a degradation in going fram WC to VAC. The renarks under Pilot Comments for the case with ship motion, pertaining to not having a preset vertical velocity to return to, pilot use of a pulse-and-wait control technique, and attempted mental integration of his vertical acceleration command inputs apply also to the case without motion and appear to substantiate the observed changes in rating.

Effect of variable gain.- Figure 8 shows that without ship motion and air disturbances there was no effect on pilot rating of decreasing pilot control gain with decreasing range using WV. However, with motion a degradation of rating across the 6-1/2 boundary occurred when going from constant gain to variable gain. The occasions when full stick inputs to make large comrections (see Pilot Carments) failed to generate suf ricient aimplane response apparently accounted for this degradation. 
Approaches with standand A-7E with APC.- For comparison with conventional control, approaches were also made with the simulated A-7E airplane with standard control system and approach power compensator. Figure a shows less favarable ratings for the conventionally-controlled airplane than ioc any of the TAFCOS test cases. This indication was less apparent wit: ship motion than without motion, wue to the severe effect that the motion hid on all the ratings as a result of the increased difficulty in keeping the miatball centered close to the ship.

\section{Touchdown Performance}

Figure 9 shows mean and standand deviation of longitudinal touchdown point (based on the 10-rum sanples) for all the cases discussed previously. The line segments extending beyond the standard deviation bars indicate the total spread of data points for each case. The horizontal dashed lines show the locations of the four arresting wires. To give a standand far somparison, it is seen that the first and fourth wires were 18.3 meters ( 60 feet) from the desired touchtown point, which is shown by the horizontal axis. Thus a spread extending beyond these limits would mean often landing short or missing all the wires and executing a bolter.

Generally, the larger standard deviations shown here were reflected in the less favorable ratings in the previous figure, and vice versa. These relationships were fairly consistent trroughout the study and the standand deviation data follow closely the pilot comments in suppont of the numerical ratings.

\section{CONCUIDING REMARKS}

Manual control of aircraft flight path trrough the TAFCOS concept has been shown to be feasible as an addition to a pre-existing automatic control system and to have potential as an improved mode of control over conventional control for the carrier approach task. Further optimization and development studies need to be made to explare this potential fully and to determine what degree of imperovement can be realistically expected.

\section{REFERENCES}

1. Smith, G. Allan, and Meyer, George: Application of the Concept of Dynamic Trim Control to Automatic Landing of Carrier Airoraft. NASA Technical Paper 1512, 1980.

2. Snith, G. Allan, and Meyer, George: Total Aircraft Flight-Control System - Balanced Open- and Closed-Loop Control with Dynamic Trim Maps. Proceedings of the Third Digital Avionics Systems Conference, Ft. Warth, Texas, Nov. 1979, IFEE Catalog No. 79cill518-0.

3. Meyer, G., and Cicolani, L. S.: A Farmal Structure for Advanced Autamatic Flight-Control Systems. NASA IN D-7940, 1975.

4. Cooper, George E., and Harper, Robert P.: The Use of Pilot Rating in the Evaluation of Aircraft Handling Qualities. NASA IN D-5153, 1969. 


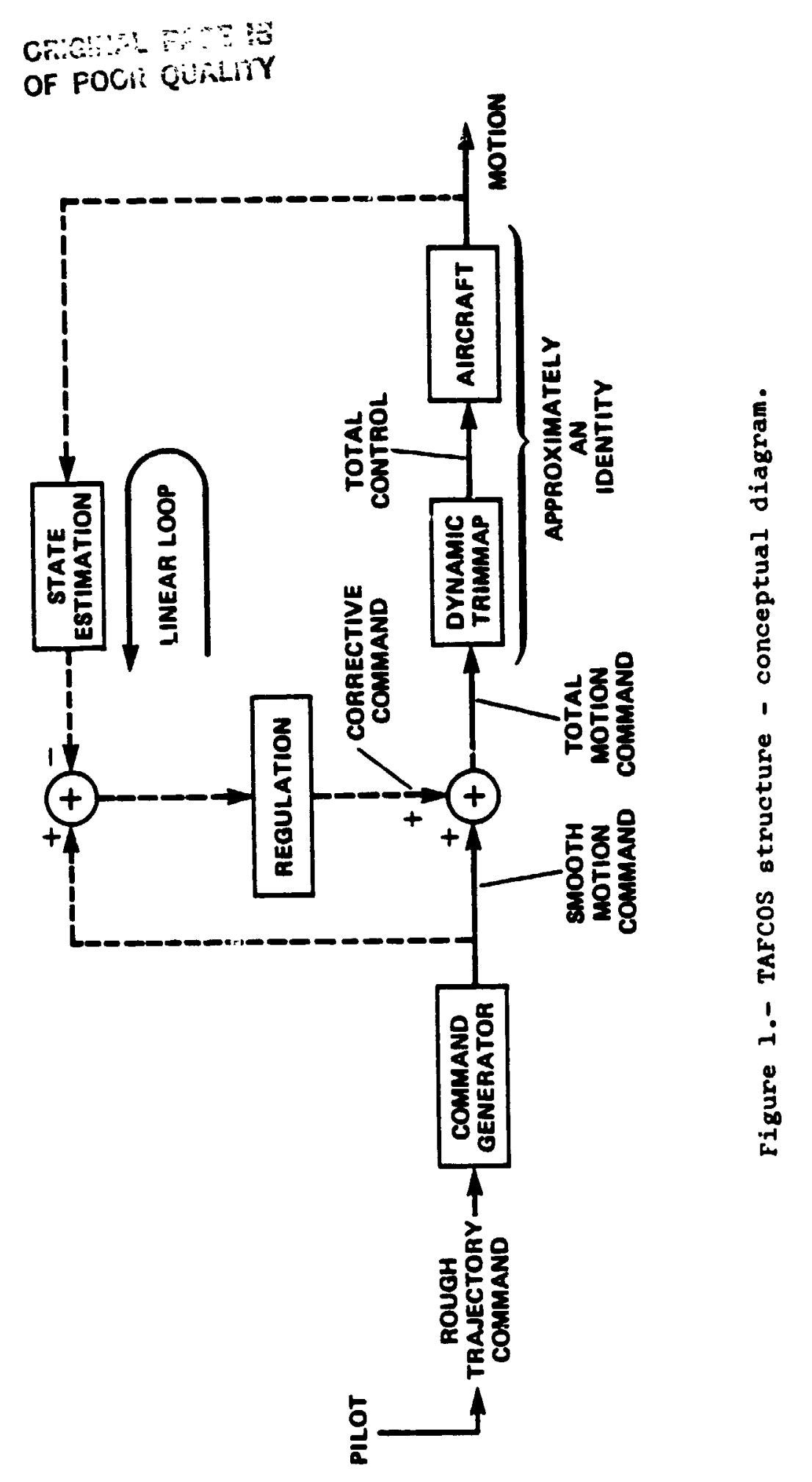


ORIGINAL PECE IS

OF POOR QUALITY

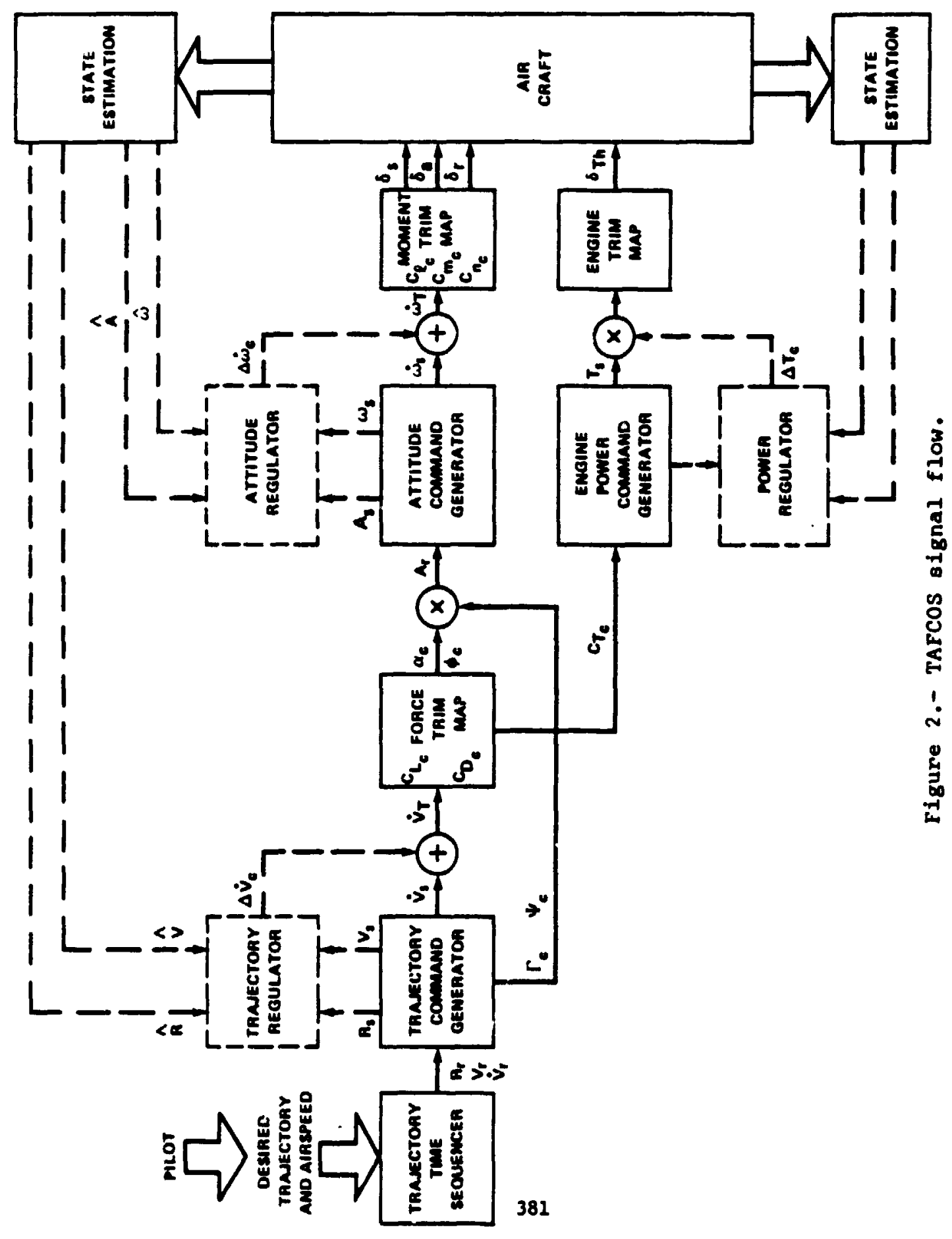




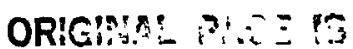

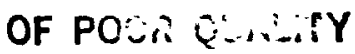

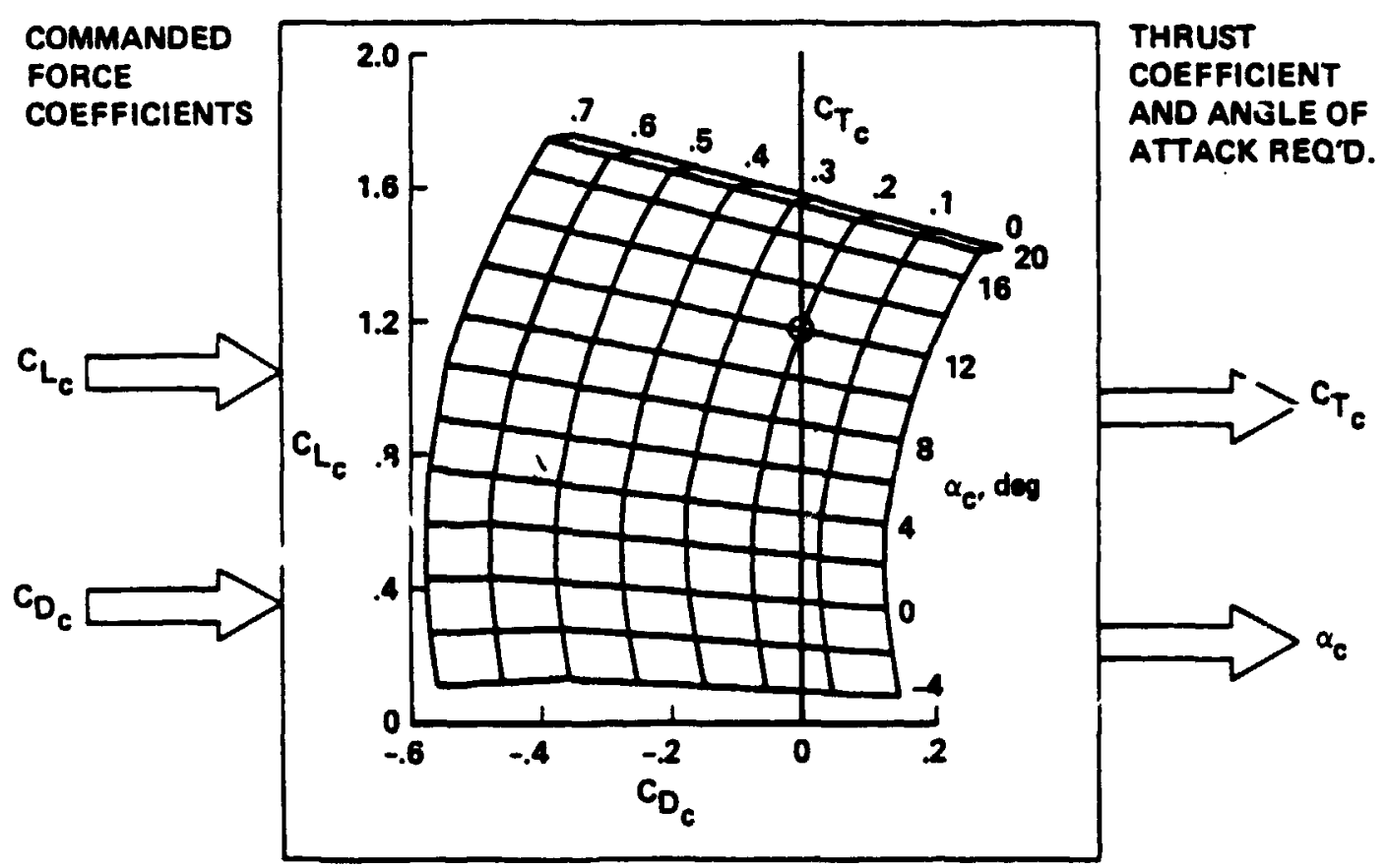

Figure 3.- Force trim map. 

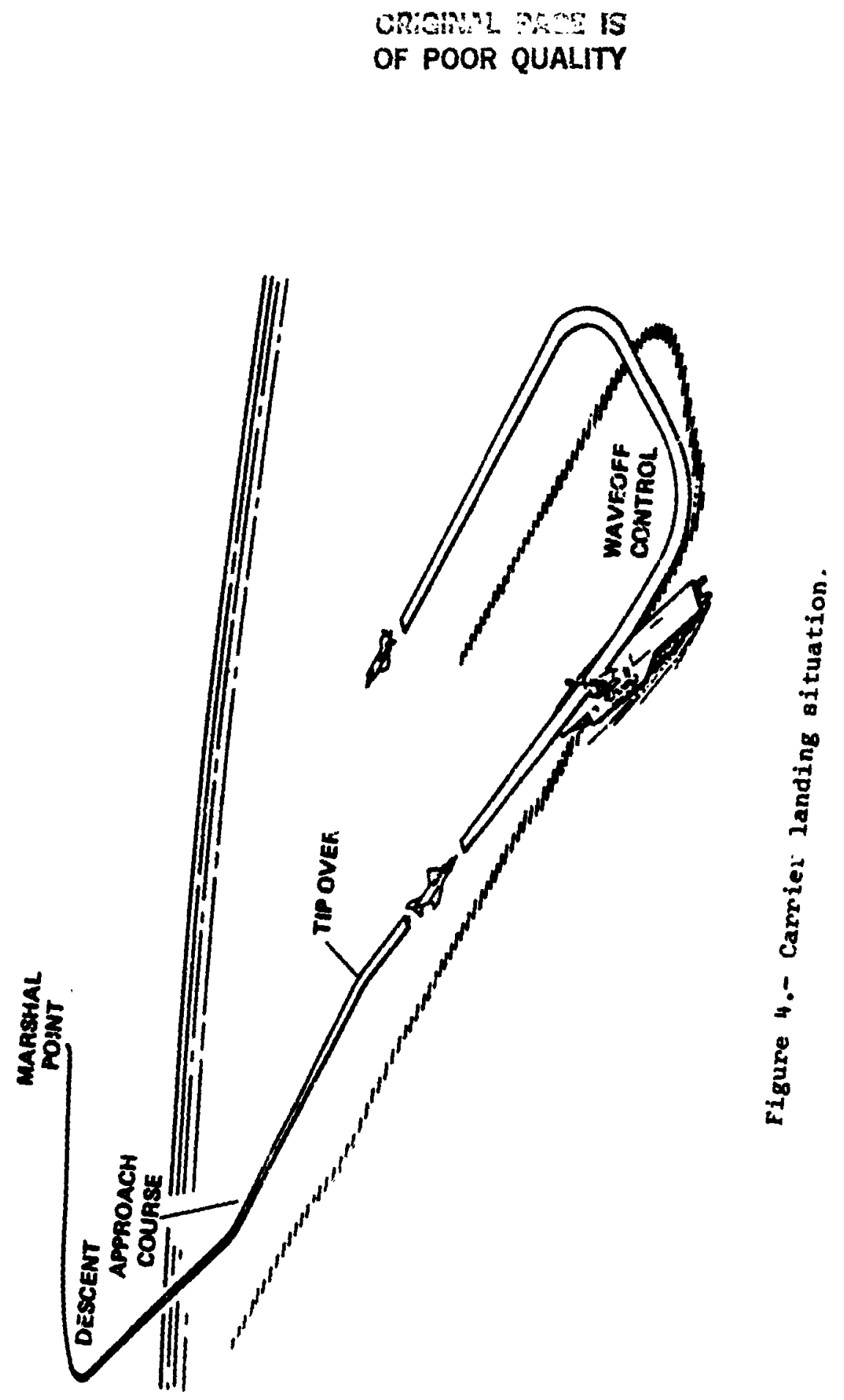


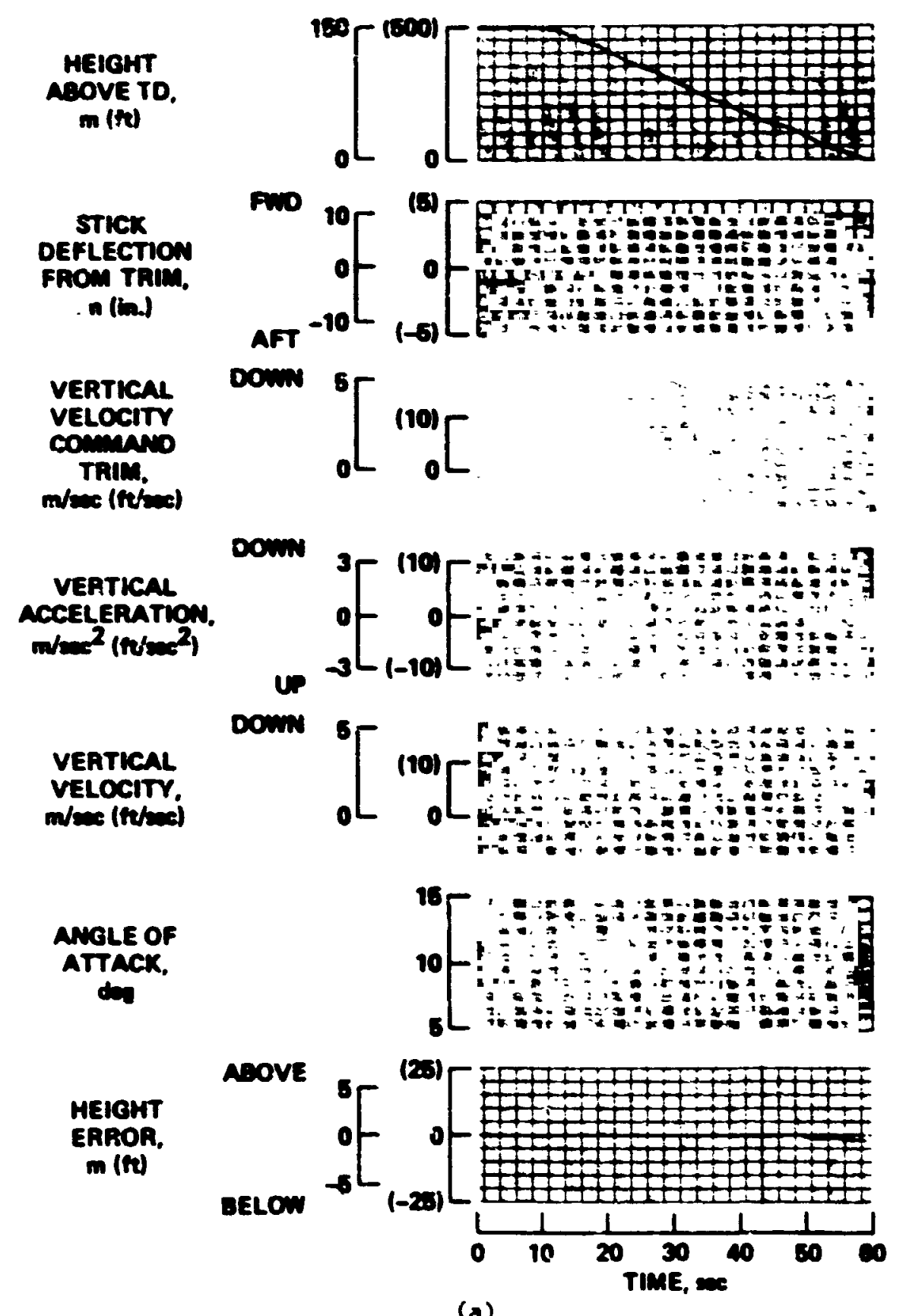

Fig'ure 5.- Time history of a manul carrier approach with TAFCOS, vertic... velocity command 
ORIGINAL PAGE IS

OF POOR QUALIT

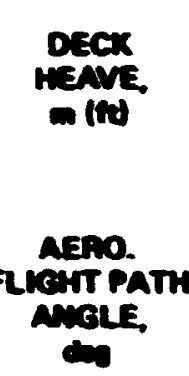

$$
\text { 王: E }
$$

MTras

ATtrTuDe.

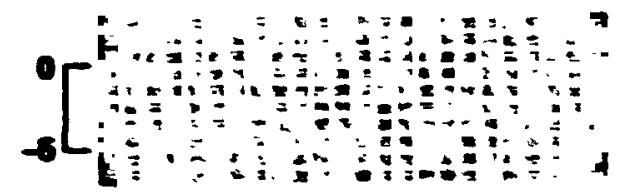

$\infty$
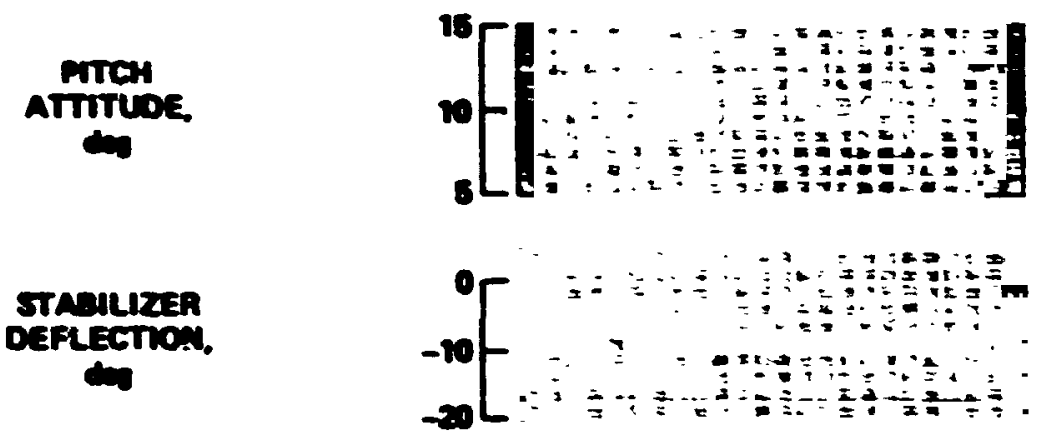

LEVER AMULE.

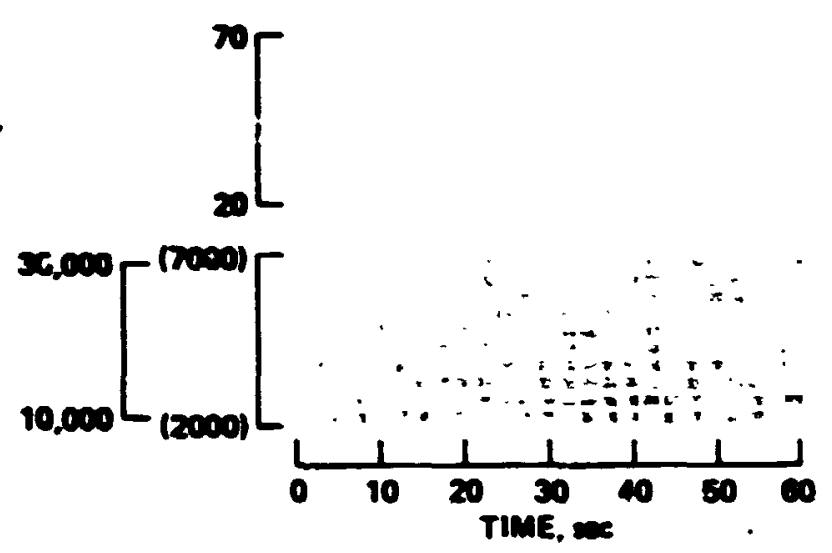

(b)

Figure 5.- Concluded. 


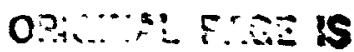

of poun qualm

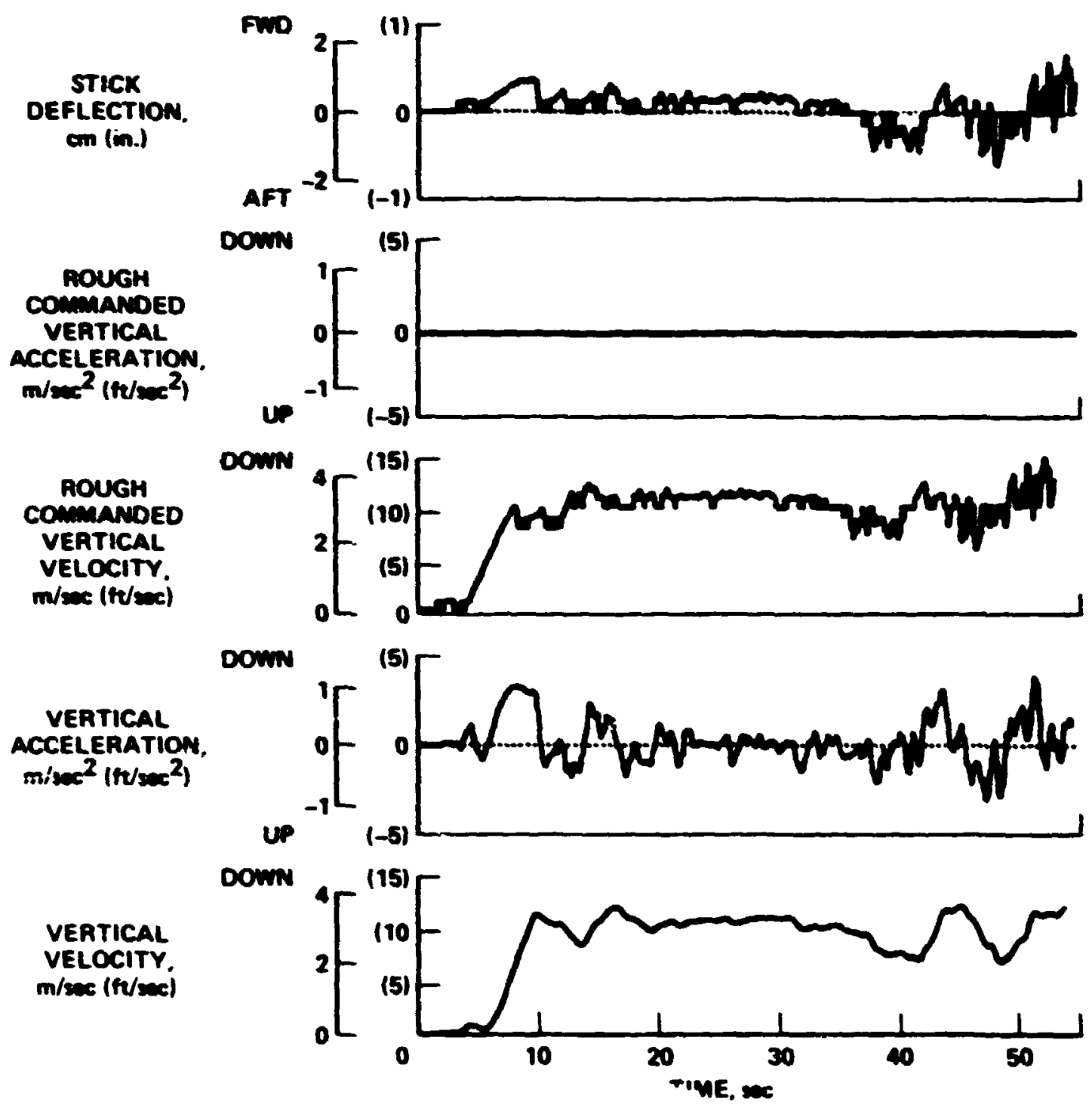

(a) Vertical velocity command, with ship motion.

Figure 6.- Comparison between TAFCOS vertical velocity command and vertical acceleration command. 
OA...L PAGE IS

OF PGOR QUALITY

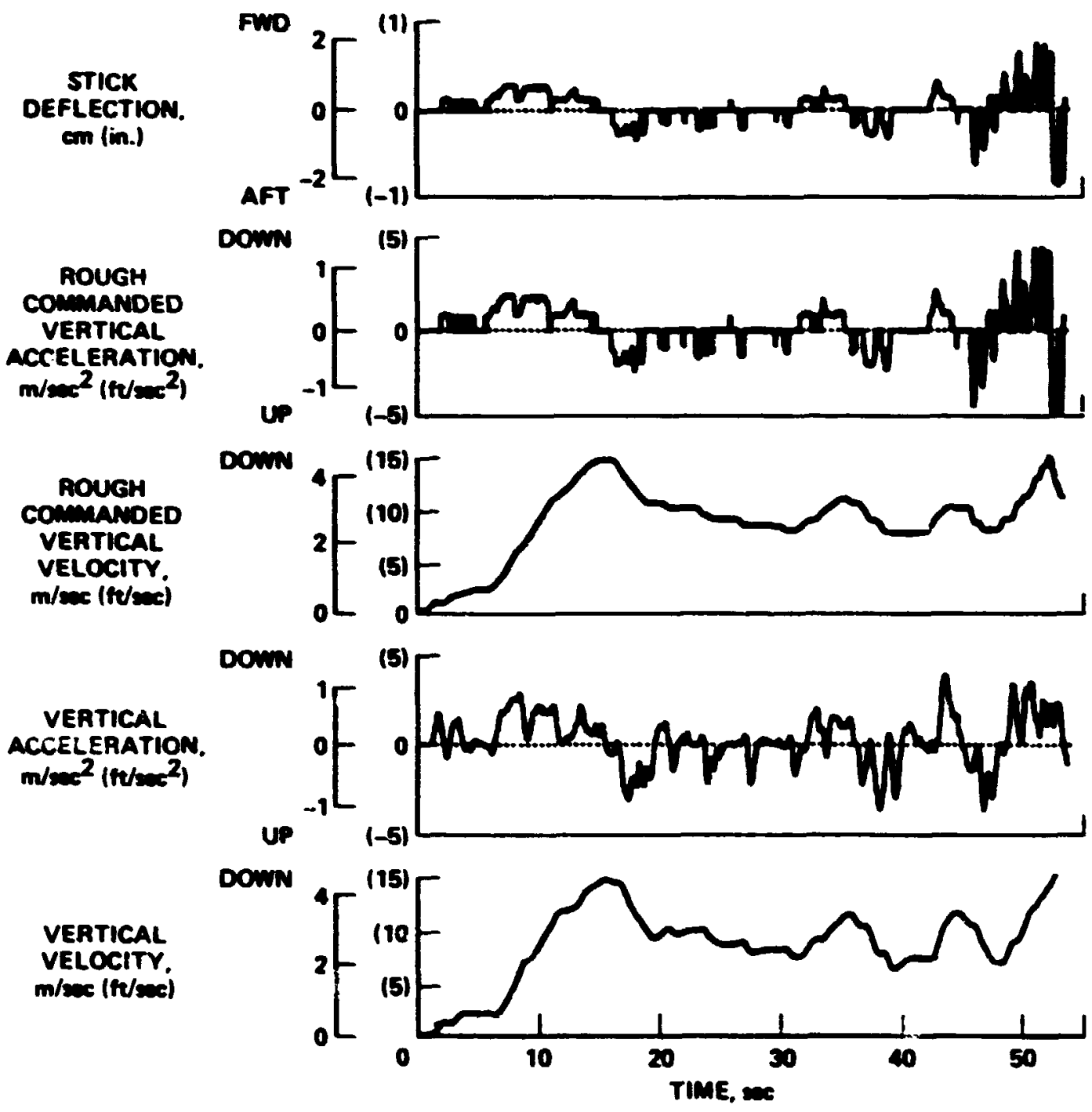

(b) Vertical acceleration comand, with ship motion.

Figure 6.. Continued. 


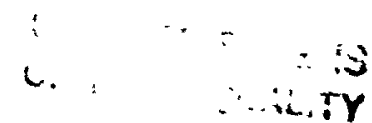
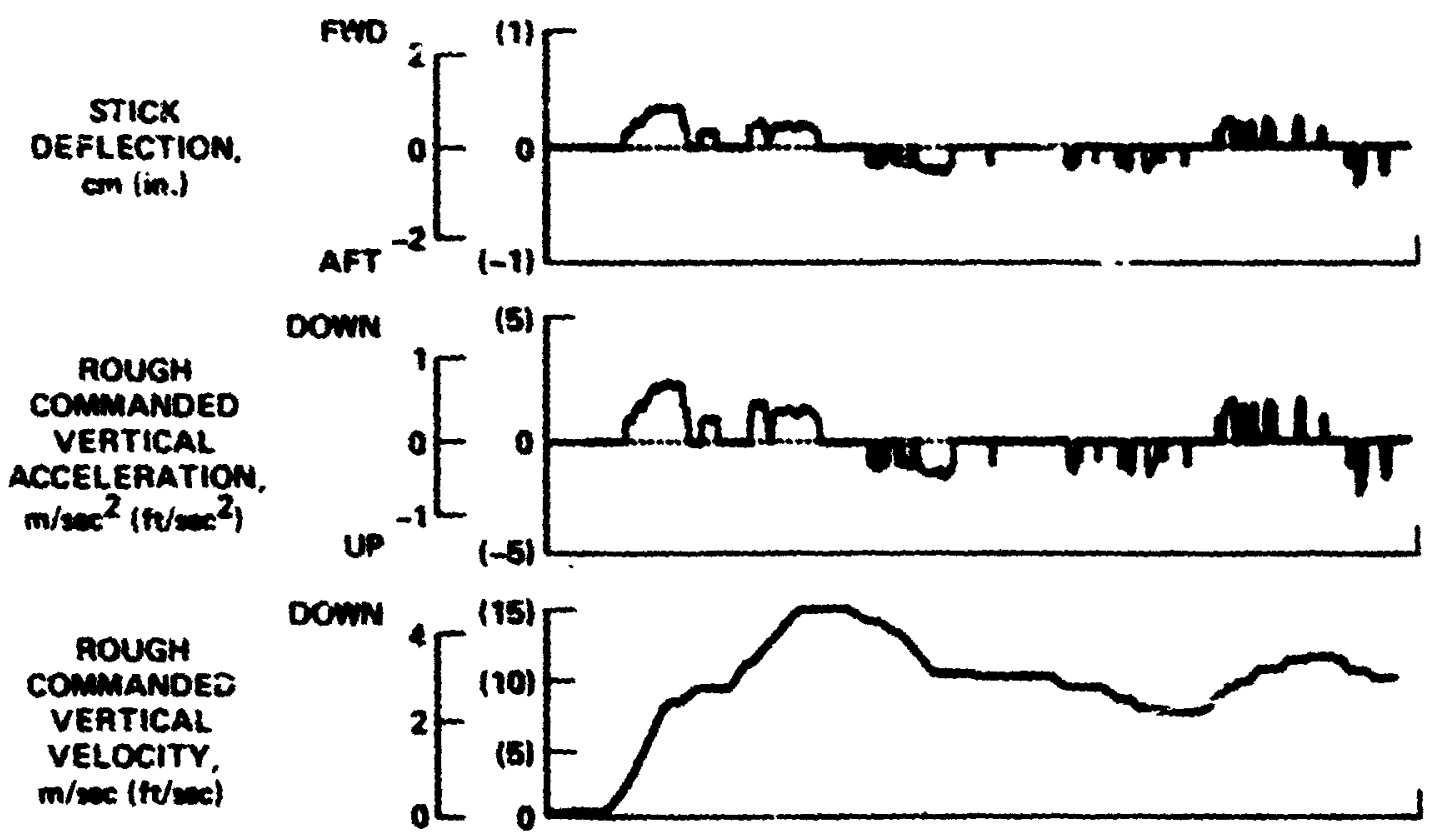

VERTICAL ACCELERATION. $m / x^{2}\left(t / 2 m x^{2}\right)$

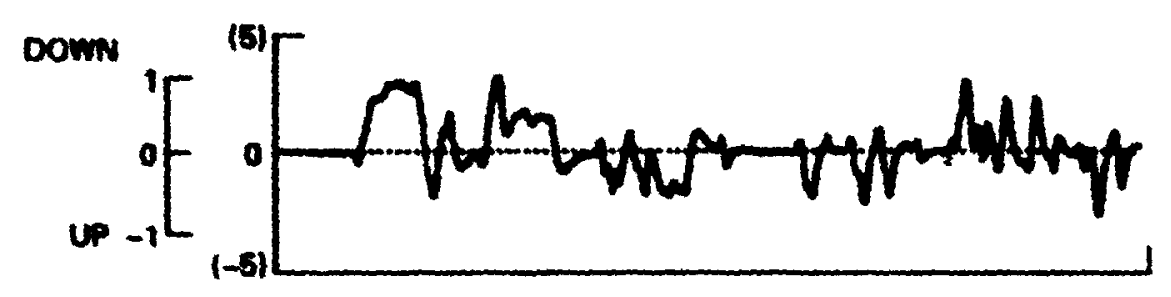

VERTICAL VELOCITY, $\mathrm{m} / \mathrm{sec}(\mathrm{t} / \mathrm{mec})$

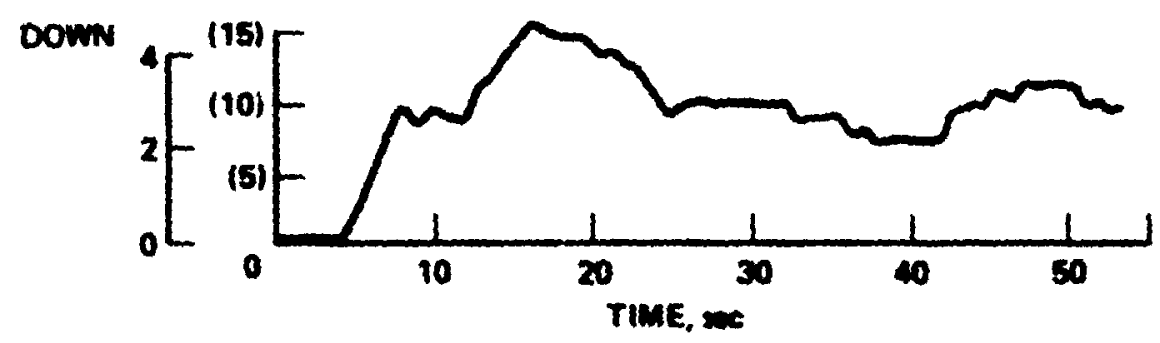

(c) Vertical acceleration comand, without ship motion.

Figure 6.- Concluded 


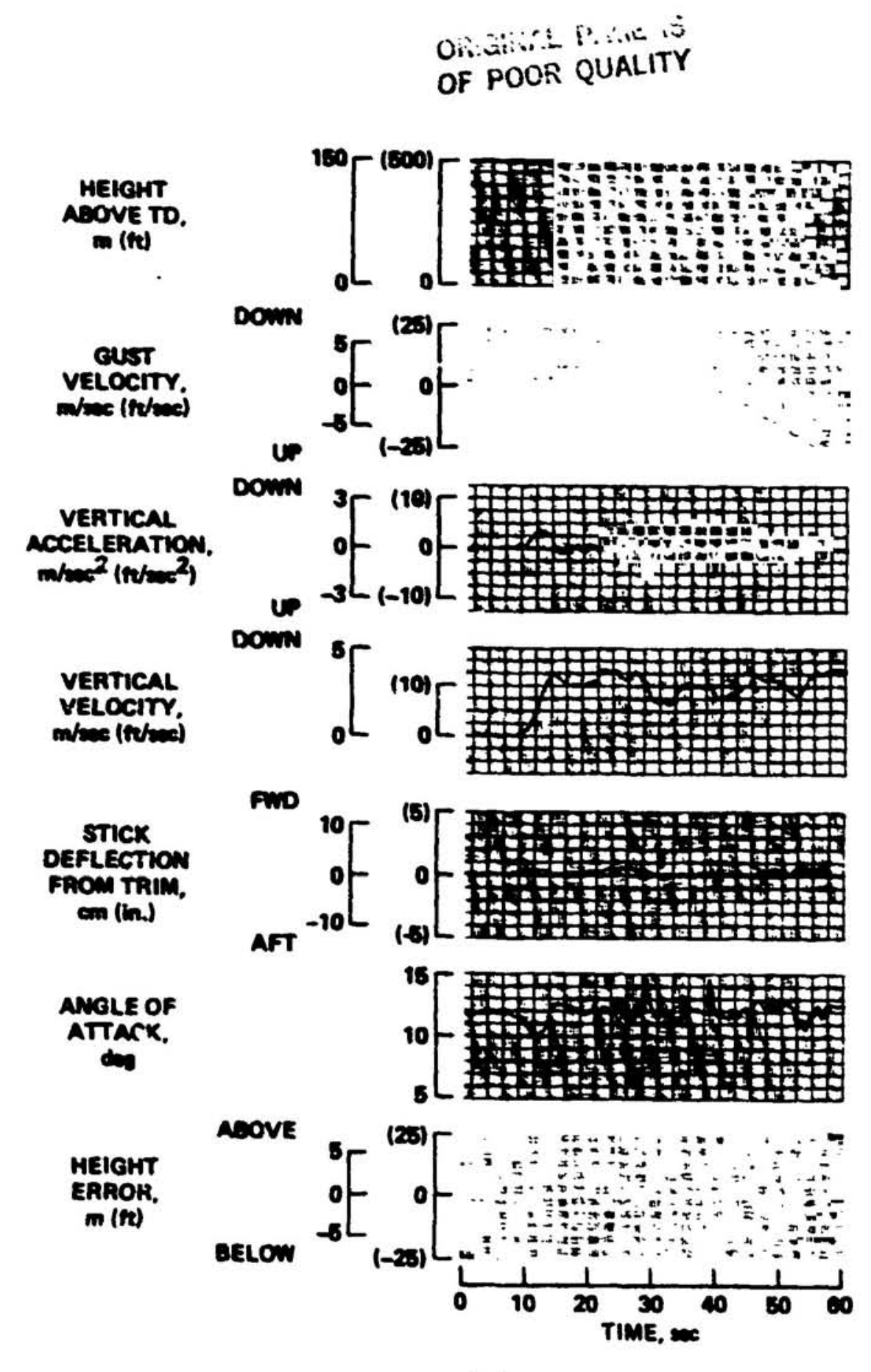

(a)

Fizure 7.- Time history of response to discrete gusts. 
Can

OF MLNR QUALTTY

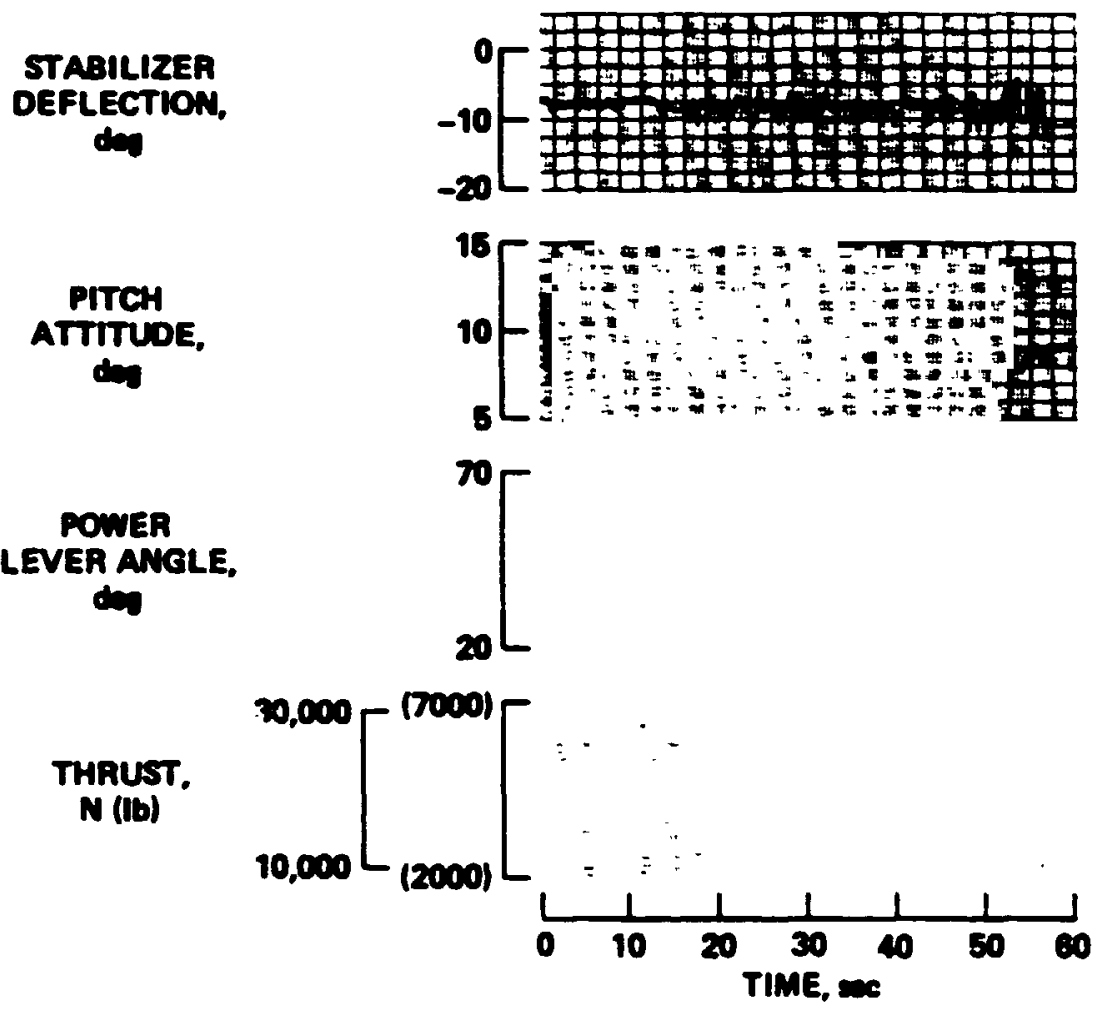

(b)

Figure 7.- Concluded 
ORIGIIAL FASE IS
OF POOR QUALIT.

Q TAFCOS

$V \equiv$ VERTICAL VELOCITY COMMAND

$A=$ VERTICAL ACCELERATION COMMANND

FLACS = VARIABLE GAIN

D STANDARD A.TE WITH ARC

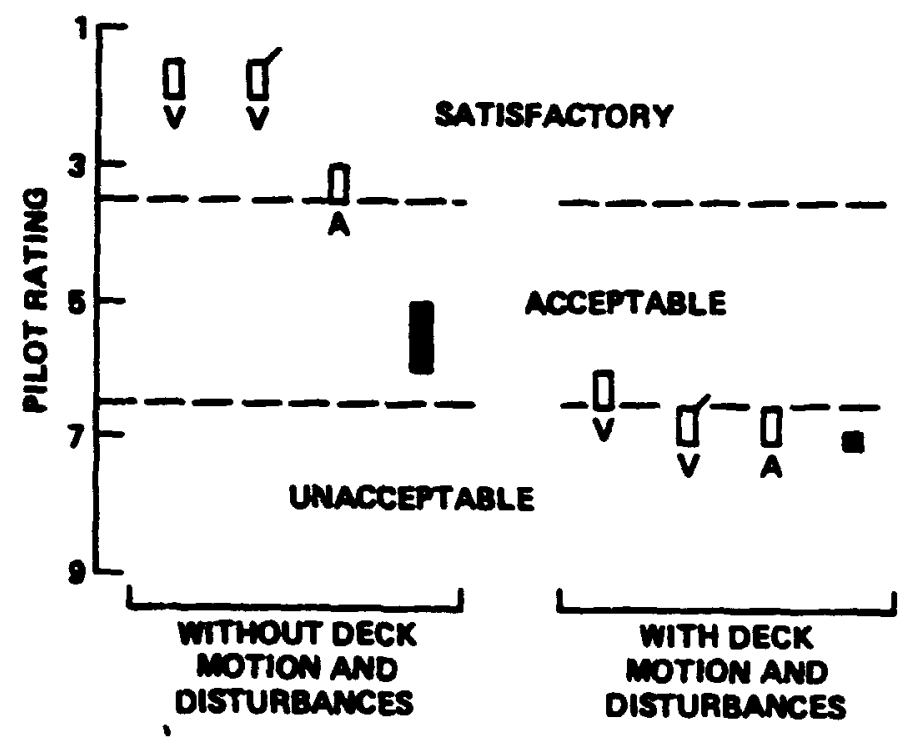

Figure 8.- Pilot rating data. 
OE:

OF PCOA QuUSitTY

$\square$ TAFCOS

$V=$ VERTICAL VELOCITY COMMAND

$A=$ VERTICAL ACCELERATION COMMAND

FLAGS = VARIABLE GAIN

OSTANDARD A-TE WTTH APC
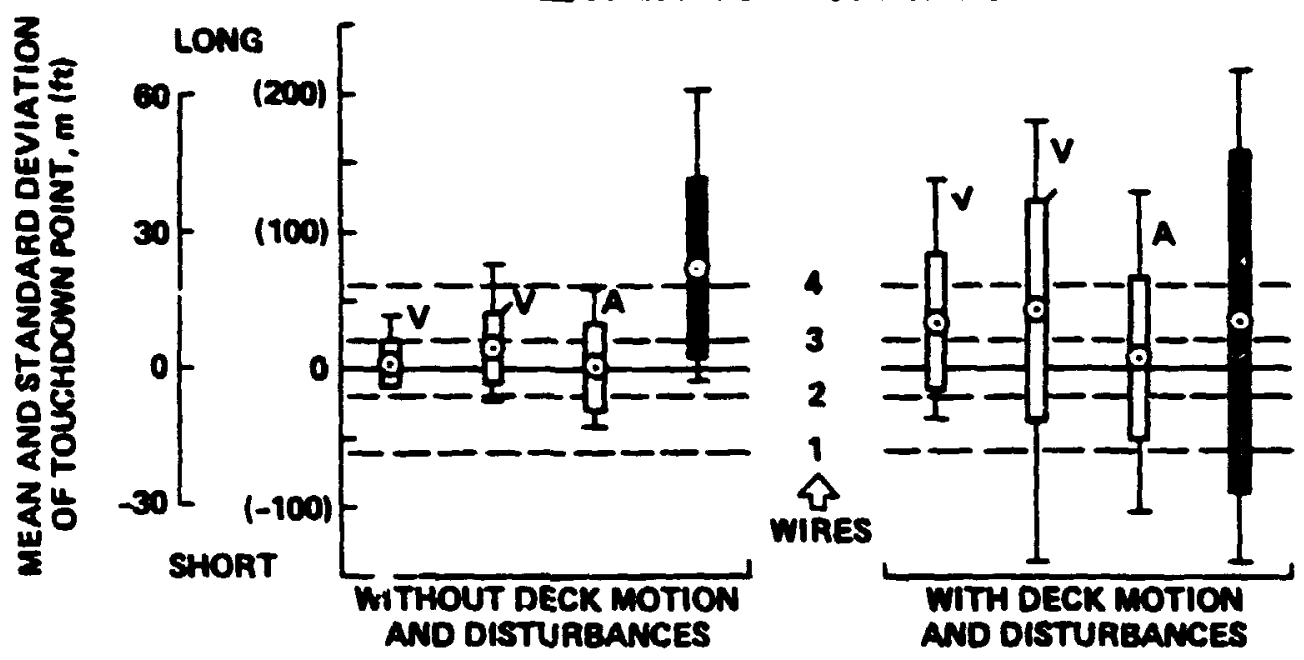

Figure 9.- Mean and standard deviation of longitudinal touchdown point. 


\section{ABSTRACT}

\section{Wind Shear Simulation Experiments}

Mark Connelly

Informatior and Decision Systems Laboratory, M.I.T., Cambridge, MA

A set of simulation experiments has demonstrated the effects of various levels of horizontal wind shear and the presence of thunderstorm cells on instrument landing performance. A theoretical analysis was carried out showing what control inputs are necessary to compensate for vertical and horizontal wind shears. A final set of simulation experiments using the suggested control technique indicates that a substantial reduction in the effects of shear can be obtained by displaying the proper dynamic information to the pilot in a timely *ishion.

\section{ABSTRACT}

\section{Combined Use of Airborne Traffic Situation Displays} And ADPanV In ATC

Two key tasks in the application of distributed managenant to the problew of providing adequate ATC capacity, safety, and efficiency at busy terminals are: (1) To follow a 3D terminsl aerospace structure and arrive at fixed waypoints within the structure precisely at pre-scheduled tiwes in the presence of a full range of wind conditions aloft (2) To monitor nearby traffic on an airborne traffic situation display to detect blunders and resolve conflicts in a safe manner. This paper describes a series of simulation experiments carried out to evaluate both of these functions. 


\section{$2 \pi 8234061^{224}$}

APPIICATION OF A PILOT COFIROL STRALEGY IDMITIPICATIOR FCEIQUE

Th A JOIIT FAA/IRASA GROULD-BASED SDLLATIOI OF HEAD-UP DISPIAYS FOR CTOL ATRCRATY*

Wayne F. Jewell

Staff Engineer, Research

Systems Technology, Inc. 2672 Bayshore-Frontage Road

Mountain View, Californis 94043

\section{ABSTRACT}

A technique for measuring a pilot's control strategy has been developed, evaluated, and applied to a realtime ground-based simulation. The technique, called the Ion-Intrusive Pilot Identiflcation Program (IIPIP), estimates the pilot's input-output describing function and combined pilot-vehicle performance parameters such as crossover frequency and phase margin by uslag a time domain model of the pilot and a least--squares identiflcation algorithm. IIPIP functions in realtim and uses "sliding" time windor to maintain freshness in the data; thus time-varying characteristics in the pilot's control strateg' can be measured.

This paper describes the salient features of IIPIP, presents the results of a performance evaluation of IIPIP, and then describes the pesults of applying IIPIP to a realtime ground-based simulation of two coupeting concepts of head-up displays (HUD) for use in conventional takeoff and landing (CTOL) aircraft. Differences in the pilot's control strategy used for the two HIDs and the head-down dispiny are quantifled in terms of differences in the pilots' describing functions and combined pilot-vehicle measurements. Conclusions based on the performance eveluation and application of IIPIP are presented and some recommendations on bow IIPIP could be used in other manuel control tasks are discussed.

\section{TIIRODUCTION}

A technique for measuring a p1lot's control strategy has been developed, evaluated, and applied to a joint FAM/rASA ground-based simulation of two competing concepts of head-up displays (HID) for use in conventional takeoff and landing (CHOI) aircraft. The technique, called the Hon-Intrusive Pllot Identification Program (IIPIP), estimes the pilot's input-output describiug runction and combined pllot-vehicle performance parameters such as crossover frequency and phase margin by using a time domatn model of the pilot and a least-squares identification algorithm. IIPIP runctions in realtime and uses a "slids" $b^{\prime \prime}$ time window to malatain freshness in the data; thus time-varying characteristics in the pilot's control strates can be measured.

- This work was sponsored by the Van-Vebiele Systems.Research Division at the IMSA Ames Research Center, Noffett Fleld, Callfornia, under contract IAS2-i0385. The IASA contract technical monitor was Dr. Richard Haines. The ground-based simulotion was a jolnt FM/masA bead-up display concept evaluation project concucted under Task Order DOT-FAT7 WAI-725 to Inter-Agency Agreement MSA-MMI 1052.151 dated March 9, 1977. 
This paper is divided into the following sections:

- Description of the salient festures of IIPIP

- Performance evaluation of IIPIP

- Application of XIPIP

- Conclusions and recaurendations.

The treatments of each of the above toplce in this paper are intentionaly terse. Nore In-depth and detalled treatments will be presented in a forthcoming IMAS contractor report'.

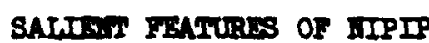

The runction of IIPIP is to estim te the describing runction of the humen operator (BO) whlle performing a miltiloop ccintrol task such as Ilying an alreraft. IIPIP makes use of well-proven rechuced-ordar models of the 10 dromics and 18 vell suited for easy implemantation an modern, high speed difital computers.

One of the dealon criteria of IIPIP was that it be able to obtain

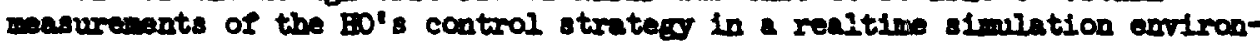
went on a noo-interforiag basis, which is why it is referred to as "nonintrusive." The result was an algorith that is rast enough and arficient enough to coesclst with the essential ccmponents of a realtise aircraft simulator. Turthermore, IIIPIP is sinple enough to use on a routine besis, whthout the use of special liputs, disturbences, or other altarntions to the Integrity of the simaletion.

While there are a mber of techniques anslable for identifying bo

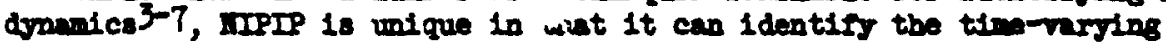
charecterletics of the BD, loes not require lenorledge of the disturbance, abi can runction in realtise. This lest attribute is adventageous because it allows a resenraber to wonttor the BD's droudc behavlor as be 18 performing the control task. The following text brieng describes the requirements for using IIPIP as vell as the inputs and outputs of IIPIP.

The Nrst step in using IIPIP is to syntbesize a loop structure of the pllot-robicle system. Thic can be besed on control system analysis and/or observation of the BD beharlor in performing the requited task. The paxt step is to represent the element of the huma opergtor if the $100 \mathrm{p}$ strucetwre with discrete transfer runctions. It is shom ${ }^{8}$ thet reduced order forws of the Ho drnandes cen be used for the discrete transfer nunctions. Then one writes difference equations uing the loop structiure and discrete transfor functioss. The paramaters of the difference equations are est1mated by using a runing multiple linear regression and sliding time window.

The running multiple linear regression starts processiog the tive historles of the pilot's control actions and the variables to be controlled until it fill up a secifled time vindor. Once the tims rindon is rilled up IIPIP slides the window along the time blstory, thus 1dentifylas any tim varylas characteristics in the p1lot's cantrol strategy. The rav outputs of IIPIP are the difference equations coefflclents (DDC). It was Ilscovered thet the DXC would behave very trangely under certain circum stances (e.B., for time-varying behavior of the BD), but the frequency response of the bo we very well bebeved. Thw the last step for IIIPIP is 


\section{ORIGINAL PAGE IS
OF POOR QUALITY}

to interpret the results in the frequency domaln. It does this by couputine frequency responses of the estimated elements of the 10 in the loop structure (i.e., descilibing functions) and combined gilot-vehtcle measures such as crossover frequency and phase rargin.

A mathematical treatwent of the NIPIP algorithm can be found', and will nct be repeated in this paper. Instead we will present herein the results of a performance evaluation of NIPIP.

\section{PERTORMAICE EVALUATION OF NI:IP}

Figure 1 shows the construct used for the performance evaluation of VIIPIP. The approsch taken was to integrate XIPIP into a simulaticn of a Boeing 727 aircraft along with the control iurs of the plight director and fast/slow speed error. Aidlog pilots were used to control the rilget director with the control colum and the fast/slow error with the throttle. Shaped white nolse was used to simiate pilot remant and injected into the control loop as shown in the flgure. The pilot-veisfcle system was disturbed with the Dryden model of atmospheric turbulence?.

The construct hown in FIg. 1 permi ted a comparison of the known parametars of the anslog pllot to the estimared outputs of NIPID in a known

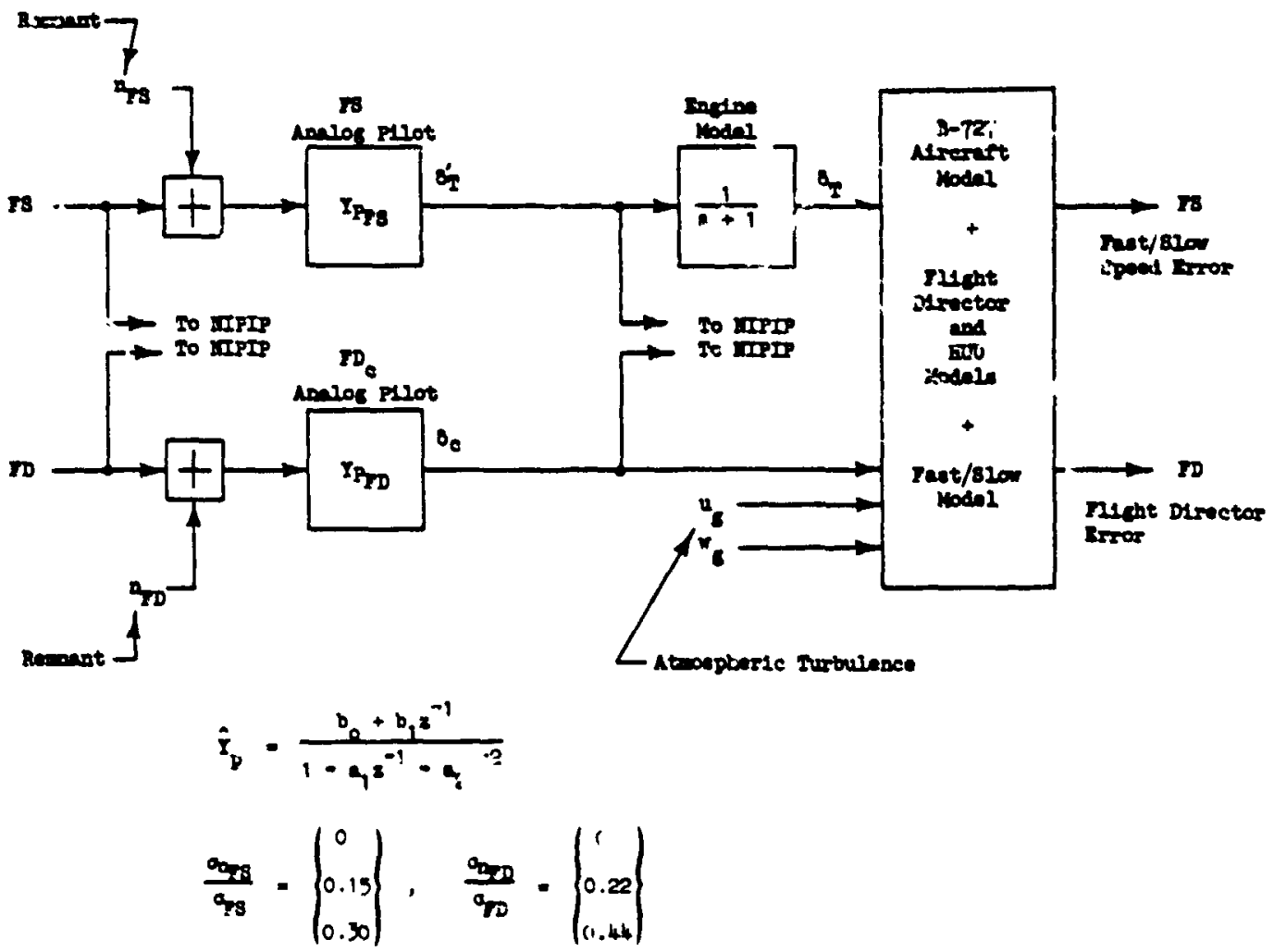

F1gure 1. Construct Used for the Purformance Bvaluntion of IIPIP 


\section{ORIGINAL FRGE IS
OF POOR QUALITY}

level of remant. The arount of remont un quantifled in ters of polseto-sigonal ratlos. For exprple,

$$
\frac{\sigma_{n}}{\sigma_{s}}
$$

In addition to evalunting the effects of pilot renant in the outports is ....., the effects of varlations in the rollowing itos. were also evaluated:

1. Leagth of the sliding the vindor, Mr. The lerger the

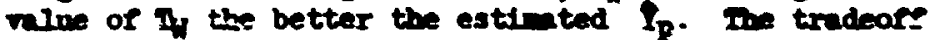
to be cossidered is that the the-varging ch-acteristics of $\hat{I}_{\mathrm{p}}$ are enced for larger values of $\mathrm{M}$.

2. IIne varlations in $Y_{P}$. That is, IIPIP we used to identify controlied veriation in the paranters of the analos pilot, $\mathbf{Y}_{\mathbf{p}}$.

3. Nuber of degrees of rreedon (DOF) in $\mathcal{F}_{p}$. Ir the muber of DOF in ip differs fron those in $I_{p}$ bow does this arfect IIPIP's ability to estimte $f_{p}^{\text {? }}$ ?

4. Pure tine dalay in $Y_{0}$. Bor does a pure tine deln 1. Ip affect the estinate af ipt

Ail of the effects listed above are cescribed in detalli. For brevity only the efrects of pllot remant wil be discused bereln, the effects of

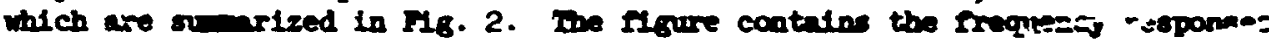

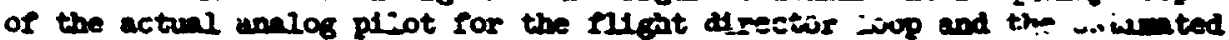
describing functions for three level of stmated pijot remant (for vero rewnet the extirated and activil frequenes reponses are identacal).

Ithe procedure used to draw P18. 2 we to use the sliding window in IIPIP to obtas a large numer of estimtes for $\mathcal{l}_{p}$. Inds pexitted to specify bounds on the upper and lower linte of the estinted $f_{p}$ for a ef ren level of remant. The floure shows that the bounds are nequency dependent, with less than \pm 1 o error in $\left|P_{\mathrm{p}}\left(\mathrm{j}_{\mathrm{O}}\right)\right|$ at or below $1 \mathrm{rad} / \mathrm{sec}$ (the crossover erequency of the fllght director loop wa 1 rad/sec) and a madn of nbout \pm 3 do error at $8 \mathrm{rad} / \mathrm{sec}$. The froquency dependence of the error in $T_{p}(j \omega) \mid$ is attribut : to the lorrbend pases ellters on both the ateopheric turbuleoce and the rempant. The matom exror in $4 \hat{y}_{p}(j o)$ we about \pm 5 deg and did not appear to be a strang runction of fre fuency.

Also note Ira Fig. 2 that the effects of remsant are noo-Iloen. Doubling the sigenal-to-nolse ratio Iran 22 to 4 percent did not double the errors in $\hat{\mathbf{I}}_{p}(\mathrm{j})$.

Wingrove 5 demontrated that scas idontirlention torhniques wlll not functici properly when lerge anounts of remant are present. There can be blases in the estinates or a tendency to 1dentify the imverse plant. The results show in $\mathrm{Mg}_{\mathrm{g}} 2$ dewonstrate that MIPIP Is not subject to either of these problems.

\section{APPLTCATIOA OF IIPIF}

IIPIP was appled to the simulntor oveluation of three afrcraft displars for use in terminal area navlgation. Simplified sketches of the three displays and a sumpry of the diaplay lawe are sbow in Mge. 3, 4, and 5. 

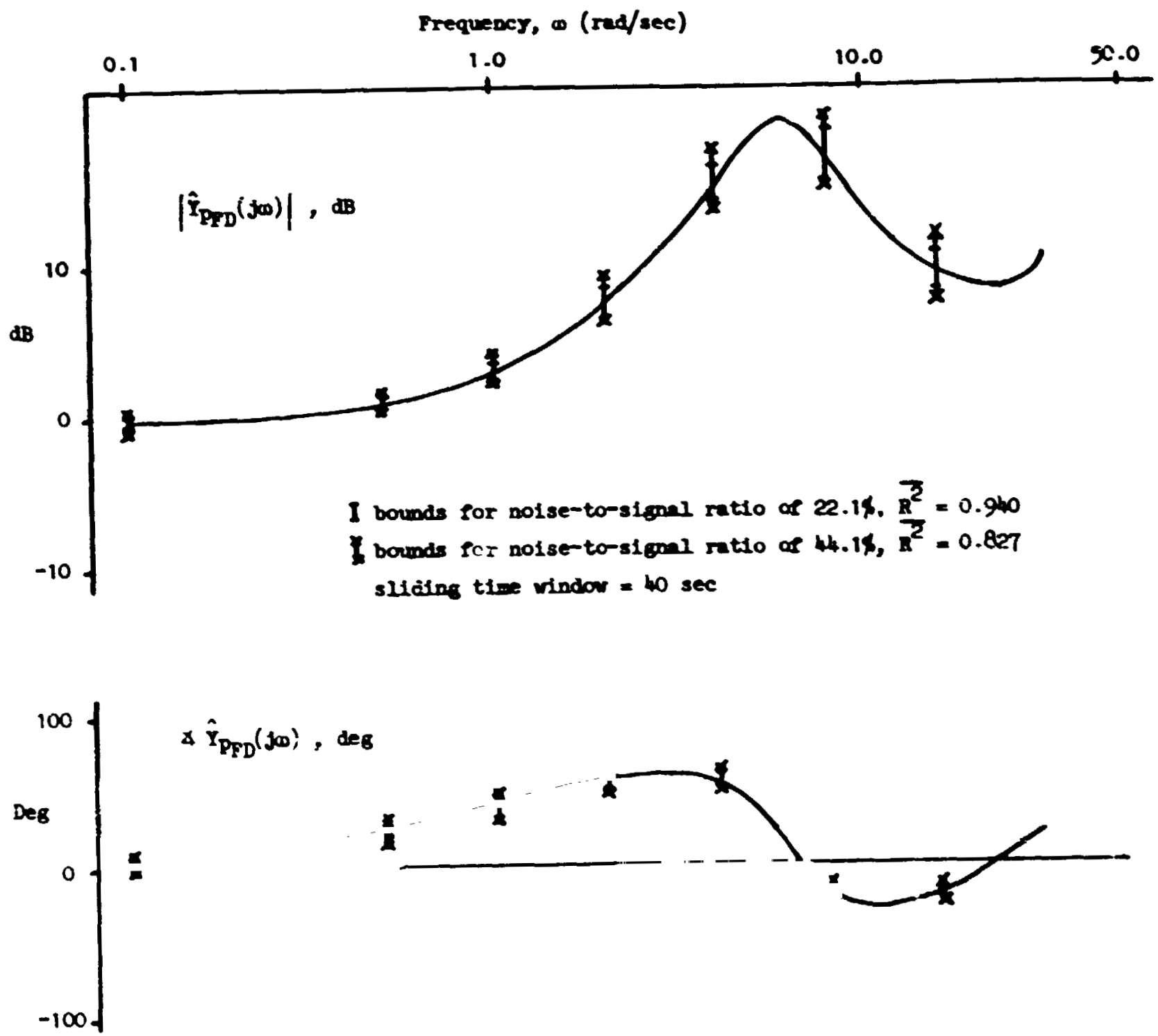

Floure 2. Brfects of P1lot Remant on Bstimated P1lot Describing Punction 
ORIGINAL PROE IS
OF POOR QUALITY

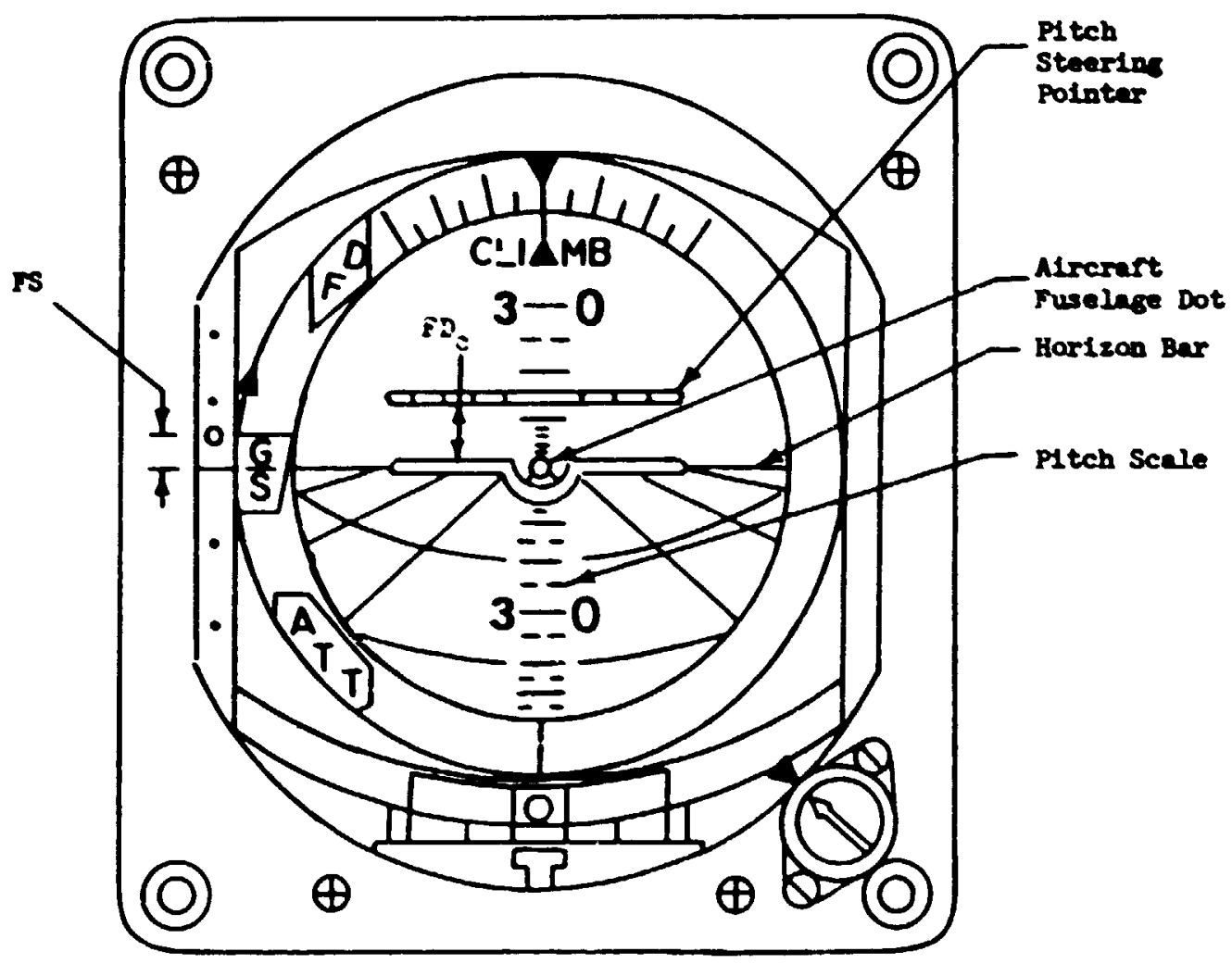

Displar control lars:

$$
\begin{aligned}
& F D_{c}=K_{\epsilon 1} \epsilon_{G / s}+\frac{15.0 s}{15.0 s+1} \theta \\
& F S=\frac{1.0}{1+1.0}\left(v-v_{\text {ror }}\right)
\end{aligned}
$$

Moure 3. Singlirled Sretch of Heac-Down 7llght Director Display 


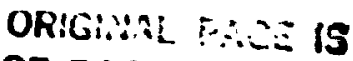

OF POOR QUALITY

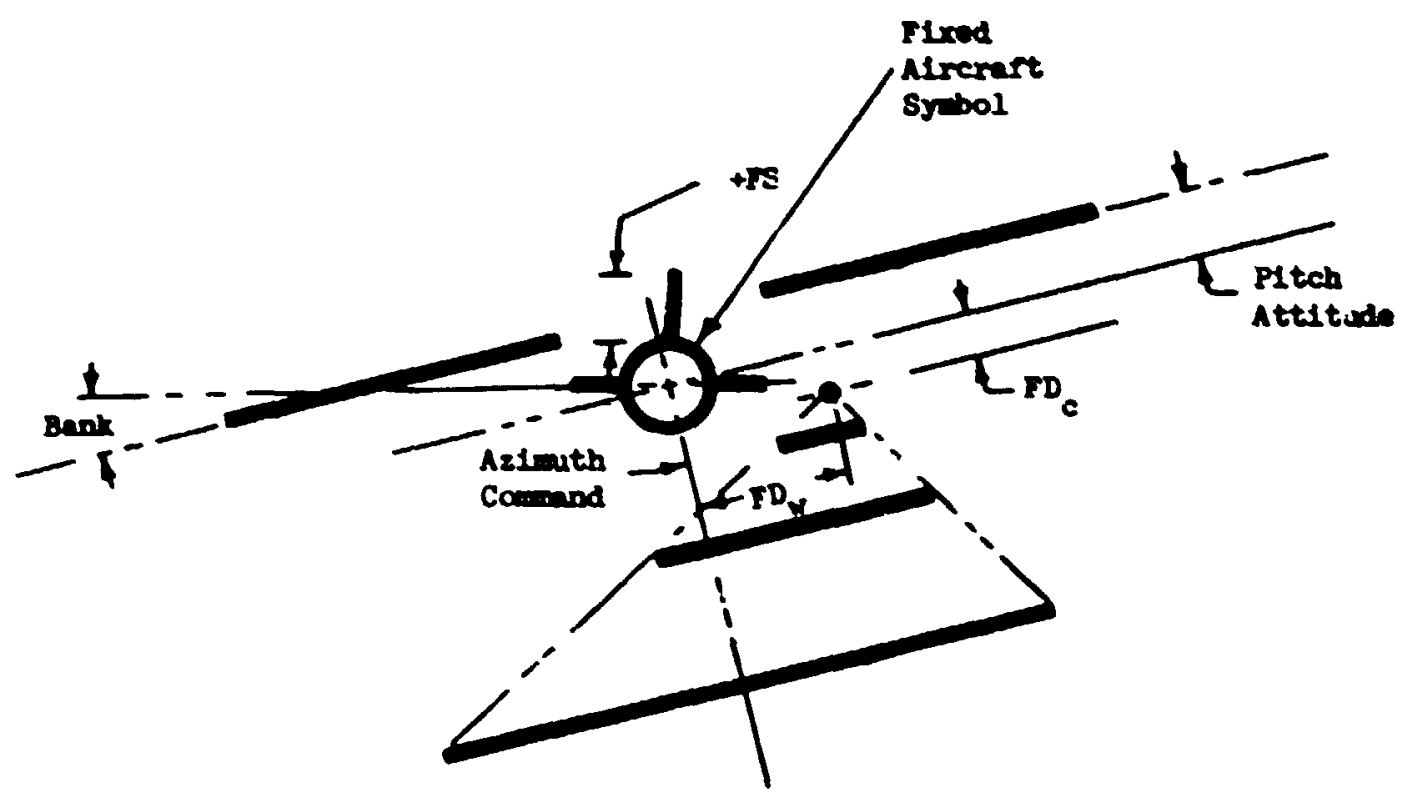

Displer control laws:

$$
\begin{aligned}
& F D_{c}=\Delta y_{v}+\frac{t}{v} \dot{j}+K_{\epsilon_{2} \epsilon_{G} / s}+\frac{0.4 s}{s+2.5} \theta \\
& F S=\frac{1.0}{s+1.0}\left(v-v_{r e s}\right)
\end{aligned}
$$

Figure 4. Simplined Sretch of FHeht Director RUD 
-
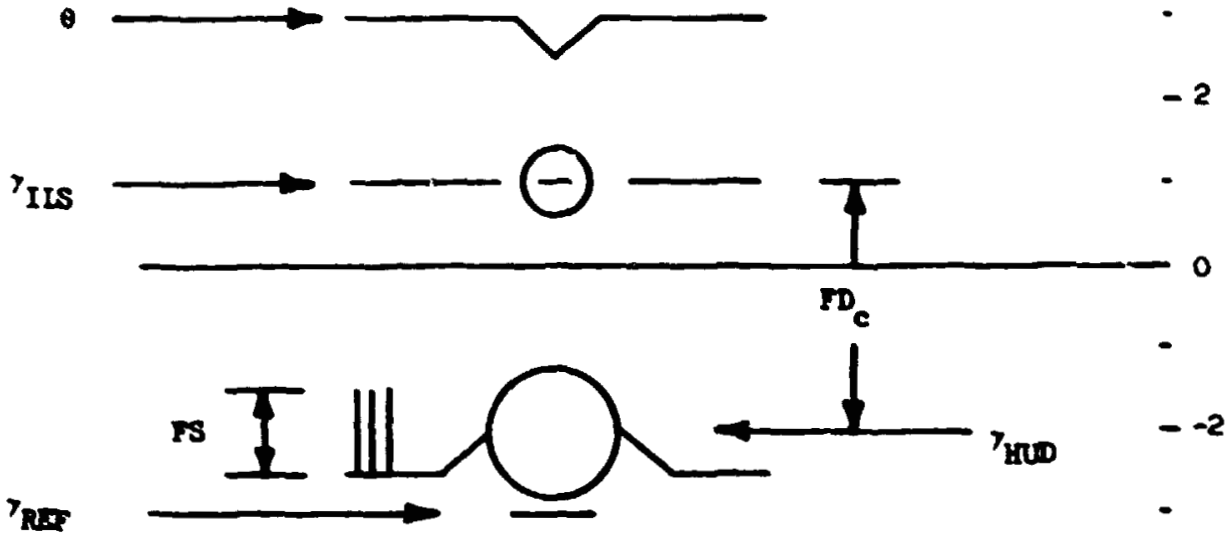

TRS

D1splay control lasm:

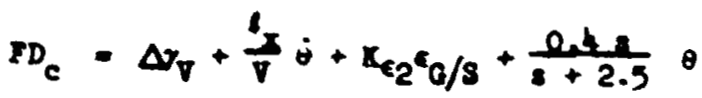

$$
\begin{aligned}
& r s=\frac{1.0}{s+1.0}\left(v-v_{\text {ref }}\right) \\
& \gamma_{\text {HUD }}=7_{v}+\frac{l_{x}}{v} \dot{\theta}+\frac{e .4 .}{s+2.5} \theta \\
& --8 \\
& \gamma_{I L S}=-\gamma_{\operatorname{BES}}-x_{\epsilon} C_{G / S} \\
& T_{\text {REP }}=\operatorname{ILS} \text { culde slope (- } 3.0 \text { des) } \\
& --10
\end{aligned}
$$

Status: Alrerart is pitched up 3 deg and on a 2 deg filoht putb angle. Glide slope is 3 dog above alrernet.

Finure 5. Siplirfed sketch of Fllot Director HUD 
The reference display, F1g. 3, was a coorentional bead-cogn ADI/ESI wth eross hairs used to display the night director siennis 10 . Ine head-down display included the normal coplement CIOL instrumentetion.

There rere two competing concepts of bead-up displars. The Nurst was called the Fight director HUD, Fig. 4, and used a Nixed alreraft symbol and a woving dot to display the vertical and lateral guidance uandsil. The second HID was called the Night path HD, FIg. 5, and used a conformal display of the alrcraft flight path nngle, the rererence ollde slope, and an angle that is proportional to the glide slope errorit. For this display, on effective flight director sigenal can be formed by using the difference betreen aircraft fight path and glide slope angles.

The aircraft was a conventional jet transport and was simuleted on a rull six degrees of rreedom motion simulator with is color visun display's. The simulation was sestricted to terminal area navigation but the pllots did have to transition rom a straight and level flight condition at $160 \mathrm{lt}$ to a -3 deg night path angle at about $130 \mathrm{kt}$ (V rep was chosen by the pllots). The data presented in this report was for an ris Dryden wodel turbulence level of 3.0 fps. Ho discrete wind shears vere simulated.

The pilot subjects used in the simulation were eleven protessional airline captains. Three of the subjects' data were selected for detalled analysis, the results of which are presented and discussed below.

The overall objectives of the simulation vere to coupare the CLIOL beaddown display to the two bead-up dispiays and to document any advantage to using a head-up display. Mng different types of data ware collected and anlyzed in support of these objectives. However, for the purposes of this paper, only those dita related to the pilots' control stretegr wlll be presented and discussed hereln.

A sumary of the experimental results related to the pilots' contial strateg obtained fram the simulation is show In Table 1. A discussion of the results, and some of the data used to support these results, is contained in the following text.

\section{TABLS 1}

\section{EXPERDIBITAL RESUTHS}

- Behavioral variation rram display-to-display

- Behavioral varlation fram pilot-to-pilot

- Identiflcation of time-varying behavior

- Detection of control strategr errors

Pigure 6 shows a plot of crossover frequency, at, plotted against phase margin, $\varphi_{n}$, for each of the three displays and three of the subject pilots. The head-down data is plotted separately from the bUI data because the display laws were different, which, of course, ciused the controlled elewent tymamics to be different. 
ORIGINAL PAGE IS
OF POOR QUALITY

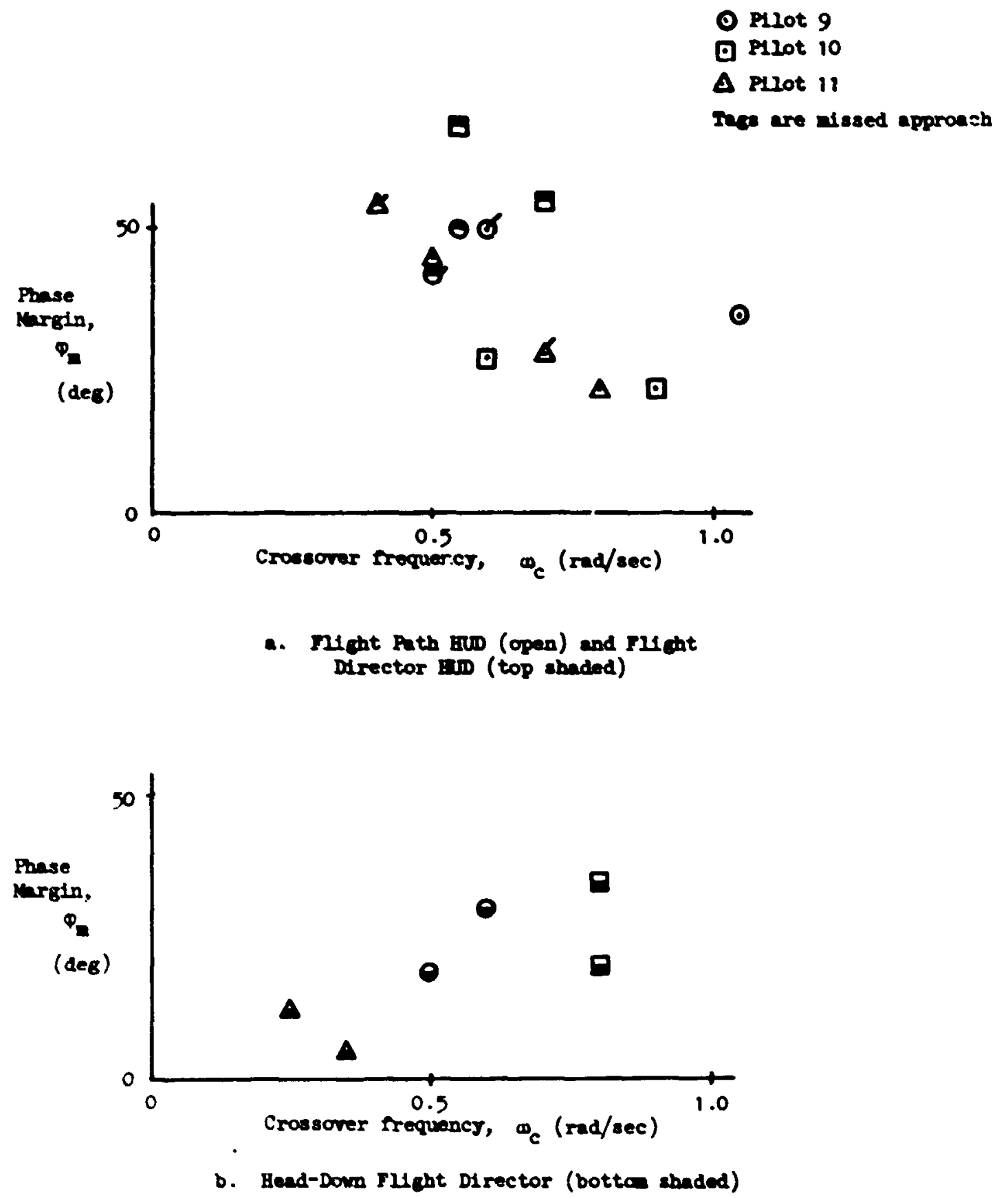

Tigure 6. Cosbloed P1lot-Veblcle Mosuremants 
It can be seen from Fig. 6 that sinilar pilot behavior for the two types of head-up displajs was obtained althouph there vas a d-f'snte trend toward NJing the Night path HUD with a higher banduridth and lower crossover frequency than with the Night director HD. The variability anos the three pilots was fairly low for the two bead-up displars but quite large for the head-dom display. However, within each pilot's data there was fairly low variability, which indicated that a pilot would adapt his orn personel combination of ac and $\phi_{m}$. Also note that the trends in the head-up versus the beai-down displays were opposite. That is, increasing $4 c_{c}$ corresponded to decreasing $\varphi_{n}$ for the bead-up display but just the opposite for the head-down display. This difference was not surprising and is due to the difference in the controlled element dymaics.

Bxamination of the describing function data revealed that all the pilots were able to $\mathrm{Fly}$ the head-up displays with a fairly high gain and use lead coupensation in their contral strategy. But the describing runctions for the head-down display exhibited a jow-bandidith, and a very lagsy type control technique. Sowe sample describing functions obtained from the simulation will be presented in a forthcoming IUSA report ${ }^{1}$.

Thus IIPIP was able to use combined pLlot-vehicle and describing runction measures to discern behavioral varlations from display to display and Iran pilot to pilot.

The pilot's describing ructions exhibited a trend in time-rarying bebavior when using the flight drector BUD and bead-dom display but to a much less degree when using the Fight path HUD. Usually wat the pilots did was to increase their gain and decrease their contral latency as they became clcser to the minimm decision altitude. This effect is demonstrated in the describing fructions shown in Fig. 7 .

NIPIP was able tc detect control strategy errors with the head-down display and the flight path gID. These were dwe to control reversals with the bead-down flight director and due to accidentally using the rrons element in the display with the flight patb HUD. The time history of Fig. 8 shows bow a control strategy errar is maifested in the IIPIP measurements.

After "Jreaking out" (i.e., beneath the clcud cover) the pilot apparently became confised as to which symbol to track in the dispiay. This caused an instability in the flight director joop. That is, positive feedback of the Plight director to control colum ( $\mathrm{Hz}$., Item 6 in the figure). This sudden change in control strateg caused a sharp decrease in the amplitude and phase of $Y_{p}$, and corresponding decreases in crossover frequency and phase margin. The unstable condition lasted for only a few seconds but it was Interesting that NIPIP responded to the control strategr error before the pilot was aware of it. In fact, when the pilot did become aware of it, he actually screamed and then rapidly applied the proper control action.

The time history of Fig. 8 also demonstrates bow IIPIP converges after the trassition from stralght and level flight to a -3 deg glide slope (Item 8 in the flgure). NIPIP's response to the flare and landing is also shown in Fig. 8 .

\section{CONCLUSIONS AND RECOMABDATIONS}

An empirical evaluation of the Non-Intrusive Pllot Identification Program (IIPIP) has demonstrated that accurate, unblased estimates or a pilot's control strategy in performing manial control tasks can be obtained 
CRIGINAL FCSE IS

OF POOR QUALITY
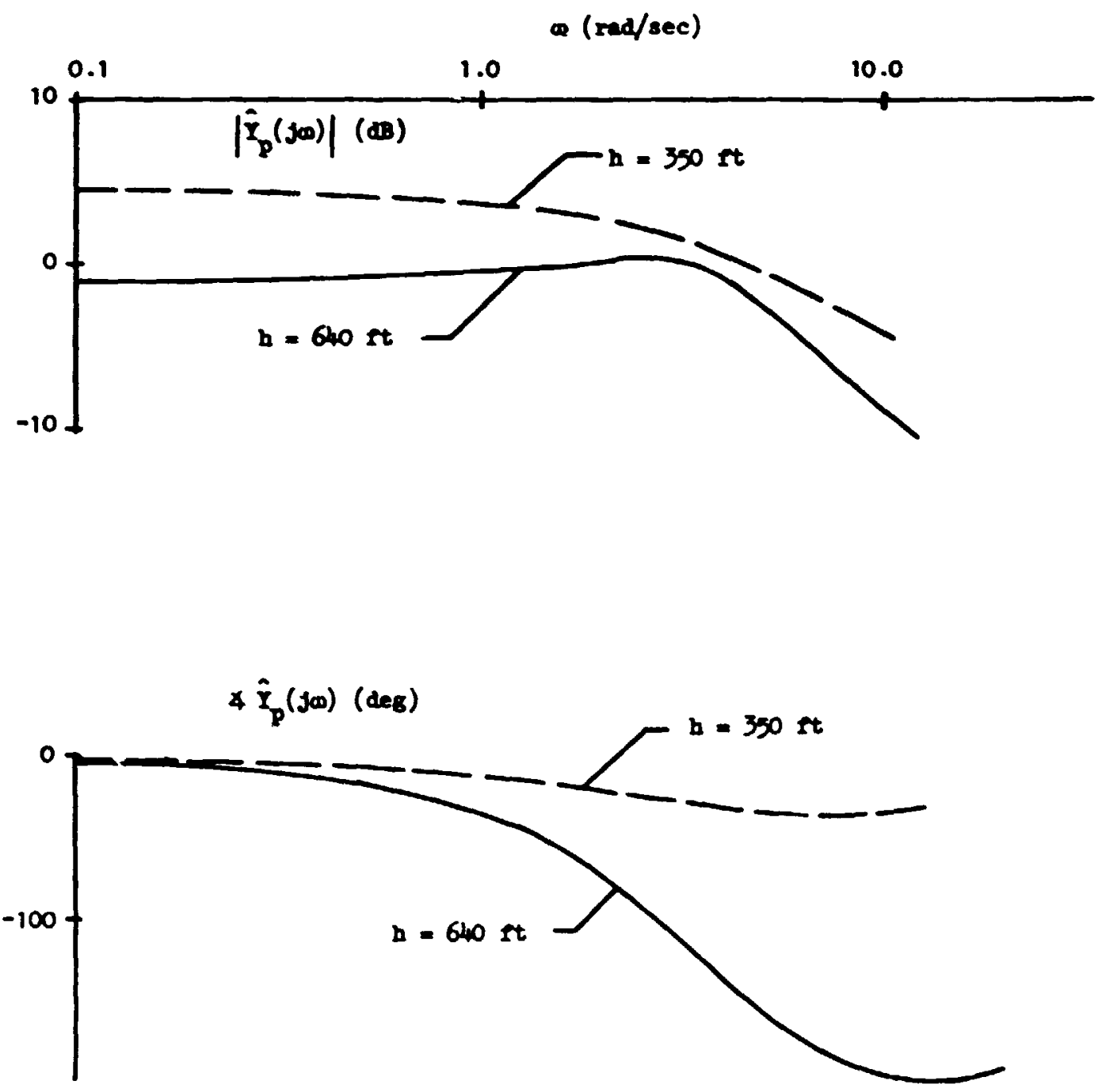

Flgure 7. Describing Function Frequency Response Using Flight Director BID (P1) 9, Rum 386) 

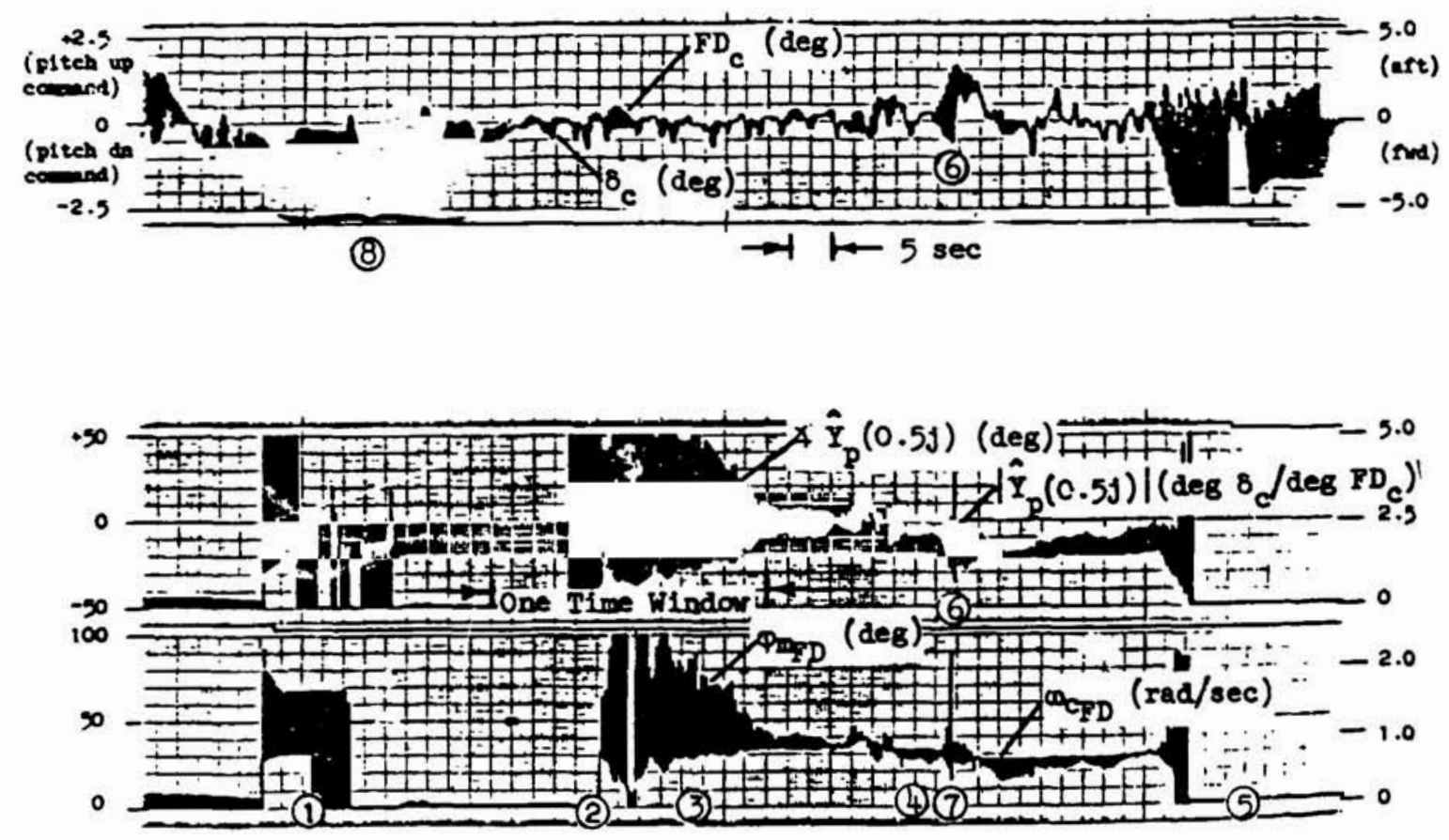
(1) Outer marker (NIPIP initialized)
(2) Time vindor rull
(3) Corvergence time of NDPIP
(4) Breakout (1.e., below cloud cover)

(5) Touchdown
(6) Pllot tracking incorrect symbol in HUD

(7) Note the sudden change in phase margin

(8) Precognitive maneurer

Figure 8. Time History on Final Approach for Run 335. Flight Fath HUD, Plot 10 
even in the presence of pllot remsant. Furthermore, it is possible to use IIIIP for maitiloop control tasks without the use of special inputs or disturbances. Time-variations in the pilot's control stretegy are ide'stifled by NIPIP through the use of a "sliding time window."

NIPIP was applied to a realtime ground-besed simulation of two crumeting concepts of head-up displays and a conventional head-down display. It was shown that behavioral variations in the pilot's control strategy from display to display and fram pilot to pilot could be measured by IIPIP. Ir was also show thet IIPIP could identify time-varying behavior in the p110; and detect certain types of control strategy errors.

For the simulation described herein no attempt was made to correlate the objective measures of IIPIP with subjective assessment of the task workload or pilot preference for a particular type of display. It is recomended that these types of subjective measurements be made in future applications of IIPIP in order to callbrate the objectlve measurements of IIIPIP with pilot opinion data.

The applicstion of IIPIP described herein was to a research project in a groumd-based simulator. It would be possible to use IIPIP ICI many otber types of mamul control tasks, whether simulated or in actual IIight. One such application is in the fleld of Ilight training. By using IIPIP, an instructor could monitor the performance and learning trends of the $s$ sudent pilot, Instead of just the performance of the combined pilot-vehicle system. Inproper or erroneous control techniques could be identifled anc the student informed of the problem.

\section{REFPREMICES}

1. Jewell, Wayne F., and Ied M. Schulman, A Pllot Control Stratera Identiffication Technione for Ire in Multitloco contionl Tasks, (forthcoutag IABA contractor report, Nay 1980).

2. NaRuer, D. T., and B. S. Krendel, Mathematical Nodels of fhmen PH lot Behardor, AGARD-AG-188, Jamuary 1974.

3. Weir, D. H., and R. H. Klein, Measurement and Analrsis of Pilot Scannine Behavilor Dureing Stmulated Instroment Approsches, ATAA Paper I0. 70-999, Ausust 17-19, 1970.

4. Nerhar, S. J., and E. Gabay, Identiflention of A Paramatreta vodel of the Human operation in Glosed Ioon Control Tasks, Technion - Israel Institute of Technology, Departwent of Aercasutical Englneertng, TAE Report Mo. 291, June 1976.

5. Wingrove, Rodney C., Compors 800 of Nathods for Identilyding P1 lot Desardibinc Bunctions Brom Closed-Iogn Opersating_Reaords, IASA III D-6235, Narch 1971.

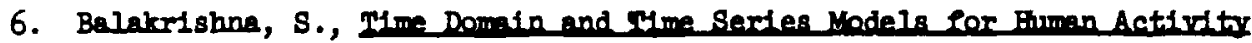
In Compensationy Tracketing Fropedmants, Rat1onal Aeronaut. :al Lab., IAL Technical Hote Wi-50, March 1976. 


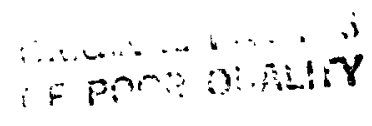

7. Astrom, K. J., and P. Bythorf, "Syctem Identiflcation - A survey," Autcontics, Vol. 7, Pergamon Preas, 1971, pp. 123-162.

8. Herrley, Robert K., and Wayne F. Jem:il, Dayelormant of a Cror PUloting

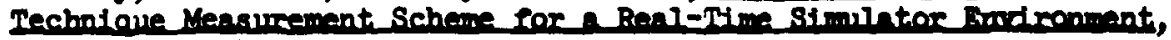
RASA CR-152294, July 1979.

9. Chalk, C. R., T. P. Neel, T. M. Harris, et al., Bacterommd Information

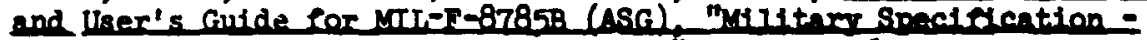

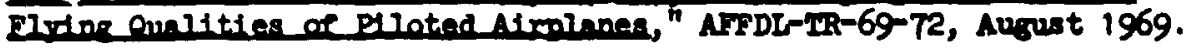

10. Hazen, M. R., and J. W. Kerrigan, B-727-200 Simulntion for sRT: Math Models and Chackount. Dath. Vodel 727, doelng Document Io. D6-44608, 23 Sep' swber 1977.

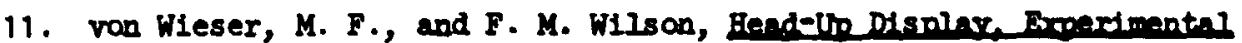
El1pht Test Propxams, 14th Corporate Aircraft Safoty Seninn, Flight Sarety Foundation Inc., Washington, D. C. . Nay 14, 1969.

12. Bray, Richard S., Bead-Is Display Format, lio. 55, unpublishod document, August 20, 197\%.

13. S1nacor1, John B., Robert I. Stapleford, Waype F. JeweIl, and John M.

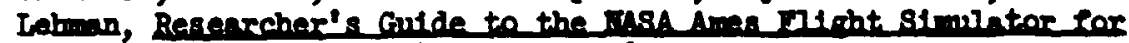

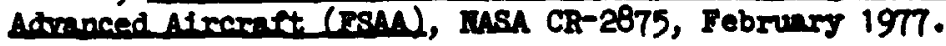


Pilot Reection to Attitude Gyro Failure

-A Flight Experiment-

Richard L. Newnen and David L. Quan

Aeroepece Engineering
Univeraity of Dayton
Dayton, Onio 45469

-Abatract-

Recently aviation safety vorkers have expresead concern about the ability of general aviation pilots to cope with a total vacuun system failure during flight in instrument wteorological conditions. Such a failures leaves the pilot with only a turn-rate gyro to maintein wingslevel flight. Two difficulties lesd to this concern. First, the pilot genarelly has som difficulty in flying the airplene by reference to the turn-rate gyro, the inclincmater, and the airspeed indicator (the socelled needle, bell, and airepeed). The second difficulty arose with the introduction of the turn coordinator wich uese en outside-in presentation - the reverse of the pilot's primary attitude gyro.

ro eveluate the severity of the problen, a flight experiment wes deaigned using a Cosena 172 airplene with the vecuu syaten nodif ied to perait total failure of the attitude and directional gyros. Nine aubject pilots, renging in experience from 170 to 5100 hours, flew simulated (hooded) instrument miseions with an unexpected gyro failure introduced at a critical point. All subjects, except for the 170 hour pilot, were inatrument rated. (The 170 hour pilot was a private pilot vorking on his instrument rating.)

All of the subject pilots wre able to mintain control of the air$\because$ ane following the gyro fallure. Only one aubject exceecied the a priori criterion of losing a maximu of 250 feet of altitude. None of the subjects flew a satisfactory VOR approsch following the failure; hower all would have found the airport afely given a ceiling of 1000 feet or better.

\section{-Introduction-}

During flight in instrument meteorological conditions (IMC), the pilot is wolly dependent on his flight inatruments for the cues noceseary to control the airplene. In particular, the attitude and directional gyros provide vital cues the pllot needs to maintain orientation in the cbsence of a vieual ground reference.

Brth of these gyrascopic instruments are ausceptible to demage from violent menuevers and to failures beceuse of thair common power supplies. 


\section{ORICINAL PAGE IS \\ OF POOR QUR.LITY}

To prevent total loas of control if either or both guros fail, : a backup instrument is required for flight in IMC. Light eirplenes use a turn-rate indicator which shows the rate of yew. This inatrument relies on gyroscopic precession to def lect a noedle and is thorefore much nore physically robuat tr an conventional attitude and jirectional gyroa. This mens that it is much 1988 likely to be danger in a menuever. To preclude loes of control ... the ovent of a pover aupply failure, turn-rate indicators are ueually powreo epparately from the other two gyros. Most light airplanes use vecuu powred attitude and heading gyroe (from an engine driven vecuun punp) eno electric turn-rate indicatars. However thare is no requirement for separatu powr applise in single-engine airplenes. These flight inotrumente and thoir charecteristics are discuesed in soveral instrument flight menuels published by the US government $(\underline{1}, \underline{2})$.

-Statement of the Problum-

It is much ware difficult for a pllot to fly en aipplene using the turn-rate indicator than the othar cor gyro instruments. This is w11known to eny instrument rated pllot. 1 seseone are threefold: Firet, the dynanice of the turn indicator how you rates, not roll information or heeding. Thze hae seen partially compeneated for in recent dasigne by tilting the sxis of the gyro to produce som enevere of roll rate ifferantion(3). Second, the turn-rate indicator provides no pitch attitude informition. The pilot wot obtain this fram his alrepend or vortical apeed indicator. While the airepeed cen be uaed, thoes proseure inatruments hove built-in lege. Third, the display format is quite different from the normal presentation. Tho pilot wat uen coveral inatruments to obtain his date. In cddition, the tiltes-. to-gyros in recent vogu ues a formet that eppora aporficielly the eave as tho attitude gyro. Howver, the ecenes of the motion is revereed.

During initial inotrument training, a great dael of tim $j:$ apent drilling the student on flying with only the turn-rate indicat: , the co-called partial penel. Virtually all of this training 18 eccomplishod by covering the attitude and directional gyros and having the otudent fly uning only "noedle, bell, and eitroped."

Although thi studint is trained to fly by roforence to the turn indicator, the is given no sxperience in detecting primry gyro feilures. These fallures cen be deceribed as prwesesion, tubling, or fresing. Fram a pilot'e point of viow, preceseion spoers to be elightly erratic wotione in both pitch and roll with a rendom input. The hading show on the directional grro siowly drifte. Tho ceues of proceselion cen be dirty bearinge, ainding girbal, or low gyrs epeed.

Tumbling is a violent preceseion, ueually ceu so by a mumever that ceuses the gibul to atrike the atope. It cen be ceusen by a cemplete power failure. To the nilot, this eppoars as if the attiudp gyro wis owining in its diepley. The directional gyro simply ep27s. if the turbling ves ceured by excending the gyro linite bi fitch or roll, the erection mechenien will slowly return tho gyros to nor ml operation.

preezing of the gyros cen be ceuced by mechenicel bi or by a caging mocheniem dosigrad to provent tumbling wan power it semourd. Thus, 
under some circumstances, a complete power failure will not result in tumbling, but will produce en unmoving display. This mull fallure can be quite difficult for the pilat to detect.

F-. ure of the comon pcwer upply (vacuun pump faslure) cen produce pre 6. in errors in both gyros if the fallure is partial. It can produce tumoling (spinning) or freezing erross if the faslure is complete. During the preliminary development of this papes, we undertook to observe an actual vacuun system failure. A Cessna 172 was flown to $12,500 \mathrm{ft}$ and the engine shut down. Approxinctely four aumutes later, passing through 9,000 ft, the attitude gyro failure. The failure node vas not apparent except by obser: ing the outside visual reference. Holding zero pitch and roll on the indicator, the airplane rolled into a thirty wegree bank soural approximately five to ten degrees nose dow. There was no indication of tubling or failure of the gyro itself. The fallure was fairly slow in deteloping.

The turn-rate indicator is also subject to errors. Becau e of its desion as a rate gyro, precession is a normal event. ine turn indication is simply a masure of the precession force caused by rotation about the airplane's vertical axis. The only possible mifunctions involve slowing or stopping of the gyro. These appoar as decreased sensitivity or as no turn indication at all.

Several factors can influence the ability of the p1lot to detect and cope vith gyro failures. These are his prof iciency, his training, and the instrument penel design.

Pilot prof ; iency inclides recency of unstrument flight experience, curlency in the airplene, and proficiency in partial panel flight. While a prof icient pilot cen certainly fly a much semoother profile, it does not necessarily follow that he will be able to detect instrument faslures more quickly just by virtue of his currency. However, a proficient pilot my have a lower workloed then a non-prof icient pilot for the seme task, wich mey help. Recency of partial penel flying experience is more likely to be signifirant than the other factors, however.

Plot training includes both initial training in instrument fly ing and any experience the pilot may have had in detectiing instrument failures. Obviously, few pilots at present have had any training in the recognition of a vacuum pump failure. Only those pilots tho have either personally experienced en instrument failure or who have had a close assoc sate who has experienced on will even be aware of the problen.

Instruarent panel design includes such factors as varnins levices (including vacuum gauges) and the design of the instruments themselves. One factor that makes partial penel flight more diff icult is the different senize of motion in recent turn-rate indicators. These new instruments present the turn in an outside-in format as opposed to the conventional inside-wt artificial horizon. The different sense of motion could have a negative effect both in detecting an attitude gyro faslure and in flying the aurplane afterwards.

Difficulties in coping with gyro fallures were reported by the National Transportation Safety Board, who reviewed several fatal general aviation accidents during the pe:iod 1969 to 1973(4). In these accidents, wich occurred turing flight in IMC with instrumient rated pllots, the Safety 


\section{ORIGINAL FAGE IS \\ OF POOR QUALTY}

Board cited vecuen syatem or flight instruments as causel factors. The Sefety board noted:

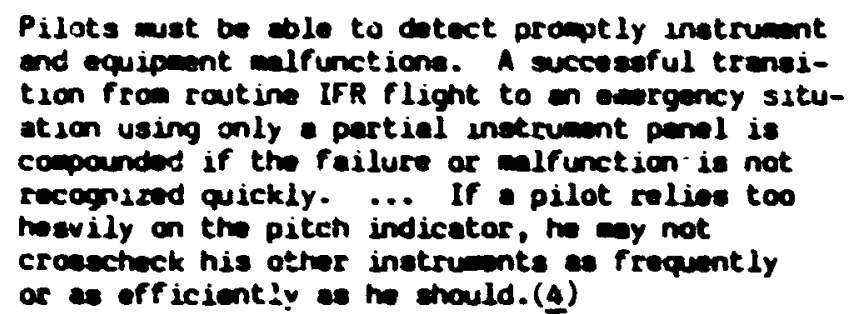

This hevy relience on the attitude indicater has bean denotrated in oye owll experients ueing experienced eirline pilots during siumulated instrument epproshas. Klein and war found that 903 of the eye dwil tim wes devotiod to the attitude and harizantal situation indicatars during simulated ILS epprosches(5). If sinilier eye desll tiens apply to ganarai avistion pllots, then the Safety Board's concern would seet to be well-founded.

In en attempt to deternin if the problem is a savere one, arelininary flight experibent was undertaker. ueing - typical ganeral aviation eirplene and a sar le of civilien and nilitary pilots.

Hethod-

Airplene A Cosene 172 we codified by ineerting a length of pleat ic tubing into the vecuen line betwen the vecum pup and the attitude and directional gyros. The plastic line was routed (out of sight of the left. seat p2lot) to a pount blow and behind the right-front seat pilot. During flight, oither the safoty pilot ar the rear-eat obenrver could pinch of the line and shut off the vecuun source to the gyros. The vecum geugs was by-pased, thus odisinating thrs cue to the subject pilots. Two subjects noticed this during prefiight rumups and were told that the gauge was incperative.

Subject Selectzon Noat subjects wre recruited from a University clase in Flight Teat Engineering teught at Wight-Patcerson AFB. Moditional subjects ere recruited from locel eirports. Table I show the pllots' experience and qualifications. All pilots completed a preexperimental questionnase and were told that the purpose of the experiment was to mesure their trecking eccurecy ouring VOR holding pat:erns or VOA epproceche (es expropriete to the flight prof ile flown). All subjects except one ere inotrument quelified. Ail but one vere current in esther civilie or military aircraft.

Following the esperiment, the subjects wre told the resl purpose of the experiment. (Most had guesend when the failure uccurred.) They then completed a post-experiwent quest ionnesre. Amons other questions, this questionneire asked for recency of partial panci flight and if they had ever experienced a similiar fallure. Nane ri the subjects had exper tenced such a faslure in IMC. 


\section{ORIGivis?ER IS \\ OF POOR Q!jALITY}

Flight Profiles Two briefed profiles were flow. One consiated of a halding pattern at a VOR. The othar we a VOR instrument spprosch to minimus. The abjects were given sufficient tim to becom confarteble before the final tack. All reported that they felt reedy far a performence mesurement. The failures introduced in the holding pattern were all started at the point of reeching the voR.

The subjects briefed to fly a VOR approech were instructed to call ainimus at the eppropriate point. Half vere told to execute a aissed approech (with the vacuun line closed off at the same instant). The other half ade a full-stop lending and the vecuun as failed during the taxi beck. These subjects were given a complex routing to follow during the subsequent takeoff. as ATC.

All ATC commications were simulated with the safety pilot ecting

The subjects continued to fly the preacribed patterns until they recognized the failure. If noceseary, they were told te continue flying as if they were in ectual weather conditions. Two wilitary pilots with linited experience vith vecum systems hed to have the comon power supply for the attitude and directional gyiss pointed out.

Following this, all subjects were provided a no-gyro redar steor by Dayton Approech Control to a VoR epproech at a nearby airport. All had to perform the interception of $f$ inal and final tracking without aid from ATC.

Date All data was hand recordad by the safety pilot and the rear seat Cbserver tho was carried on some flights. The subject!s smootheess in controlling airspeed, altitude, heeding, and treck was evaluated bofore and after =the failure. The level of turbulence present and the degree of ATC warkloed were also reported. The safety pilot for all flights was one of the athors (RLN), wo is en experienced instrument instructor pilot vith 1200 hours of flight instruction experience.

Also noted cerethe time to a failure indication on the gyro and the failure mode itself. The emount of altitude lost and the heading deviations during the failure were also noted.

The subject's post-experiment quationnaire also asked for his estiwe of the excursions ouring the failure.

Reoults-

In som woys the results were as predicted. None of the subjects was able to fly a consistent track over the ground. This wes expected. However, none of the subjects lost control of the airplene. In no cese did a subject pilot have any difficulty in mintaining wings-level flight. This is not to sey that they flew within IFR tolerences, but they did retain control of the airplene. 
Toble II showe the extent of airepead, altituds, heading, : ad treck excuraiona noted by the affety pilot and by the oubjecte themsolves in the pout experinont quatiomnires. In general the treck excursions were so bed that no consiatent wasure could bi used by the safety pilot. Before the experiment was flown, we had decided that losing $250 \mathrm{ft}$ would be considered "a loes of control." As cen be seen in the table, only on subject excesded this figure. In retroepect, this criterion was probably too strict.

Following datection of the failure, the abjects wre required to fly a VQR epproach. They ware allowed a no-gyro vector to intercept the final epproach course, but they wre required to intercept and fly the final based solely on theis ow navigation. Toble III showe the safety pilot's essesement their soothma of control both befare and following the failure. The socotmess "atter_failure" does not include the excursions during the initial part of the failure, just the flying "after sottling doen." One subject, 55, hed better performence following the failure. This particular abjoct had not been on flying status for sos tile and wen probebly still on the_learning curve. All of the othar abjects did not do we woll on the partiel penel as on the full perel.

It is worth noting the different failure deseriptions. The holding pattern failures took bout six nimutes to develop. These uevelly produced a pitch up error. . Tbiat is, the grro:showed a pitch dom lesding the pilot to raise the nowe. The directionel gyro continued to run for some time after the attitude gyro failod in nost ceses.

During the failures introduced on tabeoff or during a go-around, the failurea occarred much mre quickly. In theos cases the failure modes were not at all consistent. Tho failure descriptions are show in Teble IV.

Table $V$ ahous additional responses to quations on the post-experient questionnaire. The most comon reply to "what cue did you use to detect or notice the failure?" was the attitude gyro. Actually, the subjects reported that it was discrepencies batwoen this instrument and othar inatruments that first alerted them to a problem. Several cited inconsistent responses displayed on the artificial horizon:as they epplied control inputa.

The subjects did not feel that control ves espocially difficult following the failure. While they wre sure that previous experience did help then to fly with a partial penel, they were auch lese sure soout the value of this experience in detecting a failure. The failed gyros' ation did diatract thom during the partial penel flight.

In general the subject pilots falt that this was a realistic demonstration of instrument failure. A number of somments suggast that it would be a usoful addition to intial and recurrent instrusent training. These comments are shown in Table VI. 


\section{CR:A.:.,il FARE IS \\ OF PCON QUALITY}

Conclusions-

The prinary conclusion is that the problem of goneral ovintion pilots coping with vecuu puip failures is not as sovere a initially believed when the experiment wes deaigned. Wile the subject pilots were ressonebly current, they had not practiced partial-perel flight for wny years (in one case rimoteen years). Novertholess thoy wre cole to fiy the airplene safely and would have made a safe recovery had the weather been a $1000 \mathrm{ft}$ coiling vith one wile visibility. In spite of articles to the contrary (6), the genoral eviation pilot seem to be ble to cope with the problem. The military pilota had more difficulty, primarily beceuse of a leck of failiarity vith the syatema.

It did seen that the subjects had no clear-cut eppronch to flying a given treck on partial panel, however. They did not attempt to fly - heeding, but rather rested simply to tho notion of the deviation indicator. It would soem that this aree could be added to initiel instrunont training.

We recomend that partial penel training for initial instrument ratings bs inproved to include failure odes of the privary inetruments with sussequent tracking and at leset one VOR eppronch.

\section{fieferences-}

1 Inatrunent Flying, USAF AFM-51-37, November 1971

2 Instrument Flying Hencbook, FAA AC-61-278, Soptember 1970

Y G. J. Stinnat, C. T. Jeckson, and P. D. Talbot, The Turn Rate Indicator - - Its Interpretation as Affected by Installetion Eno ?rue Airspeed, SAE Papar to. 710380, Narch 1971

4 "Inedequate instrument Crosechecks and Untimely Datection of Instrinent and iquipmont Malfunctions," NTSB Safety Recommendstions Nes. 4.76-29 and A-76-30, March 1976

5 D. H. Weir en: R. H. Klein, mbesurenent and Anelysis of Pilot Sceming Beh:vior Ouring Simulated Instrument Approsches," Journel of Alrerof: $=0,1971,897-904$

6 B. Schiff, "Gjro Fallure," AOPA Pilot, October 1979, 4, 49-55

March 1980 


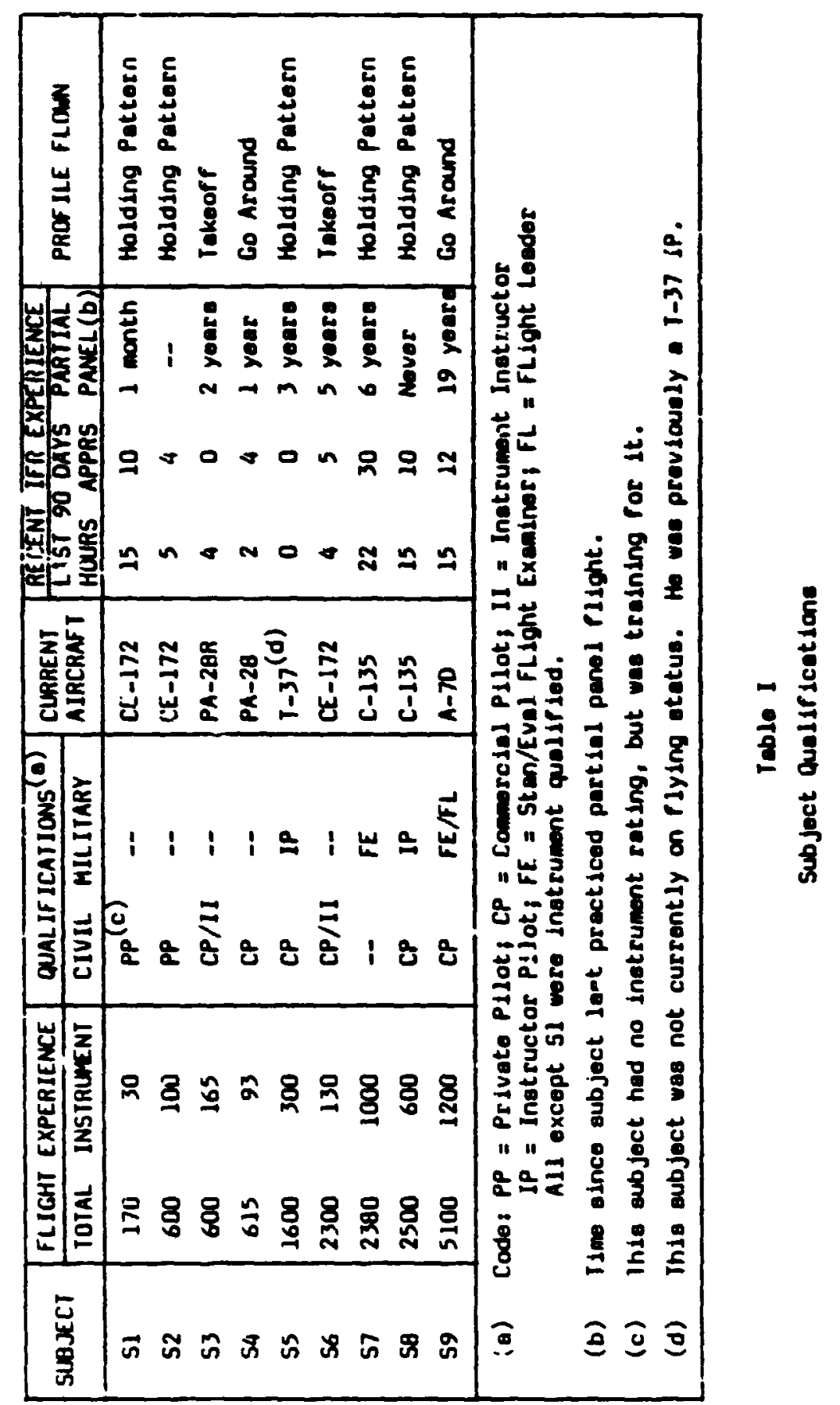

412 
ORTGH:LI PTEE IS

OF POCR QUALITY

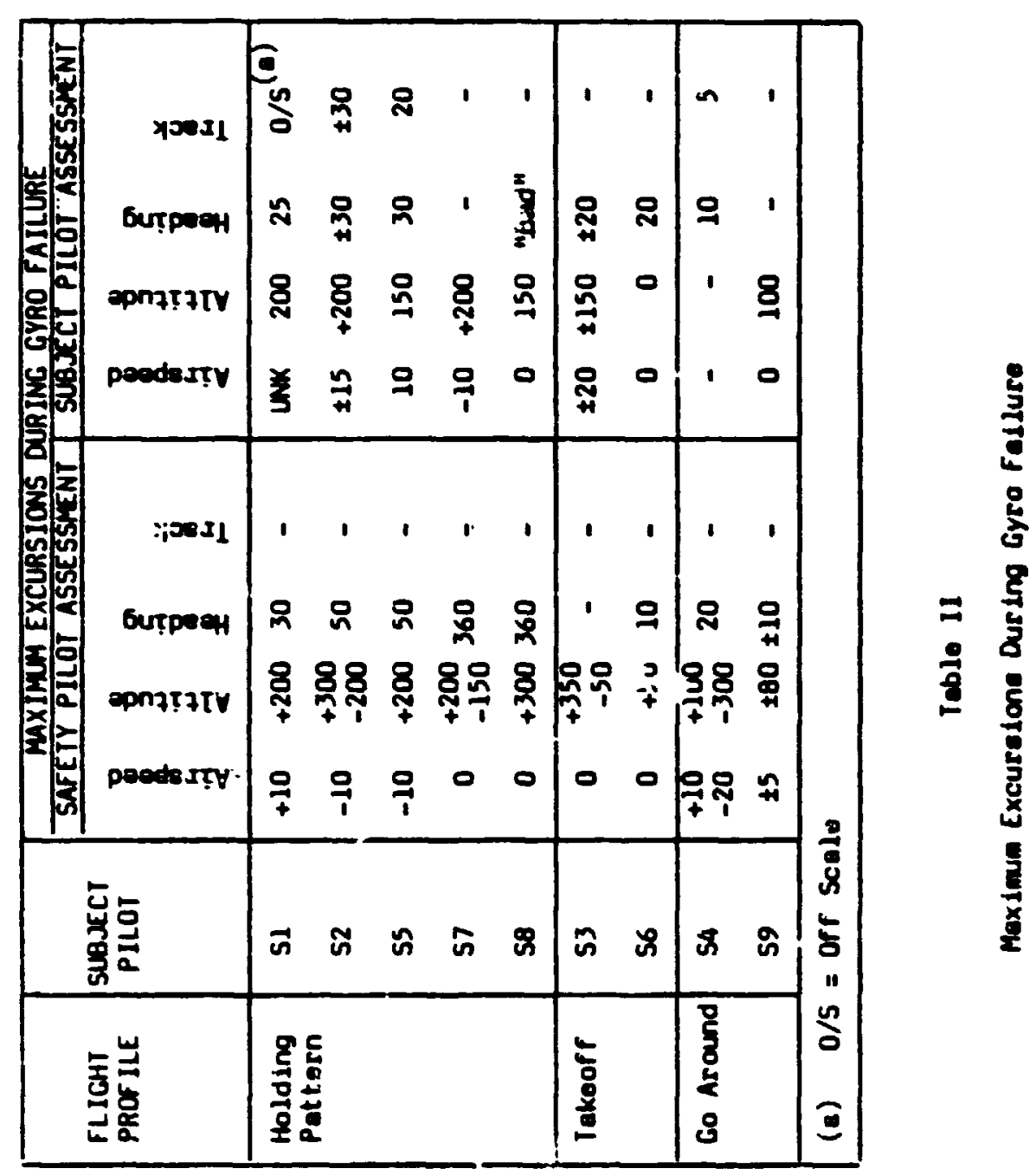


GRivin inL HASE IS

OF POOR QUALITY

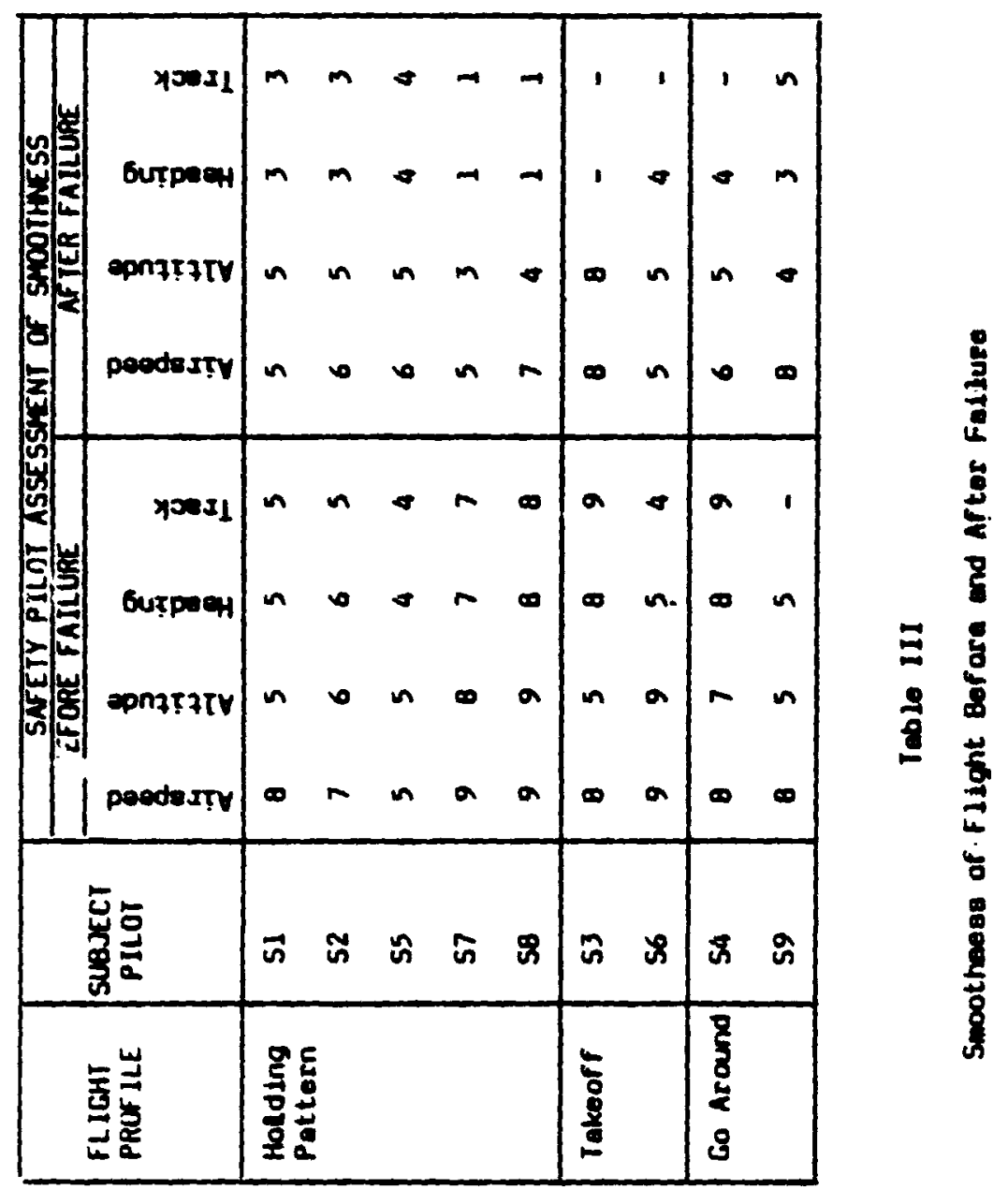


orse

OF POL: Gusinit'

\begin{tabular}{|c|c|c|c|c|c|c|}
\hline 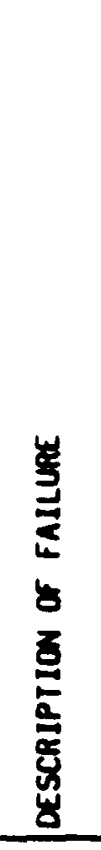 & 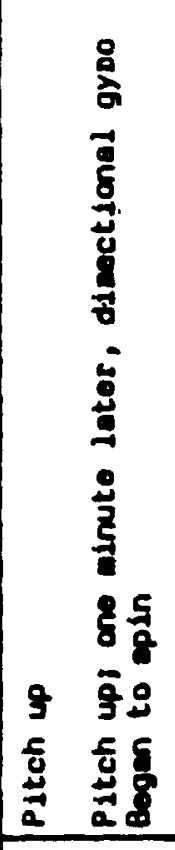 & 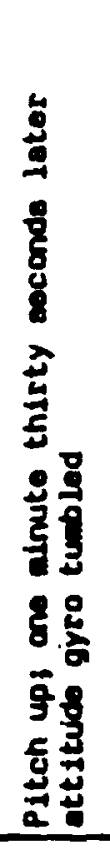 & $\begin{array}{l} \\
\end{array}$ & 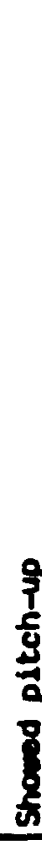 & 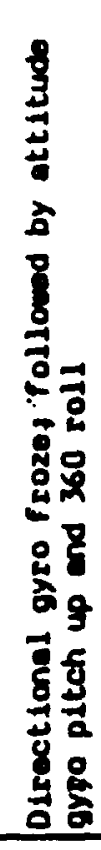 & 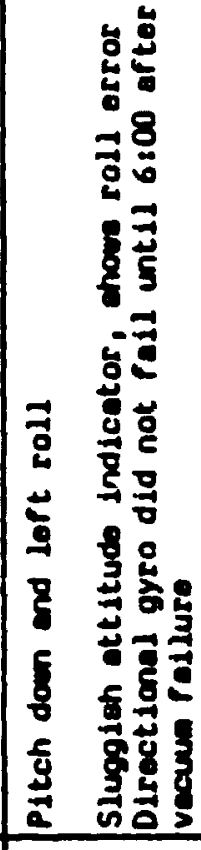 \\
\hline 㗪 & 88 & 8 & $\cong \overline{\bar{n}}$ & & $\stackrel{20}{=}$ & 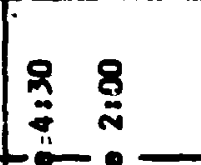 \\
\hline 兾岁 & 象 点 & $\frac{8}{2}$ & \& & & 泀 & $\frac{1}{8}$ \\
\hline 鞓 & $\vec{\sim} \tilde{\text { s }}$ & $\ddot{n}$ & n $\delta$ & $\hat{n}$ & 3 & क is \\
\hline 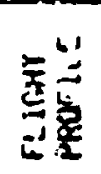 & 耸总 & & & 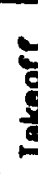 & & $\begin{array}{l}\frac{E}{2} \\
8 \\
\vdots \\
\vdots \\
8\end{array}$ \\
\hline
\end{tabular}


uti: :

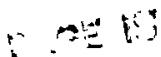

of pier num

\begin{tabular}{|c|c|c|}
\hline QLESTIONS & No. & RESPONSES \\
\hline $\begin{array}{l}\text { CUES USED } \\
\text { TO DETECT } \\
\text { FAILURE }\end{array}$ & $\begin{array}{l}8 \\
3 \\
2 \\
1 \\
1 \\
1 \\
1 \\
1\end{array}$ & $\begin{array}{l}\text { Artificial Horizon } \\
\text { Directional Gyro } \\
\text { Sound Cues } \\
\text { Airepeed } \\
\text { Devintion on Coures Indicatar } \\
\text { Altimetor. - } \\
\text { Turn and Benk } \\
\text { Vertical Speed }\end{array}$ \\
\hline $\begin{array}{l}\text { HOW DIFFI- } \\
\text { CULT WAS } \\
\text { CDNTRO } \\
\text { FQLOWING } \\
\text { FAILURE? }\end{array}$ & $\begin{array}{l}\bar{z} \\
6 \\
1 \\
-\end{array}$ & $\begin{array}{l}\text { Very Easy } \\
\text { Eagy } \\
\text { Modiun } \\
\text { Diff icult } \\
\text { Vory Difficult }\end{array}$ \\
\hline $\begin{array}{l}\text { OID PREVIOUS } \\
\text { PARTIAL } \\
\text { PANEL EXP. } \\
\text { HELP YOU }\end{array}$ & & \\
\hline $\begin{array}{l}\text { TO DETECT } \\
\text { THE FAILURE }\end{array}$ & $\begin{array}{l}3 \\
2 \\
2 \\
2 \\
-\end{array}$ & $\begin{array}{l}\text { Yos, Dof initely } \\
\text { Probebly } \\
\text { Uncertain } \\
\text { Probebly Not } \\
\text { No, Def initely }\end{array}$ \\
\hline $\begin{array}{l}\text { TO FLY } \\
\text { AF TER YOW } \\
\text { WERE ANARE } \\
\text { OF THE } \\
\text { FAILURE }\end{array}$ & $\begin{array}{l}6 \\
1 \\
2 \\
?\end{array}$ & $\begin{array}{l}\text { Yos, Dof initely } \\
\text { Probebly } \\
\text { Uncertain } \\
\text { Probebly Not } \\
\text { No, Def initaly }\end{array}$ \\
\hline $\begin{array}{l}\text { OID THE } \\
\text { FAILED } \\
\text { INDICATOAS } \\
\text { DISTRACT YOY }\end{array}$ & $\begin{array}{l}3 \\
5 \\
1\end{array}$ & $\begin{array}{l}\text { Yea, Conaiderably } \\
\text { A little } \\
\text { No }\end{array}$ \\
\hline $\begin{array}{l}\text { WAS THE } \\
\text { FAILURE } \\
\text { REALISTIC }\end{array}$ & $\begin{array}{l}9 \\
-\end{array}$ & $\begin{array}{l}\text { Yos } \\
\text { No }\end{array}$ \\
\hline
\end{tabular}

Teble V

Additional Rosponses: 
OR:a...". 20:35 Is

OF POOR QUALITY

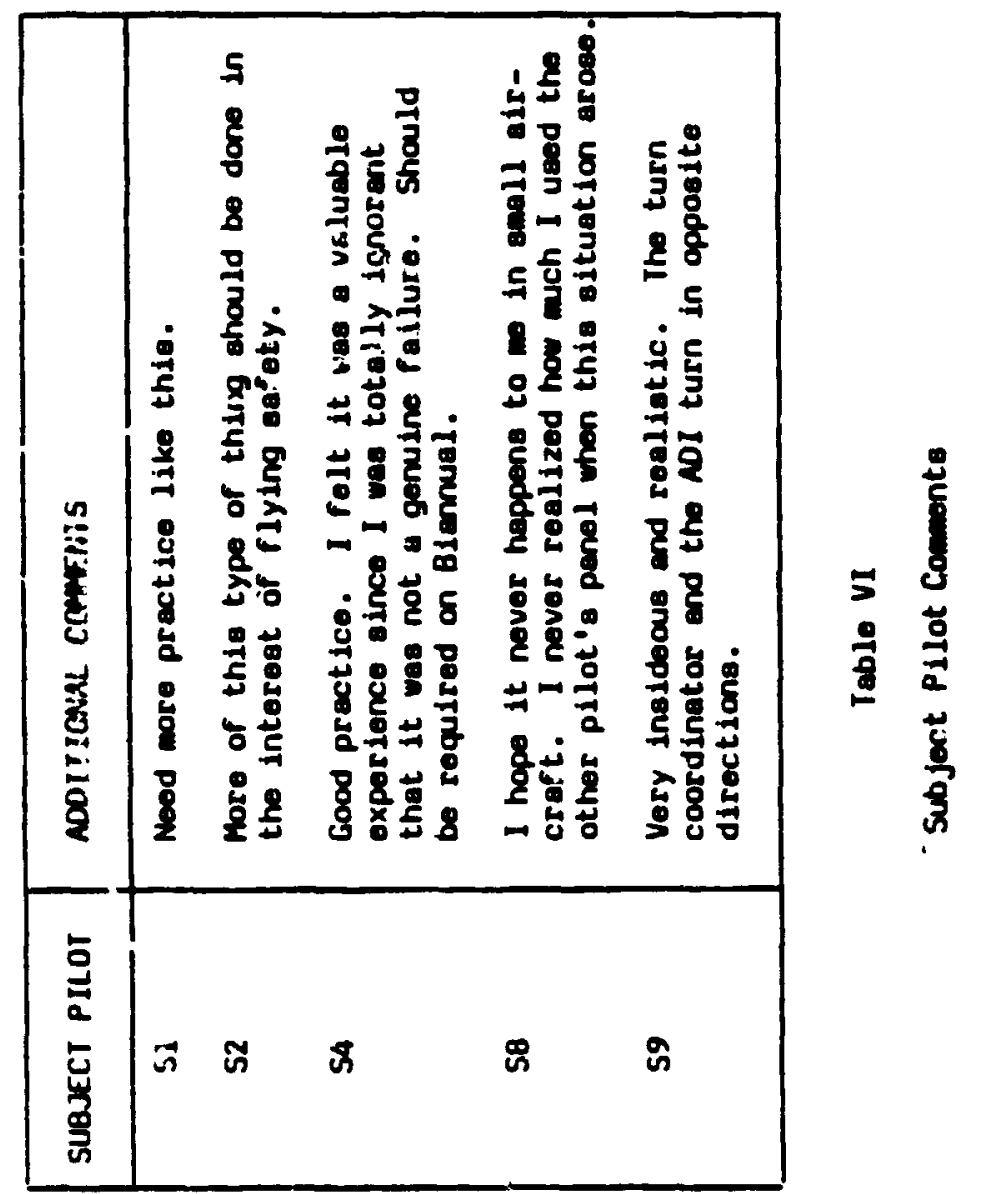


PILOT INDUCED LONG PERIOD OSCIILATIONS CRETED BY CERTAIN DISPLAY CONTIGURATIONS

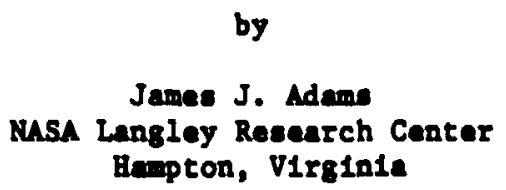

General aviation accident records show thet the nost dengerow parlod of an IFR flight is the approach to landing. One area of concern in thin water 10 the role thet inetrument dieplay configuratione play in the etab111ty of the p1lot-alreraft ayetem. P1lot reaponse studien and pllot nodeling effort have shown thet the p1lot does reepond much l1ke a linenr feedbeck control mechan1en whe controliling an alrcraft, and that a definite otabllity characterietic does result in the p1lot-alrcreft oyetem. Arcraft are designed so that in wot cases this oysten atability 1o positive (damped), but occenlons do ar1se when the ayaten becomes unstable. P1lot 1nduced osc1llations have bear an 1tem of study for some time. Op unt1l now these studien have usually centered around short pertod (around 2 to 3 esconda) 1notabllities. Long pertod unetable osc1llations can also occur, Involving large diaplaceante froe the desired flight path of the alrcraft, which affect the eafoty of elight. There 1s evidence of such long perlod lastabilities to be found in masurenente made during instrunent lending approeches. However, these Inetabilites uoually do not have time to becoes well developed before the pllot goes vieusl, and then the inotability disappears. The present etudy will cophesise the entetence of theee long period Inotabilities by opecial test techniques ande poselble by the flexibility of the stmuletson computer, and relate then to conventional general aviation Inetrument dioplay conisgurations. 


\title{
- $8234062 D_{25}$
}

DESIGN, SIMULA:ION AND EVALUATION OF ADVANCED DISPLAY CONCEPTS

FOR THE F-16 -ONTROL CORFIGURED VIFICLE

\author{
Robert $\boldsymbol{~}$. Klein* \\ GiIdance and Control Department \\ Grumman Aerostace Corporation \\ Bethpage, N.Y. 117:4 \\ Walter M. Hollister \\ Assoclace Professor, Department of Aeronautlus and Astronautics \\ Massachusetts Institute of Technology \\ Cambridge, MA 02139 \\ *research conducted at: Department of Aeronautics and Astronautics \\ Massachusetts Inst Itute of Technology \\ Cambridge, MA 02139
}

\section{ABSTRACT}

The purpose of this study was to design, simulate and evaluate advanced display concepts to augment the tracking ability of the F-16 Control Configured Vehicle (CCV). A IIterature seerch reveals that bistortcaliy CCV and display research has been conducted independentIy; the design of a display system for a CCV afrcraft should take the unlque CCV flight modes (1.e. direct fosce, pointing, translation) Into consideration. This paper dejails the recent M.I.T. study which reviewed the F-16 C,CV fllght test program, revieved current atrcraft display research, and suggests task-orlented and compensatory displays to even further enhance the capability of the F-16 CCV.

The f1xed-base M.I.T. 707 simulator was modified to represent the F-16 CCV. An 1sometric sidearm control stick and two-axis CCV thumb button were installed in the cockpit. The forward cockpit CRT was programed to present ais external scene (numbered runway, horlion) and the designed Heads Up Display. The cockptt Intertor was nodified to represent a fighter and the B-16 CCV dynamics and direct $11 \mathrm{ft}$ and side force modes were programined. Compensatory displays were designed from man:wachine considerations.

P1lots evaluated the Heads Up Display and compensatory displays durtng simulated descents in the presence of several levels of filtered, zero-mean wind gusts. During a descent from 2500 feet to the runway, the pilots tracked a point on the ruway ut1lizing the basic P-16, F-16 CCV, and F-16 CCV with advanced displays. Substantiai tracking 1mprovements resulted utilizing the CCV wodes, and the displays were found to even further enhance the tracking ability of the F-16 CCV.

\section{INTRODOCT ION}

Th: F-16 Control Conf1gured Vehicle

The F-16 CCV was selected for the M.I.T. study based on the operational twefram of the alrciaft, recent flight cest and evaluation by USAP p1lots, and avallability uf aircraft dynamics data. In 1973 the A1r Force F11ght Dynamics Laboratory contracted with General Dynamics for an 87 flight, 125 hour test program of the F-16 CCV (ref. 1). This warked the first exploitation of decoupled $1 \times$ degree-of-freedom flight path control. Completed in June 1977, Bdwards Alr Force Base test pilots avaluated the CCJ control modes 


\section{ORIGINAL PAGE IS \\ OF POOR QUALITY}

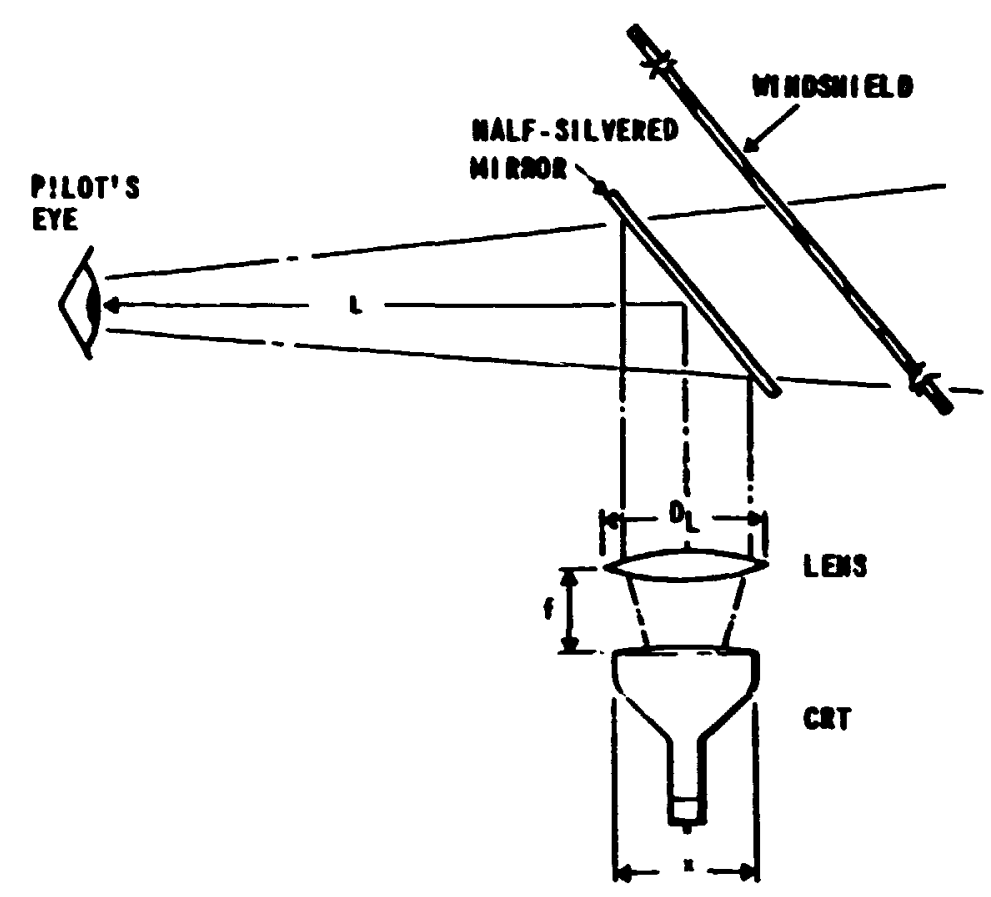

Figure 1. Heads Up Display (HUD) Optics

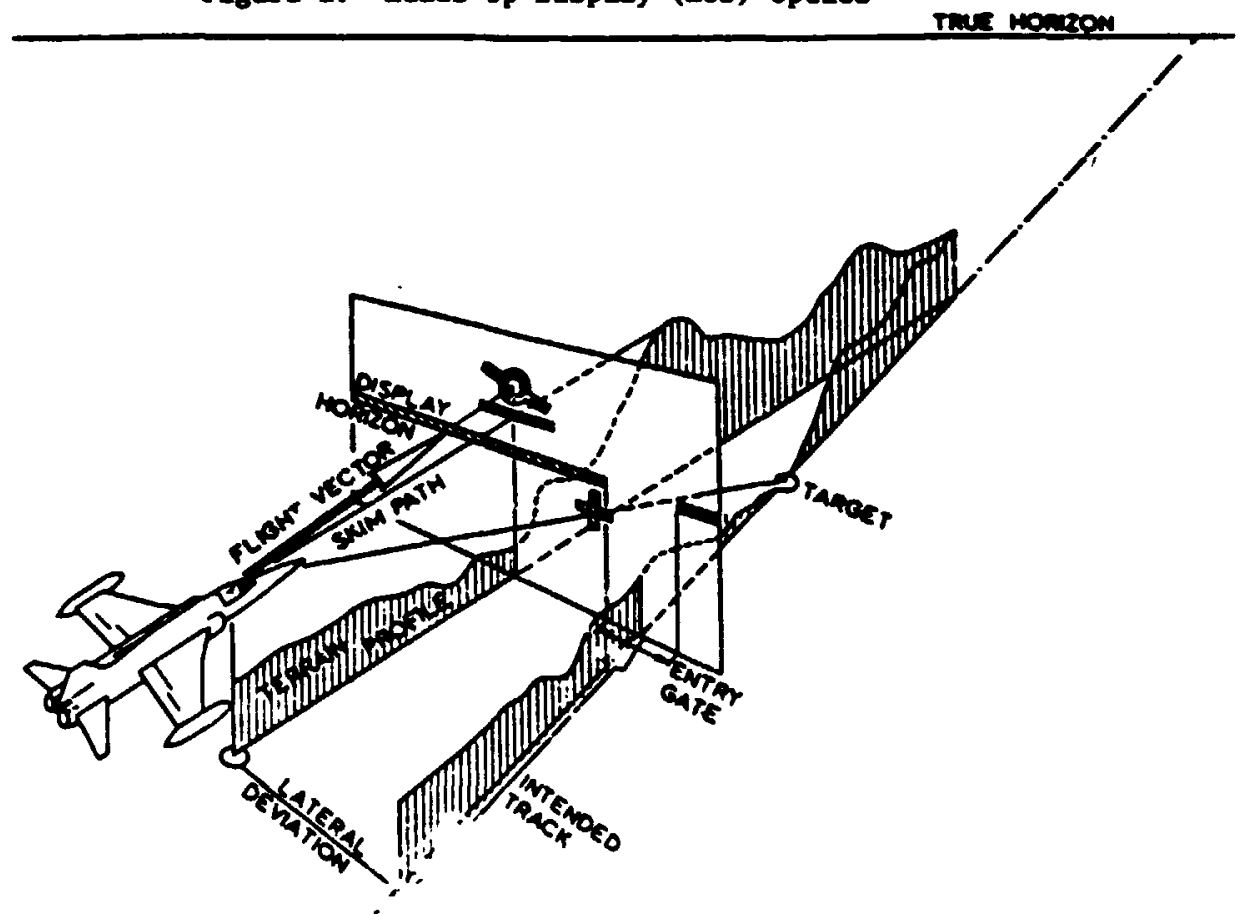

Figure 2. Exturnal Scene Appesra ace through the HUd 
for atr-to-air and atr-to-ground atselons. Escomondations ande durtes the flight test progran are lucorporated in the M.I.T. diapley.

Refereaces 2,3, and 4 detall the F-16 CCV progren. Hodifications to the F-16 include canted canards on the forvard fueelagu and odification of the flight control syaten (FCS) to inplenent the direct force. pointing ad tranelation eodes. The tria button on the sideara controller was replaced with a tro-axis. force-operated thumb button. Thus in the direct force ode, left thub pressure on the thubb button ccanands a left flat curn rate. Upward thu pressure comends direct lift. In the direct force ods, preseure on the thumb button comend the rate of change of horlzoatal and vertical fllete path engle. "Beeplng" the thusb button increments the flight path angle for anll tracking corrections. The CCV code idirect force, polatins, trenslacton) is selected on the cockpit control panel and conmended by the thub button. Hote that the pilot does not ove his heads or feet froe the conventional contiols to utilize the CCV wodes; they do not disturt normal alrcraft operation and augant the f'ghter capabillty.

During the flight test progran, gu canera files quatitatively recorded tracking performance and quilicative pllot coments were recorded. The pllots recomended higher al thority codes ( 3 g's or greater). They notea that the flight pach angle could be driven laterally without banking, elladocing the "pendulun effect" with the fixed recticle alght. Slnce the Civ alreraft effectively decouples the alrcraft attitude and velocity vectors, ateicude was no longer a cue for the afrcraft's Instantaneous destination. A Beads Op Display (HCD) presentation of the velocity vector vas recomended to restore the atticude:velocity vector cue. Meny of the wodes enhenced fighter operations in atr-ts-air and alr-to-ground taske (ref. 3).

\section{Atvenced DI jplers}

he decision to choose a Heads Of DIsplay (BUD) to augnent the CCV alrcraft operation follor froe aulysis of the CCV alrcraft/ode controller/p1lot inte.face. The flight regies in which the CCV odee will Inprove fighter perforance is in alr-to-atr combe, alr-to-ground weapons dellivery and landing in

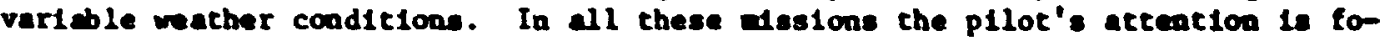
cuseed outside the arcraft at enother alrcraft, a ground target, or the rumes. The Heade Up D1splay aliow the pilot to keep h1s attention orleated outsida the caropy with his eyes focuseed at infinity. The masured ad displayed flitht Information appears in one-to-one correspondence vith the outsida world. A bUD presentation of the velo-ity vector overluyed on the external scene restorea the lost attitude: velocity vector feedback end loproves perception of the al craft fllght path. These resone strataglcally polnt to the ut1lisation of a leade Up Display to fully reallze CCV code potential.

Figure 1 lllutrates how a Head. Up Dloplay operates. By profecting flicht inforation through a lens on a half allvered at rror oriented inaide the cenopy, the pilot almitancously fievs the outside world and flight date focuseed at infinity. De, sye ere elinfnated in continually refocusalng fron the heads down instruente to the extermal scene. The sheer distance and associated delay tie in scanning froe one lnstiume ts another 1s algnifiganty reduced alnse mat of the relevant flight inforation is integrated on the tUD diaplay.

F1gure 2 showe how the flight inforation and outelde scene eprears through the kUD. The priancy lnformetion a EUD should display is the flight vector. the horizon and the intended tiack or target superimpoed on the extemal ecene. Other Inforation which can be displayed is an alrcraft attitude sybol, refer- 
ence angle-of-actack, lintt angle-of-attack (atall) and potencial pach (aireraft path in acceleraced flight). The potential pach is used for thrust magerme. then the sybol is above the velocity vector exce is chrust exists ad when the sybols colncide velocity is stabilized. When the velocity nector is above the horizon the alrcraft is clibing and wen belou the hortzon it is losins altitude. When sybolic filght data is in oae-to-one correspondeace agularly vith the outside view, alrcraft states are core easily interpreted and controlled.

For exaple, if the velocity vector, horizon, and aircraft body axis are displayed on the BUD, the folloring angles are readily apparent:

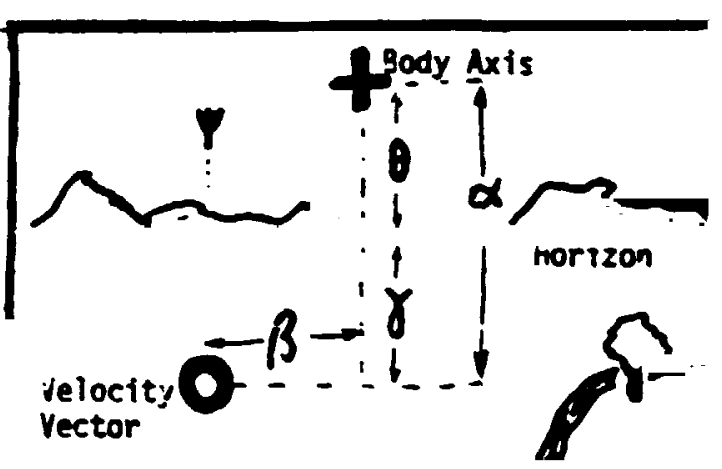

\author{
Beading $Y$ \\ sideelip $\beta$ \\ Ancle-of-attack $\alpha$ \\ Flight Path Ancle $\gamma$ \\ Pitch Angle $\theta$
}

Figurz 3. Angular Data Perceptible fron Hod Sybology

Flight inforention (euch a veloctey $\nabla$, vertical velocity h) can be visually deduced fron angular relationships between the velocity nector, body axts and horizon overlayed on the real world. The pllot ay steer the velocity vector towards an intended destination point. Any crose wind or wind gradicat (ohan) 1s Inediately apparent since the background scene will Arfft with reapect to the vilocity vector. Inediate realization of these situations allow the pilot to whe appropriate corrective control actioas.

In general, a pilot con wontor seven to elght date item without difficulty, according to research carried out by the Royal Arcraft Leteblishneat, Famborough, England. Thus the display should be desigened to show only those instrument readinge necessary for a given wode of flight. The hichest priortey data should be close to the nomanal field of vier to reduce ecen las. Inforantion should be displayed in the eppropriate analog (comeneatory) or digftal (numerical) ion to minindze pllot vortloed. Larpe eye novents should be daintzed, and the diaplay ares should phyaically sorreapond with the outside world (1.e. altitude aloag vertical aris, headins afle alons the borizootal ardo, etc.) In "natural dioplay directions" (a Flewed froe the alrcraft outvard). It is also advartageous to have the altitude, airspeed, etc. Laforntion located in the normal "T" dabhboard panel posicions (airspeed upper left, altitude upper righe, etc.) for crew traneltion to the bUd dieplas. The nearness of date to the coninal point of vier and tes priority sbould follor a gaussian distribution (the cost frequently acanned displeys closest). Displaying inforation in the eppropriate analos cape form or digttal for should atoInde Interpretive and colpensatory workload. The BUD fleld of view aust be enough so that velocity, heading, and altitude ay be peripherally dispt-jed without interfering vth target acquisition. Since angular relationahips are preserved on the BUD, and the BUD is nontally located $19^{\circ}$ from the pilot's eyes, a $10^{\prime \prime}$ HUD octeen yielde a $30^{\circ}$ field of View. This is appropriate for che 
$\pm 5^{\circ}$ potiting authority (a $10^{\circ}$ authortty square in $30^{\circ}$ by $30^{\circ}$ field) and the angle-of-attack variation fron high to low speed.

\section{DISPLAI DESIG FOR THE CCV AIRCRAFT}

In designing an appropriate display to augent CCV aircraft perfornence one must consider the display as part of the total pilot/controller/aircraft closed loop systen (figure 4). In conventional aircraft, the pilot ast utilize

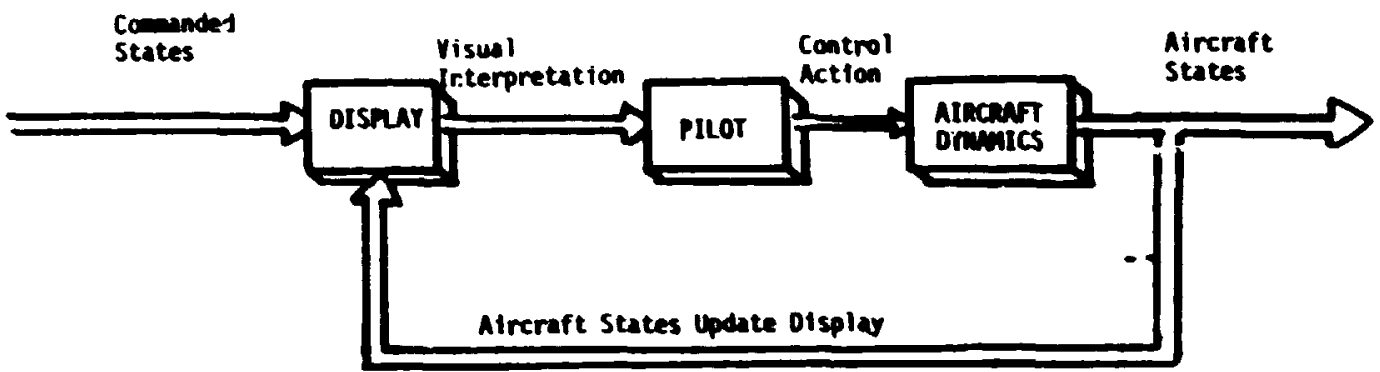

Figure 4. Tne Display Systa as part of tie Total Pilot/Aircraft Systen several controls in a closed loop fashion to bring about a comanded state. The pllot adjusts his internal transfer function to effectively decouple the coupled systen. In general, the hum is not particularly efficient in decoupling aultiple degrees-of-freedon system. Such oystem increase the workload and cupensation a p1lot aust provide in bringing about a desired state. For Instance, in alking a heading chenge, the pilot utilizes the alleron, rudder and elevator to initlate the bank, to.bank, and return to wings level flight once the desired heading change is achieved. The afrcraft is strongly coupled lateral-directionally. The pilot asst apply "lead" or aticipate when to roll out of the bank. The decoupling and lead the pllot aust apply correspond to an increase in concentration during the maneuver and thus an Increase in pilot workload.

Rerein lies the advantage of the CCV alrcraft. One coatrol ay be utilized to colnind one state. In the above exnple, the CCr pilot could just "beep" a heading angle change using the direct side force oode The rate of cinnge of heading is proportional to the lateral thub force or. "Coolle Hat" thum buttoa. The response is decoupled, and the heading char i easily conducted, ance the beading angle chmge is proportional to one inpu. istngle input: single output relationship). A sintlar analogy wy be ade with the sluggab phugold ode which is controlled by thruet and elevator setting. The direct ilft oode quickens the phugold response and comands the fllght path angle.

In designing a display for the CCV aircraft one notes that there are already ceatures of conventional displays which augent CCV perforence. The conventional systen of crosshatrs serves as an ald in compensatory tracking or nulling the diagonal of fset of a target. If oue crosshalr axds is net, the human controller knows to translate purely along that axds (figure 5). The CCV slew rate responses to horizontal ind vertical thwo button inputs are parallel to the crosshatrs. In this way CCV display design has been reduced to humen compensatory engineering analysis.

In nulling the pointing error the display should improve CCF performance if It displays alrcraft slew rate magnitude and direction. These are sensed on the thus controller (slew rate is proportional to force on thumb controller)

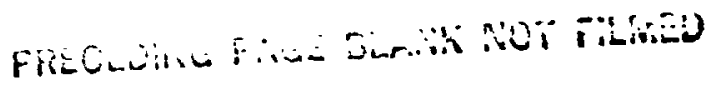




\section{OKIG:IALL PAGE IS \\ OF POOR QUALITY}
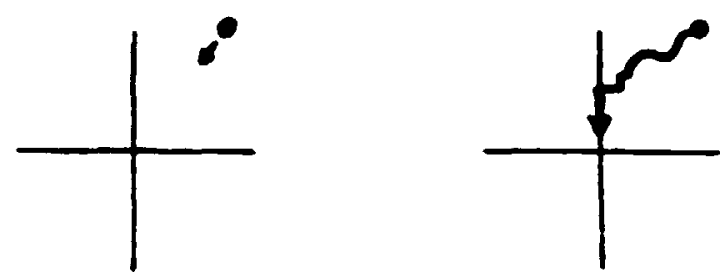

Figure 5. Nulling offsets Ut1lizing Aircraft Crosehalr Syete-

but the wuthern belleve that force engutitude ad angle are not eeneed eccurately enough by the thum. A prorer dieplay of CCV alew rates and direction of slev woild augent CCV perforemce in alr-to-alt and atr-to-ground tracketng.

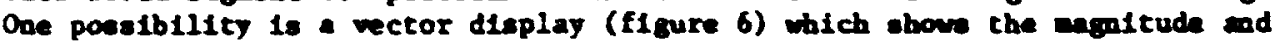
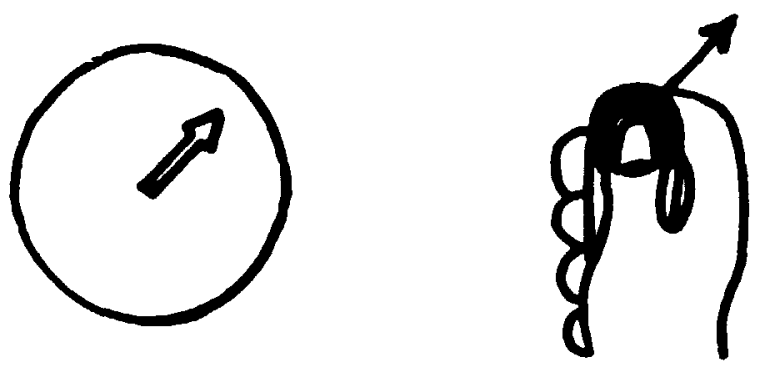

Figure 6. Vector Conpensatory Display Sirowing CCV Magnitude and Direction direction of the slew rate. The hum coetroller, vieualizing the actual slew rate apgitude and direction, can chenge the force and directina exerted on the thub controller to aull the polnting error. The overall CCV tracking capability should Inprove since the display applies an additional wore accurate feedick to the pilot than the force feedback fron the thum controller.

if there is concern that the arrow will interfere with target ecquisition, nother display could be a line showing the ingular direction of the thub force exerted on the "Coolle Bat" (figure 7). Angular date, rather then magnitude data, is presented since the thus probably eenses force level better than force direction, end thus it is force direction date that is incorporated in the display.
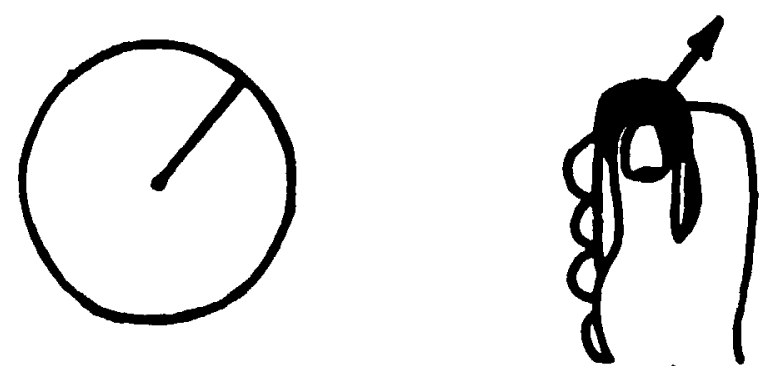

Figure 7. Angular Compenatory Fornet and CCV sode Activation 
Another feature which should be incorporated is an authority circle. With equal pointing capability in pitch and yaw, the circle 1llustrates the region in which CCV pointing modes may be utillzed. No guesswork is necessary: once the pllot acquires the target within the authority circle, he may utillze the quick, decoupled $\mathrm{CCV}$ modes for precise aiming. Thus for the pointing mode. there are two candidate compensatory formats (figures 6 and 7).

Similar magnitude and direction information could be displayed for the direct force and translation modes (e.g. Fr acceseration, vector length and direction indicates magnitude and direction of acceleration, maxim vector length inside the authority c1rcle corzesponds to maximum CCV acceleration). The nominai velocity vector circle would serve as the vector orlgin with a deadband for small force inputs. Thus elther flgure 6 or 7 could be used for compensatory tasks involving the firect force, pointing or translational CCV mode, depending on whith mocie was presently in operation.

The next step is the display of numerical flight data. This includes ai:speed, heading angle, altitude, Mach number, and rate-of-climb/sink. Tape scaleof alrspeed will be displayed alcng the left border, heading along the top, and altitude along the right border. The analog "tape" form is chosen Eince this is compensatory data and pilot workload is lower null.ing tape errors rather than reading a digital format, interpreting the data ora making an appropriate control action (rate 1aformation is lacking in the digital format). Digital values of Mach number and rate-of-climb/sink are dioplayed in boxes. In this case the numerical values are of most interest. An artificlal horizon is alse incluied in this integrated display. Basez on the at jve analysis of CCV operation and advanced displays, the candi Late lieads Up Displays in figures $\mathscr{Q}$ and 9 are proposed.

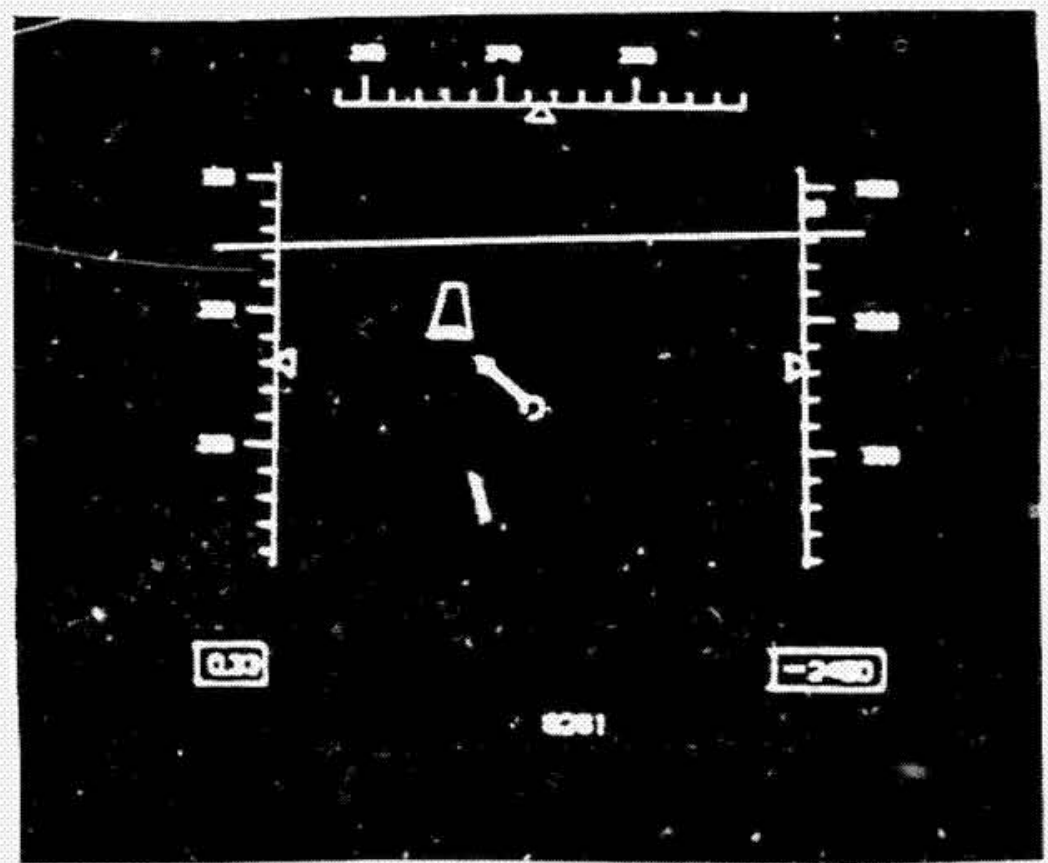

Figure 8 . Candidate reads Up Display with Compensatory Display (Arrow) 
ORIL

OF FOOR : : :

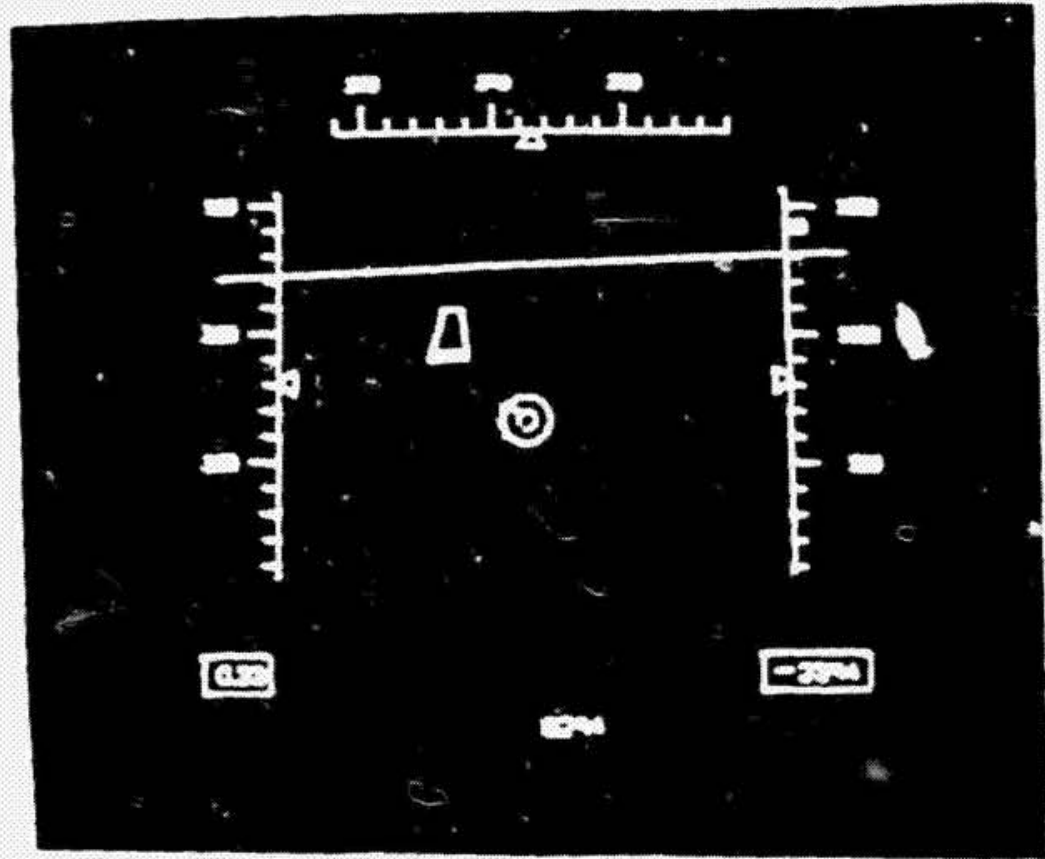

Figure 9 . Candidate tieads Up Display with Compensatory D1splay (Angular) CONVERSION OF THE 707 SIMULATOR TO THE F-16 CCV

In order to evaluate these concepts an existing 707 simulator (figure 10) was converted to an F-16 CCV simulator with an advanced Heads Up Display. Excensive modifications were made to the assembly language programs to accomodsce the F-16 aircraft dynmalcs. The Heads Up DHsplays shown in figures 8 and 9 were programed. A numbered rumay and hortzon line was added to represent the externel scene during the flight simulation. The extemal scene enhanced the fidelity of the simulation by providing alrcraft positional perspective with respect to the runway and attitude cues. The cockpit interior was modified to represent a fighter and isometric sfdearn controller (as currently utilized on the F-16) with CCV isometric thumb button was installed in the right half of the cockptt. Figure 11 outlines the operation of the simulator. The simulator pilot, viewing the HUD and extenial ecene, operates the controls (stick, CCV button, throttle, etc.) to bring about a change in alrcraft states. These mechanical inputs are converted to electrical snalog signals which are then sampled by an analog: digital converter. The signals are demultiplexed into appropriate channels for the assembly 1 anguage programs. The Adage AGT- 30 computer calculates the aircraft states and updates the HUD and external scene CRT display. An upiate occurs every $1 / 20$ second with no perceptible flicker. The previous 707 simulator is the product of ten years of research at M.I.T.

A random, zero-mean wind gust progras was written to study tracking perfornance in the presence of gusts and turbulence. The gusts were realistically generated bv flltering Gaussian white notse with the Dryden spectra wind model. The RMS amplitude of the wind was set for three discrete levels during the test progran.

Orfiginally the compensatory displays vere to indicate fust the CCV input. This yielcied somewhat encouraging tracking taprovements. The decision was made 


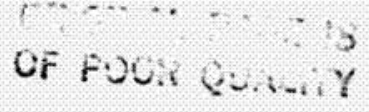

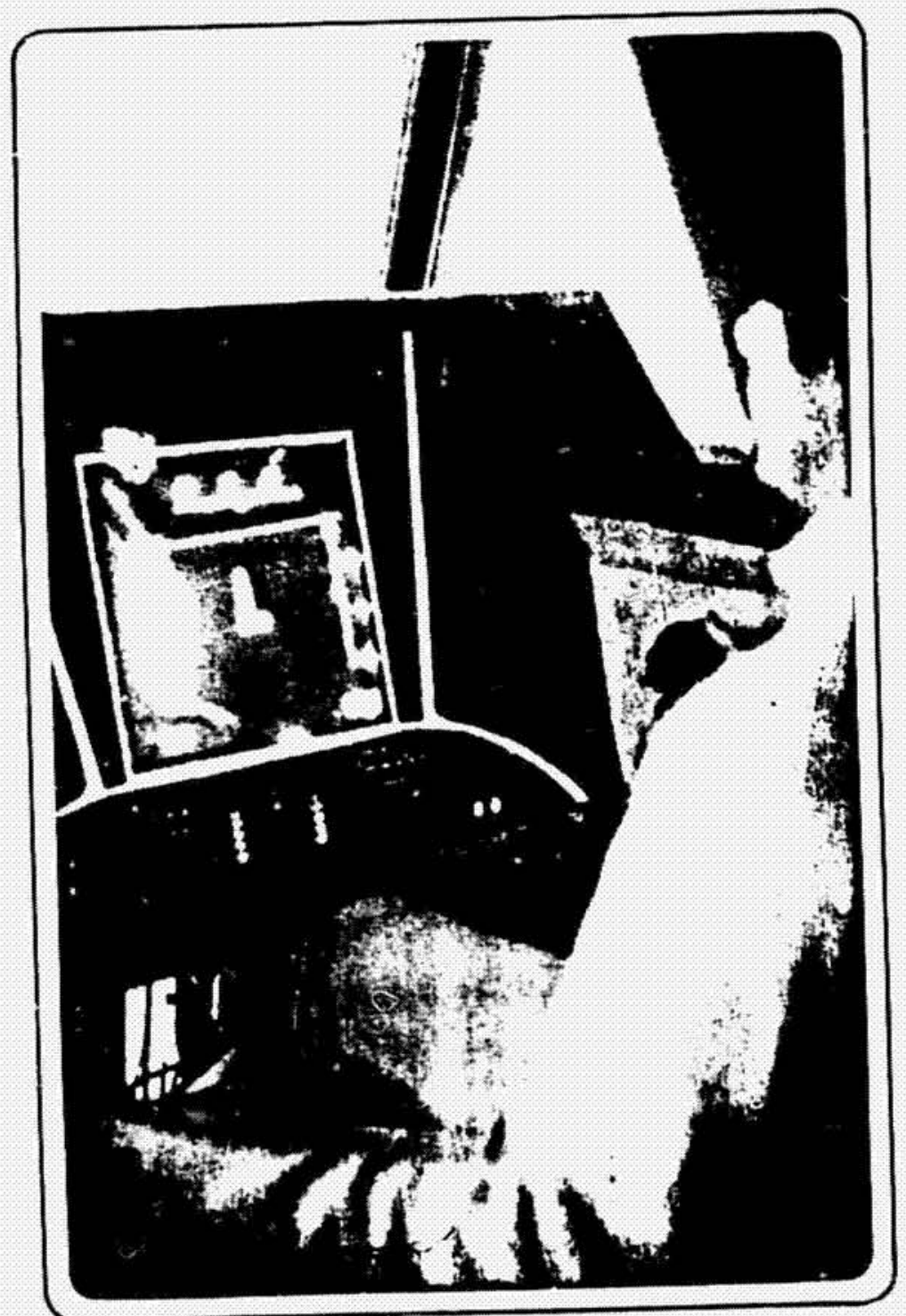

Hodification of Right Half of Cockpit to Represent the F-16 CCV with heads Up Jisplay and External View 
ORIGINAL PAGE IS

OF POOR QUALTT

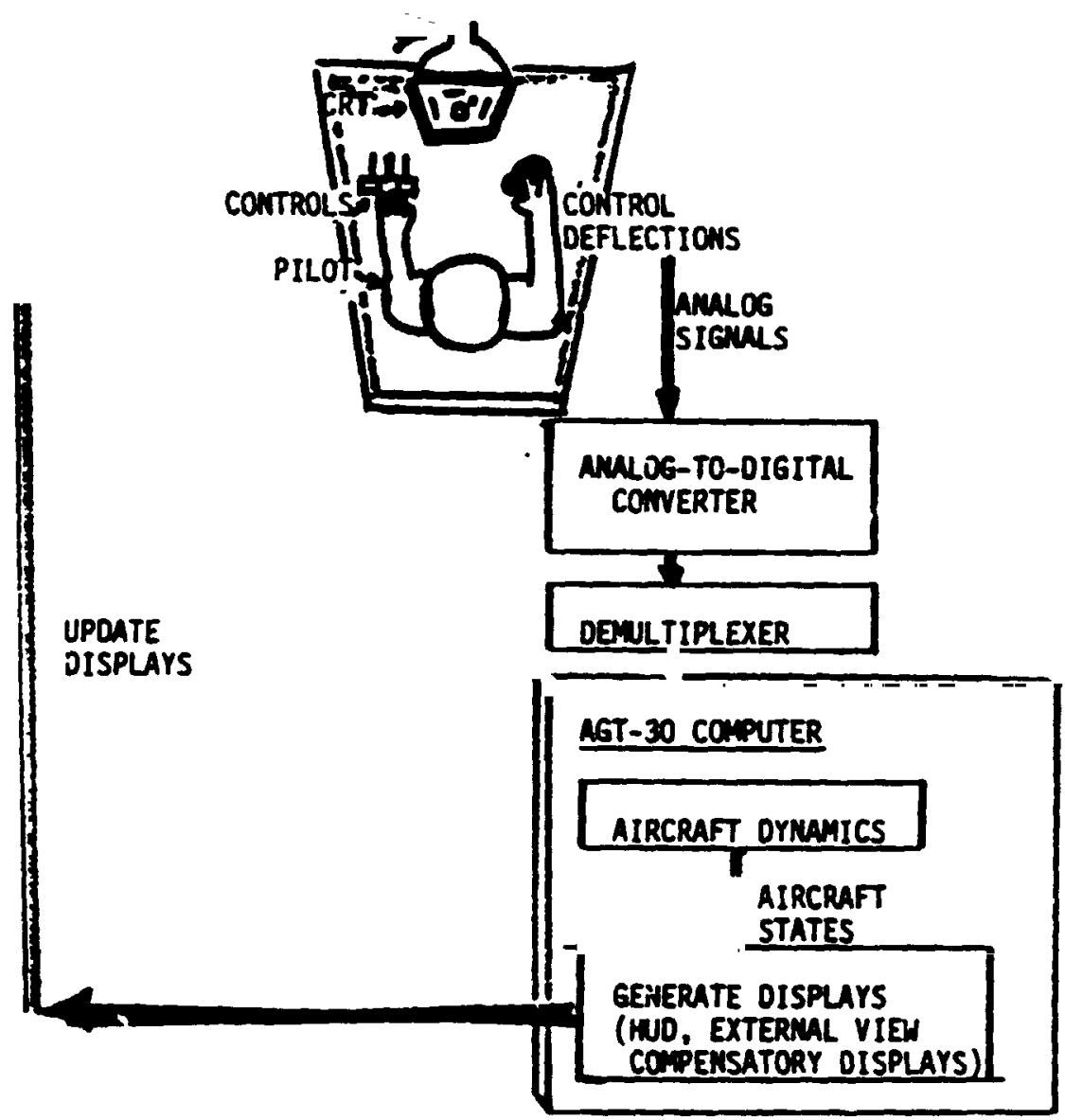

P1gure 11. Sinulator Operation with AGT-30 Computer 
to have the compensatory displays represent the vector sun of the direct force odes (thumb button lnput) and vind effects upon the alrcraft. Thus the arrow and line represent the Inertial alrcraft acceleration. The displajs therefore serve two purposes. By shoulng acceleration they provide lead to the pllot in the tracking task. The displays also provide an additional visual cue to the p13ot so when a sudden gust affects the alrcraft the p1lot asy respond inediately. The artow represents the future position (In $3 / 10$ second) of the velocity vector circle with respect to the external scene, and alds the pilot with or without wind.

\section{TEST PROGRA}

The purpose of the test progran vas to utilize the F-16 CCV simintor to det.ernine whether the CCV ades do I prove tracking perfornace over the conventional alrcraft flight wdes and if the designed compensatory displays do indeed augient CCV tracking performance. A tracking task vas prograned into the F-16 CCV simulator: tracking the alrcraft velocity vector over the rumay numbers. A progra was witten to deteradne the average tracking error (BaS) In degrees $x$ 1000. Figure 12 shows the instantaneous error BRRT which is ave-

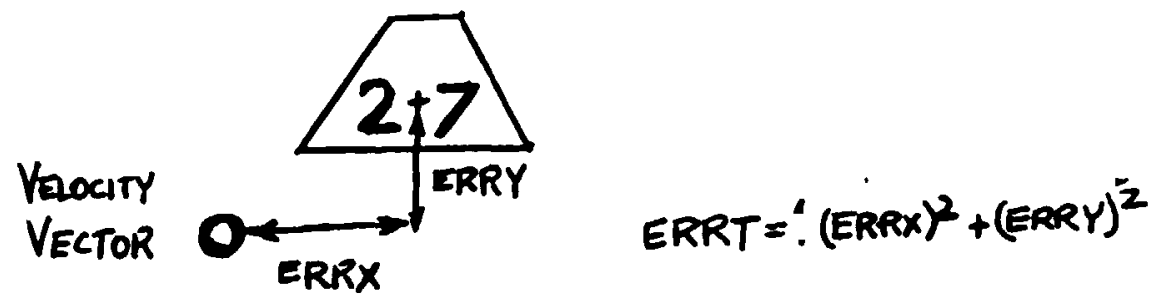

F1gure 12. Diagran Showing Tracking Error Measure

raged over tine (sapplinge occur every 1/20 second). The perfornance index or average BuS tracking error is

$$
P . I_{0}=\frac{\int_{0}^{T_{f}}(\text { ERRT }) d t}{\int_{0}^{T_{f}} d t}=\frac{1}{T_{F}} \int_{0}^{T_{f}}\left[(\text { ERRX })^{2}+(E R R Y)^{2}\right]^{X_{2}} d t
$$

A run conalst of tracking the velocity vector over the alddie of the rumay numbers during a descent fron 2500 feet to sea level. At the end of each run the average BiS tracking error was recorded. Three rung totalling 6 etnutes vere ade for each configuration (anpling t1we 1/20 second).

The four configurations of interest were the basic P-16, F-16 CCV, and P-16 CCV wth each of the conpensatory displays. Three rune were conducted for each configuration, in the prisence of no wind, woderate winds (6.6 kta Dis, peak gust $18 \mathrm{kts}$ ) and severe winds $(13.2 \mathrm{kts}$ RYs, peak guat $37 \mathrm{kts})$. The pllots flew the basic alrcraft, CCV alrcraft, and $C C V$ afrcraft with colpensatory dieplays in the presence of veriou wind levels for approxiantely 45 ainutes for failiarization with the alrcraft dynanics to alninize any bias during the testing due to learning. The tests thenselves were conducted in several different orders to ininize leaming curve blas. 


\begin{tabular}{|c|c|}
\hline HAD & CONFIGURATION \\
\hline \multirow[t]{2}{*}{ No Wind } & Basic $7-16$ \\
\hline & F-16 CCV \\
\hline \multirow[t]{4}{*}{$6.6 \mathrm{kts}$ RMS } & Basic F-16 \\
\hline & F-16 CCV \\
\hline & F-16 CCV w/ D1splay 1 \\
\hline & F-16 CCV / D1ap Lay 2 \\
\hline \multirow[t]{4}{*}{$13.2 \mathrm{kte}$ RMS } & Bas1c P-16 \\
\hline & $\mathrm{P}-16 \mathrm{CCV}$ \\
\hline & F-16 CCV */ D1aplay 1 \\
\hline & F-16 CCV y/ DLaplay 2 \\
\hline
\end{tabular}

Table 1. Test Rum Matrix

Table 1 shows the test run matrix. D1splays 1 and 2 were not tested for the no wind case since inputs do not exceed the deadband of the compensatory display. The pilots vere not aware of their tracking performance until all the rums in the entire test atrix were coupleted. No affective comants (positive or negative) were ade to the pllots to lnfluence performance. Before quintitative tracking reaults vere revealed, aubjective conents were recorded and pant flight experience outlined. The quantitative and qualitative results are given in the next section. The pilots did not have to adjust trin or thrust and therefore just utilized the stick and CCV thub button during the conduction of the cests. The pilots vere Instructed that they would be rated purely on how well they tracked the velocity vector c1rcle over the runiay nubers. The pilots vere alone in the simulator during the tests of variou configurations and wind levels. Most of the pllots had combet experience in fighters.

\section{STMULATION RESULTS}

The results of the test progran are given in table 2 . One notes the. substantial improvenent in tracking performance with CCV modes, and signifigant increase in performance with the designed displays. Table 2 shows the percent improvenent with CCV modes over the basic aircraft and percent improvement of the F-16 CCV tracking with the advanced diaplays for each p1lot. An approximateIy 40 improvement in tracking abllity with the direct force sodes compares favorably with gun camera films recorded during the Edwarda Alr Force Base flight teat progran.

A 10-15\% redurtion 1n pointing error 18 observed when the advanced displays are 1ncorporated in the F-16 CCV inulation. There is 11ttle difference ( 1 scandard deviacion $\simeq 5 \pi$ ) in perforance improvement between the two diaplays. Display 2 gives angular predictor information (both diaplays represent the sun of wind effects and CCV inputs) and display 1 gives magnitude as vell as angular Information. Since there is little difference between the two displays angnitude inforation in ihls case did not augment performance. This supports the earlier hypothesis that the thumb can sense angnitude information but cannot sense angular information well on the CCV button. It is the additional visual feedback of direction that che pllot uses to Improve his tracking perforance 10-15x. It is thia predictor or lead cue the dioplay gives of where the velocity rector circle vill be superimposed in the next $3 / 10$ second which augments the pllot:CCV alrcraft system. 
ORIC: $\because$ O: :

OF POOR Q'S:

\begin{tabular}{|c|c|c|c|c|c|c|c|c|}
\hline $\begin{array}{l}\text { CONFIGURATION AND } \\
\text { PERCEUT IMPROVERENI }\end{array}$ & $\begin{array}{c}\text { PILOT } \\
1\end{array}$ & \begin{tabular}{|c} 
PILOT \\
2 \\
\end{tabular} & $\begin{array}{c}\text { PILOT } \\
3\end{array}$ & $\begin{array}{c}\text { PILOT } \\
4\end{array}$ & $\begin{array}{c}\text { PILOT } \\
5\end{array}$ & $\begin{array}{c}\text { PILOT } \\
6 \\
\end{array}$ & MART & $\begin{array}{l}\text { STANDARD } \\
\text { DEVIATION }\end{array}$ \\
\hline$\frac{\text { NO WIND }}{\text { CCV over Basic F-16 }}$ & 20.0 & 57.7 & 23.7 & 55.6 & 48.5 & 43.8 & 41.6 & 14.5 \\
\hline$\frac{\text { WIND }=6.6 \mathrm{kts} \text { RMS }}{\text { CCV over Basic } \mathrm{F}-16}$ & 47.9 & 63.5 & 54.8 & 15.1 & 36.7 & 30.9 & 41.5 & 16.0 \\
\hline F-16 CCV w/ Display 1 & 7.3 & 18.7 & 12.4 & 18.7 & 11.8 & 9.3 & 13.0 & 4.44 \\
\hline F-16 CCV wi Display 2 & 7.2 & 15.5 & 15.2 & 19.4 & 13.0 & 10.5 & 13.5 & 3.77 \\
\hline $\begin{array}{l}\text { WLID-13.2 kts BMS } \\
\text { CCV over Basic F-16 }\end{array}$ & 15.5 & 52.4 & 50.3 & 3.1 & 22.8 & 36.0 & 30.0 & 18.0 \\
\hline F-16 CCV w/ Display 1 & 2.5 & 20.4 & 6.4 & $\overline{15.9}$ & 7.8 & 5.4 & 9.7 & 6.29 \\
\hline F-16 CCV w/ D1splay 2 & 12.6 & 17.6 & 18.4 & 4.8 & 6.9 & 9.8 & 11.7 & 5.08 \\
\hline
\end{tabular}

Table 2. Sumary of Tracking Improvements with CCV Moles ovet the Basic F-16 for Various Wind Levels (Randoe, Zero-Mean Gusts) and Sumary of Improvement in CCV Tracicing Performance with Compensatory Displays (Percentage)

\section{CONCLUSIONS}

Based on the test program utilizing the fixed-base P-16 CLV simulator with F-16 CCV dynanics, a ieads Up DIaplay with an external view of a numbered runway and horizon, an iscmetric sidearm stick with two-axis thumb bitton to command the direct force modes, and a modifled cockpit interlor, tive following conclusions were reached.

1. In the presence of no wind to moderate winds (6.6 kts RMS), the $81 x$ p1lots utilized the direct force modes to inprove RMS tracking ability $40 \%$ over that attained with the basic alrcraft.

2. In the preserice of sever winds (13.2 kts RMS), the direct force modes Improved tracking ability approximately 30\%. The decrease from (1) is probably due to the fact that large CCV Inputs are necesary in severe winds, which cause manual force coupling problens between the thumb button and sideari stick.

3. The designed displays improved the tracking capability of the 8-16 CCV 10-15\%.

4. Subjectively most pilots preferred the arrow display (display 1) over the angular d1 play (display 2); the latter was found to be more distracting.

5. Observing the tracklng resi' ts, there was no statistically signifigant difference between the two - splays. The angular display gave predictor informstion for direction. The arrow display gave magnitude and direction information. Thus the pllot primarily used direction information to improve his tracking perforaance; the additional magnitude information did not improve his performance appreclably. This correlates with the devel-

\footnotetext{
Improvements in tracking performance with diaplays 1 and 2 are referenced to the P-16 CCV without the conpensetory displays
} 
oped hypothesis that the tnumb could sense the magnitude of the CCV input well hut not its direction. The purpose cf the displey was to sho's the direction of the input, which it did. Thus the magnitude cue was already available from t:a thumb button; the direction is now avallable frou the display.

\section{ACKNOWLELGEMENT}

This research was cenducted under AFOSR Grant $78-3260$, "Cockpit Display zoncepts for New Control Capabjlities", fron the AIr Force Flight Dynamics Laboratory of Wright-Patterson Alr Force Base. T relr support 18 greatly appreciated.

\section{REFERENCES}

1. "YF-16 CCV Operational Potencial, Flying Qualities, and Parforwance Evaluetion" Richard A. Wood, Project Englneer, Michael P. Gerland, P1jing Qualities Engineer, Eawarj T. Meschko, Major, USAP, Project P1lot; Final report, Alr Force Flight Test Center, Edwards AIr Force Base, Californi3, Air Force Sys tem Command, USAF Jasuary 1978

2. "Fighter CCV Phase II Report- Detall Design", General Dynamics/ Fort Worth, October 1976, March 1976, Alr Force F1ight Dynanics Laboratory, Alr Force Systems Comand, Wright-Patterson AFB, Oh10, AFFDL-TR-76-119

3. "Fighter CCV Phase IV Report- Vol. 1 - Program Sumary", General Dynamics Corp., Fort Worth, Texas, February 1978

4. "Des18n Considerations for Implementing Integrated Mission-Tailored FJ Is $t$ Control Modes", James K. Ramage and Prank R. Swortzel, Alr Force Flight Dynamics Labora tory, Wright-Patter80n AFB, Oh10; 2fith AGARD Guldance and Control Panel Symposium, May 1978

5. "The Impact of Electronic Displays on Alrcraft Control", AGARD Conference Proceedings No. 58, Advanced Control Systems Concepts, P. Lowry, E1llot Bros., Ltd., Kent, England

6. "Control and Display Concepts for Conbat Alrcraft", Airborne Diaplay Division, Marcont Avionics, Kent, England; AGARD Conference Proceedings No. 257, Tne Impact of Integrated Guldance and Control Technology on Weapon Systems Design, May 1978.

7. "Design, Simulation and kvaluation of Advanced Display Concepts for the P-16 Control Configured Vehicle" Robert W. Kle1k, Walter M. dolliater, Department of Aeronautics and Astronautics, Massachusetts Institute of Technology, February 1980

A complete blbllography of this research is contalned in reference 7 . 


\title{
- 823406326
}

\author{
oRgull Fise is \\ of poos quAlity.
}

\begin{abstract}
SEPARATION YONT:ORING UITH FOUR TYPES OP PREDICTORS
OY A COCKEIT DISPLA" UF TRAFFIC INFOBMATLOH
\end{abstract}

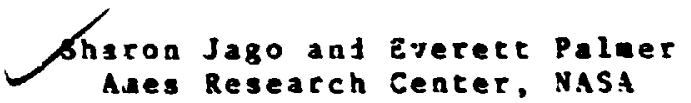

The concept of a costiple display of traffic laforazion (Cort) includes the integration of alr traffic, navlgation, cerrala ad weather inforation in sighle electroatc display in tie cocipit. The pr-sert stnjy was conducted as part of a reseach project

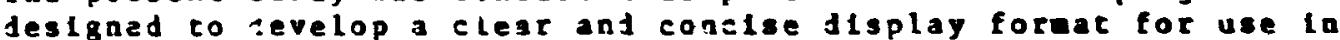
later full alselon siaulator evaluation of the cot concept. This expertaert requiret airline pllots to monitor a CDri and ake perceptual judseents conc ig the future position of alagle latrujer alreraft $1^{-}$: nohip to thelr own alrcraft (ownship). The asin experlaental varlable was the type of predictor used to display future postition of each alecraft. Predictors were referenced to the ground or to ownship anu they elther licluded tura rate information or did not. Other varlables were the ricraft': sepi-ation distance when the juigsent was lequirgd and the type of encounter (stralgt or turalng). Results lajlcate that unier these experteental contlcioas fever errors were ande when the oredictor lacluled tura cate lnforation. There was little difference in overall error rate for the curved grnund referenced and the ownship refe-enced predictors.

\section{INTRODUCTION}

Projected estinates of al traffic ladicate a marked lacrease In congestion occurrinz over the next 20 years. This Increase is expected to create a deand for greatly improved air traffic control services to alataln ir laprove presont levels of safety. Relevont to the area of safety are concerns dealing with afficleacy of flights licco and out of capactey lialeed teralnal areas. The concept of a cockpic display of traffic inforation (CDTI) is presently belng considered to jeteralie lts role in the alr craffic systen.

The cotI is displayed on a cathode-ray cube (CRT) located in the alrcraft cockpit with display created by a corputer. The Ilsplay allows the pllot to see other aircraft's position In relation to the pllot's own aircraft. The pllo:'s own position and directl af travel with respect to ace navlgation routes and terrain features are lolictced by headiag-up moving aap.

Prlor experlaents in this project were diteced toward develop!ng a clea: teasy to use display (lef. $1,2,3,4)$. Quesctions concernir.o che gene-lc i JT display were dicected coward the jlsplay ayabolisy ans factors affecting perception of eotion. cuch varlables as uidnte rate lewing toe, background and sechods 
of displayig past and future posteton of the sicerat have been considered. Alditional stulles have been ade on how to display vertical steuation lnforation on a ap dieplay (ref. 5,6).

The object of chls experinent was co evaluate different predlctors of atrcraft wotion la the horlzontal pline. Four preflecors were usej. These dere elther ground referensel or ownship referenced dith or ulthout tura rate Inforation. Also of taterest was whe er there was. Differeace in learalag alth the different presLeturs.

\section{บะтหวด}

Subjects. Sixteen alrilae pilots were pald to particlpate in this experiact. So pllot had prtor expertence ustag CDrt sybology, elfalazting the posstbility of prevlous learalag affacting the results.

Apparatus. The pllots vere seated in a two-place, flxed-base transport sinulator. The only functioning parts of the sinulator were the CRTs that displayed the traffic inforation. Responses were ade on 3 hastheld instrument.

Visual display. The CDTI ua liaplayed on a $18 \mathrm{ca} \times 18 \mathrm{ca}$ ERT. The center of the screen vas lorated 25 deg. (.44 rad) below cie horlzontal on the pllot's center line and .87 a froe the subject' eye reference polnt. The width of the terraln displayed on the CRT was 10 aautical alies $(18.5 \mathrm{ka})$. Wich thls an icale, I nautical alle $(1.85 \mathrm{ka})$ or tae ground equals $1.2 \mathrm{ce}$ on the displey. The owaship was representel by a cherron sybol with the exact location of ounship belng the cop polnt of the ayabol. The intruler was represented on the jlsplay by a circular opabol with dot la the center indtcating lis present location. Both ounship and tocruder were displayed uth ground referenced hiscory tots. Each of the eight dots laticated the past position of the afrctate over the ground at sec latervals. These sybols were prefered by nost pilots la Hart's sulies of pllot preference for varlous types of CDII syabola (ref 7,8). An area navlgation route aap provided ground objects for the background.

Encounter varlables. There vere 48 different encounters.

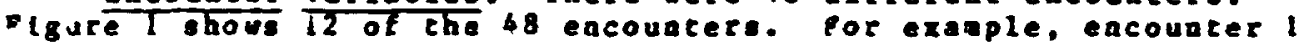
usplays the ownshtp in a heading up position. The latrujer is approachlag troa the right. In Figure l all sketches show rurvet ground referenced predictors for the purpose of lliustat:on. In 24 of the encounters the Intrujer ultiately pasjed ln front of ownship. In the realinlag 24 the latruder ultieately pased behind the oinghip. In 26 of the encounters, both trcraft went stalght and in the reaalning 24 cre or both alrcraft turned. In 24 eacouaters :he display stspped at bs oec to the polnt of closest encounter. The realaing 24 encounters soppec at 28 sec $t$ the point of the closest encounter. The paraseters for the enciunters are found in palaer et. al.

Constant encounter araneters aclujed: viewlag tiee, 8 sec, eparation distance at ancounter, $300 \mathrm{ft}$ (.9l ka), and update rates for ownshlp ant latruter. Owaship's position and heading was 

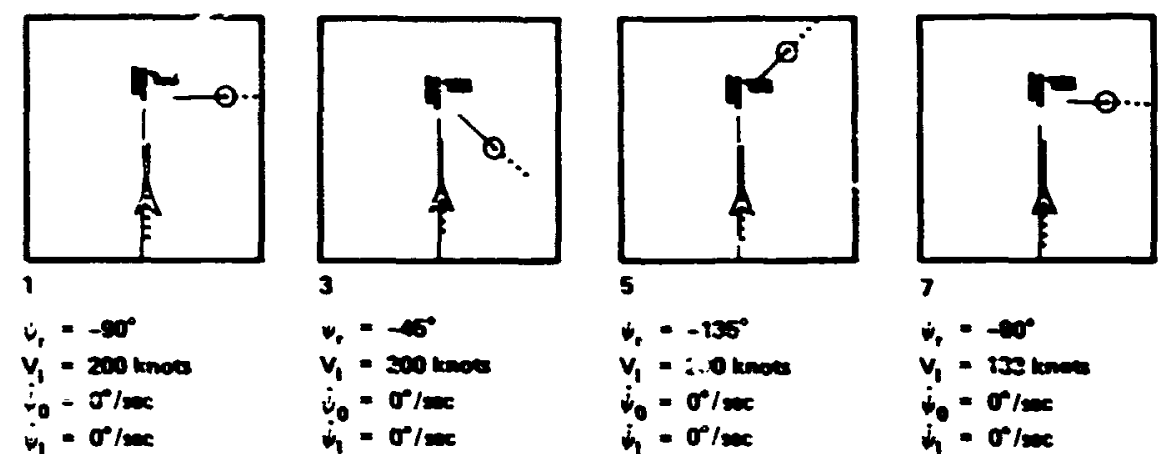

$v_{1}=200 \mathrm{knows}$

$i_{0}=\sigma / a c$

$\dot{v}_{1}=0 / \mathrm{sec}$
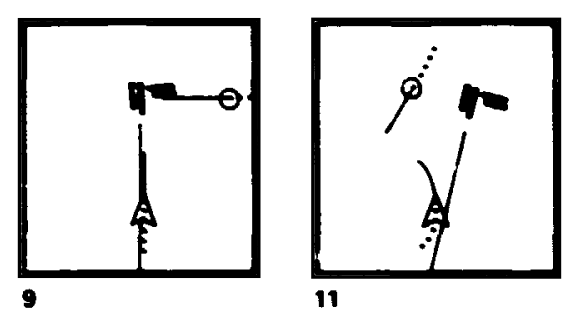

$\dot{h}_{1}=\sigma / 2$

$$
\dot{\nu}_{1}=-\infty
$$

$v_{1}=83$ loness

$\dot{j}_{0}=\sigma / \mathrm{sec}$

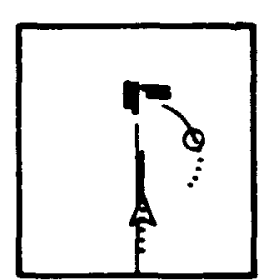

13

$\psi_{1}=-90^{\circ}$

$\nu_{1}=-\infty$

$\psi_{r}=-0^{\circ}$

$\dot{h}=0 / \omega$

$V_{1}=300$ knots

$\dot{v}_{0}=0 / \mathrm{sec}$

$\dot{\omega}_{1}=0^{\circ} / \mathrm{m}$

$v_{1}=200$ knots

$\dot{i}_{0}=-1.50 \% / \mathrm{sec}$

$\dot{\psi}_{1}=0 / \mathrm{sec}$

$v_{1}=200$ knose

$i_{0}=0 / 20$

$\dot{w}_{1}=-1.50 \%$

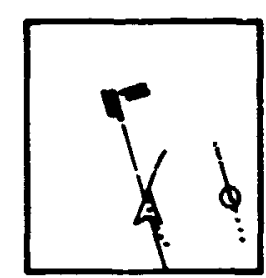

15

$v_{1}=-\alpha$

$V_{1}=200$ knots

$\dot{v}_{0}=+150 \%$

$i_{1}=0$ isec

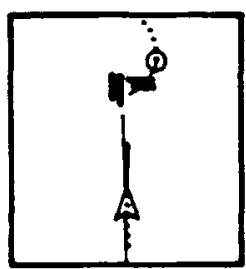

17

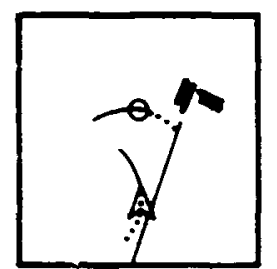

19

$\dot{\psi}_{1}=-90^{\circ}$

$v_{1}=-80$

$V_{1}=200$ knot

$\dot{v}_{0}--1.50 \% / \mathrm{sec}$

$\dot{v}_{0}=0^{\circ} / \mathrm{sec}$

$\dot{v}_{0}=0 / \mathrm{sec}$
$\dot{v}_{1}=+1.50^{\circ} / \mathrm{sec}$

$\dot{v}_{1}=-1.50^{\circ} / \mathrm{sec}$

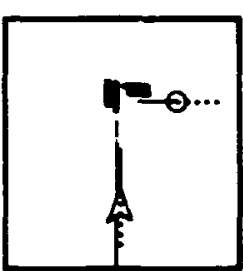

21

$\downarrow,-90$

$v_{1}=197$ know

$\dot{v}_{0}=0 / \omega$

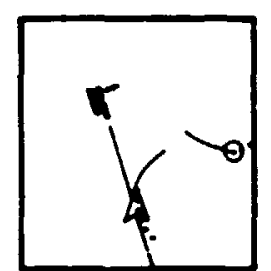

23

$\psi_{r}=-\infty 0^{\circ}$

$v_{1}=200$ know

$\downarrow_{0}=+1.50^{\circ} /=$

$\dot{\psi}_{1}=+1.50^{\circ} / \mathrm{wac}$

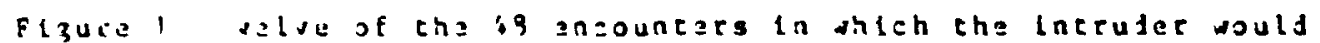
ulel. Iy pass in frone of owastip. Hil tisplays chow curvad zrouna rafercacet prejlecors. 


\title{
ORIGiti:- P:Dis \\ OF POOR QUALITY
}

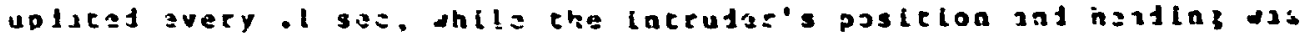
uptie:d every? sas.

Dlspliy varlables. Therz dere four contlitions of display

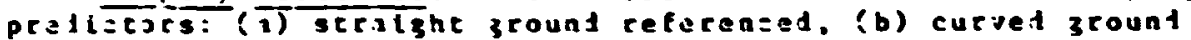
$r \geq f=r a n=31$. (c) scralihe relaelve, ial (d) curyed relativa. In tha scraliht grount referenced pretictors. the ent of tha rector indi$=2 t a t$ che projected postelon of che alrerate over the grount in 32 sac. issuntaz the alreraft alntainet lts current instantanesus zrount tracia. The curved zround refereased pretletor intlcats the

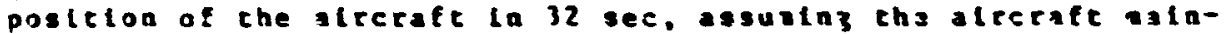
tings its curreat tura rite. In surved ancouncers chls predictor curved in proportion to the turn rite. With the atratght ralitive pretletor the and of the predtetor inticitel the incruiter's position ralacive to tha ownshlp position, flrsction, and spect le both irstift intin thele cutrent ground trick. dith the curvet relitive the ent of tha pretlctor preticts the posiction of the intruler relative to genship lf both sirceste gintaln thele current turn rates. In sncouncers dhere both ifrcefe irs zolas

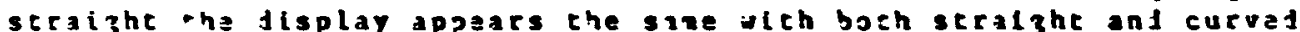
pretictors. Figurs 2 shows the siee encounter with each of tha four preilctors. No ratar nolse or tracker las uare sinulaced.
\end{abstract}

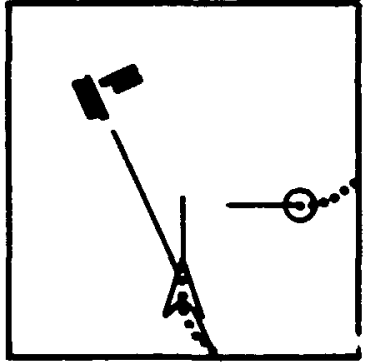

STRANGHT GAOUND-AEFEREMCED PREDHCTONS ON BOTH AIR-CRAFT (STR GAP)

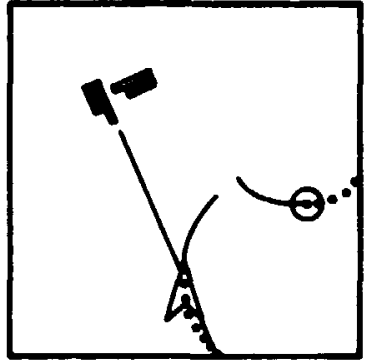

CURVED GROUND-AEFEREACED PREDICTOAS ON DOTH AIRCRAFT (CAV GAP)

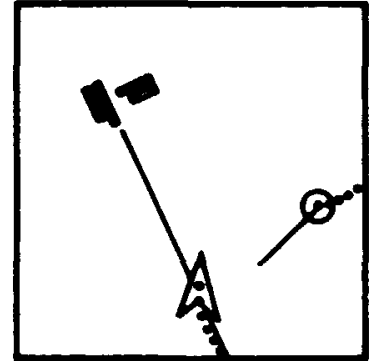

RELATIVE MAEONCTOA ON inTALDER ANO NO FAEDICTOR ON ONM SATP (ETR OAR)

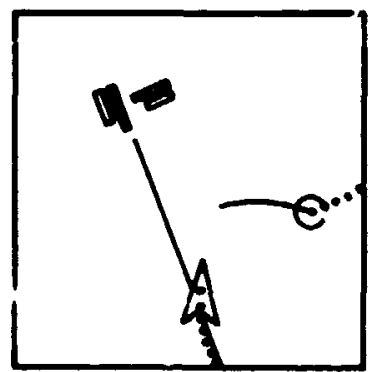

CURVED RELATIVE PREDICTOR ON INTRUDER ANO NO meorcton ON Oms ati (Chv Oup)

Flzure?. The four lispliy formats usad in the exparlisent. 


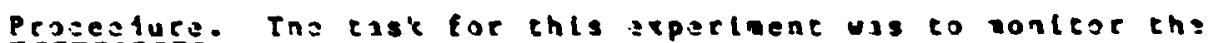

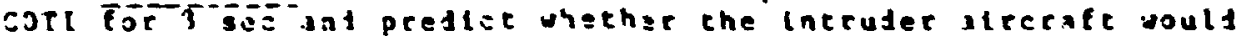
ulrtancely pass in froit of or in back of the ownshlp. The subjects Intleatel thelr declslons by pressing the approprlite butcon ox ths hint held response sultch. Two seconts ifter che intelation of cha run. cha inceuter upperes on the cot with i position. velostey, trick ingle, int turn rate ealculatej so that the Intruter uletacely pisset elther jlrectly in frone of or in bick of odnship in $5 ?$ or 35 sez. After 9 ses of viedinz tie the ERT

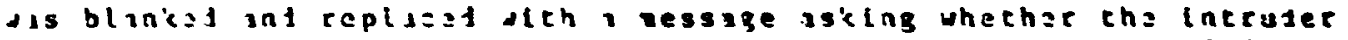
souls pass in froze or in back of ounshlp. The pllot responiel. The durds "IV FROXT" or "IV BICX" thea ippaares on the screen lailcath $\ln 3$ the sotrest jutzeent.

Four subjicts dece asigned to zach of the four contitions. Intelil oral Instructions concerainz the consept of the cort and the asnisz of tha vartous tisplay syabols were ziven. After ipproxlately onz half hour of trintas. all pllots unteruane pretest blo:k of 48 encounters ath no predlctors. At the conslusion of the pretest trlil there das lo-minute break. The pllots

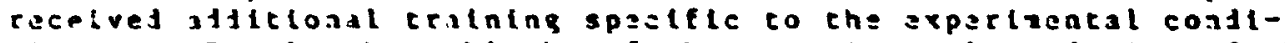
toon. Jn Diy l, thres blosks of the experingntil conjltion of the 43 anzountars ware adinisticed with 10 -ainute break betwaen blosks. On Diy 2, the subjects recelved lnstructions on the reanInz of the cort syabols for the exparteental contition ant threz zura blozks of 43 encouncers of the axperlaental conjitlon dere gid:a. The experlaent concluted with postcest block identical co the pretset blosk th no predictors. Presentation order was randoaized. In ifition. uhsther the subjest saw s sectelc encounter or les litro: lase was liso rantomizej.

\section{Results}

Table I shods tha percent ecro, for esch of tha pretlctor conticlons for stratibe and curved encounters le both distanies. It can ba sean In figure 3 int rable l that fewar errors were mile on curvet ensounters than tha pratletor injlested tha future jolnt effect of curceat cuca rate of both itreraft. Doth ground referencel ins ownship raferencel prafictors resultet in equally good perforanzes on tratigh encounters. Hodever the error rate on

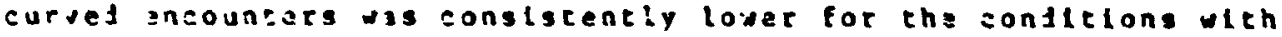
survet zroill or odnship refereacel preflecors that providet turn rate inforastion. With tura rate infornation the arror race on tha curvet ansounters das zomparable co the error rate on stralght ancuunters. The hizhesc error rates oscurad when both licrate werz curnting and th: predictors lid not inclule turn rate lnformacloa.

An inidysls of varlanzi dis conduzed on crangformed percent error rite over the four prejictor contltions, separation distinie it encuster ant type if encounter (straight or turnlnz). Table 2 shads rie risults 0 : the ANovi. Perforances over the four predicior tyoss, two sepiration dispances ad encouncer types ware signt-

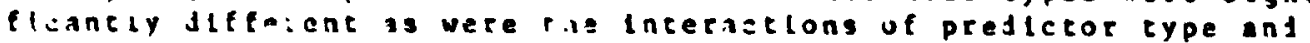

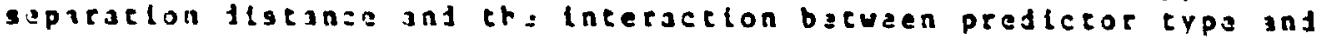
encounter eyp?. 
ORIGINAL PAGE IS

OF POOR QUALITY

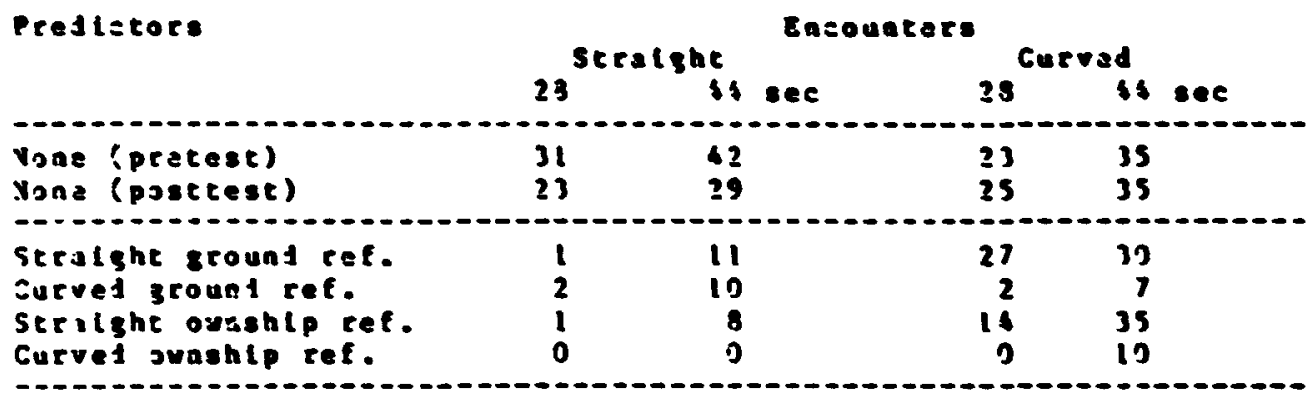

Tabl. 1. Percent error averaged sver subjscts and repltcatios

for stralght and curved encounters. Thare uere 95 trials each

per cell for ths pretest and postest as preflctor contleloas and

233 telils eash par cell for the four predictor coatitions.

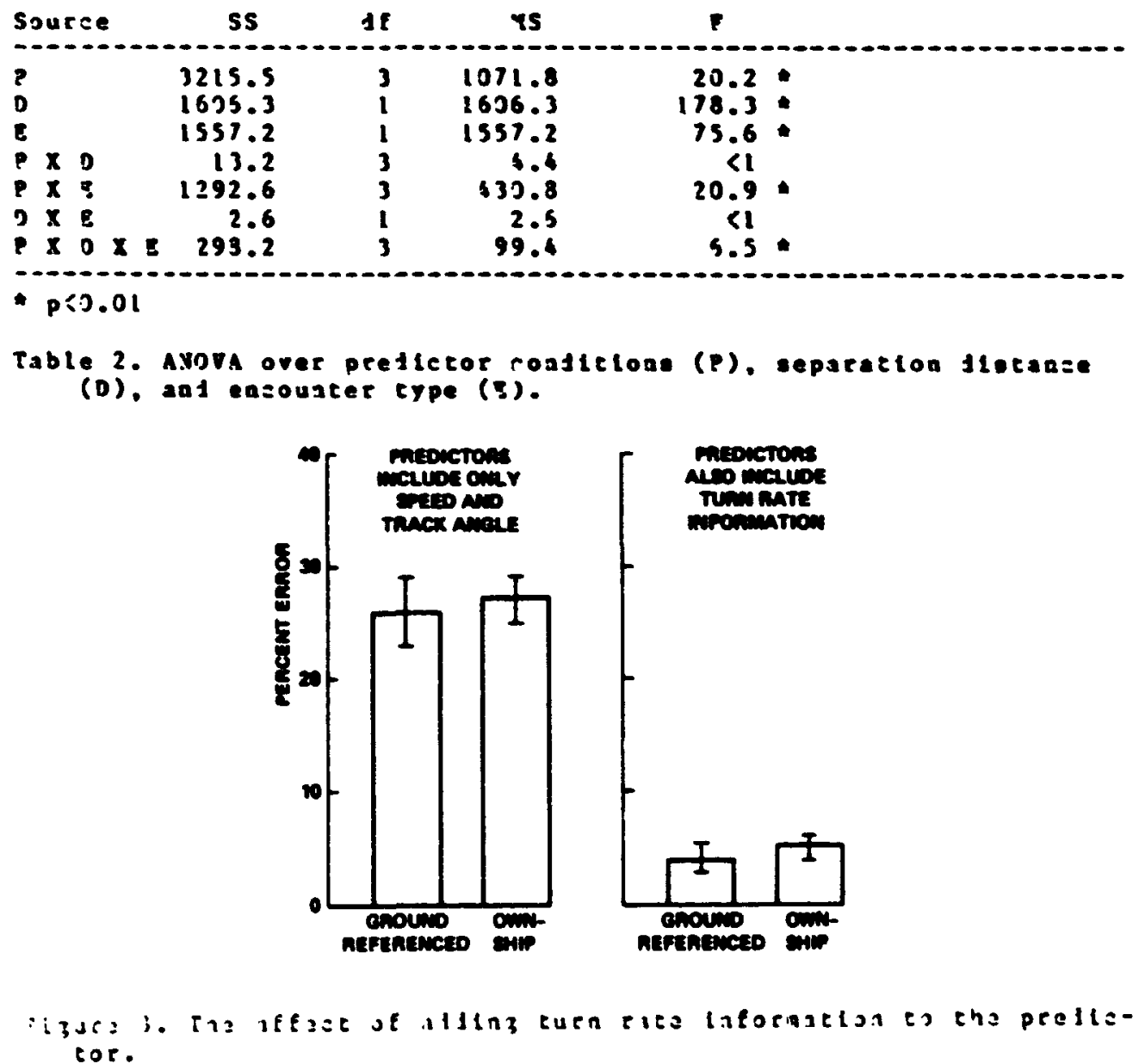


Flgurs show percent error collapsed over subjects for each of the preflctors. The taca ere shoun for ech of the replicactone serazed orer the two distances. It can be sean thet repllectous alth predictore do aot leprove psctorance on the ao predictor postest. There uas no signiflcant ifferense betueen the pretest ad postest asas. There as evldence for learalas for all predlctors except che surved oushlp referenced predictor uhlch alncalued an average error rate of 38 .

At the conelusion of the experineat the pllots vere allowed to viev the ocher predtetor condletoas. Thete pradtctor preferense was requesced. All pllots preferred predictore ilth cura cace inforation loclutes. The prefereace uas evenly ilvided becweea grount referencet and ovashlp referenced predlctors.

\section{Drscosstox}

The asta objective of thls experleant was to larestigete perforances ustaz different types of predictors. Evideace clearly shows that the addition of a predictor reduced the error rate. The percenterch was further redused when tura race laforancloa das added to the predictor.

There stil renalas a queston whether sround referencias or ownship refereasiag is the best ecthod. The percent error data on the replicatlons showed that chere vas litrle learalag with che curved owahtp referenced predictor. Although after elx replicacloas boch curved ground referenced and curved ounship referenced predictor conjlitions had silliar low ercor cates.

The question of which achod of referenclag is best is fuether clouded by the fect thet $50 \mathrm{x}$ of the erer with the curved ounship referenced predictor vas accouated for by cwo encouncers. These tuo eacouncers $(11$ and 19$)$ are both excouncers where. the owaship ts curatag. Thus the curred ounchip reforeaced prediccor coudition had very loy orerall ertor rate when these two encounters are not conside:ed. One could argue thet ownshtp referenclas is the best ecthot. Oa the other hall, the curved ground referenced predictor conticlon had aore even diseribution of error. One nuse alao question how good teferencles sechod is te lt cen be so sonfusias on evo of the encouncers and aoc coafuglag on all the ocher encounters.

Results fron the subjectiv data suggest chet che sethod of referenclag is a lajteldual preference al aoc bised on perforanse.

\section{concluston}

Thls experleenc adis to s serles of experleente designed to eveluate coti displey syabolozy la a jyanic but controlied environate. The folloulns are ceneral observations based on the daca froa this experimene. 1) The addition of predictive latoreaclon reducas ertor. 2) The best resulte were obtalaed when cura tre lacormaclon das lacluded in che prediction.

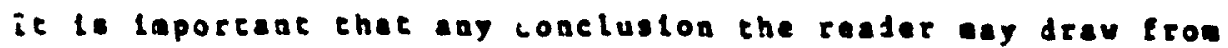


ORIGINAL PAGE IS OF POOR QUALITY
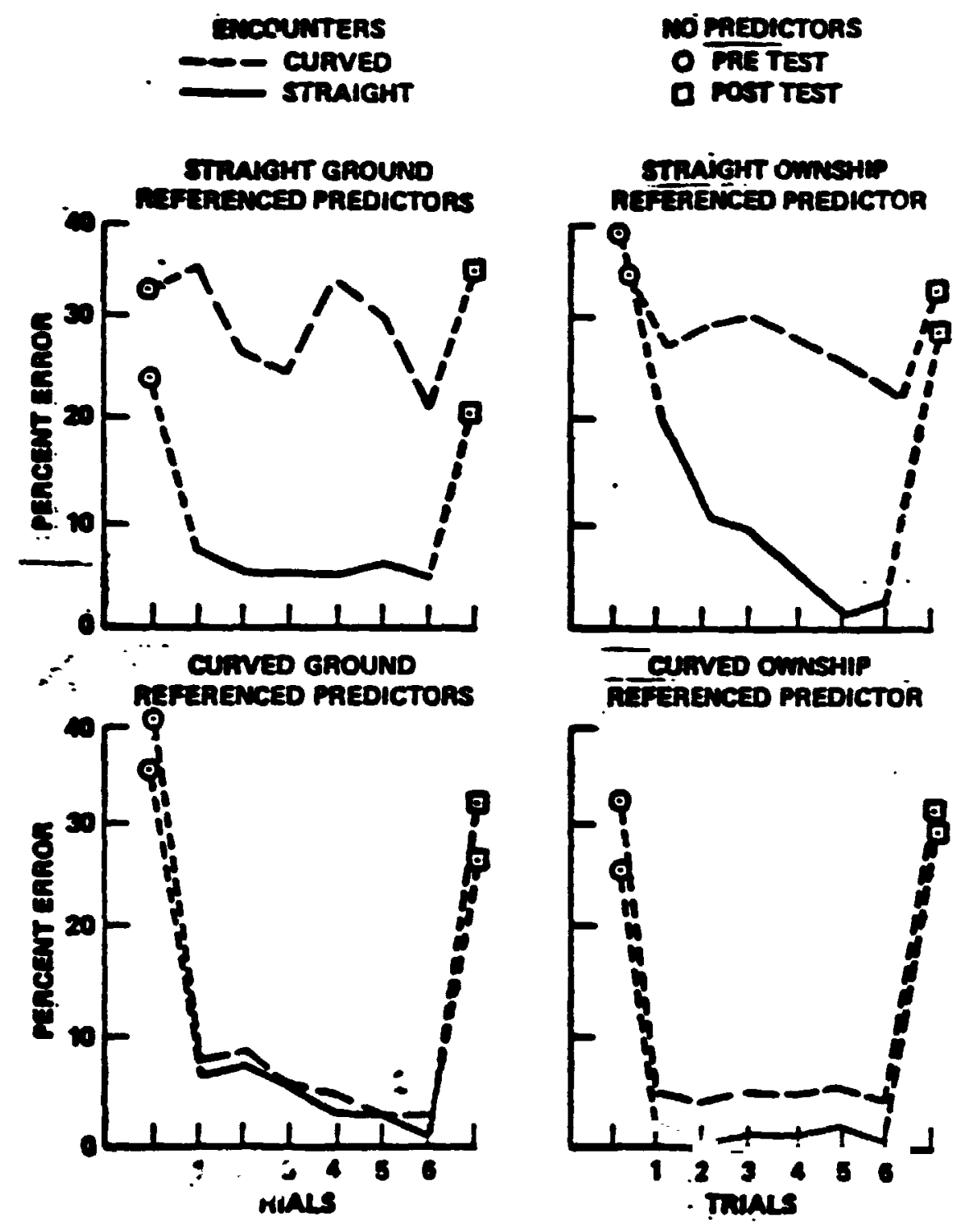

Flzure h. Learalag perfort ince with each predictor cype. Percent error collapsed orer subjects. 
chess results take lnte account tha following liattations of ths reserrch nachos: (I) The pllots coult devace thalr unintercupted atention to the task for 3 sec: (2) nather ilectift =hanged les spaet or tura rate turlng an ancounter; (3) alchouzh tha tlsplay wis tyniale, tha pllots sould not lnterset with the lisplizy to isk for nore inforation about tha Intrujar or change tha aip sale; (b) pilats =oult not cike over anuil control of tha atrcraft; (s) the passive nature of tha task and the large nuaber of crlals resultaj ia 1 task that qulckly becate routinz. The flrac two icens shruld lajt to fever errors than would be sxpacted in a real ifrcraft. The list chree itens should leas to vore ecrors than in a ral ilrcift. It is felt, however, that tha relative ilfference

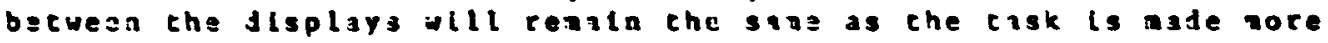
rasitisti=.

\section{References}

1. Pzleser, E. A. Baty, D. L.. ind otConior, S. L. Perception of ilectift sepiration alen vartous syibols on $a$ sospte display of craffic inforation. Papor presented at the lith innual Conferense on lanuat Control. Jelght Stitz Jniversity. Jiyton. Jhlo. 11: $=$ h 1973.

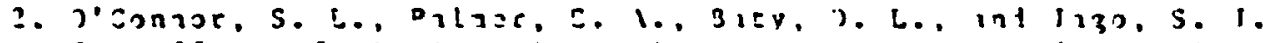

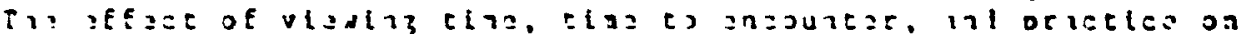

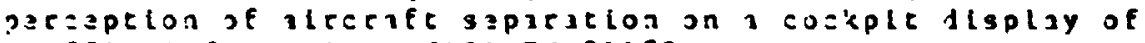
craffis inforation, VASt [y 3117$\}$.

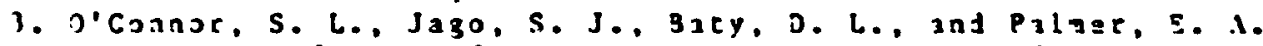
Paresption of aireraft separation jteh pliot preferred syabolozy on 3 cockplt lisplay of crafte informition, yist tit 31172 , In prepiration.

H. Buty, D. L., Jazo, S. J., O'Connor, S. L., ant Palaer, S. A. Thz sffict of lisplay uptace race, uptate cype ant backzround on perception of itreraft separation on soskpte lisplay of eraffle Inforaztion, Nist Ty 31171 , In prapirator.

5. Het. S. O. ant Lools, L. L. Evalustlon of the potential forale int sontent of coskit tisplay of traftic inforadion. To

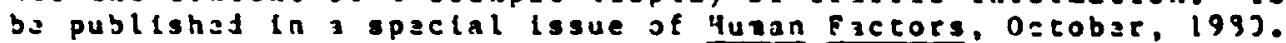

5. Hart. S. G. ind loonis, L. L. Evaluaton ind predicelon of che vertical sleustion fron horlesntal slaulition tispliy. Presentel te the $18 \mathrm{ch}$ IEge Conference on Dactston int control, Fort Liulardale. Florlia, Daceabar 1979.

7. Hart. S. G. ani Wenpz, T. E. Cockpit lisplay of teaffic Inforjutlon: jlelinz pllots' oplatoss zbout content, syabolozy, int forale, NASI TY 78501 .

3. Hare, S. 3. Content, syabolo3y, int forate of cockple tisplay of traffic inforastion: zeneral avizion pliot oplation. Praszntzi le the l 5 th innull Confarence on Yinuil Control. Diyton, Jhto, Yarch 1979. 


\title{
ORIGINAL PAGE IS \\ OF POOR QUALT.
}

\section{- $882340644_{27}$}

\author{
COMBINED DISCRETE NETWORK--CONTINUOUS CONTROI \\ AODELLING OF OPERATOR BEHAVIOR \\ R. A. Miller \\ Dept. of Industrial Systems Engineering \\ The Ohio State University \\ Columbus, Ohio 43210 \\ and \\ Deborah J. Seifert \\ Airesearch Manurzcturing Co. \\ P. O. Box 5217 \\ Dept. $60-60$ \\ Phoenix, Arizona 85010
}

ABSTBACT .

The class of systems of interest is that in which an operator is faced with a continuous control task plus one or more discrete information processing tasks. The objective is to explore a modelling approach which has the capability of realistically representing both types of tasks and the resulting interactions. The modelling approach utilizes discrete network models for the cognitive tasks and elemerts of an open-100p/closed-10op control representation for the continuous task.

The approach is demonstrated through its application to almulated Digital Avionics Information System in which subjects vere required to perform retrieval and processing tasks as well as flight control. This model differs from conventional models in that system status sampling is not necessarily continuous or perlodic. Rather, the pilot is assumed to read system status displays only as time permits and operate in a so-called ' en-loop" preprogramed rashion betreen sampling.

\section{INTRODUCTION}

It is clear to anyone participating in this conference that research on supervisory control has been increasing duriag the last few years. this study, which vas primarily exploratory and methodological in scope, fol ${ }^{\prime}$ is in that trend and the results contribute to a better understanding of human-machine systems and supervisory control modeling.

Specifically, a computer simulation approach, which.utilizes discrete network techniques to represent certaj.a cognitive and decision making tasks and a novel control model for continuous tasks, was used to explore a number ar supervisory control questions. A rather general simulation model of operator performance with algital avionics information system (DAIS) was constructed and verifled against data which had 


\title{
URIGINAL PAGE IS \\ OF POOR QUALITY
}

\begin{abstract}
been collected in a previous man-in-the-loop study. 1,2 The resulting model vas used to perform sensitivity analyses of flight control variables and explore variety of questions about task organization and performance strategy. An outline of the model and some of the more interesting results are reported here.
\end{abstract}

It must also be mentioned that in addition to the above traditional modelling objectires, a anor reason for the study was to explore the possible utilization of digital simulation methods for the design of expensive man-in-the-loop type experiments. A few suggestions tovard this end are also presented.

\section{DESGRIPTTOI OF THE DATS SinITATOR}

The DAIS simulator cockpit replaced many of the traditionally dedicated instruments, displays, and subsystem controls with interactive multipurpose displays (MPD) and multifunction keyboard switching (MITK). The rock-up cockpit had a forvard station configured simular +0 a singleengine, single-place, transonic light attack aircraft. The front panel of the cockpit was equipped with three CRT-type displays, two served multipurpose functions and the center display was used to present information concerning basic flight paraneters in moving tape format. The plight control display presented eirrent readouts of the aircraft angle of attack, 8 -load, indicated airspeed, percent of total throttle, anch number, vertical velcsity, and headiag. Information storage and retrieval was e.chieved through the use of the multi-function keyboard and the alphanumeric keyboard located on the left side of the cockpit. The cockpit also contained a throttle vith arterburner swtch and a centermounted joystick coltrol which were used, in combination witb the displayed flight information, to " $\mathrm{Fly"} \mathrm{verious} \mathrm{maneuvers.} \mathrm{Analog} \mathrm{outputs}$ from the stick, throttle, and MTK vere processed by an $N / D$ converter for input to a digital computer where further processing wes performed. The nonlinear aircrest motion equations vere simulated digitaliy and updated to respond to the positions of the stiak and the throttle. Similarly, switching instructions comsunicated to the pilot ria audio beadsets were entered through the MFK causing the MPDs to be updated.

Flight control variables vere recorded in teres of the error between the actual values and the command or desired levels. Performance scores were computed for both the flight control alone and Night control performed in conjunction wth MrK switching configurations of the wission. These scores along with dat collected concernins discrete information retrieval task times vere used to compare and evaluate the informution workload tradeoff of the proposed DAIs systen.

This system was selected for this study for severel reasons: (1) It eppeared to $b$ 2 representative of many contenporary man ine systems in that it required monitoring and discrete information pr -dsing behaviors as well as wtor control tasks, (2) prelininary performance estimates were avallable, and (3) results of this endeavor had implications for ongoing research and experimentel studies. 


\section{ORIGINAL PAGE IS \\ OF POOR QUALTY}

DESCRIPTION OF EXPERIMTDYT AND PBOCEDURES

Seven different maneuvers were employed in the flight control task. They are identified in terms of command right peremeters is defined in Table 1.

TABLE 1

BESELIXE FLIGHT CONTROL MANEUVERS

\begin{tabular}{|c|c|c|c|c|}
\hline Maneuver & $\begin{array}{l}\text { Altitude } \\
\text { (ft) }\end{array}$ & $\begin{array}{c}\text { Velocity } \\
\text { (kt) }\end{array}$ & $\begin{array}{l}\text { Vertical } \\
\text { Velocity } \\
\text { (ct/min) }\end{array}$ & G-Load \\
\hline $\begin{array}{l}1 \text { - straight and level } \\
2 \text { - left turn } \\
3 \text { - right turn } \\
4 \text { - turning dive } \\
5 \text { - stall } \\
6 \text { - turning ascent } \\
7 \text { - high-g tura }\end{array}$ & $\begin{array}{c}20,000 \\
30,000 \\
30,000 \\
=- \\
20,000 \\
30,000\end{array}$ & $\begin{array}{l}500 \\
500 \\
500 \\
500 \\
240 \\
500 \\
600\end{array}$ & $\begin{array}{r}0 \\
0 \\
0 \\
-2500 \\
0 \\
2500 \\
0\end{array}$ & $\begin{array}{l}1.0 \\
1.5 \\
1.5 \\
1.5 \\
1.0 \\
1.5 \\
3.0\end{array}$ \\
\hline
\end{tabular}

The subjects were instructed to "maintain" these parameters "or the duration of the vission (approximately 200 secs.). Flight control was scored as a runction of the difference between the desired control parameters and thit actual ones. These "deite" ( $\Delta$ ) values vere computed every 200 milliseconds. The flight pazaneters on which scoring vas based was chosen through consultation with pilots and other researchers who were able to specify on an experiential basis the minimum number of s.gnificant parameters for each mission, and the importance of a given amount of error in each paraneter. Working from this basls, a for dla was derived fo: each maneuver. The specific formulas chosen for the maneuvers used in this study are presented in Table 2.

TABLE 2

MANEUVER PERFORMANCE SCORES

Straight and Level Flying Dive/Climb

Diving/Climbing Turn

Level Turn

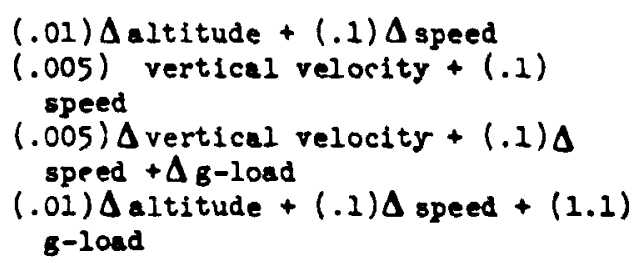

NOTE: $\triangle$ represents the mean absolute error from the command vadue.

Four levels of task difficulty were utilized for the MFK switching tasks, which required approximatei: 4, 6, 8 or 12 push-button switch actions per task. The MTK task was scored on th basis of correct completion of the switching sequence, total time required fo- correct completion, nd time per switch ation. 


\section{ORIGINAL PAGE IS \\ OF POOR QUALITY}

Three different configurations vere considered: flight control alone, Wh alone, and the combination o: Elicht control vith sutching. Pour collere students served es subjects for the experiments. Each receired approximetely 40 bours of training of he primary filght control task and at least 20 bours of treining on both the secondary WhK and combined tesks. In erery case, training was to asymptotic performance.

In the flitht control alowe secont, there vere 28 trials per subject - four for each of the seren maeurers. At the inglaning of a trial the subject was told which naneurer be wes to $I J$, inciudins the rlicht parenater vel.es to be elntained. Then he vas allowed to "rly" the timulated al rerast unt1l be wes coafident be was prepar . to start the maneuver, which be indicated by pulliag $e$ trigger on $t_{1}$ entrol stick, desleneted as the "botswltch". At that poin: a 200-second trial began with autcantic scoring and teraination by the supporting conputer pro.jen. There vere 30-second intervals between tifils.

In the we tent alone, esch subject ves also civen 28 200-second trials. There were seren trials for each of the four levels of ITK difficulty invent ceted. Thirty-second rest intervels separated trials. four different Fit takk of the civen difficulty level vere performed durins each triel period. The subject recelved pre-recorded instructions vie His earphoses concerning the tesk be wes to perform. The instructions vere followed by a tone which wes the signel te start the MrK task. The subject depreseed e "stop" button on the left side par. 1 to the right and abed of the throt'le, to ladicate he bed completed the MPT trsk. The experinenter wonitored the dupllcete displeys at his station to escertala the correctness of subject ection on the MrK.

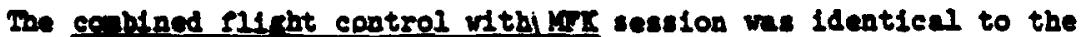
Plight contral ningle task condition exeopt as follows. Thirty secouds after the subject's sical that be val reday for scoring of the filght aneurer to start, the rocorled lastructloss for the flrst bru task vere presented. Thus the elleht control and bro single task scenarios were "orerlared" so tha: each subject had so dirlde i" "s ettention between then throuchout the staodard 28 200-second trial perlods. The . subjects vere instructed to cire flrst priority to Plicht control. A wore detalled deseription of the pro:rdures ian be found in references 1 and 2.

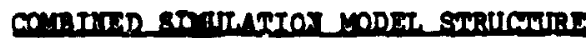

Two basic annenter types out of the seren empioyed in the DAIs real-tine simulation rere sir.lated: stiel che and leral prias and - turaine dive. these are con ldered to be the ealest and hardest flight maneuters, respectively. An opes-100p closed-100p control rodel for these mneurers besed on the tlisht equations euployed in the DaIs sinuletion vas dereloped. Conrentional coatrol models, in which the pilct 1s assured to be sampling systed stetue variab' 3 s continuouniy (or periodicelly in the discreje tine case), are taread "closed-100p" models. The proposed model differs fran that ebove in that dystee st-tus sempline 18 not necesserily contlauous nor pericdic, due to the secondary ault1function keyboard tesks imposed upon tae pliot. Therefore, the p1lot reads syste status dispiays only as tims pernits and cierates in a 
ORIGNAL PAGE IS

OF POOR QUALIT

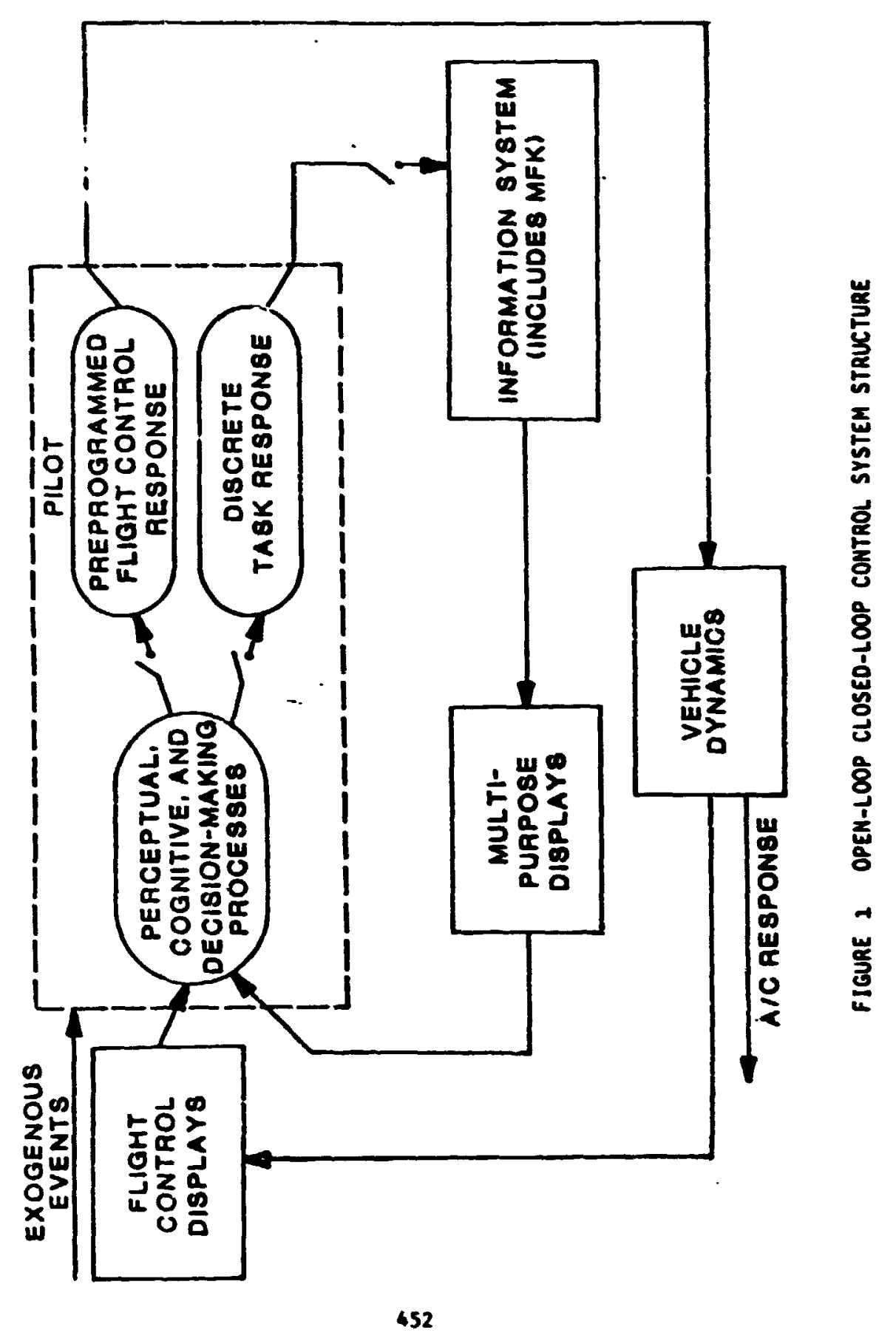

$c \cdot 6$ 


\section{ORIGINAL PAGE IS
OF POOR QUALTI}

so-called "open-loop" preprograned rashion between sampling.

Figure 1 depicts the structure of the open-loop closed-100p coatrol systen. The pilot mut encode and process information tron filcht contral displins, mitipurpose displas, and exogenous erents such as adio svitchins instructions. The flot thes evalnates this informtion as a runction of srsten status deneds, applyins decision rules and priority requirements in deternining his selected outpet coatrol or switching setions. Some of tbese ections involve conscious decisionaking on the part of the pilot; otbers are hichly dereloped parebonotor skills reguired for alght control involvies less conscious decisionnaking.

The operator is perforning in a miti-task environeat at several different behaviorel levels. Es is matiorios displars, processing informtion, Whins flicht coatrol inpurts, and storing and retrievies informetion vie the kerboard sutchins tasks. It is the nodellins o. these activities, loos vith the pllot's comitive, decislon-aning processes, to which the wodels presented bereln are addressed.

The decision-miking process an the informtion system, includins the altifunction suitching tesks, are nodeled vin discrete networt techniques. Becanse of the hierarehical structure of netwart nodels, the task ectivities of the pilot way now be represented at ean differeat levels. For exaple, tank as be used to indicate discrete

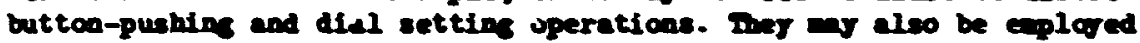
in representing sequential andor stocbntic informtion processing models. a a completely differ' it level, setwork models are used bere to achieve desirel state rarinble soplins intervels and priority scheares. The network strusture is desiened to operate at mav differeat levels sinutaneously and the is capable of representios sophisticated ma-eachine sroten betnviors. In its epplication here, the aetwork also serves a spervisors role in interfecing with the open-loop optiml control model representation of the pilot's tracking task. Dive two wodeling approckes are necbed together to form a conbined discrete netmork-conticuous optinal cootrol nodel of the huan operator.

\section{The contmolydel}

The open loop-closed loop oodel is best described in linear oystem. ters. In the case vhere the operator is assuned to be sapling continuously, his control beharior is represented as a altivariate proportican plus incegral control sys: operatins on aolse corrupted displayed e--Jr inpit. The open loop-alosed loop formintion presunes shet control rs=-ponses between sarples c: state rariables are based on a conditional meas extrepolation of the systen trujectory. The effect of sampling is to redefine or upinte the state of the extrapolation nechanien. The control response then is essentially sontinuous although the sappliac and infores:ion processing required is discontinuous.

The nodel is nost easily described in closed loop form first and thex extended to the open loop-closed loop versica. The operator's response is presuned to be proportional plus intecral and defined by a syste of the following form:

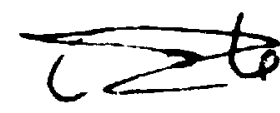




\section{ORTGNAL PAGE $\mathrm{B}$ \\ OF POOR QUALTY}

$$
\begin{aligned}
& i(t)=x(z(t)+\operatorname{sa}(t)) \\
& v(t)=x(t)+G(x(t)+\operatorname{se}(1))+\cos ()
\end{aligned}
$$

where $U(t)$ is the central rector (fore-art atick sorcanat, slde-ride

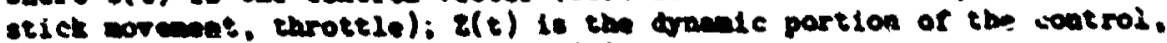

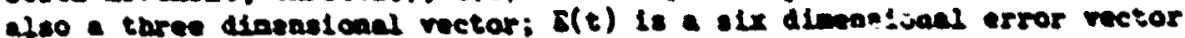
represcatine tbe deviation trom soniael valued of the itate rarlables

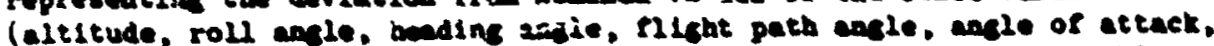

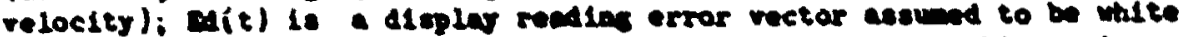

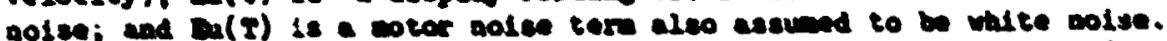

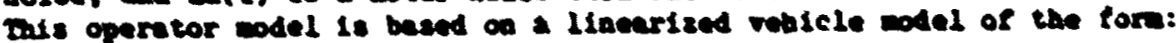

$$
\text { s(t) - } \operatorname{Nu}(t)+\omega(t)+\operatorname{se}(t)
$$

where $I(t)$ an $U(t)$ are as dofloed above, and se(t) is a procen nolas rector easund to be whlte eolse. Ine llacarised adel (actunlly two wodels. one for each evencurer) ans und to defles the coetrol pins I ad o ria optinel coatrol. In teres of the operetor nodellies proble

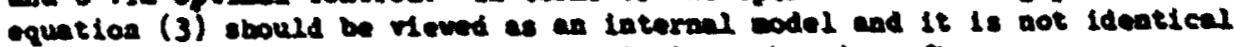
to the oon-Llacer equntions used to simiate the drerart.

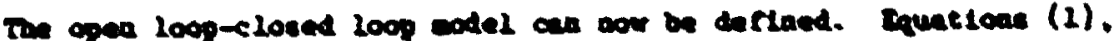

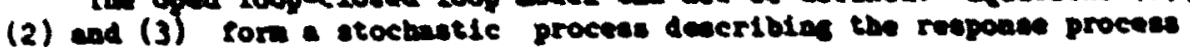
the the operator would libe to realise. In anposted forn the procenes is deacribed w:

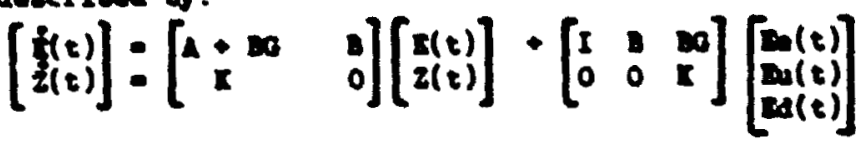

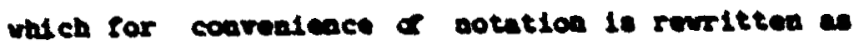

$$
\dot{i}(t) \cdot A x(t) \cdot r(t)
$$

viner.

$$
x(t)\left\{\begin{array}{l}
x(t) \\
z(t)
\end{array}\right]
$$

Doce thet

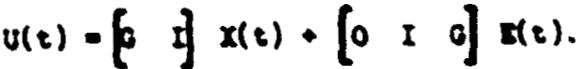

$$
\begin{aligned}
& \text { How, to obtals the ofen loop-closed loop farn, let } \\
& Y(t)=(I \text { o) } X(t)+\operatorname{sa}(t)
\end{aligned}
$$

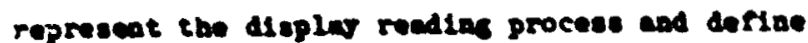

$n(t, T)+\varepsilon(x(t) / x(T)), \quad t T$.

$M(t, T)$ is twa the conditlonal wen of the procese based on a taple $r(t)$ at tim $T$. elowriv.

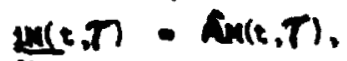

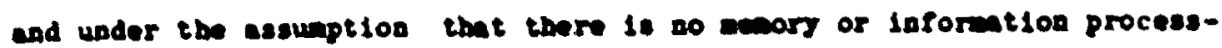

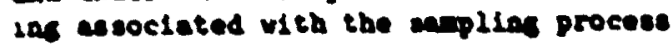

$$
n(t, T)=y(t)
$$

The aperstor's costrol response is then sesued to be of the farm

$$
u(t)=\left[\begin{array}{ll}
G & 1
\end{array}\right] n(t, T) \cdot w(t)
$$




\section{ORLGINAL PAGE $\mathbb{S}$ \\ Of POOR QuALTY}

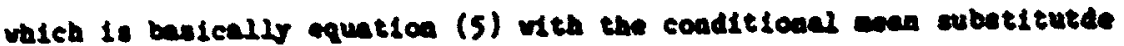
for $x(t)$ and the display error reored.

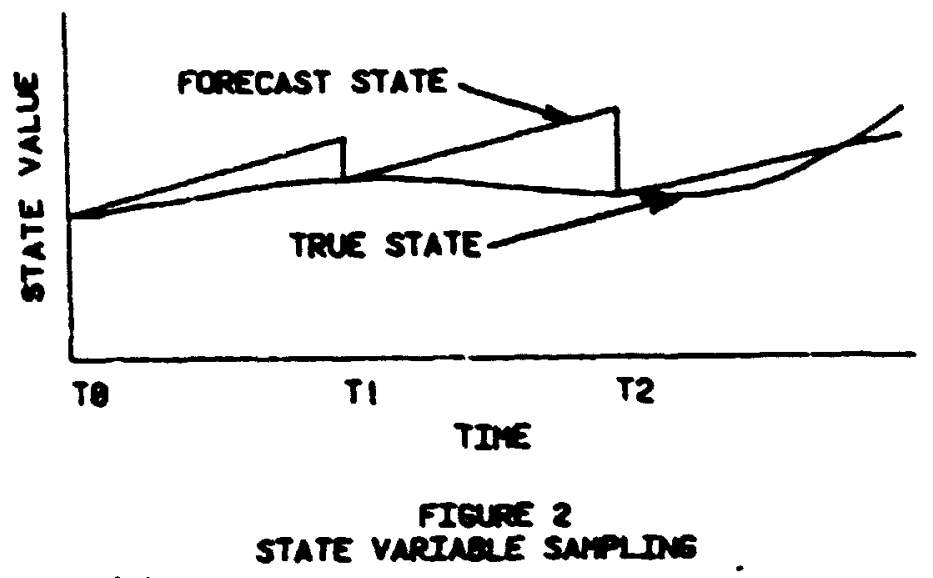

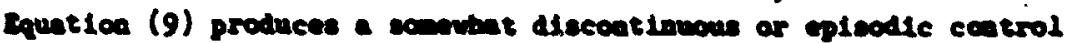

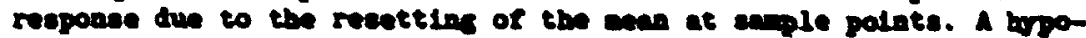

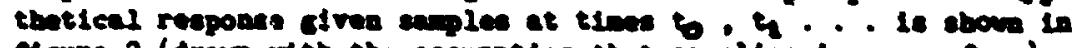

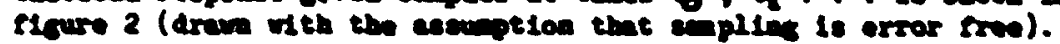

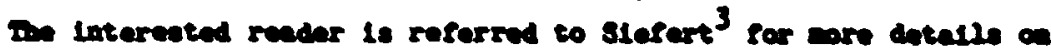

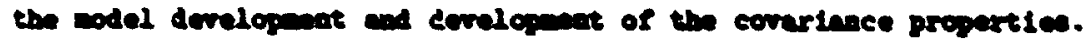

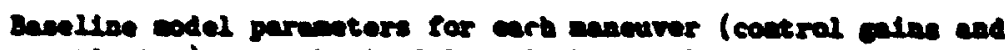
nolse statietica) wre obtalned larcely br trial and error folded to

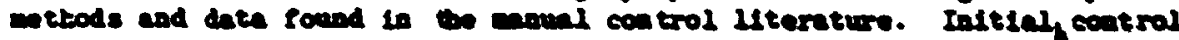

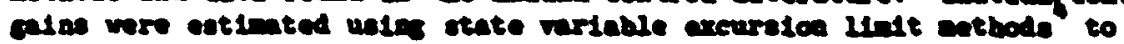
postulate a quadratic regulator optimal coetrol proble. These pare-

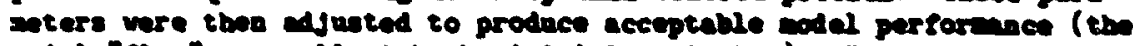

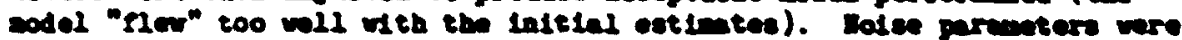

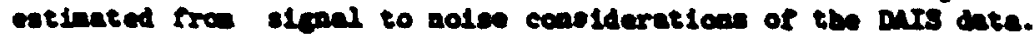

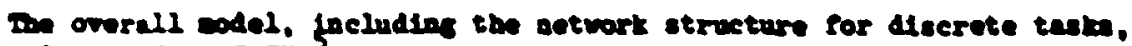
ne inplemented in surint.

\section{marmin}

The results coasist of sensitirity andyses of tho bealine sodel and som nore exploretory anelyels of elterentive tack stretedes.

Danding rodel mons

A serles of nodel ruas wre ade in a configuration is wheh ull

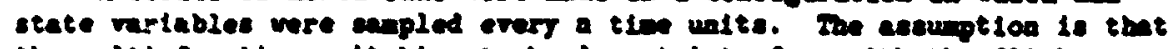

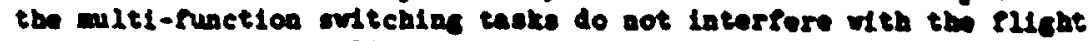

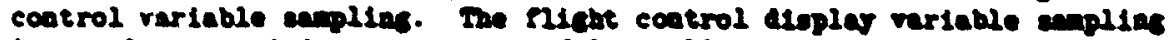
latervil wes rarled over a reage of 1 . to 10 . seconde for stralght and lerel, ad .5 to 2. seconde for turala dire. Toe reendting orerell score for three dlfferent inltiel readen auber seode are diaplayed in Tables

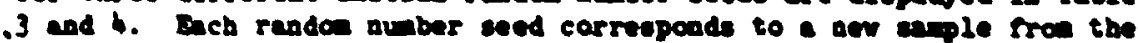
easemble of alsaloo scores. A craphleal representation of the firat date eppears in Mcure 3. The three sybole displeved in the craph denote the three differeat anples take ot the capple latervel. Of sone inportance ts the senelitivity of the scares to the eaplias interves. In

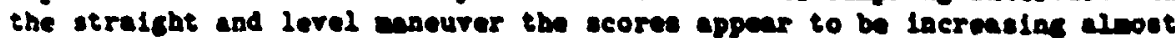
Iinearly vith the seaple laterval, wits the exception of twe 4.5 and 5.0 tiee Intervels. At 5 . the ecore jupe dreneically to .89. This would 


\section{ORIGNAL PAGE IS \\ OF PCOR QUALITY}

men 3

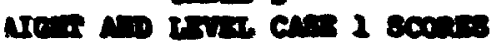

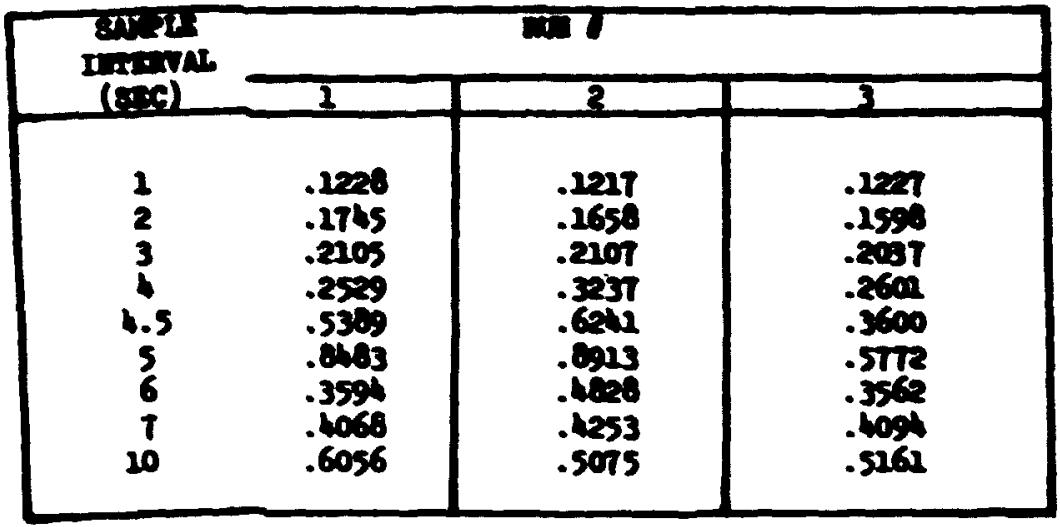

enes 4

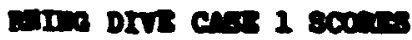

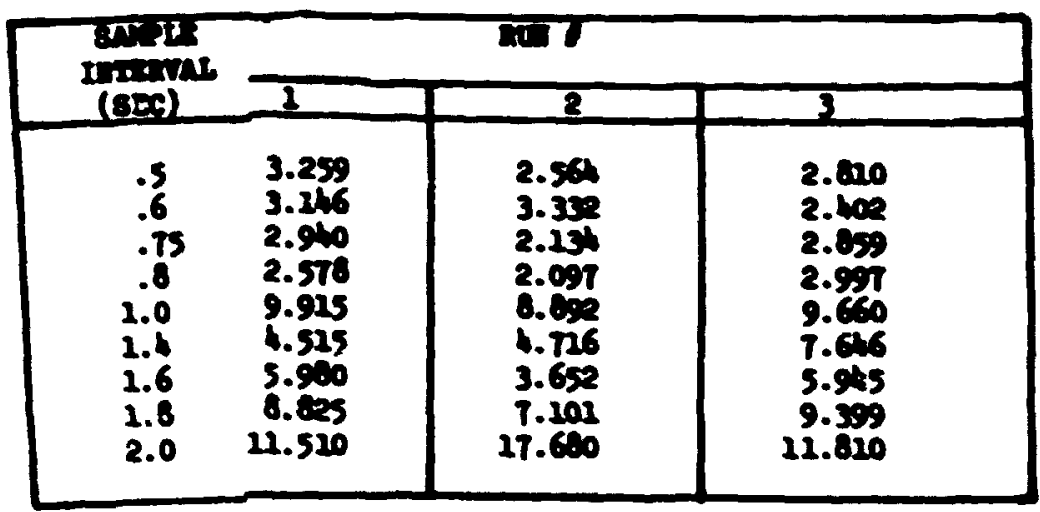




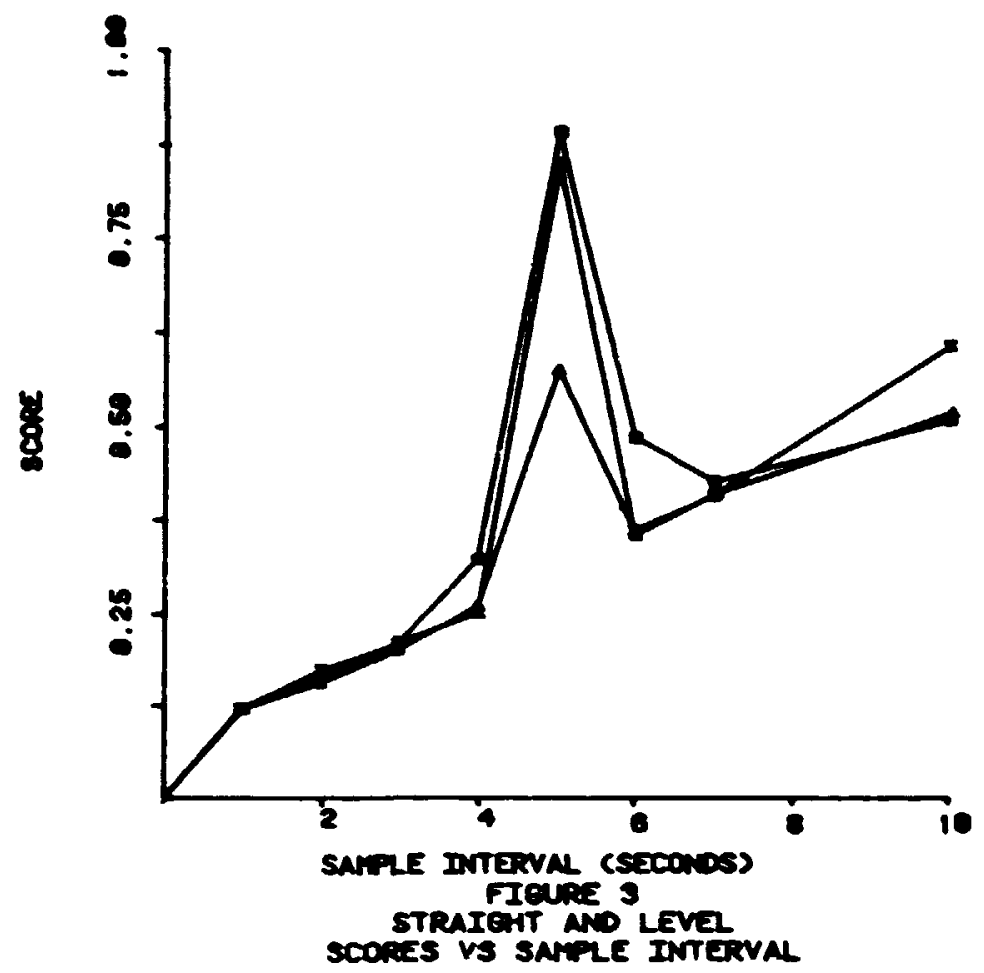

457 


\section{$C_{\cdots}: \cdots, \cdots, \cdots$

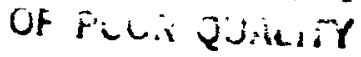

not be so surprising except that at a time interval of 6 . seconds, ine score drops down to ange betveen .35 and .48 . It gradually increases for the 7 . and 10 . second sanpling intervals.

A sinilar phenonenon occurs in the turning dive case. Between 5 and .8 the score is relatively insensitive to the sample intervel. At 1.0 the score Jums to almost 10 . Ngain, at higher sample intervals the scores drop doun; at 1.6 the score ranges between 3.6 and 5.98 . like the straight and level case, the scores begin increasing, this tine not quite so gradially.

These peaks in the scores at .5 in straight and leve, and 1.0 in turning dive, dere not expected. Closer anelysis of the nodel suggests one plausible explanation for this behavior. Plots over tine of the state variable nean statistics prodiced by the forecasting systen are revealing. These distributions have peak errors at the identical points in time where the scores peeic. After this tine, the forecasting systen generally stabilizes, although vith higher errors than in the earlj portion of the sanple interval (less than 4.0 in straight and level and 0.8 in turning dive). There appears to be a tradeof betureen obtaining estimates of flight control states at peak error points and using the "internal" estimates of state variable values.

\section{Comprison to DAIS Results}

The results appear to refiect fairly vell the performance of the DAIS subjects. In the straight and level flight alone maneuver, DAIS subjects areraged a score of . TKi with a standard deviation of .219 . Experimenters indicated that the highly notivated pilots consistently performed at the .5 level. This suggests that the nodel sanpling intervel could span up to 10 seconds and still mintain scores within one standard deriation of the DaIs subjects. Ifikerise, comparable scores can be obtained in the turning dive maneuver vith saple intervals up to 1.6 seconds where the DAIS experimental results produced a mean sccre of 5.495 with a 1.135 standard daviation.

\section{Analrais of That Briority}

It is probably quite unrealistic to assure that the FTh tasks do not interfere with the flight control variable sepling; nor is it apparent that the pilot operates in strict priority mode. He nore likely "tise shares" between flight control and switching, appearing to operate alnost in parallel. This behavior is difficult to represent in a simulation odel. One possible approach (Case 2) is to use an interleare schene during the suitching task period in vaich the pilot aiternates between an MFK subtask and a rlight control display update. With no sampling peraitted durins the individual MFK tasks.

An alternate sapling schene gives suitching priority over plight control. In this formulation (Case 3), the pilot would under no condition interrupt a keyboard task to update his contrul task. This represents an extreme or "vorst" case in terms of the count of time devoted to flight control.

Models of Cases 2 and 3 were exercised for both maneuvers. Table 5 contains a summary of the score statistics for all three cases. In Case 2, state variable sampling is performed betreen eac. of the eight MFK tasks, each of which have mean durations of 1.08 seconds. During the "flight alone" segments of the mission, sampling is performed at the regular specified interval. Thus for intervals greater than 1.08 , case 2 sarpling would actually occur more frequeatiy than in the Case 1 condition, 
TABLE 5

STRAIGIT AID LEVEE AVERUGE SCORES

\begin{tabular}{cccc}
\hline $\begin{array}{c}\text { SALPLE } \\
\text { IMTERRVAL } \\
\text { (SEC) }\end{array}$ & $\begin{array}{c}\text { CASE 1 } \\
\text { (AVERAGE) }\end{array}$ & $\begin{array}{c}\text { CASE 2 } \\
\text { (AVERAGE) }\end{array}$ & $\begin{array}{c}\text { CASE 3 } \\
\text { (AVERAGE) }\end{array}$ \\
\hline 1 & .1224 & .2330 & .2059 \\
2 & .2667 & .1599 & .2553 \\
3 & .2083 & .1972 & .2819 \\
4 & .2789 & .2551 & .4618 \\
5 & .7723 & .3293 & 1.2880 \\
6 & .3995 & .3127 & .5549 \\
7 & .4138 & .3451 & .5148 \\
10 & .5431 & .3976 & .5028 \\
\hline
\end{tabular}

and lower scores would be expected. This is precisely what occurred. At the 1 sec. sample interval, the Case 2 arerace score of .2330 is higher than the case 1 score of .1224. At all the other intervals (2 through 10), the Case 2 score is lover, as anticlpated. It is also of interest to note that the peak at 5 sec. is barely noticeable due to the increased sempling.

In Case 3 no sappling is perforwed during the MTK switching sequence, which has an average duration of 8.64 secs. The Case 3 resuits for sample intervals between 1 and 7 secs. Indicate scores which in all instances are nigher than the Case 1 scores.

Results for turning dive vere sinilar.

SEASITIVITY ANALYSIS OF COMPOMEATS OF ERROR

Three separate flight perforwance scores were recorded for each aission: (1) flight alone phase, (2) Plight and MTK switching phase, and (3) overall assion scores. In Case 3 the intuitive notion was that the scores would be auch worse (higher) during the combined rlight contrcl and switchir. segeats than during the flight alone segments, since no supling was peratted juriag these sequences. Hovever, this was not generally true. It vas decided to examine flight performance in more detall than that afforded by the three averaged scores. The simulation was rerun vitb a moring window scoring procedure besed on the previcus seven points.

A graph of the scores for the turning dive, Case 3, appear in Figure 4. The $\Delta^{\prime}$ s indicate when MPK switching is occurring. Ho clear 


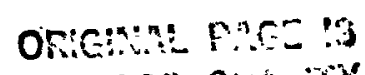

OF POOF Quftuitr
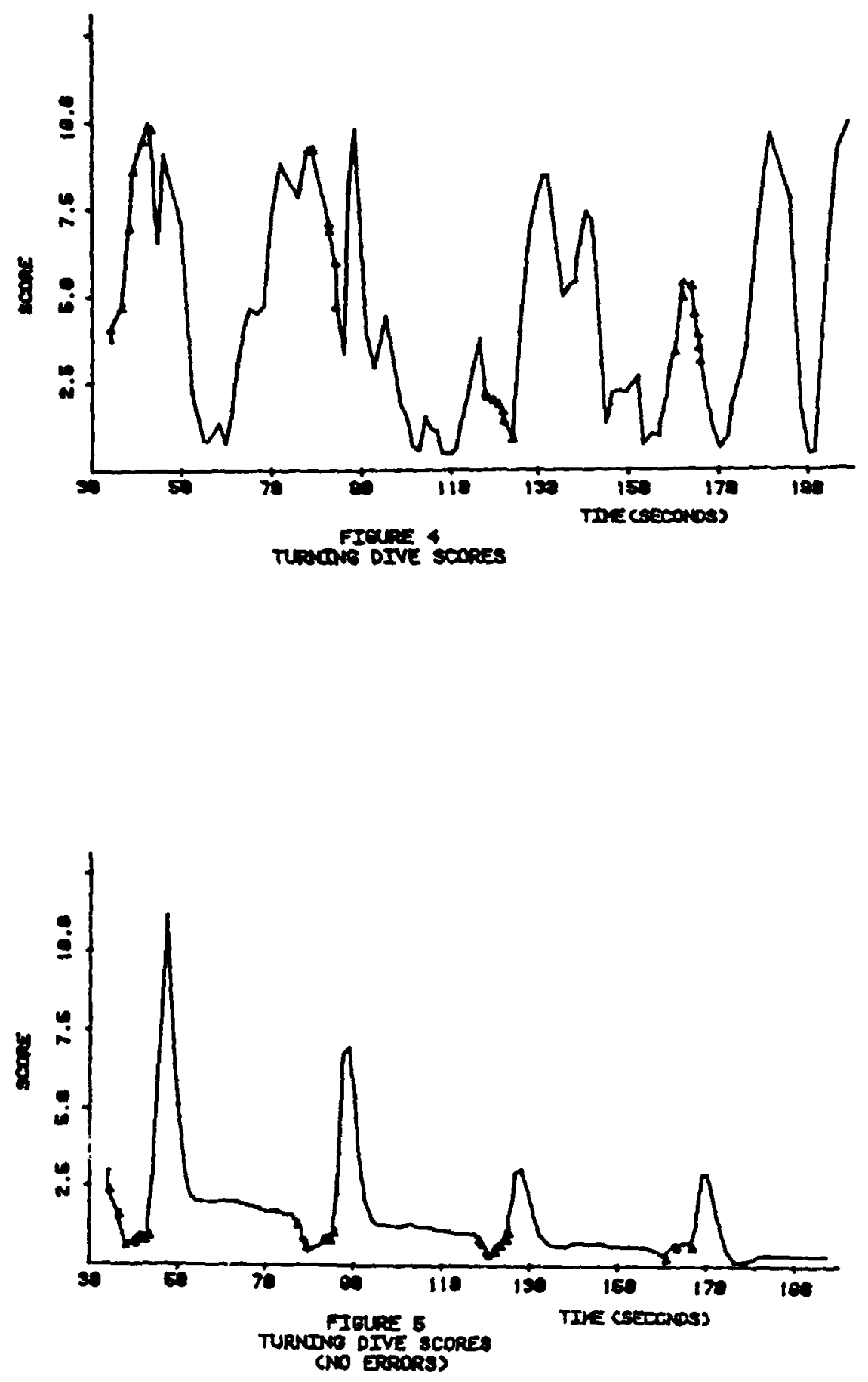
patterns or trends exist. Thers appears to be a great deal. more variability in the scores than was expect,ed, certainly wore than can be ascertained from "rean" data. The exti-me range of the scores is also of concern. At some instances the vehicle is very well controlled; at other points in time, control is much less vell established.

In an attempt to determine if these characteristics were just anomalies of ths simulation model, a similar grapb vas prepared for a "typice:" turning dive maneuver from the real-tine experiment. It sisowed the same degree of variability as the model outputs and also indicated approximately the same range of scores. It appears that the model is duplicating fairly well the perforwance of the DaIs subjects.

An attempt was ade to determine the nature of this variability. The same turning dive case 3 condition as depicted in Figure 4 vas rerun vith all the display and control input error distributions removed. The surprising, but logical, results are contained in Figure 5. It appears that the vehicle is in good coatrol upon entering the MFK task. Even though no sampling occurs during the Mrk task, the aliccraft does not 80 out of control. Howerer, immediately following the switching task, the pilot reads the displays, determines he has deviated from the command values, and beglns to correct his flight puth. He grossiy overcompensates, causing the peaks in the score, and takes approximately 10 seconds to recover.

The decreasing magnitude ofthe peaks over time is also of interest. This suggests that the system is still undergoing a stabllization period 200 seconds into the mission. This has implications on man-in-the-loop exferimental procedures. Allowing the subject sufficlent time to achieve stabilization before initiating scoring could produce results which are overly optimistic.

Next, the display errors vere added back in The results of this run indicated the same trend as the "no-error" case. Additing the $u$ (angle of attack) and $u_{2}$ (roll angle) control errors individualiy and in conjunction with the display errors produ d no significant changes. Adding $u_{1}$ and $u_{\mathrm{f}}$ together produced generally the same results. Including display errors Fith $u_{1}$ and $u_{2}$ also results in the same trend. Adding $u$ errors, hovever, jrodsces more variability and is never really in a stable mode. It more closely resembles the full error condition. This suggests that the largest contributor to the problem is the difficulty in controlling throttle $\left(u_{3}\right)$, with some additional problems with the other two control variables, u and $u_{3}$. Discussions with DAIS experimenters and more detailed examination of the data proved this to be true. It was apparent that vertical velocity was not well controlled in either maneuver, but particularly not in turaing dire. While vertical relocity is a function of all three control variables, it is most hearily determined by throttle. It was known for some time that there vere physical problems with the response characteristics of both the stick and the throttle. The stick in particular had an extensive amount of "dead space" around the center point. It is hypothesized, based on the above results and conversations with DAIS experimenters, that the DAIS subjects had an exceptionally difficult time controlling the stick and throttie, 
resulting in extensive variability of slight prameters, vertical velocity in particular. This could very well $a$ the reason why no significant effects were reported between the "Ilight alone" and "right plus MFK" conditions. The high variability caused by poor stick and throttle hardware, coupled with inadequate scuring techniques based on averages, may have masked the tive effects.

In an attempt to determine what might have happened in more realistic experiments, the model was exercised with reduced error noise. The results indicated much more sensitivity and showed significant differances between sampling strategies.

While these runs certainly did not "prove" that significant differences would have been found in the real-time man-in-the-loop experiment had the stick and throttle been better engineered, it does demonstrate the extreme sensitivity of the system to these paraneters, and indicates how main effects may very well have been hidden by their variability. It makes a case for eaploying a model such as this one for determining how well-behaved such system components must be constructed to perform in order to produce desired system characteristics.

This analysis also poj ts to the need for examining alternate scoring formulations other than the "overall" mission score employed. Ignoring the peaks in the scores immediately following the MFK switching sequence, and using only "averaged" scores, necessarily mask the true effects due to the secondary tasks. One cannot belp but to postulate that the outcome of the man-in-the-10op experiment would have been different had the controls been better and the scoring been more sensitive. Summay of Additional Analyses

In addition to the above analysis, several additional task organization and strategy questions were examined. Two of these are briefly outlined belor.

Eye movement data were used to incorporate into the model a prubabilistic finite state system which controlled scanning behavior. The model results showed little sensitivity to information gathering strategy during straight and level flight as long as velocity and altitude variables were regularly updated. For turning dive maneuvers, flight costrol required much more attention and $\mathrm{B}$-load, velocity and ver ical velocity were the key variables.

A second sampling strategy termed "probebllity out of limit-n was also examined. In this aase the variable with the highest pre ability of falling outside scme specifled window was sampled. Probability estimates were based on the mean and covariance produced by the Inear model. The sampling algorithm also required that every state variable be sampled periodically.

In straight and leve, altitude and velocity vere the two primary variables sampled- Vertical velocity and $\mathrm{B}$-load-were seldom sampled between the 10 second, "sample everything", intervals. The mean scores for all three cases fall approximately between the 3 and 4 second time intervals of the reduced error case results. 


\section{ORICinir: prag is \\ OF POOR QUALITY}

In the turning dive maneuver, vertical valocity, 6-loal, and velocity were all sampled, with vertical velosity being sampled most frequently. The other three state variables were sampled together every 5 seconds. In comparing these results to the reduced error, equal-interval sampling scores, it was found that these results fell just slightly above the 0.8 second interval scores. This suggests that similar scores can be obtained by sempling everything 0.8 seconds or by sapling one of three variables every 0.2 seconds.

Closer exanination of the individual runs produced additional insights. In the equal-interval sampling runs, the stnndard deviation of the score is approximately equal to the mean overall score. Thus there is a great deal of variability in flight control performance, as evidenced by the peaks immediately following the MFK task sequence. This is not true in the "probability out of limits" sampling case. There are no sharp peaks and the variances of the scores are much lover. These trends may be important in aralyzing worklosd issues. In peak workload or stress situations, it may be critical that the score (as an estinate of the level of flight control) not go above a certain level. at any given time, even though the average performance score is well within limits. If this type of behavior 1s required, one may opt for the "probability out of iimits" type samplins approach. This type of sampling also appears to be more represeitative of actual pilot flight performance in that the variable which deviates the most from the allowable range is the one attended to. Thus, in a sense, a bullt-in priority scheme is exercised.

\section{SUNYARY AND COLCLUSIOIS}

The feasibility of employing a combined modeling approach was demonstrated through successful application to the DaIs system. This modelling approach reduces the vaknesses of employing either network or continuous control techriques independently in modelling monitoring and supervisory control systems. The discrete task activities and decision-making processes of the humn operetor were explicitily represented alons with his continuous trickin behariors.

The approach's utility as an anclisis tool in the design of man1.2-the-loop experiments was demonstratec. It can be used to evaluate and establish operator procedures and the experimental protocol or scenario prior to actually running the experiment. For example, results of the DAIS analysis indicated that the aircraft required a relatively long sabilization perlod and, hence, provided direction for the afpropriate collection of data and the sequencias of maneuvers. This effort also demonstrated how the technique can be employed in determining optinal hardinare configurations and eccirecy requirements. The DAIS simularor stick and throttle devices vere known to have defects. The simulation outputs indicated the severity of these defects and could be used to assess accuracy requirements in order to ashleve predetermined levels of systen performance. 


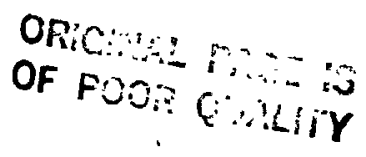

1. Brandt, W. E., Jr. and Wartluft, D. L., PI Jram Documentation for the DAIS Triple Task. Aerospace. ical Research La'soratory, AMRI-TR-75-24, Wright-Patterson AFB, Ohio, $197^{5}$.

2. Cravford, B. M., Pearsor, W. H. and Hof rman, M.S., Multipurpose Digital Sultching and Flight Control Workload. Aerospace Medical Research Laboratory, Wrignt-Fatterson AFB, Ohio, AMRL-TR-78-43, 1978.

3. Seifert, D. J., Combined Discrete Network -- Continuous Control Madeliling of Man-Machine Systems, Pid. D. Dissertation, The Ohio State University, Columbus, Ohio, 1979.

4. Baron, S. and Levison, W. H., A Display Evaluation Methodology with Application to Vertical Situation Displays for STOL Aircraft. Proceedings of Ninth Annual MASA-University Conference on Manual Control, M. I. T. , May 1973.

5. Duket, S. D., Wortman, D. B., Selfert, D. J., Hann, R. I., and Clubb, G. P. Documentation for the SAINT Sjmulation Progran. Aerospece Medical Research Labcratory, Wright-Patterson AFB, Ohio, AMRL-TR-77-63, July 1978 (a).

6. Spicurza, R. J., Pinkus, A. R., and $0^{+}$Donnell, R. D., Development of Periormance Assessient Wethodology for the Dfgitul Arionics Information System. Systems Research Laboratories, Inc., 1974 . 


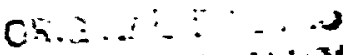

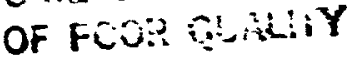

N82 34065

A mox of Bun Dactsion mitr

I mitre mocess minoning smitions(1)

Loel S. Greanstein

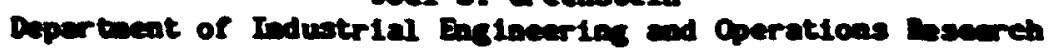

Aroinis Polftecbic Instibute ad state biveraty

Hectaburs. Viretinie 24061

ע111= B. Doure

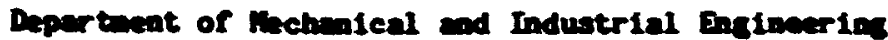

Coordlanted Seleace. Leboratory

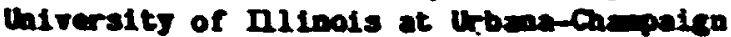

Irbane. Inlinols 61801

\title{
ABSICT
}

\begin{abstract}
Heen decision aldin in wutiple process ponitorin situntions is considered. It is proposed that turea decision aldos in enay altiple process enttorin siturtions ca be codeled in terns of the humen's detection of process related events and bis allocation of attention won processes once be reels events bove occurred. A nathoutical codel or husa erent detectioa and stention allocation perfornace in wultiple process condtoring situntions is dereloped. In assuption ade in developins the nodel is that. in atterptios to detect ereats, the buan senerates eatinates of the prosbilities that events iove occurred. In elenentary pattern recognition techaique. discrininat salysis, is used to eodel the hwan's generation of these probability estinates. The performance of the nodel is conpared to that of four subjects in a nultiple process conitorins situation requirins allocation of attention aon processes.
\end{abstract}

(1) Mhis research ws supported by the litional ceronautics and space Adanistration under mSA-lases Grant ISG-2119. 


\section{innopuctron}

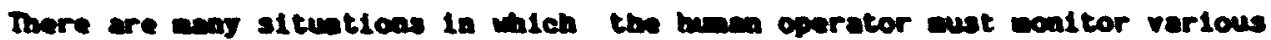

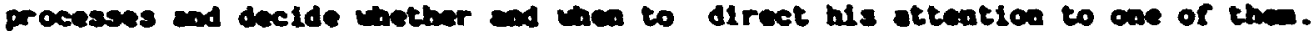
Ex mples of such multi-tost situtions include the wooltorin of industrial plents. pour systems. and alr trafrie. Product inspection and alrerart

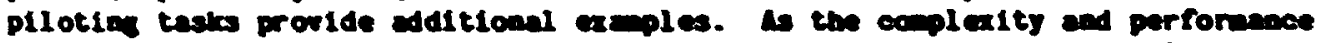
deands of wob altutions locrease, the pporator unt enpervise nore processes of erveter variety. Dere is ocasequnetly a inoreased probebllity

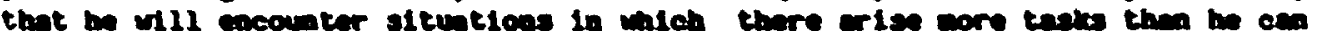
ceceptedily parform.

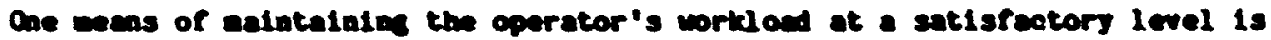

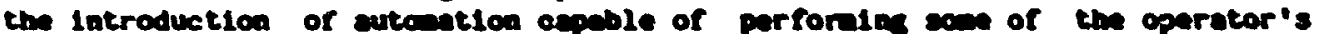
tesks. Models of the operator's talk parfornacen would be of use in

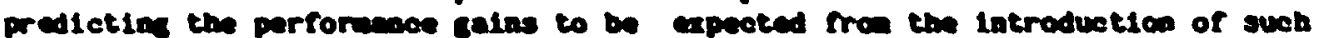
alds. Further, In systens in inloh the responslbilities for sone tasks are

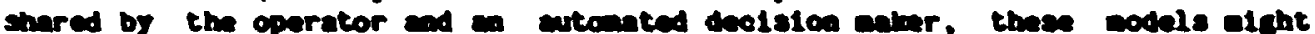
also be used within the systen to coordiate the cotions of the two decision elvers.

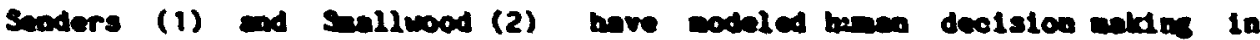
eultiple proses monttoring tasks. Senders eployed a informetica theory

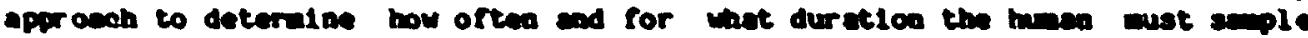
coch disply. Salluod proposed that the uneo operator forts en Internal

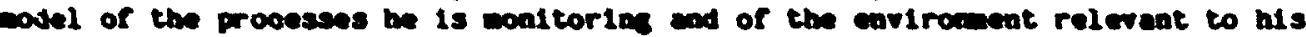
task as a result of his pat pareeptions of the . Carbonell (3.4) and Sanders ad Posaer (5) have proposed queveling theory approsebes to the codelling of

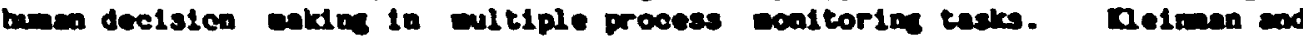
Curry (6) have applied control theoret1c techalques to develop nodels of huan performence in such tasks.

The nodels clted soove ephasi se the conitoring of displays. rather than the decisioas or cotions that result fro the huna operator's parception of the displ ayed values. The operator's notivation for monitoring the displays is the possbility that en went mich requires his ection wil oocur. The wult1-task dectsion eakd on proble codresed in this paper concerns the went detection an sotion selection decistons the oparator ankes on the basis of the Inforetion be ceins through nonttoring.

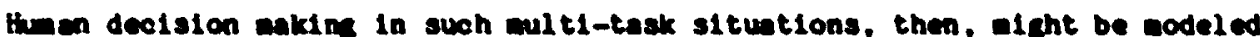
in torns of the eanner in mich the nuea detects events releted to the processes and the manner in inich he allocates his attention wor the processas once he feels erents heve cocurred. Gal and Curry (7) have developed a aodel of the hunan nonitor in a failure detection task. The nodel has two steses, the rirst a Kalman filter wich estinates the states and observations of the monitored process. and the second a deolsion eochanisu which operates on the kalmen filter residuals using sequential anelysis concepts. Sheridan and Tulge (8) have sodeled the aanner In mich the human operator alloontes his attention aon varlous tasks. They address a 


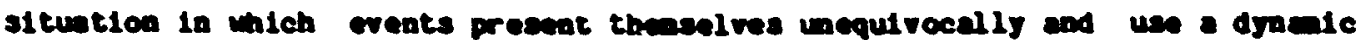

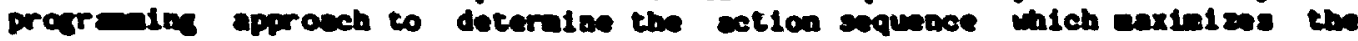
coprator's earaings.

bouse (9) he lavestigatnd the lsave of allocation of decision anding responsibility between a husan operator end en eutcasted deciston eamer. He presents a eathenetical fornulation of culti-task decision eakdos situntions appropriate to codelibe - her deciston anker. Ensed on displayed

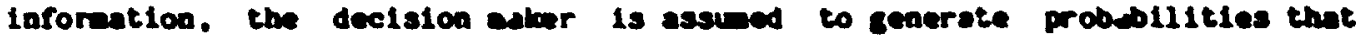
wents heve occurred in his tasks. In also generates denalty fuotions inich charecterize his perceptions of wat alght oceur in his task wile his attention 13 diverted to a particul or talk and how 100 his attection will be divertad should he decide to take a given setion. Given the estinates of event pceurrence probubilities and the perceptions of density ructions of interarrival end ectiun tines. the decision anker is assuned to choose ections so as to ainini as an appropriate cost criterion.

mis fornulation has bees applied to the destign of a conputer alded decision whins ajster wishin a pueving theory fremonork $(10,11)$. Two experineats wthin a night anegent context wre used to 1llustrate the value of this mult1-task formul ation. It wa found that the queveins theory codel provided a quite reasonsble description of eulti-task decision andes in terns of task witing tines and utllization (1.e.. fraction of tine busy) of decision alkers. The nature of the night anangent task eaplc. ed In thls research, howerer. allowed eroldance of the lasue of hou the human deciston enter detects events.

\author{
$\triangle$ moocl of human decision marimg
}

In this section we propose a nodel of huas decision making in a nultiple process conitorine situation. The nodel assues that the hum uses a wighted linear conbination of various featur -s to generate estinates of che probeb1lities of event ocourrences. A discrininant anelysis approach $(12,13)$ is eaployed to sodel the human's ceneration of these probablifty estinates. mis pattern recognition technique is anensle to real-tine, adaptive inplenentetion. A comuter aldin schene based on such a adel would have the capobility of learning to senerate appropriate event occurrence probablilty estinates through observaticn of the huan operator's task perfornance. The nodel elght then assune decision aaking responsibilities when the huan beccoses overloeded.

For each process, It is assuned that the huan extracts varlous features $x_{1}$. $j=1,2 \ldots . . p$. from his observations. These features are properties of the observations that charecter1ze (or are belleved to characterize) the presence or absence of events related to the process. Following the extraction of a sat of feotures, the value of a linear discrininant function

$$
Y=v_{1} x_{1}+\cdots+v_{p} x_{p}
$$




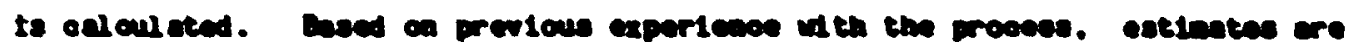

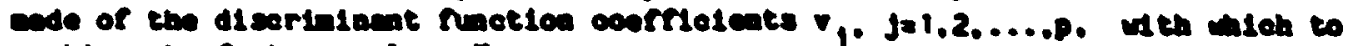

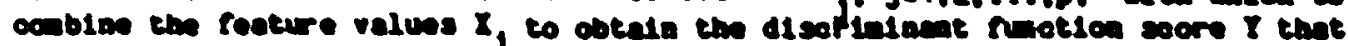

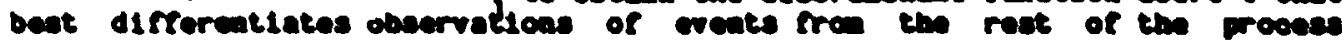

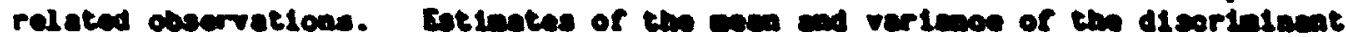

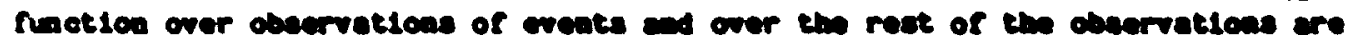

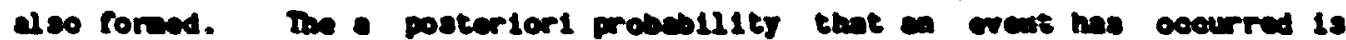

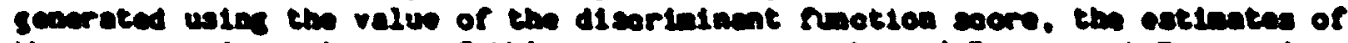

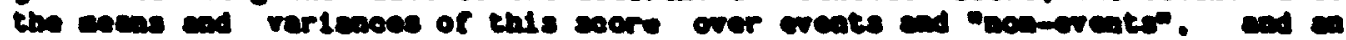

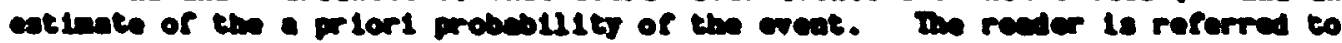

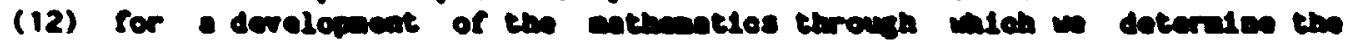

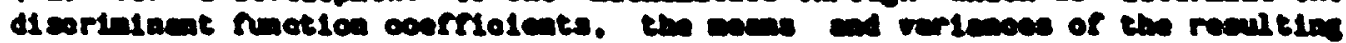

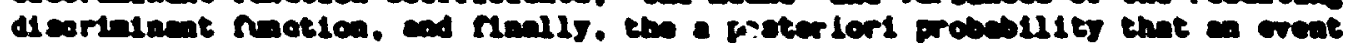

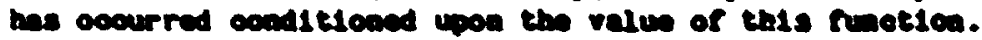

If a prosess of vibona state (event present or wot preasat) is observed.

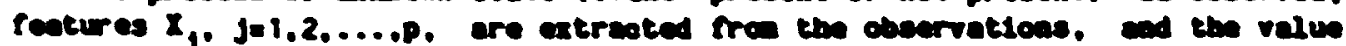

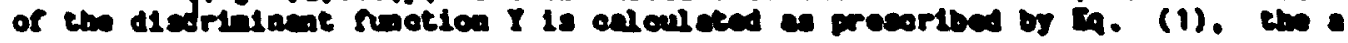

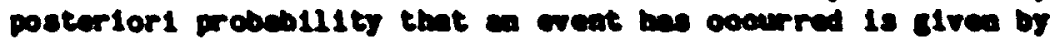

$$
P(a / x) \cdot \operatorname{ax}\left(-x_{2}^{2} / 2\right) / \sum_{k-1}^{2} \operatorname{cop}\left(-x_{2}^{2} / 2\right)
$$

nere

$$
\left.x_{k}^{2}-:-z^{(k)}\right]^{2} R_{k}(y)+\log q_{k}(y)-2 \ln R_{k}+-1,2
$$

$F(x)$ and $D_{1}(y)$ ere the group nowas and varlanses, respotively, of the

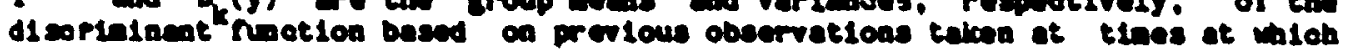
wo wedt related to the procese we prescat (k-1) ad at times at wich a

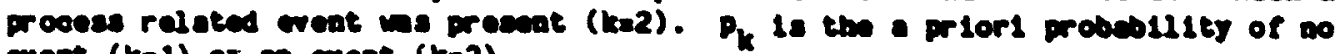
went $(k=1)$ or en ereat $(k=2)$.

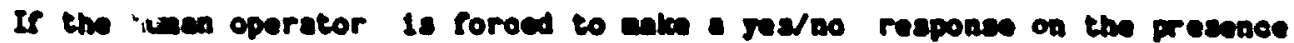

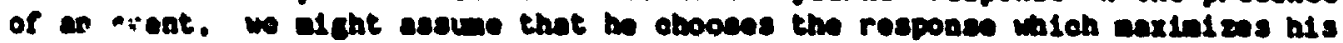

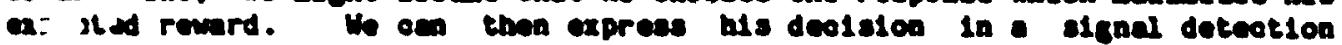
aninder and state that be ahould respond "yes. on event related to proceses 1 als occurred" if the followl of inequelity bolds:

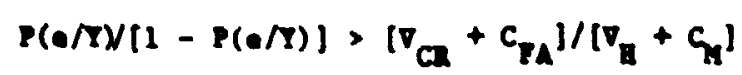


$P(a / Y)$ is the a posterlorl probbllity thot a process related event bes cocurred and is cenorated as described bove. V $V_{C F}$ is the valus of correctly respondios "no went" is correct rejection). C. "Is the cost of incorrecty

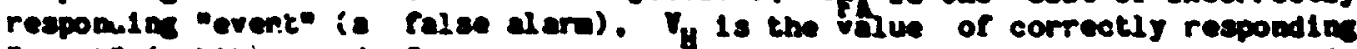
"event" (a $h(t)$ ). and $G_{n}$ is the cost of incorrectly reapondins "no event" (a aiss).

It is predicted. then, that if the operator is forced to nalue res/mo decision on the presence of a process related ereat. he cal culates the Ilkelibood ratio of the ereat (the left had alde of Eq. (4)). He compares

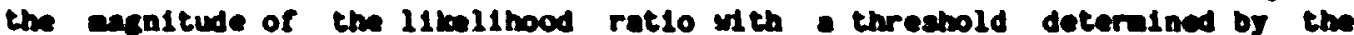
values of correct reaponses and the costs of incorrect reeponses (the rlebt hand side of Eq. (A)). He responds Eevent" if the likellhood rat10 exceeds the threshold.

In many situstions, however, the decision eaber is not forced to alke res/no decisions with respect to exch of the processes. He 13 lastead froed with a siturtion in wich the decision to take ection with respect to a process inplies the allocation of attention to that process for some nount of tine and the diversion of attention fro other processes during that tine. If w consider this decision anking proble in the context of the mothenation forvulation presented in Bouse (9) ad Douse and Greenatein (14). anocher nodeling approech suesests 1tself. It ws assuned in that formulation that the huen operator has perceptions of the probebilities that events have occurred in the processes. $p(. / 2)$. the joint probebll1ty density function of the tine betwen erents in the processes. $f(.1 z)$, and the joint probsbility density function of the ection tines for the processes. $(. / 2)$. Ine operator 1s to decide wich ections of the set $a_{0.1}, \ldots . . e_{y}$ should be perforned. ite aight choose ap (the decision to continu conitorins) in order to obtain aev information with wich he ean update $p(. /$ ). If he chooses a . 1/0. he services process 1 for some mount of tive and is unable to monilor or attend to the other $\|-1$ processes untl servicing of process 1 is coppleted.

The operator aight be nodeled as deciding whether to continue eonitoring all processes or to divert his attention to scee of the processes by utilizing his perceptions of $p(. / 2)$, $f(. / 2)$, and $e(. / 2)$ to deternint a sequence of setions wich wininite an appropriate cost criterion. If w wat to f salize

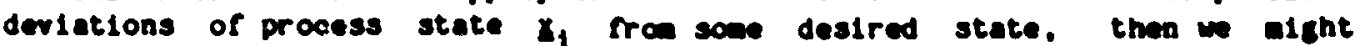
fornulate the oriterion so as to allow use of control theoretic techniques. on the other hand, If we are interested in alninizing the overeze tine rrom cecurrence of a process fallure to coppletion of sarvice to that process, yuevelns theory provides an appropriate nethodology. Because the seneral aultiple process wonitoring situntion does not inherently involve processes whose states cen be desoribed by 11 near dynale systens, we will consider a criterion involving aininization of the costs of delays in service to failed processes. In particular, let us consider the following cost criterion as one wich the operator alght seek to miniflize:

$$
E[C / T]-(1 / T) E\left[c_{1} w_{1}+c_{2} w_{2}+\ldots+c_{n} w^{*}\right]
$$




\section{ORIGINAL PAGE IS \\ OF POOR QUALTY}

where $y$ is the delay experienoed by prooece 1 and inolutee the miter the until Ifitiation of sorvice and the servieley tine. of is the cost per unit tine of delay in servioe to process 1 , and $I$ is the fount of tine for wheh the operator's atcention is diverted fro bis disaleys as a resilt of his ection sequance.

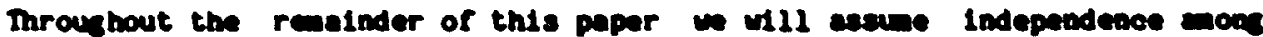
processes. Int 1s, It ull be aseved that the probsbillties of ereats having cocurred in the procesens are independent now prosesess. Thus

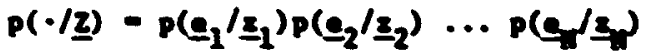

Sinilerly. the tipe betimen evento and the tine required to attend to a process are independent aos prooseses. Thus

$$
f(\cdot / \underline{z})-f_{1}\left(\underline{t}_{1} / \underline{z}_{1}\right) f_{2}\left(\underline{t}_{2} / \underline{z}_{2}\right) \ldots f_{n}\left(\underline{t}_{1} / \underline{z}_{1}\right)
$$

$\operatorname{mos}$

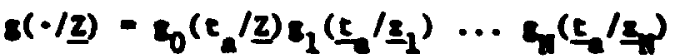

Consideration of Interdependenoles non processes wold conpl fente the calysis substantially. It should be noted bower. that the essunption of independence mon processes is. In many realistio situntions. diffioult to justify.

Let us approsch the problen by evaluatins ecoh o, for a candidate sction saquewe. Procesding fron Eql. 1 (6). (7), and (8), let us now, for the sake of slapliolty. aseune that oaly oas type of event in esoh process is of interest. Let us also asave that the tine betwen events in a process and the tine required to attend to a prooses is Independeat of the observations. $\mathbf{z}$. Then

$$
f(\cdot / \underline{z})-f_{1}\left(t_{2}\right) f_{2}\left(t_{2}\right) \cdots f_{n}\left(t_{Q}\right)
$$

and

$$
s(\cdot / \underline{z})=c_{0}\left(t_{a}\right) s_{1}\left(t_{a}\right) \cdots E_{n}\left(t_{a}\right)
$$


If the huan chooses to parfore action o, (1fJ), then the oost due to ignoring process 1 for tiee $t_{a}$. given that an drent $e_{1}$ has ocourred is

$$
c_{1}{ }^{t}
$$

and the cost due to Lenoring process 1 if an went 1 occurs efter initiation or action $;$ is

$$
\begin{array}{cl}
c_{i}\left(t_{a}-t_{e}\right) & t_{a}>t_{e} \\
0 & t_{a} \leq t_{e}
\end{array}
$$

Merefore. If the muan chooses to perform process $a_{j}(1 \neq j)$, then

$$
\begin{aligned}
& E\left[c_{1} w_{1} / a_{j}\right]-p\left(e_{1} / \varepsilon_{1}\right) c_{1} \int_{0} c_{a j} s_{j}\left(t_{a}\right) d t \\
& +\left[1-p\left(t_{1} / z_{1}\right)\right] c_{1} \quad \int_{0}^{\infty} \int_{0}^{t}\left(t_{e}-t_{e}\right) f\left(t_{e}\right) g\left(t_{2}\right) d t_{e} d t_{a}
\end{aligned}
$$
were the first, tere is the expected cost of lgnoring process i for tine $t$,
due to in event e, that has occurred, inlle the second term is the expected cost due to on evelit $t_{1}$ occurring during $t_{a}$.

If event interarrival tines in process 1 are exponentially distributed with mean $i \lambda_{1}$ and action tines are constants $t_{j}, j=0,1, \ldots, N$, then

$E\left(c_{1} w_{1} / u_{j}\right]-p\left(e_{1} / \underline{z}_{1}\right) c_{1} \tau_{j}$

$$
+\left[1-p\left(\bullet_{1} / z_{1}\right)\right] c_{1} \int_{0}^{t_{1}}\left(t_{1}-t_{1}\right) \lambda_{1} \exp \left(-\lambda_{1} t_{2}\right) d t_{0}
$$


Ind, upon carryins out the indleated integration.

$$
\begin{aligned}
& E\left[c_{1} w_{1} / a_{j}\right]=p\left(e_{1} / z_{1}\right) c_{1} t_{j} \\
& +\left[1-p\left(e_{1} / z_{1}\right)\right] c_{1}\left[c_{j}-\left(1 / \lambda_{1}\right) i 1-\exp \left(-\lambda_{1} t_{j}\right)\right]
\end{aligned}
$$

Aasue that the huan plans ahead two scticns, $a_{j}$ and $q_{k},(1 \neq j, k)$. Then $z\left[c_{1} w_{1} / a_{j}, z_{k}\right]=p\left(e_{1} / z_{1}\right) c_{1}\left(t_{j}+t_{k}\right)$

$+\left[1-p\left(e_{1} / \underline{\varepsilon}_{1}\right)\right] c_{1} \int_{0}^{t_{f}+t_{k}}\left(t_{f}+t_{k}-t_{1}\right) \lambda_{1} \exp \left(-\lambda_{1} t_{e}\right) d t_{t}$

$$
-p\left(e_{1} / z_{1}\right) c_{1}\left(t_{j}+t_{k}\right)
$$

$+\left[1-p\left(\varepsilon_{1} / z_{1}\right)\right] c_{1}\left[t_{j}+t_{k}-\left(1 / \lambda_{1}\right)\left(1-\exp \left(-\lambda_{1}\left(t_{j}+t_{k}\right)\right)\right)\right]$

Generalizin to sction sequnees of length $\|$, wh hare

$$
\begin{aligned}
& \mathrm{z}\left[c_{1} w_{1} / a_{j}, \ldots, a_{1}\right]-p\left(e_{1} / z_{1}\right) c_{1}\left(t_{1}+\ldots+t_{1}\right) \\
& +\left[1-p\left(e_{1} / z_{1}\right)\right] c_{1} \\
& \cdot\left[t_{1}+\ldots+t_{1}-\left(1 / \lambda_{1}\right)\left(1-\exp \left(-\lambda_{1}\left(t_{j}+\ldots+t_{1}\right)\right)\right]\right. \\
& 1+j, \ldots, 1
\end{aligned}
$$

Suppose action $a_{1}$ is performed. If the welting tine $w_{1}$ is aeasured from the time of fallure to the tie of service completion and 1 it is assued that servicing of process 1 precludes the possibility of fallures during servicing. then

$$
E\left[c_{1} w_{1} / a_{1}\right]-p\left(e_{1} / z_{1}\right) c_{1} t_{1}
$$


Suppose after action a other cotions a...... a are parfored. The cost to process 1 incurred by these ections is due only to the cost of ignoring process 1 if an erent o occurs after conpletion of service to process 1 isince process $i$ is in the normal state upon completion of service to $1 t$ ). Therefore

$$
\begin{aligned}
& E\left[c_{1} w_{1} / a, \ldots, a_{n}\right]= \\
& c_{1}\left[\left(t_{n}+\ldots+t_{n}\right)-\left(1 / \lambda_{1}\right)\left(1-\exp \left(-\lambda_{1}\left(t_{n}+\ldots+t_{n}\right)\right)\right)\right]
\end{aligned}
$$

So, the expected cost in process 1 incurred by an sction sequence $a_{j} \ldots, a_{1}, a_{i}, a_{n}, \ldots, a_{n}$ can be expreased as

$$
\begin{aligned}
& E\left[c_{1} w_{1} / a_{1}, \ldots, a_{1}, a_{1}, a_{1}, \ldots, a_{n}\right] \\
& p\left(z_{i} / z_{1}\right) c_{1}\left(t_{j}+\ldots+t_{1}\right) \\
& +\left[1-p\left(e_{1} / z_{1}\right)\right] c_{1} \\
& \quad \cdot\left[t_{f}+\ldots+t_{1}-\left(1 / \lambda_{1}\right)\left(1-\exp \left(-\lambda_{1}\left(t_{j}+\ldots+t_{1}\right)\right)\right)\right] \\
& +p\left(e_{1} / z_{1}\right) c_{1} t_{1} \\
& +c_{1}\left[\left(t_{1}+\ldots+t_{n}\right)\right. \\
& \left.\quad-\left(1 / \lambda_{1}\right)\left(1-\exp \left(-\lambda_{1}\left(t_{1}+\ldots+t_{n}\right)\right)\right)\right]
\end{aligned}
$$

The total cost incurred by an action sequence $, \ldots, \ldots, a_{1}, a_{1}, a_{,}, \ldots, a_{\text {p }}$ over the tine duration of the action sequence is then diven by the sumation of costs over the total number of tasks, $N$. Thus,

$$
E[c]=\sum_{1=1}^{n} \varepsilon\left[c_{1} w_{1} / a_{1}, \ldots, a_{1}, a_{1}, a_{a}, \ldots a_{n}\right]
$$


and the expected cost per unit tine inourred by the setion sequence (which is the cost criterion. Bq. (5), under conaideration) is cherefore

$E[C / T]=$

$$
\left.\sum_{1=1}^{N} E\left[c_{1} w_{1} / a_{j}, \ldots, a_{1}, a_{1}, \ldots, \ldots a_{n}\right]\right) /\left(t_{j}+\ldots+t_{n}\right)
$$

We have thus far expressed the expected cost per unit tine for an sotion sequence in terns of $p(. / z), P(. / Z)$, and $g i . / z)$, and carried through the developent of this expression for the case of expopentially distributed event interarrivel tines and constant service times. Let us now suseest a specific oodel of huean decision naking inlch considers the expected cost per unit tine of certain ation sequences and seleots tra won these oandidate sequences the sction sequence which alninizes this cost oriterion.

We sucgest that the operator aight be aodeled as initially estinating the expected cost par. unit tine incurred by the decision to continue monitorine for a period of tine. If seting with respect to any one process before nonitoring wuld not result in lower expected cost per unit tine (over the tiae interval required to sot on the proess and then monitor), the operator sioply elects to continue conitoring.

If acting with respect to a process before monitoring results in a lower expected cost per unit tine than eonitoring alone, the operator determines the ection which results in the eininu expected cost per unit tine and assigns to it the first position in his action sequence. He then deternines wether seting with respect to any of the rewaining processes before gonitoring would lower the expected cost per unit tine of his sotion sequence rurther. If it wll not, he responds to the one process he has placed in his action sequence and then continues monitoring.

If ecting with respect to one of the realning processes befcre nonitoring does lower the expected cost per unit time of his action sequence, the operator deternines the action wich results in the aininu expected cost per unit tiee and assigns to it the second position in his action sequence. The procedure continues until the addition to the sequence of an sction with respect to eny of the remaining processes does not lower the expected cost per unit time of the sequence or until setions with respect to all the processes have been included in the sequence. 


\section{EXPERIMEITAL SITUTION}

An experimental siturtion was devsioped to facilitate the study of human decision making in a jeeific aultiple jrocess monitoring task. The task involves the siaultaneous monitoring of nine dynelc processes for the occurrence of abnorual events, a sitistion representative, for sxemple, of monitoring tasks in complex industriai plants.

Figure 1 illustrates the display observed by subjects within the experinental situntion. The display is static and $1 \mathrm{~s}$ generated on a Tektronix 4010 storage tube display by a tine-shared DEC-Syste 10 digital conputar. The diaplay depicts the neasired values of the outputs of nine processes over 100 sampling intervals ( $1 . e ., 101$ measurents are depieted on the display for each process). A tine unit on the displa corresponds to the interval between successive samples of the process outputs.

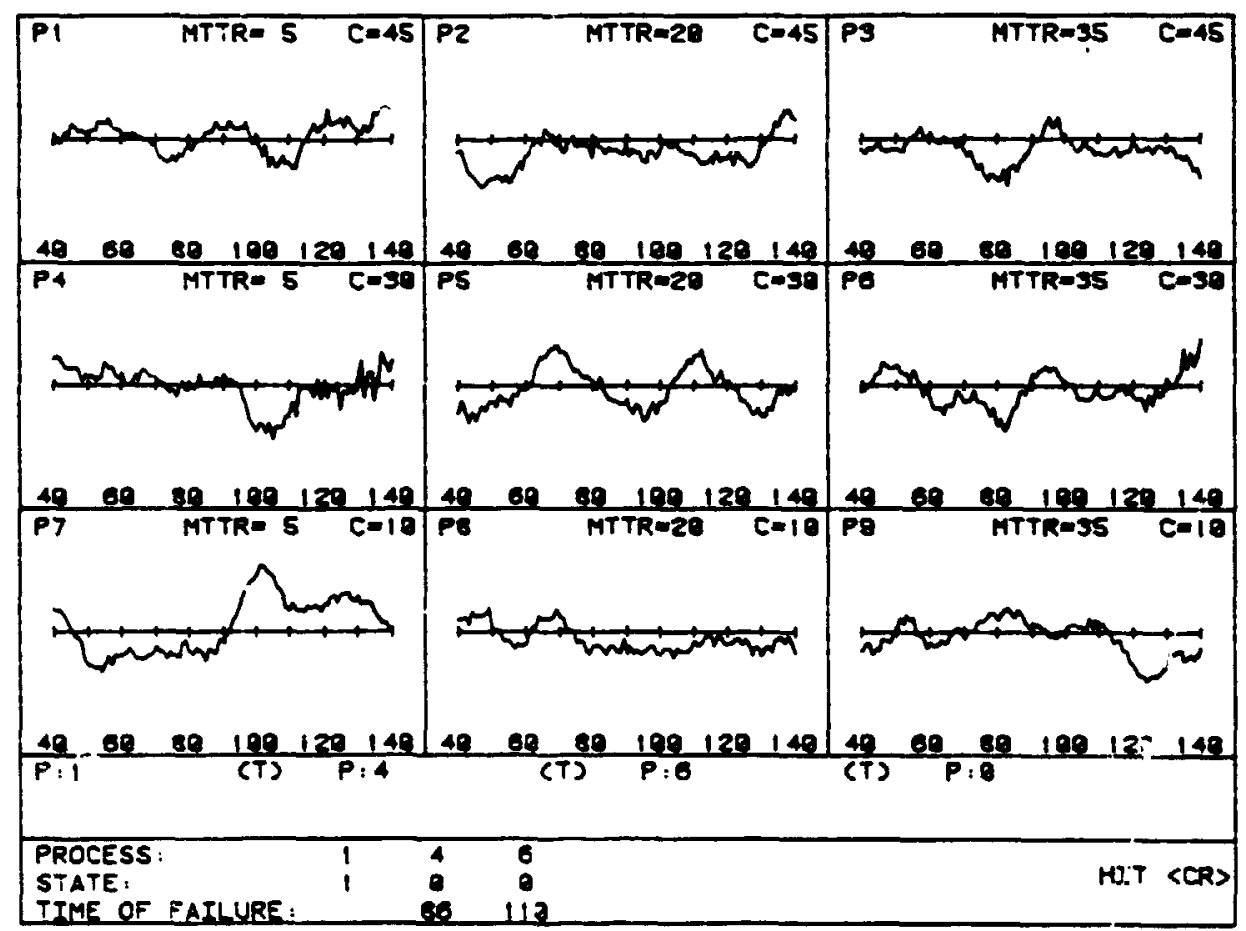

Figure 1: The multiple process monitoring situation

(Processes 4 and 6 have fall ed at times $80^{\circ}$ and 110 , respective).y. Processes 1.4, and 6 have been selected for service.) 
The processes have identioal second order system dynalcs wth a natural frequ icy of $0.15 \mathrm{rad} / \mathrm{time}$ unit and a deaping ratio of 0.5 . The inputs to the procse ies are zero-mean Gaussian white nolse sequences of identical variance. The aisplayed measurements are obtained by corrupting the process outputs with additive zero-mean Gaussian white noise sequences which normally have identical variance. The measureaent nolse variance is normally selected to vield masurements with signal-to-noise ratios of 25.0 .

An abnormal event or process fallure is defined by a gradual increase in the messurement nolse variance following process fallure such that the signal-to-nolse ratio of each messurement is jesreased to $95 \%$ of the signal-to-noise ratio of the lmediately preceding measurement. Process failure manifests itself, then, by an exponential decay of the sigrial-to-r.ulse ratio for measur ments following the tine of fallure. Thus, fall' become more pronounced with each measurement following their occurrence. is is 11lustrated in Figure 2: all nine processes have failed ot var "uints Whin the time range depicted on the display. The points at $w$ hest failures occurred have been denoted in the figure by solld verti _. - nes. These lines did not appear on the display during the experiment.

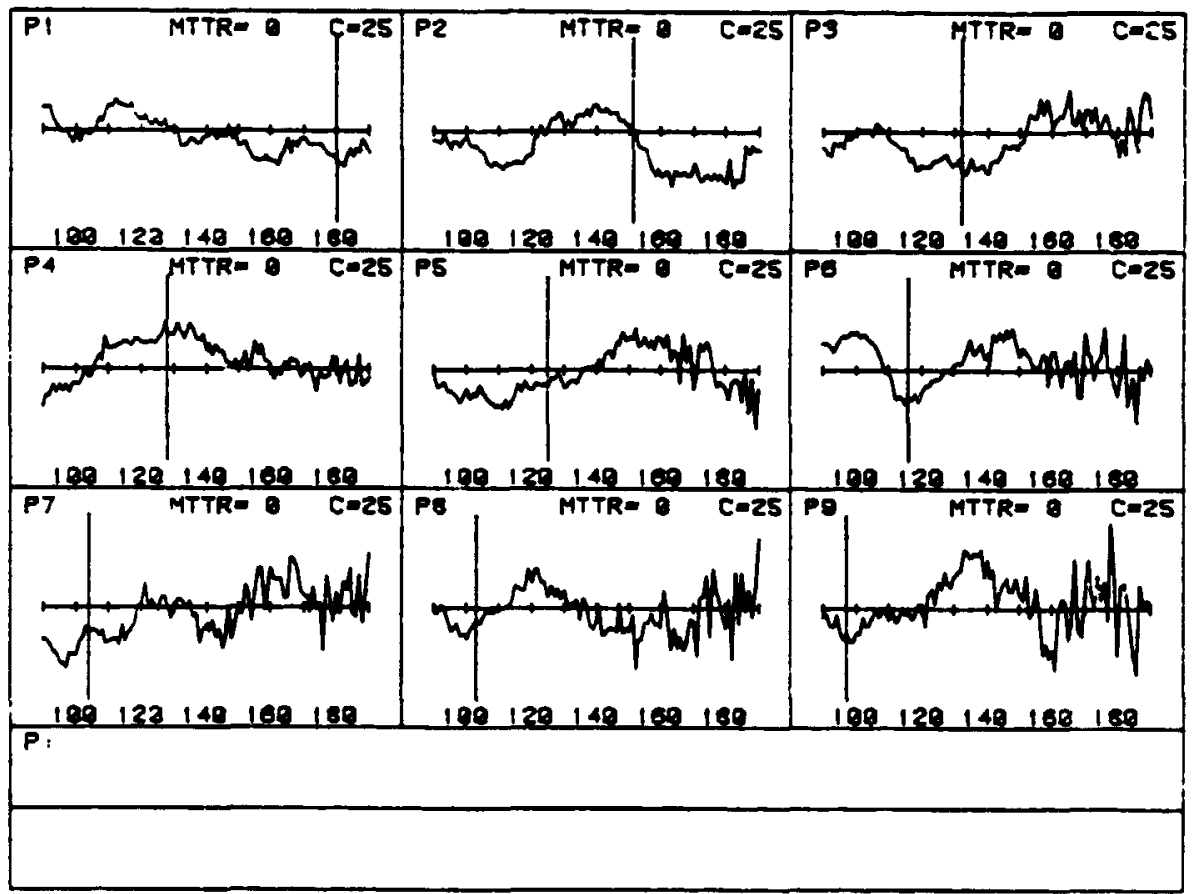

F1gure 2: A display in which all processes have failed 
While the exact nature of the subject's task in this experimental situation differs with the n-ture of the decision aaking being investigated - siaple event detection or action seiection involving allor ation of attention mons the processes -. In all cuses the subject seeks to detect events in processes and service these processes so that they are returned to the normal state. The amount of time required to service a process can be verind across the processes. If the amount of time required to servict a procts is nonzern, servicing of the process implies a diversion of attention from the other processes for this time. The cost of delaying service to a process can also be varied from process to process.

The above aspects of the situation are quantified by assoolating a set of two paremeters with each of the nine processes -- the mean time to repalr the process (MTTR), and the cost per unit time of delay of service to a falled process (C). If the times required to repalr a rrocess are assuned constant or exponentiali, distributed, then MTTR completely specifies the distribution of servine times for that process.

After scanning the nine process hilstorles depleted on the display, the subject is given an opportimity to key in the numbers of processes unich he has decided co service. He also uses a graphic cursor to enter estinates of times at which he believes fallures have occurred. Upon coapletion of his entries, the processes he has entered are serviced in the order in wich he entered them. The first process entered by the subject is serviced over on Interval which begins with the last time point displayed on the screen and extends forward the number of time units equal to the MTIR associated with the process. At the completion of this service the process is reset to normal if it has failed before. this point and service is begun on the next process entered by the subject. Whan all processes entered have been serviced, the subject is given feedback regarding the ttate of each serviced process at the instant before servicing of that process was coupleted ("1" indicating the norwal state, "O" indicating the falled state). An 1teration in an experimental trial ends with erasure of the display and the scoring of the subject's performance on the 1teration.

Another iteration is then begun by generating a new display depicting the process histories advanced in tine by on mount equal to the sum of the service times (MTTRs) 0 : the processes entered on the preceding iteration plus en additional constant inorewent. The additional increaent is included to represent the interval of time required to monitor the processes each tiae they are di 3played (this increment. will be raferred to as the mean tine to monitor the processes. MTMM). The display which would follow that shown in Figure 1 is illustrated by Figure 3. The MTTRs associeted with the processes are depicted in the figure. The MTM eaployed in the situation 11lustrated is 10 time units. It should be noted that Fies. 1 and 3 presented here as illustratiors of the experiental situation represent iterations c. displays wich would fall somewhere in the middle of a subject's experimental trial. The first iteration or display viewed by the subject in an experimental lrial would deplet. the measured values of the nine processes' outputs over a time span beginning at tiue t=0 (as labeled on the horizont.l axes) and anding at 


\section{Ofiviritil PAGE IS \\ OF POOR QUALTY}

tien ta10c.

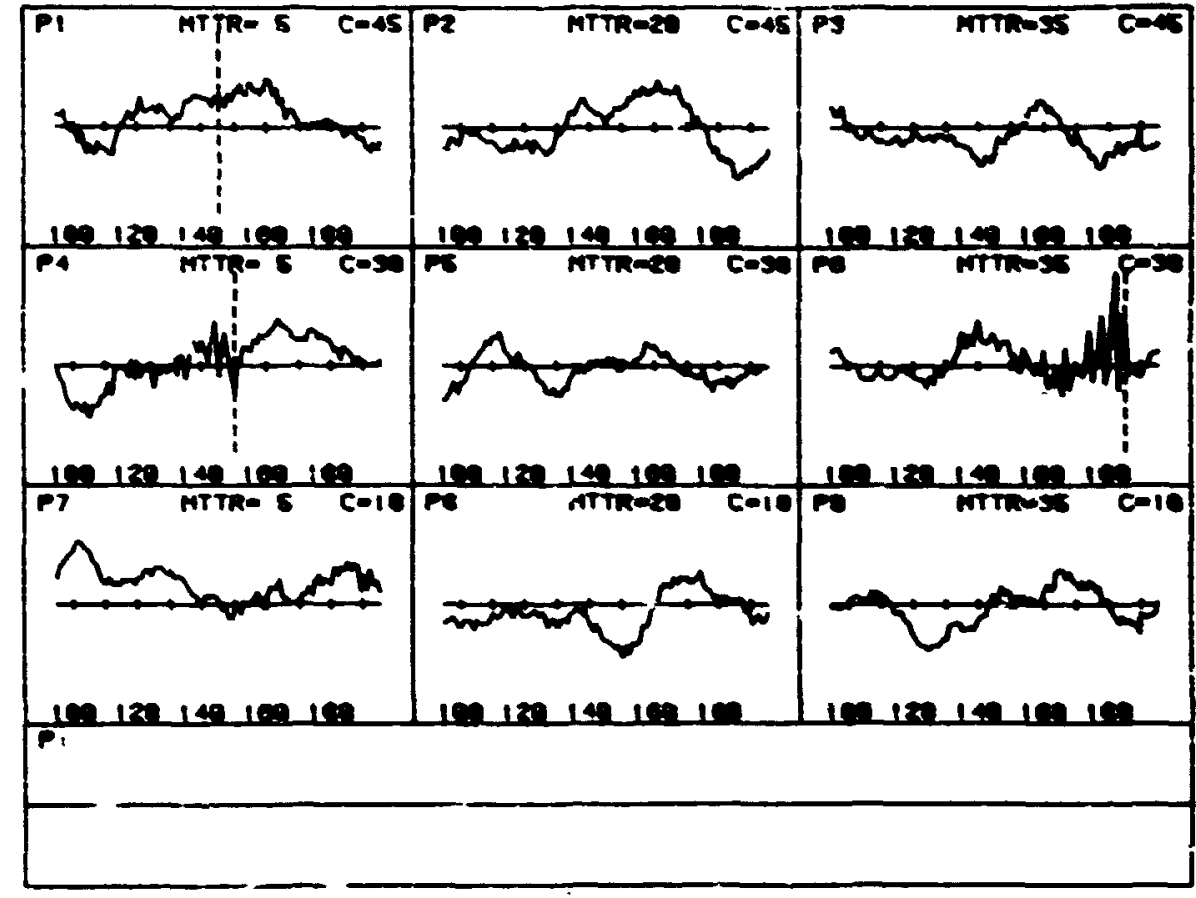

Figure 3: The displas midoh follow that show is Fig. I

(The dashed vertical limes ladicate to the subject the polnt at wioh earvice of esch process we last ocopleted.)

\section{Exrmingrt}

An experinent wa conducted aploying the nultiple proeses nonitorins situation described in the preoedin seotion. The task of the aubject in this experimental situntion was to service, or alloaste attention to, processes in - mesner mich ainialaed the total oost inourred du to delays in the sorvioling of falled proceseses.

Four aubjeots wre given six trials with the experinentel stuation over pericd of four to six days. Ench trial consisted of 25 iterations (en initial 
displey followed by 24 updatad displays) and wa of approxiantely 45 atuutes

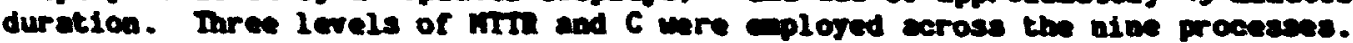
The values of $\mathrm{fIT}$ and $\mathrm{C}$ assoclated with exch of the prosesses wre as depieted in Figs. 1 and 3 . The value of $\mathrm{mIM}$ eployed in the experinent uns

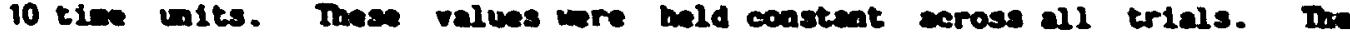
Iaterarrival tines of the fallures scheduled to occur in each process wre exposentizl Iy distributed with a eeen tine between fallures (MTrF) of 175 tibe units in all processes. Wot all scheduled fallures ectually occurred. If a fallure ws sebeduled to occur in a process in wich a previous fallure had not beea attended to, the sebaduled fallure ws deleted fron the trial. The interarrival tines used to sebodule fallures on the sucessive trials givea a subject differed fro trial to trial.

Prior to begining the six trials wth the experinental situation described sbove. the subjects mere given four trials id mich the $\mathrm{MTM}$ were set to vero and the Co to one for all processes. With zero MIT and equal C for all processes. the decision to allocate atteation to one process involved wo diversion of attention tron the other processes and a delay in servicing oas process wa no wore costly than a delay in servicins ang other process. Arter semalin the process histories depleted on the display. the sobject sibply entered the nubers of processes in which be bad decided fallures had oceurred. These trials provided the subjests at th exparience in the detection of process fallures without the adfitional task of decidins how to allocate attention mons processes with different attentional requirenents and costs. Subjects were also given several iterations of training before these trials and the later six trials. During these tralnin iterations, solld vertical lines were included on the process histories to eark ween ad where eveats had occurred (see Fit. 2). Subjects were not given say information resarding the dyanics of the processes. but vere told that they could expect the processes to exhibit sinilar characteristics hen operating nornally. They wre also not told what pormeter changes defined events, but were told that all events woul senerally exhibit sinfler charecteristics and all would beces nore pronounced as tine passed.

\section{APPLICATION OF THE MODEL TO THE EXPERIMETHAL SITUTION}

The decision aking codel sugrests t.at the huan operator in the experineatal situation just descibed extracts various featuras from his observations of the process reasurenents. He atteapts to select features inich characterlze the presence or obsence of task reloted events. Inrough his experience with the processes. the operator has forned estimates of the discrininant function coefficients with wich to conbine the features to obtain discriniaant function score. He has also forned estieates of the eeans and variances of this score over observations of events and over the rest of his observations. The operator generaies the a posteriori probsbllity that an event has occurred based on the value of the discrialnant function score. his estinates of the means and variances of the score, and his estieate of the a priori probsblity of an event occurrence. 


\section{ORIGINAL FAUE IS \\ OF POOR QUALITY}

Four features of the process ecasureents wre selected for use with the event detection nodel. Selection of these festures ws guided by the connents of experibental subjects in a sindlar situstion regarding the charecteristics of the process measurements they found useful in event detection. The first feature involves the aegnituda changes betwen successive messureants in a sequnce of the most recent measureants. The second feature involves the presence of reversals in direction in this sequance (changes from positive slope to negative. or vice versa, of the line segments conneotine the weasureents of the sequence). The third feature tests for the sinultaneous occurrence of large agnitude chonges and reversals. The fourth feature, like the first. 1s a eensure of axenitude changes, but it is auch more local in that it involves only the four nost recent measurements of the process output.

Given that events becone wore pronounced with tine following their accurrence, It seens reasonable that the nost recent process messur ments would be of srenter use in event detection than older neasurenents. Therefore. In extracting features from the process neasurenests, the values of the features over recent measureaents are wighted more heavily than the values over earlier eesureents. The wight decreases exponentially with the ce of the neasureent and the rate of this decrease is a free pareneter. Te value of the first feeture. for exmple. a measure of the angitude changes betwen successive enesurements in a sequence of the $n$ nost recent neasuremenis of a process's output. is given by

$$
\begin{aligned}
& \text { n-1 } \\
& x_{1}=\{\{\mid z(k+1)-z(k) ! \cdot \operatorname{axp}[-\beta(n-1-k)\}\} \\
& k=1 \\
& \sum_{k=1}^{n-1} \exp [-6(n-1-k)]
\end{aligned}
$$

where $z(k)$ is the $k$ th aeasureant in the sequence, $z(n)$ is the most recent measureent, and $B$ is the ree pareeter governing the relative mighting of the feature's value over recent and earller measureaents in the sequence.

The estialion of discrininant function coefficients requires a representation of normal and abnormal process measureaents. This representation was formed using the process historles diaplayed to the sub ject on his last event detection trial (1.4.. the fourth of the four trials given in which the MTTRs wre 11 zero and the $C_{s}$ all one). The process historles are separated into two groups of sequences -- noraal and abnoral. Sequences of aeasureants beginning at the polrt at mioh a process ws returned to the normal state and endins at the print at which an event occurred (or. elternatively. the polnt at unich the subjeot estinated an event occurred) ore 
defined to be normal. Sequences of neasurements beginning at the point at which an event occurred (or the point at which the subject estinated an event occurrad) and ending at the point at which the process was returned to the noral state are defined to be abnoraal. In obtaining the result: to be presented here. the points at wich the subject estiasted events occurred. rather than the actual points of occurrence, were used to define the final points of normal sequences and initial points of abnormal sequences. This was done to test the ability of the model to perform adequateiy in situations in which true event times are unknown and a human operator's identification of events and estimates of occurrence tiaes represent the only event time data available. This decision is consistent with our lcng teri goal of developing a computer aided process monitoring system.

The representation of noral and abnormal process measurements formed using the process histories of the subject's last event detection trial are used to determine discriminant function coefficients and the aeans and variances of the resulting discriminant function scores. If the model is then to be used to generate the a posteriori probability of an event in a process at a given iteration of an experimental trial, the number of process neasureaents over which the features are to be calcul ated aust be defined. It is reasonable to assume that the measurement sequence ends with the last measurcient displ ayed for the process on that iteration. However, the cutoff length which indicates when the measurewent sequence begins is a free parmeter. Values of the features over process measurements taken earlier than the cutoff are not calculated (or. effectively, are assigned zero weight).

Generation of the a posteriori probability of events in the tasks using the discriminant analysis approach requires estimates of the a priori probabllities of event occurrences in the tasks. He can approximate the tine between consecutive event arrivals to a process as an exponential distribution with parameter 1/MTBF. (This is an approximation because not all scheduled events occurred. Thus, the true mean tine between failures is somewhat larger than the nowinal value used to schedule the arrivals.)

If we let $U(t)$ be the number of fallures in a process by time $t(t>0)$, where time 0 designates the instant at which the count begins, then

$$
p(U(t)-n)=\left[(t / M T B F)^{n} \exp (-t / M T B F)\right] / n ! \quad n=0,1, \ldots ;
$$

Thus,

$$
P(U(t)=0)=\exp (-t / M B F)
$$

and the a priori probability that an event occurs in the process at or before t1me $t$ is

$$
p(U(t)+0)=1-\exp (-t / M T B F)
$$




\section{CRIGINAL PAGE IS \\ OF POOR QUALITY}

We model the subject's estinate of the tine $t$ that has elapsed since the process ws last reset to noral (and during wich a fallure nay have occurred) as the aininu of the tine since service to the process mas last completed and the tine since the first measurement presented on the current display. We thus assune that if service of a process as last conpleted at a time point earlier than ins earliest time point shown on the current display. the subject uses the earliest tice $\mathrm{p}$, it on the display as his estinate of the first point at wich a neu failure may hove occurred in the process.

Before concluding this section we wuld like to consider a modification to the basic aodel. Ipplication of the nodel as we have a +'.ined it to data obtained in the experinent preseuted is ine preceding stition reveals a disparity between the performance of the nodel and that of the experinental subjests. Spectfically, the nodel tends to respond to lower MITR and higher C processes vore often than the subjects. will it tends to respond to higher MITR and lower $C$ processes less often than the subjects. In an attept to deal with this disparity wile retaining the potential robustness of the nodel. wh wll incorporate tio additional paraeters into the model.

The first pareater is a lower probab1lity threshold. If the probsbility that an event has occurred in a process $j$ is lower than this threshold, than process $\mathrm{J}$ is not considered for inclusion in the action sequence, even if inclusion would result in a lower expected cost per unit tine than onission of the action or Inclusion of some other setion. Inis pareneter is latroduced to reduce the tendency of the nodel to respond to sone processes eore ofter. than the human operator.

The second parmeter is an upper probability threshold. If, after the deternination of an action sequence by the concatenation of actions wich successively lower the expected cost per unit tine of the sequence, there reain outsyle the sequance processes for which the probability of an event occurrence 15 greater than this threahold, these processes are added to the action sequence. Or these processes, that wose addition results in the sallest increase in the expected cost per unit tine is added to the sequence first. The realining processes are then added to the sequence in the sace manner. This parmeter is introduced to reduce the tendency of the nodel to respond to some processes less often than the humar operator.

There are, then, four free paraeters in our application of the nodel to the experimental situation - $B$. specifying the relative weighting assigned to feature values calculated over recent and older process measurements, the cutoff length, specifying the number of neasurements over which features are extracted, and two probability thresholds used to exclude or include actions in the action sequence on the basis of event probability alone. 
The decision aaking performance of the nodel was compared with that of each subject by supplying the adel with the MTIRs and $c$ s associated with each of the processes and with estimates of the a priori and a posteriori probatilities of failures in each of the processes at the tine they were displayed to the subject. The model was used to generate action sequences fur each display viewed by each sut ject on his last three trials (a total of 75 displays with 9 processes/display for each subject). These action sequences mere compared on a sequence by sequence basis with the correspondias action sequences entered by the subject.

In generating the a posteriori probabilities of fallures in each of the processes, $B$ and the cutoff length were fixed at intuitively reasonable values of 0.2 and 10 , respectively. Wo attept ws ade to deternine the values of $B$ and eutoff length wich yield the best perforaance of the model across all subjects. Although it seens reasonable to conjecture that better performance could be obtained by determinins the optinal $B$-cutoff length pair for each subject, our goal of a simple computer aiding schene notivated the decision to fix these paraeters.

In evaluating the wisdel's performance we are concerned with two aspects of decision making. First, when did the model include a specific process in its acticn sequence and how does the tining of this action compare with that of the subject's response to the process? Second. for those processes inciuded in both the model's and the subject's action sequences for a given display. how many of the model's orderings of actions within the sequence differ fro the subject's orderings?

Regarding che tining of the asdel's responses relative to that of the subject, there is sode difference in the utility of modeling tnose responses of the subject to processes inich actually require service (hits) and those responses to processes which are not falled and do not require service (false alarws). He would be particularly concerned that the ocdei respond to those processes requiring vervice that the subject responds to. and would prefer that the model slso respond to these processes at the same time as the subject. He are less concerned with the correspondence of the model's and subject's false alarns, provided the nodel does not make more false alaras than the sub ject.

Table 1 compares the performance of the aodel with. the performance of each of the four subjects. In each case, the lower and upper probability threstolds of the model were varied to achieve the best fit of the nodel's performance to the subject's perforance. The best fit was defined in terms of the difference of two performance neasures: tre number of detections by the model made only at the exact sane time as the subject's detections and the number of detections nade by the subject and aissed by the model. The latter measure was subtracted from the former and the threshold was varled to maxialze the resulting quantity. The aaxinization was done subject to the constraint that the number of fal se alarms by the model not exceed the numer of false alarws by the subject. Thus, we soughe to maximize the number of 
tines the model and subject responded to falled processes at exactly the sane tine. We sought to ainini se the nubber of tines the nodel did not reapond to a failed process to which the subject did respond to. Ind w did not pernit the notel to wake nore false al arms than the subject. It should be noted that. during the experinental trials given the subject. processes entered by the subject for service on a giren lteration wre serviced and reset to nornal before the seneration of a displas for the next iteration. Beceuse of this. wen we copare the nodel's actions wth those of the subject. It is not possible for the uodel to take action with respect to a falled process on an iteration later than the one at wich the subject acted.

TABLE 1

Comparison of nodel's perforence with subjects' perfornance

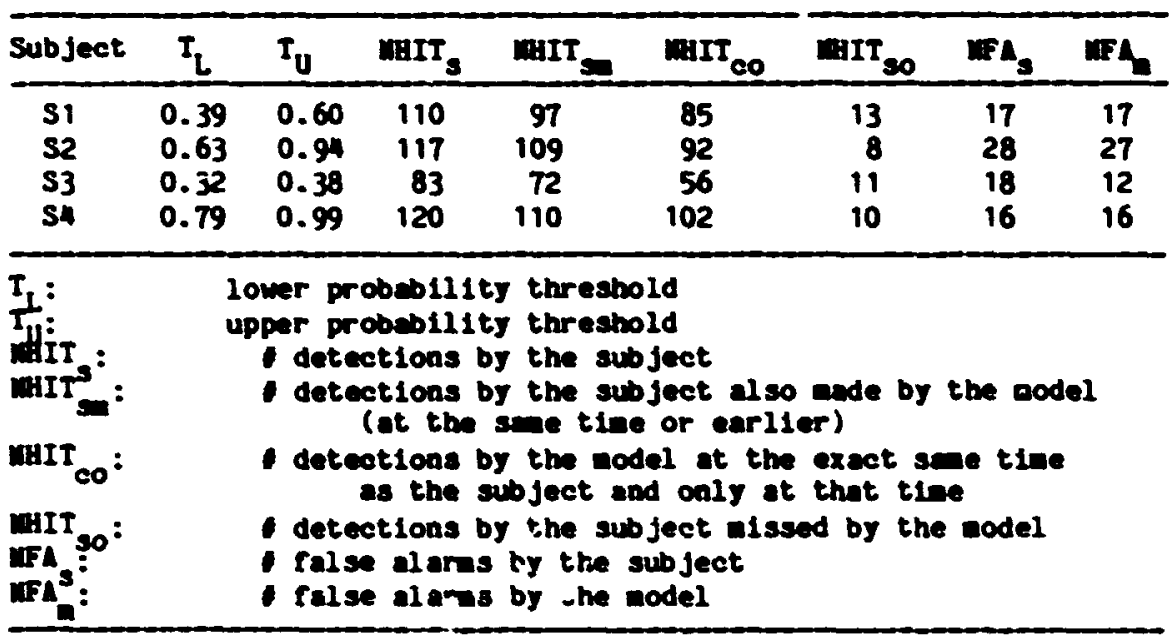

Table 1 reveals that, through the variation of the threahold paraters alone, It wa possible to obtain a high degree of correspondence between the eodel's performance and the performance of the subjects on their last three trials.. Within the constraint thet the nodel alce no wore false alarms than the subject, the nodel reaponded to 908 of the process fallures responded to by the subjects. It responded to 788 of the process fallures responded to by the subjects on the iteration of the subject's response and only on thst iteration. And, as shown, in Iable 2, for those processes included in both the nodel's and the subject's ection sequences. only 17 of the Dodel's 240 ordering decisions differed from those of the subjects. 
TABLE 2

Comparison of the model's ordering decisions with those of the subject (for responses connon to model and subject)

\begin{tabular}{lrrrr}
\hline & \multicolumn{5}{c}{ Subject } \\
\hline & 51 & $s 2$ & 53 & 54 \\
\hline Consistent decisions & 53 & 73 & 33 & 81 \\
\hline
\end{tabular}

\author{
CONCLUSION
}

The decision making model has been shown to provide a good fit to data obtained using a specific multiple process monitoring situation. The use of discriminant anclysis to model the human's generation of event probabilities fermits the model to be used in situations in which explicit models of the processes being monitored are unavallable. It also allows the model to be applied with relative ease to situations in which specific event probability estimation algorithes are available. but unwieldy. In the application described in this paper the nature of the events to be detected resulted in displayed process histories of a nonstationary nature. Four simple features of the process measurements were used to discriminate between the presence and absence of events. These features were suggested by the coments of subjects attempting to detect the events. In providing the model with examples of the values these features took on when events were present and absent, subjects' estimates of the event occurrence times were used to define events. Reasonably good perforwance was obtained without the availability of true event occurrence tines to define events for the model. Thus, the sodel performed well despite the fact that it only had subjects' qualitative descriptions of what events looked like and when they occurred.

Al though the model generally exhibited performance similar to that of the experimental subjects, analysis of the ordering decisions made by the subjects indicated that several of the subjects occasionally scheduled actions with respect to processes they didn't feel yet required attention. These processes required diversion of attention from other processes for only a small anount of time and thi-. permitted the subject to act with little risk on the possibility that the processes might require attention by the time it was available for them. The model we have presented allocates attention only to processes for which the probability of process fallure is above a threshold. It thus does not model this aspect of the subjects' performance well. 
In this paper. We have postulated a eulti-task situation in which the hinan sinultaneously monitors multiple dynaic processes for action evoking erents. The processes aay differ in priority and the human cannot attend to all processes simultaneously, but Instead aust allocate his attention ans the processes. Our goal is the development of codels of human deciston alcing anable to use in the design and inplenencation of a conputer aided process monitoring systen. Inis goal dictates several specifications for such models. First. the eodels have to be simple enough to inplenent in a real-tine enviroment. Second, they have to be capable of saspting to changing process dynamics and decision ankins criteria. Finally, they would hoperully be capable of learning the taak by "watching" the huan. We foel that the nodel proposed in this paper neets these specifications.

In this paper. the nodel was applied to an experinental situation involving the monitoring of nine independent processes wich characteristically exhibited only one type of fallure or action evoking event. In applying the aodel to this situation, very little fitting of paraeters to data was required. Some parmeters of the nodel wore fixed at values considered to be intuitively reasonaule. Features were selected in sinilar fashion, although he coments of other experinental subjects perforning decision making tasks within a sinilar altuation were also instructive. Ino threshold paraeters were varied to echleve a good fit of aodel to subject in a stuation involving event detection and attention allocation decisions.

It is clear, however. that the aodels would have to be exteaded and validated for situations auch different fro the one to which it has been applied. The developmsnt, for exeple, was carried throush assuning independence cons processes, on unrealistic assumption in eany potential applications. In siturtions in wich sone processes are interdependent, the distributions of event interarrival tines and action tines within these processes wight depend upon the instantencous configuration of the interdependent processes. While such interdependencles conplicate the proble substantislly, the general apprasch we have proposed is still applicable.

\section{REFEREMCES}

1. Senders, J. H., "The Hean Operator as a Monitor and Controller of Hultidegree of Freedon Systes," IEEE Trans. Huan Factors in Electronics, vol. HFE-5, no. 1, Pp. 2-5, Sept. 1964.

2. Sallwood, R. D.. "Internal Models and the han Instruent Honitor," IEEE Trans. Huan Factors in Electronics, vol. HFE-8, no. 3, pp. 181-187, Sapt. 1967.

3. Carbonell, J. R., "A queueing Hodel of Many-Instrunent Visual Sagpling," IEEE Trans. thenen Factors in Electronics, vol. HFE-7, no. 4, pp. 157-164, Dec. 1966. 
4. Carbonell, J. R. Ward, J. L., and Senders, J. W., "A Queueing Model of Visual Sampling: Experimental Validation," IEEE Trans. Man-Mashine Systems, vol. MMS-9, no. 3. pp. 82-87. Sept. 1968.

5. Senders, J. H. and Posner. M. J. M., "A Queveing Model of Monitoring and Supervisory Behavior," in I. B. Sheridan and G. Johanrisen, Eds.., Monitoring Behavior and Supervisory Co.strol. New York: Plenum 1976, Pp. 245-259.

j. Kleinman, D, L. and Curry, R. E., "Some New Control Theoretic Models ror Human Operator Display Monitoring," IEEE Trans. Systems, Man, and Cybernetics, vol, SMC-7, no. 11, PD. 778-784, Mov. 1977.

7. Gai. E. G. and Curry, R. E., "A Model of the Human Doserver in Failure Detection Tasks," IEEE Trans. Systems, Man, and Cybernetics, vol. SHC-6, no. 2, pp. 85-94, Feb. 1976.

8. Sheridan, T. B. and Tulga, M. K.. "A Model for Dynamic Allocation of thuan Attention Among Multiple Tasks," Proceedings of the Fourteenth Annual Conference on Manual Control, University of Southern Califernia, April, 1978, MASA CP-2060. Pp. 569-592.

9. Rouse, W. B.: "Human-Computer Interaction in Multitask Situations," IEEE Trans. Systems, Man, and Cybernetics, vol. SHC-7, no. 5, pp. 384-392. May 1977.

10. Walden, R. S. ar. Rouse, W. B., "A Queveing Model of Pilot Decisionmaking in a Multitask Fligint Management Sitution," IEEE Irans. Systeas, Man, and Cybernetics, vol. SMC-8, no. 12, Pp. 867-875, Dec. 1978.

11. Chu, Y. Y. and Rouse, W. B., "Adaptive Allocation of Decislonmaking Responsibility Between tuman and Computer in Multitask Situations." IEEE Trans. Systems, Man, and Cybernetics, vol. SMC-9, no. 12, pp. 769-778, Dec. 1979.

12. Tatsuoka, M. M., Multivariate Analysis. New York: Wiley, 1971.

13. Afifi. A. A, and Azen, S. P.. Statistical Analysis. New York: Academic Press. 1972.

14. Rouse. W. B. and Greenstein. J. S., MA Model of Human Decision Making in Mult1-Task Situations: Implications for Computer Aiding," Proceedings of the 1976 International Conference on Cybernetics and Society, Washington, DC: IEEE Systems, Man, and Cybernetics Society, November 1976, pp. $425-433$. 


\section{PROCRU: A MODEL FOR ANALYZING FLIGHT CREW PROCEDURES} IN APPROACH TO LANDING *

S. Baron, G. Zacharias, R. Muralidharan, R. Lancraft

Bolt Beranek and Newman Inc.

50 Moulton Street

Cambridge, MA 02138

The approach and landing task involves a wide range of human behaviors and activities, both cognitive and perceptual-motor. These include monitoring and information-processing, flight control, decision-making, execution of standard procedures, and communication with other crew members and with ATC. The goal of the research reported here was to develop a model for this complicated process that would provide a means for systematic exploration of questions concerning the impact of procedural and equipment design and the allocation of resources in the cockpit on performance and safety in approach-to-landing.

Given the objectives we have for the model and the nature of the issies we hope to analyzi with it, several general implications for wodelling the task emerge. First, it is clear that a system model is needed; one that accounts for the interactions of crew, procedures, vehicle, approach geometry, and environment. second, the issues of interest revolve principaliy around allocation of tasks in the cockpit and crew performance with respect to the cognitive aspects of the tasks. The model must, therefore, deal effectively with information processing and decision-making aspcets of human performance. Third, despite the high cognitive content of the approach task, a large portion of the crew's activities involves highly structured, standard procedures. These must be modelled at a level that is adequate for determining how performance on these tasks interferes with other tasks land vice-versa) and for evaluating the consequences of failure to execute important procedures. Fourth, communication among crew members and between the crew and ATC must be considered in the model, at least with respect to accounting for the transfer of information and the load imposed by such communication. Finally, to examine the impact of va-ious system conditions and assumptions, it must be possible to compute performance parameters of interest.

-Th1s work was performed under Contract NAS2-10035. NASA, Ames Research Center sponsored the research with Dr. Renwick Curry as technical monitor. 
PROCRU (Procedure Oriented Crew Model), is a simulation mode? for examining crew preicedures in approach to landing, dereioped with the above requirements in mind. It includes a system model anj a model for each crew member. The crew is assumed to be composed of three members: pllot flying (PF), pilot not flying (PNF) and second officer (SO). In the present implementation of PRC 2RO, the so model does not include any information processing or decision-making components. Rather, the so is modelled as a purely deterministic program that responds to events and generates requests. PF and PNF, on the other hand, are each represented by complex human operator models which have the same general form but differ in detail.

Briefly, PF and PNE are each assupad to have a set of "procedures" or tasks to perform. 'the procedures include both routines established "by the book" (such as checklists) and tasks to be pe:formed in some "optimizing" fashion (such as flying the airplane). The particular task chosen at a given instant in time is the one percelved to have the highest expected gain for execution at that time. The gain is a runction of mission priorities and of the percelved estimate of the state-of-the-world at that instant. This estimate is based on monitoring of the displays, the external visual ciene and auditory inputs from other crew mersers. PROCRO draws heavily on the concepts and subwodels of the Optimal Control Hodel (OCV) for the human operator for its information processing and control representation. However, there ar's many novel aspects and features of the nodel that constitute new developments.

In the remainder of this paper we present an overview of the PROCRO model and some results illustrating its operation. More details may be found in reference 2 .

1. Model Description

The basic structure of the PROCRU wodel for either PF or PNF is Illusirated in Figure 1 . The syetem wodel is the same for both crew members and is discursed first.

\subsection{System Model}

\section{Vehicle Dynanics}

The representation of vehicle dynamics must be sufficient to capture the essential aspects of the task but theze is an incentive (computational cost) to keep it as simple as posalble. Certainly, the equations of motion must be adequate to describe the position and velocity of the alrcraft relative to the nominal approach path, 
but for the issues to be addressed b": PROCRU (at least, initially), linearized equations $c$ an be used and inner-loop (high-frequency) dynamics ignored, to a first approximation. Thus, we use as a basis for the dynamic calculations in PROCRU standard point mass equations for the vehicle trajectory. 2

These equations may be written in the general form

$$
\underline{\dot{x}}=\underline{E}(\underline{x}, \underline{\underline{0}}, t)
$$

where $\underline{X}$ is the vehicle state vector and $\underline{U}$ is the control input.

The scheme utilized to "integrate" the above equations and to provide the linearizec equations needed for implementing the control and estimatior. portions of PROCRO is somewhat novel and, we believe, is in keeping with the manner in which approach trajectories are flown. Briefly, five "nominal trafectory" segments, corresponding to five standard maneuvers, are defined:

1) straight and level filight

2) decelecation at constant tlight path angle

3) turn at constant rate

4) flare (constant rate of change of flight pati at constant speed and heading))

5) descend at constant sink-rate

It is possible to determine, algebraically, for each me nuver the "tria" or "nominal" controls on. necessary to achizve the dealred condition and, moreover, to integrate the corresponding equations of motion exactiy to obtain $x_{y}(t) .2$ The equatio $s$ can then ive inearized about the particular segment to yield equations of tine form

where

$$
\underline{x}=\underline{A}_{i} \underline{x}+B_{N_{i}} \underline{u}
$$

and the subseript $\dot{N}_{i}$ means that thn gr itity is evaluated along the $\mathrm{N}_{1}$ "th segment.

We note that it is not necessary for a nominal segment to start at a particular place. In eddition, because the system matrices change from segment to segment (and from morent to moment in turn or segment), the Iinearized equations $(3,3)$ will be 
tine-varyirg (piecewise constant) over the approash trajectory. Finally, we may generallze (2) to include wind and other possible disturbances by rewriting it as

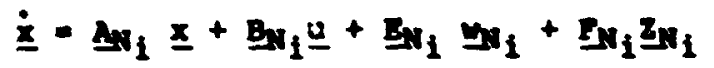

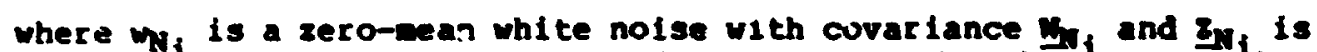
a deterintistic disturbance that is unknown to the pilot. Bquation 4 is in a form that 18 standard for applying the optinal control wode 1 (OCM) of the human operator. 1

\section{Subsystens:}

Alrcraft subsystens, such as engines, hydraulics, etc., are not nodelled in any detail. Subsyste operation, when required by procedures, is accomplished, or not, as deternined by the nodels for the crew.

\section{ATC Comunications:}

Air Traffic control vectoring comands are preprogrand as part of the approach scenar10. They take the for of auditory gu'dunce comands, to be proceseed and executed by the PF.

\section{Instruest Landing Syateas}

The Instrunent landing systen nodel includes the glide slope. localizer, outer marker and niddle marker. Computed vehicle position is used to compute "activation" of any of these ILS signals and to deternine gilde slope and localizer errors in "dots". The nodel does not presently include any bean errors but these could be added without difficulty.

\section{Information Sources:}

We assune that for basic sources or "clusters" of information are avallable Lu crew nenbers external visual scene infornation, visual information concerning vehicle state from the flight instruments, visual information concerning subsystens and audilory information.

The information from the external visual scene depends on the position and attitude of the alrcraft relative to the alrfield. Geonetric analisis allows us to define how the "displayed" quantities, $y_{s}$, depend on vehicle state and scene content. 3,4

The information on the Instrument panel can rel ate to vehicle status information (frow flight instrumtation), command 
information (froe flight directors) and subsystem information (including subsysten status and plsual "alarns"). The information nay be discrete as well as continuous. We assume this informatior. is separated into two clusters. One for vehicle state related information, $y_{I}$, and one for subersten information. For the procro analys is conducted berein, the flight displays are assuned to indicate air speed, hading, altitude, rate-of-clinb and, after bean intercept, localizer and glide slope error. The subayste: displaye are not nodelled with respect to informtion content but serve as an attention diatraction or "sink" when a procedure requiring subsystea operation is being perfored (see below).

Auditory information includes comand information from ATC. auditory alarns, and comunications from other crew menbers such as callouts, requests, etc.

\subsection{Buman Operator rodelo}

The nodels for the human operator (PF or PMF) contain subodels for conitoring. Information processing. decision-making (procedure selection) and action. These are discussed below.

\section{Honitoring}

The nonitor sub-wodel accounts for the operator's sensory Iinitations as well as for nonitoring decisiors (1.e., allocition of attention). The visual sensory linitations are nodelled in the sane anner as in the $001,1,3$ except that the perceptual delay ia neglect-d. In particular, an obeervation nolse and threshold are assoclated with each observed visual quantity. The thresholds are particularly important for external viaual scene perception; for example, in liniting the quality of avallable vertical guidance information.

Auditory information $1 \mathrm{~s}$ asound to be heard correctly. It is stored in a sewory buffer for subsequent processing.

The operator cannot process all sources of information sinultaneousiy and nust, therefore, decide which source to attend to. - In the case of visual information there is a fundanental cholce as to where to flxate, on the external world or on the instruent panel. If the Instrunent panel is chosen, the operztor must de, ide upon which ingtrument to flxate. We shall also assune that the auditory information oinllarly "competes" with the visual information for operator attention.

Thus, when auditory or subsysten information 18 requested by a procedure, attention is diverted from the flight displays and no 
information concerning the vehicle's state is obtained (except if it cones via the auditory channel from anotber crew neaber). When flight displays are being obeerved, ither for flying the airplane (for PF) or for status nonitoring (for Pur), attention is asaund to be shared ang the displars on a continuous basis instead of being restricted to a single display at a time. paocko enploya sub-optinal attention-allocation algorithe to cosute the appropriate attention-sharing etrategies.2 Bower, if a crew nember selects a procedure that results in a monitoring request: for a giren display (e.g., check alr speed), then the fraction of attention corresponding to that filght display is set to (approximately) one, and the realining attentions are set to (approxinately) zero.

\section{Inforeation Processing}

The informtion processor portion of the model consists of two aub-wodels, an "eatinator" and a "discrete event detector". The estinator is identical to that used in the ocil and is a tine-varying halman filter. The internal nodel for the filter changes with changes in dynalcs resulting from alteration of the "noninal- or fron flap or gear extensions or with changes in disturbance character latics.

The vutputs of the estinator are the estinate of the perturbed state. 2. the covariance of the estination error. $\Sigma$, and, perhaps, the innōrations sequence, and its covariance. We 111 assune that the probability distribution for $x$ Is noran, in which case $\hat{x}$ and $\Sigma$ are sufficient statistics for detērnining the conditional densit $\bar{y}$ of $x$ based on past observations $y, P(x \mid y)$. Thus, the estinator produces status information, 2 , needed for control and "subjective" probability estimates that can be used for decision-making or detection. Wote that the error coveriance, $\Sigma$, is a weasure of the operator"s uncertainty in the eatinate $\hat{\underline{X}}$ and 111 be a major factor in deterwining wonitoring decisions, as will be seen below.

The discrete event detector is Intended to nodel those aspects of operator information proceseing other than vehicle state eatilation. Typically. it is concermed rith deterining or detecting that an event has occurred which "enables" a subsequent procedure execution. The event ay be a failure (that did or did not result in an alarn), a request for action (say from ATC). or sone annunclated condition le.g.. crossing OM, glide slope active or, passing through som altitude). The Inputs to the event cetector are outputs of visual alarne, auditory information, and

- In the present Implementation of procko, it Is assured that the nowinal state $x_{n}(t)$ is known to the crew. 
the outputs of the etate estinator. The atate information la used to detect state related events auch as a destabilized approach condition.

Bighly sophisticated models exist for certain types of fallure detection based on state estination. and thege ighteventually be incorporated in the event sezector model.6 wo did not get 0 sophistlcated Initlaliy. Inetead, we assund, sinply, that the occurrence of an event 18 detected with a specified, finite probability by the crew. Bowever, the nature of the event 1 a assund to be unknown unt 11 the procedure for decoding mesagea (see below) 1s invoked. The selection of this procedure can be delayed by the requirements to perform other tasks, thus delaying the effective tine of event detection. Once the nessage associated with the event 18 decoded, it will generally result in the "enabling" or "triggering" of an appropr late procedural response.

\section{Procedure Definition and Selection}

The operator is aseuned to have a nuber of procedures or taks that any be perforind at each instant.

The definition of these procedures is an essential step in the formulation of PROCRO. All crew actions, except for the declsion as to which procedure to execute, are determined by the procedures. we emphasise that we use the term procedure here to apply to tasks in general, a procedure In these teren could have considerably nore cognitive content than alght norally be consldered to be the case.

Procedure categoriea

Table 1 categor 1 ses the approach to landing fl lght procedures for the PF and PWF. For each cremen, six categorles are shown, and for each category, specific types of procedures are itemized. we briefly discuse these categorles and types in the following paragraphs.

The vehicle control procedures aselgned to the pr are broken down into three types maneuvering control, regulatory control and retriming control. The elret involves the deterination of appropr late maneuver rates, setting trin control values to effect these rates, and wontoring for maneuver termination. In effect: open-loop maneuver control provides a weans of generating the -noninal trajectory of Bqn. 3. Regulatory control, on the other

The prubability 1a chosen to be one for this atudy, for
simplicity.


hand, involves monitoring the display perturbations away from the I.Ominal, estinating the corresponding vehicle state perturbations, and generating an appropriate perturbation control to control out the variations. Closed-loop regulatory control ensures proper execution of the desired maneuver and is nodelled using standard ocy techniques 1 . Finally, retriming control provides a weans of retriming the vehicle after a flap or gear setting change has altered the vehicle trin conditions.

The vehicle wonitoring procedures assigned to the Pwt are also broken down into two types: conitoring for vehicle status, and monitoring for event or fallure detection. The former involve: determining an appropriate nonitoring atrategy for attention shacing among the available displays, estinating the corresponding vehicle state, and evaluating the approach progress based on the current state estinate. The latter involves a sinilar process, but is centered on detecting events or fallures.

Requests and callouts ade by the PF and Prf, respectively, involve verbal responses based on estimates of current vehicle status. The flap, gear, and checklist requests ande by the PP involve deternining the vehicle's approach progress in terns of one or more trajectory/Instrunent parameters, and making the request based on the progress and in accordance with a well-defined set of request procedures. The position and altitude callouts ade by the PiF Involve a slailar process. The approach atability and runway-in-sight (RWIS) callouts, also made by the Pwe, involve the additional requirement of determining when the vehicle is in an appropr late "window" for making or not making the callout.

Subsystem monitoring and control actions made by both pilots are assumed to be event driven, and involve discrete control actions and/or diversion of attention from flight displays for approprlate subsysten servicing. For the PF, servicing the altitude alert subsystem is distingulshed from the servicing of all other subsystems, because of the interactive nature of setting the trigger point, responding to the alarm, and resetting $1 \mathrm{t}$. For the PNF, the flap and gear subsysten are called out because of their impact on approach progress, their unique status of being driven by requests from the PF, and because of the need for subprocedures involving validation of the request, and setting and checking of the subsystem involved.

Verbal achincxleigements nade by the $P F$ and $P W F$ are driven by checklist item prompts gerieraled by the so. These require the checking of an appropriate subsystem (attertion-diversion) and making the appropr late verbal response. The PNF is also assigned the duty of acknowledging the recelpt of ATC vector requests. 
The SAP/MnP terninal procedures provide for appropriate callouts, head-up/head-down witching strategles, and bises approach initiation during the terminal phase of elther the standard Approach Procedure (SNP) or the Monitored Approach (MNP) 2 Although this category of procedures could be allocate item by item to the other categories, it has been found to be nore convenient to treat it as a uniform procedural category, both for the purpose of rodelling, and for discusaton.

The elscellaneous procedures show are prinarily for the purpose of codelling convenience, and are not intended to directly represent "by-the-book" or actual procedures engaged in by the crew. They include processing and decodting of verbal commications, auditory alarms, and discrete pirual events. In addition, for the PF, they Involve selection of appropr late landing configuration paraneters.

Procedure Seiection

We assure that the operator knows what 18 to be done and, essentially, how to accomplish the objective. Eomever, he wust decide what procedure to do next. This is a decision wong alternatives and the procedure selected is assuned to be the one with the highest expected gain for execution at that tine. The Bxpected Gain for executing a procedure. BGP, is a function that is selected to reflect the urgency or priority of that procedure as well as its "value". In addition, the BGP can be a function of the "enabling" atate of the procedure. Thus, if a procedure were not "enabled" it would have zero gain and would not be chosen; if the enabling event had a ron-zero probability of occurrence, the procedure wight then be selected.

In PROCRO, we have assuned the BGP functions have the following general forn (specific expressions are given in reference 2):

$$
\operatorname{EGP}(I)=G(I)+G_{0}(I), I=1, \ldots, R
$$

where I denotes the Ith procedure, $G(I)$ is a function that ref sects the -situational relevance of the procedure and $G_{0}(I)$ is a constant that depends on the relative "value" of the prrsedure. For procedures that are triggered by the operator" internal assessment of a condition related to the vehicle state-rector, the $G$ (I) functions are appropr late subjective probabilitie., based on

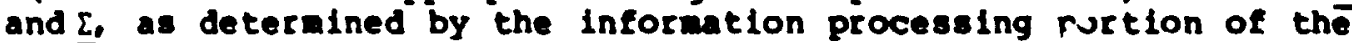
sodi. Procedures that are triggered by events, xternal to the operator, such as ATC comards, comunications frca the crew, etc., are character ized by $G^{*}$ s that are expliclt functions of tive. For 
either type of function, the gain for perforning a procedure will increase, subsequent to the perception of the triggering event, until the procedure is performed or until a tine ach that the procedure is assuned to be missed or no longer appropr late for execution.

The $G_{0}$ terms have two principal purposes. First, they are used to establish a "default" procedure for each operator by assigning a base value for BOP for that procedure that 18 greater than for any other one. (The G(I) for any other procedure nust exceed this base value before tho procedure can be selected.) For PF the default is flying the airplane, whereas for the pis it is monitoring the rehicle's status. The second purpose of the $f_{0}$ term is to establish priorities ang procedures that wight have the sane situational relevance at a given tine.

Procedures way be comprised of a number of sub-procedures, so that at the completion of each sub-procedure. a decision to continue nuat be ade. This w111 pernit interruption of such a procedure, depending on the outcone of the dectsion.

We believe that this model for procedure selection captures many inportant aspects of human performance in a nulti-task environient, and is directly relevant to investigating the efficacy of flight crew procedures. It allows for procedures to be nissed and/or Intertupted: even flying the airplane my be neglected, as can hap en. Although we do not expect sub-procedural steps to be perforined out of order with this bodeliling approuch, it would be possible to preprogran such errors if desired.

Procedure Execution

The selection and execution of a procedure will r:sult in an action or a sequence of actions. Inree types of acilons are considered: control actions, wonitoring requesis and comunications. The control actions include continuous manual flight control Inputs to the alrcraft and discrete control settings (switches, flap settings, etc.). Honttoring requests result from procedural requirements for specific information and, therefore. ralse the attention allocated to the particular information source. we note that verifying that a variable is within iinits nay not require an actual instruent check, If the operator already has a "confident" internal estimate of that variable. Comunications are verbal requesta or responses as demanded by a procedure. They Inrilude callouts, requests or comands, and comunications to ATC.

Associated with each procedural action is a tine to complete the required action. (It is possible to modify Procro to allow for 
a probabilistic aistribution of action tines). Then the operator decides to execute a specific procedure, it is assuned that he is -locked in to the appropriate node for a specifled $t i n e$. For exanple, if the procedure requires "checking" a particular instrument and it is assumed that it takes $t$ seconds to acconplish the check, then the "sonitor" will not attend to other information for that periud, nor will another procedure be executed.

In PROCRU procedural Implementation is modelled as essentially error free. However, errors in execution of procedures can occur because of improper decisions that result from a lack of information (quantity or quality) due to perceptual, procedural and workload linitations. If the effects of action errors are also to be analyzed, this is accomplished by deliberately inserting such errors directly into the wodel. It should also be pointed out that verbal comunlcation is modelled directly as the transfer of elther state, comand or event information.

\section{Model Outputs}

PROCRO generates a number of outputs that are useful for analyzing crew procedures and performance. Pirst, one can obtain full trajectory information. This information is provided at any tine in terns of the total state (TSTATE $x t$ ) (and/or the noninal state) and the perturbation or deviation (DSTATs $x$ ) from the noninal. In addition to this information, one can obtain each crew nember " 8 estimate of the state $(x h)$ and the standard deviation of the estimation error (SDSV), the attentional allocation (AT) at that time and PF's control inputs (u). These data, along with significant events, etc.. are tabulated in a fle as lilustrated in Plgure 2. PF is crew nember 1 and PIF crew nember 2.

In addition to the trajectory output, PROCRO provides three separate time lines: a procedural tine line (PTL), a nessage tine line (MTL), and a milestone time line (TL). Table 2 1ista the menonics used for these $t$ ine 1ines. The procedural tine-line, illustrated in Figure 3 for the noninal approach conditions, provides a listing of the procedures (PROC) being executed by each crew nember, the gain for doing that procedure (EGP) and the information cluster and display being attended to at a given tine. Also provided for each crew nember is the procedure that has the next highest gain for execution at that tiwe. Thus, for exanple, at time 915.4 seconds, PF was flying on instruments (scanning) and no other procedures were competing for attention. at the same

\footnotetext{
- Procedure numbers used in the PTI correspond to those in reference 2 , Table 4.20 .
} 
time, PNP was monitoring the altineter in order to nake an altitude callout (at $t=919.6$ ), while the default monitoring task was the task with the next highest prlority. shortly thereafter 1920.8 sec). PF diverts attention fron regulating about the nominal to process the callout and PWF has reverted to basic monitoring.

The message time line (Mrt) is a record of all the communication traffic and auditory signals that occur in the simulated cockpit. Figure is a mesage tive line for the nominal approach. The type of nessage (signal nawe), the source of the message and its destination, its processing status, its time of origin and processing, as well as an Indication of the signal content are all presented using memonics that are fairly transparent. For example, on the nessage tine line, we see the communication activity noted above. The $500^{\circ}$ altitude callout is made by the $\mathrm{F} / 0$ (PHF) at 919.6 seconds and directed to the CAPI (PF). It is processed (1.e. used to update PF's altitude estimate) at 921.0 seconds.

The milestone tine line (TL), Llustrated in Figure 5 , contains selected trajectory variables of interest (altitude, speed and heading), an indication of crew activity and a listing of important fight milestones and events. Note that the tiwe marker given in the TL, tgo, is the time-to-go, conputed simply as $980 \mathrm{~s}$ minus the event tile. This provides a falr approxiation to the actual tine-to-go.

\section{An Example}

The milestone tine line in Figure 5 presents an overview of crew activity for a nowinal and even-paced approach and will be discussed in detall.

The time-Iine begins with the vehicle at $10,000 \mathrm{ft}$ altitude. on a 210 deg heading, proceeding at 190 kts. In the first 50 seconds, three ATC requests, for a heading change, deceleration, and descent, are processed by both the PI and PNF. As shown in both Pigure 5 and Figure 4, each request involves: a) a msage generated by ATC sent to both the PF and PNF, b) message processing by the PF, reaulting in a new maneuver (e.g., "Prcsd Turn"), and c) message processing by the PNF, reaulting in a verbal confirmation of the ATC request (e.g.. "ATCcn"). Note that Plgure 4 shows that each confirnation mesaage (from PNP to ATC) is ignored by ATC, since the ATC module used in this simulation operates in a time-locked open-loop fashion. Naturally, a more sophisticated module would take into account the procedural activity of ATC, and incorporate the verbal conflrmatory feedback provided by the crew. 
The descent request nade by ATC at $t_{g o}=9308$ triggers a number of crew activities. As just noted, It triggers a verbal confirmation by the PNF. It also triggers the generation of a three-segment maneuver (flare/descent/flare) by the PF, in accortance with the procedure defined for such a maneuver. Thus, a Elare to -6 deg filght path is initiated at $t_{g o}=9268$, and constant sink rate is maintained until tgo $=707 \mathrm{~s}$, at which point a flare-out is initfated, and completed at tgo $=6768$. The ATC descent request also triggers an altitude alert setting by the $P F$ ("MAon" at tgo $=9228$ ).

As the vehicle approaches the requested 3500 ft altitude, the PF makes a verbal request for the ini=ial approach checklist ("IACR" at too $=6868$ ) which, as shown by Elgure 4, is processed by the $s / 0$ at $t=2948$. This then initiates the serles of IAC pronpts by the $s / 0$, shown in the next few minutes of the tine-1ine. Bach such prompt (e.g.. "IAC 1" at too $=6668$ ) results in a requirement on the PF or PNF to process that prompt (e.g.. "Procsd IAC 1" at too $=6638$ ), and verbally echo the prompt back to the s/0. Subsequent processing of the confiration by the $s / 0$ (e.g.. -Prcsd IACXI" at tgo - 6598), Initiates generation of another prompt by the $5 / 0$ (e.g.. IAC X2" at tgo $=639 \mathrm{~s}$ ). The IAC 1a concluded at $t_{g 0}=5338$ by a "IAC?n" message generated by the $s / 0$.

The descent to $3500 \mathrm{ft}$ asso triggers the altitude alert (MA) subsystem. Thus, at $h=4019 \mathrm{ft}$ the $\mathrm{M}$ becones active, which requires the $r F$ co turn it off at tgo $=709 \mathrm{~s}$, which, in turn deactivates the $A A$ at the next tine step in the simulation. Note that this occurs prior to the flare-out initlated by the F, thus providing an appropr late warning to begin the flare-out.

After the PF levels off near the requested $3500 \mathrm{ft}$ altitude, ATC requests a deceleration to $160 \mathrm{kt}$. As before, this triggers a maneuver by the PF and a masage confirmation by the PNF. Note that completion of this maneuver triggers a 5 deg flap request by the PF $\left(t_{\text {go }}=656\right)$, In accordance with the flap/speed management procedures.

Following an ATC-requested turn to $180 \mathrm{deg}$ ( $t_{\mathrm{g}}=540 \mathrm{~s}$ ), a second descent to $2000 \mathrm{ft}$ is initiated (tgo $=498 \mathrm{~g})$. The sane activity sequence is followed as in the first descent, except that ATC makes a 120 deg turn request ( $t_{g \circ}=4508$ ) while the vehicle is descending. The message is processed by both crew members (as shown in Figure (1), and confirmation 18 provided by the PNF. The PF, however, does not act on this request, but merely stores it in his memory. Once he levels off to the requested $2000 \mathrm{ft}$ altitude $\left(t_{g o}=3838\right)$, he then immediately initiates the turn to 120 deg. 
As in the initial descent, the PF requests the checklist during his levelling off to his assigned altitude ("FACR" at too 390s). Again, this initiates a serles of $s / 0$ prompts and PF and PNF confirmations, lasting until checklist termination by the $s / 0$ ("FACfn" at tgo $=1838$ ).

While the PF is turning to the requested 120 deg heading. ATC notifies the crew that they are cleared to land (tgo $=3758$ ). This message is processed by both the PF and PWF, and "Enables" a serles of velocity, altitude, and heading managenent procedures designed to ensure proper touchdown performance.

The first of these is a deceleration to $150 \mathrm{kt}$, following completion of the turn to $120 \mathrm{deg}\left(t_{\mathrm{go}}=3638\right)$. Once this speed is reached, 15 deg flaps are requested and set, by the PF and PNF respectively (tog = 349s). Shortly thereafter, the localizer becomes active, Which results in an announcesent by the PIF, which, in turn, triggers a turn to final by the PF.

During the turn, the glide slope becones active (tgo $=3268$ ), and is announced by the PN. After the turn is completed, the vehicle has achieved its final inbound heading, with a sall localizer error (not shown on the tine-line). shortly thereafter, a 2 dot low glide slope error (also not shown), triggers a gear-down request from the PF, which 18 acted on by the PNF ( $t_{g o}$ 273s).

As the vehicle approaches the glide slope, the PF initiates two decelerations in accordance vith the velocity mineuver procedures, one to $140 \mathrm{kt}$ at 1.5 dots low, and the second to the final approach speed of $139 \mathrm{kt}$, at 1 dot low. Bach of these trigger new flap requests and settings (to 25 and 30 deg) in accordance with the flap/speed management procedure.

When the vehicle 180.5 dots below the glide slope, the PF initiates a pitch down $\left(t_{g o}=218 s\right)$. This flare sets up the final descent followed for the remainder of the approach.

During the descent, the PNF announces oM activity ("Orann" at $\left.t_{g o}=1518\right)$, and makes the required $1000 \mathrm{ft}, 500 \mathrm{ft}$, and "approaching minimun"s (300 ft) callouts. Be is also monitoring 0 - $t$-the-window, and, with the $250 \mathrm{ft}$ celling simulated, makes the appropriate Rirs callout at tgo $=358$.

While the FNF is monitoring for this RHIs callout, the M alert sounds, and both pilots process this wessage. The PNF should announce MM activity during this time, but is engaged in monitoring the altimeter for his required "minimums" callout at $200 \mathrm{ft}$. Be 
makes the altitude callout slightly early (at h=215ft and tgo = 31s), and by the time he can attend to making the MM announcement, the in becomes inactive (at $t_{g o}=30 s$ ). Since the announcement procedure, as programed, reguires the $M$ to be active for an announcement to be made, the PHF remains silent.

The PF begins decelerating to the required threshold speed of $134 \mathrm{kt}$ slightly early (at tgo $=26 \mathrm{~s}$ ) and $10 \mathrm{ft}$ above the $150 \mathrm{ft}$ altitude specified for the hominal approach. 2 The final flare is initiated about 1 sec "4te and $10 \mathrm{ft}$ below the $50 \mathrm{ft}$ altitude desired for the maneuver. During this flare the Gs signal turns off because of the flace away from the glide slope beam, and the LOC signal turns off at touchdown, as required by the IOC characteristics modelied in this simulation.

The time-ilne just alscussed can be correlated with the other outputs of PROCRO to provide a falrly detalled look at the landing approach. Though the particular approach just simulated was relaxed in terupo, it is clear that more demanding scenarios can also be studied. 2 For these cases, where the demands of the task and the procedures and equipuent employed interact in complex and significant ways, a model of PROCRO's breadth should prove nost useful.

\section{Concluding Remarks}

PROCRU, a new sinulation model for analyzing crew procedures in approach to landing, has been described. The model is a system model that can account for vehicle dynamics, environmental disturbances and crew activities in information processing, decision making, contr - and communication. Crew oub-tasks are defined based on a time-line analysis of nominal procedures. Information processing and control behavior is modelled after the approach utilized in the optimal Control Model. Decision making behavior is based on maximizing subjective expected gain. The result is a complex, stochastic model for analyzing the impact on approech and landing of system, procedure and crew variables.

The PROCRO model has not been validated experimentally, though the information processing and control parts of it have been tested for manual control experiments. IN addition, for this initial implementation, several important aspects of human behavior have been simplified or neglected. Nonetheless, it is likely that even In 1ts present state of developwent, with some upgrading of wind models and vehicle dynamics, pROCRo could be used to analyze many questions of interest regarding procedures for approach and landing. 


\section{REFERENCES}

1. Rleinman, D. L., S. Baron and W. B. Levison, "A Control Theoretic Approach to Manned-Vehicle systems Analysis", IEEE Trans. on Auto. Control, Vol. AC-16, No. 6, December 1971.

2. Baron, S., C. B. Feehrer, and G. L. Zacharlas, "Analysis and Modeling of Flight Crew Procedures in Approach and Landing", BBN Inter in Report No. 4112, July 1979.

3. Baron S., and W. H. Levison, "Display Analysis with the Optimal Control Nodel of the Human Operator," Buman Factors, vol. 19, No. 5, Oct. 1977.

4. Newerinke, P. B., "A Theoretical and Bxperinental Analysis of the Outside Norld Perception Process," Pourteenth Annual Conference on Manual Control, Nasa Conference Publication 2060, Nov. 1978.

5. Levison, M. G., J. I. Elkind, and J. L. Mard, "studies on Multi-Variable Manual Control systems: A Model for rask Interference, NASA CR-1746, May 1971.

6. Gai, E. G. and R. E. Curry, "A Model of the Human Observer In Fallure Detection Taska," IEEs Transactions on systems, Man and Cyberinetics, SMC-6, No. 2, Feb. 1976. 


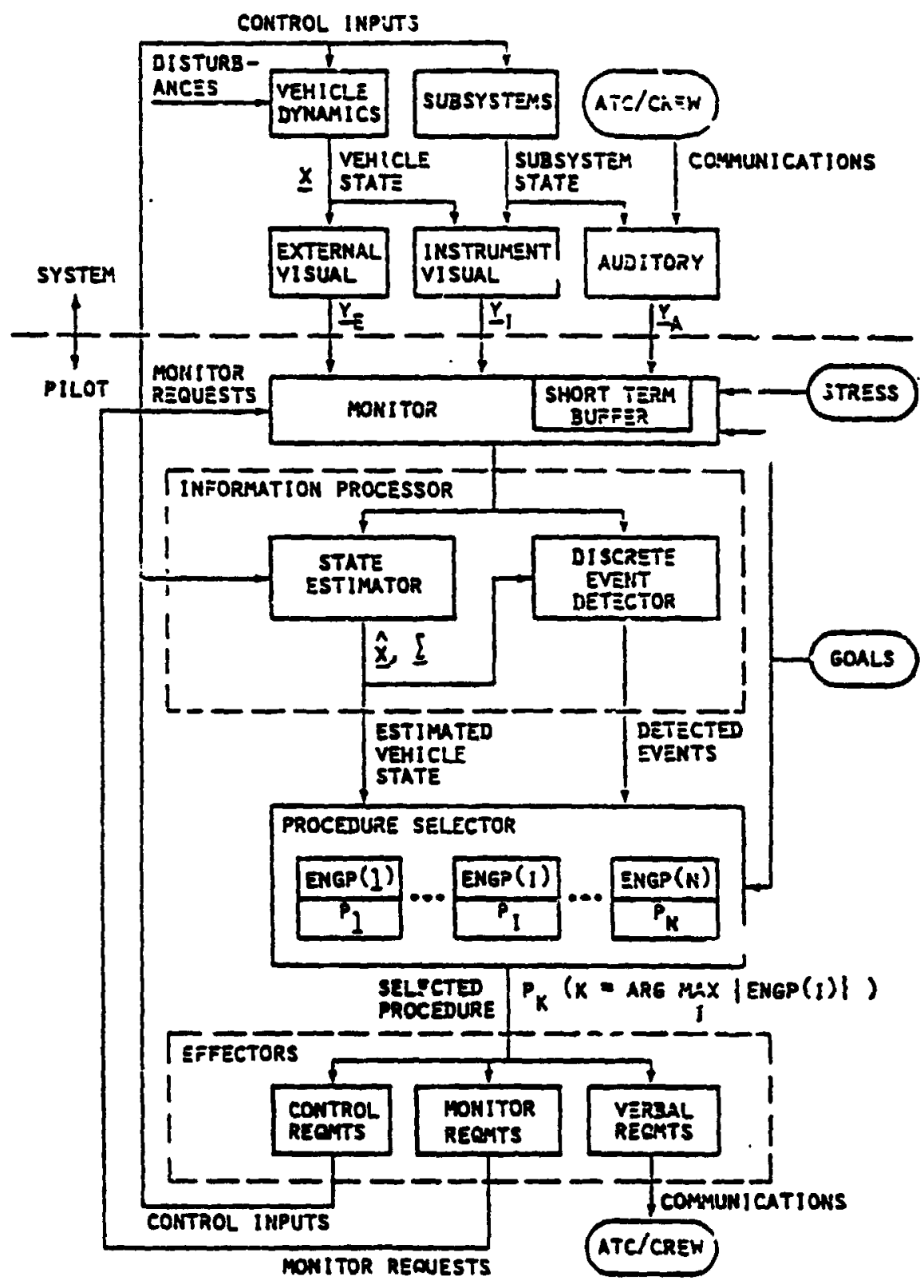

Figure 1: Model Structure for Crew Member Analysis 
URIGINAL PACE IS

OF POOF QUALITY

\begin{abstract}
Fiqure 2: Sample PROCRU Trajectory Information File (case ILS)
$\star \star$ TIMB $=5.8168+02 * \star \star$

Tstate $x t .1 .489 \mathrm{E}+04-8.619 \mathrm{E}+042.091 \mathrm{E}+03 \quad 1.599 \mathrm{E}+021.799 \mathrm{E}+32-2.942 \mathrm{E} 00$ Dstate $x: \quad i 78 \mathrm{E}-01$ 3.205E-01 1.832E-01-8.564E-02-7.831E-02 3.503E-02 $x h 1 \quad k \mid k: \quad .263 B+001.221 \mathrm{~B}+00-2.772 \mathrm{E}-01 \quad 1.923 \mathrm{E}-02 \quad 5.370 \mathrm{E}-02-2.596 \mathrm{~B}-02$ $\operatorname{xh} 2 \hat{k}: \mathrm{k}: 9.636 \mathrm{~B}-01-3.556 \mathrm{~B}+00-4.201 \mathrm{E}-01 \quad 5.574 \mathrm{E}-02-7.41 \mathrm{E}-03 \quad 3.323 \mathrm{E}-02$ SDev l $k \mid k$ : $1.251 \mathrm{~B}+021.092 \mathrm{E}+02 \quad 7.846 \mathrm{E}+00 \quad 1.971 \mathrm{E}-01 \quad 3.031 \mathrm{~B}-01 \mathrm{8.459E}-02$ SDev $2 k \mid k$ : $1.2278+02 \quad 1.081 \mathrm{E}+02 \quad 5.643 \mathrm{E}+00 \quad 2.192 \mathrm{E}-012.753 \mathrm{~B}-01 \quad 1.084 \mathrm{E}-01$ ATl: $\quad V: \quad .015$ PSI: $.240 \mathrm{B:} .010 \mathrm{Hdot}: .713 \mathrm{LOC:} .010 \mathrm{GS}: .010$ AT2: $V: .086$ PSI: $.629 \mathrm{B:} \mathrm{.112} \mathrm{Hdot:} \mathrm{.153} \mathrm{LOC:} \mathrm{.010} \mathrm{3S:} \mathrm{.010}$

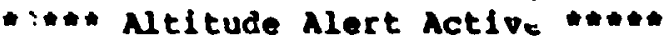
GUIDE: "Executing PLARE to $0.000 \mathrm{~s}+00$ deg at $2.001 \mathrm{~s}-01 \mathrm{deg} / \mathrm{s}$." Total u: $-8.950 E-022.5748+00$ 9.398E+03 Flaps= 5. Gear is op
\end{abstract}

\begin{abstract}
*\# TIME= 5.818B+02 \#*
Tstate $x t=1.483 \mathrm{E}+04-8.619 \mathrm{E}+04 \quad 2.088 \mathrm{E}+03 \quad 1.599 \mathrm{~B}+02 \quad 1.799 \mathrm{E}+02-2.864 \mathrm{E}+00$ Dstate $x: 1.605 E-C 1$ 3.879E-01 2.360E-01-1.082E-01-6.4678-02 7.293E-02 $x h 1 \mathrm{k} \mid \mathrm{k}: \quad 1.260 \mathrm{E}+001.172 \mathrm{~B}+00-2.823 \mathrm{E}-01-4.249 \mathrm{~B}-045.151 \mathrm{E}-021.534 \mathrm{E}-02$ $x h 2 k \mid k: \quad 1.432 \mathrm{E}+00-5.007 \mathrm{~B}+00-1.348 \mathrm{E}-01$ 1.177E-02 $1.980 \mathrm{E}-02$ 6.501E-02 SDevl $k$ k: $1.251 \mathrm{E}+02 \quad 1.092 \mathrm{E}+02 \quad 7.847 \mathrm{E}+00 \quad 1.972 \mathrm{E}-01$ 3.080E-01 $8.745 \mathrm{E}-02$ SDev $2 k \mid k: 1.227 E+02 \quad 1.081 B+02 \quad 5.644 E+00 \quad 2.192 E-01 \quad 2.7538-01 \quad 1.085 E-01$ AT1: $\quad V: 0.000$ PSI:0.000 B: 0.000 Bdot:0.000 LOC: 0.000 GS: 0.000 AT2: V: .086 PSI: $.628 \mathrm{B:} \mathrm{.112} \mathrm{Bdot:} \mathrm{.154} \mathrm{LOC:} \mathrm{.010} \mathrm{GS:} \mathrm{.010}$

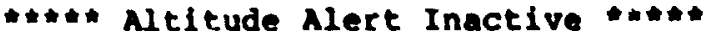

GUTDE: "Executing PrARE to $0.000 \mathrm{~s}+00$ deg at $2.001 \mathrm{~s}-01 \mathrm{deg} / \mathrm{s}$ Total u: $-8.586 \mathrm{~B}-02$ 1.955E+00 9.502E+03 Flapse 5. Geax is UP

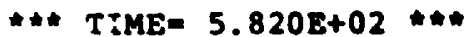

$T$ : ate $x t: 1.478 \mathrm{~B}+04-8.619 \mathrm{~B}+042.086 \mathrm{~B}+03 \quad 1.599 \mathrm{~B}+02 \quad 1.799 \mathrm{~B}+02-2.852 \mathrm{E}+00$ Dstate $x$ : $1.955 E-01$ 4.469E-01 2.933E-01-9.887E-02-6.040E-02 4.449E-02 xhl k|k: $\quad 1.258 \mathrm{E}+001.124 \mathrm{~B}+00-2.789 \mathrm{E}-01 \mathrm{1} 1.015 \mathrm{E}-02$ 4.942E-02-7.8618-03 xh2 $k \mid k=1.234 \mathrm{E}+00-4.404 \mathrm{E}+00-2.945 \mathrm{E}-02 \quad 1.631 \mathrm{~B}-02 \quad 2.031 \mathrm{E}-02 \quad 5.046 \mathrm{~B}-02$ SDevl $k \mid k$ : $1.252 E+021.0925+02$ 7.848E+00 1.9725-01 3.1285-01 9.0218-02 SDev 2 k $k$ : $1.227 \mathrm{~B}+02 \quad 1.081 \mathrm{E}+02 \quad 5.644 \pi+00 \quad 2.192 \mathrm{E}-01 \quad 2.753 \mathrm{E}-01 \quad 1.085 \mathrm{E}-01$ ATl: $\quad v_{2} 0.000$ PST:0.000 B: 0.000 Bdot:0.000 LOC:C.000 GS: 0.000 AT2: $\quad V: \quad .086$ PSI: $.628 \mathrm{H}: .112$ hdot: $.153 \mathrm{LOC}: .010 \mathrm{GS}: .010$ GUIDE: - Executing PLARs to $0.000 \mathrm{E}+00$ deg at $2.001 \mathrm{E}-01 \mathrm{deg} / \mathrm{s}$ " Total u: $-8.236 \mathrm{E}-022.3018+00$ 9.606E+03 Flaps- 5. Gear is UP
\end{abstract}


Figure 3: Sample PROCRU Procedure Time Line (nase IIS)

\section{CAPTAIR}

TIMB PROC:EGP CIUST DISP PROC:EGP

$\begin{array}{rrr}0.0 & 26: & .30 \\ 1.2 & 1: & .32 \\ 1.4 & 26: & .30 \\ 2.2 & 5: & .32 \\ 2.6 & 5: & .32 \\ 3.6 & 5: & .32 \\ 4.2 & 26: & .30 \\ 22.2 & 4: & .97 \\ 24.2 & 26: & .30 \\ 31.2 & 1: & .32 \\ 31.4 & 26: & .30 \\ 32.2 & 5: & .32 \\ 32.6 & 5: & .32 \\ 33.6 & 5: & .32 \\ 34.2 & 26: & .30 \\ 51.2 & 1: & .32 \\ 51.4 & 26: & .30 \\ 52.0 & 4: & .33 \\ 52.6 & 4: & .33 \\ 53.6 & 4: & .33 \\ 54.0 & 5: & .85 \\ 56.0 & 9: 1.00 \\ 58.0 & 26: & .30 \\ 83.4 & 4: & .36 \\ 85.4 & 26: & .30 \\ 269.4 & 1: 1.00 \\ 269.6 & 26: & .30 \\ 270.4 & 26: & .30 \\ 270.6 & 26: & .30 \\ 270.8 & 24: & .32 \\ 272.8 & 4: 1.00 \\ 274.8 & 26: & .30 \\ 294.2 & 2: & .31 \\ 295.2 & 26: & .30 \\ 302.6 & 4: & .75 \\ 304.6 & 26: & .30 \\ 311.2 & 1: & .32 \\ 311.4 & 26: & .30 \\ 312.2 & 5: & .32 \\ 312.6 & 5: & .32 \\ 313.6 & 5: & .32 \\ 314.2 & 26: & .30 \\ 315.6 & 26: & .30 \\ & & \end{array}$

Instr Scan $0:-00$ Audio SBsys $26:-30$ Instr Scan 5: .14 Instr Scan $26: .30$ Instr Scan 26: .30 Instr Scan $0: .00$ Instr Scan 26: .30 Instr Scan 0: .00 Audio SBsys 25: .30 Instr Scan 5: .14 Instr Scan 26: .30 Instr Scan 26: .30 Instr Scan 26: .30 Instr Scan $0: .00$ Audio SB:ys 26: .30 Instr Scan 5: .14 Instr Scan 26: . 3C Instr Scan 26: .30 Instr Scan 26: . 30 Audio SBsys 26: .30 Instr Scan $0: .00$ Instr Scan 26: .30 Instr Scan $0: .00$ Audio SBsys 26: .30 Instr Scan 24: .04 Instr Scan 24: .27 Audio sBsys 26: .36 Instr Scan 26: .30 Instr Scan $0: .00$ Audio sBsys 26: .30 Instr Scan $0: .00$ Instr Scan 26: .30 Instr Scan 0: .00 Audio SBsys 26: .30 Inste s=an 5: .14 Instr Scan 26: .30 Instr Scan 26: .30 Instr Scan 26: .30 Instr Scan 0: .00 Instr Scan $0: .00$ Instr Scan 26: .30 Instr Scan 26: .30 Insti Scan 24: .22

\section{FIRS: OFFICER}

PROC:EGP CLUST DISP PROC:EGP

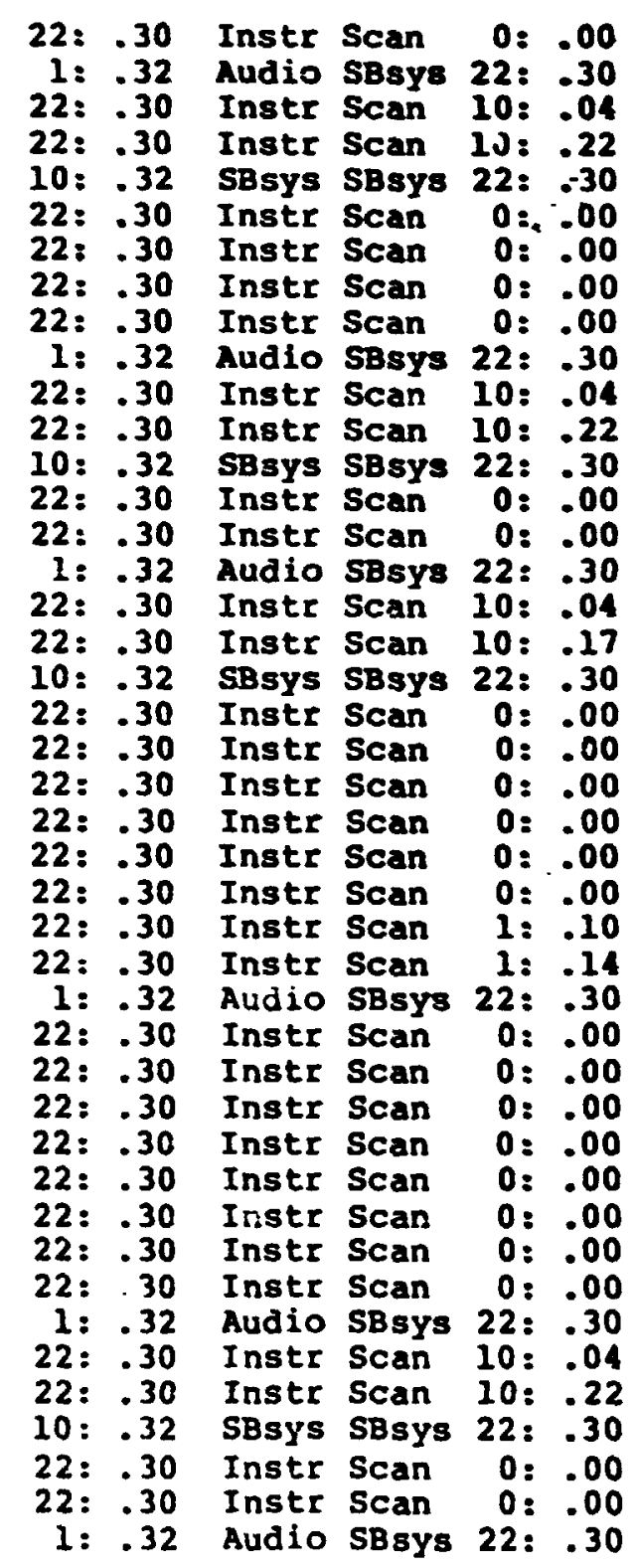




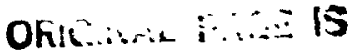

OF POOF. C"ALITY

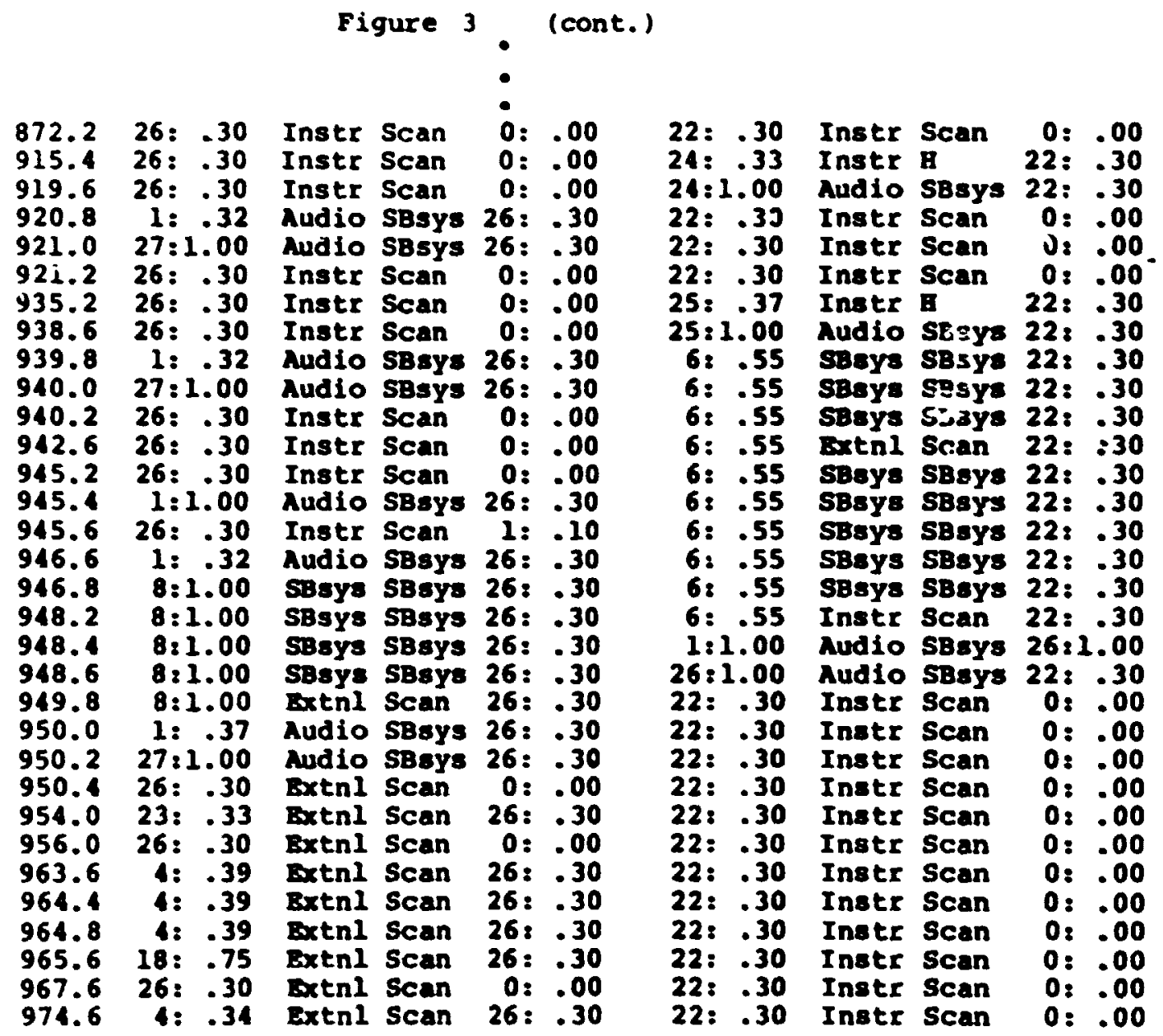


Figure 4: Sample PROCRU Message Time-line (case 1LS)

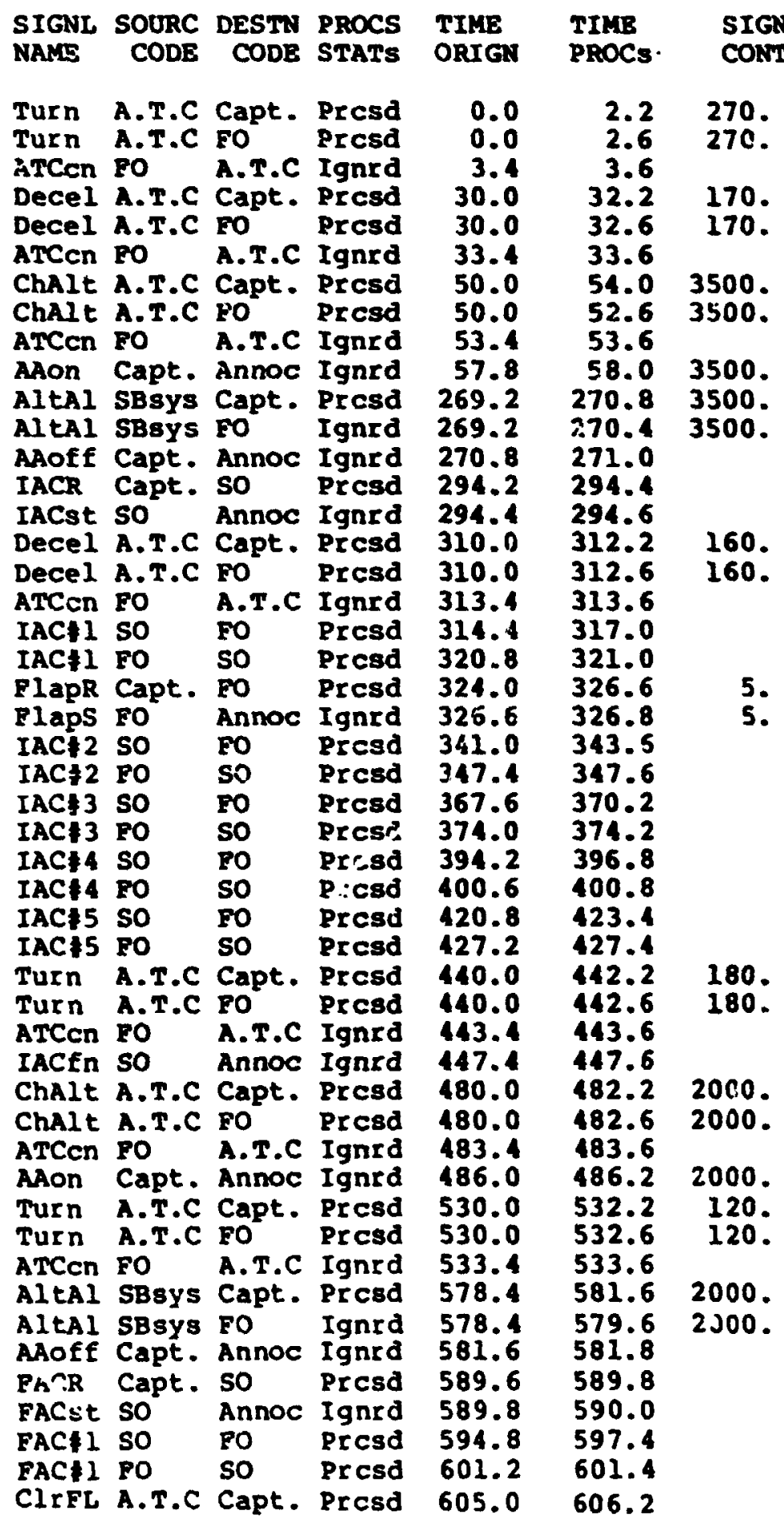


Figur, \& (cont.)

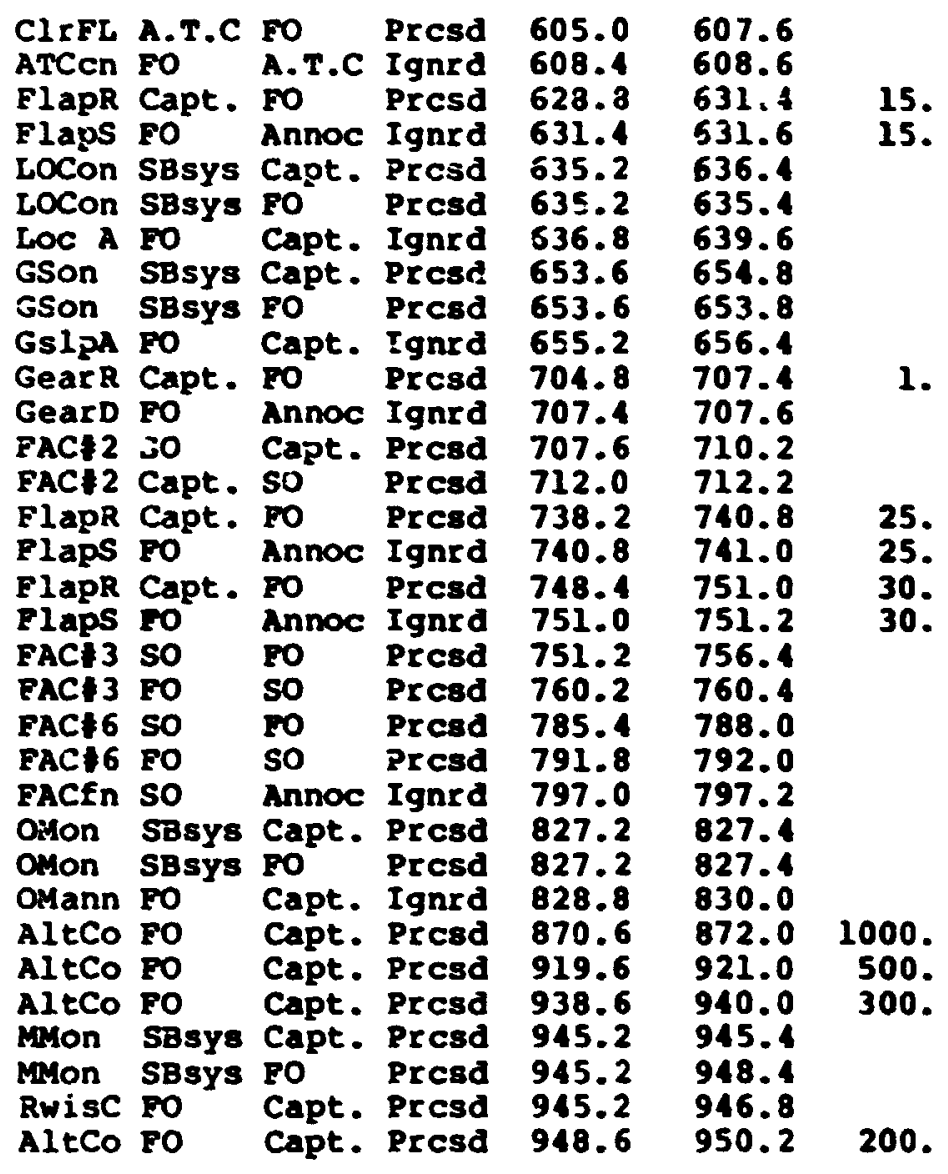


Figure 5: Sample Procro Milestone Time-Line (Case ILS)

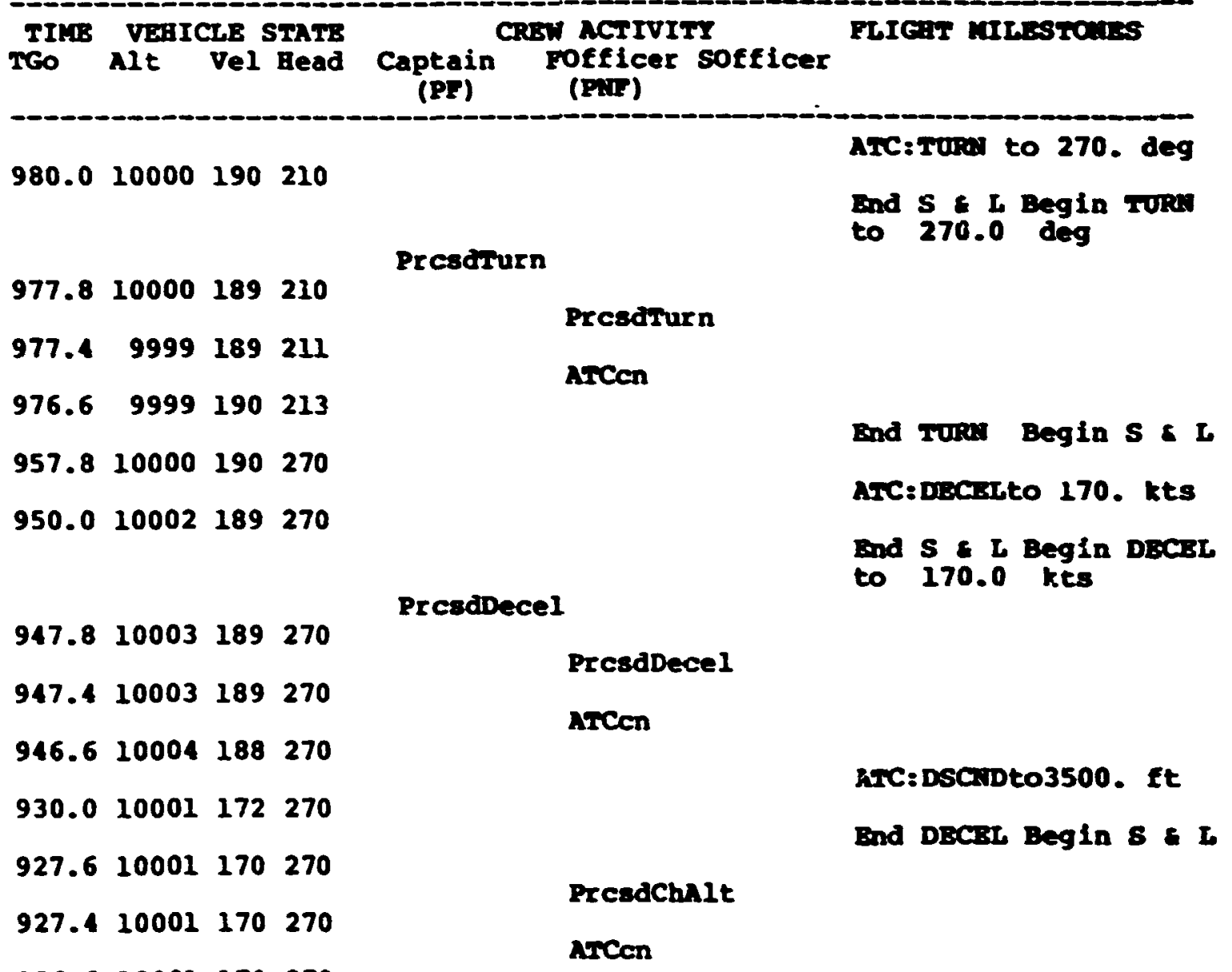

Bnd 5 i Begin Funds

Prcsachnit

to $-6.0 \mathrm{deg}$

926.010001170270

$922.29995 \quad 170270$

Mon

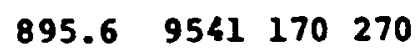

$710.8 \quad 4019 \quad 170 \quad 270$

$709.2 \quad 3972 \quad 170 \quad 270$

Prcsanital

Bnd FLaris Regin DScir to 3947.0 ft

M active

\section{Nofe}

M Inactive 
Figure 5 (cont.)

End DSCNT Begin FLA

$\begin{array}{lllll}707.2 & 3912 & 170 & 269\end{array}$

$\begin{array}{lllll}685.8 & 3500 & 170 & 269\end{array}$

$\begin{array}{llll}685.6 & 3498 \quad 170 & 269\end{array}$

$\begin{array}{llll}676.6 & 3466 \quad 169 & 269\end{array}$

$670.0 \quad 3465 \quad 170269$

$\begin{array}{llll}667.8 & 3465 & 170 & 269\end{array}$

Prcsabecel

Incet

Prcsalrch

End FIARE Begin $s=L$ ATC: DECELto 160. kts

End $S$ I Begin DECEL to $160.0 \mathrm{kts}^{2}$

667.43465169269

666.63465168269

$665.6 \quad 3465167269$

$663.0 \quad 3465165269$

$\begin{array}{llll}659.2 & 3465 \quad 161 \quad 269\end{array}$

$659.0 \quad 3465 \quad 161269$

$\begin{array}{llll}657.6 & 3465 \quad 159 & 269\end{array}$

$656.0 \quad 3466 \quad 159269$

653.43467159270

$639.0 \quad 3464 \quad 160270$

636.43464160269

$632.6 \quad 3465 \quad 159269$

632.43465159269

$612.43467 \quad 159269$

$609.8 \quad 3467 \quad 159269$

$606.0 \quad 3467 \quad 159269$

$605.8 \quad 3467 \quad 159269$

$\begin{array}{lllll}585.8 & 3463 \quad 160 \quad 270\end{array}$

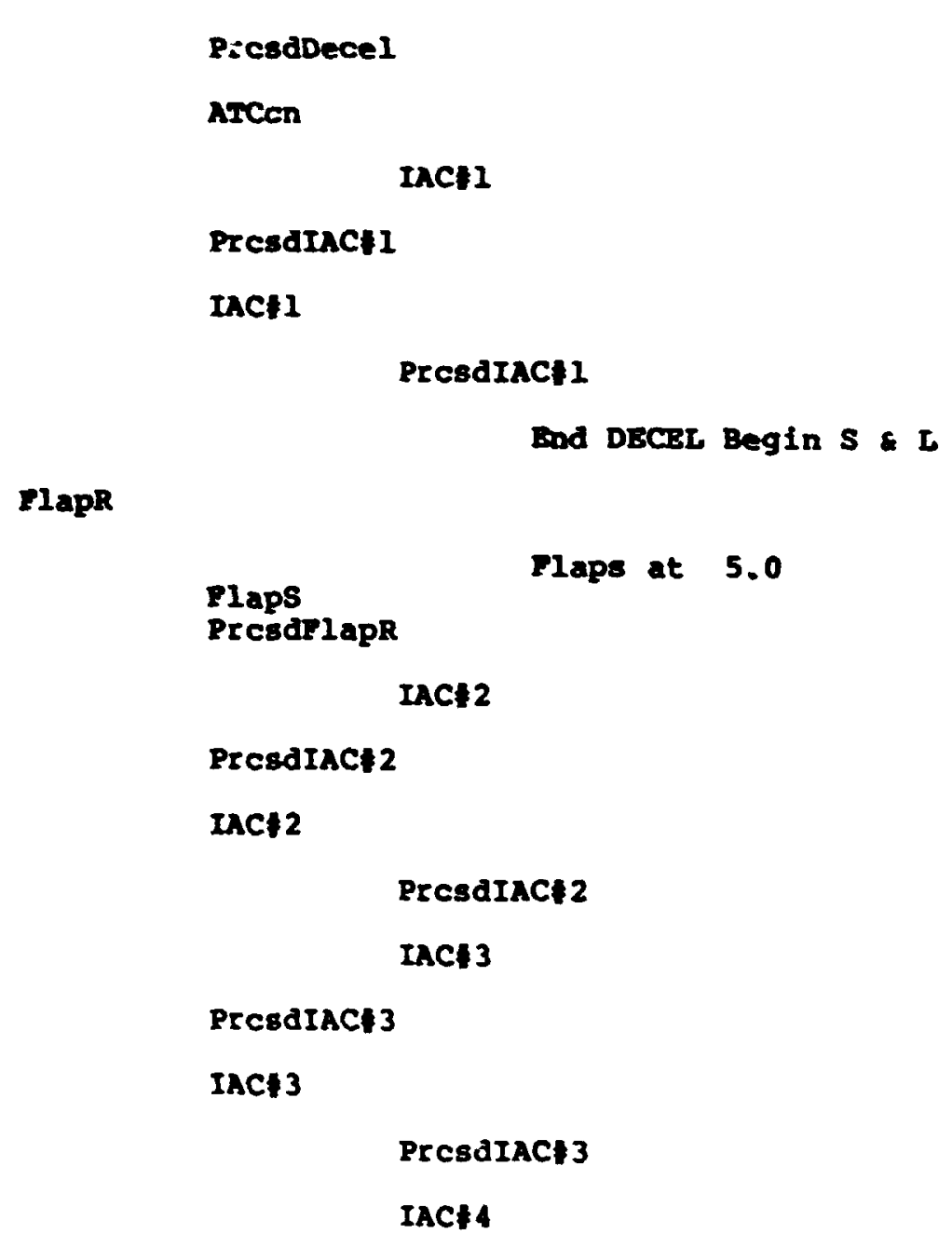


Report No. 1374

Figure 5 (cont.)

$\begin{array}{lllll}583.2 & 3463 & 160 & 270\end{array}$

579.43463160270

$579.2 \quad 3463 \quad 160270$

$559.23465 \quad 159270$

$556.63464 \quad 159269$

$\begin{array}{llll}552.8 & 3463 & 160 & 270\end{array}$

$\begin{array}{llll}552.6 & 3463 & 160 & 270\end{array}$

$540.0 \quad 3462 \quad 160270$

$\begin{array}{llll}537.8 & 3463 & 160 & 270\end{array}$

$537.43463160 \quad 268$

536.63464159266

$\begin{array}{llll}532.6 & 3464 & 160 \quad 254\end{array}$

$507.8 \quad 3464160 \quad 180$

$500.0 \quad 3465 \quad 159 \quad 180$

$497.8 \quad 3465159180$

497.43465159180

$496.6 \quad 3464 \quad 159 \quad 180$

$494.0 \quad 3457 \quad 160 \quad 180$

481.23334260180

$450.0 \quad 2866 \quad 159179$

$447.8 \quad 2834 \quad 159 \quad 179$

$447.4 \quad 2828 \quad 259 \quad 279$

$446.6 \quad 2825 \quad 159 \quad 179$
Prcsdiact4

IAC 1

Presdiaci4

IAC\$5

Prcsdract 5

IAC $\$ 5$

PresdIAC $\$ 5$

ATC: TURN to 180 . deg

and $S$ I I Begin TURA

Prcedrurn to 180.0 deg

PrcsdTurn

Axcen

IACfn

End TURA Begin $S$ \& $I$ ATC:DSCNDEO2000. ft

Fnd $S$ I Begin plars

Prcsdchalt to $-3.2 \mathrm{deg}$

Prceachalt

ATCen

Mon

End FLARB Begin DSCNT
to 2118.5 ft

ATC:TURN to 120 . Ang

Prcsdturn

Prcsdturn

arcen 
Figure 5 (cont.)

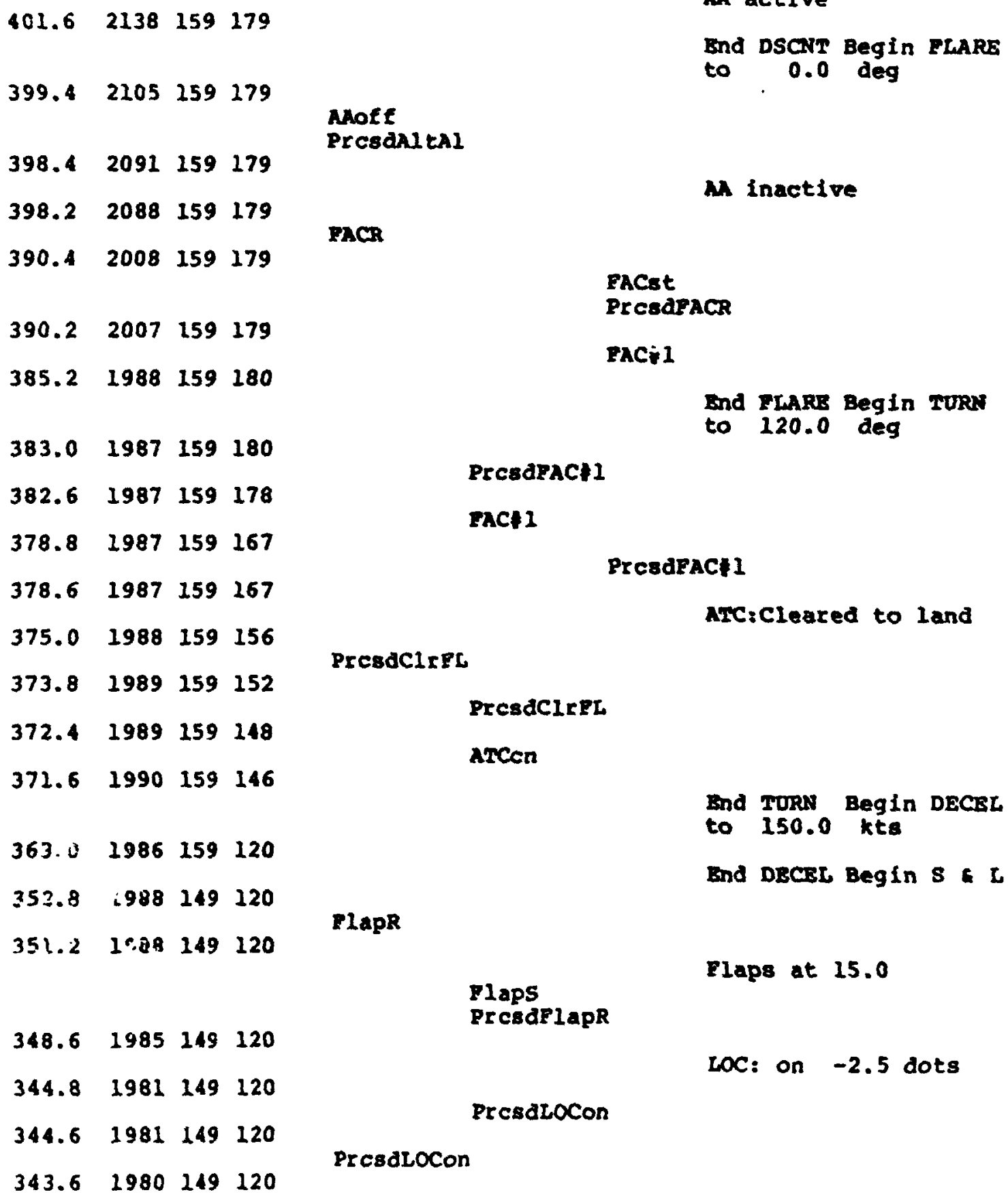

PrCa

FACst

Prcsdpacr

Facil 1

Bnd FLAR Begin TUR: to $120.0 \mathrm{deg}$

Prcsapacel 1

IAcs 1

Presafact 1

ArC:Cleared to land

PresdClrec

Prcsaciret

Arcon

Ylaps

End TURA Begin DECEL to $150.0 \mathrm{kts}$

Find DEcEL Begin $S \leftarrow \tau$

FlapR

PrcsdflapR

Rlaps at 15.0

LOC: on -2.5 dots

PrcsdLocon

Presdlocon 
Figure 5 (cont.)

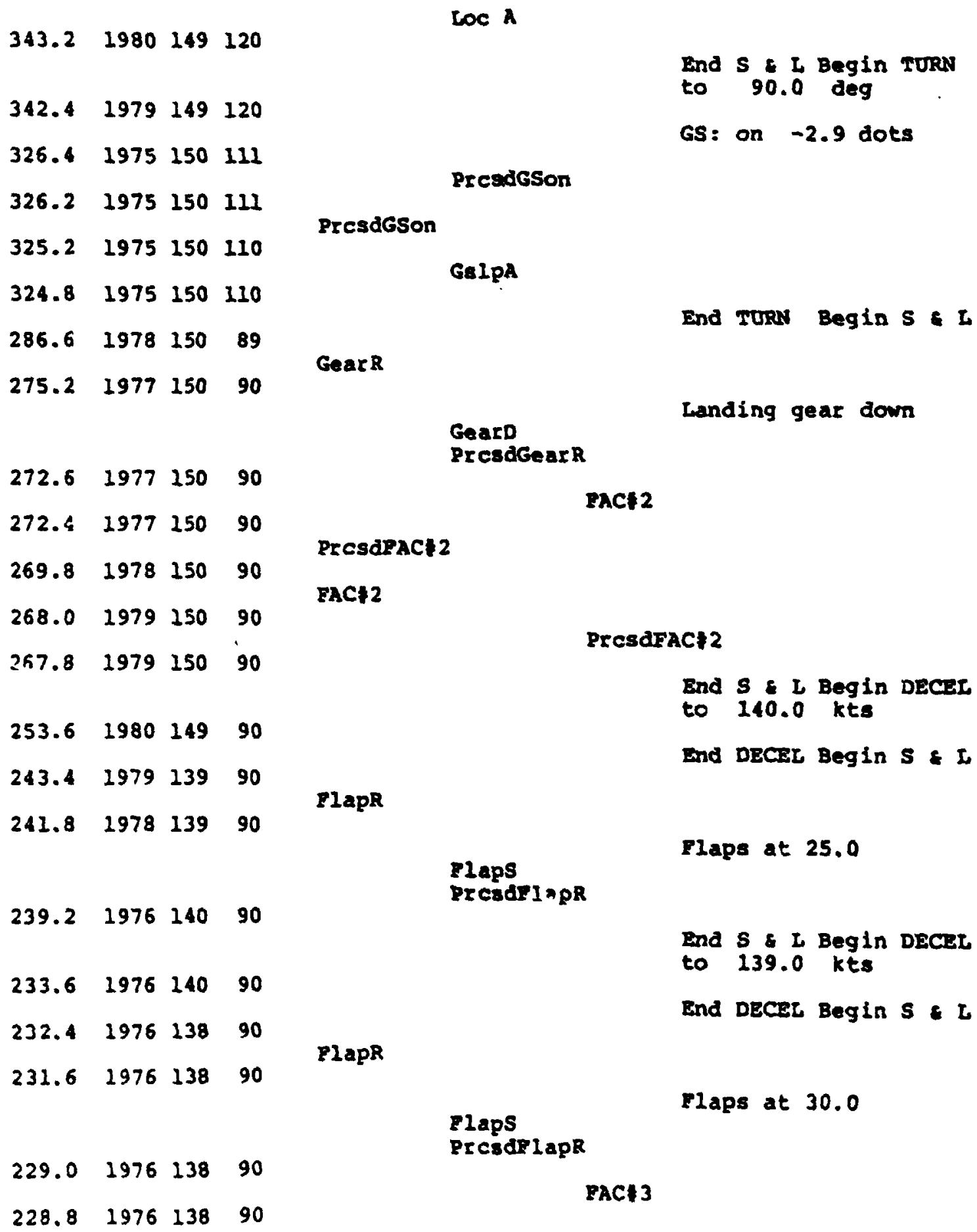




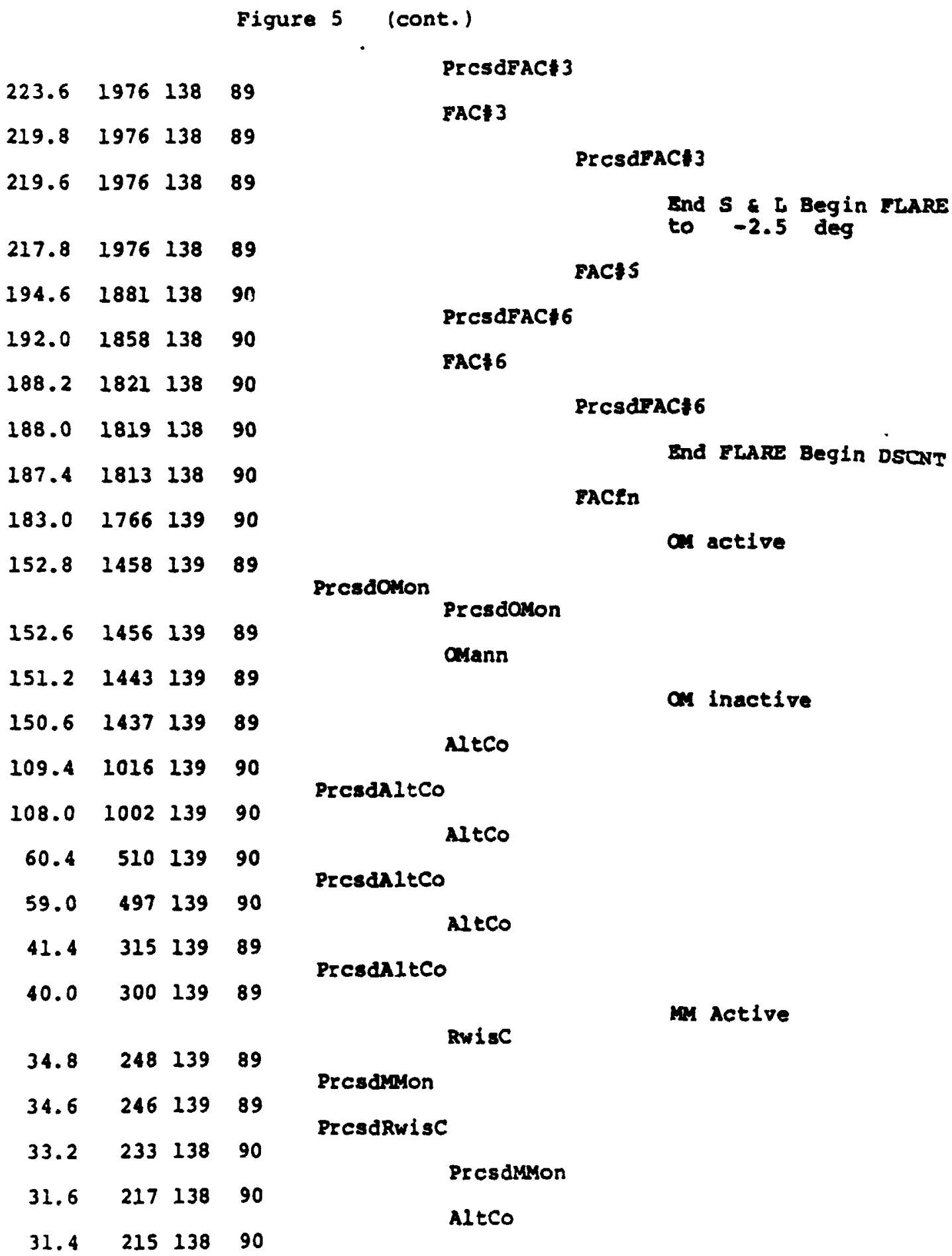


Figure 5 (cont.)

$\begin{array}{rrrr}30.4 & 205 & 138 & 90 \\ 29.8 & 199 & 138 & 90 \\ 26.0 & 160 & 138 & 90 \\ 15.2 & 49 & 133 & 89 \\ 14.4 & 41 & 133 & 89 \\ 12.0 & 20 & 133 & 90 \\ 8.2 & 0 & 133 & 89\end{array}$

M inactive

End DSCNT Begin DECEL to $134.0 \mathrm{kts}$

End DECEL Begin DSCNT End DSCNT Begin FLARE to $0.0 \mathrm{deg}$

GS off

LOC off 


\begin{tabular}{l|c}
\multicolumn{1}{c|}{ PF } & PNF \\
\hline 1. Vehicle Control Procedures & 1. Vehicle itonitor Procedures \\
\hline $\begin{array}{ll}\text { a) Maneuver } & \text { a) Vehicle status determination } \\
\text { b) Regulate } & \text { b) Failure detection ard } \\
\text { identification }\end{array}$
\end{tabular}

2. Request Procedures
a) Flap request
b) Gear request
c) Checklist initiate reques

3. Subsysten Proccdures
a) Altitude kert monitor/ cont, 01
b) Misc. Subsystem monitor/ control

4. Acknowledgement procedures
a) Checklist item acknowledge- ment

5. SAP\%iMAP Terminal Proceaures

6. Miscellaneous procedures

a) General message processini

b) Landing parameter selection
2. Calloizt Procedures
a) Vehicle positjon callout
b) Altituce callout
c) Assroach stability callout

3. Subsystem Proceciures

a) Flsp monits/control

b) Gezr monitor/contro:.

c) Misc. suisystin monitor/ control

4. Acknow ledgement ?roceduzes

a) Checklist item acknowledgemeist

b) ATC request acknowledgement

5. SAP/MPD Terminal Procedures

6. Misceilaneous Procedures

a) General message processing 


$$
\text { of poli gualtiy }
$$

Table 2: Mnemonics for Tine Li zes

\begin{tabular}{|c|c|}
\hline FlapR & Flap request \\
\hline GearR & Gear request \\
\hline DCR & Begin descent check?ist = request \\
\hline IACR & Begin initial afproach checklist request \\
\hline FACR & Begin final approach checklist request \\
\hline OMA & Outer marker active callout \\
\hline LOCA & Localize: upture ca:ilout \\
\hline Gs 10A & Glide slope alive callout \\
\hline AltCo & Altitude cailout \\
\hline AppDs & Approach destabilization cellout \\
\hline Rwisc & Runway in sight callout \\
\hline ATCen & Confirmacion of ATC msg. \\
\hline$D C \# 1$ & Descent checklist iten $\# 1$ \\
\hline IAC $\$ 1$ & Initial approach checklist item $\$ 1$ \\
\hline IAC\$2 & Initial approach checixist item $\$ 2$ \\
\hline IAC\#3 & Initial approach elecklist item $\$ 3$ \\
\hline IAC $\$ 4$ & Initial approach checklist item $\$ 4$ \\
\hline$I \cdot . \$ 5$ & Initial approach checnlist item $\$ 5$ \\
\hline FAC\$1 & Final approach checklist item 1 \\
\hline FAC $\$ 2$ & Einal approach checklist item 2 \\
\hline FAC $\$ 3$ & Fi.121 approach checklist item $\$ 3$ \\
\hline FAC $\$ 6$ & Final approach checklist item $\$ 6$ \\
\hline SBck & Speed brakes armed - check. \\
\hline SBSOn & Seat belt sign on annourcament \\
\hline Flaps & Flaps set announcemenc \\
\hline Gear D & Landing gear down announcerent \\
\hline ILLON & Inboard landing lights on announcement \\
\hline
\end{tabular}


Table 2: (Cont.)

\begin{tabular}{|c|c|}
\hline SBarm & Speed brakes armed announcerent \\
\hline NSSOn & No smoking sign on ainouncernent \\
\hline ASon & Anti skid on annourcenent \\
\hline GPWon & Ground proxinity waxning system on announcement \\
\hline Anon & Altitude alest on announcement \\
\hline AAOEF & Altitude alert off anrouncement \\
\hline Locon & Localizer on \\
\hline GSon & Glide slope o: \\
\hline OMon & Outer marker on \\
\hline Mon & Middle mazxer on \\
\hline GPWSa & Ground proximity warning system alert on \\
\hline AltAl & Aititude alers on \\
\hline Dece 1 & Decel command \\
\hline Turn & Turn command \\
\hline Flare & Flare command \\
\hline Chalt & Change Altitude command \\
\hline DCst & starting descent checklist announcenent \\
\hline IACst & Starting inftial approach checklist announcement \\
\hline FACst & Starting final approach checklist announcement \\
\hline DCEn & Finished descent checklist announcement \\
\hline IACEn & Finished initial approach shecklist announcement \\
\hline FACEn & Finished final approach checklist announcement \\
\hline Clrfi & Cleared for landing announcement \\
\hline CIgON & Continuous ignition on ansouncenent \\
\hline MMa & Middle maxker active cal lout \\
\hline ChgRI & "taking control" announcement \\
\hline
\end{tabular}




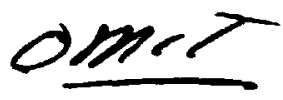

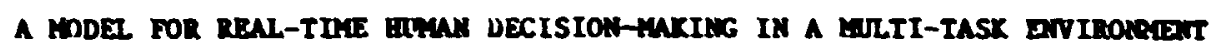

\author{
P. Krishna-Rao
Arye R. Ephrath \\ Arye R. Ephrath
David L. Kleinas. \\ The University of Connecticut \\ Storrs, Connecticut 06268, USA
}

\begin{abstract}
A doniont thrust in future an-anchlne systens appears to be avay from nanual control to partial, If oot full, autonation. In this direction, the role of the hisan operator is shifting fron that of a direct systen controller to one of a monitor of eultiple tasks, or a supervisor of several seni-autonated subsystems. The operator's primary task in these systens is to extract information from his environent and integrate it for action selection and implenentation. Bowever, the iuan brings to the an-achine systen various lnhereat linitations, such as reaction ine delays, linited resolving power and randomess, that linit his ability and degrade the overall systen perforance. In order to properly analyze and evaluate a man-anchine system, clear understanding of hum's capabilities as a real-time lecision anker is Indispensable.

The prejent research has sought to understand huma decision-akking and task selection procedures in dynamic aulti-task eavironment. The approach has been to assimilate the results of a joint experimeatal and analytic progran into normentive cptimal decision moom (ODM) for predicting human task sequencing perforance. To this end, a general wult-task paradigm is developed wherein tasks of different value (priorily), di -ation (processing time), and deadline (opportunity window) compete for the attention of the human operator. This is the type of situation
\end{abstract}


OFIGUANLL FIET IS

OF POOR QiR:ITY

the huran operator eacounters in Ma target seiection, Air-traffic control, oultitargeteing, production scheduling, etc.

The optinal dectsion wodel (ONy) coneists of two separable blocks: information processor and decision-alker. The taforation-processor etinates the statistics of the 'dectsion state' which provides the complete runnins sumery of past actions and estinates. These estinates, along with the task values, are used in a mopic decision strategy, based on sent-Markov dectsioa procese (STDP) formilation, to obcain optian decisione. A novel feature of our wodelins approech is that it explicitly lacorporates huan linitations into the informetor-processing and decision-acking stages. The codel can be exercised eicher in a sempls-path or in a covariance propagation node.

The data are obtained usins buen subjects. The codel-date validation effort consisted of compering (1) the probability of acting on task at tin t; (11) the probability of completins a task by tine t; (111) the incremental reward carned at tine $t$; (Iv) the accumulated revard anraed by $t 100 t$; and $(v)$ the probabllity that the husa conlits an error (1.e., starts on a task he can not complete). Excellent model-daca agrecent was obtained for several experimental cooditions. 
APPLICATION OF OPTIMAL COMTROL PRINCIPLES TO DESCRIBE THE SUPERVISORY COWTROL BEAAVIOR OF AM CREW RIDEERS

\author{
Chris Aale \\ Systens Resench Laboratories, Inc. \\ Deyton, Ohio \\ Capt. George J. Valentino \\ Air Force Merospace Medical Research Laboratories \\ Uright-Patterson AFB, Ohio
}

\begin{abstract}
Supervisory decision anking and control behavior within a $\mathrm{C}^{3}$ oriented, ground based veapon systen is being studied. The progran involves expirical investigation of the sequence of control strategies used during engagenect of aircraft targets. An engagement is conceptuall; divided into several stages which include initial informtion processing activity, tracking, and ongoing adaptive control decisions.
\end{abstract}

Following a brief description of model parameters, two experinents which served as initial investigation into the accuracy of assuptions regarding the inportance of situation assessment in procedure selection are outlined. Prelininary analysis of the results upheld the validity of the assurptions regarding strategic inforation processing and cue-criterion relationship learaing. These results indicate that this wodel structure should be useful in studies of supervisory decision behavior.

\title{
INTRODUCTION
}

Principles of an optimal control wodel ars currently being applied in the study of supervisory decision processes in a simulated MA setting. The control wodei currently being developed in our progran at AFARL is divided into three afor stages; a display processor, an information processor, and a procedure processor. A diagran of the codel organization is given in Figure 1. In the display processing stage, certain display components are selected and differentialiy weighted to yield a subjectively optinized display for further evaluation. The infornation processor then uses this display subset to generate a current estimte of systen state and to detect specific events whtch my influence subsequent systen operatiun. Finally, the procedure processor selects an appropriate procedure based on the combination of systen state and detected events, and implesents that procedure verbally ad/or anually. Th1s procedure selection is the stage which we are primarily interested in investigsting.

We are currently concentrating our efforts on the operation of what we feel is the anjor aspect of procedure selection; the situation assessinent process. This is considered to be of anjor Imortance because the tactical decisions concerning system operation are based on the outcone of this process.

Figure 2 depicts a flow chart description of the selection of a systen operating aode. Inspection of this figure reveals the inportance of the situation assessor in this process. State estimate and event information enter the assessor from the Ralman filter. A percelved situation is output and this serves as data in subsequent processes. An cutcome computer estimates $P_{K}$ and $P_{S}$ for each wode alternative. Each of the oodes is then 


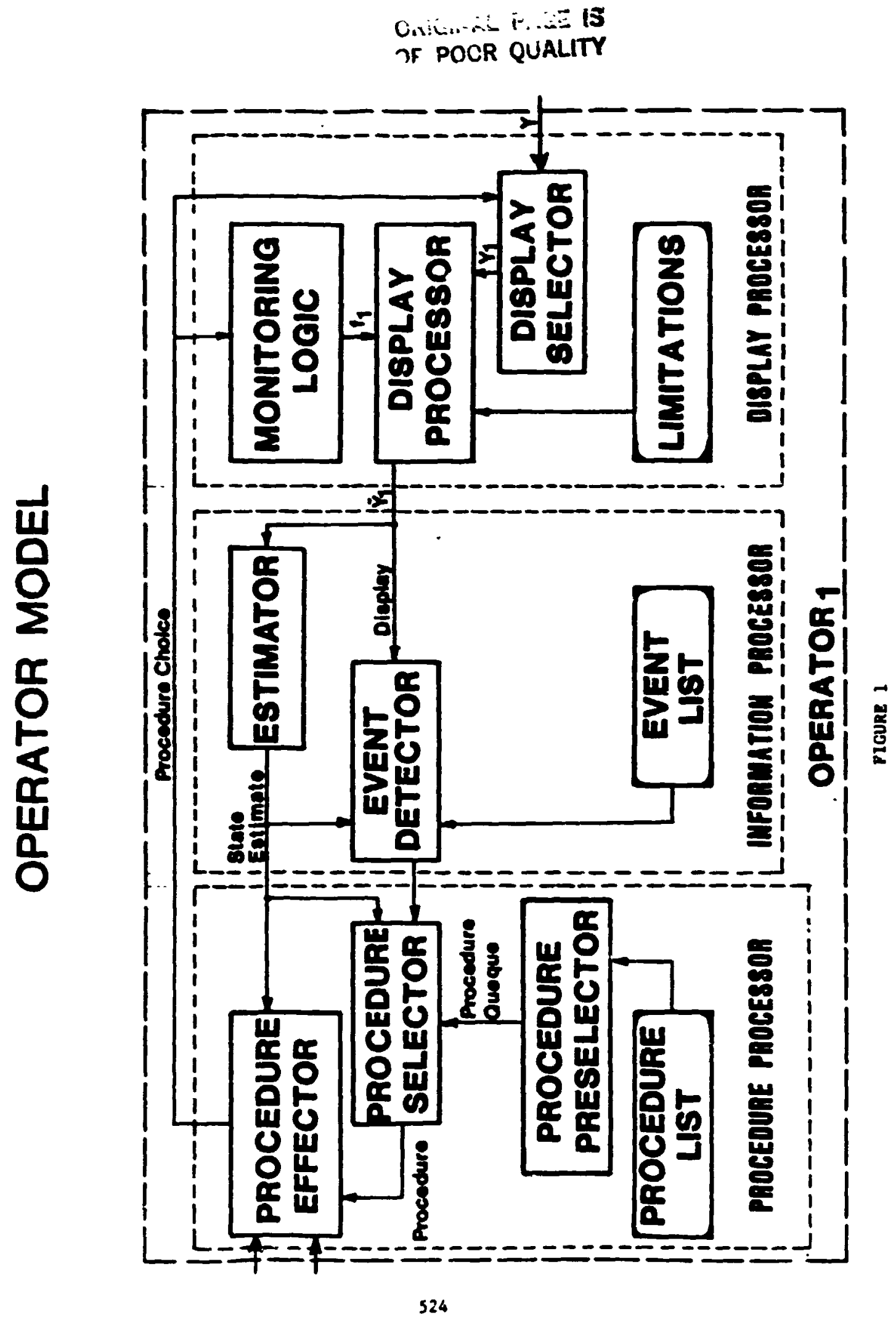


chis:m . …tis

OF POOR QUALIEY

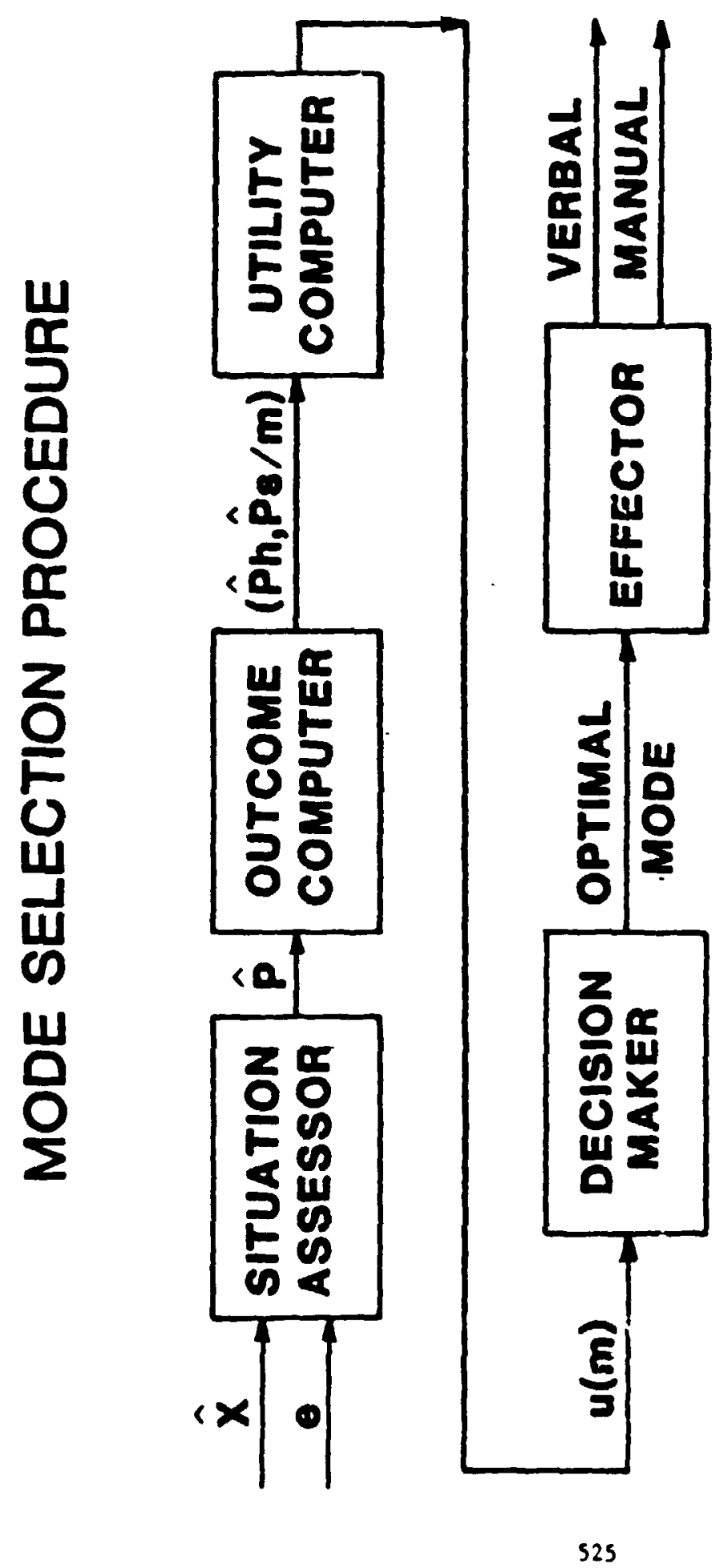

물 
assigned a weight on the basis of expected utility, and the decision naker selects the most optimal mode based on this measure.

One of the major tasks engaged in by the AAA comander in asessing a situation is the learning of the variety of relationships that exist betveen the display subset asociated with an Inconing target and his systen's probability of successfully engaging that target. The inforantion upon which these relationships depend is usully probabilistic, and often inconplete or contradictory. It is critical that strategles which allow accurate predictions of target behavior be developed quickly. The development of such strategies can often be impeded for two reasons. First, as entioned above, is the probabiliatic nature of the avallable daca. Second, the valua of the available information is usually not constant. Since information is differentially valuable, the absence of certain types of inforation froe a total display ay be nore danging to rapid and efficient control perforance than the absence of other types of Information. Two experinents were conducted to explore the implications of these two assertions.

\section{ETPERTIMIT I}

One way of rapidly and efficiently assessing a sttuntion is to utilize only a subset of the cotal informetion display which is anageable, and yet, approaches sowe optinal level of informetiveness. Such a display would vary in form 0 . Ial to trial. That 1s, the anount of information necessary for an optimal wecision alght change across trials, but wore importantly, the type of specific information needed ight change over trials due to the conditional and interdependent nature of Infornation. If, when placed under a time constraint, a comander engages in strategic informetion processing in order to assess a stcuation, the results should be detectable as conditional information hierarchies. The puxpose of this study was to atterpt to expose such hierarchies which subjects ught for when exposed to time constrained Information search requirenents. Subjects were to select an operating wode and target cholce which was appropriate to the Information present on that trial. In order to ane these cholces, it was necessary for the subject to request the information sequentially. The task was structured such that it was not possible to access all available information before the end of a trial. Thus, the subjects had to search for an optins.l informational configuration on each trial by bullding the display elenent by element. We expected that this requirenent would result in differentiai display construction. This $1 \mathrm{~s}$ because the nature of the situation process requires a display wich possesses enough informetion for an optini cholce apong alternatives, while at the save time keeplng the anount of Information within manageable ilates. These two conditions are satisfied only when the display conforws to certain configurations defined by the interteletionships of the information present on that given trial. Because of this, recelpt of each new plece of information should influence requests for subsequent information such that a pattern of informational interrelationships should emerge.

Information was displayed on a Vector General CRT and consisted of four categories; trajectory of the target (flyby, zigzag, fink), and presence or absence of ECM, OCM, and ARM. In order to obtain specific inforation, 
subjects had to activees a sertes of category request buttons. Informacion requents could occur ooly at S-second Intervals. Spectfic inforwition recelved followlas ench request was randouly deterndaed.

On balf the trials, one target was present and on the other half, cwo targets were preseat. Ou double target trials, appenrance of the second target followed the flrst at an lacerval of betwen 2 seconds and 14 seconds. Whenever a second carget appenred, the potenetal informeton set doubled in sta.

The resultes of each ertal were represented accordtag to a dectator eres forme (Figure 3). Analyals indicated ehat opetinal display conseruceion did lodead follow a pactern which resulted in displays chsracterized by condieloonl locerte dependence. That 1s, the ordinal relationships betreen category requants vere conditional upon the specific information recelved at each request. This supports the 1dex that sfeuntion assesseent is a process charscterlied by senceh strategies resulting in displays which allow opctanl seate estinetion and subsequent procedure selection. Further anelysis, alchough still in progress, has resulted in esetantion of coodiclonal

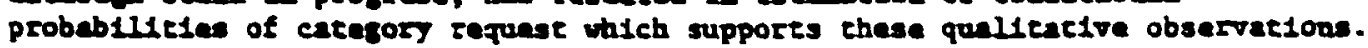

\section{mexposir II}

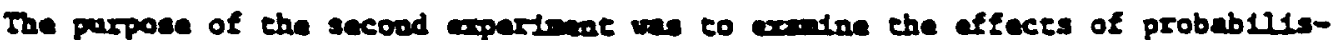

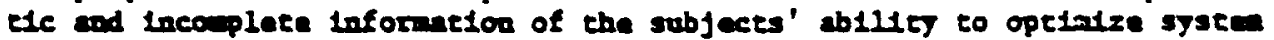

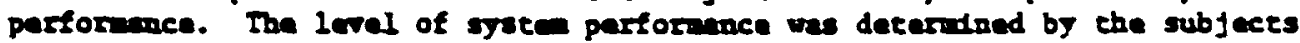
ab1115 to lens the relationohtps that adsed betwen the given toformat100 and bls/ber subsequeat concrol behaviors. These cue-criterton relaelooshipe were ravenied by a teadbeck antric thich lodicated a oonentary

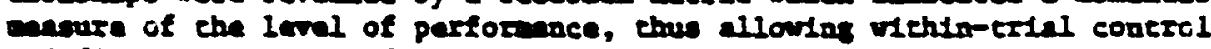
oodiflcations which, if correct. could resule in performance isprovernent.

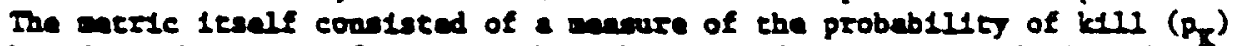
based or the range of ecetows that the connoder ase take durting the course of an engagemat. These include selection of operacing mode, firing range, and burse duracton.

Oa each trial subjects recelved probabllistic toformat100 regardiog che presence of countermasures (ECM, OCY, AMY), a vell w identification of the carget's trafectory, and target postition laforantion. Counteranasure probeb1115 toformetion ranged from 0 to 1.00 and wen normally distributed $(\bar{x}=.50 ; 50-7.20)$. At son predeceratined range the probabilities chinged to eleber 0 or 1.00 to ladtcate absence or presence of the counternearure. The trafectory of the target was ade avallable at a range of $7.3 \mathrm{k}$ and res elther a Elfoy, z1gzas, or jlok. Target position inforantion locluded range, extrith, and clestude and vas avaliable in proportions of eleher $.33, .66$, or 1.00 . On each trial ehe subjects eack was to select an

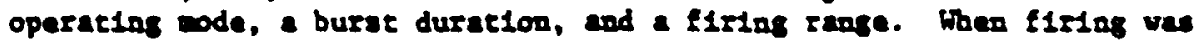
latelated, burst duration and a j-secood forced delay between burses were compuer controlled. Durlas flrlos, aubjects recelved an lancancuneous $P_{R}$ score which was updared each second. The score wa besed on the characteriatics of the target, the burst durat1on, ade chose, and range et each secood of fire. At any tim during flrias, subfects could stop fire and 


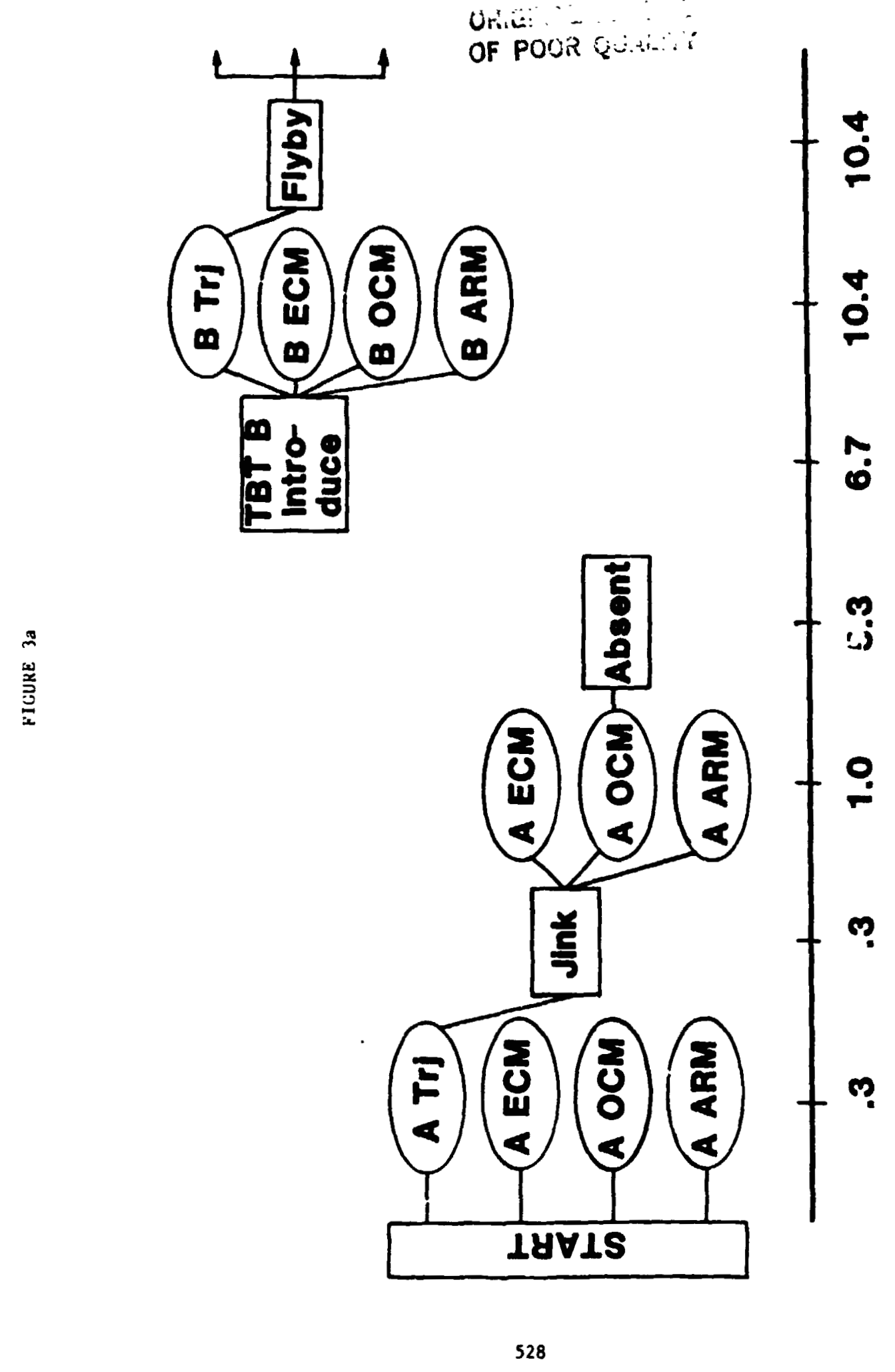




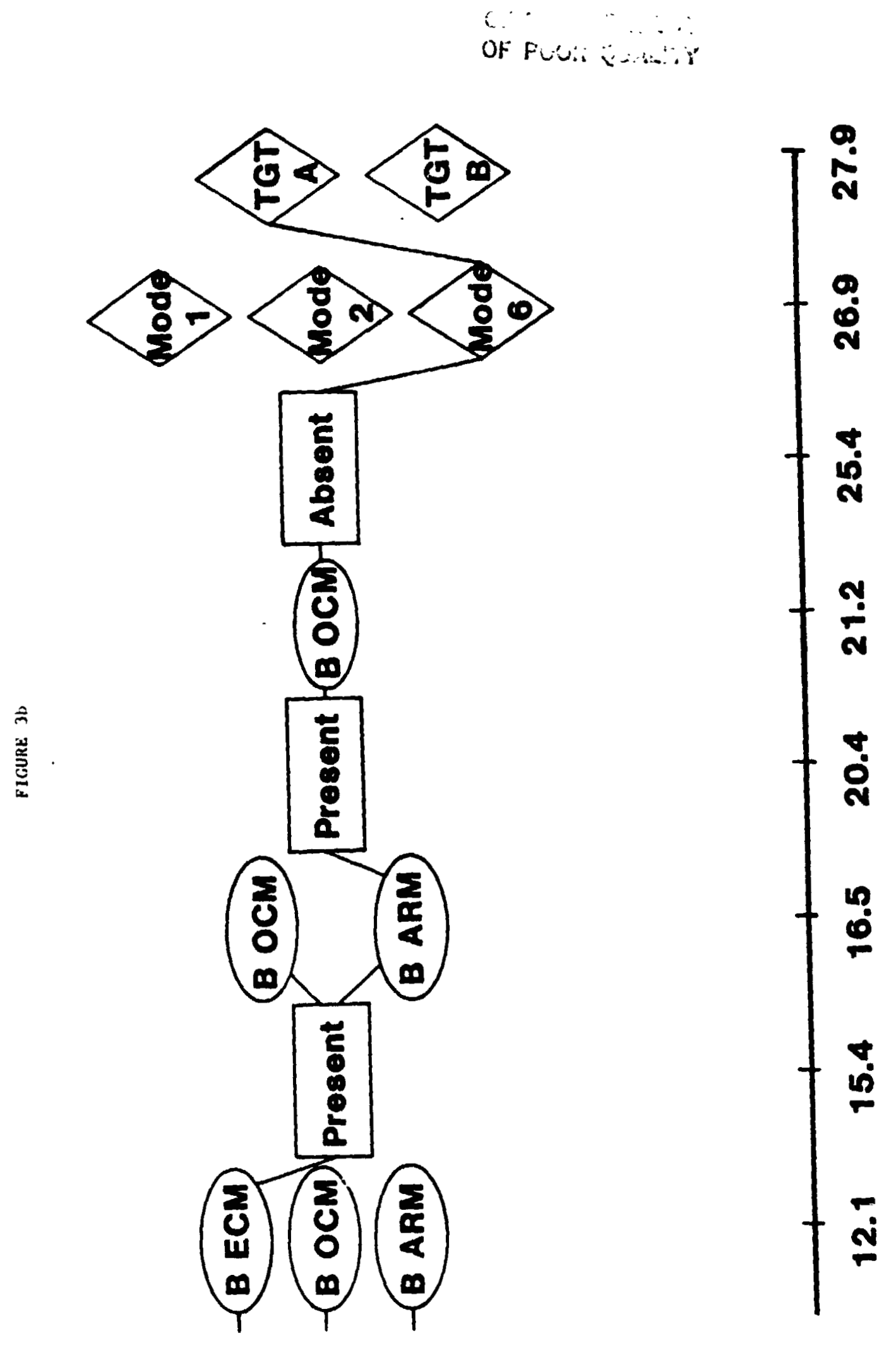


execute any sertes of actlons; changes in mode, firing rate, etc. At the end of each trial, a cumulative $p_{K}$ based on intrat-ial performance was displayed.

The analysis of this data was based on the following assumption. When presented with suboptimal displays subjects possess the capability of learning the relationships between these displays and the control actions which will result in optimal system performance. Th1s deductive capability would be realized as an ablifty on the part of the subject to discriminate among the alternatives available to him/her. Such discriminative ability should be sensitive to statistical analysis. Accordingl;, two discriminante analyses were performed using the display elements as predictors and mode choice as the variable to be discriminated.

\section{RESULTS}

The first analysis considered only the presence or absence of target position information, in addition to trajectory and countermeasure probabil1ties. A stepwise analysis was performed using the minimum $D$ squared selection criteria. Seven of the elght variables entered the equation; the only variable not contributing significantly to discriminative power was altitude information. The two discriminsnt functions resulting from this analysis accounted for all of the mode selection varlability, wth the first function explaining 94.09 percent of this variabillty. Both the final wetghts attached to each prediction, and the order in which varlables were entered into the equation, support the Idea that subjects were engaging in a selective information evaluation process, the Intent of which was to evaluate the utilfty of each avallable alternative, eliminate those which vere Inappropriate, and select the one which would yleld the highest expicted performance.

The final function, with seven of the eight vartables considered, revealed that crajectory name was the most neavily welghted variable, followed in order, by the probabilities of ECM, ARM, and OCX. The presence or absence of target position information resulted in low, although still algnificant, welghtings. These weights indicate that subjects were comparing the alternatives against one another primarily on the basis of that information which would allow the most rapid discrimination among, and elimination of, modes in terms of their defining characteristics.

This interpretation is supported by the order if entry. At the Initial step of the analysis, the variable providing the most discriminating power was the probability of OCM. Th1s seems to Indlcate the subfects were Initially evaluating the alternative set on the basis of the utility of radar capabillty under the conditions presert, thus allowing an inttial crude evalua$t$ Ion of mode ut1litlep in cerms of the mos sallent separating feature of the mode set. Step 2 uf the analysis (probablilty of ECM entered), 1mplies that the subject 18 attempting to furthrr discriminate among radar vs. nonradar ut1lities. The entry of trajer sry name on the third step, and probability of ARM on the fourth step, confirms this 1dea. At this point, the subject is now able to discriminate maximally between all three mode alternatives in terms of the usefulness of eacil. Further entrance of predictors into the equation results in little increase in discriminative power. 
A classification table indicated that a total of 79.25 percent of the cases were placed Into the appropriate group wabersh1p category by the discrialnant functions. The anjor source of exror in the overall classification was due to a complece inability to correctly claselfy mode 2 selections into the approprtate group. Only 2.1 percent of such cases were correctly classifled. This is compared to correct classifications for wodes 1 and 3 of 61.8 percent and 90.5 percent, respectively.

The second analysis considered those trials on which the sctual values of tise position information was available. The outcom of this analysis took a somewhat different form than did the first analyais. With regard to variable weightings, two types of position information, alug with trafectory ane, asounad the most imfortance. These two were az1muth and altitude information. The order of entry was also different from the fi-st analyals. Azlouth information was the first to cater the analysis. This is not surprising. since the presence of thls value allows subfects to accurately infer the trajectory of the target, as well as obtalning azdmith informat1on. Given this knowledge, the next three sost important types of information were the probabilities of BCY, ABY, and OCY, respectively. Agatn, this is in line with the idea that subjects were atterpting to eliminate alternatives, and thus uncertainty on the basis of defining characteristics of the wodes. Thus, on those trials when ECY probubllity was low, the next mot Important conaideration wes the probabilly of ARM. Once this probebilfty had been evaluated, OCM probebillty, by virtue of 1ts lafluence on node 6 usefulness, was evaluated. Inspection of the level of discriminability revealed that, beyond this polnt, the entry of other predictors contributed very little liscriminative power.

The classification table for this analysis revanled a successful group membership prediction of 83.47 percent. Again, the anfor source of classif1cation erro: was the inability to correctly predict mode 2 ambership. Of the mode 2 selections, 4.30 percent were incorrectly cleselfied as belonging in the sode 1 group, and 95.70 percent were incnrrectly placed in the ande 6 group. Seventy-six percent of the mode 1 selections were correctly classifled in th1s analysis, and 90.90 percent of the wde 6 cholces were placed correctly.

P1nelly, we feel that some comments are uarranted concerning one of the mote etriking aspects of this experimed, thet is, the complete inability to accurately predict mode 2 selections on the besis of the 1nformation avallable to the subfect. Sow reflection on the properties and capabilities of the three oodes Indicates that, perhaps, this result should not have been totally unexpected. Activation of sode 2 requires that the subject utilize aapects nat are ind1genous to both modes 1 (radar range Information) and 6 (annual az and el estimation). Thus, sode 2 can be chought of a falling along a continuw betwaen modes 1 and 6 . Since the informetion that is belig welghted sost heavily by the subject has the greatest affect on elther mode 1 (trajectory, BCY, ARY) or mode 6 (trajectory, OCY), and slace the strategy of the subjects seeme to be based on rap1d, and somewhat noncompensatory, elimination of alternatives, ade 2 is of ten eliminated from consideration along with elimination of the sode whose defining characteristics are being matched against target attributes at that tep in the decision 
process. This leads to the result that, in the few cases in which mode 2 is selected, it is almost imposible to classify correctly because the variables used fin classificacion are not considered to apply primartly to mode 2. In short, it appears that conceptually mode 2 has no unique defining characteristics.

\section{CONCLUSIONS}

Preliminary analyses of these data indicate that the following conclusions are ncssible.

1. In order to assess a situation optianlly, subjects will engage in strategic Information search designed to extract maximum usefulness from a display, which limits that display to a size that is within huoan processing linitations. Th1s will result in a limted number of display structures characterized by hierarchles which are defined by the Interdependencies of the Information set.

2. Subject's control decislons are based upon an ability to Infer the relationship between information displays possessing sisoptinal valldIty and a subsequent outcowe. This capability manifests ltwelf as an ability to discrindnate, from anong a set of alternatives, that alternative which will maximiz, the cue-criterion relationohip, as indexed by outcome feedback.

Subsequent work in our laboratorles related to these twm experiments will focus on the structuring of the various information search and processing strategies employed by the commander and on the factors which influence the activation and use of these various strategles. Additionally, we plan to investigate variables effecting the cognitive activic; lnvolved in the comander's utillzation of the relationohip between external conditicis aud his knowledge and creative we of syoten capabilities. 
Douglass R. Arnott

13 Devonshire Place Hunt ington station Nev York 11746
T. Govindaraj

School of Industrial Engineering Purdue University, Grisson Mali Hest Lafayette. IN 47907

\section{ABSTRACT}

Control of a slowly responding complex dynaic system such as a large supertanker poses special probiens for the human. Forming an internal wodet of such a systee is wore difficult then that of systens whose response characteristics match those of the hums wore closely. For instance, due to slow response, quick control actions such as those required in flying an aircraft are not needed. Instead control actions must be besed on inforaction over a inger tiae span. The model should have appropriate features to handle such situations. It is not clear as to what types of display aids might be helpful in forming the internal wodel and/or for better control. Experinents were conducted to study this problen. Experienced ship's crew members aneuvered a sieulated ship in real tive. The simulation was periormed using a graphics display run by a PDP $11 / 40$ minicomputer. The vaneuvers consisted of piloting a large ship along a narrow waterway. Pret ivinary results suggest that the huan operztes as a feedforward controller utilizing the previeu information for 'gross changes' in heading, and as a teerback controller for correcting suall deviations. The instrunents displyyed on the deck do not seem to be helpful in all situations. In fact, evider ce seems to indicate that some of the displays might even interfere with the pilot's attempt to form a good internal model.

\section{INTRODUCTION AMD MOTIVATION}

Traditionally, in ship simulators and in crew training the basic operating hypothesis has been based on task behavior training. The crew were trained in operstions unere they could respond to a set of stimuli in a pre-deternined fashion. This had its origins, perhaps, in airplane simulators, and other operations where enough time was usually not available for detailed aralysis of the state of the system. When sufficient time is not available for thinking through - pioblen it becomes necessary to use strategies whereby conditioned responses substitute for fast and timely actions.

Such a situation does not prevail in the operation of a ship due to the slow changes in speed and heading. If the crew has sufficient tidining it is possible to have a good internal model of the ship and be able to control it based on the actual state. In fact, in aircraft operations it is vell known that the pilot operates as if he has a good internal model. Usually, the huan operator uses information provided by the system as feedback to correct for errors and, generally for inproving the performance.

Hovever, in slow systens such as piloting a ship, feedback may not always be helpful. Feedback sould prevent the form 3 tion of the internal nodel initiclly, 
and/or interfere with the operation of the internal nodel later. When the operator has an insufficient codel 0 i the systee under control, it is possible that he fails to analyze the situation carefully and acts iapulsively based on the feedback inforation. Under these conditions, it as be advantageous to rewove some (or wost) of the feedback displays so that he is forced to think through the situation and act accordingly. Even in cases where feedback is helpful, proper fore of feedback is essential. Relevance of various instruments, and quantitie. to be ceasured and displayed must be carefully chosen. Understanding what $t$ aponents are impo ant, wat the input/output relationships are etc are ieportant. Experiments were conducted to study various factors discussed above. adeling efforts are being ande to understand better the various quentities involved, and how they affect performance.

Depending upon the familiarity of the huan with the system under control one or wore of the following codes of inforation may be used by the huan. The operation could be open loop or closed loop, or some form of feedback and/or feedforuard inforeation could be used. Instruments ay reflect comanded quantities and response quantities. These se some of the issues to be considered in the experiments and in codeling.

\section{EXPERIMUNT}

Dynaics of a large supertaniker of 250,000 dut was siaulated on a PDP $11 / 40$ computer with the VTII Graphics system. A cock up of the ship's console was used to control the dynatics of the ship. The console had ship's wheel and throttle control. The equations of cotion were taken from constock.

The display generated by the computer is shown in Figure 1, and is siailar to the view from the bridge of a large supertanker. The ship's bow remained fixed and the background moved past the ship. A three dimensional view was presented corresponding to the observer's height of 80 feet. The instrunents available for display were: compass, rate of turn indicator, tachometer, rudder angle indicator, speed indicator, and tiwe display. Any combination of the displays could be included in eny particulor experieent.

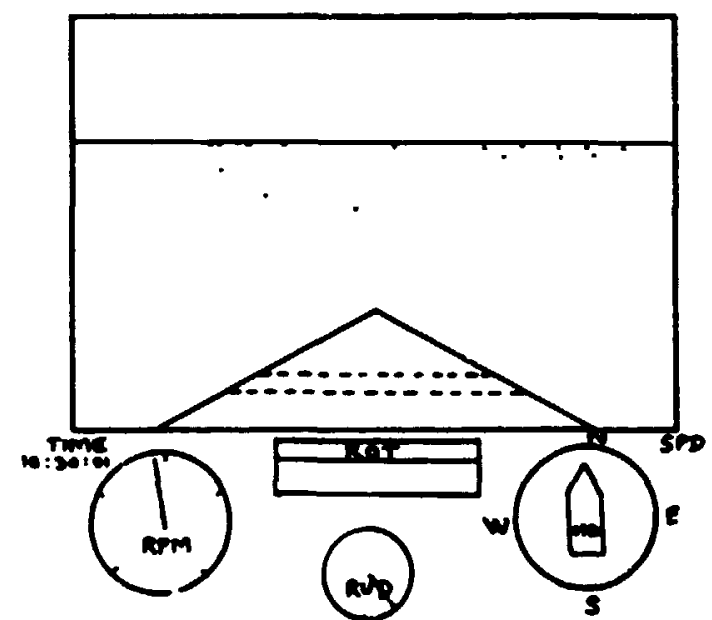

Figure 1 
The anneuvering area of the ship was based on the Savarnah River, with some codifications to accomodate a supertanker, and to take into account the liaited capabilities of the computer. The essential detsils were included houever, and the scenario provided opportunites for a nuber of different maneuvers within $21 / 2$ hour tine period.

The subjects vere instructed about the operation of the ship, and vere shown the lay out of the buoys that define the course. During the experinent. they had access to a chart of the course. The basic aneuvers to be perforaed by the subjects were:

1. Accelerate and enter the moin buoyed channel from stopped position.

2. Turn in the chennel ot various angles and speeds.

3. Enter a buyed channel, decelerate and remain at a slower speed.

4. Maintain set heading of the vessel.

The experinent consisted of four phoses. In the first phase, all the displays were available. The passage was up the river. The subjects were instructed in the proper use of the controls to obtain desired response. Some of the important characteristics were explained. In particular, the subjects vere instructed as follous:

1. A strean of water over the rudder is needed to produce a radial acceleration. This could be achieved either by a forward velocity of the ship or by an increase in propeller RPW. For a given formard velocity, on increase in RPM would increase the velocity of the streen of yater over the propeller.

2. Control of the ship could be achieved by acceleration. Rate of Turn (ROT) and speed reflect 1 any changes in control.

In addition, maxiaun rudder rate and RPF acceleration were pointed out to the subjects ( $3 \mathrm{deg} / \mathrm{sec}$ and I RPm/sec respectively.) The subjects were also oware of a slight instability in the ship's dynamics.

In the second phase, the subjects were alloved two instruments of their choice. The reeaining instrunents wer? not available. As in the first phase, the passage was up the river. The subjects were trained in such a way that nost of the instruments becane unavailable for feedback. At the end of this phase, usually lasting a single run, the subjects had enough training to be able to maneuver the ship without any instrument.

No instruaents were available for the third phase. Hence, it was not possible to apply some input and watch the effect on the instrinent display. The only feedback was by observing the view fron the bridge after any control input. Due to the inherent sloviess of the dynamics of the ship, the controls had to be carefully chosen, based on analysis of the situation. since 30-40 seconds would have elapsed before the results of sone response would be evident in the view tron the bridge, inmediate teedback yould be all but impossible.

in the fourth phase, inst:uments vere nut ovailable, and the passege was down the river. This forced the subjects to spproach the turns at different speeds l zing different plans for the maneuvers. Therefore the course seemed quite different is the subjects. This phase was used as the final test ing of the subjects' control behavior. 
During the experiment, infornation concerning inputs (rudder angle and throttle (RPW) requests), and the position of the ship (coordinates) was collected. The data were collected for all phases except for the second phase when the subjects were trained to pilot the ship without the use of feedback displays (instruments). At the end of every aneuver, the subjects wre also asked to fill out a questionaire concerning the efforts in performing that maneuver.

Since the lateral control was achieved by changes in radial acceleration, produced either by using the rudder angle or by changing the RPM of the propeller (or a ccebination of both), the control input of the subject was converted into an equivalent rudder input. For given comination of rudder and throttle inputs, the equivalent rudder input was calculated as that input that would produce the same rate of turn if rudder alone were to be applied. This is based on the assuaption that the subject used a combination of controls to get sone desired radial acceleration. It is presuned that the input applied was chosen eainly to get the desired radial acceleration.

\section{THE SUAJCTS}

Four subjects participated in the experisent, involving wore than fifty hours of simulated operation. In teras of Us Coast Guard Licenses, two (6SA,RPH) were "Third Mates of Stean Vesssels of Any Tomage, Upon Oceans". In addition, they were licensed "Third Assistant Engimeers of Steen and Hotor Vessels of any Horse Pover". One of then (RPW) also had the classification of "Chief Engineer of Uninspected Towing Vessels of Any Horsepouer, Upon Rivers." The third subject (FE6) was "Chief tate of Stean Vessels of Any Tonnage, Upon Oceans." The most experienced subject (DAH) is "Master of Stean Vessels of Any Tonnage, Upon Oceans." Since all of them had a lot of experience in real ships, their transition to the simulator was seooth and fast.

\section{POSSIBLE MODES OF CONTROL}

The main control characteristics of interest concern - Lateral sotion of the ship along the channel. At various points in the course of the aaneuver, the ship had to make turns at va ious angles and at various speeds. It is our desire to be able to codel the control behavior in terms of some analytical wethods. Possible wodes of control are: open loop control without making use of any form of feedback (utilizing only the feedforward inforation about the desired course), closed loop control with feedback from instantaneous feedback from the instruments on the bridge, closed loop control besed solely on the information abtained from observations on the deck, and a combination of various feedback and feedforward controls. It is also possible that the controller is capable of separating :he controls into one or more regions, and identifying proper course of action. Appropriate controls can then be applied to get the desired performance.

In a purely open loop system, for changes in heading, the control action would be based on the difference between the feedforvard inforation and some fixed reference. The resulting control would consist of single pulse or a step of finite duration to initiate turn, and a similar action in the opposite direction to bring the ROT back to zero. Unless the control system is calibrated to compensate for any directional instabilities, no additional control actions will be involved in the operation of such a systen. 
On the other hand, in a closed loop system, the control actions would be based on the error between the desired heading and the actual heading. Since there would be some error until the desired heading is resched, continuous control vill result. In practice, this would anifest itself as a muber of pulses closely spaced together. Control would be zero only when the error becones zero.

It is also possible that the subject merely functions as an open loop (feedforward) controller as long as the error reasins within some tolerance limit. When this liait is exceeded, action is taken to reduce the deviation and linit the drift. Depending upon the tolerance the subject has for the error or deviation there could be additional control pulses along the course of the turn. This situation would result in a control behavior having a nuber of pulses at various points in time. This would be someuhere between the comoletely open loop and completely closed loop systems.

\section{EXPERIMENTAL RESULTS}

The discussions of the previous section are meant to provide a franework for analyzing the results of the experinent. In this section, results for all four of the subjects are discussed. (Detailed results are given in Arnote ${ }^{2}$.) Each subject will be considered separately in an effort to understand the possible mode(s) of operation.

From the results for subject fE6, it appears that he behaved as a feedforward-feedback controller wost of the time. Though only feedforward con trol is used initially (open loop), apparently error builds up rapidly, and there appears to be a need io compensate for the error by usiny proper amount of control aleost continuously. Equivalent control inputs increase after an initial open loop-like behavior. He could control the ship without using any of the instrument displays, though the control effort appeared to be much more than that required when feedboit from the instruments were available. But according to the response from to the questione ire, $h$ is stress level was lower when there were no instruents. Apparentiy this indicates that his visual workload was reduced when instrument displays were rewoved. The perfaraance in holding a steady course did not suffer when the displays vere absent. Renoval of the feedback displays did not seem to affect his performance in any of the phases.

In turns, OAH seemed to perform as a feedforward-feedback device. However, in some turns his controls were almost continuous, similar to that of a closed loop controller. His ability to hold a steady course without the instruments was not as good as having then to aid in control. Apparently it was difficult to get sufficient information about the course of the ship without the aid of displays. In fact, the information in the questionaire suggests that he wight be trying to obtain the information fros the display of the environment. The response to the questionaire suggests that he could be using the inforation more efficiently by analyzing the situation more carefully and using the internal model more effectively.

There was a tendency for GSA to act as a closed loop controller when instrument displays were available for feedback, and also when he transitioned into mode with feedback displays removed. Apparently he could not develop a sufficiently accurate internal model and had to rely on feedback information either 
from the instruments or fron the view from the bridge. As experience increased, he started to act wore like en oren loop controller or a combination of feedback-feedforward controller. From the questionaire and frce the data on control and track, it appears that the feedback displays interfered with the formation of a good internal model. He devoted so much tiee to the inforaation dislayed on the instruments that he coucd not think about the consequences of any action.

When the displays provided the feedback, the subject RPH was controlling wore like an open loop controller. Later, with more experience, he started to act wore like - feedforward-feidbuck controller. His oerformance did not suffer appreciably when feedba:k information provided by the instrunents was absent.

\section{DISCUSSION AMD POSSIBLE APPROACMES TO MODELING}

Though the experiments were rather detailed, the results are preliminary. These results seem to suggest that conbination of feedforward and feedback inforation is used by the subjects to control the ship in lateral wotion. From the results obtained when the instrunents vere available it appears that they were not always helpful for control. In fact, during some phases they wight have been a hindrance because of the aisleadirin information about control assulting froe the responses of the instruments thease'ves. They light also have increased the subject's workload.

then inforation concerning the future trajectory is available for some tibe it has been found tiat the humen uses a combinatjon of feedback and feed forward controls. In particular, the work of Donjes ${ }^{3}$ on codeling the car driver seens relevant. He found that gross changes in dirertion were controlled as if the control was open loop and ninor deviations from the desired trajectory were then corrected in a closed loop fashion. In a preview control task, Govindaraj and Rouse obtained siailar results. It was found that some form of feedforward and feedback inforaation was used for control. It was also found that control was applied only when the perceived error exceeded a certain tolerance level. Control was therefore interaittent. This type of control behavior was characteristic of any of the subject uns in our experiaent.

modeling efforts are undervay to study this type of control. In particular, it will be interesting to find out if there are thresholds for errors and/or controls. This wight give an indication of the relative anounts of feeöack and feedforward information. Detailed experieents will then be conducted to verify the modeling results. The nodel wiglt also be helpful in understanding wich of the feedback displays are more useful and which wight even be haraful in the developent of good control habits.

It is possible that there is a hierarchical control approach that the pilot uses in contr 1 . Depending upon the relative iaportance of various errors (or some other information) control might take different forms. Different levels in the modei wight be able to take care of appropriate phases in the information. Delegation of authority for control to different levels wight be done by some siaple device such as a comoination lor pass-high pass filter or some other complex mechanism. These and other possible methods will be explored in greater detail. Models developed will be validated by running detailed experiments. 


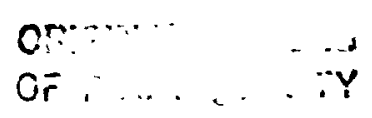

\section{ACKMOULEDEMENT}

The coefficients in the equations used for the simulation were provided by Marine Safety International, and are their proprietary property. Their help and cooperation is gratefully acknouledged.

\section{REFERENCES}

[1] Comstock,J. P., Ed., Principles of Navai Architecture, The Society of Maval Architects and Marine Engineers, Mey York. ?967.

[2] Arnott, D. R. "Evaluating Man as an Open Loop Control Device in a slow, Complex, Oynamic System". M.S. Thesis, Departeent of Mechanical and Industrial Engineering, University of Illinoss at Urbana-Charnaign, 1980.

[3] Donjes, E. "A Two-Level Model of Driver Steering Behavior", Muan factors, Vol.20, No.6, Decenber 1978.

[4] Govindaraj, T. and Rouse, H. B. "Human Controller Modeling in Environments that Include Mon-Control Tasks", Proceedings of the 18th IEEE Conference on Decision and Control, Fort Lauderdale, Florida, December 12-14, 1979. 
Supervision of dynamic systems:

Monitoring, decision-making and control.

Ted N. White"

DELFT UNIVERSITY OF IECHNOLOCY

The Netherlands

\section{ABSTRACT}

Effects of task variables on the perf-rwance of the hum supervisor by means of wodelling techniques are aiscussed. The task variables considered are: The dynamic3 of the system, the task to be performed, the enviromental discurbances and the observation noise.

A relationship between task variables and parameters of a suparvisory model is assumed. The model, reported by Kok and Van Wijk consists of three parts: (1) The observer part is chought to be a full order optieal observer, (2) the decision-making part is stated as a se: of decision miles, and (3) the controller part is given by a control 1 as.

The observer part generates, on the basis of the system output and the.consrol actions, an estimate of the state of the system and its associated variance. The outputs of the observer part are then used by the decision-making part to determine the instants in time of the observation actions on the cae hand and the controls actions on the other. The controller part makes use of the estimeted stat co derive the sititude(s) of the control action(s).

In adrition to the identification of the model parameters, b' a random searct, method, a more paychologically orieuted method is use1, primarily based on statistics. The psychological approsch deals with a direct comparison of the aumber of control actions, the amplitudes of those control actions, and the number of observation actions generated by the operator as a function of the task variables mentioned before.

The system theoretical and the paychological approach will be discussed and a comparison of the reaults, using both approaches, will be given.

- This research is spoosored by the Metherlands Organization for the Advancemeat of Pure Research (ZiO). 


\section{ORIGINAL PAGE IS \\ OF PUOR QUALITY}

\section{INIRODUCTION}

Due to the ever increasing automation in industry the task of the human operator has shifted from direct manual control to supervisory control. However, this task still can be considered as a control task, but on a higher mental level and of a discrete character. This means that only when deviations of the observed rariables beyond the specified boundaries are detected, due to failures and/or disturbances in the automated syster. corrective actions are initiated. Thesefore, the task involves monitoring the system, as well as decision making and control. For the optional design of man-machine interface (RAIF) a profound understanding of the supervisor's behavior is necessary. This can be obtained by modeling the huwan operator's behavior, for instance during supervision of a system in steady state mode. For this purpose descriptive models, or normative models, can be used.

\section{IÉSCRIPTIOS OF A SUPERVISORY YODER}

In this paper ve consider the rerification of a normative model describing the human operator control of slovly responding complex systems.

The model is based on the concepts of the Optimel Control Model [Baron, Reiman 1969; Keimmn, Baron, Levison, 1971] and wes proposed by Kok and Van Wijk [3].

The purpose of the model is to describe man behavior in relationship vith a set-point controlled process in a stendy state mode.

The model is based on the bypotheses that the operator has knowledge about: o the system dynamics,

- the statistical properties of the disturbances acting on the syatem and o the task to be performed.

It is assumed that the operator's knovledge is perfect, that the model can be described by a set of libear differential equations and that the system is relatively slor in comperison to the neuro-muscular system of the bumen being. The structure of the wodel is rurther kesed on the bypotheses that the operator eatimates the state of the system independent of the control task. So, the seperation theorem of optimal inear siltering and control is accepted beze is a basic mechanism of the operator's behavior. The model then consists of an observer part, a controller part and a decision making nart (see Fig. 1).

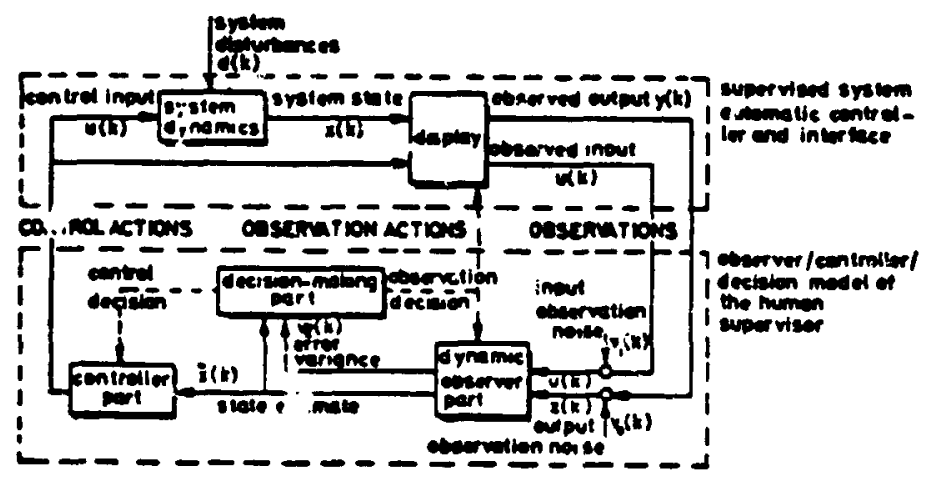

Iig. I The model of the buman operator 


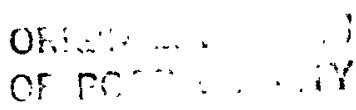

The observer part models the observation behavior of the supervisor.

Based on the knowledge of the system dymanics, the values of the observed output variables, the noise statistics and the applied inputs on the system, a reconstruction or estimate $\underline{\hat{x}}(t)$ of the process state and its associated variance $V_{Z}$ is generated by the observer pert. The reconstruction mechanism is modeled by a Kalman predictor algori.bm.

The controller part determines the amplitude of the discrete control actions based on the estimated value of the state.

The runction of the decision making part is twofold. Using the estimated value of the state and its associated variance, the decision makins part determines the instants in time that new sbservation actions are to be taken as well as the instants in time that a controller action should take olace.

The decision making part for the observation actions (D.O.) is modeled by a hyperbolic decision line, whereas the decision making part for the controller actions (D.C.) is modeled as a straight decision line.

See rig. 2 and 3.
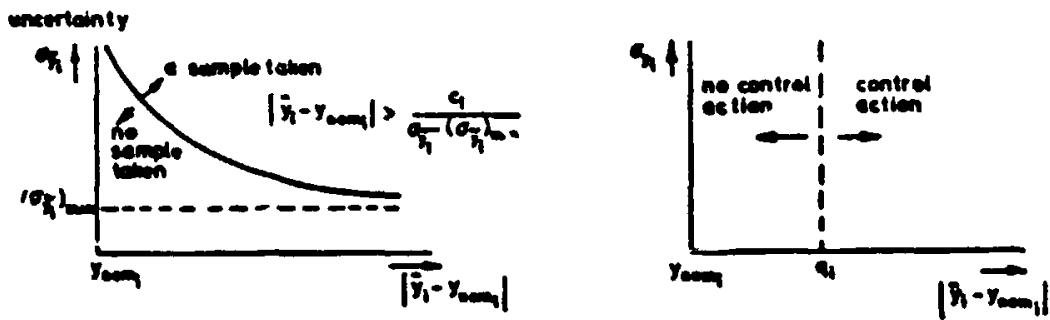

Pig. 2, 3 Structure of the Decision Making Part

The parameters are; $c_{i}$ - the curve parameter of the decision line, $\sigma_{\mathbf{y}_{j} \text { min }}$ - the minimal accepted uncertainty and $q_{i}$ - the upper or lover tolerance 5 lated to the aominal output value, where $i$ denotes the $i-t h$ outout varisble and $g_{i}$ the estimated output variable.

\section{MODEL ITPOTHESES}

For the verification of the $m$.del we consider the so-celled task variables in relation to the outputs of the model.

The (independent) task variables are: o the dyanic of the system

- the noise parameters

o the display structure and

o the supervis?ry task to be pertormed

Fram the behavior of the operator there are quantities which can be measured directly such as:

- the aumber of observetion uctions

0 the sumber of control actions and

- the amplitude ce the control actions 


\section{OFIGIAL PAEE IS \\ OF POOR QUALITY}

Since the quantities measured are the observed outputs of the supervisor, they should be related to the structure of the model.

As variations in the display structure can only effect the himan pattern recognition and reconstruction of the state, it is postulated that:

o the effect of the task variable "variations of the structure of the display" will be sllected in the nuz jer of observation actions and not in the number of controller actions.

It is rurther postulated that:

- the effect of the task variable "variations of the intensity of the system disturbances" will be zerlected in the number of control action. and in an additional number of observation actions.

It rill, however, not be reflected in the mean of amplitudes of the controller actions. See Table 1.

Table

Number of Obs.Act. Number of Contr.Act. Amplitude of Contr.Act.

Variations of the intensity of the system disturbances

Variations of the display structure

\begin{tabular}{|c|c|c|}
\hline$x$ & $x$ & \\
\hline$x$ & & \\
\hline
\end{tabular}

In a later phase hypothesies with regards to the parameters of the three different parts or the model will be postulated and rerified.

\section{DESCRIPTIOA OF THE PRJCDSS}

To rerify the model hypotheses a computer simulation of a linear slow responding more or less complex system wes developed. He took an example studied by Camobell and Shirley [4] srom the Foxboro Company. The setpoint santrrilled prucess (utility plant) consists of a boiler, a backpressure turbine and a condensing turbine. The process bas three inputs (s high pressure controller, a how controller of the low pressure steam and a powter controller) and three outputs (the pressure of the high pressurestear, the flow of the low pressur 2 steam and the totel amount of electricity produced. See tig. 4 .

The process is disturbed by first order flitered white noise.

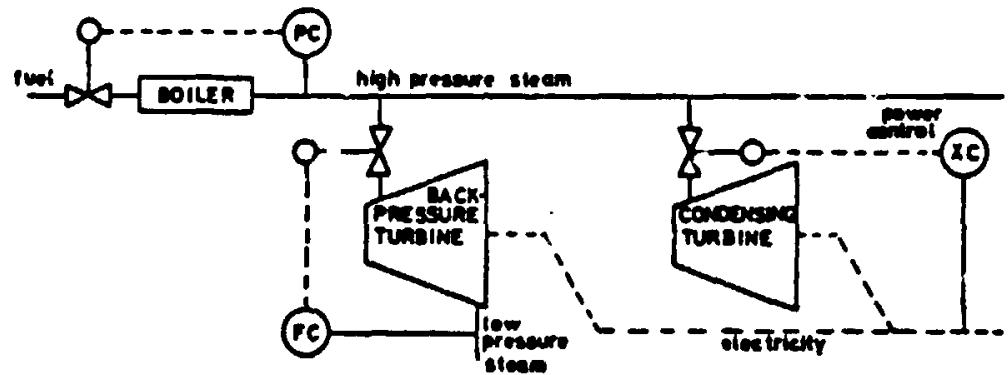

Fig. 4 Structure of the process 


\section{OR:B? \\ Cér PCOR QLingsir}

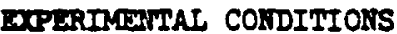

The task of the operator is to keep the three 1 gitally displayed outputs vithin the specified boundaries using one or more of the three setpoint control inouts.

Righ pressure steam is displayed continuously, the flow and power are displayed on requast during 5 seconds.

Four task conditions have been specified.

The system disturbances and the display structure were varied brth on two jevels, keeping the task to be farformed and the system dyarics the same for all experiments.

The conditions are indiceted as follows. a $b_{1}, a_{1} b_{2}, a_{2} b_{1}$ anc $3-b_{2}$. of represents a low leve 1 of system disturbances and az a high ll ... bl stands for local alarm which means that the oper-tor knows exactif which output is out of the boundary specified and in what direction. The actuaj value of the flow and the power can le obtained by taking a sample. b2 stands for central alarm. This means tat tae operator onl. knows that one or more outputs are beyond the limits. Additional

information in terms of the requested samples is required to determine the actunl state of the syster. It has been assumed before that the sipervisor hus a perfect internal representation, which means that his behavior should be stationary and that he should not be in a iearaing phase anjmore. Fig. 5 shows 86 sessions of the total of 123 sessions of 45 minute: vith one subject. Due to learaing effects only the last aine sessions " each condition have been used to rerify the postulated aypotheses.

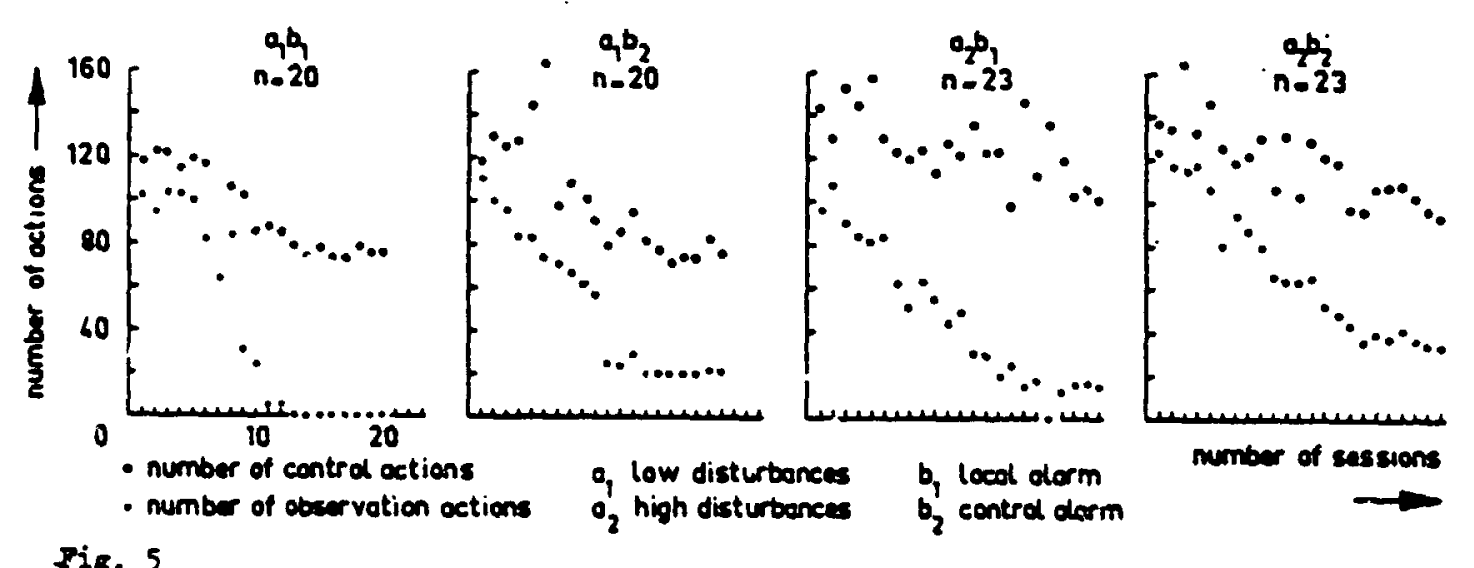

Fig. 5

\section{RESULTS}

Both the hypotbeses postulated vith respect to sapli=s and with respect to control sctions vere pand to be irue. For the results of the stetistical

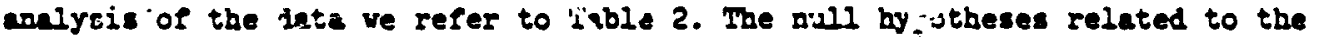
mean $u$ (number of samples and control cctions per run) is teated

$\mathrm{H}_{0}: \mathrm{H}_{1} \mathrm{y2}_{2}$. Sincs it is not known whetbor thes wo groups to be compered bave the same myieves, an P-test or enalysif of variance of the sample vuriarse is pe $\because$ ged. The aull byootbescs is nov $E_{0}: \sigma_{t}^{2}=\alpha^{2}$ ar. a s.coificance $i$ or $x=.01$ is ecceoted bere.

If the probn $\because$ - for the velue is greate: than a then the rull hypotheses $\mathrm{H}_{0}: \sigma_{1}^{2}: \sigma_{2} i \mathrm{is}$ pied. The significares of $\mathrm{H}_{0}: \mu_{1} \neq \mathrm{u}_{2}$ is then based on the srobability vo-de for tbs poolrt rariance estimate. If the probability 
for $F$ is lest than or equal to a then the mull upotbeses $x_{0}: \sigma_{1}^{2}=\sigma_{2}^{2}$ is rejected. The significance of $\mathrm{E}_{0}=u_{1} \neq \mathrm{u}_{2}$ is extrepolated fron the separate varience estimate.

able $2+-1.5$

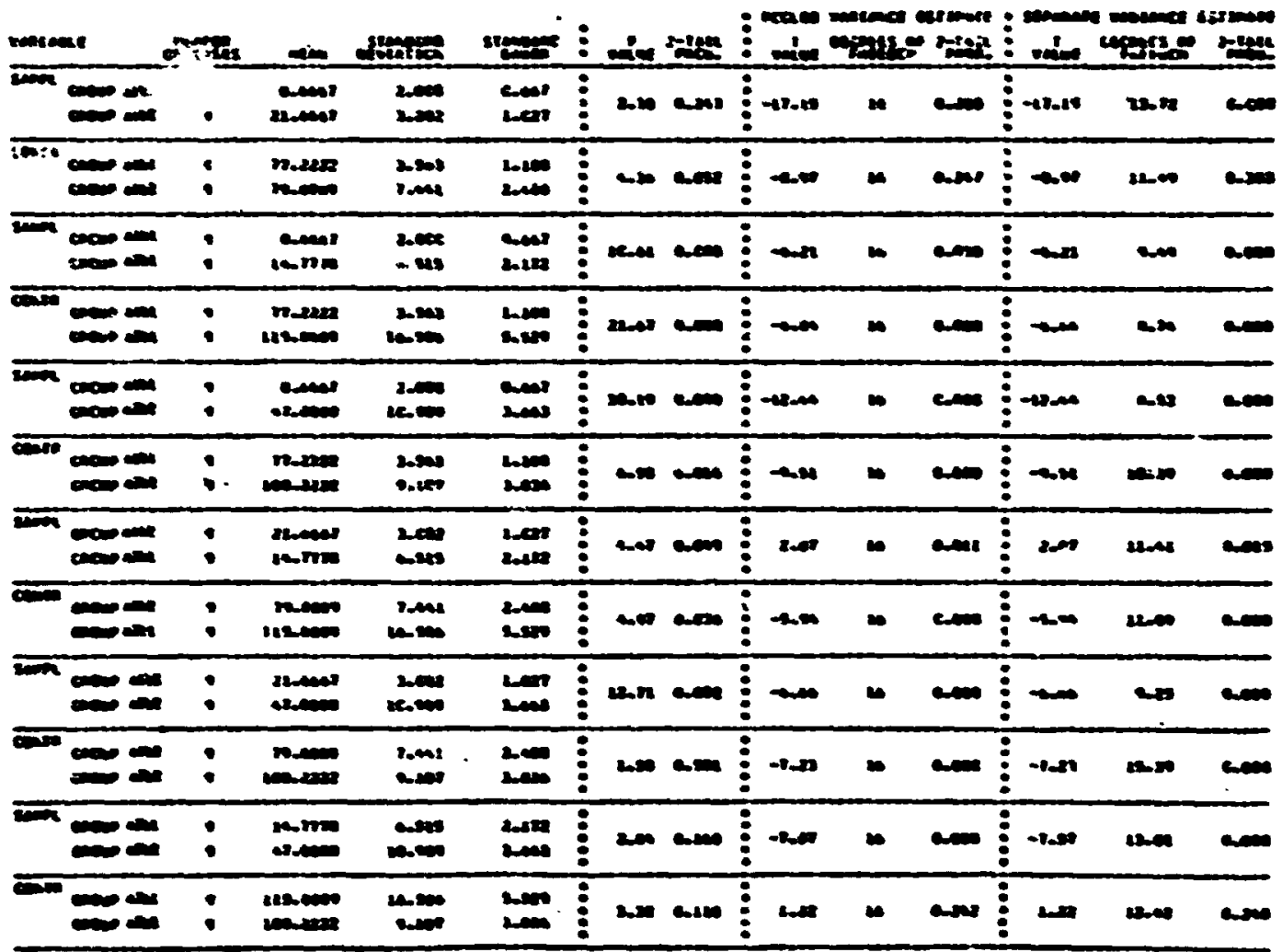

Fic. 6 shows the 991 reliabilits interval of a F-Studeat diftribution for ench of the fow conditions.

the sen effects bur ben foud on a 958 reliabilits interval vith a Iess trained scbject.

Fron these result the soparate effects of the levels of the tor tank variables on the bebvior of the supervisor are clear.

co parios Fire. 6 and 7, it albo soliow that the sobject increases his nober of control setions then the syster is wore disturbed, but be coes ot change the flitudes of the control.

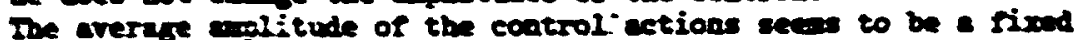
quantitj besed on the syoten dranics and the given tesk; bowever, these tall vriablys have not been varied dwing the four conditions. Daine the Anelrsis of Varience for each input, it allo follow that for the given set of nengrenents no differences in the men aplitude can be found (see Fig. T).

We cen conclade that shangins the displey structure does sot influence the nuber of serples. Cunging the level of the disturbances does bave en 


\section{ORIC!AHiL PAGE IS \\ OF POOR QUALITY}
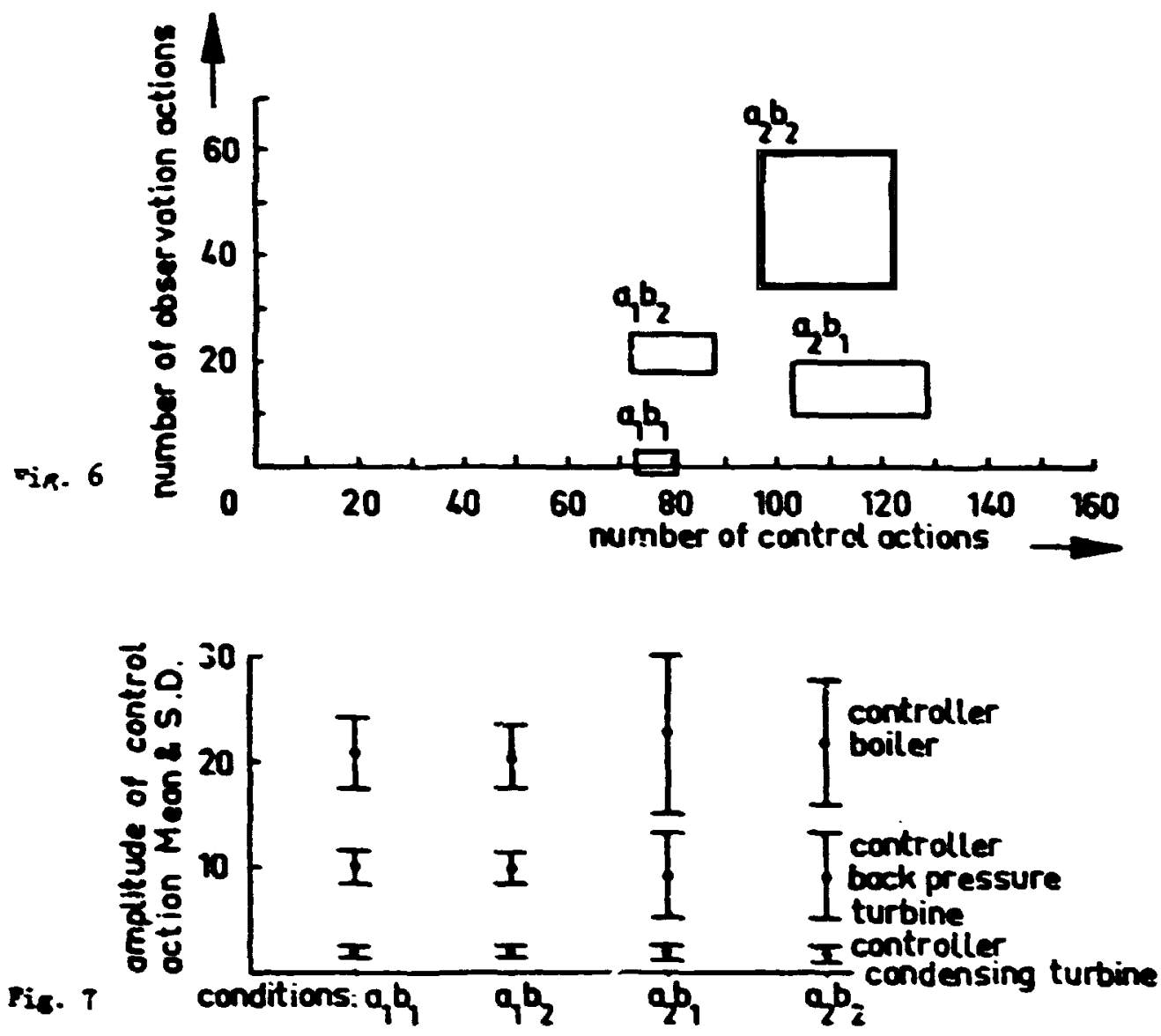

Pis. $T$ conditions: $a, b_{1} \quad a_{1} b_{2} \quad a_{1} \quad q_{2}^{b}$

influesce on the sapiing behnior and tie miber of coetrol ections.

Ive wea plitude vill bot ebange for sech conditioc: only sone chenge or the standard deviation die to the discurbances do occur.

- Cinlad Rusparca

In this paper the stated hpotbeses were tested and found to be tron. In fact the surves dealt vith a $2 \times 2 \times 1 \times 1$ desicm. Beceuse the 'teal requireneats' and the 'sjste dranics' have oot been changed vithin the $-a r$ conditions, we plan to change the talk requirenents for the ocxt eper ineots. The boundaries specified vill be decreesed while leeping the other condition as before.

Oo the basis of the stracture of tbe nodel, acr urpotheses have been posiviated to relate the pareneters of the dicfereat parts of the nodel to the tank rarinoles anptioned before.

These codel hypotheses are:

- the parantera of the observer part are independent of the supervicory takk and are oaly s ruction of the dranics of the systen, the structure of the display and the aoise paranters.

- the paranters of the controlier part are indepeadent of the observatia

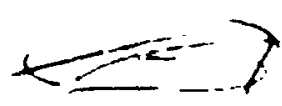




\section{ORIGINAL PANẼ 13 \\ OF POOR QUALITY}

process and are onf a ruction of the dromics of the syoten and the supervisors tack.

Tuble 3 represents the postulated relationabip betwon tak veriables and the paresters of the different parts of the nodel. The croee $X$ viens deperadency.

\section{Tabe 3}

a) Varietions of the syaten disturbaces

b) Variations of the displar

c) Veriations of the teal requirneats

d) Veriations of the spoten orenics
Des.P. D.O. D.C. Coatr.P.

\begin{tabular}{|l|l|l|l|}
\hline$x$ & $x$ & & \\
\hline$x$ & $x$ & & \\
\hline & & $x$ & $x$ \\
\hline
\end{tabular}

Hext to the the parmater ideatification, fore subjects vill be imvertigated to incrone the rtatiaticel sipnificance of the resulte To rinal part of this resulte vill be calin with the lart

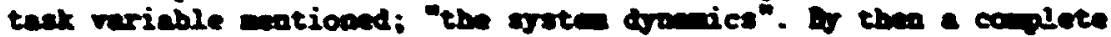

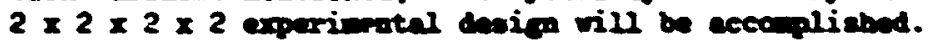

\section{D.1.2.0.}

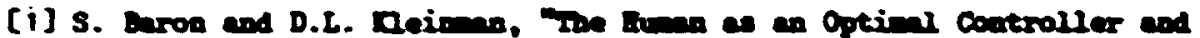

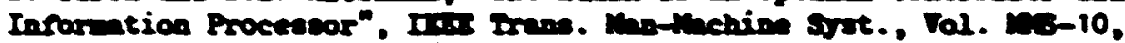
to. 1. pp. 9-17, March 1969.

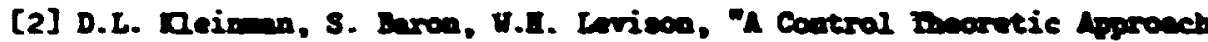

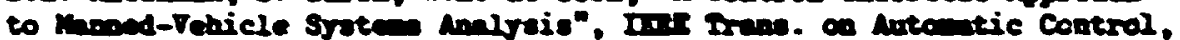
Tal. AC-16, Do. 6, pp. 82t-832, Decedber 1971.

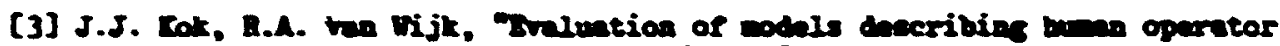

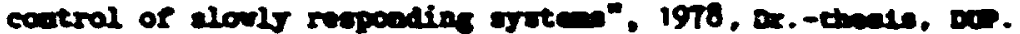

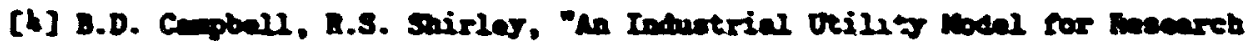

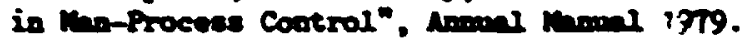


Adrancesents in automating man-enchine systers will change the role of the huan monitor. Many treditional vigilance studies are not broad enough to expose the decision-aking nrocesses involved in inferential contoring of coplex vigilance tasks. In order to investigate vigilance problems in modem manmechine systems, a paragign has been designed to assess beth sinple and infereatial onitoring. The paradig consists of a siculated heat-regulator system that can be anually or autcontically operated. The systei's indicators will allow enitors to be ware of system walfunctioning wich can be inferred frow eultiple information soirrees.

The experiontal situation will allow varying degrees of automation in a set of control and monitoring tasks. The tasks will inwolve detection of amifunctions and varying levels of decision-making to correct the mifunctions. The level of decision-ming will depend on the level of automation allocatid to the computer or to the hum onftor. The first set of experiments will address how dectsion-making (in terns of reaction tilie and errors) is affectad by task coplexity and knowledge of results. Subjects will monitor I-hour of simple syste operation with no inferential task required. The siple onitoring wil be a detection task only. Thy will also monitor l-hour of systea operation requifing operational dacision eaking in a diagrostic task. Three levels of $\mathrm{KR}$ will be assigned to three groups; no KR, partial KR, and total KR.

The initial study is designed to provide information about the following questions with respect to cperational onitoring tasks:

a) Does performance change, indicated by an increase in nuber of errors and response tilu, during a i-hour inferential monitoring task?

b) Hill performance differ between sible detection task and inferential diagnostic task?

c) Does KR have an effect on the nuber of errors and RT during a 1-hour inferential monitoring task?

Eighteen maive college wen will serve as paid wolunteers for this study. Each subject will be randoaly assigned to one of three greips: no KR, partial KR, and total KR. Analysis of the data will be a design of 2(task complexfty) $x$ (feedback) $\times 6$ (tille segments) analysis of variance with repeated measures on task complexity and time. There will be bo sets of experimental data.. The first will be the total errors for each temporal block. The second will be the latency of each response. The basic data will be collected by the POP-12 computer. 


\section{T82. 34070}

EFFECTS OF MOTIVATTON ON CAR-POLLOAING

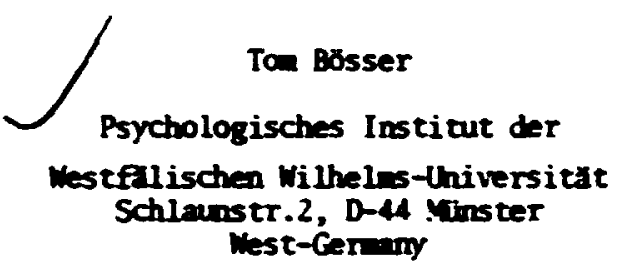

ABSTRACT. Speed- and distance control by autcobile-drivers is described best by linear ndels when the leading vehicles speed varies randouly and wen the driver is motivated to keep a large distance. A car-following experinent required subjects to follor at 'safe' or at 'close' distance. Transfer-characteristics of the driver were extented by 1 octave when following 'closely'. Vonlinear properties of drivers control-wovemes are assuned to reflect different motivation-dependent control strategies.

INIRODUCTION. The auto obile driver's capability to control speed and distance to other cars is of considerable inportance for trafficsafety, traffic flow, the usable capacity of the highray-systen, and partly determines fusl-consu ption. Autantisation of this task can not be experted in the foreseeable future, even then a servo-system ast be adapted to existing traffic and thus requires the identification of human control-behaviour in this task.

Investigations of car-foliowing by DREYER (1979) and HARTwIOH (1971) showed that driver's control of speed and distance in real and simulated car-following-experiments can be described adequately by 
linear models, where speed-difference between leading and follaring vehicle and distance are considered to be the inputs to the driver. Fram observations of driving behaviour under natural conditions on the notorway in an instrumented vehicle we concluded that undar these conditions driver's speed-control is predictable only to a sall extent by linear describing functions.

This is partly due to the variability of traffic conditions, which require only part of the tive to follow a leading veh. $\rightarrow$, Also distances between cars on average are wch shorter than those observed in other experimental investigations, wich excludes the neccessity to use high-frequency control-behaviour in order to avoid collisions. Linear wodels of car-following seen to describe driver's behaviour best, when the speed variations of the leading vehicle can not be predicted fros eraffic further aboud or from the course of the roed, wich under ordinary driving canditions is possible nost of the tiv. Linear wels sen to be deficient in that they can not represent responss to step-like changes in the input variables, which ocour rarely, but are of grest ipportance for safe driving. Secondly thy do not represent the fact that performance-criteria for speed- and Listance control in driving are determiued by the driver's motivational state, where safety considerations, haste, confort, risk-taking and cost are considered and an optinl course is deternined.

Henual control experiments and control of wore expessive vehicles like aiplanes differ from driving on autaobile in that wotivation can be controlled and held constant in these siturtions. The ain of the investigation reported here is to explore the influence of notivational processes on car-following performance.

PROCEDURE. Experiments were carried out in an average saloon-car which was instrumented to allowed recording of speed, throttleposition, and other variables not considered here, on paftape. In addicion the traffic-situntion ahead was recorded on video-tape, which was used to determine distance to the leading vehicle by an online photometric 
techniqus. For analysis data ware filtered and stored with a sapline rate of $2.93 \mathrm{~Hz}$.

A Er-following experibent was conducted on an infrequenty used pare of the notonwy during tines of low traffic. The leading car varied its speed beowen 70 and $90 \mathrm{kw} / \mathrm{h}$ eccording to a 5-level pras with a length of 05 intervals and a clock-frequancy of $0.2 \mathrm{~Hz}$, thus representing a frequancy rane of 1 to .006 $\mathrm{Hz}$.

The properties of this test-sequences were selected to allow identifieation of behaviour in the high-frequency-range. Eight subjects (experienced drivers) followed this course four times, orice with the instruction to follow at a 'safe' distance and twice at 'close' distance.

Data obcainod were anclyzed in the frequancy-domin with FFTProcedures (BENAT \& PIERSOL, 1971).

RESULIS. The functions shown are averages of 8 subjeces. Distance beneen cars is wreh lower under 'ciose' condition (Fig. 1. Wote that aeasurement of shore distances was linited by the field of view of the video canera, thus zero-discance represents a distance $\leqslant$ in.) Power spectral dansity of distance is reduced accordingly over the whole frequency-range represented in the signal under the 'close' condition (Fig. 2). Power speceral density of speed shows that the 'close' condition introduces wore high-frequency variance and reduces low frequency variance (Fig. 3). Throttle position, which is the essential sutput-variable of the driver for speod-and distance-control, shows a probability-distribution with a lower peak and wre frequent occurrence ¿f extreme throttle-positions (Fig. 4), indicating mxima-force control and a time-optimal strutegy. Puner spectru of throtele position (Fig. S) shows that hiph-frequenty-power is increased by the instruction to follow closely. Coherence between the distance to the leading vehicle the essential input variable for the driver - and throttle position shows that the transfer-characteristics of the driver are extended chrough the instruction to follow at close distance by approximately one octave (Fig. O). 
DISCISSION. Results demonstrate that hum control-behaviour depends on motivation, which was varted in this case by instructing the driver. In the present experiments the transfer-characteristics of the driver extended to a higher frequency-range than was found in other investigations. This can be assuned to be due to the fact that in these investigations different input-signals to the driver were geprated, were through preview the driver was able to control speed adequety by aviding the neccessity for high-froquency control behaviour. This was not possible in the present case, as speed variations of the leading vehicle were not predictable.

Distances between vehicles under natural driving conditions are wore sinilar to distances observed under the 'close' condition. This can also be attributed to the fact that norml traffic-conditions allow prodiction of spoed-chenges ahead and the allow drivers to be confident of their ability to control these short distances without neccessity of high-frequency control-behaviour.

Whereas in the lourfrequency range driver's control wovenents can be apprazinated by limear nodals, a large proportion of the high-froquency power containst in the signels recordad is not related in a linear fashion to the input signal. This wy be do to nonlinaer controlstrategies, e.g. 'bang-bang'-control or adptive processes like those proposed by costrallo (1968). It is isighly plausible to assue a nonlinear aspmetric mighting of the error in the ecntrol of distance between vehicles - a large distance does not lead to undesirable consequences, short distance however represents a highly dingerous siturtion and ay introduce a nonlinear strategy to avoid this situation.

Although the instruction to follow 'closely' introduces high-frequency power into the throctle-sigmal, a considerable proportion is contained in the bigmal under the 'safe' conditions. The throttle-signal was predicted from the estinated nomparmotric transfer-function and the distance to the leading car. Fig. I shows this for one subject under 'close' and 'safe' folloving. It can be seen that high-frequency variations under the 'safe' condition are present, but not related linearly to distance. In comparison under the 'close' conditions these high- 
frequency actions are highly correlated with the imput-sigmal, as is represented by the coherence-function. This indicates that the change in control-activity can be described partly by the synchronisation of the high-frequency control movements to the irput-signal. All subjects reported driving under the 'close' condition to be highly strainful and axh wore difficult than normal driving. He can therefore conclude hypothetically, that drivers adjust their contro-activities to the input-signals in such a way as to make high-frequency c.untrol umecessary. This can be achieved by increasing the set point for distance to the leading vehicle and giving low weight to deviations of distance from setpoint. Nonlinear properties of control behaviour with 'safe' distance may reflect a control strategy rechxing workload, whereas nonlinear properties cf 'close' following represent a tim-optimnl strategy.

Motivational variables can be assumad to limit the adaptability of the driver to traffic-conditions and to properties of the vehicle and the raad beyond the linitations represented by the perceptual-wotor system.

Bendat, J.S., Piersol, A.G.

Randan Data: Analys is and Measurenent Procedures, New York: Wiley, 1971

Coste:10, R.G.

The Surge Model of the Nell-Trained thman Operator in Simple Manual

Control. IEEE Trans. Ven-Machine Systens, Vc: MS-9 (1968), pp. 2-9

Dreyer, $W$.

Lungsdynamische Untersuchung des Regelkreises Fahrer-Fahrzeug.

Bericht Nr. 525 des Instituts für Fahrzeugtechnik, TU Braunschmaig 1979

Hartwich, E.

Langsdyrimik und Folgebewegung des Straßenfahrzeugs und inr Einflub auf das Verhalten der Fahrieugschlange, Dissertation, Damstadt 1971

M. Artmann, L. Cremers, A. Isfort, E.M. Melchior and H. Zeissig participated at various stages of the investigation. This work wes supported by Deutsche Forschungsgemeinschaft (BO $642 / 1,2$ ). Technical support from Audi-NSU A.G., Volkswagen A.G. and Opel A.G. is gretefully actonowledged. 

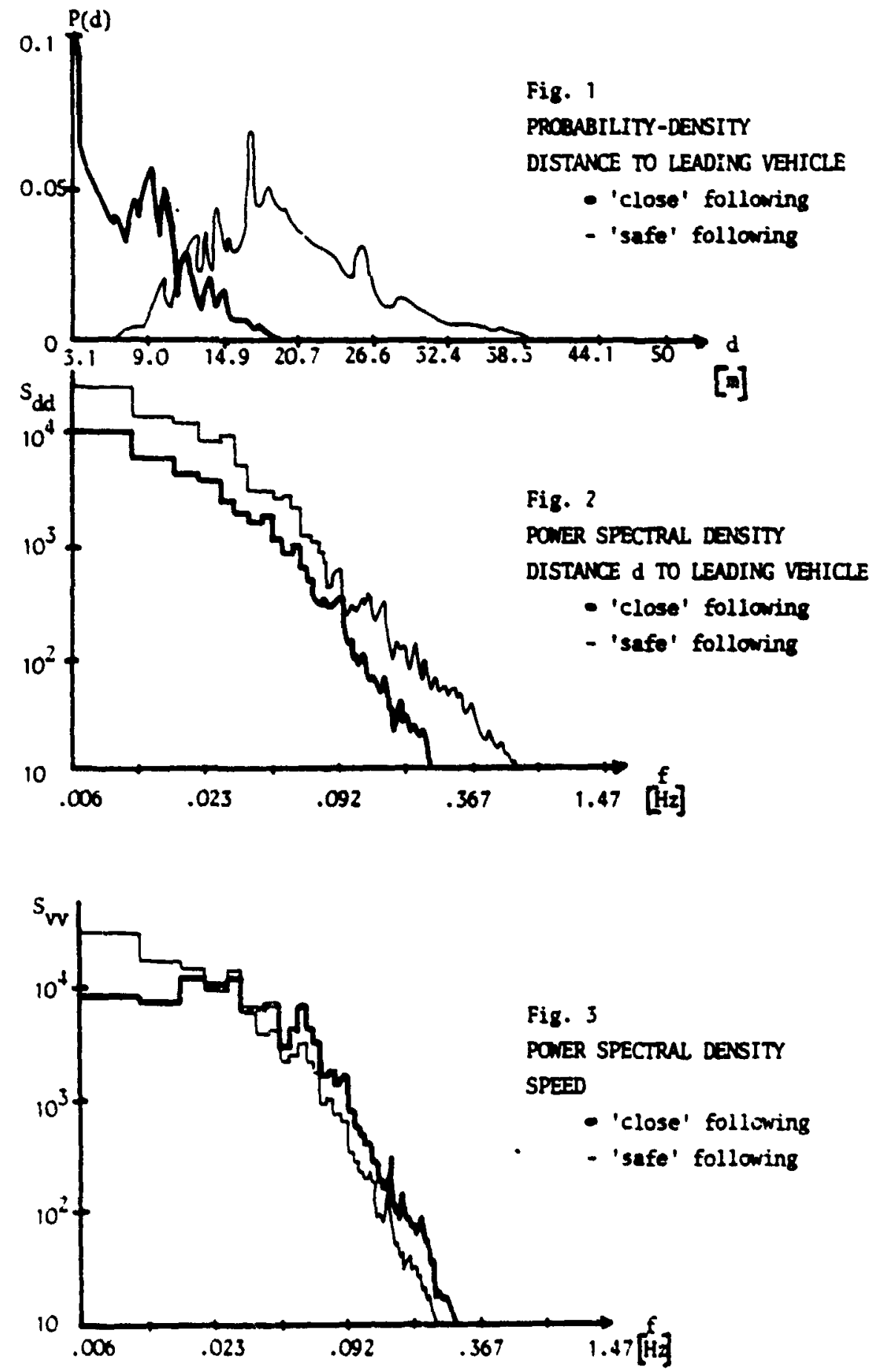

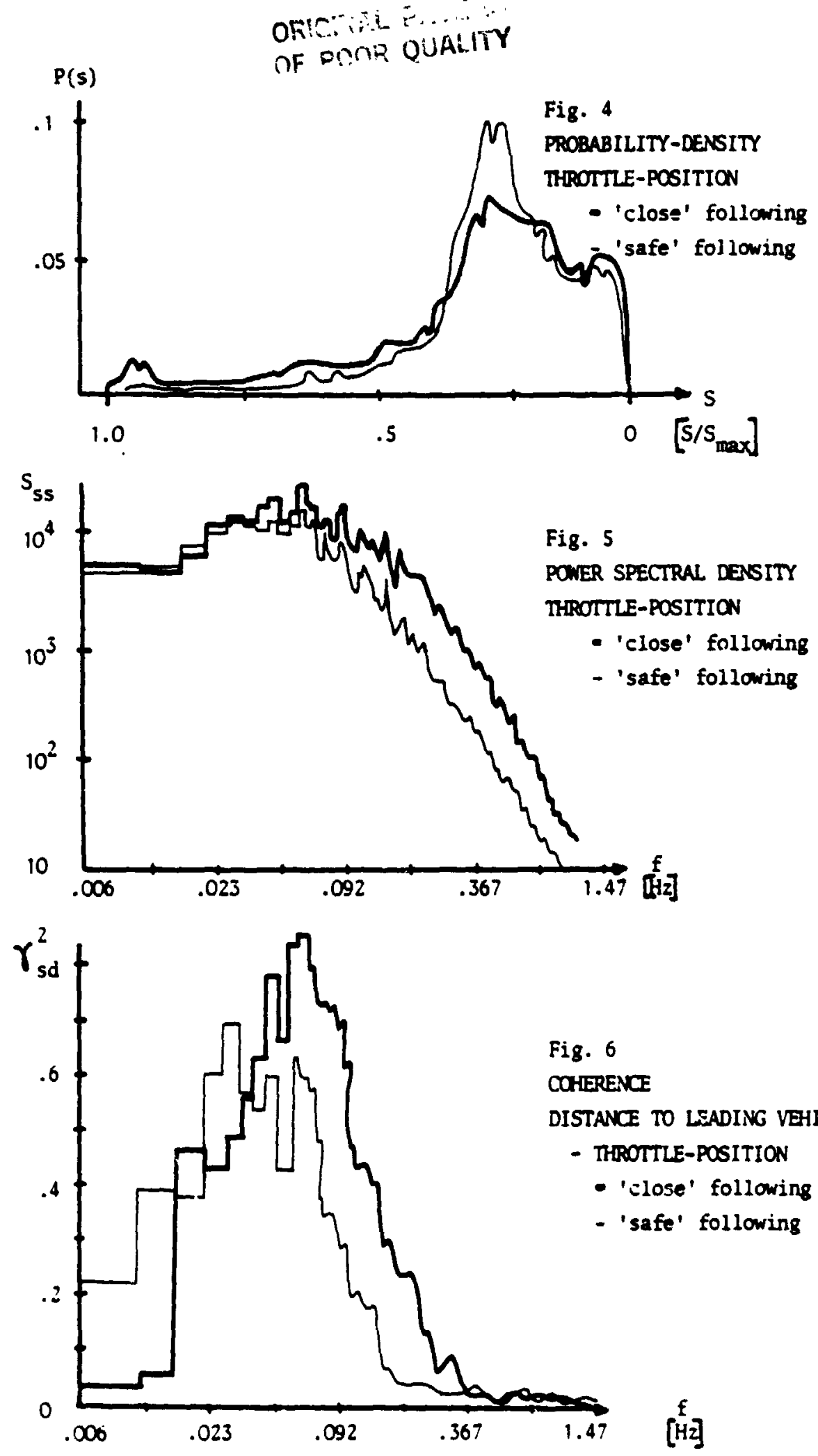
ORiGiNAL PRE IS

OF POOR QUALITY
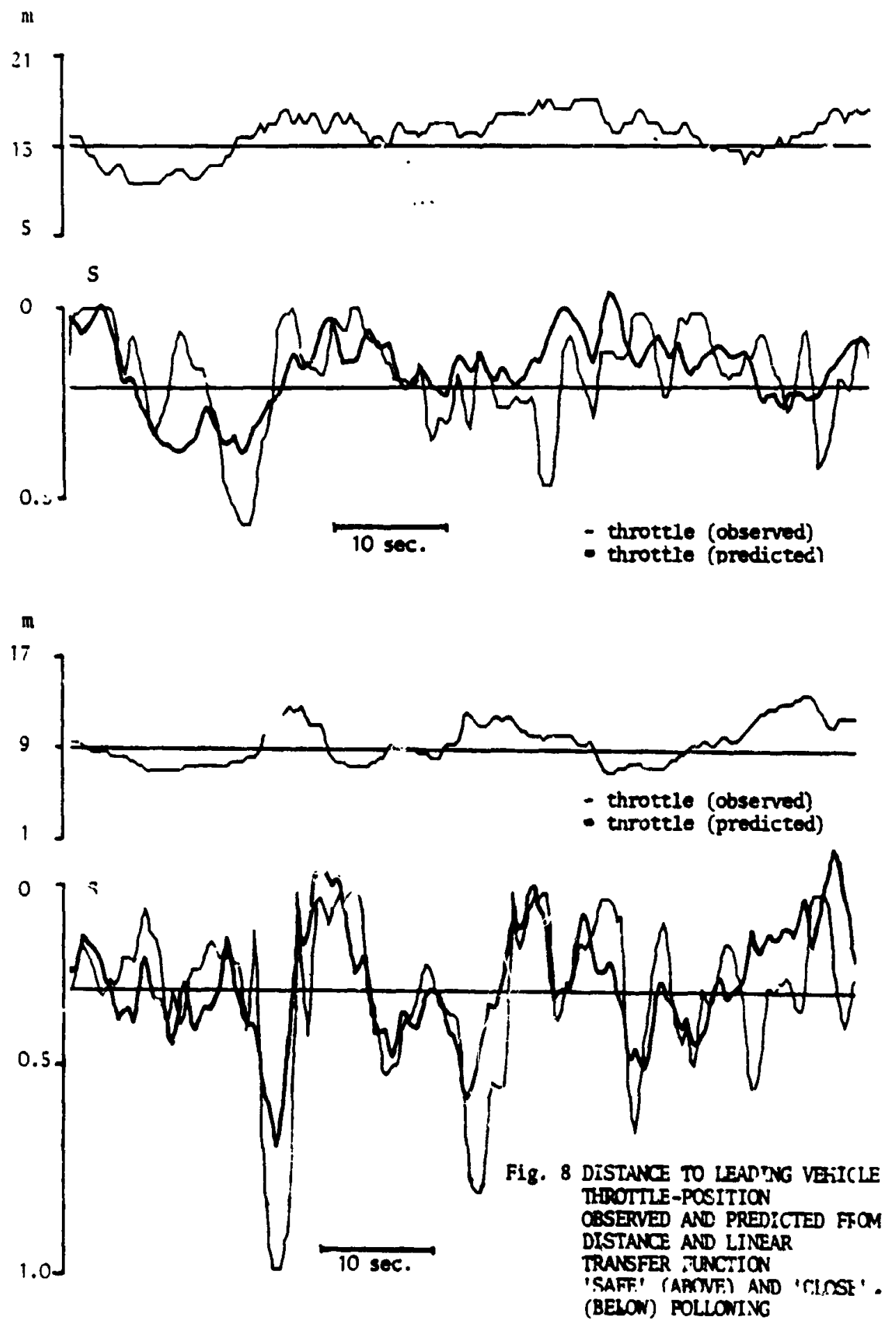


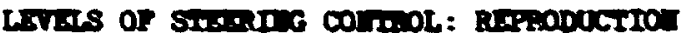

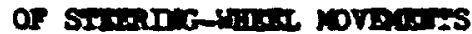

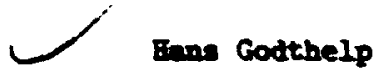 \\ Inntitute for Pareption IIO \\ Soevertores \\ on Entherind
}

\title{
ABsrancr
}

A schentic description of the stees 2 os contral process is presented. It is show that this process cen be decribed in term of levels of cantral. Level of control will depend on driver's skill in string ve of 'clever' stratecies

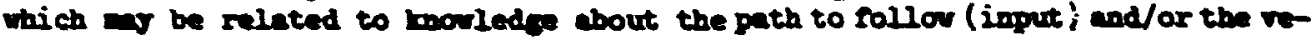

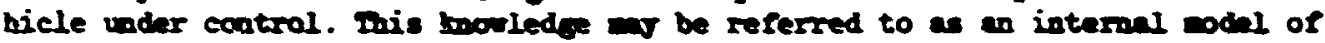
- particular talk elensat. Interal inforention, as derived fros thea interonl codals vill probebly be used together vith proprioceptive feedback. It is brpotbenized that the efriciency of the hi ber levels of ccatral vill be depeadent on the eccurecy of both the internal and proprioceptiv informatica. Baced on this researeh philosopho a series of experinents is carried out. Two prelininary experibents vere doce in order to andrse subjects' ability to reproduce steering-wheel positions and wovenants vithout visuri feedback. Steering-wheel ancle aplitude, steeriog force and eovenert frequency vere inrolved as independant neriebles.

\section{Irrioductror}

The devion of a safe trarric araten requiras a rood understanding of the aleweats in the sprten. In artonbile driving these elenents are the driver, the rehicle and the rondwo envirounent. The latter two elements serve as the sretea to be controlled by the driver. Fehicle and enviromentel charecteristics cen be aren in ethentical term and the understanding of both these elenets is fairly sood. Bowerer, optirisetion of rehicle and enviranneatal characteristics can oly be ade ive surficient knouledge about driver's capabilities. It is weful to distinguish three min espects of a driver's tesk: naviontion, gridance and rebicle contral. Invipation deal vith route selectica. Guidance involves the proceseing of infortation on other vehicle $n-$ tion, obetacle locetion, roed ceometry etc. leadins to the desired rebicle speed and path. Finally, rehicle control ifplies the processes of speed and path (or steering-) control itself. We vill minls par attention to the drirer's capatilities in steeries control.

Steerioc controi tacks ean be de ribed in tern of levels of control (trendel and MeRuar'. Perr", Meituer et al.', Douges"). Levels of control are related to the use of sore or less 'clerer' stratecies. Strategies cauld be of a perceptual nature, for exple wen preview is used. Strategies could also be of conitive cricin wen driver we internal representations or nodels cbout the

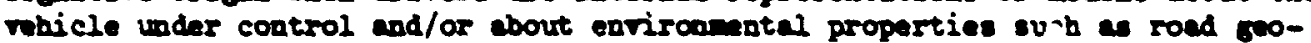
netry. 


\section{ORIGINAL P:Z: IS
OF POOR QUALITY}

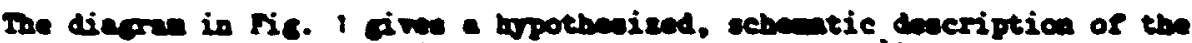

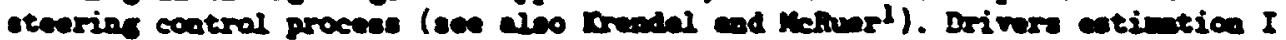

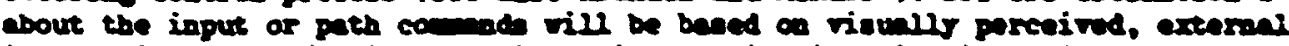
informetion is and/or interres input informtion $i_{i}$ wich is derived fron the

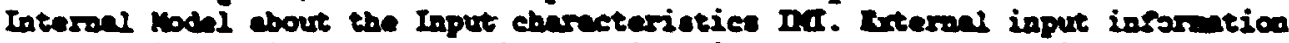

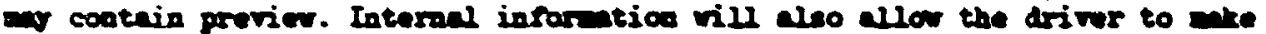
predicticas about i.

Drive entintion 0 sbout the output or vhicle motions 0 vill be bened on visunly pereeived, extereal infarmtion on and/or on interonl input inforention oi. This letter type of inporntion vill be a roult of a interplar be-

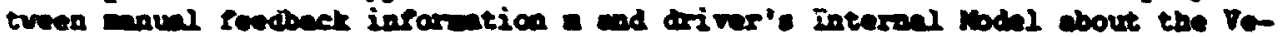
hicle (V) charecterictice $\mathbf{D T}$.

precogrutive

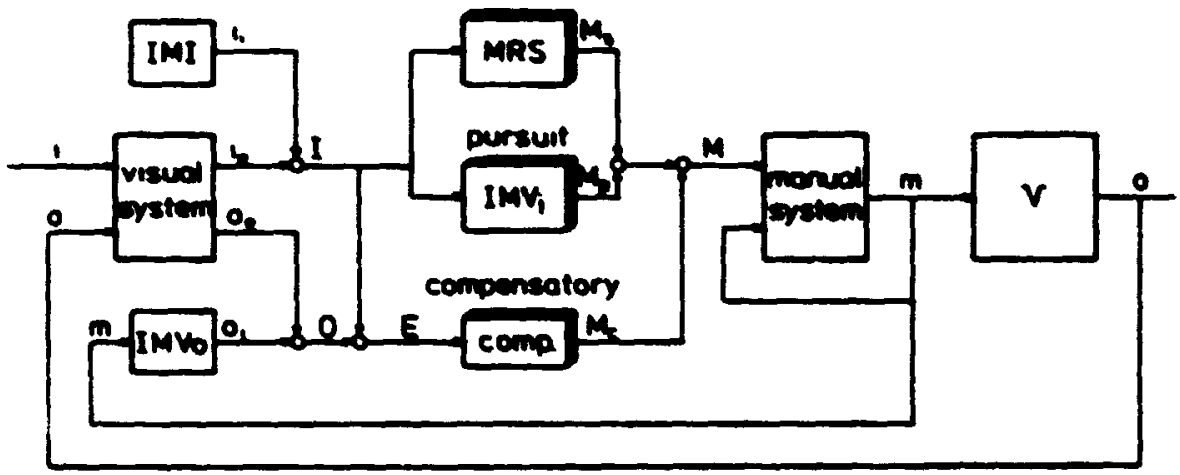

Fic. I schentic deceriptice of the eteoring centrol prosena.

It is bypothesized that level of control in a particular stenrine tank vill

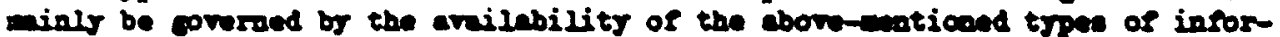
ntion. At the bichest, procogitiv level drives alke ves of their experience vith the ceen trpe of teel condition, i.e. thair intersel models about the input and the vaicle properties. Mis experience vill leed to the develop-

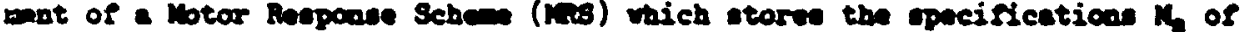
the mound costrol ections that should be ald uder the particuler conditioss. Althoun Schridt ${ }^{3}$ limits the velidity of his sches theory to the learnine of

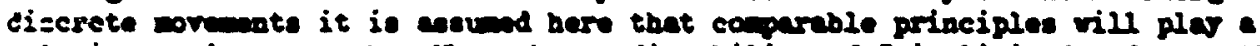
rale in continuou take. Man the prodictability of I is linited - dus to the structure of if or dus to abecece of Da - driver nv still use their frorledo about the rebicle characteriotics. Control vill take plece at the pursuit

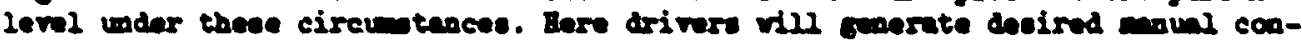
trol action to uaing I (vith its roduced prodictebility) es input and rolviac on the internal sodel about the prarice of the vaicle uder coatrol ( $D N_{i}$ ) as a mans of weiptins between I and $K_{p}$.

It ar te hupothesised that driver priferily will anerate control actions a

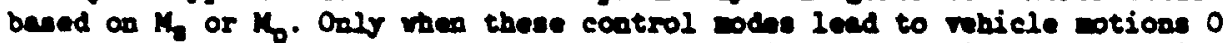
thet - compred to I - abor wo error I wich it bayond driver's criterion, the compensetory level of contral cons into oparation. It is at this lowest level of control that driver cenerate correctione $K_{t}$ oo the denired manul control actions.

It is oucreeted that the attentional demade of a particuler etearing teak de-

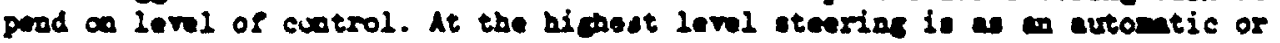


'Open loop' procese, vberees et the lower levels steering is enre 'closed loop' or under consciou contral. Compennatory ateering has been studied in mar

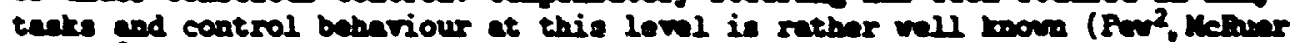
et $2 .{ }^{3}$ ). The characteriatice of the pursuit level in steving as artenobile mere illuntrated by Neliuer et $1 . .^{3}$ and Doapes". Nutber description eopecielly vith regand to the nelative ifportence of the purauit and conpasatory level are neceseng.

Yery little is known about steeriog task in wich wotor proprans are uned. "It is at this level that our understanding and eodels are post incoplete" $\left(\right.$ Pew $\left.{ }^{2}\right)$.

In the present studs the precomitive and pursuit levels of control will be subjected to surther andrais. Speciel attention vill be iven to pzoprioceptive feedback, thereby considerios the role of steering force or "esatrol feel" in particular. Fen quantitativ deta avilabie on this letter point and it is expected that the described oodel vili give the opportivity to quntify the role of control feel es a part of the proprioceptiv inforntion an a. Related to this is the quetion of the relative ipportance of rievel and proprioceptive feedbeck at the different ievels of control. Can the interplas betwen the proprioceptive syaten and the MiS and DN-blocks reduce the loed put on the visunl sroteal Conversely it can be quationed bor the sount of visunl attention roquired for a particular steerias takk cen be influenced by selecting the proper input and/or vebicle charmcteristics.

Lnt we apin considar the diecren of Fic. 1. In the procees of tranaferrins inpute $i$ into enval contral ections $n$, three njor subprocesses are - hpothetically - dietingriabed:

1. Os the perceptunl side there is the transfarmation fron input i and output 0 into the estintion I and 0 .

2. These estinations should be translated into the specification for the desired mnual control action M. Specirications av invalve manal force, position, velocity (tining) and eccelerstion. At this centrel part of the process the Was ead/or DWi blocks vill pley a role.

3. Finuly on the sotor side, the tranaformtion ron desired (K) to tunl (II) control sction takes plece. $M$ sbown in Fig. I it is suerested thes a proprioceptive feedback path is in operation ot this point, nicins compesetory corrections on the transformtion fron $M$ to $\mathbf{M}$.

The opes'stors' akill in each of these subprocesses vill ultinately deternine the efriciency of the precomitive and/or pursitit level of control. Spperinants under vay now deel with tracking predictable and unpredictable inputs under partially occluded conditions. In this way the decree to which internal and external inforation are evilable (and thus level of control) is experimatelly reried.

The present paper describes two prelininary experinants wich vere done in order to ot quantitative data about subjects' ability to tranefore deaired (M) to acturl (I) mounl control actions. In a roproduction task subjects reproduced discrete and cuntinuou steering-weel woventa. Ihese relatively irple take vere chosen to cet a Nrot impression of the influence of the solloving independent variebles: steering-wheel wovent eplitude, frequency and steering force.

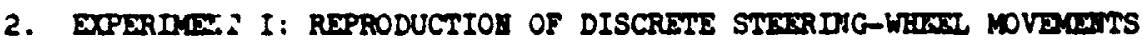

\subsection{Beckeround}

Rperimet I ves designed to collect quantitative data cbout the $M$ to a transformation in a discrete positioning tank.

In a roproduction experiment subjects learaed a diecrste steerinc-wbel anv- 


\section{ORICI:: : : : j \\ OF POOR QUALITY}

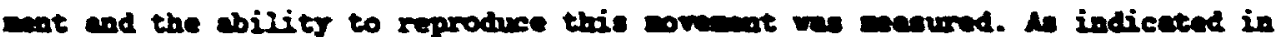
the introductios the results of this 1 to a trensformtion rifot be vectul in evelutinc the role of the precoenitive and perrevit levels of control in steering tanks.

Literaturs shows a numer of experinents in wich subjects had to reproduce band/ or eveants under constrained conditions. The purpose of wot of these experineate vas to andrse the nuction of severel types of resolock cues. A distinction cen be ande between position, aplitude, tim, velocits and force as componemts of indi idual representation of a crenent. Gundr illustreted that vith lase (in tere of distence) novenats subjects ue minl position information, wils with short ovenate alitud (tim x velocity) information

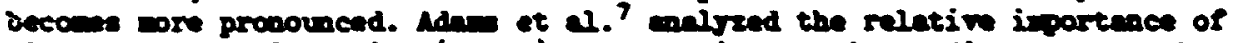

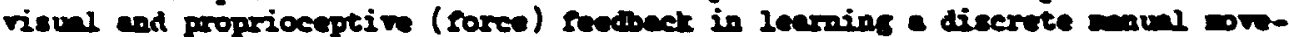
nent. In their experimat the ole of the force cue as a compoent of subject's skill in refroduction vas illustrated. Bowerer, it appeared thet the erriciency of this feedbeck cues rifht be etteaunted when leerning tares plece vith vieun and proprioceptiv feedbeck combined. The present experinent wer designed such thet the effect of wowenent lenth and ateering forfe on the sccurac of eovenent reproduction could be eralunted.

\subsection{Mothod}

\subsubsection{Subjecte}

Treive ale subjects (So) perticipated in the experinat, 11 of then wiver-

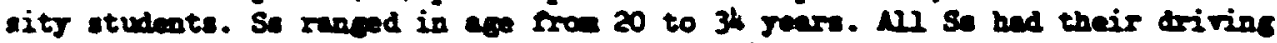
license for at leant two rears. All Se vere rifit-bunded, altboud three subjects indiceted that this priorits wes not very prosornced.

\subsubsection{Instrumentation}

The experiment vas carried out in the mock-up of the driving inulator of the Inetitute or Perception. This cock-up is a Volro the vith ite ari cinal steerins whe vith 0.22 a rediu. Spoke are wowted is the rheel at 56.5 decrees to the left and to the rifte fron the ais samecting the uppar and lovent point of the meel. The eacle between the steering-meal plane and the rertical aris throus the isntre of the meel is 15 derees. The steering theel axis is connected vith a potentionater wich wenures the steeriog-abeel ancle coatinwuly. Steering force is cencreted by mens of an electric torqu wotor, Amin W19, aich is consected with the steerins whel aris by a cearbelt driw.

\subsubsection{Exprins:ttal condition}

In a vith n-subjegts desico, So reproduced four steerigenteel poeitione. The positions - $30^{\circ}$ to the left $\left(\delta_{0}=-30^{\circ}\right)$ and $10^{\circ}, 30^{\circ}$ and $50^{\circ}$ to the rimt $\left(\delta_{2}=: 9^{\circ}, 30^{\circ}, 50^{\circ}\right)$. The ervents and to be reproduced in combinetion vith th- teeringheel ril tarce levels i.e. $0 \mathrm{~K}, \mathrm{~T} .5 \mathrm{I}$ and $15 \mathrm{I}$, giving totel nuwer of 12 sovenent condition. For the ateering-force conditions the relsion between steerincmeel encle and steering force ve linear, i.e. the vaeel ves opring-centered.

\section{2 .4 Prooedure}

Subjects vere hijodfolded during the experimat. The seat ves edjusted so that So could crefortebly bold the steering wee'- vith their are slichtly bent. Ss vere inftructed to bo:d the steering weel such that their thubs rested on the upper left and richt opokes.

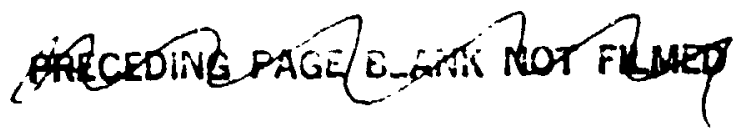




\section{Gi:- : : : \\ OF POOR Gunitit}

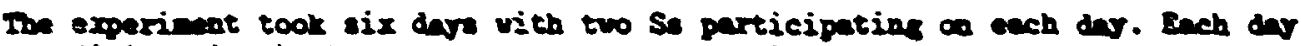
val divided in 24 blocke. The two sa altermativaly performa a block. In a block th- sem eovenent we presented and ruprodnced for $h 0$ coreceutive triels. Sequence of wrenent conditions ven rendoritied over Ss. In all condition the centre ponition of the steering woel $(6, \cdots \infty)$ served as the starting point. In eech trial $S$ ectively wred the stecring vteel to a stimlu position arted by an anditory sipal. Actually. the sipol arted an aree of plus and winu to around the stimulus ancle. Than Sa word the sterering veel back to the startine position wich ves arted by a sop. Hext to this stimulue presentetion Ss vere required to reproduce the noveneat as accuretely as possible vithout the aid of the varning sipen. Thus ane triel consisted of a criterion (or

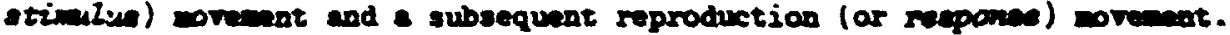
A block of 40 triels of a particular movent condition leoted about 15 mis.

\subsubsection{Data ancityois}

Both stimulu and reapor se encle were reconded. Wases and standard deviations for the atimulu and response ancles is vell as the alobraic exror vere calculated over the last 25 triels of each block. The difference between stinulue and response within a triel was taken as elebraic error. Perfarmace on the first 15 trials wes not teked into the final enalreis in arder to overecen habituntion and/or transfer effects and for the sake of carrespondeces vith the date andreis of experinent II. Differences in neans and stendard deviom ticas vere teated by anvirsis of rerience (ADVA).

\subsection{Results}

Reaults shoved wo differences between the $30^{\circ}$ worement to the left and the

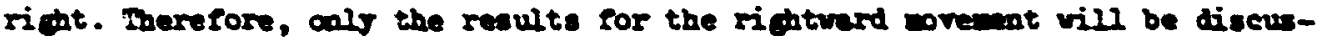
sed, see Fic. 2. The pecervl overaboot effect for the wen turned out to be sicoificent ( $p<0.01$ ). Anurzing the aleebraic ersora it turaed out thet the tendencr exiets far the overnoot effect to be about equal for the $30^{\circ}$ and $50^{\circ}$ ovesnats and less for the $10^{\circ}$ novenent. An NoVA on the urobraic errors indicated that be interaction, steering-ibeel ancle $x$ stesrine foree, wa not si coificant. However, then ouls the $10^{\circ}$ wovenent condition vere connidernd a si pificent effect ( $p<0.05$ ) of stewine farce res found, indicating an increaned overshoot teadency with the crestest steering force.
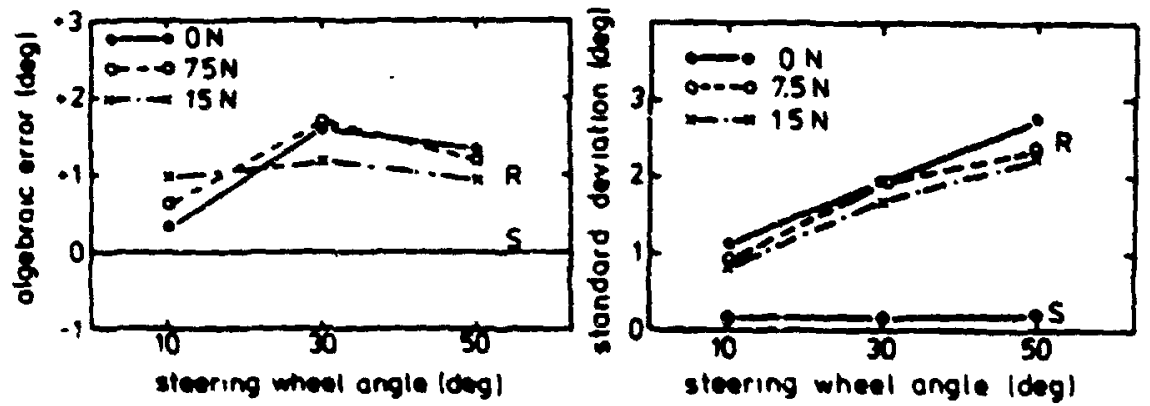

Fig. 2 Mans and standard devistions of the stimulin (S) and response (R) movenents for the sorenent conditicos in Experinent I. 
Pic. 2 also give the vuriation of the standard devietion as a function of

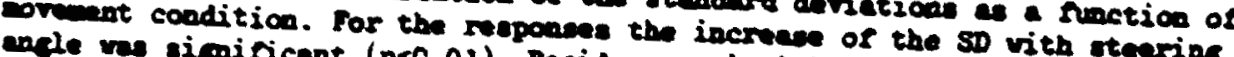

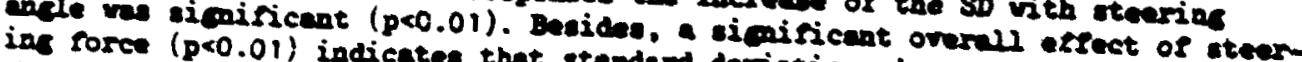
when steveribe force is evilable.

\subsection{Discussion}

The purpose of experizent I wa to wasure the erfect of coveent lencth and reproduction should bornece in roproduction. Subjects' performace duriog

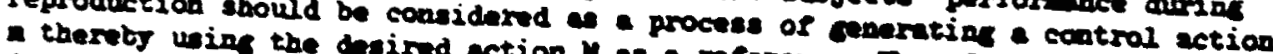

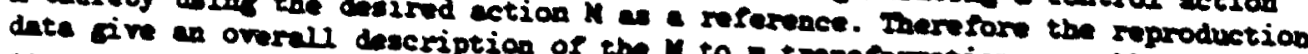

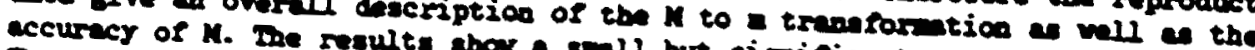

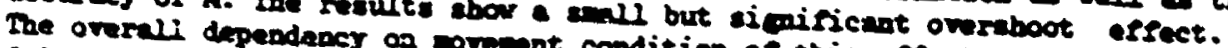

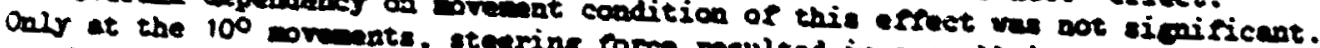

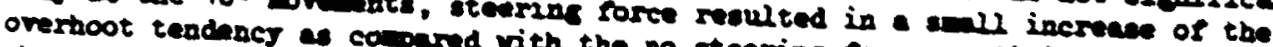
the overahoot teadency in steering the stearine foree candition. Obvioundy.

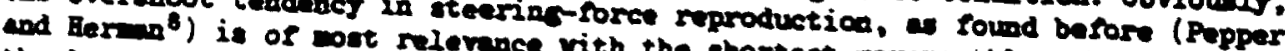

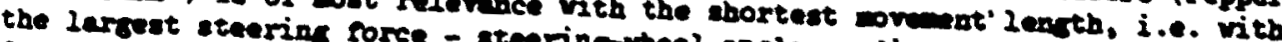

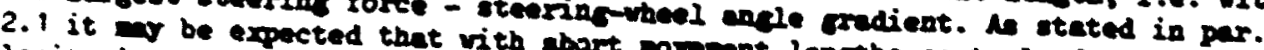

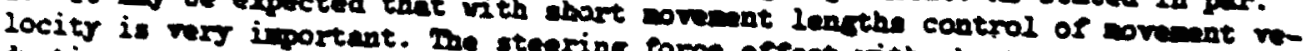

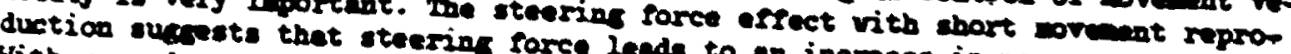
With recard to reproduction eceurecy the date an incsease in covent wiocity. are of creat ipportance. Both etery the dete on rariability in reproduxtion

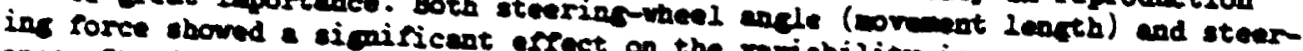
ance. Stendard derietions ano offect on the varibbility in reaponse perfor

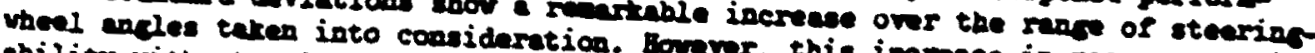

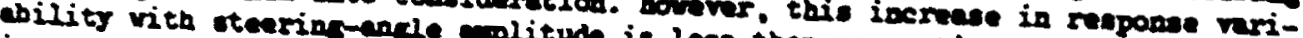

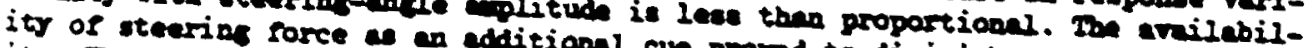
ity. The relative inportance of this cu prond to dinivish response rariebiz-

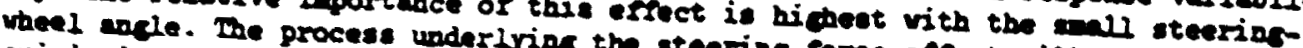

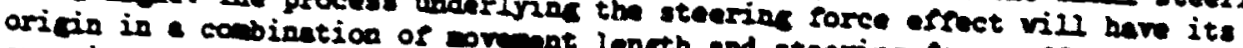

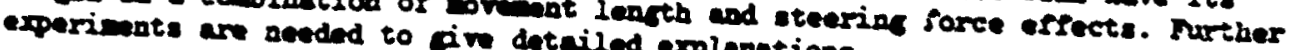

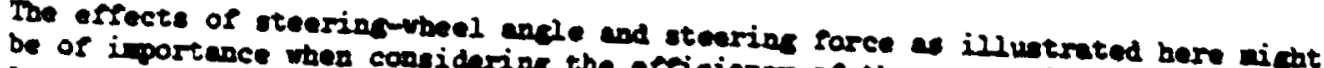
level of control in continuous the efrieiency of the precocoitiv and purauit

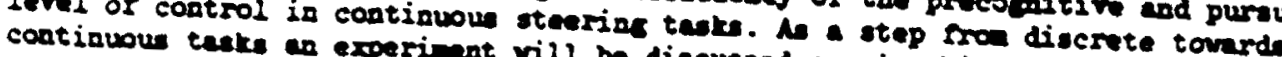
continuous wrenente was etudied.

\section{(3) \\ 3.1 Bectround}

- continuous vas carried out in ordar to aclree the $M$ to a tranoformation in

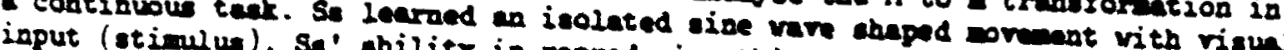
cluded condition. abe ality in reproducins tbis novent (mepones) under ocad nteeriar-wherel analrzed. Stoerias-vhesl ancle aplitude, stearios force Reaponse beheriour vill creis depend on the taken an the indepeadent rariebles.

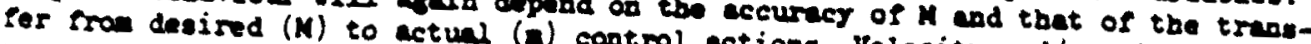
rora could also play role. 


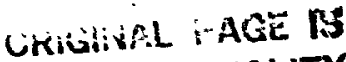 \\ OF POOR QUALITY}

Vossiug analrzed timing aspects of precognitive control under occluded conditions. So learned a continuou wovent pattern under visual pursuit conditions and reproduced the wrent vith ' $l i$ fhts out'. The 'Open loop' cenerated covewent patters lanted about 108 longer then the stioulus wovent. The question renized whether this tirins-oversboot effect is related to:

1. correct novenent velocity/position orershoot or

2. Evenent velocity undershoot/correct positioning.

Experiment II should give sore date on this point.

In 'conventional' sine-rave tracking experiments it has been illustreted (Pen et 1.10 , Maduleno et 1.11 ) that belor frequencies of $0.5 \mathrm{~Hz}$ error detection and correction echnoise plar an ipportant role, vhile at hipher frequenciea tracking behaviour becones more and more autonomous i.e. vith the aid of pattern-generation mechnois. Nithoueh both frequency and movent aplitude (together resulting in a secific novenat velocity) vill be of importance, it av be expected that these phenonen vill affect precogitive coatrol. As a consequence it wy be sugsested that in 'repid' sovenents the loss of risual guidnce (occlusion) vill be less detrinentel than in slow wovents. Besides, it ax be expected that the role of the proprioceptive areten in the overal: accurecy of remponses vill be limited in the nore rapid wovenats. Consequint15, the avilability of an additional cue like steering force could be bot effective in 100 morements. Whether this sursestion is vilid vill, of course, depend on the role of steering force in rapid wrements. Fron a percepturl point of view this role $\square$ be linited. However, the ructioning of steerine force in rapid sovenents is largely unbown and steering forces could have atabilizins effect on the execution of this sjpe of moventa.

\subsection{Nethod}

\subsubsection{Subjecte}

Treoty-four mile ss participated in the experinent. All of then vere university students. So ranged in age fron 20 to 30 gears. All Sa had their driving license for at least two yeare. Hone of then toxis part in Experiment I. AIl Ss vere rifot-handed, although four si indicated that this priority was not rers pronounced.

\subsubsection{Inotrumentation}

The experiments vere carried out in the same mock-up ss used in Experinent I. As stimulu sovenent a visul pursuit tracking task ves used. Visunl presentaticos vere ade vith the aid of a TV projector which was situated ebove the car. Two vertical lines, vere projected on a screen situnted at 2.90 in rroat of Sa' bead position. The upper vertical libe served a the target while the lower was controlled by the $\mathrm{s}$. The lines vere projected just above and be10 Ss' ere heicht this istter heicht being $1.20 \mathrm{~m}$. The heiph of the vertical lines vas $19 \mathrm{ch}$ vith a interopace of $2 \mathrm{~cm}$. Line vidth vas $3.5 \mathrm{em}$. The win betreen S.' cursor and steering-wheel angle vas $1.12 \mathrm{~cm}$ laternd displacement ( 0.22 decrees of visul angle) per degree of ateering-aheel angle.

\subsubsection{Experimental conditions}

In a partly vithin- partly between-subjects desion Ss reproduced six steeringteel wrewents. The svement pattern was based on a sine vere vitb a modification at the start and end of the wovent. Fig. 3a show the wovenent pattern described in term of ateering-wbeel ancle anplitude SA and requency F. The 


\section{ORIGINAL PAGE IS \\ OF POOR QUALTY}

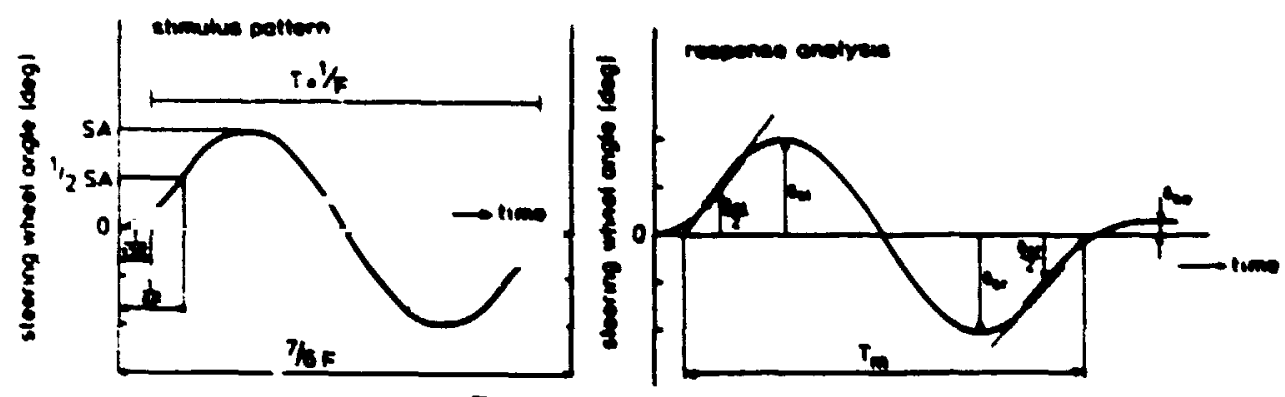

Fic. 3 Stimulu pattern and reaponse andrsis for movents in Eparinent II. SA = steering-weel ancle aplitude;

F requacy (Bs);

- Mequencs (redisece);

T. a calculated sovenent tine (s)

Stimulue pattern can be described as:

$0<t<1 / 67: \delta_{0}=\operatorname{si}(1-\cos \Delta t)$

$1,65<t<1 / 8: 8,-s a$ sin $(0 t-x, 5)$

$1 / F<t<7 / 6 F: 8=\sin (\cos (u t-8 / 3)-1)$

first part of the movent wa to the left. Bepin and ad odification rov

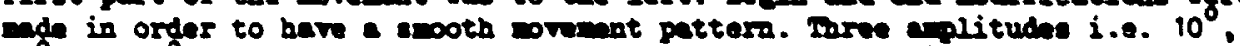
$30^{\circ}$ and $90^{\circ}$ and two mequencies i.e. $0.2 \mathrm{ks}(0.4 \mathrm{mad} / \mathrm{s}$ and $0.5 \mathrm{ks}(\mathrm{mrd} / \mathrm{s})$ were taken into consideretion, airing a total umber of eix stenring-wheel

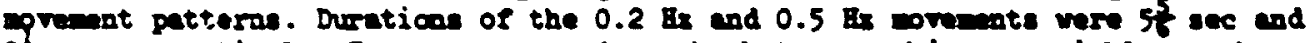
If sec reppectively. Prequency served as the between-subjects rariable so that 12 So reproduced the 0.2 Bs eovenents, wile the other 12 se roproduced the $0.5 \mathrm{Bs}$ wovents. All of the novenat patterne vere roproduced at each of three

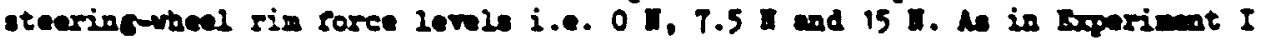
the relation between stenring force and otenring-weel ancle ven linear. Steering-weel ancle aplitude and steerinc farce vere ued acain as the vithin-abject variablas.

\subsubsection{Procudure}

So' seat and handarip vere adjunted al in Eperiment f. The experiment took 12

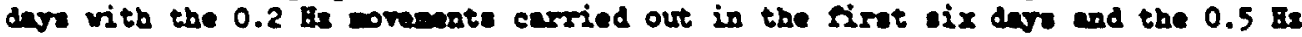

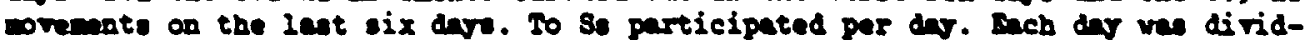
ed into 18 blocks. The two 50 elternativir persored a block. In a block the sam sovent ves presented and reproduced for 40 consecutive triels. Sequence of conent conditione me randorised over Se for the vithin-aubjecte part of the experimatel desion. Pureuit tracking of the movent pattera served as the etimulu pbase of each trial. The startios position of both tise target line and So' cursor vere in correnpondence vith the centre position of the steering whel. The atartios monent of the tarest wrenent could be anticipated vith the aid of a varains ai mal.

This sicoll ves a limt spot thet ves projected on the screen at $20 \mathrm{~cm}$ to the richt of the target line. Before the start of the tarcet wovent this spot mored to the left $(20 \mathrm{ca} / \mathrm{eac})$. The tarcet noveent atarted as soon so the licht 
ORIGIIR:

OF POO.R Qunisit

spot touched the tarest line. After trecking the stirulus mosent so bed to close their eyes and reproduce the orvennt a sccuretely a possible vithout the aid of risual feedbeck. After this response wremant Sa released the steerin whel. Then the steering weel ves set in the starting position acin by the experimenter. Thu, Sa did not get feedback about the tercinal position of the response sovement. A block of 40 triels ves cerried out in about 15 ain and $10 \mathrm{kin}$ for the $0.2 \mathrm{ks}$ and $0.5 \mathrm{kz}$ ovenents respectively.

\subsubsection{Dato analyois}

Both stimulus and response presents vere recorded continuounly with a saple rete of 105 suples for each wrenent. Kane and standard daviations vere celculated for arresat-aplitude errors to the left $\left(\delta_{\mathrm{s}}\right)$. to the rifht $\left(\delta_{\mathrm{ar}}\right)$

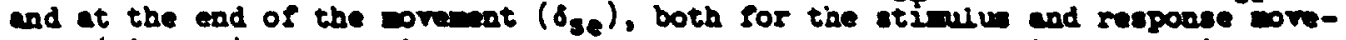
ment (Fic. 3b). Nusebraic error between acturl wovent aplitide and ideel

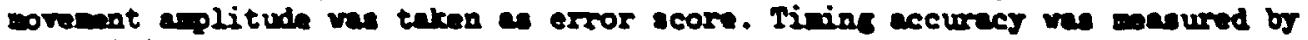
determining the wovenent $t i=T_{n}$, for which the start and end of each ovenat vere calculated by var of a least square fit, thereby constructinc a recression line through the eight data points surrounding the point $\delta_{8}=1 \delta_{s}$ (start) and $\delta_{s}=i \delta_{s r}$ (end) (see Fig. 30). Tining sccurec wa calculated in relation vith the ane type of wrecent time of the 'ideal wovent. Therefore tirins accurecy is presented in tern of percents too slow or too fast. Nans and standard deviations vere celculated for thene percentages as vell.

Performance uncer stimulue conditions vas mesured by daternining the inteorated error sccre during pursuit tracking. An eveluntion of these date indiceted that wot of the habituating, learaing and/or tranefer effecte occurred durios the first 15 trials of each block. For thet reason mans and standard deviations of amplitude and tirinc accuracy vere calculated over the last 25 trials of each block. Differences in wans and standard deviation vere apio tested on their statistical simificance by MWVA.

\subsection{Results}

A sbown in Table I the priens part of the movent (to the left) bas a reartable orershoot tendeacy (p<0.01) A SR I SA interection (p<0.05) pointe to the ruct that the overnoont effect is less pronounced for the $10^{\circ}$ movenat conditions. In the second part of the novenat (to the right) the overshoot effect is lese ( $0.2 \mathrm{~Hz}$ condition) or even dieappeared $(0.5 \mathrm{~Hz}$ condition). In the latter condition an uderahoot effect can be noted for the $50^{\circ}$ novenent condition. Steering force does not beevily influence the overnboot/undershoot effect. Oaly in the $0.2 \mathrm{Ex}$ condition the steerioc-force level of 15 a tends to result in less orernhoot as compared with the 0 a condition.

The stendard deriations of the movemat ampitudes show wore or less the sam effects for the novent parte to the left and the richt. Standard deviations are hichly dependent on sorement uplitude vith the largest deviations for the largest movenet anplitudes (see Fic. 4). The F I SI 2 SR interaction indicates that for the 0.2 He condition the slopes of the $S$ and $R$ curves differ aimifichntly ( $p<0.01$ ), whereas for the 0.5 He condition tbe $S$ and $R$ curves are retber parallel. The anilability of steerinc sorce leade to decresee in aplitude stendard deriatiuns. For the eorement to the left this effect bolds for both the stimulue and response worement. For the eovenat to the richt eteerias

SR - stimulue response

SP = steering force

SA - steering-wbel encle anplitude

$$
F \text { - requacy }
$$


Table I Nan elcubraic wovennt-aplitude error for the wrenat conditions in Experiment II ( 1 - leftrard, $r$ = richtward part of the evrement, oreruboot positiv).

\begin{tabular}{|c|c|c|c|c|c|c|c|c|c|}
\hline $\begin{array}{l}\text { Novement } \\
\text { eplitude } \\
\text { (dee.) }\end{array}$ & $\begin{array}{l}\text { Porce } \\
\text { aplitude } \\
\text { (I) }\end{array}$ & $\mathbf{s}$ & 0.2 & & R & $\mathbf{s}$ & A & ${ }^{8 x}$ & $\mathbf{R}$ \\
\hline $10^{\circ}$ & $\begin{array}{l}0 \\
7.5 \\
15\end{array}$ & $\begin{array}{l}0.45 \\
0.29 \\
0.14\end{array}$ & $\begin{array}{l}2.06 \\
4.13 \\
2.89\end{array}$ & $\begin{array}{r}0.27 \\
0.19 \\
-0.03\end{array}$ & $\begin{array}{l}1.69 \\
2.95 \\
1.37\end{array}$ & $\begin{array}{l}0.32 \\
0.11 \\
0.42\end{array}$ & $\begin{array}{l}2.80 \\
3.04 \\
4.16\end{array}$ & $\begin{array}{l}0.33 \\
0.07 \\
0.06\end{array}$ & $\begin{array}{l}0.96 \\
1.61 \\
1.53\end{array}$ \\
\hline $30^{\circ}$ & $\begin{array}{l}0 \\
7.5 \\
15\end{array}$ & $\begin{array}{r}0.22 \\
0.02 \\
-0.05\end{array}$ & $\begin{array}{l}6.06 \\
5.83 \\
5.21\end{array}$ & $\begin{array}{r}0.11 \\
-0.19 \\
-0.20\end{array}$ & $\begin{array}{l}3.22 \\
1.57 \\
1.50\end{array}$ & $\begin{array}{l}-0.02 \\
-0.63 \\
-0.46\end{array}$ & $\begin{array}{l}4.30 \\
4.15 \\
4.70\end{array}$ & $\mid \begin{array}{l}0.01 \\
-0.43 \\
-0.36\end{array}$ & $\begin{array}{r}-0.60 \\
0.57 \\
1.05\end{array}$ \\
\hline $50^{\circ}$ & $\begin{array}{l}0 \\
7.5 \\
15\end{array}$ & $\begin{array}{l}-0.43 \\
-0.44 \\
-0.39\end{array}$ & $\begin{array}{l}7.82 \\
5.86 \\
3.72\end{array}$ & $\begin{array}{r}0.09 \\
-0.11 \\
-0.40\end{array}$ & $\begin{array}{l}5.65 \\
3.87 \\
2.27\end{array}$ & $\begin{array}{l}-1.17 \\
-1.30 \\
-1.61\end{array}$ & $\begin{array}{l}4.16 \\
1.94 \\
2.16\end{array}$ & $\begin{array}{l}-0.40 \\
-0.88 \\
-0.85\end{array}$ & $\begin{array}{l}-0.86 \\
-4.76 \\
-0.53\end{array}$ \\
\hline
\end{tabular}
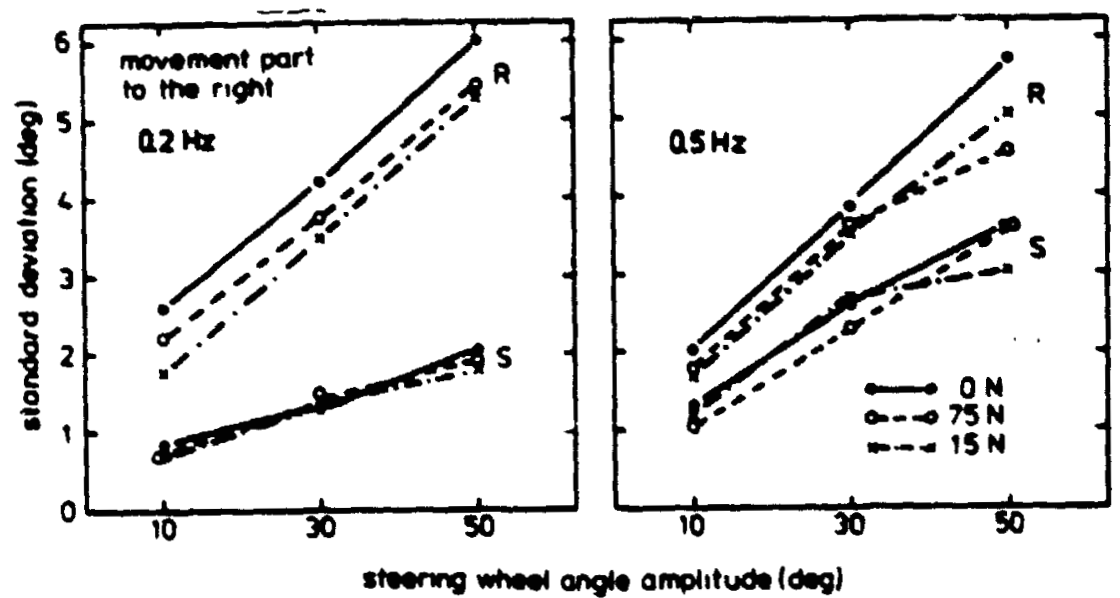

Fic. it Standerd deviation of the steering-whesl and applitude for the noveent conditions is Experimat II.

force ainly influanced the standard deriations of the ropponse eoranats ( $S T \times$ SR interaction).

Means and standard deviations of the relative errors in tivins are shown in Fic. 5. Tirias aceuracy under stimulu conditions is rather good. Both novent aplitude and steoring force in luence tivine eccurecy in reproduction. In wat coadition reproduction time are too lask, eapecially with the $30^{\circ}$ and $50^{\circ}$ aplitudes. Onj in the sovents with the levest velocits levels (0.2 Is. and anditudes) and with steerinc porce arilable the tendeney to reproduce movenent time too lone dieappeare. Novenet tiles ov be too short in these

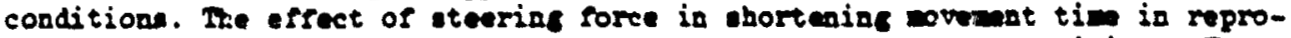

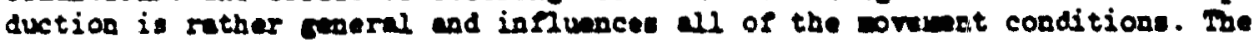
relative error is timinc accurecy in responses is sommat lares under $0.5 \mathrm{Bz}$ sonditions as compared with the 0.2 as condition. 

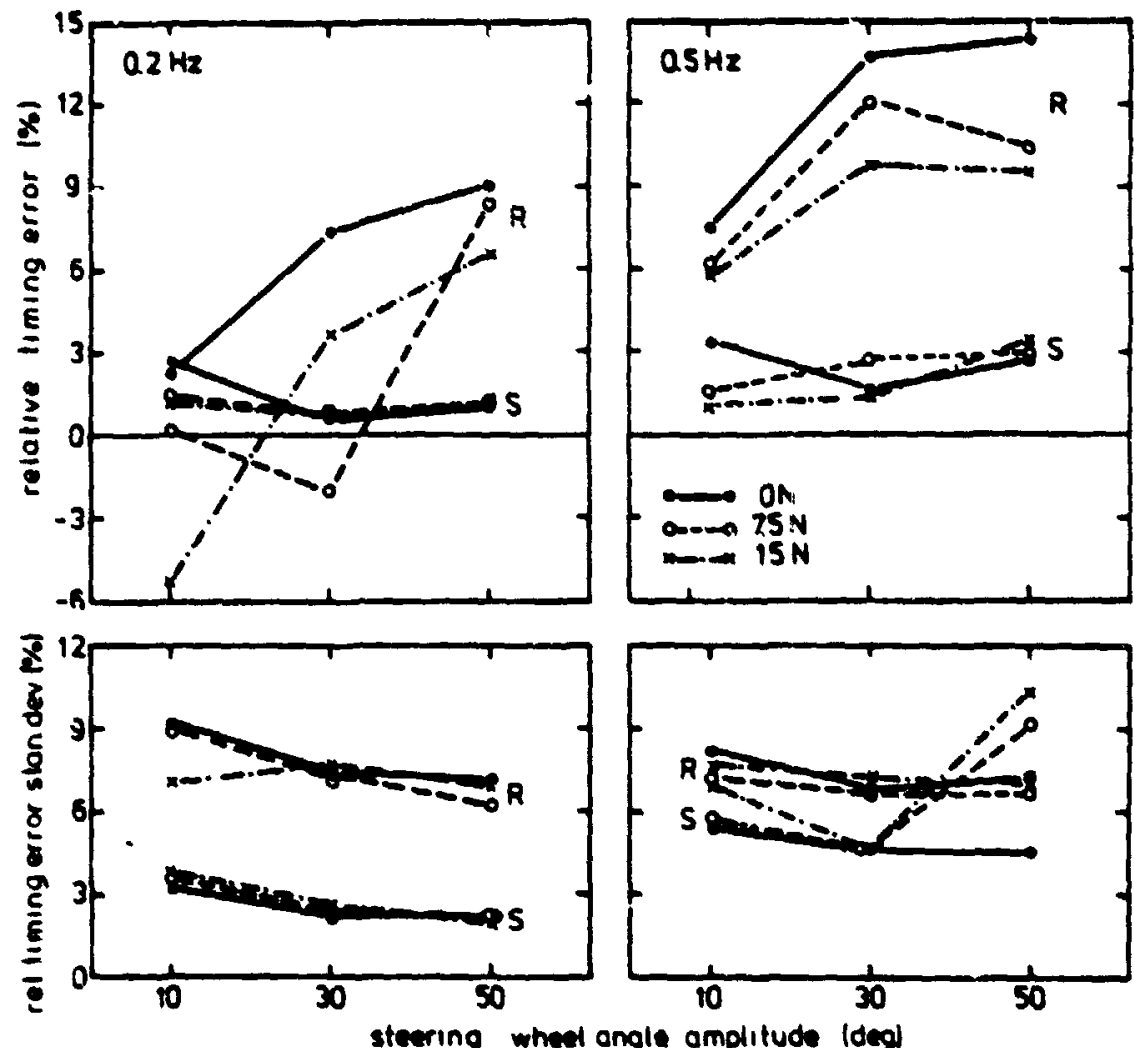

Rig. 5 Mans and atendard deriations of the relative errors in timing for the movent conditions is Eperimat II.

Regarding the standare devietions of the tiring error the $\mathrm{F}$ SR interection ( $p<0.01$ ) indicates that differences betreen stimulus and response worennts are lese in the $0.5 \mathrm{Hs}$ condition as cospared with the $0.2 \mathrm{kz}$ eovenat. This effect is in correspondence with the effect that was noted for the standerd derictions of the poresent anlitude.

\subsection{Discueqion}

The purpose of Experiment II vas to inveatigate the efficiency of the $M$ to $m$ transforation in a continuow tank and to mesure the effects of prement. aplitude, swivency and steering force on reproduction perforance in this type of tauk.

Mans and otendard deriations for the criterion or stimulue novente ay be

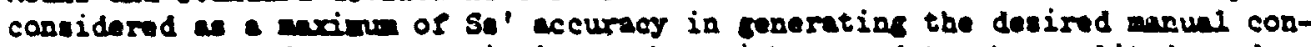
trol actions $M$. The resulte indicete that vith regard to the aplitude ard tirias oreraboot/underaboot tendency the etimulue wovents vere ratber accurate. Anplitude tendard deviations for tiallue conditione (Fiz. 4) show that the reribbility increases elightly vitb soresent aplitude and requency. These date suerest that the veriability in atimulus soreants is mingly dependant on covament velocity. Fig. 6 may serve a a illuetration and presents aplitude atendard deviations (primery movement part) under stimulu conditions a a function of movement relocity. The maximu value of the velocity is the primary 


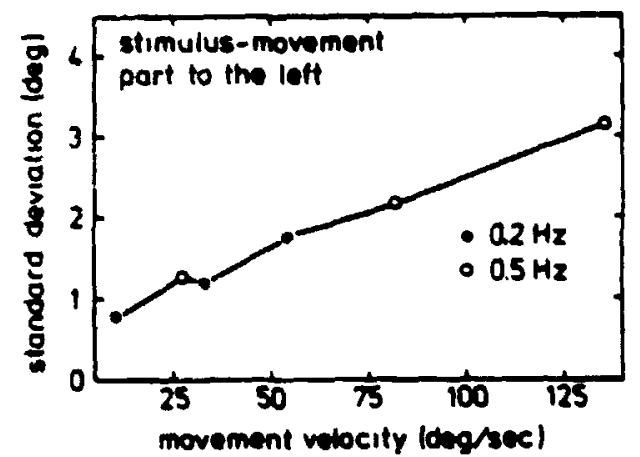

Pig. 6 Standard deviations of the steering-rbeel ancle emplituds " i.es - timulu conditions sis the $c$ snt mevent relocity conditione vere taken over steering fort is.

pert of the worement is taken as wovent relocity. The steeriog force effect on amplitude standard deviations indicates thai the reriability of the stimulus movements is slichtly decreased when steering force is arailable.

Timing atandard deviation under stimulue conditions (Fic. 5) shor that the veriability in timing for the $0.5 \mathrm{~Hz}$ movemat is about trice that of the $0.2 \mathrm{ks}$ movenent, which points to the fact that timing variability is rather canstant in seconds i.e. about 150 meec.

Behariour in reponces mar be considered as SA' accurecy in ceneratize the actunl control actions w wen usins the $\mathrm{M}$ respresente:sion as a refernoce. The response date should therefore esain be considered in an overell description of the $M$ to $n$ tranformation and the accuracy of . Mans of aplitude and tiring beberiour under response conditions are influenced by worent condit $10 n$ s.

Fie. 7 cives wan reletive aplitude and tirins arrom as a sunction of sovesent rolocity.

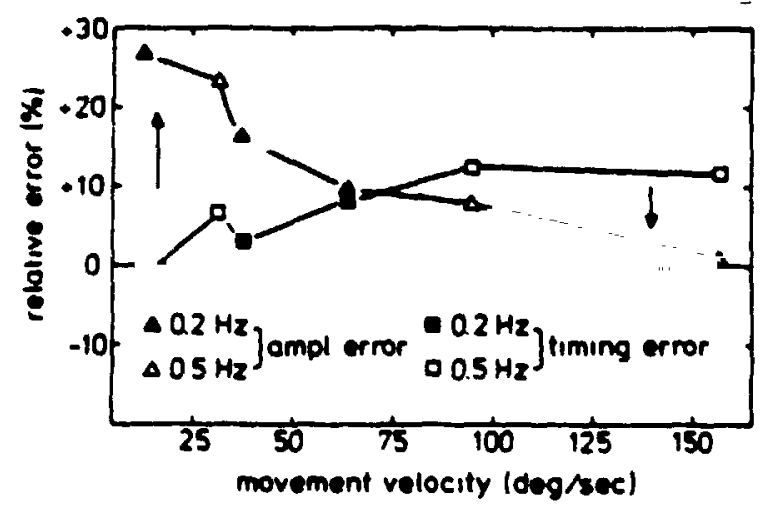

Fic. 7 Relative aplitudo and tiring errors for the disferent wrement velocity conditicas. Nane vere taken over steering-force levils.

Note in Fig. $T$ that aplitude errore are presentsd as relative errore, i.e. As - percentage of the movent aplitude. Relative aplitude errore vere calculated by takine the sun of the alcobraic error of the leftrard and ri chtrard part of the wovenot dirided by trice the corenot aplitude. Marime velocity between the leftrard and richtward part of the corasent me taken as movenat relocity.

Throe areas can be distinguisbed is Tic. 7:

A With lov covenet velocity timing errore are and, aplitude showe e ajor overshoot effect and sovemat relocity is too hiph. 
B In the aree of moderate movement velocity both timing and amplitude abow a slight and about equul overshoot effect vhereby novenent velocity is largeLy correct.

C With bich wovement velocities relative amplitude errors are amin. Therefore the timing overshoot tendency in this area indicates ta:t woremst velocity in responses vere too low, i.e. velocity undersboot tendency. Steering force reduces timing overshoot or my even result in timi:18 under. shoot. Analyring this effect leads to the sugsestion that for the low relocity movement conditions steering force results in a decrease of the positioning overshoot tendency without influencing wovement velocity. For rapid movements steering force minly influences movement velocity vitnout influencing positioning. As a result the velocity undershoot effect as noted under $C$ is reduced with steering force available. This latter effect way have also played a role for the $10^{\circ}$ movement condition in Experiment $I$.

Ampli: ie standard deviations under response conditions (Fig. 4) show a remartable increase vith movement amplitude. For the $0.2 \mathrm{kz}$ movement condition the difference betreen stimilus and response movements can largely be explained by the positioning accuracy anta from Enstriment I. This explanation does not ompletely hold for the $0.5 \mathrm{~Hz}$ movement condition. In the latter condition the variability under stimulus conditions is greater as compared with the $0.2 \mathrm{~Hz}$ movemants. Nevertheless the response variability sor the $0.5 \mathrm{~Hz}$ movements is about the same ss for the $0.2 \mathrm{~Hz}$ movements. This effect shu $\mathrm{Id}$ be considered in reletion with the rather high sccuracy of the means of the $7.5 \mathrm{~Hz}$ movement anplitudes. Together these data sugsest that vith slow movenents both posetioning and relocity (in)eccuracy are of importance, wherens with repid movements beheviour is controlled by relocity ar 1 timing accuracy.

The min steering force eliect in reducing amplitude variability holde for botb the $0.2 \mathrm{kz}$ and $0.5 \mathrm{~Hz}$ movenent conditions. The data ran Experimant I illustreted the functioning of steering fores in reducing positioning rariability. Experiment II indicated that steering force may also influence movement velocity. Therefore, the steering-fore effect on amplitude variability na be a result of a reduction in both positioning and relocity reriebility for slow morements. With rapid movements seericg force probably minly reduces velonily veriability.

In sumary it can be stated that the combined results of Experiment II show that at the lover move. : velocities the positioning eccurecy of continuous movements under time constraint is worse when compared vith shat of discrete movements vithout tia constraints. The adjitional role of velocity overahoot was illustrated. For rapid wovenest. 3 a relocicy undershcot effect may occur, wich - together vith a slight tiaing orershoot tendency - leads to the situation that the positioning accuracy for rapid movenents may be better than those for slow movements.

Movement velocity proved to be major factos which largely determi. as the relative importance of positioning, velocity and timing accurecy. The role of steering force can be divided in three parts. Firstly, steering force decreases positioning overshoot effects of low velocity movements. Secondly, steering force reduces the velocity underahoot effect of rapid movenents and finclily steering force reduces positioning rariability.

As mentioned in the introquction he relevancy of the present dais will be tested nurther is an experiment on precogoitive and pursuit tracking. In this latter experiment tracking of predictable and unpredictable lnputs will $b$ ? analyzed under conditions with and ithout occlusion. Thus the role of the internal r.presentations IMV and MRS a sunctioning in combination witb the propicioceptive system may be evalunted in more detail. 


\section{ORIGINAL : : : \\ OF POOR CUALIIY}

\section{Rxriniucres}

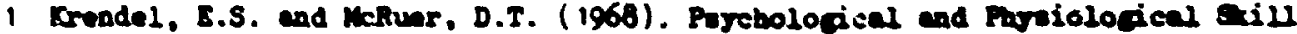

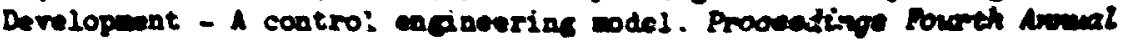
Confermos on Morual Comtrol.

2 Pew, R.H. (1974). Euma Perceptunl Notar Porfornace. M.A. Tantorits (rd.). In: Bunen Inforwation Pxoseseing, Chepter 1, 1-39.

3 MeRuer, D.T., NILe, R.b , Weir, D.R. and Qein, A.A. (1977). New reaule in Driver Steering Control Bodele. Bman Footors, 19 (4), 301-397.

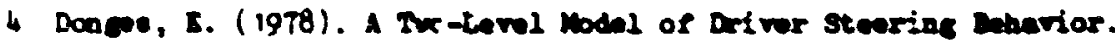
thanan Faotors. $20(6), 691-707$.

5 Schridt, ".A. (1975). A seben theors of disernte etor aill learaing. Pay ologioal Revion, 82, 225-260.

- Gundry, J. (19T5). The ve of locetion and dictence in reproducing difrer-

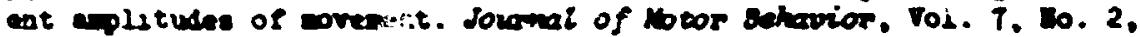
91-100.

7 Mdar, J.A., Copher, D. and Lintern, G. (1977). Frfecte of risul and pro-

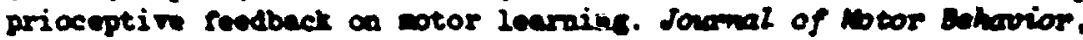
Vol. 9, En. 1, 11-23.

8 Pepper, A.L. and Berma, L.M. (1970). Decay and interfarace effects in the ahort-tern retention of a diecrete wotor ect. foumal of stporimental

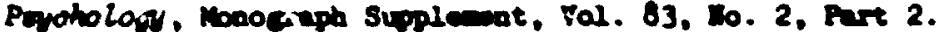

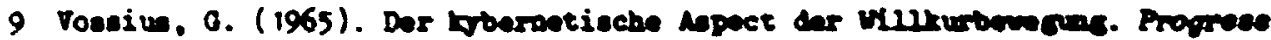

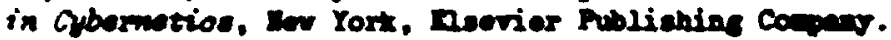

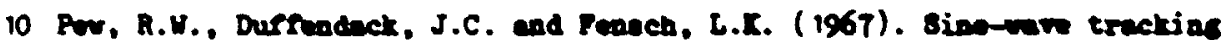

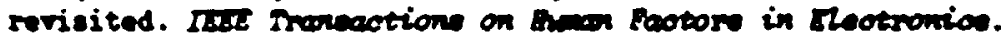
Vol. ET-8, Ec. 2, 130-134.

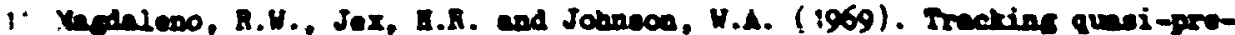

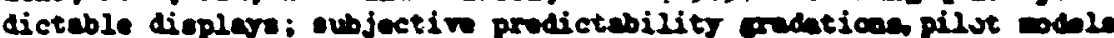
for periodic and serrorbend inputs. Proosadinge Rifith Arwal confor ence on Monal control. 


$$
\begin{aligned}
& \text { OR:...:? } \\
& \text { of potis in....t. }
\end{aligned}
$$

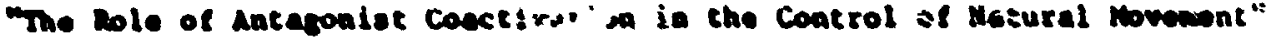

$$
\text { Dy }
$$

Maville Mogein. Th.D.

Lectetene Profeseor, Mchanical Ineinering

nopectureste Insticuse of Tachmilocy

\section{anstiuct}

Twe control of the lepodance obout the joints of the ratural cunculoakeletel eystec by conctivation of entegonis: mecle grouge is described. The consequences of the bility to control jolat impodance are diecuesed. laeed on the ebilley to control inpodape on expleation of tho erucial role played by two-jolat cuseles in che control of estural sovecent is propoed. The inplicetione with reopect to the control of zenipulaters and the codelias of the buen operator are dlecwesed.

Subeitced to the Sixteanth Aanual Conterence on Manual Control. 1980 


\section{ORIGIIAL PAGE IS \\ OF POOR QUALITY}

\section{ImTHODUCIIOA}

The work presented in this paper is part of an ongoint project wose object is to coatrol exteraslly powered assistive devices such as prostheses and orthoses using bioelectric signals such as the electrical activity of puscle. Substantial progress has been asde on the sigan acquisition problen, $(1)$ and the anjor focus of present efforts on this project is the correct interpretation of the ecquired sigaals. Our objective is to determioe fron the available bioelectric sigaals wht the operator"s motor iatent is and to deduce ihat the natural limb would bave done in responss, then geaserate the appropriace comand siganls so that the assisfive device will do whet the natural linb vould bave done. Our wrt has yielded new insights into the control of wovenent, som of wich are presented in this paper.

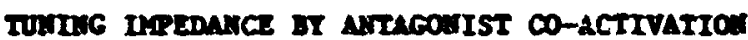

Correct interpretation of bioelectric signals is derived fron a knowledge of wecle wechanics ad functional anatons. In addition to peretating the forces wich ceuse morement, ascles behave as cunable aprings. If the length of a mecle is fired, the isoneric contractile force increases as function of the activation level of ascle. Honever, if the length of the asele is allowed to change, the stiffness of the muscle (or wre generally, its nehunical inpedanss) al wo increases with increasing wacle ectivation(263). Anatonically, auscles are arranged about the joints in entaponist or opposing pairs. A puszling aspect of ascular coordination is that under mon circunstances ancagonist vacles are active simultanaousiy. Bacause co-activation costainput shenical eners but does not cootribute to the echenical wort output of the limb, it represents an energy diseconom, Onder the reasonable assuption that the wajority of wrements are tailored so as to nininize eners costo wile accoiplishing the resk objectives, the purpose of co-activation needs to be explainad. As shown in Figure 1 co-actrvation of encagonise ancles permics independent control of the torque about a joint and the rotatioosl stiffness or inpedance about the joint. Thus the co-activation of antagoniat mucles provides an inportant rehicle for edaptive tunins of the systen parmeters which is indepeodent of feedback, that is, open-loop.

Polit and Bizzi(4)bave showa that denferented onkeye can perforn raxzetacq. ition wovents in the presence of external enchanical disturbances and In the absence of any affereat feedback. This is possible because a given level of co-acivation of acegoniet mecles defines an equilibriu coodition for the joint. Displeceent of the $1 \mathrm{i}$ b from this equilibrius position results in the seberation of a restoring torque thich is a function of the enchanical properties of tis mucle and is independent of afferent feedbeck. Furthermore, if the activities of the antagonist wucles are increased simultaneously, the aquilibriu condition of the joint can reasin unchanged wile the stiffness about that equilibrius condition is increaned (See Pigure 1).

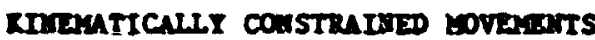

The eoility to tune the mechenical tredence of the jointe can aimplify cowents ade egainet exteranl kinentic cuestraiats. For example consider the problea of turning a crank handle or opening a door: If the stiffaeses about the joints are high, as is the case in ast anoipulators, the end point of the eanipulator ust be coved in the required circular are with high positional accuracy or high interface forces wili resulc. This is difficult because it requires accurate knowledge of the location of the binge and of the 


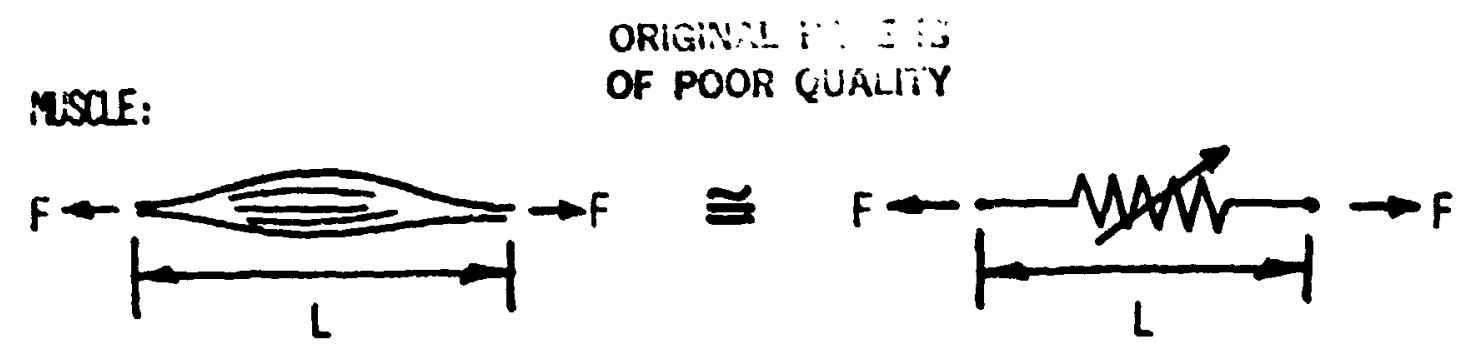

Assume linear force-length relation: $F \cdot u k\left(L-L_{0}\right): \quad \partial F / \partial L=u k$

(F: force; L: length; $L_{0}$ : rest length; $u$ : neural input; $k$ : constant)

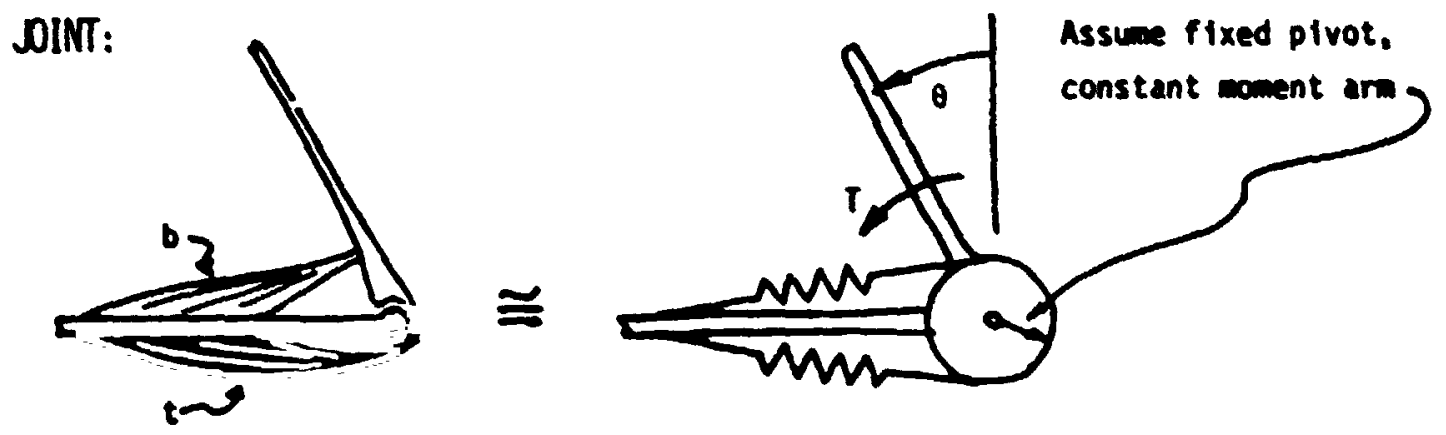

Scale variables such that: $T_{b}-u_{b}(1-K \theta):-T_{t}-u_{t}(1+K \theta)$

$0<u_{b}<1: 0<u_{t}<1: T_{0}>0:-T_{t}>0:$ for $-\pi / 2<\theta<\pi / 2$

( $T$ : torque; $K$ : constant; $C$ : Jeint angle)

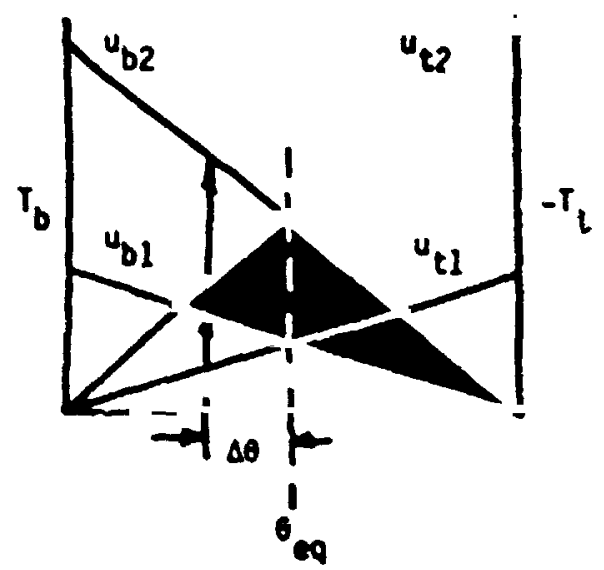

The net torque, $T_{n}$, is the Iffference

betwen the agonist. and antagonist torques.

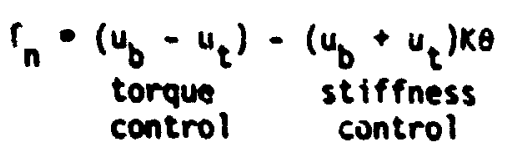

If external torque is zero, $T_{n}=0 a$ :

equilibrium. Thus:

$$
\begin{aligned}
& \theta_{e q}=\frac{\left(u_{b}-u_{t}\right)}{\left(u_{b}+u_{t}\right) k}-\frac{\left(u_{b} / u_{t}-1\right)}{\left(u_{b} / u_{t}+1\right) k} \\
& \text { If } u_{t}>0
\end{aligned}
$$

FIQRE 1: CONTRO OF JOINT STIFFNESS BY

ANTAGONIST CO-ACTIVATION 
the perpendicular distance between the hinge and the handle, in addition to the ability to control the position of the end point accurately. In contrast if the stiffnesses about the joints are $10 \mathrm{w}$, as is the case in the antural linb, the end effector need only exert a forcs in the general direction of the wovewent, allowing the kinematic constraint to deternine the details of che end point trajectory. However, a target-acquisition wovenent such as that required to grasp the handle vill require high positional accurecy and this in curn ay dictate high stiffnesses about the joints. The ability to tune the stiffnesses about the joinr. peraits the manipulator to operace successfully under both conditicus.

Successful ennipulation against kinemetic constrsints requires not only that the ispedance about the anipulator joints be tunable but thrt the inpedance of the end effector be controllable. That is, anipulation will be sirFlified if it is possible to specify the wovenent of the end efivi $\ldots$ in tesponst to arbitrary disturbance forces. Consider the problen of inserting a per into a hole: Voder the action of the lateral forces resulting fron the aiselignent of the peg with respect to the hole the end effector aust wore ii a direction so as to reduce these forces. Onder the ection of the torques wich could cause wedging and jming the end effector mut rotate so as to reduce these torques. However, disturbance forces in the direction of insertion of the peg into the hole ant be overcome. Thus we have specified the desired values of the elemets of the stiffness antrix or tensor wich relates the applied forces and torques to the resulting positional and angular sovenats. It has been shown (5) that provision of appropriate stiffress or complience in an industrial menipulator considerably simplifies teake involving anipuletion of objects againt kinemetic constraints such as, for exsple, che insertion of a shaft into a bearing.

IID EFFECTOR STIFTNESS CONTROL.

the question now is: If the stiffness abost esch joint (or along each degree of freedom) can be dictated, can the stiffness tensor which deternides the ntion of the end effector in response to arbitrary force inputs be specified? To address this question ve consider the movenents of a planar, trodegree-of-freedou, :attesian-coordinate anipulator as thown in Figure 2.

The actuators which produce the wovenents of the cursor are depicted as springs. The stiffness censor for the curaor is wot easily inveatigated by finding the potential energy stored in the spring as a function of the deviation of the cursor froe its equilioriu position wich is assuned to be at the origin of the coordinate system. If ve let the stiffouss of the horizontal springs of the maipulator snown in Figure 2 becone very large wile the stiffness of the vertical springs becones very sall then the potential energy function is a very loag, astrow "valley" oriented along the vertical axis. Conversely, if the verticsi springs becoes infinitely stiff while the horisontal springs becowe infinitely couplizat the potential energy fupction becones a long, narrow "valleg" oriented along the horizontal axis. If the vertical and horisontal stifinesses are finite and equal, the energy function becoese a boul-shaped depression with its lovest point at the equilibrium position. For a siven set of spring otiffnesses the contours of constant potential energy are ellipses. The oriencation of the potential energy "valley" is given by the priacipsl eigenvector of the stiffness tensor and the vidth, or espect ratio, of the potential energy "valley" is given by the ratio of eigenvalues of the stiffness tensor.

If the stiffress tensor could be completely specified then the "valley" of the potencial energy function sould be pointed in any direction and could be 


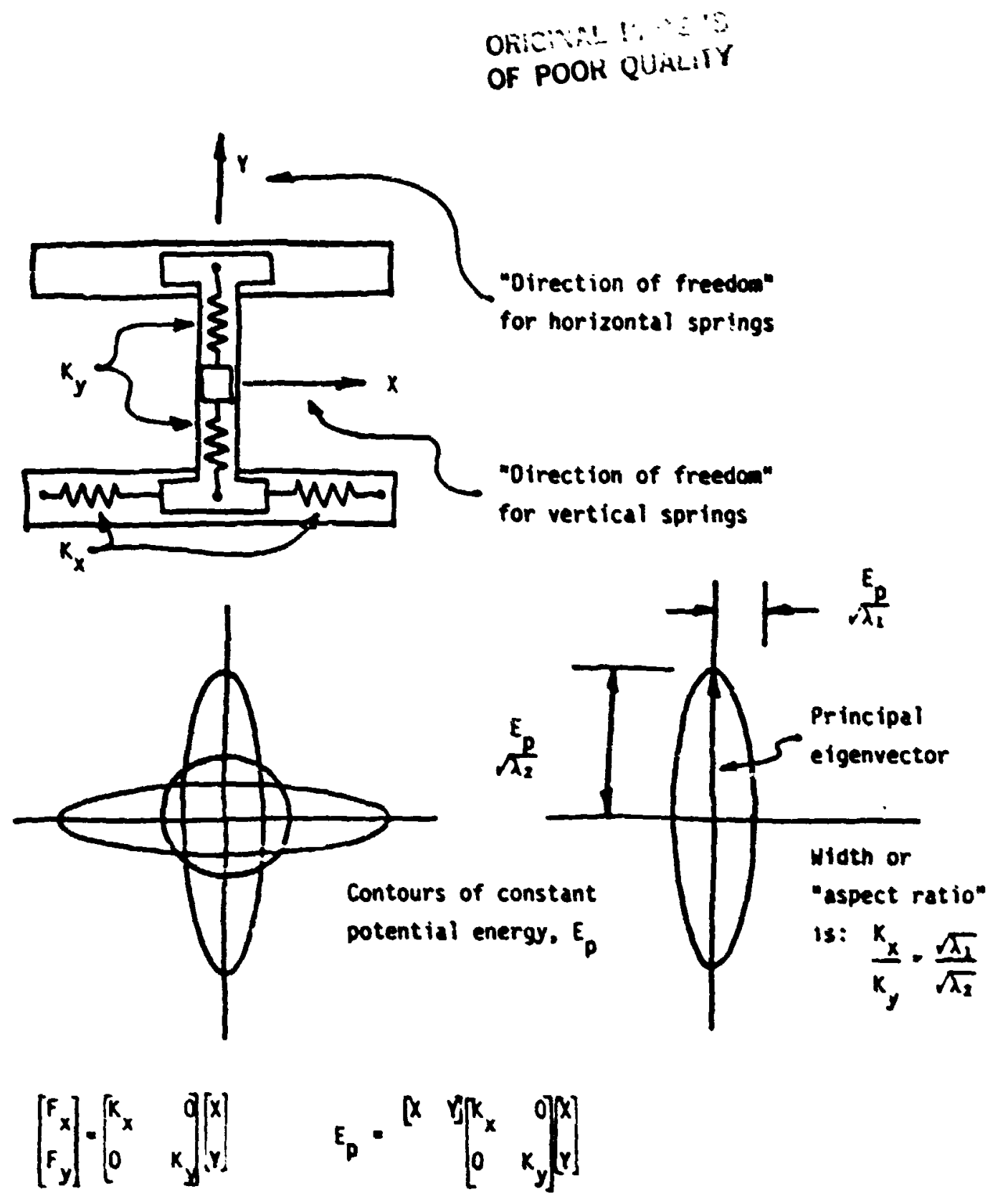

FIGRE 2. hYPOTHETICAL PLANAR CARTESIAN¿OORDINATE MANIPULATOR 
ORIGINRl F:az;

OF POOR QUALITY

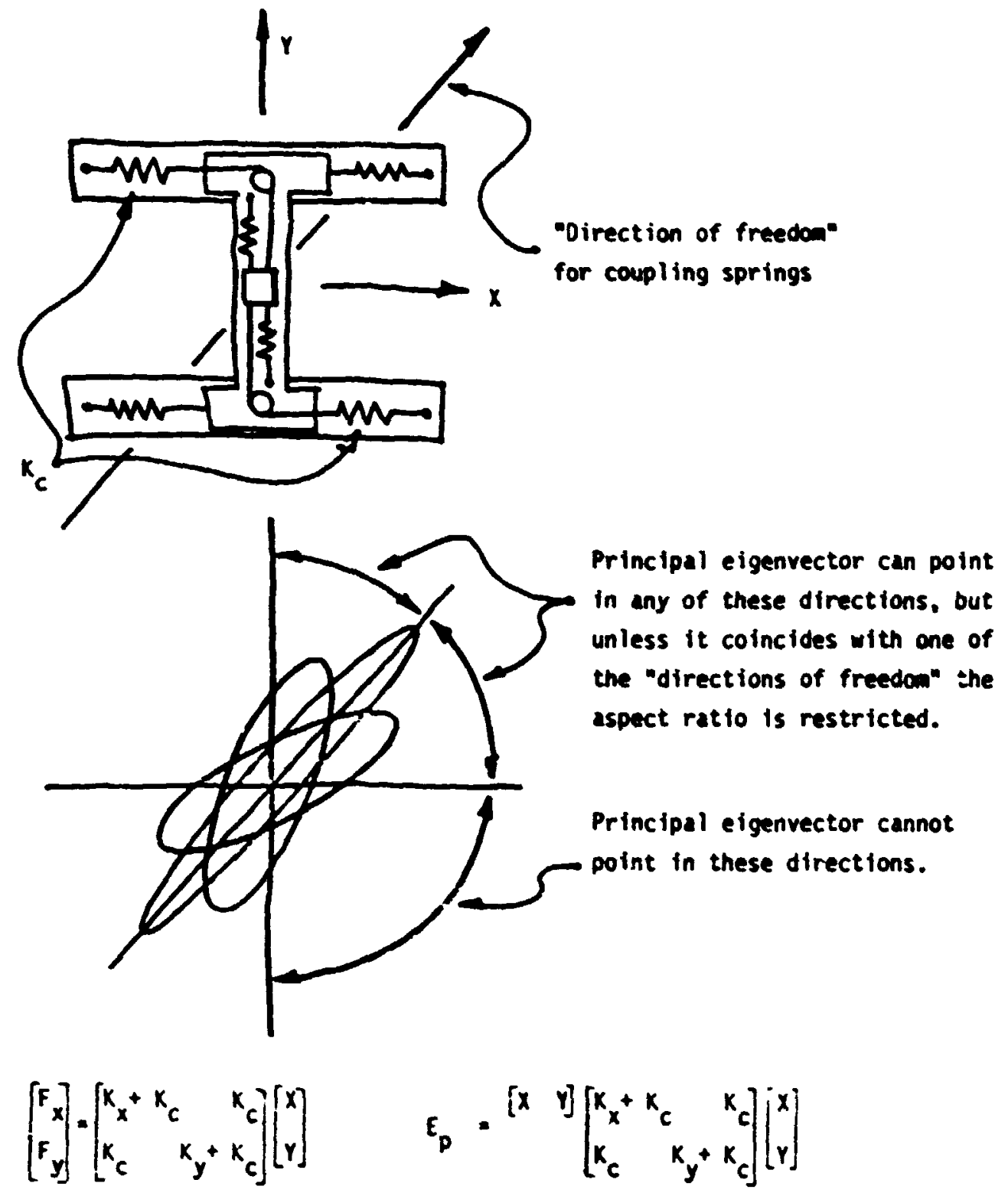

FIGRE 3. PLANAR MANIPULATOR WITH

COUPLING SPRINGS 


\section{ORIGINAL FAGË is \\ OF POOR QUALITY}

given any desired width. This cannot be echieved with $\mathrm{Cl}$ : systen shown in Figure 2. The principal eigenvector of the sciffnass tensor can only be pointed along one or the other of the coordinate axes. Hower, if we add the pair of coupling springs show in Figure 3 the situetion chenges. If the etiffoess of these eprings is ade large while the stiffnesses of ocher springs are allowed to approach zero then the cursor vill be free to cove only along the diagonal shown. This is the "direction of treedow" associated with this pair of springs. The "directions of freedoe" associated with the horizontal and vertical springs are the vertical and horizontal axes respectively. It is clear that the principal aigenvector of the stiffness tensor for the cirsor can now be oriented alung this diegonal direction of freedoe. Furtherwre, the width of the potentia! energy "valley" can be apecified at vill. In eddition, it can readily be show that the principal eigenvector of the stiffness tensor can be oriented alon, any of the directions shown in Figure 3 between the directions of freedon. However, if the principal igenvector does Dot coincide with one of the three directions of treedoe then the ratio of eigenvalues of the stiffness tensor is constrained such that a lower limit is placed on the width of the potential energy valley; that is, the valley cannot be ande infinitely narsow. In general it can be shown that if the angle between two directions of freedom is lese that 90 degrees then the principal igenvector of the stiffness tensor can be oriented along any direction between these two directions of freedow. The wore acute the angle between the directions of freedow the narrover the potentill energy function valley cen be ande when the principal eigenvector of stifiness tensor is ofiented midvay between the two directions of fretiom.

DOLE of TwO-JoINT wSches

The anelogy between the "manipulator" of Figure 2 and 3 and the maculoskeletel systea is dizect: The presence of the two-joint auscles means tivet the principal eigenvector of the stiffness censor of the end affector can be oriented in almost all directions. This canot be achieved using the singlejoint muscles alone. If ve consider wotions of the upper liab in a horizontel plane and wodel the upper limb as a two-link kinemetic chain then ve can define directions of freedos as in the case of the cartesian-coordinate manipulator. If the single-joint elbo auscles (4.g. brachialis, adial and lateral heads of tricepe, etc.) are sade iofinitely siff wile all other auscles are made Infinitely compliant the direction of freadom is a circular arc cantered bout the shoulder exis (See Figure 4a). If the single-joint shoulder wuscles (e.s. anterior and posterior deltoid, etc.) are ade infinitely stift while all other muscles are ade infinitely compliant the diraction of frendom is a circular arc cantered abour the elbow axis (See figure 4a). The direction of freedor associated with the two-joint auscles (e.8. biceps. long heed of triceps) will be a function of the precise enetomical connections of the wueles to the limbs. For eiaplicity we make the quantitatively ineccurate but qualitatively correct essumption that the two-joiot auscles act with fixed and equal mone arwe about the shoulder and lbow joint. Under these assumptions, if the two-joint muscles are mede infinitely stiff wile the single-joint muscles are infinitely cooplj th then a kinmatic constraiot has been imposed upon the veluas of the shoulder and abov angles such that the absolute angle of the forears with respect to the thorax is fixed. As a result the and effecter describes a ciruclar arc a show in Figure $4 b$. This is che direction of freedos associeted with the two-joint muscles. If we look at the effect of the single and double-joint macles taken together ve can see that for a wide range of positions in the morament space the directions of freedoe intersact one another at ecute angles such that the principal eiganvector of the atiffnese censor of the end effector can be oriented along any direcwion (See Figure 4c). This is not possible vith the single-joine muscles alone. 
ORIGINAL FA:S

OF POOR QUALITY

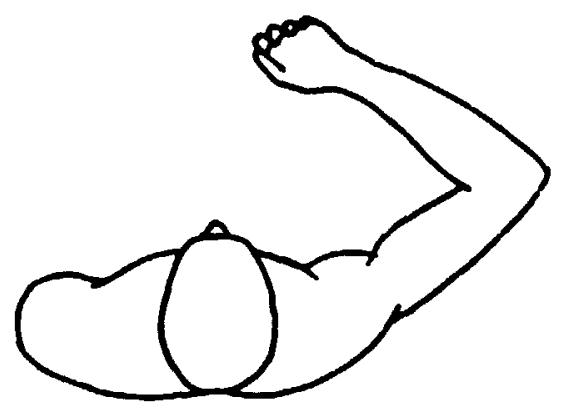

Assume movement in a horizontal plane, forearm and hand rigid, lbow and shoulder to be simple pivots, all muscles to have constant moment arms.
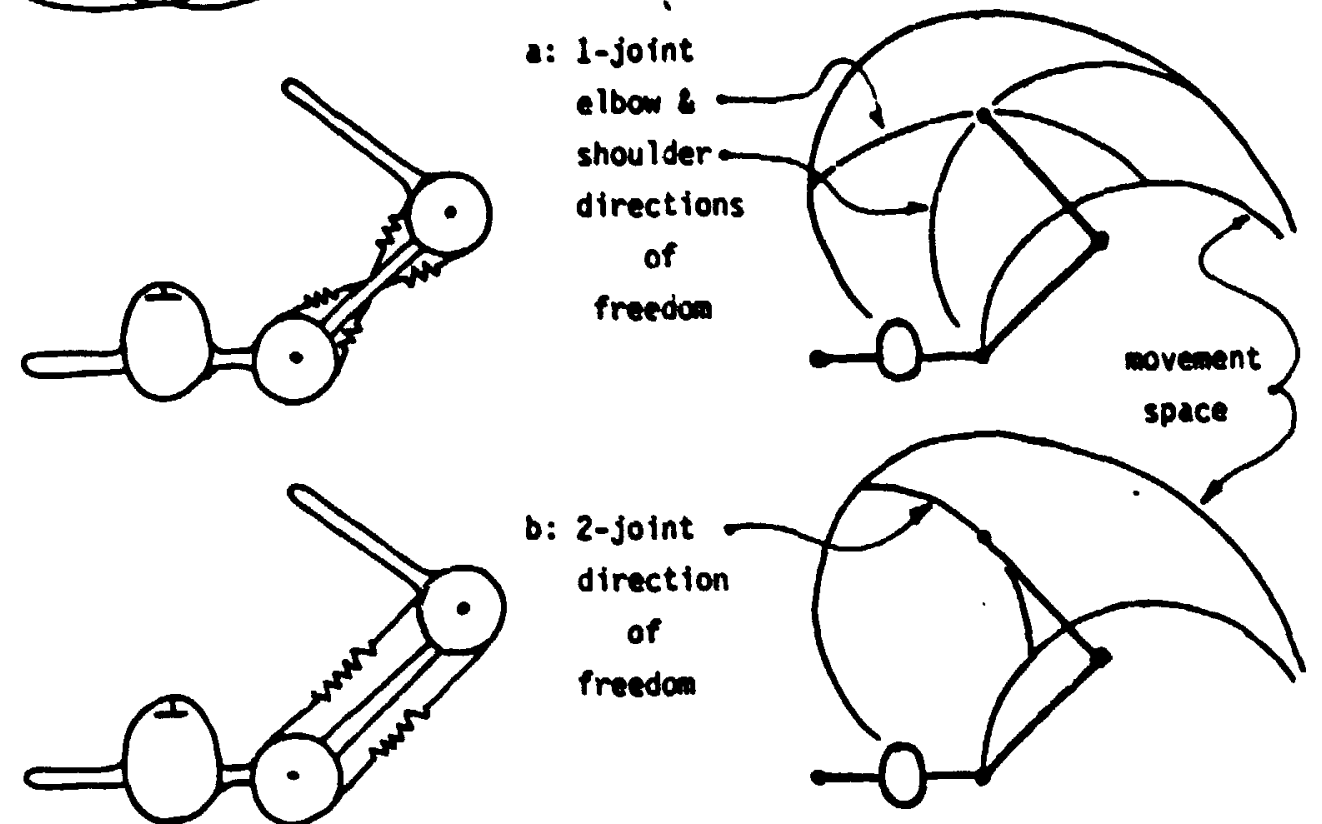

c: directions

of

freedon

for 1-

and

2-joint

muscles

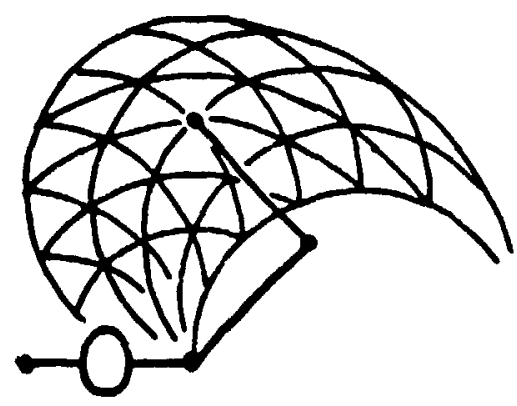

FIGURE 4. "DIRECTIONS OF FREEDOM" FOR THE UPPER LIMB 


\section{ORIGINAL PAGE IS \\ OF POOR QUALITY}

FIÄAL POSITION CONTROL

One of the fascinating consequences of the springlike properties of muscle is that in the case of wotion about a single joint the natire wovenat could be controlled simply by specifying the final equilibriun position(4). The biocontroller would anely specify the appropriate set of auscle ectivities required to define the equilibrium position of the joint and allow the inherent mechenical properties of the wseulo-skeletal systea to take care of the details of the movement. It is not suggested that this is the only or even the predominant mode of natural movewent, but it could be significantly advantageous to the central nervous system as the biocontroller need only intervene in the control of wovement once every several hundred milliseconds or so thus allowing the higher levels of the centrel aervous syetem to be focu:sd on other tasks. The quastion now axises: Could a similar control schewe vork for wultiple-degree-of-freedom bovenents? It is essy to show that if only single-joint wuscles are used then for a large number of reasonable combinations of start positions and carget (final) postions it is not possible to achieve the almost-straight-line trajectory between start and target wich is typically observed for unconstrained movesents. For example, if the stere position and target position lie on an arc such that in both the start and terget positions the angle of the upper arm is identical, only the angle of the forearm being different, then if the muscles are activated such that the equilibrium condition for the limb is at the target position the shoulder muscles can generate no torque about the shoulder joint wen the $1 \mathrm{imb}$ is at rest in the start position. Thus the net force vector at the end effector due to the epringlike properties of the musculo-skeletal system wust point in direction such that it ince. cts the shoulder joint (See Figure 5a). This will result in a mevent which suings wide of the typically observed path between the start and targe positions. However, the addition of the two-joint wuscles considerably changes matters: For the combinasion of start and target positions described above the two-joint muscles provide the necessary freedom to allow the force vector at the end effector to point directly at the target position (See Figure 5b). Furtherwore, the potentiel energy function for deviations about the equilibrium (target) position can be set up such that the anergy function is a narrow "valley" running from the equilibrium position to the start position. This would mean that the end effector would tand to follow the "valley bottom" and aove along an approximately straight line trajectory. Again, this opens up the intriguing possibility that large portions of the time hietory of the wotion of the end effector could be controlled by the inherent properties of the musculo-skeletal system with only minimal intervention from the higher levels of the central nervous system.

\section{RELEVANCS TO MANIPULATOR CONTROL AND KOMAN OPERATOR MODELING}

Froa the foregoing analysis it follows that if the etiffness or impedance teneor for the end effector of any manipulator is to be fully controllable theo it wili be necessary to provide adaptable coupling between two or more degrees of freedow of the manipulator. This coupling may be provided mechanically, as in the natural limb, or electronicaly vie feedback. Either vay, the coupling abould provide an adaptable kinematic constraint siailar to that imposed by the wuti-joint muscles in the natural limb. As wentioned earlier, controlling the end effector impedance vill considerably simplify manipulation against external kinemaric constraints. Another perspective is that impedance provides - convenient and natital "language" for the commication of wotor intent between the controller and the effector (i.e. the manipuletor). Two common modes of anipulator control are position control and "force" control. The former, in wich the desired position or trajectory of the manipulator is specified, works well for free manipulations, the movements being ralativeiy insensitive to ex- 
ORIGINAL PAGE IS
OF POOR QUALITY

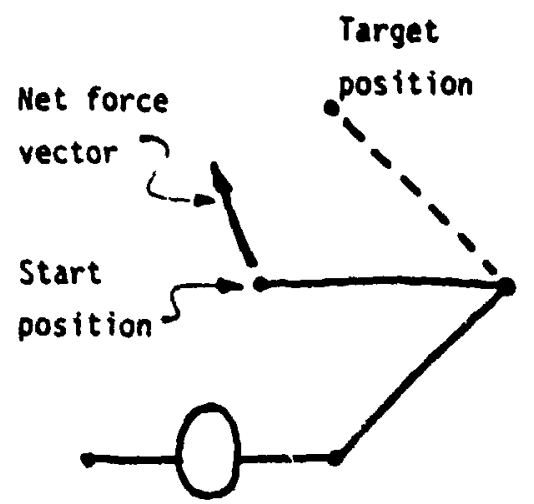

Assume the muscle activities are set up such that at equilibrium the end effector is in the target position.

a: If only the 1-joint muscles are used the net force vector at the end effector when it is in the start position must point as shown.
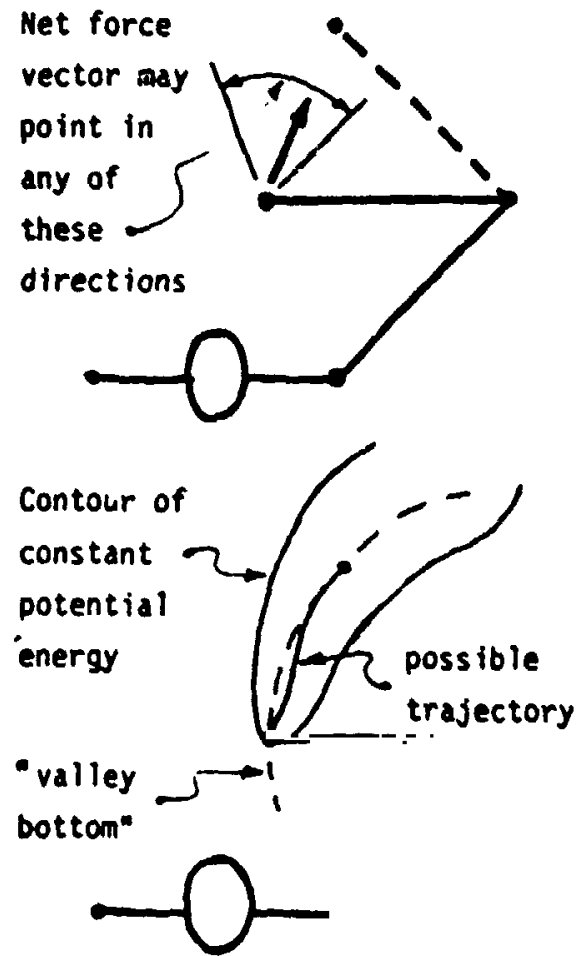

b: If 1- and 2-jaint muscles are used the net force vector may point directly at the target, or in any of the drections shown.

$c:$ If the potential energy function is set up approprlately then the end effector may tend to follow the approximately stratght trajectory shown.

FIGURE 5. TWO-JOINT FINAL POSITION CONTROL 


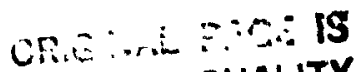 \\ OF POOR QUALITY}

ternal disturbences, but causes difficulty when dealing with external kinewatic constraints. The latter, in wich forces or torques are comanded, is better suited to manipulation against constraints, but does not perform vell on free movements. In the former the movement "primitives" are positions; in the latter they are ferces or rasques. However, the foragoing analysis indicates taat the "directions of freedom" associated with each of the manipulator actuators should be regarded as the movenent "primitives". In other words, the "controlled variable" should not be pusition nor force, but iapedance (or stiffness). Looked at from the point of view of impedance control, position control and force control are simply degenerate or extreme cases of impedance control. That is, position control inplies very high stiffnesses or impedances, while force control implies very low (zero) stiffnesses or impedances. A manipulator with controllable impedance should have far greater capabilities than either a forcecontrolled or a position-controlled manipulator and shouli be equally successful at constrained manipulation and free movement.

The human ability to control impedance must be included in models of the human operator. Essentially the human operator is capable of adjusting his own mectanical system parameters to optimise performance on a task. This will be wost evident in manipulation of tools or machine controls. For example, high levels of comactivation may yield good positional control over a tool or joystick due to increased meciranical coupling (good "grip"), but the same mechanical coupling implies increased transmission of vibration and shock loads. In vibratory environment the skilled operator may tune his mechanical impedance to fird the optimum trade off between these effects.

Co-activation costs input chemical energy to the muscles without yielding output mechanical work and undue co-activation will lead to eaxly fatigue. An unakilled operator, being unable to predict any excernal disturbances, may co-activate excessiveiy to requce their effects on tis movemecns. A sicilied operator, wore familiar with the nature of external discurbances, may lect for lower levels of co-activation and as asult avoid fatigue. Howevar, even the skilled operator might opt for high co-activation in less familiar circumstances such semergencies. Thus co-activation of antegonists ray prove useful as a measure of movemant skill and mental workload. 


\section{ACKHOWEDGERENTS}

The work reported in this paper wes supported by the Mational Scieaces Foundation under Grant PPFR-7917348. 
ORIGINAL. PAGE IS

OF POOF QUALITY

\section{REFERENCES}

1. Hogan, N. and Mann, R.W., "Myoelectric Signal Processing: Optimal Estimation Applied to Electromyography, Purt I \& II," IEEE Transections on Biomedical Engineering (in prese)

2. liazon, P., "Dynamic Stiffness and Crossbridge Action in Muacle," Biophys. Struct. Hechanism, Vol. 4, pp. 15-25 (1978)

3. Zahalak, G.I. and Heyman, S.J., "A Quantitative Evaluation of the Frequency-Response Characteristics of Active Human Skeletal Muacle in Vivo," Journal of Biomechanical Engineering, Vol. IC., pp. 28-.37 (February 1979)

4. Polit, A. and Bizzi, E., "Characteristics of Motor Piograms Underlying Arm Movements in Monkeys," Journal of Neurophysiology. Vol 42 No. 1, Pp. 183-194, (Jan., 1979)

5. Nevins, J.0. and Whitney, R.E., "Computer Controlled Assembly," Scientific American, 701.238 , No. 2 Pp. 62-74 (Feb., 1978) 
A COMPARISON OF COAtrol moES FOR TIKE-DEAVER

REDTE MNIPULATION

\section{ERECORY P STARR}

\section{i. INTROOUCTION}

Transaission time delay in the commication channel of a manual control system degrades performance by preventing the hman operator from inediately seeing the resu!ts of his actions.

A time delay can exist in remote manipulation systess. caused by long comunication distances or banduidth 1 iaitations. Ferrell [i] conducted the first research in time-delayed manipulation using a to degree-of-freedon anipulator. His subjects, working at time delays of $1.0,2.1$, and $3.2 \mathrm{~s}$. could accomplish tasks even requiring great accuracy. The subjects spontaneously adopted a pattern of woving cautiously. then waiting to see the results of their actions. In experiments with a six degree-of-freedom master-s! are manipulator systen and time delays of 1.0 to $6 \mathrm{~s}, 81$ ack [2] saw thrt subjects tried to use the wove-and-wait strategy; but there were often difficulties. The subjects seemed to have a problem in holding the master arm stationary wile wating for feedback. Any uncesired drifting of the aster an introduced a discrepancy betreen the positions of the master and slave. This discrepancy was not perceived because of the time delay. The subject would then begin his next wove with an inherent error.

The difficulty of effectively using the move-and-wait strategy with a aster-slave manipulator suggested that rate control might be a more effe:tive control wode with time delay. Manipulator rate controllers are usually mitiaxis joysticks or switchboxes and are invariably constructed so that when the merator yisnes to hold the manipulator stationary, he can simply rewove his hand from the controller. This eliminates the possibility of undesired manipulator wotion and should aid the operator in using the moveind-wa it strategy.

The research sumarized in this paper was conducted to compare masterslave and rate control of a manipulator. Four time delays were used. These delays $(0.0,0.33,1.0$, and $3.0 \mathrm{~s})$ allowed us to examine the effect of time delay on control-mode performance. A peg transfer task was used, with automated data acquisition.

\section{i1. CONTRCL-MODE IMPLEAEMTATION}

The MASA-Ames manipulator, designed by Vykukal et al. [3], was used in all experiments. This manipulator consists of conical fiberglass sections connecteo rotational joints The motion of these joints resembles the twisting of nested sections of stovepipe. There are seven rotational joints, plus the parallel-jaw end effector.

The master arm used with this manipulator is geometrically similar to the slave, although sifghtly scaled down. The operator's arm is inserted into the master arm, and analog position servos control the slave position.

The master had several undesirable characteristics. Foremost was preference for motion in certain directions, caused by the static and viscous 


\section{ORIGINAL PAL S
OF POOR QUALIY}

joint friction cabinad with the mster's umusul gecontry. In addition. the operator could not wove the mster thrugh its full range of otton.

One to the pecullar grometry of the hae arm. It was mecessary to use resolved wotion rete control (mix). concel ived by intitney [4]. In Bim. - digital computer coordintes the individeal joint rates. The operator specifles direction and speed of the hand without concerning hisself with the Individul joint rates.

A six degree-of-freedon isemetric Jasstick ws used as the rate controller. Using this joystick. the coperitor could comand hand trenslationel and angular velocity along axes of a Cartastan coordinate systen find In the hand Itself. See Flgure 1. For a coplete description of this rate control Irelementation, see Starr [5].

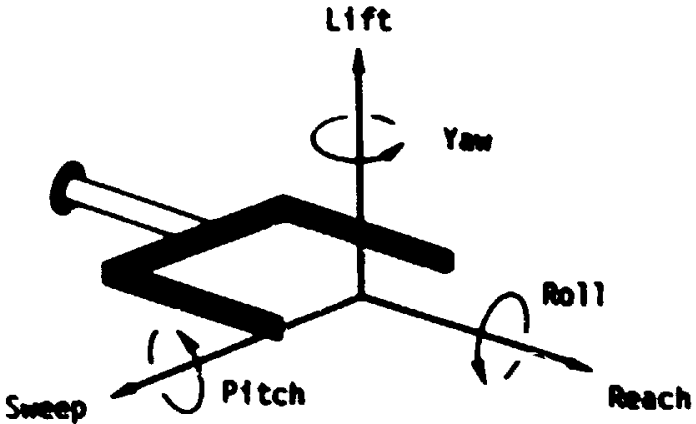

Fig. 1. Hand-mounted coordimate system.

The Josstick had a siall but noticeable count of crosstalk. aking it difficult to cause wotion in only one direction. To oervit wotion along oniy one axis. an operator-activated sutteh wa provided which selected only the largest output signal.

\section{TEE EXPERIMENT}

Task

A pag transfer task was used to compare the two control modes. The operator extracted the peg from the left-hand receptacle. placed it in the right-hand one. numved it from the right and replaced it back in the left one. The subject as required to fully insert the peg before relasing it.

The receptacles ware placed 8 in $(20 \mathrm{~cm})$ apart, and both wre counted on - table wich was tllted back tominds the mipulator at an angle of $32^{\circ}$ wt th the horizontal. Furtheriore. the right-hand receptacle was tilted any from the left at an engle of $17^{\circ}$. thus requiring a reortentastion of the peg before insertion.

Three pegs were used wth this task. All wre $4-$ in $(10.2 \mathrm{~cm})$ long. and were $0.75-0.90-$, and $0.99-1 \mathrm{n}$ dlameter $(19.1-, 22.9-$, and $25.1-\mathrm{a})$. The clearance between the pegs and the $1-1 \mathrm{n}(25.4-i)$ ) hole was $0.25,0.10$, and 0.01 in $(6.35,2.54$, and $0.25 \mathrm{~m})$. respectively. 


\section{Deta Acquisition}

The division of a task into simpler subtasks has ben shom to be useful in industrial engineering research. Such division of ccmpletion tim ws attempted by Blacker [6] in a peg transfer manipulation task. The tim diviston ws done by the subjeat using a foot switch. and Blackmer acknowledged shat the results were not precise enough to permit any conclusions.

The overali completion tive in the mg trinsfer task described here, from peg liftoff to tcuchdom, was divided into three separate completion times, each representing a subtask. These sut: s.sks were witidrawal, transport. and adjustment; insertion. defined as follins.

wichulraved began at peg liftuff and ended when the peg left the receptacie.

Tuasport began when the peg left the receptacle and ended when the peg was 2 in from the edge of the target hole.

Adjus omenc/iuscrtion began when the peg wa $2 \mathrm{~cm}$ from the edge of the hole and ended at touchdom of the peg.

The state of the task was monitored by a computer which accumulated the subtask completion times and recorded them on agnetic tape. These times were accurate to within $1 / 30 \mathrm{~s}$.

The withdraal time gives an indication of effectiveness in anipulation with external contact forces there tenminal accuracy is not crucial. The transport time represents effectiveness in coarse pasitioning. Finally, the adjustment/insertion time reflects performance in two types of wotion: ar unconstrained fine-position segment where terminal accuracy is the goal (adjustiment), and an externally constrained segment where force accommodation may be necessary.

Experibent Design

A factorial experiment design was used, the variables being control ode C. time delay $T$, peg size $P$. and iask direction $D$ (left-to-right or right-toleft). Because of time constraint plus equipment fallures, we were able to use only one subject.

\section{Procedure}

After learning, the subject performed 27 replications of the task at each combination of variables, for a total of 960 replications. Peg size and time delay were randomized within each control wode. At the 1.0- and 3.0-s tise delays. the subject complained of fatigue and frustration when using masterslave control.

\section{RESULIS AND DISCUSSION}

\section{Withdrawa 1}

The withdrawal times versus time delay for each peg size appear in Figs. 2-4. along with least square regression lines. The reptical lines through the data polnts are one standard deviation.

Comparing the regression lines at each peg size, one can sie the degradation of master-slave control as peg size increases. With peg 1. which had the greatest clearance, master-slave control resulted in lower withdrawal times at each delay. These times were significantly different at the 1 percent level. 
original pacte is

OF PCOR Q: ALITY

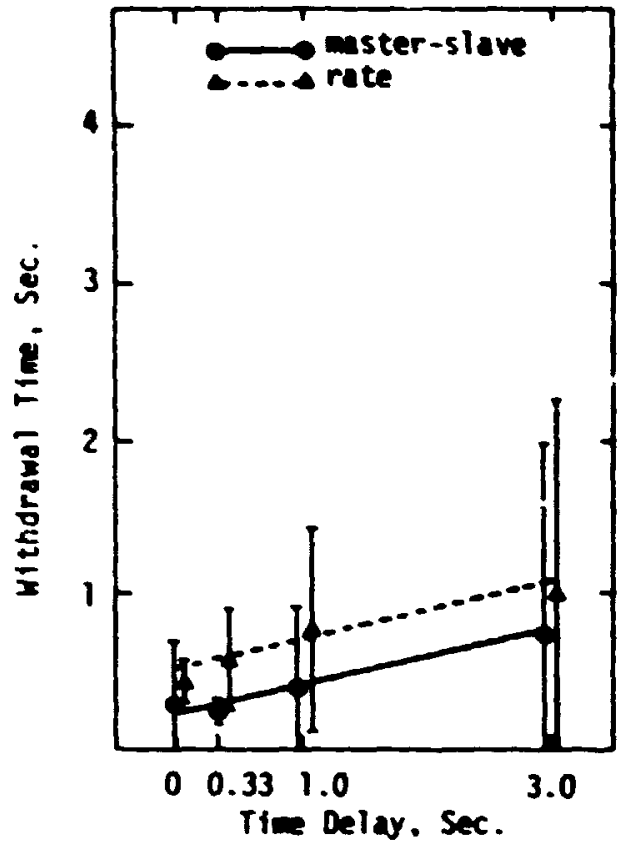

Fig. 2. Mithdramal tife versus tise delay. peg 1.

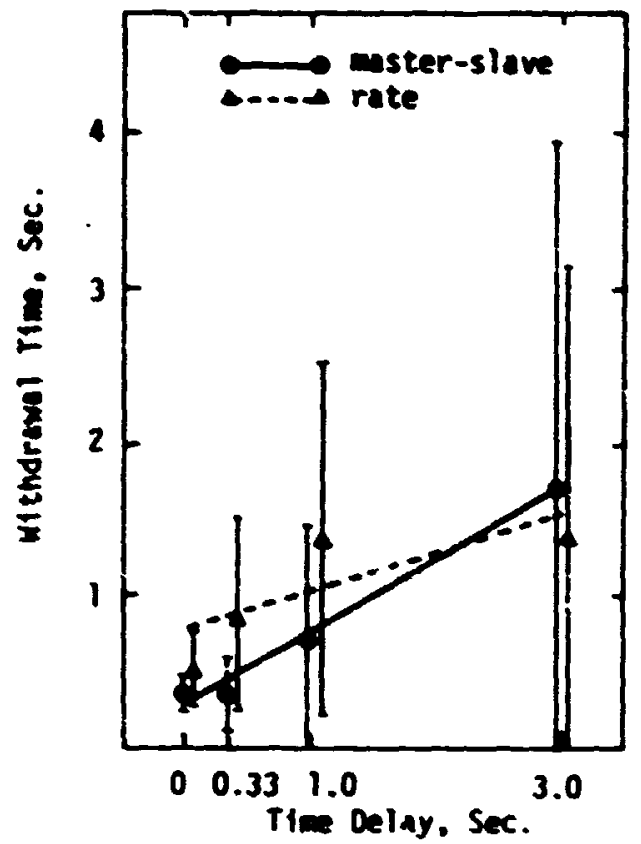

F1g. 3. Withdremil time versus time delay, peg 2.

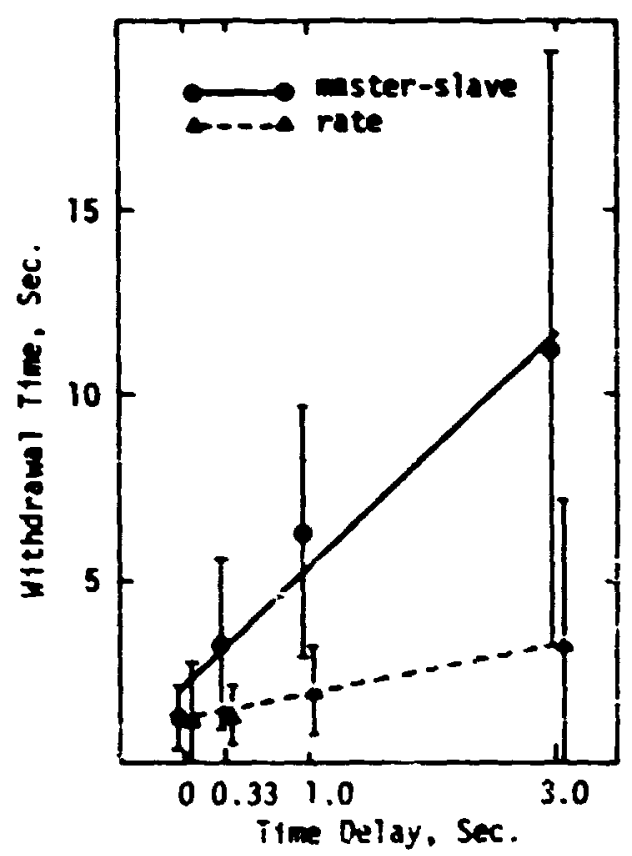

rig. 4. Withdramal time versus

time delay, peg 4. 


\section{ORIGINAL PAGE IS \\ OF POOR QUALITY}

With peg 2, mster-slave control was superfor at the laner thrse delays (I8 significance level), but at the 3.0-; delay, rate control had a lower withdrami tice, althcugh not significant. With pag 3, rate control had lower withdrawl times at all delays with 18 significance. The standard deviations of the mster-slave withdrawal times with peg 3 were more than toice as large as those of rate control. Indicating that jaining ma tave occurred ...th aster-slave control.

The superiority of aster-slave control in withdrawal of pegs 1 and 2 both with and without time delay can be explained by considering the type of motion necessary. With these pegs the clearance is large enough so that a perfectly axial withdranel is not neeted to avoid binding. Mithdranel becomes - coarse motion, emphasizing speed rather than directional accuracy. The mster-slaw system had higher speed capability than the rate control system, due to the rate gain we used. Thus master-slave would be expected to have lower withdramal times with pegs 1 and 2 . Wth peg 3, homever, the withdrmal changes character. The clearance of 0.01 in $(0.25 \mathrm{~mm})$ between peg and hole results in a withdrawal segment stressing directional accuracy.

The angular clearance, or wobble angle, shows the directional accuracy needed for withdrawal better than the radial clearance. Woble angle versus insertica depth for the three pegs is shown in Fig. 5. Peg 3 has a much smaller wobbie angle than pegs 1 and 2 , especially as it nears botton.

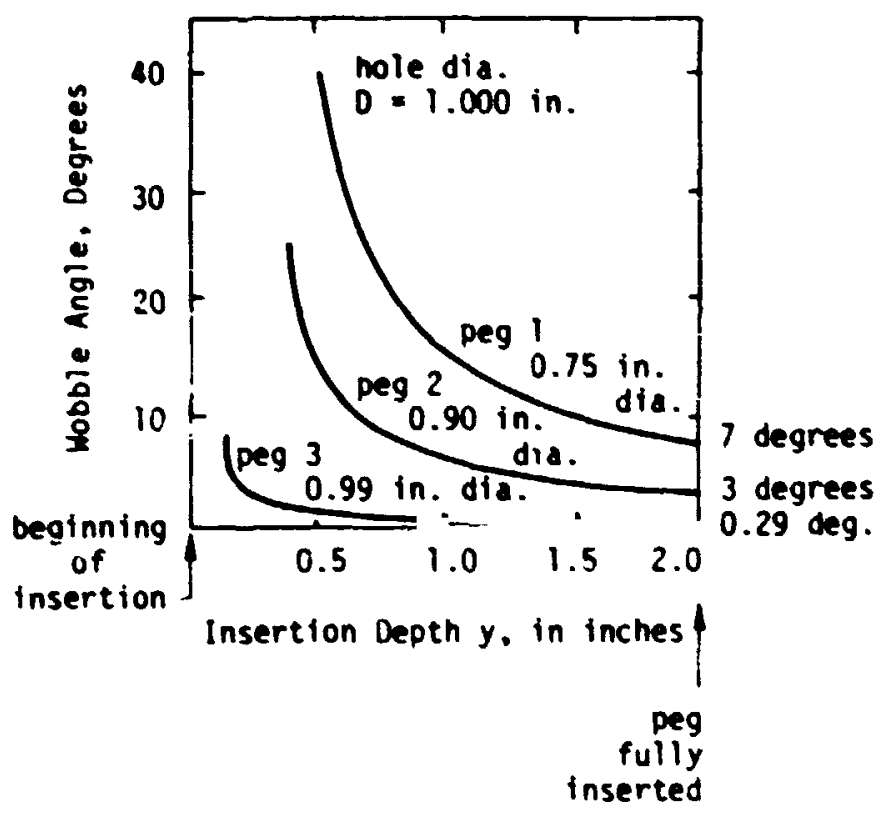

Fig. 5. Wobble angle versus insertion depth for three pegs. 


\section{ORIGINAL i.VU: IS
OF POOR QUALITY}

When e tin delay was present, the subject had to mow open-loop. The withdruml times suggest that the rate control system had better open-loop cirectional accuracy. Wth rete control, the subjert oriented the hand parallel to the top of the bl ck, grasped the peg. and issued a pure "Ilft" command. The hind would move back along the hole axis and extrect the pag cleanly. The operator-controlled sutteh enabling gemeration of a pure con and ws helpful during withdreml.

when using master-slave control. the subject had to monitor and attempt to null contuct forces betmen the peg and the receptacle. Active force feedback would have been very helpful. but Ferrell [7] has show that active force feedosck can cause instability when a tim diay is present.

\section{Transport}

Fig. 6 shows transport tim versus time delay for each peg size and control mode. The regression lines are pooled over peg size. Transport time does not appaer to vary consistently with peg size for elther control mode.

A t-test mo on the transport times pooled over pag size showed that anster-slawe control produced significantly lawer transport tias at all time delays. This is to be expected considering the higher speed capability of mster-slave and the laportance of speed during transport.

Fig. 7 shows transport time versus tim delay for each control aode and task direction. The transport times for aster-siave control, direction 2 , are far lowr at all delays than for direction 1 . and lower than rate control in either direction.

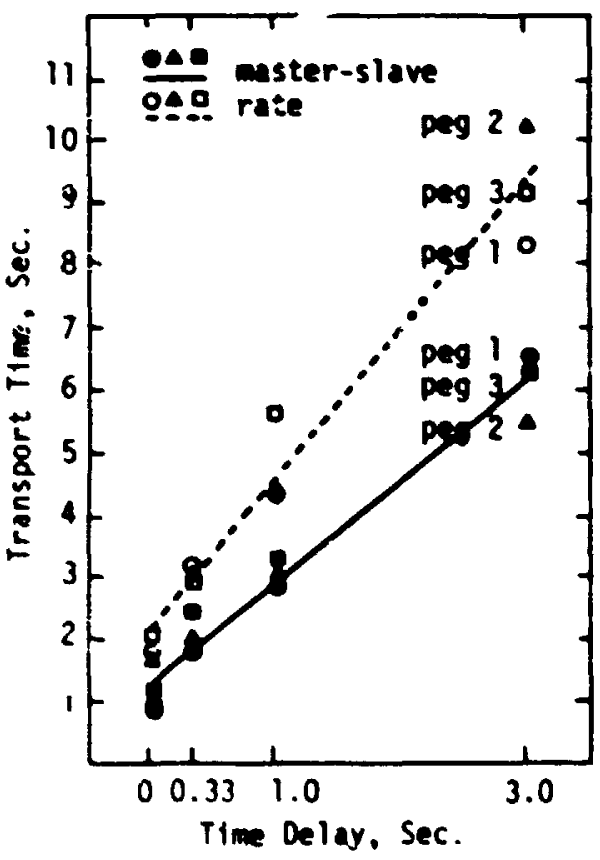

Fig. 6. Transport time versus time delay, all pegs.

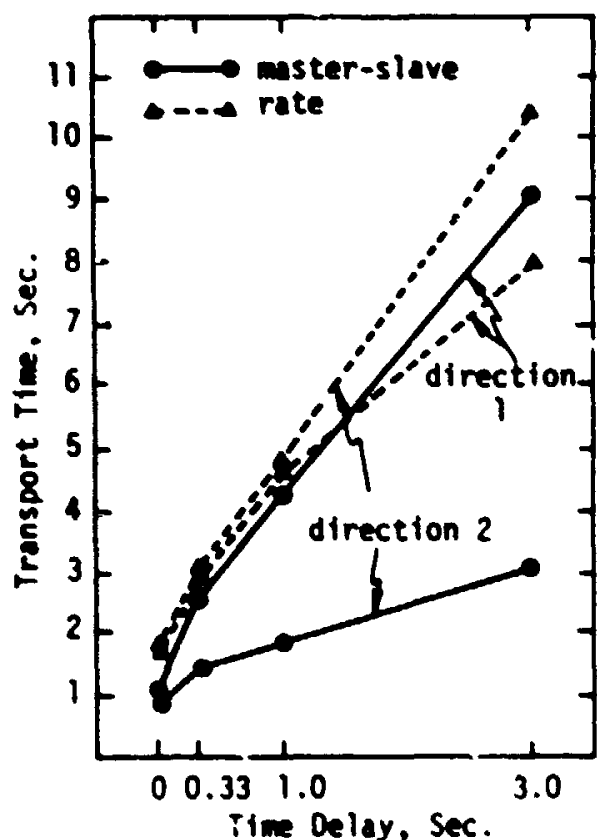

F19. 7. Transport time versus time delay, directions 1 and 2 . 
The most likely explanation for this difference is the varying mechanical impedance of the master. Since the master has seven degrees of freedom, its joint rotations during direction 2 mere not necessarily the reverse of those during direction 1 . Transport in direction 1 apparently involved more joint rotation and did not match one of the master's low-impedance directions. The nonisotropic nature of this master-slave system is not true of resoived rate control, which decouples the operator from the geometry of the arm and permits motion in any direction with equal ease.

\section{Adjustment/Insertion}

Figs. 8-ic show that the adjustment/insertion times follow a pattern similar to the wi hadrawal times, with rate control degrading less with tine delay. The similarity is because insertion is the reverse of withdrawal, since we required the subject to guide the peg to the bottom of the hole.

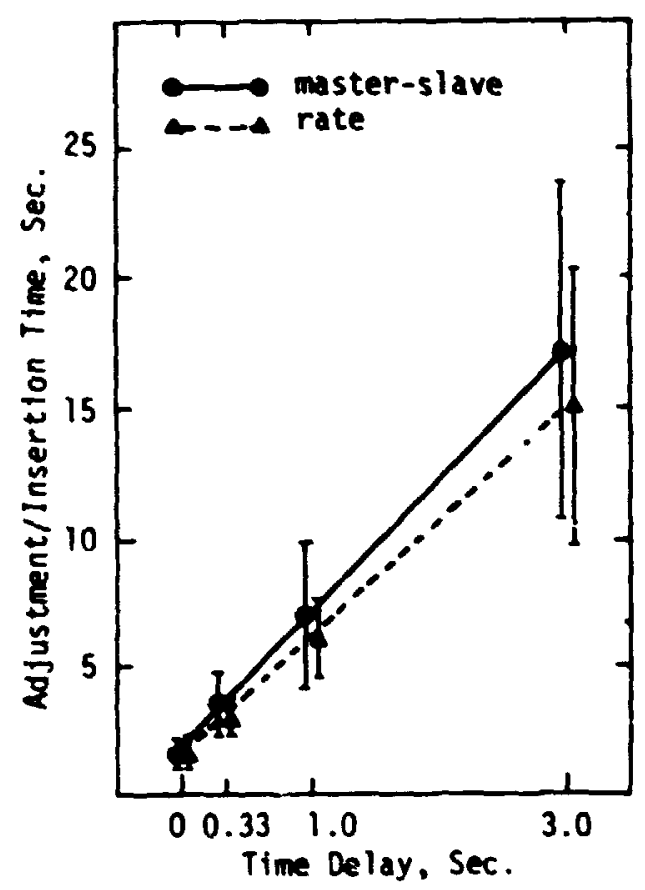

Fig. 8. Adjustment/insertion time versus time delay, peg 2.

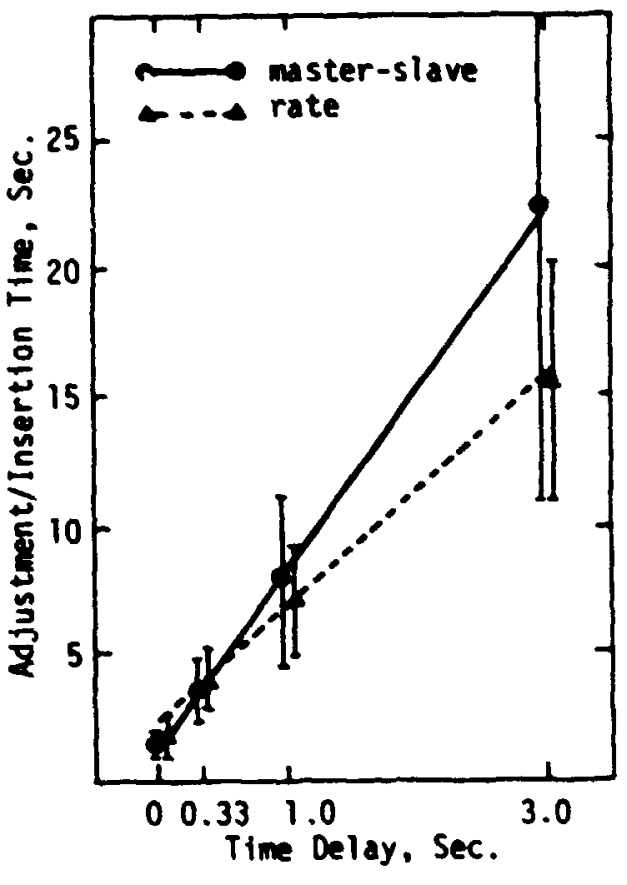

Fig. 9. Adjus timent/insertion time versus titue delay, peg 3.

\section{v. CONCLUSIONS}

Judging from these results, which are certairly inconclusive due to the use of anly one subject, resolved motion rate control appears to be more effective than master-siave control for those parts of a time-delayed manipulation task emphasizing accuracy. Master-slave control was superior to rate control with no time selay, but degraded more rapidly with delay. This is partially due to the easa of holding the manipulator stationary with rate control, thus allowing motionless pauses to recelve feedback. However, some 


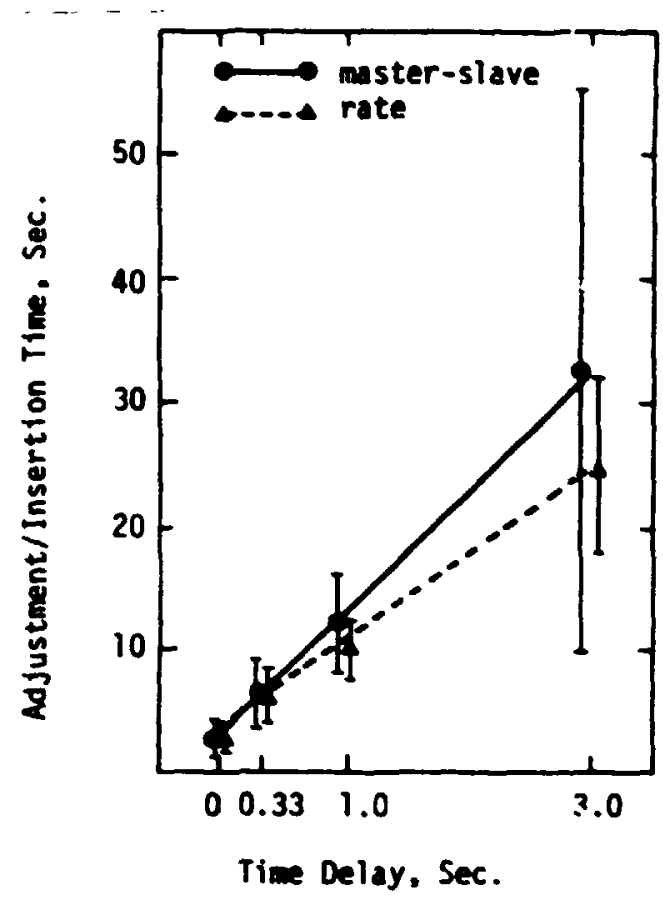

Fig. 10. Adjustment/insertion time versus time delay, peg 3.

of rate control's superiority may be the result of better open-loop positioning accuracy. which was not directly masured.

Also significant was the difficulty of the task as reported by the subject. Then perforning with the 3.0-5 time delay, he becalme physically and mertally fatlgued much more quickly than with master-slave control.

These results suggest that perhaps combined master-slave/rate control would be more appropriate for time-delayed mantpulation. Master-slave control would be used for coarse positioning, and rate control for fine positioning.

We recognize that the results of this experiment apply only to the MASAAres manipulator system. For example, a fully counterbalanced master would reduce the subject's physical workload and may increase open-loop positioning accuracy. Nevertheless, It has been shown that rate control has advantages in time-delayed manipulation. 


\section{REFERENCES}

[1] W. R. Ferrell, "Rewote mantpulation with transmission delay," MASA TM D-2665, Feb. 1965.

[2] J. H. Black, Jr., "Factorial study of remote manipulation with transmission time delay," M.S. thes is, MIT, 1970.

[3] H. C. Vykukal et al. "An anthropomorphic master-slave manipulator," Proc. Ist Conf. Remotely Manred Systems, Calif. Inst. of Tech., 1972.

[4] $D$. E. Whitney, "Resolved-motion rate control of manipulators and human prostheses," IEEE Trans. Man-Machine Syst,, vol. MNS-10, no. 2, pp. 47-53, 1969.

[5] G. P. Starr, "A comparison of control modes for time-delayed renote manipulation," Ph.D. dissertation, Dept. Mech. Engr., Stanford Univ., 1978.

[6] R. H. Blackmer et al. "Remote manipulators and mass transfer study," AFAPL-TR-68-75, Mright-Patterson AFB, Nov., 1968.

[7] H. R. Ferrell, "Delayed force feedback," Hunar Factors, vol. 8, no. 5, PD. 449-455. 


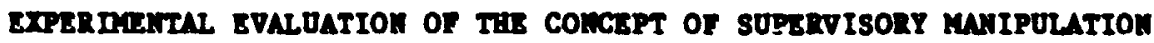

T.L. Brooks

Robotice and Teleoperator Group Jet Propulsion Laboratory California Inetituce of Technology
T.B. Sheridan

Man-Hachine Syote Laboratory

Messachusetts Inetitute of Technology

\section{Abetract}

A computer-controlled teleoperator syaten which is besed on tankreferenced sensor-aided control has been developed to etudy supervisery ani-

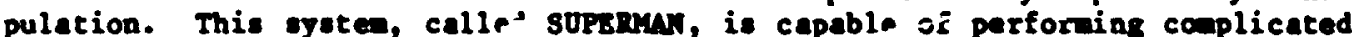
takk in real-tine by utilixing the operator for high-level functions releced to the unpredictable portions of a takk, while the subordinate anchine perfores the more vell-defined subtakk under human supervison.

To deternine whether supervisory control schens such as these offer any advantage over nanual control under real-time conditzune, a nuber of experinents involving both aimple and complicated taks were perforead. Six representative tasks vere chosen for the study: (1) obtaining a tool fron a rack, (2) returning the tool to the rack, (3) renoving aut, (4) placing saples in a sorage bin, (5) opening and closing a valve, and (6) digsing with a shovel. The experimente were perforeed under simulated conditions using four fores of manul control (i.e., witch rate, joystick rate, mater-slave position control, and enster-lave with force feedback), as vell as supervisory control. Through these experinents the effectivenese and quality of control were evaluated on the basis of the time required to complete each portion of the task and the type and number of errors which occurred.

Even under the "beet" control conditione (i.e., no degraded sensor or control loops we to tise deleys, restricted bandwidths, etc.) eupervisory control was found to improve perfornance for all form of anual control except force-reflecting anter-blave which was found to be slightly faster than supervisory control, b sore prone to errors. With degraded sensor or control loope it is fairly predictable that supervisory control will show even wre advantage, through the latter experiments are yat to be done.

\section{DNTRODUCTION}

Teleoperator: have traditionally relied on relatively einple and direct an-achine interfeces is control. However, with the advent of microcomputers and edvanced eeneor techniques it is now poseible to deaign end build a hierarchical control syeten in which the operator is responsible for the higher-level functions related to the unpredictable portions of the tank, while the subordinte nachine parfore the wore well-defined ubtaks under human supervision. Control besed on a eupervisor-subordinate reletionship ouch as this is celled "oupervisory control" [1]. In seneral, the human operator comanicates interniteently with the computer, end the computer, in turn and continuously in tine, controls the eeneors and ectuators of the vehicle and anipulator. In eesence, the teleoperator oyater acte a an autonosous "robot" for short periods while in the pursuit of task gosls previously prograned by the operator or updated on the last sycle of connnication. This node of control prosises eore precision for certain taks, lese susceptibility to failure in the event of comunication channel breakdown, and greater efficiency than direct huan control. 


\section{ORIGINAL PAGE IS
OF POOR QUALITY}

To investigate the relative mits of supervisory control applied to teleoperators, a task-referenced sensor-aided supervieory eyescen, called SUPERMA, vas built and experinente were perforned. This paper vill evaluate those experiments and bo comperison of various conventional control wodes with supervisory control, demotrate thet supervisory annipulation does improve perforwance in the majority of caues.

\section{MLTHOD}

\section{Apperatue}

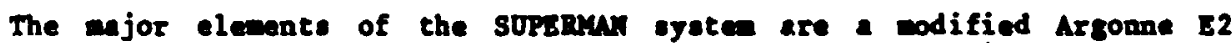
mater-slave ennipulator with ix degreas-of-freadon, a dedicated control interface (DASI), and an Interdata 70 cocputer. thesigned for efficient anaecinizs interection with both analog and spbolic control inpute, the syote. can be comanded by a variety of conventional control wodes as will as eupervisory. In addition, tine delay andor noise can be added for experiental purposes.

Using both analog and aybolic comande, anipulation can be taught and/or denonstrated to the computer. Trained anipulations can be transforead fron one coordinate aysten to another so that once the seneric characteriatica of a task have been learned, the eachine can perform ainilar taeks in different locations without further trainins. When the huma operator requires " particular trained anipulation be eimply "initialises" the new coordinate eyeten relative to the old by noving the teleoperator hand to the sterting point of the task (e.8., grasping a nut or valve handle) and sigals for execution. Certain objects in the task environent can, of coures, anintain their original coordinates. For a comlete developent of task trangformatione related to eupervisory control see refe. 2 and 3.

since the anipulator can sense the forces senerated during the teak, eupervisory program can call for repeated wovements which, upon certain touch conditions beccaing true, branch into other novecente. For exaple, repeated hand wovenats can grasp a mut, unscrew it by one revolution, pull beck to test whether it is off and, if it is, plece it in a bucket or, if it is not, repeat the operation. Sinilax supervisory prograne have been applied to ettaching a nut to a bolt, opening and closing valve, ocooping dirt and to on. Further information on the suptem syeten can be found in ref. 3 .

ine anaipulator laboratory wat arranged at thow in fig. 1 during the experiments. To simuluie renote conditions the operator viewed the taek envirowent through either a won or 2-view televioion eyetea. The video gyatca coneisted of two bleck and white high-resolution 9 in. maitors, a fixed cenre with wide angle leas, and a soon cener with pan tilt.

Figure 2 ohowa the anipulator envirorant and the experimental taoks designed for this atudy. The tool reck and saple buckets reanined in the locetions how throushout the experinents eince these pieces of equipent are ueually rigidly ateched to the teleoperator vehicle in real epplicetions. Aleo shown in the figure are the wovable task hub and task boerd on which representative task such a valven, bolts, etc vere wounted. The location of the task bub and board were changed throughout the stud to simlate the randon task/vahicle relationobipe which are typical of the arbitrary enviroments found in arine and epace epplications. 


\section{ORIGINAL PACE IS \\ OF PONR QUALITY}

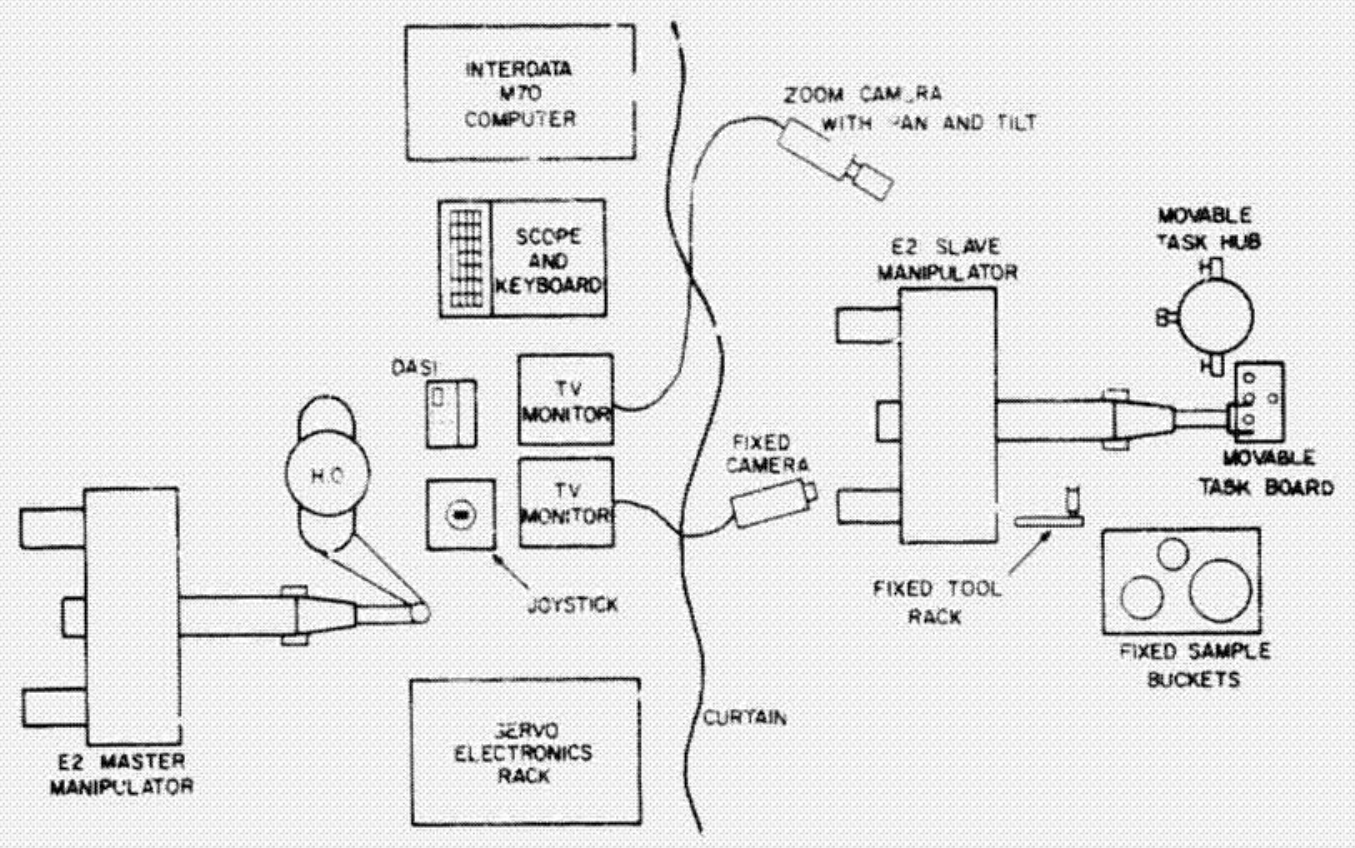

Fig. 1. Schewatic of Experisental Layout

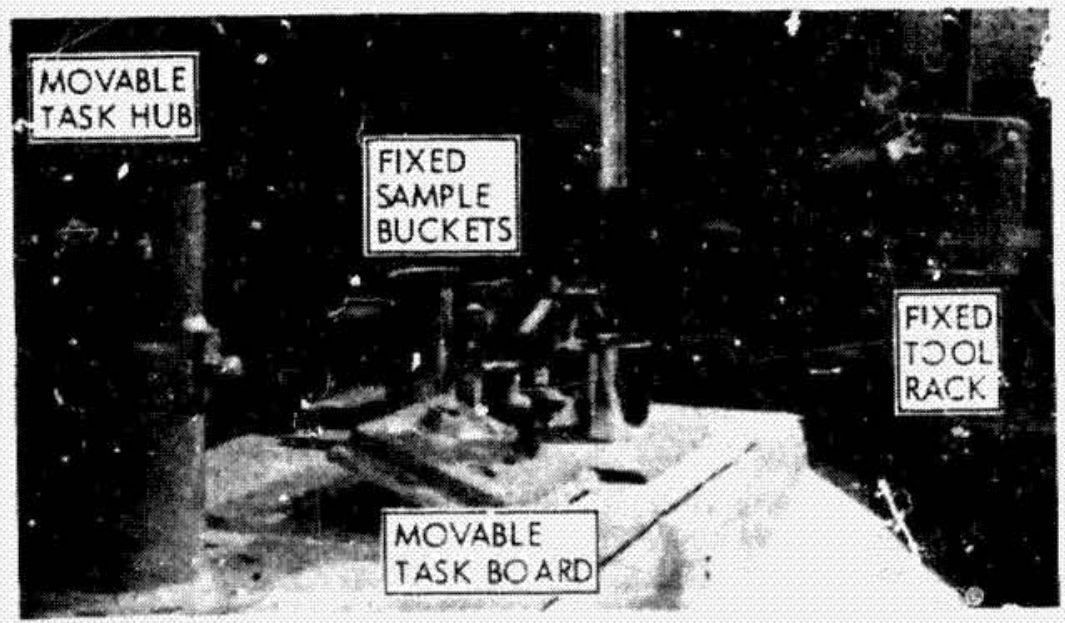

Fig. 2: Task Hub, Task Board, Sample Buckets, and 3.01 Rack 


\section{ORIGINAL PAGE IS
OF POOR QUALITY}

\section{Experienteal Deoirn}

six besic take were identified for experimentel investigations (1) tool retrieval; (2) tool recum; (3) taking a nut off; (4) graspins an object and placing it in a container; (S) opening/clooing a valves ad (6) digeing. In addition. Cour ennuel control codes wre delinested es importent experieorital pereanter : (1) witch fixed racei (2) joyetick variable racei (3) aneter-alevr ition control, and (4) eneter-elave position control vith force reflection. With regerd to the video arreagenent: both woo ad 2-view conditione were tested for comperieon. Due to tim conotrainte ouly thres ubjecte wre used for four of the teeke (tool retrievai, cool return, nutoff and sempler), and only one oubject was cend for the reanining two (open/ close valve and dieser). sach experiment was pertorned 5 time by ecch oubject to obtain a statiatical wes and atendard doviation. Both eanual and unpervisory control were used.

These conditions result in a total of 1120 experiental rune. Since thie would require en inordinate mount of tien, the experinentel land was reduced to 680 runs by poting that 1000 of the taske, or portions if the takke, hed constant coaputer execution tiens (eve ref. 3 tor details).

\section{Subjecte and Training}

Three clasese of eubjects were uned for thene experienate, one-experienced, four well trained, and two untrained subjects.

The wall trained oubjects had an average of 20 hours training given in 15 ninute intervale for each of the control codes. Generally, after the oubjecte precticed for 15 ainutes vith a particular coatrol code a imulated task vee perforeed. When the eubjecte appeared to thow a plateau, experiente wre begun. Since the experieente usually etretched over a period of -evezal deje, the oubjecte were eoked to "repertorn" some of the taske due to - "Discake". If the oubjects showed earked improvement the tasks were performed agaia until the learning curve levelled off. The four trained oubjects wre given incentivee to perfore $w 11$ in the fcrm of bonuses wich would be ewerded to the bete combined time and error rates in any control caticory.

The first whthor wes used at the baseline experienced eubject. With over 200 hours of prectice on maipuletor eyetens and intinate koowledge of the SUPERMA oye:co, it as be reasonably aneuned that the exparienced eubject underwent litrle or 0 leerniag. The experienced eubject parforned all of the teske without " "warm-up" period.

The untrained aubjecte had a tocal of 3 houre training tim for all control codee (i.e., 30 ainutes per control sode and viewins cundition). The leaming curres of the untrained eubjects wero not obeervet. The only requirament placed on thair trainiag eeseicas was to ineure that eech control node was given equal training tiae. After the 3 pno-hour fenilierire and

\footnotetext{
IAlthough it esy appear that the tool retrievel and return taske are eimply the reverse procedure of one another, these caske do heve fundenentally different requiremonte. To clarify, conoider that the retrievel takk required the eubjecte to locate $7 / 8 \times 3 / 4$ inch tool handle with the end effector docking plate while the return cask required the eubjecte to ante two $1 / 8$ inch pine and holea.
} 


\section{TRIGINAL PAIE IS OF PUOR QUALITY}

edjuetsest periode were over tne subjects we ellowed 2 houra of reet and the expericents we begun.

\section{Procedure}

The experiments wete ecored on the basis of recorded tim and errore. The subjects were not given specific instructions to mininize either quality, but only to weigh the equally. Each subject was, hovever, given a criterion by which successful completion of the task would to meaured (these criteria will be epecified on the following peges). The experienats were not redone when errors occurred, regardlese of the engicude, unlese it was imposible to procend with the task (e.8., a collision with an object that blew a ruse, atc.). The task were randonized whenever possible to atetete the effecte of variables which the experimentere were not eware of (e.8., perticularly easy or difficult taok positions, short term leamins effects, ets.). All tasks atarted fron prespecified position so that comprisons of supervisory initialization times could be aede acrose control wodes.

The procedure for each of the representative leaks was a followa:

a) Tool-Retrieval Task - The first rask required the subject to start with the end effector positioned near the task hub. On the experimeater's sigal, the subject coved the end effector tc the tool rack, obtained tre cool, being aure it was properly seated in the hand, and returned ith the teel to the starting postion. The oubjects wre told thit the success or failure of the tash was meseured by whether a solid connection between the cool handle and and effectcr was achieved. Execution of this task under supervisory control simply iavolved a button push.

b) Tool-Return Teak - For the second taak the ubject started fron position next to the task hub with the tool in hand, and on the experimenter's ignal, moved to the reck, replaced the tool insurins that it was properly seated, and returned to the initial position. The operators wre told that the success or failure of the taek was deternined by whether or not the tool was properly repleced on the rack. To properly seat the tool on the rack required that both of the $1 / 8$ inch rack pine were engaged in the handle and that the tool was conpletely punhed onto the pina. Thin talk vas executed under supervisory control through a simple button push.

c) Nut-Resoval Taak - This experient began with the end effector posicioned over the valve on the task hub. On the experimenter's ig nal, the subject noved the end effector from the valve to the nut, oriented the hand, and removed the nut. The seneral procedure used by the subjacts and computer was to turn $i 80 \%$, pull back to test if the nut was off, and thes either reverse $180^{\circ}$ and continue, or rewove the aut. Orior to the tasn, the operators were told that the task would be considered successfully compisted if the nut could be removed without losing it. Inder supervisory control the sperator initialized the rask by woving from the starting position to the nut, orienting the hand with the rotational axis of the nut, and - igmaling the computer to remove it.

d) Sapling Task - The fourth task required the subject to pick-up thirteen randoely placed samples and put the in one of two buckets according to their ice. The eubjects were told ther their success 


\section{ORIGIVAL PACE IS \\ OF POOR QUALITY}

or failure to coplete the task would be neaured by bov and ecer ples wro ouccenfully pleced in the proper buckets. Onder eupervieory control the operator initialized the teak by plecios the and -ffector over the seple end elgalias the computer to plece it in the appropriate bucket. The computer returned coatrol to the subject at the location wre the enple wee ereeped. The operator thee coved to another emple, initialised, and continued until all 13 ecoples were in the buckets.

1) Opoa/Close Valve Tent - This experiment required the oubject to pooition the ead effector over the wut on the tack bub, and then, on the experimenter's oiroal, the oubject coved to the velwe, oriented the hand, end opened or cloesd the relve en required (openias and closias takk wre witched after each experiesat). The subject vas required to coatioue until the valve operation vas coplote. To initialise this teak under euparvisory coatrol the operetor oriented the end effector on the rotational axis of the valve and oiganled the computer either to open or close it a required. The computer checked the rotational torques to deternim if the taok hed been compleced.

f) Digrias Tack - The final takk required the subject to rene apo-

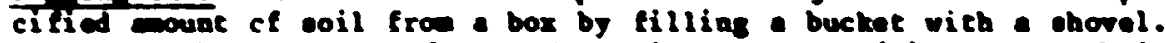
This cask is conpoed of a mber of subteskes (1) the shovel is pooitioned to wove the soil, (2) the shovel is puehed into the ooil and lifted oue, and (3) the coil is traneported to the bucket and dropped in. The subject wee required to coatione until the bucket ves filled. Onder eupervieory control the poeiticains of the ohovel was perforned eavually (1.e., the operator docided when and where to digl wile the ecooping and droppins ectione were executed by the computer.

\section{Esolss}

It has been show by a nuber of inventigatore that the tine required to perform a cask can be attributed to a waber of distinctly differnet wotions. For exepple, on claenification divides the task tin for control with a ties delay into encente rulated to pet, tranoport, and position cotime [4]. For a per-io-the-hole teak nill [5] heo ohow thet there are two independent wotione which deternim the toth cask tien uoder anmul control - erose travel and preciaioa. This paper vill use a eilalar ochen to describe the tank conplation tim lor a eupervisory ayetere

$$
t_{T}=t_{1} \cdot \mathbf{t}
$$

wher

$$
t_{t}
$$

Task Tim

tr - Time required by the humen operator to initialise the talk. This tin is priearily a function of the initiel handtaak locetione and the eanual control code ueed to locete the thak.

tp - Ti= required of the computer to pertor the teek. This tim is priearily a function of the teak cosplexity.

The deternination of these tiese is rather oisple due to the discontinuity in control which accurs during the trede from eanual initialisation to computer 
execution (this "discontinuity" is a desired result since trading of control should be "apparent" $[3,6]$ ).

Figures 3-6 are plots of typical deca (see legend belon for figure abbreviations). The data recorded durias the supervisory experiments have been divided into initialization and perforance times to indicate the tire spent by each action. Each of the tiae bars is the result of data averaged over two trained subjects, except for fig. 6 which is averaged over three trained subjects. The lines to the left of the anual control tars give the range over which the trained subjects perforned the task. Fo- cumparison, the arerage time for an inexperienced subject to perfor the first three tasks is also given (denoted by triangles). The nean times of the untrained subject: vere always above the axim value of the trained subjects for the sane task and control wode. The lower portion of each figure (figs. 3b-6b) plots the gean nuber of errors uhics occurred under annul and supervisory control (for apecific breakdown of tire individual errors see ref. 3 ).

\title{
LEGEND: Rey to Abbreviations Jsed in Text
}

\author{
MS - Master $\rightarrow$ lave with force feedback \\ MS 10 FTS - Master $\rightarrow$ lave without force feedback \\ JVAC - Joystick variable race control \\ SVRC - Suitch fixed/variable rate control
}

\section{EVALUATION}

\section{Manual Control}

Predictably, the task completion tiace increased with control complexity for all tasks. Viewing conditions (nono and 2-viev) appeared to affect tasks which required precision woveneats (e.g., retura tool and nut-off), but had little or no effect on the less precise tasks (e.g., sapling). In general, the number of errurs increased as the control complexity increased from anster-slave tc suitch rate. However, for sone of the tasks a sharp decrease in errors was noticed between joystick and sutch rate control (e.g., see figs. 5b and 6b). This effect is attributable to two factors: (1) the increased atcention and care each operator exhibited during witch rate control modes (i.e, to nove from point A to point B requires considerable thought and effort with witch race control, but under joystick control the desired movement only requires push on the stick), and (2) the coincidental watching of the task degrees of freedon and control degrees of freedon (e.g., in the valve or nut-off tasks the axis of rotation corresponded with the hand axis of rotation).

Table 1 gives the ratio of task completion times for each control eode with respect to the "best" control case, anter-alave with force feedback. The ratios are given for each subject, task and viewing condition. The untrained subjects are denoted by $\mathrm{Ul}$ and U2, th.e trained subjects are denoted by $T 1, T 2, T 3$ and $T 4$, and the experienced subject is denoted by $E 1$. The cable shows a nuber of interesting trends: (1) the ratios increase with increasing control complexity, (2) the ratio are approxiately constant across subjects (both trained and untrained) within given task, (3) the ratios are constant across vieving conditions, and (4) the ratios are not constant across tasks (the tasks have been arranged in the table so that the itio increases as the page is read from top to botton). A number of other investigators have found sinilar trends $[7,8,9,10]$. 


\section{OR!GINAL PACE IS \\ OF POOR QUALITY}

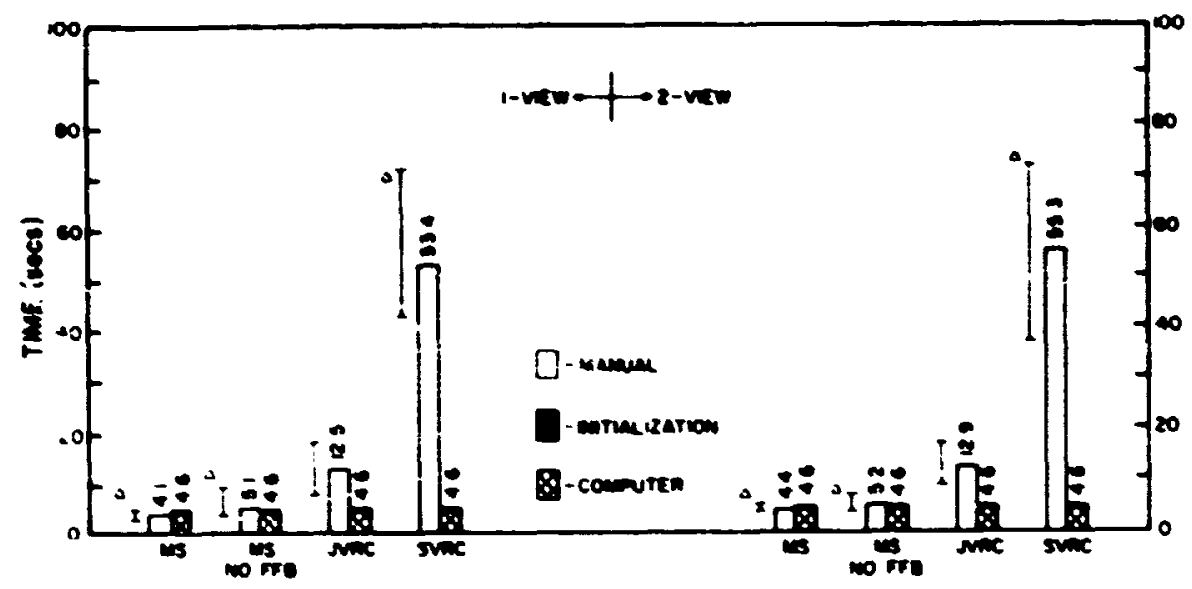

Fig. 3a: Averase Tool-hecrievel Tim. Bach ber gives the average tim of two subjects. The $\Delta$ aybol represents the wan tive for an untrained esbjezt. The capped lines show the total range of date for the crained ubjects.

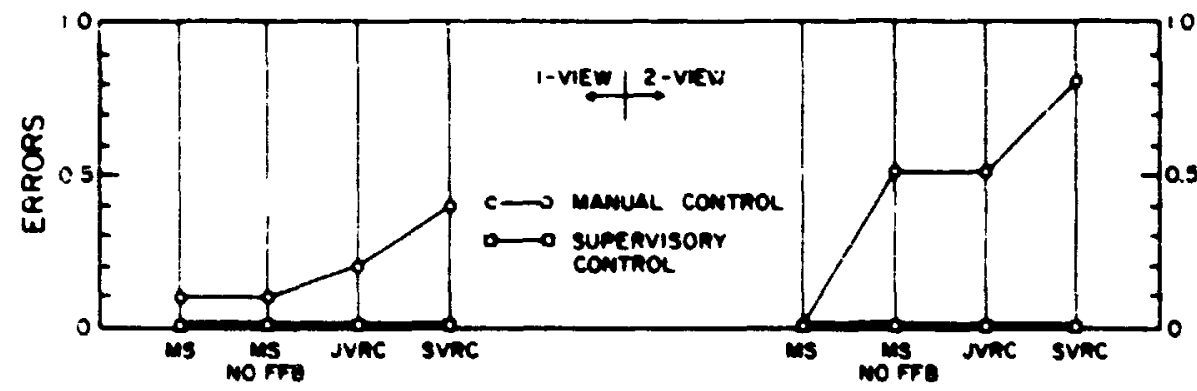

Fis. 3b: Expected Nuber of Tool-nstrieval Errors. Each data point represents the averace error rate of two trained eubjects. Possible errors included collisions, dropping the tool, and not seating the hend:e in the exd effector properly. 
Or.GIISILL PAGE IS
OF POOR QUALITY

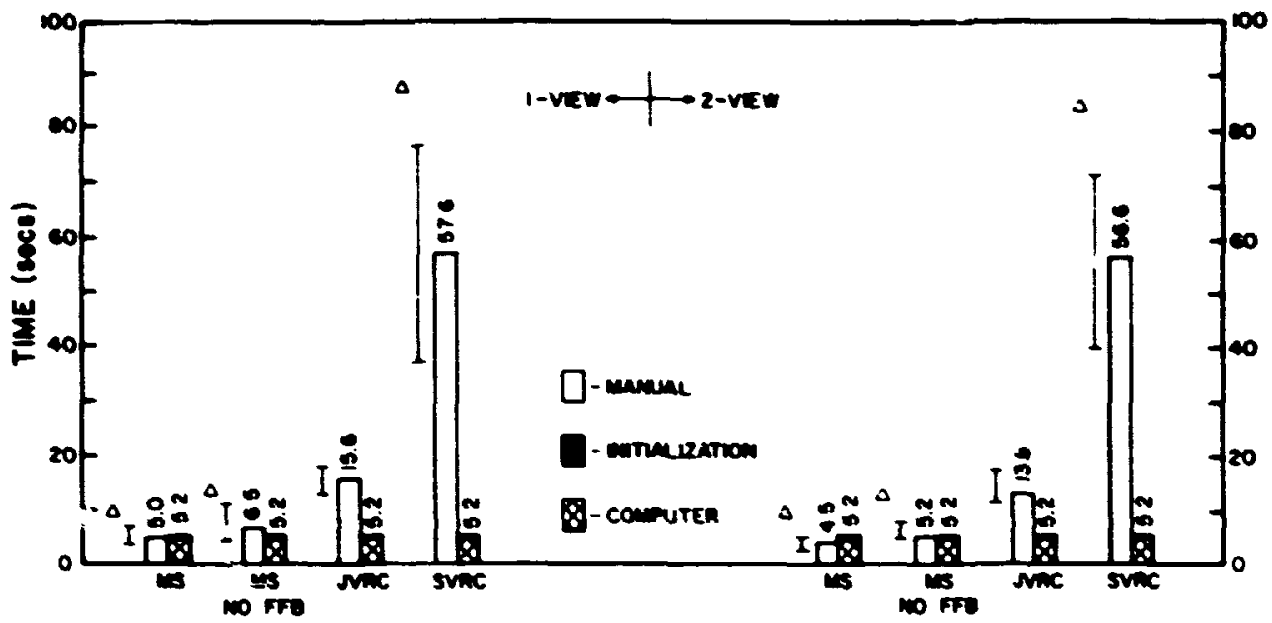

Fig. 4a: Average Tool-Return Tine. Bach bar represents the average tive of two trained subjects ad each $\Delta$ gives the sean tive for en untrained subject. The capped lines represent the total range of data for the trained subjects.

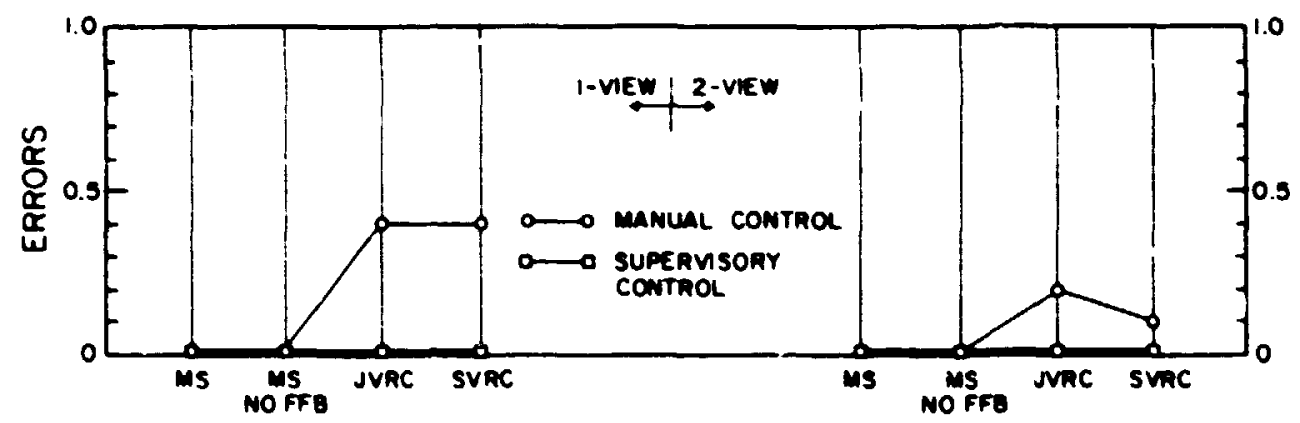

Fig. 4b: Expected Nuber of Tool-Return Errorg. Each data point cepresents the average error rate of two trained subjects. ponsible errors included collisions, dropping the tool, and not seating the handle on the rack properly. 


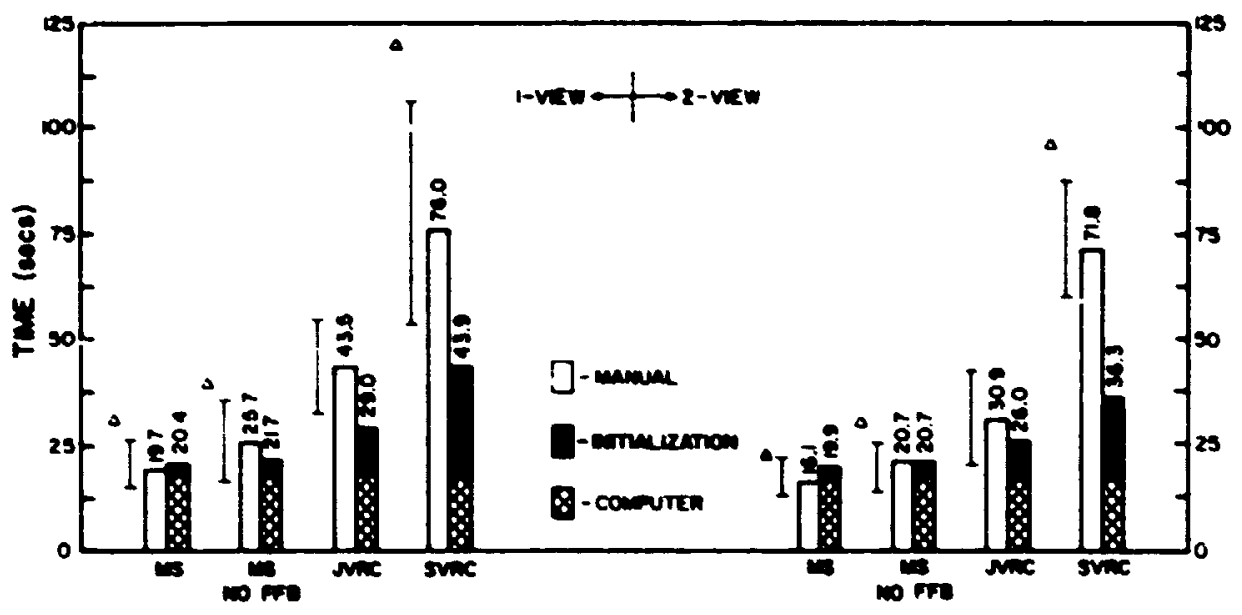

Fif. Sa: Average Nut-lecovel Time. Bech bar represente the arerage time of two trained subjects and each $\Delta$ sives the Ean tim for an untrained subject. The capped lices represent the totel range of date for the trained subject.

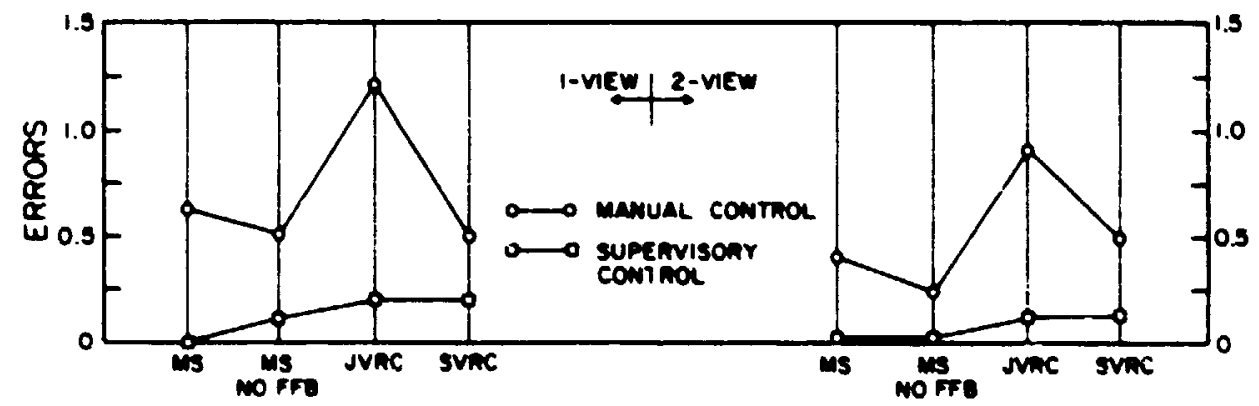

Fig. 5b: Expected Muber of llut-Reoval 8rrors. Each data point represente the average error rate of two treined oubjects. Poseible errors iacluded collieione and droppirs the nut. 


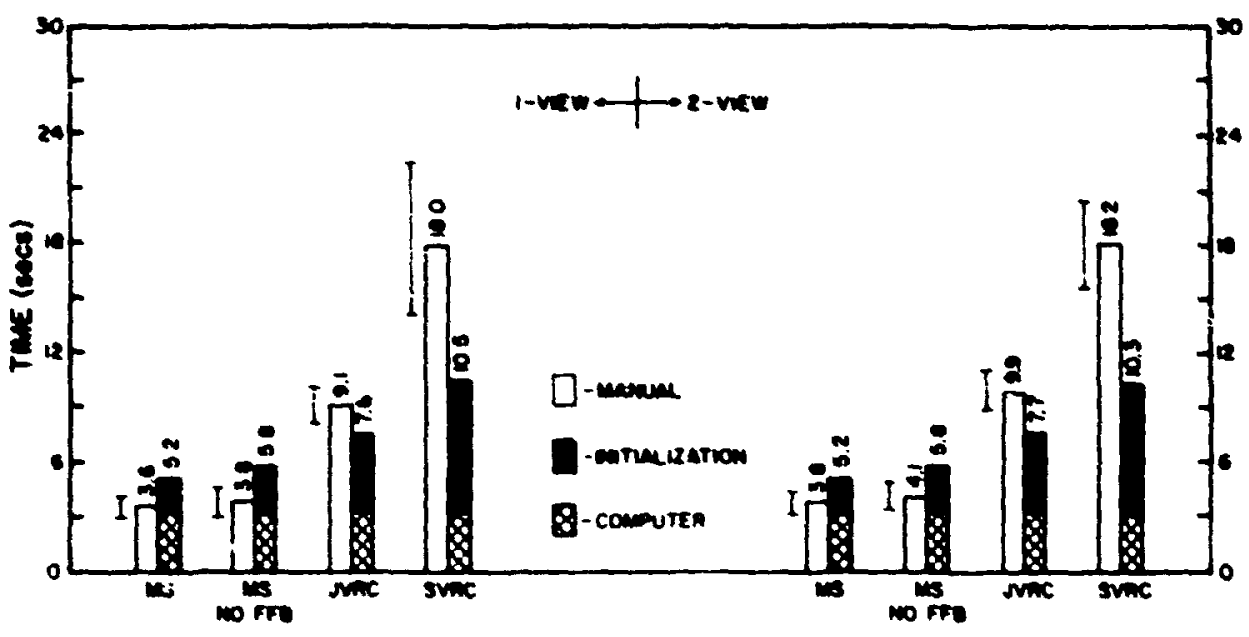

Fig. 6a: Avarage Sapling Time. Each bar represente the man tine of three trained oubjects. The capped lines represent the cotal range of date for the subjects.

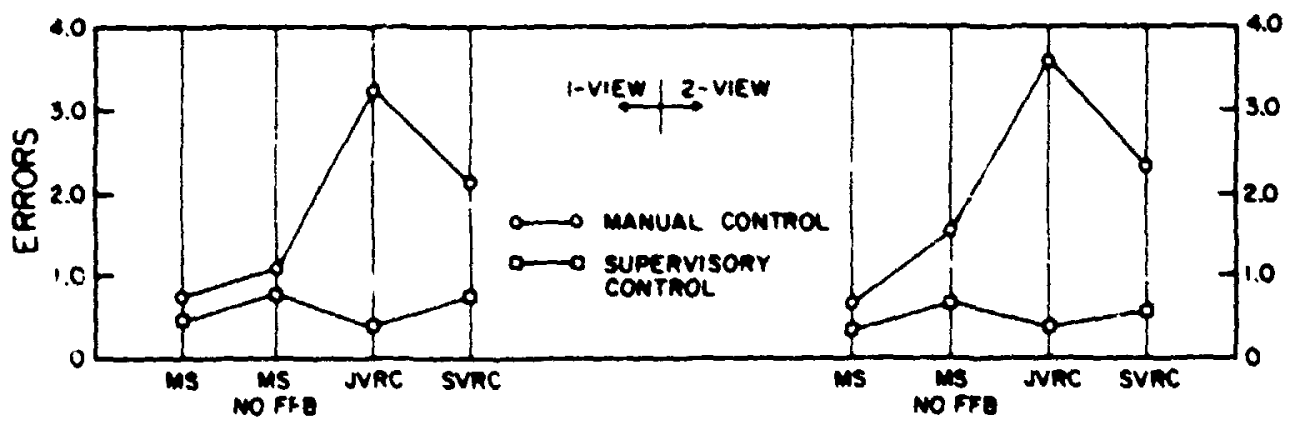

Fig. 6bs Expected Tuber of Sepling Errors. Each deta point represent: the average error rate of three trained subjects for 13 saplins ections. Possible errors included collisions, nissed buckete, lost emples, and (under eupervisory control) pressing the wrons button. 
Table 1: Ratio of Tiec to Perforn Taok Oader Given Control Mode to Tim to Perfore Task Ooder Mester-Slave vith Force Feedbeck (GI/rs).

\begin{tabular}{|c|c|c|c|c|c|c|c|c|c|}
\hline & \multicolumn{4}{|c|}{ I-vIEW } & \multicolumn{4}{|c|}{ 2-VIEU } & \\
\hline & ns & No 15 & JYRC & SVRC & 45 & 20 5 FFe & Jvac & Syare & \\
\hline $\begin{array}{l}\text { YALVE } \\
i=\infty\end{array}$ & 12 & 1.2 & 1.4 & 3.6 & 1.0 & 1.1 & 1.6 & 39 & EI \\
\hline $\begin{array}{l}30 \pi-0.0 F \\
2-00 \%\end{array}$ & $\begin{array}{l}1.0 \\
10 \\
1.0\end{array}$ & $\begin{array}{l}1.2 \\
1.4 \\
1.3\end{array}$ & $\begin{array}{l}2.2 \\
2.2\end{array}$ & $\begin{array}{l}13 \\
3.3 \\
3.9\end{array}$ & $\begin{array}{l}1.0 \\
1.0 \\
10\end{array}$ & $\begin{array}{l}1.3 \\
1.2 \\
1.4\end{array}$ & $\begin{array}{l}2.0 \\
1.8\end{array}$ & $\begin{array}{l}1.4 \\
4.5 \\
4.9\end{array}$ & $\begin{array}{l}n \\
\mathbf{c} \\
\mathbf{u 2}\end{array}$ \\
\hline $\operatorname{sim}_{3-000}$ & $\begin{array}{l}1.0 \\
1.0 \\
1.0\end{array}$ & $\begin{array}{l}1.1 \\
1.0 \\
1.0\end{array}$ & $\begin{array}{l}2.5 \\
2.8 \\
2.4\end{array}$ & $\begin{array}{l}5.1 \\
5.3 \\
4\end{array}$ & $\begin{array}{l}1.0 \\
1.0 \\
1.0\end{array}$ & $\begin{array}{l}1.1 \\
1.0 \\
1.1\end{array}$ & $\begin{array}{l}2.7 \\
2.5 \\
2.6\end{array}$ & $\begin{array}{l}4.4 \\
5.1 \\
4.9\end{array}$ & $\begin{array}{l}12 \\
13 \\
13\end{array}$ \\
\hline $\begin{array}{l}\text { scooper } \\
=-00 \%\end{array}$ & 1.0 & 1.1 & 3.9 & 10.6 & 1.0 & 1.2 & 3.9 & 10.9 & E) \\
\hline $\begin{array}{l}\text { RETURT-TOO } \\
6-00 \mathrm{~F}\end{array}$ & $\begin{array}{l}1.0 \\
1.0 \\
1.0\end{array}$ & $\begin{array}{l}1.8 \\
1.4 \\
1.4\end{array}$ & $\begin{array}{l}3.6 \\
2.7\end{array}$ & $\begin{array}{r}10.7 \\
12.2 \\
9.0\end{array}$ & $\begin{array}{l}1.0 \\
1.0 \\
1.8\end{array}$ & $\begin{array}{l}1.2 \\
1.3 \\
1.4\end{array}$ & 3.4 & $\begin{array}{c}12.1 \\
13.3 \\
9.7\end{array}$ & $\begin{array}{l}T \\
E \\
\text { EI } \\
\text { II }\end{array}$ \\
\hline $\begin{array}{c}\text { aT-roa } \\
6.00 \mathrm{~d}\end{array}$ & $\begin{array}{l}1.0 \\
1.0 \\
1.0\end{array}$ & $\begin{array}{l}1.1 \\
1.4 \\
1.4\end{array}$ & 3.8 & $\begin{array}{r}13.0 \\
13.0 \\
8.3\end{array}$ & $\begin{array}{l}1.0 \\
1.0 \\
1.9\end{array}$ & $\begin{array}{l}1.2 \\
1.2 \\
1.3\end{array}$ & $\begin{array}{l}3.3 \\
2.6\end{array}$ & $\begin{array}{l}12.1 \\
13.2 \\
11.8\end{array}$ & $\begin{array}{l}T A \\
\text { EI } \\
\text { UI }\end{array}$ \\
\hline
\end{tabular}

\section{Supervisory Control}

A. would be expected, the tien required by the computer to perfore its portion of the tank renined fixed regardlese of the manal control mode fron wich the human operator iseued the execution comand. 4100 , since the only action required of the operator to initiate the tool-retrieval and return tesks was button push, the absence of initielisation tims in figa. 3 sod 4a was not surprisins. The reanining teaks, including those not shown in this paper, had initialization time as sociated with the overall task tim. A. eeen in fige. 3 and 6 the iritielisation tines increased with control complexity.

bible 2 gives the ratios of the task completion times under annual consto? to the tines under oupervieory control. The ratios are given for mach unject, caek and viewing condition. The ratios relative to computer conturl (Tab, 1 2) do not show the sen treads as those relative to aster-lave soas $0^{\circ}$ (Table 1). It is interesting to note that in contrast to the cornistent. ratios of Table 1 , the computer coutrol ratios of the untrained oubjects ats oignificently higher than the trained eubjectes clearly, untrained oubjects aio core fron eupervisory control than trained subjects. Gaine from supervisory control for eny nanual code are seen to be wot ignificant for takt which do not require initialization procedures otber than button pueh (i.e., tool-retrieval and tool-return). The coatrol oode colums clearly indicate the results of the suprour experinente: (1) eater-slave with force teedback rarely benefite fron supervisory control, (2) anoter - lave vithout force feedback can profit fron eupervisory control in tasks which require force feedbeck, and (3) boch form of rate.control car be aided by eupervisory routices regardlese of the takk. 
Table 2: Ratio of Time to Perforn Taak Doder Mamal Control to Tim to Parfore Takk Joder Supervisory Control ( $\mathrm{mC} / \mathrm{SC}$ ).

\begin{tabular}{|c|c|c|c|c|c|c|c|c|c|}
\hline & \multicolumn{4}{|c|}{ I-Yick } & \multicolumn{4}{|c|}{ 2-VIEW } & \\
\hline & ins & ${ }_{10}^{\mathrm{NS}} \mathrm{FFB}$ & JVRC & SVRC & its & 10 ${ }^{175} \mathrm{FB}$ & JVRC & SVRC & \\
\hline $\begin{array}{l}\text { VAL VE } \\
\text { 1.DOF }\end{array}$ & 1.1 & 1.3 & 12 & 23 & 0.3 & 0.9 & 11 & 2.0 & E1 \\
\hline $\begin{array}{l}\text { "IUT -OFF } \\
2.00 F\end{array}$ & $\begin{array}{l}1.0 \\
0.9 \\
1.5\end{array}$ & $\begin{array}{l}1.2 \\
1.2 \\
1.9\end{array}$ & 1.6 & $\begin{array}{l}2.0 \\
1.5 \\
2.5\end{array}$ & $\begin{array}{l}0.8 \\
0.8 \\
1.1\end{array}$ & $\begin{array}{l}1.1 \\
0.9 \\
1.5\end{array}$ & $\begin{array}{l}1.2 \\
1: 1\end{array}$ & $\begin{array}{l}2.1 \\
1.9 \\
2.0\end{array}$ & $\begin{array}{l}T 1 \\
\text { E1 } \\
\text { U2 }\end{array}$ \\
\hline $\begin{array}{l}\text { SAMPLER } \\
\text { J-DOF }\end{array}$ & $\begin{array}{l}0.7 \\
0.7 \\
0,6\end{array}$ & $\begin{array}{l}0.7 \\
0.7 \\
06\end{array}$ & $\left\{\begin{array}{l}12 \\
12 \\
12\end{array}\right.$ & $\begin{array}{l}1.8 \\
1.6 \\
17\end{array}$ & $\begin{array}{l}0.8 \\
0.7 \\
0.7\end{array}$ & $\begin{array}{l}0.8 \\
0.7 \\
0.7\end{array}$ & $\begin{array}{l}1.3 \\
1.3 \\
1.3\end{array}$ & $\begin{array}{l}1.9 \\
1.9 \\
1.9\end{array}$ & $\begin{array}{l}12 \\
13 \\
\text { E1 }\end{array}$ \\
\hline $\begin{array}{l}\text { SCOPPER } \\
\text {,-DOF }\end{array}$ & 05 & 0.6 & 1.9 & 4. $\mathrm{B}$ & 0.5 & 0.6 & 1.9 & 4.9 & El \\
\hline $\begin{array}{c}\text { RE TUPFi - TOO } \\
\sigma-D O F\end{array}$ & $\begin{array}{l}0.9 \\
1.1 \\
1.9\end{array}$ & $\begin{array}{l}1.0 \\
1.5 \\
2.6\end{array}$ & $\begin{array}{l}3.2 \\
2.8\end{array}$ & $\begin{array}{r}94 \\
12.8 \\
16.9\end{array}$ & $\begin{array}{l}0.9 \\
0.9 \\
17\end{array}$ & $\begin{array}{l}1.0 \\
1.1 \\
2.4\end{array}$ & $\begin{array}{l}3.0 \\
2.3\end{array}$ & $\begin{array}{l}10.6 \\
11.3 \\
16.3\end{array}$ & $\begin{array}{l}T 4 \\
E 1 \\
\text { U1 }\end{array}$ \\
\hline $\begin{array}{l}\text { GET - TOa } \\
\text { 6-DOF }\end{array}$ & $\begin{array}{l}0.8 \\
1.0 \\
1.8\end{array}$ & $\begin{array}{l}0.9 \\
1.3 \\
2.6\end{array}$ & $\begin{array}{l}3.2 \\
2.3\end{array}$ & $\begin{array}{l}10.8 \\
12.5 \\
15.3\end{array}$ & $\begin{array}{l}1.0 \\
0.9 \\
1.4\end{array}$ & $\begin{array}{l}1.2 \\
1.1 \\
1.7\end{array}$ & $\begin{array}{l}3.2 \\
2.4\end{array}$ & $\begin{array}{l}11.7 \\
12.4 \\
16 \mathrm{~J}\end{array}$ & $\begin{array}{l}\text { Th } \\
\text { हा } \\
\text { ป }\end{array}$ \\
\hline
\end{tabular}

In all cases the error rates for supervisory control were lese than and ual control. However, an interesting error was noted during the sapling experinents - occassionally the subjects pressed an incorrect button sending the somple to the wrong bucket.

\section{DIScoss IOn}

Theoretically there is no reason why eater-slave with force feedback should be any faster than eupervisory control. Consider that the computer could simply nimic the huan operator' bet trajectory, and hence, be at least as fast. Unfortunately, in practice there io alway a certain overhead associated with retransformation of coordinates, trajectory calculations and sensor logic. Also, it vas generally observed that the sujjects were anking adaptive, orchestrated notions, whereas the conputer was linited to eore rigidly defined trajectories and states. In light of these observations it can be said that the faster anster-slave times ake core of a statenent about the direction that future etudies dealing with supervisory control ahould take than they do bout ite potential in teleoperator eysten.

Although the experiments were not designed to measure the effectiveness of supervisory control during extended periods of ennipulation, an interesting observation was wade after the experimate hed been conpleted - the manusl experiments had been performed with reat periods between each run because the ubjects complained of fatigue and boredos, while the supervicory experiwents had been unintentionally run back-to-back ince fatigue and boredom were not noted. Prom the observations it could be surmised that as task 


\section{ORIGIMAL PAGE IS \\ OF POOR QUALITY}

beconse wore involved and complex, boredon and fatigue will becone increasingly important factors, tipping the scales even further in favor of supervisory control. However, experiments to validate this otatenent have ret to be performed.

\section{6. conczusion}

Even under "ideal" control conditions supervisory control was found to be wore efficient and effective (as deternined fron the task completion tines and enaipulation erroro) then witch rate control, jojetick rate control, and anter-alave position control. Bilateral forcerreflecting anter-siave was found to be slightly faster than aupervieory coatrol, but wre prone to errors. Since the experinente were perforned under "ideal" conditions, it can be reasonbly predicted that eupervisory control will shod even wre advantage when used with derraded seneor or control loope (e.8., tim delays, linited bandwidth, etc.), though the latter experinents rennin to be done. In addition, an a posteriori observation of the experimental procedure eppears to indicate that the effects of oparator fatigue and boredon during extended periode of manipulation can be aignificantly reduced through supervisory control.

\section{Acknowledreont}

The research described in this paper was carried out at the Hasachusetto Inatitute of Technolog under Sea Grant Wo. 04-7-158-44079 and OxR Mo. n00014-77-c-0256. The presentation is oponsored by the Jet Propulsion Laboratory, Californie Inetitute of Technologs under MASA contract Mo. MS7-100.

\section{References}

1. Rerrel, W.R., and Sheridan, T.B., "Supervisory Contro! of Rente Manipur lation," Ime Spectru, Vol. 4, No. 10, October 1967, Pp. 81-88.

2. Brooks, T.L., "Supervisory Manipulation Based on the Concepts of Absolute ve Relative and Fixed ve Moving Tauks," to appear in the Proceedinge of ASIE International Couputer Technology Conference, Sen Irancisco, Califoraia, Auguet 12-14, 1980.

3. Brooke, T.L., and sheridan, T.B., "sursman: A syoten for supervisory Manipalation and the study of Buna/Computer Interections," MIT Sea Grant Report Mo. MISG 79-20, July 1979, Massechusette Inetitute of Technologs.

4. Black, J.H., "Factorel Study of Reote Manipulation with Trananiseion Tine Delay," Mester's Thesis, M.I.T., December 1970.

5. Hill, J.H., "Two Measures of Perfornence in a Peg-in-Bole Manipulation Takk with Porce Feedbeck," Thirteenth Annual Conference on Manual Control, Ceabridge, M, June 1977.

6. Sheridan, T.B. and Verplank, W.L., "Bumen and Compucer Control of Oodersea Teleoperators," ManHachine Syeten Laboratory Report, Masechusette Institute of Technolosy, July 1978.

7. Peech, A.J., Hill, R.G., and Klepser, M.F., "Perfornance Comarisons of Scube Divers vi. Subarsible Manipulator Controller" in Ondersea Work," Offuhore Technolors Conference, Boustor, TX., 1971. 
OR:B:?:? : $: 2$

OF POOR Quitity

8. Mullen, D.P., "An Evaluation of Resolved Motion Rate Control for Reste Manipulators," Master' Thesis, M.I.T., January 1973.

9. Peech, A.J., Berteche, W.R., "Perfornance Meseurement for Onderses Systems," Parfornance Bveluation of Prosremable Robots and Kanipulation, mBS Special Publication \$459, October 1976.

10. Freeden, L.A., Crooks, W.H., and Cosn, P.P., "TV Requirements for Manipulation in Space," Mechanise and Machine Theory, 1977, Vol. 12, Pp. 425-438. 
l ALUATION OF "SMART" SENSOR DISPLAYS FOR MULTIDIMENSTONAL PRECISION CONTROL OF SPACE SHUTTLE REMOTE MANIPULATOR

A. R. Bejczy

Yember of the Technical staff Jet Propulsion Laboratory

California Institute of Technology Pasadena, California 91103

\author{
J. W. Browo \\ Aerospace Engineer Section Heud \\ Crew Station Design Section \\ Lyndon B. Jotnsou Space Canter \\ Houston, Texas 77058
}

\section{Abstract}

An .enhanced proximity sensor and display system has been developed ac the Jet Propulsion Laboratory (JPL) and tested on the full scale Space Shutele Remote Manipulator at the Johnson Space Center (JSC) Manipulator Development Facility (MDF). The sensor system, integrated with a four-claw end effactor, measures range error up to 6 lnches, and pitch and yaw alignment errors rithin \pm 15 deg., and displays error data on both graphic and numeric displays. The graphic display shows pitch and yaw errors with 1 deg. resolution and range error with 0.2 inches resolution in an integrated format. The ruveric display resclution is 0.1 lach for range errc. and $0.5 \mathrm{deg}$. for pitch and yay errors. The errors are referenced to the end effectir control axes through approprlate data processing by a dedicated ricrocomputer acting on the sensor data in real time. Both display boxes contain a green lamp which indlcates whether the combination of range, p1tch and yuw errors will assure a succesciul grapple. More than 200 test rune were completed in early 1980 by three operators at JSC for grasplng static and capturing lowly moving targets. The test gon was to Investigate methods to minfintze cerminal range and allgment errors by utillzing range, pitch and yow error information from the seneor displays. Reduced errors wil reduce preload on payload grapple Elxture. The test runs alded by seneor displays were contrasted with test runs whout sensor display alds. The paper describes the enhanced sensor and display system, the test runs and results. The tests have Indlcated that the use of graphic/numerlc displays of proxdmity sensor Information improves precision control of grasp/capture range by more than a factor of two for both static and dyaric grapple conditions.

\section{INTRODUCTION}

manual control of the $15.2 \mathrm{~m}$. (50 ft.) Iong Space Shuttle Rewote Manipulator System (RMS) requires delicate balance in the information and control con11tions. This requirement is particularly delicate when the target is near the grasp envelope of the end effector: a precise knowledge of small raxige or allgment errors can have a large effect on the success of or preloat -asociated with the grasp.

Prevlous1y (Ref. 1), a proxdmity sensor system was developed at the Jet Propulsion Laboratory (JPL) and Integrated with a four-claw end effecto: of Johnson Space Ceater (JSC). The sensor system con' sts of four proximity sensors, and wa designed to supplement the visuai intormation for control. It proHdes guldance data to the operator when the target is near the end effector's graep envelope where visual perception of range, pitch and yaw eriors are poor. In previous ground teats at the JSC Manipulator Development Facility (MDF), the use of the seneor syster was restricted to the verdfication of a "successful grasp state" before the operator Inftlated the grasp. Even the use of restricted proxdmity sensor information proved to be valuable for 1mproving costrol performance. 


\section{ORIGINAL FHCE IS \\ CS POOR QUALITY}

In order to extend the ut1lity of proxtaity sensor informetion for srasp or capture control, two new "smart" displays (a graphlc and aumetic) have been develuped at JPL and cested at JSC recenty. The purpose of the new displays is $c 0$ show the operator th. values of range, pitch and yaw error: refereaced to end ef fector axes, in addition to lndicating whether the conbination of these tintee errors w111 assurn a jucceseful grasp of the target. The display if range, pitch and ya error values wen anticipaced to ald the operacor to SAa-control the grasp with respect to chese three errors within the grasp envelope. The tests have verified the ancicipeted utillty of the decalled displays of error inforantion, but rassed a nuber of questions regardiag a ueful integration of proxiatey saneot and vieual information.

\section{2. "SThrT" DISPLAYS}

The aew displays are being used wich the proxinity sensor sysece devel. oped for the prevlous tests in 1978 and described in detall in (Ref. 1). How ever, the effective sensing range of the sensor systen has been exteoded electronically tron 5 to 6.5 inches. The effective depch of che grasp envelope of the four-claw end effector 1 . bout 3 inches. Consequeatly, the seasor systea can look stead of the grasp eavelope by 3.5 laches. The une of this seneor systea diplies that the ewo latcral and roll weallgneat errors withis the grasp envelope are controlles visualiy.

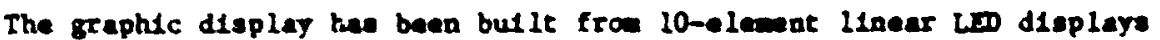
encapoulced in one chip. vith lndividual addresabble anode and cathode for ench - leacar in the chip. The graphic dieplay revolution 100.2 laches $) 0.308 \mathrm{o}$ ) per display element in depth, and l degree per dapley elemen in pitch and yau errors. (See F1g. 1.) The quancitative value of exch error bar is lecreang way fron the center green hap. Bexce, zero error for each bar is at the center of the display. This focuses the operator's atcention to a sngle "goel polat" on the displar cowards which all error bers should be decreased and where the "green IIght" ould be on for successful grasp.

Note that dapth error is indicated with wo identical bers cooverging in a parallex-type view arrangenent towerde the ceater green lesp. Thts renders the display wre symetric and facilitates the distinction between angular and depth-error bars. The green 11 ght "on" condletion ladicates that the exdselag combination of depth, pitch and yaw errore vill allow a successful grasp.

The graphsc diepley also concalos toon secarator. It provides a "succese tone" (a hort beep tone. - distingulehed in frequency fron the "succese (one") when the target reaches the senning range or liaves the senulag range. The maxinur. epth eanolng range shown on the dieplay is 6 lnches (or $15 \mathrm{~cm}$ ). PItch end ya errors are indicated in the range of \pm 15 deg. Actually. the varaing beep tone provides an advance varing alnce it is acifvated at a dietance of about 6.3 laches which 10 oot shown or the dieplay. The dieplay lo ectivated ooly at 6 Iaches distace.

The numerle dieplay resolution 1.0 .1 inch $(0.254 \mathrm{~cm})$ In depth erro: and 0.5 deg in enpular errors. It also has the "green uccese las-". The nuertc dieplay can eleo be epplled to perforeance evaluation by the une of hold/raset artech. Thie mitch can be connecteri the grasp roncrol clrcult. bince, it can autonatcally reglater die rous jepth. pitch and yaw errora it the soment of grappje.

The new displaye are driven by a sagle board Intel $80 / 20$ alcroprocessor which linearlizes the eeneor deta and proceseses the Itrearirad data through 
ORIGINAL $\Gamma_{\therefore:}:$ is

OF PCOS QUARití

preselected "success alporith". An approprlate "surisse algorith" can be selected in the computer through a BCD surcch. The algoriches can be referenced :o Altemative roll orlentaclons of the ead effector pitch and yan axes, and can ustlize alcenative aumertc definitions for "successful grapple envelope" in tere of andine and ainiau values of allowable depeh, pitch and yaw errors.

Altigethar 32 display drive progre conblactions have been implecented: 2 alporith altematives, with 4 altemative sets of paraneters used in 4 aiternative reference frmes. The basic "success algorith" is the conlc algorith (describedin Ref. 1) us:ng all four or only three out of four sensors. The four sets of trapezold paracters are listed in Tabla 1 togecher with the BCD progra select switch ensigronts.

Algortetalc selection of pitch and yaw reference axes by four 90 deg. rotaelon steps (see digit $X$ on the $B C D$ dial la Table 1) allows four alternative end effector countings/viewings, keplag the pttch and yew error display formet unchanged in the display boxes. Furthareore. for a fixed and effector sounciagl viewing, the algorithelc rotation of pltch and yaw reference axes by 180 deg. w1l change pitch and yaw error polartey in the display fornat. This allow aro alternative correlatfors tetween displacencot direction of hand controller and corresponding change in error bar length. The two altermetive cortelations are: the error bal changes leagth a) in the direction or b) opposite to the direction of the had controller displacenat.

Figure 2 sumarizes the sensor. control and display reference franes together with the actual pltch and yew error staces for digit $x=0$ on t.e BCD dial surtch. The anthenatics related to these trenoforations is sumarized in the Appeadix.

F1 gure 3 shows a earget approach sequance as seen on the "sante" displays.

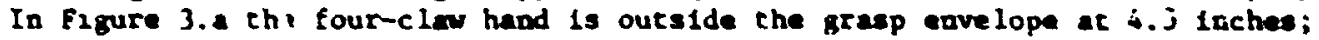
the center green lap is off. In Figure 3.8 the four-claw hand is inalde the grapp exvelope at $2 . n$ Inches, and the combination of renge. pitch and jav errors allow succeseful grasp; green lap 1s on. In Etgure 3.c tbe four-clew haod is Ioside grasp anviope with great ly reduced errors ailming a fine-controlled grasp; green lap 1s on. Figure shows the algortehale rotertions of pitch and yai error axas in the J1splaye by 90 degree scaps for e flxed end effector wount 1ag/viewing.

The display boxes contaln the appiopriate decoding and LED drive electrontcs.

\section{GROUND TESTS}

More than 200 test runs were completed in early 1980 by three operators fur graeplag static and capturlas lowly woolng targets using the simulated full scale Shute le wanipulator ar at the JSC rDF. The overall test goal vas to invent1gate cethods to alnialize terainal range and alsalignent of the andpulator end effector by utilizing quantitative information fron the range. pitch and you error semsor displays. Reduced errors will reduce preloed on the payload grapple flxtura. The operators vere asked to observe predefined error angla within the graep envelope. The cast runs alied by sensor displaya were contrasted with ceac runs with restricted cr no sensor display alds. In this last case the operator hed to rely ipon direct vision and/or TV inforantion. The TV informetion was enhanced with. visul carget cues. 
UF POUR QLALií

Table 1. Parameter sets for conic algorithn with trapezoid formula, and progran select dial for display drive algorithas

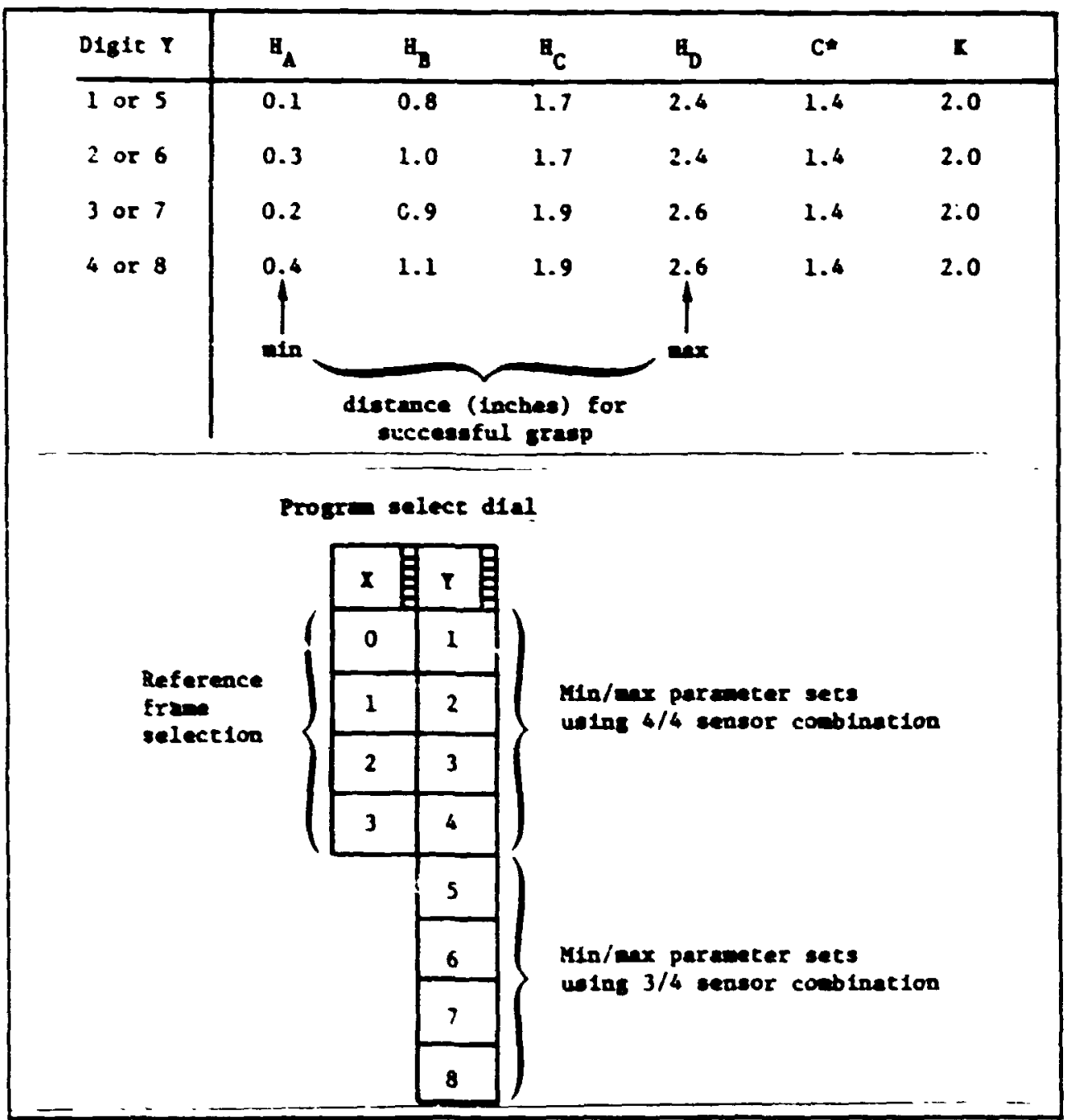

The test fectllty and equlpent heve been deectibed 1a datall 10 (Ref. I).

The srapple target counted on the payloed represented the unt used in the pos tlight syetea. The target is uned in conjunction with tha closed circult iv (CCTV) cemre wounted on the wrdst of the menspulator, which is controlled in the end of ector coordinate syste. This reference syete allow for the operator to $c .01$ the tip pastion and attitude of the end effector using only the CCTV cemara feadback in a "fly-to" nanoer: a comand raght woves the and effector to the right along $1 \mathrm{ts} Y$ ands, aegative roll canad rotates the end effector counterejockerse (viand down the and) about 1ts loogitudinal axds. 


\section{ORICINAL $\because \therefore \therefore:$ \\ OF POOR QUALIIV}

The visul target, counced above the grapple fixture, 1 deel dend to per-

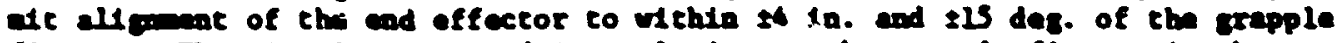
f1xcure. The viounl target and its relation to the srapple fixture $1 \mathrm{~s}$ shors schentically !n Fis. 5. The center rod of the visual target providen cued for

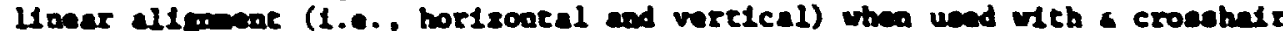

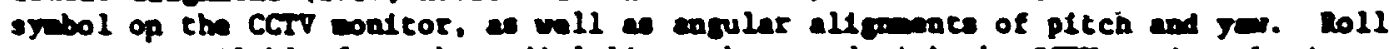
cues are evallabie fron the redial lines when ued wich the CCIV wonttor hor1-

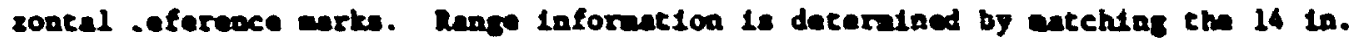
hordscatel tarset lines to the roll raference earke on the CCIV wattor. Onderstaodab15. range is tine sost difficult parameter to deterniae from the visul cues. especially durias dyandc srappling.

The test runs are sumarised in table 2. In addition to the tese rusen, an cqual count of eralning rune were leo conducted.

In the static teses, the payloed was located in the Shutrle payloed bey a show in Mg. 6. The Dis operator. positloned at the aft cabin wortecation.

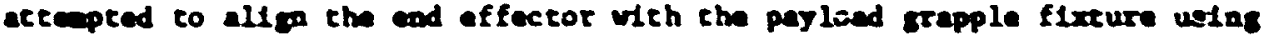

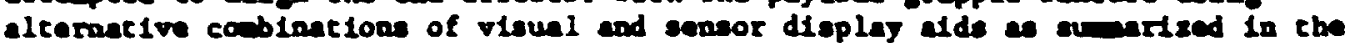
test run entr1x given in Tab1e 2. The operators were asted to poeltion the and

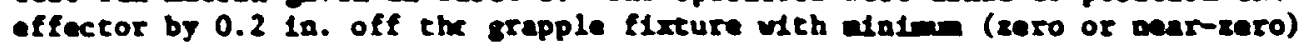
allguent errors. When the operator indlcated that the poeftloning and alformet

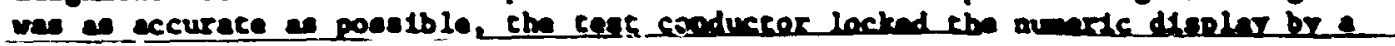

Table 2. Tost run entrlx

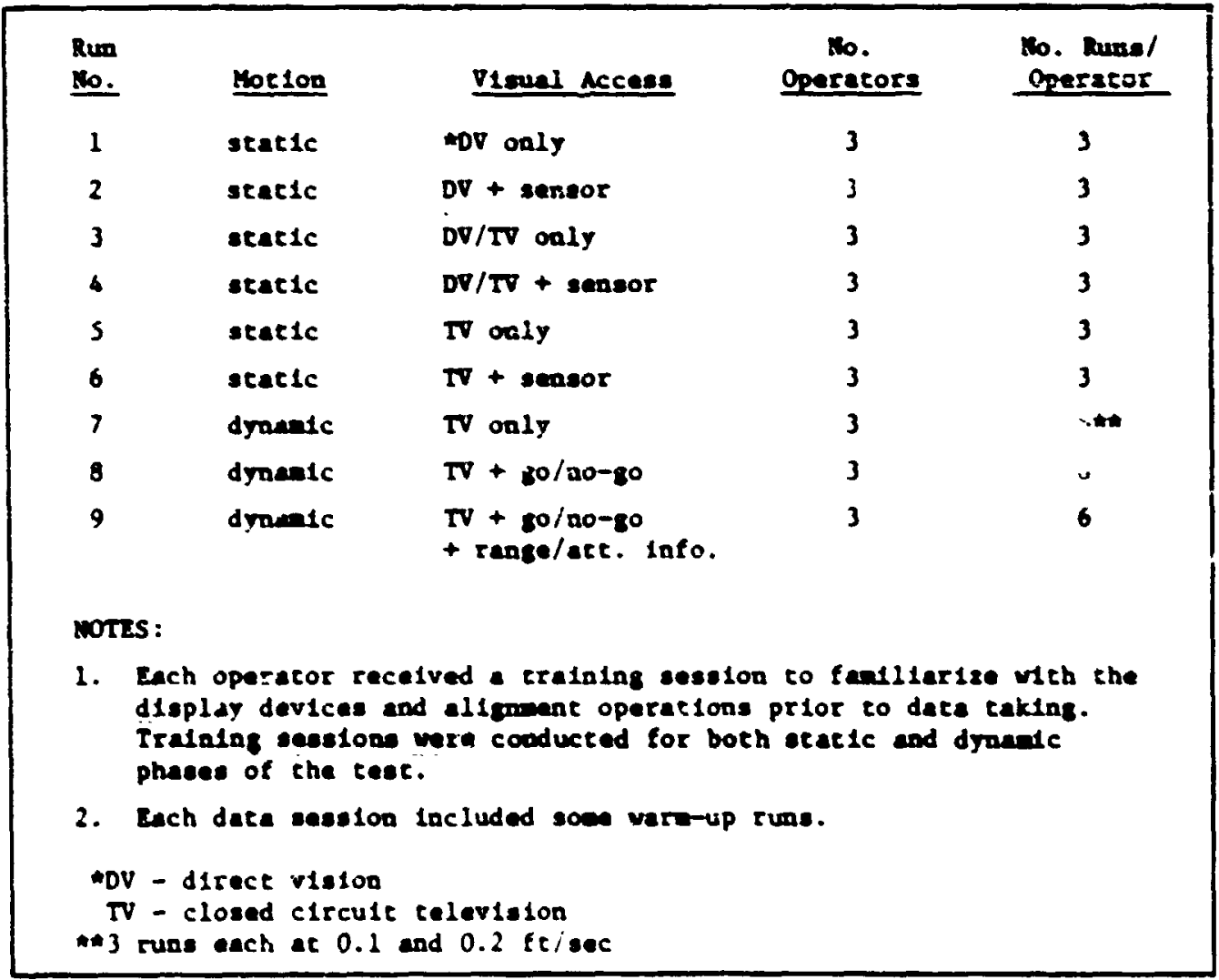


resoce ortch, theraby weeurlas range. pltch and yew accuracy achieved by the operator. The data were racorded anually for analyeis.

In tha dyanic testa, the tack wa to capture payload translating at 0.1 and $0.2 \mathrm{ft} / \mathrm{sec}$ speed ecroes the twF alr bearlag floor. The payloed (a black box equipped with the grapple fixcure and visual target) ves counted on an air sled

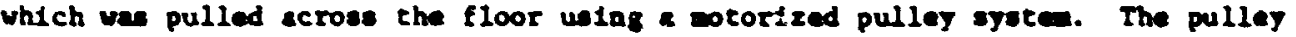
syste vas placed at about 10 deg. angle relative to the payloed bay. The operators vere anked to postetion the and effector as close as poselble to the grapple

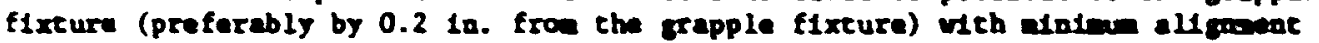
error. Dirfas the dyoulc tests, the displey lockdas circult wes liaked to the RSS grapp control switch so that the comand to execute graap locked the range, picch and yeu error values shown on the aunerle display. The data were recorded anoully for asalyals.

The sensor displaye were located near the IV eonitor as show in FIg. 7 . Figure 7 shows a etartc gresp tast scese. The error values shown on the displays are the actual e-cors of ito pre-graep state that can be seen diractly through the cablo aft vindor. The viounl aseesment of range, p1tch and yer errors is quite poor relative to the ectuel error values showe on the displase. Figure 8 showe the operators whte the IV and seneor displaye during the tests. Figure 9

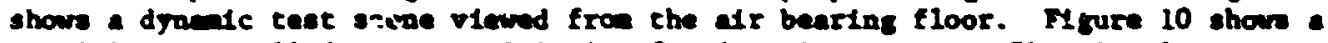
precision controlled raise poeftioulng for dyomic capture. The ol rual target described in F1,. 5 is provented in F1g. 10.

The followles data were collected durlas the tests: the to allm/capture;

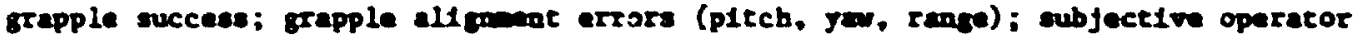
coments; Fideo taping: covle and still photorrapty.

\section{TEST DATA ND EVALOATIOA}

Table 3 presents a brief quanticative sunary of the scacte ceat data. Bowever, caution ant be exercised in draning conclualoes fron data related to a stat1st1cal population of three test operatora. As seen in Table 3, tbe wee of the graphic and auneric seneor displaye inproves pracialon poeltioning perforance by eore than a factor of two. Thle reoule applies to the tralaing runs as wil as to the fland ras. The everage ertors are computed relative to the 0.2 10. off-renge fron the srapple l1xture the operators were aeked to observe. Eence, the true 1ndividus: errors are plua/ntaus errors. The $100 \mathrm{~g}$ grean lap "on" reault Indicates tiut, uning the sensor displaye, the operators never weat below the requested $0.2 \mathrm{ln}$. off-renge. Hithout semeor displays. the operators could control this :ondition only with 632 succese. That 1s, la one out of three cases they went below the $0.2 \mathrm{ln}$. off-range. Note aleo that tralniag hes a constderable effect on the flacl results. The flonl run data are in each case bettar by a factor of two is compared to the traloing rua data.

Table 4 presents a brtef quaticative sumary of the dyande test data. In this table, the average errors are compuond relative to a true sero-lenel error.

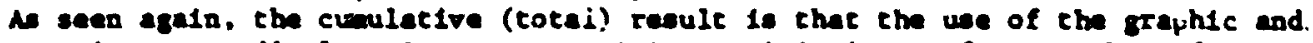
aumertc seaser displaye isproves preclaton postefoning perforance by a factor of two. Bowner, in the dyante caee there are interesting lodividual (hean factors) variences. For one operator, the graphtc/muerlc dieplay did not help too much; he obtalned the factor of two perforsence inprovenent by ualng only the "green lep" sensor display. Dut for anothar oparisor, the wee of the grophic/ nueric displays actually helped to inprove the precision positioning perforance 


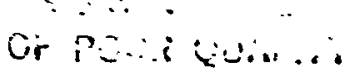

Table 3. Sumary of seac1e test data

\begin{tabular}{|c|c|c|c|c|}
\hline & \multicolumn{2}{|c|}{ Using sensor displays } & \multicolumn{2}{|c|}{ Without sensor displeys } \\
\hline & $\begin{array}{l}\text { drerage } \\
\text { range } \\
\text { error (1n.) }\end{array}$ & $\begin{array}{l}\text { Grean } \\
\text { succeas } \\
1 \text { lep" } \\
\text { "on" }\end{array}$ & $\begin{array}{l}\text { Average } \\
\text { range } \\
\text { error (to.) }\end{array}$ & $\begin{array}{l}\text { Green } \\
\text { succese } \\
\text { lep } \\
\text { "on" }\end{array}$ \\
\hline 27 Training runs & 0.23 & no dare & 0.48 & no data \\
\hline 27 Final runs & 0.075 & 1007 & 0.2 & $63 \pi$ \\
\hline
\end{tabular}

Table 4. Sumary of dyanic test dara

\begin{tabular}{l|c|c|c|} 
Operator & $\begin{array}{c}\text { Using graphic } \\
\text { and nuveric } \\
\text { sensui displays }\end{array}$ & $\begin{array}{c}\text { Using only } \\
\text { "green lanp" } \\
\text { sensor display }\end{array}$ & $\begin{array}{c}\text { Without } \\
\text { seasor } \\
\text { displays }\end{array}$ \\
\hline range error (in.) & $\begin{array}{c}\text { Average } \\
\text { range error (1n.) }\end{array}$ & $\begin{array}{c}\text { Average } \\
\text { range error (in.) }\end{array}$ \\
\hline No. 1. 6 runs sach & 0.4 & 1.3 & 1.4 \\
Jo. 2.6 runs each & 0.5 & 0.8 & 1.1 \\
No. 3,6 runs each & 0.9 & 0.5 & 1.0 \\
\hline Total of 18 runs & 0.6 & 0.9 & 1.2
\end{tabular}

by wre than a factor of three. Note aiso that there is a factor of cwo veriation between operators' performance withtn each colung of Table 4 releced to the wae of graphic/ouneric and only "green lasp" displaye, wht le the colun related to test rums without sensor displays does not show that much variation betreen operators.

It is Interesting to corpare the dymand and static teats. In ganeral, the precision postelocing perforance in the static tests is betcer by a factor cf s1x as coupared to the positioning performance in the dyondc cests. Obvilously. the time pressure and tracking deand in the dranatc capture taske have a great impact on precision positioning performance.

The Individual operator coments can be sumertzed as follows:

(1) In gesural, the sensor displaye are useful and helpful.

(2) The pitch and yew error bars should be colored different fron the range error bars on the graphic display.

(3) In the drande tests. ine doninane help come fron meripheral perception of the graphlc error bers and "green lap." The nuverlc display could not be used effectively during the jynatc capture tasks. 
(4) In the static tests, the nueric display proved to be useful and provided an extrareassurance over the graphic display.

(5) The "ault1-piece" and "mult1-area" display organizacton can be countexpoductive then there are tine constralnts. An integrated displey organization should be preferred, e.g., within the frowe of the TV conttor.

(5) A control strategy is aeeded to effectively utilize the error informacton obtafnable fron the displaye.

(7) Often, the concrollablifty cf the eanipulator did sot allow to correct for errors shown on the display.

\section{5. conctusions}

The tests deonstrated the ut\$lity of the end effector proxditity sensor and display systen in facilftating accurate range posicloning and in reducing alfgment errors during grapple of e static payload. The advantages of aple "go/00-go" slgonl ("green lap") or a core qualleative "graphic" display durlng dyondc capture vere underscored. The test also demonstrated the importance of lenruing curve conalderatton, a vell as the exhasis of operator control itrategles in using and Integrating avallable infornetion withtn reasonable workloed ranges. The teses also demonerated the aced for developing wore integrated displare, such that the operator can achleve a better visunl concentration. The developent of integrated displays for qualltatively different and oultidinonstonel Informaction ratses interestins challenges as discused in (Bef. 2).

\section{Ackoowled gent}

The sensor and display developent work has been carried cut at the Jet Propulafion Laboratory, Callfornla Inetituce of Iechnologs, uoder MASA Contract Bo. MS7-100. The contriburton of H. C. Prtans and R. S. Dotson to the display hardware and softrare developent, respectively, is ackoowledged. The tests were supported by the Spacecraft Daelon Diviation of JSC.

\section{References}

1. A. R. Bajczy, J. H. Brown and J. L. Lewls, Evaluaclon of Proxdatty Sensor Alded Grap Control for Shutrle RYS, Proceedinge of the 15th Annual Conference on Manul control, Wright State Onfveralty, Daytor. Ohio, Harch 20-22, 1979.

2. A. K. Befczy, Kineathetc and Graphic Feedback for Integrated Operator Control, Proceediags of the 6th Amual advanced Control Conference, Man-Minchine Interfaces for Induatrial Control, Purdue Ontversity. H. Lafayette, Indiana, Apri1 28-30, 1980.

\section{APPLDIX}

\section{Traneformation of Error Vartables}

Among the three "success" algorithe 1eplemented for the previous tests, the "contc" algortith proved to be the not uneful one. Therefore, only the "contc" success al gortth has been used for the 1980 tests 10 both variations: for all four sensors and for any three out of the four sensors. For easy reference, the algorith is repeated here uning the sybols explatned below. 


\section{OR:-2:D: \\ OF PUOR C:iristir}

Squnre-Symerric Configuration of Four Proxintty Sensor on JSC Tou-'Cle End Effector

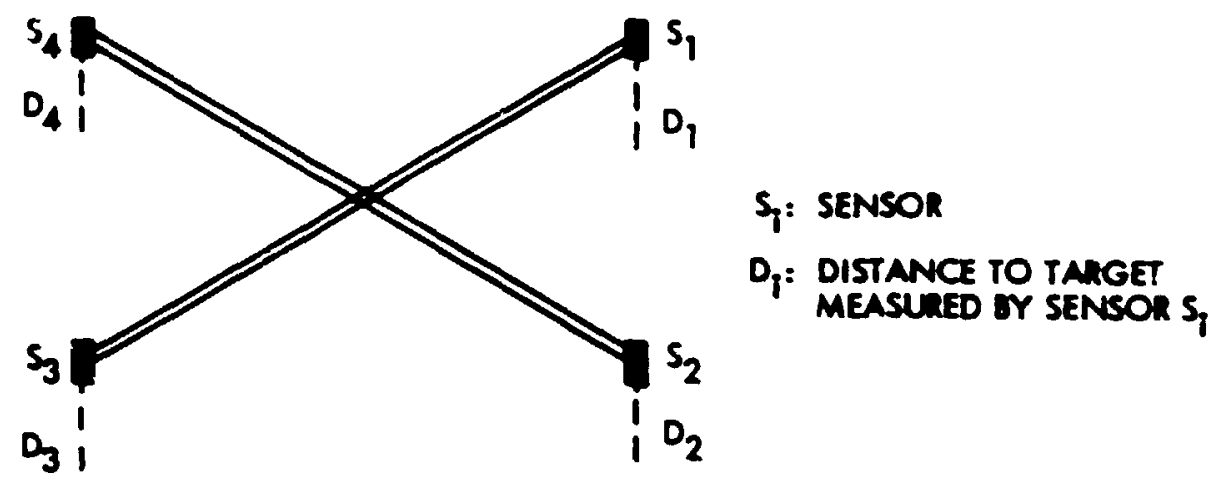

Measurenents and Trapezold Formula:

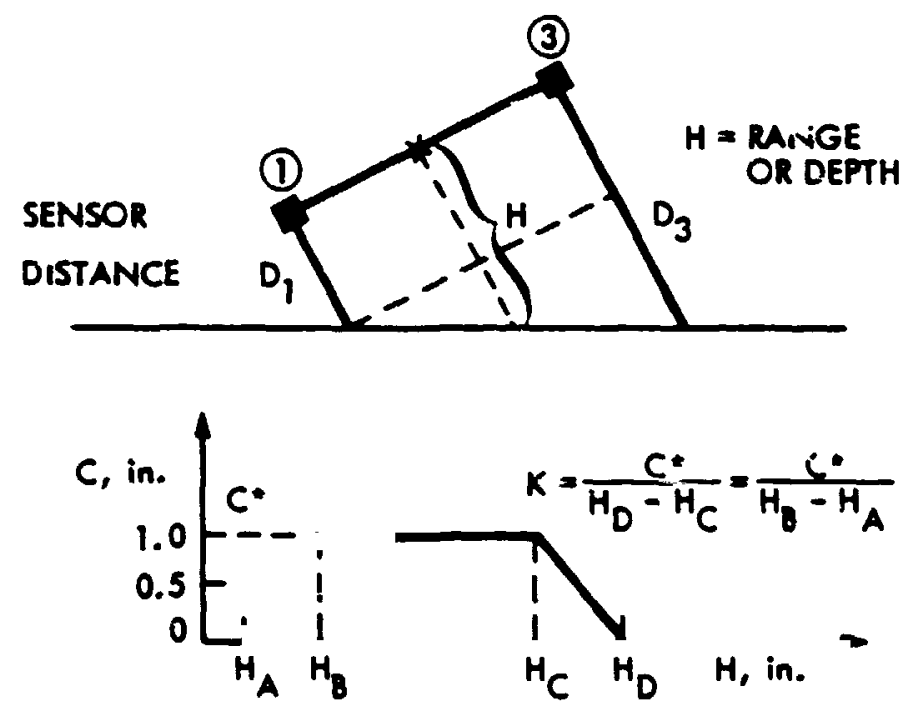

$C$ IS A MEASURE FOR PITCH AND YAW ERRORS; $C=f(h)$

$H_{A}, H_{B}, H_{C}, H_{D}$ AND $K$ (ANO MPLICITLY ALSO C*) ARE PRESET CONSTANTS
F(H) IS GIVEN QY THE TRAPEZOIO FORMULA SHOWN ABOVE 
The end effector range relacive to the grapple fixture is referenced to the center of the end effector wich is aiso the center of the end effector coordinate frane. Therefore, the range (H) computations defined below and applied in the previous cests are invariant to the coordinate frane rotations:

$$
\begin{gathered}
H-1 / 2\left(D_{1}+D_{3}\right) \text { or } H-1: 2\left(D_{2}+D_{4}\right) \\
\text { Alternatively, } B-1 / 4\left(D_{1}+D_{2}+D_{3}+D_{4}\right)
\end{gathered}
$$

The trapezold formule and the quadratic condition (conic expression) are also inveriant to the coordinate frame rotations. Therefore, the quedratic condition (Eq. 3) can be used without transforation to drive the success display:

$$
\left(D_{1}-D_{3}\right)^{2}+\left(D_{2}-D_{4}\right)^{2} \leq L-[f(H)]^{2}
$$

Consequently, the "contc" success algortth can be stated in a form 1dentical to the one implemented for the previous tests:

$$
\begin{aligned}
& \text { (1) } H_{A} \leq H \leq H_{D} \\
& \text { WHERE } H=1 / 2\left(D_{1}+D_{3}\right) \\
& 1 / 2\left(D_{2}+D_{4}\right) \\
& \text { (2) } \begin{array}{l}
\left(D_{1}-D_{3}\right)^{2}+\left(D_{2}-D_{4}\right)^{2} L \\
\text { WHERE } L=C^{2}=[H(H)]^{2}
\end{array} \\
& \text { IF OCTH CONDITIONS ARE TRUE } \\
& \text { THEN LIGHT/WUZZER ARE ON, } \\
& \text { OTHENWISE OFF }
\end{aligned}
$$

\footnotetext{
"Irue" (or "Ilght/buzzer on") Dans thet the existins combination of depth, pitch and yaw errors vill allow a successful grasp.

For the "three out of the four ensoors" vartation of the coatc algorithm (that 1s, when any one of the four sensor signels 1s alselag), the conputation of the aissing $D_{1}$ eassurenent frow the existing chree sensor sigals is 1 dentical to the one laplemented for tha previous tests.

The diaplay of plich and yaw errces referenced to the end effector pitch and yaw control axes requires to transfors the differeaced sensor data, $\left(D_{1}-D_{3}\right)$ and $\left(D_{2}-D_{4}\right)$, fron the sensor referance fram 10 the end effector reference fram. The four transforesions opecifled : ubnequencly will correspond to four poselble rotatloral eounclags of the ea. effector to the wrist, and will also allow to eelect pitch and yaw error pol. rity in the flxed graphics display forant.
} 
As a conventent inftial refarence, we defiat pitch and yav error polarifles mescured in the sensor fran and shown in the graphic display frane (Figs, 1, 2) as follows:

$$
\begin{aligned}
& D_{3}-D_{1} \triangleq D_{31}-E_{p}^{s} \\
& D_{4}-D_{2} \triangleq D_{42}=E_{y}^{s}
\end{aligned}
$$

If the pitch and yaw sontrol axes were identical with the sensor reference dxes, the definitions given by Eqs. 5 and 6 would correspond to the case when the error bars in the display frame are changing length in the direction of the hand controller displacenent.

Tr.e relation between sensor and end effector reference axes is shown in F1g. 2. This figure shows the view looking from the wrist cowards the end effector. Note that $A$, B and yellow strip are existing marks on the claws. Note also that the end effector control axes, An and BB, are along the claws.

The basic transformation of pitch and yaw error vectors from the $\mathrm{S}_{1} \mathrm{~S}_{3}$ and $S_{2} S_{4}$ axes to the $A A$ and $B B$ axes is as follows:

$$
\left(\begin{array}{cc}
a & -a \\
a & a
\end{array}\right)\left(\begin{array}{c}
D_{31} \\
D_{42}
\end{array}\right)-\left(\begin{array}{c}
E_{A A} \\
E_{B B}
\end{array}\right)-\left(\begin{array}{c}
E_{p}^{0} \\
E_{y}^{0}
\end{array}\right) ; a=1 / \sqrt{2}
$$

Hence,

$$
\begin{aligned}
& E_{p}^{0}=a\left(D_{31}-D_{42}\right) \\
& E_{y}^{0}=a\left(D_{31}+D_{42}\right)
\end{aligned}
$$

Note that $E_{p}^{\circ}$ and $E_{y}^{\circ}$ are in the graphic display reference frame.

Suppose that the end effector (togecher with the sensors) is rotated by $90 \mathrm{deg}$. $\mathrm{ccw}$. when mounted to the wrist, without changing the physical direction of pitch and yaw axes as defined in the graphic display frame (F18. 1). This requires the following transformation:

$$
\left(\begin{array}{cc}
0 & 1 \\
-1 & 0
\end{array}\right)\left(\begin{array}{c}
E_{p}^{0} \\
E_{y}^{0}
\end{array}\right)=\left(\begin{array}{c}
E_{y}^{0} \\
-E_{p}^{0}
\end{array}\right) \cdot\left(\begin{array}{c}
E_{p}^{1} \\
E_{y}^{1}
\end{array}\right)
$$


Hence, for 90 deg. rotacion we have:

$$
\begin{aligned}
& E_{p}^{1}=E_{y}^{0}=a\left(D_{31}+D_{42}\right) \\
& E_{y}^{1}=-E_{p}^{0}=-a\left(D_{31}-D_{42}\right)
\end{aligned}
$$

Note again that $E_{p}^{1}$ and $E_{y}^{1}$ are in the graphic displey reference frame.

If the ead effector (rogether with the sensors) 18 rotated by 280 deg.

ccw. when wounted to the wriat, and the phyalcal direction of pitch and yaw axes are kept fixed at show in the graphic display fram, then we have to perfore the following transforation:

$$
\left(\begin{array}{cc}
-1 & 0 \\
0 & -1
\end{array}\right)\left(\begin{array}{c}
E_{p}^{0} \\
E_{y}^{0}
\end{array}\right)-\left(\begin{array}{c}
-E_{p}^{0} \\
-E_{y}^{0}
\end{array}\right)-\left(\begin{array}{c}
E_{p}^{2} \\
E_{y}^{2}
\end{array}\right)
$$

Hence, for $180^{\circ}$ deg. rotation we have

$$
\begin{aligned}
& E_{p}^{2}=-E_{p}^{0}=-a\left(D_{31}-D_{42}\right) \\
& E_{y}^{2}=-E_{y}^{2}=-2\left(D_{31}+D_{42}\right)
\end{aligned}
$$

270 deg. rotation, having the sane conditions a for the 90 degree or 180 degree rotations, will require the following transformation:

$$
\left(\begin{array}{cc}
0 & -1 \\
1 & 0
\end{array}\right)\left(\begin{array}{c}
E_{p}^{0} \\
E_{y}^{0}
\end{array}\right)=\left(\begin{array}{c}
-E_{y}^{0} \\
E_{p}^{0}
\end{array}\right)-\left(\begin{array}{l}
E_{p}^{3} \\
E_{y}^{3}
\end{array}\right)
$$

Hence, for 270 deg. rotation we have:

$$
\begin{aligned}
& E_{p}^{3}=-E_{y}^{0}=-2\left(D_{31}+D_{42}\right) \\
& E_{y}^{3}=E_{p}^{0}=-\left(D_{31}-D_{42}\right)
\end{aligned}
$$

Note that $E_{p}^{2}, E_{y}^{2}, E_{p}^{3}$, and $E_{y}^{3}$ are in the graphic display referance frame. 

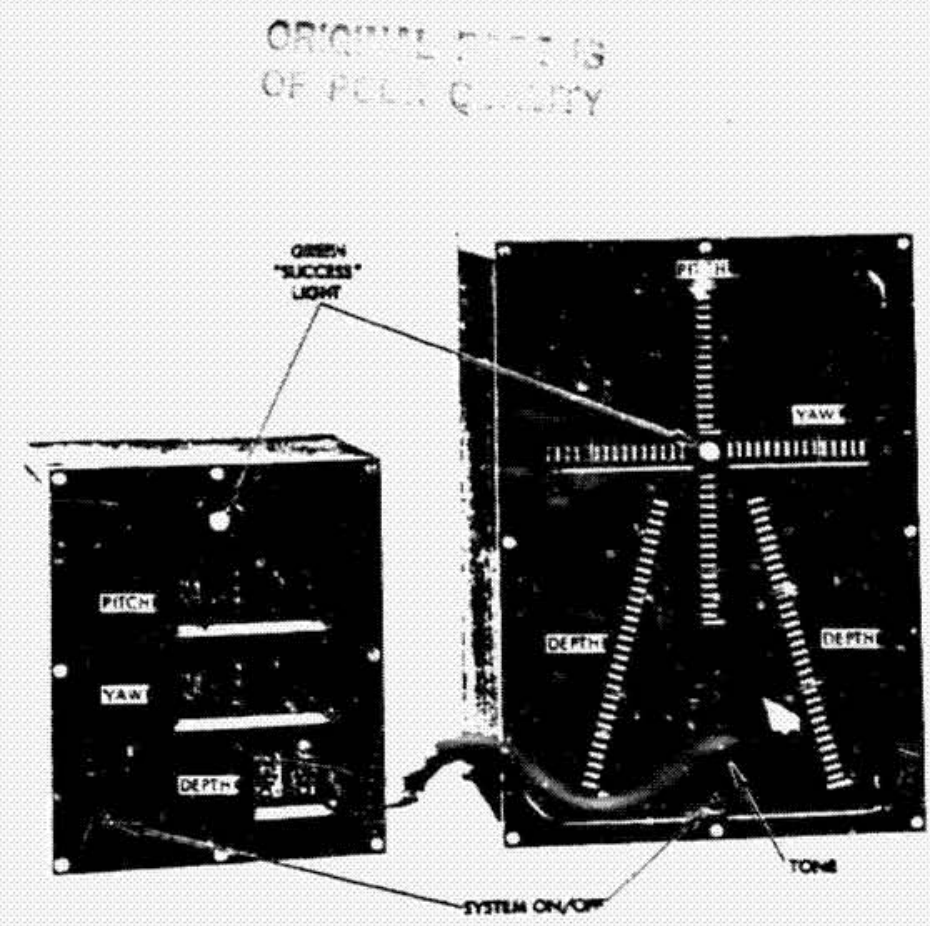

Figurc 2. Event-driven graphic and numertic displays of data from proximity sensor system integrated with four-claw end effector
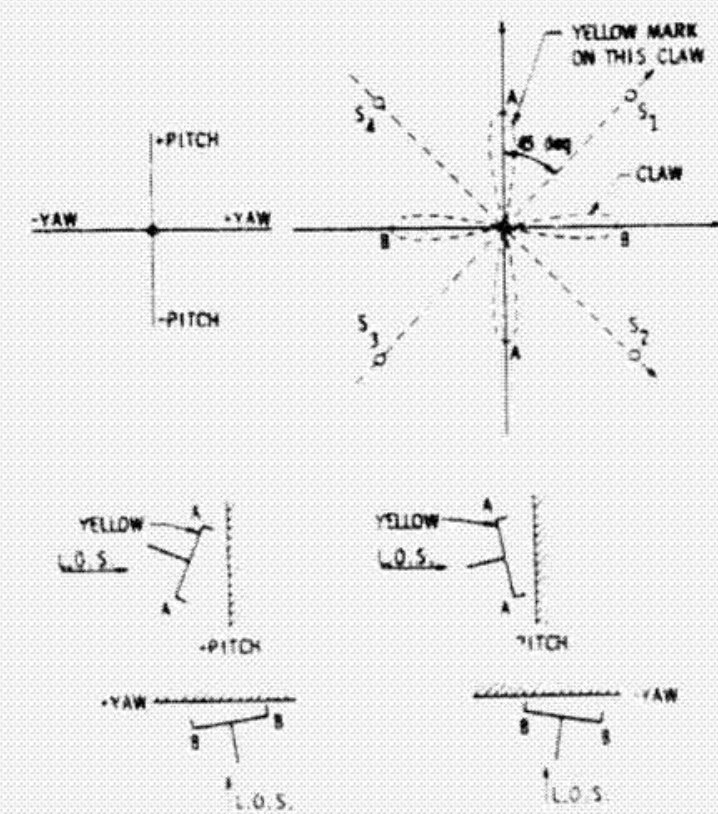

\section{View: looking from wrist towards end effector.}

Flgute $\therefore$ Sencor, control and display reterence :tamas: error states for $\mathrm{X}=0$ on the BCD $d: a l$ switch 


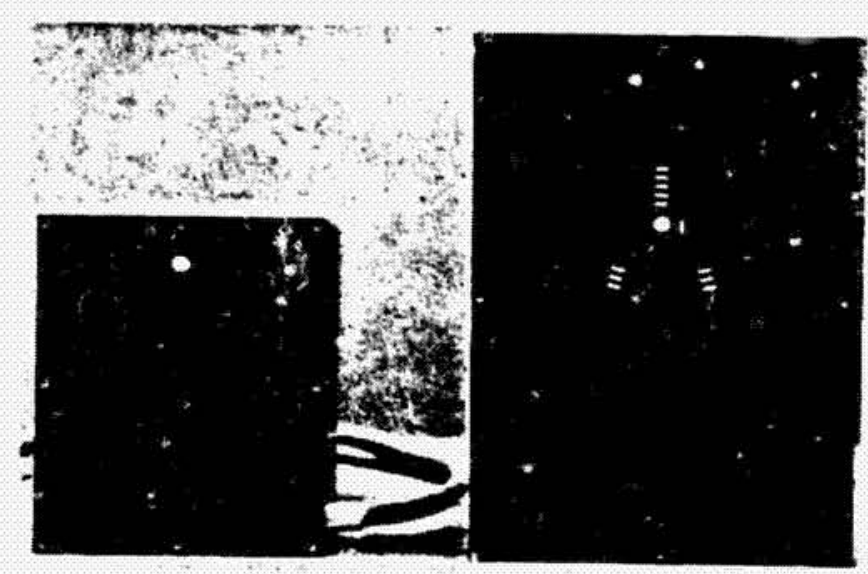

c) INSIDE GRASP ENVELOPE WITH GREATLY REDUCED ERRORS FOR A FINE-CONTROLLED GRASP; GREEN LAMP ON.

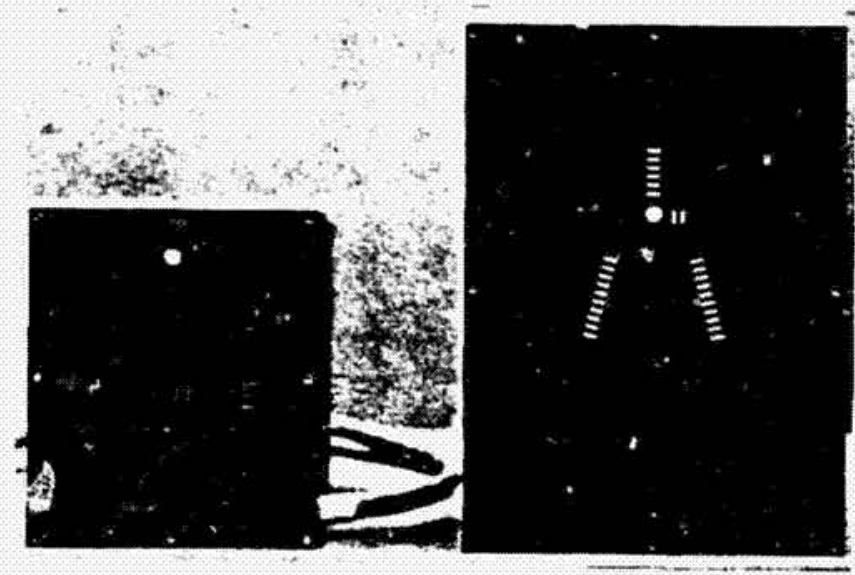

b) INSIDE GRASP ENVELOPE. ERROR COMBINATION ALLOWS SUCCESSFUL GRASP; GREEN LAMP ON.

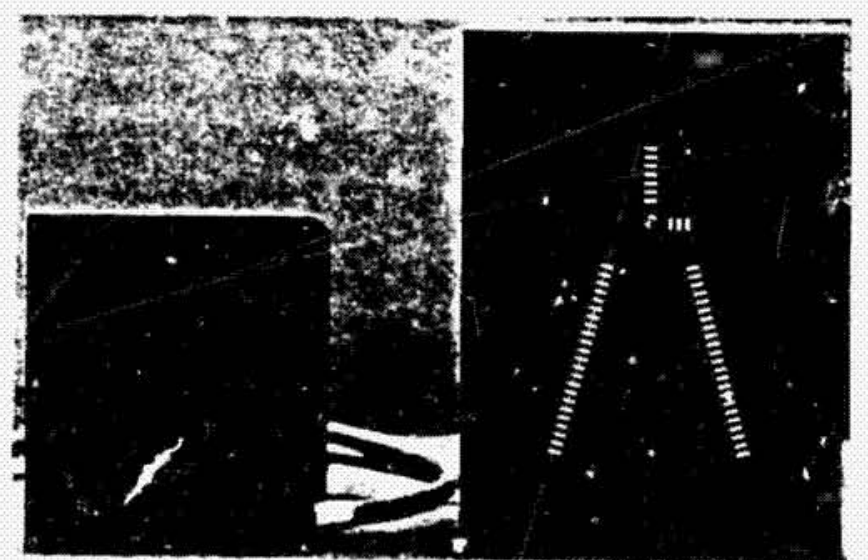

a) DUTSIDE GRASP ENVELOPE AT 4.5 inches RANGE; GREEN LAMP OFF.

Figure 3. Target apfroach sequence as seen on che "ssart" displays. (Sequence from botcom to top.) 

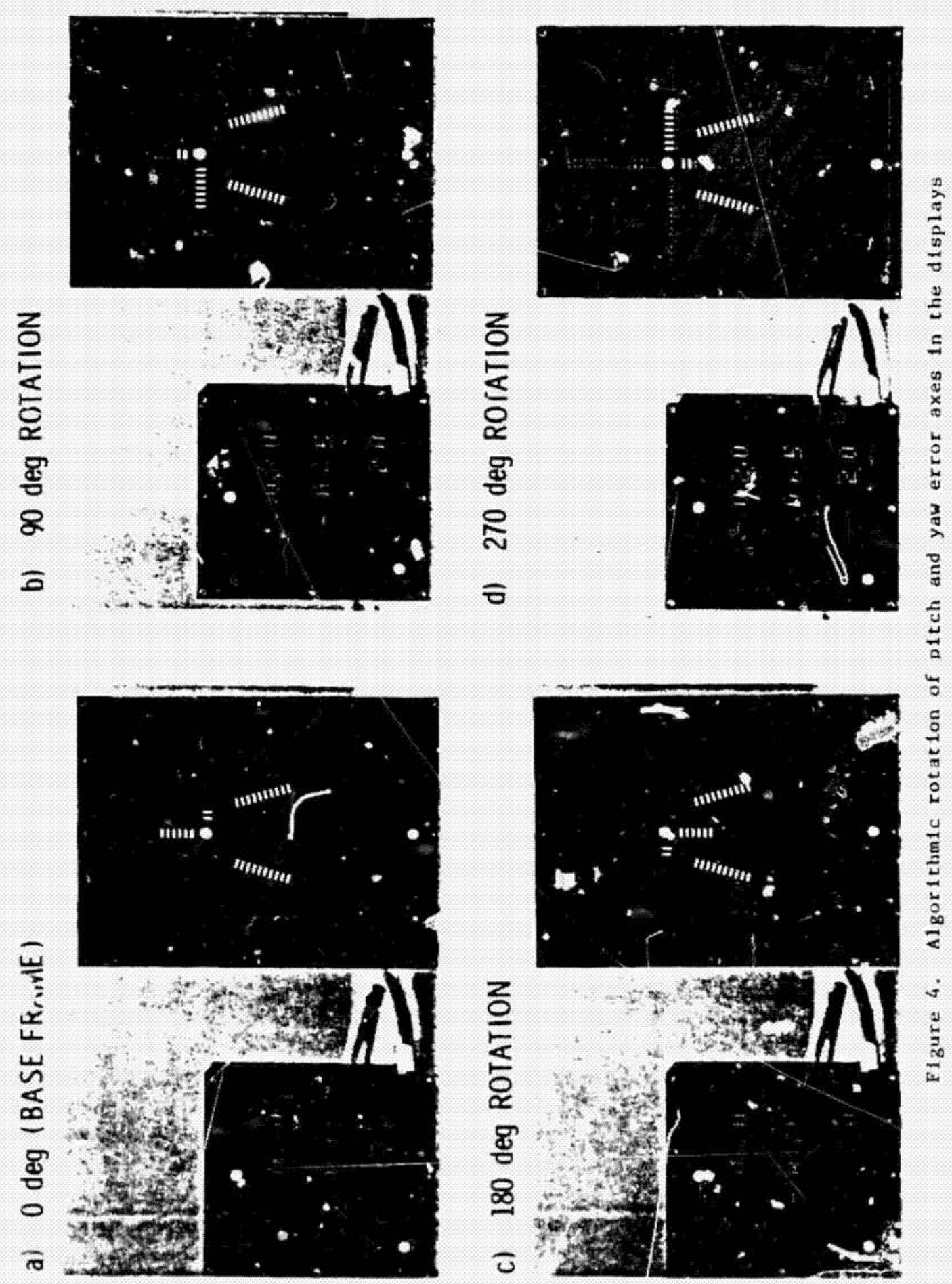


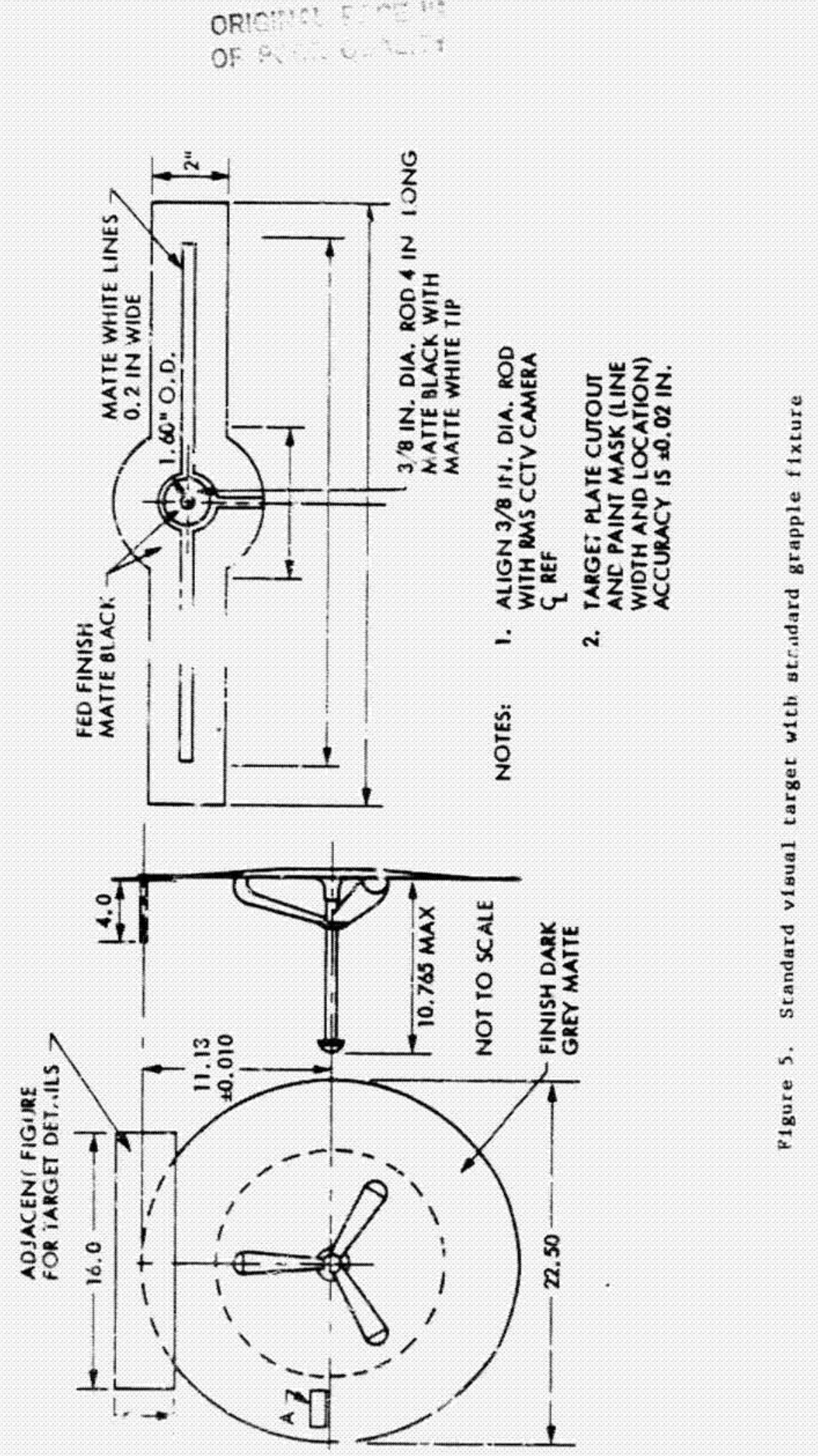




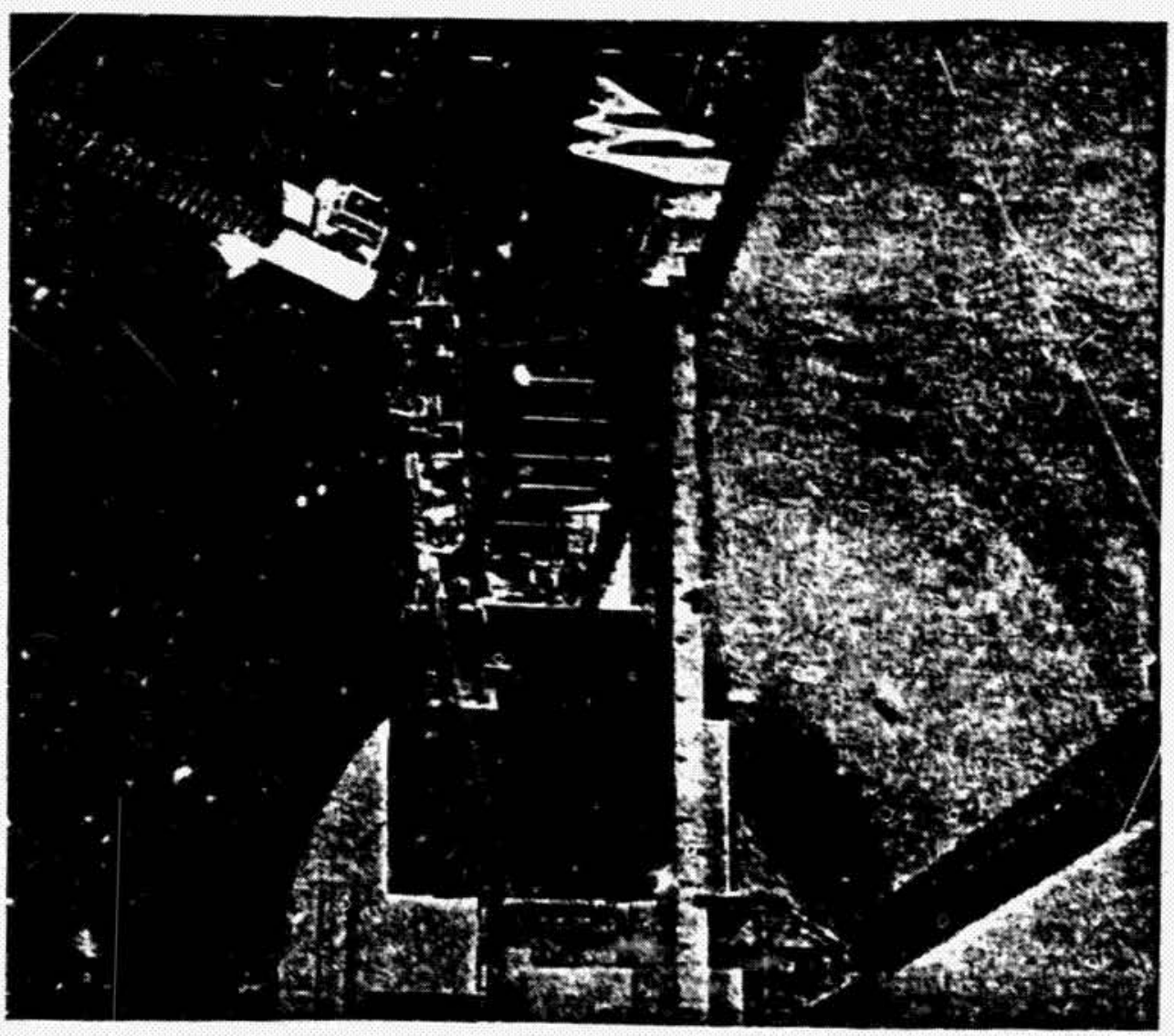

בे

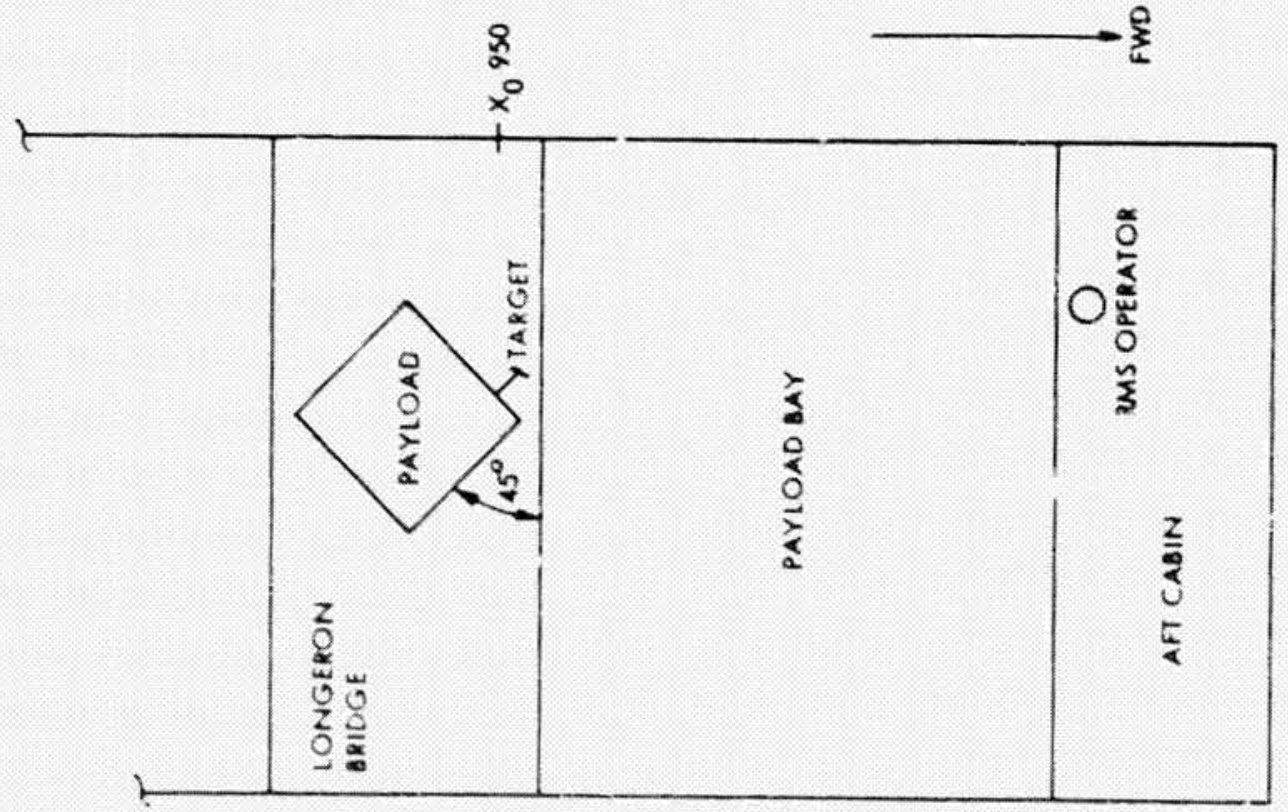




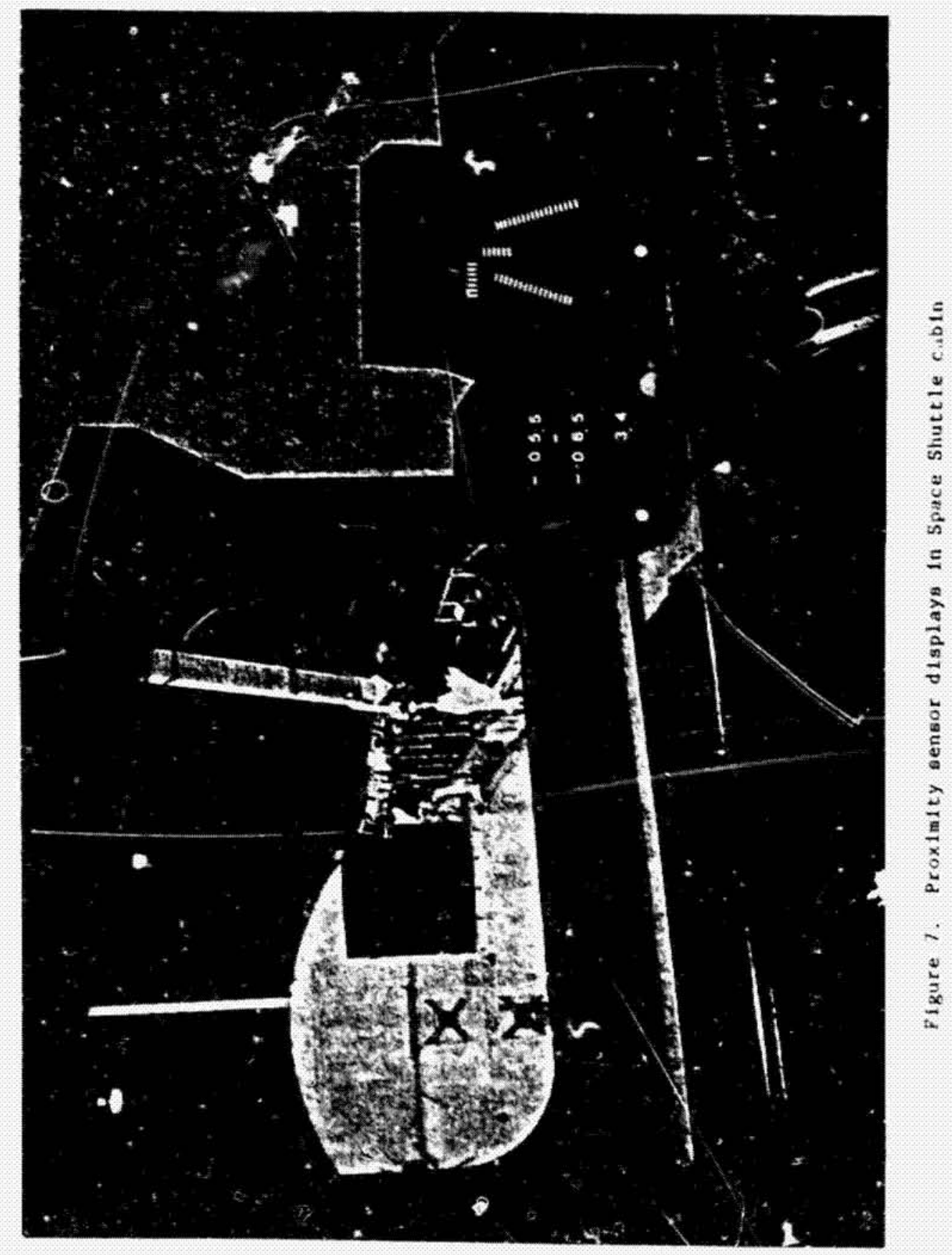



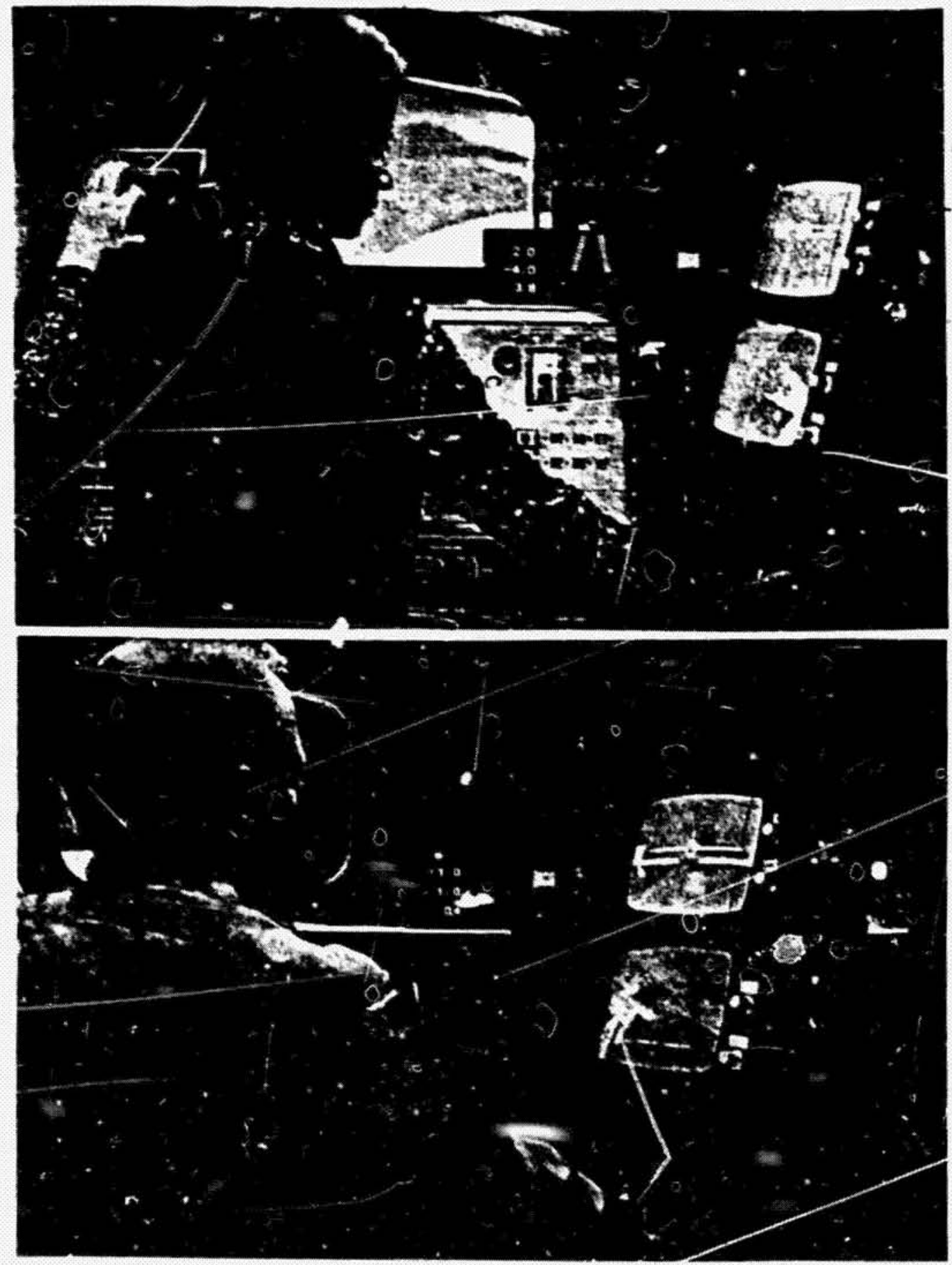

Figure S. iperators using proxianty sensot displavs in Shutcle cato

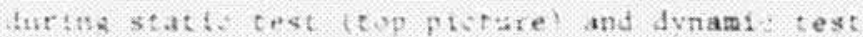
fiwe: yistitel 
ORIGINAL FH:

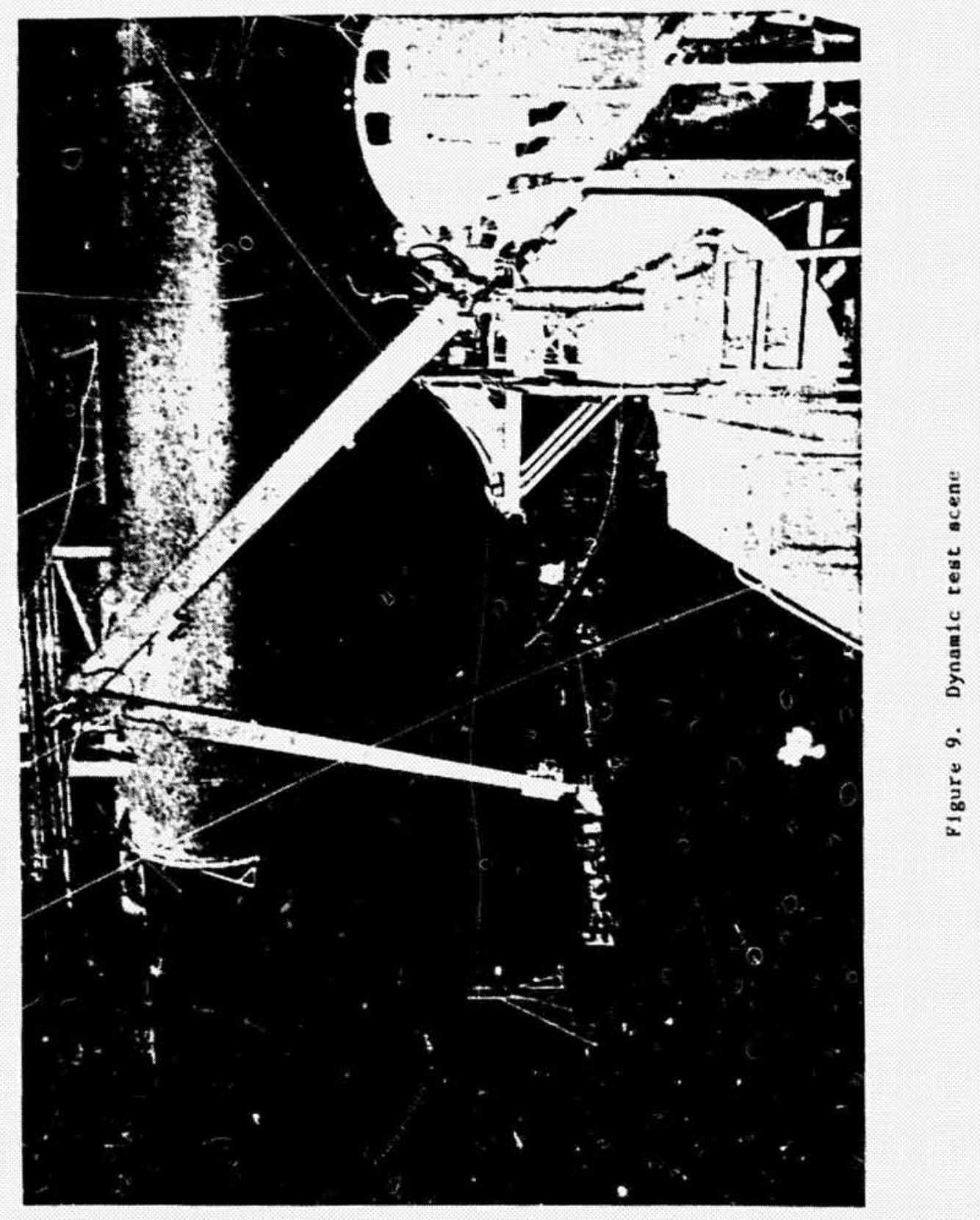



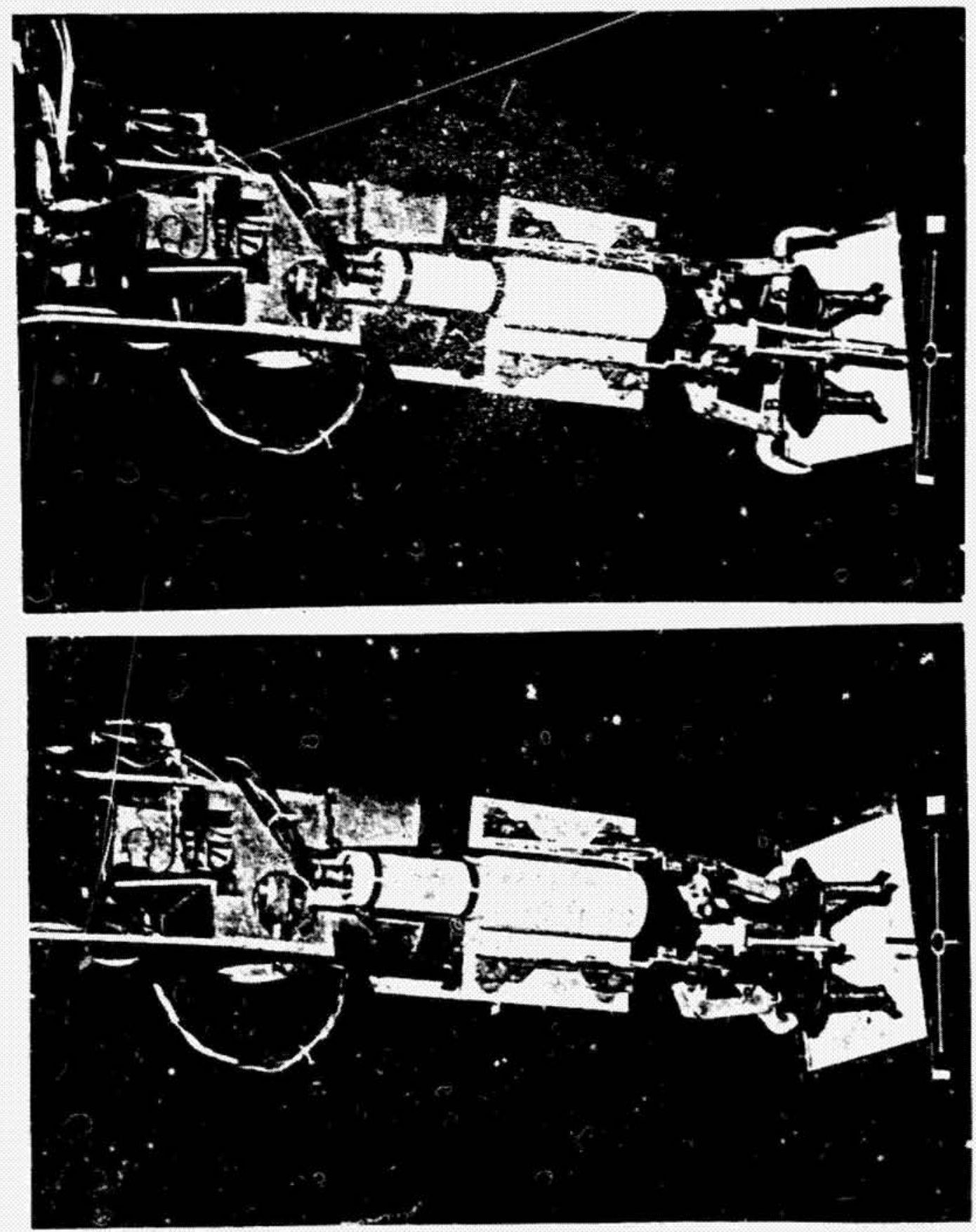

Figure 10. Precision controlled grasp 


\section{A HEW FEEDBACK INSTRUMENT FOR ROBOTS AND MAHIPULATORS, AND ITS USE IIN}

ROBOT TEACHING, SELF CORRECTION AND LEARNING

By

D. S. Seltzer and

D. E. Whitney

The Charles Stark Draper Laboratory, Inc.

Cambridge, MA 02138

\section{Abstract}

A new type of tactile sensing device, the Instrumented Remote Center (Jinpliance (IRCC) has been developed for use with industrial robots and nanipulators. The IRCC combines a passive mechanical error-absorbing structure with instrumentation capable of measuring position errors to a resolution of $0.1 \mathrm{~mm}$ and angular errors to a resolution of $10^{-3}$ radians. The IRCC can ald a robot operator during teaching by pr-viding tactile information. Current experiments indicate that this information can be utilized by either displaying it to the operator, or incorporating it directly in a computercontrolled feedback loop. Future research efforts will examine the use of the IRCC for performance wonitoring and correction fo, long term effects such as tool wear, part variation, and robot drift. The approach is based on Kalman filter models of the robot, the sensor, and an ensemble of repeated operations such as pal - transfers or assemblies. Applications include searching a visually occluded enviroment, tracking drift, sorrecting initial condition errurs or detecting malfunctions. 
THE NOSC/MIT SUBMERSIBLE MUNIPULATOR: AN EXPERINENT IN REIDTE SUPE RNISORY CONTROL OF A MICROPROCESSOR BASED ROBOT

\author{
Dana Yoerger \\ thoma Sheridan \\ Masachusetts Institute of Dechnology
}

This paper is a progress report on the developnent of an experimentai free-swimuing submersible with a manipulator arm. The system will function in the undersea environment while being controlled remotely in a superviscry mode by a human operator. The electrically powied arm is controlled by the human operator with the ald of microcomputers both on the submersible and on the surface.

Develogment will begin with a manual control system and a tether for commintcation to and from the vehicle. After supervisory concepts such as preprogramed tasks, motion compensation, and active accomodation have been implemented, the vehicle will be made free swimaing. Commication will then be accomplished througt. an acoustic data link.

Due to the limited bandridth and delays imposed by the acoustic data int, continuous manual control via the human operator is not possible. Thererure, the manipulator wet be able to complete tasks with only high level crmands trom the surface. Vehicle motion, unexpected collisions, as well as subetanilid position errors met be dealt with by the relatively modest microcomuter. The microcomputer on the surface will be used to provide the operator with computer aided dir plays to further reduce the -ffects of the acoustic link. 
ANALYSIS OF DRIVER PERFORMANCE UNDER REDUCED VISIBILITY

Wolf-Diater Kospler

Farschungsinstitut fuer Anthropotechnik (FAT)

D-5307 Wochtberg, F.R. Germany

\begin{abstract}
Mathematical modals describing vehicle dynomics as wall os humen bahavior moy be useful in evaluating driver performance and in establishing dasign criterio for vahicles more compatible with man. In 1977, a two-lewl modal of driver steering behovior was developed, but its parameters mere identified for clear visibility conditions only. Since driver performence degrades under conditions of reducad visibility, e.9. fog, the two-level model should be investigated to determine its applicability to such conditions.

The data analysis of a recently parformed driving simulation experiment showed that the model still performed recsonobly wall under fos conditions, although there was a degradation in its predictive copacity during fog. Some odditional parameters offecting anticipation and log time moy improve the model's performonce for reduced visibility conditions.
\end{abstract}

\title{
1. INTRODUCTION AND TWO-LEVEL MODEL
}

Mothematical modals moy be useful in evoluating driver parformance and in eatiblishing desion criteria for vehicles more compatibie with man. The state of the sot of mathematical description of cor dynamies is rather high. However, there is still a lack of information about the dynamic behovior of car drivers.

Rased $2 n$ the idea that human behavior in lateral vehicle control can be describand in terms of a multi-level control reak, Donges [1] hos developed a mo-level modal of driver steering behovior. The model is split into onticipatory and compensotory rakk levels (Fig. 1) which ore working in perallol.

At the anticipotory level, the diver is presented with an outside forword view of the required poth curvature $K_{S}$ which serves as the forcing function. Percaiving the future course of the rood, the is able to react with a sieering angle $\lambda_{S}$ in advance to turns and obstocles.

At the compensotory level, the driver compores actual and required path by obeerving, -. o., heoding angle error and lateral cuviation $y$ of the vehicle. From this information, a compensotory Staering angle $\lambda_{R}$ is deduced to correct the course of the cor. 


\section{ORIGLint
OF POOR Q}

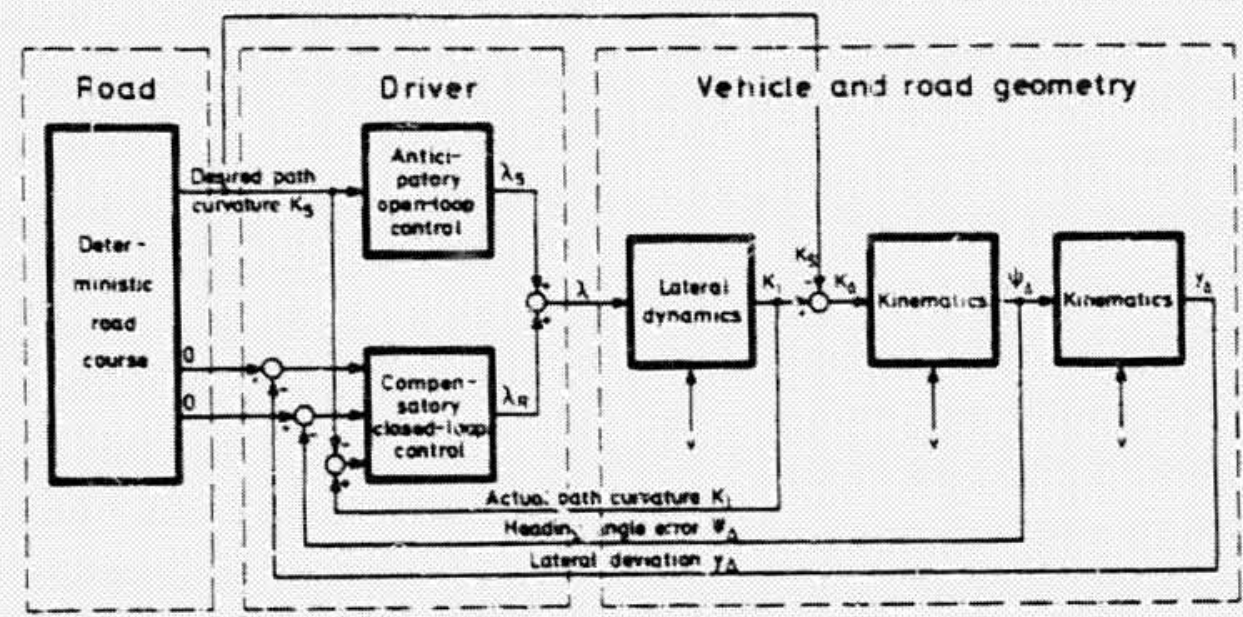

Fig. 1: A schemctic diagram of the two-level model of driver steering behevior in the driver-vehicle-rood system (from Donges [1])

So far, parameters for this model hove only been identified for clear visibility condipians. Driver performance, however, degrades under conditions of reduced visibility (Mclean $2^{-}$, and others $3 ; 4 ; 5 ; 67$ ). The two-level model should be able to predict this degradation since reduced visibility, e.g., fog will mainly affect the anticipotory level (Fig. 2).
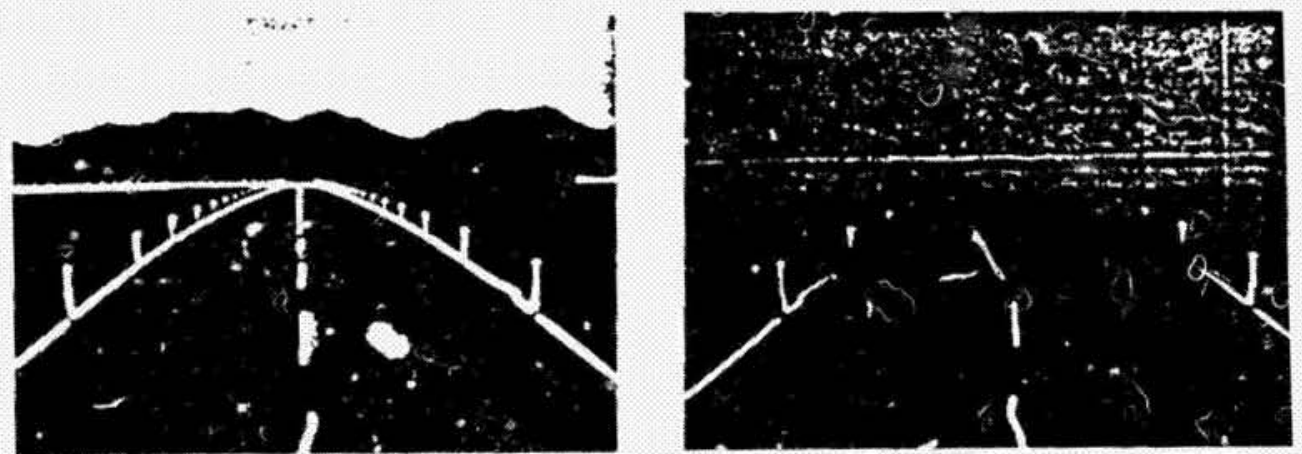

F. 3. 2 : Visual simulation with a stylized two lane road
a) when clear
b) during fog

With clear visibility, the apparent movement of the mountain scenery provides cues about the heoding behavior of the car. The direction of an approaching turn as well as how sharp the turn is can aiso be determined. With this information and based on perhaos his velocity or distance, idgment ic the curve, the drive: is able to make a suitable steering movament. In fog, he gers less information on app.saching turns.

In consequence, porameters of the two-level model may change. 


\section{origintit prat is \\ of POCFi Quinint}

To examine this supposition and to find out if this model in general is able to predict the degraded performance reasonably well, a driving simulation experiment has been set up and performed ? .

\section{DRIVING SIMULATOR AND EXPERIMENTAL PROCEDURE}

The simulator used (Fig. 3) includes a real car cabin converted to simulation purposes, longitudinal and lateral vehicle dynamics, driving noise, rolling motion and the outside forward view. The stylized image of the rood can be presented to the driver undes several visibility conditions (see again Fig. 2) $8^{-}$.

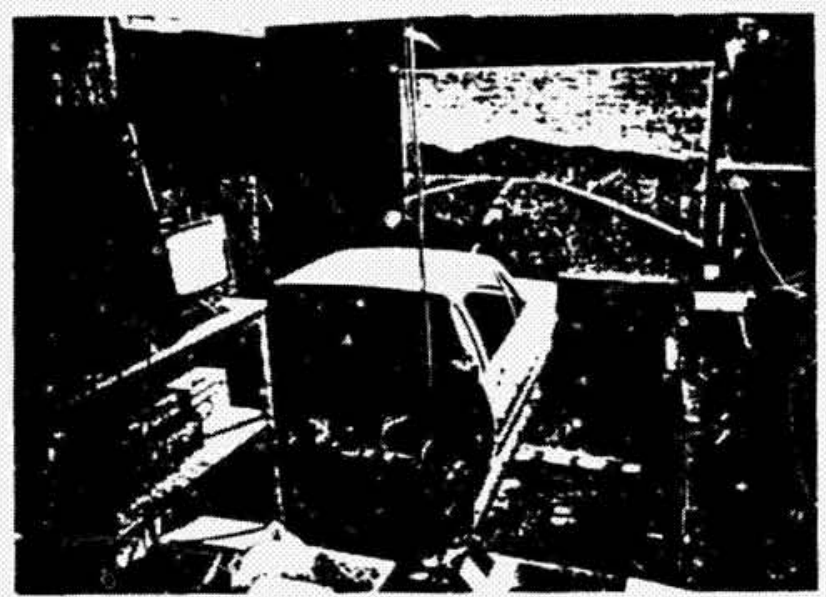

Fig. 3 : The Driving Simulator of the FAT

In the experimen; visibility condition, i.e, clear and fog (visibility ranges of $400 \mathrm{~m}$ and $33 \mathrm{~m}$ respectively) wos the independent variable. The dependent variables of interest here included the measures:

velocity
steering angle
heading angle error
lateral deviation

and the model parameters for the anticipatory and compensa ry levels:

\begin{tabular}{|c|c|}
\hline $\begin{array}{l}\text { anticipotion time } \\
\text { lag time } \\
\text { steering gain }\end{array}$ & $\begin{array}{l}\text { time delay } \\
\text { heoding gain } \\
\text { deviation gain }\end{array}$ \\
\hline
\end{tabular}

Six experienced mcle drivers took part in the experime it. hey were instructed to drive safaly but as quickly as conditions permit. The driving task consisted of s.x laps on c closed rood circuit. Aiter two training sessions of 20 minutes each under clea: conditions, the experiments ivere run at intervals of one day. 


\section{ORIGINAL Fa: IS \\ OF POOR QUALITY}

\section{RESULTS AND DISCUSSION}

As one might expect, mean lap speeds for each person and for the group were lower for fog conditions with $17 \mathrm{~m} \cdot \mathrm{s}^{-1}$ (meters per second) than when elear which wos $27 m \cdot s^{-1}$ (Fig. 4).

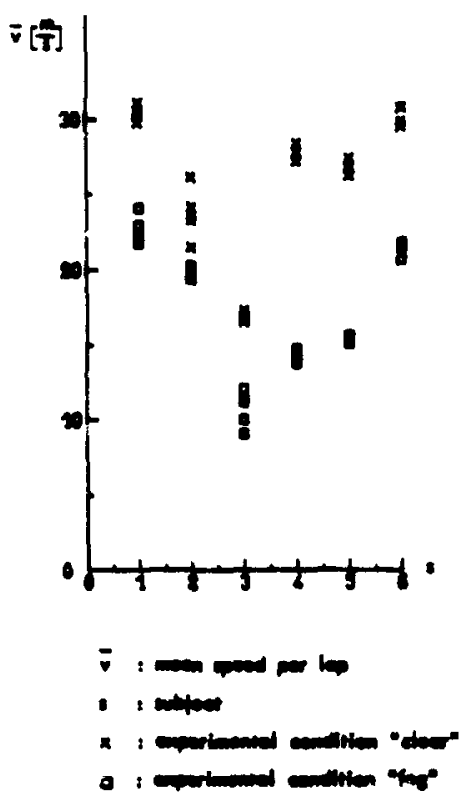

Fig. 4: Mean lap speeds for different subjects and visibility conditions
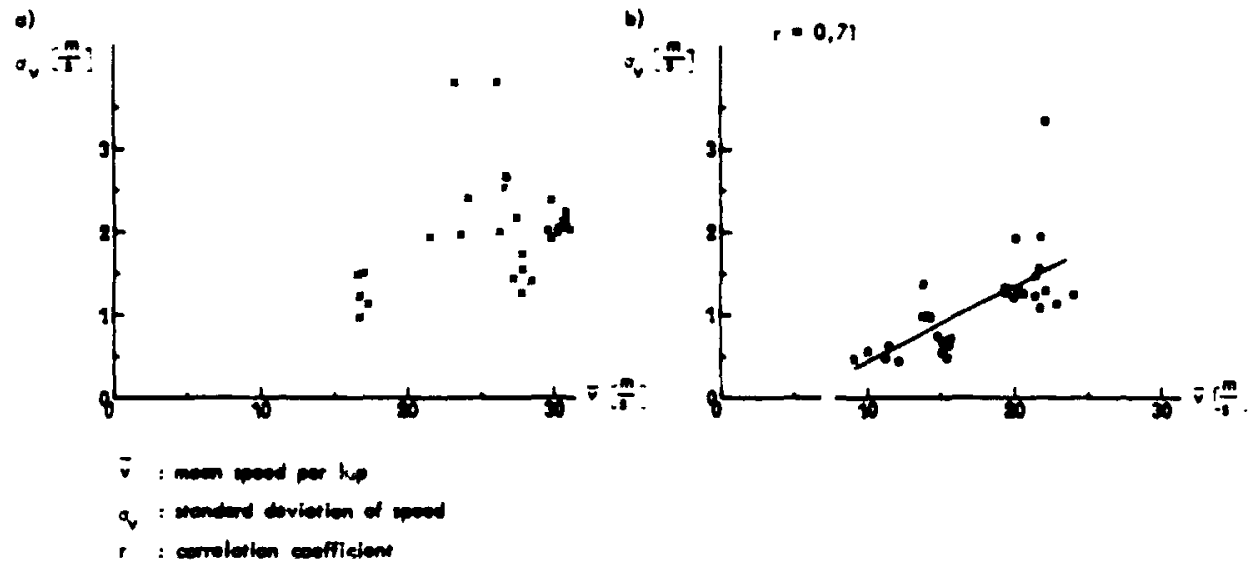

Fig. 5 : Spaed variability a a function of speed
a) when clear
b) during fog 
In adoition, lap speeds were less variable urider the fog condition with a standerd enviation of 1.3 compared with 2.1 for the clear condition (see Fig. 5), probebly due to the more restricted speed renge available to the subjects.

Also, during fog conditions driving behavior is more. nservative [3] leading subjects to refrain from increasing their speeds between curves (see also FG in fig. 8a).

In both experimento' conditions, lane deviations increased with wiving speed and the absolute values of lane devictions were approximately the same below $18 \mathrm{~m} \cdot \mathrm{s}^{-1}$. Above this speed, obsolute lane deviations increased more unde. the fog condition (Fig. 6).

a)

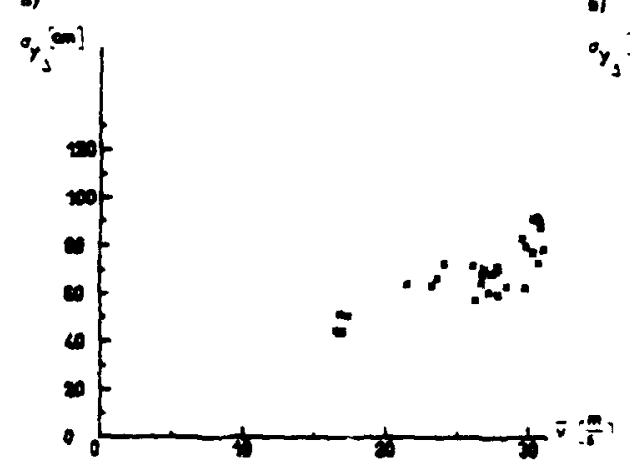

$$
\text { ": : }
$$

Fig. 6 : Lone deviation as a function of speed
a) when clear
b) during fog

The test course censists of 24 segments of sonstant curvature. A step in rood arvature occurs where two of these segments join together. When clear, this is seen long before it is reached by the driver so that he is able to react in udvance. Tix histories (means and standard deviations overaged over 30 individual tim histories) of the thpondent variables under clear and fog conditions orn shown in Figurs 7 for a left hand tum.

The speed variation is quite small though six subjects cre involved (see Fig. 7c). When it is clear, the stearing reaction shown in the left part of fig. 7d is starting at a cartain time prior to the step change. The steering angle shows a lagged transient with a small overshoot. The succes of this reaction is illustrated by the fact that the lateral deviation (Fig. 7f) tends to be evenly distributed around the center.* line with $a$ bias in the direction of the curve, i.e., more left de riations in left hand turns.

In the right part of Fig. 7, the time histories undar feg concitions are shown. The steering reaction (Fig. 7d) storts late in response to the step chonpo iesulting in a large lane deviation to the right of the center-line in o left turn (Fig. 7f). This grach diso show tuep transient with a lorge overshoot. Clearly, the reduesd informution in $i=$ is co: tition does no: permit the driver to porform prepel ly. 


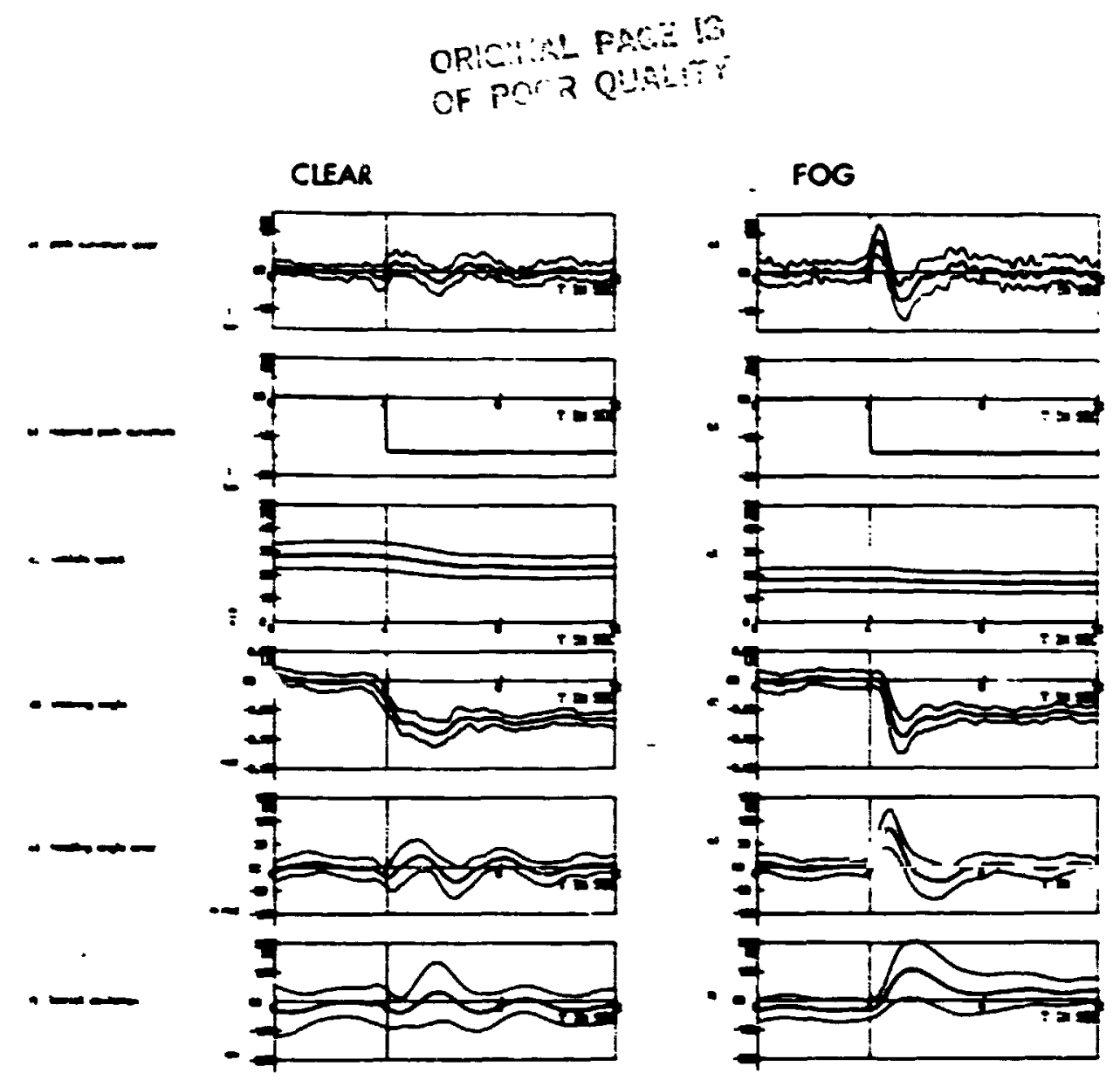

Fig. ? : Time histories of gystem voriables in a left arve for cleor and fog conditions

In course sogments similer to the dbovementioned, the six parameters of the two-tewel modal hove been identified. At mis time, the identificotion is comploked for rwo reprosentutive course exprents, a right and a laft hand hum. The parameters of the two-level model did in foct change to a cartain extent under the fog condition eapecially enticipotion time oce been in the following Toble 1 .

Table 1 : Porameter means of the nwo-level modal for cleor and foo conditions

\begin{tabular}{|c|c|c|c|}
\hline Mocid Lovel & Peromerer & Cleor & Fog \\
\hline Anticipotony Levol & $\begin{array}{l}\text { enticipotion time (exc.) } \\
\text { log time } \\
\text { stwering gain (dag.x km) }\end{array}$ & $\begin{array}{l}0.40 \\
0.41 \\
0.31\end{array}$ & $\begin{array}{r}-0.14 \\
0.54 \\
0.26\end{array}$ \\
\hline Compersotory Level & $\begin{array}{l}\text { time deloy (be.) } \\
\text { hacoding goin(deg./deg.) } \\
\text { deviation gain (deg./cm) }\end{array}$ & $\begin{array}{l}0.34 \\
0.33 \\
0.0039\end{array}$ & $\begin{array}{l}0.63 \\
0.39 \\
0.0043\end{array}$ \\
\hline $\begin{array}{l}\text { steming sensitivity } \\
\text { steering ratio }\end{array}$ & $\left(\right.$ deg. $\left..^{-1} \times \mathrm{km}^{-1}\right)$ & 0.16 & $2^{0.17}$ \\
\hline
\end{tabular}


To give on impresion of the efficiency of the mo-level modal, combined time histories of one diver, the diver model and its components are shown in Fig. 8 for on orbitrurily chowen excmple for each of the visibility conditions.

\section{CLEAR}

FOG

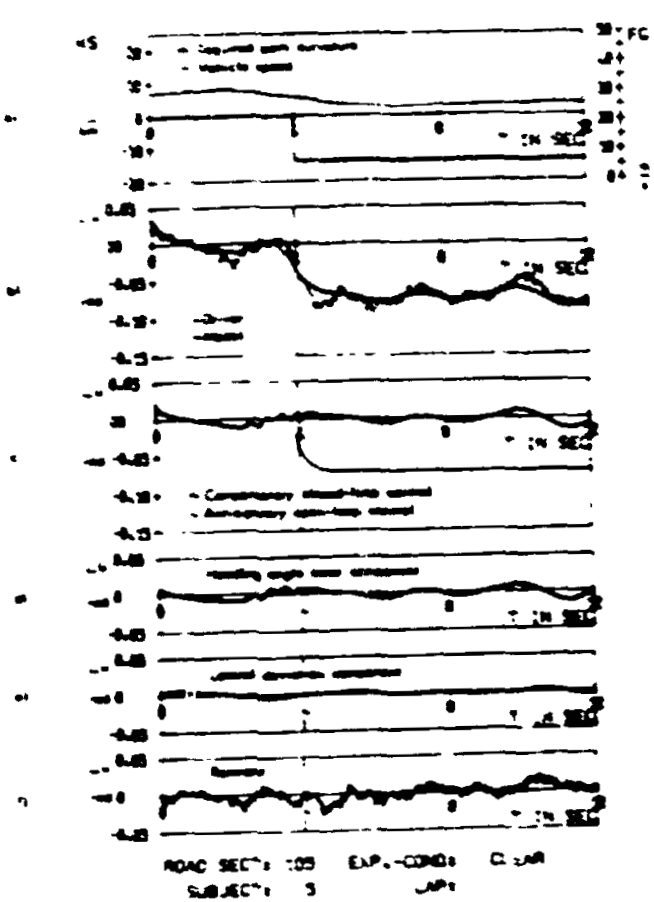

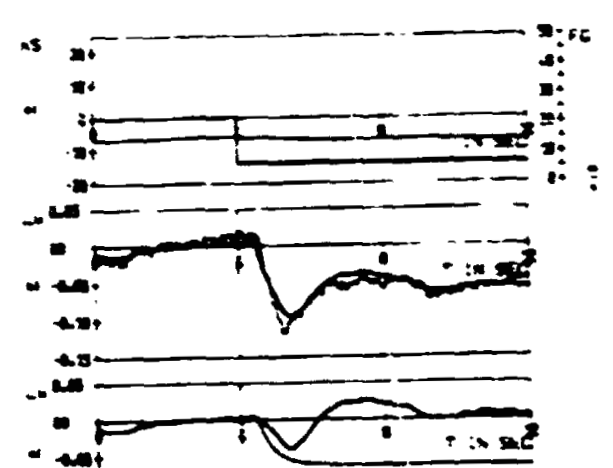

- ter

$\rightarrow$

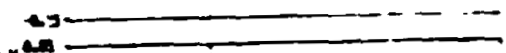

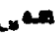

$-1$

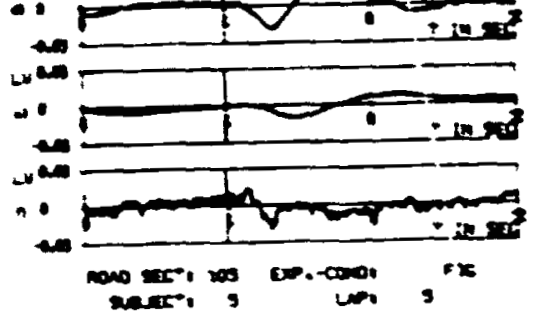

Fig. 8 : Time histories of steering angles (LW) of one driver, driver model and diver modal components

Required path arroture (KS) and rehicle speed (FG) are shown in Fig. 80 to describe the experimental situation. A. $\mathrm{um}$ con see in Fig. $8 \mathrm{~b}$, the two-level model predicts tiver stearing reaction reasenably well in clear and fog conditions although batter so under elear conditions which fnllows from the derailed dato anolysis. It hurrs oul that for tath canditions heading angle inputs account for the lorgest port (see Fig. 80) of the compensatory level response shown in Figure 8c.

In foj, the modal occounts for a smoller portion of the steering reaction of the anticiparory level. One reasor. is that the chosen first order lag is not oble to reproduas the overshoor which occared in the for 'se Fig. Bb). Besides, the tronsient of the matel is nct as steep os the experimental doto show (Fig. $8 b$ and c). This is because the onficipotion time TA could not always be identified correctly by the lecest mean square meshod ued here. Diring fog, the driver mokes steering movements to the left or right, nol really knowing when a rurn will appear and what kind of turn this wil be. These ecrly steering movements moy be interpreted by the model as early reactions to the arve.

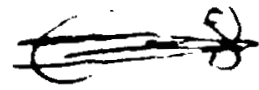




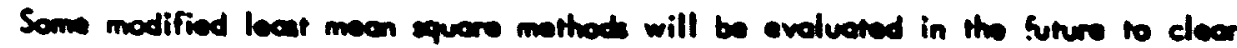
owoy this dafect. It abo eppear thot the mo-level modbl could, parthepe, be improwed for limind visibility conditions by ineluding odtitional peremeter offecting onticipotion and log rims.

\section{REFERENGS}

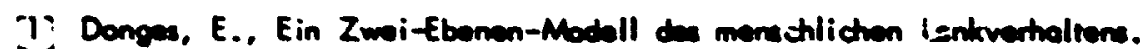

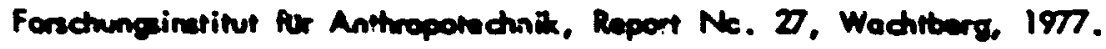

[2] Meleon, J.R., Hoffwom, E.R., The Effects of Reatricted Rovien on Driver Sreering Control and Performonco. Humen Foctors, 15(1973)4, p. 21-430.

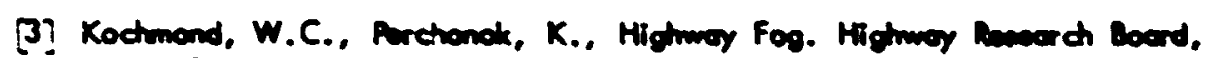
Report No. 95, Duffolo, Nr. 1970.

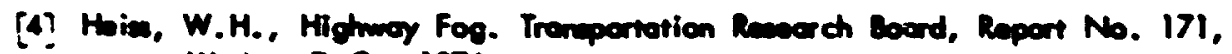
Weh.. O.C., 1976.

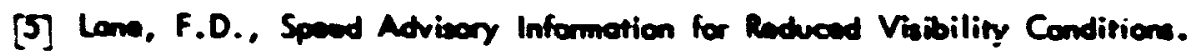
Nins, Solem, Oreg., 1975.

[6] Allen, R.W.. Meluer, D.T., Driver Skering Dynemia Mocoured in a Cor Simulaver under o Romos of Viability and Rood-mathing Condi:ions.

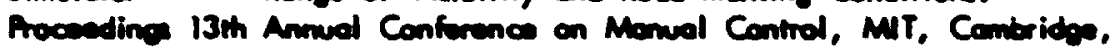
Mre.. 1977. p. 180-196.

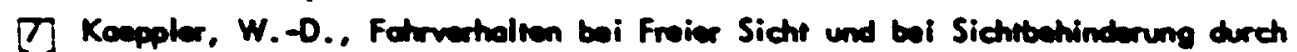
Nabol. Forschungeinatisut for Anchroporschnik, Wochrbers Roport will be publiahad).

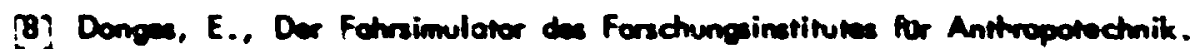
Report No. 41. Wachiterg, 1998. 


\begin{tabular}{|c|c|c|c|}
\hline $\begin{array}{l}\text { 1. Report No. } \\
\text { NASA TM- } 84273\end{array}$ & 2. Government Accession No. & \multicolumn{2}{|c|}{ 3. Recipient's Catralog No. } \\
\hline \multirow{2}{*}{\multicolumn{2}{|c|}{$\begin{array}{l}\text { 4. Title and Subtitle } \\
\text { SIXTEENTH ANNUAL CONFERENCE ON MANUAL CONTROL* }\end{array}$}} & \multicolumn{2}{|c|}{$\begin{array}{l}\text { 5. Report Date } \\
\text { July } 1982\end{array}$} \\
\hline & & \multicolumn{2}{|c|}{ 6. Pertorming Organization Code } \\
\hline \multicolumn{2}{|l|}{ 7. Author(s) } & \multicolumn{2}{|c|}{$\begin{array}{l}\text { 8. Performing Organization Repart No. } \\
\text { A-9000 }\end{array}$} \\
\hline & & \multicolumn{2}{|l|}{ 10. Work Unit No. } \\
\hline \multirow{2}{*}{\multicolumn{2}{|c|}{$\begin{array}{l}\text { 9. Performing Organization Name and Address } \\
\text { Massachusetts Institute of Technology, Cambridge, } \\
\text { Mass. 02139 and NASA Ames Research Center, Moffett } \\
\text { Fie1d, CA } 94035\end{array}$}} & \multicolumn{2}{|c|}{ 11. Contract or Grent No. } \\
\hline & & \multirow{2}{*}{\multicolumn{2}{|c|}{$\begin{array}{l}\text { 13. Trpe of Report and Period Covered } \\
\text { Technical Memorandum }\end{array}$}} \\
\hline \multirow{2}{*}{\multicolumn{2}{|c|}{$\begin{array}{l}\text { 12. Sponsoring Agency Name and Address } \\
\text { National Aeronautics and Space Administration, } \\
\text { Washington, D.C. } 20546\end{array}$}} & & \\
\hline & & \multicolumn{2}{|c|}{ 14. Sponsoring Agency Code } \\
\hline \multicolumn{4}{|c|}{$\begin{array}{l}\text { 15. Suplementary Notes } \\
\text { * Proceedings of a meeting held at Massachusetts Institute of Technology, } \\
\text { Cambridge, Massachusetts, May } 5-7,1980\end{array}$} \\
\hline \multicolumn{4}{|c|}{$\begin{array}{l}\text { 16. Abstract } \\
\text { This volume contains a compilation of written versions of papers } \\
\text { presented at the Sixteenth Annual Conference on Manual Control in a meeting } \\
\text { held at the Massachusetts Institute of Technology, Cambridge, July 5-7, } \\
1980 \text {. Nine main topics were covered in this three-day conference in } \\
\text { sessions titled: Operator Modeling, Measurement of Human Response, Mental } \\
\text { Workload, Pilot/Operator Opinion, Effects of Motion, Aircraft Displays, } \\
\text { Supervisory Control, Automobile Driving, and Remote Manipulation. }\end{array}$} \\
\hline $\begin{array}{l}\text { 17. Key Words (Suggested by Author(s)/ } \\
\text { Manual Control, Physiological } \\
\text { Contro1, Displays, Vehicle handling } \\
\text { qualities, Operator performance, } \\
\text { Simulation }\end{array}$ & $\begin{array}{l}\text { 18. Oistriburion Staten } \\
\text { Unlimi ted }\end{array}$ & \multicolumn{2}{|c|}{ Subject Category - 54} \\
\hline $\begin{array}{l}\text { 19. Security Classit. (of this report) } \\
\text { Unclassified }\end{array}$ & $\begin{array}{l}\text { 20. Security Classif. for this pagel } \\
\text { Unclassified }\end{array}$ & $\begin{array}{l}\text { 21. No. of Pages } \\
647\end{array}$ & $\begin{array}{r}\text { 22. Price } \\
\text { A26 }\end{array}$ \\
\hline
\end{tabular}

*For sale by the National Technical Information Service, Springfield, Virginia 22161 